\title{
A Study of Hazardous Air Pollutants at the Tidd PFBC Demonstration Plant
}

\section{Topical Report}

October 1994

Work Performed Under Contract No.: DE-FC2 1-89MC26042

For
U.S. Department of Energy
Office of Fossil Energy
Morgantown Energy Technology Center
Morgantown, West Virginia

By American Electric Power Service Corporation Columbus, Ohio

WIHIBUTION OF THIS ROOUMENT IS UNIMUTFO LIOIAIBUTION OF THIS DOCUMENT IS UNLIMTEO DISTRIBUTION OF THIS DOCUMENT IS UNLIMITED in

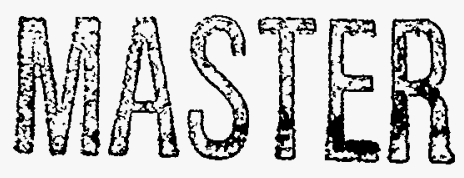




\section{DISCLAIMER}

This report was prepared as an account of work sponsored by an agency of the United States Government. Neither the United States Government nor any agency thereof, nor any of their employees, makes any warranty, express or implied, or assumes any legal liability or responsibility for the accuracy, completeness, or usefulness of any information, apparatus, product, or process disclosed, or represents that its use would not infringe privately owned rights. Reference herein to any specific commercial product, process, or service by trade name, trademark, manufacturer, or otherwise does not necessarily constitute or imply its endorsement, recommendation, or favoring by the United States Government or any agency thereof. The views and opinions of authors expressed herein do not necessarily state or reflect those of the United States Government or any agency thereof.

This report has been reproduced directly from the best available copy.

Available to DOE and DOE contractors from the Office of Scientific and Technical Information, 175 Oak Ridge Turnpike, Oak Ridge, TN 37831; prices available at (615) 576-8401.

Available to the public from the National Technical Information Service, U.S. Department of Commerce, 5285 Port Royal Road, Springfield, VA 22161; phone orders accepted at (703) 487-4650. 


\section{DISCLAIMER}

Portions of this document may be illegible in electronic image products. Images are produced from the best available original document. 


\title{
A Study of Hazardous Air Pollutants at the Tidd PFBC Demonstration Plant
}

\author{
Topical Report
}

Work Performed Under Contract No.: DE-FC21-89MC26042

\author{
For \\ U.S. Department of Energy \\ Office of Fossil Energy \\ Morgantown Energy Technology Center \\ P.O. Box 880 \\ Morgantown, West Virginia 26507-0880 \\ By \\ American Electric Power Service Corporation \\ Ohio Power Company \\ 1 Riverside Plaza \\ Columbus, Ohio 43215
}




\section{EXECUTIVE SUMMARY}

The U.S. Department of Energy (DOE) Clean Coal Technology (CCT) Program is a joint effort between government and industry to develop a new generation of coal utilization processes. In 1986, the Ohio Power Company, a subsidiary of American Electric Power (AEP), was awarded cofunding through the CCT program for the Tidd Pressurized Fluidized Bed Combustor (PFBC) Demonstration Plant located in Brilliant, Ohio. The Tidd PFBC unit began operation in 1990 and was later selected as a test site for an advanced particle filtration (APF) system designed for hot gas particulate removal. The APF system was sponsored by the DOE Morgantown Energy Technology Center (METC) through their Hot Gas Cleanup Research and Development Program.

A complementary goal of the DOE CCT and METC R\&D programs has always been to demonstrate the environmental acceptability of these emerging technologies. The Clean Air Act Amendments of 1990 (CAAA) have focused that commitment toward evaluating the fate of hazardous air pollutants (HAPs) associated with advanced coal-based and hot gas cleanup technologies. Radian Corporation was contracted by AEP to perform this assessment of HAPs at the Tidd PFBC demonstration plant with funding from the DOE-METC Hot Gas Cleanup R\&D program. The objective of this study is to assess the major input, process, and emission streams at Plant Tidd for the HAPs identified in Title III of the CAA.A.

\section{Site Description}

The boiler at Plant Tidd is a bubbling bed, pressurized fluidized bed combustor (PFBC) rated at $70 \mathrm{MWe} ; 55 \mathrm{MW}$ is produced by a steam turbine generator and $15 \mathrm{MW}$ is produced by depressurizing the hot flue gas in a gas turbine generator. Total plant load during the test period was steady at 45 to $46 \mathrm{MW}$, which is representative of stable, long-term operation. A slurry of Pittsburgh No. 8 bituminous coal (3.4\% sulfur) is fed to the PFBC unit along with dolomite sorbent to control $\mathrm{SO}_{2}$ emissions. Particulate matter is controlled by primary and secondary cyclones in series with an electrostatic precipitator (ESP). Formation of $\mathrm{NO}_{\mathrm{x}}$ is minimized because of relatively low combustion temperatures within the PFBC process.

An additional feature of the Plant Tidd facility is a demonstration-scale hot gas clean-up system. Treated gas from one of the seven cyclones is directed to a ceramic barrier, advanced particle filter (APF), and back-up cyclone. The treated gas is then returned to the process upstream of the ESP. The APF operated at approximately $1350^{\circ} \mathrm{F}$ during the test period. The ceramic candles were backpulsed approximately every 30 minutes to remove particulate matter captured on the outside of the candles. 


\section{Sampling Locations}

Four flue gas stream locations were tested: ESP inlet, ESP outlet, APF inlet, and APF outlet. Other process streams sampled were raw coal, coal paste, sorbent, bed ash, cyclone ash, individual ESP hopper ash, APF ash, and service water.

\section{Sample Collection}

Radian's approach to meeting the test objectives utilized established sampling methods (where possible) and a sampling strategy consistent with that of the DOE-sponsored program, "Comprehensive Assessment of Air Toxics Emissions from Coal-Fired Utility Boilers," and the EPRI-sponsored Field Chemical Emissions Monitoring (FCEM) program. Samples were collected with the boiler operating at steady-state conditions and in triplicate over four days (April 12-15, 1994).

\section{Quality. Assurance and Quality Control}

During sample collection, quality assurance audits were conducted by Radian's internal QA auditor. Radian's auditor also conducted a performance evaluation audit by submitting "double-blind" (identity and composition unknown) samples to the analytical laboratories. Quality control procedures involved the evaluation of results for field and laboratory blank samples, duplicate field samples, matrix-spiked and surrogate-spiked samples, and laboratory control samples.

Overall, QA/QC data associated with this program indicate that measurement data are acceptable and can be used with confidence. The QA/QC results indicate that the quality control mechanisms were effective in ensuring measurement data reliability within the expected limits of sampling and analytical error.

\section{Plant Operating Conditions}

During sample collection, operating conditions were continuously monitored using a computerized data acquisition system which logged process information as five-minute averages. In addition, ESP operating data (voltages and currents for each field) were logged hourly by the on-site Radian engineer. Overall, all processes were very stable, and the key operating parameters were within the targeted range during the entire test period. Continuous emission monitors were operated during the test period, providing data for sulfur dioxide, nitrogen oxides, opacity, and carbon monoxide at the ESP outlet location. These data indicate steady process operation and ESP performance.

\section{Analytical Results}

Samples were analyzed for trace elements, minor and major elements, anions, volatile organic compounds, dioxin/furan compounds, ammonia, cyanide, formaldehyde, and semivolatile organic compounds. The particle size distribution in the ESP inlet and outlet gas streams and collected ash from individual ESP hoppers was also determined. Analytical 
results have been tabulated in detail as mean values with $95 \%$ confidence intervals. In the detailed data tabulations, some data have been identified with flags; for example, where background analyte levels in the sampling media exceeded $30 \%$ of the uncorrected sample result.

\section{Data Analysis: Mass Balances, Removal Efficiencies, and Emission Factors}

Emission factors, removal efficiencies, and other results rely on measurement data that are near the limit of detection or below it for many of the substances of interest. For that reason, uncertainty analyses and the calculation of confidence intervals were performed as part of this program. The method used to determine uncertainties in calculated results is based on "Measurement Uncertainty". 1

The following observations are results of the data analysis:

- Material balances were calculated for 26 elements. Sixteen of these elements met the target closure objectives of $70-130 \%$ for balance around the plant. Nineteen elements met a closure criteria of 50-150 percent. Closures could not be estimated for four species (antimony, cadmium, molybdenum, and silver) because they were not detected in several of the outlet ash streams.

- Use of the ICP-MS analytical technique to analyze vapor phase multi-metals train samples at the four gas locations provided superior detection limits and allowed quantification of vapor phase trace metals at low $\mathrm{ng} / \mathrm{Nm}^{3}$ levels-below the detection limits of standard ICP-AES and GFAAS techniques.

- Removal efficiencies for non-volatile metals were generally greater than $95 \%$ across the ESP. Less than $10 \%$ removal was observed for volatile species such as chloride, fluoride, and mercury.

- The particulate removal efficiency of the APF system wạs measured at 99.99 percent. Removal efficiencies for most non-volatile metals was greater than $99.5 \%$ across the APF. Removals of less than $30 \%$ were measured for mercury, selenium, chloride and fluoride. Approximately $40 \%$ removal of $\mathrm{SO}_{2}$ was measured across the APF system as well as some removal for ammonia (25\%), cyanide (69\%), and formaldehyde (94\%).

- High resolution GC/MS analysis of the Modified Method 5 sampling train components provided detection limits for selected polycyclic aromatic hydrocarbons at 2 to 5 orders of magnitude lower than low resolution GC/MS. Quantification of PAHs at these lower levels provides a better estimate of emissions.

- Hexavalent chromium analyses conducted in an on-site laboratory provided measurable results slightly above blank levels. Compared to total chromium results for the ESP outlet stream, chromium (VI) was measured at $37 \%$ of the total chromium concentration; however, additional research and validation of this method for coal-fired power plant flue gas is needed. 
- Emission factors have been calculated for the target trace species detected in the ESP outlet gas and are presented in Table ES-1.

- Particle size distribution (PSD) results for the ESP inlet and outlet flue gas measurements were consistent and repeatable. PSD results for ash collected from the four ESP hoppers show a progressive shift downward in the mean particle diameter through the ESP. The particle size range collected in the first and second ESP field hoppers is consistent with that of the ESP inlet gas particulate. The mean aerodynamic particle diameter at the ESP inlet was $3.5 \mu \mathrm{m}$ with less than approximately $8 \%$ of the particles below $1 \mu \mathrm{m}$.

\section{Recommendations and Considerations}

Some technical issues have been identified during this study that may warrant further consideration. Among these are the following sampling, analytical and/or process related issues:

- Contamination of the APF outlet particulate phase samples with chromium, nickel, and molybdenum associated with the Inconel 800 components of the hot gas sampling system was observed;

- Improved detection limits are required for some trace elements in gas stream particulate and process solid samples to facilitate complete material characterizations and balance closures;

- Analysis of multiple reagent blanks is necessary to provide a more representative statistical value for background levels of target analytes in the sampling media when samples are analyzed by highly sensitive analytical techniques;

- Gas sampling methods for semi-volatile organic compounds should be studied to determine if benzoic acid, phthalate esters, and other related compounds are sampling artifacts associated with the reactivity of flue gas components on XAD-2 resin; and

- The hexavalent chromium sampling method has not been validated for application to flue gas from coal-fired combustion systems and should be thoroughly evaluated for sampling bias and precision.

\section{References}

1. American Society of Mechanical Engineers. Measurement Uncertainty: Instruments and Apparatus. PTC 19.1-1985 (reaffirmed 1990), pp 1-65. United Engineering Center, New York, NY. Published by the American National Standards Institute. 
Table ES-1

Emission Factors

\begin{tabular}{|c|c|c|}
\hline & $\mathrm{lb} / 10^{12} \mathrm{Btu}$ & $95 \% \mathrm{CI}$ \\
\hline \multicolumn{3}{|l|}{ Anions } \\
\hline Chloride & 83,000 & 4,000 \\
\hline Fluoride & 5,600 & 270 \\
\hline \multicolumn{3}{|l|}{ Reduced Species } \\
\hline Ammonia & 140 & 7 \\
\hline Cyanide & 610 & 29 \\
\hline \multicolumn{3}{|l|}{ Selected Elements ${ }^{2}$} \\
\hline Arsenic & 1.2 & 0.06 \\
\hline Barium & 0.92 & 0.04 \\
\hline Beryllium & 0.26 & 0.0012 \\
\hline Cadmium & 2.2 & 0.11 \\
\hline Chromium & 4.6 & 0.22 \\
\hline Chromium (VI) & 1.7 & 0.08 \\
\hline Copper & 5.3 & 0.25 \\
\hline Lead & 0.8 & 0.038 \\
\hline Manganese & 8.5 & 0.41 \\
\hline Mercury & 18 & 1 \\
\hline Molybdenum & 0.31 & 0.015 \\
\hline Nickel & 7.4 & 0.35 \\
\hline Selenium & 49 & 2.3 \\
\hline Silver & 0.5 & 0.024 \\
\hline Vanadium & 1.2 & 0.06 \\
\hline \multicolumn{3}{|l|}{ Aldehydes } \\
\hline Formaldehyde & 5.1 & 0.24 \\
\hline \multicolumn{3}{|c|}{ Volatile Organic Species ${ }^{\mathbf{a}, \mathbf{b}}$} \\
\hline Benzene & 6.6 & 0.32 \\
\hline Carbon Disulfide & 1.0 & 0.05 \\
\hline \multicolumn{3}{|l|}{ PAHs by HRGC/MS } \\
\hline Acenaphthylene & $1.2 \times 10^{-1}$ & $5.8 \times 10^{-3}$ \\
\hline 2-Chloronaphthalene & $1.2 \times 10^{-3}$ & $5.7 \times 10^{-5}$ \\
\hline
\end{tabular}


Table ES-1 (Continued)

\begin{tabular}{|c|c|c|}
\hline & lb/10 12 Btu & $95 \% \mathrm{CI}$ \\
\hline \multicolumn{3}{|l|}{ PAHs by Method $8270^{c, d}$} \\
\hline Acetophenone & $3.9^{e}$ & 0.2 \\
\hline Benzoic Acid & 160 & 8 \\
\hline Isophorone & $21^{e}$ & 1 \\
\hline Phenol & $1.2^{e}$ & 0.06 \\
\hline \multicolumn{3}{|l|}{ Dioxin/furan Species ${ }^{a, f}$} \\
\hline $1,2,3,4,6,7,8$-Heptachlorodibenzofuran & $6.4 \times 10^{-6}$ & $3.1 \times 10^{-6}$ \\
\hline Octachlorodibenzofuran & $1.2 \times 10^{-5}$ & $5.8 \times 10^{-7}$ \\
\hline Total Heptachlorodibenzo-p-dioxin & $1.4 \times 10^{-5}$ & $6.7 \times 10^{-7}$ \\
\hline Total Heptachlorodibenzofuran & $4.5 \times 10^{-6}$ & $2.1 \times 10^{-7}$ \\
\hline Total Hexachlorodibenzofuran & $1.4 \times 10^{-5}$ & $6.7 \times 10^{-7}$ \\
\hline Total Pentachlorodibenzofuran & $4.3 \times 10^{-6}$ & $2.1 \times 10^{-7}$ \\
\hline
\end{tabular}

- Only those compounds with an average concentration above the detection limit are included.

b Methylene chloride, toluene, and other halogenated hydrocarbons are not included because their presence is strongly suspected to be the result of contamination from common field and laboratory reagents.

c Substances for which the reagent blank background levels were greater than or equal to $30 \%$ of the sample result are not included because their quantification is considered suspect.

d Phthalate esters are not included because their presence is suspected to be either the result of resin contamination from plasticizers commonly found in the laboratory environment, or a sampling artifact.

- Reported concentration is between the quantitation limit and the method detection limit. Results in this range are considered uncertain.

${ }^{f}$ Results are less than five times the detection limit. 


\section{CONTENTS}

Section

Page

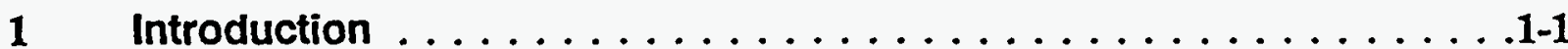

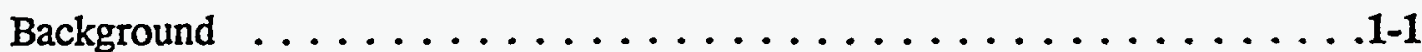

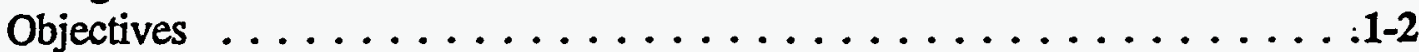

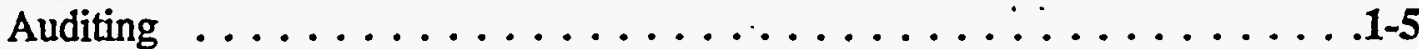

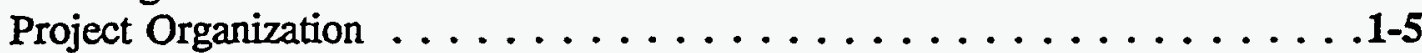

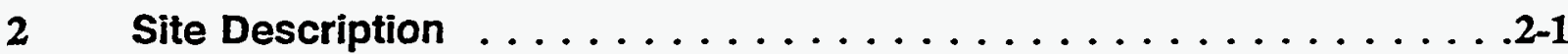

Site Description . . . . . . . . . . . . . . .

Hot Gas Cleanup . . . . . . . . . . . . . . 2-3

Sampling Locations . . . . . . . . . . . . . . . . 2-4

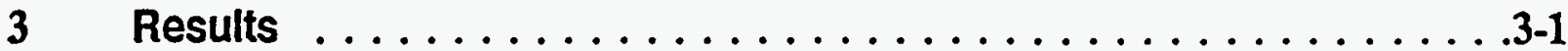

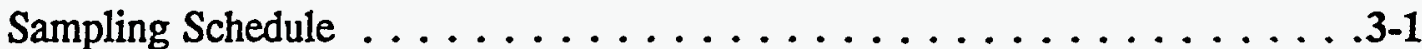

Data Treatment ........................ . . . .

Coal and Dolomite . . . . . . . . . . . . . . . . .3-8

Ash Streams . . . . . . . . . . . . . . . . . . . .

Service Water ......................... . . . . . .

ESP Inlet and Outlet Gas . . . . . . . . . . . . . . .

Inorganic Species . . . . . . . . . . . . . . . . .3-17

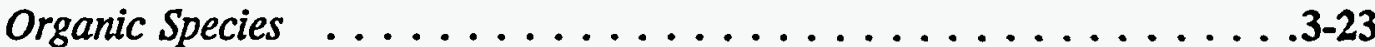

APF Inlet and Outlet Gas . . . . . . . . . . . . . . . . . .

Inorganic Species . . . . . . . . . . . . . . .36

Organic Species . . . . . . . . . . . . . . . .3-41

ESP System Control Efficiency $\ldots \ldots \ldots \ldots \ldots \ldots \ldots \ldots \ldots . \ldots .50$

APF System Control Efficiency . . . . . . . . . . . . . . 3-50

Emission Factors . . . . . . . . . . . . . . . . .3-53

Particle Size Distribution Data . . . . . . . . . . . . 3-53

Radionuclide Data . . . . . . . . . . . . . . . . 3-62

Chromium (VI) Measurements . . . . . . . . . . . . . . 3-62

4 Data Evaluation . . . . . . . . . . . . . . . . . . . 4-1

Process Operation During Testing $\ldots \ldots \ldots \ldots \ldots \ldots \ldots \ldots . . \ldots \ldots$

Sample Collection . . . . . . . . . . . . . . . 
Analytical Quality Control Results $\ldots \ldots \ldots \ldots \ldots \ldots \ldots \ldots$. . . . .

Detailed QC Results . . . . . . . . . . . . . . . . . . 4-19

Metals .......................4-20

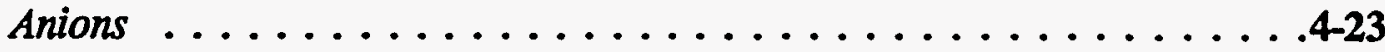

Chromium (VI) and Total Chromium . . . . . . . . . .4-24

Volatile Organic Compounds . . . . . . . . . . . . . .425

Semivolatile Organic Compounds . . . . . . . . . . . . 4-25

Polycyclic Aromatic Hydrocarbons (PAHs) by HRGC/MS . . . . . . 4-26

Formaldehyde ......................4-26

Ammonia . . . . . . . . . . . . . . . . . . . . 4-27

Cyanide .........................4-27

Dioxins and Furans $(P C D D / P C D F) \quad \ldots \ldots \ldots \ldots \ldots \ldots \ldots .428$

Ultimate/Proximate . . . . . . . . . . . . . . .4-28

Material Balances . . . . . . . . . . . . . . . . . . 4-29

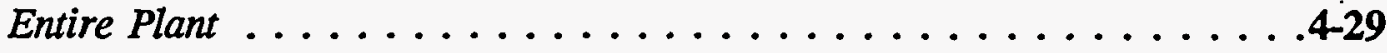

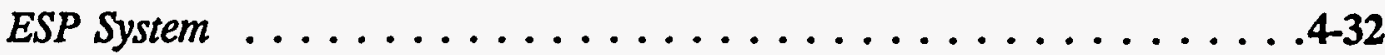

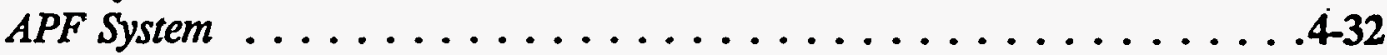

Recommendations and Considerations $\ldots \ldots \ldots \ldots \ldots \ldots \ldots \ldots .4 .42$

APF Outlet Particulate Contamination . . . . . . . . . 4-33

Improved Detection Limits . . . . . . . . . . . .433

Multiple Reagent Blanks . . . . . . . . . . . . . . . 4-33

Gas Sampling Methods for Semivolatile Organic Compounds . . . . . . 4-34

Hexavalent Chromium Sampling and Analysis . . . . . . . . 4-34

References ........................4-34

5 Example Calculations $\ldots \ldots \ldots \ldots \ldots \ldots \ldots \ldots \ldots \ldots \ldots \ldots$

Stream Flow Rates . . . . . . . . . . . . . . . . . . 5-1

Means and Confidence Intervals for Stream Concentrations $\ldots \ldots \ldots \ldots$ 5-2

Unit Energy Emission Factors . . . . . . . . . . . . . . . . 5-4

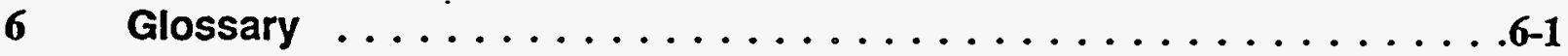




\section{LIST OF TABLES}

Table

Page

1-1 Target Analytes $\ldots \ldots \ldots \ldots \ldots \ldots \ldots \ldots \ldots \ldots \ldots \ldots \ldots$

2-1 Sampling Locations at Plant Tidd $\ldots \ldots \ldots \ldots \ldots \ldots \ldots \ldots \ldots \ldots \ldots$

2-2 Analyses Performed for Solid and Liquid Streams $\ldots \ldots \ldots \ldots \ldots \ldots$ 2-6

2-3 Analyses Performed for Gas Streams $\ldots \ldots \ldots \ldots \ldots \ldots \ldots \ldots . \ldots \ldots$

3-1 Coal Paste Composition ........................ 3-9

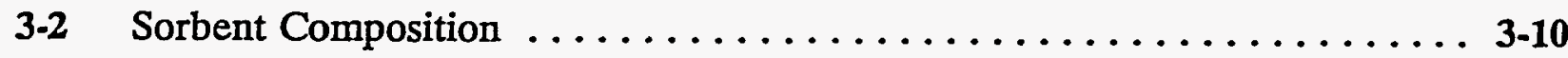

3-3 Ash Stream Compositions - Inorganic Species ............. 3-12

3-4 Ash Stream Compositions - Organic Species ............... 3-14

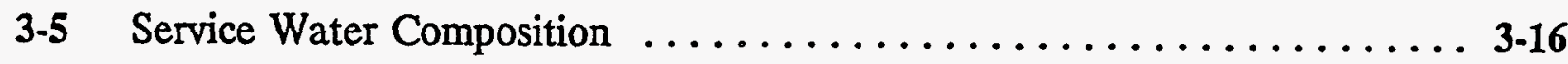

3-6 ESP Inlet Gas Composition - Inorganic Species $\ldots \ldots \ldots \ldots \ldots \ldots \ldots$ 3-18

3-7 ESP Outlet Gas Composition - Inorganic Species ........... 3-20

3-8 ESP Inlet Gas Composition - VOST and Method 23 Species ........ 3-24

3-9 Results for Semivolatile Organic Species at the ESP Inlet . . . . . . . . 3-26

3-10 ESP Outlet Gas Composition - VOST and Method 23 Species ....... 3-28

3-11 Results for Semivolatile Organic Species at the ESP Outlet ....... 3-30

3-12 APF Inlet Gas Composition - Inorganic Species ... . . . . . . . . 3-37

3-13 APF Outlet Gas Composition - Inorganic Species ........... 3-39 
3-14 APF Inlet Gas Composition - VOST and Method 23 Species ....... 3-42

3-15 Results for Semivolatile Organic Species at the APF Inlet ........ 3-44

3-16 APF Outlet Gas Composition - VOST and Method 23 Species ....... 3-46

3-17 Results for Semivolatile Organic Species at the APF Outlet $\ldots \ldots \ldots \ldots$ 3-48

3-18 ESP and APF Control Efficiencies $\ldots \ldots \ldots \ldots \ldots \ldots \ldots \ldots \ldots \ldots \ldots \ldots \ldots$

3-19 Emissions Factors for ESP Outlet Gas $\ldots \ldots \ldots \ldots \ldots \ldots \ldots \ldots \ldots \ldots$

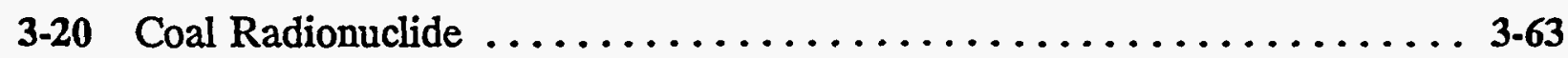

3-21 Ash Stream Radionuclide $\ldots \ldots \ldots \ldots \ldots \ldots \ldots \ldots \ldots \ldots \ldots \ldots . \ldots \ldots$

3-22 Chromium (VI) and Total Chromium Results for the ESP Outlet ..... 3-65

4-1 Summary of Process Monitoring Data $\ldots \ldots \ldots \ldots \ldots \ldots \ldots \ldots \ldots$

4-2 Types of Quality Control Samples .................. 4-5

4-3 Types of Quality Control Data $\ldots \ldots \ldots \ldots \ldots \ldots \ldots \ldots \ldots \ldots \ldots \ldots \ldots$

4-4 Analytical Results for Audit Samples $\ldots \ldots \ldots \ldots \ldots \ldots \ldots \ldots \ldots$ 4-10

4-5 Material Balance Results $\ldots \ldots \ldots \ldots \ldots \ldots \ldots \ldots \ldots \ldots \ldots$ 4-30

4-6 Material Balance Stream Flow Rates $\ldots \ldots \ldots \ldots \ldots \ldots \ldots \ldots .4 .31$ 


\section{LIST OF FIGURES}

Figure

Page

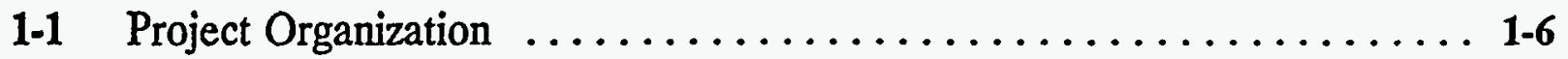

2-1 Plant Tidd Process Flow Diagram $\ldots \ldots \ldots \ldots \ldots \ldots \ldots \ldots \ldots .2-2$

3-1 ESP Inlet and Outlet Sampling Schedule $\ldots \ldots \ldots \ldots \ldots \ldots \ldots \ldots$ 3-2

3-2 APF Inlet and Outlet Sampling Schedule $\ldots \ldots \ldots \ldots \ldots \ldots \ldots \ldots .3$

3-3 Sample Times for Solid and Liquid Process Streams $\ldots \ldots \ldots \ldots \ldots$ 3-4

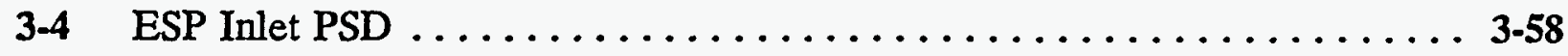

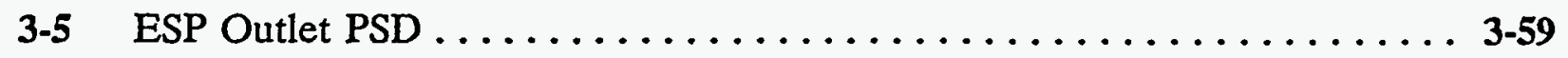

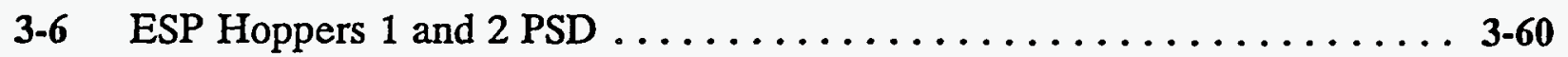

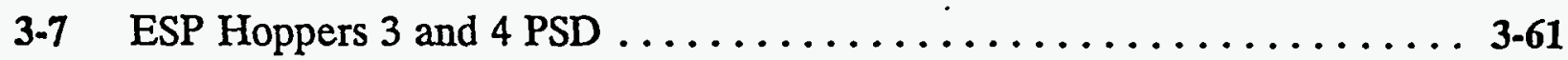




\section{INTRODUCTION}

\section{Background}

The U.S. Department of Energy (DOE) Clean Coal Technology (CCT) Program focuses on developing a new generation of coal utilization processes. One objective of the program is to move the most promising of the advanced coal-based technologies into the commercial marketplace through a series of demonstrations cofunded by government and industry. The DOE-Morgantown Energy Technology Center (METC) Hot Gas Cleanup Research and Development Program examines advanced technologies for application to hot gas streams in coal combustion and gasification systems. One objective is to aid in designing hot gas cleanup technologies for second-generation pressurized-fluidized bed combustor (PFBC) units.

In the first round of CCT solicitations in 1986, the Ohio Power Company, a subsidiary of American Electric Power (AEP), was awarded funding for the Tidd PFBC demonstration plant in Brilliant, Ohio. The Tidd PFBC unit began operation in late 1990 and was later selected by the DOE-METC R\&D program as a test facility for an advanced particle filtration (APF) system.

Because of continuing concern that the use of coal as an energy source could cause significant environmental impact, a complementary goal of the DOE CCT and METC R\&D programs has always been to demonstrate the environmental acceptability of these projects. The Clean Air Act Amendments of 1990 (CAAA) added another focus to DOE's environmental protection commitment; evaluating the fate of hazardous air pollutants (HAPs) associated with the demonstration of advanced coal-based and hot gas cleanup technologies. 
The study of HAPs at the Tidd PFBC demonstration plant was funded by the DOE Hot Gas Cleanup R\&D program through AEP to assess the major input, process, and emission streams for the HAPs identified in Title III of the CAAA. Included in this assessment were the inlet and outlet gas and solid samples from the APF system and the electrostatic precipitator (ESP). The resulting data from this study are used to generate emission factors for the HAPs so that the environmental acceptability of commercialized PFBC technologies can be assessed.

Radian Corporation was selected to perform the HAPs assessment at the Tidd PFBC demonstration plant with the advanced particle filter in operation. This report presents the results of that assessment.

\section{Objectives}

The specific objectives of this project are:

- To collect and analyze representative solid, liquid, and gas samples of all specified input and output streams of the Tidd PFBC Plant, including the advanced particle filtration system, for selected hazardous air pollutants contained in Title III of the CAAA;

- To determine the removal efficiencies of the APF and ESP subsystems for selected pollutants;

- To calculate material balance closures for selected pollutants in specified subsystems of the power plant and for the entire plant;

- To determine the concentrations of the respective pollutants associated with the particulate and vapor-phase fractions of the specified flue gas streams;

- To determine hexavalent chromium stack emissions; and

- To provide data (emission factors) for use in comparing emissions and system data from Plant Tidd with similar studies on conventional coal-fired power plants.

Table 1-1 lists the chemical substances selected for analysis during this project. 
Table 1-1

\section{Target Analytes}

\begin{tabular}{|c|c|c|c|}
\hline \multicolumn{4}{|c|}{ Trace Elements } \\
\hline $\begin{array}{l}\text { Antimony } \\
\text { Arsenic } \\
\text { Barium } \\
\text { Beryllium } \\
\text { Boron }\end{array}$ & $\begin{array}{l}\text { Cadmium } \\
\text { Chromium, total } \\
\text { Cobalt } \\
\text { Copper } \\
\text { Lead }\end{array}$ & $\begin{array}{l}\text { Manganese } \\
\text { Mercury } \\
\text { Molybdenum } \\
\text { Nickel } \\
\text { Phosphorus } \\
\end{array}$ & $\begin{array}{l}\text { Selenium } \\
\text { Silver } \\
\text { Vanadium }\end{array}$ \\
\hline \multicolumn{4}{|c|}{ Radionuclides } \\
\hline \multicolumn{4}{|c|}{ Hexavalent Chromium } \\
\hline \multicolumn{4}{|l|}{ Anions } \\
\hline \multicolumn{4}{|c|}{$\begin{array}{l}\text { Chloride (HCl) } \\
\text { Fluoride (HF) } \\
\text { Sulfate } \\
\text { Phosphate }\end{array}$} \\
\hline \multicolumn{4}{|c|}{ Reduced Species } \\
\hline \multicolumn{4}{|l|}{$\begin{array}{l}\text { Ammonia } \\
\text { Cyanide }\end{array}$} \\
\hline \multicolumn{4}{|c|}{ Dioxins/Furans } \\
\hline \multicolumn{4}{|c|}{ Volatile Organics } \\
\hline $\begin{array}{l}\text { Benzene } \\
\text { Bromoform } \\
\text { Carbon Dis } \\
\text { Carbon Tet } \\
\text { Chlorobenz } \\
\text { Chloroform } \\
\text { 1,4-Dichlor } \\
\text { cis-1,3-Dic } \\
\text { trans-1,3-D } \\
\text { Ethyl Benz } \\
\text { Ethyl Chlo } \\
\text { Ethylene D } \\
\text { Ethylidene } \\
\text { Formaldehy } \\
\text { Methyl Bro } \\
\text { Methyl Chl }\end{array}$ & $\begin{array}{l}\text { e } \\
\text { opene } \\
\text { (1,2-Dichloroethane) } \\
\text { le (1,1-Dichloroethane) } \\
\text { omomethane) } \\
\text { lloromethane) }\end{array}$ & $\begin{array}{l}\text { Methyl Chlor } \\
\text { Methyl Ethyl } \\
\text { Methylene Ch } \\
\text { Propylene Dic } \\
\text { Styrene } \\
\text { 1,1,2,2-Tetrar } \\
\text { Tetrachloroetl } \\
\text { Toluene } \\
\text { 1,1,2-Trichlo } \\
\text { Trichloroether } \\
\text { Vinyl Acetate } \\
\text { Vinyl Chlorid } \\
\text { Vinylidene Cl } \\
\text { m,p-Xylene } \\
\text { o-Xylene }\end{array}$ & $\begin{array}{l}\text { 1-Trichloroethane) } \\
\text { Butanone) } \\
\text { hloromethane) } \\
\text { 2-Dichloropropane) } \\
\text { e } \\
\text {-Dichloroethene) }\end{array}$ \\
\hline
\end{tabular}


Table 1-1 (Continued)

\begin{tabular}{|c|c|c|}
\hline \multicolumn{3}{|l|}{ Semivolatile Organics } \\
\hline $\begin{array}{l}\text { Acenaphthene } \\
\text { Acenaphthylene } \\
\text { Acetophenone } \\
\text { 4-Aminobiphenyl } \\
\text { Aniline } \\
\text { Anthracene } \\
\text { Benzidine } \\
\text { Benzo(a)anthracene } \\
\text { Benzo(a)pyrene } \\
\text { Benzo(b)fluoranthene } \\
\text { Benzo(g,h,i)perylene } \\
\text { Benzo(k)fluoranthene } \\
\text { Benzoic Acid } \\
\text { Benzyl Alcohol } \\
\text { 4-Bromophenyl Phenyl Ether } \\
\text { Butylbenzylphthalate } \\
\text { 4-Chloro-3-Methylphenol } \\
\text { p-Chloraniline } \\
\text { bis(2-Chloroethoxy)methane } \\
\text { bis(2-Chloroethyl)ether } \\
\text { bis(2-Chloroisopropyl)ether } \\
\text { 2-Chloronaphthalene } \\
\text { 2-Chlorophenol } \\
\text { 4-Chlorophenyl Phenyl Ether } \\
\text { Chrysene } \\
\text { bis(2-Ethylhexyl)phthalate } \\
\text { Fluoranthene } \\
\text { Fluorene } \\
\text { Hexachlorobenzene } \\
\text { Hexachlorobutadiene } \\
\text { Hexachlorocyclopentadiene } \\
\text { Hexachloroethane } \\
\end{array}$ & $\begin{array}{l}\text { Indeno(1,2,3-cd)pyrene } \\
\text { Isophorone } \\
\text { 2-Methylnaphthalene } \\
\text { 2-Methylphenol (o-cresol) } \\
\text { 4-Methylphenol (p-cresol) } \\
\text { N-Nitrosodimethylamine } \\
\text { N-Nitrosodiphenylamine } \\
\text { N-Nitrosopropylamine } \\
\text { Naphthalene } \\
\text { 2-Nitroaniline } \\
\text { 3-Nitroaniline } \\
\text { 4-Nitroaniline } \\
\text { Nitrobenzene } \\
\text { Di-n-octylphthalate } \\
\text { Dibenz(a,h)anthracene } \\
\text { Dibenzofuran } \\
\text { Dibutylphthalate } \\
\text { 1,2-Dichlorobenzene } \\
\text { 1,3-Dichlorobenzene } \\
\text { 1,4-Dichlorobenzene } \\
\text { 3,3-Dichlorobenzidine } \\
\text { 2,4-Dichlorophenol } \\
\text { Diethylphthalate } \\
\text { p-Dimethylaminoazobenzene }\end{array}$ & $\begin{array}{l}\text { 2,4-Dimethylphenol } \\
\text { Dimethylphthalate } \\
\text { 4,6-Dinitro-2-methylphenol } \\
\text { 2,4-Dinitrophenol } \\
\text { 2,4-Dinitrotoluene } \\
\text { 2,6-Dinitrotoluene } \\
\text { 2-Nitrophenol } \\
\text { 4-Nitrophenol } \\
\text { Pentachloronitrobenzene } \\
\text { Pentachlorophenol } \\
\text { Phenanthrene } \\
\text { Phenol } \\
\text { Pyrene } \\
\text { 1,2,4-Trichlorobenzene } \\
\text { 2,4,5-Trichlorophenol } \\
\text { 2,4,6-Trichlorophenol }\end{array}$ \\
\hline \multicolumn{3}{|l|}{ Additional Elements } \\
\hline $\begin{array}{l}\text { Aluminum } \\
\text { Calcium } \\
\text { Iron } \\
\text { Magnesium } \\
\text { Potassium } \\
\text { Sodium } \\
\text { Titanium }\end{array}$ & & \\
\hline
\end{tabular}


Emission factors, removal efficiencies, and other results rely on measurement data that vary and which may be near or below the limit of detection for many of the substances of interest. This report includes uncertainty analysis and confidence intervals to assess the precision of the data.

\section{Auditing}

During the field sampling program conducted at Plant Tidd in April 1994, quality assurance (QA) audits were conducted by Radian Corporation's internal QA auditor. Radian's audit provided an objective, independent assessment of the sampling procedures, data gathering, and measurement activities to ensure the production of reliable and useful results. The audit provided a review of calibration documentation, documentation of QC data, completeness of data forms and notebooks, data review/validation procedures, sample logging procedures, and others. Included in this audit was the preparation and analysis of analytical standards as blind samples for assessing the potential bias associated with the analytical methods. The audit results and responses to the auditor's comments are provided in Section 4.

\section{Project Organization}

Figure 1-1 shows the organization of this project. 

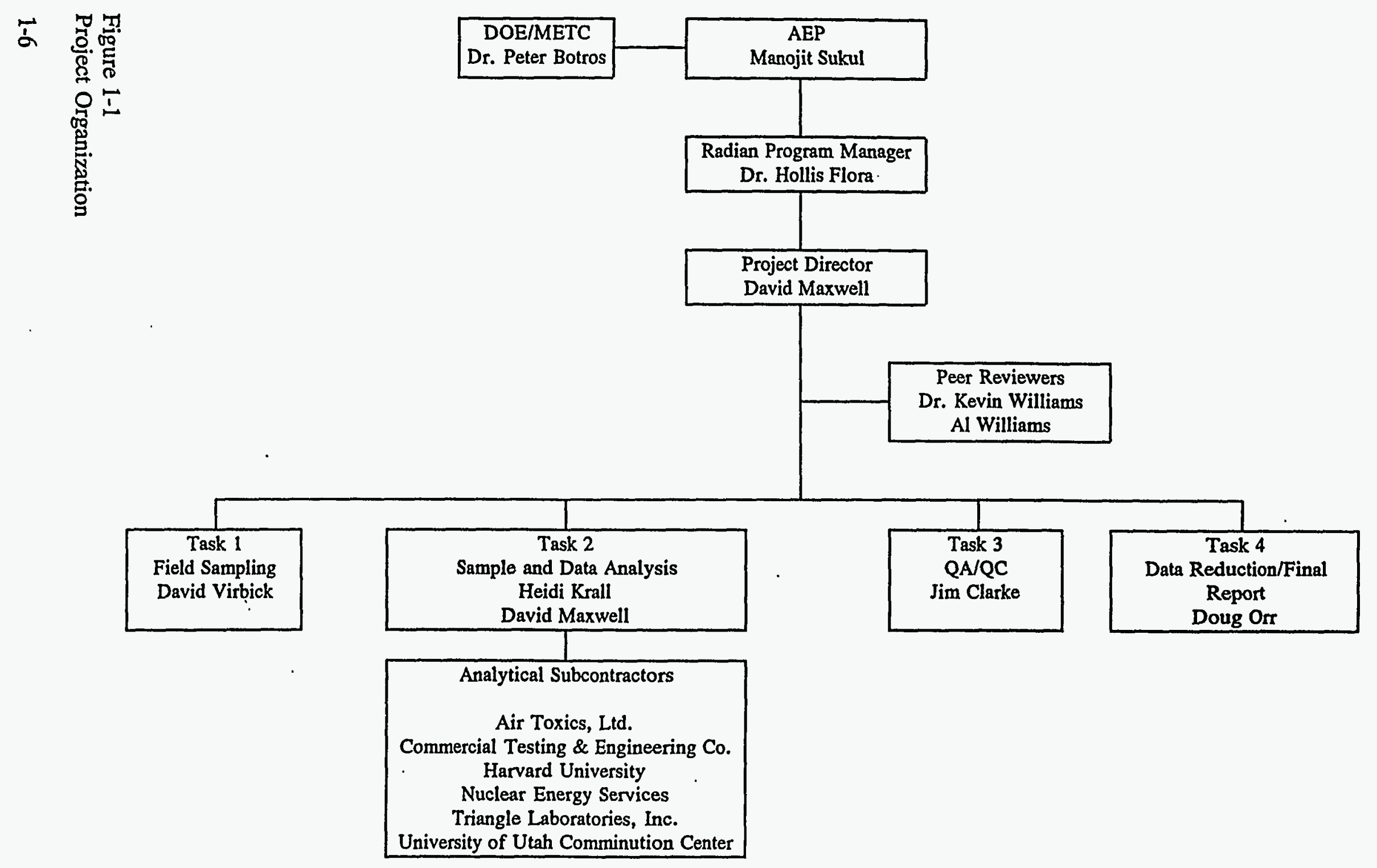


\section{SITE DESCRIPTION}

This section presents a description of the test site and sampling locations used during the test period. Deviations from the sampling locations described in the test plan are also discussed.

\section{Site Description}

Plant Tidd, located in Brilliant, Ohio, is operated by Ohio Power Company, a subsidiary of American Electric Power (AEP). The boiler at the Plant Tidd site is a bubbling-bed, pressurized fluidized bed combustor (PFBC) rated at $70 \mathrm{MWe}$ full load. Total plant load during the test period was 45 to $46 \mathrm{MW} ; 37 \mathrm{MW}$ was produced by a steam turbine generator and $8 \mathrm{MW}$ was produced by depressurizing the hot flue gases through a gas turbine generator. The process operating conditions for the unit were selected by AEP and represent typical long-term operating conditions for the process. A simple schematic of the unit is shown in Figure 2-1.

Crushed coal (Pittsburgh No. 8, bituminous) is combined with water from a nearby river to produce a coal paste which was approximately 25 weight percent moisture. The paste is fed to the combustion chambers along with crushed dolomite. The material is fluidized by high velocity combustion air in the water-cooled boiler. Mean bed temperatures in the combustion chambers were controlled at approximately $1500^{\circ} \mathrm{F}$ during the test period. As the coal is combusted, the calcium carbonate in the dolomite or limestone is calcined to form quick lime which then reacts with the sulfur dioxide and oxygen in the combustion gases to form solid calcium sulfate. This reaction removes sulfur dioxide from the combustion gases, thus controlling $\mathrm{SO}_{2}$ emissions. Test data from this program show approximately $90 \%$ removal of sulfur dioxide in the combustor. Formation of nitrogen oxides $\left(\mathrm{NO}_{\mathrm{x}}\right)$ is minimized because of the relatively low combustion temperature of the PFBC process. 


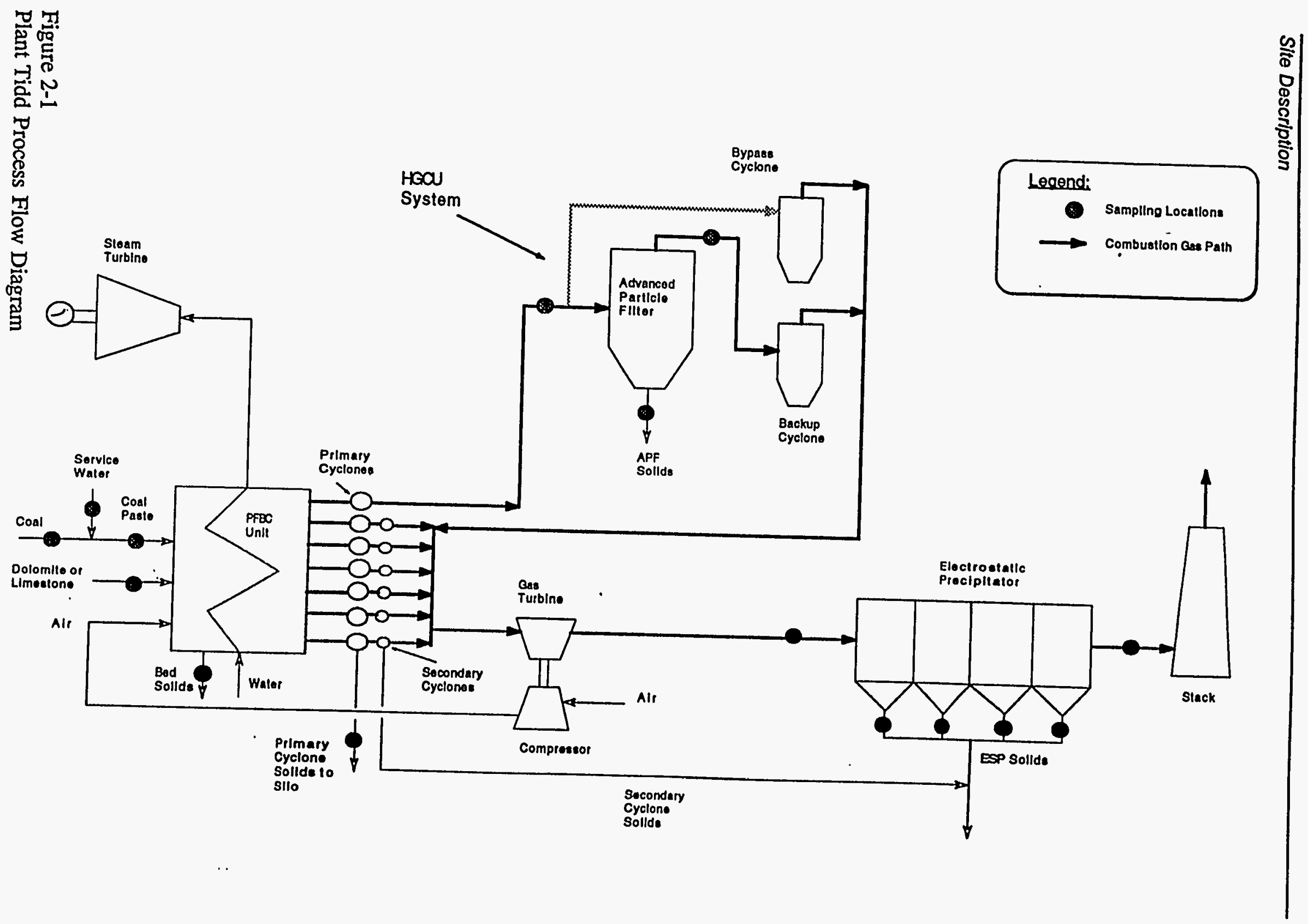


After releasing heat to the in-bed, water-cooled boiler tubes, the particulate-laden combustion gases flow into seven parallel, two-stage cyclones. These cyclones remove approximately 93\% of the entrained solids (primarily sulfated lime, unreacted lime, ash, and unburned carbon) from the gases. The combustion gases then flow to the ASEA Stal GT-35P gas turbine where they are expanded and then exit through the turbine exhaust gas economizer. Final particulate removal from the gases is achieved in an electrostatic precipitator (ESP) before the gases are released to the atmosphere.

Bed ash, which comprises about $45 \%$ of the total ash produced, is removed from the bottom of the combustor periodically through a lock hopper system. Solids collected by the primary cyclone are transported to a storage silo using a pressurized pneumatic transport system. Secondary cyclone solids are combined with the material collected in the ESP. All solids are transported by truck off site for disposal.

\section{Hot Gas Cleanup}

A research feature of the Plant Tidd facility is a demonstration-scale hot gas cleanup (HGCU) system, as shown in Figure 2-1. Treated gas from one of the seven cyclone systems (approximately one-seventh of the total gas flow from the combustor) is diverted to a ceramic barrier, advanced particle filter (APF) and back-up cyclone, and directed back to the outlet header of the secondary cyclones. The APF uses Schumacher silicon carbide candles in a cluster/ plenum arrangement developed by Westinghouse Corporation to filter the gas. Tempering air was added to the system during the test period to control ash bridging within the APF system, reducing the APF inlet gas temperature from $1500^{\circ} \mathrm{F}$ to approximately $1350^{\circ} \mathrm{F}$.

Each candle element in the APF is a porous ceramic cylinder which is closed on the bottom and open at the top. Hot, particulate-laden gas flows through the outer surface of the candles and the clean gas exits through the inner cylinder of the candles. The candle clusters are back-pulsed sequentially on a continuous cycle by nine pulse injectors to remove particulate matter captured on the outside of the candles. The pulse cycle during the test period was 
approximately every 30 minutes. Entrained solids removed in the APF system are collected and transported by truck off site for disposal.

\section{Sampling Locations}

Process streams that were sampled during the test are listed in Table 2-1 along with a brief description of the planned sampling location and any deviations from the planned location. Solid, liquid, and gas stream sampling locations are illustrated in Figure 2-1. Ports at the APF inlet and outlet and ESP outlet were located a sufficient distance from flow disturbances to allow collection of representative samples. Samples were collected from single 4-inch diameter horizontal ports at the APF inlet and outlet. Two 4-inch diameter ports (one horizontal and one vertical port 90 degrees apart) were available at the ESP outlet. The five 4-inch diameter horizontal ports at the ESP inlet were located less than 8 duct diameters downstream of a bend in the duct; therefore, this sample location was considered nonideal. Velocity and particulate loading measurements at the ESP inlet may not be representative because of the proximity of sample ports to this flow disturbance.

Solid and liquid stream samples were collected at intervals that accounted for the residence times within the system so that solid and liquid samples corresponded to gas sampling periods. The inlet air to the PFBC unit was not sampled because this stream was not considered at major source of any HAP substance measured in this study. The procedures for collecting, preserving, and analyzing samples are presented in Appendix A. Tables 2-2 and 2-3 present an overview of the types of analyses performed on these process streams.

All streams were sampled from the planned locations, with the exception of the sorbent and APF ash streams. A different sample location was used for the sorbent because the gear box on the autosampler at the East sorbent injector became jammed on the first day of testing. An alternate location at the diversion gate upstream of the East and West silos was used to collect sorbent samples on Day 2 and Day 3. This change did not adversely affect sample representativeness. Once on site, the crew identified an improved sampling location for the 


\section{Table 2-1}

\section{Sampling Locations at Plant Tidd}

\begin{tabular}{||l|l||}
\hline \multicolumn{1}{|c|}{ Process Stream } & \multicolumn{1}{c|}{ Sampling Location } \\
\hline Coal a & Solid automatic sampler on feed belt to crusher. \\
\hline Coal Paste & Paddle belt feeder to storage tank. \\
\hline Sorbent (Dolomite) & $\begin{array}{l}\text { Automatic sampler on east sorbent injector (planned). } \\
\text { Diversion gate upstream of both the East and West sorbent silos } \\
\text { (actual). }\end{array}$ \\
\hline Bed Ash & Bed ash collector before ash conveyor. \\
\hline ESP Ash & ESP Hoppers 11 and 12; Hoppers 13 and 14 sampled on last day. \\
\hline Primary Cyclone Ash & Automatic samplers on ash storage silo. \\
\hline APF Ash & $\begin{array}{l}\text { Sampled upon loading into disposal trucks (planned). } \\
\text { Bottom of APF ash collector (actual). }\end{array}$ \\
\hline Service Water & Tap on low pressure service water header. \\
\hline APF Inlet Gas & Single 4-inch-diameter port on APF inlet duct. \\
\hline APF Outlet Gas & Single 4-inch-diameter port on APF outlet duct. \\
\hline ESP Inlet Gas & Five 4-inch-diameter ports on ESP inlet duct. \\
\hline ESP Outlet Gas & Two 4-inch-diameter ports on ESP outlet duct. \\
\hline
\end{tabular}

Raw coal samples were collected as a backup to the coal paste sample. 
Table 2-2

Analyses Performed for Solid and Liquid Streams

\begin{tabular}{||l|c|c|c|c|c|c|c|c||}
\hline \multicolumn{1}{|c|}{ Analysis } & Coal & $\begin{array}{c}\text { Coal } \\
\text { Paste }\end{array}$ & $\begin{array}{c}\text { Sorbent } \\
\text { (Dolomite) }\end{array}$ & $\begin{array}{c}\text { Service } \\
\text { Water }\end{array}$ & $\begin{array}{c}\text { Bed } \\
\text { Ash }\end{array}$ & $\begin{array}{c}\text { ESP } \\
\text { Ash }\end{array}$ & $\begin{array}{c}\text { Primary } \\
\text { Cyclone } \\
\text { Ash }\end{array}$ & $\begin{array}{c}\text { APF } \\
\text { Ash }\end{array}$ \\
\hline Metals & & $\checkmark$ & $\checkmark$ & $\checkmark$ & $\checkmark$ & $\checkmark$ & $\checkmark$ & $\checkmark$ \\
\hline Anions & & $\checkmark$ & $\checkmark$ & $\checkmark$ & $\checkmark$ & $\checkmark$ & $\checkmark$ & $\checkmark$ \\
\hline Semivolatile Organics & & & & & $\checkmark$ & $\checkmark$ & $\checkmark$ & $\checkmark$ \\
\hline Particle Size Distribution & & & & & & $\checkmark$ & & \\
\hline Ultimate/Proximate & & $\checkmark$ & & & & & & \\
\hline Radionuclides & & $\checkmark$ & & & $\checkmark$ & $\checkmark$ & $\checkmark$ & $\checkmark$ \\
\hline Carbon & & & & & $\checkmark$ & $\checkmark$ & $\checkmark$ & $\checkmark$ \\
\hline Dioxins/Furans & & & & & & $\checkmark$ & $\checkmark$ & $\checkmark$ \\
\hline Moisture & & $\checkmark$ & & & & & & $\checkmark$ \\
\hline
\end{tabular}

Raw coal samples, collected as alternate feedstock samples, were not analyzed.

Table 2-3

Analyses Performed for Gas Streams

\begin{tabular}{|c|c|c|c|c|}
\hline Analysis & $\begin{array}{c}\text { APF Inlet } \\
\text { Gas }\end{array}$ & $\begin{array}{l}\text { APF Outlet } \\
\text { Gas }\end{array}$ & \begin{tabular}{|c|} 
ESP \\
Inlet Gas
\end{tabular} & $\begin{array}{c}\text { ESP Outlet } \\
\text { Gas }\end{array}$ \\
\hline Particulate Loading & $\checkmark$ & $\checkmark$ & $\checkmark$ & $\checkmark$ \\
\hline Metals $\mathrm{s}^{\mathrm{a}}$ & $\checkmark$ & $\checkmark$ & $\checkmark$ & $\checkmark$ \\
\hline Anions ${ }^{a}$ & $\checkmark$ & $\checkmark$ & 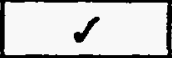 & $\checkmark$ \\
\hline Ammonia/Cyanide & $\checkmark$ & $\checkmark$ & 4 & $\checkmark$ \\
\hline Formaldehyde & $\checkmark$ & 8 & $\checkmark$ & $r$ \\
\hline Volatile Organics & $\checkmark$ & $\checkmark$ & 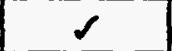 & $\checkmark$ \\
\hline Semivolatile Organics ${ }^{\mathrm{a}}$ & $\checkmark$ & $\checkmark$ & $r$ & 2 \\
\hline Dioxins/Furans ${ }^{b}$ & $\checkmark$ & $\bar{\checkmark}$ & $\checkmark$ & $\checkmark$ \\
\hline Particle Size Distribution & & & $\checkmark$ & $\therefore \checkmark$ \\
\hline Hexavalent Chromium & & & & $\checkmark$ \\
\hline
\end{tabular}

A Particulate and vapor phases analyzed separately.

b Solid- and vapor-phase fractions were combined prior to analysis for all streams except APF outlet. 
APF ash. Instead of sampling from the disposal trucks, as planned, a sample point was identified at the bottom of the APF ash collection system. 


\section{RESULTS}

This section summarizes the results of the stream characterization for the Tidd PFBC demonstration plant. Sampling, preparation, and analytical methods are described in Appendix A. Detailed analytical data for each individual sample can be found in Appendix B.

\section{Sampling Schedule}

Samples were collected during the week of April 11, 1994. Figures 3-1 and 3-2 show the gas stream sample times for the ESP and APF systems, respectively. Figure 3-3 shows the sample collection periods for solid and liquid process streams. Three valid sample sets for each stream were obtained.

Every attempt was made to collect inlet and outlet gas samples for a given sample type over the same time period so that results would provide a meaningful comparison. All ESP inlet and outlet gas samples were collected simultaneously as shown in Figure 3-1. Run 1 multimetals and anions train samples at the APF inlet were invalidated because of particulate breakthrough across the filter; these samples were recollected later in the test period. The higher than expected particulate loadings at the APF inlet caused delays in gas sample collection; therefore, the test period was extended one day to allow for collection of all three $\mathrm{PAH}$, dioxin/furan, and volatile organic trains.

\section{Data Treatment}

Several conventions have been developed for treating the test data and developing average concentrations of substances in the various streams. 


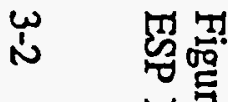

昰

क्ष

言

응

क

苛

宫

号

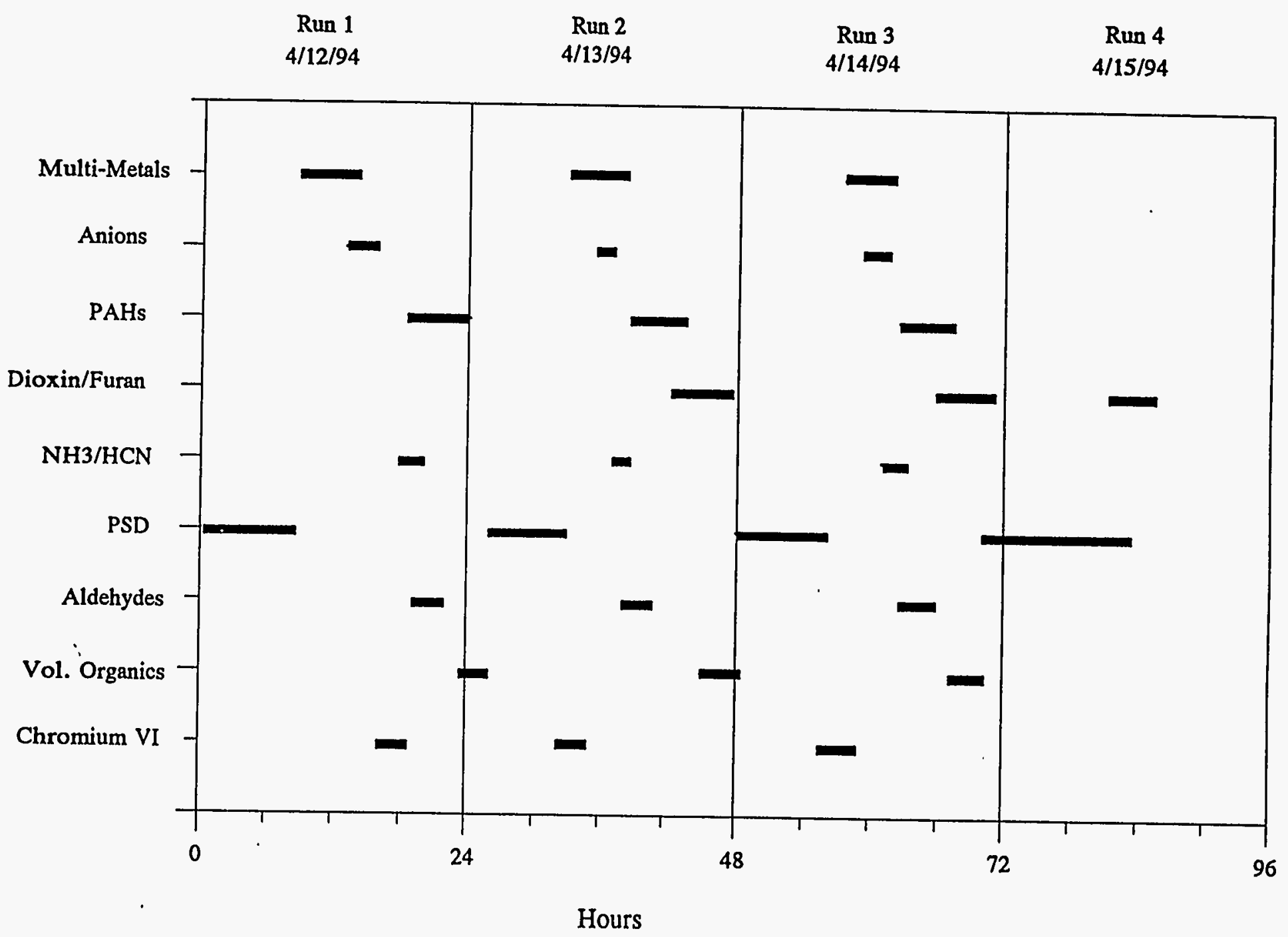

Run 1

4/14/94

声

Hours 


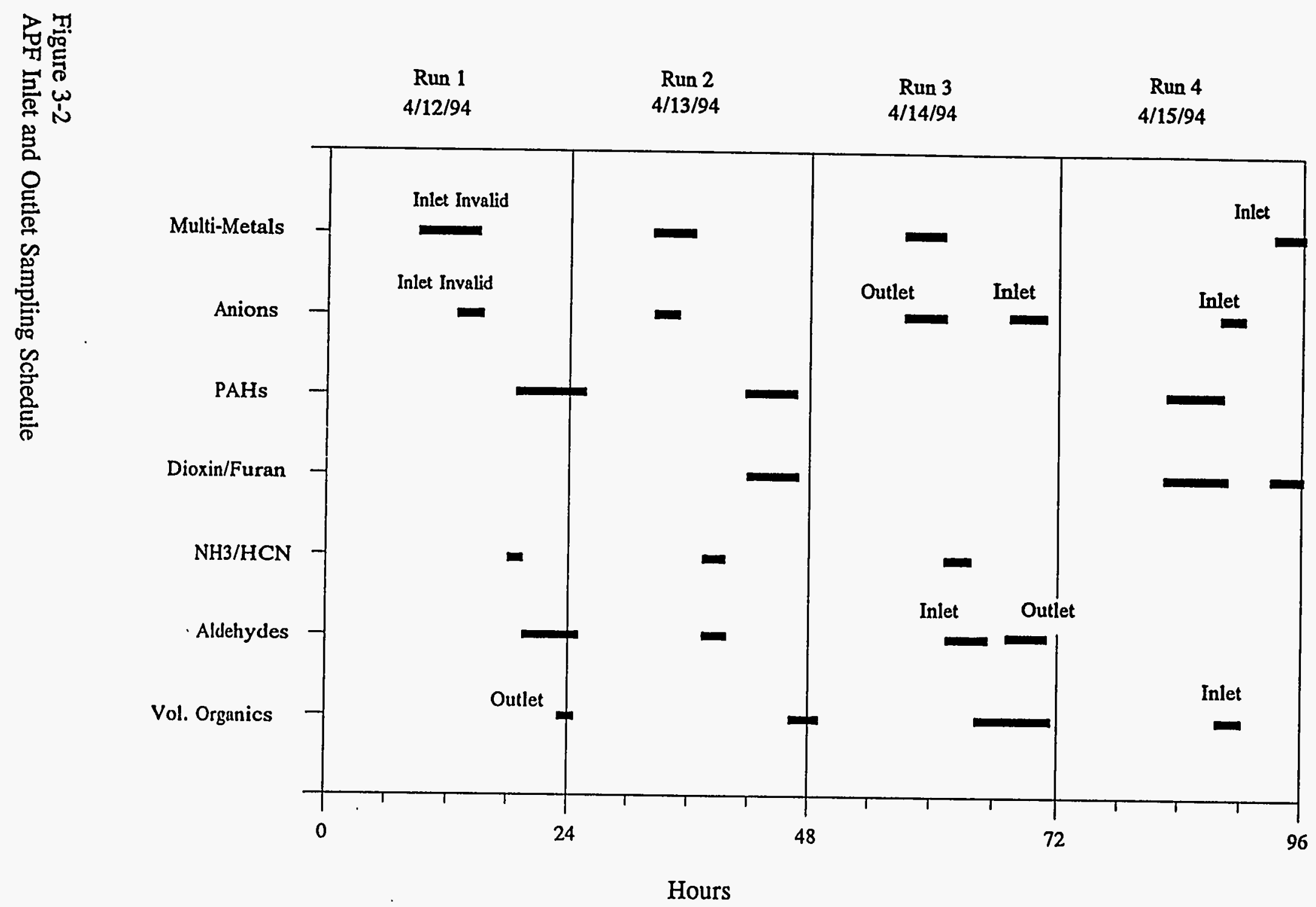




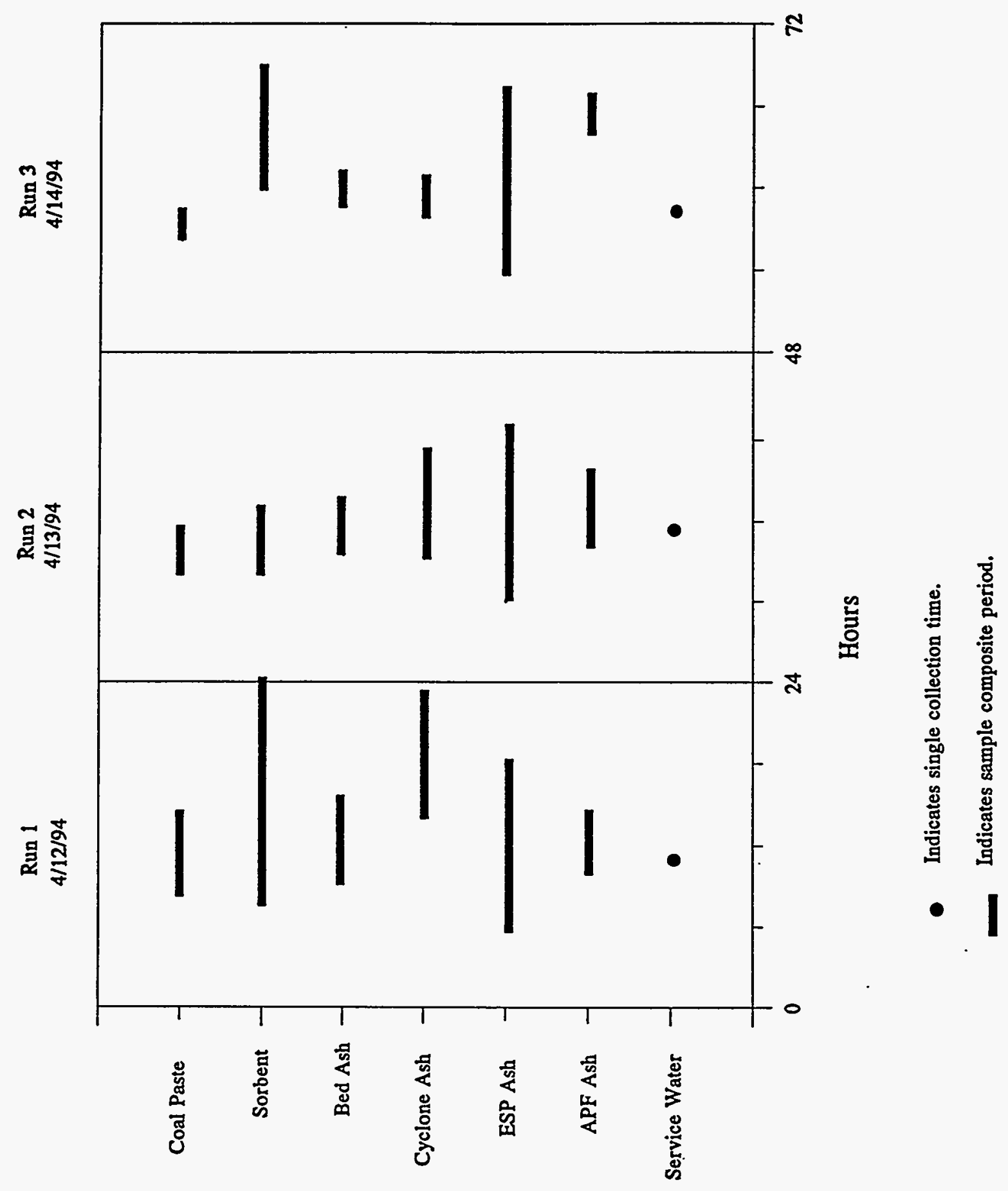

Figure 3-3

Sample Times for Solid and Liquid Process Streams 
To determine the total concentration for gas streams within a run, both the solid- and vaporphase contributions were considered; however, the absence of some detectable concentrations in either (or both) phase(s) required that conventions be developed for dealing with these data. These conventions are summarized below:

Case 1: The concentrations in both the solid and vapor phases are above detection limits.

Case 2: The concentrations in both the solid and vapor phases are below detection limits.

Case 3: The concentration in one phase is above the detection limit, and the concentration in the other phase is below the detection limit.

For inorganic constituents of interest other than $\mathrm{HF}, \mathrm{HCl}, \mathrm{NH}_{3}, \mathrm{HCN}$, and mercury, the flue gas stream data from previous studies of coal-fired power plants have shown that most of the material is present in the solid phase, and that only a small fraction is generally found in the vapor phase. The opposite is generally true for organic species. Thus, the following conventions were selected for defining the total gas stream concentrations:

- For Case 1, the total concentration is the sum of the concentrations in the vapor and solid phases.

For example, the total selenium concentration in the ESP inlet gas for Run 1 is calculated as follows:

Selenium in the solid phase $=52 \mu \mathrm{g} / \mathrm{Nm}^{3}$

Selenium in the vapor phase $=20 \mu \mathrm{g} / \mathrm{Nm}^{3}$

Total selenium in the ESP inlet gas $=72 \mu \mathrm{g} / \mathrm{Nm}^{3}$

- For Case 2, the total conceritration is considered to be the detection limit in the solid phase. 
For example, the total silver concentration in the ESP inlet gas for Run 1 is calculated as follows:

Silver in the solid phase $=\mathrm{ND}(2.1) \mu \mathrm{g} / \mathrm{Nm}^{3}$

Silver in the vapor phase $=\mathrm{ND}(1.6) \mu \mathrm{g} / \mathrm{Nm}^{3}$

Total silver in the ESP inlet gas $=\mathrm{ND}(2.1) \mu \mathrm{g} / \mathrm{Nm}^{3}$

- For Case 3, multiple conventions have been established, depending on the group of substances being considered.

For metals train results, if the substance is not detected in the solid phase and detected in the vapor phase at levels below the detection limit of the solid phase, the total concentration is reported as the detection limit of the solid phase and total is flagged to note that the substance was detected at low levels in the vapor phase.

For example, the total antimony concentration in the ESP inlet gas for Run 1 is calculated as follows:

Antimony in the solid phase $=\mathrm{ND}(3.2) \mu \mathrm{g} / \mathrm{Nm}^{3}$

Antimony in the vapor phase $=0.016 \mu \mathrm{g} / \mathrm{Nm}^{3}$

Total antimony in the ESP inlet gas $=\mathrm{ND}(3.2) \mu \mathrm{g} / \mathrm{Nm}^{3}$

For metals train results, if the substance is not detected in the vapor phase and detected in the solid phase, the vapor-phase component is considered to be equal to zero.

For example, the total lead concentration in the ESP inlet gas for Run 1 is calculated as follows:

Lead in the solid phase $=76 \mu \mathrm{g} / \mathrm{Nm}^{3}$ 
Lead in the vapor phase $=\mathrm{ND}(0.005) \mu \mathrm{g} / \mathrm{Nm}^{3}$

Total lead in the ESP inlet gas $=76 \mu \mathrm{g} / \mathrm{Nm}^{3}$

For semivolatile organic compounds, if the substance is not detected in the solid phase and detected in the vapor phase, the reported total is the concentration in the vapor phase.

For example, the total 2-chloronaphthalene concentration in the APF inlet gas for Run 1 is (refer to Table 3-15) calculated as follows:

2-chloronaphthalene in the solid phase $=\mathrm{ND}(0.09) \mathrm{ng} / \mathrm{Nm}^{3}$

2-chloronaphthalene in the vapor phase $=5.9 \mathrm{ng} / \mathrm{Nm}^{3}$

Total 2-chloronaphthalene in the ESP inlet gas $=5.9 \mathrm{ng} / \mathrm{Nm}^{3}$

Historical test data for conventional power systems has indicated that $\mathrm{HCl}, \mathrm{HF}$, and mercury are present primarily in the vapor phase (although mercury is sometimes also detected in the solid phase). One would also expect that semivolatile organic compounds would be primarily associated with the vapor phase. For Case 2, the total concentration of each of these species is considered to be the detection limit in the vapor phase. For Cases 1 and 3 , the methodologies are unchanged from those described above.

The following criteria were used when averaging the results of different runs:

- When all values for a given variable were above the detection limit, the mean concentration was calculated as the true arithmetic mean.

- For results that included values both above and below the detection limit, one-half the detection limit was used to calculate the mean. For example:

\begin{tabular}{lll} 
Analytical Values & Calculation & Mean Value \\
\hline $10,12, \mathrm{ND}(8)$ & {$[10+12+(8 / 2)] / 3$} & 8.7
\end{tabular}


By convention, the calculated mean is not allowed to be smaller than the largest detection limit value. In the following example, using one-half the detection limit would yield a calculated mean of 2.8. This is less than the highest detection limit obtained; therefore, the reported mean is $\mathrm{ND}(4)$.

Analytical Values

$5, \mathrm{ND}(4), \mathrm{ND}(3)$
Calculation

$[5+(4 / 2)+(3 / 2)] / 3=2.8$
Mean Value

$\mathrm{ND}(4)$

- When all analytical results for a given variable are below the detection limit, the mean is reported as $\mathrm{ND}(\mathrm{x})$, where the $\mathrm{x}$ is the largest detection limit. The bias estimate (used where calculating confidence intervals for other parameters) is one-half of the detection level, and no confidence interval is reported.

Calculations were performed with unrounded numbers, and the results were rounded for presentation in the tables; therefore, slight differences in calculated means and confidence intervals are attributable to round-off errors.

\section{Coal and Dolomite}

Tables 3-1 and 3-2 show the analytical results for the coal paste and sorbent samples, respectively. Appendix A describes the analytical methods used for each combination of substance and stream. Measurements of the concentrations reported here were made using what Radian considered to be the best method for each matrix. Typically, the method with the lowest detection limit was chosen, except when QA/QC audit results indicated significant problems with precision or bias for a particular technique. Additional information regarding selection of data is provided in Section 4. For each substance, a mean was calculated, along with the $95 \%$ confidence interval about the mean. The confidence interval is the range about the mean wherein the probability is $95 \%$ that he true mean lies. For example, according to the three results shown in Table 3-1, it can be said, with $95 \%$ certainty, that the true mean 
Table 3-1

\section{Coal Paste Composition ( $\mu \mathrm{g} / \mathrm{g}$, dry unless noted)}

\begin{tabular}{|c|c|c|c|c|c|c|}
\hline Substance & $\begin{array}{l}\text { Analytical } \\
\text { Method }\end{array}$ & Run 1 & Run 2 & Run 3 & Mean & $95 \% \mathrm{CI}$ \\
\hline Date & & $4 / 12 / 94$ & $4 / 13 / 94$ & $4 / 14 / 94$ & & \\
\hline Gross Load (MW) & DAS & 46 & 46 & 45 & & \\
\hline Coal Paste Rate (lb/hr, dry) & DAS & 33,750 & 33,570 & 33,020 & 33,500 & 940 \\
\hline Coal Paste Solids (wt\%) & Gravimetric & 75.0 & 74.6 & 75.1 & 74.9 & 0.7 \\
\hline HHV (Btu/lb, dry) & Proximate & 12,900 & 12,700 & 12,600 & 12,700 & 380 \\
\hline Ash (wt \%, dry) & Ultimate & 11.2 & 11.8 & 14.1 & 12 & 4 \\
\hline Sulfur (wt $\%$, dry) & Ultimate & 3.1 & 3.4 & 3.6 & 3.4 & 0.6 \\
\hline \multicolumn{7}{|l|}{ Major Species } \\
\hline Aluminum & INAA & 14,800 & 15,300 & 16,800 & 15,600 & 2,600 \\
\hline Calcium & ICP-AES & 1,100 & 1,400 & 1,400 & 1,300 & 430 \\
\hline Iron & INAA & 20,200 & 17,200 & 23,200 & 20,200 & 7,500 \\
\hline Magnesium & ICP-AES & 840 & 820 & 910 & 860 & 120 \\
\hline Potassium & INAA & 5,040 & 4,310 & 3,540 & 4,300 & 1,900 \\
\hline Sodium & INAA & 310 & 407 & 297 & 340 & 150 \\
\hline Titanium & ICP-AES & 680 & 680 & 720 & 690 & 60 \\
\hline \multicolumn{7}{|l|}{ Target Species } \\
\hline Antimony & INAA & 0.44 & 0.47 & 0.52 & 0.48 & 0.10 \\
\hline Arsenic & INAA & 38 & 50 & 48 & 45 & 17 \\
\hline Barium & ICP-AES & 49 & 51 & 61 & 54 & 16 \\
\hline Beryllium & ICP-AES & 1.7 & 1.5 & 1.6 & 1.6 & 0.3 \\
\hline Boron & ICP-AES & 79 & 83 & $\operatorname{ND}(3.0)$ & 55 & 114 \\
\hline Cadmium & GFAAS & 0.080 & 0.060 & 0.19 & 0.11 & 0.17 \\
\hline Chlorine & SIE & 990 & 1,300 & 1,200 & 1,200 & 390 \\
\hline Chromium & ICP-AES & 15 & 17 & 17 & 16 & 3 \\
\hline Cobalt & INAA & 3.7 & 3.9 & 4.2 & 3.9 & 0.6 \\
\hline Copper . & ICP-AES & 6.8 & 6.7 & 7.4 & 7.0 & 0.9 \\
\hline Fluorine & SIE & 120 & 99 & 120 & 110 & 30 \\
\hline Lead & GFAAS & 6.0 & 6.0 & 7.0 & 6.3 & 1.4 \\
\hline Manganese & INAA & 22 & 26 & 29 & 26 & 9. \\
\hline Mercury & CVAAS & 0.16 & 0.16 & 0.13 & 0.15 & 0.04 \\
\hline Molybdenum & INAA & 1.2 & 0.30 & ND (0.51) & 0.58 & 1.3 \\
\hline Nickel & INAA & 12 & 8 & 18 & 13 & 12 \\
\hline Phosphorus & ICP-AES & 90 & 97 & 100 & 96 & 13 \\
\hline Selenium & INAA & 1.6 & 1.8 & 1.9 & 1.8 & 0.4 \\
\hline Silver & INAA & 0.80 & 0.44 & 0.64 & 0.63 & 0 \\
\hline Vanadium & INAA & 25 & 21 & 26 & 24 & 6 \\
\hline
\end{tabular}

$\mathrm{CI}=$ Confidence interval.

ND $=$ Not detected at the concentration in parentheses. 
Table 3-2

Sorbent Composition ( $\mu \mathrm{g} / \mathrm{g}$, as fired unless noted)

\begin{tabular}{|c|c|c|c|c|c|c|}
\hline Substance & $\begin{array}{l}\text { Analytical } \\
\text { Method }\end{array}$ & Run 1 & Run 2 & Run 3 & Mean & $95 \% \mathrm{CI}$ \\
\hline Date & & $4 / 12 / 94$ & $4 / 13 / 94$ & $4 / 14 / 94$ & & \\
\hline $\begin{array}{l}\text { Flow Rate } \\
\text { (lb/hr, as fired) }\end{array}$ & DAS & 18,000 & 21,000 & 19,000 & 19,300 & 3,800 \\
\hline \multicolumn{7}{|l|}{ Major Species } \\
\hline Aluminum & ICP-AES & 659 & 662 & 632 & 651 & 41 \\
\hline Calcium & ICP-AES & 193,000 & 192,000 & 193,000 & 193,000 & 1,400 \\
\hline Iron & ICP-AES & 2,130 & 2,430 & 2,160 & 2,240 & 410 \\
\hline Magnesium & ICP-AES & 106,000 & 106,000 & 106,000 & 106,000 & 0 \\
\hline Potassium & ICP-AES & 240 & 218 & 255 & 238 & 46 \\
\hline Sodium & ICP-AES & 194 & 19.8 & 202 & 198 & 10 \\
\hline Titanium & ICP-AES & 7.49 & 10.9 & 9.65 & 9.35 & 4.29 \\
\hline Sulfate & IC & 6,420 & 6,370 & 6,460 & 6,420 & 110 \\
\hline \multicolumn{7}{|l|}{ Target Species } \\
\hline Antimony & ICP-AES & ND (4.9) & ND (5.5) & $\mathrm{ND}(5.5)$ & ND (5.5) & - \\
\hline Arsenic & GFAAS & 2.2 & 2.1 & 1.2 & 1.9 & 1.3 \\
\hline Barium & ICP-AES & 3.5 & 3.5 & 3.4 & 3.5 & 0.09 \\
\hline Beryllium & ICP-AES & 0.049 & $\mathrm{ND}(0.031)$ & ND $(0.031)$ & ND (0.031) & - \\
\hline Boron & ICP-AES & 33 & 31 & 34 & 33 & 3 \\
\hline Cadmium & GFAAS & 0.14 & 0.17 & 0.093 & 0.14 & 0.10 \\
\hline Chloride & SIE & 370 & 340 & 250 & 320 & 160 \\
\hline Chromium & ICP-AES & 2.8 & 2.9 & 2.9 & 2.8 & 0.1 \\
\hline Cobalt & ICP-AES & 0.46 & ND (0.5) & $\mathrm{ND}(0.50)$ & $\mathrm{ND}(0.5)$ & - \\
\hline Copper & ICP-AES & ND $(0.42)$ & ND (0.47) & $\mathrm{ND}(0.47)$ & ND $(0.47)$ & - \\
\hline Fluoride & SIE & 300 & 210 & 140 & 210 & 200 \\
\hline Lead & GFAAS & 7.3 & 6.2 & 7.2 & 6.9 & .2 \\
\hline Manganese & ICP-AES & 72 & 73 & 72 & 72 & 1 \\
\hline Mercury & CVAAS & ND (0.012) & ND $(0.012)$ & ND (0.012) & $\mathrm{ND}(0.012)$ & - \\
\hline Molybdenum & ICP-AES & 1.4 & 1.3 & 1.6 & 1.5 & 0.4 \\
\hline Nickel & ICP-AES & 20 & 17 & 1 & 12 & 26 \\
\hline Phosphorus & ICP-AES & $\mathrm{ND}(6.1)$ & $\mathrm{ND}(6.8)$ & $\mathrm{ND}(6.8)$ & $\mathrm{ND}(6.8)$ & - \\
\hline Selenium & GFAAS & 0.90 & 0.48 & 0,98 & 0.79 & 0.68 \\
\hline Silver & ICP-AES & $\mathrm{ND}(0.37)$ & ND (0.41) & ND (0.41) & ND (0.41) & - \\
\hline Vanadium & ICP-AES & 4.8 & 4.9 & 5.2 & 4.9 & 0.5 \\
\hline
\end{tabular}

$\mathrm{CI}=$ Confidence interval.

$\mathrm{ND}=$ Not detected at the concentration in parentheses. 
arsenic concentration in the coal paste was between 28 and $62 \mu \mathrm{g} / \mathrm{g}$. Calculation of this confidence interval is discussed in Section 5.

For those substance which could not be quantified, the notation " $\mathrm{ND}(x)^{\circ}$ is used. This means "not detected at a concentration of $x$." The detection limit can vary according to sample size, sample preparation, and analytical method. All of the target species were detected in the coal paste. Levels of the target species were generally nuch lower in the sorbent, with the exception of fluoride, manganese and molybdenum.

\section{Ash Streams}

Tables 3-3 and 3-4 show the mean compositions of inorganic and organic species in the bed ash, cyclone ash, APF ash, and ESP ash. The ESP ash sample represents ash collected from the first two hoppers of the ESP. Composite samples were prepared by combining ESP ash collected from Hopper 1 with ash from Hopper 2 in a ratio of 90:10, respectively.

The compositions of the ash streams illustrate the differences and similarities between solid byproducts produced by conventional pulverized coal (PC) and PFBC combustion. The bed ash from the PFBC system is a dense, coarse material consisting prima-Iy of sulfated lime, unreacted lime, magnesite, and char, making it very different from PC iyproducts. Trace metals, which can either volatilize in the combustion process or volatiliza/recondense on the fine particulate matter, are present at relatively low levels in the bed marerial compared to the other ash streams. The cyclone ash is comparable to fly ash from a PC unit, with the exception that it contains a significant amount of spent sorbent material. The ESP and APF ashes are very similar to the ash produced in a conventional PC boiler (i.e., higher levels of aluminum, potassium, sodium, and titanium). These ashes contain smarer amounts of spent dolomite and a greater percentage of the fine coal ash particulate; thereiore, concentrations of trace metals are highest in these two streams due to the volatilization condensation mechanism associated with the fine particulate. This is particularly evicient for beryllium and lead where the concentrations in the ESP ash are 12 to 17 times higher man the concentration in the bed ash. Concentrations of major coal elements such as aluminum and titanium are 
$\stackrel{\omega}{\stackrel{\omega}{*}}$ Table 3-3

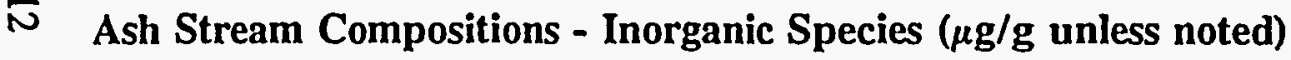

\begin{tabular}{|c|c|c|c|c|c|c|c|c|c|}
\hline \multirow[b]{2}{*}{ Substance } & \multirow{2}{*}{$\begin{array}{c}\text { Analytical } \\
\text { Method }\end{array}$} & \multicolumn{2}{|c|}{ Bed Ash } & \multicolumn{2}{|c|}{ Cyclone Ash } & \multicolumn{2}{|c|}{ APF Ash } & \multicolumn{2}{|c|}{ ESP Ash } \\
\hline & & Mean & $95 \% \mathrm{CI}$ & Mean & $95 \% \mathrm{CI}$ & Mean & $95 \% \mathrm{CI}$ & Mean & $95 \% \mathrm{CI}$ \\
\hline Flow Rate $(\mathrm{lb} / \mathrm{hr})$ & & 9,300 & 2,100 & 10,300 & 3,290 & 313 & 61 & 775 & 76 \\
\hline \multicolumn{10}{|l|}{ Major Species } \\
\hline Aluminum & ICI-AI:S & 8,900 & $7,0.50$ & $31,9(x)$ & $2,8(0)$ & $54,8(X)$ & 5,380 & 60,400 & $10,1(x)$ \\
\hline Calcium & ICP-AES & 164,000 & 8,600 & 124,000 & 8,960 & 87,500 & 7,430 & 89,700 & 15,000 \\
\hline Iron & ICP-AES & 15,300 & 13,700 & 50,200 & 1,940 & 28,700 & 1,250 & 27,400 & 2,500 \\
\hline Mugnnміuแ! & ICP-AI:S & 125.000 & 18,000 & $71), 300$ & 1,190 & 16,500 & 4,770 & 45,600 & 5,800 \\
\hline Potassium & ICP-AES & 1,010 & 1,000 & 6,350 & 960 & 12,600 & 1,030 & 15,400 & 1,320 \\
\hline Sodium & ICP-AES & 219 & 65 & 963 & 217 & 2,100 & 240 & 2,600 & 90 \\
\hline Titanium & ICP-AES & 485 & 390 & 1,670 & 170 & 2,920 & 370 & 3,760 & 360 \\
\hline Carbon (wt\%) & Ultimate & 3.5 & 0.5 & 5.3 & 0.4 & 0.1 & 0.1 & 0.23 & 0.48 \\
\hline Sulfur (wt\%) & Ultimate & 7.8 & 0.8 & 3.9 & 0.3 & 16 & 2.3 & 9.2 & 20 \\
\hline \multicolumn{10}{|l|}{ Target Species } \\
\hline Antimony & ICP-AES & ND (54) & -- & ND (40) & - & ND (50) & - & ND (59) & - \\
\hline Arsenic & :GFAAS & 71 & 27 & 93 & 16 & 270 & 71 & 380 & 62 \\
\hline Barium & ICP-AES & 34 & 25 & 150 & 16 & 200 & 31 & 220 & 29 \\
\hline Beryllium & ICP-AES & 0.65 & 0.49 & 3.8 & 1.2 & 6.5 & 2.1 & 8.0 & 2.4 \\
\hline Boron & ICP-AES & 96 & 16 & 110 & 29 & 310 & 630 & 60 & 130 \\
\hline Cadmium & GFAAS & ND (1.6) & - & 0.35 & 0.21 & 1.6 & 0.1 & 1.9 & 0.2 \\
\hline Chloride & SIE & 890 & 380 & 360 & 110 & 110 & 380 & $\mathrm{ND}(78)$ & - \\
\hline Chromium & ICP-AES & 19 & 6 & 44 & 4 & 74 & 8 & 94 & 10 \\
\hline Cobalt & ICP-AES & 13 & 5 & 13 & 5 & 16 & 7 & 22 & 6 \\
\hline Copper & ICP-AES & ND (4.6) & - & ND (3.7) & -. & $\mathrm{ND}(4.2)$ & - & 6.5 & 12 \\
\hline
\end{tabular}


Table 3-3 (Continued)

\begin{tabular}{|c|c|c|c|c|c|c|c|c|c|}
\hline \multirow[b]{2}{*}{ Substance } & \multirow{2}{*}{$\begin{array}{l}\text { Analytical } \\
\text { Method }\end{array}$} & \multicolumn{2}{|c|}{ Bed Ash } & \multicolumn{2}{|c|}{ Cyclone Ash } & \multicolumn{2}{|c|}{ APF Ash } & \multicolumn{2}{|c|}{ ESP Ash } \\
\hline & & Mean & $95 \% \mathrm{CI}$ & Mean & $95 \% \mathrm{CI}$ & Mean & $95 \%$ CI & Mean & $95 \% \mathrm{CI}$ \\
\hline Fluoride $^{\mathrm{a}}$ & SIE & 100 & 14 & 110 & 93 & ND (12) & - & 110 & 91 \\
\hline Lead & GFAAS & 5.0 & 3.2 & 19 & 6 & 69 & 19 & 84 & 48 \\
\hline Manganese & ICP-AES & 100 & 32 & 110 & 7 & 100 & 5 & 110 & 9 \\
\hline Mercury & CVAAS & ND $(0.010)$ & - & ND (0.012) & - & $\mathrm{ND}(0.012)$ & - & $\mathrm{ND}(0.012)$ & - \\
\hline Molybdenum & ICP-AES & ND (3.5) & - & ND (2.8) & - & ND (3.3) & -- & ND (3.8) & - \\
\hline Nickel & ICP-AES & $N D(11)$ & $\cdots$ & 14 & 36 & 29 & 29 & 50 & 38 \\
\hline Phosphorus & ICP-AES & $\mathrm{ND}(70)$ & - & $\mathrm{ND}(71)$ & - & $\mathrm{ND}(71)$ & - & $\mathrm{ND}(71)$ & - \\
\hline Selenium & GFAAS & 4.6 & 1.4 & 4.0 & 7.6 & ND (0.99) & . $\quad-$ & 4.9. & 1.2 \\
\hline Silver & ICP-AES & ND (4.1) & $m$ & $\mathrm{ND}(3.3)$ & $-\cdots$ & ND (3.8) & - & $\mathrm{ND}(4.4)$ & - \\
\hline Vanadium & ICP-AES & 20 & 10 & 55 & 12 & 87 & 13 & 120 & 17 \\
\hline
\end{tabular}

a $Q A / Q C$ results and material balance evaluations indicate that ash stream results are likely biased low.

$\mathrm{Cl}=$ Confidence interval.

ND $=$ Not detected at the concentration in parentheses. 
$\stackrel{\sim}{\leftrightarrows}$ Table 3-4

Ғ Ash Stream Compositions - Organic Species ( $\mu \mathrm{g} / \mathrm{g}$, unless noted)

\begin{tabular}{|c|c|c|c|c|c|c|c|c|}
\hline \multirow[b]{2}{*}{ Substance } & \multicolumn{2}{|c|}{ Bed Ash } & \multicolumn{2}{|c|}{ Cyclone Ash } & \multicolumn{2}{|c|}{ AṔF Ash } & \multicolumn{2}{|c|}{ ESP Ash } \\
\hline & Mean & $95 \% \mathrm{CI}$ & Mean & $95 \% \mathrm{CI}$ & Mean & 95\% CI & Mean & 95\% CI \\
\hline Flow Rate $(\mathrm{lb} / \mathrm{hr})$ & $.9,300$ & 2,100 & 10,300 & 3,290 & 313 & 61 & 775 & 76 \\
\hline \multicolumn{9}{|c|}{ Semivolatile Organic Species } \\
\hline bis(2-Ethylhexyl)phthalate & $\mathrm{ND}(0.05)$ & - & $\mathrm{ND}(0.05)$ & - & $\mathrm{ND}(0.05)$ & - & 0.34 & 0.91 \\
\hline \multicolumn{9}{|c|}{ Dioxin and Furan Species (pg/g) } \\
\hline $1,2,3,4,6,7,8-\mathrm{HpCDD}$ & NS & - & $\mathrm{ND}(0.9)$ & - & $\mathrm{ND}(0.6)$ & - & 1.4 & 1.0 \\
\hline $2,3,4,6,7,8-\mathrm{HxCDF}$ & NS & - & $\mathrm{ND}(0.4)$ & - & 0.3 & 0.3 & $\mathrm{ND}(0.8)$ & - \\
\hline Total HpCDD & NS & - & $\mathrm{ND}(0.9)$ & - & $\mathrm{ND}(0.6)$ & - & 2.3 & 1.0 \\
\hline Total HxCDD & NS & -- & $\mathrm{ND}(0.7)$ & - & $\mathrm{ND}(0.4)$ & - & 5.8 & 1.8 \\
\hline Total HxCDF & NS & - & $\mathrm{ND}(0.4)$ & .- & 0.3 & 0.3 & $\mathrm{ND}(0.8)$ & -- \\
\hline Total PeCDD & NS & -- & $\mathrm{ND}(0.7)$ & $\cdots$ & $\mathrm{ND}(0.4)$ & - & 4.6 & 1.5 \\
\hline Total TCDD & NS & - & $\mathrm{ND}(0.4)$ & -- & $\mathrm{ND}(0.3)$ & -- & 3.2 & 0.9 \\
\hline
\end{tabular}

$\mathrm{CI}=$ Confidence interval.

$\mathrm{ND}=$ Not detected at the concentration in parentheses.

NS $=$ Not sampled.

HpCDD = Heptachlorodibenzo-p-dioxin.

$\mathrm{H} x \mathrm{CDF}=$ Hexachlorodibenzofuran

$\mathrm{H} \times \mathrm{CDD}=$ Hexachlorodibenzo-p-dioxin.

PeCDD $=$ Pentachlorodibenzo-p-dioxin.

TCDD $=$ Tetrachlorodibenzo-p-dioxin. 
generally five to seven times higher in the ESP ash than in the bed ash. Enrichment factors for ash streams relative to the ash in the coal/dolomite feed were not calculated as part of this study. The coal ash content and trace species composition shown in Table 3-1 can be used in conjunction with the ash stream elemental compositions shown in Table 3-3 to calculate enrichment factors for each ash stream. It is also interesting to note the difference in the carbon content of the various ash streams. The bed ash and cyclone ash contain roughly $4 \%$ to $5 \%$ carbon, whereas the APF ash and ESP ash contain about $0.1 \%$ to $0.2 \%$ carbon.

None of the target semivolatile organic compounds were present in the ash stream at levels above the detection limits, with the exception of bis(2-ethylhexyl)phthalate in the ESP ash. Levels of this compound in the three ESP ash samples ranged from $0.06 \mu \mathrm{g} / \mathrm{g}$ to $0.75 \mu \mathrm{g} / \mathrm{g}$. Phthalate esters are typical plasticizers commonly attributed to plastic bottles, bags, etc., used in the field laboratory environment. Although all samples for organic compound analyses were collected in glass jars, the presence of this phthalate compound is most likely due to contamination.

Results for dioxin and furan compounds indicate that none of the target compounds were detected in the cyclone ash samples. 2,3,4,6,7,8-hexachlorodibenzofuran and total hexachlorodibenzofuran were detected in all three APF ash samples at a mean concentration of $0.3 \mathrm{pg} / \mathrm{g}$ (picograms/gram). 1,2,3,4,6,7,8-heptachlorodibenzo-p-dioxin, total heptachlorodibenzo-p-dioxin, total hexachlorodibenzo-p-dioxin, total pentachlorodibenzo-pdioxin, and total trichlorodibenzo-p-dioxin were detected in all three ESP ash samples at concentrations in the range of 1.4 to $5.8 \mathrm{pg} / \mathrm{g}$.

\section{Service Water}

Characterization data for the plant service water are shown in Table 3-5. Levels of target inorganic species indicate that the service water does not contribute significant amounts of these species to the process. 
Table 3-5

Service Water Composition ( $\mu \mathrm{g} / \mathrm{mL}$ unless noted)

\begin{tabular}{|c|c|c|c|c|c|c|}
\hline Substance & $\begin{array}{l}\text { Analytical } \\
\text { Method }\end{array}$ & Run 1 & Run 2 & Run 3 & Mean & $95 \% \mathrm{CI}$ \\
\hline Date & & $4 / 12 / 94$ & $4 / 13 / 94$ & $4 / 14 / 94$ & & \\
\hline Flow Rate $(\mathrm{lb} / \mathrm{hr})$ & DAS & 11,250 & 11,430 & 10,980 & 11,220 & 570 \\
\hline Flow Rate $(\mathrm{L} / \mathrm{hr})$ & DAS & 5,100 & 5,200 & 5,000 & 5,100 & 250 \\
\hline \multicolumn{7}{|l|}{ Major Species } \\
\hline Aluminum & ICP-AES & 1.3 & 2.2 & 1.9 & 1.8 & 1.2 \\
\hline Calcium & ICP-AES & 24 & 26 & 22 & 24 & 5 \\
\hline Iron & ICP-AES & 3.0 & 4.7 & 4.5 & 4.1 & 2.3 \\
\hline Magnesium & ICP-AES & 6.3 & 6.7 & 5.8 & 6.2 & 1.2 \\
\hline Potassium & ICP-AES & 1.6 & 1.8 & 1.8 & 1.7 & 0.3 \\
\hline Sodium & ICP-AES & 10 & 11 & 10 & 10 & 1 \\
\hline Sulfate & IC & 59 & 58 & 47 & 55 & 17 \\
\hline Phosphorus & ICP-AES & $\mathrm{ND}(0.06)$ & $\mathrm{ND}(0.06)$ & $\mathrm{ND}(0.06)$ & $\mathrm{ND}(0.06)$ & - \\
\hline $\begin{array}{l}\text { Total phosphate } \\
\text { (as P) }\end{array}$ & Colorimetry & $\mathrm{ND}(0.02)$ & $\mathrm{ND}(0.02)$ & 0.03 & $\mathrm{ND}(0.02)$ & - \\
\hline \multicolumn{7}{|l|}{ Target Species } \\
\hline Antimony & ICP-AES & $\mathrm{ND}(0.076)$ & $\mathrm{ND}(0.076)$ & $\mathrm{ND}(0.076)$ & $\mathrm{ND}(0.076)$ & - \\
\hline Arsenic & GFAAS & $\mathrm{ND}(0.00065)$ & 0.0011 & 0.0017 & 0.0011 & 0.0017 \\
\hline Barium & ICP-AES & 0.049 & 0.069 & 0.066 & 0.061 & 0.027 \\
\hline Beryllium & ICP-AES & 0.0016 & 0.00054 & 0.0046 & 0.0022 & 0.0052 \\
\hline Boron & ICP-AES & 0.043 & 0.041 & 0.042 & 0.042 & 0.002 \\
\hline Cadmium & GFAAS & $\mathrm{ND}(0.00027)$ & $\mathrm{ND}(0.00027)$ & $\mathrm{ND}(0.00027)$ & $\mathrm{ND}(0.00027)$ & - \\
\hline Chloride & IC & 12 & 12 & 12 & 12 & 1 \\
\hline Chromium & ICP-AES & $\mathrm{ND}(0.0052)$ & $\mathrm{ND}(0.0052)$ & 0.00788 & $\mathrm{ND}(0.0052)$ & - \\
\hline Cobalt & ICP-AES & 0.0071 & 0.0046 & $\mathrm{ND}(0.0041)$ & 0.0046 & 0.0063 \\
\hline Copper & ICP-AES & 0.013 & 0.017 & 0.021 & 0.017 & 0.010 \\
\hline Lead & GFAAS & 0.0063 & 0.012 & 0.013 & 0.010 & 0.009 \\
\hline Manganese & ICP-AES & 0.29 & 0.44 & 0.43 & 0.39 & 0.21 \\
\hline Mercury & CVAAS & $\mathrm{ND}(0.00003)$ & $\mathrm{ND}(0.00003)$ & $\mathrm{ND}(0.00003)$ & $\mathrm{ND}(0.00003)$ & - \\
\hline Molybdenum & ICP-AES & $\mathrm{ND}(0.0074)$ & $\mathrm{ND}(0.0074)$ & 0.00739 & $\mathrm{ND}(0.0074)$ & - \\
\hline Nickel & ICP-AES & $\mathrm{ND}(0.014)$ & $\mathrm{ND}(0.014)$ & 0.0145 & $\mathrm{ND}(0.014)$ & - \\
\hline Selenium & GFAAS & $\mathrm{ND}(0.0018)$ & $\mathrm{ND}(0.0018)$ & $\mathrm{ND}(0.0018)$ & $\mathrm{ND}(0.0018)$ & - \\
\hline Silver & ICP-AES & $\mathrm{ND}(0.0052)$ & $\mathrm{ND}(0.0052)$ & $\mathrm{ND}(0.0052)$ & $\mathrm{ND}(0.0052)$ & - \\
\hline Titanium & ICP-AES & 0.014 & 0.023 & 0.025 & 0.021 & 0.015 \\
\hline Vanadium & ICP-AES & 0.0053 & $\mathrm{ND}(0.0045)$ & 0.0076 & 0.0051 & 0.0066 \\
\hline
\end{tabular}




\section{ESP Inlet and Outlet Gas}

\section{Inorganic Species}

Tables 3-6 and 3-7 show the concentrations of the target inorganic analytes in the ESP inlet and outlet gas streams, respectively. The data are presented as solid and vapor-phase compositions, along with the mean concentrations and confidence intervals of the combined phases. Although the data are presented as solid- and vapor-phase concentrations, it is important to note that the Method 29 multi-metals train has not been validated by EPA for determination of phase splits. For ease of interpretation, researchers typically assume that the material collected on the filter represents the solid-phase composition, while the material collected in the impinger solutions represent vapor-phase composition. It is possible for extremely fine particulate matter to penetrate the pores of the filter and be collected in the nitric acid/hydrogen peroxide impinger solution. The gas flow rate data represent the average of the flow rate measurements obtained from all the trains which were traversed in the duct for a given run.

The solid-phase multi-metals train data from the ESP outlet have been corrected for the background levels associated with the quartz filters. At the ESP inlet, filtered gas particulate matter was analyzed separately from the filter media, so background corrections were not necessary. Vapor-phase data have been corrected for the background levels present in the nitric acid/hydrogen peroxide impinger reagent due to the lower detection limits provided by ICP-MS and the significance of the background levels compared to the samples.

Reported solid-phase concentrations for antimony, barium, beryllium, chromium, cobalt, copper, manganese, molybdenum, nickel, silver, vanadium, and all major species were determined by ICP-AES. Arsenic, cadmium, lead, and selenium were determined by GFAAS. Mercury was determined by CVAAS. Chloride and sulfate were determined by IC, while fluoride was determined by SIE. 
$\stackrel{\omega}{\stackrel{\omega}{\omega}}$ Table 3-6

$\stackrel{\infty}{ }$ ESP Inlet Gas Composition - Inorganic Species ( $\mu \mathrm{g} / \mathrm{Nm}^{3}$ unless noted)

\begin{tabular}{|c|c|c|c|c|c|c|c|c|c|c|}
\hline \multirow[b]{2}{*}{ Substance } & \multicolumn{4}{|c|}{ Solid Phase } & \multicolumn{4}{|c|}{ Vapor Phase } & \multicolumn{2}{|c|}{ Total } \\
\hline & Run 1 & Run 2 & Run 3 & Run 4 & Run 1 & Run 2 & Run 3 & Run 4 & Mean & $95 \% \mathrm{CI}$ \\
\hline Date & $4 / 12 / 94$ & $4 / 13 / 94$ & $4 / 14 / 94$ & $4 / 15 / 94$ & $4 / 12 / 94$ & $4 / 13 / 94$ & $4 / 14 / 94$ & $4 / 15 / 94$ & & \\
\hline Gas Flow Rate (dscfm) ${ }^{a}$ & 153,000 & 151,000 & 153,000 & 146,000 & & & & & 151,000 & 5,300 \\
\hline Gas Flow Rate $\left(\mathrm{Nm}^{3} / \mathrm{hr}\right)^{\mathrm{a}}$ & 242,000 & 240,000 & 242,000 & 231,000 & & & & & 239,000 & 8,500 \\
\hline Particulate Matter $(\mathrm{lb} / \mathrm{hr})$ & 778 & 809 & 800 & & & & & & 796 & 39 \\
\hline Particulate Matter $\left(\mathrm{mg} / \mathrm{Nm}^{3}\right)$ & 1,460 & 1,530 & 1,500 & & & & & & 1,500 & 96 \\
\hline \multicolumn{11}{|l|}{ Major Species } \\
\hline Aluminum & 72,600 & 55,900 & 73,500 & NS & 36 & 43 & 66 & NS & 67,400 & 24,600 \\
\hline Calcium & 107,000 & 87,900 & 114,000 & NS & 180 & 260 & 370 & NS & 103,000 & 33,000 \\
\hline Iron & 32,500 & 27,900 & 34,100 & NS & 31 & 30 & 370 & NS & 31,500 & 8,200 \\
\hline Magnesium & 54,400 & 44,900 & 57,600 & NS & 26 & 27 & 58 & NS & 52,300 & 16,500 \\
\hline Phosphorus & 30 & 26 & 30 & NS & $\mathrm{ND}(19)$ & $\mathrm{ND}(19)$ & $\mathrm{ND}(17)$ & NS & 28 & 6 \\
\hline Potassium & 18,000 & 13,100 & 17,800 & NS & $\mathrm{ND}(250)$ & $\mathrm{ND}(250)$ & $\mathrm{ND}(230)$ & NS & 16,300 & 6,870 \\
\hline Sodium & 3,390 & 2,460 & 3,090 & NS & 207 & 294 & 250 & NS & 3,230 & 1,060 \\
\hline Sulfate & $9,441,000$ & $9,151,000$ & $9,260,000$ & NS & 795,000 & 756,000 & 784,000 & NS & $10,100,000$ & 411,000 \\
\hline Titanium & 4,430 & 3,360 & 4,340 & NS & 1.2 & 1.6 & 3.0 & NS & 4,040 & 1,480 \\
\hline \multicolumn{11}{|l|}{ Target Species } \\
\hline Ammonia & NS & NS & NS & NS & 160 & 95 & 120 & NS & 130 & 87 \\
\hline Antimony & $\mathrm{ND}(3.2)$ & $\mathrm{ND}(2.9)$ & ND(76) & NS & 0.016 & 0.016 & 0.017 & NS & ND(76) & - \\
\hline Arsenic & 450 & 380 & 420 & NS & 0.34 & 0.26 & 0.36 & NS & 420 & 87 \\
\hline Barium & 260 & 190 & 270 & NS & $\mathrm{ND}(0.005)$ & $\mathrm{ND}(0.005)$ & $\mathrm{ND}(0.005)$ & NS & 240 & 110 \\
\hline Beryllium & 10 & 6.8 & 8.7 & NS & $\mathrm{ND}(0.005)$ & $\mathrm{ND}(0.005)$ & 0.026 & NS & 8.6 & 4.2 \\
\hline Boron & 1.2 & 2.5 & 4.4 & NS & 200 & 210 & 190 & NS & 200 & 23 \\
\hline
\end{tabular}


Table 3-6 (Continued)

\begin{tabular}{|c|c|c|c|c|c|c|c|c|c|c|}
\hline \multirow[b]{2}{*}{ Substance } & \multicolumn{4}{|c|}{ Solid Phase } & \multicolumn{4}{|c|}{ Vapor Phase } & \multicolumn{2}{|c|}{ Total } \\
\hline & Run 1 & Run 2 & Run 3 & Run 4 & Run 1 & Run 2 & Run 3 & Run 4 & Mean & $95 \% \mathrm{CI}$ \\
\hline Cadmium & 3.7 & 2.3 & 2.3 & NS & 1.1 & 0.22 & 0.15 & NS & 3.2 & 3.3 \\
\hline Chloride & 1,600 & 1,800 & 860 & NS & 68,000 & 67000 & 74,000 & NS & 71,000 & 7,200 \\
\hline Chromium (multi-metals) & 150 & 100 & 120 & NS & 3.8 & 0.76 & 26 & NS & 130 & 60 \\
\hline Cobalt & 22 & 20 & 26 & NS & 0.019 & 0.019 & 1.1 & NS & 23 & 9 \\
\hline Copper & 11 & 17 & $\mathrm{ND}(6.7)$ & NS & 0.63 & 0.23 & 2.4 & NS & 11 & 19 \\
\hline Cyanide & NS & NS & NS & NS & 870 & 610 & 390 & NS & 630 & 590 \\
\hline Fluoride & 4,100 & 3,200 & 2,300 & NS & 7,000 & 6,300 & 6,400 & NS & 9,800 & 3,100 \\
\hline Lead & 76 & 70 & 75 & NS & $\mathrm{ND}(0.005)$ & $\mathrm{ND}(0.005)$ & $\mathrm{ND}(0.005)$ & NS & 73 & 8 \\
\hline Manganese & 130 & 150 & 140 & NS & 1.2 & 1.2 & 3.3 & NS & 140 & 22 \\
\hline Mercury(total) & 0.079 & 0.050 & 0.072 & NS & 15 & 16 & 15 & NS & 16 & 2 \\
\hline Mercury (nitric impingers) & - & - & -- & NS & 12 & 14 & 13 & NS & - & - \\
\hline $\begin{array}{l}\text { Mercury (permanganate } \\
\text { impingers) }\end{array}$ & - & - & -- & NS & 3.4 & 2.1 & 1.7 & NS & - & - \\
\hline Molybdenum & $\mathrm{ND}(1.6)$ & $\mathrm{ND}(3.4)$ & $\mathrm{ND}(1.2)$ & NS & 0.14 & $\mathrm{ND}(0.008)$ & 3.3 & NS & $\mathrm{ND}(3.4)^{b}$ & - \\
\hline Nickel & 50 & 43 & 49 & NS & 0.15 & 0.20 & 29 & NS & 57 & 45 \\
\hline Selenium & 52 & 43 & 41 & NS & 20 & 14 & 17 & NS & 62 & 21 \\
\hline Silver & $\mathrm{ND}(2.1)$ & 0.45 & $\mathrm{ND}(5.7)$ & NS & $\mathrm{ND}(1.6)$ & $\mathrm{ND}(1.6)$ & ND(1.4) & NS & $\mathrm{ND}(5.7)$ & - \\
\hline Vanadium & 130 & 100 & 130 & NS & 1.5 & 0.83 & 0.94 & NS & 120 & 42 \\
\hline
\end{tabular}

Assumed equal to the measured ESP outlet gas flow rate. Measured ESP inlet flow rate are considered non-representative because of the non-ideal sampling location.

${ }^{b}$ Substance detected in the vapor phase at low levels. Reported value is an upper limit.

$\mathrm{CI}=$ Confidence interval.

$\mathrm{ND}=$ Not detected at the concentration in parentheses.

NS $=$ Not sampled. 
$\omega$ Table 3-7

$\widetilde{\sim}$ ESP Outlet Gas Composition - Inorganic Species ( $\mu \mathrm{g} / \mathrm{Nm}^{3}$ unless noted)

\begin{tabular}{|c|c|c|c|c|c|c|c|c|c|c|}
\hline \multirow[b]{2}{*}{ Substance } & \multicolumn{4}{|c|}{ Solid Phase } & \multicolumn{4}{|c|}{ Vapor Phase } & \multicolumn{2}{|c|}{ Total } \\
\hline & Run 1 & Run 2 & Run 3 & Run 4 & Run 1 & Run 2 & Run 3 & Run 4 & Mean & $95 \% \mathrm{CI}$ \\
\hline Date & $4 / 12 / 94$ & $4 / 13 / 94$ & $4 / 14 / 94$ & $4 / 15 / 94$ & $4 / 12 / 94$ & $4 / 13 / 94$ & $4 / 14 / 94$ & $4 / 15 / 94$ & & \\
\hline Gas Flow Rate (dscfm) & 153,000 & 151,000 & 153,000 & 146,000 & & & & & 151,000 & 5,300 \\
\hline Gas Flow Rate $\left(\mathrm{Nm}^{3} / \mathrm{hr}\right)$ & 242,000 & 240,000 & 242,000 & 231,000 & & & & & 239,000 & 8,500 \\
\hline Particulate Matter $(\mathrm{lb} / \mathrm{hr})$ & 33 & 4.4 & 29 & & & & & & 22 & 38 \\
\hline Particulate Matter $\left(\mathrm{mg} / \mathrm{Nm}^{3}\right)$ & 61 & 8.2 & 54 & & & & & & 41 & 72 \\
\hline \multicolumn{11}{|l|}{ Major Species } \\
\hline Aluminum & 140 & 56 & 29 & NS & 38 & 42 & 53 & NS & 120 & 126 \\
\hline Calcium & 270 & 227 & 152 & NS & 213 & 256 & 342 & NS & 490 & 14 \\
\hline Iron & 220 & 705 & 92 & NS & 42 & 48 & 61 & NS & 392 & 793 \\
\hline Magnesium & 110 & 94 & 61 & NS & 25 & 16 & 30 & NS & 114 & 55 \\
\hline Phosphonus & 3.4 & 3.8 & 3.1 & NS & $\mathrm{ND}(16)$ & $\mathrm{ND}(19)$ & ND(16) & NS & 3.4 & 0.8 \\
\hline Potassium & 39 & 24 & 18 & NS & $\mathrm{ND}(210)$ & $\mathrm{ND}(250)$ & $\mathrm{ND}(210)$ & NS & 27 & 26 \\
\hline Sodium & 77 & 48 & 36 & NS & 287 & 310 & 338 & NS & 360 & 23 \\
\hline Sulfate & 450 & 4,940 & 198 & NS & 780,000 & 746,000 & $--^{b}$ & NS & 766,000 & 188,000 \\
\hline Titanium & 16 & 5.9 & 4.0 & NS & 1.2 & 1.6 & 1.8 & NS & 10 & 16 \\
\hline \multicolumn{11}{|l|}{ Target Species } \\
\hline Ammonia & NS & NS & NS & NS & 94 & 130 & 93 & NS & 110 & 54 \\
\hline Antimony & $\mathrm{ND}(2.0)$ & $\mathrm{ND}(2.1)$ & $N D(2.0)$ & NS & 0.013 & 0.017 & 0.023 & NS & $\mathrm{ND}(2.1)^{\mathrm{a}}$ & $\cdots$ \\
\hline Arsenic & 0.78 & 1.1 & 0.63 & NS & 0.16 & 0.24 & 0.26 & NS & 1.0 & 0.5 \\
\hline Barium & 1.9 & 0.19 & 0.11 & NS & $\mathrm{ND}(0.004)$ & $\mathrm{ND}(0.005)$ & $\mathrm{ND}(0.004)$ & NS & 0.74 & 7.5 \\
\hline Beryllium & 0.01 & $\mathrm{ND}(0.012)$ & $\mathrm{ND}(0.011)$ & NS & $\mathrm{ND}(0.004)$ & $\mathrm{ND}(0.005)$ & 0.048 & NS & 0.021 & 0.17 \\
\hline Boron & NA & NA & $\mathrm{NA}$ & NS & 170 & 160 & 160 & NS & 170 & 19 \\
\hline
\end{tabular}


Table 3-7 (Continued)

\begin{tabular}{|c|c|c|c|c|c|c|c|c|c|c|}
\hline \multirow[b]{2}{*}{ Substance } & \multicolumn{4}{|c|}{ Solid Phase } & \multicolumn{4}{|c|}{ Vapor Phase } & \multicolumn{2}{|c|}{ Total } \\
\hline & Run 1 & Run 2 & Run 3 & Run 4 & Run 1 & Run 2 & Run 3 & Run 4 & Mean & $95 \% \mathrm{CI}$ \\
\hline Cadmium & 0.67 & 0.27 & 0.38 & NS & $\mathrm{ND}(0.005)$ & 0.55 & 3.5 & NS & 1.8 & 4.5 \\
\hline Chloride & 1.3 & 1.2 & 3.8 & NS & 66,000 & 66,000 & 69,000 & NS & 67,000 & 5,200 \\
\hline Chromium (multi-metals) & 1.7 & 1.8 & 0.8 & NS & 1.4 & 0.89 & 4.7 & NS & 3.7 & 3.7 \\
\hline Cobalt & $\mathrm{ND}(0.19)$ & $N D(0.19)$ & $\mathrm{ND}(0.18)$ & NS & 0.020 & 0.048 & 0.065 & NS & $\mathrm{ND}(0.19)^{\mathrm{a}}$ & - \\
\hline Copper & 1.6 & 2.3 & 0.71 & NS & 0.46 & 2.2 & 4.9 & NS & 4.1 & 4.4 \\
\hline Cyanide & NS & NS & NS & NS & 810 & 370 & 300 & NS & 490 & 680 \\
\hline Fluoride & $\mathrm{ND}(0.12)$ & 0.13 & $\mathrm{ND}(0.12)$ & NS & 5,100 & 4,100 & 4,300 & NS & 4,500 & 1,400 \\
\hline Lead & 1.4 & $\mathrm{ND}(0.027)$ & $\mathrm{ND}(0.13)$ & NS & $\mathrm{ND}(0.004)$ & $\mathrm{ND}(0.005)$ & 0.53 & NS & 0.65 & 3.8 \\
\hline Manganese & 2.4 & 7.4 & 1.0 & NS & $\mathrm{ND}(0.006)$ & 1.0 & 8.7 & NS & 6.9 & 9.8 \\
\hline Mercury (total) & 0.0042 & 0.0045 & $\mathrm{ND}(0.0082)$ & NS & 15 & 15 & 14 & NS & 15 & 1 \\
\hline Mercury (nitric impingers) & - & - & - & NS & 13 & 14 & 12 & NS & - & - \\
\hline $\begin{array}{l}\text { Mercury (permanganate } \\
\text { impingers) }\end{array}$ & - & - & $-\cdots$ & NS & 1.8 & 1.6 & 1.9 & NS & - & - \\
\hline Molybdenum & 0.32 & $\mathrm{ND}(0.13)$ & 0.37 & NS & $\mathrm{ND}(0.007)$ & $\mathrm{ND}(0.008)$ & 0.071 & NS & 0.25 & 0.57 \\
\hline Nickel & 0.98 & 8.8 & 1.3 & NS & 0.72 & 1.3 & 4.9 & NS & 6.0 & 11 \\
\hline Selenium & 19 & 19 & 19 & NS & 13 & 19 & 30 & NS & 39 & 21 \\
\hline Silver & $\mathrm{ND}(0.15)$ & 1.0 & $\mathrm{ND}(0.15)$ & NS & $\mathrm{ND}(1.3)$ & $\mathrm{ND}(1.6)$ & $\mathrm{ND}(1.3)$ & NS & 0.40 & 1.4 \\
\hline Vanadium & 0.24 & 0.18 & 0.14 & NS & 0.67 & 0.85 & 1.0 & NS & 1.0 & 0.33 \\
\hline
\end{tabular}

a Substance detected in vapor phase at low levels. Reported concentration is an upper limit.

b Value considered suspect. Data were not used in the calculation of the mean total concentration.

$\mathrm{CI}=$ Confidence interval.

$\mathrm{NA}=$ Not analyzed.

$N D=$ Not detected at the concentration in parentheses.

NS $=$ Not sampled. 
QA/QC audit sample results for the following target species did not meet the 75\%-125\% recovery objective for the filtered particulate matter audit sample: cadmium (919\%), cobalt (51\%), manganese (69\%), molybdenum (129\%), and selenium (175\%). However, matrix spike results for these elements in the samples indicate good analytical precision and accuracy. These results indicate a potential bias in the reported particulate-phase ESP outlet results for these substances. Refer to Section 4 for a detailed discussion of QA/QC results.

Reported vapor-phase concentrations for the target species were determined by ICP-MS, with the exception of boron (ICP-AES), mercury (CVAAS), and silver (ICP-AES). Other techniques such as GFAAS and ICP-AES were also used for many of the species; however, the ICP-MS data were selected based on their superior detection limits and performance. In most cases, the levels of target species in the vapor phase at the ESP outlet were below detection limits for GFAAS and ICP-AES methods; therefore, the use of the ICP-MS technique provided a means to accurately quantify the very low levels found in the gas streams. All major metal species were determined by ICP-AES.

Boron, chloride, fluoride, mercury and selenium were quantified in the vapor phase at both the ESP inlet and outlet locations because of their high volatility at the temperatures within the ESP (approximately $350^{\circ} \mathrm{F}$ ). Levels of vapor-phase mercury in the nitric acid/hydrogen peroxide and potassium permanganate impinger solutions were similar at both locations. Approximately $10-15 \%$ of the total vapor-phase mercury was found in the permanganate impinger solutions, which is believed to capture the elemental species of mercury $\left(\mathrm{Hg}^{\circ}\right)$. Conversely, the nitric acid/hydrogen peroxide impinger solution contained $85-90 \%$ of the vapor-phase mercury and is believed to capture ionic mercury species. Essentially $100 \%$ of the mercury entering the system exits in the ESP outlet gas. For chloride, fluoride, and selenium, these percentages are somewhat smaller: $80 \%, 30 \%$, and $24 \%$, respectively. Ammonia and cyanide were quantified in both the ESP inlet and outlet gas at levels well above detection limits.

QA/QC results for ICP-MS analysis of the nitric acid impinger solutions indicate that vaporphase results for antimony, selenium, and nickel may be biased slightly low based on 
recovery data for the audit samples (recoveries in the $60-70 \%$ range were reported). Matrixspiked sample results indicate acceptable analytical accuracy for all species except selenium. Major species such as aluminum, calcium, iron, magnesium, sodium, and titanium were detected in the vapor-phase fractions at similar levels at both locations after background corrections were applied. QA/QC audit sample results for calcium, potassium, and sodium indicate a high bias in the ICP-AES method used to measure these species in this matrix near the detection limit. Recovery results for the nitric acid/hydrogen peroxide impinger audit sample indicate recoveries of $151 \%$ (calcium), $1420 \%$ (potassium), and $321 \%$ (sodium). Thus, sample results for these elements may be biased high.

\section{Organic Species}

Tables 3-8 and 3-9 show the concentrations of the target organic species in the ESP inlet gas. Tables 3-10 and 3-11 show results for organic species in the ESP outlet gas. Since the number of volatile and semivolatile organic compounds analyzed was quite large and very few compounds were detected, only those species which were present at levels above the detection limit in one or more samples are reported. PAH species measured by Method 8270 , which were present at levels between the detection limit and the quantitation limit, are flagged with a "J" symbol. Results in this range are considered uncertain. The quantitation limit was defined by the laboratory as one-half of the lowest point on the linear calibration range. The lowest point on the linear range was $20 \mu \mathrm{g} / \mathrm{mL}$ for all species; therefore, the quantitation limit was defined as $10 \mu \mathrm{g} / \mathrm{mL}$. The detection limits for each species were calculated using an area of 10,000 for all analytes which were not found in the samples. The reported detection limits are the average detection limits achievable over time for a given instrument type and are determined by statistical evaluation of the background noise associated with the samples. Complete results for substances which were not detected are provided in Appendix B.

The following volatile organic compounds were detected in VOST samples collected at the ESP inlet: 1,2-dichloroethane, benzene, carbon disulfide, chloromethane, methylene chloride, and toluene. None of these substances were detected in the reagent blanks which 


\begin{tabular}{|c|c|c|c|c|c|c|c|}
\hline$\left(b^{\circ} \varepsilon\right) a N$ & $L L$ & $z \cdot s$ & $\tau \cdot s$ & $\left(\varepsilon^{\prime} t\right) \propto N$ & 6.8 & SN & HaगO \\
\hline$\exists t^{\circ} \varepsilon$ & 82 & tb & $E \boldsymbol{E D}$ & $\forall \varepsilon$ & LS & SN & aवวo \\
\hline$\left(0^{\prime} I\right) \mathrm{dN}$ & - & $(L \cdot I) a N$ & $\left(s^{\circ} I\right) \propto N$ & $\exists \angle \cdot I$ & $(L \cdot I) a N$ & SN & HGOL-8'L'E'Z \\
\hline$I ' Z$ & $0 b^{\circ} 0$ & $I^{\circ} \varepsilon$ & g 6.2 & $g^{\prime} \exists \varepsilon^{\prime} \varepsilon$ & $g^{\prime} \exists \tau^{\circ} \varepsilon$ & SN & JGDXH-8 ${ }^{6} L^{\prime} 9^{6} t^{6} E^{6} Z$ \\
\hline$\left(0^{\circ} \mathrm{I}\right) \mathrm{dN}$ & - & $(L \cdot I) d N$ & $(L \cdot I) \propto N$ & $\left(66^{\circ} 0\right) \mathrm{CN}$ & छ $96^{\circ} 0$ & SN & gajod-8 $L^{\prime} L^{\prime} \varepsilon^{\prime} z^{\prime} I$ \\
\hline$\left(0^{\circ} \mathrm{I}\right) \mathrm{aN}$ & - & $\left(0^{\circ} \mathrm{Z}\right) \mathrm{aN}$ & $(0.2) a N$ & $(L \cdot l) a N$ & $2 \cdot 2$ & SN & IवDX $H^{\prime}-8^{\prime} L^{\prime} 9^{\prime} E^{\prime} Z^{\prime} I$ \\
\hline$\exists+\cdot 1$ & $9 \cdot 9$ & $\varepsilon^{\cdot} \varepsilon$ & $80 . \tau$ & ב $99^{\circ}$ & $\exists t^{\circ} 9$ & SN & IGכX $H-8^{6} L^{\prime} \nabla^{\prime} E^{\prime} Z^{\prime} I$ \\
\hline$\left(8^{\circ} \tau\right) a N$ & - & $\left(t^{*} t\right) d N$ & $\left(t^{\circ} t\right) a N$ & $(L \cdot \tau) d N$ & $\left(I^{\circ} b\right) \mathrm{dN}$ & SN & 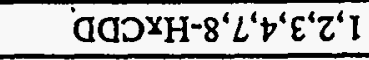 \\
\hline$\left(t^{\prime} I\right) a N$ & $\tau \cdot \tau$ & $\varepsilon \cdot I$ & $0^{\circ} \mathrm{Z}$ & $\exists 99^{\circ}$ & ヨ $Z \varepsilon^{\circ} 0$ & SN & $H^{\prime} \partial^{d} H-8^{\prime} L^{\prime} 9^{\prime} t^{\prime} E^{\prime} Z^{\prime} I$ \\
\hline$\left(8^{\prime} \mathrm{Z}\right) \mathrm{aN}$ & $s^{*} t$ & $\varepsilon^{\cdot} S$ & 6.9 & $\exists \varepsilon^{*} \varepsilon$ & 6.9 & SN & 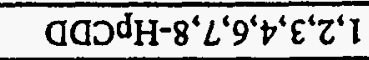 \\
\hline \multicolumn{8}{|r|}{ 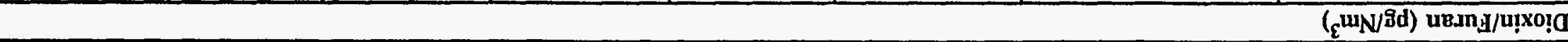 } \\
\hline$\left(s^{\circ} 0\right) a N$ & $L \cdot I$ & $\mathrm{qI} \cdot \mathrm{I}$ & SN & $q^{2} I$ & $8^{8} 1$ & $\left(8^{\circ} 0\right) a N$ & วuən|OL \\
\hline$\left(s^{\circ} 0\right) \square N$ & 81 & $\mathrm{q}^{\circ} 9$ & SN & ${ }_{q} S^{*} \varepsilon$ & $q$ t & $\left(8^{\circ} 0\right) \mathrm{aN}$ & 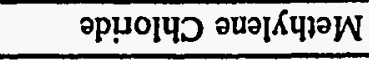 \\
\hline$\left(s^{\prime} 0\right) ם N$ & $t \varepsilon^{*} 0$ & $q^{q} \varepsilon^{\prime} I$ & SN & ${ }_{q} I^{\prime} I$ & $q b^{\prime} 1$ & ${ }_{q} E^{*} l$ & 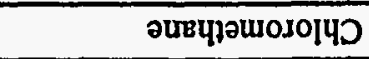 \\
\hline$\left(s^{\circ} 0\right) \square N$ & $6 S^{\circ} 0$ & 0.1 & SN & 0.1 & $\varepsilon \cdot I$ & E8.0 & oplyins!d uoquro \\
\hline$\left(s^{\prime} 0\right) a N$ & 0.9 & 0.8 & SN & $L \cdot 9$ & II & $s^{\circ} 9$ & วuəzuəg \\
\hline$\left(s^{*} 0\right) \square N$ & $t \cdot z$ & $78^{\circ} 0$ & SN & $\left(9^{\circ} 0\right)$ वN & $\left(s^{\prime} 0\right)$ aN & 0.2 & 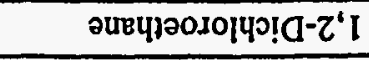 \\
\hline \multicolumn{8}{|r|}{ LSOA } \\
\hline & $00 S^{\prime} 8$ & $000^{6} I t 2$ & $000^{\prime}$ IEZ & $000^{\prime} \tau+\tau$ & $000^{\prime} 00 \mathrm{Z}$ & $000^{\prime} z \not z$ & 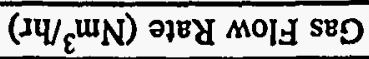 \\
\hline & $00 \varepsilon^{\prime} S$ & $000^{\prime} \mathrm{ZSI}$ & $000^{\prime} 9 b I$ & $000^{\prime} E S I$ & $000^{\circ}$ ISI & $000^{\circ} \mathrm{ESI}$ & (ujosp) ว]EY MOIJ SED \\
\hline & & & $t 6 / S I / b$ & $t 6 / t / / t$ & $t 6 / \varepsilon I / b$ & $t 6 / 2 \mathrm{I} / \mathrm{t}$ & PjeG \\
\hline 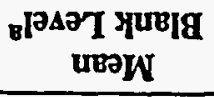 & ID \%\$6 & uвอพ & uny & $\varepsilon$ uny & $z$ uny & I uny & әJuвpsqns \\
\hline
\end{tabular}

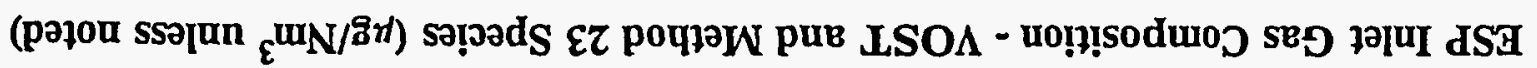
8-E əवस्L 
Table 3-8 (Continued)

\begin{tabular}{|c|c|c|c|c|c|c|c|}
\hline Substance & Run 1 & Run 2 & Run 3 & Run 4 & Mean & 95\% CI & $\begin{array}{c}\text { Mean } \\
\text { Blank Level }^{\mathrm{a}}\end{array}$ \\
\hline Total HpCDD & NS & 6.4 & 3.6 & 11 & 6.8 & 8.6 & $\mathrm{ND}(2.8)$ \\
\hline Total HpCDF & NS & $2.6 \mathrm{E}$ & $3.3 \mathrm{E}$ & 2.6 & 2.8 & 0.98 & $\operatorname{ND}(1.7)$ \\
\hline Total HxCDD & NS & $1.6 \mathrm{E}$ & 2.4 & $2.5 \mathrm{E}$ & 2.2 & 1.2 & $\mathrm{ND}(2.1)$ \\
\hline Total $\mathrm{HxCDF}$ & NS & $7.2 \mathrm{~B}$ & $6.5 \mathrm{E}, \mathrm{B}$ & 6.3 & 6.7 & 1.1 & 2.1 \\
\hline Total PeCDD & NS & 3.2 & $2.0 \mathrm{E}$ & 2.2 & 2.4 & 1.7 & $\operatorname{ND}(1.4)$ \\
\hline Total PeCDF & NS & 5.4 & $0.98 \mathrm{E}$ & 2.2 & 2.8 & 5.6 & $\mathrm{ND}(1.0)$ \\
\hline Total TCDD & NS & $\mathrm{ND}(1.7)$ & 1.6 & $1.7 \mathrm{E}$ & $\mathrm{ND}(1.7)$ & - & $\mathrm{ND}(1.4)$ \\
\hline Total TCDF & NS & $\mathrm{ND}(1.7)$ & $1.6 \mathrm{E}$ & $\mathrm{ND}(1.5)$ & $\mathrm{ND}(1.7)$ & - & $\mathrm{ND}(1.0)$ \\
\hline \multicolumn{8}{|l|}{ Aldehydes } \\
\hline Formaldehyde & 8.7 & 4.5 & 3.0 & NS & 5.4 & 7.4 & ND \\
\hline
\end{tabular}

a Calculated based on the mean level in the reagent blank divided by the mean gas sample volume.

${ }^{b}$ Levels in the field blanks are $230 \%$ of the sample value.

$B$ indicates the substance was detected in the reagent blanks at $\geq 30 \%$ of the sample value.

$E$ indicates value is an estimated upper limit.

$\mathrm{Cl}=$ Confidence interval

$\mathrm{ND}=$ Not detected at the concentration in parentheses.

NS $=$ Not sampled.

$\mathrm{HpCDD}=$ Heptachlorodibenzo-p-dioxin.

$\mathrm{HpCDF}=$ Heptachlorodibenzofuran.

$\mathrm{HxCDD}=$ Hexachlorodibenzo-p-dioxin.

$\mathrm{H} x \mathrm{CDF}=$ Hexachlorodibenzofuran.

PeCDD = Pentachlorodibenzo-p-dioxin.

PeCDF = Pentachlorodibenzofuran.

TCDD = Tetrachlorodibenzo-p-dioxin.

TCDF $=$ Tetrachlorodibenzofuran.

OCDD = Octachlorodibenzo-p-dioxin.

un

OCDF = Octachlorodibenzofuran. 


\begin{tabular}{|c|c|c|c|c|c|c|c|c|}
\hline$L I$ & $8+1$ & $80^{\circ} \mathrm{t}$ & g $s^{\prime} \varepsilon$ & 91 & gIt & $86^{\circ} 6$ & g $0^{\circ} \mathrm{S}$ & ouaI $K_{d}$ \\
\hline 69 & 865 & $8<2$ & g $Z E$ & 89 & g SI & g $\varepsilon I$ & $8+2$ & 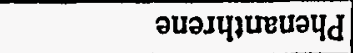 \\
\hline 0 ott & g OLE & $8 \varepsilon L$ & 8002 & g 08I & g OSI & g $0 \angle \varepsilon$ & g obl & әиәрвцापdeN \\
\hline 61 & 8 SS & $8 \varepsilon b$ & g ZE & 890 & g $\varepsilon \mathrm{l}$ & 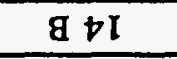 & 891 & 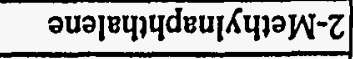 \\
\hline$S^{\circ} \varepsilon$ & 86.7 & $88 L^{\circ} 0$ & $899^{\circ} 0$ & 6.1 & $8 L^{\prime} Z$ & $8 S L^{\circ} 0$ & g $s^{\circ} z$ & องวอม $K \mathrm{~d}\left(\mathrm{p} \partial-\varepsilon^{\prime} Z^{\prime} I\right)$ ouəpul \\
\hline 0.9 & g 2I & $8 t^{\circ} L$ & 88.9 & g ol & 86.2 & $g \varepsilon^{\cdot} \varepsilon$ & $8 I^{\circ} \mathrm{b}$ & auason[] \\
\hline $9 I$ & 881 & $\mathfrak{I I}$ & 80I & $8 I$ & $\mathbf{g} L^{\circ} \varepsilon$ & 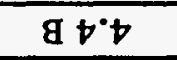 & $8 \nabla^{\circ} L$ & 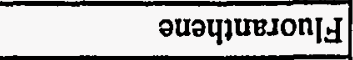 \\
\hline $2 \cdot b$ & $\mathbf{g} L \cdot \mathbf{I}$ & $81 b^{\circ} 0$ & $\left(\varepsilon Z^{\circ} 0\right) \sigma N$ & $g s t^{\circ} 0$ & $t^{\circ} \varepsilon$ & $\left(I s^{\circ} 0\right)$ aN & $8+9^{\circ} 0$ & วนววะม \\
\hline $9^{\circ} \mathcal{E}$ & $8 z^{\circ} b$ & $s^{\prime} l$ & 6.1 & $\varepsilon \cdot \tau$ & $g \tau^{\prime} \tau$ & 8 9. I & g $S^{\circ} \varepsilon$ & 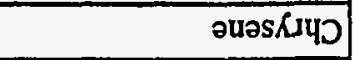 \\
\hline $9 \cdot I$ & $\varepsilon^{\cdot} I$ & 6.1 & $I \cdot I$ & $65^{\circ} 0$ & $850^{\circ} 0$ & $2 I^{\circ} 0$ & $690^{\circ} 0$ & 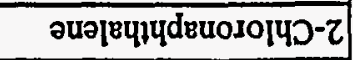 \\
\hline$s^{\prime} z$ & $\boldsymbol{g} \angle \cdot I$ & \& $S D^{\circ} 0$ & g ZZE & $\varepsilon 6^{\circ} 0$ & g $\varepsilon^{\cdot} I$ & $862^{\circ} 0$ & $\mathbf{g} L \cdot I$ & 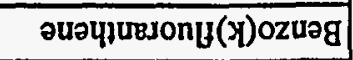 \\
\hline$\varepsilon^{*}$ & $8 \varepsilon^{\circ} 9$ & $g t^{\circ} \mathbf{I}$ & $g+1$ & $8 s \cdot \tau$ & gE $E^{\prime} S$ & $86{ }^{\circ} \mathrm{z}$ & $8 z^{\circ} s$ & 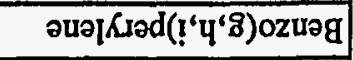 \\
\hline $9 \cdot 9$ & $89^{\circ} \mathrm{b}$ & g s'l & $81 \cdot 1$ & $\nabla 2$ & $88^{\circ} \mathrm{Z}$ & $886^{\circ} 0$ & $80^{\circ} \mathrm{s}$ & 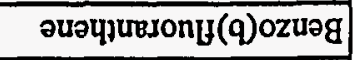 \\
\hline$z^{\prime} \mathcal{\varepsilon}$ & 8I'Z & g $95^{\circ} 0$ & \& $\angle E^{\circ} 0$ & $\varepsilon \cdot I$ & gI'I & $829^{\circ} 0$ & $g z \cdot z$ & əuอIKd(B)ozuəg \\
\hline$z \cdot z$ & $89^{\circ} \mathrm{I}$ & $\varepsilon 9^{\circ} 0$ & g z $Z \varepsilon^{\circ} 0$ & $98^{\circ} 0$ & g 0.1 & g $\angle E^{\circ} 0$ & 89.1 & 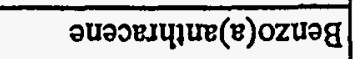 \\
\hline SI & g I's & $8+6^{\circ} 0$ & $g I \cdot I$ & II & $8 \angle t^{\circ} 0$ & $806^{\circ} 0$ & $\mathrm{~g} I \cdot I$ & 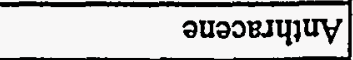 \\
\hline $9 b$ & $\varepsilon 2$ & $\varepsilon t$ & $6 I$ & $S^{\circ} 9$ & g $S t^{\circ} 0$ & $g+s^{\circ} 0$ & g $\varepsilon S^{\circ} 0$ & 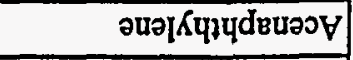 \\
\hline SE & $\mathbf{g} \mathbf{I} \mathbf{z}$ & $86 . \mathrm{L}$ & g ZI & $\mathbb{g} \mathfrak{S E}$ & $82 \cdot 2$ & $g s^{\prime} \varepsilon$ & $88^{\circ} 1$ & 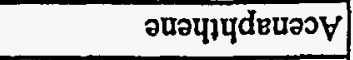 \\
\hline \multicolumn{9}{|c|}{$\left({ }_{\varepsilon} \mathrm{w}_{N} / \mathrm{s} u\right)$ SW/Dग\&H $\delta q$ SHYd } \\
\hline I $\% \$ 6$ & UвəJW & $\varepsilon$ ung & $\tau$ uny & I uny & $\varepsilon$ ung & zuny & I uny & \multirow[t]{2}{*}{ әวuвpsqns } \\
\hline \multicolumn{2}{|c|}{ [870] } & \multicolumn{3}{|c|}{ әSEqd JodB $\Lambda$} & \multicolumn{3}{|c|}{ 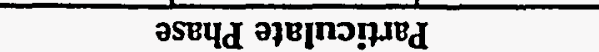 } & \\
\hline
\end{tabular}


Table 3-9 (Continued)

\begin{tabular}{|c|c|c|c|c|c|c|c|c|}
\hline \multirow[b]{2}{*}{ Substance } & \multicolumn{3}{|c|}{ Particulate Phase } & \multicolumn{3}{|c|}{ Vapor Phase } & \multicolumn{2}{|c|}{ Total } \\
\hline & Run 1 & Run 2 & Run 3 & Run 1 & Run 2 & Run 3 & Mean & $95 \% \mathrm{CI}$ \\
\hline \multicolumn{9}{|c|}{$\begin{array}{l}\text { Semivolatile Organic Compounds } \\
\text { by } 8270\left(\mu \mathrm{g} / \mathrm{Nm}^{3}\right)\end{array}$} \\
\hline Acetophenone & $\mathrm{ND}(2.9)$ & $\mathrm{ND}(2.3)$ & $\mathrm{ND}(2.6)$ & $4.1 \mathrm{~J}$ & $4.7 \mathrm{~J}$ & $2.5 \mathrm{~J}$ & $3.8 \mathrm{~J}$ & 2.9 \\
\hline Benzoic acid & $\mathrm{ND}(11)$ & $\mathrm{ND}(9.0)$ & $\mathrm{ND}(9.8)$ & $120 \mathrm{E}$ & $220 d$ & $120 \mathrm{~d}$ & $150 \mathrm{~d}$ & 140 \\
\hline Butylbenzylphthalate & $\mathrm{ND}(1.4)$ & $\mathrm{ND}(1.2)$ & $\mathrm{ND}(1.3)$ & $0.70 \mathrm{~J}$ & $\mathrm{ND}(0.44)$ & $\mathrm{ND}(0.48)$ & $\mathrm{ND}(0.48)$ & -- \\
\hline Di-n-butylphthalate & $110 \mathrm{~d}$ & $5.1 \mathrm{~J}, \mathrm{~B}$ & $2.3 \mathrm{~J}, \mathrm{~B}$ & $11 \mathrm{~B}$ & $2.0 \mathrm{~J}, \mathrm{~B}$ & 29 & $52 \mathrm{~d}, \mathrm{~J}, \mathrm{~B}$ & 150 \\
\hline Di-n-octylphthalate & $\mathrm{ND}(0.69)$ & $\mathrm{ND}(0.56)$ & $\mathrm{ND}(0.64)$ & $\mathrm{ND}(0.30)$ & $0.19 \mathrm{~J}$ & $\mathrm{ND}(0.70)$ & $\mathrm{ND}(0.70)$ & $\cdots$ \\
\hline Diethylphthalate & $\mathrm{ND}(1.5)$ & $\mathrm{ND}(1.2)$ & $\mathrm{ND}(1.3)$ & $0.77 \mathrm{~J}$ & $0.97 \mathrm{~J}$ & $\mathrm{ND}(0.35)$ & $0.64 \mathrm{~J}$ & 0.78 \\
\hline bis(2-Ethylhexyl)phthalate & $8.5 \mathrm{~B}$ & $4.7 \mathrm{~J}, \mathrm{~B}$ & $5.5 \mathrm{~J}, \mathrm{~B}$ & $470 d$ & 9.0 & $1.2 \mathrm{~J}, \mathrm{~B}$ & $170 \mathrm{~d}, \mathrm{~J}, \mathrm{~B}$ & 670 \\
\hline Hexachlorobenzene & $\mathrm{ND}(3.8)$ & $\mathrm{ND}(3.3)$ & $\mathrm{ND}(3.4)$ & 34 & $\mathrm{ND}(1.3)$ & $\mathrm{ND}(1.4)$ & 12 & 47 \\
\hline Isophorone & $\mathrm{ND}(1.7)$ & $\mathrm{ND}(1.5)$ & $\mathrm{ND}(1.6)$ & $\mathrm{ND}(0.39)$ & $6.8 \mathrm{~J}$ & 11 & $6.1 \mathrm{~J}$ & 14 \\
\hline Naphthalene & $5.3 \mathrm{~J}, \mathrm{~B}$ & $\mathrm{ND}(0.92)$ & $\mathrm{ND}(1.0)$ & $0.67 \mathrm{~J}, \mathrm{~B}$ & $0.73 \mathrm{~J}, \mathrm{~B}$ & $\mathrm{ND}(0.34)$ & $2.3 \mathrm{~J}, \mathrm{~B}$ & 8.0 \\
\hline 4-Nitrophenol & $\mathrm{ND}(12)$ & $\mathrm{ND}(10)$ & $\mathrm{ND}(11)$ & $\mathrm{ND}(1.7)$ & 0.47 & $\mathrm{ND}(2.0)$ & $\mathrm{ND}(1.4)$ & -- \\
\hline Phenol & $\mathrm{ND}(2.4)$ & $\mathrm{ND}(2.0)$ & $\mathrm{ND}(2.2)$ & $2.8 \mathrm{~J}$ & $3.0 \mathrm{~J}$ & $1.7 \mathrm{~J}$ & $2.5 \mathrm{~J}$ & 1.8 \\
\hline
\end{tabular}

B indicates the substance was detected in the reagent blank at levels greater than or equal to $30 \%$ of the sample value.

$J$ indicates that the concentration was less than the quantitation limit of the method but above the detection limit.

$d$ indicates that the undiluted sample exceeded the calibration range of the instrument; result shown is for the diluted sample.

$\mathrm{CI}=$ Confidence interval.

$N D=$ Not detected at the concentration in parentheses. 
Table 3-10

ESP Outlet Gas Composition - VOST and Method 23 Species

\begin{tabular}{|c|c|c|c|c|c|c|c|}
\hline Substance & Run 1 & Run 2 & Run 3 & Run 4 & Mean & 95\% CI & $\begin{array}{c}\text { Mean } \\
\text { Blank Level }^{\mathrm{a}}\end{array}$ \\
\hline Date & $4 / 12 / 94$ & $4 / 13 / 94$ & $4 / 14 / 94$ & $4 / 15 / 94$ & & & \\
\hline Gas Flow Rate (dscfm) & 153,000 & 151,000 & 153,000 & 146,000 & 152,000 & 5,300 & \\
\hline Gas Flow Rate $\left(\mathrm{Nm}^{3} / \mathrm{hr}\right)$ & 242,000 & 240,000 & 242,000 & 231,000 & 241,000 & 8,500 & \\
\hline \multicolumn{8}{|l|}{ VOST $\left(\mu \mathrm{g} / \mathrm{Nm}^{3}\right)$} \\
\hline Bromodichloromethane & 0.6 & $\mathrm{ND}(0.5)$ & $\mathrm{ND}(0.5)$ & NS & $\mathrm{ND}(0.5)$ & - & $\mathrm{ND}(2.5)$ \\
\hline Bromoform & $\mathrm{ND}(0.5)$ & $\mathrm{ND}(0.5)$ & $\mathrm{ND}(0.5)$ & NS & $\mathrm{ND}(0.5)$ & - & $\mathrm{ND}(2.5)$ \\
\hline Bromomethane & 0.7 & $\mathrm{ND}(0.5)$ & $\mathrm{ND}(0.5)$ & NS & $\mathrm{ND}(0.5)$ & $\cdots$ & $\mathrm{ND}(0.5)$ \\
\hline Chloroethane & 1.1 & $\mathrm{ND}(0.5)$ & $\mathrm{ND}(0.5)$ & NS & $\mathrm{ND}(0.5)$ & 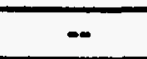 & $\mathrm{ND}(0.5)$ \\
\hline Chloroform & $\mathrm{ND}(0.5)$ & 0.5 & $\mathrm{ND}(0.5)$ & NS & $\mathrm{ND}(0.5)$ & $\cdots$ & $\mathrm{ND}(0.5)$ \\
\hline 1,1,1-Trichloroethane & 0.7 & 0.60 & 37 & NS & 13 & 52 & $\mathrm{ND}(0.5)$ \\
\hline 1,2-Dichloroethane & 16 & 2.5 & 2.5 & NS & 7.0 & 20 & $\mathrm{ND}(0.5)$ \\
\hline Benzene & 3.8 & 5.4 & 6.8 & NS & 5.4 & 3.7 & $\mathrm{ND}(0.5)$ \\
\hline Carbon Disulfide & 1.0 & 0.7 & 0.74 & NS & 0.83 & 0.42 & $\mathrm{ND}(0.5)$ \\
\hline Chloromethane & 6.7 & $\mathrm{ND}(0.5)$ & 3.7 & NS & 3.5 & 8.0 & $\mathrm{ND}(0.5)$ \\
\hline Methylene Chloride & $2.1^{6}$ & $0.82^{b}$ & $5.8^{6}$ & NS & $2.9^{b}$ & 6.4 & $\mathrm{ND}(0.5)$ \\
\hline Toluene & $0.95^{6}$ & $1.7^{6}$ & $0.89^{6}$ & NS & $1.2^{6}$ & 1.1 & $\mathrm{ND}(0.5)$ \\
\hline \multicolumn{8}{|l|}{ Dioxin/Furan (pg/Nm $\left.{ }^{3}\right)$} \\
\hline $1,2,3,4,6,7,8-\mathrm{HpCDD}$ & NS & 5.3 & 11 & $1.9 \mathrm{E}$ & 5.9 & 11 & $\mathrm{ND}(2.8)$ \\
\hline $1,2,3,4,6,7,8-\mathrm{HpCDF}$ & NS & $\mathrm{ND}(1.6)$ & $7.3 \mathrm{E}$ & $7.5 \mathrm{E}$ & 5.2 & 9.5 & $\mathrm{ND}(1.4)$ \\
\hline $1,2,3,4,7,8-\mathrm{HxCDD}$ & NS & $\mathrm{ND}(3.1)$ & $\mathrm{ND}(3.9)$ & $\mathrm{ND}(3.6)$ & $\mathrm{ND}(3.9)$ & - & $\mathrm{ND}(2.8)$ \\
\hline $1,2,3,4,7,8-\mathrm{HxCDF}$ & NS & $1.9 \mathrm{E}$ & $1.5 \mathrm{E}, \mathrm{B}$ & 10 & 4.5 & 12 & $1.4 \mathrm{E}$ \\
\hline $1,2,3,4,7,8,9-\mathrm{HpCDF}$ & NS & $\mathrm{ND}(2.8)$ & $\mathrm{ND}(3.9)$ & $\mathrm{ND}(4.0)$ & $\mathrm{ND}(4.01)$ & - & $\mathrm{ND}(2.4)$ \\
\hline $1,2,3,6,7,8-\mathrm{HxCDD}$ & NS & $\mathrm{ND}(2.5)$ & $\mathrm{ND}(3.2)$ & $\mathrm{ND}(2.9)$ & $\mathrm{ND}(3.2)$ & $\cdots$ & $\mathrm{ND}(2.1)$ \\
\hline $1,2,3,6,7,8-\mathrm{HxCDF}$ & NS & $\mathrm{ND}(1.2)$ & $\mathrm{ND}(1.8)$ & 2.4 & $\mathrm{ND}(1.77)$ & - & $\mathrm{ND}(1.0)$ \\
\hline
\end{tabular}


Table 3-10 (Continued)

\begin{tabular}{|c|c|c|c|c|c|c|c|}
\hline Substance & Run 1 & Run 2 & Run 3 & Run 4 & Mean & $95 \% \mathrm{CI}$ & $\begin{array}{c}\text { Mean } \\
\text { Blank Level }^{\mathrm{a}}\end{array}$ \\
\hline $1,2,3,7,8-\mathrm{PeCDF}$ & NS & $\mathrm{ND}(1.2)$ & $\mathrm{ND}(1.8)$ & $2.3 \mathrm{E}$ & $\mathrm{ND}(1.77)$ & - & $\mathrm{ND}(1.0)$ \\
\hline $2,3,4,6,7,8-\mathrm{HxCDF}$ & NS & $2.9 \mathrm{E}, \mathrm{B}$ & $3.9 \mathrm{~B}$ & $4.0 \mathrm{~B}$ & 3.58 & 1.6 & 2.1 \\
\hline $2,3,4,7,8-\mathrm{PeCDF}$ & NS & $\mathrm{ND}(1.2)$ & $\mathrm{ND}(1.8)$ & $1.5 \mathrm{E}$ & $\mathrm{ND}(1.77)$ & - & $\mathrm{ND}(1.0)$ \\
\hline $2,3,7,8-\mathrm{TCDF}$ & NS & $\mathrm{ND}(1.2)$ & $\mathrm{ND}(1.6)$ & 1.8 & $\mathrm{ND}(1.59)$ & - & $\mathrm{ND}(1.0)$ \\
\hline OCDD & NS & 48 & 110 & $30 \mathrm{E}$ & 62 & 100 & $3.4 \mathrm{E}$ \\
\hline OCDF & NS & 6.1 & 20 & $\mathrm{ND}(6.2)$ & 9.90 & 23 & $\mathrm{ND}(3.4)$ \\
\hline Total HpCDD & NS & 11 & 20 & 3.9 & 11 & 20 & $\mathrm{ND}(2.8)$ \\
\hline Total HpCDF & NS & $\mathrm{ND}(1.9)$ & 7.5 & 2.4 & 3.60 & 8.6 & $\mathrm{ND}(1.7)$ \\
\hline Total HxCDD & NS & $\mathrm{ND}(2.8)$ & $2.9 \mathrm{E}$ & $\mathrm{ND}(3.3)$ & $\mathrm{ND}(3.28)$ & - & $\mathrm{ND}(2.1)$ \\
\hline Total HxCDF & NS & $6.3 \mathrm{E}, \mathrm{B}$ & $6.4 \mathrm{~B}$ & 22 & 11 & 22 & 2.1 \\
\hline Total PeCDD & NS & $1.3 \mathrm{E}$ & $\mathrm{ND}(2.8)$ & $\mathrm{ND}(1.8)$ & $\mathrm{ND}(2.83)$ & - & $\mathrm{ND}(1.4)$ \\
\hline Total PeCDF & NS & $\mathrm{ND}(1.2)$ & 3.2 & 6.7 & 3.49 & 7.5 & $\mathrm{ND}(1.0)$ \\
\hline Total TCDD & NS & $\mathrm{ND}(1.2)$ & $8.0 \mathrm{E}-07$ & $\mathrm{ND}(1.5)$ & $\mathrm{ND}(1.46)$ & - & $\mathrm{ND}(1.4)$ \\
\hline Total TCDF & NS & $\mathrm{ND}(6.2 \mathrm{E}-07)$ & $\mathrm{ND}(1.6)$ & 1.8 & $\mathrm{ND}(1.59)$ & $\overline{-}$ & $\mathrm{ND}(1.0)$ \\
\hline \multicolumn{8}{|l|}{ Aldehydes $\left(\mu \mathrm{g} / \mathrm{Nm}^{3}\right)$} \\
\hline Formaldehyde & 5.1 & 3.5 & 3.6 & NS & 4.1 & 2.3 & ND \\
\hline
\end{tabular}

a Calculated based on the mean level in the reagent blank divided by the mean gas sample volume.

bevels in the field blanks are $\geq 30 \%$ of the sample value.

$B$ indicates the substance was detected in the reagent blanks at $\geq 30 \%$ of the sample value.

$E$ indicates value is an estimated upper limit.

$\mathrm{CI}=$ Confidence interval.

$\mathrm{ND}=$ Not detected at the concentration in parentheses.

NS $=$ Not sampled.

HpCDD = Heptachlorodibenzo-p-dioxin

$\mathrm{HpCDF}=$ Heptachlorodibenzofuran.

HXCDD = Hexachlorodibenzo-p-dioxin.

$\mathrm{HxCDF}=$ Hexachlorodibenzofuran.

PeCDD = Pentachlorodibenzo-p-dioxin.

PeCDF $=$ Pentachloorodibenzofuran

TCDD = Tetrachlorodibenzo-p-dioxin.

TCDF = Tetrachlorodibenzofuran.

in $\quad O C D D=$ Octachlorodibenzo-p-dioxin.

जิ OCDF = Octachlorodibenzofuran. 


\begin{tabular}{|c|c|c|c|c|c|c|c|c|}
\hline$L \cdot \mathcal{E}$ & $a I^{\circ} \mathrm{b}$ & 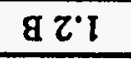 & $80^{\circ} \varepsilon$ & 80.2 & g $s^{\prime} 1$ & 89.2 & g I'z & $\partial \operatorname{\partial \nu } \kappa_{\mathrm{d}}$ \\
\hline 86 & 889 & g SZ & g zz & \& SE & g II & 880 & g EE & 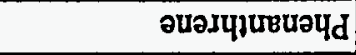 \\
\hline OSI & g OEI & 829 & G OLI & $8+6$ & $8<I$ & 861 & $\bar{g} \mathfrak{s I}$ & 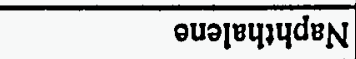 \\
\hline$\angle 9$ & 8 S8 & 8 19 & $86 S$ & goII & g $\varepsilon \cdot S$ & $8+I$ & $80 \mathrm{I}$ & 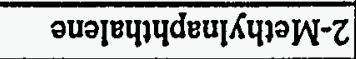 \\
\hline $8^{\circ} 9$ & 867 & L'S & $869^{\circ} 0$ & $826^{\circ} 0$ & g EE:0 & $89 \varepsilon^{\prime} 0$ & g $6 L^{\circ} 0$ & 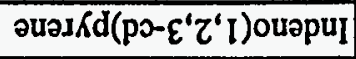 \\
\hline$Z \cdot L$ & g $\mathbf{\varepsilon l}$ & $86{ }^{\circ} \mathrm{L}$ & 80.5 & $8+8$ & $\boldsymbol{g} \varepsilon \widetilde{Z}$ & gII & $89^{\circ} \mathrm{S}$ & 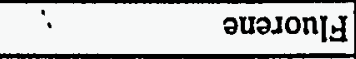 \\
\hline 6.6 & g ZI & $8+9$ & $80^{\circ} \mathrm{S}$ & $2 I$ & g $0 . \tau$ & 89.5 & $8 \tau^{\circ}$ & auaquirexong \\
\hline- & $\left(s 9^{\circ} 0\right) a N$ & g SE. & $\left(s 9^{\circ} 0\right) d \mathrm{~N}$ & $g+s^{\circ} 0$ & $\left(b \tau^{\circ} 0\right) \mathrm{aN}$ & $\left(\left\llcorner\varepsilon 0^{\circ} 0\right) \mathrm{aN}\right.$ & $\left(990^{\circ} 0\right) \mathrm{dN}$ & 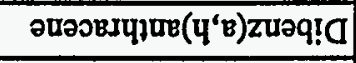 \\
\hline$\tau \cdot I$ & $88^{\circ} 1$ & $86^{\circ} 0$ & $g \tau L^{\circ} 0$ & 9.1 & $8 \nabla 6^{\circ} 0$ & \& IS"0 & $95^{\circ} 0$ & 2uอs KsYว \\
\hline $0 . \tau$ & $\angle 6^{\circ} 0$ & $\tau \varepsilon^{\circ} 0$ & $\tau L^{\prime} 0$ & 6.1 & $\left(0 I^{\circ} 0\right) a N$ & $\left(\not 20^{\circ} 0\right) \mathrm{aN}^{\circ}$ & $\left(610^{\circ} 0\right) d \mathrm{~N}$ & 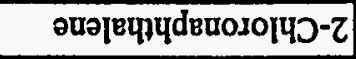 \\
\hline $9 t^{\circ} 0$ & \& $S L^{\circ} 0$ & $65^{\circ} 0$ & $8+t^{\circ} 0$ & $0 L^{\circ} 0$ & $\mathrm{~g} E I^{\circ} 0$ & $8+I^{\circ} 0$ & $8 s Z^{\circ} 0$ & 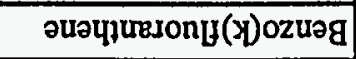 \\
\hline $0 \Omega$ & g 29 & $08 \mathrm{I}$ & 89.1 & $89^{\circ} 1$ & $82 \cdot 1$ & g $98^{\circ} 0$ & $\mathrm{~g} \tau^{\prime} \boldsymbol{Z}$ & 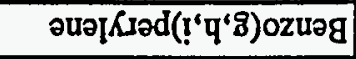 \\
\hline$I \cdot I$ & g $0 . \tau$ & g I'I & g t. I & $L \cdot I$ & g $0 S^{\circ} 0$ & $895^{\circ} 0$ & $\mathrm{~g} \varepsilon 8^{\circ} 0$ & 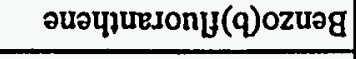 \\
\hline $0 . \tau$ & $806^{\circ} 0$ & $\mathrm{ZN}$ & $829^{\circ} 0$ & $\varepsilon \cdot I$ & $89 I^{\circ} 0$ & $8 \angle I^{\circ} 0$ & $886^{\circ} 0$ & วuəIKd(g)ozuəg \\
\hline $99^{\circ} 0$ & $868^{\circ} 0$ & $\angle 8^{\circ} 0$ & g $90^{\circ} 0$ & $819^{\circ} 0$ & $892^{\circ} 0$ & g SIO0 & \& $\mathfrak{E E} 0$ & 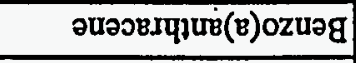 \\
\hline$I L L^{\circ} 0$ & gI' $\tau$ & g $S^{\prime} \mathbf{I}$ & g $28^{\circ} 0$ & $80^{\circ} \mathrm{I}$ & g EE 0 & 89.1 & $g I \cdot I$ & 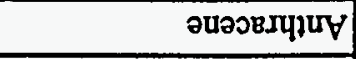 \\
\hline $0 S Z$ & 86 & olz & $t 5$ & $8+8$ & $g+2 \cdot 0$ & $8 S L^{\circ} 0$ & $g \nabla s^{\circ} 0$ & 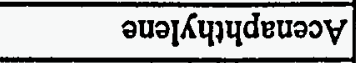 \\
\hline $0 \varepsilon z$ & $g S L$ & $08 \mathrm{I}$ & $g \varepsilon Z$ & $\mathbf{g} \mathbf{S I}$ & g $26^{\circ} 0$ & $89 \%$ & g 6.1 & 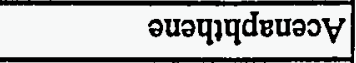 \\
\hline \multicolumn{9}{|c|}{$\left({ }_{\varepsilon}^{w_{N} / 8 u}\right)$ SW/JD\&H אq SHVd } \\
\hline $13 \% 56$ & uвəW & $\mathcal{E}$ uny & $z$ uny & I uny & $\varepsilon$ ung & $\tau$ uny & I uny & \multirow[t]{2}{*}{ әoüpqns } \\
\hline \multicolumn{2}{|c|}{ [8]0] } & \multicolumn{3}{|c|}{ әSEपd JodB $\Lambda$} & \multicolumn{3}{|c|}{ 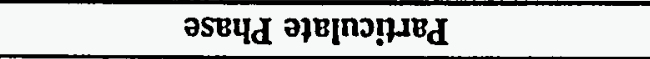 } & \\
\hline
\end{tabular}


Table 3-11 (Continued)

\begin{tabular}{|c|c|c|c|c|c|c|c|c|}
\hline \multirow[b]{2}{*}{ Substance } & \multicolumn{3}{|c|}{ Particulate Phase } & \multicolumn{3}{|c|}{ Vapor Phase } & \multicolumn{2}{|c|}{$\overline{\text { Total }}$} \\
\hline & Run 1 & $\operatorname{Run} 2$ & Run 3 & Run 1 & Run 2 & Run 3 & Mean & $95 \% \mathrm{CI}$ \\
\hline \multicolumn{9}{|c|}{$\begin{array}{l}\text { Semivolatile Organic Compounds } \\
\text { by } 8270\left(\mu \mathrm{g} / \mathrm{Nm}^{3}\right)\end{array}$} \\
\hline Acetophenone & $\mathrm{ND}(1.6)$ & $\mathrm{ND}(1.7)$ & $\mathrm{ND}(2.4)$ & $3.0 \mathrm{~J}$ & $2.7 \mathrm{~J}$ & $3.8 \mathrm{~J}$ & $3.1 \mathrm{~J}$ & 1.4 \\
\hline Benzoic acid & $\mathrm{ND}(6.2)$ & $N D(6.4)$ & $\mathrm{ND}(11)$ & $110 \mathrm{~d}$ & $150 \mathrm{~d}$ & $140 \mathrm{~d}$ & $130 \mathrm{~d}$ & $\overline{43}$ \\
\hline Dibenzofuran & $\mathrm{ND}(0.72)$ & $\mathrm{ND}(0.72)$ & $\mathrm{ND}(1.1)$ & $0.079 \mathrm{~J}$ & $\mathrm{ND}(0.30)$ & $\mathrm{ND}(1.5)$ & $\mathrm{ND}(1.5)$ & - \\
\hline Di-n-butylphthalate & $\mathrm{ND}(0.39)$ & $2.4 \mathrm{~J}, \mathrm{~B}$ & 32 & 19 & $\overline{6.3 \mathrm{~B}}$ & 14 & 25 & 48 \\
\hline Diethylphthalate & $\mathrm{ND}(0.85)$ & $\mathrm{ND}(0.86)$ & $\mathrm{ND}(1.2)$ & $3.3 \mathrm{~J}$ & $N D(0.30)$ & $\mathrm{ND}(1.4)$ & $\mathrm{ND}(3.3)$ & - \\
\hline bis(2-Ethylhexyl)phthalate & $1.4 \mathrm{~J}, \mathrm{~B}$ & $\mathrm{ND}(0.61)$ & $0.64 \mathrm{~J}, \mathrm{~B}$ & 22 & $1.6 \mathrm{~J}, \mathrm{~B}$ & 14 & $13 \mathrm{~J}, \mathrm{~B}$ & 27 \\
\hline Isophorone & $\mathrm{ND}(1.0)$ & $\mathrm{ND}(1.0)$ & $\mathrm{ND}(1.4)$ & 20 & $\mathrm{ND}(0.39)$ & 31 & 17 & 39 \\
\hline Naphthalene & $\mathrm{ND}(0.65)$ & $\mathrm{ND}(0.67)$ & $\mathrm{ND}(0.94)$ & $0.78 \mathrm{~J}, \mathrm{~B}$ & $0.44 \mathrm{~J}, \mathrm{~B}$ & $0.92 \mathrm{~J}, \mathrm{~B}$ & $0.71 \mathrm{~J}, \mathrm{~B}$ & 0.61 \\
\hline Phenol & ND(1.3) & $\mathrm{ND}(1.4)$ & $\mathrm{ND}(2.0)$ & $1.2 \mathrm{~J}$ & $1.2 \mathrm{~J}$ & $\mathrm{ND}(0.74)$ & $0.95 \mathrm{~J}$ & $1: 2$ \\
\hline
\end{tabular}

B indicates the substance was detected in the reagent blank at levels greater than or equal to $30 \%$ of the sample value.

$\mathrm{J}$ indicates that the concentration was less than the quantitation limit of the method but above the detection limit.

$\mathrm{d}$ indicates that the undiluted sample result exceeded the calibration range of the instrument; results are shown for the diluted samples.

$\mathrm{CI}=$ Confidence interval.

ND $=$ Not detected at the concentration in parentheses.

NR = Not reported. Internal standard was not detected; therefore, substance could not be quantified. 
are used to assess background levels in the sampling media; however; chloromethane, methylene chloride, and toluene were detected in the field blank samples, indicating potential field contamination for these three substances. The presence of toluene and methylene chloride are not unexpected, since these solvents are routinely used to rinse probes after sample collection and were present at all four gas sampling locations. 1,2-dichloroethane and carbon disulfide were present at levels which were less than five times the detection limit $\left(0.5 \mu \mathrm{g} / \mathrm{Nm}^{3}\right)$; therefore, the presence of these species in the ESP inlet gas is uncertain. Benzene was not present in the reagent blank and was the only species consistently detected in the samples at levels greater than five times the detection limit; therefore, it is considered a process-generated compound. Mean benzene concentrations were $8 \mu \mathrm{g} / \mathrm{Nm}^{3}$ at the ESP inlet and $5.4 \mu \mathrm{g} / \mathrm{Nm}^{3}$ at the ESP outlet.

A similar set of volatile organic compounds were detected at the ESP outlet in one or more samples: bromodichloromethance, bromoethane, chloroethane, 1,1,1-trichloroethane, 1,2dichloroethane, benzene, carbon disulfide, chloromethane, methylene chloride, and toluene. Bromodichloromethane, bromoethane, and chloroethane were detected at levels less than five times the detection limit in only one of the three samples and are not considered to be present in the ESP outlet gas. The presence of chloromethane, methylene chloride, and toluene is due to field contamination. 1,1,1-trichloroethane levels were less than five times the detection limit in two of the three samples; therefore, its presence in the ESP outlet gas is uncertain. The presence of the halogenated hydrocarbon species in the ESP inlet and outlet gas is attributed to an unknown source of solvents or refrigerants in the field environment and they are not considered to be process-generated compounds.

Method 23 results for dioxin and furan compounds and congeners indicate some species were detected in both the ESP inlet and outlet gas at $\mathrm{pg} / \mathrm{Nm}^{3}$ levels (near the detection limit). For many of the compounds detected, background levels associated with the reagent blank were similar to the levels found in the samples (refer to Section 4 for a detailed discussion of the blank results for organic compounds); these results are flagged with the " $B$ " symbol. Compounds or congeners detected in one or more ESP outlet samples, but not detected in the reagent blank include: $1,2,3,4,6,7,8$-heptachlorodibenzofuran, octachlorodibenzofuran, total 
heptachlorodibenzo-p-dioxin, total heptachlorodibenzofuran, total hexachlorodibenzofuran, and total pentachlorodibenzofuran.

Data for semivolatile organic compounds at the ESP inlet and outlet are summarized in Tables 3-9 and 3-11, respectively. Samples were analyzed by standard GC/MS as specified in Method 8270 and by high resolution HRGC/MS as specified in CARB Method 29 for a selected subset of the species listed in Method 8270. The high resolution GC/MS technique provided detection limits which were three to four orders of magnitude lower than those obtained with the conventional GC/MS technique.

All of the 18 compounds analyzed by HRGC/MS were detected in the samples collected at the ESP inlet and outlet, with the exception of dibenz(a,h)anthracene at the ESP outlet. However, because of the extremely low detection limits for the HRGC/MS method, most substances were also detected in the reagent and field blanks at levels similar to those found in the samples. The "B" flag is used in Tables 3-9 and 3-11 to denote cases where the background levels in the blanks were greater than or equal to $30 \%$ of the levels found in the samples. Acenaphthylene and 2-chloronaphthalene were the only substances detected in the ESP inlet and outlet gas samples and not present in the blanks at significant levels. For those substances flagged with a "B" symbol, accurate quantification by HRGC/MS is not possible; however, the reported results do provide an indication of the maximum possible concentration of these substances present in the gas streams and, as such, should provide useful information for use in health risk assessments.

Six semivoiatile organic compounds routinely detected in ESP inlet and outlet samples analyzed by conventional GC/MS include: acetophenone, benzoic acid, di-n-butylphthalate, diethylphthalate, bis(2-ethylhexyl)phthalate, hexachlorobenzene, isophorone, naphthalene, and phenol. The phthalate esters detected in these samples are typical plasticizers commonly attributed to plastic bottles, bags, etc. used in the field laboratory environment. Sample and blank concentrations are comparable; since phthalates are ubiquitous in the laboratory environment, their presence is most likely due to contamination. Although, acetophenone, isophorone, hexachlorobenzene, phenols, and benzene (discussed previously) are potential 
products of coal devolatilization, their presence is more likely attributed to oxidation of the XAD resin. Concentrations of these substances (on the order of 1-6 $\mu \mathrm{g} / \mathrm{Nm}^{3}$ ) were also between the quantification limit and detection limits of the method, thus increasing the uncertainty in these results. Levels of naphthalene in the blanks were greater than $30 \%$ of the samples values.

Benzoic acid was measured in the ESP inlet and outlet gas samples at mean concentrations of $150 \mu \mathrm{g} / \mathrm{Nm}^{3}$ and $130 \mu \mathrm{g} / \mathrm{Nm}^{3}$, respectively.

Benzoic acid is not on the CAAA of 1990 list of 189 toxic substances, but it is noteworthy that all of the detected organic compounds are aromatic and share a common toluene, benzene, or substituted-benzene structure. Benzoic acid may be a degradation product of $\mathrm{XAD}$ resin in the acidic environment that exists while sampling flue gas streams with high moisture, $\mathrm{SO}_{2}$, and $\mathrm{NO}_{\mathrm{x}}$ levels. However, Radian knows of no scientific studies that have been conducted to determine if this compound, and possibly other compounds, are generated as a sampling artifact.

\section{APF Inlet and Outlet Gas}

The elevated temperature $\left(1350^{\circ} \mathrm{F}\right)$ and pressure (135 psig) at the APF inlet and outlet locations made it necessary to design a unique sampling system to extract gas samples at these locations. The capacity of the system was also designed to allow quantification of the extremely low particulate loadings in the APF outlet gas. Particulate matter was filtered outside the duct and filter temperatures were maintained at approximately $500-600^{\circ} \mathrm{F}$. A detailed discussion of the APF sampling system is provided in Appendix A. Unlike the moveable, glass-lined probes used at the ESP inlet and outlet, the APF sampling system used a fixed probe made of Inconel 800 (a chromium/nickel alloy material). The fixed probe design did not allow the APF inlet and outlet ducts to be traversed; however, samples were collected at isokinetic sampling rates at a single point in the center of the duct. Since there are no significant flow disturbances at either location, evenly distributed gas flow would be expected within the duct at both the APF inlet and outlet locations. Therefore, the impact of 
the fixed probe design is expected to be minimal. The use of the chromiuminickel alloy introduced the potential for chromium and nickel contamination in the sampling system; however, both the fixed probe and Inconel 800 material were necessary to meet the safety requirements for the plant and ensure safe operation of the system.

Laboratory tests were conducted at Radian before the on-site testing to evaluate the potential for chromium and nickel contamination from the APF sampling system. These tests consisted of heating a section of the Inconel 800 tubing to $1600^{\circ} \mathrm{F}$ in a muffe furnace and passing $100 \mathrm{dscf}$ of ambient air through the tubing over a period of approximately two hours. The air was bubbled through a series of impingers containing the nitric acid/nydrogen peroxide reagent used in the metals train. The impinger solutions were subsequently analyzed for chromium, nickel, and iron by ICP-AES. Following these tests. the Inconel 800 tubing was examined and exfoliation on the surface of the tubing was noced. In addition, small flecks of this exfoliated material were also found in the impinger solutions. Chromium, nickel, and iron were detected in the impinger solutions when analyzed by ICP-AES and the presence of these species is attributed to the presence of the exfoliated meierial. Results of these laboratory tests indicated that chromium and nickel contamination mey occur during field sampling at the APF locations and the contamination was expected to be significant at the APF outlet location because of the extremely low particulate loading.

As discussed later in this section, test data indicate abnormally high levels of chromium, molybdenum, and nickel in the particulate multi-metals train samples collected at the APF outlet. The presence of these elements is attributed to exfoliation of the Incorel 800 probe material. Levels of these species in the APF outlet particulate matter were 2-3 orders of magnitude higher than expected; therefore, these data should be considered nonrepresentative. 
Results

\section{Inorganic Species}

Tables 3-12 and 3-13 show the concentrations of the target inorganic analytes in the APF inlet and outlet gas streams, respectively. The analytical methods chosen for each substance were identical to those chosen for the ESP inlet and outlet gas streams.

The solid-phase multi-metals train data from the APF outlet have been corrected for the background levels associated with the quartz filters. Vapor-phase data have been corrected for the background levels present in the nitric impinger reagent. No corrections were necessary at the APF inlet since the particulate matter was analyzed separately from the ceramic filter media. The potential biases discussed above for the ESP inlet and outlet gas streams also apply to the APF gas stream results.

The measured particulate loadings at the APF inlet are approximately three times larger than those measured at the ESP inlet. This is the expected result, since unlike the ESP inlet gas, the gas fed to the APF system is not treated in a secondary cyclone. The levels of particulate-phase metals measured at the APF inlet are consistent with the higher particulate loading relative to the ESP inlet.

Concentrations of target species in the vapor phase at the APF inlet were generally higher than levels measured at the ESP inlet, presumably because of the increased volatility at the elevated temperatures of the APF gas stream $\left(1350^{\circ} \mathrm{F}\right.$ versus $350^{\circ} \mathrm{F}$ at the ESP locations). It is interesting to note that the distribution of mercury between the nitric acid/hydrogen peroxide and permanganate impinger solutions at the APF outlet is distinctly different than the distribution observed at the ESP locations and the APF inlet location. Approximately $1-2 \%$ of the total vapor-phase mercury was captured in the permanganate impinger solution at the APF outlet compared to $10-15 \%$ at the other three gas sampling locations. This indicates that the form of mercury may change as the gas passes through the APF system. 
Table 3-12

APF Inlet Gas Composition - Inorganic Species ( $\mu \mathrm{g} / \mathrm{Nm}^{3}$ unless noted)

\begin{tabular}{|c|c|c|c|c|c|c|c|c|c|c|}
\hline \multirow[b]{2}{*}{ Substance } & \multicolumn{4}{|c|}{ Solid Phase } & \multicolumn{4}{|c|}{ Vapor Phase } & \multicolumn{2}{|c|}{ Total } \\
\hline & Run 1 & Run 2 & Run 3 & Run 4 & Run 1 & Run 2 & Run 3 & Run 4 & Mean & $95 \% \mathrm{CI}$ \\
\hline Date & $4 / 12 / 94$ & $4 / 13 / 94$ & $4 / 14 / 94$ & $4 / 15 / 94$ & $4 / 12 / 94$ & $4 / 13 / 94$ & $4 / 14 / 94$ & $4 / 15 / 94$ & & \\
\hline Gas Flow Rate (dscfm) ${ }^{a}$ & 21,800 & 21,600 & 21,800 & 20,800 & & & & & 21,500 & 760 \\
\hline Gas Flow Rate $\left(\mathrm{Nm}^{3} / \mathrm{hr}\right)^{\mathrm{a}}$ & 34,600 & 34,200 & 34,600 & 33,000 & & & & & 34,100 & 1,200 \\
\hline Particulate Matter $(\mathrm{lb} / \mathrm{hr})$ & 274 & 359 & 290 & 327 & & & & & 312 & 60 \\
\hline Particulate Matter (mg/ $\left./ \mathrm{Nm}^{3}\right)$ & 3,590 & 4,760 & 3,810 & 4,500 & & & & & 4,170 & 880 \\
\hline \multicolumn{11}{|l|}{ Major Species } \\
\hline Aluminum & NS & 271,000 & 235,000 & 210,000 & NS & 1,190 & 395 & 263 & 239,000 & 78,100 \\
\hline Calcium. & NS & 474,000 & 356,000 & 323,000 & NS & 2,500 & 1,220 & 700 & 386,000 & 199,000 \\
\hline Iron & NS & 153,000 & 120,000 & 114,000 & NS & 332 & 173 & 136 & 129,000 & 51,900 \\
\hline Magnesium & NS & 249,000 & 187,000 & 170,000 & NS & 1,070 & 817 & 214 & 203,000 & 104,000 \\
\hline Phosphoris & NS & $\mathrm{ND}(310)$ & $N D(260)$ & $\mathrm{ND}(240)$ & NS & $\mathrm{ND}(19)$ & $\mathrm{ND}(16)$ & $\mathrm{ND}(17)$ & $\mathrm{ND}(310)$ & - \\
\hline Potassium & NS & 62,600 & 54,000 & 44,300 & NS & 280 & $\mathrm{ND}(220)$ & $\mathrm{ND}(230)$ & 53,700 & 23,100 \\
\hline Sodium & NS & 10,100 & 8,880 & 7,750 & NS & 123 & 135 & 148 & 9,100 & 2,930 \\
\hline Sulfate & NS & $3,850,000$ & $4,589,000$ & $2,682,000$ & NS & 954,000 & 811,000 & 791,000 & $4,560,000$ & $2,450,000$ \\
\hline Titanium & NS & 14200 & 12,600 & 10,500 & NS & 63 & 19 & 13 & 12,500 & 4,530 \\
\hline \multicolumn{11}{|l|}{ Target Species } \\
\hline Ammonia & NS & NS & NS & NS & 250 & 180 & 170 & NS & 200 & 120 \\
\hline Antimony & NS & $\mathrm{ND}(270)$ & $N D(220)$ & $\mathrm{ND}(190)$ & NS & 0.085 & 2.8 & 0.043 & 0.96 & 3.9 \\
\hline Arsenic & NS & 1,400 & 1,000 & 830 & NS & 7.9 & 2.2 & $\mathrm{ND}(0.005)$ & 1,100 & 750 \\
\hline Barium & NS & 970 & 890 & 710 & NS & 4.8 & 1.5 & 2.3 & 860 & 330 \\
\hline Beryllium & NS & 28 & 27 & 24 & NS & 0.23 & 0.063 & 0.053 & 27 & 5 \\
\hline Boron & NS & NA & NA & NA & NS & 210 & 200 & 250 & $220^{b}$ & 56 \\
\hline
\end{tabular}




\begin{tabular}{|c|c|c|c|c|c|c|c|c|c|c|}
\hline \multirow[b]{2}{*}{ Substance } & \multicolumn{4}{|c|}{ Solid Phase } & \multicolumn{4}{|c|}{ Vapor Phase } & \multicolumn{2}{|c|}{ Total } \\
\hline & Run 1 & Run 2 & Run 3 & Run 4 & Run 1 & Run 2 & Run 3 & Run 4 & Mean & $95 \% \mathrm{CI}$ \\
\hline Cadmium & NS & 6.9 & 8.2 & 5.0 & NS & $\mathrm{ND}(0.006)$ & $\mathrm{ND}(0.006)$ & 0.31 & 6.8 & 3.7 \\
\hline Chloride & NS & 1100 & 5,300 & 1,100 & NS & 72,000 & 65,000 & 79,000 & 75,000 & 12,000 \\
\hline Chromium (multi-metals) & NS & 490 & 400 & 620 & NS & 3.0 & 13 & 41 & 520 & 310 \\
\hline Cobalt & NS & 88 & 73 & 48 & NS & 0.22 & 0.15 & 0.43 & 70 & 50 \\
\hline Copper & NS & 95 & 63 & 170 & NS & 7.7 & 44 & 68 & 150 & 190 \\
\hline Cyanide & NS & NS & NS & NS & 1,600 & 1,600 & 960 & NA & 1,400 & 920 \\
\hline Fluoride & NS & 770 & 1.800 & 640 & NS & 6,900 & 6,000 & 7,200 & 7,800 & 310 \\
\hline Lead & NS & 290 & 240 & 200 & NS & 2.9 & 1.1 & 1.2 & 240 & 120 \\
\hline Manganese & NS & 520 & 440 & 380 & NS & 8.7 & 3.2 & 33 & 460 & 160 \\
\hline Mercury (total) & NS & $N D(0.050)$ & $\mathrm{ND}(0.046)$ & $\mathrm{ND}(0.042)$ & NS & 16 & 16 & 17 & 16 & 2 \\
\hline Mercury (nitric impingers) & NS & -- & -- & - & NS & 16 & 15 & 16 & - & - \\
\hline $\begin{array}{l}\text { Mercury (permanganate } \\
\text { impingers) }\end{array}$ & NS & -- & -- & $\cdots$ & NS & 0.30 & 0.53 & 0.28 & -- & -- \\
\hline Molybdenum & NS & $\mathrm{ND}(18)$ & $\mathrm{ND}(14)$ & 66 & NS & 0.71 & 1.2 & 5.9 & 25 & 100 \\
\hline Nickel & NS & 110 & 160 & 300 & NS & 19 & 25 & 58 & 220 & 300 \\
\hline Selenium & NS & 54 & 49 & 51 & NS & 18 & 15 & 14 & 67 & 12 \\
\hline Silver & NS & $\mathrm{ND}(20)$ & $\mathrm{ND}(16)$ & $\mathrm{ND}(14)$ & NS & $\mathrm{ND}(1.6)$ & $\mathrm{ND}(1.4)$ & $\mathrm{ND}(1.4)$ & $\mathrm{ND}(20)$ & - \\
\hline Vanadium & NS & 450 & 380 & 330 & NS & 3.1 & 1.7 & 1.9 & 390 & 150 \\
\hline
\end{tabular}

assumed equal to $1 / 7$ th of the measured ESP outlet gas flow rates.

b Vapor phase only.

$\mathrm{CI}=$ Confidence interval.

$\mathrm{NA}=$ Not analyzed.

$N D=$ Not detected at the concentration in parentheses.

NS $=$ Not sampled. 


\begin{tabular}{|c|c|c|c|c|c|c|c|c|c|c|}
\hline 68 & $.09 \varepsilon$ & $08 \varepsilon$ & $0 z \varepsilon$ & $06 \varepsilon$ & $\mathrm{SN}$ & SN & $\mathrm{VN}$ & $\mathrm{VN}$ & $\forall N$ & rosog \\
\hline 6100 & $020^{\circ} 0$ & $810^{\circ} 0$ & EI0.0 & $820^{\circ} 0$ & SN & SN & $\left(s I 00^{\circ} 0\right) \square N$ & $\left(0200^{\circ} 0\right) \mathrm{aN}$ & $\left(8100^{\circ} 0\right) \mathrm{dN}$ & wn!̣IIKJəg \\
\hline $21^{\circ} 0$ & $8 \varepsilon 0^{\circ} 0$ & $\left(\mathrm{~s} 00^{\circ} 0\right) \mathrm{dN}$ & $\left(s 00^{\circ} 0\right) \mathrm{aN}$ & $\left(900^{\circ} 0\right) \subset \mathrm{N}$ & SN & SN & $6+00^{\circ} 0$ & $\angle I 0^{\circ} O$ & $160^{\circ} 0$ & wunyseg \\
\hline$L \cdot I$ & $6 . \varepsilon$ & $0^{\circ} \varepsilon$ & 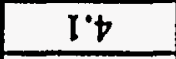 & $6^{\circ} \varepsilon$ & $\mathrm{SN}$ & $\mathrm{SN}$ & $\angle Z^{\circ} 0$ & $9 \varepsilon^{\circ} 0$ & $120^{\circ}$ & ग!นəSدV \\
\hline- & ( $\left(9 \varepsilon^{\prime} 0\right) \mathrm{aN}^{\prime}$ & $220^{\circ} 0$ & $E E 0^{\circ} 0$ & $\varepsilon Z 0^{\circ} 0$ & SN & SN & $\left(92^{\circ} 0\right) \square \mathrm{N}$ & $\left(9 \varepsilon^{\circ} 0\right) \subset \mathrm{N}$ & $\left(\varepsilon E^{\circ} 0\right) a N$ & Suouṇuty \\
\hline SS & OSI & SN & OZI & OSI & $O L I$ & $\mathrm{SN}$ & SN & $\mathrm{SN}$ & SN & в!̣uourury \\
\hline & & & & & & & & & & 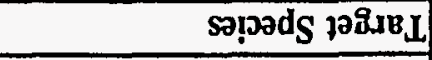 \\
\hline$\angle 0$ & $z^{\prime} z$ & $6 . I$ & $I \cdot Z$ & $I \cdot Z$ & SN & SN & $2 \varepsilon Z^{\circ} 0$ & $606^{\circ} 0$ & [90.0 & unกุư์ฺ̣!I \\
\hline $9 z b^{\circ} s 8$ & $000^{\prime} 26 t$ & $000^{\circ}+\angle t$ & $000^{\circ} 0<t$ & $000^{\prime} z \varepsilon S$ & SN & SN & $z S$ & 68 & $8 E$ & 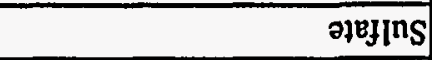 \\
\hline $06 I$ & $6 S E$ & 092 & olt & $09 \varepsilon$ & SN & $\mathrm{SN}$ & $\left(+l^{\circ} 0\right)$ ON & $t \cdot 1$ & $\left(L I^{\circ} 0\right) \subset N$ & un!̣pos \\
\hline- & $(L \cdot \tau) ם N$ & $(0 S Z) \mathrm{aN}$ & $(0 \varepsilon z) d \mathrm{~N}$ & $(082) \mathrm{aN}$ & SN & SN & $\left(0^{\circ} \mathrm{z}\right) \mathrm{aN}$ & $(L \cdot Z)$ đN & $\left(t^{\circ} \mathrm{Z}\right) \mathrm{aN}$ & wn!̣sstiod \\
\hline- & $\left(s b^{\circ} 0\right)$ aN & $(8 \mathrm{I}) \mathrm{aN}$ & $(L I) \propto N$ & $(\mathrm{IZ}) \mathrm{aN}$ & SN & SN & $\left(Z E^{\circ} 0\right) G N$ & $\left(s b^{\circ} 0\right) a N$ & $\left(0 t^{\circ} 0\right) a N$ & snsoydsoqd \\
\hline 6 & 92 & 02 & SI & $\mathfrak{E Z}$ & SN & SN & $\varepsilon \cdot I$ & $8 \cdot 2$ & $\left(\varepsilon s^{*} 0\right) \propto N$ & 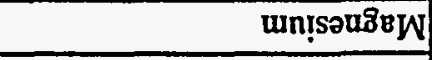 \\
\hline $00 I^{\prime} I$ & ole & 85 & 018 & $L E$ & $\mathrm{SN}$ & SN & $8 \cdot 2$ & $\varepsilon \cdot L$ & $6 \cdot 1$ & uod \\
\hline I8I & 062 & 012 & $09 \varepsilon$ & 082 & SN & SN & $L Z$ & $8^{\circ} \mathrm{S}$ & $260^{\circ} 0$ & นun!७ำ \\
\hline OI & 85 & $\varepsilon S$ & $6 S$ & SS & SN & SN & $t \tau$ & $8^{\circ} \mathrm{t}$ & $\angle 8^{\circ} 0$ & unu?̣unIy \\
\hline & & & & & & & & & & sə!̣วds xo!̣iN \\
\hline 270 & IE.0 & & & & & $89^{\circ} 0$ & $81^{\circ} 0$ & $\left\lfloor\varepsilon^{\prime} 0\right.$ & $\$ \angle 0^{\circ} 0$ & 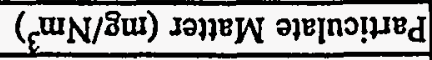 \\
\hline $0 \varepsilon 0^{\circ} 0$ & $\varepsilon Z 0^{\circ} 0$ & & & & & 600.0 & $\$ 10^{\circ} 0$ & $\$ 20.0$ & $9500^{\circ} 0$ & 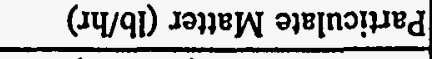 \\
\hline $00 Z^{6} I$ & $001^{\prime} \nabla \varepsilon$ & & & & & $000^{\circ} \varepsilon \varepsilon$ & $009^{4}+\varepsilon$ & $00 Z^{\prime} \triangleright \varepsilon$ & $009^{6}+\varepsilon$ & 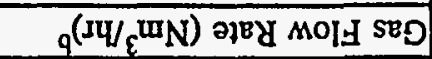 \\
\hline $09 L$ & $00 s^{\prime} I Z$ & & & & & $008^{\circ} 02$ & $008^{\prime} \mathrm{IZ}$ & $009^{\prime} \mathrm{IZ}$ & $008^{\circ} \mathrm{IZ}$ & 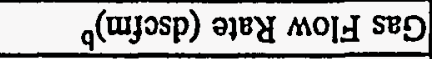 \\
\hline & & $t 6 /$ SI/t & $t 6 / t / 1 / t$ & $t 6 / \varepsilon I / t$ & $\$ 6 / 2 I / 5$ & $t 6 / S I / t$ & $t 6 / t i / t$ & $t 6 / \varepsilon I / t$ & $t 6 / 2 \mathrm{l} / \mathrm{t}$ & әңв \\
\hline $10 \% 96$ & uEอW & p uny & $\varepsilon$ uny & $\tau$ ung & I uny & $t$ ung & $\varepsilon$ uny & $z$ und & I uny & \multirow[t]{2}{*}{ วouвpsqnS } \\
\hline \multicolumn{2}{|c|}{ [870 L } & \multicolumn{4}{|c|}{ गSEपू Jod8 $\Lambda$} & \multicolumn{4}{|c|}{ әSBपd P!jOS } & \\
\hline
\end{tabular}


$\stackrel{\omega}{+}$ Table 3-13 (Continued)

\begin{tabular}{|c|c|c|c|c|c|c|c|c|c|c|}
\hline \multirow[b]{2}{*}{ Substance } & \multicolumn{4}{|c|}{ Solid Phase } & \multicolumn{4}{|c|}{ Vapor Phase } & \multicolumn{2}{|c|}{ Total } \\
\hline & Run 1 & Run 2 & Run 3 & Run 4 & Run 1 & Run 2 & Run 3 & Run 4 & Mean & $95 \% \mathrm{CI}$ \\
\hline Cadmium & $\mathrm{ND}(0.0043)$ & $\mathrm{ND}(0.0048)$ & $\mathrm{ND}(0.0035)$ & NS & NS & $\mathrm{ND}(0.007)$ & $\mathrm{ND}(0.006)$ & $\mathrm{ND}(0.006)$ & $\mathrm{ND}(0.005)$ & - \\
\hline Chloride & 0.19 & 0.16 & $\mathrm{ND}(0.11)$ & NS & NS & 73,000 & 50,000 & 60,000 & 61,000 & 28,000 \\
\hline Chromium (multi-metals) & $8.0^{d}$ & $13^{d}$ & $8.9^{d}$ & NS & NS & 1.7 & 150 & 3.2 & 60 & 200 \\
\hline Cobalt & $\mathrm{ND}(0.030)$ & $\mathrm{ND}(0.033)$ & $\mathrm{ND}(0.024)$ & NS & NS & 0.020 & 0.83 & 0.061 & 0.30 & 1.1 \\
\hline Copper & $\mathrm{ND}(0.028)$ & $\mathrm{ND}(0.031)$ & $\mathrm{ND}(0.022)$ & NS & NS & 0.77 & 0.88 & 0.75 & 0.80 & 0.2 \\
\hline Cyanide & NS & NS & NS & NS & 510 & 430 & 360 & NS & 430 & 190 \\
\hline Fluoride & 0.046 & 0.22 & 0.12 & NS & NS & 9,400 & 8,900 & 8,500 & 8,900 & 1,200 \\
\hline Lead & 0.019 & 0.035 & 0.033 & NS & NS & $\mathrm{ND}(0.006)$ & $\mathrm{ND}(0.005)$ & $\mathrm{ND}(0.005)$ & 0.029 & 0.022 \\
\hline Manganese & 0.21 & 0.62 & 0.14 & NS & NS & 0.72 & 22 & 0.56 & 8.1 & 30 \\
\hline Mercury (total) & $\mathrm{ND}(0.00027)$ & $\mathrm{ND}(0.00030)$ & $\mathrm{ND}(0.00021)$ & NS & NS & 16 & 14 & 14 & 15 & 2.6 \\
\hline Mercury (nitric impingers) & $\cdots$ & - & - & NS & NS & 13 & 9.4 & 9.3 & - & - \\
\hline $\begin{array}{l}\text { Mercury (permanganate } \\
\text { impingers) }\end{array}$ & - & -- & -- & NS & NS & 2.9 & 4.9 & 4.8 & - & - \\
\hline Molybdenum & $3.4^{d}$ & $6.5^{\mathrm{d}}$ & $2.9^{d}$ & NS & NS & 3.4 & 3.4 & 7.7 & 9.1 & 6.1 \\
\hline Nickel & $\mathrm{ND}(0.26)$ & $1.3^{\mathrm{d}}$ & $0.34^{d}$ & NS & NS & 6.7 & 89 & 54 & 51 & 100 \\
\hline Selenium & $\mathrm{ND}(0.0044)$ & $\mathrm{ND}(0.0050)$ & \begin{tabular}{|l|}
$N D(0.0036)$ \\
\end{tabular} & NS & NS & 46 & 41 & 58 & 49 & 22 \\
\hline Silver & 0.31 & 0.37 & 0.14 & NS & NS & $\mathrm{ND}(1.8)$ & $\mathrm{ND}(1.5)$ & $\mathrm{ND}(1.6)$ & 0.27 & 0.3 \\
\hline Vanadium & 0.96 & 0.81 & 0.85 & NS & NS & 1.0 & 1.4 & 1.0 & 2.0 & 0.5 \\
\hline
\end{tabular}

a Detected in the vapor phase at low levels. Reported value is an upper limit.

b Assumed equal to $1 / 7$ th of the ESP outlet gas flow rate.

c Vapor phase only.

${ }^{d}$ Results indicate the presence of Iriconel 800 residue in the particulate matter. Data are considered biased high.

$\mathrm{Cl}=$ Confidence interval.

$\mathrm{NA}=$ Not analyzed.

$\mathrm{ND}=$ Not detected at the concentration in parentheses.

NS $=$ Not sampled. 


\section{Organic Species}

Tables 3-14 and 3-15 show the concentrations of the target organic compounds in the APF inlet gas. Tables 3-16 and 3-17 show the results for organic compounds in the APF outlet gas. For volatile and semivolatile organic compounds, only those species which were present at levels above the detection limit in one or more samples are reported.

Levels of volatile organic compounds at the APF inlet and outlet were similar to the levels observed at the ESP locations. Methylene chloride and toluene are likely present due to field contamination. With the exception of carbon disulfide at the APF outlet (mean concentration $=25 \mu \mathrm{g} / \mathrm{Nm}^{3}$ ), most of these species were detected at levels less than five times the detection limit; therefore, their presence in the APF gas samples is uncertain. Benzene was quantified in two of the three APF inlet samples at levels greater than five times the detection limit. At the APF outlet, benzene was found at levels greater than five times the detection limit in only one of the three samples. Mean concentrations of benzene were 3.0 and 3.1 $\mu \mathrm{g} / \mathrm{Nm}^{3}$ at the APF inlet and outlet, respectively.

Dioxin and furan results for the APF inlet indicate all of the species were present in the gas at levels which are 2 to 3 orders of magnitude greater than detection limits. Concentrations of the various dioxin/furan compounds or congeners ranged from $8.1 \mathrm{pg} / \mathrm{Nm}^{3}$ for $2,3,7,8$ tetrachlorodibenzo-p-dioxin to $2300 \mathrm{pg} / \mathrm{Nm}^{3}$ for total pentachlorodibenzo-p-dioxin. Levels in the reagent blank were insignificant compared to the sample results at the APF inlet.

At the APF outlet, the front (filter) and back (resin) half of the Method 23 train were analyzed separately. None of the dioxin and furan species were detected in the front half sample. The results presented in Table 3-15 are the back half results only; the front half concentrations were assumed to be zero for the purpose of calculating a total concentration. Detection limits for the front-half samples can be found in Appendix B. Levels of dioxin/furan compounds and congeners at the APF outlet were much lower than those observed at the APF inlet. Mean concentrations for those species which were detected in the samples but not detected at significant levels in the reagent blanks (i.e., less than $30 \%$ of the 


\begin{tabular}{|c|c|c|c|c|c|c|c|}
\hline$(I \cdot z) a N$ & $0 L I$ & 091 & $\varepsilon 8$ & $0 z z$ & $0 L I$ & SN & 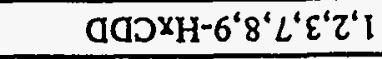 \\
\hline$\left(0^{\circ} \mathrm{I}\right) \mathrm{aN}$ & $0 \varepsilon Z$ & OEI & $\exists 0 \varepsilon Z$ & $\varepsilon 6$ & $\exists \subseteq 9$ & SN & saJod-8 $8^{6} L^{6} E^{\prime} Z^{\prime} I$ \\
\hline (b.I)an & $\varepsilon L$ & $8 L$ & $\angle D$ & $00 \mathrm{I}$ & 18 & SN & GaJ ${ }^{\partial}-8^{\prime} L^{\prime} \varepsilon^{\prime} Z^{\prime} I$ \\
\hline$(0.1) \mathrm{dN}$ & otl & 56 & $E S$ & 091 & $9 L$ & SN & 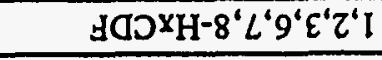 \\
\hline$(I \cdot \tau) a N$ & OZI & OZI & $Z L$ & OLI & OEI & SN & 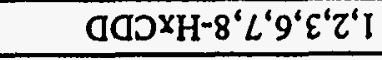 \\
\hline$\left(b^{\prime} z\right) \triangle N$ & SE & $2 S$ & $6 \varepsilon$ & $\angle 9$ & 60 & $\mathbf{S N}$ & $\pm a^{d} J^{d}-6^{6} 8^{6} L^{\prime} b^{6} E^{\prime} Z^{\prime} l$ \\
\hline$\exists b^{\circ} I$ & 096 & 062 & 091 & 005 & 012 & $\mathrm{SN}$ & HGวXH-8 ${ }^{\prime} L^{6} t^{\prime} E^{\prime} Z^{\prime} I$ \\
\hline$\left(8^{\circ} \mathrm{z}\right) \mathrm{dN}$ & OSI & OII & IS & $0<I$ & oll & SN & 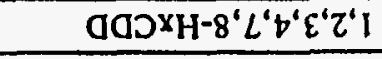 \\
\hline$\left(b^{\circ} 1\right) a N$ & OSE & 082 & $06 I$ & obt & 012 & SN & $\Delta a^{d} J^{d}-8^{\prime} L^{\prime} 9^{\prime} b^{\prime} \varepsilon^{\prime} Z^{4} l$ \\
\hline$\left(8^{\prime} \mathrm{Z}\right) \mathrm{aN}$ & $0<t$ & 09t & $0 L 2$ & OS9 & 09t & SN & aब放 $H-8^{6} L^{6} 9^{6} t^{6} \varepsilon^{6} Z^{6} I$ \\
\hline \multicolumn{8}{|c|}{ 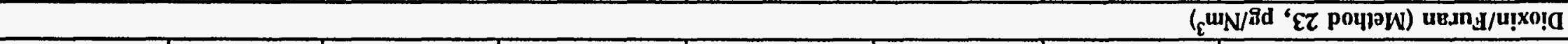 } \\
\hline$\left(s^{\circ} 0\right) \subset N$ & $L \cdot I$ & $9^{9} 0$ & $q \cdot 1$ & $\left(9^{\circ} 0\right) \mathrm{dN}$ & $\left(9^{\circ} 0\right)$ QN & $\mathbf{S N}$ & จuอn|OL \\
\hline$\left(s^{\circ} 0\right) \Subset N$ & $I L$ & $\mathrm{q} Z 2$ & SS & $q I I$ & $9^{8} 0^{\circ}$ & $\mathbf{S N}$ & 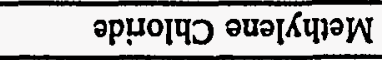 \\
\hline$\left(s^{\circ} 0\right) a N$ & 8.5 & $L \cdot Z$ & $66^{\circ} t$ & $6 . \tau$ & $\left(s^{\circ} 0\right)$ aN & $\mathbf{S N}$ & 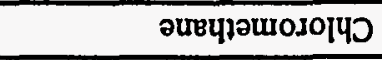 \\
\hline$\left(s^{*} 0\right) \mathrm{aN}$ & 6.1 & L.O & $9^{\circ} 1$ & $\left(9^{\circ} 0\right) \mathrm{dN}$ & $\left(9^{\circ} 0\right) \subset N$ & $\mathbf{S N}$ & นщојолоүчว \\
\hline$\left(s^{\circ} 0\right) a N$ & $\angle Z$ & $S^{\circ} 9$ & $6 I$ & $\left(9^{\prime} 0\right) \subset \mathrm{N}$ & $\left(9^{\circ} 0\right) \subset \mathrm{N}$ & SN & 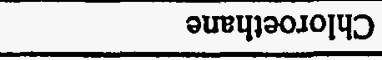 \\
\hline$\left(s^{\prime} 0\right) a N^{\prime}$ & $\varepsilon$ & $L^{\cdot} \varepsilon$ & $I \cdot t$ & $\tau \cdot s$ & 8.1 & SN & 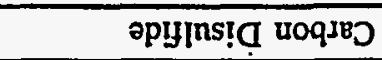 \\
\hline$\left(s^{\circ} 0\right) \propto N$ & $6{ }^{\circ} \varepsilon$ & $0 . \varepsilon$ & $L^{\circ} \varepsilon$ & $I \circ$ & $\tau \cdot I$ & $\mathbf{S N}$ & əuəzuəg \\
\hline \multicolumn{8}{|r|}{ 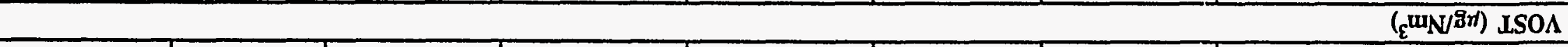 } \\
\hline & $00 z^{\prime} I$ & $00 I^{\circ} \nabla \varepsilon$ & $000^{\prime} \varepsilon \varepsilon$ & $009^{6}+\varepsilon$ & $00 Z^{\prime} \triangleright \varepsilon$ & $009^{6} \nabla \varepsilon$ & $\left(\mathrm{I \Psi} / \mathcal{E}^{\mathrm{W}} \mathrm{N}\right)$ ә]вY MOIH SBD \\
\hline & $09 L$ & $00 S^{6} I 2$ & $008^{\prime} 02$ & $008^{\prime} 12$ & $009^{\prime} \mathrm{IZ}$ & $008^{\circ} \mathrm{IZ}$ & 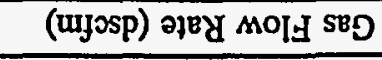 \\
\hline & & & $\nabla 6 / S I / t$ & $66 / t / / t$ & $t 6 / \varepsilon I / t$ & $66 / 21 / 6$ & ajed \\
\hline 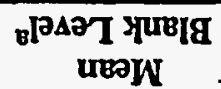 & $15 \% 56$ & uBow & $b$ uny & $\mathcal{E}$ uny & $z$ und & I uny & әวuвjsqns \\
\hline
\end{tabular}


Table 3-14 (Continued)

\begin{tabular}{|c|c|c|c|c|c|c|c|}
\hline Substance & Run 1 & Run 2 & Run 3 & Run 4 & Mean & $95 \% \mathrm{CI}$ & $\begin{array}{c}\text { Mean } \\
\text { Blank Level }^{\mathrm{a}}\end{array}$ \\
\hline $1,2,3,7,8,9-\mathrm{HxCDF}$ & NS & 18 & 42 & 9.3 & 23 & 42 & $\mathrm{ND}(1.7)$ \\
\hline $2,3,4,6,7,8-\mathrm{HxCDF}$ & NS & 90 & 160 & 53 & 100 & 140 & 2.1 \\
\hline $2,3,4,7,8-\mathrm{PeCDF}$ & NS & $110 \mathrm{E}$ & 150 & 53 & 100 & 120 & $\mathrm{ND}(1.0)$ \\
\hline $2,3,7,8-\mathrm{TCDD}$ & NS & $6.5 \mathrm{~B}$ & 12 & 5.8 & 8.1 & 8.7 & $\mathrm{ND}(1.4)$ \\
\hline $2,3,7,8-\mathrm{TCDF}$ & NS & 170 & 400 & 93 & 220 & 390 & $\mathrm{ND}(1.0)$ \\
\hline OCDD & NS & 490 & 800 & 330 & 540 & 590 & $3.4 \mathrm{E}$ \\
\hline OCDF & NS & 160 & 250 & 240 & 210 & 130 & $\mathrm{ND}(3.4)$ \\
\hline Total HpCDD & NS & 940 & 1,400 & 560 & 970 & 1,000 & $\mathrm{ND}(2.8)$ \\
\hline Total HpCDF & NS & 340 & 690 & 310 & 450 & 530 & $\mathrm{ND}(1.7)$ \\
\hline Total HxCDD & NS & 1,900 & 2,400 & 1,100 & 1,800 & 1,600 & $\mathrm{ND}(2.1)$ \\
\hline Total $\mathrm{HxCDF}$ & NS & 700 & 1,600 & 510 & 930 & 1,400 & 2.1 \\
\hline Total PeCDD & NS & 2,600 & 3,000 & 1,400 & 2,300 & 2,100 & $\mathrm{ND}(1.4)$ \\
\hline Total PeCDF & NS & 610 & 2,000 & 540 & 1,000 & 2,000 & $\mathrm{ND}(1.0)$ \\
\hline Total TCDD & NS & 2,600 & 2,900 & 1,200 & 2,200 & 2,300 & $\mathrm{ND}(1.4)$ \\
\hline Total TCDF & NS & 1,600 & 3,200 & 740 & 1,800 & 3,100 & $\mathrm{ND}(1.0)$ \\
\hline \multicolumn{8}{|l|}{ Aldehydes $\left(\mu \mathrm{g} / \mathrm{Nm}^{3}\right)$} \\
\hline Formaldehyde & 40 & 150 & 17 & NS & 68 & 170 & \\
\hline
\end{tabular}

a Calculated based on the mean of the levels in the reagent blanks divided by the mean gas sample volume for the three sample runs.

$b$ Levels in the field blanks are $\geq 30 \%$ of the sample value.

$E$ indicates value is an estimated upper limit.

$\mathrm{Cl}=$ Confidence interval.

$N D=$ Not detected at the concentration in parentheses.

NS $=$ Not sampled.

$\mathrm{HpCDD}=$ Heptachlorodibenzo-p-dioxin.

$\mathrm{HpCDF}=$ Heptachlorodibenzofuran.

$\mathrm{H} \times \mathrm{CDD}=$ Hexachlorodibenzo-p-dioxin.

$\mathrm{H} \times \mathrm{CDF}=$ Hexachlorodibenzofuran.

PeCDD = Pentachlorodibenzo-p-dioxin

PeCDF = Pentachlorodibenzofuran.

TCDD $=$ Tetrachlorodibenzo-p-dioxin.

TCDF = Tetrachlorodibenzofuran.

OCDD = Octachlorodibenzo-p-dioxin.

OCDF = Octachlorodibenzofuran. 


\begin{tabular}{|c|c|c|c|c|c|c|c|c|}
\hline$\varepsilon \cdot L$ & g oI & 8 8'z & $\mathrm{gSS}^{\prime} \mathcal{E}$ & 80.6 & 01 & $z \cdot L$ & $8 \tau \cdot \varepsilon$ & $2 \operatorname{\partial u} \kappa_{d}$ \\
\hline 95 & $8 \angle 9$ & 8 It & g \&b & 892 & 96 & $8 \angle \tau$ & $8 \angle I$ & 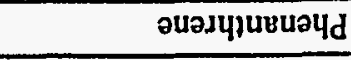 \\
\hline $09 L$ & g OLE & 8 061 & $80 S I$ & $00 L$ & $8+2$ & g LI & $8<I$ & 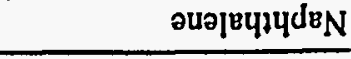 \\
\hline OSI & g oSI & 002 & OtI & 862 & $89 . \mathrm{L}$ & $88^{\circ} \mathrm{S}$ & $86^{\circ} s$ & әиว|вцाц \\
\hline$L \mathcal{L}$ & $80^{\circ} \varepsilon$ & $8 \varepsilon 9^{\circ} 0$ & $860^{\circ} 0$ & $8 \cdot 1$ & $9^{\circ} \varepsilon$ & $0 \%$ & $865^{\circ} 0$ & ouar $\delta d\left(p 0-\varepsilon^{\prime} Z^{\prime} I\right)$ ourpuI \\
\hline$t I$ & g SI & g ol & $8 \angle \cdot 8$ & 86.5 & Ol & g ع.9 & $g \varepsilon^{\circ} \varepsilon$ & auasonj] \\
\hline ZI & 9I & g $L S S$ & g $\varepsilon^{\circ} 8$ & $q \varepsilon^{\circ} L$ & $t \boldsymbol{t}$ & 5.8 & gI. & 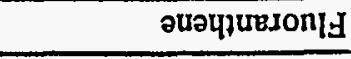 \\
\hline- & $g(I \cdot I) d N$ & $8 \angle I^{\circ} 0$ & $\left(\varepsilon Z^{\circ} 0\right) \propto N$ & $(I \cdot I) \propto N$ & $\tau \cdot 2$ & $(\tau \cdot \tau)$ वN & $\left(s 2^{\circ} 0\right) a^{\prime}$ & 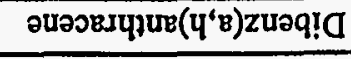 \\
\hline S*9 & $8 t^{\circ}$ & $826^{\circ} 0$ & \& $2 S^{\circ} 0$ & $8 \angle 8^{\circ} 0$ & $s^{\prime} 9$ & $I \cdot \varepsilon$ & g s.I & วนวSאIYว \\
\hline$S^{\prime} \varepsilon$ & $6^{\circ} \mathrm{S}$ & $\varepsilon^{\prime} L$ & $s^{\prime} t$ & $6 . S$ & $\left(81^{\circ} 0\right) a N$ & $\left(2 I^{\circ} 0\right) \mathrm{dN}$ & $\left(680^{\circ} 0\right) d \mathrm{~N}$ & 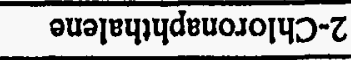 \\
\hline$S^{\prime} E$ & $88^{\circ} 1$ & gโ $โ \varepsilon^{\prime} 0$ & $861^{\circ} 0$ & $16^{\circ} 0$ & $I^{\circ} \varepsilon$ & $\$ 99^{\circ}$ & $g z \tau^{\circ} 0$ & 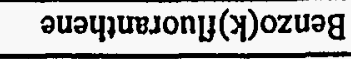 \\
\hline $9^{\circ} \mathrm{S}$ & g oI & g $z \cdot I$ & $866^{\circ} 0$ & $1 \cdot 9$ & $2 I$ & $\varepsilon \cdot 8$ & $g b^{\circ} z$ & 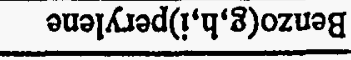 \\
\hline $9^{\circ} \mathrm{S}$ & $86^{\circ} \varepsilon$ & 80.1 & $889^{\circ} 0$ & $8 s^{\circ} I$ & $6 \cdot 5$ & $\varepsilon \tau$ & $859^{\circ} 0$ & auวq\}ưsionfy(q)ozueg \\
\hline$s \cdot z$ & gI'z & $890^{\circ} 0$ & $\left(\tau \nabla^{\circ} 0\right) \subset \mathrm{N}$ & 16.0 & $8^{\prime} \mathrm{Z}$ & $L \cdot I$ & g E $b^{\circ} 0$ & วuəIKd(g)ozuəg \\
\hline$L \cdot I$ & 8 9. I & $80 S^{\circ} 0$ & $8 S Z^{\circ} 0$ & $69^{\circ} 0$ & 8.1 & $\varepsilon \cdot I$ & $\mathrm{~g} \angle Z^{\circ} 0$ & 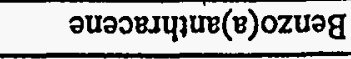 \\
\hline$I \cdot b$ & g s'z & \& $9 L^{\circ} 0$ & $8 \angle 6^{\circ} 0$ & $\left(96^{\circ} 0\right) \subset N$ & $\tau \cdot \varepsilon$ & 86.1 & $889^{\circ} 0$ & วuวอвsपุाน \\
\hline 6.8 & g s'9 & 0.6 & OI & $\varepsilon^{\circ} b$ & g $\angle \varepsilon^{\circ} 0$ & $\mathbf{8} \angle Z^{\circ} 0$ & $88 I^{\circ} 0$ & 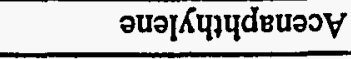 \\
\hline$\varepsilon t$ & g 92 & g ol & $g+b$ & $8 \mathrm{IZ}$ & $\mathbf{g} \boldsymbol{b}^{\circ} \mathbf{I}$ & \& $96^{\circ} 0$ & g $\angle 8^{\circ} 0$ & 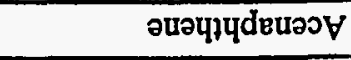 \\
\hline \multicolumn{9}{|c|}{$\left({ }_{\varepsilon} w_{N} / \mathcal{I} u\right)$ SW/DD dH $^{\prime} \delta q$ SHVd } \\
\hline ID \%56 & uEojw & $\varepsilon$ uny & $\tau$ uny & I uny & $\mathcal{E}$ uny & z ung & I ung & \multirow[t]{2}{*}{ әJuвzsqns } \\
\hline \multicolumn{2}{|c|}{ [MOL } & \multicolumn{3}{|c|}{ әseपג Jode $\Lambda$} & \multicolumn{3}{|c|}{ 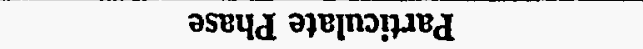 } & \\
\hline
\end{tabular}


Table 3-15

Results for Semivolatile Organic Species at the APF Inlet $\left(\mu \mathrm{g} / \mathrm{Nm}^{3}\right)$

\begin{tabular}{|c|c|c|c|c|c|c|c|c|}
\hline \multirow[b]{2}{*}{ Substance } & \multicolumn{3}{|c|}{ Particulate Phase } & \multicolumn{3}{|c|}{ Vapor Phase } & \multicolumn{2}{|c|}{ Total } \\
\hline & Run 1 & Run 2 & Run 3 & Run 1 & Run 2 & Run 3 & Mean & $95 \% \mathrm{CI}$ \\
\hline \multicolumn{9}{|c|}{$\begin{array}{l}\text { Semivolatile Organic Compounds } \\
\text { by } 8270\left(\mu \mathrm{g} / \mathrm{Nm}^{3}\right)\end{array}$} \\
\hline Acetophenone & $\mathrm{ND}(2.8)$ & $\mathrm{ND}(2.7)$ & $\mathrm{ND}(2.9)$ & $1.4 \mathrm{~J}$ & $1.7 \mathrm{~J}$ & $2.6 \mathrm{~J}$ & $1.9 \mathrm{~J}$ & 1.6 \\
\hline Benzoic acid & $N D(10)$ & ND(10) & $\mathrm{ND}(11)$ & 88 & $120 \mathrm{~d}$ & 110 & 110 & 45 \\
\hline (1)i-n-lumlylulithuluto & $3,1 \mathrm{~J}, 11$ & 20) & 11 & $1.3 \mathrm{~J}, 1]$ & $5.4 \mathrm{~J}, 11$ & 55 & 3211 & 77 \\
\hline bis(2-Ethylhexyl)phthalate & $1.2 \mathrm{~J}, \mathrm{~B}$ & $\mathrm{ND}(1.1)$ & $\mathrm{ND}(1.2)$ & $1.1 \mathrm{~J}, \mathrm{~B}$ & $\mathrm{ND}(0.62)$ & $1.5 \mathrm{~J}, \mathrm{~B}$ & $1.4 \mathrm{~B}$ & 2.5 \\
\hline 2-Methylnaphthalene & $\mathrm{ND}(1.7)$ & $\operatorname{ND}(1.6)$ & $\mathrm{ND}(1.7)$ & $N D(1.3)$ & $N D(0.70)$ & $0.082 \mathrm{~J}$ & $N D(1.3)$ & -- \\
\hline Naphthulano & $N D(1.1)$ & $N D(1.1)$ & $N D(1.1)$ & $N D(0.81)$ & $N D(0.45)$ & $0.73 \mathrm{~J}, \mathrm{~B}$ & $N D(0.81)$ & - \\
\hline 2-Nitrophenol & $\mathrm{ND}(5.1)$ & $N D(5.1)$ & $\mathrm{ND}(5.3)$ & $N D(3.8)$ & $\mathrm{ND}(2.7)$ & $0.28 \mathrm{~J}$ & $\mathrm{ND}(3.8)$ & - \\
\hline 4-Nitrophenol & $\mathrm{ND}(12)$ & ND(12) & ND(13) & $\mathrm{ND}(8.5)$ & $0.65 \mathrm{~J}$ & $0.54 \mathrm{~J}$ & $\mathrm{ND}(8.5)$ & - \\
\hline Phenol & $\mathrm{NL})(2.3)$ & $\mathrm{ND}(2.3)$ & $\mathrm{ND}(2.4)$ & $N D(1.7)$ & $\mathrm{ND}(1.4)$ & $0.66 \mathrm{~J}$ & $\mathrm{ND}(1.7)$ & - \\
\hline Benzo(a)anthracene & $\mathrm{ND}(0.84)$ & 0.82 & $\mathrm{ND}(0.89)$ & $\mathrm{ND}(0.51)$ & $\mathrm{ND}(0.50)$ & $N D(0.33)$ & $\mathrm{ND}(0.51)$ & $\cdots$ \\
\hline bis(2-Chloroethoxy)methane & $\mathrm{ND}(2.5)$ & $\mathrm{ND}(2.5)$ & $\mathrm{ND}(2.5)$ & $N D(2.6)$ & $N D(1.9)$ & 1.5 & $\mathrm{ND}(0.70)$ & $\mathrm{ND}(1.9)$ \\
\hline
\end{tabular}

B indicates the substance was detected in the reagent blank at levels greater than or equal to $30 \%$ of the sample value.

$\mathrm{J}$ indicates that the concentration was less than the quantitation limit of the method but above the detection limit.

d indicates that the undiluted sample results exceeded the calibration range of the instnument. The sample wis diluted and the results for the diluted sumples uro shown. 
w Table 3-16

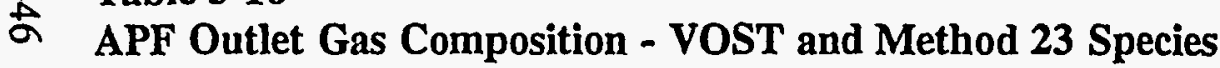

\begin{tabular}{|c|c|c|c|c|c|c|c|}
\hline Substance & Run 1 & Run 2 & Run 3 & Run 4 & Mean & $95 \% \mathrm{CI}$ & $\begin{array}{c}\text { Mean } \\
\text { Blank Level }^{\mathrm{a}}\end{array}$ \\
\hline Date & $4 / 12 / 94$ & $4 / 13 / 94$ & $4 / 14 / 94$ & $4 / 15 / 94$ & & & \\
\hline Gas Flow Rate (dscfm) & 21,800 & 21,600 & 21,800 & 20,800 & 21,500 & 760 & \\
\hline Gas Flow Rate $\left(\mathrm{Nm}^{3} / \mathrm{hr}\right)$ & 34,600 & 34,200 & 34,600 & 33,000 & 34,100 & 1,200 & \\
\hline \multicolumn{8}{|l|}{ VOST $\left(\mu \mathrm{g} / \mathrm{Nm}^{3}\right)$} \\
\hline Chloroform & 0.7 & $\mathrm{ND}(0.5)$ & 0.5 & NS & $\mathrm{ND}(0.5)$ & 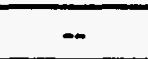 & $\mathrm{ND}(0.5)$ \\
\hline Benzene & 8.0 & 0.5 & 0.8 & NS & 3.1 & 7.7 & $\mathrm{ND}(0.5)$ \\
\hline Bromomethane & $\mathrm{ND}(0.4)$ & $N D(0.5)$ & 2.2 & NS & 0.89 & 2.9 & $\mathrm{ND}(0.5)$ \\
\hline Carbon Disulfide & 21 & 31 & 23 & NS & 25 & 62 & $\mathrm{ND}(0.5)$ \\
\hline Chloromethane & 5.1 & $\mathrm{ND}(0.5)$ & 2.3 & NS & 2.6 & 3.5 & $\mathrm{ND}(0.5)$ \\
\hline Methylene Chloride & 1,500 & 280 & 330 & NS & 720 & 1,800 & $\mathrm{ND}(0.5)$ \\
\hline Toluene & $2.6^{b}$ & $\mathrm{ND}(0.4)$ & $0.6^{\mathrm{b}}$ & NS & $1.2^{b}$ & 3.2 & $\mathrm{ND}(0.5)$ \\
\hline \multicolumn{8}{|l|}{ Dioxin/Furan (pg/ $\left.\mathrm{Nm}^{3}\right)$} \\
\hline $1,2,3,4,6,7,8-\mathrm{HpCDD}$ & NS & 22 & 10 & 8.8 & 14 & 18 & $\mathrm{ND}(2.8)$ \\
\hline $1,2,3,4,6,7,8-\mathrm{HpCDF}$ & NS & 17 & 13 & 11 & $14 \mathrm{~B}$ & 7.8 & $\mathrm{ND}(1.4)$ \\
\hline $1,2,3,4,7,8-\mathrm{HxCDD}$ & NS & $2.3 \mathrm{E}$ & $\mathrm{ND}(5.6)$ & $\mathrm{ND}(7.1)$ & $\mathrm{ND}(7.1)$ & 0.0 & $\mathrm{ND}(2.8)$ \\
\hline $1,2,3,4,7,8-\mathrm{HxCDF}$ & NS & 24 & 15 & 9.1 & $16 \mathrm{~B}$ & 19 & $1.4 \mathrm{E}$ \\
\hline $1,2,3,4,7,8,9-\mathrm{HpCDF}$ & NS & $3.3 \mathrm{E}$ & 5.2 & $\mathrm{ND}(7.1)$ & $\mathrm{ND}(7.1)$ & - & $N D(2.4)$ \\
\hline $1,2,3,6,7,8-\mathrm{HxCDD}$ & NS & 5.7 & $\mathrm{ND}(4.5)$ & $\mathrm{ND}(6.0)$ & $\mathrm{ND}(6.0)$ & - & $\mathrm{ND}(2.1)$ \\
\hline $1,2,3,6,7,8-\mathrm{HxCDF}$ & NS & 5.5 & 3.5 & $\mathrm{ND}(3.0)$ & 3.5 & 4.9 & $\mathrm{ND}(1.0)$ \\
\hline $1,2,3,7,8-\mathrm{PeCDD}$ & NS & $2.7 \mathrm{E}$ & $\mathrm{ND}(5.3)$ & $\mathrm{ND}(6.0)$ & $\mathrm{ND}(6.0)$ & - & $\mathrm{ND}(1.4)$ \\
\hline $1,2,3,7,8-\mathrm{PeCDF}$ & NS & 6.8 & $\mathrm{ND}(3.0)$ & $\mathrm{ND}(3.0)$ & 3.1 & 0.61 & $N D(1.0)$ \\
\hline $1,2,3,7,8,9-\mathrm{HxCDD}$ & NS & 5.7 & 5.3 & $\mathrm{ND}(6.3)$ & $\mathrm{ND}(6.3)$ & $\cdots$ & $\mathrm{ND}(2.1)$ \\
\hline
\end{tabular}


Table 3-16 (Continued)

\begin{tabular}{|c|c|c|c|c|c|c|c|}
\hline Substance & Run 1 & Run 2 & Run 3 & Run 4 & Mean & $95 \% \mathrm{CI}$ & $\begin{array}{c}\text { Mean } \\
\text { Blank Level } \\
\end{array}$ \\
\hline $1,2,3,7,8,9-\mathrm{HxCDF}$ & NS & 2.5 & $\mathrm{ND}(3.4)$ & $N D(4.1)$ & $\mathrm{ND}(4.1)$ & - & $\mathrm{ND}(1.7)$ \\
\hline $2,3,4,6,7,8-\mathrm{HxCDF}$ & NS & $6.0 \mathrm{~B}$ & $3.8 \mathrm{~B}, \mathrm{E}$ & $3.4 \mathrm{E}, \mathrm{B}$ & 4.4 & 3.5 & 2.1 \\
\hline $2,3,4,7,8-\mathrm{PeCDF}$ & NS & $3.3 \mathrm{E}$ & $\mathrm{ND}(3.0)$ & $\mathrm{ND}(3.0)$ & $\mathrm{ND}(3.0)$ & - & $\mathrm{ND}(1.0)$ \\
\hline $2,3,7,8-\mathrm{TCDD}$ & NS & $1.0 \mathrm{E}$ & $\mathrm{ND}(3.4)$ & $N D(3.0)$ & $\mathrm{ND}(3.4)$ & - & $\mathrm{ND}(1.4)$ \\
\hline $2,3,7,8-\mathrm{TCDF}$ & NS & 12 & 4.5 & $\mathrm{ND}(1.1)$ & 5.7 & 14 & $\mathrm{ND}(1.0)$ \\
\hline OCDD & NS & $43 \mathrm{E}$ & $34 \mathrm{E}$ & 35 & 37 & 13 & $3.4 \mathrm{E}$ \\
\hline OCDF & NS & 66 & 42 & $34 \mathrm{E}$ & 47 & 42 & $\mathrm{ND}(3.4)$ \\
\hline Total HpCDD & NS & 22 & 10 & 8.8 & 14 & 18 & $\mathrm{ND}(2.8)$ \\
\hline Total HpCDF & NS & 24 & 20 & 14 & 19 & 13 & $\mathrm{ND}(1.7)$ \\
\hline Total $\mathrm{H} \times \mathrm{CDD}$ & NS. & 46 & $3.8 \mathrm{E}$ & 5.2 & 18 & 59 & $\mathrm{ND}(2.1)$ \\
\hline Total HxCDF & NS & 51 & 18 & $8.6 \mathrm{~B}$ & 26 & 56 & 2.1 \\
\hline Total PeCDD & NS & 41 & $11 \mathrm{E}$ & $\mathrm{ND}(6.0)$ & 19 & 50 & $\mathrm{ND}(1.4)$ \\
\hline Total PeCDF & NS & 53 & $7.5 \mathrm{E}$ & 4.0 & 21 & 68 & $N D(1.0)$ \\
\hline Total TCDD & NS & 130 & 14 & $N D(3.0)$ & 47 & 170 & $N D(1.4)$ \\
\hline Total TCDF & NS & 99 & 12 & 2.8 & 38 & 130 & $\mathrm{ND}(1.0)$ \\
\hline \multicolumn{8}{|l|}{ Aldehydes } \\
\hline Formaldehyde & 3.6 & 4.1 & 3.8 & NS & 3.9 & 0.6 & \\
\hline
\end{tabular}

a Calculated based on the mean level in the reagent blank divided by the mean gas sample volume.

$b$ Levels in the field blanks are $\geq 30 \%$ of the sample value.

$B$ indicates the substanice was detected in the reagent blanks at $\geq 30 \%$ of the sample value.

$E$ indicates value is an estimated upper limit.

$\mathrm{CI}=$ Confidence interval.

$\mathrm{ND}=$ Not detected at the concentration in parentheses.

NS $=$ Not sampled.

HpCDD = Heptachlorodibenzo-p-dioxin.

HpCDF = Heptachlorodibenzofuran.

$\mathrm{HXCDD}=$ Hexachlorodibenzo-p-dioxin

$\mathrm{H} \times C D F=$ Hexachlorodibenzofuran.

PeCDD = Pentachlorodibenzo-p-dioxin

$\mathrm{PeCDF}=$ Pentachlorodibenzofuran.

TCDD = Tetrachlorodibenzo-p-dioxin.

TCDF = Tetrachlorodibenzofuran.

OCDD = Octachlorodibenzo-p-dioxin.

OCDF = Octachlorodibenzofuran. 
Table 3-17

Results for Semivolatile Organic Species at the APF Outlet

\begin{tabular}{|c|c|c|c|c|c|c|c|c|}
\hline \multirow[b]{2}{*}{ Substance } & \multicolumn{3}{|c|}{ Particulate Phase } & \multicolumn{3}{|c|}{ Vapor Phase } & \multicolumn{2}{|c|}{ Total } \\
\hline & Run 1 & Run 2 & Run 3 & Run 1 & Run 2 & Run 3 & Mean & $95 \% \mathrm{CI}$ \\
\hline \multicolumn{9}{|c|}{ PAHs by HR GC/MS (ng/Nm $\left.{ }^{3}\right)$} \\
\hline Acenaphthene & $0.1 \mathrm{~B}$ & $0.080 \mathrm{~B}$ & $0.28 \mathrm{~B}$ & $70 \mathrm{~B}$ & $9.5 \mathrm{~B}$ & $31 \mathrm{~B}$ & $37 \mathrm{~B}$ & 76 \\
\hline Acenaphthylene & $0.027 \mathrm{~B}$ & $0.017 \mathrm{~B}$ & $0.078 \mathrm{~B}$ & 27 & $1.3 \mathrm{~B}$ & $3.5 \mathrm{~B}$ & $10 \mathrm{~B}$ & 35 \\
\hline Anthracene & $0.16 \mathrm{~B}$ & $0.097 \mathrm{~B}$ & $0.34 \mathrm{~B}$ & $0.25 \mathrm{~B}$ & $0.53 \mathrm{~B}$ & $0.78 \mathrm{~B}$ & $0.72 \mathrm{~B}$ & 0.92 \\
\hline Benzo(a)anthracene & 0.070 & 0.077 & $0.043 \mathrm{~B}$ & $0.26 \mathrm{~B}$ & $0.26 \mathrm{~B}$ & $0.38 \mathrm{~B}$ & $0.36 \mathrm{~B}$ & 0.13 \\
\hline Benzo(a)pyrene & 0.090 & $0.044 \mathrm{~B}$ & $0.078 \mathrm{~B}$ & NR & $0.28 \mathrm{~B}$ & $0.31 \mathrm{~B}$ & $0.27 \mathrm{~B}$ & 0.39 \\
\hline Benzo(b)fluoranthene & $0.15 \mathrm{~B}$ & $0.17 \mathrm{~B}$ & $0.11 \mathrm{~B}$ & $0.80 \mathrm{~B}$ & $0.71 \mathrm{~B}$ & $0.87 \mathrm{~B}$ & $0.93 \mathrm{~B}$ & 0.13 \\
\hline Benzo(g,h,i)perylene & 0.48 & 0.79 & 0.30 & 53 & $1.2 \mathrm{~B}$ & $1.1 \mathrm{~B}$ & $19 \mathrm{~B}$ & 74 \\
\hline Benzo(k)fluoranthene & $0.033 \mathrm{~B}$ & $0.027 \mathrm{~B}$ & $0.032 \mathrm{~B}$ & $0.41 \mathrm{~B}$ & $0.32 \mathrm{~B}$ & $0.28 \mathrm{~B}$ & $0.37 \mathrm{~B}$ & 0.17 \\
\hline 2-Chloronaphthalene & $\mathrm{ND}(0.028)$ & $N D(0.015)$ & $\mathrm{ND}(0.019)$ & $\mathrm{ND}(0.070)$ & $\mathrm{ND}(0.13)$ & 0.40 & 0.17 & 0.50 \\
\hline Chrysene & $0.13 \mathrm{~B}$ & 0.27 & 0.23 & $0.73 \mathrm{~B}$ & $0.38 \mathrm{~B}$ & $0.77 \mathrm{~B}$ & $0.83 \mathrm{~B}$ & 0.43 \\
\hline Dibenz(a,h)anthracene & $\mathrm{ND}(0.073)$ & $\mathrm{ND}(0.018)$ & $\mathrm{ND}(0.026)$ & $0.41 \mathrm{~B}$ & $\mathrm{ND}(0.24)$ & $0.23 \mathrm{~B}$ & $0.25 \mathrm{~B}$ & $0.3 \dot{3}$ \\
\hline Fluoranthene & $0.61 \mathrm{~B}$ & $0.37 \mathrm{~B}$ & $1.0 \mathrm{~B}$ & $4.7 \mathrm{~B}$ & $3.9 \mathrm{~B}$ & $7.2 \mathrm{~B}$ & $5.9 \mathrm{~B}$ & 5.1 \\
\hline Fluorene & $0.71 \mathrm{~B}$ & $0.47 \mathrm{~B}$ & $1.7 \mathrm{~B}$ & $6.0 \mathrm{~B}$ & $3.8 \mathrm{~B}$ & $9.2 \mathrm{~B}$ & $7.3 \mathrm{~B}$ & 8.2 \\
\hline Indeno(1,2,3-cd)pyrene & $0.092 \mathrm{~B}$ & 0.17 & $0.092 \mathrm{~B}$ & $0.65 \mathrm{~B}$ & $0.58 \mathrm{~B}$ & $0.48 \mathrm{~B}$ & $0.69 \mathrm{~B}$ & 0.25 \\
\hline 2-Methylnaphthalene & $1.1 \mathrm{~B}$ & $0.99 \mathrm{~B}$ & $2.4 \mathrm{~B}$ & $51 \mathrm{~B}$ & $24 \mathrm{~B}$ & $22 \mathrm{~B}$ & $34 \mathrm{~B}$ & 39 \\
\hline Naphthalene & $2.9 \mathrm{~B}$ & $2.8 \mathrm{~B}$ & $3.2 \mathrm{~B}$ & $140 \mathrm{~B}$ & $380 \mathrm{~B}$ & $380 \mathrm{~B}$ & $300 \mathrm{~B}$ & 350 \\
\hline Phenanthrene & $3.4 \mathrm{~B}$ & $3.1 \mathrm{~B}$ & $8.3 \mathrm{~B}$ & $24 \mathrm{~B}$ & $19 \mathrm{~B}$ & $39 \mathrm{~B}$ & $32 \mathrm{~B}$ & 33 \\
\hline Pyrene & 1.1 & $0.30 \mathrm{~B}$ & $0.63 \mathrm{~B}$ & $1.1 \mathrm{~B}$ & $1.8 \mathrm{~B}$ & $3.4 \mathrm{~B}$ & $2.8 \mathrm{~B}$ & 2.7 \\
\hline
\end{tabular}


Table 3-17 (Continued)

\begin{tabular}{|c|c|c|c|c|c|c|c|c|}
\hline \multirow[b]{2}{*}{ Substance } & \multicolumn{3}{|c|}{ Particulate Phase } & \multicolumn{3}{|c|}{ Vapor Phase } & \multicolumn{2}{|c|}{ Total } \\
\hline & Run 1 & Run 2 & Run 3 & Run 1 & Run 2 & Run 3 & Mean & $95 \% \mathrm{CI}$ \\
\hline \multicolumn{9}{|c|}{$\begin{array}{l}\text { Semivolatile Organic Compounds } \\
\text { by } 8270\left(\mu \mathrm{g} / \mathrm{Nm}^{3}\right)\end{array}$} \\
\hline Acetophenone & $\mathrm{ND}(0.44)$ & $\mathrm{ND}(0.36)$ & $\mathrm{ND}(0.40)$ & $2.0 \mathrm{~J}$ & $1.6 \mathrm{~J}$ & $2.8 \mathrm{~J}$ & $2.1 \mathrm{~J}$ & 1.5 \\
\hline Benzoic acid & $\mathrm{ND}(1.6)$ & $\mathrm{ND}(1.4)$ & $\mathrm{ND}(1.5)$ & $130 \mathrm{~d}$ & 110 & $23 d$ & $84 d$ & 140 \\
\hline Di-n-butylphthalate & 18 & 1.2 & 10 & $3.7 \mathrm{~J}, \mathrm{~B}$ & $1.0 \mathrm{~J}, \mathrm{~B}$ & 100 & 45 & 150 \\
\hline bis(2-Ethylhexyl)phthalate & $0.094 \mathrm{~J}, \mathrm{~B}$ & $0.10 \mathrm{~J}, \mathrm{~B}$ & $0.070 \mathrm{~J}, \mathrm{~B}$ & $1.0 \mathrm{~J}, \mathrm{~B}$ & $0.52 \mathrm{~J}, \mathrm{~B}$ & 9.9 & 3.9 & 13 \\
\hline Isophorone & $\mathrm{ND}(0.26)$ & $\mathrm{ND}(0.22)$ & $\mathrm{ND}(0.25)$ & $1.7 \mathrm{~J}$ & $\mathrm{ND}(0.38)$ & $\mathrm{ND}(0.40)$ & $0.70 \mathrm{~J}$ & 2.2 \\
\hline Phenol & $\mathrm{ND}(0.37)$ & $\mathrm{ND}(0.30)$ & $\mathrm{ND}(0.33)$ & $1.3 \mathrm{~J}$ & $0.65 \mathrm{~J}$ & $1.2 \mathrm{~J}$ & $1.0 \mathrm{~J}$ & 0.85 \\
\hline
\end{tabular}

B indicates the substance was detected in the reagent blank at levels greater than or equal to $30 \%$ of the sample.

$\mathrm{J}$ indicates that the concentration was less than the quantitation limit of the method but above the detection limit.

$d$ indicates that the undiluted sample result exceeded the calibration range of the instrument; results are shown for the diluted sample.

$\mathrm{Cl}=$ Confidence interval.

$N D=$ Not detected at the concentration in parentheses.

NR = Not reported. Internal standard was not detected; therefore, substance could not be quantified. 
sample value) ranged from $3.5 \times 10^{-6} \mu \mathrm{g} / \mathrm{Nm}^{3}$ for $1,2,3,6,7,8$-hexachlorodibenzofuran to $4.7 \times 10^{-5} \mu \mathrm{g} / \mathrm{Nm}^{3}$ octachlorodibenzofuran. The apparent reduction of dioxin/furan concentrations across the APF system may be due to condensation of these species on the particulate matter in the APF gas. Data for the APF and ESP ash (Table 3-4) indicate the presence of some dioxin/furan compounds at $\mathrm{pg} / \mathrm{g}$ levels.

Results for semivolatile organic compounds measured in the APF inlet and outlet gas are presented in Tables 3-15 and 3-17, respectively. Results are very similar to those discussed above for the ESP inlet and outlet gas steams. The same compounds were detected at similar concentrations at both the ESP and APF locations. The discussion presented previously also applies to the results for the APF gas streams.

\section{ESP System Control Efficiency}

Table 3-18 presents the removal efficiencies for the ESP system, listed by species. The average particulate removal efficiency was calculated to be $97.2 \%$ based on the data collected during the three Method 29 train tests. Little or no removal is indicated for chloride (6\%), mercury (4\%) and $\mathrm{SO}_{2}(2 \%)$. Modest removal was measured for cadmium (44\%), copper (62\%), fluoride (54\%), selenium (37\%), ammonia (16\%), cyanide (21\%), and formaldehyde

(24\%). Removal of other target species is much higher, ranging from $90 \%$ (nickel) to 99.8\% (arsenic).

\section{APF System Control Efficiency}

Estimates of the APF system control efficiency are also shown in Table 3-18. Over 1300: dscf of gas was collected during each test run at the APF outlet to quantify the particulate loading. The mean measured particulate removal efficiency was 99.993 percent. Low removals are indicated for chloride (18\%), fluoride (-15\%), and mercury $(9 \%)$. Modest removals were observed for molybdenum (63\%), nickel (77\%), selenium (27\%), ammonia (25\%), and cyanide (69\%). Removals for major elements ( $\mathrm{Al}, \mathrm{Ca}, \mathrm{Ti}$, etc.) were comparable to the removal observed for particulate matter. 
Table 3-18

\section{ESP and APF Control Efficiencies}

\begin{tabular}{|c|c|c|c|c|}
\hline \multirow[b]{2}{*}{ Substance } & \multicolumn{2}{|l|}{ ESP } & \multicolumn{2}{|l|}{ APF } \\
\hline & Mean Removal (\%) & $95 \% \mathrm{CI}$ & Mean Removal (\%) & $95 \% \mathrm{CI}$ \\
\hline Particulate & 97.2 & 4.8 & 99.99 & 0.01 \\
\hline Antimony & NC & - & $>65$ & $\overline{-}$ \\
\hline Arsenic & 99.8 & 0.1 & 99.6 & 0.2 \\
\hline Barium & 99.7 & 3.1 & 99.996 & 0.014 \\
\hline Beryllium & 99.8 & 4.0 & $>99.9$ & - \\
\hline Boron & NC & - & NC & - \\
\hline Cadmium & 44 & 150 & $>99.9$ & - \\
\hline Chloride (total) & 6.0 & 7.7 & 18 & 39 \\
\hline $\mathrm{HCl}^{\mathrm{a}}$ & 4 & 10 & 11 & 33 \\
\hline Chromium & 97.2 & 2.2 & $89^{b}$ & 40 \\
\hline Cobalt & $>99.2$ & - & 99.6 & 1.6 \\
\hline Copper & 62 & 41 & 99.5 & 0.7 \\
\hline Fluoride (total) & 54 & 13 & -15 & 16 \\
\hline $\mathrm{HF}^{\mathrm{a}}$ & 32 & 16 & -33 & 25 \\
\hline Lead & 99.1 & 5.1 & 99.99 & 0.01 \\
\hline Manganese & 95.2 & 6.8 & $98.2^{6}$ & 6.6 \\
\hline Mercury & 4 & 40 & 9 & 39 \\
\hline Molybdenum & NC & 43 & $63^{b}$ & 82 \\
\hline Nickel & 90 & 15 & $77^{6}$ & 38 \\
\hline Selenium & 37 & 29 & 27 & 26 \\
\hline Silver & NC & - & NC & - \\
\hline Vanadium & 99.2 & 0.2 & 99.5 & 0.2 \\
\hline Aluminum & 99.8 & 0.2 & 99.98 & 0.01 \\
\hline Calcium & 99.5 & 0.2 & 99.9 & 0.04 \\
\hline Iron & 98.8 & 2.5 & 99.8 & 0.9 \\
\hline Magnesium & 99.8 & 0.1 & 99.99 & 0.005 \\
\hline Potassium & 99.8 & 0.1 & $>99.995$ & - \\
\hline Sodium & 88.9 & 3.5 & 96.2 & 1.8 \\
\hline Titanium & 99.7 & 0.4 & 99.98 & 0.01 \\
\hline Ammonia & 16 & 42 & 25 & 31 \\
\hline Cyanide & $\overline{21}$ & 92 & 69 & 15 \\
\hline Formaldehyde & 24 & 66 & 94 & 20 \\
\hline Sulfur (total) & 92 & - & 89 & 4 \\
\hline $\mathrm{SO}_{2}$ & 2 & - & 42 & 11 \\
\hline
\end{tabular}

Assumes that the vapor-phase concentration of the anion is present as $\mathrm{HCl}$ or $\mathrm{HF}$.

b May not be representative of actual APF performance.

$\mathrm{NC}=$ Not calculated. Substance was not detected in the inlet gas stream.

$>$ indicates the reported removal efficiency is a lower limit. The substance was not detected in the device outlet gas. Detection limit was used to estimate a lower limit for the removal efficiency.

$\mathrm{CI}=$ Confidence interval. 
The relatively low removal efficiencies for chromium, molybdenum, and nickel, relative to the total particulate removal, suggests either 1) a significant fraction of these elements exists in the vapor phase and is not removed; or 2) that contamination from the Inconel 800 sampling probe or elsewhere in the process equipment may have occurred within the APF outlet particulate matter. A comparison of the mean particulate-phase composition on a $\mu \mathrm{g} / \mathrm{g}$ basis at all four gas locations and collected ash from these systems is shown below:

\begin{tabular}{|c|c|c|c|c|c|c|}
\hline & ESP Inlet & ESP Ash & ESP Outlet & APF Inlet & APF Ash & APF Outlet \\
\hline Chromium ( $\mu \mathrm{g} / \mathrm{g})$ & 82 & 94 & 35 & 110 & 74 & 66,500 \\
\hline Molybdenum $(\mu \mathrm{g} / \mathrm{g})$ & $<2$ & $<3.8$ & 6 & 7 & $<3.3$ & 27,700 \\
\hline Nickel $(\mu g / g)$ & 32 & 29 & 270 & 130 & 50 & 2,600 \\
\hline
\end{tabular}

The abnormally high concentrations of chromium, molybdenum, and nickel in the APF outlet particulate matter shown above strongly suggest that residue from the Inconel 800 components of the sampling system is present in the particulate matter. The particulate-phase concentrations of these species reported for the APF outlet should be considered biased high.

Examination of the data in Table 3-13 indicates high levels of chromium, cobalt, iron, manganese, and nickel (all potential components of the Inconel 800 or stainless steel components of the sampling system) in the vapor phase at the APF outlet, particularly for Run 2. However, elevated levels were not observed for those elements primarily associated with the fly ash component of the particulate matter (e.g., aluminum, antimony, arsenic, beryllium, calcium, copper, lead, magnesium, selenium, titanium, and vanadium). Since the filters used at the APF outlet have a pore size of about $0.45 \mu \mathrm{m}$, it is possible that any residue from the probe less than about $0.45 \mu \mathrm{m}$ diameter could have penetrated the filter at the APF outlet resulting in abnormally high levels of the metallic elements in the vapor phase. Since the PSD results of the ESP inlet and outlet ash indicate very little ash material in the less than $0.5 \mu \mathrm{m}$ diameter fraction, penetration of fly ash across the sampling system filters is expected to be minimal. Therefore, vapor-phase data for chromium, cobalt, iron, manganese, and nickel for Run 2 may not be representative of the actual vapor-phase 
composition at the APF outlet. Calculated control efficiencies for chromium, manganese, molybdenum, and nickel may not be representative of actual APF performance.

If the ESP outlet particulate composition is used to estimate the particulate-phase removal of these species across the APF, values of $99.997 \%$ (chromium), $99.98 \%$ (nickel), and 99.993\% (molybdenum) are obtained. These values are more consistent with the overall particulate removal measured across the APF system.

Data from the anions train indicate approximately $40 \%$ removal of $\mathrm{SO}_{2}$ across the APF system, presumably because of reaction of the $\mathrm{SO}_{2}$ with the sorbent material on the surface of the ceramic candles. The $\mathrm{SO}_{2}$ measurements made during the three tests were consistent with the levels of $\mathrm{SO}_{2}$ measured by the plant's CEM system at both the APF inlet and outlet; both data sets suggest $\mathrm{SO}_{2}$ removal occurs across the APF unit.

\section{Emission Factors}

Table 3-19 provides calculated ESP outlet emissions factors for all of the target species. Emissions factors are presented on $\mathrm{a} \mathrm{b} / 10^{12} \mathrm{Btu}$ heat input basis. Emissions factors for inorganic substances detected in the ESP outlet gas range from 83,000 lb/trillion Btu (chloride) to $0.31 \mathrm{lb} /$ trillion Btu (molybdenum). The range of emission factors for organic species is $4.3 \times 10^{-6}=\mathrm{lb} /$ trillion Btu (pentachlorodibenzofuran) to $6.6 \mathrm{lb} /$ trillion Btu (benzene).

\section{Particle Size Distribution Data}

Particle size distributions (PSDs) were determined for the ash material collected at the ESP inlet, ESP outlet, and the each of the four ESP hoppers. PSDs for the gas stream particulate matter were determined using an "in-stack" cascade impactor which separated the entrained particulate matter into 11 fractions (10 impacted fractions and one filter fraction) according to aerodynamic particle size. ESP hopper ash samples were analyzed by laser diffraction to determine the physical diameter of the particles. Results from the laser diffraction analyses of the ESP hopper ash were converted from physical particle diameters to aerodynamic 
Table 3-19

Emission Factors for ESP Outlet Gas (lb/10 12 Btu, unless noted)

\begin{tabular}{|c|c|c|}
\hline Substance & Emission Factor & $95 \% \mathrm{CI}$ \\
\hline Particulate $\left(\mathrm{lb} / 10^{6} \mathrm{Btu}\right)$ & 0.051 & 0.09 \\
\hline \multicolumn{3}{|l|}{ Inorganic Species } \\
\hline Ammonia & 140 & 7 \\
\hline Antimony & $\mathrm{ND}(2.6)$ & - \\
\hline Arsenic & 1.2 & 0.06 \\
\hline Barium & 0.92 & 0.044 \\
\hline Beryllium & 0.026 & 0.0012 \\
\hline Boron & 210 & 10 \\
\hline Cadmium & 2.2 & 0.11 \\
\hline Chloride (total) & 83,000 & 4,000 \\
\hline Chromium & 4.6 & 0.22 \\
\hline Cobalt & $\mathrm{ND}(2.4)$ & - \\
\hline Copper & 5.3 & 0.25 \\
\hline Cyanide & 610 & 29 \\
\hline Fluoride (total) & 5600 & 270 \\
\hline Lead & 0.80 & 0.038 \\
\hline Manganese & 8.5 & 0.41 \\
\hline Mercury (total) & 18 & 1 \\
\hline Molybdenum & 0.31 & 0.015 \\
\hline Nickel & 7.4 & 0.35 \\
\hline Selenium & 49 & 2.3 \\
\hline Silver & 0.50 & 0.024 \\
\hline Vanadium & 1.2 & 0.06 \\
\hline Chromium (VI) & 1.7 & 0.08 \\
\hline \multicolumn{3}{|l|}{ Organic Species } \\
\hline Formaldehyde & 5.1 & 0.24 \\
\hline 1,1,2,2-Tetrachloroethane & $\mathrm{ND}(0.7)$ & - \\
\hline 1,1,2-Trichloroethane & $\mathrm{ND}(0.7)$ & - \\
\hline 1,1-Dichloroethane & $\mathrm{ND}(0.7)$ & - \\
\hline 1,1-Dichloroethene & $\mathrm{ND}(0.7)$ & - \\
\hline 1,2-Dichlorobenzene & $\mathrm{ND}(0.7)$ & - \\
\hline 1,2-Dichloropropane & $\mathrm{ND}(0.7)$ & - \\
\hline 1,3-Dichlorobenzene & $\mathrm{ND}(0.7)$ & - \\
\hline 1,4-Dichlorobenzene & $N D(0.7)$ & - \\
\hline
\end{tabular}


Table 3-19 (Continued)

\begin{tabular}{|c|c|c|}
\hline Substance & Emission Factor & 95\% CI \\
\hline 2-Butanone & ND(3.3) & - \\
\hline 2-Hexanone & $\mathrm{ND}(3.3)$ & - \\
\hline 4-Methyl-2-Pentanone & $N D(3.3)$ & - \\
\hline Acetone & $\mathrm{ND}(3.3)$ & - \\
\hline Bromodichloromethane & $\mathrm{ND}(0.7)$ & - \\
\hline Bromoform & $\mathrm{ND}(0.7)$ & - \\
\hline Bromomethane & $\mathrm{ND}(0.7)$ & - \\
\hline Carbon Tetrachloride & $\mathrm{ND}(0.7)$ & - \\
\hline Chlorobenzene & $\mathrm{ND}(0.7)$ & - \\
\hline Chloroethane & $N D(0.7)$ & - \\
\hline Chloroform & $\mathrm{ND}(0.7)$ & - \\
\hline cis-1,3-Dichloropropene & $\mathrm{ND}(0.7)$ & - \\
\hline Dibromochloromethane & $\mathrm{ND}(0.7)$ & - \\
\hline Ethyl Benzene & $\mathrm{ND}(0.7)$ & - \\
\hline $\mathrm{m}, \mathrm{p}$-Xylene & $\mathrm{ND}(0.7)$ & - \\
\hline 0-Xylene & $\mathrm{ND}(0.7)$ & - \\
\hline Styrene & $\mathrm{ND}(0.7)$ & - \\
\hline Tetrachloroethene & $\mathrm{ND}(0.7)$ & - \\
\hline trans-1,2-Dichloroethene & $\mathrm{ND}(0.7)$ & - \\
\hline trans-1,3-Dichloropropene & $\mathrm{ND}(0.7)$ & - \\
\hline Trichloroethene & $\mathrm{ND}(0.7)$ & - \\
\hline Trichlorofluoromethane & $\mathrm{ND}(0.7)$ & - \\
\hline Vinyl Acetate & $\mathrm{ND}(3.3)$ & - \\
\hline Vinyl Chloride & $\mathrm{ND}(0.7)$ & - \\
\hline 1,1,1-Trichloroethane & $16^{2}$ & 1 \\
\hline 1,2-Dichloroethane & $8.7^{2}$ & 0.41 \\
\hline Benzene & 6.6 & 0.32 \\
\hline Carbon Disulfide & 1.0 & 0.05 \\
\hline Chloromethane & $4.4^{2}$ & 0.21 \\
\hline Methylene Chloride & $3.6^{8}$ & 0.17 \\
\hline Toluene & $1.4^{2}$ & 0.07 \\
\hline
\end{tabular}


Table 3-19 (Continued)

\begin{tabular}{|l|c|c|}
\hline \multicolumn{1}{|c|}{ Substance } & Emission Factor & $95 \%$ CI \\
\hline $1,2,3,4,6,7,8-\mathrm{HpCDD}$ & $7.3 \mathrm{E}-06^{\mathrm{b}, \mathrm{c}}$ & $3.5 \mathrm{E}-07$ \\
\hline $1,2,3,4,6,7,8-\mathrm{HpCDF}$ & $6.4 \mathrm{E}-06^{\mathrm{c}}$ & $3.1 \mathrm{E}-07$ \\
\hline $1,2,3,4,7,8-\mathrm{HxCDD}$ & $\mathrm{ND}(4.8 \mathrm{E}-6)$ & - \\
\hline $1,2,3,4,7,8-\mathrm{HxCDF}$ & $5.6 \mathrm{E}-06^{\mathrm{b}, c}$ & $2.7 \mathrm{E}-07$ \\
\hline $1,2,3,4,7,8,9-\mathrm{HpCDF}$ & $\mathrm{ND}(5.0 \mathrm{E}-6)$ & - \\
\hline $1,2,3,6,7,8-\mathrm{HxCDD}$ & $\mathrm{ND}(3.9 \mathrm{E}-6)$ & - \\
\hline $1,2,3,6,7,8-\mathrm{HxCDF}$ & $\mathrm{ND}(2.2 \mathrm{E}-6)$ & - \\
\hline $1,2,3,7,8-\mathrm{PeCDD}$ & $\mathrm{ND}(3.5 \mathrm{E}-6)$ & - \\
\hline $1,2,3,7,8-\mathrm{PeCDF}$ & $\mathrm{ND}(2.2 \mathrm{E}-6)$ & - \\
\hline $1,2,3,7,8,9-\mathrm{HxCDD}$ & $\mathrm{ND}(4.4 \mathrm{E}-6)$ & - \\
\hline $1,2,3,7,8,9-\mathrm{HxCDF}$ & $\mathrm{ND}(3.5 \mathrm{E}-6)$ & - \\
\hline $2,3,4,6,7,8-\mathrm{HxCDF}$ & $4.4 \mathrm{E}-06^{\mathrm{b}, c}$ & $2.1 \mathrm{E}-07$ \\
\hline $2,3,4,7,8-\mathrm{PeCDF}$ & $\mathrm{ND}(2.2 \mathrm{E}-6)$ & - \\
\hline $2,3,7,8-\mathrm{TCDD}$ & $\mathrm{ND}(2.0 \mathrm{E}-6)$ & - \\
\hline $2,3,7,8-\mathrm{TCDF}$ & $\mathrm{ND}(2.0 \mathrm{E}-6)$ & - \\
\hline OCDD & $7.7 \mathrm{E}-05^{\mathrm{b}, \mathrm{c}}$ & $3.7 \mathrm{E}-06$ \\
\hline OCDF & $1.2 \mathrm{E}-05^{\mathrm{c}}$ & $5.8 \mathrm{E}-07$ \\
\hline TOTAL HpCDD & $1.4 \mathrm{E}-05^{\mathrm{c}}$ & $6.7 \mathrm{E}-07$ \\
\hline TOTAL HpCDF & $4.5 \mathrm{E}-06^{\mathrm{c}}$ & $2.1 \mathrm{E}-07$ \\
\hline TOTAL HxCDD & $\mathrm{ND}(4.1 \mathrm{E}-6)$ & - \\
\hline TOTAL HxCDF & $1.4 \mathrm{E}-05^{\mathrm{c}}$ & $6.7 \mathrm{E}-07$ \\
\hline TOTAL PeCDD & $\mathrm{ND}(3.5 \mathrm{E}-6)$ & - \\
\hline TOTAL PeCDF & $4.3 \mathrm{E}-06^{\mathrm{c}}$ & $2.1 \mathrm{E}-07$ \\
\hline TOTAL TCDD & $\mathrm{ND}(1.8 \mathrm{E}-6)$ & - \\
\hline TOTAL TCDF & $\mathrm{ND}(2.0-\mathrm{E}-6)$ & - \\
\hline & & -6 \\
\hline
\end{tabular}

- Methylene chloride, toluene, and other halogenated hydrocarbons are suspected to be present as a reșult of contamination.

bubstance was detected in the reagent blank at greater than or equal to $30 \%$ of the sample result. Results are considered to be bias high. Quantification is suspect.

c Substance was quantified at less than five times the detection limit.

$\mathrm{CI}=$ Confidence interval.

$\mathrm{HpCDD}=$ Heptachlorodibenzo-p-dioxin.

HpCDF = Heptachlorodibenzofuran.

HxCDD = Hexachlorodibenzo-p-dioxin.

$\mathrm{HxCDF}=$ Hexachlorodibenzofuran.

PeCDD = Pentachlorodibenzo-p-dioxin.

PeCDF = Pentachlorodibenzofuran.

TCDD = Tetrachlorodibenzo-p-dioxin.

TCDF $=$ Tetrachlorodibenzofuran.

OCDD = Octachlorodibenzo-p-dioxin.

OCDF = Octachlorodibenzofuran. 
particle diameters so that they could be compared to the cascade impactor results from the ESP inlet location. Physical and aerodynamic particle sizes are related by the following equation:

$$
\mathrm{D}_{\mathrm{a}}=\mathrm{D}_{\mathrm{p}} /(\rho)^{0.5}
$$

where

$$
\begin{aligned}
D_{a} & =\text { aerodynamic particle size }(\mu \mathrm{m}) \\
D_{p} & =\text { physical particle size }(\mu \mathrm{m}) \\
\rho & =\text { particle specific gravity (assumed to be } 2.0 \text { ) }
\end{aligned}
$$

In this case, the specific gravity of the material collected at the ESP outlet was assumed to be equal to 2.0. Specific gravity for typical fly ash can range from 2.0 to 2.8. The selection of this value does not have a significant impact on the ESP hopper PSD. results.

Results for each of the three runs at the gas stream locations were combined to obtain the average PSD plots shown in Figures 3-4 and 3-5 for the ESP inlet and outlet, respectively. Similarly, the results for the samples collected from each of the four ESP hoppers were combined to obtain the average PSD plots shown in Figures 3-6 and 3-7. PSD plots for individual samples and hoppers are provided at the end of Appendix $\mathrm{C}$ along with the detailed PSD results. Weight gains from the initial precutter fraction of the impactor were not included in the PSD analysis, since these weight gains caused the total particulate loadings to become abnormally high. The large weight gains associated with right angle precutter fractions are believed to be caused by collection of large rust/asin particles from the walls of the sample ports as the impactors were inserted into the duct. Rust flakes and a : reddish-brown discoloration were noted in the precutter fractions.

As expected, data for the ESP hoppers show a downward shift in the particle size distribution from the first to the last hopper (i.e., Hopper \#1 to Hopper \#4) since the largest particles are easily collected in the first field of the ESP. One would also expect that the PSD data for 


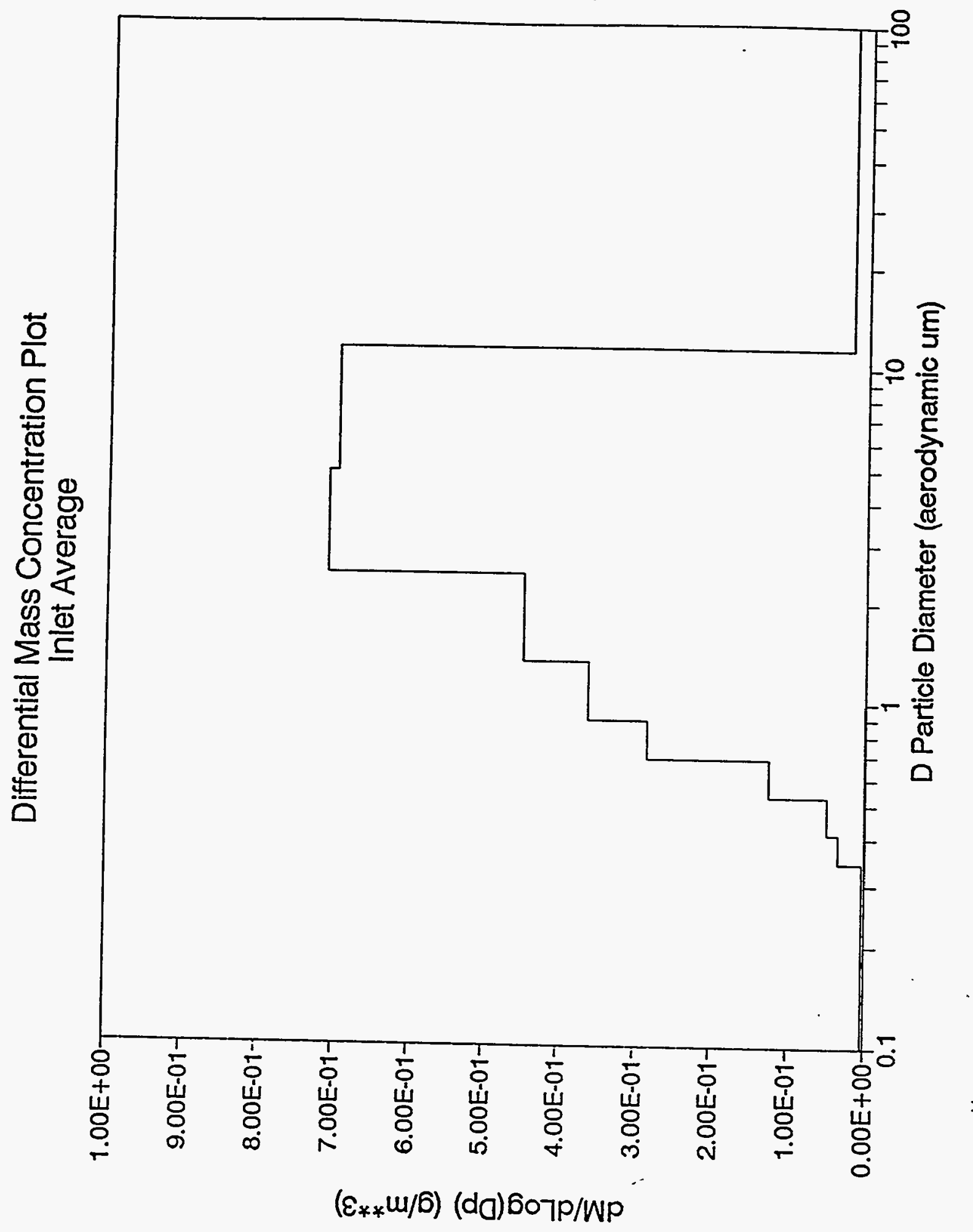

Figure 3-4

ESP Inlet PSD 

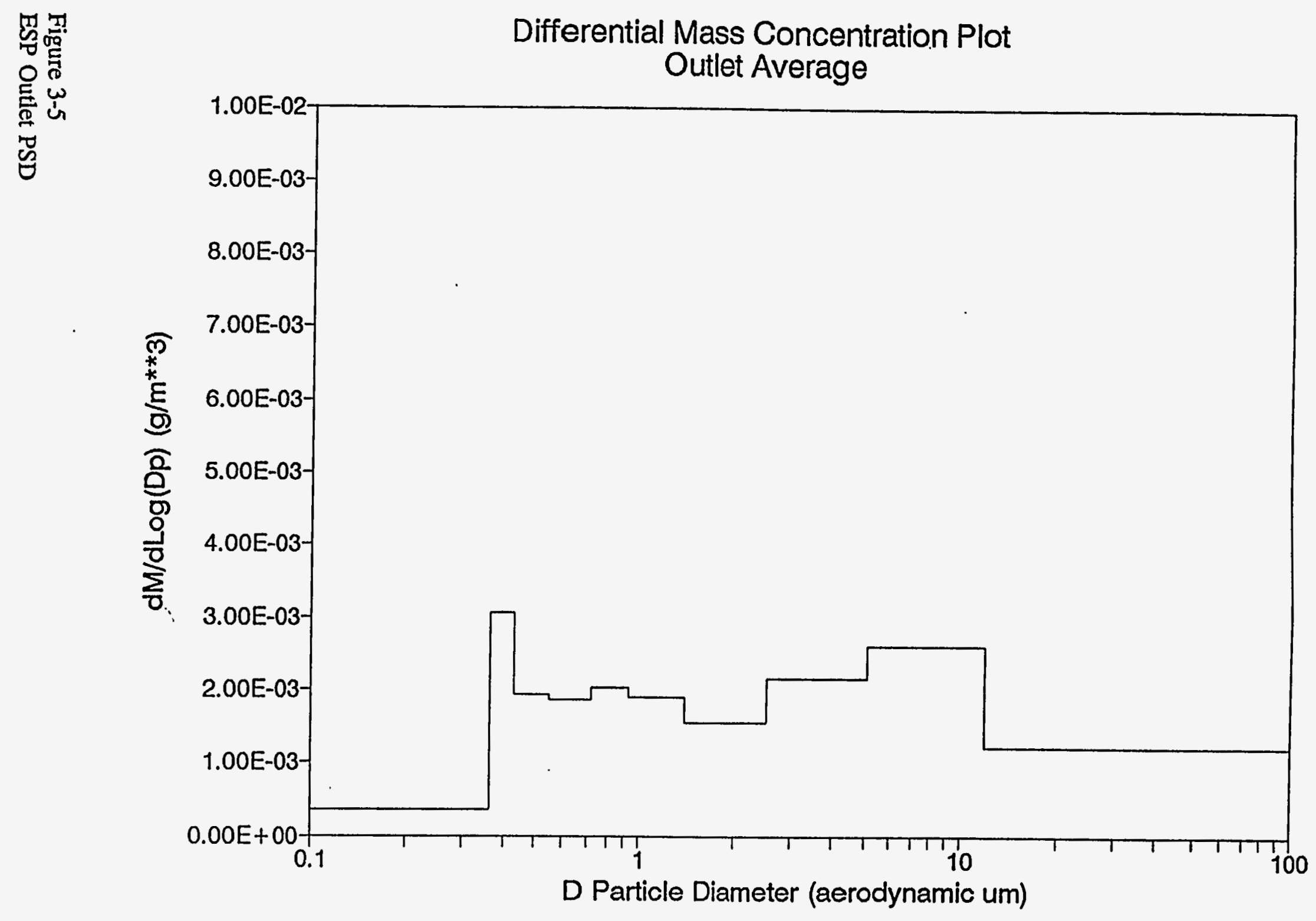

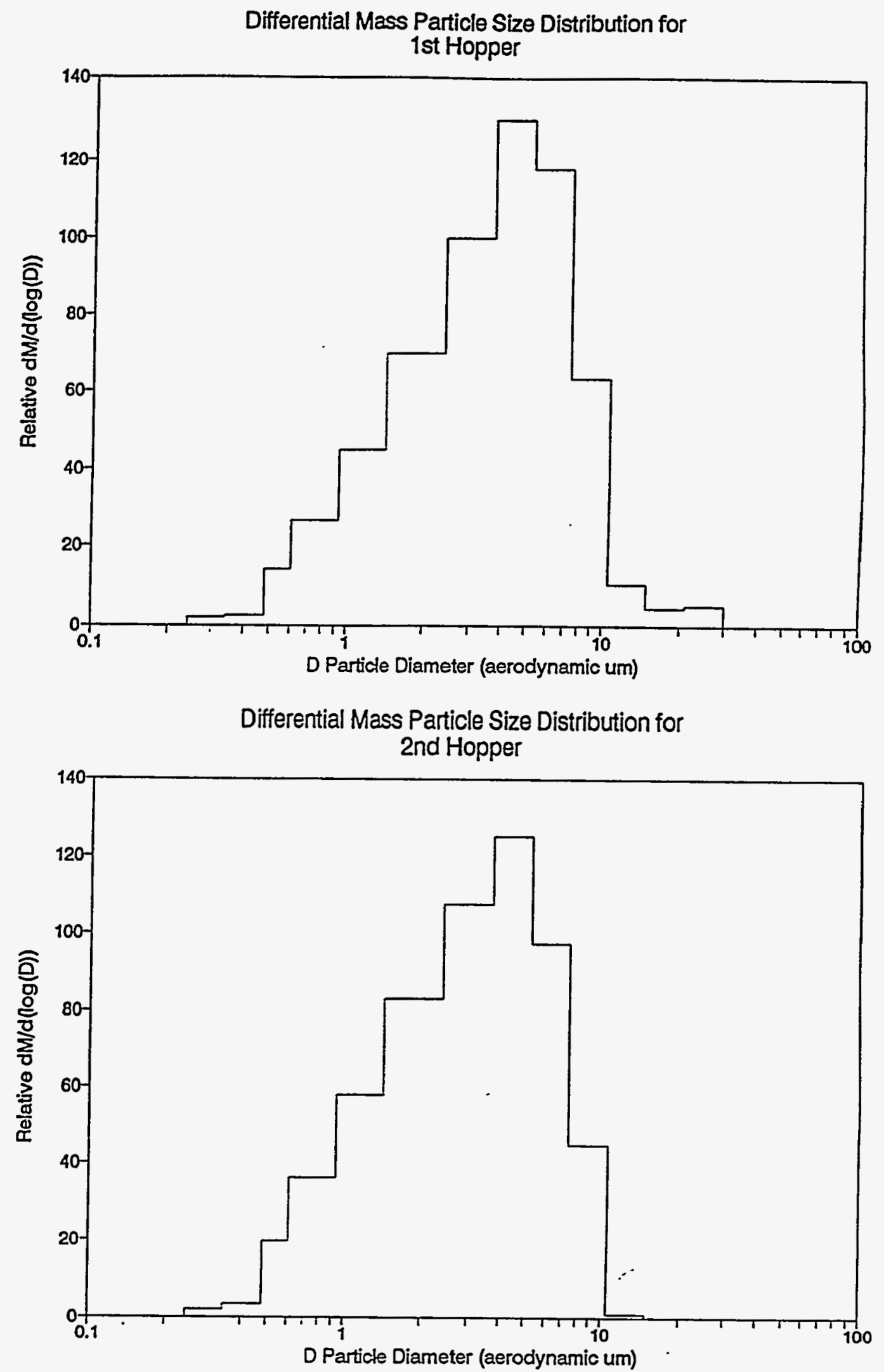

Figure 3-6

ESP Hoppers 1 and 2 PSD 

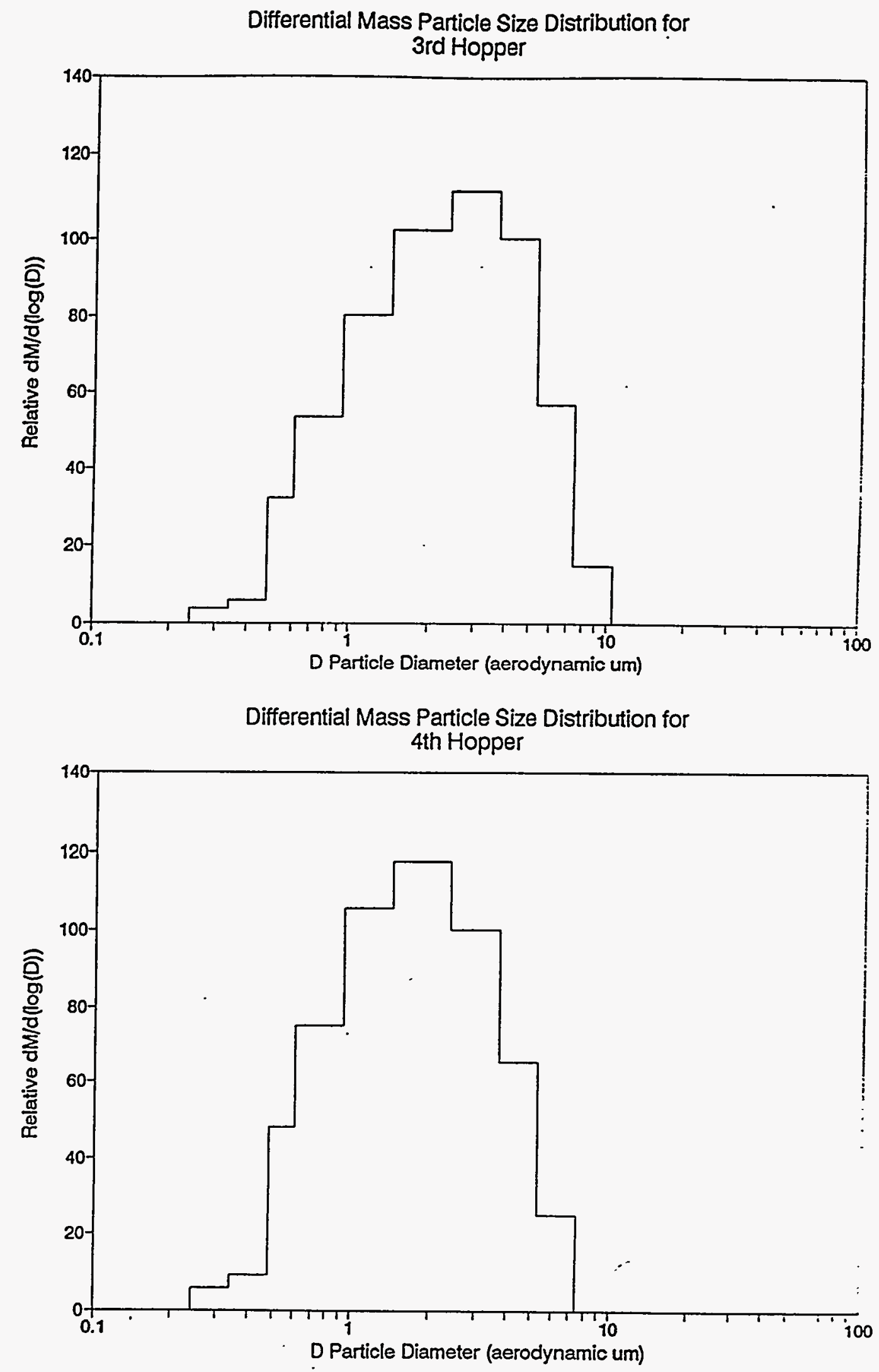

Figure 3-7

ESP Hoppers 3 and 4 PSD 
Results

the ESP inlet and the first ESP hopper to be similar, since these samples represent the same material. Comparison of the data shown in Figures 3-4 and 3-6 show that this is generally true. ESP inlet PSDs indicate particle diameters range from approximately $0.3 \mu \mathrm{m}$ to $10 \mu \mathrm{m}$ with a median diameter of about 3.5 $\mu \mathrm{m}$. Data for ESP Hopper \#1 indicate particle sizes in approximately the $0.2 \mu \mathrm{m}$ to $30 \mu \mathrm{m}$ range with a median diameter of about $3 \mu \mathrm{m}$. The lack of particles in the $10 \mu \mathrm{m}$ to $30 \mu \mathrm{m}$ range at the ESP inlet reflects the exclusion of the cyclone precutter fraction from the PSD analysis.

\section{Radionuclide Data}

Results of the radionuclide analyses performed on the coal and ash streams, expressed in activity units of picocuries per gram of sample, are summarized in Tables 3-20 and 3-21, respectively. The highest levels of radionuclides were found in the APF and ESP ash samples, both of which show very similar results. All of the ash results are consistent with the relative amount found in the coal (i.e., species with the largest levels in the coal also show the largest levels in the ash streams).

\section{Chromium (VI) Measurements}

Results for the chromium (VI) samples collected at the ESP outlet are shown in Table 3-22. Background levels in the reagent blank accounted for greater than $65 \%$ of the chromium (VI) detected in the samples; therefore, the data presented in Table 3-22 have been corrected for background contributions. The samples were analyzed on site by IC to determine chromium (VI) concentrations and, subsequently, analyzed by ICP-AES to determine the total chromium concentrations. Total chromium results for the nitric acid rinses indicated all of the chromium was accounted for in the impinger solutions. The mean chromium (VI) concentrations represent about $27 \%$ of the total chromium concentrations measured in the ESP outlet gas.

Experience has shown that measurement of hexavalent chromium can be very difficult in electric utility flue gas. A brief discussion of the technical implications of determination of 
Table 3-20

\section{Coal Radionuclide (pCi/g)}

\begin{tabular}{||l|c|c|c|c|c|}
\hline \multicolumn{1}{|c|}{ Substance } & Run 1 & Run 2 & Run 3 & Mean & 95\% CI \\
\hline Date & $\cdot$ & & & & \\
\hline Actinium-228 @338 KeV & ND(0.01) & 0.15 & 0.21 & 0.12 & 0.26 \\
\hline Actinium-228 @911 KeV & 0.15 & 0.15 & 0.07 & 0.12 & 0.11 \\
\hline Actinium-228 @968 KeV & 0.16 & ND(0.02) & 0.22 & 0.13 & 0.27 \\
\hline Bismuth-212 @727 KeV & 0.48 & ND(0.31) & 0.11 & ND(0.31) & - \\
\hline Bismuth-214 @1120.4 KeV & 0.02 & 0.09 & 0.39 & 0.17 & 0.50 \\
\hline Bismuth-214 @1764.7 KeV & 0.28 & 0.05 & 0.01 & 0.11 & 0.17 \\
\hline Bismuth-214 @609.4 KeV & 0.22 & 0.27 & 0.28 & 0.26 & 0.24 \\
\hline K-40 @1460 KeV & 1.3 & 1.6 & 2.0 & 1.6 & 1.6 \\
\hline Lead-210 @46 KeV & 0.88 & 0.09 & 0.49 & 0.49 & 0.54 \\
\hline Lead-212 @238 KeV & 0.08 & 0.12 & 0.3 & 0.17 & 0.33 \\
\hline Lead-214 @295.2 KeV & 0.17 & 0.23 & 0.14 & 0.18 & 0.18 \\
\hline Lead-214 @352.0 KeV & 0.34 & 0.32 & 0.15 & 0.27 & 0.23 \\
\hline Radium-226 @186.0 KeV & 0.19 & 0.62 & $\mathrm{ND}(0.1)$ & 0.27 & 0.75 \\
\hline Thallium-208 @583 KeV & 0.04 & 0.05 & 0.04 & 0.04 & 0.04 \\
\hline Thallium-208 @860 KeV & $\mathrm{ND}(0.14)$ & 0.1 & 0.05 & 0.09 & 0.15 \\
\hline Thorium-234 @63.3 KeV & 0.02 & $\mathrm{ND}(0.1)$ & 0.61 & 0.23 & 0.83 \\
\hline Thorium-234 @92.6 KeV & $\mathrm{ND}(0.1)$ & 0.22 & $\mathrm{ND}(0.08)$ & 0.10 & 0.25 \\
\hline Uranium-235 @143.8 KeV & 0.01 & 0.04 & $\mathrm{ND}(0.01)$ & 0.02 & 0.05 \\
\hline \hline
\end{tabular}

$\mathrm{CI}=$ Confidence interval.

$\mathrm{ND}=$ Not detected at the concentration in parentheses. 
Results

Table 3-21

Ash Stream Radionuclide (pCi/g, unless noted)

\begin{tabular}{||l|c|c|c|c|c|c|c|c||}
\hline \multirow{2}{*}{ Substance } & \multicolumn{2}{|c|}{ Bed Ash } & \multicolumn{2}{c|}{ Cyclone Ash } & \multicolumn{2}{c|}{ APF Ash } & \multicolumn{2}{c|}{ ESP Ash } \\
\cline { 2 - 10 } & Mean & $95 \%$ CI & Mean & $\begin{array}{c}95 \% \\
\text { CI }\end{array}$ & Mean & $95 \%$ CI & Mean & $\begin{array}{c}95 \% \\
\text { CI }\end{array}$ \\
\hline Actinium-228 @338 KeV & 0.23 & 0.20 & 0.68 & 0.27 & 1.1 & 0.80 & 1.2 & 0.14 \\
\hline Actinium-228 @911 KeV & 0.06 & 0.10 & 0.56 & 0.10 & 1.1 & 0.90 & 0.99 & 0.26 \\
\hline Actinium-228 @968 KeV & 0.05 & 0.09 & 0.60 & 0.53 & 0.62 & 0.52 & 1.1 & 0.56 \\
\hline Bismuth-212 @727 KeV & 0.21 & 0.08 & 0.71 & 1.5 & 1.2 & 1.9 & 1.3 & 0.74 \\
\hline Bismuth-214 @1120.4 KeV & 0.47 & 0.65 & 1.1 & 0.25 & 2.1 & 2.4 & 1.8 & 0.52 \\
\hline Bismuth-214 @1764.7 KeV & 0.42 & 0.29 & 0.97 & 0.38 & 2.1 & 2.8 & 1.6 & 0.14 \\
\hline Bismuth-214 @609.4 KeV & 0.59 & 0.32 & 0.99 & 0.06 & 1.9 & 1.2 & 1.8 & 0.25 \\
\hline K-40 @1460 KeV & 1.0 & 0.26 & 6.6 & 1.9 & 14 & 12 & 11 & 1.4 \\
\hline Lead-210 @46 KeV & 0.28 & 0.63 & 1.3 & 1.4 & 4.0 & 3.0 & 4.8 & 8.9 \\
\hline Lead-212 @238 KeV & 0.19 & 0.29 & 0.63 & 0.09 & 1.8 & 1.8 & 0.97 & 0.07 \\
\hline Lead-214 @295.2 KeV & 0.51 & 0.20 & 1.0 & 0.15 & 1.7 & 1.4 & 1.8 & 0.38 \\
\hline Lead-214 @352.0 KeV & 0.59 & 0.17 & 1.1 & 0.25 & 2.2 & 1.8 & 1.9 & 0.29 \\
\hline Radium-226 @186.0 KeV & 1.0 & 1.3 & 2.0 & 1.3 & 3.3 & 4.0 & 2.6 & 1.1 \\
\hline Thallium-208 @583 KeV & 0.06 & 0.07 & 0.22 & 0.07 & 0.42 & 0.33 & 0.36 & 0.14 \\
\hline Thallium-208 @860 KeV & $\mathrm{ND}(0.28)$ & - & ND(0.44) & - & 0.25 & 0.78 & 0.28 & 0.29 \\
\hline Thorium-234 @63.3 KeV & 0.99 & 1.6 & 1.0 & 1.8 & 3.5 & 3.9 & 1.6 & 1.7 \\
\hline Thorium-234@92.6 KeV & 0.14 & 0.27 & 0.48 & 1.0 & 0.50 & 1.5 & 0.70 & 0.88 \\
\hline Uranium-235 @143.8 KeV & 0.07 & 0.08 & 0.12 & 0.07 & 0.21 & 0.24 & 0.16 & 0.07 \\
\hline \hline
\end{tabular}


Table 3-22

Chromium (VI) and Total Chromium Results for the ESP Outlet $\left(\mu \mathrm{g} / \mathrm{Nm}^{3}\right)$

\begin{tabular}{||l|c|c|c|c|c|c||}
\hline \multicolumn{1}{|c|}{ Substance } & Method & $\begin{array}{c}\text { Run 1 } \\
4 / 12 / 94\end{array}$ & $\begin{array}{c}\text { Run 2 } \\
4 / 13 / 94\end{array}$ & $\begin{array}{c}\text { Run 3 } \\
4 / 14 / 94\end{array}$ & Mean & 95\% CI \\
\hline $\begin{array}{l}\text { Chromium (VI) } \\
\text { (impinger) }\end{array}$ & IC & $2.2^{\mathrm{a}}$ & $0.96^{\star}$ & $1.0^{2}$ & 1.4 & 1.7 \\
\hline $\begin{array}{l}\text { Total Chromium } \\
\text { (impinger solution) }\end{array}$ & ICP-AES & 5.1 & $\mathrm{ND}(1.1)$ & 9.8 & 5.2 & 11 \\
\hline $\begin{array}{l}\text { Total Chromium } \\
\text { (nitric acid rinse) }\end{array}$ & ICP-AES & $\mathrm{ND}(0.2)$ & $\mathrm{ND}(0.2)$ & $\mathrm{ND}(0.4)$ & $\mathrm{ND}(0.4)$ & - \\
\hline $\begin{array}{l}\text { Total Chromium } \\
\text { (Method 29) }\end{array}$ & $\begin{array}{c}\text { ICP-AES } \\
\text { ICP/MS }\end{array}$ & 3.1 & 2.7 & 5.5 & 3.7 & 3.7 \\
\hline
\end{tabular}

- Background concentrations in the reagent blank were $\geq 65 \%$ of the sample values. Results have been corrected for background levels.

$\mathrm{CI}=$ Confidence interval.

$\mathrm{ND}=$ Not detected at the concentration in parentheses. 
Results.

chromium (CI) in stack gas and, in particular, in combustion sources and utility sources is included here. Additional details regarding chromium (VI) sampling are included in Appendix A.

The chromium (VI) method depends on the solubility and stability of chromium (VI) in basic aqueous solution. The method calls for the use of a strong base in a solution contained in the impingers and recycled to the probe tip for early gas contact and flushing to the probe walls. The method is theoretically sound but has some limitations when applied to combustion sources in general and utility flue gases specifically.

As mentioned above, chromium (VI) is stable in a strong alkaline solution ( $\mathrm{pH}>\sim 9$ ), but all combustion gas streams contain large amounts of $\mathrm{CO}_{2}$ (10-20\%), which is an acid gas, and serves to lower the $\mathrm{pH}$ of the impinger solution. As a result, the $\mathrm{pH}$ may dip lower than desirable during sampling. As a further complication, utility flue gas contains significant levels of $\mathrm{SO}_{2}$ (100 ppm or more). $\mathrm{SO}_{2}$ is also an acid gas but is a reductant as well, so the impinger solution designed to absorb chromium (VI) aiso absorbs $\mathrm{CO}_{2}$ and $\mathrm{SO}_{2}$. The result of this is a lowered $\mathrm{pH}$ and a solution which contains an oxidant [chromium (VI)] and a reductant $\left(\mathrm{SO}_{2} / \mathrm{HSO}_{3}{ }^{-}\right)$. As the $\mathrm{pH}$ falls, the redox couple becomes more favorable, and any chromium (VI) present may be reduced by $\mathrm{SO}_{2} / \mathrm{HSO}_{3}^{-}$and not detected as chromium (VI). 


\section{4}

\section{DATA EVALUATION}

Three methods were used to evaluate the quality of data obtained from the tests at Plant Tidd. First, the process data were examined to determine if the unit was operating at normal, steady-state conditions during the test periods. Second, the QA/QC protocol for sampling and analytical procedures (i.e., equipment calibration and leak checks, dúplicate analyses, blanks, spikes, standards, etc.) was evaluated. In addition, QC sample results (presented in Appendix D) were compared with project objectives. Third, material balances were calculated for various systems within the plant. Material balances involve the summation and comparison of mass flow rates in several streams, often sampled and analyzed by different methods. Closure within an acceptable range can be used as an indicator of accurate results for streams that contribute significantly to the overall inlet or outlet mass rates.

\section{Process Operation During Testing}

Process operating data were examined to ensure that operation was stable during the sampling periods. Measurements were available in five-minute intervals from the plant computerized data acquisition system. Table 4-1 shows the mean value and coefficient of variation ( $\mathrm{CV}$, standard deviation divided by the mean) for key process parameters associated with the combustor, ESP, and APF systems. In addition, process data trend plots are included in Appendix E.

The CVs were calculated to evaluate process stability. Steady combustor operation was maintained during each of the test runs, as indicated by the low CVs for the total load, the coal paste feed rate, the mean bed temperature, and the bed outlet oxygen levels (see Table 4-1). The sorbent feed rate (CVs of 18 to $24 \%$ ) showed greater variability than the other combustor parameters. However, this amount of variability is typical of normal operation 
ث Table 4-1

Summary of Process Monitoring Data

\begin{tabular}{|c|c|c|c|c|c|c|c|c|c|}
\hline \multirow[b]{3}{*}{ Combustor Parameters } & \multirow[b]{3}{*}{ Units of Measure } & \multirow{2}{*}{\multicolumn{2}{|c|}{$\frac{\text { Run } 1}{04-12-94}$}} & \multirow{2}{*}{\multicolumn{2}{|c|}{$\frac{\text { Run 2 }}{\text { 04-13-94 }}$}} & \multirow{2}{*}{\multicolumn{2}{|c|}{$\begin{array}{c}\text { Run 3 } \\
04-14-94\end{array}$}} & \multirow{2}{*}{\multicolumn{2}{|c|}{$\begin{array}{c}\text { Run } 4 \\
04-15-94\end{array}$}} \\
\hline & & & & & & & & & \\
\hline & & Mean & CV (\%) & Mean & $\mathrm{CV}(\%)$ & Mean & $\mathrm{CV}(\%)$ & Mean & CV (\%) \\
\hline Total Load & $\mathrm{MW}$ & 46 & 2.1 & 46 & 1.9 & 45 & 1.9 & 46 & 2.7 \\
\hline Steam Turbine Load & $\mathrm{MW}$ & 38 & 2.2 & 37 & 2.1 & 37 & 2.1 & 38 & 2.5 \\
\hline Gas Turbine Load & $M W$ & 8.3 & 4.2 & 9.0 & 3.6 & 8.0 & 3.4 & 8.0 & 6.0 \\
\hline Coal Paste Feed Rate & $10^{3} \mathrm{lb} / \mathrm{hr} \mathrm{r}^{\mathrm{a}}$ & 45 & 1.5 & 45 & 1.5 & 44 & 1.8 & 45 & 2.2 \\
\hline Sorbent Feed Rate & $10^{3} \mathrm{lb} / \mathrm{hr} \mathrm{a}^{\mathrm{a}}$ & 18 & 18 & 21 & 21 & 19 & 19 & 18 & 24 \\
\hline Mean Bed Temperature & ${ }^{\circ} \mathrm{F}$ & 1499 & 0.3 & 1497 & 0.3 & 1497 & 0.3 & 1497 & 0.3 \\
\hline Bed Level & inches & 122 & 1.3 & 115 & 0.5 & 113 & 0.4 & 112 & 0.9 \\
\hline Bed Outlet Oxygen & $\%$ vol. & 6.9 & 4.0 & 7.0 & 4.1 & 6.9 & 4.3 & 6.5 & 6.0 \\
\hline \multicolumn{10}{|l|}{ ESP Parameters } \\
\hline ESP Outlet Opacity & $\%$ & 10 & 7.5 & 10 & 4.3 & 10 & 8.6 & 11 & 6.0 \\
\hline ESP Outlet CO & ppmv & 33 & 30 & 35 & 15 & 34 & 23 & 36 & 16 \\
\hline ESP Outlet $\mathrm{SO}_{2}$ & ppmv & 182 & 10 & 178 & 12 & 179 & 11 & 181 & 13 \\
\hline ESP Outlet $\mathrm{NO}_{\mathrm{x}}$ & ppmv & 143 & 9 & 145 & 10 & 138 & 10 & 137 & 10 \\
\hline ESP Outlet Oxygen & $\%$ vol. & 7.0 & 1.7 & 7.0 & 2.2 & 7.0 & 2.8 & 6.6 & 2.7 \\
\hline ESP Outlet Temperature & ${ }^{\circ} \mathrm{F}$ & 404 & 0.2 & 403 & 0.3 & 405 & 0.3 & 403 & 0.4 \\
\hline \multicolumn{10}{|l|}{ APF Parameters } \\
\hline APF Inlet Temperature & ${ }^{\circ} \mathrm{F}$ & 1352 & 0.8 & 1364 & 0.8 & 1347 & 1.7 & 1359 & 1.1 \\
\hline APF Outlet Temperature & ${ }^{\circ} \mathrm{F}$ & 1322 & 0.6 & 1328 & 0.9 & 1329 & 1.8 & 1322 & 1.0 \\
\hline APF Differential Pressure & inches $\mathrm{H}_{2} \mathrm{O}$ & 116 & 5 & 117 & 5 & 116 & 6 & 118 & 6 \\
\hline
\end{tabular}

" Feed rate reported on an "as fired" basis.

$\mathrm{CV}=$ Coefficient of variation (standard deviation divided by the mean). 
since the sorbent feed system cycles between the east and west feeder systems approximately every $21 / 2$ hours. The total load was controlled at approximately $46 \mathrm{MW}$ throughout the test period which is representative of stable, long-term operation.

Stable ESP operations were also indicated by the low CVs for ESP outlet opacity. ESP outlet $\mathrm{CO}$ (CVs of 15 to $30 \%$ ) and $\mathrm{SO}_{2}$ levels (CVs of 10 to $13 \%$ ) were typically more variable than other parameters. ESP outlet $\mathrm{SO}_{2}$ levels increased for a short period each time the sorbent feed system switched from the east feeder to the west feeder. These fluctuations are typical of normal operation.

Data for APF system parameters indicate stable operation of this system during all test periods. APF differential pressure measurements indicate that the APF pulse-cleaning cycle was approximately 30 minutes during all tests. APF inlet gas temperatures were approximately $200^{\circ} \mathrm{F}$ cooler than design $\left(1350^{\circ} \mathrm{F}\right.$ versus $\left.1550^{\circ} \mathrm{F}\right)$ because tempering air was added to the system during the test period. The cooler gas temperature and reduced load during the tests made it necessary to adjust the gas sampling rate through the gas cooling apparatus at both the APF inlet and outlet. Since the gas cooling system was designed for an inlet gas temperature of $1550^{\circ} \mathrm{F}$ and a unit load of $70 \mathrm{MW}$; a reduction in the gas sampling rate was necessary to ensure that an isokinetic sampling rate was maintained at these locations.

\section{Sample Collection}

Appendix A describes the sampling procedures used at Plant Tidd. Several factors indicate representative sample collection. First, the key components of the sampling equipment-pitot tubes, thermocouples, orifice meters, dry gas meters, and sampling nozzles-had been calibrated before use in the field; the calibrations are on file at Radian Corporation. Second, the sampling runs were well documented. Third, all flue gas samples (except one) were collected at rates between 90 and $110 \%$ of the isokinetic rates. Fourth, sufficient data were collected using standard sampling and analytical methods to ensure acceptable data completeness and the comparability of the measurements. 
Following are some significant observations about sample collection:

- The multi-metals and anions samples collected at the APF inlet during Run 1 (4/12/94) were voided because of breakthrough of particulate matter across the thimble filter into the impinger solutions. The higher than expected particulate loading exceeded the capacity of the filter, resulting in filter gasket failure and particle penetration. During subsequent runs, additional filters were added in series to prevent breakthrough. The completeness objective of three valid runs was met despite this problem.

- The sampling systems at the APF inlet and outlet were designed to allow gas samples to cool only after the gas entered the recoverable quartz tubing portion of the sampling train. However, the quartz tubing broke repeatedly during the initial test runs because the quartz tube ball joint could not withstand the thermal stresses at $600^{\circ} \mathrm{F}$. To solve this problem, the heat tracing tape was removed from the sample line downstream of the orifice meter to allow the gas to cool slightly. Skin temperatures at the header sample valves were typically $250-350^{\circ} \mathrm{F}$ after this modification. Because most of the quartz tubes were broken during the initial test, subsequent tests at the APF locations were conducted by connecting the Teflon ${ }^{\otimes}$ tubing directly to the sample valves. This modification should have no measurable affect on the results.

\section{Analytical Quality Control Results}

Quality control (QC) information obtained for the Tidd PFBC HAPs project is related to measurement precision, accuracy (which includes precision and bias), and blank effects, determined using various types of replicate, spiked, and blank samples. The specific characteristics evaluated depend on the type of QC checks performed. For example, blanks may be prepared at different stages in the sampling and analysis process to isolate the source of a blank effect. Table 4-2 summarizes the QC measures used as part of the data evaluation protocol and the characteristic information obtained. The absence of any of these types of quality QC checks does not necessarily reflect poorly on the quality of the data but does limit the ability to estimate the magnitude of the measurement error and, hence, prevents placing an estimate of confidence in the results.

Different QC checks provide different types of information, particularly pertaining to the sources of inaccuracy, imprecision, and blank effects, as shown in Table 4-2. As part of the Tidd PFBC HAPs project, measurement precision and accuracy are typically estimated from 


\section{Table 4-2}

\section{Types of Quality Control Samples}

\begin{tabular}{|c|c|}
\hline QC Activity & Characteristic Measured \\
\hline \multicolumn{2}{|l|}{ Precision } \\
\hline $\begin{array}{l}\text { Replicate samples collected over time under } \\
\text { the same conditions }\end{array}$ & $\begin{array}{l}\text { Total variability, including process or temporal, sampling, } \\
\text { and analytical, but not bias. }\end{array}$ \\
\hline $\begin{array}{l}\text { Duplicate field samples collected } \\
\text { simultaneously }\end{array}$ & $\begin{array}{l}\text { Sampling plus analytical variability at the actual sample } \\
\text { concentrations. }\end{array}$ \\
\hline Duplicate analyses of a single sample & Analytical variability at the actual sample concentrations. \\
\hline Matrix- or media-spiked duplicates & $\begin{array}{l}\text { Sampling plus analytical variability at an established } \\
\text { concentration. }\end{array}$ \\
\hline Laboratory control sample duplicates & Analytical variability in the absence of sample matrix effects. \\
\hline Surrogate-spiked sample sets & $\begin{array}{l}\text { Analytical variability in the sample matrix but at an } \\
\text { established concentration. }\end{array}$ \\
\hline \multicolumn{2}{|l|}{ Accuracy (including bias and precision) } \\
\hline Matrix-spiked samples & $\begin{array}{l}\text { Analyte recovery in the sample matrix, indicating possible } \\
\text { matrix interferences and other effects. In a single sample, } \\
\text { includes both random error (imprecision) and systematic error } \\
\text { (bias). }\end{array}$ \\
\hline Media-spiked samples & $\begin{array}{l}\text { Similar to matrix-spiked samples. Used where a matrix- } \\
\text { spiked sample is not feasible, such as certain stack sampling } \\
\text { methods. }\end{array}$ \\
\hline Surrogate-spiked samples & $\begin{array}{l}\text { Analyte recovery in the sample matrix, to the extent that the } \\
\text { surrogate compounds are chemically similar to the } \\
\text { compounds of interest. Primarily used as indicator of } \\
\text { analytical efficacy. }\end{array}$ \\
\hline Laboratory control samples (LCS) & $\begin{array}{l}\text { Analyte recovery in the absence of actual sample matrix } \\
\text { effects. Used as an indicator of analytical control. }\end{array}$ \\
\hline Standard reference material & Analyte recovery in a matrix similar to the actual samples. \\
\hline \multicolumn{2}{|l|}{ Blank Effects } \\
\hline Field blank & $\begin{array}{l}\text { Total sampling plus analytical blank effect, including. } \\
\text { sampling equipment and reagents, sample transport and } \\
\text { storage, and analytical reagents and equipment. }\end{array}$ \\
\hline Trip blank & $\begin{array}{l}\text { Blank effects arising from sample transport and storage. } \\
\text { Typically used only for organic compound analyses. }\end{array}$ \\
\hline Method blank & $\begin{array}{l}\text { Blank effects inherent in the analytical method, including } \\
\text { reagents and equipment. }\end{array}$ \\
\hline Reagent blank & Blank effects from reagents used. \\
\hline
\end{tabular}


QC indicators that cover as much of the total sampling and analytical process as feasible. Precision and accuracy measurements are based primarily on the actual sample matrix. The precision and accuracy estimates obtained experimentally during the test programs are compared with data quality objectives (DQOs) established for this project.

The DQOs are not intended to be used as validation criteria but as empirical estimates of the precision and accuracy that would be expected from existing reference measurement methods that are considered acceptable. Although analytical precision and accuracy are relatively easy to quantify and control, sampling precision and accuracy are unique to each site and each sample matrix. Data that do not meet these objectives are not necessarily unacceptable. Rather, the intent is to document the precision and accuracy actually obtained, and the objectives serve as benchmarks for comparison. The effects of not meeting the objectives should be considered in light of the intended use of the data.

A summary of the types of $\mathrm{QC}$ data evaluated for this project is presented in Table 4-3. Appendix D presents detailed quality control sample results for blank samples (Table D-1), precision and accuracy measurements (Table D-2), and organic surrogate-spiked samples (Table D-3). In each table, the sample type, sample matrix, and sample stream are provided to identify the process samples directly related to the $\mathrm{QC}$ results. Most of the $\mathrm{QC}$ results met the project objectives.

Blank samples include laboratory method blanks, field blanks, and reagent/trip blanks. Laboratory method blank results are presented for samples where a digestion or other sample preparation technique is performed by the laboratory. Method blanks are performed with the preparation reagents only and the results indicate the potential level of contamination derived from the preparation method alone.

Field blanks are samples collected in the field that have undergone all preparation and handling steps with no exposure to samples. Typically this applies only to the gas samples where the sampling train is prepared, leak checked, and recovered with no sample gas introduced. Field blank results provide an indication of potential contamination from field 
Table 4-3

Types of Quality Control Data

\begin{tabular}{|c|c|c|c|c|c|c|c|c|c|c|c|c|}
\hline \multirow[b]{2}{*}{$\begin{array}{c}\text { Analysis } \\
\text { (Grouped by } \\
\text { Source/Mntrix) }\end{array}$} & \multicolumn{4}{|c|}{ Precision } & \multicolumn{4}{|c|}{ Accuracy } & \multicolumn{4}{|c|}{ Blank } \\
\hline & $\begin{array}{c}\text { Dup } \\
\text { Field } \\
\text { Simmples } \\
\end{array}$ & $\begin{array}{c}\text { Dup Lab } \\
\text { Annlysis }\end{array}$ & $\begin{array}{l}\text { Matrix or } \\
\text { Media } \\
\text { Spiked } \\
\text { Dup }\end{array}$ & $\begin{array}{l}\text { Lob Control } \\
\text { Simmle Dup }\end{array}$ & $\begin{array}{l}\text { Matrix } \\
\text { or } \\
\text { Media } \\
\text { Spike }\end{array}$ & $\begin{array}{l}\text { Surrogate } \\
\text { Spike }\end{array}$ & $\begin{array}{c}\text { Lab } \\
\text { Control } \\
\text { Sample }\end{array}$ & $\begin{array}{c}\text { Standard } \\
\text { Reference } \\
\text { Muterinl }\end{array}$ & $\begin{array}{l}\text { Field } \\
\text { Blunk }\end{array}$ & $\begin{array}{l}\text { Trip } \\
\text { Blank }\end{array}$ & $\begin{array}{l}\text { Method } \\
\text { Blank }\end{array}$ & $\begin{array}{c}\text { Reagent } \\
\text { Blank }\end{array}$ \\
\hline \multicolumn{13}{|l|}{ Gas Streams } \\
\hline Metals - Vapor Phase & & & $\checkmark$ & 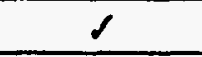 & $\alpha$ & & $\checkmark$ & & $\checkmark$ & & $\checkmark$ & 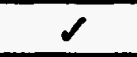 \\
\hline Metals - Solid Phase & & & $\checkmark$ & $\checkmark$ & $\checkmark$ & & $\checkmark$ & $\checkmark$ & $\checkmark$ & & $\checkmark$ & $\checkmark$ \\
\hline Anions - Vapor Phase & & & $\checkmark$ & $\checkmark$ & $\checkmark$ & & $\checkmark$ & & $\checkmark$ & & $\checkmark$ & $r$ \\
\hline Anions - Solid Phase & & & $\checkmark$ & $\checkmark$ & $\checkmark$ & & $\checkmark$ & & $\checkmark$ & & $\checkmark$ & $\checkmark$ \\
\hline Chromium (VI) & & & $\checkmark$ & & $\checkmark$ & & $\checkmark$ & & $\mathcal{L}$ & & & $\checkmark$ \\
\hline Total Chromium & & & $\checkmark$ & & $\checkmark$ & & 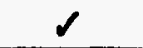 & & $\checkmark$ & & $\checkmark$ & $\checkmark$ \\
\hline Volatile Organics & & & & & & $\checkmark$ & $\checkmark$ & & $\checkmark$ & $\checkmark$ & $\checkmark$ & \\
\hline Semivolatile Organics & & & & & & $\checkmark$ & & & 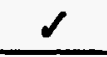 & 2 & $\checkmark$ & \\
\hline Formaldehyde & & $\checkmark$ & & & $\checkmark$ & & 1 & & $\mathcal{J}$ & & $\alpha$ & $\checkmark$ \\
\hline Ammonia & & & $\checkmark$ & & $\checkmark$ & . & $\checkmark$ & & $\alpha$ & & $\checkmark$ & $\mathscr{\sim}$ \\
\hline Cyanide & & & $\checkmark$ & & $\checkmark$ & & $\checkmark$ & & $\checkmark$ & & $\checkmark$ & $\checkmark$ \\
\hline PAHs & & & & & & 1 & & & $\checkmark$ & $\Omega$ & $\checkmark$ & \\
\hline PCDD/PCDF & & & & & & $\checkmark$ & & & $\checkmark$ & $\sim$ & $\checkmark$ & \\
\hline \multicolumn{13}{|l|}{ Coal } \\
\hline Metals & $\checkmark$ & $\checkmark$ & & & & & & $\checkmark$ & & & & \\
\hline Radionuclides & $\checkmark$ & . & & & & & & & & & & \\
\hline Anions & $\checkmark$ & 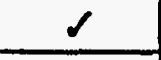 & & & & & & $\checkmark$ & & & & \\
\hline Ultimate/Proximate & $\checkmark$ & & & & & & & $\alpha$ & & & & \\
\hline
\end{tabular}


$\stackrel{\infty}{\infty}$ Table 4-3 (Continued)

\begin{tabular}{|c|c|c|c|c|c|c|c|c|c|c|c|c|}
\hline \multirow[b]{2}{*}{$\begin{array}{c}\text { Analysis } \\
\text { (Grouped by } \\
\text { Source/Matrix) }\end{array}$} & \multicolumn{4}{|c|}{ Precision } & \multicolumn{4}{|c|}{ Accuracy } & \multicolumn{4}{|c|}{ Blank } \\
\hline & $\begin{array}{c}\text { Dup } \\
\text { Field } \\
\text { Samples }\end{array}$ & $\begin{array}{l}\text { Dup Lab } \\
\text { Analysis }\end{array}$ & $\begin{array}{c}\text { Matrix or } \\
\text { Media } \\
\text { Spiked } \\
\text { Dup }\end{array}$ & $\begin{array}{l}\text { Lab Control } \\
\text { Sample Dup }\end{array}$ & $\begin{array}{l}\text { Matrix } \\
\text { or } \\
\text { Media } \\
\text { Spike }\end{array}$ & $\begin{array}{c}\text { Surrogate } \\
\text { Spike }\end{array}$ & $\begin{array}{l}\text { Lab } \\
\text { Control } \\
\text { Sample }\end{array}$ & $\begin{array}{c}\text { Standard } \\
\text { Reference } \\
\text { Material }\end{array}$ & $\begin{array}{l}\text { Field } \\
\text { Blank }\end{array}$ & $\begin{array}{c}\text { Trip } \\
\text { Blank }\end{array}$ & $\begin{array}{l}\text { Method } \\
\text { Blank }\end{array}$ & $\begin{array}{c}\text { Reagent } \\
\text { Blank }\end{array}$ \\
\hline \multicolumn{13}{|l|}{ Bed Ash and Fly Ash } \\
\hline Metals & 1 & & 1 & & 1 & & & $\checkmark$ & & & 2 & \\
\hline Anions & 1 & & 1 & & $\checkmark$ & & & 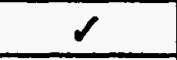 & & & 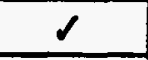 & \\
\hline Radionuclides & 1 & & & & & & & & & & & \\
\hline Semivolatile Organics & 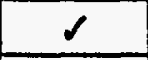 & & $\checkmark$ & & 2 & 1 & 1 & & & & 1 & \\
\hline PCDD/PCDF & $\checkmark$ & & & & & 1 & & & & & $r$ & \\
\hline Carbon & 2 & & & & - & & & & & & & \\
\hline Particle Size Dist. & 1 & & & & & & & & & & & \\
\hline \multicolumn{13}{|l|}{ Service Water } \\
\hline Metals & 2 & & 1 & & $\checkmark$ & & 2 & & & & 1 & \\
\hline Anions & 1 & & 1 & & 1 & & $\checkmark$ & & & & 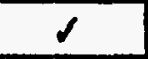 & \\
\hline \multicolumn{13}{|l|}{ Dolomite Sorbent } \\
\hline Metals & 1 & & 1 & & $\checkmark$ & & 1 & & & & $\checkmark$ & \\
\hline Anions & 1 & & 4 & & $\checkmark$ & & $\checkmark$ & & & & $\checkmark$ & \\
\hline
\end{tabular}


reagents, sample recovery, airborne contaminants, and any analytical preparation method; however, the identification of any one contaminant source is not possible.

Reagent blanks are samples of the prepared reagents or sampling media used to collect field samples. Blank filters, XAD resin, prepared impinger solutions, and VOST tubes are all examples of reagent blanks. Reagent blank results help identify the amount of target analytes present in the samples due specifically to the reagent or sampling media itself.

Analytical precision measurements for inorganic analytes are derived from matrix spiked and/or standard sample results. Results of duplicate sample and duplicate matrix spike sample analyses are used to assess analytical precision. Table D-2 presents the results of these analyses. QC results that are outside the specified data quality objectives are flagged and indicate the potential for analytical bias or imprecision. Surrogate spike samples are limited to the analysis of organic compounds and are used to assess analytical accuracy (Table D-3).

A performance audit was conducted as an independent check to evaluate the data produced. The performance audit addressed the chemical analysis of the samples collected and the physical measurements supporting the field sampling effort. The laboratories conducting the analyses were given performance audit samples prepared by spiking representative sample matrices with target analytes at representative concentration levels. Results for the audit samples for the field and laboratory activities were compiled and discussed in an audit report submitted to the project team on July 15,1994 . Table 4-4 presents a summary of analytical results for the audit samples. A list of concerns was presented as a part of that report. The concerns, as stated in the report, are listed below followed by the response from the project team (in italics).

- Particulate matter collection efficiency in the QC audit sample at the ESP inlet was 50 percent.

Incomplete rinsing or recovery of solids deposited in the probe and/or filter losses during disassembly of the filter holder are likely contributors to low sample recovery. In this 
Table 4-4

Analytical Results for Audit Samples

\begin{tabular}{|c|c|c|c|c|c|c|c|c|}
\hline$L_{a b} \mathbf{a}^{n}$ & Sample ID & Matrix & Analyte & Units & $\begin{array}{c}\text { Lab } \\
\text { Result }\end{array}$ & \begin{tabular}{|c|} 
Reference \\
Value
\end{tabular} & $\begin{array}{l}\text { Percent } \\
\text { Recovery }\end{array}$ & $\begin{array}{c}\text { Audit } \\
\text { Objectire }\end{array}$ \\
\hline \multicolumn{9}{|c|}{ Multi-Metals Trains } \\
\hline Radian & $\begin{array}{l}\text { AEP-QD02MMFD } \\
\text { AEP-QD02MMAP }\end{array}$ & $\begin{array}{l}\text { Filter } \\
\text { Acetone PNR }\end{array}$ & \begin{tabular}{|l} 
Particulate \\
Weight
\end{tabular} & gram & 0.0601 & 0.1198 & 50 & NS \\
\hline \multirow[t]{24}{*}{ Radian } & AEP-QD02MMAP & Acetone PNR & Aluminum & $\mu \mathrm{g} / \mathrm{g}$ & 97,715 & 140,000 & $70 Q$ & $75-125$ \\
\hline & AEP-QD02MMNR & $\mathrm{HNO}_{3} \mathrm{PNR}$ & Antimony & $\mu \mathrm{g} / \mathrm{g}$ & ND & 7 & $\mathrm{NA}$ & $75-125$ \\
\hline & \multirow[t]{22}{*}{ AEP-QD02MMFD } & \multirow[t]{22}{*}{ Filter } & Arsenic & $\mu \mathrm{g} / \mathrm{g}$ & 180 & 145 & 124 & $75-125$ \\
\hline & & & Barium & $\mu \mathrm{g} / \mathrm{g}$ & 854 & 1,500 & $57 Q$ & $75-125$ \\
\hline & & & Beryllium & $\mu \mathrm{g} / \mathrm{g}$ & 9.9 & 12 & 82 & $75-125$ \\
\hline & & & Cadmium & $\mu \mathrm{g} / \mathrm{g}$ & 9.19 & 1 & $919 \mathrm{Q}$ & $75-125$ \\
\hline & & & Calcium & $\mu \mathrm{g} / \mathrm{g}$ & 14,147 & 11,100 & $127 \mathrm{Q}$ & $75-125$ \\
\hline & & & Chromium & $\mu \mathrm{g} / \mathrm{g}$ & 149 & 196 & 76 & $75-125$ \\
\hline & & & Cobalt & $\mu \mathrm{g} / \mathrm{g}$ & 23.4 & 46 & $51 Q$ & $75-125$ \\
\hline & & & Copper & $\mu \mathrm{g} / \mathrm{g}$ & 123 & 118 & 104 & $75-125$ \\
\hline & & & Iron & $\mu g / g$ & 46,995 & 94,000 & $50 \mathrm{Q}$ & $75-125$ \\
\hline & & & Lead & $\mu \mathrm{g} / \mathrm{g}$ & 60.2 & 72.4 & 83 & $75-125$ \\
\hline & & & Magnesium & $\mu \mathrm{g} / \mathrm{g}$ & 5,033 & 4,550 & 111 & $75-125$ \\
\hline & & & Manganese & $\mu \mathrm{g} / \mathrm{g}$ & 131 & 190 & $69 \mathrm{Q}$ & $75-125$ \\
\hline & & & Mercury & $\mu \mathrm{g} / \mathrm{g}$ & 0.192 & 0.16 & 120 & $75-125$ \\
\hline & & & Molybdenum & $\mu \mathrm{g} / \mathrm{g}$ & 37.3 & 29 & $129 \mathrm{Q}$ & $75-125$ \\
\hline & & & Nickel & $\mu \mathrm{g} / \mathrm{g}$ & 111 & 127 & 87 & $75-125$ \\
\hline & & & Phosphorus & $\mu \mathrm{g} / \mathrm{g}$ & ND & NA & $\mathrm{NA}$ & $75-125$ \\
\hline & & & Potassium & $\mu \mathrm{g} / \mathrm{g}$ & 13,463 & 18,800 & $72 Q$ & $75-125$ \\
\hline & & & Selerium & $\mu \mathrm{g} / \mathrm{g}$ & 18.1 & 10.3 & $175 Q$ & $75-125$ \\
\hline & & & Silver & $\mu \mathrm{g} / \mathrm{g}$ & ND & NA & $\mathrm{NA}$ & $75-125$ \\
\hline & & & Sodium & $\mu \mathrm{g} / \mathrm{g}$ & 1,586 & 1,700 & 93 & $75-125$ \\
\hline & & & Titanium & $\mu \mathrm{g} / \mathrm{g}$ & 5,808 & 8,000 & $73 Q$ & $75-125$ \\
\hline & & & Vanadium & $\mu \mathrm{g} / \mathrm{g}$ & 229 & 300 & 76 & $75-125$ \\
\hline \multirow[t]{12}{*}{ Radian } & \multirow[t]{12}{*}{ AEP-QD01MMHT } & \multirow[t]{12}{*}{$\mathrm{HNO}_{3}$ Impingers } & Aluminum & $\mathrm{mg} / \mathrm{L}$ & 0.0101 & NA & NA & $75-125$ \\
\hline & & & Antimony & $\mathrm{mg} / \mathrm{L}$ & 0.183 & 0.20 & 91 & $75-125$ \\
\hline & & & Arsenic & $\mathrm{mg} / \mathrm{L}$ & $1.85^{2}$ & 2.00 & 92 & $75-125$ \\
\hline & & & Barium & $\mathrm{mg} / \mathrm{L}$ & 0.190 & 0.20 & 95 & $75-125$ \\
\hline & & & Beryllium & $\mathrm{mg} / \mathrm{L}$ & 0.210 & 0.20 & 105 & $75-125$ \\
\hline & & & Boron ${ }^{\circ}$ & $\mathrm{mg} / \mathrm{L}$ & 0.0385 & $\overline{N A}$ & $\overline{N A}$ & $75-125$ \\
\hline & & & Cadmium & $\mathrm{mg} / \mathrm{L}$ & $0.296^{a}$ & 0.20 & $148 Q$ & $75-125$ \\
\hline & & & Calcium & $\mathrm{mg} / \mathrm{L}$ & 0.302 & 0.20 & $151 \mathrm{Q}$ & $75-125$ \\
\hline & & & Chromium & $\mathrm{mg} / \mathrm{L}$ & 1.72 & 2.00 & 86 & $75-125$ \\
\hline & & & Cobalt & $\mathrm{mg} / \mathrm{L}$ & 0.191 & 0.20 & 95 & $75-125$ \\
\hline & & & Copper & $\mathrm{mg} / \mathrm{L}$ & 0.437 & 0.50 & 87 & $75-125$ \\
\hline & & & Iron & $\mathrm{mg} / \mathrm{L}$ & ND & NA & NA & $75-125$ \\
\hline
\end{tabular}


Table 4-4 (Continued)

\begin{tabular}{|c|c|c|c|c|c|c|c|c|}
\hline Leab & Sample ID & Matrix & Analyte & Units & $\begin{array}{l}\text { Lab } \\
\text { Result }\end{array}$ & $\begin{array}{c}\text { Reference } \\
\text { Value }\end{array}$ & \begin{tabular}{|l|} 
Percent \\
Recovery
\end{tabular} & $\begin{array}{c}\text { Audit } \\
\text { Objective }\end{array}$ \\
\hline \multirow[t]{13}{*}{ Radian } & \multirow[t]{13}{*}{ AEP-QD01MMHT } & \multirow[t]{13}{*}{$\mathrm{HNO}_{3}$ Impingers } & Lead & $\mathrm{mg} / \mathrm{L}$ & $1.91^{2}$ & 2.00 & 95 & $75-125$ \\
\hline & & & Magnesium & $\mathrm{mg} / \mathrm{L}$ & 0.186 & 0.20 & 93 & $75-125$ \\
\hline & & & Manganese & $\mathrm{mg} / \mathrm{L}$ & 0.221 & 0.20 & 110 & $75-125$ \\
\hline & & & Mercury & $\mathrm{mg} / \mathrm{L}$ & 4.36 & 5.00 & 87 & $75-125$ \\
\hline & & & Molybdenum & $\mathrm{mg} / \mathrm{L}$ & 0.154 & 0.20 & 77 & $75-125$ \\
\hline & & & Nickel & $\mathrm{mg} / \mathrm{h}$ & 0.444 & 0.50 & 89 & $75-125$ \\
\hline & & & Phosphorus & $\mathrm{mg} / \mathrm{L}$ & ND & NA & NA & $75-125$ \\
\hline & & & Potassium & $\mathrm{mg} / \mathrm{L}$ & 2.85 & 0.20 & $1,425 \mathrm{Q}$ & $75-125$ \\
\hline & & & Selenium & $\mathrm{mg} / \mathrm{L}$ & $0.175^{a}$ & 0.20 & 87 & $75-125$ \\
\hline & & & Silver & $\mathrm{mg} / \mathrm{L}$ & 0.0269 & $0.20^{b}$ & $N A^{b}$ & $75-125$ \\
\hline & & & Sodium & $\mathrm{mg} / \mathrm{L}$ & 0.642 & 0.20 & $321 \mathrm{Q}$ & $75-125$ \\
\hline & & & Titanium & $\mathrm{mg} / \mathrm{L}$ & 0.00294 & NA & NA & $75-125$ \\
\hline & & & Vanadium & $\mathrm{mg} / \mathrm{L}$ & 0.443 & 0.5 & 89 & $75-125$ \\
\hline \multirow{15}{*}{$\begin{array}{l}\text { Harvard } \\
\text { ICP/MS }\end{array}$} & \multirow[t]{15}{*}{ AEP-QD02MMHT } & \multirow[t]{15}{*}{$\mathrm{HNO}_{3}$ Impingers } & Antimony & $\mu \mathrm{g} / \mathrm{L}$ & 3.48 & 5.0 & $70 Q$ & $75-125$ \\
\hline & & & Arsenic & $\mu \mathrm{g} / \mathrm{L}$ & 8.97 & 10.0 & 90 & $75-125$ \\
\hline & & & Barium & $\mu \mathrm{g} / \mathrm{L}$ & 10.66 & 10.0 & 107 & $75-125$ \\
\hline & & & Beryllium & $\mu \mathrm{g} / \mathrm{L}$ & 11.45 & 10.0 & 114 & $75-125$ \\
\hline & & & Cadmium & $\mu \mathrm{g} / \mathrm{L}$ & 9.40 & 10.0 & 94 & $75-125$ \\
\hline & & & Chromium & $\mu \mathrm{g} / \mathrm{L}$ & 9.37 & 10.0 & 94 & $75-125$ \\
\hline & & & Cobalt & $\mu \mathrm{g} / \mathrm{L}$ & 8.80 & 10.0 & 88 & $75-125$ \\
\hline & & & Copper & $\mu \mathrm{g} / \mathrm{L}$ & 8.80 & 10.0 & 88 & $75-125$ \\
\hline & & & Lead & $\mu \mathrm{g} / \mathrm{L}$ & 9.49 & 10.0 & 95 & $75-125$ \\
\hline & & & Manganese & $\mu \mathrm{g} / \mathrm{L}$ & 9.23 & 10.0 & 92 & $75-125$ \\
\hline & & & Mercury & $\mu \mathrm{g} / \mathrm{L}$ & 10.78 & 10.0 & 108 & $75-125$ \\
\hline & & & Molybdenum & $\mu \mathrm{g} / \mathrm{L}$ & 5.26 & 5.0 & 105 & $75-125$ \\
\hline & & & Nickel & $\mu \mathrm{g} / \mathrm{L}$ & 6.97 & 10.0 & $70 Q$ & $75-125$ \\
\hline & & & Selenium & $\mu \mathrm{g} / \mathrm{L}$ & 6.20 & 10.0 & $62 Q$ & $75-125$ \\
\hline & & & Vanadium & $\mu \mathrm{g} / \mathrm{L}$ & 9.41 & 10.0 & 94 & $75-125$ \\
\hline Radian & AEP-QD01MMHI & $\mathrm{KMnO}_{4}$ Impingers & Mercury & $\mathrm{mg} / \mathrm{L}$ & 0.479 & 0.400 & 120 & $75-125$ \\
\hline \multicolumn{9}{|c|}{ Anions Train } \\
\hline \multirow[t]{3}{*}{ Radian } & \multirow[t]{3}{*}{ AEP-QD01ANIT } & \multirow{3}{*}{$\begin{array}{l}\mathrm{Na}_{2} \mathrm{CO}_{3} / \mathrm{NaHCO}_{3} \\
\text { Impingers }\end{array}$} & Chloride & $\mathrm{mg} / \mathrm{L}$ & 284 & 297 & 96 & $80-120$ \\
\hline & & & Fluoride & $\mathrm{mg} / \mathrm{L}$ & 9.22 & 9.8 & 94 & $80-120$ \\
\hline & & & Sulfate & $\mathrm{mg} / \mathrm{L}$ & 8,680 & 10,000 & 86 & $80-120$ \\
\hline
\end{tabular}


Table 4-4 (Continued)

\begin{tabular}{|c|c|c|c|c|c|c|c|c|}
\hline Lab & Sample ID & Matrix & Analyte & Units & $\begin{array}{c}\text { Lab } \\
\text { Result }\end{array}$ & \begin{tabular}{|c|}
$\begin{array}{c}\text { Reference } \\
\text { Value }\end{array}$ \\
\end{tabular} & \begin{tabular}{|c|}
$\begin{array}{c}\text { Percent } \\
\text { Recovery }\end{array}$ \\
\end{tabular} & $\begin{array}{c}\text { Audit } \\
\text { Objective }\end{array}$ \\
\hline \multicolumn{9}{|c|}{ Ammonia/Cyanide Train } \\
\hline Radian & AEP-QD01NHIP & $\mathrm{H}_{2} \mathrm{SO}_{4}$ Impinger & Ammonia & $\mathrm{mg} / \mathrm{L}$ & 1.31 & 0.27 & $485 \mathrm{Q}$ & $80-120$ \\
\hline Radian & AEP-QD01NHIP & ZnOAc Impinger & Cyanide & $\mathrm{mg} / \mathrm{L}$ & 0.0257 & 0.10 & $26 Q$ & $75-125$ \\
\hline \multicolumn{9}{|c|}{ Chromium (VI) Trains } \\
\hline Radian & AEP-QD01CRIP & $\mathrm{KOH}$ Impinger & Chromium(VI) & $\mu \mathrm{g} / \mathrm{L}$ & 19.35 & 16 & 121 & $75-125$ \\
\hline Radian & AEP-QD01CRIP & $\mathrm{KOH}$ Impinger & Tot. Chrome & $\mu \mathrm{g} / \mathrm{L}$ & 22 & 16 & $138 Q$ & $75-125$ \\
\hline \multicolumn{9}{|c|}{ Service Water } \\
\hline \multirow[t]{24}{*}{ Radian } & \multirow[t]{24}{*}{ AEP-QD01SWMM } & \multirow[t]{24}{*}{ Service Water } & Aluminum & $\mathrm{mg} / \mathrm{L}$ & 0.126 & NA & NA & $75-125$ \\
\hline & & & Antimony & $\mathrm{mg} / \mathrm{L}$ & 1.06 & 0.99 & 107 & $75-125$ \\
\hline & & & Arsenic & $\mathrm{mg} / \mathrm{L}$ & $0.870^{2}$ & 1.00 & 87 & $75-125$ \\
\hline & & & Barium & $\mathrm{mg} / \mathrm{L}$ & 0.0021 & NA & NA & $75-125$ \\
\hline & & & Beryllium & $\mathrm{mg} / \mathrm{L}$ & 0.97 & 0.96 & 101 & $75-125$ \\
\hline & & & Boron & $\mathrm{mg} / \mathrm{L}$ & 0.314 & NA & NA & $75-125$ \\
\hline & & & Cadmium & $\mathrm{mg} / \mathrm{L}$ & $0.853^{2}$ & 0.94 & 91 & $75-125$ \\
\hline & & & Calcium & $\mathbf{m g} / \mathbf{L}$ & 1.12 & 1.00 & 112 & $75-125$ \\
\hline & & & Chromium & $\mathrm{mg} / \mathrm{L}$ & 0.976 & 1.03 & 95 & $75-125$ \\
\hline & & & Cobalt & $\mathrm{mg} / \mathrm{L}$ & 0.954 & 1.00 & 95 & $75-125$ \\
\hline & & & Copper & $\mathrm{mg} / \mathrm{L}$ & 0.996 & 1.03 & 97 & $75-125$ \\
\hline & & & Iron & $\mathrm{mg} / \mathrm{L}$ & 1.02 & 1.02 & 100 & $75-125$ \\
\hline & & & Lead & $\mathrm{mg} / \mathrm{L}$ & $0.934^{2}$ & 1.01 & 92 & $75-125$ \\
\hline & & & Magnesium & $\mathrm{mg} / \mathrm{L}$ & 0.968 & 1.06 & 91 & $75-125$ \\
\hline & & & Manganese & $\mathrm{mg} / \mathrm{L}$ & 0.978 & 1.02 & 96 & $75-125$ \\
\hline & & & Molybdenum & $\mathrm{mg} / \mathrm{L}$ & 1.00 & 1.06 & 94 & $75-125$ \\
\hline & & & Nickel & $\mathbf{m g} / \mathrm{L}$ & 0.979 & 1.02 & 96 & $75-125$ \\
\hline & & & Phosphorus & $\mathrm{mg} / \mathrm{L}$ & ND & NA & NA & $75-125$ \\
\hline & & & Potassium & $\mathrm{mg} / \mathrm{L}$ & 0.0968 & NA & NA & $75-125$ \\
\hline & & & Selenium & $\mathrm{mg} / \mathrm{L}$ & $0.936^{a}$ & 0.99 & 94 & $75-125$ \\
\hline & & & Silver & $\mathrm{mg} / \mathrm{L}$ & ND & NA & NA & $75-125$ \\
\hline & & & Sodium & $\mathrm{mg} / \mathrm{L}$ & 0.286 & NA & NA & $75-125$ \\
\hline & & & Titanium & $\mathrm{mg} / \mathrm{L}$ & 0.936 & 1.01 & 93 & $75-125$ \\
\hline & & & Vanadium & $\mathrm{mg} / \mathrm{L}$ & 0.966 & 1.01 & 96 & $75-125$ \\
\hline Radian & AEP-QD02SWMM & Service Water & Mercury & $\mathrm{mg} / \mathrm{L}$ & 0.0724 & 0.08 & 90 & $75-125$ \\
\hline \multirow[t]{4}{*}{ Radian } & \multirow[t]{4}{*}{ AEP-QD01SWAN } & \multirow[t]{4}{*}{ Service Water } & Chloride & $\mathrm{mg} / \mathrm{L}$ & 31.0 & 33.0 & 94 & $80-120$ \\
\hline & & & Fluoride & $\mathrm{mg} / \mathrm{L}$ & 1.91 & 1.7 & 112 & $80-120$ \\
\hline & & & Sulfate & $\mathrm{mg} / \mathrm{L}$ & 44.4 & 50.0 & 89 & $80-120$ \\
\hline & & & Phosphate & $\mathrm{mg} / \mathrm{L}$ & ND & NA & NA & $80-120$ \\
\hline
\end{tabular}


Table 4-4 (Continued)

\begin{tabular}{|c|c|c|c|c|c|c|c|c|}
\hline Lab & Sample ID & Matrix & Analyte & Units & $\begin{array}{c}\text { Lab } \\
\text { Result }\end{array}$ & \begin{tabular}{|c|} 
Reference \\
Value
\end{tabular} & $\begin{array}{l}\text { Percent } \\
\text { Recovery }\end{array}$ & $\begin{array}{c}\text { Audit } \\
\text { Objective }\end{array}$ \\
\hline \multicolumn{9}{|c|}{ Dolomite Sorbent } \\
\hline \multirow[t]{27}{*}{ Radian } & \multirow[t]{27}{*}{ AEP-QDOOSOAN } & \multirow[t]{27}{*}{ Sorbent } & Aluminum & $\mu \mathrm{g} / \mathrm{g}$ & 60.4 & 1,193 & $5 Q$ & $75-125$ \\
\hline & & & Antimony & $\mu \mathrm{g} / \mathrm{g}$ & ND & NA & NA & $75-125$ \\
\hline & & & Arsenic & $\mu \mathrm{g} / \mathrm{g}$ & $3.48^{2}$ & NA & NA & $75-125$ \\
\hline & & & Barium & $\mu \mathrm{g} / \mathrm{g}$ & 1.89 & NA & NA & $75-125$ \\
\hline & & & Beryllium & $\mu g / g$ & 0.0108 & NA & NA & $75-125$ \\
\hline & & & Boron & $\mu \mathrm{g} / \mathrm{g}$ & ND & NA & NA & $75-125$ \\
\hline & & & Cadmium & $\mu \mathrm{g} / \mathrm{g}$ & 0.587 & NA & NA & $75-125$ \\
\hline & & & Calcium & $\mu \mathrm{g} / \mathrm{g}$ & 191,000 & 215,000 & 89 & $75-125$ \\
\hline & & & Chromium & $\mu \mathrm{g} / \mathrm{g}$ & 1.51 & NA & NA & $75-125$ \\
\hline & & & Cobalt & $\mu g / g$ & ND & NA & NA & $75-125$ \\
\hline & & & Copper & $\mu \mathrm{g} / \mathrm{g}$ & 0.900 & NA & NA & $75-125$ \\
\hline & & & Iron & $\mu \mathrm{g} / \mathrm{g}$ & 1,400 & 1,960 & $71 Q$ & $75-125$ \\
\hline & & & Lead & $\mu \mathrm{g} / \mathrm{g}$ & $0.220^{2}$ & NA & NA & $75-125$ \\
\hline & & & Magnesium & $\mu \mathrm{g} / \mathrm{g}$ & 108,000 & 127,800 & 85 & $75-125$ \\
\hline & & & Manganese & $\mu \mathrm{g} / \mathrm{g}$ & 161 & 232 & $69 \mathrm{Q}$ & $75-125$ \\
\hline & & & Mercury & $\mu \mathrm{g} / \mathrm{g}$ & ND & NA & NA & $75-125$ \\
\hline & & & Molybdenum & $\mu \mathrm{g} / \mathrm{g}$ & 0.0676 & NA & NA & $75-125$ \\
\hline & & & Nickel & $\mu \mathrm{g} / \mathrm{g}$ & 0.0186 & NA & NA & $75-125$ \\
\hline & & & Phosphorus & $\mu \mathrm{g} / \mathrm{g}$ & ND & 43 & NA & $75-125$ \\
\hline & & & Potassium & $\mu \mathrm{g} / \mathrm{g}$ & 60.8 & 996 & $6 Q$ & $75-125$ \\
\hline & & & Selenium & $\mu \mathrm{g} / \mathrm{g}$ & $1.81^{a}$ & NA & NA & $75-125$ \\
\hline & & & Silver & $\mu \mathrm{g} / \mathrm{g}$ & ND & NA & NA & $75-125$ \\
\hline & & & Sodium & $\mu \mathrm{g} / \mathrm{g}$ & 50.6 & 74 & $68 \mathrm{Q}$ & $75-125$ \\
\hline & & & Titanium & $\mu \mathrm{g} / \mathrm{g}$ & 7.41 & 120 & $6 Q$ & $75-125$ \\
\hline & & & Vanadium & $\mu \mathrm{g} / \mathrm{g}$ & 3.63 & NA & NA & $75-125$ \\
\hline & & & Chloride & $\mu \mathrm{g} / \mathrm{g}$ & 0 & NA & NA & $75-125$ \\
\hline & & & Fluoride & $\mu \mathrm{g} / \mathrm{g}$ & 14.9 & NA & NA & $75-125$ \\
\hline \multicolumn{9}{|c|}{ Coal Paste } \\
\hline \multirow[t]{8}{*}{ CT\&E } & \multirow[t]{8}{*}{ AEP-QDOOGCCM } & \multirow[t]{8}{*}{ Coal } & Arsenic & $\mu \mathrm{g} / \mathrm{g}$ & 8.5 & 10.3 & 82 & $75-125$ \\
\hline & & & Barium & $\mu \mathrm{g} / \mathrm{g}$ & 32 & 32.76 & 98 & $75-125$ \\
\hline & & & Beryllium & $\mu \mathrm{g} / \mathrm{g}$ & 1.2 & 1.33 & 90 & $75-125$ \\
\hline & & & Boron & $\mu \mathrm{g} / \mathrm{g}$ & 71 & 72.3 & 98 & $75-125$ \\
\hline & & & Cadmium & $\mu \mathrm{g} / \mathrm{g}$ & $0.10 / 0.08$ & 0.11 & 91 & $75-125$ \\
\hline & & & Calcium & $\mu \mathrm{g} / \mathrm{g}$ & 900 & 861 & 104 & $75-125$ \\
\hline & & & Chromium & $\mu \mathrm{g} / \mathrm{g}$ & 17 & 16.3 & 104 & $75-125$ \\
\hline & & & Copper & $\mu \mathrm{g} / \mathrm{g}$ & 7.5 & 8.47 & 88 & $75-125$ \\
\hline
\end{tabular}


Table 4-4 (Continued)

\begin{tabular}{|c|c|c|c|c|c|c|c|c|}
\hline Lab & Sample ID & Matrix & Analyte & Units & $\begin{array}{c}\text { Lab } \\
\text { Result }\end{array}$ & \begin{tabular}{|c|}
$\begin{array}{c}\text { Reference } \\
\text { Value }\end{array}$ \\
\end{tabular} & \begin{tabular}{|c|} 
Percent \\
Recovery
\end{tabular} & $\begin{array}{c}\text { Audit } \\
\text { Objective }\end{array}$ \\
\hline \multirow[t]{15}{*}{ CT\&E } & \multirow[t]{15}{*}{ AEP-QDOOGCCM } & \multirow[t]{15}{*}{ Coal } & Lead & $\mu \mathrm{g} / \mathrm{g}$ & 7 & 6.00 & 117 & $75-125$ \\
\hline & & & Magnesium & $\mu g / g$ & 470 & 420 & 112 & $75-125$ \\
\hline & & & Mercury & $\mu g / g$ & 0.20 & 0.14 & $143 Q$ & $75-125$ \\
\hline & & & Molybdenum & $\mu g / g$ & $<3$ & 2.19 & NA & $75-125$ \\
\hline & & & Phosphorus & $\mu g / g$ & 38 & NA & NA & $75-125$ \\
\hline & & & Selenium & $\mu g / g$ & 0.8 & 1.83 & $44 \mathrm{Q}$ & $75-125$ \\
\hline & & & Titanium & $\mu \mathrm{g} / \mathrm{g}$ & 660 & 690 & 96 & $75-125$ \\
\hline & & & Chloride & $\mu \mathrm{g} / \mathrm{g}$ & 1,230 & 860 & 143 & $75-125$ \\
\hline & & & Fluoride & $\mu g / g$ & 70 & 58 & 121 & $75-125$ \\
\hline & & & Carbon & $\%$ & 72.33 & 72.08 & 100 & $75-125$ \\
\hline & & & Hydrogen & $\%$ & 4.76 & 4.96 & 96 & $75-125$ \\
\hline & & & Nitrogen & $\%$ & 1.43 & 1.39 & 103 & $75-125$ \\
\hline & & & Sulfur & $\%$ & 3.28 & 3.26 & 101 & $75-125$ \\
\hline & & & Ash & $\mathscr{H}$ & 11.94 & 11.56 & 103 & $75-125$ \\
\hline & & & HHV & Btu/b & 12,923 & 12,888 & 100 & $75-125$ \\
\hline \multirow[t]{21}{*}{ NC State } & \multirow[t]{21}{*}{ AEP-QDOOGCCM } & \multirow[t]{21}{*}{ Coal } & Aluminum & $\mu g / g$ & 14,734 & 13,075 & 113 & $75-125$ \\
\hline & & & Antimony & $\mu g / g$ & 0.543 & 0.64 & 85 & $75-125$ \\
\hline & & & Arsenic & $\mu \mathrm{g} / \mathrm{g}$ & 18.97 & 10.33 & $184 Q$ & $75-125$ \\
\hline & & & Barium & $\mu g / g$ & 57.9 & 32.76 & $177 \mathrm{Q}$ & $75-125$ \\
\hline & & & Cadmium & $\mu \mathrm{g} / \mathrm{g}$ & 2.087 & 0.11 & $1,897 \mathrm{Q}$ & $75-125$ \\
\hline & & & Calcium & $\mu g / g$ & 1785 & 861 & $207 Q$ & $75-125$ \\
\hline & & & Chromium & $\mu g / g$ & 20.6 & 16.30 & $126 \mathrm{Q}$ & $75-125$ \\
\hline & & & Cobalt & $\mu g / g$ & 5.75 & 5.50 & 104 & $75-125$ \\
\hline & & & Copper & $\mu \mathrm{g} / \mathrm{g}$ & 12.2 & 8.47 & $144 Q$ & $75-125$ \\
\hline & & & Iron & $\mu \mathrm{g} / \mathrm{g}$ & 22,314 & 20,031 & 111 & 75-125 \\
\hline & & & Magnesium & $\mu \mathrm{g} / \mathrm{g}$ & 631 & 420 & $150 Q$ & $75-125$ \\
\hline & & & Manganese & $\mu g / g$ & 20.9 & 18.35 & 114 & $75-125$ \\
\hline & & & Mercury & $\mu \mathrm{g} / \mathrm{g}$ & 0.058 & 0.14 & $41 Q$ & $75-125$ \\
\hline & & & Molybdenum & $\mu g / g$ & 0.628 & 2.19 & $29 \mathrm{Q}$ & $75-125$ \\
\hline & & & Nickel & $\mu g / g$ & 16.2 & 14.07 & 115 & $75-125$ \\
\hline & & & Potassium & $\mu g / g$ & 1,859 & 1.762 & 105 & $75-125$ \\
\hline & & & Selenium & $\mu \mathrm{g} / \mathrm{g}$ & 1.96 & 1.83 & 107 & $75-125$ \\
\hline & & & Silver & $\mu \mathrm{g} / \mathrm{g}$ & 0.303 & $\mathrm{NA}$ & $\mathrm{NA}$ & $75-125$ \\
\hline & & & Sodium & $\mu \mathrm{g} / \mathrm{g}$ & 344 & 367 & 94 & $75-125$ \\
\hline & & & Titanium & $\mu \mathrm{g} / \mathrm{g}$ & 1013 & 690 & $147 \mathrm{Q}$ & $75-125$ \\
\hline & & & Vanadium & $\mu \mathrm{g} / \mathrm{g}$ & 35.8 & 31.01 & 115 & $75-125$ \\
\hline
\end{tabular}


Table 4-4 (Continued)

\begin{tabular}{|c|c|c|c|c|c|c|c|c|}
\hline Lab & Sample ID & Matrix & Analyte & Units & $\begin{array}{c}\text { Lab } \\
\text { Result }\end{array}$ & $\begin{array}{c}\text { Reference } \\
\text { Value }\end{array}$ & $\begin{array}{l}\text { Percent } \\
\text { Recovery }\end{array}$ & $\begin{array}{c}\text { Audit } \\
\text { Objective }\end{array}$ \\
\hline \multicolumn{9}{|c|}{$\begin{array}{l}\text { ESP Ash, APF Ash, } \\
\text { Bed Ash, Cyclone Ash }\end{array}$} \\
\hline \multirow[t]{24}{*}{ Radian } & \multirow[t]{24}{*}{ AEP-QDOOFAMM } & \multirow[t]{24}{*}{ Ash } & Aluminum & $\mu g / g$ & 107,000 & 140,000 & 76 & $75-125$ \\
\hline & & & Antimony & $\mu \mathrm{g} / \mathrm{g}$ & ND & 7 & NA & $75-125$ \\
\hline & & & Arsenic & $\mu g / g$ & $174^{a}$ & 145 & 120 & $75-125$ \\
\hline & & & Barium & $\mu g / g$ & 1,120 & 1,500 & 75 & $75-125$ \\
\hline & & & Beryllium & $\mu g / g$ & 10.3 & 12 & 86 & $75-125$ \\
\hline & & & Cadmium & $\mu g / g$ & $1.06^{2}$ & 1.0 & 106 & $75-125$ \\
\hline & & & Calcium & $\mu g / g$ & 8,090 & 11,100 & $73 Q$ & $75-125$ \\
\hline & & & Chromium & $\mu g / g$ & 171 & 196 & 87 & $75-125$ \\
\hline & & & Cobalt & $\mu g / g$ & 44.4 & 46 & 96 & $75-125$ \\
\hline & & & Copper & $\mu g / g$ & 88.8 & 118 & 75 & $75-125$ \\
\hline & & & Iron & $\mu g / g$ & 78,200 & 94,000 & 83 & $75-125$ \\
\hline & & & Lead & $\mu g / g$ & $71.0^{2}$ & 72.4 & 78 & $75-125$ \\
\hline & & & Magnesium & $\mu g / g$ & 3,020 & 4,550 & 66 & $75-125$ \\
\hline & & & Manganese & $\mu g / g$ & 138 & 190 & $73 Q$ & $75-125$ \\
\hline & & & Mercury & $\mu g / g$ & 0.180 & 0.16 & 112 & $75-125$ \\
\hline & & & Molybdenum & $\mu g / g$ & 20.7 & 29 & $71 Q$ & $75-125$ \\
\hline & & & Nickel & $\mu \mathrm{g} / \mathrm{g}$ & 110 & 127 & 87 & $75-125$ \\
\hline & & & Phosphorus & $\mu \mathrm{g} / \mathrm{g}$ & ND & NA & NA & $75-125$ \\
\hline & & & Potassium & $\mu g / g$ & 16,000 & 18,800 & 85 & $75-125$ \\
\hline & & & Selenium & $\mu g / g$ & $11.7^{\mathrm{a}}$ & 10.3 & 114 & $75-125$ \\
\hline & & & Silver & $\mu g / g$ & 0.147 & NA & NA & $75-125$ \\
\hline & & & Sodium & $\mu g / g$ & 1,430 & 1,700 & 84 & $75-125$ \\
\hline & & & Titanium & $\mu \mathrm{g} / \mathrm{g}$ & 726,0 & 8,000 & 91 & $75-125$ \\
\hline & & & Vanadium & $\mu g / g$ & 269 & 300 & 90 & $75-125$ \\
\hline \multirow[t]{2}{*}{ Radian } & \multirow[t]{2}{*}{ AEP-QDOOFAAN } & \multirow[t]{2}{*}{ Ash } & Chloride & $\mu g / g$ & 0.0 & NA & NA & $80-120$ \\
\hline & & & Fluoride & $\mu \mathrm{g} / \mathrm{g}$ & 38.2 & NA & $\mathbf{N A}$ & $80-120$ \\
\hline
\end{tabular}

Analytical result from GFAAS method.

b Silver precipitated in the solution during audit sample preparation; this result should be used for qualitative assessment only.

NA $=$ Not applicable or not able to be calculated.

ND $=$ Not detected.

NS $=$ None specified

$Q=$ Outside of audit objective for recovery. 
sample, the unrecovered mass was approximately 0.05 gram. At the ESP inlet where the recovered particulate mass for actual samples was approximately 5 grams, this amount of sample loss is not significant. However, at the ESP outlet where the recovered particulate mass was much lower, sample losses or incomplete particulate recovery may be more significant. Since a particulate audit sample was not collected by the sampling team at the ESP outlet, their recovery technique cannot be assessed.

- Ammonia QC audit sample recovery was $485 \%$ at $0.27 \mathrm{mg} / \mathrm{L}$, outside the accuracy objective of 80-120 percent. Cyanide QC audit sample recovery was $26 \%$ at $0.10 \mathrm{mg} / \mathrm{L}$, also outside the accuracy objective of $80-120$ percent.

The ammonia audit sample was prepared in fresh impinger solution and required a fivefold dilution to reduce acidity prior to distillation and analysis. Since the audit sample concentration was prepared near the method detection limit, sample dilution lowered the concentration to a level where there is a greater degree of uncertainty in the analytical result. Actual field samples did not require dilution and the $Q C$ results for matrix spikes and matrix spike duplicates indicate excellent analytical precision and recovery.

The cyanide audit sample was prepared using an EPA water quality standard as the source material. An investigation of possible causes for low recovery revealed that a complex form of cyanide (iron ferricyanide) was used in the EPA standard which is susceptible to photodegradation. In the event the source material was exposed to sunlight prior to audit sample preparation, photodegradation may explain the low recovery, although there is no evidence to confirm this. In the laboratory, field samples were spiked with a cyanide salt solution (free cyanide) which more closely simulates the dissociation of HCN in solution. The recovery results for these matrix spike samples indicate excellent analytical precision and accuracy. However, firm conclusions regarding the accuracy of the cyanide analysis cannot be made based on the audit sample results.

- Eleven target metals ( $\mathrm{Al}, \mathrm{Ba}, \mathrm{Ca}, \mathrm{Cd}, \mathrm{Co}, \mathrm{Fe}, \mathrm{Mn}, \mathrm{Mo}, \mathrm{K}, \mathrm{Se}$, and $\mathrm{Ti}$ ) did not meet the recovery objective for the particulate matter audit sample.

Quartz filter blanks are analyzed along with the samples to determine the background . metal concentrations contributed by the filter media. Blank results equilibrated to the tare weight of the sample filters are subtracted from the samples to determine the filtered particulate metal concentrations. In some cases, the result is the difference between two relatively high, or similarly low concentrations thereby increasing the uncertainty of the background-corrected result.

- Four target metals ( $\mathrm{Ca}, \mathrm{Cd}, \mathrm{K}$, and $\mathrm{Na}$ ) did not meet the recovery objective for the vapor-phase metals impinger audit sample analyzed by ICP-AES and GFAAS.

Audit sample concentrations were near the ICP-AES detection limit for sodium and potassium. The reasons for high recovery of calcium and cadmium are unknown; however, the matrix spike recoveries for these elements were within the recovery objective 
range. The metal concentrations in the audit sample prepared for ICP-AES and GFAAS analysis were between 200 and 5000 parts per billion (ppb). These concentrations were significantly higher than the actual sample concentrations, but were made that way to provide detectable concentrations for these techniques. Cadmium results by ICP/MS were selected for reporting since audit results for cadmium by ICP/MS met the data quality objectives.

- Three target metals ( $\mathrm{Sb}, \mathrm{Ni}$, and $\mathrm{Se}$ ) did not meet the recovery objective for the vaporphase metals impinger audit sample submitted to Harvard for ICP/MS analysis.

The metal concentrations prepared in the audit sample for ICP/MS analysis were 5 and $10 \mathrm{ppb}$, much closer to the actual sample concentrations and therefore more representative of the technique's performance on the gas impinger samples. Antimony and nickel were recovered at $70 \%$, slightly lower than the $80 \%$ recovery objective; however, matrix spike recoveries for these elements were within the desired range and demonstrate acceptable accuracy in the sample matrix.

The quantitation of selenium is subject to interferences from the argon plasma in ICP/MS. Low recovery (62\%) is caused by incomplete resolution of the selenium mass peak at 79 atomic mass units (amu) from the much larger Ar-Ar mass peak at 80 amu. Selenium recovery in the matrix spike was also low at 71 percent. These results indicate that vapor-phase selenium results may be biased low.

- Six target metals ( $\mathrm{Al}, \mathrm{Fe}, \mathrm{Mn}, \mathrm{K}, \mathrm{Na}$, and $\mathrm{Ti}$ ) did not meet the recovery objective for the dolomite sorbent audit sample.

Dolomite samples were digested with nitric acid and hydrogen peroxide by EPA Method SW-3050. This procedure is generally adequate for the digestion of calcium and magnesium, which accounts for $99 \%$ of the sample matrix. The amounts of major coal ash minerals (silica, alumina, titania, etc.) are relatively small and do not affect the material balances for these elements. The digestion procedure applied here does not use hydrofluoric acid (HF) which is required to dissolve the oxides of aluminum, silicon, titanium, and others that may be bound in the inert matrix. A mixed acid digestion which includes HF should be considered for future laboratory analyses if the level of inert substances is thought to be a significant contributor to the mass flow rates of these materials.

- Two target metals ( $\mathrm{Hg}$ and $\mathrm{Se}$ ) did not meet the recovery objective for the coal audit sample submitted to CT\&E.

The coal audit sample selected for this project was taken from coal collected at the Ohio Power Cardinal Station as part of a recent round robin coal study sponsored by the Department of Energy. ${ }^{1}$ This coal audit sample is not a standard reference material; however, it has been well characterized for all of the target analytes, and it is representative of the Pittsburgh \#8 bituminous coal feedstock at Plant Tidd. 
The variability inherent in coal mercury measurements was demonstrated in the DOE round robin study and has been the subject of studies sponsored by the Electric Power Research Institute (EPRI) and others. ${ }^{2}$ Although the recovery of mercury by the double gold amalgamation technique was $143 \%$ of the mean value reported, it is within two standard deviations of the mean for all results reported in the round robin study. These results reflect the variability and uncertainty typically encountered with coal mercury determinations.

Selenium values by GFAAS were not selected for reporting as a result of the audit sample recovery. The INAA results for selenium were selected since the audit sample recovery by INAA was within the recovery objective at 107 percent.

- Ten target metals (As, $\mathrm{Ba}, \mathrm{Ca}, \mathrm{Cd}, \mathrm{Cr}, \mathrm{Cu}, \mathrm{Mg}, \mathrm{Hg}$, Mo and $\mathrm{Ti}$ ) did not meet the recovery objective for the coal audit sample submitted to NC State.

All elements not meeting the audit sample recovery objectives for INAA were analyzed by alternative analytical procedures. The results reported from the alternative procedures were within the recovery objectives and were reported in lieu of the INAA results with the exception of arsenic.

INAA results. for arsenic were selected for reporting over those determined by GFAAS in spite of the apparent failure of INAA to meer the desired recovery objectives. Based on the audit sample recovery data, GFAAS results were initially selected for calculating material balance closures. However, the use of GFAAS arsenic values resulted in a closure of $213 \%$, while a closure of $129 \%$ was obtained using INAA arsenic values. Since audit sample recovery results were used to select the most accurate data for reporting, the individual results used to determine the mean arsenic value of the coal audit sample were reviewed for consistency and accuracy. Twenty-two results for arsenic were averaged to obtain a mean concentration of $10.3 \mu \mathrm{g} / \mathrm{g}(\mathrm{CV}=0.33)$. The analytical methods used to measure arsenic in the round robin study included GFAAS, ICP/MS, INAA, and cold vapor atomic fluorescence (CVAF). Based on arsenic results obtained for an SRM coal sample analyzed with the round robin samples, ICP/MS results were the most accurate and consistent, followed by INAA results. The average arsenic result of the audit sample as determined by ICP/MS in the round robin study was $13.28 \mu \mathrm{g} / \mathrm{g}$. The arsenic result by INAA in the audit sample was $18.97 \mu \mathrm{g} / \mathrm{g}$ or $143 \%$ of the ICP/MS average. Although this result still suggests a high analytical bias, supporting information indicates that the INAA result for arsenic is more accurate than the GFAAS result. It is also reasonable to expect that the direct analysis of coal by INAA would provide more complete quantitation of arsenic. This is based on the volatile nature of this element and the potential for losses during sample digestion for GFAAS analysis.

- Three target metals ( $\mathrm{Ca}, \mathrm{Mn}$, and $\mathrm{Mo}$ ) did not meet the recovery objective for the fly ash audit sample.

The recovery percentages for $\mathrm{Ca}, \mathrm{Mn}$, and $\mathrm{Mo}$ are $73 \%, 73 \%$, and $71 \%$, respectively. These are very close to the recovery objective of $75 \%$ and indicate a possible analytical 
bias. Sample digestion is assumed complete based on the $91 \%$ recovery of titanium. Measurement results for $\mathrm{Ca}, \mathrm{Mn}$, and Mo may be biased slightly low in ash streams.

\section{Detailed QC Results}

Precision is a measure of the reproducibility of measurements under a given set of conditions. It reflects the distribution or scatter of the data and is expressed as the standard deviation or coefficient of variation (CV, standard deviation divided by the mean). For duplicates, precision is expressed as the relative percent difference (RPD).

Accuracy is a measure of agreement between a value generated by a specific procedure and the assumed or accepted known value and includes both bias and precision. Bias is the persistent positive or negative deviation of the method average value from the assumed or accepted known value.

The efficiency of the analytical procedure for a given sample matrix is quantified by the analysis of spiked samples containing target or indicator analytes or other quality assurance measures, as necessary. However, all spikes, unless made to the flowing stream ahead of sampling, produce only estimates of the recovery of the analyte through all of the measurement steps occurring after the addition of the spike. A good spike recovery tells little about the concentration of the analyte in the sample before spiking, but it does provide an indication of a method's ability to accurately measure an analyte in a given sample matrix.

Representativeness expresses the degree to which the sampling data accurately and precisely represent a characteristic of a population, parameter variations at a sampling point, or an environmental condition. Representativeness is improved by making certain that sampling locations are properly selected and that a sufficient number of samples are collected.

Comparability is a qualitative parameter expressing the confidence with which one data set can be compared with another.' Sampling data should be comparable to other measurement data for similar samples collected under similar conditions. This goal is achieved using 
standard techniques (wherever possible) to collect and analyze representative samples and by reporting analytical results in appropriate units. Data sets can be compared with confidence when the precision and accuracy are known.

Completeness is an expression of the number of valid measurements obtained compared with the number planned for a given study. The goal to generate three valid sample results for each measurement parameter was met.

A discussion of the overall measurement precision, accuracy, and blank effects is presented below for each set of analytes. The individual QC sample results used to assess these analytical measurements are presented in Appendix D. This assessment of data quality is limited to the analytical techniques used to determine the results selected for reporting.

\section{Metals}

Precision. The analysis of matrix spike/matrix spike duplicate (MS/MSD) samples, or analytical duplicate samples provided the basis for assessing analytical precision. The precision objective for metals in all samples was 20\% RPD.

In general, good analytical precision is indicated for almost all of the target metals in all sample matrices. Noteworthy exceptions include cadmium in coal by GFAAS (22\% RPD), calcium in dolomite (45\% RPD), silver in ash (70\% RPD), and selenium in both gas particulate- and vapor-phase samples by GFAAS. Poor analytical precision for these metals in these streams increases the uncertainty associated with the measured value.

Other metals failing to meet the precision objective include aluminum (71\% RPD), calcium (34\% RPD), and magnesium (63\% RPD) in an acetone probe/nozzle rinse (PNR) sample, and phosphorus (43\% RPD) in a filter sample. The impact of imprecise analytical measurements for these samples is less because they each represent only a fraction of the total gas particulate samples specific to the ESP. 
Accuracy. Recovery data for matrix spikes, analytical spikes, and standard reference materials (SRMs) provided the basis for assessing analytical accuracy. For most of the analytical techniques, the accuracy objective was $75-125 \%$ spike, or standard recovery. Performance audit samples submitted to the laboratory as blind samples also served as indicators of analytical accuracy in the coal, dolomite sorbent, and ash matrices. Audit sample results not meeting program objectives were discussed earlier in this section.

Matrix spiked samples and performance audit samples were used to estimate the accuracy of the flue gas vapor-phase metals analyses. Six of the metals analyzed recorded audit sample recoveries outside the specified objective: antimony, calcium, nickel, potassium, selenium, and sodium. Only selenium failed to meet recovery objectives in both the audit and matrix spike samples.

Poor selenium recovery was experienced in the vapor-phase samples analyzed by GFAAS (4-61\%) and ICP/MS (62-71\%). In response to the poor recovery by direct GFAAS analysis, the method of standard additions (MSA) was used to reanalyze the impinger samples for selenium. The GFAAS-MSA result for selenium in the audit standard was $\mathbf{8 7 \%}$ and the remaining sample results were in close agreement with the ICP/MS results. Based on this recovery data, ICP/MS results were selected for reporting, although they may be biased low.

Gas particulate-phase samples were characterized in two different batches depending on the particulate loading of the sample. Matrix spikes and a standard reference fly ash material. (NIST 1633a) were used to estimate the accuracy of the particulate-phase metals analyses for the APF and ESP inlet samples. Six of the metals analyzed recorded spike recoveries outside the specified objective: aluminum, calcium, lead, magnesium, selenium, and silver. Matrix spike recoveries for all of these elements were in the range of 58-72\% except silver (15-18\%) and may indicate a low bias in the results.

The analytical accuracy of gas particulate samples analyzed in conjunction with filters (APF and ESP outlet) was estimated using analytical spikes and a standard reference fly ash 
material aspirated onto a filter as an audit sample. The audit sample results were discussed earlier in this section. Analytical spike recoveries below the desired recovery range were experienced for aluminum, calcium, magnesium, selenium, silver, and titanium in an acetone PNR sample from the ESP inlet. Matrix spike recoveries for all target metals associated with filter samples met the recovery objective except for one phosphorus spike (153\%).

Matrix spikes and SRMs were used to estimate the accuracy of the fly ash, bed ash, and dolomite sorbent metals analyses. In the ash matrices, matrix spike recoveries for aluminum (70\%), calcium (73\%), magnesium (64\%), and silver (27\%) did not meet the program objective. Fly ash SRM recovery results for calcium (73\%), manganese (73\%), and molybdenum (71\%) were also reported slightly below the objective range. Matrix spike recoveries outside the program objectives were experienced in the dolomite sorbent for calcium (286\%), cobalt (74\%), and iron (74\%).

All matrix spike and audit sample results for metals in service water were between 93 and $108 \%$, well within the specified recovery range.

Blank Effects. The field blank impinger samples analyzed by ICP-AES, GFAAS, CVAAS, and ICP/MS showed no significant levels of field contamination when compared to the reagent blank analyses. Relative to the actual gas impinger samples, the background levels detected in the reagent blank are significant (greater than $30 \%$ of the sample result), especially at the trace levels detected by ICP/MS. Significant concentrations of calcium, iron, magnesium, manganese, and sodium were also detected by ICP-AES in the blanks. All sample results for vapor-phase metals have therefore been corrected to account for the background concentrations found in the reagents.

Filter media blanks were also analyzed to determine the levels of target metals present in the quartz filters. Significant levels of aluminum, barium, calcium, chromium, magnesium, molybdenum, and sodium were reported. Arsenic, cadmium, lead, mercury, and selenium were also detected in the filter media at levels more than five times the detection limit. 
Background corrections were also performed for gas-particulate samples analyzed in the presence of filter media (APF and ESP outlet).

\section{Anions}

Precision. The precision of anion analyses in coal and ash samples was estimated using duplicate analyses. The precision estimates for chloride and sulfur in the ash and dolomite samples met the objective of $20 \% \mathrm{RPD}$, as did the precision estimates for chloride, fluoride, and sulfur in the coal. Analytical results for chloride, fluoride, and sulfate in the flue gas particulate- and vapor-phase samples, as well as the service water samples, all met the precision objectives. Precision estimates for fluoride in ash and dolomite were between 25 and $33 \%$ RPD, slightly outside the objective.

Accuracy. Matrix spikes were used to estimate the accuracy of anion analyses in ash and flue gas samples. All anions met the recovery objective for flue gas analysis accuracy. All anions in ash met the accuracy objective with the exception of fluoride. The recovery of fluoride in the ash was below the project objective (32\% compared to $75-125 \%$ ). A performance audit sample and a standard reference material were analyzed to provide accuracy estimates for coal. Chloride recovery was $143 \%$ and fluoride recovery was $121 \%$ in the performance audit sample (objective of $80-120 \%$ ). For the standard reference materials, chloride recovery was $101 \%$ for NBS SRM 1632-b and $87 \%$ for a coal standard from a recent laboratory round-robin study. Fluoride recovery in the standard reference material was 110 percent.

No reference values were available for the dolomite sorbent audit sample; therefore, no estimate of accuracy was obtained. However, anions in the sorbent material are minor constituents that are not expected to play a major role in material balance calculations. For service water, a single matrix spike recovery of $62 \%$ for fluoride was the only result outside the expected range of recovery. 
Low fluoride spike recoveries were experienced in many of the sample matrices analyzed. Fluoride results, particularly in ash samples, are likely biased low. An investigation into the possible causes has identified aluminum and iron as potential interferents with the specific ion electrode analysis method. This is particularly significant in the analysis of fluoride in ash samples which are prepared by fusion with sodium hydroxide. Separation of fluoride by distillation from the ash fusion matrix is suggested as a means to provide an interference-free analytical matrix.

Blank Effects. Field blank impinger solutions and probe/nozzle rinses were analyzed for chloride, fluoride, and sulfate. The concentrations of these anions were above reporting limits in many of the blanks but well below the levels observed in the samples. The levels of chloride, fluoride, and sulfate found in the field blank for the flue gas solid phase were $4 \%$, $3 \%$, and $2 \%$ of the concentrations in the samples, respectively; therefore, these data should not be affected by the blank levels. The field blank associated with the vapor-phase samples contained all of the anions at levels much lower than those found in the vapor-phase samples. The method blanks associated with the stack gas samples showed fluoride at levels less than five times the detection limit; much higher levels of fluoride were observed in the associated samples. Sulfur was also observed in the method blank associated with the sorbent samples at a level near the detection limit, but at a higher concentration than those observed in the samples. Therefore, the results for sulfur in the sorbent samples may be overestimated.

\section{Chromium (VI) and Total Chromium}

Precision. The precision of the chromium (VI) and total chromium analyses was assessed by matrix spike duplicate analyses. All results met the RPD objective of 20 percent.

Accuracy. The accuracy of the analyses was estimated using performance audit spike recoveries. Recovery of chromium (VI) was within the $75-125 \%$ objective, and recovery of total chromium was slightly outside the objective at 138 percent. Total chromium sample data may be slightly overestimated. 
Blank Effects. Low concentrations of total chromium were reported in the field and reagent blanks, but none of the values were more than five times the expected detection limit. Chromium (VI) concentrations in the field and reagent blanks were significant when compared to the gas impinger samples. Background concentrations in the reagent blank accounted for over $65 \%$ of the chromium (VI) concentration measured in the samples. Chromium (VI) results were background corrected for reporting and emission factor calculations.

\section{Volatile Organic Compounds}

Precision. The precision of the volatile organic compounds measured for this project was not assessed.

Accuracy. The accuracy of the analyses was estimated using surrogate spike recoveries. Recovery of all surrogates (1,2-dichloroethane-d4, toluene-d8, and 4-bromofluorobenzene) was within the compound specific objective.

Blank Effects. The trip and method blanks show no results above the detection limit for the target compounds. Concentrations of chloromethane, methylene chloride, and toluene were reported in the field blank, but only methylene chloride is present at more than five times the expected detection limit. Methylene chloride and toluene are common contaminants from field laboratory operations. The range of results ( 48 to $230 \mathrm{ng}$ ) for methylene chloride suggests that no specific, consistent source of the contamination was present.

\section{Semivolatile Organic Compounds}

Precision. The precision of the semivolatile organic compounds measured for this project was not assessed.

Accuracy. The accuracy of the analyses was estimated using surrogate spike recoveries. All vapor-phase sample surrogate spikes were recovered within the accuracy expectations. 
Data Evaluation

Recovery of several surrogates in the cyclone ash and gas particulate-phase samples were outside the compound specific objectives.

- Blank Effects. The trip and method blanks show no results above the expected detection limit for the target compounds, except for a single naphthalene result of $4.77 \mu \mathrm{g}$. Concentrations of bis(2-ethylhexyl)phthalate and naphthalene were reported in the field blank, but only naphthalene is present at more than five times the expected detection limit. Reported results for naphthalene have the potential to be overestimated at low levels.

\section{Polycyclic Aromatic Hydrocarbons (PAHs) by HRGC/MS}

Precision. The precision of the PAH analytical results was not evaluated.

Accuracy. The accuracy of the PAH analytical results was evaluated using surrogate spike recoveries. All recoveries were within the project objective of 50-150 percent.

Blank Effects. Many low-level measurements were reported for the trip, field, and method blanks. Concentrations ranged from 0.13-309 ng for the compounds in the method blank and 0.19-129 $\mathrm{ng}$ for the compounds in the trip blank. Field blank results ranged from 0.06$1050 \mathrm{ng}$. For compounds found in the samples, the results have been flagged if trip blank results for PAHs exceed $30 \%$ of the sample value.

\section{Formaldehyde}

Precision. The precision of formaldehyde measurements was assessed from duplicate analyses. Results for formaldehyde at two different concentration levels was excellent, with both RPDs within 5 percent.

Accuracy. The accuracy of the analyses was estimated using matrix spike recoveries. Both spikes were recovered within the accuracy objective of 50-150 percent. 
Blank Effects. The reagent and method blanks show no results above the expected detection limit for formaldehyde. Significant concentrations of formaldehyde were reported in the field blank, at more than ten times the expected detection limit. Reported results for formaldehyde in the APF outlet and ESP inlet and outlet gas streams have the potential to be overestimated at low levels.

\section{Ammonia}

Precision. The precision of ammonia measurements was assessed from matrix spike duplicate analyses. Results for ammonia met the $20 \%$ RPD objective.

Accuracy. The accuracy of the analyses was estimated using matrix spike recoveries and a performance audit sample. The audit sample recovery was $485 \%$ at a theoretical concentration of $0.27 \mathrm{mg} / \mathrm{L}$. A laboratory flag was attached to the audit sample result stating that the acidity of the sample was so high that an unusually small sample aliquot was taken for analysis. Since it appears that the audit sample was not distilled and analyzed in exactly the same manner as routine field samples, no firm conclusions about the accuracy of ammonia analysis can be made based on the performance audit. Both matrix spikes were recovered within the accuracy objective of $80-120$ percent.

Blank Effects. The field, reagent, and method blanks all show results above the expected detection limit for ammonia. None of these blank results is greater than five times the expected detection limit.

\section{Cyanide}

Precision. The precision of cyanide measurements was assessed from matrix spike duplicate analyses. Results for cyanide met the $20 \%$ RPD objective.

Accuracy. The accuracy of the analyses was estimated using matrix spike recoveries and a performance audit sample. Both matrix spikes were recovered within the accuracy objective 
of 75-125 percent. The audit sample recovery was $26 \%$ of a prepared concentration of $0.1 \mathrm{mg} / \mathrm{L}$. For the audit sample, an EPA water quality standard was used which may have degraded as discussed previously in this section. The EPA standard material was not analyzed, so no data are available to confirm the standard's theoretical value.

Blank Effects. The field, reagent, and method blanks all show results below the expected detection limit for cyanide.

\section{Dioxins and Furans (PCDD/PCDF)}

Precision. The precision of the PCDD/PCDF analyses was not assessed.

Accuracy. The accuracy of the analyses was estimated using surrogate spike recoveries. Nearly all spike recoveries were within the project objective. The four recoveries outside the objective were within $10 \%$ of the lower limit of the objective.

Blank Effects. Low concentrations of eight compounds in the method, trip, and field blanks associated with these samples were observed. All concentrations reported for the blank results were near the analytical detection limits. Sample concentrations, which were also near the detection limits of many compounds, may be slightly overestimated for these compounds.

\section{Ultimate/Proximate}

Precision. The precision of ultimate/proximate analyses was not assessed.

Accuracy. The accuracy of the ultimate/proximate analyses for coal was estimated using performance audit sample recoveries. All recoveries were within the accuracy objective of $75-125 \%$ recovery. 
Blank Effects. Ultimate/proximate test parameters are generally not subject to blank or background assessments.

\section{Material Balances}

Evaluating data consistency can be another overall data quality evaluation tool. Material balances for major elements can be used to verify the internal consistency of stream flow rates. Material balance closures for trace species can be used to indicate whether the samples collected were representative with respect to the trace element concentrations and can help identify analytical biases in one or more types of samples.

Table 45 shows the results of the material balances around the entire plant, the ESP system and the APF system. Closure is defined as the ratio of outlet to inlet mass rates for a particular substance. A $100 \%$ closure indicates perfect agreement. When trace substances are analyzed, a closure of between $70 \%$ and $130 \%$ has been set as a goal for the Tidd PFBC HAPs project. This range reflects the typical level of uncertainty in the measurements and, therefore, allows one to interpret the inlet and outlet mass flow rates as being equivalent. The 95\% confidence intervals about the closures have been calculated using error propagation analysis, which is discussed in Appendix G. Inlet streams and their associated flow rates for each material balance system are provided in Table 4-6. Flow rates are presented in units consistent with the reported stream concentrations to facilitate mass flow rate determinations. A brief description of the methods for determining flow rates is also provided in Table 4-6.

\section{Entire Plant}

As shown in Table 4-5, 10 of the 19 target elements have closures around the entire plant that meet the project goal. The target elements that do not meet the closure goal are copper ( $<37 \%)$, fluorine (58\%), mercury (155\%), nickel $(<45 \%)$, and selenium (148\%). Closures could not be determined for antimony, cadmium, molybdenum, and silver because these elements were not detected in the major outlet ash streams. Closures for the other major 
Table 4-5

Material Balance Results

\begin{tabular}{|c|c|c|c|c|c|c|}
\hline & \multicolumn{2}{|c|}{ Entire Plant } & \multicolumn{2}{|c|}{ ESP System } & \multicolumn{2}{|c|}{ APF System } \\
\hline Substance & Closure (\%) & 95\% CI & Closure $(\mathscr{\%})$ & $95 \%$ CI & Closure (\%) & 95\% CI \\
\hline \multicolumn{7}{|c|}{ Target Species } \\
\hline Antimony & $\mathrm{NC}$ & - & NC & - & NC & - \\
\hline Arsenic & 129 & 36 & 134 & 21 & 101 & 59 \\
\hline Barium & 111 & 27 & 134 & 63 & 97 & 29 \\
\hline Beryllium & 101 & 22 & 137 & 59 & 101 & 27 \\
\hline Boron & 91 & 140 & 126 & 95 & NC & - \\
\hline Cadmium & NC & - & 140 & 124 & 95 & 43 \\
\hline Chlorine & 105 & 24 & 94 & 8 & 83 & 29 \\
\hline Chromium & 122 & 21 & 107 & 51 & 70 & 36 \\
\hline Cobalt & 119 & 49 & 137 & 44 & 97 & 55 \\
\hline Copper & $<37$ & - & 129 & 184 & $<12$ & - \\
\hline Fluorine & 58 & 22 & 47 & 13 & 120 & 16 \\
\hline Lead & 95 & 3 & 167 & 97 & 120 & 44 \\
\hline Manganese & 102 & 2 & 119 & 14 & 92 & 25 \\
\hline Mercury & 155 & 33 & 96 & 9 & 91 & 13 \\
\hline Molybdenum & NC & - & NC & - & $<92$ & - \\
\hline Nickel & $<45$ & - & 138 & 95 & 77 & 80 \\
\hline Selenium & 148 & 87 & 74 & 27 & $<79$ & - \\
\hline Silver & $\mathrm{NC}$ & - & NC & - & $\mathrm{NC}$ & - \\
\hline Vanadium & 97 & 4 & 136 & 38 & 95 & 29 \\
\hline \multicolumn{7}{|l|}{ Other Species } \\
\hline Aluminum & .89 & 17 & 131 & 40 & 95 & 25 \\
\hline Calcium & 78 & $0: 1$ & 128 & 35 & 94 & 42 \\
\hline Iron & 96 & 27 & 128 & 27 & 93 & 30 \\
\hline Magnesium & 99 & 0.1 & 127 & 33 & 95 & 42 \\
\hline Potassium & 61 & 20 & 138 & 60 & 98 & 33 \\
\hline Sodium & 99 & 25 & 128 & 42 & 93 & 30 \\
\hline Titanium & 109 & 19 & 136 & 53 & 98 & 28 \\
\hline
\end{tabular}

Closure goal for the Tidd PFBC HAPs project is $70-130$ percent.

$\mathbf{C I}=$ Confidence interval 
Table 4-6

Material Balance Stream Flow Rates

\begin{tabular}{|c|c|c|c|c|}
\hline Stream & $\begin{array}{l}\text { Mean Flow } \\
\text { Rate }\end{array}$ & $95 \% \mathrm{CI}$ & $\begin{array}{l}\text { Units of } \\
\text { Measure }\end{array}$ & How Calculated \\
\hline \multicolumn{5}{|l|}{ Entire Plant } \\
\hline Coal Paste (inlet) & 15,170 & 430 & kg/hr, dry & $\begin{array}{l}\text { Five-minute averages from the plants data } \\
\text { acquisition system and coal paste moisture } \\
\text { determinations. }\end{array}$ \\
\hline Sorbent (inlet) & 8,620 & 1,020 & $\mathrm{~kg} / \mathrm{hr}$, as fired & $\begin{array}{l}\text { Five-minute averages from the plants data } \\
\text { acquisition system. }\end{array}$ \\
\hline Bed Ash (outlet) & 4,220 & 970 & $\mathrm{~kg} / \mathrm{hr}$, dry & $\begin{array}{l}\text { Data from AEP bed ash generation test on } \\
4 / 9 / 94 . \\
\text { Test conditions: Coal paste }=45 \mathrm{KPPH} \text { (as } \\
\text { fired), } \mathrm{MW}=46 \text {, sorbent }=19.8 \mathrm{KPPH} \text {. }\end{array}$ \\
\hline $\begin{array}{l}\text { Cyclone Ash } \\
\text { (outlet) }\end{array}$ & 4,690 & 1,490 & $\mathrm{~kg} / \mathrm{hr}, \mathrm{dry}$ & $\begin{array}{l}\text { Average of the cyclone ash rate determined } \\
\text { from material balances for magnesium, } \\
\text { titanium, and sodium. }\end{array}$ \\
\hline APF Ash (outlet) & 142 & 28 & $\mathrm{~kg} / \mathrm{hr}, \mathrm{dry}$ & $\begin{array}{l}\text { Measured particulate loading data collected at } \\
\text { the APF inlet and outlet. }\end{array}$ \\
\hline ESP Ash (outlet) & 352 & 35 & $\mathrm{~kg} / \mathrm{hr}$, dry & $\begin{array}{l}\text { Measured particulate loading data collected at } \\
\text { the ESP inlet and outlet. }\end{array}$ \\
\hline $\begin{array}{l}\text { ESP Outlet Gas } \\
\text { (outlet) }\end{array}$ & 238,700 & 8,500 & $\mathrm{Nm}^{3} / \mathrm{hr}$ & $\begin{array}{l}\text { Direct measurement at the ESP outlet } \\
\text { location. }\end{array}$ \\
\hline \multicolumn{5}{|l|}{ APF System } \\
\hline $\begin{array}{l}\text { APF Inlet Gas } \\
\text { (inlet) }\end{array}$ & 34,100 & 1,200 & $\mathrm{Nm}^{3} / \mathrm{hr}$ & $\begin{array}{l}\text { Assumed equal to } 1 / 7 \text { th of the ESP outlet gas } \\
\text { rate. }\end{array}$ \\
\hline $\begin{array}{l}\text { APF Outlet Gas } \\
\text { (outlet) }\end{array}$ & 34,100 & 1,200 & $\mathrm{Nm}^{3} / \mathrm{hr}$ & $\begin{array}{l}\text { Assumed equal to } 1 / 7 \text { th of the ESP outlet gas } \\
\text { rate. }\end{array}$ \\
\hline APF Ash (outlet) & 142 & 28 & $\mathrm{~kg} / \mathrm{hr}, \mathrm{dry}$ & $\begin{array}{l}\text { Measured particulate loading data collected at } \\
\text { the APF inlet and outlet. }\end{array}$ \\
\hline \multicolumn{5}{|l|}{ ESP System } \\
\hline $\begin{array}{l}\text { ESP Inlet Gas } \\
\text { (inlet) }\end{array}$ & 264,900 & 44,400 & $\mathrm{Nm}^{3} / \mathrm{hr}$ & $\begin{array}{l}\text { Direct measurement at the ESP inlet location. } \\
\text { ESP outlet rate used in the material balance. }\end{array}$ \\
\hline $\begin{array}{l}\text { ESP Outlet Gas } \\
\text { (outlet) }\end{array}$ & 238,700 & 8,500 & $\mathrm{Nm}^{3} / \mathrm{hr}$ & $\begin{array}{l}\text { Direct measurement at the ESP outlet } \\
\text { location. }\end{array}$ \\
\hline ESP Ash (outlet) & 352 & 35 & $\mathrm{~kg} / \mathrm{hr}, \mathrm{dry}$ & $\begin{array}{l}\text { Measured particulate loading data collected at } \\
\text { the ESP inlet and outlet. }\end{array}$ \\
\hline
\end{tabular}

$\mathrm{CI}=$ Confidence interval. 
species met the project goal, with the exception of potassium (61\%). For mercury and selenium, the closures are slightly above the desired range and the wide $95 \%$ confidence intervals indicate that imprecision may be partially responsible for the high closures. For copper, fluorine, and nickel, the results may indicate an analytical bias in one or more of the process streams.

\section{ESP System}

Closures for the ESP system were typically in the $125-135 \%$ range, which is slightly outside the project goal. This indicates that the ESP ash rate, calculated from the measured particulate loadings at the ESP inlet and outlet, may be biased slightly high. Concentrations of antimony, molybdenum, and silver were below detection limits in one or more of the inlet or outlet streams; therefore, closures could not be calculated around the ESP.

\section{APF System}

All closures around the APF system met the project goal except copper $(<12 \%)$. Closures could not be determined for antimony, boron, and silver because substances were not detected in the inlet and outlet streams. Again, the low closure for copper indicates an analytical bias in one or more of the process streams. The relatively wide $95 \%$ confidence intervals for most of the target and other major elements in the ESP and APF material balances reflect the inherent variability in the gas stream measurements.

\section{Recommendations and Considerations}

Some technical issues have been identified during this study that may warrant further consideration. Some significant sampling, analytical and/or process related issues are discussed below. 


\section{APF Outlet Particulate Contamination}

Comparison of the composition of the APF outlet particulate matter with the composition of the ESP outlet, ESP inlet, and APF inlet particulate matter indicates high levels of chromium, nickel, and molybdenum. This suggests residue from the Inconel 800 probe material may be present in the collected particulate matter. The contribution from this residue becomes significant at the APF outlet where the particulate loading is 1-2 orders of magnitude lower than those measured at the ESP outlet.

\section{Improved Detection Limits}

The following elements were below the detection limits in the particulate phase at the ESP outlet and/or APF outlet: Antimony, cobalt, copper, chromium, molybdenum, and silver. In addition, the following elements were below detection limits in one or more of the ash streams: Antimony, cadmium, copper, molybdenum, nickel, and silver. Detection limits could be improved by application of the ICP-MS analytical technique for these substances with slight modifications of the sample preparation procedures.

\section{Multiple Reagent Blanks}

As part of this test program, single reagent blank samples were submitted for analysis to provide a qualitative assessment of background levels in the sampling media. In addition, two field blank samples were also collected and analyzed to enable assessment of contamination possibly introduced during sample preparation and recovery. Using conventional analytical techniques, this series of blank samples provides an adequate assessment of background analyte levels-usually below method detection limits. With the more sensitive analytical techniques, there are fewer results below the detection limit, so it is more difficult to differentiate between background and sample contributions. Multiple reagent blanks for multi-metals train filters and impinger solutions, and the filters and XAD-2 resin used in the MM5 sampling train for semivolatile organics could be analyzed to provide a more sound 
statistical average for estimating background concentrations in the sampling media and performing reliable background corrections.

\section{Gas Sampling Methods for Semivolatile Organic Compounds}

The gas sampling method for semivolatile organic compounds should be studied to confirm the suspicion that benzoic acid and phthalate esters detected in the flue gas samples are sampling artifacts. The presence of benzoic acid, and other intermediate oxidation products of naphthalene could possibly arise from the reaction of flue gas components with the XAD-2 resin matrix. Sulfur and nitrogen oxides in the flue gas combine with condensed moisture in the resin traps to form acids. These acids may be contributing to the breakdown of the resin into the by-products detected most frequently in the vapor-phase sample fraction.

\section{Hexavalent Chromium Sampling and Analysis}

The hexavalent chromium sampling method has not been validated for application to flue gas from coal-fired combustion systems and should be thoroughly evaluated for sampling bias and precision. The analytical method is relatively sound, but the fate of $\mathrm{Cr}(\mathrm{VI})$ during sampling in a recirculating caustic impinger solution with constant exposure to $\mathrm{CO}_{2}$ and $\mathrm{SO}_{2}$ is not well defined. Multiple sampling trains should be used in parallel to obtain duplicate spiked and duplicate unspiked samples simultaneously from the same location in the process duct. Multiple samples providing spike recovery and duplicate sample results will provide an indication of method accuracy and precision.

\section{References}

1. Lawrence W. Rosendale and Matthew S. DeVito. Interlaboratory Variability and Accuracy of Coal Analyses in the U.S. Department of Energy Utility Air Toxics Assessment Program. CONSOL, Inc. Library, PA (1994). 
2. J. Lengyel, Jr., M.S. DeVito, and R.A. Bilonick, "Interlaboratory and Intralaboratory Variability in the Analyses of Mercury in Coal," paper presented at the Air \& Waste Management Association Annual Meeting. Cincinnati, OH (1994). 


\section{5}

\section{EXAMPLE CALCULATIONS}

This section describes the methodology and sample calculations used to develop the results discussed in Section 3. Specifically, the calculation of stream flow rates, emission factors, mean values, and confidence intervals are presented.

\section{Stream Flow Rates}

Table 4-6 in Section 4 contains information about the stream flow rates used in the material balance calculations. Coal paste and sorbent feed rates were determined from five-minute averages from the plant's data acquisition system. The bed ash rate was determined from data supplied by the Plant Tidd personnel. This data was from a bed ash generation test conducted on April 9, 1994, during operating conditions very similar to those used during the air toxics test period (ash generation test conditions: $46 \mathrm{MW}$, coal paste rate $=$ $45,000 \mathrm{lb} / \mathrm{hr}$, sorbent rate $=19,800 \mathrm{lb} / \mathrm{hr}$ ). Therefore, the bed ash rate is considered representative of plant operation during the air toxics tests. The APF and ESP ash rates were calculated using measured particulate loading data and gas flow rate data for each run as follows:

Ash rate $=$ (inlet loading $\mathrm{x}$ inlet gas rate) - (outlet loading $\mathrm{x}$ outlet gas rate)

For the ESP ash rate, the ESP inlet and outlet gas rates were assumed equal to the measured ESP outlet gas rate. The ESP outlet gas rate was selected because that sampling point is configured to minimize flow disturbances upstream and downstream of the sample ports, thus providing more reliable flow rate measurements. For the APF ash rate, the inlet and outlet gas rates were assumed equal to $1 / 7$ th of the measured ESP outlet gas flow rate. The 
cyclone ash rate was determined by calculating overall plant material balances for magnesium, titanium and sodium as follows:

Cyclone ash rate $=[($ coal rate $\mathrm{x}$ concentration of element $)+$ (sorbent rate $\mathrm{x}$ concentration of element) - (ESP ash rate $x$ concentration of element) - (APF ash rate $x$ concentration of element) - (bed ash rate $x$ concentration of element) - (ESP outlet gas rate $x$ concentration of element) $] \div$ concentration of element in cyclone ash

These elements were selected on the basis of the superior quality of the analytical data for the coal, sorbent, and major ash streams, as indicated by QA/QC data. The final cyclone ash rate used in the material balance calculations was the average of the cyclone ash rates determined for each element.

The flow rates in the ESP inlet and outlet were measured directly during sampling. The flow rate of the APF inlet and outlet were assumed to be equal to 1/7th of the measured ESP outlet gas flow rates. This assumption was based on plant design information supplied by Plant Tidd personnel.

\section{Means and Confidence Intervals for Stream Concentrations}

The mean concentration and $95 \%$ confidence interval (CI) about the mean were calculated for each target substance in the coal, sorbent, ash streams, and gas streams. The means were calculated according to the conventions listed in Section 3. Equations used to calculate $95 \%$ confidence intervals are presented in Appendix G. Example calculations are presented here for arsenic in the ESP inlet gas; these results were shown in Table 3-6.

The concentration data (in $\mu \mathrm{g} / \mathrm{Nm}^{3}$ ) given for arsenic are:

\begin{tabular}{|c|c|c|c|}
\hline & Run 1 & $\underline{\operatorname{Run} 2}$ & Run 3 \\
\hline Solid Phase & 450 & 380 & 420 \\
\hline Vapor Phase & 0.34 & 0.26 & 0.36 \\
\hline Total & 450.3 & 380.3 & 420.4 \\
\hline
\end{tabular}


The mean is calculated from the individual run totals:

$$
\begin{aligned}
\text { Mean } & =(450+380.3+420.4) / 3 \\
& =417
\end{aligned}
$$

The sample standard deviation of the individual run totals is calculated:

$$
\begin{aligned}
S_{p} & =\sqrt{\left[(450.3-417)^{2}+(380.3-417)^{2}+(420.4-417)^{2}\right] / 2} \\
& =35.1
\end{aligned}
$$

The standard deviation of the mean is calculated according to Equation 6 in Appendix $G$ for $\mathbf{N}=3$ :

$$
\begin{aligned}
S_{\bar{p}} & =\frac{35.1}{\sqrt{3}} \\
& =20.3
\end{aligned}
$$

The bias error is found by root-sum-squaring the product of the bias error and the sensitivity from each run (see Equation 2 in Appendix G). According to the conventions listed in Section 3, no bias error is assigned to values above detection limits, whereas a bias error of one-half the detection limit is assigned to values below detection limits. The sensitivity of the mean to each run in this case is one-third.

$$
\begin{aligned}
\beta_{\mathrm{z}} & =\sqrt{(1 / 3 \times 0)^{2}+(1 / 3 \times 0)^{2}+(1 / 3 \times 0)^{2}} \\
& =0
\end{aligned}
$$

The total uncertainty in the result is found from Equation 1 in Appendix G:

$$
U_{r}=\sqrt{\beta_{r}^{2}+\left(t \times S_{\vec{p}}\right)^{2}}
$$




$$
\begin{aligned}
& =\sqrt{0^{2}+(4.3 \times 20.3)^{2}} \\
& =87
\end{aligned}
$$

Thus, the result is reported as $420 \pm 87 \mu \mathrm{g} / \mathrm{Nm}^{3}$.

\section{Unit Energy Emission Factors}

In addition to the gas-phase concentrations, unit-energy-based emission factors have been developed for each target substance. These values were determined by calculating the mass flow of a substance in the ESP outlet gas (mean concentration times mean flow rate) and dividing by the mean heat input to the boiler during testing. The mean heat input is the product of the mean coal flow rate and the mean higher heating value (HHV) of the coal.

As an example, the calculation of the emission factor for arsenic is presented. The mean coal paste flow rate is $33,450 \mathrm{lb} / \mathrm{hr}$ on a dry basis. The mean HHV of the coal is 12,700 Btu/lb on a dry basis. Multiplying the coal flow rate by the HHV gives a mean heat input of 425 million Btu/hr. The mean arsenic mass flow through the stack (the product of the mean concentration, $1.0 \mu \mathrm{g} / \mathrm{Nm}^{3}$, and the mean gas flow rate, $239,000 \mathrm{Nm}^{3} / \mathrm{hr}$ ) is $0.239 \mathrm{~g} / \mathrm{hr}$ or $0.000526 \mathrm{lb} / \mathrm{hr}$. When the mean mass flow rate is divided by the mean heat input, an emission factor of $1.2 \mathrm{lb} / 10^{12} \mathrm{Btu}$ is obtained, as shown in Table 3-19.

The 95\% confidence intervals for emission factors were calculated according to the equations presented in Appendix G. For each parameter (ESP outlet gas flow rate, concentration, coal flow rate, and HHV) the mean, standard deviation, number of points, and bias estimates were used to calculate the combined uncertainty in the mean emission factors. 


\section{GLOSSARY}

AAS

acfm

AEP

APF

AS

ASTM

Btu.

CARB

CEM

CEMS

CI

$\mathrm{C}_{\mathrm{p}}$

CT\&E

CVAAS

DAS

$\Delta P$

DGA

DL

DNPH

DQO

dscfm

EPA

ESP

FPAs
Atomic absorption spectrophotometry

Actual cubic foot (feet) per minute

American Electric Power Service Corporation

Advanced particle filter

Analytical standard

American Society for Testing and Materials

British thermal unit

California Air Resources Board

Continuous emission monitor

Continuous emission monitoring system

Confidence interval

Pitot tube coefficient

Commercial Testing \& Engineering

Cold vapor atomic absorption spectrophotometry

Data acquisition system

"Delta P"; pressure drop; pressure difference (measured in inches of water column)

Double gold amalgamation

Detection limit

Dinitrophenylhydrazine

Data quality objective

Dry standard ( $1 \mathrm{~atm} .68^{\circ} \mathrm{F}$ ) cubic foot (feet) per minute

U.S. Environmental Protection Agency

Electrostatic Precipitator

Analytical services laboratory of Radian Corporation 
GC/MS Gas chromatography/mass spectrometry (low resolution)

GFAAS Graphite furnace atomic absorption spectrophotometry

HAP Hazardous Air Pollutant

HGCU Hot Gas Clean Up (System)

HHV Higher heating value

HRGC/MS High-resolution gas chromatography/mass spectrometry

ICP-AES Inductively coupled plasma-atomic emission spectrometry

ICP-MS Inductively coupled plasma-mass spectrometry

INAA Instrumental neutron activation analysis

IS Internal standard

MS/MSD Matrix spike/matrix spike duplicate

NA

Not applicable

NC

Not calculated

ND

$\mathrm{Nm}^{3}$

Not detected (below detection limit)

Normal cubic meter(s): $1 \mathrm{~m}^{3} @ 0^{\circ} \mathrm{C}$ and $1.0 \mathrm{~atm}$ (equivalent to $37.44 \mathrm{ft}^{3} @ 68^{\circ} \mathrm{F}$ and $\left.1.0 \mathrm{~atm}\right)$

$\mathrm{NO}_{\mathrm{x}}$

Nitrogen oxides

Orsat

Method of fixed-gas $\left(\mathrm{O}_{2}, \mathrm{CO}_{2}, \mathrm{CO}\right)$ analysis

$\mathrm{PAH} \quad$ Polycyclic aromatic hydrocarbon

PCDD Polychlorinated dibenzodioxin

PCDF Polychlorinated dibenzofuran

PFBC Pressurized fluidized bed combustion

PNR Probe and nozzle rinse

POM Polycyclic organic matter

QA Quality assurance

QC Quality control

RPD Relative percent difference

PSD Particle size distribution

RS Recovery standard

RSF Relative sensitivity factor (used in mass spectrometry) 
scf

Standard cubic foot (feet): $1 \mathrm{ft}^{3} @ 68^{\circ} \mathrm{F}$ and $1.0 \mathrm{~atm}$ (equivalent to $0.02671 \mathrm{~m}^{3} @ 0^{\circ} \mathrm{C}$ and $\left.1.0 \mathrm{~atm}\right)$

scfm

Standard cubic foot (feet) per minute

SIE

Specific ion electrode

SVOC

Semivolatile organic compound; semivolatile organic chemical

SW-846

Publication number of "Test Methods for Evaluating Solid Waste"

SS

Surrogate spike

TCLP

Toxicity characteristic leaching procedure

Tenax

An organic resin used for sample collection

UV-Vis

Ultraviolet-visible

VOC

Volatile organic compound; volatile organic chemical

VOST

Volatile organic sampling train

$\mathrm{XAD}$

An organic resin used for sample collection 
APPENDICES 


\section{CONTENTS}

$\begin{array}{ll}\text { Appendix } & \text { Page }\end{array}$

A Sample Collection, Pretreatment and Analytical Procedures ....... A-1

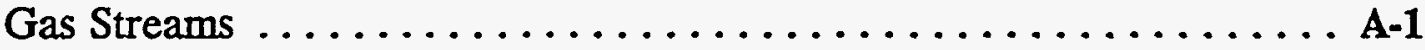

Particulate Loading . ....................... A-10

Particulate- and Vapor-Phase Metals .................11

Anions ............................... A

Ammonia/Hydrogen Cyanide ......................20

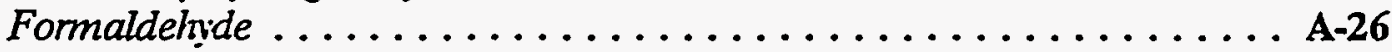

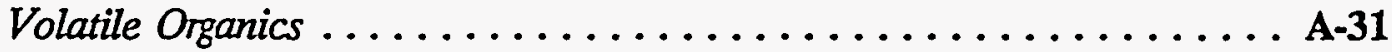

Semivolatile Compounds .......................

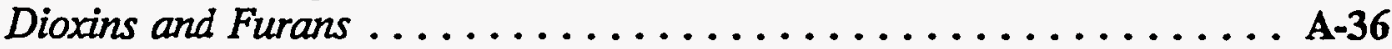

Particle Size Distribution $\ldots \ldots \ldots \ldots \ldots \ldots \ldots \ldots \ldots \ldots \ldots \ldots \ldots \ldots$

Hexavalent Chromium ..................... A-41

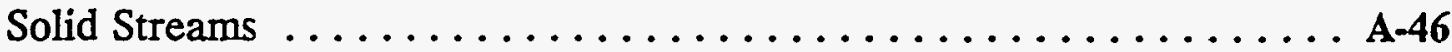

Raw Coal ...........................4.46

Coal Paste Sampling ....................... A-46

Coal Paste Analysis . . . . . . . . . . . . . . . . . . A-47

Dolomite Sorbent Sampling . . . . . . . . . . . . . A-50

Dolomite Sorbent Analysis ....................5 A

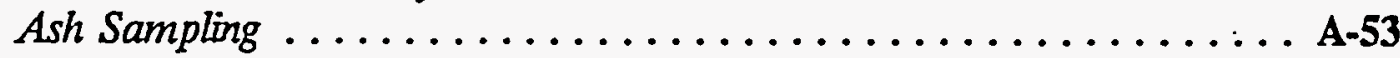

Ash Analysis . . . . . . . . . . . . . . . . . . . . . A-57

Service Water Sampling and Analysis $\ldots \ldots \ldots \ldots \ldots \ldots \ldots \ldots$ A-60

Metals ..........................

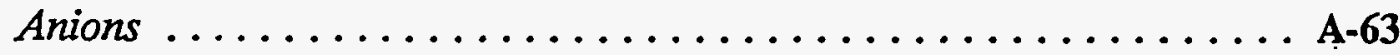

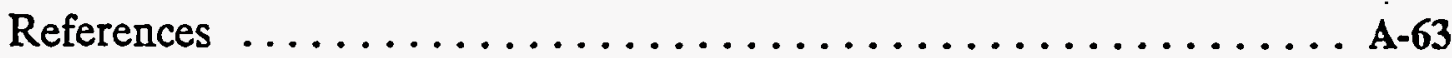

B Detailed Analytical Data $\ldots \ldots \ldots \ldots \ldots \ldots \ldots \ldots \ldots \ldots$ B-1

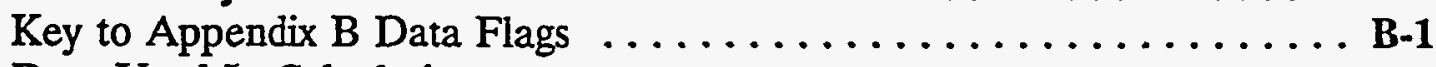

Data Used In Calculations . . . . . . . . . . . . . . . . B

Data Not Used In Calculations $\ldots \ldots \ldots \ldots \ldots \ldots \ldots \ldots$ B-93

C Source Sampling Data Summary and PSD Plots $\ldots \ldots \ldots \ldots \ldots$ C-1

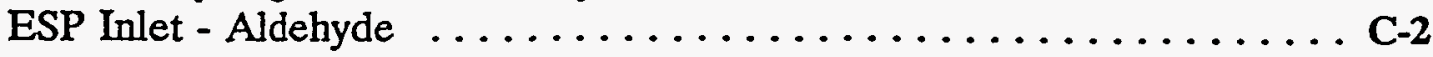


ESP Inlet - Ammonia/Hydrogen Cyanide $\ldots \ldots \ldots \ldots \ldots \ldots \ldots$ C-3

ESP Inlet - Anions $\ldots \ldots \ldots \ldots \ldots \ldots \ldots \ldots \ldots \ldots \ldots \ldots \ldots \ldots \ldots \ldots \ldots \ldots$

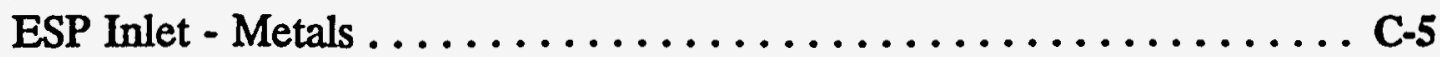

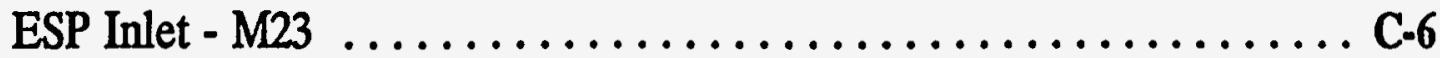

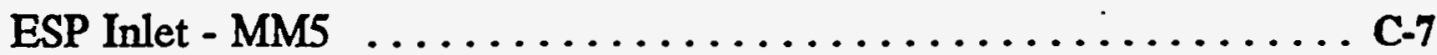

ESP Inlet - VOST $\ldots \ldots \ldots \ldots \ldots \ldots \ldots \ldots \ldots \ldots \ldots \ldots \ldots \ldots \ldots \ldots \ldots$

ESP Outlet - Aldehyde ....................... C-9

ESP Outlet - Ammonia/Hydrogen Cyanide $\ldots \ldots \ldots \ldots \ldots \ldots \ldots$ C-10

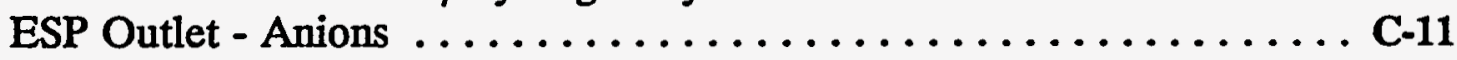

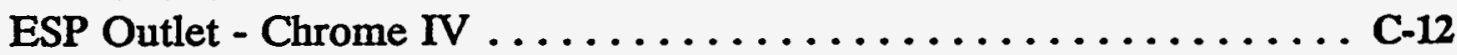

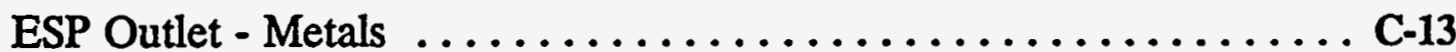

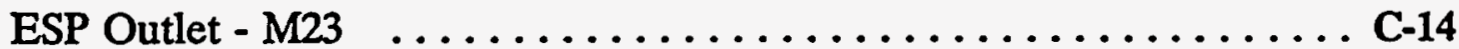

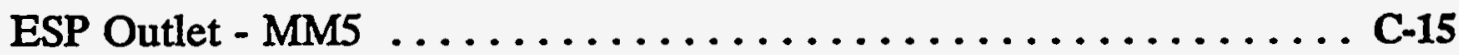

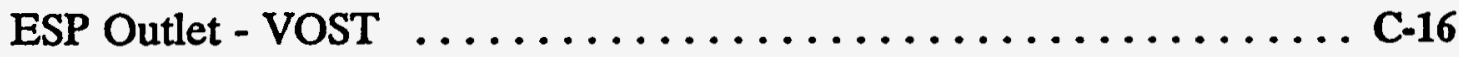

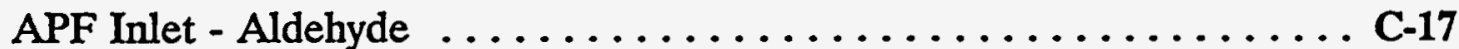

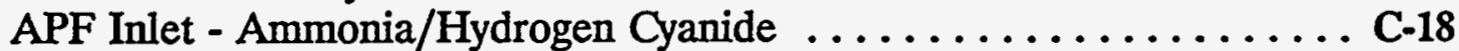

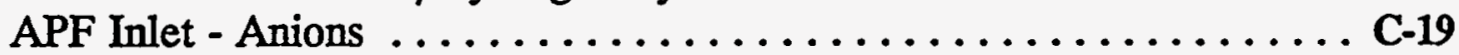

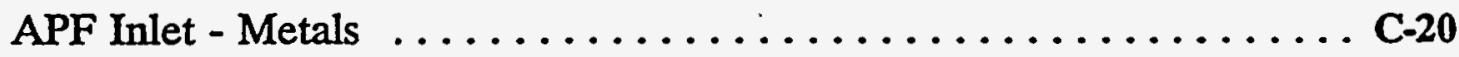

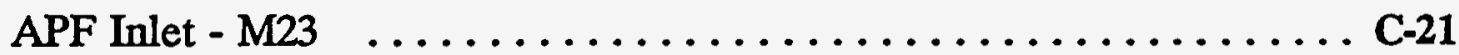

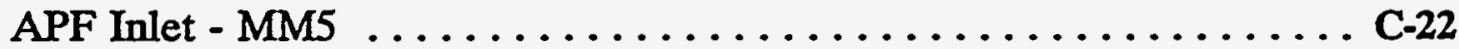

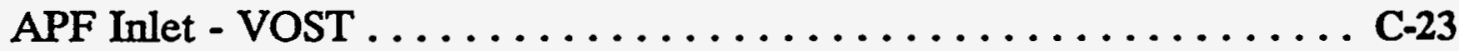

APF Outlet - Aldehyde ...................... C-24

APF Outlet - Ammonia/Hydrogen Cyanide .............. C-25

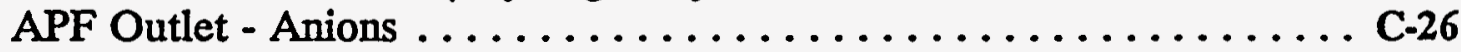

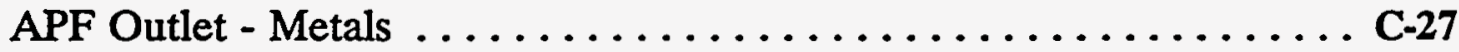

APF Outlet - M23 ....................... C-28

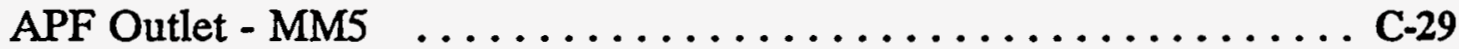

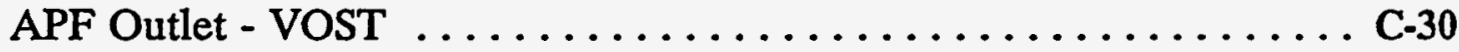

APF Sampling Locations Data Summary $\ldots \ldots \ldots \ldots \ldots \ldots \ldots \ldots$ C-31

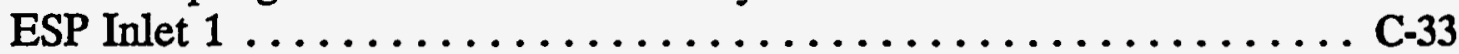

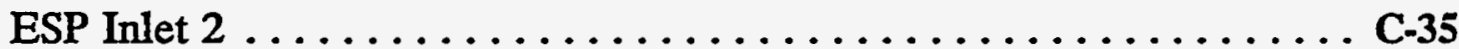

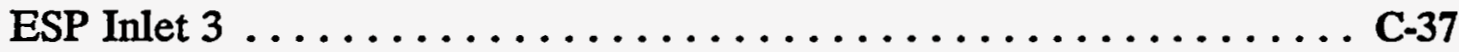

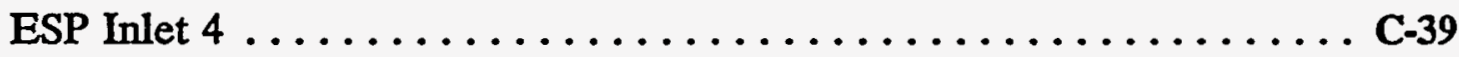

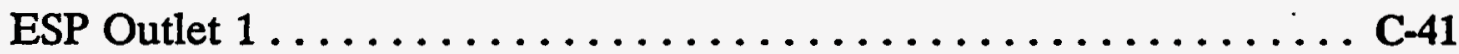

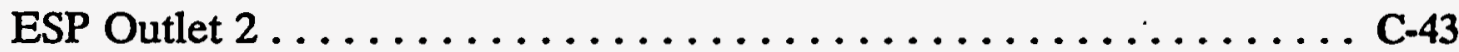

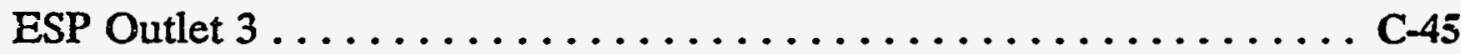

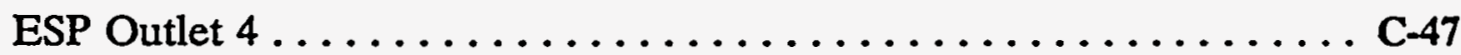

Differential Mass Concentration Plot - Inlet $1 \ldots \ldots \ldots \ldots \ldots \ldots$ C-49

Differential Mass Concentration Plot - Inlet $2 \ldots \ldots \ldots \ldots \ldots \ldots$ C-50

Differential Mass Concentration Plot - Inlet 3 ............ C-51

Differential Mass Concentration Plot - Inlet $4 \ldots \ldots \ldots \ldots \ldots \ldots$ C-52

Differential Mass Concentration Plot - Outlet $1 \ldots \ldots \ldots \ldots \ldots \ldots$ C-53

Differential Mass Concentration Plot - Outlet $2 \ldots \ldots \ldots \ldots \ldots \ldots$ C-54

Differential Mass Concentration Plot - Outlet $3 \ldots \ldots \ldots \ldots \ldots \ldots$ C-55

Differential Mass Concentration Plot - Outlet $4 \ldots \ldots \ldots \ldots \ldots \ldots$ C-56

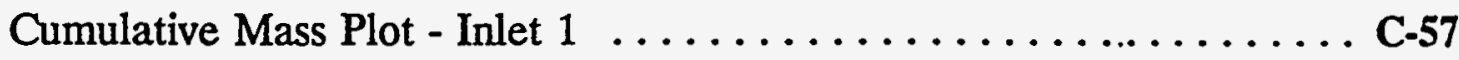

Cumulative Mass Plot - Inlet $2 \ldots \ldots \ldots \ldots \ldots \ldots \ldots \ldots \ldots \ldots \ldots \ldots \ldots$ 
Cumulative Mass Plot - Inlet $3 \ldots \ldots \ldots \ldots \ldots \ldots \ldots \ldots$ C-59

Cumulative Mass Plot - Inlet $4 \ldots \ldots \ldots \ldots \ldots \ldots \ldots \ldots \ldots$ C-60

Cumulative Mass Plot - Outlet $1 \ldots \ldots \ldots \ldots \ldots \ldots \ldots \ldots \ldots \ldots \ldots \ldots \ldots \ldots$

Cumulative Mass Plot - Outlet $2 \ldots \ldots \ldots \ldots \ldots \ldots \ldots \ldots \ldots$ C-62

Cumulative Mass Plot - Outlet $3 \ldots \ldots \ldots \ldots \ldots \ldots \ldots \ldots \ldots$ C-63

Cumulative Mass Plot - Outlet $4 \ldots \ldots \ldots \ldots \ldots \ldots \ldots \ldots$ C-64

Differential Mass Particle Size Distribution for ESP Hopper 1, Run 1 .. C-65

Differential Mass Particle Size Distribution for ESP Hopper 1, Run 2 .. C-66

Differential Mass Particle Size Distribution for ESP Hopper 1, Run 3 . . C-67

Differential Mass Particle Size Distribution for ESP Hopper 1, Run 3

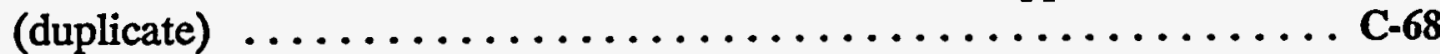

Differential Mass Particle Size Distribution for ESP Hopper 2, Run 1 . . C-69

Differential Mass Particle Size Distribution for ESP Hopper 2, Run 2 .. C-70

Differential Mass Particle Size Distribution for ESP Hopper 2, Run 3 . . C-71

Differential Mass Particle Size Distribution for ESP Hopper 2,

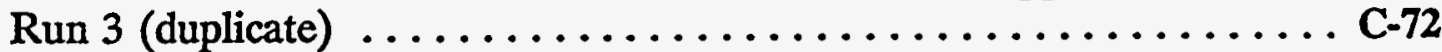

Differential Mass Particle Size Distribution for ESP Hopper 3, Run 3 . . C-73

Differential Mass Particle Size Distribution for ESP Hopper 3,

Run 3 (duplicate) . ......................... C-74

Differential Mass Particle Size Distribution for ESP Hopper 4, Run 3 . . C-75

Differential Mass Particle Size Distribution for ESP Hopper 4,

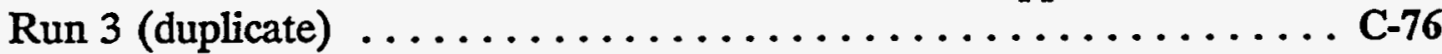

D Quality Assurance/Quality Control Results $\ldots \ldots \ldots \ldots \ldots \ldots$ D-1

E Process Data Trend Plots $\ldots \ldots \ldots \ldots \ldots \ldots \ldots \ldots \ldots \ldots \ldots$ E-1

F Field Sampling Equipment Calibration Records and Field

Data Sheets ............................ F-1

G Uncertainty Formulas $\ldots \ldots \ldots \ldots \ldots \ldots \ldots \ldots \ldots \ldots \ldots$ G-1

Nomenclature $\ldots \ldots \ldots \ldots \ldots \ldots \ldots \ldots \ldots \ldots \ldots \ldots \ldots \ldots$ G-2 


\section{LIST OF TABLES}

Table

\section{Page}

A-1 Field Sampling Completed for Gas Streams $\ldots \ldots \ldots \ldots \ldots \ldots \ldots$ A-2

A-2 Field Sampling Completed for Coal, Sorbent, and Service Water $\ldots \ldots \ldots$ A-3

A-3 Field Sampling Completed for Ash Samples ................. A-4

A-4 Analyte List for Inorganic Parameters . . . . . . . . . . . A-5

A-5 Analyte List for Organic Parameters ................. 4-6

A-6 List of Radionuclides $\ldots \ldots \ldots \ldots \ldots \ldots \ldots \ldots \ldots \ldots \ldots \ldots \ldots \ldots \ldots \ldots \ldots$

A-7 Description and Recovery of Method 29 (Multi-Metals) Sampling

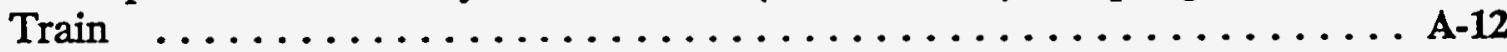

A-8 Description and Recovery of Anions Sampling Train ............. A-21

A-9 Description and Recovery of Ammonia and Hydrogen Cyanide Sampling Train . ............................... A-27

A-10 Description and Recovery of Aldehydes Sampling Train .......... A-29

A-11 Description and Recovery of Modified Method 5 (Semivolatile and PAHs 429) Sampling Train ...........................

A-12 Description and Recovery of Method 23 (Dioxins/Furans) Sampling Train . A-37

A-13 Description and Recovery of the Particle Size Distribution Sampling Train . A-42

A-14 Description and Recovery of $\mathrm{Cr}^{+6}$ Sampling Train $\ldots \ldots \ldots \ldots \ldots$ A-44

A-15 Description and Recovery of Coal Paste $\ldots \ldots \ldots \ldots \ldots \ldots \ldots \ldots$ A-48 
A-16 Description and Recovery of Dolomite Sorbent $\ldots \ldots \ldots \ldots \ldots \ldots$ A-51

A-17 Description and Recovery of Bed Ash $\ldots \ldots \ldots \ldots \ldots \ldots \ldots \ldots \ldots$ A-54

A-18 Description and Recovery of Primary Cyclone Ash $\ldots \ldots \ldots \ldots \ldots \ldots$ A-55

A-19 Description and Recovery of APF Ash $\ldots \ldots \ldots \ldots \ldots \ldots \ldots \ldots \ldots$ A-56

A-20 Description and Recovery of ESP Ash $\ldots \ldots \ldots \ldots \ldots \ldots \ldots \ldots \ldots$ A-58

A-21 Description and Recovery of Service Water $\ldots \ldots \ldots \ldots \ldots \ldots \ldots$ A-61

D-1 Summary of Blank Sample Results $\ldots \ldots \ldots \ldots \ldots \ldots \ldots \ldots \ldots$ D-2

D-2 Precision and Accuracy Estimates $\ldots \ldots \ldots \ldots \ldots \ldots \ldots \ldots \ldots \ldots \ldots \ldots \ldots$

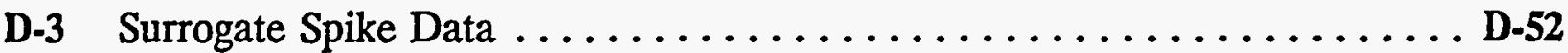




\section{LIST OF FIGURES}

Figure

Page

A-1 APF High Pressure Sampling System $\ldots \ldots \ldots \ldots \ldots \ldots \ldots \ldots$ A-9

A-2 Gas Particulate Sample Preparation and Analysis Plan for Metals (ESP Outlet)

A-3 Gas Particulate Sample Preparation and Analysis Plan for Metals (ESP Inlet)

A-4 Gas Particulate Sample Preparation and Analysis Plan for Metals (APF Outlet)

A-5 Gas Particulate Sample Preparation and Analysis Plan for Metals (APF Inlet) A-16

A-6 Flue Gas Impinger Sample Preparation and Analysis Plan for Metals . . . . A-17

A-7 Flue Gas Impinger Sample Preparation and Analysis Plan for Mercury ... A-18

A-8 Gas Particulate Sample Preparation and Analysis Plan for Anions (APF Outlet)

A-9 Gas Particulate Sample Preparation and Analysis Plan for Anions (APF Inlet and ESP Inlet)

A-10 Gas Particulate Sample Preparation and Analysis Plan for Anions (ESP Outlet)

A-11 Flue Gas Impinger Sample Preparation and Analysis Plan for Anions

A-12 Flue Gas Impinger Sample Preparation and Analysis Plan for Ammonia and Cyanide 
A-13 Flue Gas Impinger Sample Preparation and Analysis Plan for Formaldehyde

A-14 VOST Sorbent Sample Preparation and Analysis Plan for Volatile Organic Compounds

A-15 Flue Gas Sample Preparation and Analysis Plan for Semivolatile Organic Compounds and PAHs

A-16 Flue Gas Sample Preparation and Analysis Plan for Dioxins and Furans (ESP Inlet and Outlet and APF Inlet)

A-17 Flue Gas Sample Preparation and Analysis Plan for Dioxins and Furans (APF Outlet only)

A-18 Gas Impinger Sample Preparation and Analysis for $\mathrm{Cr}^{+6}$ and Total Chromium ............................ A 45

A-19 Coal Sample Preparation and Analysis Plan $\ldots \ldots \ldots \ldots \ldots \ldots \ldots$ A-49

A-20 Sorbent Sample Preparation and Analysis Plan $\ldots \ldots \ldots \ldots \ldots \ldots$ A-52

A-21 Ash Sample Preparation and Analysis Plan $\ldots \ldots \ldots \ldots \ldots \ldots$ A-59

A-22 Liquid Sample Preparation and Analysis Plan $\ldots \ldots \ldots \ldots \ldots \ldots \ldots$ A-62 


\section{APPENDIX A: SAMPLE COLLECTION, PRETREATMENT, AND ANALYTICAL PROCEDURES}

This appendix describes in detail the procedures Radian used during the HAPs testing at Plant Tidd to collect, handle, and analyze each process stream sample. An overview of the gas, solid, and liquid sample collection and analysis performed for this project is presented in Tables A-1, A-2, and A-3. Where analyte groups such as "metals" or "semivolatile organics" are referenced, a complete list of the target analytes is provided in Tables A-4 through A-6.

Radian used established sampling and analytical methods wherever possible to provide comparable and useable data. Modifications or adaptations to these methods are noted and described appropriately. All deviations from the procedures outlined in the test plan are discussed.

\section{Gas Streams}

Gas stream samples were collected at the ESP inlet and outlet and APF inlet and outlet ducts. Samples from each of these streams were analyzed for particulate loading, metals, acid gases (anions), ammonia and cyanide, formaldehyde, volatile organics, semivolatile organics, and dioxins/furans. Particle size distribution (PSD) measurements were performed at the ESP : inlet and outlet only, and samples for hexavalent chromium emissions were collected only at the ESP outlet.

Gas sampling at the APF inlet and outlet ducts required a fixed sampling probe because of the high process gas temperature and pressure. Consequently, the APF inlet and outlet gas 
Table A-1

Field Sampling Completed for Gas Streams

\begin{tabular}{|c|c|c|c|c|c|c|c|}
\hline Analysis & $\begin{array}{c}\text { ESP } \\
\text { Inlet } \\
\end{array}$ & $\begin{array}{c}\text { ESP } \\
\text { Outlet }\end{array}$ & $\begin{array}{l}\text { APF } \\
\text { Inlet }\end{array}$ & $\begin{array}{l}\text { APF } \\
\text { Outlet }\end{array}$ & $\begin{array}{c}\text { Field } \\
\text { Blanks }^{\mathbf{a}}\end{array}$ & $\begin{array}{l}\text { Media } \\
\text { Blanks }^{b}\end{array}$ & $\begin{array}{l}\text { PE Audit } \\
\text { Samples }\end{array}$ \\
\hline Particulate Loading & $3 / 3^{c}$ & $3 / 3$ & $3 / 3$ & $3 / 3$ & $2 / 2$ & $1 / 1$ & $1 / 1$ \\
\hline Metals ${ }^{d}$ & $3 / 3$ & $3 / 3$ & $3 / 3$ & $3 / 3$ & $2 / 2$ & $1 / 1$ & $1 / 1$ \\
\hline Anions $^{\mathrm{d}}$ & $3 / 3$ & $3 / 3$ & $3 / 3$ & $3 / 3$ & $2 / 2$ & $1 / 1$ & $1 / 1$ \\
\hline Ammonia/Cyanide ${ }^{e}$ & $3 / 3$ & $3 / 3$ & $3 / 3$ & $3 / 3$ & $2 / 2$ & $1 / 1$ & $1 / 1$ \\
\hline Formaldehyde ${ }^{e}$ & $3 / 3$ & $3 / 3$ & $3 / 3$ & $3 / 3$ & $2 / 2$ & $1 / 1$ & - \\
\hline Volatile Organics ${ }^{c}$ & $6 / 6^{f}$ & $6 / 6^{f}$ & $6 / 6^{f}$ & $6 / 6^{f}$ & $12 / 12^{8}$ & $1 / 1$ & - \\
\hline Semivolatile Organics $^{d}$ & $3 / 3$ & $3 / 3$ & $3 / 3$ & $3 / 3$ & $2 / 2$ & $1 / 1$ & - \\
\hline Dioxins/Furans & $3 / 3^{h}$ & $3 / 3^{h}$ & $3^{h} / 3$ & $3 / 3^{d}$ & $2 / 2$ & $1 / 1$ & - \\
\hline Particle Size Distribution & $3 / 3$ & $3 / 3$ & - & - & - & $1 / 1$ & - \\
\hline Hexavalent Chromium ${ }^{\mathrm{h}}$ & - & $3 / 3$ & - & - & $1 / 1$ & $1 / 1$ & $1 / 1$ \\
\hline
\end{tabular}

"A field blank is collected at the ESP inlet and at the APF inlet to assess the effect of sample handling at these two locations.

bedia blanks refer to prepared reagents for impinger solutions, blank VOST tubes, XAD resin cartridges, and blank filters.

c Samples planned/samples completed.

d Both particulate and vapor phases analyzed, separately.

- Vapor phase analysis only.

f Two 20-L samples collected per run.

$g$ One field blank collected per location per run.

h Particulate and vapor phases combined for single analysis. 
Table A-2

Field Sampling Completed for Coal, Sorbent, and Service Water

\begin{tabular}{|c|c|c|c|c|c|c|c|c|c|c|}
\hline \multirow[b]{2}{*}{ Analysis } & $\begin{array}{l}\text { Raw } \\
\text { Coal }^{\mathrm{a}}\end{array}$ & \multicolumn{3}{|c|}{ Coal Paste } & \multicolumn{3}{|c|}{ Sorbent (Dolomite) } & \multicolumn{3}{|c|}{ Service Water } \\
\hline & $\begin{array}{c}\text { Field } \\
\text { Samples }\end{array}$ & $\begin{array}{c}\text { Field } \\
\text { Samples }\end{array}$ & $\begin{array}{c}\text { Field } \\
\text { Duplicates }\end{array}$ & $\begin{array}{c}\text { PE } \\
\text { Audit } \\
\text { Samples }\end{array}$ & $\begin{array}{c}\text { Field } \\
\text { Samples }\end{array}$ & $\begin{array}{c}\text { Field } \\
\text { Duplicates }\end{array}$ & $\begin{array}{c}\text { PE } \\
\text { Audit } \\
\text { Samples }\end{array}$ & $\begin{array}{c}\text { Field } \\
\text { Samples }\end{array}$ & $\begin{array}{c}\text { Field } \\
\text { Duplicates }\end{array}$ & $\begin{array}{c}\text { PE } \\
\text { Audit } \\
\text { Samples }\end{array}$ \\
\hline Ultimate/Proximate/HHV & $1 / 1^{b}$ & $3 / 3$ & $1 / 1$ & $1 / 1$ & - & - & $\overline{-}$ & - & - & - \\
\hline Metals & $1 / 1$ & $3 / 3$ & $1 / 1$ & $1 / 1$ & $3 / 3$ & $1 / 1$ & $1 / 1$ & $3 / 3$ & $1 / 1$ & $1 / 1$. \\
\hline Anions . & $1 / 1$ & $3 / 3$ & $1 / 1$ & $1 / 1$ & $3 / 3$ & $i / 1$ & $1 / 1$ & $3 / 3$ & $1 / 1$ & $1 / 1$ \\
\hline Radionuclides & $1 / 1$ & $3 / 3$ & $1 / 1$ & - & - & - & -. & - & - & - \\
\hline$\%$ Moisture & $1 / 1$ & $3 / 3$ & $1 / 1$ & -- & $3 / 3$ & $1 / 1$ & $\cdots$ & - & - & - \\
\hline
\end{tabular}

- Raw coal samples held for possible analysis pending data quality assessment of coal paste results.

b Samples planned/samples completed. 
$\$$ Table A-3

Field Sampling Completed for Ash Samples

\begin{tabular}{|c|c|c|c|c|c|c|c|c|c|}
\hline \multirow[b]{2}{*}{ Analysis } & \multicolumn{2}{|c|}{ Bed Ash } & \multicolumn{2}{|c|}{ Primary Cyclone Ash } & \multicolumn{2}{|c|}{$\begin{array}{c}\text { ESP Ash } \\
\text { (4 Hoppers) }\end{array}$} & \multicolumn{2}{|c|}{ APF Ash } & \multirow[b]{2}{*}{$\begin{array}{l}\text { QC Audit } \\
\text { Samples }\end{array}$} \\
\hline & $\begin{array}{c}\text { Field } \\
\text { Samples }\end{array}$ & $\begin{array}{c}\text { Field } \\
\text { Duplicates }\end{array}$ & $\begin{array}{c}\text { Field } \\
\text { Samples }\end{array}$ & $\begin{array}{c}\text { Field } \\
\text { Duplicates }\end{array}$ & $\begin{array}{c}\text { Field } \\
\text { Samples }\end{array}$ & $\begin{array}{c}\text { Field } \\
\text { Duplicates }\end{array}$ & $\begin{array}{c}\text { Field } \\
\text { Samples }\end{array}$ & $\begin{array}{c}\text { Field } \\
\text { Duplicates }\end{array}$ & \\
\hline Metals & $3 / 3^{a}$ & $1 / 1$ & $3 / 3$ & $1 / 1$ & $3 / 3^{b}$ & $1 / 1$ & $3 / 3$ & $1 / 1$ & $1 / 1$ \\
\hline Anions & $3 / 3$ & $1 / 1$ & $3 / 3$ & $1 / 1$ & $3 / 3^{b}$ & $1 / 1$ & $3 / 3$ & $1 / 1$ & $1 / 1$ \\
\hline Radionuclides & $3 / 3$ & $1 / 1$ & $3 / 3$ & $1 / 1$ & $3 / 3^{b}$ & $1 / 1$ & $3 / 3$ & $1 / 1$ & - \\
\hline Carbon & $3 / 3$ & $1 / 1$ & $3 / 3$ & $1 / 1$ & $3 / 3^{b}$ & $1 / 1$ & $3 / 3$ & $1 / 1$ & - \\
\hline Semivolatile Organics & $3 / 3$ & $1 / 1$ & $3 / 3$ & $1 / 1$ & $3 / 3^{b}$ & $1 / 1$ & $3 / 3$ & $1 / 1$ & $\cdots$ \\
\hline Dioxins/Furans & 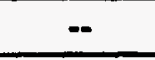 & $\cdots$ & $3 / 3$ & $1 / 1$ & $3 / 3^{6}$ & $1 / 1$ & $3 / 3$ & $1 / 1$ & $-\infty$ \\
\hline Particle Size Distribution & $-\infty$ & -. & - & -- & $12 / 8^{c}$ & $4 / 4$ & $-\infty$ & - & - \\
\hline
\end{tabular}

a Samples planned/samples completed.

${ }^{b}$ ESP fly ash composite samples.

${ }^{c}$ ESP Fields 1 and 2 were sampled in triplicate; Fields $1-4$ were sampled in duplicate during final run. 
Table A-4

Analyte List for Inorganic Parameters

\begin{tabular}{|c|c|}
\hline Trace Elements & Major Elements \\
\hline Antimony ${ }^{\mathrm{a}}$ & Aluminum \\
\hline Arsenic $^{2}$ & Calcium \\
\hline Barium ${ }^{a}$ & Iron \\
\hline Beryllium ${ }^{a}$ & Magnesium \\
\hline Boron & Potassium \\
\hline Cadmiuma & Sodium \\
\hline Hexavalent Chromium ${ }^{b}$ & Titanium \\
\hline Chromium, total ${ }^{\mathfrak{a}}$ & Ultimate/Proximate Parameters \\
\hline Cobalt ${ }^{2}$ & Carbon \\
\hline Coppera & Hydrogen \\
\hline Lead $^{a}$ & Nitrogen \\
\hline Manganese $^{a}$ & Sulfur \\
\hline Mercury ${ }^{2}$ & Ash \\
\hline Molybdenuma & Volatile Matter \\
\hline Nickel $^{a}$ & Fixed Carbon \\
\hline \multicolumn{2}{|l|}{ Selenium ${ }^{a}$} \\
\hline \multicolumn{2}{|l|}{ Silver } \\
\hline \multicolumn{2}{|l|}{ Vanadium $^{a}$} \\
\hline \multicolumn{2}{|l|}{ Ionic Species } \\
\hline \multicolumn{2}{|l|}{ Chloride ( $\mathrm{Cl}$ ) } \\
\hline \multicolumn{2}{|l|}{ Fluoride $(\mathrm{F})$} \\
\hline \multicolumn{2}{|l|}{ Phosphates (as Total P) } \\
\hline \multicolumn{2}{|l|}{ Sulfates $\left(\mathrm{SO}_{4}^{-2}\right)$} \\
\hline \multicolumn{2}{|l|}{ Ammonia } \\
\hline Cyanide & \\
\hline
\end{tabular}

These elements were analyzed by ICP-MS in the gas impinger samples.

${ }^{b}$ Hexavalent chromium in ESP outlet flue gas only.

c Phosphorus is determined by ICP-AES in all samples except service uater where phosphorus is measured as total phosphate. 
Table A-5

\section{Analyte List for Organic Parameters}

\begin{tabular}{|c|c|c|}
\hline Volatile Organics (Method 8240) & \multicolumn{2}{|c|}{ Semivolatile Organics (Method 8270/CARB 429 } \\
\hline Benzene & Acenaphthene ${ }^{b}$ & 2,4-Dimethylphenol \\
\hline Bromoform & Acenaphthylene $\mathrm{b}^{\mathrm{b}}$ & Dimethylphthalate \\
\hline Carbon Disulfide & Acetophenone & 4,6-Dinitro-2-methylphenol \\
\hline Carbon Tetrachloride & 4-Aminobiphenyl & 2,4-Dinitrophenol \\
\hline Chlorobenzene & Aniline & 2,4-Dinitrotoluene \\
\hline Chloroform & Anthracene ${ }^{b}$ & 2,6-Dinitrotoluene \\
\hline 1,4-Dichlorobenzene & Benzidine & bis(2-Ethylhexyl)phthalate \\
\hline cis-1,3-Dichloropropene & Benzo(a)anthracene ${ }^{b}$ & Fluoranthene ${ }^{b}$ \\
\hline trans-1,3-Dichloropropene & Benzo(a)pyrene ${ }^{b}$ & Fluorene $^{b}$ \\
\hline Ethyl Benzene & Benzo(b)fluoranthene ${ }^{\mathrm{b}}$ & Hexachlorobenzene \\
\hline Ethyl Chloride (Chloroethane) & Benzo $(g, h, i)$ perylene $^{\mathrm{b}}$ & Hexachlorobutadiene \\
\hline Ethylene Dichloride (1,2-Dichloroethane) & Benzo(k)fluoranthene ${ }^{b}$ & Hexachlorocyclopentadiene \\
\hline Ethylidene Dichloride (1,1-Dichloroethane) & Benzoic Acid & Hexachloroethane \\
\hline Methyl Bromide (Bromomethane) & Benzyl Alcohol & Indeno(1,2,3-cd)pyrene ${ }^{\mathrm{b}}$ \\
\hline Methyl Chloride (Chloromethane) & 4-Bromophenyl Phenyl Ether & Isophorone \\
\hline Methyl Chloroform (1,1,1-Trichloroethane) & Butylbenzylphthalate & 2-Methylnaphthalene ${ }^{b}$ \\
\hline Methyl Ethyl Ketone (2-Butanone) & 4-Chloro-3-Methylphenol & 2-Methylphenol (o-cresol) \\
\hline Methylene Chloride (Dichloromethane) & p-Chloroaniline & 4-Methylphenol (p-cresol) \\
\hline Propylene Dichloride (1,2-Dichloropropane) & bis(2-Chloroethoxy)methane & N-Nitrosodimethylamine \\
\hline Styrene & bis(2-Chloroethyl)ether & N-Nitrosodiphenylamine \\
\hline 1,1,2,2-Tetrachloroethane & bis(2-Chloroisopropyl)ether & \begin{tabular}{|l|} 
N-Nitrosopropylamine \\
\end{tabular} \\
\hline Tetrachloroethene & 2-Chloronaphthalene ${ }^{b}$ & Naphthalene $^{\mathrm{b}}$ \\
\hline Toluene & 2-Chlorophenol & 2-Nitroaniline \\
\hline 1,1,2-Trichloroethane & 4-Chlorophenyl Phenyl Ether & 3-Nitroaniline \\
\hline Trichloroethene & Chrysene $^{\mathrm{b}}$ & 4-Nitroaniline \\
\hline Vinyl Acetate & Di-n-octylphthalate & Nitrobenzene \\
\hline Vinyl Chloride & Dibenz(a,h)anthracene ${ }^{b}$ & 2-Nitrophenol \\
\hline Vinylidene Chloride (1,1-Dichloroethene) & \begin{tabular}{|l|} 
Dibenzofuran \\
\end{tabular} & 4-Nitrophenol \\
\hline $\mathrm{m}, \mathrm{p}$-Xylene & Dibutylphthalate & Pentachloronitrobenzene \\
\hline 0 -Xylene & 1,2-Dichlorobenzene & \begin{tabular}{|l|} 
Pentachlorophenol \\
\end{tabular} \\
\hline 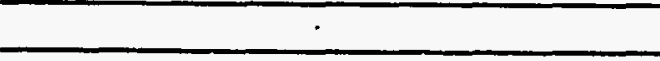 & 1,3-Dichlorobenzene & Phenanthrene $^{b}$ \\
\hline & 1,4-Dichlorobenzene & \begin{tabular}{|l|} 
Phenol \\
\end{tabular} \\
\hline & 3,3-Dichlorobenzidine & Pyrene $^{b}$ \\
\hline & 2,4-Dichlorophenol & 1,2,4-Trichlorobenzene \\
\hline & Diethylphthalate & 2,4,5-Trichlorophenol \\
\hline & p-Dimethylaminoazobenzene & 2,4,6-Trichlorophenol \\
\hline
\end{tabular}

a These are the volatile organic compounds detected by VOST (Method 8240) that are listed in the Clean Air Act list of hazardous air pollutants.

b These semivolatile organic compounds were analyzed in the gas samples by CARB Method 429 using high resolution GC/MS. 
Table A-6

List of Radionuclides

\begin{tabular}{||l||}
\hline \multicolumn{1}{|c|}{ Gamma Emitters } \\
\hline Actinium-228 @ $338 \mathrm{KeV}$ \\
\hline Actinium-228 @ $911 \mathrm{KeV}$ \\
\hline Actinium-228 @ 968 KeV \\
\hline Bismuth-212 @ $727 \mathrm{KeV}$ \\
\hline Bismuth-214 @ $609.4 \mathrm{KeV}$ \\
\hline Bismuth-214 @ $1120.4 \mathrm{KeV}$ \\
\hline Bismuth-214 @ $1764.7 \mathrm{KeV}$ \\
\hline Lead-210 @ 46 KeV \\
\hline Lead-212 @ 238 KeV \\
\hline Lead-214 @ 295.2 KeV \\
\hline Lead-214 @ 352.0 KeV \\
\hline Potassium-40 @ $1460 \mathrm{KeV}$ \\
\hline Radium-226 @ $186.0 \mathrm{KeV}$ \\
\hline Thallium-208 @ 583 KeV \\
\hline Thallium-208 @ 860 KeV \\
\hline Thorium-234 @ $63.3 \mathrm{KeV}$ \\
\hline Thorium-234 @ 92.6 KeV \\
\hline Uranium-235 @ 143 KeV \\
\hline
\end{tabular}


sampling approach varied from the standard EPA Method $5^{1}$ sampling approach used at the ESP inlet and outlet ducts. The difference, however, was limited to the collection of particulate matter. In the fixed probe system, hot-gas filters were used to collect particulate matter. Multiple gas samples were then collected for vapor-phase species from a header downstream of the filter. The Method 5 approach specifies a single filter for each independent sampling train.

A schematic of the fixed probe sampling system designed for the Plant Tidd APF unit is shown in Figure A-1. The system was designed to sample the process gas isokinetically at a single point in the center of the duct. Gas cooling was accomplished by thermal convection through the sample line. Sample gas was cooled from $1350^{\circ} \mathrm{F}$ to approximately $600^{\circ} \mathrm{F}$ to safely operate the isolation ball valve. A flow orifice and sample control valve downstream of the filter were used to maintain isokinetic sampling rates.

To keep volatile species from condensing in the sample line downstream of the filter, the filter holder and all downstream components were heat traced and kept at or above the temperature of the gas entering the filter holder. The system was designed to allow gas samples to cool only after the gas entered the recoverable quartz tubing portion of the sampling train. However, the quartz tubing broke repeatedly during the initial test runs because the ball joint could not withstand the thermal stresses at $600^{\circ} \mathrm{F}$. To solve this problem, the heat tracing tape was removed from the sample line downstream of the orifice meter to allow the gas to cool slightly. Skin temperatures at the header sample valves were typically $250-350^{\circ} \mathrm{F}$ after this modification. Because most of the quartz tubes were broken during the initial test, subsequent tests at the APF inlet were conducted using Teflon ${ }^{\circledast}$ tubing instead of quartz. This modification is not judged to have any affect on the gas samples. The tubing that connects the impinger train to the fixed probe sample header was directly comparable to the sampling train components found downstream of the heated filter in the EPA Method 5 sampling train and was rinsed and recovered accordingly. 


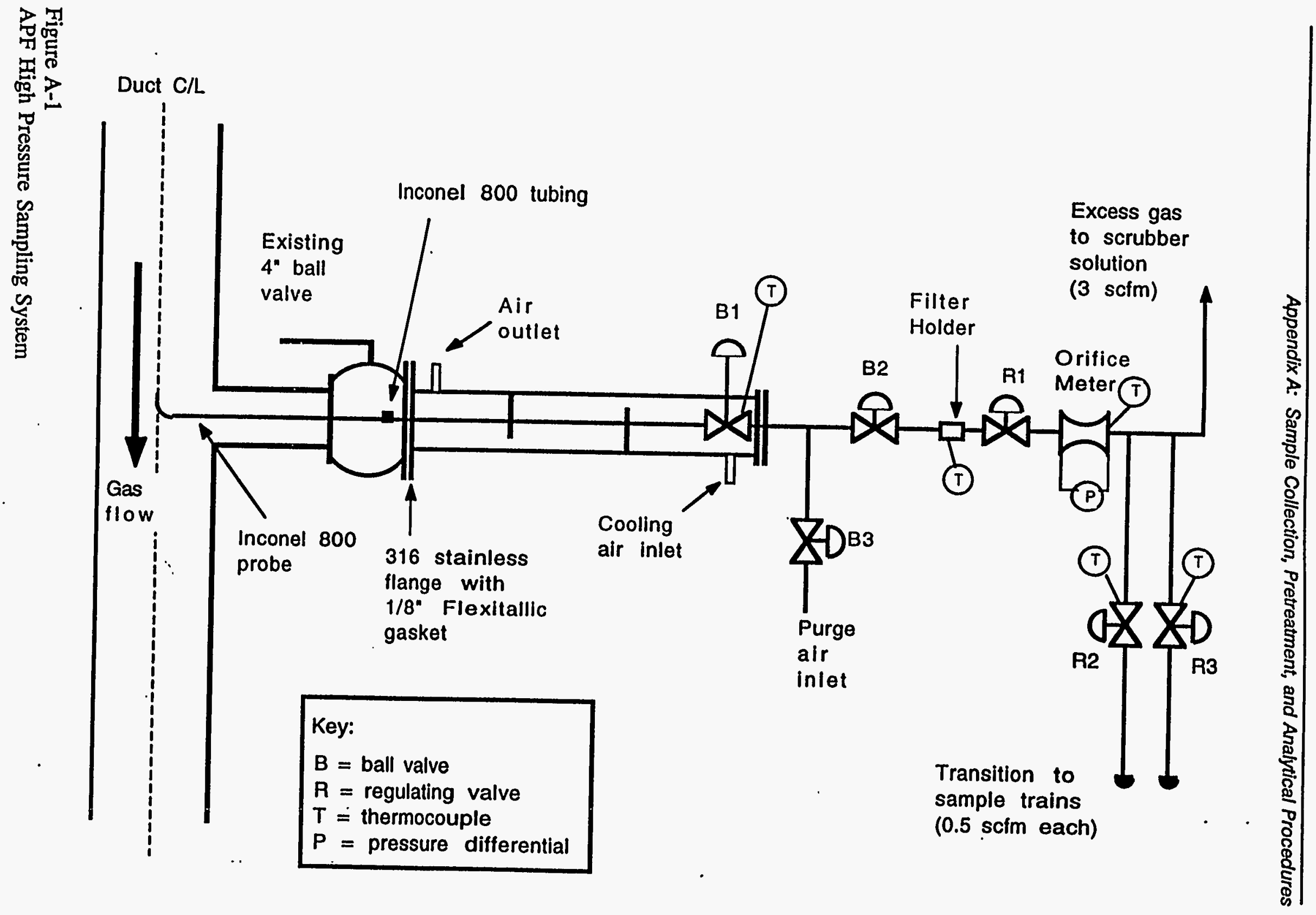


Appendix A: Sample Collection, Pretreatment, and Analytical Procedures

\section{Particulate Loading}

EPA Reference Method 5 was used to determine the particulate loading at the ESP inlet and outlet sampling locations. This method was performed in conjunction with the multi-metals sampling train to provide compatible particulate loading and particulate metals concentration data. Although not specified in Method 5 for determining particulate loading, quartz-fiber filters were used in place of glass-fiber filters to reduce background trace element contamination. Samples were collected isokinetically at multiple points across the duct as specified by EPA Reference Methods $1^{2}$ and $2 .^{3}$

At the APF inlet sampling location, the fixed probe system equipped with an allundumceramic thimble filter was used to collect isokinetic samples from a single point in the center of the duct. A $47 \mathrm{~mm}$ quartz-fiber filter in a high pressure Gelman filter holder was used in place of the allundum thimble at the APF outlet. Breakthrough of particulate occurred across the thimble filter during initial tests at the APF inlet because of the higher than expected particulate loading. To solve this problem, a second thimble filter assembly was installed in series and filters were changed out approximately every two hours to avoid exceeding the filter capacity. On Days 3 and 4, a third backup filter (high-pressure Gelman) was added downstream of the two thimble filters. The gas flow through the filter was determined by taking pressure differential readings and gas temperature readings across the flow orifice. The total gas flow through the filter was calculated using the orifice diameter, gas temperature and pressure at the orifice, and the sampling time.

Filters from both systems were recovered and weighed to determine the particulate mass collected. At the ESP sampling locations, particulate matter was also rinsed and recovered from the sampling nozzle and probe. Rinsing of the fixed high-pressure sampling probe was not feasible. Any wall losses or solids deposition inside the probe were assumed to be insignificant relative to the overall sample mass collected. 


\section{Particulate- and Vapor-Phase Metals}

Collection of particulate- and vapor-phase metals was performed in conjunction with the particulate loading runs using the procedures detailed in EPA Draft Method $29.4^{4}$ Method 29 is similar to Method 5 with a few sample train modifications. Method 29 requires replacement of the stainless steel nozzle and probe liner used in Method 5 with glass components. The particulate material was collected on quartz fiber filters, replacing the standard glass fiber filters normally used with Method 5.

At the APF inlet and outlet, the sampling probe was constructed of a high chromium-nickel alloy (Inconel 800) for strength and corrosion resistance a the high process temperature. The use of probe materials other than glass or quartz is a modification to Method 29 specific to the APF inlet and outlet sample locations.

Vapor-phase metals were collected in a series of impinger solutions. The first two impingers contained a dilute nitric acid and hydrogen peroxide $\left(\mathrm{HNO}_{3} / \mathrm{H}_{2} \mathrm{O}_{2}\right)$ solution. The third impinger was empty. The next two impingers contained acidic potassium permanganate . $\left(\mathrm{KMnO}_{4} / \mathrm{H}_{2} \mathrm{SO}_{4}\right)$ solution for mercury collection. These impingers were followed by one dry impinger, and an impinger filled with silica gel. Approximately 90 to 100 dry standard cubic feet (dscf) of gas were collected isokinetically.

A description of the sampling train and sample fraction recovery for the multi-metals sampling train is presented in Table A-7. The sample fractions generated by the multi-metals sampling train and an overview of the sample handling process are shown in Figures A-2 through A-7. These particulate- and vapor-phase sample fractions were prepared and analyzed separately for the elements listed in Table A-4.

Particulate Phase. The filter samples were desiccated and weighed to a constant weight (defined as successive weight determinations within $0.5 \mathrm{mg}$ at 6 -hour intervals). For samples collected at the ESP, the acetone probe and nozzle rinses (PNR) were evaporated, desiccated, and also weighed to a constant weight. For the ESP outlet, the nitric acid PNR was added to 
Table A-7

Description and Recovery of Method 29 (Multi-Metals) Sampling Train

\begin{tabular}{|c|c|c|c|c|}
\hline Component & Contents & Recovery" & Container & $\begin{array}{l}\text { Preparation } \\
\text { \& Analysis }\end{array}$ \\
\hline $\begin{array}{l}\text { Probe Nozzle Rinse and front } \\
\text { half of filter holder rinse }\end{array}$ & NA & $\begin{array}{l}\text { Rinse probe, nozzle, and front half of filter holder } \\
\text { with acetone into sample container. }\end{array}$ & $500 \mathrm{~mL}$ amber glass bottle & $\begin{array}{l}\text { See Figures } A-2 \\
\text { and A-3 }\end{array}$ \\
\hline $\begin{array}{l}\begin{array}{l}\text { Probe Nozzle Rinse and front } \\
\text { half of filter holder rinse }\end{array} \\
\end{array}$ & NA & $\begin{array}{l}\text { Rinse probe, nozzle, and front half of filter holder } \\
\text { with } 0.1 \mathrm{~N} \mathrm{HNO}_{3} \text { into sample container. }\end{array}$ & $500 \mathrm{~mL}$ amber glass bottle & $\begin{array}{l}\text { See Figures A-2 } \\
\text { and A-3 }\end{array}$ \\
\hline Filter $^{b}$ & Tared quartz filter & Place filter in sample container. & Plastic petri dish & $\begin{array}{l}\text { See Figures A-2 } \\
\text { through A-4 }\end{array}$ \\
\hline Thimblec & Tared thimble ceramic & Place thimble in sample container. & Glass jar & See Figure A-5 \\
\hline Transfer Line Rinsed & NA & $\begin{array}{l}\text { Rinse transfer line with } 0.1 \mathrm{~N} \mathrm{HNO}_{3} \text { into sample } \\
\text { container. }\end{array}$ & \multirow{3}{*}{$\begin{array}{l}\text { Combine transfer line rinse } \\
\text { and Impingers } 1 \text { and } 2 \text { in a } \\
1000 \mathrm{~mL} \text { amber glass bottle }\end{array}$} & \multirow[t]{3}{*}{ See Figure A-6 } \\
\hline Impinger \#1 & $\begin{array}{l}5 \% \text { nitric acid in } 10 \% \\
\text { hydrogen peroxide }(200 \mathrm{~mL})\end{array}$ & $\begin{array}{l}\text { Recover impinger solution, then rinse impinger and } \\
\text { connecting glassware with } 0.1 \mathrm{~N} \mathrm{HNO}_{3} \text { into sample } \\
\text { container. }\end{array}$ & & \\
\hline Impinger $\$ 2$ & $\begin{array}{l}5 \% \text { nitric acid in } 10 \% \\
\text { hydrogen peroxide }(200 \mathrm{~mL})\end{array}$ & $\begin{array}{l}\text { Recover impinger solution, then rinse impinger } \\
\text { and connecting glassware with } 0.1 \mathrm{~N} \mathrm{HNO}_{3} \text { into sam- } \\
\text { ple container. }\end{array}$ & & \\
\hline Impinger \#3 & Dry & $\begin{array}{l}\text { Recover condensate, then rinse impinger and } \\
\text { connecting glassware with } 0.1 \mathrm{~N} \mathrm{HNO}_{3} \text { into sample } \\
\text { container. }\end{array}$ & \multirow[t]{3}{*}{$\begin{array}{l}\text { Combine Impingers } 3,4 \text {, and } 5 \\
\text { in a } 1000 \mathrm{~mL} \text { amber glass } \\
\text { bottle. }\end{array}$} & \multirow[t]{3}{*}{ See Figure A-7 } \\
\hline Impinger $\# 4$ & $\begin{array}{l}4 \% \text { potassium permanganate in } \\
10 \% \text { sulfuric acid }(200 \mathrm{~mL})\end{array}$ & $\begin{array}{l}\text { Recover impinger solution, then rinse impinger and } \\
\text { connecting glassware with fresh } \mathrm{KMnO}_{4} \text { solution into } \\
\text { sample container. }\end{array}$ & & \\
\hline Impinger \#5 & $\begin{array}{l}4 \% \text { potassium permanganate in } \\
10 \% \text { sulfuric acid }(200 \mathrm{~mL})\end{array}$ & $\begin{array}{l}\text { Recover impinger solution, then rinse impinger with } \\
\text { fresh } \mathrm{KMnO}_{4} \text { solution into sample container. }\end{array}$ & & \\
\hline Impinger $\$ 4$ - Second Rinse & NA & $\begin{array}{l}\text { Rinse impinger with } 8 \mathrm{~N} \mathrm{HCl} \text { into sample container. } \\
\text { Not to exceed } 25 \mathrm{~mL} \mathrm{HCl} \text {. }\end{array}$ & \multirow[t]{2}{*}{$250 \mathrm{~mL}$ amber glass bottle } & \multirow[t]{2}{*}{ See Figure A-7 } \\
\hline Impinger $\# 5$ - Second Rinse & NA & $\begin{array}{l}\text { Rinse impinger with } 8 \mathrm{~N} \mathrm{HCl} \text { into sample container. } \\
\text { Not to exceed } 25 \mathrm{ml} \mathrm{HCl} \text {. }\end{array}$ & & \\
\hline Impinger $\$ 6$ & Silica Gel $(300 \mathrm{~g})$. & Replace when exhausted. & None & None \\
\hline
\end{tabular}

NA = Not applicable.

All impingers were weighed prior to recovery to determine gas sample moisture content by EPA Reference Method 4.

ESP inlet and outlet and APF outlet.

APF inlet only.

d Includes back half of filter holder at ESP inlet and outlet; and gas cooling system at APF inlet and outlet. 


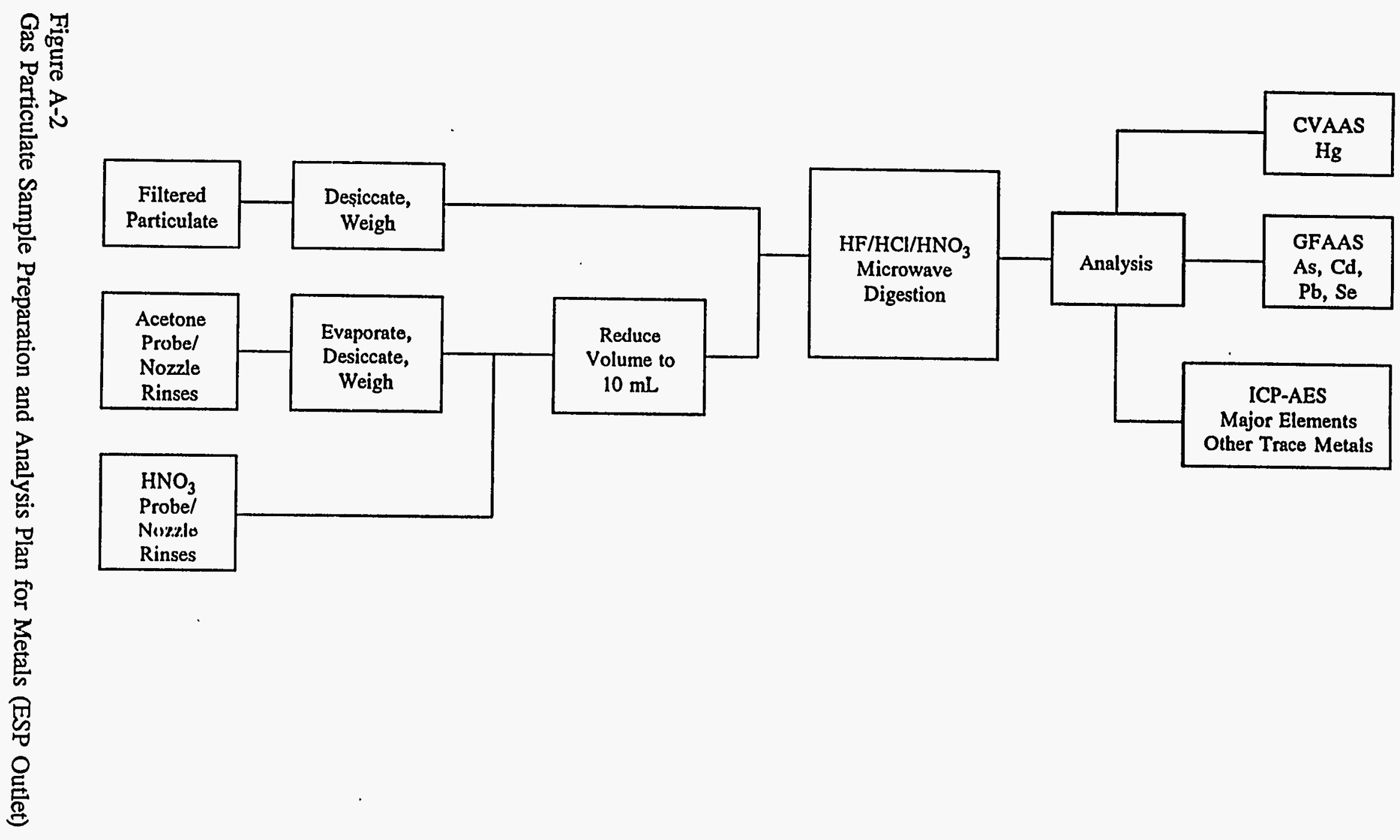




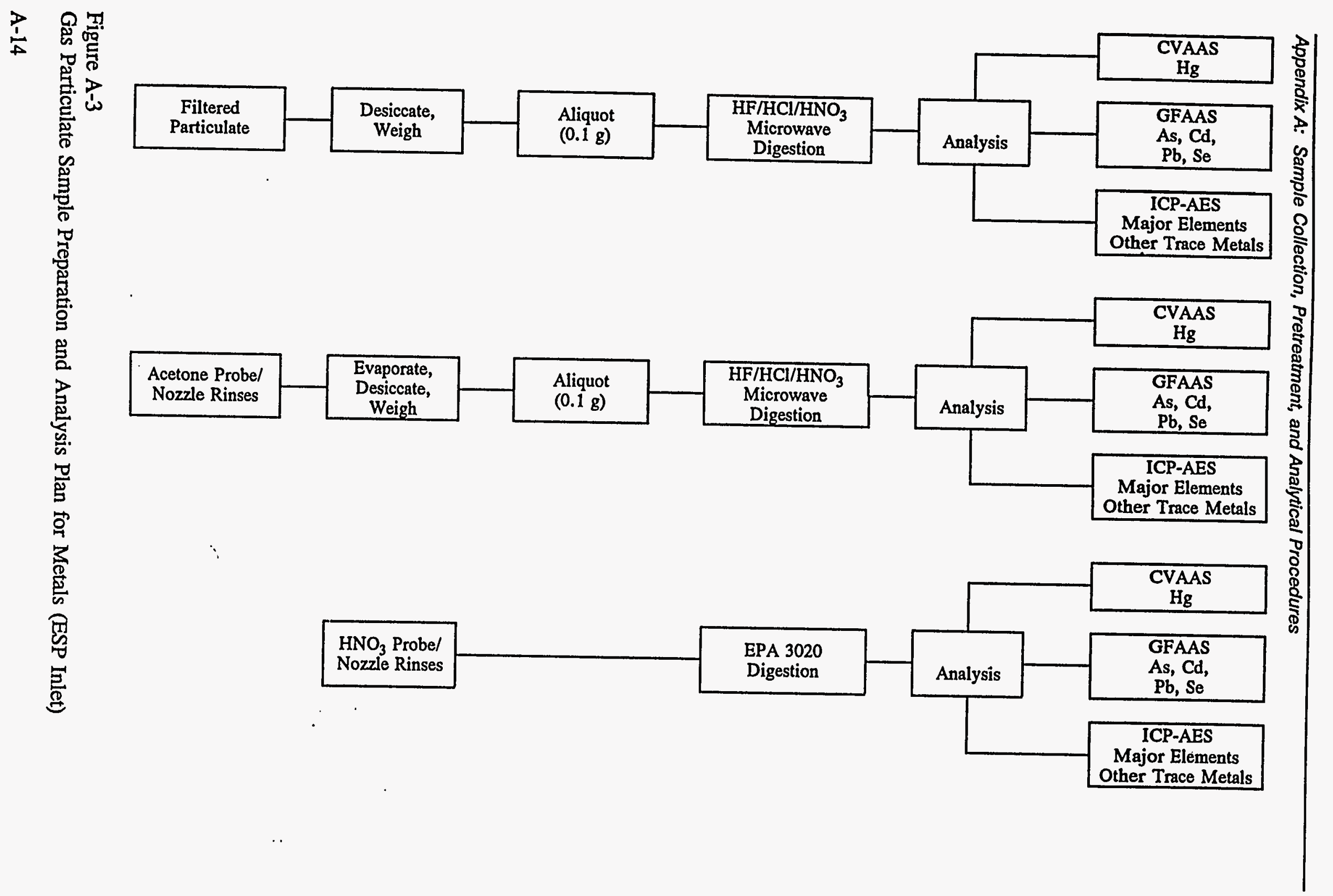




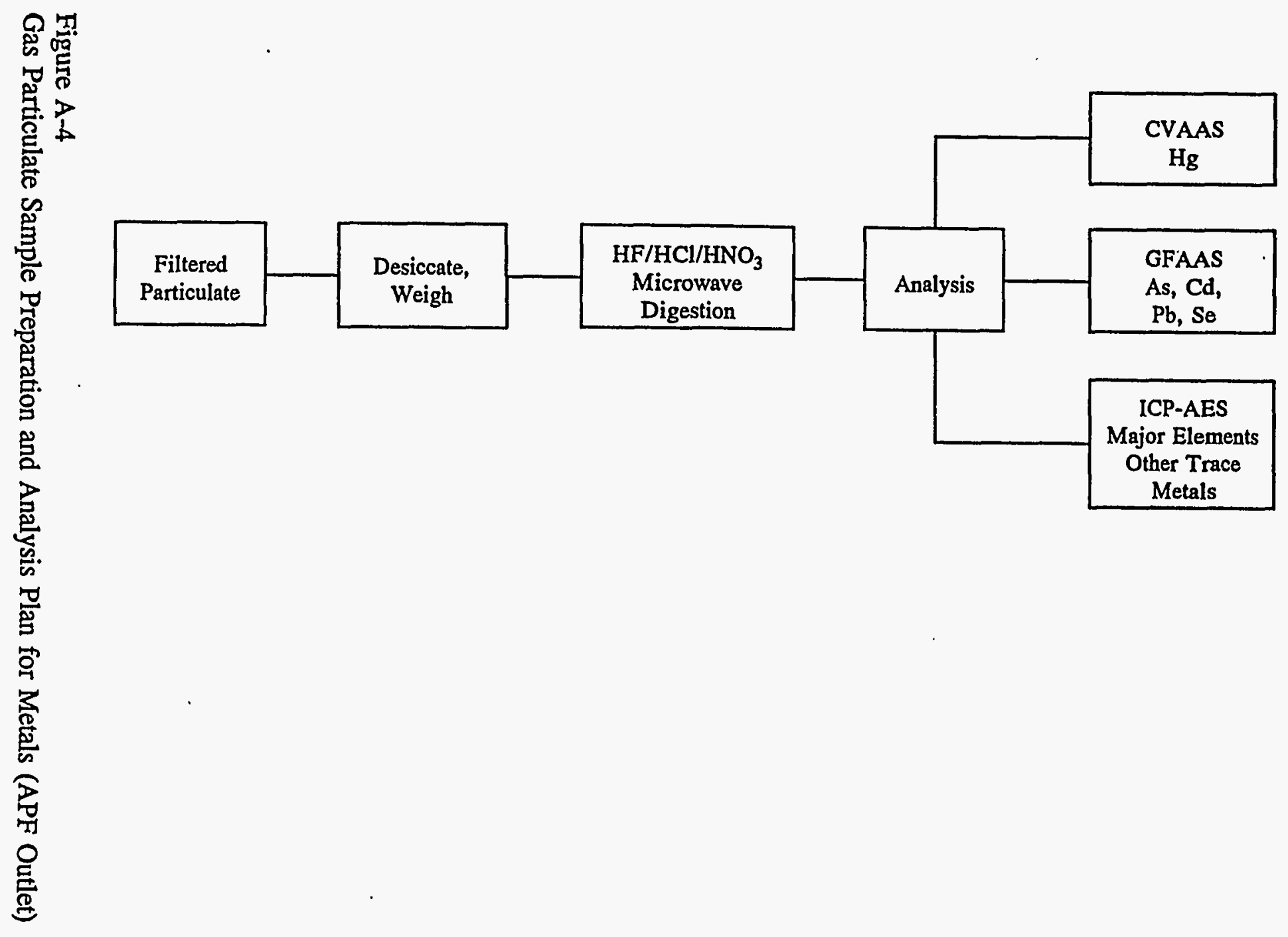

$\frac{p}{4}$ 


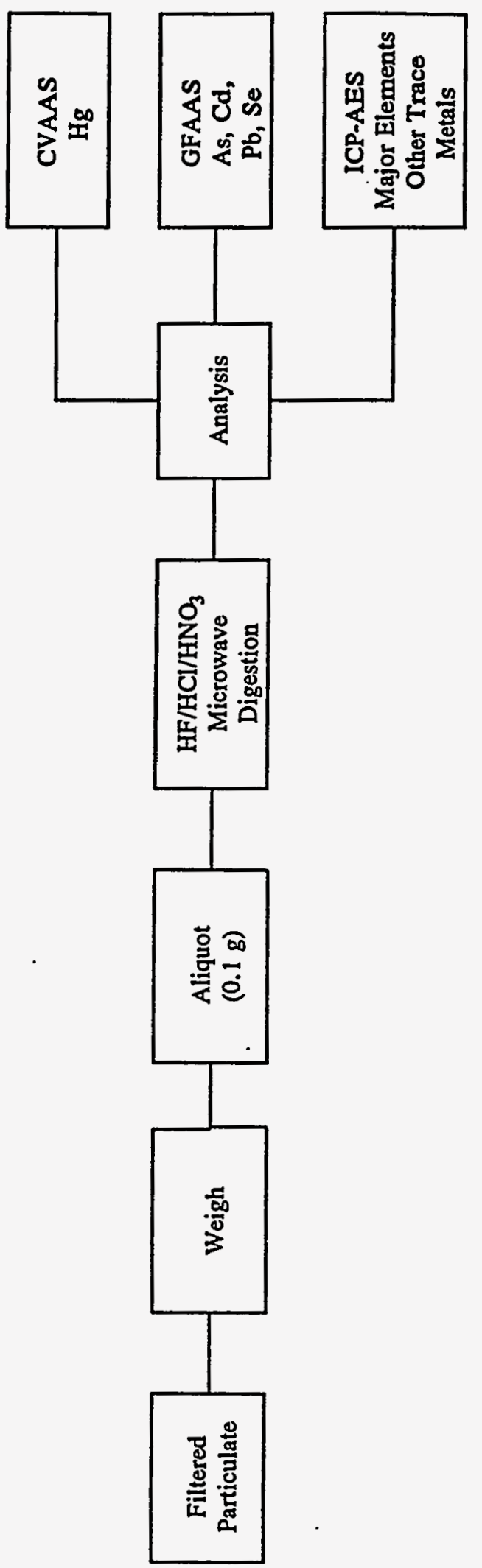

Figure A-5

Gas Particulate Sample Preparation and Analysis Plan for Metals (APF Inlet) A-16 


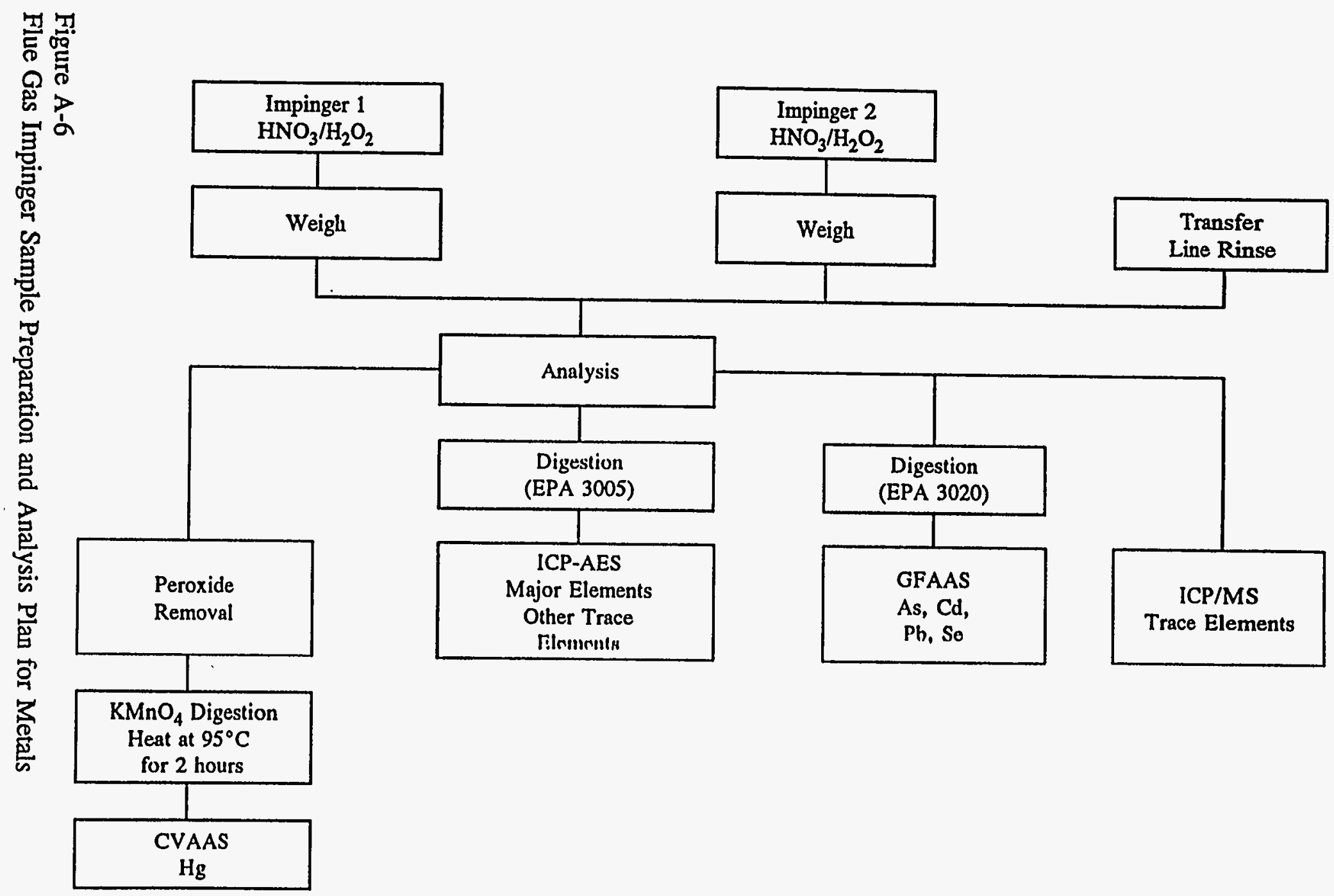




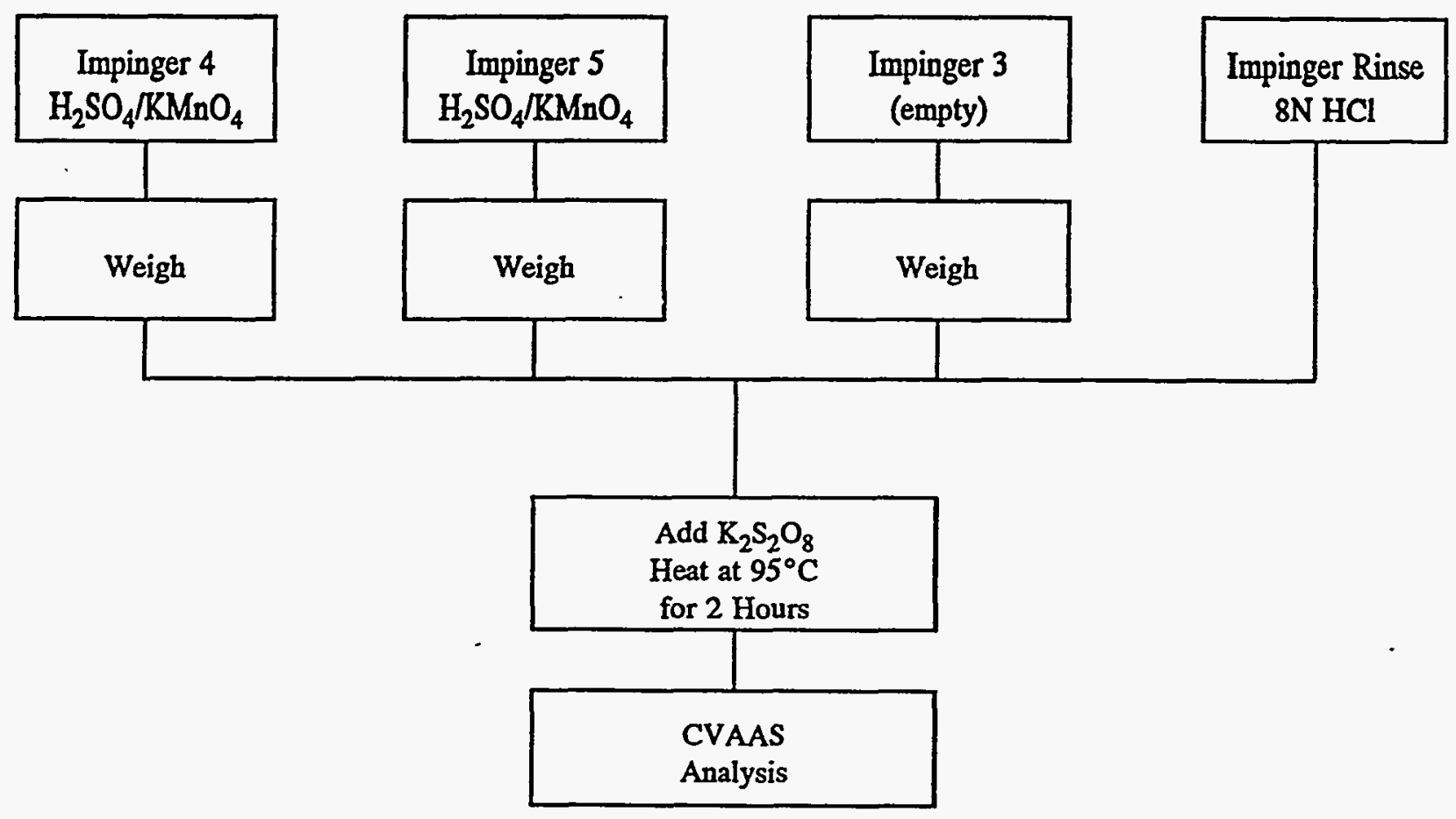

Figure A-7. Flue Gas Impinger Sample Preparation and Analysis Plan for Mercury 
the solids recovered from the acetone PNR, and the volume reduced to $10 \mathrm{~mL}$ by evaporation on a hot plate. This volume was quantitatively transferred, along with the filter, to a microwave-digestion vessel. The total particulate sample from the collected gas was microwave digested ${ }^{5}$ with a mixture of hydrofluoric, hydrochloric, and nitric acids. For the ESP inlet, the nitric acid PNR and the acetone PNR were analyzed separately due to the high mass loadings recovered on the filter and in the acetone PNR. The APF outlet samples were analyzed similarly to the ESP outlet samples, without the presence of probe rinses. The APF inlet particulate was collected and analyzed directly.

The digestates were analyzed for metals (except boron) by a combination of techniques including inductively coupled plasma atomic emission spectroscopy (ICP-AES) ${ }^{6}$ and graphite furnace atomic absorption spectroscopy (GFAAS). ${ }^{7,8,9,10}$ Mercury was determined from an aliquot of the microwave digestate by cold vapor atomic absorption spectroscopy (CVAAS). ${ }^{11}$ Boric acid was added to the digestate to solubilize metal fluorides that precipitate during the digestion. This addition of boric acid makes the analysis of boron in these samples impractical; however, boron was determined in all collected ash samples from the ESP, APF, and cyclone systems as described later.

Vapor Phase. The two $\mathrm{HNO}_{3} / \mathrm{H}_{2} \mathrm{O}_{2}$ impinger samples were combined, digested, and analyzed for metals by ICP-AES and GFAAS. Aliquots of undigested impinger solutions were analyzed by ICP/MS. ${ }^{12}$ A separate aliquot was removed for mercury analysis and the excess peroxide in the sample matrix was eliminated by the addition of solid $\mathrm{KMnO}_{4}$ until a pale pink color persisted. The sample was then digested in $\mathrm{KMnO}_{4} / \mathrm{H}_{2} \mathrm{SO}_{4}$ solution and analyzed for mercury by CVAAS. ${ }^{13}$

The contents of the third impinger, the two $\mathrm{KMnO}_{4} / \mathrm{H}_{2} \mathrm{SO}_{4}$ impingers, and the hydrogen chloride $(\mathrm{HCl})$ impinger rinse sample were combined and an aliquot was digested in $\mathrm{KMnO}_{4} / \mathrm{H}_{2} \mathrm{SO}_{4}$ solution and analyzed for mercury by CVAAS. 


\section{Anions}

The Method 5 train was used to collect vapor phase and particulate samples for acid gas species. Hydrochloric, hydrofluoric, and sulfuric acids along with sulfur dioxide and sulfur trioxide were collected using two impingers each containing $200 \mathrm{~mL}$ of a carbonatel bicarbonate solution containing hydrogen peroxide. Approximately 30-45 dscf of gas was collected at each location.

A description of the sampling train and sample fraction recovery for the Method 5 anions sampling train is presented in Table A-8. The sample fractions generated by the anions/acid gas sampling train and an overview of the sample handling process are shown in Figures A-8 through A-11. The particulate and vapor phases were prepared and analyzed separately for chloride, fluoride, and sulfate.

Particulate Phase. The filter was desiccated and weighed prior to being combined with the PNR. The PNR sample was evaporated, desiccated, and weighed before being combined with the filter sample. The particulate matter was then sonicated with $100 \mathrm{~mL}$ of fresh carbonate/bicarbonate solution. The carbonate solution was analyzed for chloride and sulfate by ion chromatography (IC) $)^{14}$ and fluoride was determined by specific ion electrode (SIE). 15

Vapor Phase. The impinger solutions received from the test site were sent directly to the analytical laboratory for chloride and sulfate analysis by IC, and fluoride analysis by SIE ${ }^{16}$.

\section{Ammonia/Hydrogen Cyanide}

Sample collection for ammonia and hydrogen cyanide in the gas streams was performed in conjunction with the Method 5 anions sampling train. Similarly, gas was extracted isokinetically at a single point in the duct through the anions train filter, then directed to an impinger train. For ammonia collection, $0.1 \mathrm{~N}$ sulfuric acid was placed in the first two impingers of the sampling train. The low $\mathrm{pH}$ of the $\mathrm{H}_{2} \mathrm{SO}_{4}$ solution allowed $\mathrm{HCN}$ to pass 
Table A-8

Description and Recovery of Anions Sampling Train

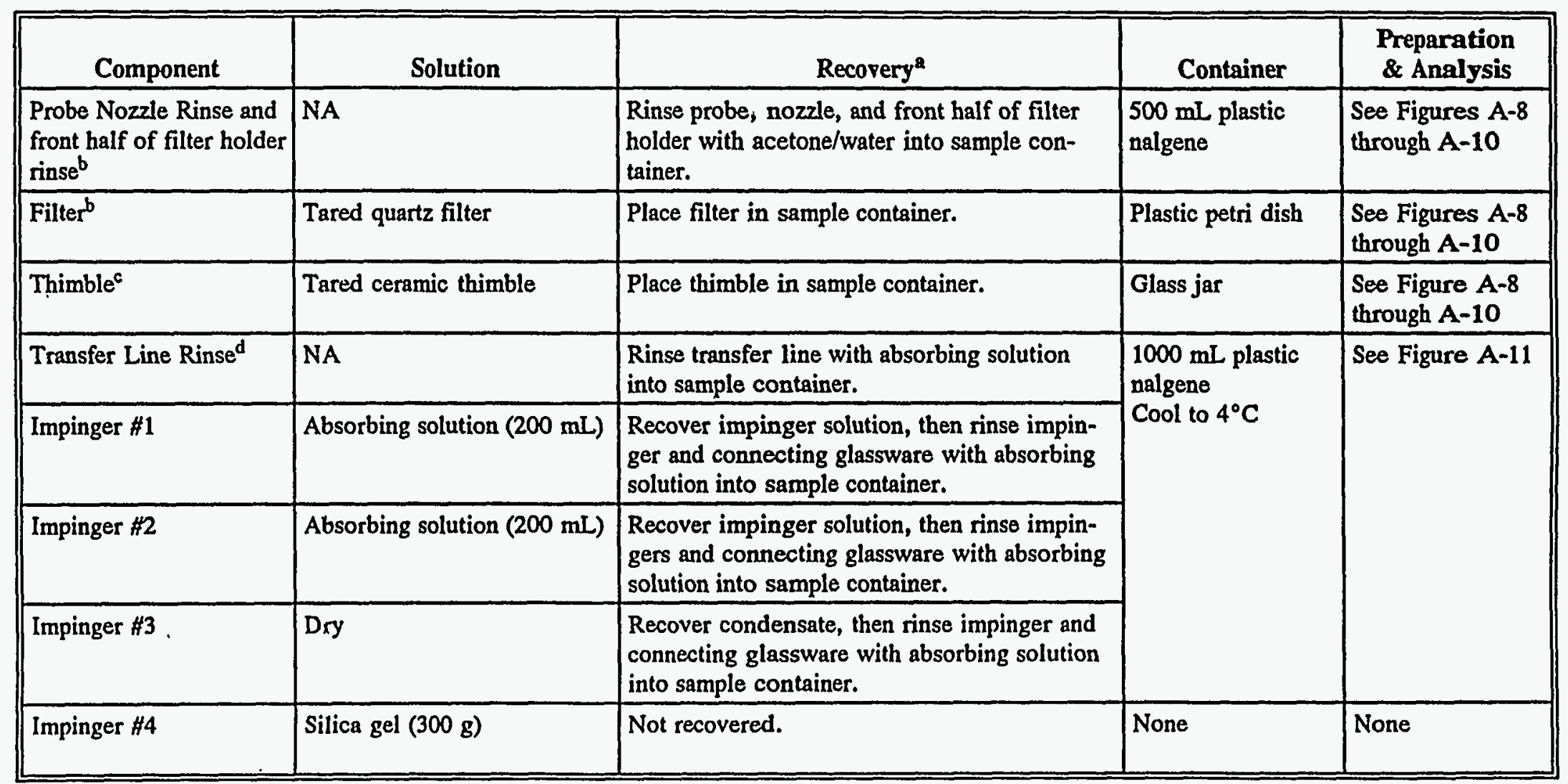

All impingers were weighed prior to recovery.

$\checkmark$ ESP inlet and outlet and APF outlet.

c APF inlet only.

d Includes back half of filter holder at ESP inlet and outlet and gas cooling system at APF inlet and outlet. $\mathrm{NA}=$ Not applicable. 


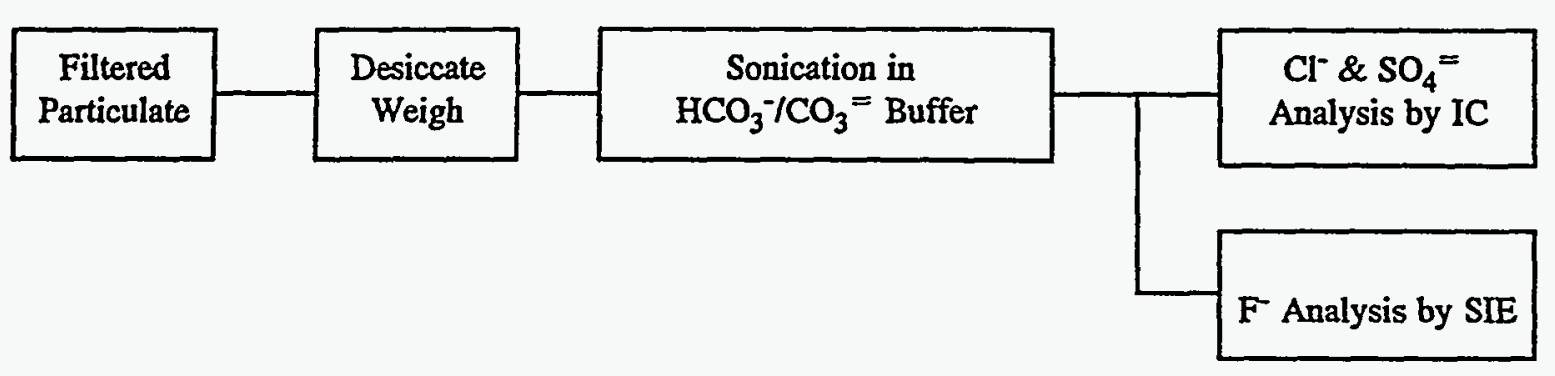

Figure A-8

Gas Particulate Sample Preparation and Analysis Plan for Anions (APF Outlet) 


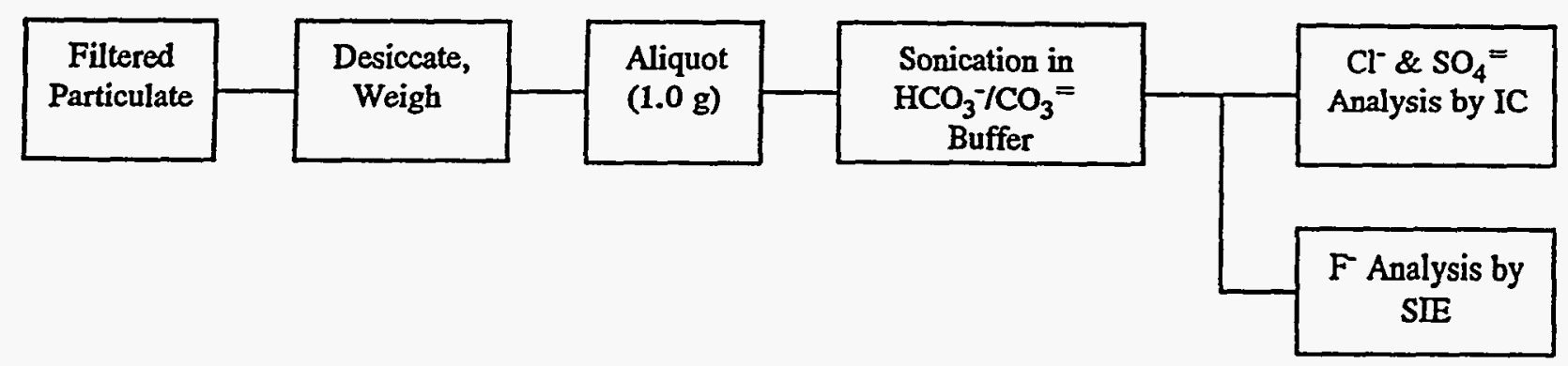

Figure A-9

Gas Particulate Sample Preparation and Analysis Plan for Anions (APF Inlet and ESP Inlet) 


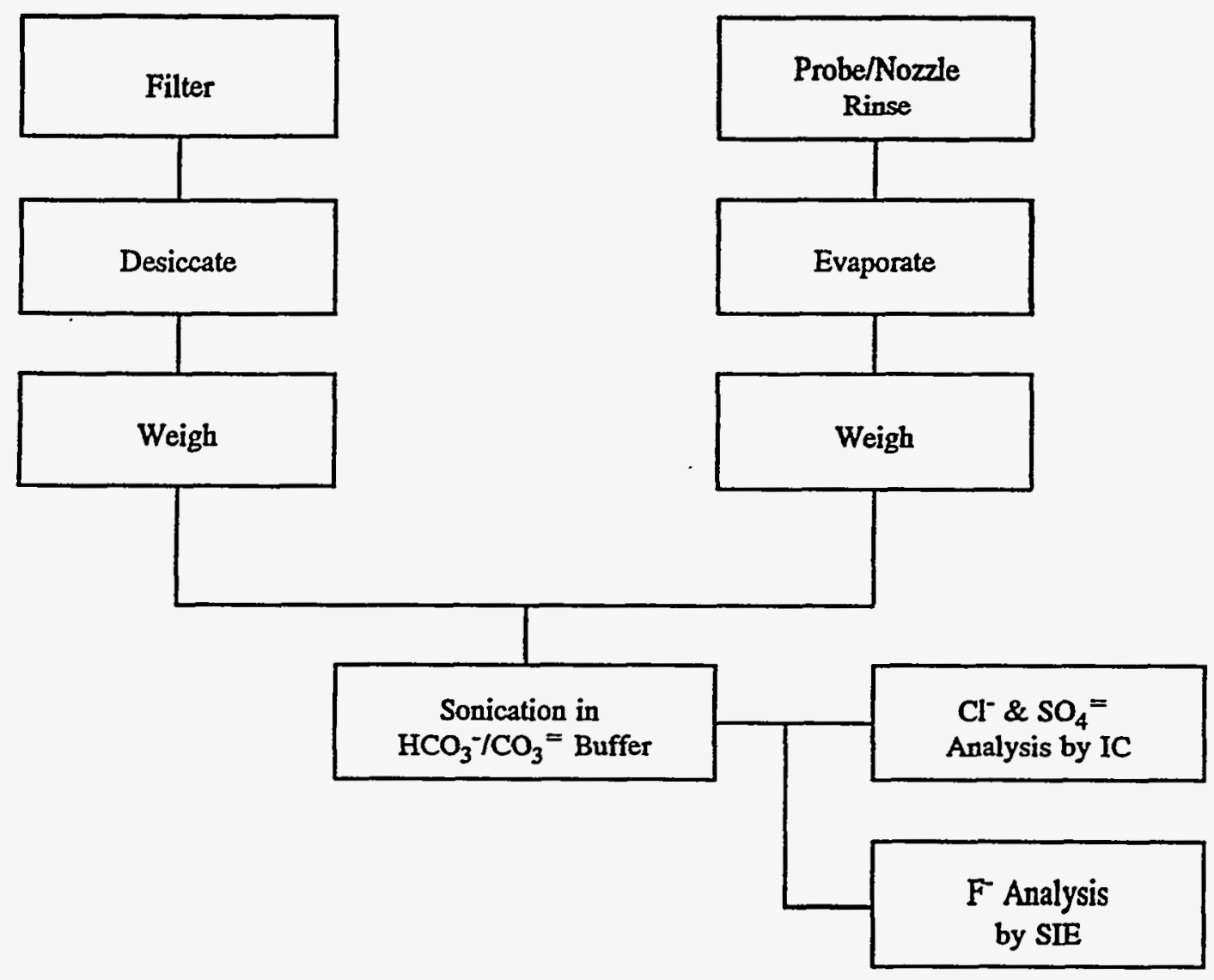

Figure A-10

Gas Particulate Sample Preparation and Analysis Plan for Anions (ESP Outlet) 


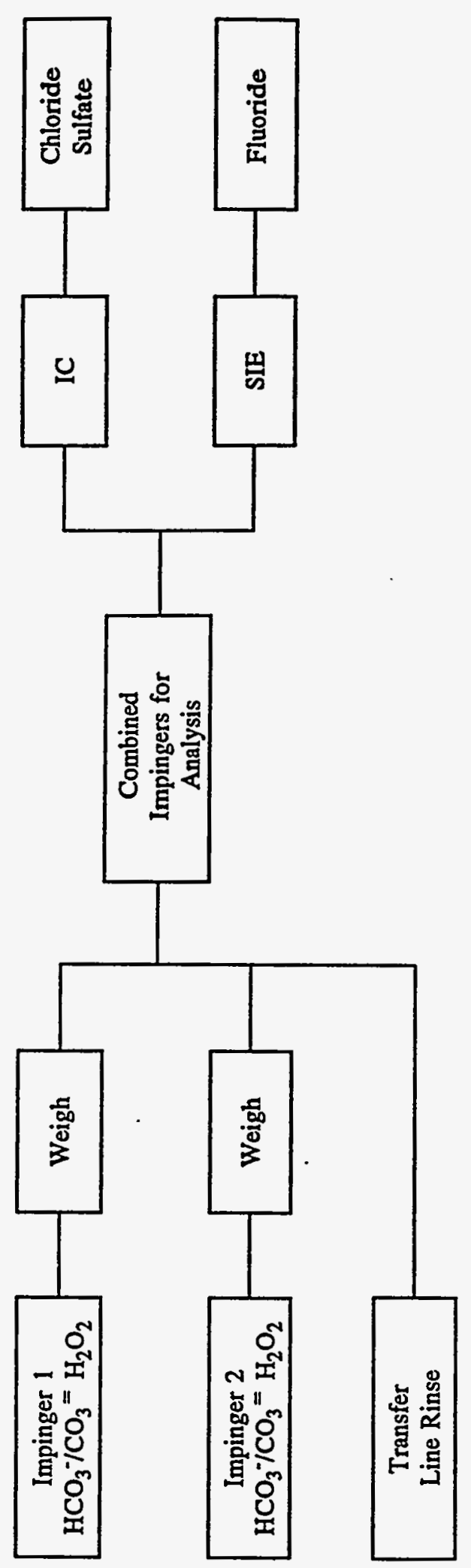

Figure A-11

Flue Gas Impinger Sample Preparation and Analysis Plan for Anions 
Appendix A: Sample Collection, Pretreatment, and Analytical Procedures

through. A 2\% zinc acetate solution was placed in the fourth and fifth impingers for the collection of cyanide. The gas sample volume for each run was approximately 40 to 60 dscf.

A description of the sampling train and sample fraction recovery for the ammonia/hydrogen cyanide trains is presented in Table A-9. The sample fractions generated by the combined ammonia/hydrogen cyanide sampling train were sent directly to the laboratory for analysis as shown in Figure A-12. The sulfuric acid impinger solutions $\left(0.1 \mathrm{~N} \mathrm{H}_{2} \mathrm{SO}_{4}\right)$ were prepared for analysis by distillation according to EPA Method $350.2^{17}$ and the recovered distillates were analyzed by EPA $350.1,{ }^{18}$ an automated colorimetric method. Cyanide impinger samples (0.1 M zinc acetate) were digested and analyzed according to EPA Method 9012. 19

\section{Formaldehyde}

Formaldehyde was collected using an acidic solution of 2,4-dinitrophenylhydrazine (DNPH) according to EPA Method $0011^{20}$ Approximately 60 dscf of gas was collected isokinetically in conjunction with the anions sampling train using the same filter for particulate removal. The impinger solutions were combined into one sample along with the methylene chloride glassware rinses. The solutions were sealed in amber glass containers with Teflon ${ }^{\circledR}$ closures and stored at $4^{\circ} \mathrm{C}$.

A description of the sampling train and sample fraction recovery for the aldehydes sampling train is presented in Table A-10. The sample fractions generated by the aldehydes sampling train and an overview of the sample handling process are shown in Figure A-13. The aqueous and methylene chloride layers of the sample were separated, and the aqueous fraction was then extracted with fresh methylene chloride. The methylene chloride portion of the sample and the aqueous extract are then combined. Since low levels of formaldehyde were expected, if any, an aliquot of this extract was concentrated during a solvent exchange procedure into acetonitrile. The resulting extract was then analyzed by high performance liquid chromatography (HPLC) according to EPA Method 0011A. Air Toxics, Ltd. was subcontracted to perform this analysis. 
Table A-9

Description and Recovery of Ammonia and Hydrogen Cyanide Sampling Train

\begin{tabular}{|c|c|c|c|c|}
\hline Component & Solution & Recovery ${ }^{a}$ & Container & $\begin{array}{l}\text { Preparation } \\
\text { \& Analysis }\end{array}$ \\
\hline Transfer Line Rinse $^{b}$ & $\mathrm{NA}$ & $\begin{array}{l}\text { Rinse transfer line with deionized water into } \\
\text { sample container. }\end{array}$ & \multirow[t]{4}{*}{$1000 \mathrm{~mL}$ Nalgene bottle } & \multirow[t]{4}{*}{ See Figure A-12 } \\
\hline Impinger \#1 $\left(\mathrm{NH}_{3}\right)$ & $0.1 \mathrm{~N} \mathrm{H}_{2} \mathrm{SO}_{4}(200 \mathrm{~mL})$ & $\begin{array}{l}\text { Recover impinger solution, then rinse impinger } \\
\text { and connecting glassware with deionized water } \\
\text { into sample container. }\end{array}$ & & \\
\hline Impinger ${ }^{2}\left(\mathrm{NH}_{3}\right)$ & $0.1 \mathrm{~N} \mathrm{H}_{2} \mathrm{SO}_{4}(200 \mathrm{~mL})$ & $\begin{array}{l}\text { Recover impinger solution, then rinse impinger } \\
\text { and connecting glassware with deionized water } \\
\text { into sample container. }\end{array}$ & & \\
\hline Impinger \#3 & Dry & $\begin{array}{l}\text { Recover condensate, then rinse impinger and } \\
\text { connecting glassware with deionized water into } \\
\text { sample container. }\end{array}$ & & \\
\hline Impinger \#4 (CN) & $0.1 \mathrm{M} \mathrm{ZnOAc}(200 \mathrm{~mL})$ & $\begin{array}{l}\text { Recover impinger solution, then rinse impinger } \\
\text { and connecting glassware with deionized water } \\
\text { into sample container. }\end{array}$ & \multirow[t]{2}{*}{$\begin{array}{l}1000 \mathrm{~mL} \text { Nalgene bottle } \\
\text { Cool to } 4^{\circ} \mathrm{C}\end{array}$} & \multirow[t]{2}{*}{ See Figure A-12 } \\
\hline Impinger \#5 (CN) & $0.1 \mathrm{M} \mathrm{ZnOAc}(200 \mathrm{~mL})$ & $\begin{array}{l}\text { Recover impinger solution, then rinse impinger } \\
\text { and connecting glassware with deionized water } \\
\text { into sample container. }\end{array}$ & & \\
\hline Impinger \#6 & Silica Gel $(300 \mathrm{~g})$ & Not recovered. & None & None \\
\hline
\end{tabular}

all impingers were weighed prior to analysis.

${ }^{b}$ Includes back half of filter holder at ESP inlet and outlet and gas cooling system at APF inlet and outlet.

$\mathrm{NA}=$ Not applicable. 


\begin{tabular}{|c|c|c|c|}
\hline $\begin{array}{c}\mathrm{H}_{2} \mathrm{SO}_{4} \\
\text { Impingers }\end{array}$ & $\begin{array}{c}\text { Distillation } \\
\text { EPA } 350.2\end{array}$ & $\begin{array}{c}\text { Ammonia Analysis } \\
\text { EPA 350.1 }\end{array}$ \\
\cline { 2 - 3 }
\end{tabular}

\begin{tabular}{|c|c|c|c|}
\hline $\begin{array}{c}\text { Zinc Acetate } \\
\text { Impingers }\end{array}$ & $\begin{array}{c}\text { Distillation } \\
\text { EPA } 9012\end{array}$ \\
\cline { 2 - 3 } & EPA 9012 \\
\hline
\end{tabular}

Figure A-12

Flue Gas Impinger Sample Preparation and Analysis Plan for Ammonia and Cyanide 
Table A-10

Description and Recovery of Aldehydes Sampling Train

\begin{tabular}{|c|c|c|c|c|}
\hline Component & Solution & Recovery ${ }^{2}$ & Container & $\begin{array}{l}\text { Preparation } \\
\text { \& Analysis }\end{array}$ \\
\hline $\begin{array}{l}\text { Transfer Line } \\
\text { Rinse }^{\mathrm{b}}\end{array}$ & NA & $\begin{array}{l}\text { Rinse transfer line with } \mathrm{MeCl}_{2} \\
\text { into sample container. }\end{array}$ & \multirow{4}{*}{$\begin{array}{l}1000 \mathrm{~mL} \text { amber glass } \\
\text { bottle } \\
\text { Cool to } 4^{\circ} \mathrm{C}\end{array}$} & \multirow[t]{4}{*}{ See Figure A-13 } \\
\hline Impinger \#1 & $\begin{array}{l}\text { DNPH solution } \\
(200 \mathrm{~mL})\end{array}$ & $\begin{array}{l}\text { Recover impinger solution, then } \\
\text { rinse impinger and connecting } \\
\text { glassware with } \mathrm{MeCl}_{2} \text { into } \\
\text { sample container. }\end{array}$ & & \\
\hline Impinger $\$ 2$ & $\begin{array}{l}\text { DNPH solution } \\
(200 \mathrm{~mL})\end{array}$ & $\begin{array}{l}\text { Recover impinger solution, then } \\
\text { rinse impinger and connecting } \\
\text { glassware with } \mathrm{MeCl}_{2} \text { into } \\
\text { sample container. }\end{array}$ & & \\
\hline Impinger \#3 & Dry & $\begin{array}{l}\text { Recover condensate into sample } \\
\text { container. }\end{array}$ & & \\
\hline Impinger \#4 & Silica gel $(300 \mathrm{~g})$ & Not recovered. & None & None \\
\hline
\end{tabular}

all impingers will be weighed prior to recovery.

b Includes back half of filter holder at ESP inlet and outlet and gas cooling system at APF inlet and outlet.

NA $=$ Not applicable. 


\begin{tabular}{|c|c|c|c|c|}
\hline $\begin{array}{l}\text { Combined DNPH } \\
\text { Impingers, } \\
\mathrm{MeCl}_{2} \text { Rinse }\end{array}$ & $\underset{\text { Extraction }}{\mathrm{MeCl}_{2}}$ & $\begin{array}{l}\text { Solvent Exchange } \\
\text { into Acetonitrile }\end{array}$ & Concentration & $\begin{array}{l}\text { Analysis } \\
\text { by HPLC }\end{array}$ \\
\hline
\end{tabular}

Figure A-13

Flue Gas Impinger Sample Preparation and Analysis Plan for Formaldehyde 


\section{Volatile Organics}

Benzene, toluene, and other volatile organic compounds were sampled using a volatile organic sampling train (VOST). The VOST is described in Method $0030^{21}$ in SW-846. Volatile organics were removed from the sample gas by sorbent traps maintained at $20^{\circ} \mathrm{C}$. The first sorbent trap contains Tenax resin and the second trap contains Tenax resin and petroleum-based charcoal. A dry gas meter was used to measure the volume of gas passed through the pair of traps. Sample volumes of $20 \mathrm{~L}$ were collected on two separate pairs of traps at a rate of $0.5 \mathrm{~L} / \mathrm{min}$.

Leak checks were performed before and after collection of each pair of resin traps. After the post-collection leak check was been completed, the traps were sealed with their end caps and returned to their respective glass containers for storage and transport. During storage and transportation, the traps were kept $\operatorname{cool}\left(<4^{\circ} \mathrm{C}\right)$.

The sample fractions generated by the VOST and an overview of the sample handling process are shown in Figure A-14. The Tenax and Tenax/charcoal cartridges were sent directly from the test site to the analytical laboratory for volatile organic compound analysis. The contents of the Tenax and Tenax/charcoal cartridges were spiked with internal standards and surrogates, thermally desorbed according to EPA Method $5040^{22}$, and directly analyzed for the compounds listed in Table A-5 by GC/MS according to EPA Method $8240 .{ }^{23}$ Air Toxics, Ltd. was subcontracted to perform VOST analyses.

\section{Semivolatile Compounds}

Semivolatile organic compounds (SVOCs) were collected using a Modified Method 5 (MM5) ${ }^{24}$ sampling train. The probe washes, filter catches, XAD sorbent traps, and aqueous condensate were extracted and analyzed for SVOCs by a combination of analytical protocols, SW-846 Method $8270^{25}$ and CARB Method $429 .{ }^{26}$. 


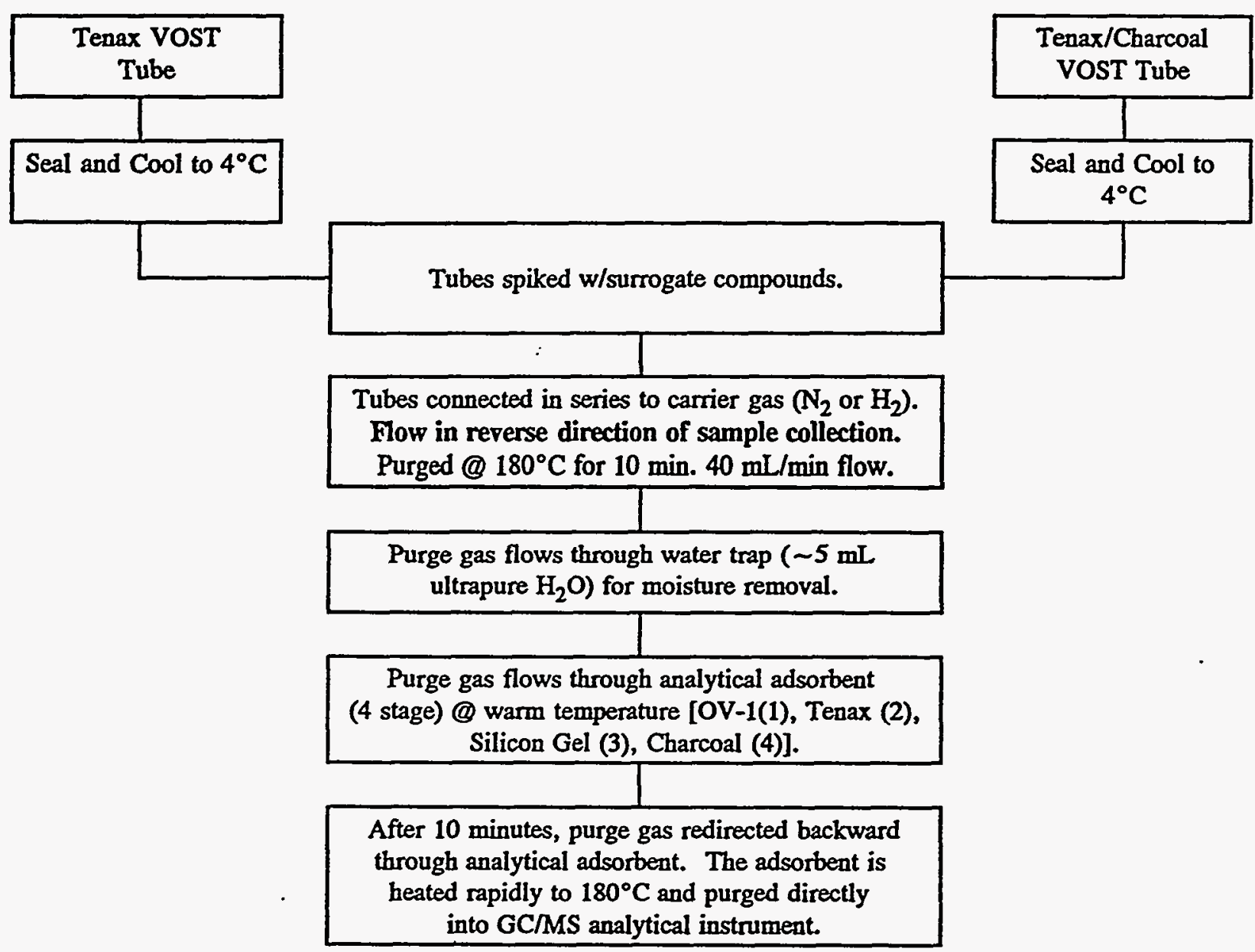

Figure A-14

VOST Sorbent Sample Preparation and Analysis Plan for Volatile Organic Compounds 
The MM5 sampling protocol is Method 0010 in SW-846. The sampling system consists of a heated probe, heated filter, sorbent module, and pumping and metering unit.

From the heated filter, sample gas entered a sorbent module. The sorbent module consists of a water-cooled condenser followed by an XAD- 2 resin trap. After the resin trap was a dry, modified Greenburg-Smith impinger (a standard size impinger without the dispersion plate at the base of the glass nozzle as specified in Method 0010) which collected the aqueous condensate.

Samples were collected isokinetically at a sampling rate of approximately $0.5 \mathrm{dscfm}$ for each train. Approximately 100 to $125 \mathrm{dscf}$ of gas were collected by each train over a minimum sampling period of two hours.

Sampling train preparation and sample retrieval was performed in a controlled environment to reduce the possibility of sample contamination. Prior to assembly, each component of the sampling train was thoroughly rinsed with methylene chloride.

After sample collection, the ends of the sampling train were sealed with solvent-rinsed foil and returned to the clean-up area for sample retrieval. The filter was recovered and placed in a glass petri dish that was rinsed with methylene chloride. Aqueous condensate collected in the first two impingers and in the sorbent trap were transferred to amber glass bottles rinsed with methylene chloride with Teflon-lined screw cap closures.

A description of the sampling train and sample fraction recovery for the MM5 sampling train is presented in Table A-11. The sample fractions generated by the MM5 sampling train and an overview of the sample handling process are shown in Figure A-15. The particulatephase and vapor-phase sample fractions were analyzed separately for the semivolatile organic compounds presented in Table A-5. The sample extracts were split to provide analysis of the particulate and vapor phase samples by both SW-8270 and CARB Method 429 protocols. 
Table A-11

Description and Recovery of Modified Method 5 (Semivolatile and PAHs 429) Sampling Train

\begin{tabular}{|c|c|c|c|c|}
\hline Component & Solution & Recovery $^{2}$ & Container & $\begin{array}{l}\text { Preparation } \\
\text { \& Analysis }\end{array}$ \\
\hline Probe/Nozzle Rinse ${ }^{b}$ & NA & $\begin{array}{l}\text { Rinse probe, nozzle, and front half of filter } \\
\text { holder with } \mathrm{MeCl}_{2} \text { into sample container. }\end{array}$ & $\begin{array}{l}500 \mathrm{~mL} \text { amber glass bottle. } \\
\text { Cool to } 4^{\circ} \mathrm{C} \text {. }\end{array}$ & See Figure A-15 \\
\hline Filter $^{b}$ & Pretreated quartz filter & Place filter in sample container. & $\begin{array}{l}\text { Glass petri dish. } \\
\text { Cool to } 4^{\circ} \mathrm{C} \text {. }\end{array}$ & See Figure A-15 \\
\hline Thimble $^{c}$ & Tared thimble & Place thimble in sample container. & $\begin{array}{l}\text { Glass jar. } \\
\text { Cool to } 4^{\circ} \mathrm{C} \text {. }\end{array}$ & See Figure A-15 \\
\hline XAD Cartridge & XAD-2 resin & Senl resin cartridge. & $\begin{array}{l}\text { Wrap in aluminum foil. } \\
\text { Cool to } 4^{\circ} \mathrm{C} \text {. }\end{array}$ & Soo Figure A-15 \\
\hline Transfer Line Rinse ${ }^{d}$ & NA & $\begin{array}{l}\text { Rinse transfer line with } \mathrm{MeCl}_{2} \text { into sample } \\
\text { container. }\end{array}$ & \multirow{5}{*}{$\begin{array}{l}1000 \mathrm{~mL} \text { amber glass } \\
\text { bottle. } \\
\text { Cool to } 4^{\circ} \mathrm{C}\end{array}$} & \multirow[t]{5}{*}{ See Figure A-15 } \\
\hline Condenser & NA & $\begin{array}{l}\text { Rinse condenser with } \mathrm{MeCl}_{2} \text { into sample } \\
\text { container. }\end{array}$ & & \\
\hline Impinger \#1 & Dry & $\begin{array}{l}\text { Recover condensate, then rinse impinger } \\
\text { and connecting glassware with } \mathrm{MeCl}_{2} \text { into } \\
\text { sample container. }\end{array}$ & & \\
\hline Impinger $\# 2$ & $\begin{array}{l}\text { Ultrapure water } \\
(200 \mathrm{~mL})\end{array}$ & $\begin{array}{l}\text { Recover impinger solution, then rinse } \\
\text { impinger and connecting glassware with } \\
\mathrm{MeCl}_{2} \text { into sample container. }\end{array}$ & & \\
\hline Impinger \#3 & $\begin{array}{l}\text { Ultrapure water } \\
(200 \mathrm{~mL})\end{array}$ & $\begin{array}{l}\text { Recover impinger solution, then rinse } \\
\text { impinger and connecting glassware with } \\
\mathrm{MeCl}_{2} \text { into sample container. }\end{array}$ & & \\
\hline Impinger \#4 & Silica gel $(300 \mathrm{~g})$ & Not recovered. & None & None \\
\hline
\end{tabular}

a All impingers were weighed prior to analysis.

b ESP inlet and outlet and APF outlet.

APF inlet only.

d Includes back half of filter holder at ESP inlet and outlet and gas cooling system at APF inlet and outlet.

$\mathrm{NA}=$ Not applicable. 


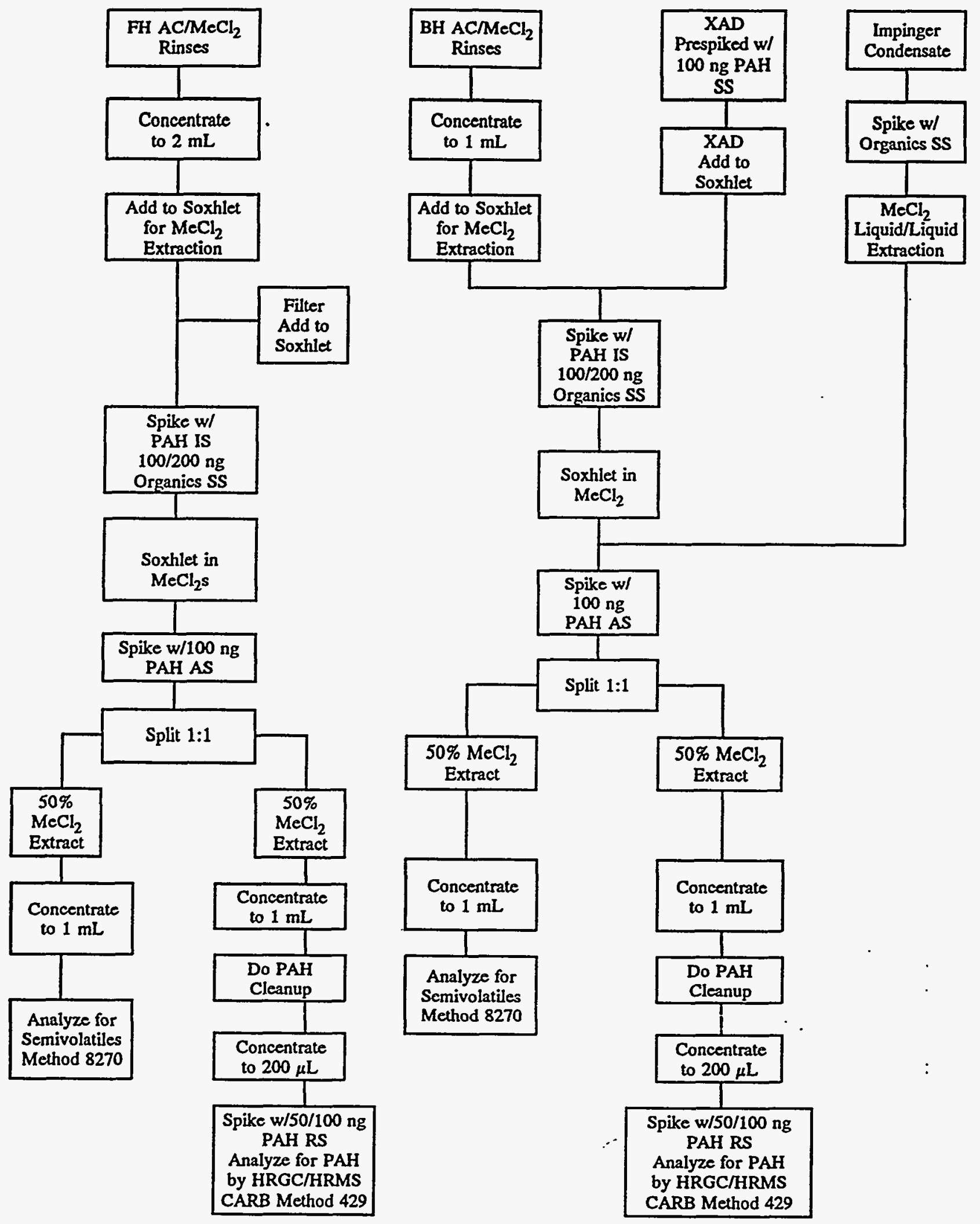

Figure A-15

Flue Gas Sample Preparation and Analysis Plan for Semivolatile Organic Compounds and PAHs 
The particulate phase consisted of the front-half acetone/methylene chloride PNR and the filter. The vapor phase consisted of the back-half acetone/methylene chloride rinse, the $\mathrm{XAD}$ resin, and the impinger condensate. The combined acetone/methylene chloride PNR/filter fraction and XAD fractions were soxhlet-extracted separately with methylene chloride. The impinger condensate fraction was liquid-liquid extracted with methylene chloride. The XAD extract and the impinger condensate extract were then combined, concentrated to $1 \mathrm{~mL}$, and analyzed by gas chromatography/mass spectrometry (GC/MS) according to EPA Method 8270 and by high resolution GC/MS according to CARB Method 429. Triangle Laboratories, Inc. was subcontracted to perform these analyses.

\section{Dioxins and Furans}

Sampling for dioxins and furans in the selected gas streams was performed using EPA Reference Method 23.27 Sample collection procedures specified in Method 23 were followed with the following exception: All train component rinses were performed with methylene chloride and acetone. The toluene rinse was then performed and added to the respective front half and back half acetone/methylene chloride rinse samples.

Adding the toluene rinses to the other solvent rinses provided a single sample for analysis of all congeners of dioxins and furans. Sample rate, volume and procedures were identical to the MM5 procedures described previously.

At the APF outlet, the particulate- and vapor-phase sample fractions were prepared and analyzed separately. At all other sampling locations, the particulate- and vapor-phase samples were combined for a single analysis. A description of the sampling train and sample fraction recovery for the Method 23 sampling train is presented in Table A-12. The sample fractions generated by the Method 23 sampling train and an overview of the sample handling process are shown in Figures A-16 and A-17.

Particulate Phase. The particulate phase consisted of the combined front-half toluene and acetone/methylene chloride rinses, and the filtered particulate matter. The toluene/ 
Table A-12

Description and Recovery of Method 23 (Dioxins/Furans) Sampling Train

\begin{tabular}{|c|c|c|c|c|}
\hline Component & Solution & Recovery ${ }^{a}$ & Container & $\begin{array}{l}\text { Preparation } \\
\text { \& Analysis }\end{array}$ \\
\hline Probe/Nozzle Rinse ${ }^{\text {b }}$ & NA & $\begin{array}{l}\text { Rinse probe, nozzle, and front half of filter } \\
\text { holder with } \mathrm{MeCl}_{2} \text {, acetone, then toluene into sample } \\
\text { container. }\end{array}$ & $\begin{array}{l}500 \mathrm{ml} \text { amber glass bottle. } \\
\text { Cool to } 4^{\circ} \mathrm{C} \text {. }\end{array}$ & $\begin{array}{l}\text { See Figures } A-16 \\
\text { and } A-17\end{array}$ \\
\hline Filter ${ }^{b}$ & $\begin{array}{l}\text { Pretreated quartz } \\
\text { filter }\end{array}$ & Place filter in sample container. & $\begin{array}{l}\text { Glass petri dish. } \\
\text { Cool to } 4^{\circ} \mathrm{C} \text {. }\end{array}$ & $\begin{array}{l}\text { See Figures } A-16 \\
\text { and } A-17\end{array}$ \\
\hline Thimble $^{c}$ & Thimble & Place thimble in sample container. & $\begin{array}{l}\text { Glass jar. } \\
\text { Cool to } 4^{\circ} \mathrm{C} \text {. }\end{array}$ & $\begin{array}{l}\text { See Figures } A-16 \\
\text { and } A-17\end{array}$ \\
\hline Transfer Line Rinse ${ }^{\mathrm{d}}$ & $\sqrt{\mathrm{NA}}$ & $\begin{array}{l}\text { Rinse transfer line with } \mathrm{MeCl}_{2} \text {, acetone, then } \\
\text { toluene into sample container. }\end{array}$ & \multirow[t]{2}{*}{$\begin{array}{l}1000 \mathrm{~mL} \text { amber glass bottle. } \\
\text { Cool to } 4^{\circ} \mathrm{C} \text {. }\end{array}$} & \multirow[t]{2}{*}{$\begin{array}{l}\text { See Figure } A-16 \\
\text { and } A-17\end{array}$} \\
\hline Condenser & NA & $\begin{array}{l}\text { Rinse condenser with } \mathrm{MeCl}_{2} \text {, acetone, then } \\
\text { toluene into sample container. }\end{array}$ & & \\
\hline XAD Cartridge & Spiked XAD-2 resin & Seal resin cartridge. & $\begin{array}{l}\text { Wrap in aluminum foil. } \\
\text { Cool to } 4^{\circ} \mathrm{C} \text {. }\end{array}$ & $\begin{array}{l}\text { See Figure } A-16 \\
\text { and } A-17\end{array}$ \\
\hline Impinger \#1 & Dry & $\begin{array}{l}\text { Recover condensate, then rinse impinger and } \\
\text { connecting glassware with } \mathrm{MeCl}_{2} \text {, acetone, then } \\
\text { toluene into sample container. }\end{array}$ & \multirow[t]{3}{*}{ Discard. } & \multirow[t]{3}{*}{ None } \\
\hline Impinger $\# 2$ & $\begin{array}{l}\text { Ulirapure water ( } 200 \\
\text { mL) }\end{array}$ & $\begin{array}{l}\text { Recover impinger solution, then rinse impinger and con- } \\
\text { necting glassware with } \mathrm{MeCl}_{2} \text {, acetone, then toluene } \\
\text { into sample container. }\end{array}$ & & \\
\hline Impinger $\# 3$ & $\begin{array}{l}\text { Ultrapure water (200 } \\
\text { mL) }\end{array}$ & $\begin{array}{l}\text { Recover impinger solution, then rinse impinger and } \\
\text { connecting glassware with } \mathrm{MeCl}_{2} \text {, acetone, then toluene } \\
\text { into sample container. }\end{array}$ & & \\
\hline Impinger $\$ 4$ & Silica Gel $(300 \mathrm{~g})$ & Not recovered. & None & None \\
\hline
\end{tabular}

all impingers were weighed prior to recovery.

${ }^{b}$ ESP inlet and outlet and APF outlet.

c APF inlet only.

"Includes back half of filter holder at ESP inlet and oullet and gas cooling system at APF inlet and outlet.

$\mathrm{NA}=$ Not applicable. 


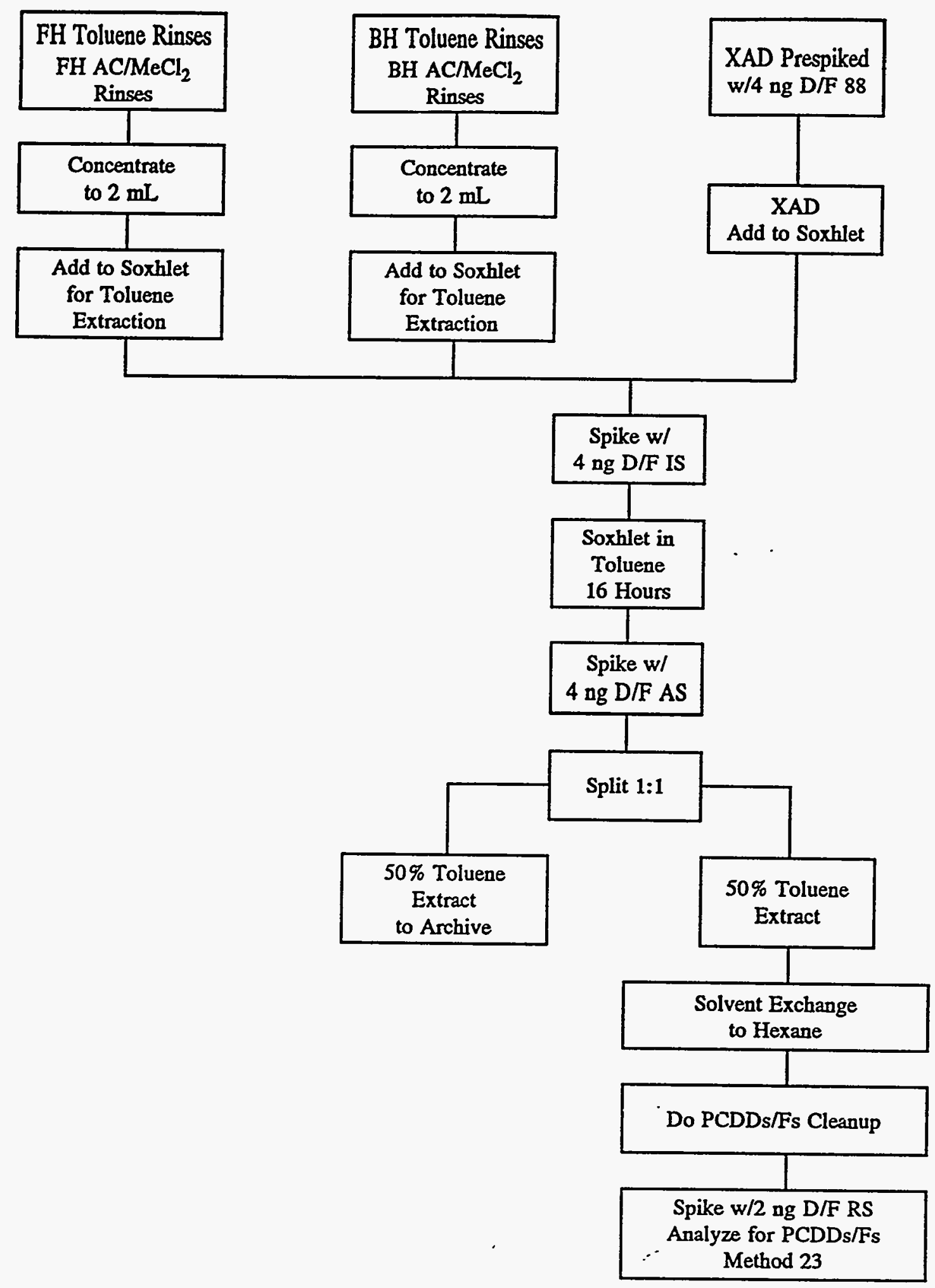

Figure A-16

Flue Gas Sample Preparation and Analysis Plan for Dioxins and Furans (ESP Inlet and Outlet and APF Inlet) 


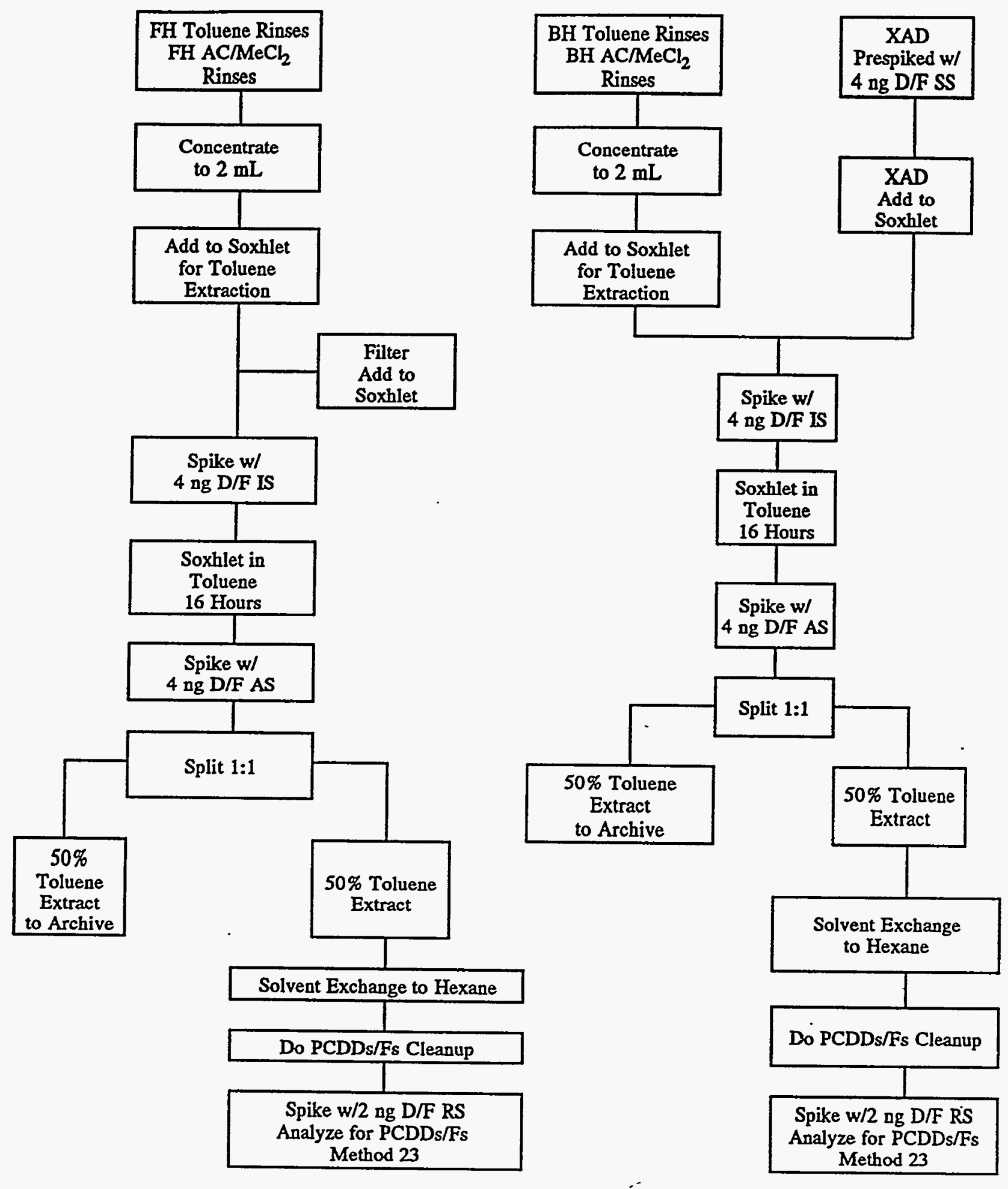

Figure A-17

Flue Gas Sample Preparation and Analysis Plan for Dioxins and Furans (APF Outlet only) 
acetone/methylene chloride rinse was concentrated to $2 \mathrm{~mL}$ and added to the filter fraction (and XAD fraction if particulate and vapor phases were combined). This was then spiked with internal standards and extracted with toluene. The extract was spiked with alternate standards and then split into two fractions. One fraction was archived while the other fraction was extracted with toluene, solvent-exchanged, spiked with recovery standards, and then analyzed by high resolution GC/MS according to EPA Method 23.

Vapor Phase. The vapor phase consisted of the combined back-half toluene/acetone/ methylene chloride rinse, and the XAD resin. The toluene/acetone/methylene chloride rinses were combined, concentrated to $2 \mathrm{~mL}$, and added to the XAD fraction (and particulate fraction if particulate and vapor phases were combined). This was then spiked with internal standards and extracted with toluene. The extract was spiked with alternate standards and then split into two fractions. One fraction was archived while the other fraction is extracted with toluene, solvent exchanged, spiked with recovery standards, and then analyzed by high resolution GC/MS according to EPA Method 23.

The QA/QC sample requirements for the Method 23 dioxins and furans trains are provided in the following table. Triangle Laboratories, Inc. was subcontracted to perform the high resolution GC/MS analyses.

\section{Particle Size Distribution}

The particle size distribution (PSD) of material in the sample gas was measured using cascade impactors at the ESP inlet and outlet. These impactors classify particulate matter with respect to aerodynamic particle size.

The impactor separates the particulate matter into 11 size fractions (10 impacted fractions and one fraction collected on a back-up filter). The impactor stages were selected to provide 10 cut-points at aerodynamic particle diameters of $<0.1 \mu \mathrm{m}$ to $>11 \mu \mathrm{m}$. The isokinetic flow rate through the sampling nozzle was precalculated for a single point in the duct representing the average gas velocity. To maintain specified cut-points, the flow rate through the 
impactor was kept constant. This nullifies the performance of traverses where adjusting the flow rate for variations in stack gas velocity is necessary. After sampling, the impactor was unloaded, the collected particulate material desiccated, and then weighed. The particulate mass collected on each stage was used to calculate the PSD. As planned, particle size distribution samples were not collected at the APF inlet and outlet because of the severe conditions and incompatibility of the sampling system for PSD measurements.

A description of the sampling train and sample fraction recovery for the PSD sampling train is presented in Table A-13.

\section{Hexavalent Chromium}

ESP outlet gas samples for hexavalent chromium were collected using the EPA method for $\mathrm{Cr}(\mathrm{VI}) .{ }^{28}$ Gas samples totaling 40-60 dscf were collected isokinetically at a single point representative of the average gas velocity. As specified in the method, all sampling train components were Teflon ${ }^{\circledR}$. This eliminated the interferences experienced with chromium adsorption onto glass components.

Sulfur dioxide $\left(\mathrm{SO}_{2}\right)$ and carbon dioxide $\left(\mathrm{CO}_{2}\right)$ create an adverse chemical environment that affects the preservation and determination of $\mathrm{Cr}(\mathrm{VI})$ in gas streams from coal-combustion sources. The EPA method for $\mathrm{Cr}(\mathrm{VI})$, validated for incinerator flue gases, specifies a $0.10 \mathrm{~N}$ potassium hydroxide (KOH) impinger solution for gas sampling. A $1.0 \mathrm{~N} \mathrm{KOH}$ solution was used for the test at Plant Tidd as discussed in the following paragraphs.

The $\mathrm{KOH}$ provides a solution $\mathrm{pH}>9$ that inhibits the reduction of $\mathrm{Cr}(\mathrm{VI})$ to $\mathrm{Cr}$ (III). For a 40 dscf gas sample at the $200 \mathrm{ppmv} \mathrm{SO}_{2}$ concentration in the ESP outlet gas, all of the $\mathrm{KOH}$ in a 0.1 normal solution would have been neutralized by the $\mathrm{SO}_{2}$. The $\mathrm{SO}_{2}$ effectively reduces the solution $\mathrm{pH}$, and thereby increases the potential for reducing $\mathrm{Cr}(\mathrm{VI})$, potentially biasing the results low. The presence of $\mathrm{CO}_{2}$ in the flue gas also reacts with the $\mathrm{KOH}$ to produce a carbonate/bicarbonate buffered solution with a lower $\mathrm{pH}(\mathrm{pH} \sim 8.3)$. In solutions 
Table A-13

Description and Recovery of the Particle Size Distribution Sampling Train

\begin{tabular}{|c|c|c|c|c|}
\hline Component & Contents & Recovery & Container & $\begin{array}{l}\text { Preparation } \\
\text { \& Analysis }\end{array}$ \\
\hline \begin{tabular}{|l|} 
Glass Fiber \\
Substrates (3) \\
\end{tabular} & $\begin{array}{l}1 \text { set glass fiber } \\
\text { substrates } \\
\end{array}$ & $\begin{array}{l}\text { Place substrates in individual } \\
\text { sample containers. }\end{array}$ & $\begin{array}{l}\text { Plastic petri } \\
\text { dish }\end{array}$ & $\begin{array}{l}\text { Desiccate and weigh } \\
\text { to nearest } 0.1 \mathrm{mg} \\
\end{array}$ \\
\hline Filter & & $\begin{array}{l}\text { Place filter in individual } \\
\text { sample container. }\end{array}$ & $\begin{array}{l}\text { Plastic petri } \\
\text { dish }\end{array}$ & $\begin{array}{l}\text { Desiccate and weigh } \\
\text { to nearest } 0.1 \mathrm{mg}\end{array}$ \\
\hline Impinger \#1 & $3 \% \mathrm{H}_{2} \mathrm{O}_{2}$ & Not recovered. & None & None \\
\hline Impinger \#2 & Dry & Not recovered. & None & None \\
\hline Impinger \#3 & Silica gel $(300 \mathrm{~g})$ & Not recovered. & None & None \\
\hline
\end{tabular}


with a $\mathrm{pH}<9$, preservation of $\mathrm{Cr}(\mathrm{VI})$ is less effective. The reaction of $\mathrm{CO}_{2}$ in caustic solutions is unavoidable; however, additional $\mathrm{KOH}$ can be added in the impinger solution to prevent an $\mathrm{SO}_{2}$-induced drop in $\mathrm{pH}$. Therefore, for the $\mathrm{Cr}(\mathrm{VI})$ tests at Plant Tidd, a 1.0 normal $\mathrm{KOH}$ solution was used to prevent the $\mathrm{pH}$ from dropping below that of the resulting carbonate/bicarbonate buffer.

Increasing the $\mathrm{KOH}$ concentration above $1.0 \mathrm{~N}$ is counterproductive. The concentration of $\mathrm{CO}_{2}$ in the flue gas would have required a $\mathrm{KOH}$ concentration in excess of 20 normal to maintain a $\mathrm{pH}>8.3$. This concentration is unattainable. In addition, the background level of $\mathrm{Cr}(\mathrm{VI})$ in the $\mathrm{KOH}$ reagent tends to obscure the low levels of $\mathrm{Cr}(\mathrm{VI})$ potentially detectable in the sample.

The impinger solutions recovered from the EPA $\mathrm{Cr}(\mathrm{VI})$ sampling train were analyzed on site immediately after collection to minimize reduction of any $\mathrm{Cr}(\mathrm{VI})$ to $\mathrm{Cr}(\mathrm{III})$. The $\mathrm{pH}$ of each sample was measured prior to analysis with a $\mathrm{pH}$ color strip. All samples showed a $\mathrm{pH}>9$ which was sufficient to inhibit the reduction of $\mathrm{Cr}(\mathrm{VI})$ to $\mathrm{Cr}(\mathrm{III})$. The analysis was performed using an IC equipped with a post-column reactor and UV-VIS detector as specified in the sampling method. A concentrator column was used to load samples and an eluent solution of ammonium sulfate and ammonium hydroxide was used as the mobil phase. An acidic solution of 1,5-diphenyl carbazide was applied in the post-column reactor to develop a colored chromium complex with an absorbance maximum of $540 \mathrm{~nm}$. The absorbance of the sample was measured at this wavelength to determine the concentration of $\mathrm{Cr}(\mathrm{VI})$ in the impinger sample. Following recovery of the caustic impinger solution, the sampling train was rinsed with $0.1 \mathrm{~N} \mathrm{HNO}_{3}$. These rinses and the caustic impinger solution were returned to Radian's Austin laboratory for total chromium analysis as a cross-check against the $\mathrm{Cr}(\mathrm{VI})$ results. Total chromium was determined on these samples by ICP emission spectroscopy.

A description of the sampling train and sample fraction recovery for the $\mathrm{Cr}(\mathrm{VI})$ sampling train is presented in Table A-14. The sample fractions generated by the $\mathrm{Cr}(\mathrm{VI})$ sampling train and an overview of the sample handling process are shown in Figure A-18. 
Table A-14

Description and Recovery of $\mathrm{Cr}^{+6}$ Sampling Train

\begin{tabular}{|c|c|c|c|c|}
\hline Component & Solution & Recovery & Container & $\begin{array}{l}\text { Preparation } \\
\text { \& Analysis }\end{array}$ \\
\hline $\begin{array}{l}\text { Probe/Nozzle } \\
\text { Rinse }\end{array}$ & NA & $\begin{array}{l}\text { Rinse probe nozzle, aspirator } \\
\text { sample and recirculation lines } \\
\text { with DI water into sample } \\
\text { container. }\end{array}$ & \multirow[t]{4}{*}{$\begin{array}{l}500 \mathrm{~mL} \text { plastic } \\
\text { bottle }\end{array}$} & \multirow[t]{4}{*}{ See Figure A-18 } \\
\hline Impinger \#1 & $\begin{array}{l}1.0 \mathrm{~N} \mathrm{KOH} \\
(150 \mathrm{~mL})\end{array}$ & $\begin{array}{l}\text { Recover impinger, then rinse } \\
\text { impinger and connecting } \\
\text { Teflon }{ }^{\oplus} \text { with DI water into } \\
\text { sample container. }\end{array}$ & & \\
\hline Impinger $\# 2$ & $\begin{array}{l}1.0 \mathrm{~N} \mathrm{KOH} \\
(75 \mathrm{~mL})\end{array}$ & $\begin{array}{l}\text { Recover impinger, then rinse } \\
\text { impinger and connecting } \\
\text { Teflon }{ }^{\otimes} \text { with DI water into } \\
\text { sample container. }\end{array}$ & & \\
\hline Impinger \#3 & $\begin{array}{l}1.0 \mathrm{~N} \mathrm{KOH} \\
(75 \mathrm{~mL})\end{array}$ & $\begin{array}{l}\text { Recover impinger, then rinse } \\
\text { impinger and connecting } \\
\text { Teflon }{ }^{\oplus} \text { with DI water into } \\
\text { sample container. }\end{array}$ & & \\
\hline Impinger $\# 4$ & Dry & Not recovered. & None & None \\
\hline Impinger \#5 & Silica gel $(300 \mathrm{~g})$ & Not recovered. & None & None \\
\hline $\begin{array}{l}\text { Nitric Acid } \\
\text { Impinger Rinses }\end{array}$ & NA & $\begin{array}{l}\text { Rinse all impingers and } \\
\text { connecting Teflon }{ }^{\star} \text { with } 0.1 \mathrm{~N} \\
\mathrm{HNO}_{3} \text {. }\end{array}$ & $\begin{array}{l}500 \mathrm{~mL} \text { plastic } \\
\text { bottle }\end{array}$ & $\begin{array}{l}\text { Analyze for } \\
\text { total chromium }\end{array}$ \\
\hline
\end{tabular}




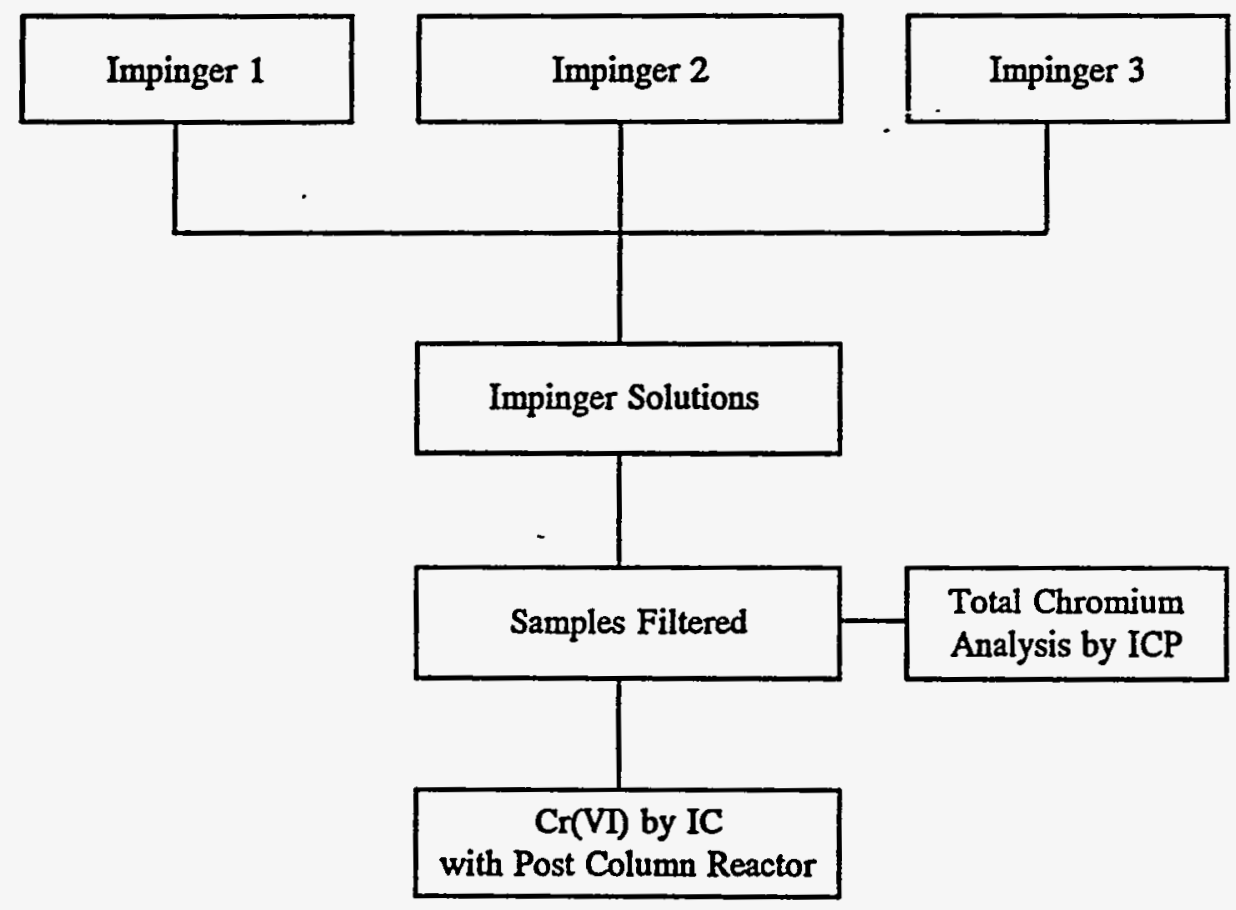

Figure A-18

Gas Impinger Sample Preparation and Analysis for $\mathrm{Cr}^{+6}$ and Total Chromium 


\section{Solid Streams}

There were seven solid process streams identified for HAP sampling. Feed streams included the raw coal fed to the grinding mill, the coal-water paste fed to the PFBC, and the dry dolomite sorbent. Collected ash streams included the bed ash from the bottom of the PFBC unit, the primary cyclone ash, the APF ash, and the ESP hopper ash (four hoppers). The sample collection and analysis approach for each of these streams is presented in this section. An overview of the field sampling requirements for solids is shown in Tables A-2 and A-3. Duplicate samples were collected during one of the three test runs to assess sample collection precision.

\section{Raw Coal}

Samples of raw coal were collected from the coal conveyer by an ASTM autosampler. This sample, although it may be representative of the coal feedstock, was not the best representation of the coal fed to the PFBC unit since a four- to six-hour delay exists between sample collection and actual feed to the PFBC unit. The raw coal is mixed with water and pulverized to make a paste (70-75\% coal by weight) which is fed to a mixing tank that supplies the unit with fuel. The coal paste provided the most representative fuel sample since it is closest to the point of injection. Nevertheless, raw coal samples were collected daily and held as a backup should coal paste sample integrity be questioned. Sample splits of the raw coal collected by the ASTM sampling.system were stored at room temperature in sealed plastic bags.

\section{Coal Paste Sampling}

Coal paste is a $70-75$ wt\% slurry that is fed to the PFBC boiler. The paste is mixed in a run tank before being fed to the PFBC. The residence time is approximately two hours. For each run, multiple grab samples were taken at half-hour intervals from the paddle feeder when the paddle feeder was actively feeding coal paste to the mixing tank. The collection started approximately one hour before gas sampling to ensure that the sample was 
representative of the burned mixture. The samples were composited and collected into a five-gallon bucket which was labeled, sealed, and sent to Radian's laboratories for preparation and analysis. Table A-15 presents the sampling plan.

Coal Paste Preparation. The coal paste in each bucket was thoroughly mixed and subsampled for drying. Weights were obtained on one subsample of the coal paste before and after drying at $104^{\circ} \mathrm{C}$ to determine the weight percent of solids in the paste. A second subsample was air dried, ground to -60 mesh, and sealed in plastic bags for the analyses shown in Figure A-19. All results were reported on a dry coal basis.

\section{Coal Paste Analysis}

Metals. A fraction of the subsample was analyzed by instrumental neutron activation (INAA). ${ }^{29}$ A second subsample was prepared and analyzed by ASTM D $3683^{30}$ for target elements (beryllium, phosphorus, and lead) which cannot be determined by INAA. In addition, ASTM D $3684^{31}$ was used to prepare and analyze samples for some of the more volatile metals such as arsenic, cadmium, and selenium. This technique combusts the prepared coal sample in a closed oxygen combustion bomb containing a small amount of nitric acid. The bomb washings were recovered and analyzed by GFAAS. Mercury was determined by combusting a sample and trapping the mercury vapors using a double gold amalgamation technique. The amalgamated mercury was thermally desorbed and analyzed by cold vapor atomic absorption spectroscopy (DGAA-CVAAS). ${ }^{32}$

Anions. Chlorine and fluorine in coal were determined by ASTM D4208 33 and D3761, ${ }^{34}$ respectively. Prepared coal samples were combusted in a closed oxygen combustion bomb containing a dilute basic solution. The bomb washings were analyzed by SIE.

Ultimate, Proximate, and Higher Heating Value. In conjunction with the other analyses, higher heating value (HHV), proximate (intrinsic moisture, volatile and fixed carbon, and ash), and ultimate (percent carbon, hydrogen, nitrogen, sulfur, oxygen, and ash) analyses were performed according to standard ASTM procedures. ${ }^{35,36,37}$ 
Appendix A: Sample Collection, Pretreatment, and Analytical Procedures

Table A-15

Description and Recovery of Coal Paste

\begin{tabular}{|c|c|c|c|c|c|}
\hline Parameter & $\begin{array}{c}\text { Sample } \\
\text { Frequency }\end{array}$ & $\begin{array}{l}\text { Sample } \\
\text { Handling }\end{array}$ & Preservation & Container & $\begin{array}{l}\text { Preparation } \\
\text { \& Analysis }\end{array}$ \\
\hline Metals & \multirow{5}{*}{$\begin{array}{l}\text { Hourly during coal } \\
\text { paste feed to stor- } \\
\text { age tank. }\end{array}$} & \multirow{5}{*}{$\begin{array}{l}\text { Grab samples } \\
\text { composited } \\
\text { directly into a } 5 \\
\text { gallon plastic } \\
\text { bucket }\end{array}$} & \multirow{5}{*}{$\begin{array}{l}\text { Sealed } \\
\text { container }\end{array}$} & \multirow{5}{*}{$\begin{array}{l}\text { Air-dried } \\
\text { sample } \\
\text { aliquots split } \\
\text { into sealed } \\
\text { plastic bags }\end{array}$} & \multirow[t]{5}{*}{ See Figure A-19 } \\
\hline Anions (Cl, F) & & & & & \\
\hline Radionuclides & & & & & \\
\hline HHV & & & & & \\
\hline Ultimate/ Proximate & & & & & \\
\hline
\end{tabular}




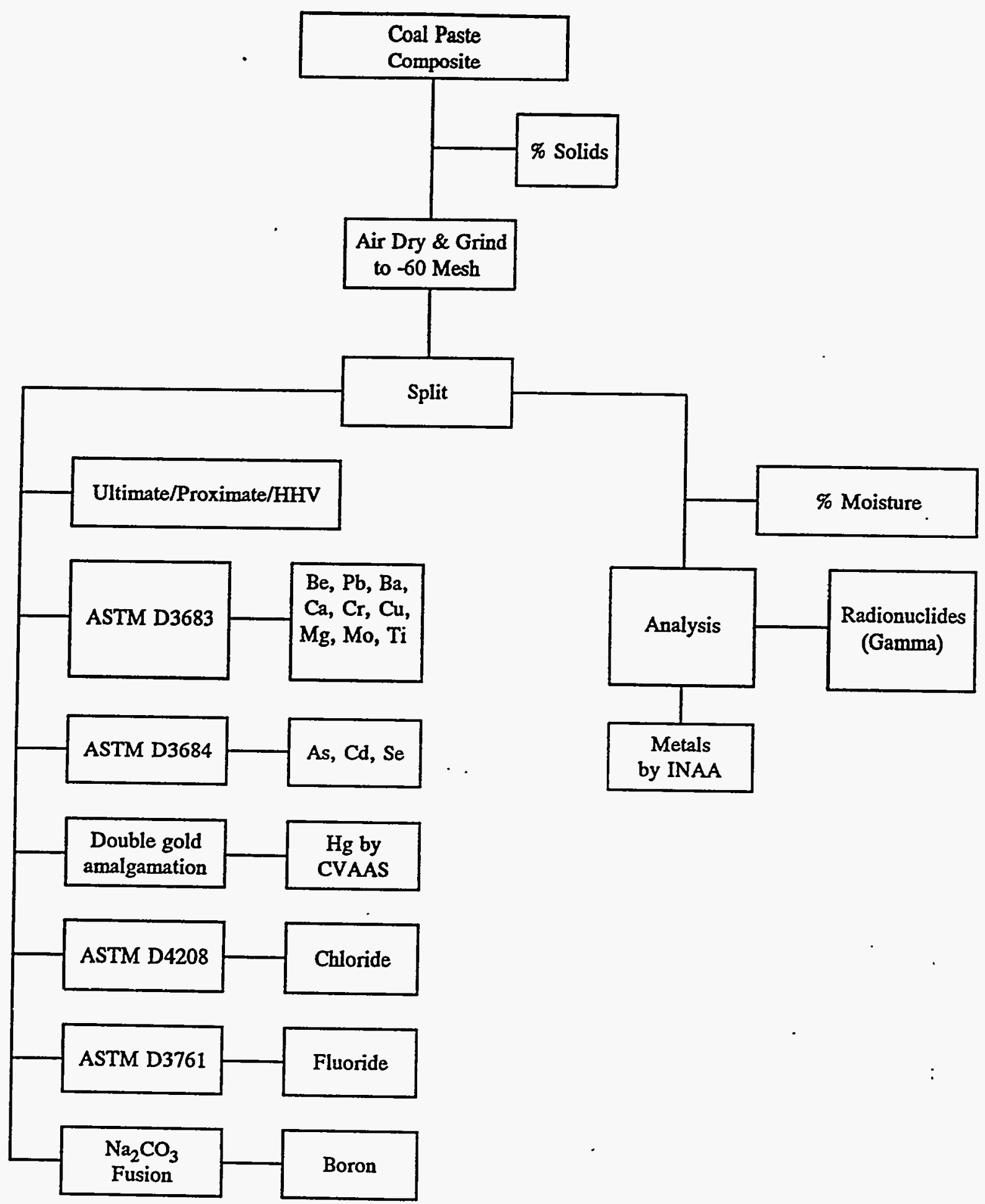

Figure A-19

Coal Sample Preparation and Analysis Plan 
Radionuclides. Coal samples were analyzed by EPA Method $901.1 .^{38}$ This method uses gamma emitting spectrometry to measure radioactivity through gamma decay.

\section{Dolomite Sorbent Sampling}

The original plan called for collection of a run composite from the autosampler at the sorbent storage silo. However, the autosampler experienced mechanical problems on Days 1 and 2 of the test, so Run 3 samples were collected from the diversion gate upstream of the east and west silos. A single grab sample was collected 12 hours before the beginning of Run 3 to account for the lag time in the hopper. The samples were collected in plastic bottles, labeled, and sent to Radian laboratories for preparation and analysis. Table A-16 presents the sampling plan.

\section{Dolomite Sorbent Analysis}

Metals. The sorbent samples were air dried, ground to pass through a 60 -mesh sieve, then subsampled for mercury analysis by CVAAS. Aliquots of the remaining material were digested with nitric acid by EPA Method $3050 .{ }^{39}$ The digestate was analyzed by ICP-AES and GFAAS.

Anions. Separate preparatory techniques were necessary for the analysis of fluoride, chloride, and sulfate in these solids. All sample aliquots were taken from the ground, airdried material prepared for metal analysis. Fluoride sample aliquots were prepared by fusion with sodium hydroxide. ${ }^{40}$ The fusion melt was dissolved in deionized water and analyzed potentiometrically by fluoride-specific ion electrode. Samples for chloride analysis were . prepared by mild digestion in nitric acid. The digestate was analyzed potentiometrically by chloride-specific ion electrode. For the analysis of sulfate, the sample was digested in $\mathrm{HCl}^{41}$ and the digestate was analyzed by IC. 
Table A-16

Description and Recovery of Dolomite Sorbent

\begin{tabular}{||l|l|l|l|l|l||}
\hline \multicolumn{1}{|c|}{ Parameter } & \multicolumn{1}{|c|}{$\begin{array}{c}\text { Sample } \\
\text { Frequency }\end{array}$} & \multicolumn{1}{|c|}{$\begin{array}{c}\text { Sample } \\
\text { Handling }\end{array}$} & Preservation & \multicolumn{1}{c|}{ Container } & \multicolumn{1}{c|}{$\begin{array}{c}\text { Preparation } \\
\text { \& Analysis }\end{array}$} \\
\hline Metals & $\begin{array}{l}\text { 1 daily run } \\
\text { sample from } \\
\text { autosampler or } \\
\text { diversion gate } \\
\text { upstream of } \\
\text { silos. }\end{array}$ & $\begin{array}{l}\text { Grab sample } \\
\text { collected from } \\
\text { autosampler into } \\
\text { a sealed plastic } \\
\text { container. }\end{array}$ & None & $\begin{array}{l}\text { Air dried sample } \\
\text { aliquots split into } \\
\text { sealed plastic } \\
\text { bags. }\end{array}$ & See Figure A-20 \\
\hline $\begin{array}{l}\text { Anions } \\
\left(\mathrm{Cl}, \mathrm{F}, \mathrm{SO}_{4}\right)\end{array}$ & & & \\
\hline
\end{tabular}




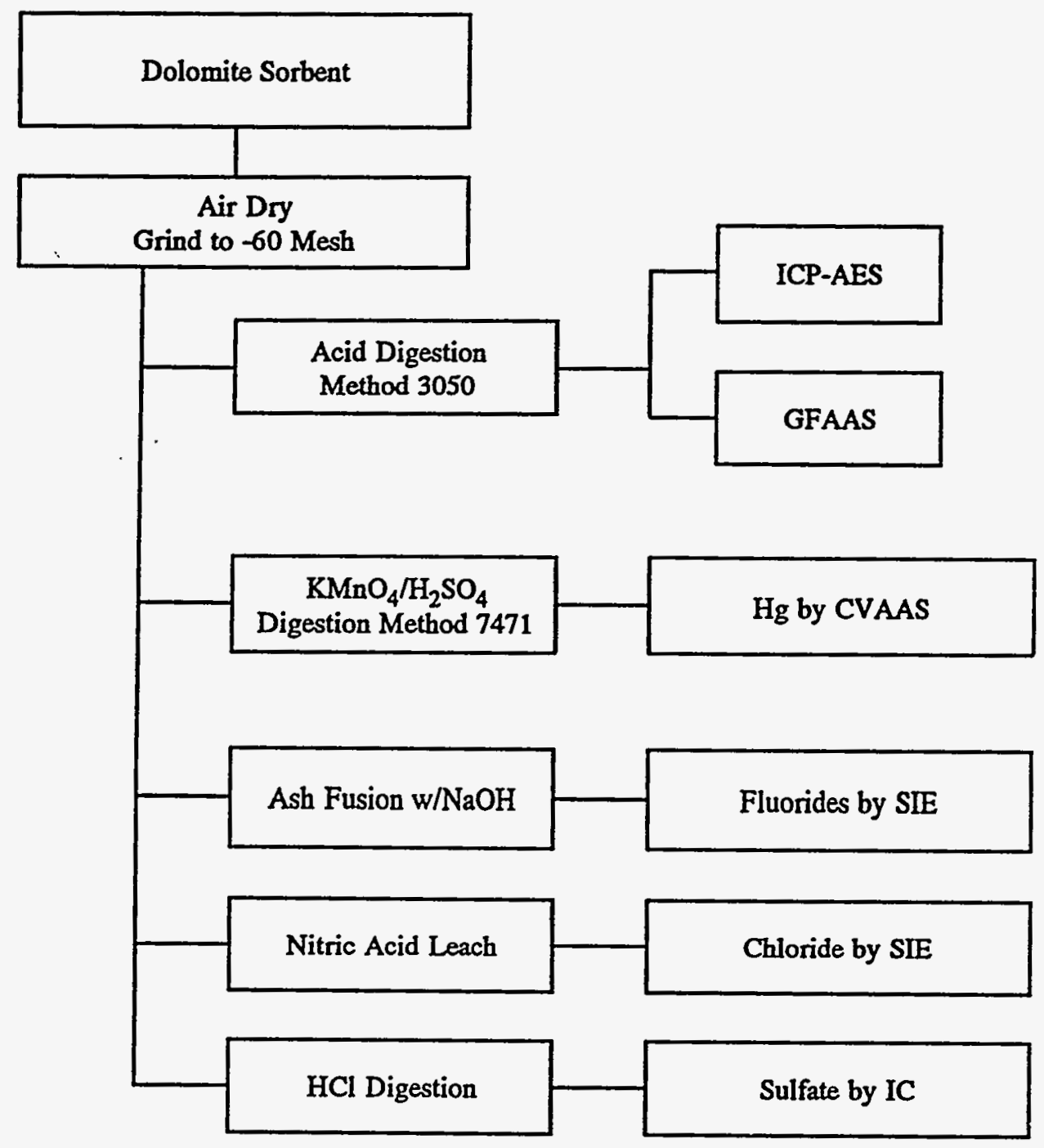

Figure A-20

Sorbent Sample Preparation and Analysis Plan 


\section{Ash Sampling}

Ash was collected by autosampler at the primary cyclone and by composited grab samples at the other locations. Each composite was collected on site in two separate labeled containers. Plastic containers were used for samples targeted for inorganic analysis, and $1 \mathrm{~L}$ amber glass bottles were used for samples for organic analysis. Samples for organic analysis were cooled immediately after collection and stored at $4^{\circ} \mathrm{C}$.

Bed Ash. Bed ash was grab-sampled manually as the ash was dumped to the ash conveyer. The grab samples were collected during each ash dumping cycle during the sample run and composited directly into a galvanized metal container. The daily composite was tumbled, riffled, and split for inorganic and organic analysis. Table A-17 presents the sample handling and preservation techniques.

Primary Cyclone Ash. This ash was collected from the facility's autosampler located at the ash feed line into the storage silo. The sampler was purged prior to a run and allowed to fill throughout the run period. The sampling frequency of the autosampler was set for sample collection every 15 minutes. The autosampler was not functioning properly during Run 3 , so fewer sample cuts were obtained for the composite. Table A-18 presents the sample handling and preservation techniques.

APF Ash. The initial plan was to collect multiple grab samples of the APF ash from the ash collection truck. However, an alternate sampling location at the bottom of the APF ash lockhopper was identified once the crew arrived on site. The lockhopper system was disengaged a minimum of two times during each run to allow collection of grab samples from the system. These grab samples were then composited to obtain a run composite. Table A-19 presents the sample handling and preservation techniques.

ESP Ash. The ESP system was made up of four fields with two hoppers per field. ESP Fields 1 and 2 were dumped each morning before the test began and samples were collected at the end each test period for metals and anions analyses. ESP Fields 3 and 4 were dumped 
is Table A-17

D Description and Recovery of Bed Ash

\begin{tabular}{|c|c|c|c|c|c|}
\hline Parameter & Sample Frequency & Sample Handling & \begin{tabular}{|l} 
Preservation \\
\end{tabular} & Container & $\begin{array}{l}\text { Preparation } \\
\& \text { Analysis }\end{array}$ \\
\hline Metals & \multirow{6}{*}{$\begin{array}{l}\text { Grab samples collected } \\
\text { during each ash dumping } \\
\text { cycle. }\end{array}$} & \multirow{5}{*}{$\begin{array}{l}\text { Grab samples composited } \\
\text { directly into a galvanized } \\
\text { metal can. } \\
\text { Riffle bulk composite collect } \\
\text { into a plastic container. }\end{array}$} & \multirow[t]{5}{*}{ None } & \multirow{5}{*}{$\begin{array}{l}\text { Plastic bottle or sealed } \\
\text { plastic bags }\end{array}$} & \multirow{6}{*}{ See Figure A-2 } \\
\hline $\begin{array}{l}\text { Anions } \\
\left(\mathrm{Cl}, \mathrm{F}, \mathrm{PO}_{4}, \mathrm{SO}_{4}\right)\end{array}$ & & & & & \\
\hline Radionuclides & & & & & \\
\hline Carbon & & & & & \\
\hline PSD & & & & & \\
\hline Semivolatile Organics & & $\begin{array}{l}\text { Riffle bulk composite collect } \\
\text { into separate sample bottles. }\end{array}$ & Cool to $4^{\circ} \mathrm{C}$ & $1000 \mathrm{~mL}$ amber glass bottle & \\
\hline
\end{tabular}


Table A-18

Description and Recovery of Primary Cyclone Ash

\begin{tabular}{|c|c|c|c|c|c|}
\hline Parameter & Sample Frequency & Sample Handling & Preservation & Container & $\begin{array}{l}\text { Preparation } \\
\text { \& Analysis }\end{array}$ \\
\hline Metals & \multirow{6}{*}{$\begin{array}{l}\text { Every } 15 \text { minutes by } \\
\text { autosampler. }\end{array}$} & \multirow{4}{*}{$\begin{array}{l}\text { Daily run composite collected from } \\
\text { autosampler into a plastic bottle. }\end{array}$} & \multirow[t]{4}{*}{ None } & \multirow{4}{*}{$\begin{array}{l}\text { Plastic bottle or } \\
\text { sealed plastic bag }\end{array}$} & \multirow[t]{6}{*}{ See Figure A-21 } \\
\hline $\begin{array}{l}\text { Anions }\left(\mathrm{Cl}, \mathrm{F}, \mathrm{PO}_{4}\right. \\
\left.\mathrm{SO}_{4}\right)\end{array}$ & & & & & \\
\hline Radionuclides & & & & & \\
\hline Carbon & & & & & \\
\hline Dioxins and Furans & & \multirow{2}{*}{$\begin{array}{l}\text { Bulk composite split into separate } \\
\text { sample bottles. }\end{array}$} & \multirow[t]{2}{*}{ Cool to $4^{\circ} \mathrm{C}$} & \multirow{2}{*}{$\begin{array}{l}1000 \mathrm{~mL} \text { amber glass } \\
\text { bottle }\end{array}$} & \\
\hline Semivolatile Organics & & & & & \\
\hline
\end{tabular}


Table A-19

\&ू Description and Recovery of APF Ash

\begin{tabular}{|c|c|c|c|c|c|}
\hline Parameter & Sample Frequency & Sample Handling & Preservation & Container & $\begin{array}{l}\text { Preparation } \\
\text { \& Analysis }\end{array}$ \\
\hline Metals & \multirow{6}{*}{$\begin{array}{l}\text { Minimum of two grab } \\
\text { samples during each test run. }\end{array}$} & \multirow{4}{*}{$\begin{array}{l}\text { Multiple grab samples taken from } \\
\text { the APF ash hopper. Collected as } \\
\text { a bulk composite in a plastic bottle. }\end{array}$} & \multirow[t]{4}{*}{ None } & \multirow[t]{4}{*}{ Plastic bottle } & \multirow[t]{6}{*}{ See Figure A-21 } \\
\hline $\begin{array}{l}\text { Anions }\left(\mathrm{Cl}, \mathrm{F}, \mathrm{PO}_{4},\right. \\
\left.\mathrm{SO}_{4}\right)\end{array}$ & & & & & \\
\hline Radionuclides & & & & & \\
\hline Carbon & & & & & \\
\hline Dioxins and Furans & & \multirow{2}{*}{$\begin{array}{l}\text { Bulk composite split into amber } \\
\text { glass bottles. }\end{array}$} & \multirow[t]{2}{*}{ Cool to $4^{\circ} \mathrm{C}$} & \multirow{2}{*}{$\begin{array}{l}1000 \mathrm{~mL} \text { amber } \\
\text { glass bottle }\end{array}$} & \\
\hline Semivolatile Organics & & & & & \\
\hline
\end{tabular}


at the beginning of the first test period. Samples were collected after the ash was allowed to accumulate over a three-day period so that enough material could be obtained for analysis. Table A-20 presents the sample handling and preservation techniques.

Ash Preparation. All ash samples were collected dry. Bed ash samples were ground to pass through a 60-mesh sieve prior to taking aliquots for mercury analysis. All other ash samples did not require grinding. Figure A-21 presents the sampling handling and preparation procedures for each ash sample analyzed for the following analytes.

\section{Ash Analysis}

Metals. Samples were digested in a microwave digestion vessel using nitric, hydrochloric, and hydrofluoric acids. The digestate was analyzed by ICP-AES and GFAAS. Mercury was analyzed by CVAAS (EPA Method 7471).

Anions. Separate preparatory techniques were necessary for analysis of fluoride, chloride, and sulfur in ash. All sample aliquots were taken from the ground, air-dried material prepared for trace element analysis. Subsamples for fluoride analysis were fused with sodium hydroxide. The fusion melt was dissolved in deionized water and analyzed potentiometrically by fluoride-specific ion electrode. Ash samples for chloride analysis were prepared by mild digestion in nitric acid. The digestate was analyzed potentiometrically by chloride-specific ion electrode. Sulfur analysis was performed directly on the ground sample by ASTM Method D4239. ${ }^{42}$

Semivolatile Organic Compounds. Ash samples targeted for SVOC analyses were separated at the test site and shipped directly to the laboratory. The ash samples were soxhlet-extracted in methylene chloride by EPA Method $3540 .{ }^{43}$ The extracts were then analyzed by GC/MS according to EPA Method 8270 . 
Table A-20

\& Description and Recovery of ESP Ash

\begin{tabular}{|c|c|c|c|c|c|}
\hline Parameter & Sample Frequency & Sample Handling & Preservation & Container & $\begin{array}{l}\text { Preparation } \\
\text { \& Analysis } \\
\end{array}$ \\
\hline Metals & \multirow{5}{*}{$\begin{array}{l}\text { Fields } 1 \& 2 \text { : Daily at end } \\
\text { of test period. } \\
\text { Fields } 3 \& 4: \text { At conclusion } \\
\text { of test run. }\end{array}$} & \multirow{5}{*}{$\begin{array}{l}\text { Grab samples composited into } \\
\text { plastic containers as a bulk } \\
\text { composite for each field. }\end{array}$} & \multirow[t]{5}{*}{ None } & \multirow{5}{*}{$\begin{array}{l}\text { Plastic bottle or } \\
\text { sealed plastic bag. }\end{array}$} & \multirow[t]{7}{*}{ See Figure A-21 } \\
\hline Anions $\left(\mathrm{Cl}, \mathrm{F}, \mathrm{SO}_{4}\right)$ & & & & & \\
\hline Radionuclides & & & & & \\
\hline Carbon & & & & & \\
\hline PSD & & & & & \\
\hline Dioxins and Furans & \multirow{2}{*}{$\begin{array}{l}\text { Fields } 1 \& 2: \text { Daily at end } \\
\text { of test period. } \\
\text { Fields } 3 \& 4: \text { At conclusion } \\
\text { of test run. }\end{array}$} & \multirow{2}{*}{$\begin{array}{l}\text { Bulk composite split into } \\
\text { amber glass bottles. }\end{array}$} & \multirow[t]{2}{*}{ Cool to $4^{\circ} \mathrm{C}$} & \multirow{2}{*}{$\begin{array}{l}1000 \mathrm{~mL} \text { amber glass } \\
\text { bottle. }\end{array}$} & \\
\hline Semivolatile Organics & & & & & \\
\hline
\end{tabular}




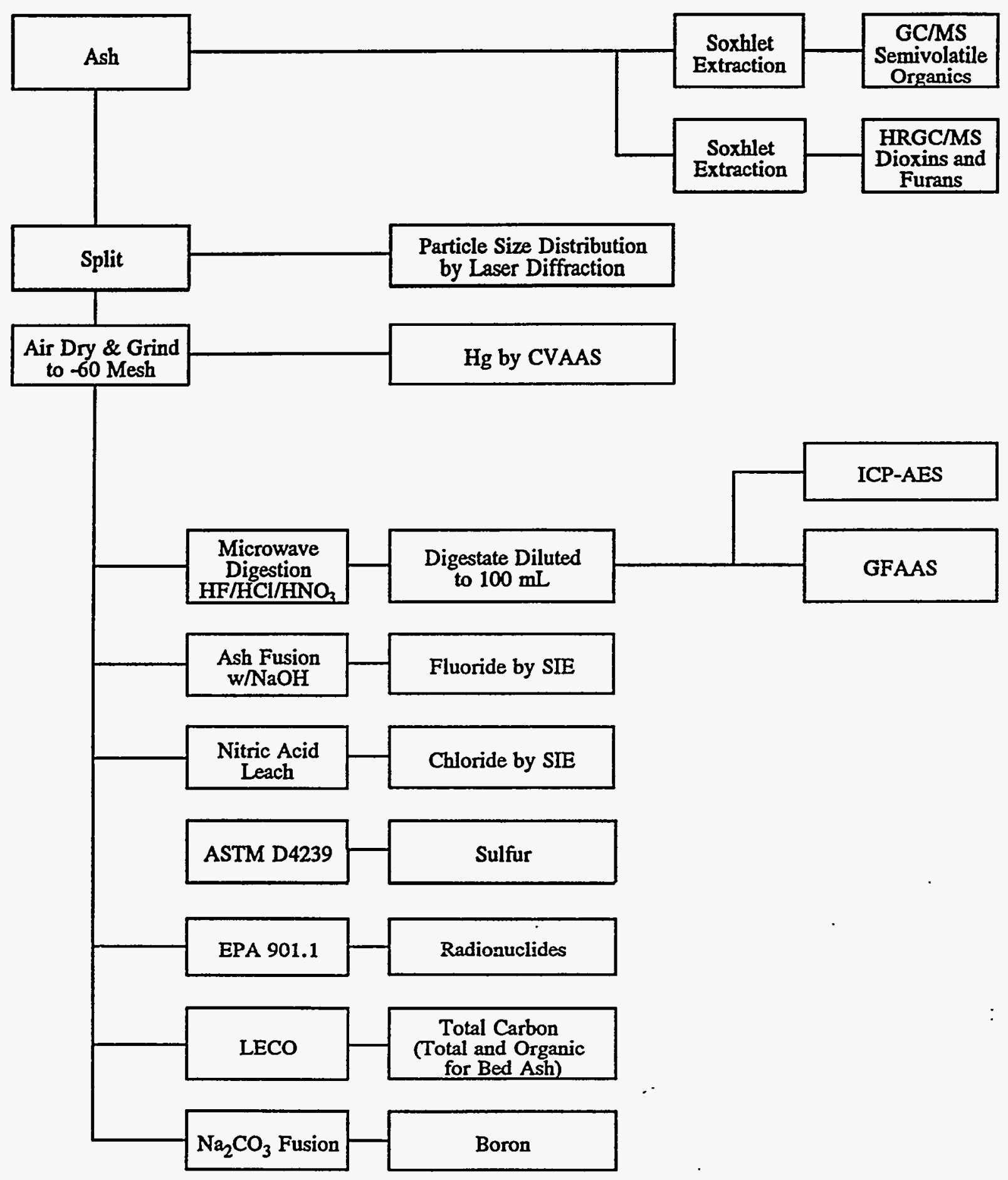

Figure A-21

Ash Sample Preparation and Analysis Plan 
Dioxins and Furans. Ash samples analyzed for dioxins and furans were separated on site and shipped chilled directly to the laboratory for analysis. The ashes were toluene soxhletextracted and purified. The extract was analyzed using high resolution GC/MS. Both preparation and analysis are a part of EPA Method 8290.44

Particle Size Distribution. Dry ash samples from the individual ESP fields were analyzed for PSD by laser diffraction using the Microtrac analyzer. Sample aliquots of well-mixed ash were suspended in either water or alcohol and injected into the recirculation system of a Microtrac particle-size analyzer.

Radionuclides. Ash samples were analyzed by EPA Method 901.1. This method uses gamma emitting spectrometry to measure radioactivity through gamma decay.

Carbon. Ash samples were analyzed for percent carbon by a LECO carbon-hydrogennitrogen analyzer. This analyzer combusts the sample in an oxygen atmosphere and measures the carbon dioxide in the combustion gas.

\section{Service Water Sampling and Analysis}

Plant service water was the only liquid stream sampled. A single grab sample was collected daily to represent the coal paste make-up water source during active paste preparation. The daily composite was collected into plastic sample bottles. Samples for metals analysis were preserved on site with $\mathrm{HNO}_{3}$ to a $\mathrm{pH}<2$. Samples for anions were cooled to $4^{\circ} \mathrm{C}$. Table A-21 presents the sampling plan, and Figure A-22 lists the sample preparation and analysis procedures.

\section{Metals}

The unfiltered service water samples were prepared for total metal analysis according to EPA Methods $3005^{45}$ and $3020 .{ }^{46}$ The samples were vigorously digested in concentrated nitric acid to dissolve any suspended material that may be present in the samples. The 
Table A-21

Description and Recovery of Service Water

\begin{tabular}{||l|l|l|l|l|l||}
\hline \multicolumn{1}{|c|}{ Parameter } & \multicolumn{1}{|c|}{$\begin{array}{c}\text { Sample } \\
\text { Frequency }\end{array}$} & \multicolumn{1}{|c|}{ Sample Handling } & Preservation & Container & $\begin{array}{l}\text { Preparation } \\
\text { \& Analysis }\end{array}$ \\
\hline Metals & $\begin{array}{l}\text { Once daily during } \\
\text { coal paste } \\
\text { preparation. }\end{array}$ & $\begin{array}{l}\text { Grab samples collected } \\
\text { directly into plastic } \\
\text { bottle containing } \\
\text { preservative. }\end{array}$ & $\begin{array}{l}\mathrm{HNO}_{3} \text { to } \\
\mathrm{pH}<2\end{array}$ & $\begin{array}{l}1000 \mathrm{~mL} \\
\text { plastic bottle }\end{array}$ & $\begin{array}{l}\text { See Figure } \\
\mathrm{A}-22\end{array}$ \\
\cline { 3 - 5 } $\begin{array}{l}\text { Anions } \\
\left(\mathrm{Cl}, \mathrm{F}, \mathrm{PO}_{4}, \mathrm{SO}_{4}\right)\end{array}$ & $\begin{array}{l}\text { Grab samples collected } \\
\text { directly into 1 L plastic } \\
\text { bottle. }\end{array}$ & Cool to 4${ }^{\circ} \mathrm{C}$ & & \\
\hline
\end{tabular}




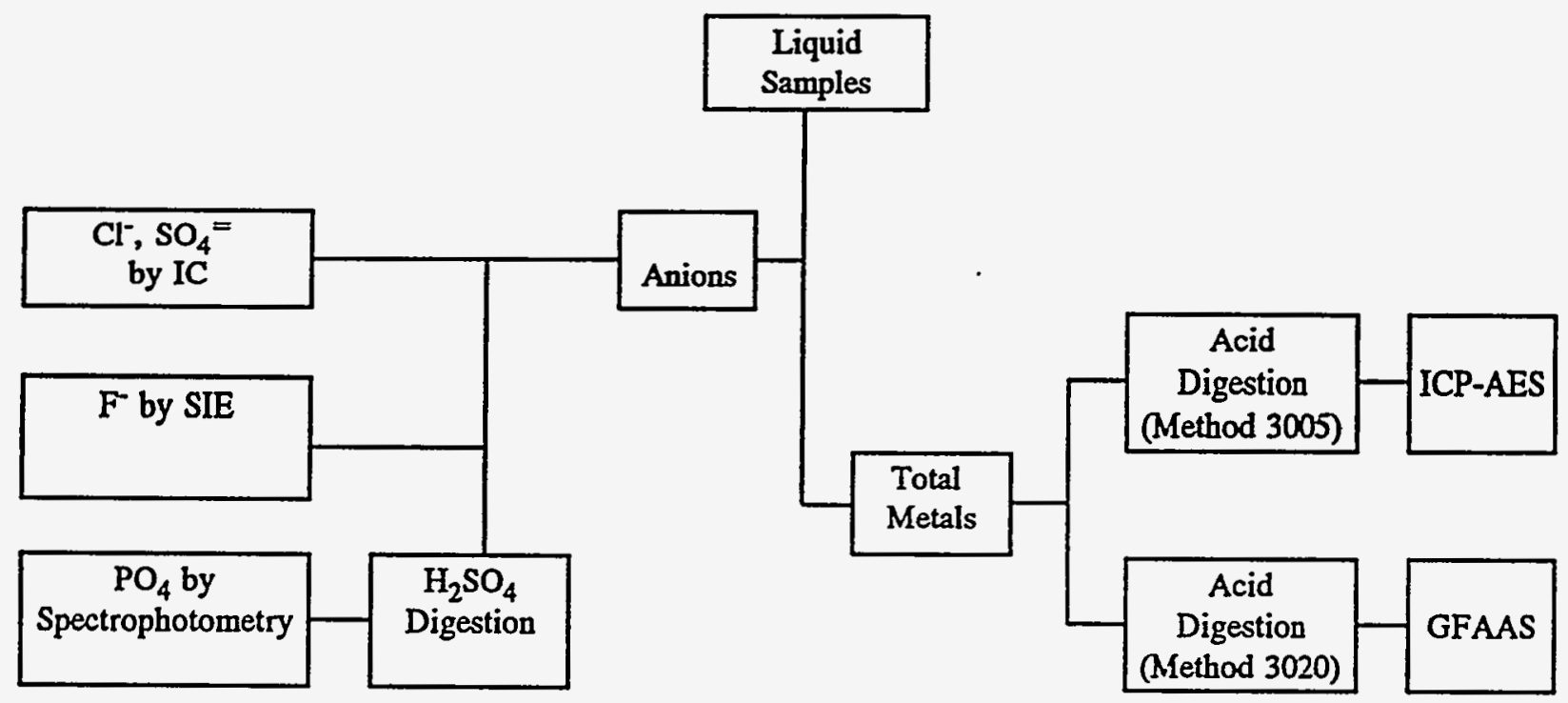

Figure A-22

Liquid Sample Preparation and Analysis Plan 
digestates were diluted to a known volume and analyzed by ICP-AES and GFAAS. Mercury was determined by EPA Method 7470 .

\section{Anions}

Sample aliquots for the analysis of chloride, fluoride, sulfate, sulfite, and phosphate were collected in separate containers and filtered. Chloride and sulfate were determined by IC according to EPA Method 300.0. Fluoride was determined potentiometrically by fluoride SIE. Phosphate was determined spectrophotometrically as a measure of total phosphorus after the sample was digested according to EPA Method 365.1.

\section{References}

1. U.S. Environmental Protection Agency. "Method 5: Determination of Particulate Emissions from Stationary Sources," Code of Federal Regulations. Title 40, Part 60, Appendix A.

2. U.S. Environmental Protection Agency. "Method 1: Sample and Velocity Traverses for Stationary Sources," Code of Federal Regulations. Title 40, Part 60, Appendix A.

3. U.S. Environmental Protection Agency. "Method 2: Determination of Stack Gas Velocity and Volumetric Flow Rate," Code of Federal Regulations. Title 40, Part 60, Appendix A.

4. U.S. Environmental Protection Agency. "Method 29: Determination of Metals Emissions in Exhaust Gases from Hazardous Waste Incineration and Similar Combustion Processes." Proposed Method, Code of Federal Regulations. Title 40, Part 266, Subpart $\mathrm{H}$.

5. U.S. Environmental Protection Agency, Office of Solid Waste. "Method 3051: Microwave Assisted Acid Digestion of Sediments, Sludges, Soils and Oils," Test Methods for Evaluating Solid Waste. SW-846, 3rd ed. Washington, DC (November 1986). Issued in November 1990 update.

6. U.S. Environmental Protection Agency, Office of Solid Waste. "Method 6010: Inductively Coupled Plasma Atomic Emission Spectroscopy," Test Methods for Evaluating Solid Waste. SW-846, 3rd ed. Washington, DC (November 1986). 
7. U.S. Environmental Protection Agency, Office of Solid Waste. "Method 7060: Arsenic (AA, Furnace Technique)," Test Methods for Evaluating Solid Waste. SW-846, 3rd ed. Washington, DC (November 1986).

8. U.S. Environmental Protection Agency, Office of Solid Waste. "Method 7131: Cadmium (AA, Furnace Technique," Test Methods for Evaluating Solid Waste. SW846, 3rd ed. Washington, DC (November 1986).

9. U.S. Environmental Protection Agency, Office of Solid Waste. "Method 7421: Lead (AA, Fumace Technique," Test Methods for Evaluating Solid Waste. SW-846, 3rd ed. Washington, DC (November 1986).

10. U.S. Environmental Protection Agency, Office of Solid Waste. "Method 7740: Selenium (AA, Furnace Technique," Test Methods for Evaluating Solid Waste. SW-846, 3rd ed. Washington, DC (November 1986).

11. U.S. Environmental Protection Agency, Office of Solid Waste. "Method 7471: Mercury in Solid or Semisolid Waste (Manual Cold-Vapor Technique," Test Methods for Evaluating Solid Waste. SW-846, 3rd ed. Washington, DC (November 1986).

12. U.S. Environmental Protection Agency, Office of Solid Waste. "Method 6020: Inductively Coupled Plasma-Mass Spectrometry," Test Methods for Evaluating Solid Waste. SW-846, 3rd ed. Washington, DC (November 1986). Issued in November 1990 update.

13. U.S. Environmental Protection Agency, Office of Solid Waste. "Method 7470: Mercury in Liquid Waste (Manual Cold-Vapor Technique)," Test Methods for Evaluating Solid Waste. SW-846, 3rd ed. Washington, DC (November 1986).

14. J.W. O'Dell, J.D. Pfaff, M.E. Gales, and G.D. McKee. U.S. Environmental Protection Agency, Environmental Monitoring and Support Laboratory. "Test Method: The Determination of Inorganic Anions in Water by Ion Chromatography-Method 300.0." EPA-600/4-84-017. Cincinnati, OH (March 1984).

15. U.S. Environmental Protection Agency, Environmental Monitoring and Support Laboratory. "Fluoride, Method 340.2 (Potentiometric, Ion Selective Electrode)," Methods for Chemical Analysis of Water and Wastes. EPA-600/4-79-020. Cincinnati, OH (revised March 1983).

16. U.S. Environmental Protection Agency, Environmental Monitoring and Support Laboratory. "Phosphorus, All Forms, Method 365.2 (Colorimetric, Ascorbic Acid, Single Reagent)," Methods for Chemical Analysis of Water and Wastes. EPA-600/4-79-020. Cincinnati, OH (revised March 1983). 
17. U.S. Environmental Protection Agency, Environmental Monitoring and Support Laboratory. "Method 350.2: Nitrogen, Ammonia (Colorimetric; Titrimetric; Potentiometric Distillation Procedure)," Methods for Chemical Analysis of Water and Wastes. EPA600/4-79-020. Cincinnati, OH (March 1983).

18. U.S. Environmental Protection Agency, Environmental Monitoring and Support Laboratory. "Method 350.1: Nitrogen, Ammonia (Colorimetric, Automated Phenate)," Methods for Chemical Analysis of Water and Waste. EPA-600/4/79-020. Cincinnati, OH (March 1983).

19. U.S. Environmental Protection Agency, Office of Solid Waste. "Method 9012: Total and Amenable Cyanide (Colorimetric, Automated UV)," Test Methods for Evaluating Solid Waste. SW-848 3rd ed. Washington, DC (November 1986).

20. U.S. Environmental Protection Agency. "Method 0011: Sampling for Aldehyde and Ketone Emissions from Stationary Sources," Code of Federal Regulations. Title 40, Part 266, Appendix IX, Section 3.5.

21. U.S. Environmental Protection Agency, Office of Solid Waste. "Method 0030: Volatile Organic Sampling Train," Test Methods for Evaluating Solid Waste. SW-846, 3rd ed. Washington, DC (November 1986).

22. U.S. Environmental Protection Agency, Office of Solid Waste. "Method 5040: Protocol for Analysis of Sorbent Cartridges from Volatile Organic Sampling Train," Test Methods for Evaluating Solid Waste. SW-846, 3rd ed. Washington, DC November 1986).

23. U.S. Environmental Protection Agency, Office of Solid Waste. "Method 8240: Gas Chromatography/Mass Spectrometry for Volatile Organics," Test Methods for Evaluating Solid Waste. SW-846, 3rd ed. Washington, DC (November 1986).

24. U.S. Environmental Protection Agency, Office of Solid Waste. "Method 0010: Modified Method 5 Sampling Train," Test Methods for Evaluating Solid Waste. SW846, 3rd ed. Washington, DC (November 1986).

25. U.S. Environmental Protection Agency, Office of Solid Waste. "Method 8270: Gas Chromatography/Mass Spectrometry for Semivolatile Organics: Capillary Column Technique," Test Methods for Evaluating Solid Waste. SW-846, 3rd ed. Washington, DC (November 1986).

26. State of California Air Resources Board. "Method 429: Polycyclic Aromatic Hydrocarbons (PAH) Emissions Stationary Source Test Methods." Methods for Determining Emissions of Toxic Air Contaminants from Stationary Sources, Vol 3. Sacramento, CA (September 1989). 
Appendix A: Sample Collection, Pretreatment, and Analytical Procedures

27. U.S. Environmental Protection Agency. "Method 23-Determination of Polychlorinated Dibenzo-p-Dioxins and Polychlorinated Dibenzofurans from Stationary Sources," Code of Federal Regulations. Title 40, Part 60, Appendix A.

28. United States Environmental Protection Agency. "Determination of Hexavalent Chromium Emissions from Stationary Sources (Method $\mathrm{Cr}^{+6}$ )," Code of Federal Regulations. Title 40, Part 266, Appendix IX, Section 3.2.

29. J.N. Weaver. "Neutron Activation Analysis of Trace Elements in Coal, Fly Ash, and Fuel Oils," Analytical Methods for Coal and Coal Products. C. Karr, Jr., ed. Vol: 1, Chapter 12, pp. 377-401. Academic Press, New York (1979).

30. "Standard Method for Trace Elements in Coal and Coke Ash by Atomic Absorption," 1991 Annual Book of ASTM Standards. Section 5, Vol. 5.05, Method D-3683. American Society for Testing and Materials. Philadelphia, PA (1991).

31. "Test Method for Total Mercury in Coal by the Oxygen Bomb Combustion/Atomic Absorption Method," 1991 Annual Book of ASTM Standards. Section 5, Vol. 5.05, Method D-3684-78. American Society for Testing and Materials. Philadelphia, PA (1991).

32. Analytical Methods for Determining Mercury in Coal and Coal Mine Water. Report No. 2, Trace Element Program at Bituminous Coal Research, Inc. (July 1975).

33. "Test Method for Total Chlorine in Coal by Oxygen Bomb Combustion/Ion Selective Electrode Method, " 1991 Annual Book of ASTM Standards. Section 5, Vol. 5.05, Method D-4208-91. American Society for Testing and Materials. Philadelphia, PA (1991).

34. "Test Method for Total Fluorine in Coal by the Oxygen Bomb Combustion/Ion Selective Electrode Method," 19.91 Annual Book of ASTM Standards. Section 5, Vol. 5.05, Method D-3761-91. American Society for Testing and Materials. Philadelphia, PA (1991).

35. "Standard Practice of Ultimate Analysis of Coal and Coke," 1991 Annual Book of ASTM Standards. Section 5, Vol. 5.05, Method D-3176-89. American Society for Testing and Materials. Philadelphia, PA (1991).

36. "Standard Practice of Proximate Analysis of Coal and Coke," 1991 Annual Book of ASTM Standards. Section 5, Vol. 5.05, Method D-3172-89. American Society for Testing and Materials. Philadelphia, PA (1991).

37. "Standard Test Method for Gross Calorific Value of Coal and Coke by the Adiabatic Bomb Calorimeter," 1991 Annual Book of ASTM Standards, Section 5, Vol. 5.05, Method D-2015-85. American Society for Testing and Materials. Philadelphia, PA (1991). 
38. U.S. Environmental Protection Agency. "Method 901.1," Prescribed Procedures for the Measurement of Radioactivity in Drinking Water. EPA-600/4-80-032 (1980).

39. U.S. Environmental Protection Agency, Office of Solid Waste. "Method 3050: Acid Digestion of Sediments, Sludges, and Soils," Test Methods for Evaluating Solid Waste. SW-846, 3rd ed. Washington, DC (November 1986).

40. N.R. McQuaker and M. Gumey. "Determination of Total Fluoride in Soil and Vegetation Using and Alkali Fusion-Selective Ion Electrode Technique," Analytical Chemistry. Vol. 49, No. 1, pp. 53-56 (January 1977).

41. "Preparation of Solid Samples by Acid Dissolution." In: "Method L1-Sulfate/Total Sulfur Analysis by Ion Exchange, Acid-Base Titration." FGD Chemistry and Analytical Methods Handbook, Volume 2: Chemical and Physical Test Methods, Revision 1. RP1031-4, CS-3612, TOL No. 5., pp. L1-15 to L1-16. Prepared for Electric Power Research Institute. Palo Alto, CA (November 1988).

42. "Standard Test Methods for Sulfur in the Analysis Sample of Coal and Coke Using High Temperature Tube Furnace Combustion Methods, " 1991 Annual Book of ASTM Standards. Section 5, Vol. 5.05, Method D-4239-85. American Society for Testing and Materials. Philadelphia, PA (1991).

43. U.S. Environmental Protection Agency, Office of Solid Waste. "Method 3540: Soxhlet Extraction," Test Methods for Evaluating Solid Waste. SW-846, 3rd ed. Washington, DC (November 1986).

44. U.S. Environmental Protection Agency, Office of Solid Waste. "Method 8290: Polychlorinated Dibenzodioxins (PCDFs) By High-Resolution Gas Chromatography/ High-Resolution Mass Spectrometry (HRGC/HRMS)," Test Methods for Evaluating Solid Waste. SW-846, 3rd ed. Washington, DC (November 1986).

45. U.S. Environmental Protection Agency, Office of Solid Waste. "Method 3005: Acid Digestion of Waters for Total Recoverable or Dissolved Metals for Analysis by Flame Atomic Absorption Spectroscopy or Inductively Coupled Plasma Spectroscopy," Test Methods for Evaluating Solid Waste. SW-846, 3rd ed. Washington, DC (November 1986).

46. U.S. Environmental Protection Agency, Office of Solid Waste. "Method 3020: Acid Digestion of Aqueous Samples and Extracts for Total Metals for Analysis by GFAAS: Spectroscopy," Test Methods for Evaluating Solid Waste. SW-846, 3rd ed. Washington, DC (November 1986). 


\section{APPENDIX B: DETAILED ANALYTICAL DATA}

\section{Key to Appendix B Data Flags}

\begin{tabular}{|c|l|}
\hline Comment & \multicolumn{1}{|c|}{ Description } \\
\hline B & Analyte detected in method blank. \\
\hline C & Result corrected with reagent blank result. \\
\hline E & Result exceeds instrument calibration range. \\
\hline F & $\begin{array}{l}\text { PCDF peak eluted at the same time as the associated diphenyl ether (DPE) } \\
\text { and the DPE peak intensity is 10\% or more of the PCDF peak intensity. }\end{array}$ \\
\hline G & Estimated result because of coelution with sulfur dioxide. \\
\hline J & Result is less than the quantitation limit but greater than the detection limit. \\
\hline S & Result is an estimate because of saturated peak. \\
\hline
\end{tabular}


Appendix B: Detailed Analytical Data

\section{DATA USED IN CALCULATIONS}

B-3 
Analytical Data Used In Calculations

Stream: APF Ash Collection Method: Grab Composite Sample Type: Fly Ash

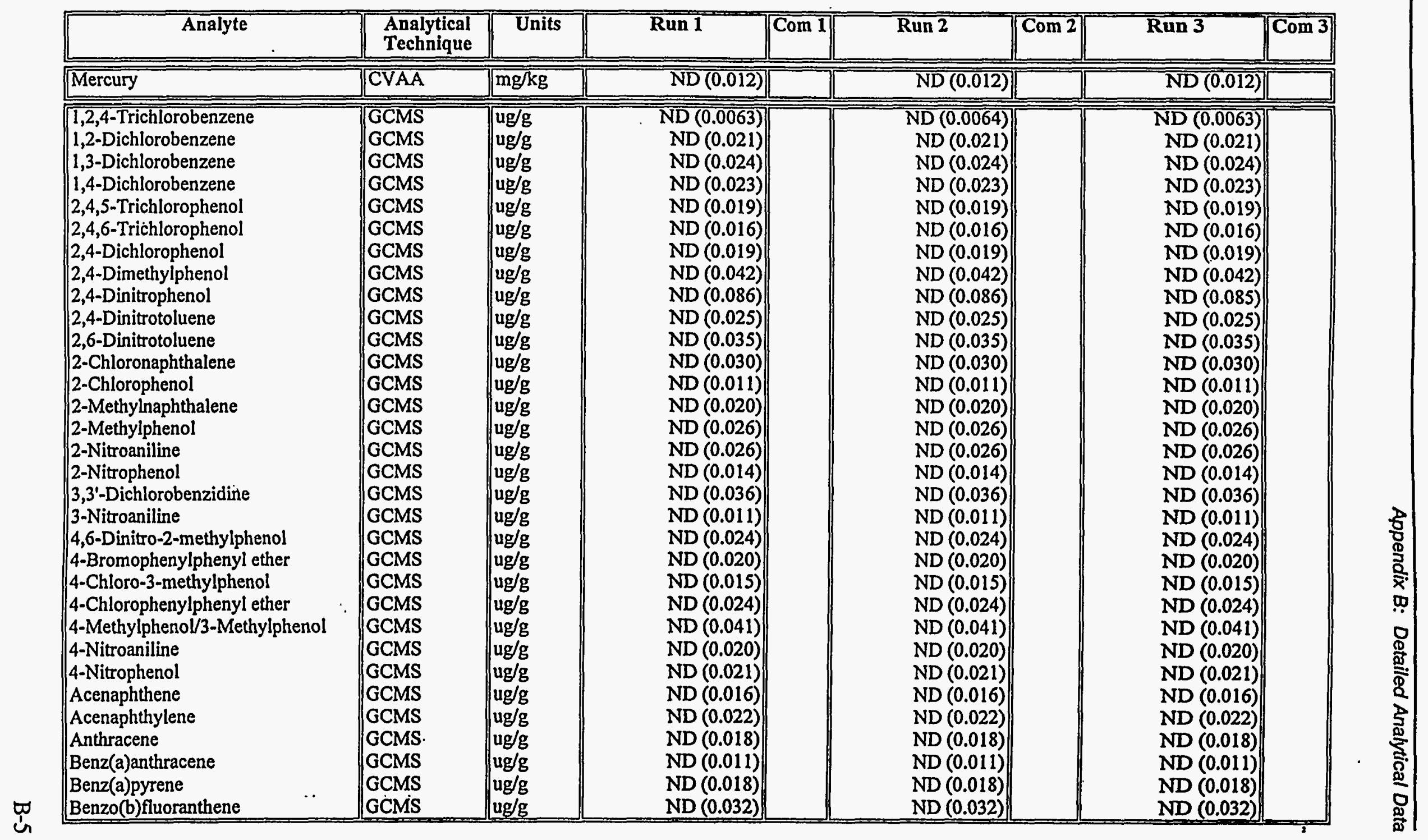


Stream: APF Ash Collection Method: Grab Composite Sample Type: Fly Ash

\begin{tabular}{|c|c|c|c|c|c|c|c|c|}
\hline Analyte & $\begin{array}{l}\text { Analytical } \\
\text { Technique }\end{array}$ & Units & Run 1 & Com 1 & Run 2 & Com 2 & Run 3 & $\operatorname{Com} 3$ \\
\hline $\begin{array}{l}\text { Benzo(g,h,i)perylene } \\
\text { Benzo(k)fluoranthene } \\
\text { Benzoic acid } \\
\text { Benzyl alcohol } \\
\text { Butylbenzylphthalate } \\
\text { Chrysene } \\
\text { Di-n-butylphthalate } \\
\text { Di-n-octylphthalate } \\
\text { Dibenz(a,h)anthracene } \\
\text { Dibenzofuran } \\
\text { Diethylphthalate } \\
\text { Dimethylphthalate } \\
\text { Diphenylamine/N-NitrosoDPA } \\
\text { Fluoranthene } \\
\text { Fluorene } \\
\text { Hexachlorobenzene } \\
\text { Hexachlorobutadiene } \\
\text { Hexachlorocyclopentadiene } \\
\text { Hexachloroethane } \\
\text { Indeno(1,2,3-cd)pyrene } \\
\text { Isophorone } \\
\text { N-Nitroso-di-n-propylamine } \\
\text { Naphthalene } \\
\text { Nitrobenzene } \\
\text { Pentachlorophenol } \\
\text { Phenanthrene } \\
\text { Phenol } \\
\text { Pyrene } \\
\text { bis(2-Chloroethoxy)methane } \\
\text { bis(2-Chloroethyl)ether } \\
\text { bis(2-Chloroisopropyl)ether } \\
\text { bis(2-Ethylhexyl)phthalate } \\
\text { p-Cliloroumilino }\end{array}$ & \begin{tabular}{|l} 
GCMS \\
GCMS \\
GCMS \\
GCMS \\
GCMS \\
GCMS \\
GCMS \\
GCMS \\
GCMS \\
GCMS \\
GCMS \\
GCMS \\
GCMS \\
GCMS \\
GCMS \\
GCMS \\
GCMS \\
GCMS \\
GCMS \\
GCMS \\
GCMS \\
GCMS \\
GCMS \\
GCMS \\
GCMS \\
GCMS \\
GCMS \\
GCMS \\
GCMS \\
GCMS \\
GCMS \\
GCMS
\end{tabular} & $\begin{array}{l}\mathrm{ug} / \mathrm{g} \\
\mathrm{ug} / \mathrm{g} \\
\mathrm{ug} / \mathrm{g} \\
\mathrm{ug} / \mathrm{g} \\
\mathrm{ug} / \mathrm{g} \\
\mathrm{ug} / \mathrm{g} \\
\mathrm{ug} / \mathrm{g} \\
\mathrm{ug} / \mathrm{g} \\
\mathrm{ug} / \mathrm{g} \\
\mathrm{ug} / \mathrm{g} \\
\mathrm{ug} / \mathrm{g} \\
\mathrm{ug} / \mathrm{g} \\
\mathrm{ug} / \mathrm{g} \\
\mathrm{ug} / \mathrm{g} \\
\mathrm{ug} / \mathrm{g} \\
\mathrm{ug} / \mathrm{g} \\
\mathrm{ug} / \mathrm{g} \\
\mathrm{ug} / \mathrm{g} \\
\mathrm{ug} / \mathrm{g} \\
\mathrm{ug} / \mathrm{g} \\
\mathrm{ug} / \mathrm{g} \\
\mathrm{ug} / \mathrm{g} \\
\mathrm{ug} / \mathrm{g} \\
\mathrm{ug} / \mathrm{g} \\
\mathrm{ug} / \mathrm{g} \\
\mathrm{ug} / \mathrm{g} \\
\mathrm{ug} / \mathrm{g} \\
\mathrm{ug} / \mathrm{g} \\
\mathrm{ug} / \mathrm{g} \\
\mathrm{ug} / \mathrm{g} \\
\mathrm{ug} / \mathrm{g} \\
\mathrm{ug} / \mathrm{g} \\
\mathrm{ug} / \mathrm{g}\end{array}$ & $\begin{array}{r}\text { ND (0.018) } \\
\text { ND (0.027) } \\
\text { ND (0.099) } \\
\text { ND (0.048) } \\
\text { ND (0.025) } \\
\text { ND (0.019) } \\
\text { ND (0.010) } \\
\text { ND (0.019) } \\
\text { ND (0.023) } \\
\text { ND (0.013) } \\
\text { ND (0.012) } \\
\text { ND (0.016) } \\
\text { ND (0.025) } \\
\text { ND (0.014) } \\
\text { ND (0.011) } \\
\text { ND (0.017) } \\
\text { ND (0.022) } \\
\text { ND (0.054) } \\
\text { ND (0.033) } \\
\text { ND (0.016) } \\
\text { ND (0.0100) } \\
\text { ND (0.026) } \\
\text { ND (0.022) } \\
\text { ND (0.013) } \\
\text { ND (0.0063) } \\
\text { ND (0.018) } \\
\text { ND (0.033) } \\
\text { ND (0.015) } \\
\text { ND (0.011) } \\
\text { ND (0.015) } \\
\text { ND (0.019) } \\
\text { ND (0.054) } \\
\text { ND (0.032) }\end{array}$ & & $\begin{array}{c}\text { ND (0.018) } \\
\text { ND (0.027) } \\
\text { ND (0.099) } \\
\text { ND (0.048) } \\
\text { ND (0.025) } \\
\text { ND (0.019) } \\
\text { ND (0.010) } \\
\text { ND (0.019) } \\
\text { ND (0.023) } \\
\text { ND (0.013) } \\
\text { ND (0.012) } \\
\text { ND (0.016) } \\
\text { ND (0.025) } \\
\text { ND (0.014) } \\
\text { ND (0.011) } \\
\text { ND (0.018) } \\
\text { ND (0.022) } \\
\text { ND (0.054) } \\
\text { ND (0.033) } \\
\text { ND (0.016) } \\
\text { ND (0.010) } \\
\text { ND (0.026) } \\
\text { ND (0.022) } \\
\text { ND (0.013) } \\
\text { ND }(0.0064) \\
\text { ND (0.018) } \\
\text { ND (0.034) } \\
\text { ND (0.015) } \\
\text { ND (0.011) } \\
\text { ND (0.015) } \\
\text { ND (0.019) } \\
\text { ND (0.054) } \\
\text { ND (0.033) }\end{array}$ & & $\begin{array}{r}\text { ND }(0.018) \\
\text { ND (0.027) } \\
\text { ND (0.099) } \\
\text { ND (0.047) } \\
\text { ND (0.025) } \\
\text { ND (0.019) } \\
\text { ND (0.010) } \\
\text { ND (0.019) } \\
\text { ND (0.022) } \\
\text { ND (0.013) } \\
\text { ND (0.012) } \\
\text { ND (0.015) } \\
\text { ND (0.025) } \\
\text { ND (0.014) } \\
\text { ND (0.011) } \\
\text { ND (0.017) } \\
\text { ND (0.022) } \\
\text { ND (0.054) } \\
\text { ND (0.033) } \\
\text { ND (0.016) } \\
\text { ND (0.0100) } \\
\text { ND (0.026) } \\
\text { ND (0.022) } \\
\text { ND (0.013) } \\
\text { ND (0.0063) } \\
\text { ND (0.018) } \\
\text { ND (0.033) } \\
\text { ND (0.015) } \\
\text { ND (0.011) } \\
\text { ND (0.015) } \\
\text { ND (0.019) } \\
\text { ND (0.054) } \\
\text { ND (0.032) }\end{array}$ & \\
\hline
\end{tabular}


Analytical Data Used In Calculations

Stream: APF Ash Collection Method: Grab Composite Sample Type: Fly Ash

\begin{tabular}{|c|c|c|c|c|c|c|c|c|}
\hline Analyte & $\begin{array}{l}\text { Analytical } \\
\text { Technique }\end{array}$ & Units & Run 1 & Com 1 & $\overline{\text { Run 2 }}$ & Com 2 & Run 3 & Com 3 \\
\hline $\begin{array}{l}\text { Arsenic } \\
\text { Cadmium } \\
\text { Lead } \\
\text { Selenium }\end{array}$ & $\begin{array}{l}\text { GFAA } \\
\text { GFAA } \\
\text { GFAA } \\
\text { GFAA }\end{array}$ & $\begin{array}{l}\mathrm{mg} / \mathrm{kg} \\
\mathrm{mg} / \mathrm{kg} \\
\mathrm{mg} / \mathrm{kg} \\
\mathrm{mg} / \mathrm{kg}\end{array}$ & $\begin{array}{r}235 \\
1.54 \\
63.7 \\
\mathrm{ND}(0.99)\end{array}$ & $\begin{array}{l}\mathrm{B} \\
\mathrm{B}\end{array}$ & \begin{tabular}{l|}
274 \\
1.54 \\
78.2 \\
1.08
\end{tabular} & $\begin{array}{l}\overline{\mathrm{B}} \\
\mathrm{B}\end{array}$ & $\begin{array}{r}291 \\
1.61 \\
66.4 \\
\mathrm{ND}(0.96)\end{array}$ & $\begin{array}{l}\mathrm{B} \\
\mathrm{B}\end{array}$ \\
\hline 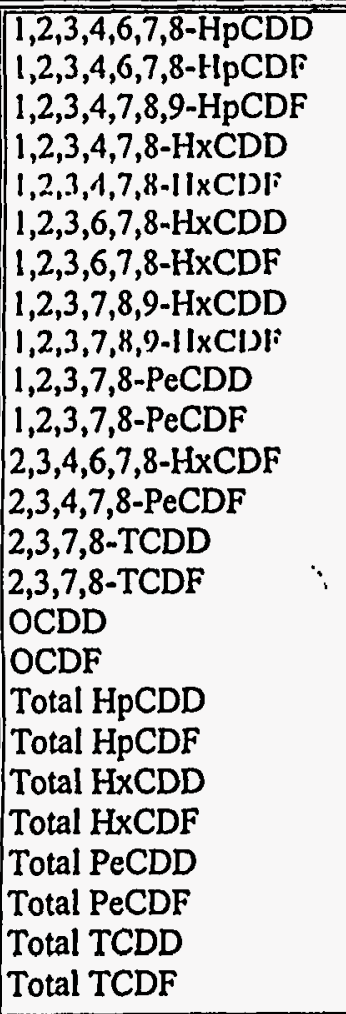 & $\begin{array}{l}\text { HR GCMS } \\
\text { HR GCMS } \\
\text { HR GCMS } \\
\text { HR GCMS } \\
\text { IIR GCMS } \\
\text { HR GCMS } \\
\text { HR GCMS } \\
\text { HR GCMS } \\
\text { III GCMS } \\
\text { HR GCMS } \\
\text { HR GCMS } \\
\text { HR GCMS } \\
\text { HR GCMS } \\
\text { HR GCMS } \\
\text { HR GCMS } \\
\text { HR GCMS } \\
\text { HR GCMS } \\
\text { HR GCMS } \\
\text { HR GCMS } \\
\text { HR GCMS } \\
\text { HR GCMS } \\
\text { HR GCMS } \\
\text { HR GCMS } \\
\text { HR GCMS } \\
\text { HR GCMS }\end{array}$ & $\begin{array}{l}\mathrm{ppt} \\
\mathrm{ppt} \\
\mathrm{ppt} \\
\mathrm{ppt} \\
\mathrm{ppt} \\
\mathrm{ppt} \\
\mathrm{ppt} \\
\mathrm{ppt} \\
\mathrm{ppt} \\
\mathrm{ppt} \\
\mathrm{ppt} \\
\mathrm{ppt} \\
\mathrm{ppt} \\
\mathrm{ppt} \\
\mathrm{ppt} \\
\mathrm{ppt} \\
\mathrm{ppt} \\
\mathrm{ppt} \\
\mathrm{ppt} \\
\mathrm{ppt} \\
\mathrm{ppt} \\
\mathrm{ppt} \\
\mathrm{ppt} \\
\mathrm{ppt} \\
\mathrm{ppt}\end{array}$ & $\begin{array}{l}\text { ND (0.60) } \\
\text { ND (0.30) } \\
\text { ND (0.50) } \\
\text { ND (0.50) } \\
\text { ND (0.30) } \\
\text { ND (0.40) } \\
\text { ND (0.20) } \\
\text { ND (0.40) } \\
\text { NI) (0.30) } \\
\text { ND (0.40) } \\
\text { ND (0.30) } \\
0.480 \\
\text { ND (0.20) } \\
\text { ND (0.30) } \\
\text { ND (0.20) } \\
\text { ND (0.80) } \\
\text { ND (0.70) } \\
\text { ND (0.60) } \\
\text { ND (0.30) } \\
\text { ND (0.40) } \\
0.480 \\
\text { ND (0.40) } \\
\text { ND (0.20) } \\
\text { ND (0.30) } \\
\text { ND (0.20) }\end{array}$ & & $\begin{array}{r}\text { ND (0.30) } \\
\text { ND (0.10) } \\
\text { ND (0.20) } \\
\text { ND (0.20) } \\
\text { NI (0.10) } \\
\text { ND (0.20) } \\
\text { ND (0.10) } \\
\text { ND (0.20) } \\
\text { NI (0.20) } \\
\text { ND (0.20) } \\
\text { ND (0.10) } \\
0.270 \\
\text { ND (0.10) } \\
\text { ND (0.10) } \\
\text { ND (0.090) } \\
0.290 \\
\text { ND (0.30) } \\
\text { ND (0.30) } \\
\text { ND (0.20) } \\
\text { ND (0.20) } \\
0.270 \\
\text { ND (0.20) } \\
\text { ND (0.10) } \\
0.150 \\
\text { ND (0.090) }\end{array}$ & & 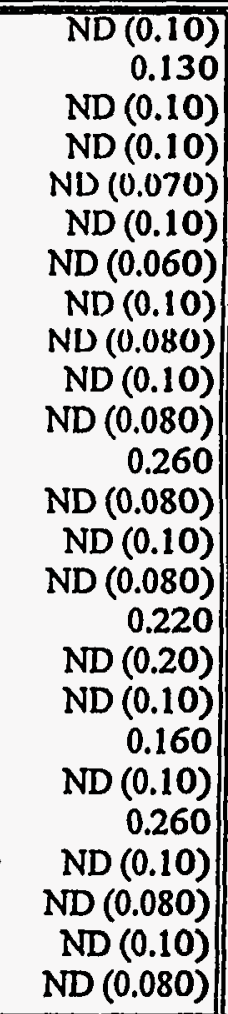 & \\
\hline $\begin{array}{l}\text { Aluminum } \\
\text { Antimony } \\
\text { Barium }\end{array}$ & $\begin{array}{l}\text { ICAP } \\
\text { ICAP } \\
\text { ICAP. }\end{array}$ & $\begin{array}{l}\mathrm{mg} / \mathrm{kg} \\
\mathrm{mg} / \mathrm{kg} \\
\mathrm{mg} / \mathrm{kg}\end{array}$ & $\begin{array}{r}55100 \\
\text { ND (45) } \\
198\end{array}$ & $\overline{\mathbf{B}}$ & $\begin{array}{r}52500 \\
\text { ND (49) } \\
189\end{array}$ & & $\begin{array}{r}56800 \\
\mathrm{ND}(50) \\
214\end{array}$ & $\overline{\mathbf{B}}$ \\
\hline
\end{tabular}


Stream: APF Ash Collection Method: Grab Composite Sample Type: Fly Ash

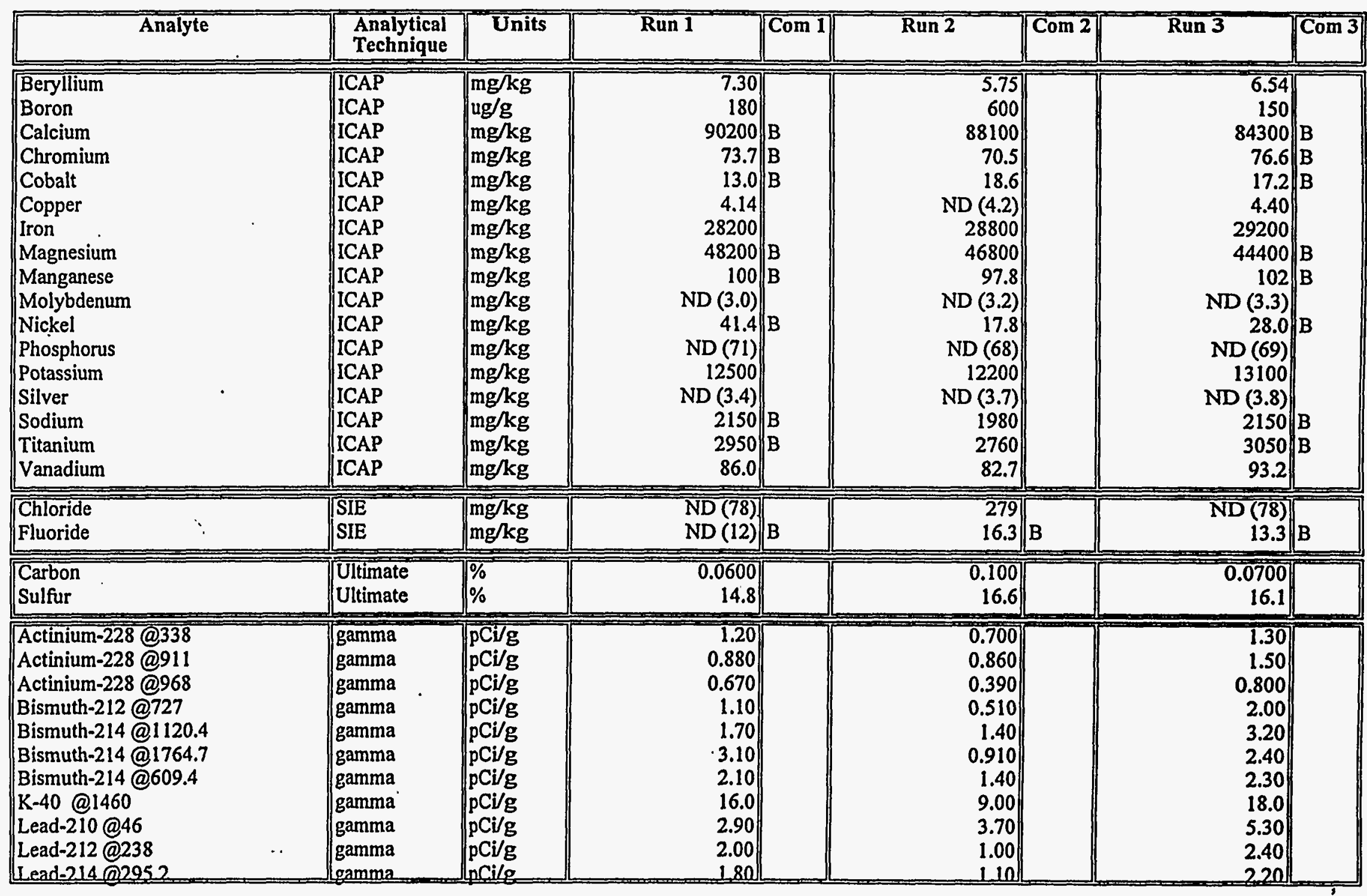




\section{Analytical Data Used In Calculations}

Stream: APF Ash Collection Method: Grab Composite Sample Type: Fly Ash

\begin{tabular}{|c|c|c|c|c|c|c|c|c|}
\hline Analyte & $\begin{array}{l}\text { Analytical } \\
\text { Technique }\end{array}$ & Units & Run 1 & Com 1 & Run 2 & $\widehat{C o m ~ 2}$ & Run 3 & $\mathrm{Com} 3$ \\
\hline $\begin{array}{l}\text { Lead-214@352.0 } \\
\text { Radium-226 @186.0 } \\
\text { Thallium-208 @583 } \\
\text { Thallium-208 @860 } \\
\text { Thorium-234 @63.3 } \\
\text { Thorium-234 @92.6 } \\
\text { Uranium-235 @143.8 }\end{array}$ & $\begin{array}{l}\text { gamma } \\
\text { gamma } \\
\text { gamma } \\
\text { gamma } \\
\text { gamma } \\
\text { gamma } \\
\text { gamma }\end{array}$ & $\begin{array}{l}\mathrm{pCi} / \mathrm{g} \\
\mathrm{pCi} / \mathrm{g} \\
\mathrm{pCi} / \mathrm{g} \\
\mathrm{pCi} / \mathrm{g} \\
\mathrm{pCi} / \mathrm{g} \\
\mathrm{pCi} / \mathrm{g} \\
\mathrm{pCi} / \mathrm{g}\end{array}$ & \begin{tabular}{r|}
2.40 \\
5.10 \\
0.390 \\
0.610 \\
2.60 \\
0.200 \\
0.310
\end{tabular} & & $\begin{array}{r}1.40 \\
1.90 \\
0.300 \\
N D(0.12) \\
2.50 \\
0.0900 \\
0.120\end{array}$ & & \begin{tabular}{r|}
2.80 \\
3.00 \\
0.560 \\
0.0700 \\
5.30 \\
1.20 \\
0.190
\end{tabular} & \\
\hline
\end{tabular}

Stream: APF Ash Collection Method: Grab Composite Sample Type: Fly Ash FD

\begin{tabular}{|c|c|c|c|c|c|c|c|c|}
\hline Analyte & $\begin{array}{l}\text { Analytical } \\
\text { Technique }\end{array}$ & Units & Run 1 & Com 1 & Run 2 & Com 2 & Run 3 & Com 3 \\
\hline Mercury & CVAA & $\mathrm{mg} / \mathrm{kg}$ & & & & & ND $(0.012)$ & \\
\hline $\begin{array}{l}\text { 1,2,4-Trichlorobenzene } \\
\text { 1,2-Dichlorobenzene } \\
\text { 1,3-Dichlorobenzene } \\
\text { 1,4-Dichlorobenzene } \\
\text { 2,4,5-Trichlorophenol } \\
\text { 2,4,6-Trichlorophenol } \\
\text { 2,4-Dichlorophenol } \\
\text { 2,4-Dimethylphenol } \\
\text { 2,4-Dinitrophenol } \\
\text { 2,4-Dinitrotoluene } \\
\text { 2,6-Dinitrotoluene } \\
\text { 2-Chloronaphthalene } \\
\text { 2-Chlorophenol } \\
\text { 2-Methylnaphthalene } \\
\text { 2-Methylphenol } \\
\text { 2-Nitroaniline } \\
\text { 2-Nitrophenol } \\
\text { 3,3'-Dichlorobenzidine } \\
\text { 3-Nitroaniline }\end{array}$ & $\begin{array}{l}\text { GCMS } \\
\text { GCMS } \\
\text { GCMS } \\
\text { GCMS } \\
\text { GCMS } \\
\text { GCMS } \\
\text { GCMS } \\
\text { GCMS } \\
\text { GCMS } \\
\text { GCMS } \\
\text { GCMS } \\
\text { GCMS } \\
\text { GCMS } \\
\text { GCMS } \\
\text { GCMS } \\
\text { GCMS } \\
\text { GCMS } \\
\text { GCMS } \\
\text { GCMS }\end{array}$ & $\begin{array}{l}\mathrm{ug} / \mathrm{g} \\
\mathrm{ug} / \mathrm{g} \\
\mathrm{ug} / \mathrm{g} \\
\mathrm{ug} / \mathrm{g} \\
\mathrm{ug} / \mathrm{g} \\
\mathrm{ug} / \mathrm{g} \\
\mathrm{ug} / \mathrm{g} \\
\mathrm{ug} / \mathrm{g} \\
\mathrm{ug} / \mathrm{g} \\
\mathrm{ug} / \mathrm{g} \\
\mathrm{ug} / \mathrm{g} \\
\mathrm{ug} / \mathrm{g} \\
\mathrm{ug} / \mathrm{g} \\
\mathrm{ug} / \mathrm{g} \\
\mathrm{ug} / \mathrm{g} \\
\mathrm{ug} / \mathrm{g} \\
\mathrm{ug} / \mathrm{g} \\
\mathrm{ug} / \mathrm{g} \\
\mathrm{ug} / \mathrm{g}\end{array}$ & & & : & & $\begin{array}{l}\text { ND (0.0064) } \\
\text { ND (0.021) } \\
\text { ND (0.024) } \\
\text { ND (0.023) } \\
\text { ND (0.019) } \\
\text { ND (0.016) } \\
\text { ND (0.019) } \\
\text { ND (0.042) } \\
\text { ND (0.086) } \\
\text { ND (0.025) } \\
\text { ND (0.035) } \\
\text { ND (0.030) } \\
\text { ND (0.011) } \\
\text { ND (0.020) } \\
\text { ND (0.026) } \\
\text { ND (0.026) } \\
\text { ND (0.014) } \\
\text { ND (0.036) } \\
\text { ND (0.011) }\end{array}$ & \\
\hline
\end{tabular}




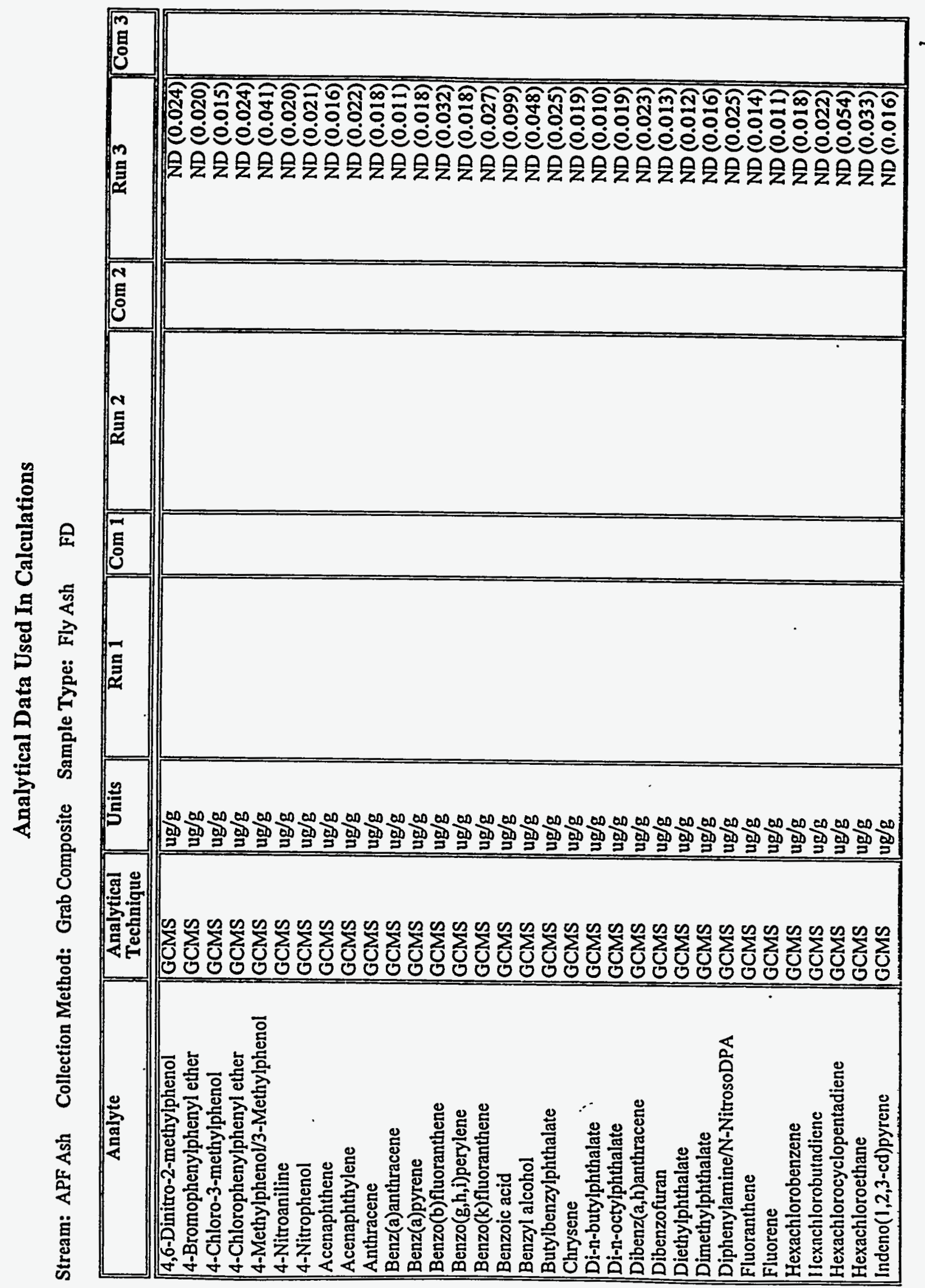

B-10 


\section{Analytical Data Used In Calculations}

Stream: APF Ash Collection Method: Grab Composite Sample Type: Fly Ash FD

\begin{tabular}{|c|c|c|c|c|c|c|c|c|}
\hline Analyte & $\begin{array}{l}\text { Analytical } \\
\text { Technique }\end{array}$ & Units & Run 1 & Com 1 & Run 2 & Com 2 & Run 3 & Com 3 \\
\hline $\begin{array}{l}\text { Isophorone } \\
\text { N-Nitroso-di-n-propylamine } \\
\text { Naphthalene } \\
\text { Nitrobenzene } \\
\text { Pentachlorophenol } \\
\text { Phenanthrene } \\
\text { Phenol . } \\
\text { Pyrene } \\
\text { bis(2-Chloroethoxy)methane } \\
\text { bis(2-Chloroethyl)ether } \\
\text { bis(2-Chloroisopropyl)ether } \\
\text { bis(2-Ethylhexyl)phthalate } \\
\text { p-Chloroaniline }\end{array}$ & $\begin{array}{l}\text { GCMS } \\
\text { GCMS } \\
\text { GCMS } \\
\text { GCMS } \\
\text { GCMS } \\
\text { GCMS } \\
\text { GCMS } \\
\text { GCMS } \\
\text { GCMS } \\
\text { GCMS } \\
\text { GCMS } \\
\text { GCMS } \\
\text { GCMS }\end{array}$ & $\begin{array}{l}\mathrm{ug} / \mathrm{g} \\
\mathrm{ug} / \mathrm{g} \\
\mathrm{ug} / \mathrm{g} \\
\mathrm{ug} / \mathrm{g} \\
\mathrm{ug} / \mathrm{g} \\
\mathrm{ug} / \mathrm{g} \\
\mathrm{ug} / \mathrm{g} \\
\mathrm{ug} / \mathrm{g} \\
\mathrm{ug} / \mathrm{g} \\
\mathrm{ug} / \mathrm{g} \\
\mathrm{ug} / \mathrm{g} \\
\mathrm{ug} / \mathrm{g} \\
\mathrm{ug} / \mathrm{g}\end{array}$ & & & & & $\begin{array}{l}\text { ND (0.010) } \\
\text { ND (0.026) } \\
\text { ND (0.022) } \\
\text { ND (0.013) } \\
\text { ND (0.0064) } \\
\text { ND (0.018) } \\
\text { ND (0.034) } \\
\text { ND (0.015) } \\
\text { ND (0.011) } \\
\text { ND (0.015) } \\
\text { ND (0.019) } \\
\text { ND (0.054) } \\
\text { ND (0.033) }\end{array}$ & \\
\hline \begin{tabular}{|l} 
Arsenic \\
Cadmium \\
Lead \\
Selenium
\end{tabular} & $\begin{array}{l}\text { GFAA } \\
\text { GFAA } \\
\text { GFAA } \\
\text { GFAA }\end{array}$ & $\begin{array}{l}\mathrm{mg} / \mathrm{kg} \\
\mathrm{mg} / \mathrm{kg} \\
\mathrm{mg} / \mathrm{kg} \\
\mathrm{mg} / \mathrm{kg}\end{array}$ & & & & & $\begin{array}{r}285 \\
1.53 \\
60.3 \\
\mathrm{ND}(0.96)\end{array}$ & B \\
\hline \begin{tabular}{||l}
$1,2,3,4,6,7,8-\mathrm{HpCDD}$ \\
$1,2,3,4,6,7,8-\mathrm{HpCDF}$ \\
$1,2,3,4,7,8,9-\mathrm{HpCDF}$ \\
$1,2,3,4,7,8-\mathrm{HxCDD}$ \\
$1,2,3,4,7,8-\mathrm{HxCDF}$ \\
$1,2,3,6,7,8-\mathrm{HxCDD}$ \\
$1,2,3,6,7,8-\mathrm{HxCDF}$ \\
$1,2,3,7,8,9-\mathrm{HxCDD}$ \\
$1,2,3,7,8,9-\mathrm{HxCDF}$ \\
$1,2,3,7,8-\mathrm{PeCDD}$ \\
$1,2,3,7,8-\mathrm{PeCDF}$ \\
$2,3,4,6,7,8-\mathrm{HxCDF}$ \\
$2,3,4,7,8-\mathrm{PeCDF}$ \\
$2,3,7,8-\mathrm{TCDD}$ \\
$2,3,7,8-\mathrm{TCDF}$
\end{tabular} & $\begin{array}{l}\text { HR GCMS } \\
\text { HR GCMS GCMS } \\
\text { HR GCMS } \\
\text { HR GCMS } \\
\text { HR GCMS } \\
\text { HR GCMS } \\
\text { HR GCMS } \\
\text { HR GCMS } \\
\text { HR GCMS } \\
\text { HR GCMS } \\
\text { HR GCMS } \\
\text { HR GCMS } \\
\text { HR GCMS } \\
\text { HR GCMS }\end{array}$ & $\begin{array}{l}\mathrm{ppt} \\
\mathrm{ppt} \\
\mathrm{ppt} \\
\mathrm{ppt} \\
\mathrm{ppt} \\
\mathrm{ppt} \\
\mathrm{ppt} \\
\mathrm{ppt} \\
\mathrm{ppt} \\
\mathrm{ppt} \\
\mathrm{ppt} \\
\mathrm{ppt} \\
\mathrm{ppt} \\
\mathrm{ppt} \\
\mathrm{ppt}\end{array}$ & & & & & $\begin{array}{r}\text { ND (0.40) } \\
\text { ND (0.20) } \\
\text { ND (0.30) } \\
\text { ND (0.30) } \\
\text { ND (0.20) } \\
\text { ND (0.30) } \\
\text { ND (0.10) } \\
\text { ND (0.30) } \\
\text { ND (0.20) } \\
\text { ND (0.40) } \\
\text { ND (0.20) } \\
0.210 \\
\text { ND (0.20) } \\
\text { ND (0.20) } \\
0.180\end{array}$ & 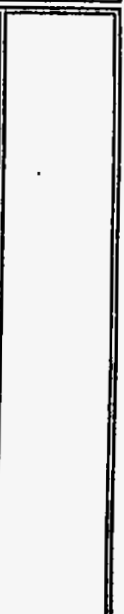 \\
\hline
\end{tabular}


Stream: APF Ash Collection Method: Grab Composite Sample Type: Fly Ash FD

\begin{tabular}{|c|c|c|c|c|c|c|c|c|}
\hline Analyte & $\begin{array}{l}\text { Analytical } \\
\text { Technique }\end{array}$ & Units & Run 1 & Com 1 & $\overline{R u n ~} 2$ & Com 2 & $\overline{R u n 3}$ & Com 3 \\
\hline \begin{tabular}{|l} 
OCDD \\
OCDF \\
Total HpCDD \\
Total HpCDF \\
Total HxCDD \\
Total HxCDF \\
Total PeCDD \\
Total PeCDF \\
Total TCDD \\
Total TCDF
\end{tabular} & $\begin{array}{l}\text { HR GCMS } \\
\text { HR GCMS } \\
\text { HR GCMS } \\
\text { HR GCMS } \\
\text { HR GCMS } \\
\text { HR GCMS } \\
\text { HR GCMS } \\
\text { HR GCMS } \\
\text { HR GCMS } \\
\text { HR GCMS }\end{array}$ & $\begin{array}{l}\mathrm{ppt} \\
\mathrm{ppt} \\
\mathrm{ppt} \\
\mathrm{ppt} \\
\mathrm{ppt} \\
\mathrm{ppt} \\
\mathrm{ppt} \\
\mathrm{ppt} \\
\mathrm{ppt} \\
\mathrm{ppt}\end{array}$ & & & $:$ & & \begin{tabular}{r|} 
ND $(0.60)$ \\
ND $(0.50)$ \\
ND $(0.40)$ \\
ND (0.30) \\
ND (0.30) \\
0.210 \\
ND (0.40) \\
ND (0.20) \\
ND (0.20) \\
0.180 \\
\end{tabular} & \\
\hline \begin{tabular}{|l} 
Aluminum \\
Antimony \\
Barium \\
Beryllium \\
Boron \\
Calcium \\
Chromium \\
Cobalt \\
Copper \\
Iron \\
Magnesium \\
Manganese \\
Molybdenum \\
Nickel \\
Phosphorus \\
Potassium \\
Silver \\
Sodium \\
Titanium \\
Vanadium
\end{tabular} & $\begin{array}{l}\text { ICAP } \\
\text { ICAP } \\
\text { ICAP } \\
\text { ICAP } \\
\text { ICAP } \\
\text { ICAP } \\
\text { ICAP } \\
\text { ICAP } \\
\text { ICAP } \\
\text { ICAP } \\
\text { ICAP } \\
\text { ICAP } \\
\text { ICAP } \\
\text { ICAP } \\
\text { ICAP } \\
\text { ICAP } \\
\text { ICAP } \\
\text { ICAP } \\
\text { ICAP } \\
\text { ICAP }\end{array}$ & $\begin{array}{l}\mathrm{mg} / \mathrm{kg} \\
\mathrm{mg} / \mathrm{kg} \\
\mathrm{mg} / \mathrm{kg} \\
\mathrm{mg} / \mathrm{kg} \\
\mathrm{ug} / \mathrm{g} \\
\mathrm{mg} / \mathrm{kg} \\
\mathrm{mg} / \mathrm{kg} \\
\mathrm{mg} / \mathrm{kg} \\
\mathrm{mg} / \mathrm{kg} \\
\mathrm{mg} / \mathrm{kg} \\
\mathrm{mg} / \mathrm{kg} \\
\mathrm{mg} / \mathrm{kg} \\
\mathrm{mg} / \mathrm{kg} \\
\mathrm{mg} / \mathrm{kg} \\
\mathrm{mg} / \mathrm{kg} \\
\mathrm{mg} / \mathrm{kg} \\
\mathrm{mg} / \mathrm{kg} \\
\mathrm{mg} / \mathrm{kg} \\
\mathrm{mg} / \mathrm{kg} \\
\mathrm{mg} / \mathrm{kg}\end{array}$ & & & & & \begin{tabular}{|r|r|}
56500 & \\
$\mathrm{ND}(41)$ & \\
217 & \\
6.61 & \\
105 & \\
83600 & \\
76.4 & $\mathrm{~B}$ \\
18.6 & $\mathrm{~B}$ \\
6.61 & \\
29100 & \\
44500 & $\mathrm{~B}$ \\
103 & $\mathrm{~B}$ \\
$\mathrm{ND}(2.7)$ & \\
26.2 & $\mathrm{~B}$ \\
$\mathrm{ND}(69)$ & \\
13600 & \\
$\mathrm{ND}(3.1)$ & \\
2250 & $\mathrm{~B}$ \\
3090 & $\mathrm{~B}$ \\
93.4 & \\
\end{tabular} & \begin{tabular}{|l} 
B \\
B \\
B \\
B \\
B \\
B \\
B \\
\\
$B$ \\
$B$
\end{tabular} \\
\hline \begin{tabular}{|l} 
Chloride \\
Fluoride
\end{tabular} & $\begin{array}{l}\text { SIE } \\
\text { SIE }\end{array}$ & $\begin{array}{l}\mathrm{mg} / \mathrm{kg} \\
\mathrm{mg} / \mathrm{kg}\end{array}$ & & & & & $\begin{array}{r}261 \\
23.2\end{array}$ & B \\
\hline
\end{tabular}



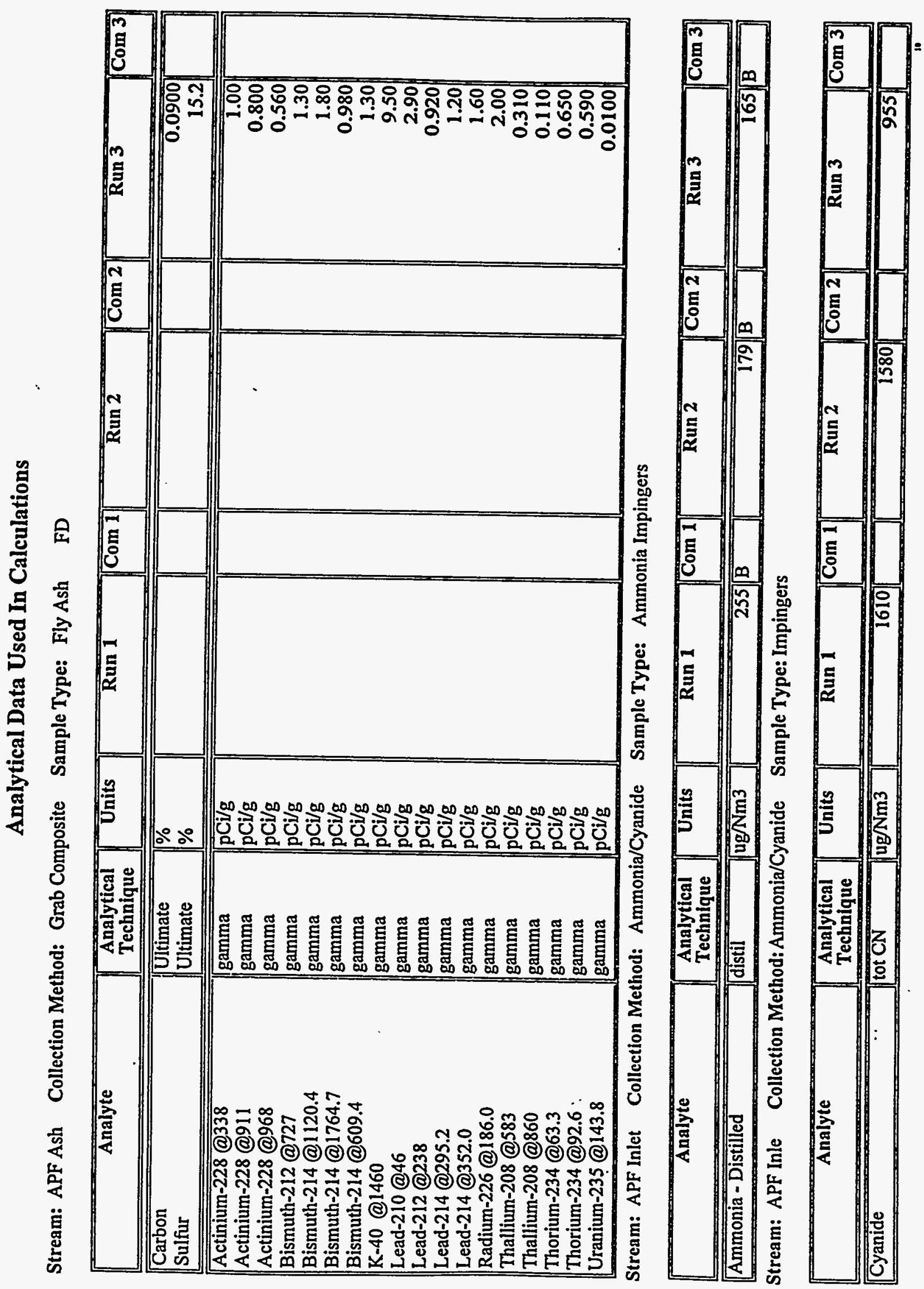
Stream: APF Inlet Collection Method: Anions Train Sample Type: Filtered Solids

\begin{tabular}{|c|c|c|c|c|c|c|c|c|}
\hline Analyte & $\begin{array}{l}\text { Analytical } \\
\text { Technique }\end{array}$ & Units & Run 1 & Com 1 & Run 2 & Com 2 & Run 3 & $\mathrm{Com} 3$ \\
\hline $\begin{array}{l}\text { Chloride } \\
\text { Chloride } \\
\text { Sulfate } \\
\text { Sulfate } \\
\end{array}$ & {$\left[\begin{array}{l}\mathrm{IC} \\
\mathrm{IC} \\
\mathrm{IC} \\
\mathrm{IC}\end{array}\right.$} & $\begin{array}{l}\mathrm{ug} / \mathrm{Nm} 3 \\
\mathrm{ug} / \mathrm{g} \\
\mathrm{ug} / \mathrm{Nm} 3 \\
\mathrm{ug} / \mathrm{g}\end{array}$ & $\begin{array}{r}1050 \\
287 \\
2680000 \\
736000 \\
\end{array}$ & & $\begin{array}{r}1100 \\
231 \\
3850000 \\
805000 \\
\end{array}$ & & $\begin{array}{r}5260 \\
1520 \\
4590000 \\
1330000\end{array}$ & \\
\hline $\begin{array}{l}\text { Fluoride } \\
\text { Fluoride } \\
\end{array}$ & $\begin{array}{l}\text { SIE } \\
\text { SIE }\end{array}$ & $\begin{array}{l}\mathrm{ug} / \mathrm{Nm} 3 \\
\mathrm{ug} / \mathrm{g}\end{array}$ & $\begin{array}{l}639 \\
175 \\
\end{array}$ & C & $\begin{array}{l}772 \\
162 \\
\end{array}$ & $\begin{array}{l}\mathrm{C} \\
\mathrm{C}\end{array}$ & $\begin{array}{r}1840 \\
532 \\
\end{array}$ & C \\
\hline
\end{tabular}

Stream: APF Inlet Collection Method: Anions Train Sample Type: Impingers + TLR

\begin{tabular}{|c|c|c|c|c|c|c|c|c|}
\hline Analyte & $\begin{array}{l}\text { Analytical } \\
\text { Technique }\end{array}$ & Units & Run 1 & Com 1 & Run 2 & Com 2 & Run 3 & Com 3 \\
\hline $\begin{array}{l}\text { Chloride } \\
\text { Sulfate }\end{array}$ & IIC & $\begin{array}{l}\mathrm{ug} / \mathrm{Nm} 3 \\
\mathrm{ug} / \mathrm{Nm} 3\end{array}$ & $\begin{array}{r}79100 \\
791000\end{array}$ & & $\begin{array}{r}71700 \\
953000\end{array}$ & & $\begin{array}{r}65400 \\
811000\end{array}$ & \\
\hline Fluoride & SIE & ug $/ \mathrm{Nm} 3$ & 7240 & $B$ & 6860 & $\overline{\bar{B}}$ & 5950 & W \\
\hline
\end{tabular}

Stream: APF Inlet Collection Method: M001la Sample Type: Impingers + MeCl2

\begin{tabular}{|c|c|c|c|c|c|c|c|c|}
\hline Analyte & $\begin{array}{l}\text { Analytical } \\
\text { Technique }\end{array}$ & Units & Run 1 & Com 1 & Run 2 & Com 2 & Run 3 & Com 3 \\
\hline Formaldehyde & HPLC & ug/Nm3 & 39.9 & & 146 & & 17.0 & \\
\hline
\end{tabular}

Stream: APF Inlet Collection Method: M29 Sample Type: Filtered Solids

\begin{tabular}{|c|c|c|c|c|c|c|c|c|c|}
\hline Analyte & & $\begin{array}{l}\text { Analytical } \\
\text { Technique }\end{array}$ & Units & Run 1 & Com 1 & Run 2 & Com 2 & Run 3 & Com 3 \\
\hline Mercury & & CVAA & ug/Nm3 & $\mathrm{ND}(0.042)$ & & ND (0.050) & & $\mathrm{ND}(0.046)$ & \\
\hline $\begin{array}{l}\text { Arsenic } \\
\text { Cadmium } \\
\text { Lead } \\
\text { Selenium }\end{array}$ & . & $\begin{array}{l}\text { GFAA } \\
\text { GFAA } \\
\text { GFAA } \\
\text { GFAA }\end{array}$ & $\begin{array}{l}\text { ug/Nm3 } \\
\text { ug/Nm3 } 3 \\
\text { ug/Nm3 } 3 \\
\text { ug/Nm3 }\end{array}$ & $\begin{array}{r}831 \\
4.96 \\
196 \\
50.7 \\
\end{array}$ & & \begin{tabular}{r|}
1420 \\
6.93 \\
287 \\
54.0
\end{tabular} & & \begin{tabular}{r|}
1030 \\
8.23 \\
236 \\
48.6
\end{tabular} & \\
\hline
\end{tabular}


Analytical Data Used In Calculations

Stream: APF Inlet Collection Method: M29 Sample Type: Filtered Solids

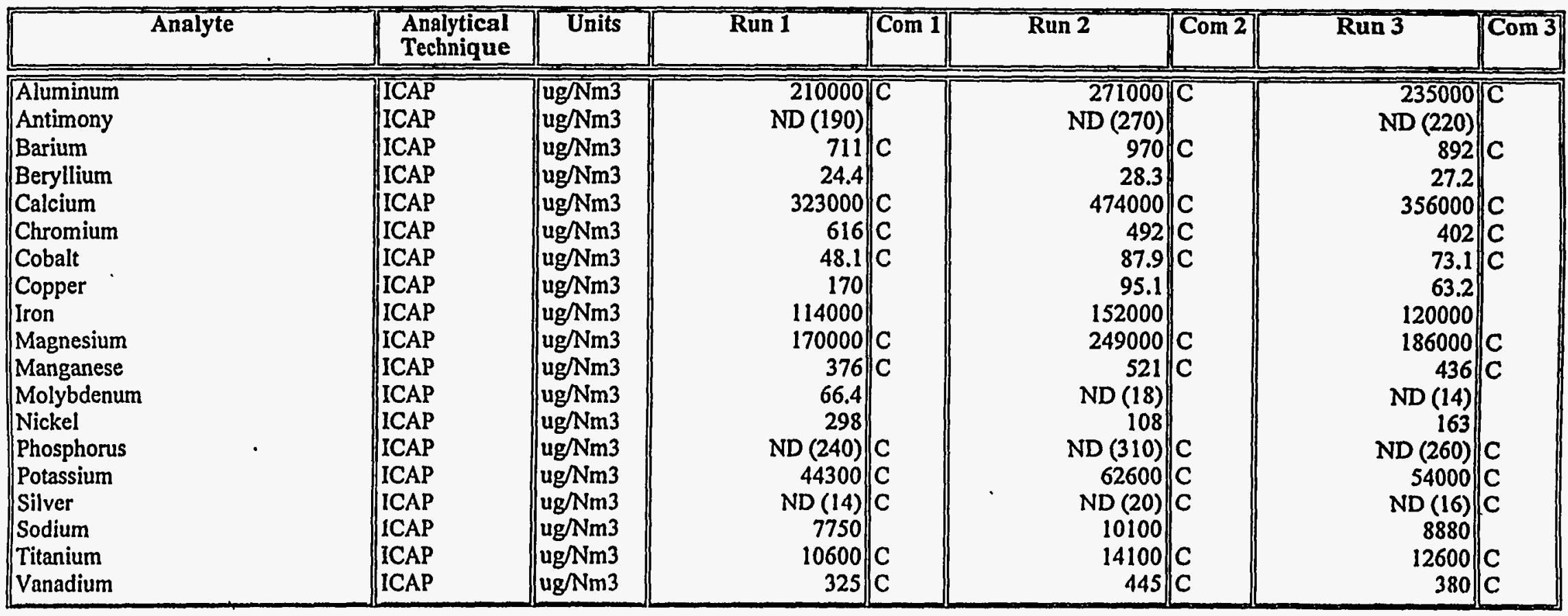

Stream: APF Inlet Collection Method: MMS Sample Type: Filtered Solids

\begin{tabular}{|c|c|c|c|c|c|c|c|c|c|}
\hline Analyte & & $\begin{array}{l}\text { Analytical } \\
\text { Technique }\end{array}$ & Units & Run 1 & Com I & Run 2 & Com 2 & Run 3 & Com 3 \\
\hline $\begin{array}{l}\text { 1,2,4-Trichlorobenzene } \\
\text { 1,2-Dichlorobenzene } \\
\text { 1,3-Dichlorobenzene } \\
\text { 1,4-Dichlorobenzene } \\
\text { 2,4,5-Trichlorophenol } \\
\text { 2,4,6-Trichlorophenol } \\
\text { 2,4-Dichlorophenol } \\
\text { 2,4-Dimethylphenol } \\
\text { 2,4-Dinitrophenol }\end{array}$ & $\cdot$ & $\begin{array}{l}\text { GCMS } \\
\text { GCMS } \\
\text { GCMS } \\
\text { GCMS } \\
\text { GCMS } \\
\text { GCMS } \\
\text { GCMS } \\
\text { GCMS } \\
\text { GCMS }\end{array}$ & $\begin{array}{l}\mathrm{ug} / \mathrm{Nm} 3 \\
\mathrm{ug} / \mathrm{Nm} 3 \\
\mathrm{ug} / \mathrm{Nm} 3 \\
\mathrm{ug} / \mathrm{Nm} 3 \\
\mathrm{ug} / \mathrm{Nm} 3 \\
\mathrm{ug} / \mathrm{Nm} 3 \\
\mathrm{ug} / \mathrm{Nm} 3 \\
\mathrm{ug} / \mathrm{Nm} 3 \\
\mathrm{ug} / \mathrm{Nm} 3\end{array}$ & $\begin{array}{l}\text { ND (2.9) } \\
\text { ND (2.7) } \\
\text { ND (2.6) } \\
\text { ND (2.5) } \\
\text { ND (4.3) } \\
\text { ND (4.6) } \\
\text { ND (3.4) } \\
\text { ND (3.8) } \\
\text { ND (13) }\end{array}$ & & $\begin{array}{l}\text { ND (2.8) } \\
\text { ND (2.7) } \\
\text { ND (2.5) } \\
\text { ND (2.4) } \\
\text { ND (4.3) } \\
\text { ND (4.6) } \\
\text { ND (3.3) } \\
\text { ND (3.7) } \\
\text { ND (13) }\end{array}$ & & $\begin{array}{l}\text { ND (2.9) } \\
\text { ND (2.8) } \\
\text { ND (2.7) } \\
\text { ND (2.6) } \\
\text { ND (4.5) } \\
\text { ND (4.8) } \\
\text { ND (3.5) } \\
\text { ND (3.9) } \\
\text { ND (13) }\end{array}$ & \\
\hline
\end{tabular}


Strenm: APF Inlet Collection Method: MM5 Sample Type: Filtered Solids

\begin{tabular}{|c|c|c|c|c|c|c|c|c|}
\hline Analyte & $\begin{array}{l}\text { Analytical } \\
\text { Technique }\end{array}$ & Units & Run 1 & Com 1 & Run 2 & Com 2 & $\operatorname{Run} 3$ & Com 3 \\
\hline \begin{tabular}{|l} 
2,4-Dinitrotoluene \\
2,6-Dinitrotoluene \\
2-Chloronaphthalene \\
2-Chlorophenol \\
2-Methylnaphthalene \\
2-Methylphenol \\
2-Nitroaniline \\
2-Nitrophenol \\
3,3'-Dichlorobenzidine \\
3-Nitroaniline \\
4,6-Dinitro-2-methylphenol \\
4-Aminobiphenyl \\
4-Chloro-3-methylphenol \\
4-Nitroaniline \\
4-Nitrophenol \\
Acenaphthene \\
Acenaphthylene \\
Acetophenone \\
Aniline \\
Anthracene \\
Benzidine \\
Benzo(b)fluoranthene \\
Benzo(g,h,i)perylene \\
Benzo(k)fluoranthene \\
Benzoic acid \\
Benzyl alcohol \\
Butylbenzylphthalate \\
Chrysene \\
Di-n-butylphthalate \\
Di-n-octylphthalate \\
Dibenz(a,h)anthracene \\
Dibenzofuran \\
Diethylphthalate
\end{tabular} & \begin{tabular}{|l} 
GCMS \\
GCMS \\
GCMS \\
GCMS \\
GCMS \\
GCMS \\
GCMS \\
GCMS \\
GCMS \\
GCMS \\
GCMS \\
GCMS \\
GCMS \\
GCMS \\
GCMS \\
GCMS \\
GCMS \\
GCMS \\
GCMS \\
GCMS \\
GCMS \\
GCMS \\
GCMS \\
GCMS \\
GCMS \\
GCMS \\
GCMS \\
GCMS \\
GCMS \\
GCMS \\
GCMS \\
GCMS \\
GCMS
\end{tabular} & 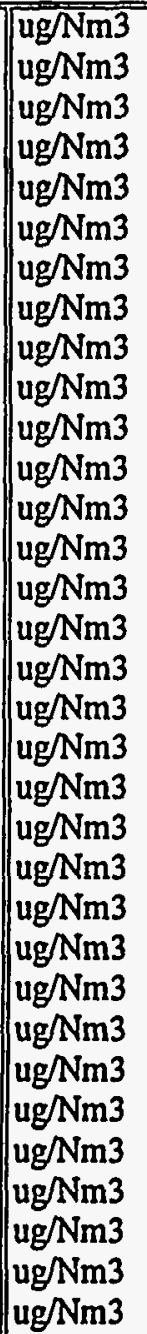 & $\begin{array}{r}\text { ND(4.2) } \\
\text { ND (6.0) } \\
\text { ND (1.7) } \\
\text { ND (2.8) } \\
\text { ND (1.7) } \\
\text { ND (3.4) } \\
\text { ND (6.1) } \\
\text { ND (5.1) } \\
\text { ND (3.1) } \\
\text { ND (5.4) } \\
\text { ND (7.6) } \\
\text { ND (1.6) } \\
\text { ND (3.7) } \\
\text { ND (5.0) } \\
\text { ND (12) } \\
\text { ND (1.9) } \\
\text { ND (1.1) } \\
\text { ND (2.8) } \\
\text { ND (2.2) } \\
\text { ND (1.1) } \\
\text { ND (2.2) } \\
\text { ND (0.94) } \\
\text { ND (0.91) } \\
\text { ND (1.0) } \\
\text { ND(10) } \\
\text { ND (5.2) } \\
\text { ND (1.5) } \\
\text { ND (0.89) } \\
\text { 3.09 } \\
\text { ND(0.82) } \\
\text { ND (1.1) } \\
\text { ND (1.2) } \\
\text { ND (1.4) }\end{array}$ & BJ & $\begin{array}{r}\text { ND (4.2) } \\
\text { ND (6.0) } \\
\text { ND (1.7) } \\
\text { ND (2.8) } \\
\text { ND (1.6) } \\
\text { ND (3.3) } \\
\text { ND (6.1) } \\
\text { ND (5.1) } \\
\text { ND (3.1) } \\
\text { ND (5.3) } \\
\text { ND (7.7) } \\
\text { ND (1.6) } \\
\text { ND (3.7) } \\
\text { ND (5.0) } \\
\text { ND (12) } \\
\text { ND (1.9) } \\
\text { ND (1.1) } \\
\text { ND (2.7) } \\
\text { ND (2.2) } \\
\text { ND (1.1) } \\
\text { ND (2.1) } \\
\text { ND (0.95) } \\
\text { ND (0.91) } \\
\text { ND (1.0) } \\
\text { ND (10) } \\
\text { ND (5.1) } \\
\text { ND (1.5) } \\
\text { ND (0.87) } \\
20.3 \\
\text { ND (0.82) }(1.4) \\
\text { ND (1.1) }\end{array}$ & B & $\begin{array}{r}\text { ND (4.4) } \\
\text { ND (6.2) } \\
\text { ND (1.8) } \\
\text { ND (2.9) } \\
\text { ND (1.7) } \\
\text { ND (3.5) } \\
\text { ND (6.3) } \\
\text { ND (5.3) } \\
\text { ND (3.4) } \\
\text { ND (5.5) } \\
\text { ND (8.3) } \\
\text { ND (1.8) } \\
\text { ND (3.9) } \\
\text { ND (5.2) } \\
\text { ND (13) } \\
\text { ND (2.0) } \\
\text { ND (1.1) } \\
\text { ND (2.9) } \\
\text { ND (2.3) } \\
\text { ND (1.2) } \\
\text { ND (2.3) } \\
\text { ND (0.96) } \\
\text { ND }(0.93) \\
\text { ND (1.0) } \\
\text { ND (11) } \\
\text { ND (5.3) } \\
\text { ND (1.6) } \\
\text { ND (0.95) } \\
1.5) \\
\text { ND (0.84) }\end{array}$ & B \\
\hline
\end{tabular}




\section{Analytical Data Used In Calculations}

Stream: APF Inlet Collection Method: MM5 Sample Type: Filtered Solids

\begin{tabular}{|c|c|c|c|c|c|c|c|c|}
\hline Analyte & $\begin{array}{l}\text { Analytical } \\
\text { Technique }\end{array}$ & Units & Run 1 & Com 1 & Run 2 & Com 2 & Run 3 & $\longdiv { \operatorname { C o m } 3 }$ \\
\hline $\begin{array}{l}\text { Dimethylphthalate } \\
\text { Fluoranthene } \\
\text { Fluorene } \\
\text { Hexachlorobenzene } \\
\text { Hexachlorobutadiene } \\
\text { Hexachlorocyclopentadiene } \\
\text { Hexachloroethane } \\
\text { Indeno(1,2,3-cd)pyrene } \\
\text { Isophorone } \\
\text { N-Nitroso-di-n-propylamine } \\
\text { Naphthalerie } \\
\text { Nitrobenzene } \\
\text { Pentachloronitrobenzene } \\
\text { Pentachlorophenol } \\
\text { Phenanthrene } \\
\text { Phenol } \\
\text { Pyrene } \\
\text { bis(2-Chloroethoxy)methane } \\
\text { bis(2-Chloroethyl)ether } \\
\text { bis(2-Ethylhexyl)phthalate }\end{array}$ & $\begin{array}{l}\text { GCMS } \\
\text { GCMS } \\
\text { GCMS } \\
\text { GCMS } \\
\text { GCMS } \\
\text { GCMS } \\
\text { GCMS } \\
\text { GCMS } \\
\text { GCMS } \\
\text { GCMS } \\
\text { GCMS } \\
\text { GCMS } \\
\text { GCMS } \\
\text { GCMS } \\
\text { GCMS } \\
\text { GCMS } \\
\text { GCMS } \\
\text { GCMS } \\
\text { GCMS } \\
\text { GCMS }\end{array}$ & 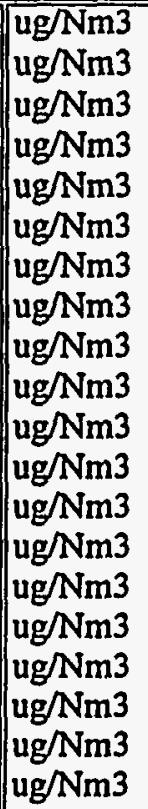 & $\begin{array}{r}\text { ND (1.6) } \\
\text { ND (0.87) } \\
\text { ND (1.6) } \\
\text { ND (3.5) } \\
\text { ND (4.7) } \\
\text { ND (6.4) } \\
\text { ND (5.1) } \\
\text { ND (0.81) } \\
\text { ND (1.7) } \\
\text { ND (5.1) } \\
\text { ND (1.1) } \\
\text { ND (2.9) } \\
\text { ND (16) } \\
\text { ND (8.1) } \\
\text { ND (1.1) } \\
\text { ND (2.3) } \\
\text { ND (0.75) } \\
\text { ND (2.5) } \\
\text { ND (3.0) } \\
1.20\end{array}$ & . & \begin{tabular}{r|} 
ND (1.6) \\
ND (0.88) \\
ND (1.6) \\
ND (3.6) \\
ND (4.7) \\
ND (6.4) \\
ND (5.1) \\
ND (0.82) \\
ND (1.7) \\
ND (5.0) \\
ND (1.1) \\
ND (2.9) \\
ND (16) \\
ND (8.1) \\
ND (1.1) \\
ND (2.3) \\
ND (0.74) \\
ND (2.5) \\
ND (3.0) \\
ND (1.1)
\end{tabular} & & $\begin{array}{c}\mathrm{ND}(1.6) \\
\mathrm{ND}(0.95) \\
\mathrm{ND}(1.7) \\
\mathrm{ND}(3.8) \\
\mathrm{ND}(4.9) \\
\mathrm{ND}(6.6) \\
\mathrm{ND}(5.3) \\
\mathrm{ND}(0.83) \\
\mathrm{ND}(1.8) \\
\mathrm{ND}(5.3) \\
\mathrm{ND}(1.1) \\
\mathrm{ND}(3.0) \\
\mathrm{ND}(17) \\
\mathrm{ND}(8.8) \\
\mathrm{ND}(1.2) \\
\mathrm{ND}(2.4) \\
\mathrm{ND}(0.81) \\
\mathrm{ND}(2.6) \\
\mathrm{ND}(3.1) \\
\mathrm{ND}(1.2)\end{array}$ & \\
\hline
\end{tabular}

Stream: APF Inlet Collection Method: MM5 Sample Type: XAD Resin/Impingers + MeCl2

\begin{tabular}{|c|c|c|c|c|c|c|c|c|}
\hline Analyte & $\begin{array}{l}\text { Analytical } \\
\text { Technique }\end{array}$ & Units & Run 1 & Com 1 & $\overline{\text { Run } 2}$ & $\overline{C o m ~} 2$ & Run 3 & $\mathrm{Com} 3$ \\
\hline
\end{tabular}


Stream: APF Inlet Collection Method: MM5 Sample Type: XAD Resin/Impingers + $\mathrm{MeCl} 2$

\begin{tabular}{|c|c|c|c|c|c|c|c|c|}
\hline Analyte & $\begin{array}{l}\text { Analytical } \\
\text { Technique }\end{array}$ & Units & Run 1 & Com 1 & Run 2 & Com 2 & Run 3 & $\operatorname{Com} 3$ \\
\hline \begin{tabular}{|l} 
2,4-Dinitrophenol \\
2,4-Dinitrotoluene \\
2,6-Dinitrotoluene \\
2-Chloronaphthalene \\
2-Chlorophenol \\
2-Methylnaphthalene \\
2-Methylphenol \\
2-Nitroaniline \\
2-Nitroplicnol \\
3,3'-Dichlorobenzidine \\
3-Nitroaniline \\
4,6-Dinitro-2-methylphenol \\
4-Aminobiphenyl \\
4-Chloro-3-methylphenol \\
4-Nitroaniline \\
4-Nitrophenol \\
Acenaphthene \\
Acenaphthylene \\
Acetophenone \\
Aniline \\
Anthracene \\
Benzidinc \\
Benzo(b)nuoranthene \\
Benzo(g,h,i)perylene \\
Benzo(k)fluoranthene \\
Benzoic acid \\
Benzyl alcohol \\
Butylbenzylphthalate \\
Chrysene \\
Di-n-butylphthalate \\
Di-n-octylphthalate \\
Dibenz(a,h)anthracene \\
Dibenzofuran
\end{tabular} & \begin{tabular}{|l} 
GCMS \\
GCMS \\
GCMS \\
GCMS \\
GCMS \\
GCMS \\
GCMS \\
GCMS \\
GCMS \\
GCMS \\
GCMS \\
GCMS \\
GCMS \\
GCMS \\
GCMS \\
GCMS \\
GCMS \\
GCMS \\
GCMS \\
GCMS \\
GCMS \\
GCMS \\
GCMS \\
GCMS \\
GCMS \\
GCMS \\
GCMS \\
GCMS \\
GCMS \\
GCMS \\
GCMS \\
GCMS
\end{tabular} & 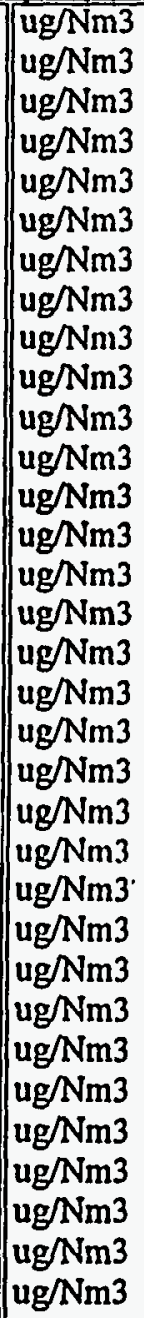 & 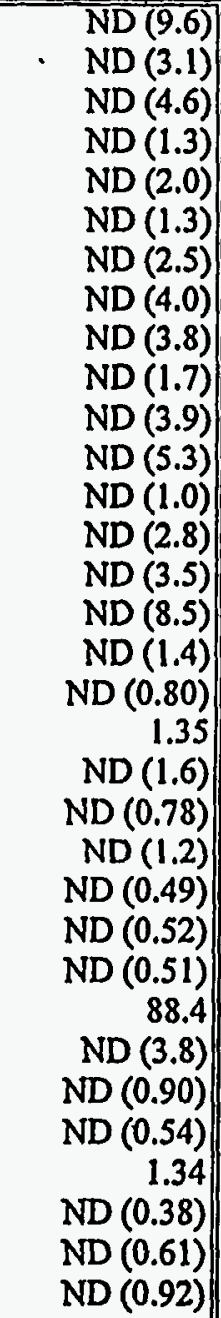 & $\mathrm{J}$ & $\begin{array}{r}\text { ND (5.3) } \\
\text { ND (1.8) } \\
\text { ND (2.6) } \\
\text { ND (0.73) } \\
\text { ND (1.2) } \\
\text { ND (0.70) } \\
\text { ND (1.7) } \\
\text { ND (2.5) } \\
\text { ND (2.7) } \\
\text { ND (2.1) } \\
\text { ND (2.2) } \\
\text { ND (3.2) } \\
\text { ND (0.50) } \\
\text { ND (1.5) } \\
\text { ND (1.9) } \\
0.645 \\
\text { ND (0.76) } \\
\text { ND (0.45) } \\
1.75 \\
\text { ND(1.2) } \\
\text { ND (0.36) } \\
\text { ND (1.1) } \\
\text { ND (0.61) } \\
\text { ND (0.56) } \\
\text { ND (0.61) } \\
124 \\
\text { ND (2.5) } \\
\text { ND (0.74) } \\
\text { ND (0.54) } \\
\text { ND (0.53 } \\
\text { ND (0.75) } \\
\text { ND (0.46) }\end{array}$ & $E$ & 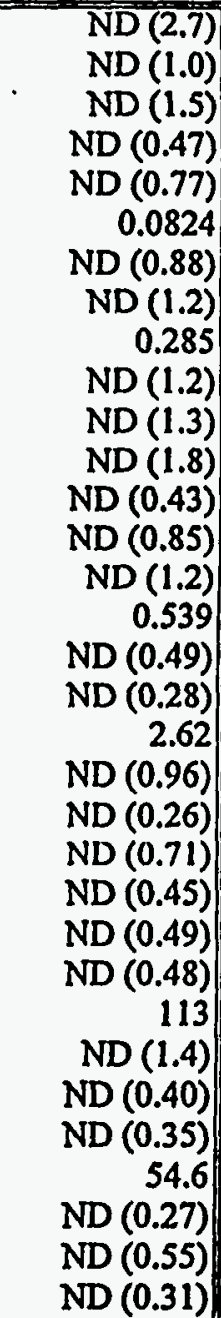 & $\mathbf{J}$ \\
\hline
\end{tabular}




\section{Analytical Data Used In Calculations}

Stream: APF Inlet Collection Method: MM5 Sample Type: XAD Resin/Impingers + MeCl2

\begin{tabular}{|c|c|c|c|c|c|c|c|c|}
\hline Analyte & $\begin{array}{l}\text { Analytical } \\
\text { Technique }\end{array}$ & Units & Run 1 & Com 1 & Run 2 & Com 2 & Run 3 & Com 3 \\
\hline $\begin{array}{l}\text { Dicthylphthalate } \\
\text { Dimethylphthalate } \\
\text { Fluoranthene } \\
\text { Fluorene } \\
\text { Hexachlorobenzene } \\
\text { Hexachlorobutadiene } \\
\text { Hexachlorocyclopentadiene } \\
\text { Hexachloroethane } \\
\text { Indeno(1,2,3-cd)pyrene } \\
\text { Isophorone } \\
\text { N-Nitroso-di-n-propylamine } \\
\text { Naphthalene } \\
\text { Nitrobenzene } \\
\text { Pentachloronitrobenzene } \\
\text { Pentachlorophenol } \\
\text { Phenanthrene } \\
\text { Phenol } \\
\text { Pyrene } \\
\text { bis(2-Chloroethoxy)methane } \\
\text { bis(2-Chloroethyl)ether } \\
\text { bis(2-Ethylhexyl)phthalate }\end{array}$ & $\begin{array}{l}\text { GCMS } \\
\text { GCMS } \\
\text { GCMS } \\
\text { GCMS } \\
\text { GCMS } \\
\text { GCMS } \\
\text { GCMS } \\
\text { GCMS } \\
\text { GCMS } \\
\text { GCMS } \\
\text { GCMS } \\
\text { GCMS } \\
\text { GCMS } \\
\text { GCMS } \\
\text { GCMS } \\
\text { GCMS } \\
\text { GCMS } \\
\text { GCMS } \\
\text { GCMS } \\
\text { GCMS } \\
\text { GCMS }\end{array}$ & 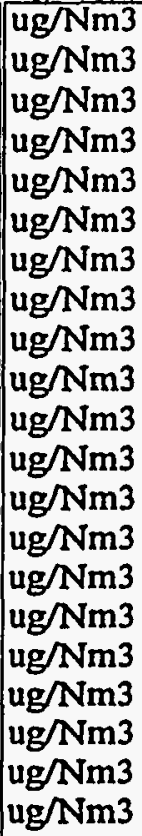 & $\begin{array}{r}\text { ND (1.1) } \\
\text { ND (1.2) } \\
\text { ND (0.55) } \\
\text { ND (1.2) } \\
\text { ND (2.6) } \\
\text { ND (3.7) } \\
\text { ND (4.4) } \\
\text { ND (4.0) } \\
\text { ND (0.45) } \\
\text { ND (1.3) } \\
\text { ND (3.6) } \\
\text { ND (0.81) } \\
\text { ND (2.2) } \\
\text { ND (10) } \\
\text { ND (6.7) } \\
\text { ND (0.79) } \\
\text { ND (1.7) } \\
\text { ND (0.52) } \\
\text { ND (1.9) } \\
\text { ND (2.3) } \\
1.08\end{array}$ & $\| J$ & $\begin{array}{c}\text { ND (0.46) } \\
\text { ND (0.61) } \\
\text { ND (0.34) } \\
\text { ND (0.54) } \\
\text { ND (1.4) } \\
\text { ND (2.3) } \\
\text { ND (2.3) } \\
\text { ND (2.5) } \\
\text { ND (0.56) } \\
\text { ND (0.91) } \\
\text { ND (2.8) } \\
\text { ND (0.45) } \\
\text { ND (1.7) } \\
\text { ND (3.1) } \\
\text { ND (3.0) } \\
\text { ND (0.36) } \\
\text { ND (1.4) } \\
\text { ND (0.36) } \\
\text { ND (1.5) } \\
\text { ND (1.9) } \\
\text { ND (0.62) }\end{array}$ & & $\begin{array}{r}\text { ND (0.30) } \\
\text { ND (0.37) } \\
\text { ND (0.25) } \\
\text { ND (0.37) } \\
\text { ND (1.2) } \\
\text { ND (1.5) } \\
\text { ND (1.3) } \\
\text { ND (1.5) } \\
\text { ND (0.43) } \\
\text { ND (0.38) } \\
\text { ND (1.1) } \\
0.734 \\
\text { ND (0.66) } \\
\text { ND (2.6) } \\
\text { ND (2.6) } \\
\text { ND (0.26) } \\
0.659 \\
\text { ND (0.22) } \\
\text { ND (0.70) } \\
\text { ND (0.90) } \\
1.47\end{array}$ & BJ \\
\hline
\end{tabular}

Stream: APF Inlet Collection Method: Multimetals Train Sample Type: Mercury Impingers

\begin{tabular}{|c|c|c|c|c|c|c|c|c|}
\hline Analyte & $\begin{array}{l}\text { Analytical } \\
\text { Technique }\end{array}$ & Units & Run 1 & Com 1 & Run 2 & Com 2 & Run 3 & Com 3 \\
\hline Mercury & CVAA & ug/Nm3 & 0.299 & & 0.530 & & 0.284 & \\
\hline
\end{tabular}

Stream: APF Inlet Collection Method: Multimetals Train Sample Type: Nitric Acid Impingers + TLR

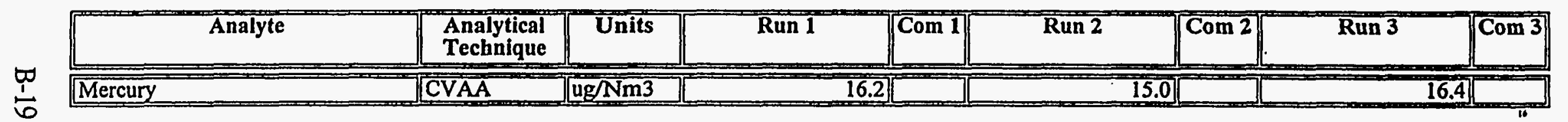




\section{Analytical Data Used In Calculations}

Stream: APF Inlet Collection Method: Multimetals Train Sample Type: Nitric Acid Impingers + TLR

\begin{tabular}{|c|c|c|c|c|c|c|c|c|}
\hline Analyte & $\begin{array}{l}\text { Analytical } \\
\text { Technique }\end{array}$ & Units & Run 1 & $\longdiv { \operatorname { C o m } 1 }$ & Run 2 & Com 2 & Run 3 & $\mathrm{Com} 3$ \\
\hline \begin{tabular}{|l|} 
Aluminum \\
Barium \\
Boron \\
Calcium \\
Iron \\
Magnesium \\
Phosphorus \\
Potassium \\
Silver \\
Sodium \\
Titanium \\
\end{tabular} & $\begin{array}{l}\text { ICAP } \\
\text { ICAP } \\
\text { ICAP } \\
\text { ICAP } \\
\text { ICAP } \\
\text { ICAP } \\
\text { ICAP } \\
\text { ICAP } \\
\text { ICAP } \\
\text { ICAP } \\
\text { ICAP }\end{array}$ & $\begin{array}{l}\mathrm{ug} / \mathrm{Nm} 3 \\
\mathrm{ug} / \mathrm{Nm} 3 \\
\mathrm{ug} / \mathrm{Nm} 3 \\
\mathrm{ug} / \mathrm{Nm} 3 \\
\mathrm{ug} / \mathrm{Nm} 3 \\
\mathrm{ug} / \mathrm{Nm} 3 \\
\mathrm{ug} / \mathrm{Nm} 3 \\
\mathrm{ug} / \mathrm{Nm} 3 \\
\mathrm{ug} / \mathrm{Nm} 3 \\
\mathrm{ug} / \mathrm{Nm} 3 \\
\mathrm{ug} / \mathrm{Nm} 3 \\
\end{array}$ & $\begin{array}{r}263 \\
1.59 \\
246 \\
703 \\
136 \\
214 \\
\text { ND (17) } \\
\text { ND }(220) \\
\text { ND (1.4) } \\
148 \\
12.7 \\
\end{array}$ & \begin{tabular}{|l}
$\mathrm{BC}$ \\
$\mathrm{BC}$ \\
$\mathrm{BC}$ \\
$\mathrm{BC}$ \\
$\mathrm{BC}$ \\
$\mathrm{C}$ \\
$\mathrm{BC}$ \\
$\mathrm{B}$ \\
$\mathrm{BC}$
\end{tabular} & $\begin{array}{r}1190 \\
6.05 \\
209 \\
2510 \\
332 \\
1070 \\
\text { ND }(19) \\
282 \\
\text { ND (1.6) } \\
123 \\
63.3 \\
\end{array}$ & $\begin{array}{l}\mathrm{BC} \\
\mathrm{BC} \\
\mathrm{BC} \\
\mathrm{BC} \\
\mathrm{BC} \\
\mathrm{C} \\
\mathrm{BC} \\
\mathrm{B} \\
\mathrm{BC}\end{array}$ & $\begin{array}{r}395 \\
2.32 \\
205 \\
1220 \\
174 \\
817 \\
\text { ND (16) } \\
\text { ND (220) } \\
\text { ND (1.4) } \\
135 \\
18.7\end{array}$ & \begin{tabular}{|l}
$\mathrm{BC}$ \\
$\mathrm{BC}$ \\
$\mathrm{BC}$ \\
$\mathrm{BC}$ \\
$\mathrm{BC}$ \\
$\mathrm{C}$ \\
$\mathrm{BC}$ \\
$\mathrm{B}$ \\
$\mathrm{BC}$
\end{tabular} \\
\hline $\begin{array}{l}\text { Antimony } \\
\text { Arsenic } \\
\text { Barium } \\
\text { Beryllium } \\
\text { Cadmium } \\
\text { Chromium } \\
\text { Cobalt } \\
\text { Copper } \\
\text { Lead } \\
\text { Manganese } \\
\text { Molybdenum } \\
\text { Nickel } \\
\text { Selenium } \\
\text { Vanadium }\end{array}$ & $\begin{array}{l}\text { ICPMS } \\
\text { ICPMS } \\
\text { ICPMS } \\
\text { ICPMS } \\
\text { ICPMS } \\
\text { ICPMS } \\
\text { ICPMS } \\
\text { ICPMS } \\
\text { ICPMS } \\
\text { ICPMS } \\
\text { ICPMS } \\
\text { ICPMS } \\
\text { ICPMS } \\
\text { ICPMS }\end{array}$ & $\begin{array}{l}\text { ug/Nm3 } \\
\text { ug/Nm3 } \\
\text { ug/Nm3 } \\
\text { ug/Nm3 } \\
\text { ug/Nm3 } / \mathrm{Nm} \\
\mathrm{ug} / \mathrm{Nm} 3 \\
\mathrm{ug} / \mathrm{Nm} 3 \\
\mathrm{ug} / \mathrm{Nm} 3 \\
\text { ug/Nm3 } \\
\mathrm{ug} / \mathrm{Nm} 3 \\
\mathrm{ug} / \mathrm{Nm} 3 \\
\mathrm{ug} / \mathrm{Nm} 3 \\
\mathrm{ug} / \mathrm{Nm} 3 \\
\mathrm{ug} / \mathrm{Nm} 3\end{array}$ & $\begin{array}{r}0.0433 \\
1.71 \\
\text { ND (0.0047) } \\
0.0528 \\
0.309 \\
41.1 \\
0.431 \\
67.5 \\
1.23 \\
33.2 \\
5.87 \\
58.3 \\
14.4 \\
1.88\end{array}$ & $\begin{array}{l}\mathrm{C} \\
\mathrm{C} \\
\mathrm{C} \\
\mathrm{C} \\
\mathrm{C} \\
\mathrm{C} \\
\mathrm{C} \\
\mathrm{C} \\
\mathrm{C} \\
\mathrm{C} \\
\mathrm{C} \\
\mathrm{C}\end{array}$ & \begin{tabular}{r|}
0.0852 \\
7.85 \\
4.83 \\
0.233 \\
$\mathrm{ND}(0.0063)$ \\
2.95 \\
0.218 \\
7.68 \\
2.90 \\
8.73 \\
0.702 \\
19.4 \\
18.4 \\
3.06
\end{tabular} & $\begin{array}{l}C \\
C \\
C \\
C \\
C \\
C \\
C \\
C \\
C \\
C \\
C \\
C\end{array}$ & \begin{tabular}{rr|}
2.76 \\
2.23 \\
1.55 \\
0.0635 \\
ND $(0.0055)$ \\
12.9 \\
0.149 \\
44.3 \\
1.09 \\
3.21 \\
1.22 \\
25.3 \\
14.8 \\
1.67
\end{tabular} & $\begin{array}{l}C \\
C \\
C \\
C \\
C \\
C \\
C \\
C \\
C \\
C \\
C \\
C\end{array}$ \\
\hline
\end{tabular}

Stream: APF Inlet Collection Method: PCDD/PCDF for Dioxins and Furans (M23) Sample Type: Filtered Solids/Solvent Rinses/XAD Resin

\begin{tabular}{|c|c|c|c|c|c|c|c|c|}
\hline Analyte & $\begin{array}{l}\text { Analytical } \\
\text { Technique }\end{array}$ & Units & Run 1 & Com 1 & Run 2 & $\overline{\operatorname{Com} 2}$ & Run 3 & $\longdiv { \operatorname { C o m } 3 }$ \\
\hline $\begin{array}{l}1234678-\mathrm{HpCDD} \\
\text { 1234678-HpCDF }\end{array}$ & $\begin{array}{l}\text { Meth 23X } \\
\text { Meth 23X }\end{array}$ & $\begin{array}{l}\mathrm{ug} / \mathrm{Nm} 3 \\
\mathrm{ug} / \mathrm{Nm} 3\end{array}$ & $\begin{array}{l}0.000268 \\
0.000189\end{array}$ & & $\begin{array}{l}0.000458 \\
0.000206\end{array}$ & & $\begin{array}{l}0.000866 \\
0.000693\end{array}$ & \\
\hline
\end{tabular}




\section{Analytical Data Used In Calculations}

Stream: APF Inlet Collection Method: PCDD/PCDF for Dioxins and Furans (M23) Sample Type: Filtered Solids/Solvent Rinses/XAD Resin

\begin{tabular}{|c|c|c|c|c|c|c|c|c|}
\hline Analyte & $\begin{array}{l}\text { Analytical } \\
\text { Technique }\end{array}$ & Ũnits & Run 1 & Com 1 & Run 2 & Com 2 & Run 3 & $\overline{\operatorname{Com} 3}$ \\
\hline $\begin{array}{l}123478-\mathrm{HXCDD} \\
123478-\mathrm{HxCDF} \\
1234789-\mathrm{HpCDF} \\
123678-\mathrm{HxCDD} \\
123678-\mathrm{HxCDF} \\
12378-\mathrm{PeCDD} \\
12378-\mathrm{PeCDF} \\
123789-\mathrm{HxCDD} \\
123789-\mathrm{HxCDF} \\
234678-\mathrm{HxCDF} \\
23478-\mathrm{PeCDF} \\
\text { 2378-TCDD } \\
\text { 2378-TCDF } \\
\text { OCDD } \\
\text { OCDF } \\
\text { TOTAL HpCDD } \\
\text { TOTAL HpCDF } \\
\text { TOTAL HXCDD } \\
\text { TOTAL HXCDF } \\
\text { TOTAL PeCDD } \\
\text { TOTAL PeCDF } \\
\text { TOTAL TCDD } \\
\text { TOTAL TCDF }\end{array}$ & $\begin{array}{l}\text { Meth 23X } \\
\text { Meth 23X } \\
\text { Meth 23X } \\
\text { Meth 23X } \\
\text { Meth 23X } \\
\text { Meth 23X } \\
\text { Meth 23X } \\
\text { Meth 23X } \\
\text { Meth 23X } \\
\text { Meth 23X } \\
\text { Meth 23X } \\
\text { Meth 23X } \\
\text { Meth 23X } \\
\text { Meth 23X } \\
\text { Meth 23X } \\
\text { Meth 23X } \\
\text { Meth 23X } \\
\text { Meth 23X } \\
\text { Meth 23X } \\
\text { Meth 23X } \\
\text { Meth 23X } \\
\text { Meth 23X } \\
\text { Meth 23X }\end{array}$ & 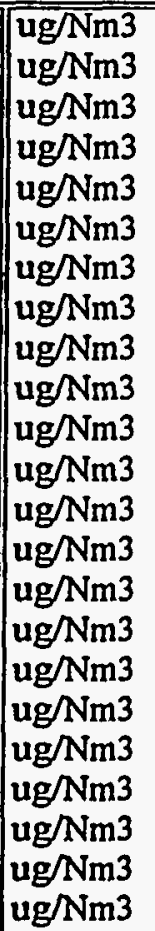 & \begin{tabular}{r||}
0.0000510 \\
0.000160 \\
0.0000394 \\
0.0000723 \\
0.0000530 \\
0.0000466 \\
0.0000333 \\
0.0000831 \\
0.00000934 \\
0.0000526 \\
0.0000530 \\
0.00000575 \\
0.0000933 \\
0.000331 \\
0.000237 \\
0.000564 \\
0.000309 \\
0.00114 \\
0.000509 \\
0.00136 \\
0.000538 \\
0.00116 \\
0.000744
\end{tabular} & B & $\begin{array}{rr}0.000105 \\
0.000213 \\
0.0000493 \\
0.000128 \\
0.0000758 \\
0.0000813 \\
0.0000648 \\
0.000174 \\
0.0000182 \\
0.0000900 \\
0.000107 \\
0.00000648 \\
0.000174 \\
0.000492 \\
0.000156 \\
0.000939 \\
0.000340 \\
0.00187 \\
0.000698 \\
0.00263 \\
0.000609 \\
0.00258 \\
0.00159\end{array}$ & F & \begin{tabular}{r|}
0.000248 \\
0.000802 \\
0.0000874 \\
0.000209 \\
0.000243 \\
0.000132 \\
0.000185 \\
0.000269 \\
0.0000663 \\
0.000234 \\
0.000300 \\
0.0000182 \\
0.000628 \\
0.00114 \\
0.000353 \\
0.00191 \\
0.00106 \\
0.00308 \\
0.00253 \\
0.00351 \\
0.00334 \\
0.00327 \\
0.00490
\end{tabular} & B \\
\hline
\end{tabular}

Stream: APF Inlet Collection Method: VOST Sample Type: Tenax-Tenax + Charcoal A

\begin{tabular}{|c|c|c|c|c|c|c|c|c|c|}
\hline Analyte & & $\begin{array}{l}\text { Analytical } \\
\text { Technique }\end{array}$ & $\overline{\text { Units }}$ & Run 1 & Com 1 & Run 2 & $\overline{\text { Com 2 }}$ & Run 3 & $\longdiv { \operatorname { C o m } 3 }$ \\
\hline
\end{tabular}




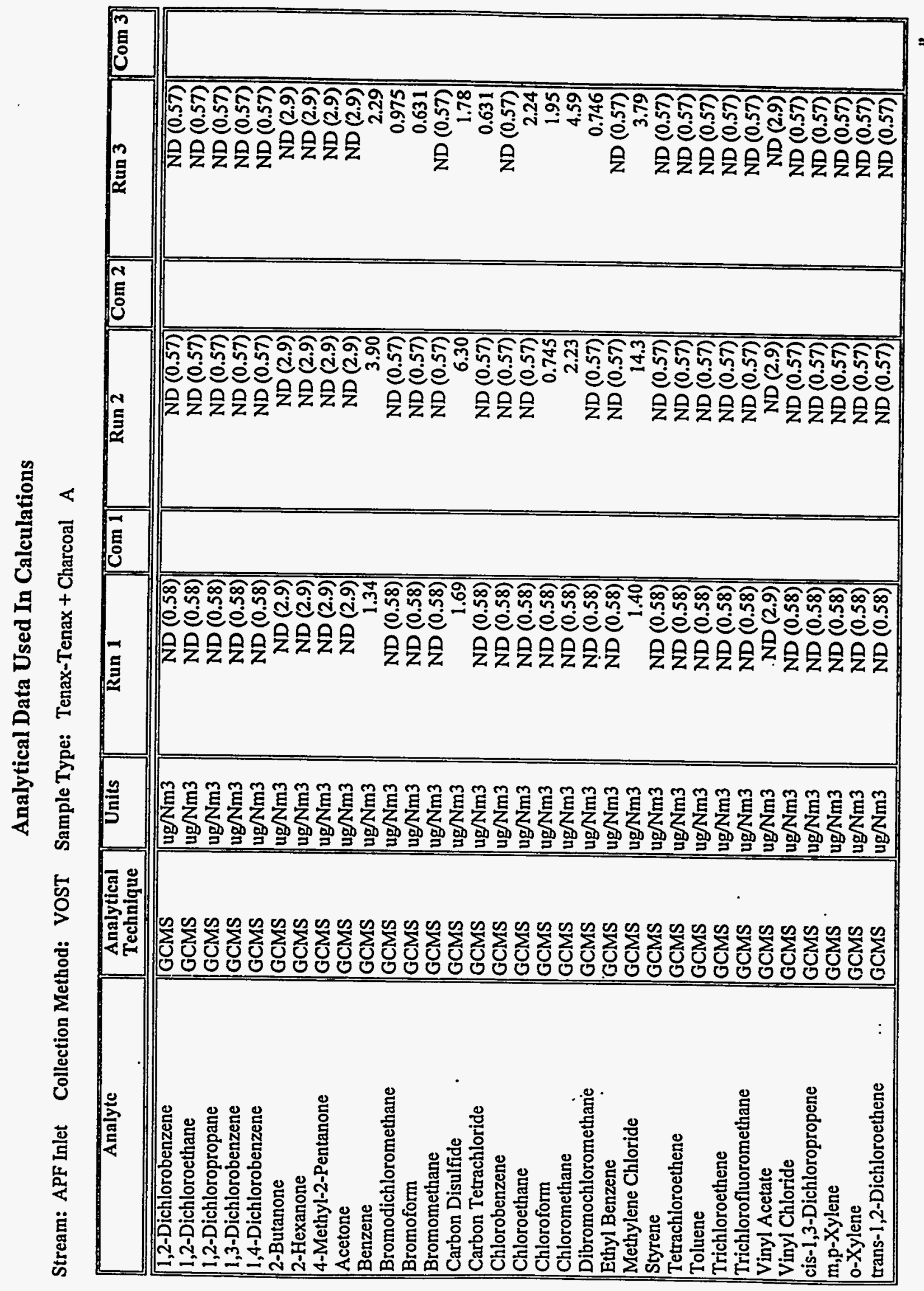


Analytical Data Used In Calculations

Stream: APF Inlet Collection Method: vOST Sample Type: Tenax-Tenax + Charcoal A

\begin{tabular}{|l|l|l|l|l|l|l|l|l|}
\hline Analyte & $\begin{array}{l}\text { Analytical } \\
\text { Technique }\end{array}$ & Units & Run 1 & Com 1 & Run 2 & Com 2 & Run 3 & Com 3 \\
\hline \hline trans-1,3-Dichloropropene & GCMS & ug/Nm3 & ND (0.58) & & ND (0.57) & & \\
\hline
\end{tabular}

Stream: APF Inlet Collection Method: vOST Sample Type: Tenax-Tenax + Charcoal B

\begin{tabular}{|c|c|c|c|c|c|c|c|c|}
\hline Analyte & $\begin{array}{l}\text { Analytical } \\
\text { Technique }\end{array}$ & Units & Run 1 & Com 1 & Run 2 & Com 2 & Run 3 & Com 3 \\
\hline \begin{tabular}{|l}
$1,1,1-$ Trichloroethane \\
1,1,2,2-Tetrachloroethane \\
1,1,2-Trichloroethane \\
1,1-Dichloroethane \\
1,1-Dichloroethene \\
1,2-Dichlorobenzene \\
1,2-Dichloroethane \\
1,2-Dichloropropane \\
1,3-Dichlorobenzene \\
1,4-Dichlorobenzene \\
2-Butanone \\
2-Hexanone \\
4-Methyl-2-Pentanone \\
Acetone \\
Benzene \\
Bromodichloromethane \\
Bromoform \\
Bromomethane \\
Carbon Disulfide \\
Carbon Tetrachloride \\
Chlorobenzene \\
Chloroethane \\
Chloroform \\
Chloromethane \\
Dibromochloromethane \\
Ethyl Benzene \\
Methylene Chloride
\end{tabular} & \begin{tabular}{|l} 
GCMS \\
GCMS \\
GCMS \\
GCMS \\
GCMS \\
GCMS \\
GCMS \\
GCMS \\
GCMS \\
GCMS \\
GCMS \\
GCMS \\
GCMS \\
GCMS \\
GCMS \\
GCMS \\
GCMS \\
GCMS \\
GCMS \\
GCMS \\
GCMS \\
GCMS \\
GCMS \\
GCMS \\
GCMS \\
GCMS \\
GCMS
\end{tabular} & 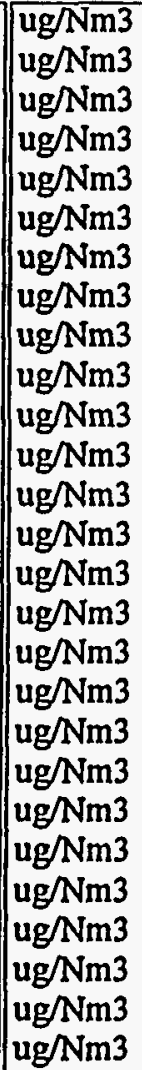 & $\begin{array}{r}\text { ND (0.53) } \\
\text { ND (0.53) } \\
\text { ND (0.53) } \\
\text { ND (0.53) } \\
\text { ND (0.53) } \\
\text { ND (0.53) } \\
\text { ND (0.53) } \\
\text { ND (0.53) } \\
\text { ND (0.53) } \\
\text { ND (0.53) } \\
\text { ND (2.6) } \\
\text { ND (2.6) } \\
\text { ND (2.6) } \\
\text { ND (2.6) } \\
1.11 \\
\text { ND (0.53) } \\
\text { ND (0.53) } \\
\text { ND (0.53) } \\
1.90 \\
\text { ND (0.53) } \\
\text { ND (0.53) } \\
\text { ND (0.53) } \\
\text { ND (0.53) } \\
0.793 \\
\text { ND (0.53) } \\
\text { ND (0.53) } \\
\text { ND (0.53). }\end{array}$ & & $\begin{array}{r}\text { ND (0.58) } \\
\text { ND (0.58) } \\
\text { ND (0.58) } \\
\text { ND (0.58) } \\
\text { ND (0.58) } \\
\text { ND (0.58) } \\
\text { ND (0.58) } \\
\text { ND (0.58) } \\
\text { ND (0.58) } \\
\text { ND (0.58) } \\
\text { ND (2.9) } \\
\text { ND (2.9) } \\
\text { ND (2.9) } \\
\text { ND (2.9) } \\
4.32 \\
\text { ND (0.58) } \\
\text { ND (0.58) } \\
\text { ND (0.58) } \\
4.03 \\
\text { ND (0.58) } \\
\text { ND (0.58) } \\
\text { ND (0.58) } \\
\text { ND (0.58) } \\
3.57 \\
\text { ND (0.58) } \\
\text { ND (0.58) } \\
8.07\end{array}$ & & $\begin{array}{r}\text { ND (0.59) } \\
\text { ND (0.59) } \\
\text { ND (0.59) } \\
\text { ND (0.59) } \\
\text { ND (0.59) } \\
\text { ND (0.59) } \\
\text { ND (0.59) } \\
\text { ND (0.59) } \\
\text { ND (0.59) } \\
\text { ND (0.59) } \\
\text { ND (2.9) } \\
\text { ND (2.9) } \\
\text { ND (2.9) } \\
\text { ND (2.9) } \\
5.15 \\
\text { ND (0.59) } \\
\text { ND (0.59) } \\
\text { ND }(0.59) \\
6.44 \\
\text { ND (0.59) } \\
\text { ND (0.59) } \\
35.7 \\
1.29 \\
5.21 \\
\text { ND (0.59) } \\
\text { ND (0.59) } \\
105\end{array}$ & $E$ \\
\hline
\end{tabular}


Stream: APF Inlet Collection Method: VOST Sample Type: Tenax-Tenax + Charcoal B

\begin{tabular}{|c|c|c|c|c|c|c|c|c|}
\hline Analyte & $\begin{array}{l}\text { Analytical } \\
\text { Technique }\end{array}$ & Units & Run 1 & $\longdiv { \text { Com I } }$ & Run 2 & Com 2 & Run 3 & Com 3 \\
\hline $\begin{array}{l}\text { Styrene } \\
\text { Tetrachloroethene } \\
\text { Toluene } \\
\text { Trichloroethene } \\
\text { Trichlorofluoromethane } \\
\text { Vinyl Acetate } \\
\text { Vinyl Chloride } \\
\text { cis-1,3-Dichloropropene } \\
\text { m,p-Xylene } \\
\text { o-Xylene } \\
\text { trans-1,2-Dichloroethene } \\
\text { trans-1,3-Dichloropropene }\end{array}$ & $\begin{array}{l}\text { GCMS } \\
\text { GCMS } \\
\text { GCMS } \\
\text { GCMS } \\
\text { GCMS } \\
\text { GCMS } \\
\text { GCMS } \\
\text { GCMS } \\
\text { GCMS } \\
\text { GCMS } \\
\text { GCMS } \\
\text { GCMS }\end{array}$ & $\begin{array}{l}\text { ug/Nm3 } \\
u g / N m 3 \\
u g / N m 3 \\
u g / N m 3 \\
u g / N m 3 \\
u g / N m 3 \\
u g / N m 3 \\
\text { ug/Nm3 } \\
u g / N m 3 \\
u g / N m 3 \\
u g / N m 3 \\
u g / N m 3\end{array}$ & $\begin{array}{l}\text { ND }(0.53) \\
\text { ND }(0.53) \\
\text { ND }(0.53) \\
\text { ND }(0.53) \\
\text { ND }(0.53) \\
\text { ND }(2.6) \\
\text { ND }(0.53) \\
\text { ND }(0.53) \\
\text { ND }(0.53) \\
\text { ND }(0.53) \\
\text { ND }(0.53) \\
\text { ND }(0.53)\end{array}$ & & $\begin{array}{l}\mathrm{ND}(0.58) \\
\text { ND (0.58) } \\
\text { ND (0.58) } \\
\text { ND (0.58) } \\
\text { ND(0.58) } \\
\text { ND (2.9) } \\
\text { ND (0.58) } \\
\text { ND (0.58) } \\
\text { ND (0.58) } \\
\text { ND (0.58) } \\
\text { ND (0.58) } \\
\text { ND (0.58) }\end{array}$ & & $\begin{array}{r}N D(0.59) \\
0.644 \\
2.46 \\
\text { ND }(0.59) \\
\text { ND (0.59) } \\
\text { ND (2.9) } \\
\text { ND (0.59) } \\
\text { ND (0.59) } \\
1.17 \\
\text { ND (0.59) } \\
\text { ND (0.59) } \\
\text { ND (0.59) }\end{array}$ & \\
\hline
\end{tabular}

Stream: APF Outlet Collection Method: Ammonia/Cyanide Sample Type: Ammonia Impingers

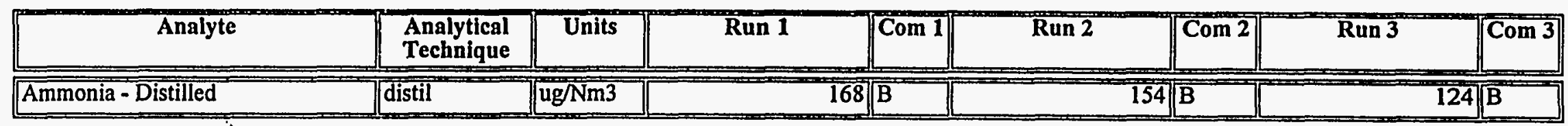

Stream: APF Outle Collection Method: Ammonia/Cyanide Sample Type: Impingers

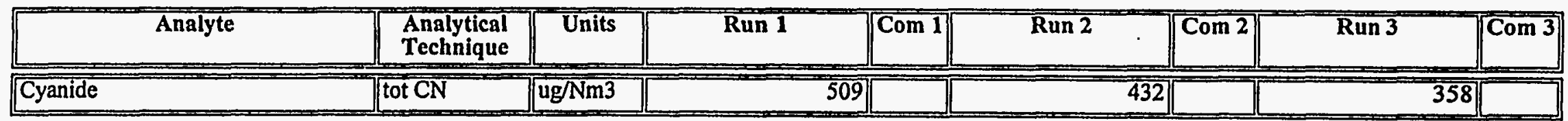

Stream: APF Outlet Collection Method: Anions Train Sample Type: $47 \mathrm{~mm}$ Filter + Solids

\begin{tabular}{|c|c|c|c|c|c|c|c|c|c|}
\hline Analyte & & $\begin{array}{l}\text { Analytical } \\
\text { Technique }\end{array}$ & Units & Run 1 & Com 1 & Run 2 & $\overline{\operatorname{Com} 2}$ & Run 3 & $\overline{\mathrm{Com} 3}$ \\
\hline \begin{tabular}{|l|} 
Chloride \\
Chloride \\
Sulfate
\end{tabular} &.. & \begin{tabular}{|l|} 
IC \\
IC \\
IC \\
\end{tabular} & $\begin{array}{l}\mathrm{ug} / \mathrm{Nm} 3 \\
\mathrm{ug} / \mathrm{g} \\
\mathrm{ug} / \mathrm{Nm} 3\end{array}$ & $\begin{array}{c}0.192 \\
4060 \\
37.8 \\
\end{array}$ & $\begin{array}{l}\mathrm{C} \\
\mathrm{C}\end{array}$ & \begin{tabular}{r|}
0.155 \\
407 \\
83.6
\end{tabular} & $\begin{array}{l}\bar{C} \\
\mathrm{C}\end{array}$ & $\begin{array}{r}\mathrm{ND}(0.11) \\
\mathrm{ND}(570) \\
52.3\end{array}$ & $\begin{array}{l}\text { C } \\
C\end{array}$ \\
\hline
\end{tabular}




\section{Analytical Data Used In Calculations}

Stream: APF Outlet Collection Method: Anions Train Sample Type: $47 \mathrm{~mm}$ Filter + Solids

\begin{tabular}{|c|c|c|c|c|c|c|c|c|}
\hline Analyte & $\begin{array}{l}\text { Analytical } \\
\text { Technique }\end{array}$ & Units & $\overline{\text { Run 1 }}$ & Com 1 & Run 2 & $\longdiv { \operatorname { C o m } 2 }$ & $\overline{\operatorname{Run} 3}$ & $\longdiv { \mathrm { Com } 3 }$ \\
\hline Sulfate & $\overline{\mathrm{IC}}$ & ug/g & $\overline{8801000}$ & & 219000 & & 262000 & \\
\hline $\begin{array}{l}\text { Fluoride } \\
\text { Fluoride }\end{array}$ & $\begin{array}{l}\text { SIE } \\
\text { SIE }\end{array}$ & $\begin{array}{l}\mathrm{ug} / \mathrm{Nm} 3 \\
\mathrm{ug} / \mathrm{g}\end{array}$ & $\begin{array}{r}0.0463 \\
980\end{array}$ & $\begin{array}{l}\mathrm{C} \\
\mathrm{C}\end{array}$ & $\begin{array}{r}0.219 \\
575\end{array}$ & $\begin{array}{l}\bar{C} \\
\mathrm{C}\end{array}$ & $\begin{array}{r}0.117 \\
584\end{array}$ & $\begin{array}{l}C \\
C\end{array}$ \\
\hline
\end{tabular}

Stream: APF Outlet Collection Method: Anions Train Sample Type: Impingers + TLR

\begin{tabular}{|c|c|c|c|c|c|c|c|c|}
\hline Analyte & $\begin{array}{l}\text { Analytical } \\
\text { Technique }\end{array}$ & Units & Run 1 & $\overline{C o m ~ 1 ~}$ & Run 2 & $\overline{\text { Com } 2}$ & Run 3 & $\widehat{C o m 3}$ \\
\hline \begin{tabular}{|l|l|} 
Chloride \\
Sulfate
\end{tabular} & $\begin{array}{l}\mathrm{IC} \\
\mathrm{IC}\end{array}$ & $\begin{array}{l}\mathrm{ug} / \mathrm{Nm} 3 \\
\mathrm{ug} / \mathrm{Nm} 3\end{array}$ & $\begin{array}{r}60100 \\
474000 \\
\end{array}$ & & $\begin{array}{r}72700 \\
532000 \\
\end{array}$ & & $\begin{array}{r}50400 \\
470000\end{array}$ & \\
\hline Fluoride & SIE & ug $/ \mathrm{Nm}^{3}$ & 8500 & $\bar{B}$ & 9430 & $\overline{\mathrm{B}}$ & 8870 & B \\
\hline
\end{tabular}

Stream: APF Outlet Collection Method: M0011a Sample Type: Impingers + MeCl2

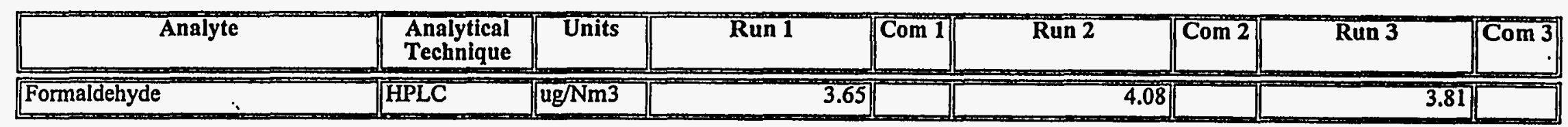

Stream: APF Outlet Collection Method: M29 Sample Type: $47 \mathrm{~mm}$ Filter + Solids

\begin{tabular}{|c|c|c|c|c|c|c|c|c|}
\hline Analyte & $\begin{array}{l}\text { Analytical } \\
\text { Technique }\end{array}$ & Units & Run 1 & Com 1 & Run 2 & $\overline{\text { Com 2 }}$ & Run 3 & Com 3 \\
\hline Mercury & CVAA & ug/Nm3 & $\mathrm{ND}(0.00027)$ & $\bar{C}$ & $\mathrm{ND}(0.00030)$ & $\overline{\bar{C}}$ & $\mathrm{ND}(0.00021)$ & C \\
\hline $\begin{array}{l}\text { Arsenic } \\
\text { Cadmium } \\
\text { Lead } \\
\text { Selenium } \\
\end{array}$ & $\begin{array}{l}\text { GFAA } \\
\text { GFAA } \\
\text { GFAA } \\
\text { GFAA }\end{array}$ & $\begin{array}{l}\mathrm{ug} / \mathrm{Nm} 3 \\
\mathrm{ug} / \mathrm{Nm} 3 \\
\mathrm{ug} / \mathrm{Nm} 3 \\
\mathrm{ug} / \mathrm{Nm} 3\end{array}$ & $\begin{array}{r}0.212 \\
\mathrm{ND}(0.0043) \\
0.0191 \\
\mathrm{ND}(0.0044) \\
\end{array}$ & $\mathrm{C}$ & $\begin{array}{r}0.361 \\
\text { ND }(0.0048) \\
0.0346 \\
\text { ND }(0.0050)\end{array}$ & $\bar{c}$ & $\begin{array}{r}0.271 \\
\mathrm{ND}(0.0035) \\
0.0334 \\
\mathrm{ND}(0.0036)\end{array}$ & $C$ \\
\hline \begin{tabular}{|l} 
Aluminum \\
Antimony \\
Barium
\end{tabular} & $\begin{array}{l}\text { ICAP } \\
\text { ICAP } \\
\text { ICAP }\end{array}$ & $\begin{array}{l}\text { ug/Nm3 } \\
\text { ug/Nm3 } \\
\text { ug/Nm3 }\end{array}$ & $\begin{array}{r}0.875 \\
\mathrm{ND}(0.32) \\
0.0914 \\
\end{array}$ & C & $\begin{array}{r}4.81 \\
\mathrm{ND}(0.36) \\
0.0174\end{array}$ & & $\begin{array}{r}2.41 \\
\text { ND }(0.26) \\
0.00491\end{array}$ & C \\
\hline
\end{tabular}


Stream: APF Outlet Collection Method: M29 Sample Type: $47 \mathrm{~mm}$ Filter + Solids

\begin{tabular}{|c|c|c|c|c|c|c|c|c|}
\hline Analyte & $\begin{array}{l}\text { Analytical } \\
\text { Technique }\end{array}$ & Units & Run 1 & Com 1 & $\overline{\overline{\text { Run } 2}}$ & $\overline{\text { Com 2 }}$ & Run 3 & $\longdiv { \mathrm { Com } \mathrm { 3 } }$ \\
\hline Beryllium & $\overline{\mathrm{ICAP}}$ & ug/Nm3 & $\overline{\mathrm{ND}}(0.0018)$ & & $\mathrm{ND}(0.0020)$ & & $\mathrm{ND}(0.0015)$ & \\
\hline Calcium & ICAP & $\mathrm{ug} / \mathrm{Nm} 3$ & 0.0923 & C & 5.82 & C & 2.68 & C \\
\hline Chromium & ICAP & $\mathrm{ug} / \mathrm{Nm} 3$ & 8.00 & C & 12.9 & C & 8.89 & C \\
\hline Cobalt & ICAP & $\mathrm{ug} / \mathrm{Nm} 3$ & ND (0.030) & C & $\mathrm{ND}(0.033)$ & C & $\operatorname{ND}(0.024)$ & C \\
\hline Copper & ICAP & $\mathrm{ug} / \mathrm{Nm} 3$ & ND (0.028) & & ND (0.031) & & $\operatorname{ND}(0.022)$ & \\
\hline Iron & ICAP & $u g / \mathrm{Nm}^{2}$ & 1.39 & C & 7.29 & C & 2.84 & C \\
\hline Magnesium & ICAP & ug/Nm3 & ND (0.53) & C & 2.79 & C & 1.30 & C \\
\hline Manganese & ICAP & ug/Nm3 & 0.205 & & 0.619 & & 0.137 & \\
\hline Molybdenum & ICAP & ug $/ \mathrm{Nm} 3$ & 3.35 & C & 6.48 & C & 2.92 & C \\
\hline Nickel & ICAP & ug/Nm3 & 0.257 & C & 1.26 & C & 0.344 & C \\
\hline Phosphorus & ICAP & $\mathrm{ug} / \mathrm{Nm} 3$ & $N D(0.40)$ & C & $\mathrm{ND}(0.45)$ & C & $\mathrm{ND}(0.33)$ & C \\
\hline Potassium & ICAP & ug/Nm3 & $\mathrm{ND}(2.4)$ & C & ND (2.7) & C & $\mathrm{ND}(2.0)$ & C \\
\hline Silver & ICAP & $\mathrm{ug} / \mathrm{Nm} 3$ & 0.312 & & 0.372 & & 0.138 & \\
\hline Sodium & ICAP & ug/Nm3 & ND (0.17) & C & 1.39 & C & ND (0.14) & C \\
\hline Titanium & ICAP & $\mathrm{ug} / \mathrm{Nm} 3$ & 0.0606 & C & 0.409 & C & 0.232 & C \\
\hline Vanadium & ICAP & ug/Nm3 & 0.959 & C & 0.814 & C & 0.848 & C \\
\hline
\end{tabular}

Stream: APF Outlet Collection Method: MM5 Sample Type: $47 \mathrm{~mm}$ Filter

\begin{tabular}{|c|c|c|c|c|c|c|c|c|}
\hline Analyte & $\begin{array}{l}\text { Analytical } \\
\text { Technique }\end{array}$ & Units & Run I & Com 1 & Run 2 & Com 2 & Run 3 & Com 3 \\
\hline $\begin{array}{l}\text { 1,2,4-Trichlorobenzene } \\
\text { 1,2-Dichlorobenzene } \\
\text { 1,3-Dichlorobenzene } \\
\text { 1,4-Dichlorobenzene } \\
\text { 2,4,5-Tricliloroplicnol } \\
\text { 2,4,6-Trichlorophenol } \\
\text { 2,4-Dichlorophenol } \\
\text { 2,4-Dimethylphenol } \\
\text { 2,4-Dinitrophenol } \\
\text { 2,4-Dinitrotoluene } \\
\text { 2,6-Dinitrotoluene } \\
\text { 2-Chloronaphthalene }\end{array}$ & $\begin{array}{l}\text { GCMS } \\
\text { GCMS } \\
\text { GCMS } \\
\text { GCMS } \\
\text { GCMS } \\
\text { GCMS } \\
\text { GCMS } \\
\text { GCMS } \\
\text { GCMS } \\
\text { GCMS } \\
\text { GCMS } \\
\text { GCMS }\end{array}$ & $\begin{array}{l}\text { ug/Nm3 } \\
\text { ug/Nm3 } 3 \\
\text { ug/Nm3 } \\
\text { ug/Nm3 } 3 \\
\text { ug/Nm3 } \\
\text { ug/Nm3 } \\
\text { ug/Nm3 } \\
\text { ug/Nm3 } \\
\text { ug/Nm3 } \\
\text { ug/Nm3 } \\
\text { ug/Nm3 } \\
\text { ug/Nm3 }\end{array}$ & $\begin{array}{l}\text { ND (0.44) } \\
\text { ND (0.43) } \\
\text { ND (0.40) } \\
\text { ND (0.39) } \\
\text { ND (0.68) } \\
\text { ND (0.72) } \\
\text { ND (0.52) } \\
\text { ND (0.58) } \\
\text { ND (2.0) } \\
\text { ND (0.66) } \\
\text { ND (0.94) } \\
\text { ND (0.27) }\end{array}$ & & $\begin{array}{l}\text { ND (0.37) } \\
\text { ND (0.35) } \\
\text { ND (0.34) } \\
\text { ND (0.32) } \\
\text { ND (0.58) } \\
\text { ND (0.62) } \\
\text { ND (0.44) } \\
\text { ND (0.49) } \\
\text { ND (1.7) } \\
\text { ND (0.56) } \\
\text { ND (0.80) } \\
\text { ND (0.23) }\end{array}$ & & $\begin{array}{l}\text { ND (0.42) } \\
\text { ND (0.39) } \\
\text { ND (0.37) } \\
\text { ND (0.36) } \\
\text { ND (0.63) } \\
\text { ND (0.67) } \\
\text { ND (0.49) } \\
\text { ND (0.55) } \\
\text { ND (1.9) } \\
\text { ND (0.61) } \\
\text { ND (0.87) } \\
\text { ND }(0.25)\end{array}$ & \\
\hline
\end{tabular}




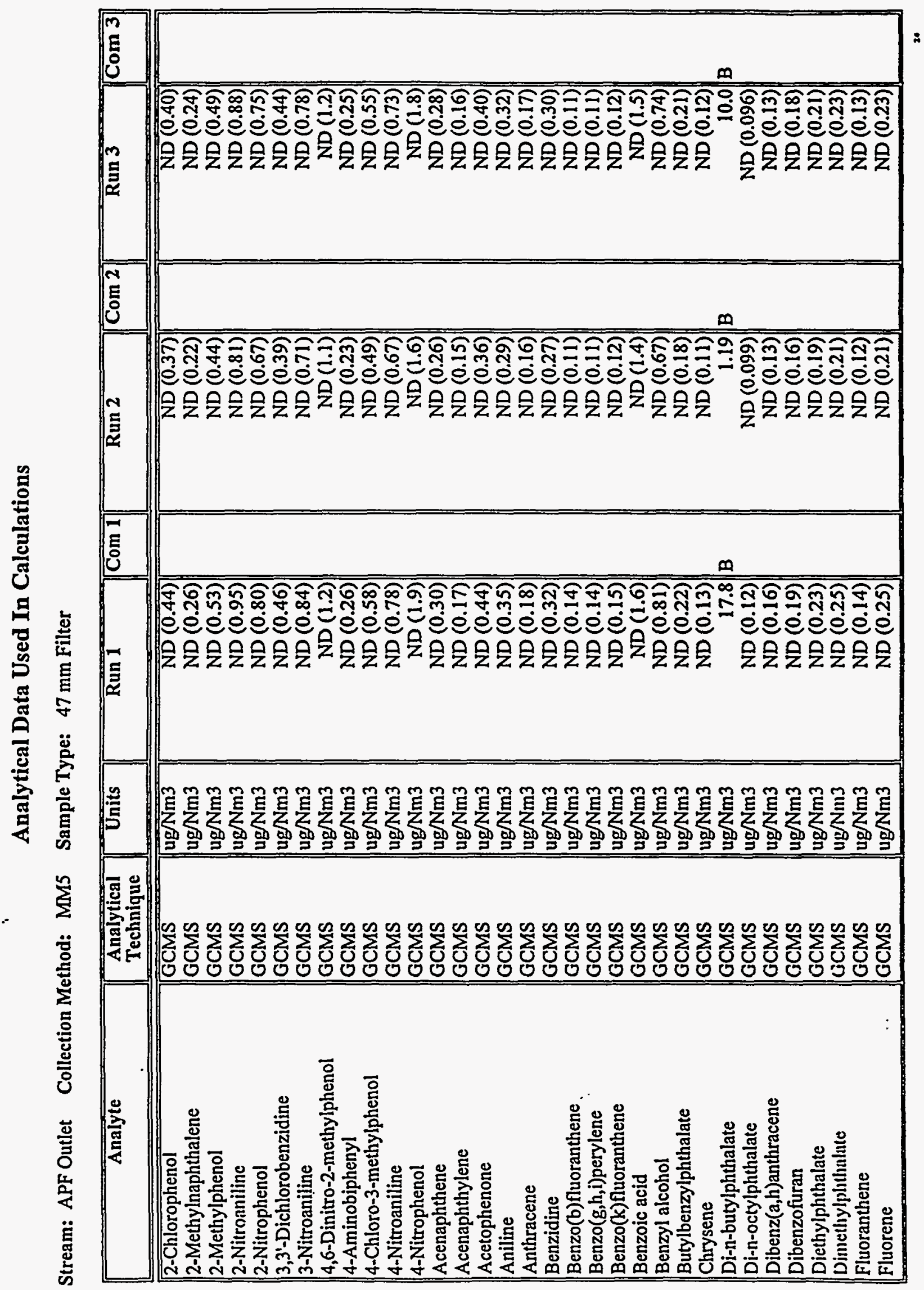


Stream: APF Outlet Collection Method: MM5 Sample Type: $47 \mathrm{~mm}$ Filter

\begin{tabular}{|c|c|c|c|c|c|c|c|c|}
\hline Analyte & $\begin{array}{l}\text { Analytical } \\
\text { Technique }\end{array}$ & Units & Run 1 & $\operatorname{Com~1~}$ & Run 2 & Com 2 & Run 3 & Com 3 \\
\hline $\begin{array}{l}\mid \text { Hexachlorobenzene } \\
\text { Hexachlorobutadiene } \\
\text { Hexachlorocyclopentadiene } \\
\text { Hexachloroethane } \\
\text { Indeno(1,2,3-cd)pyrene } \\
\text { Isophorone } \\
\text { N-Nitroso-di-n-propylamine } \\
\text { Naphthalene } \\
\text { Nitrobenzene } \\
\text { I'entuchloronitrobenzenc } \\
\text { Pentachlorophenol } \\
\text { Phenanthrene } \\
\text { Phenol } \\
\text { Pyrene } \\
\text { bis(2-Chloroethoxy)methane } \\
\text { bis(2-Chloroethyl)ether } \\
\text { bis(2-Ethylhexyl)phthalatc }\end{array}$ & \begin{tabular}{|l} 
GCMS \\
GCMS \\
GCMS \\
GCMS \\
GCMS \\
GCMS \\
GCMS \\
GCMS \\
GCMS \\
GCMS \\
GCMS \\
GCMS \\
GCMS \\
GCMS \\
GCMS \\
GCMS \\
GCMS
\end{tabular} & 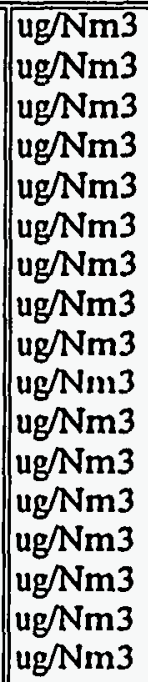 & $\begin{array}{r}\text { ND (0.56) } \\
\text { ND (0.73) } \\
\text { ND (1.0) } \\
\text { ND (0.81) } \\
\text { ND (0.12) } \\
\text { ND (0.26) } \\
\text { ND (0.80) } \\
\text { ND (0.17) } \\
\text { ND (0.45) } \\
\text { ND (2.5) } \\
\text { ND (1.3) } \\
\text { ND(0.17) } \\
\text { ND (0.37) } \\
\text { ND (0.11) } \\
\text { ND (0.39) } \\
\text { ND(0.48) } \\
0.0940\end{array}$ & BJ & $\begin{array}{r}\text { ND (0.50) } \\
\text { ND (0.62) } \\
\text { ND (0.85) } \\
\text { ND (0.67) } \\
\text { ND (0.099) } \\
\text { ND (0.22) } \\
\text { ND (0.67) } \\
\text { ND (0.14) } \\
\text { ND (0.38) } \\
\text { ND (2.3) } \\
\text { ND (1.1) } \\
\text { ND (0.16) } \\
\text { ND (0.30) } \\
\text { ND (0.094) } \\
\text { ND (0.33) } \\
\text { ND (0.40) } \\
0.103\end{array}$ & BJ & $\begin{array}{r}\text { ND (0.53) } \\
\text { ND (0.69) } \\
\text { ND (0.93) } \\
\text { ND (0.74) } \\
\text { ND (0.095) } \\
\text { ND (0.25) } \\
\text { ND (0.73) } \\
\text { ND (0.16) } \\
\text { ND (0.43) } \\
\text { ND (2.4) } \\
\text { ND (1.2) } \\
\text { ND (0.16) } \\
\text { ND (0.33) } \\
\text { ND (0.10) } \\
\text { ND (0.37) } \\
\text { ND (0.44) } \\
0.0703\end{array}$ & \\
\hline
\end{tabular}

Stream: APF Outlet Collection Method: MM5 Sample Type: XAD Resin/Impingers + MeCl2

\begin{tabular}{|c|c|c|c|c|c|c|c|c|}
\hline Analyte & $\begin{array}{l}\text { Analytical } \\
\text { Technique }\end{array}$ & Units & Run I & Com I & Run 2 & $\overline{\mathrm{Com} 2}$ & Run 3 & Com 3 \\
\hline $\begin{array}{l}\text { 1,2,4-Trichlorobenzene } \\
\text { 1,3-Dichlorobenzene } \\
\text { 1,4-Dichlorobenzene } \\
\text { 2,4,5-Trichlorophenenol } \\
\text { 2,4,6-Trichlorophenol } \\
\text { 2,4-Dichlorophenol } \\
\text { 2,4-Dimethylphenol } \\
\text { 2,4-Dinitrophenol } \\
\text { 2,4-Dinitrotoluene } \\
\text { 2,6-Dinitrotoluene }\end{array}$ & $\begin{array}{l}\text { GCMS } \\
\text { GCMS } \\
\text { GCMS } \\
\text { GCMS } \\
\text { GCMS } \\
\text { GCMS } \\
\text { GCMS } \\
\text { GCMS } \\
\text { GCMS } \\
\text { GCMS } \\
\text { GCMS }\end{array}$ & $\begin{array}{l}\mathrm{ug} / \mathrm{Nm} 3 \\
\mathrm{ug} / \mathrm{Nm} 3 \\
\mathrm{ug} / \mathrm{Nm} 3 \\
\mathrm{ug} / \mathrm{Nm} 3 \\
\mathrm{ug} / \mathrm{Nm} 3 \\
\mathrm{ug} / \mathrm{Nm} 3 \\
\mathrm{ug} / \mathrm{Nm} 3 \\
\mathrm{ug} / \mathrm{Nm} 3 \\
\mathrm{ug} / \mathrm{Nm} 3 \\
\mathrm{ug} / \mathrm{Nm} 3 \\
\mathrm{ug} / \mathrm{Nm} 3\end{array}$ & $\begin{array}{l}\mathrm{ND}(1.4) \\
\mathrm{ND}(1.3) \\
\mathrm{ND}(1.2) \\
\mathrm{ND}(1.1) \\
\mathrm{ND}(2.1) \\
\mathrm{ND}(2.2) \\
\mathrm{ND}(0.68) \\
\mathrm{ND}(1.5) \\
\mathrm{ND}(6.1) \\
\mathrm{ND}(2.0) \\
\mathrm{ND}(3.0)\end{array}$ & & $\begin{array}{r}\text { ND (0.89) } \\
\text { ND (0.75) } \\
\text { ND (0.70) } \\
\text { ND (0.69) } \\
\text { ND(1.1) } \\
\text { ND(1.2) } \\
\text { ND (0.49) } \\
\text { ND (0.82) } \\
\text { ND (2.7) } \\
\text { ND (1.0) } \\
\text { ND (1.5) }\end{array}$ & & $\begin{array}{r}\mathrm{ND}(0.94) \\
\mathrm{ND}(0.83) \\
\mathrm{ND}(0.78) \\
\mathrm{ND}(0.76) \\
\mathrm{ND}(1.1) \\
\mathrm{ND}(1.2) \\
\mathrm{ND}(0.51) \\
\mathrm{ND}(0.86) \\
\mathrm{ND}(2.7) \\
\mathrm{ND}(1.0) \\
\mathrm{ND}(1.5)\end{array}$ & \\
\hline
\end{tabular}




\section{Analytical Data Used In Calculations}

Stream: APF Outlet Collection Method: MM5 Sample Type: XAD Resin/Impingers $+\mathrm{MeCl}$

\begin{tabular}{|c|c|c|c|c|c|c|c|c|}
\hline Analyte & $\begin{array}{l}\text { Analytical } \\
\text { Technique }\end{array}$ & Units & Run 1 & Com 1 & Run 2 & Com 2 & Run 3 & $\overline{C o m} 3$ \\
\hline
\end{tabular}


Stream: APF Outlet Collection Method: MM5 Sample Type: XAD Resin/Impingers $+\mathrm{MeCl} 2$

\begin{tabular}{|c|c|c|c|c|c|c|c|c|}
\hline Analyte & $\begin{array}{l}\text { Analytical } \\
\text { Technique }\end{array}$ & Units & Run 1 & Com 1 & Run 2 & $\overline{C \text { Com 2 }}$ & Run 3 & Com 3 \\
\hline $\begin{array}{l}\text { Fluorene } \\
\text { Hexachlorobenzene } \\
\text { Hexachlorobutadiene } \\
\text { Hexachlorocyclopentadiene } \\
\text { Hexachloroethane } \\
\text { Indeno(1,2,3-cd)pyrene } \\
\text { Isophorone } \\
\text { N-Nitroso-di-n-propylamine } \\
\text { Naphthalene } \\
\text { Nitrobenzene } \\
\text { Pentachloronitrobenzene } \\
\text { Pentachlorophenol } \\
\text { Phenanthrene } \\
\text { Phenol } \\
\text { Pyrene } \\
\text { bis(2-Chloroethoxy)methane } \\
\text { bis(2-Chloroethyl)ether } \\
\text { bis(2-Ethylhexyl)phthalate }\end{array}$ & $\begin{array}{l}\text { GCMS } \\
\text { GCMS } \\
\text { GCMS } \\
\text { GCMS } \\
\text { GCMS } \\
\text { GCMS } \\
\text { GCMS } \\
\text { GCMS } \\
\text { GCMS } \\
\text { GCMS } \\
\text { GCMS } \\
\text { GCMS } \\
\text { GCMS } \\
\text { GCMS } \\
\text { GCMS } \\
\text { GCMS } \\
\text { GCMS } \\
\text { GCMS }\end{array}$ & $\begin{array}{l}\text { ug/Nm3 } \\
\text { ug/Nm3 } \\
\text { ug/Nm3 } \\
\text { ug/Nm3 } \\
\text { ug/Nm3 } \\
\text { ug/Nm3 } \\
\text { ug/Nm3 } \\
\text { ug/Nm3 } \\
\text { ug/Nm3 } \\
\text { ug/Nm3 } \\
\text { ug/Nm3 } \\
\text { ug/Nm3 } / N 3 \\
\text { ug/Nm3 } \\
\text { ug/Nm3 } \\
\text { ug/Nm3 } \\
\text { ug/Nm3 } \\
\text { ug/Nm3 } \\
\text { ug/Nm3 }\end{array}$ & $\begin{array}{r}\mathrm{ND}(0.63) \\
\mathrm{ND}(1.3) \\
\mathrm{ND}(2.2) \\
\mathrm{ND}(2.7) \\
\mathrm{ND}(2.5) \\
\mathrm{ND}(15) \\
1.71 \\
\mathrm{ND}(2.8) \\
\mathrm{ND}(0.43) \\
\mathrm{ND}(1.6) \\
\mathrm{ND}(3.1) \\
\mathrm{ND}(3.0) \\
\mathrm{ND}(0.35) \\
1.28 \\
\mathrm{ND}(0.44) \\
\mathrm{ND}(1.5) \\
\mathrm{ND}(1.8) \\
1.03\end{array}$ & $\mathbf{J}$ & $\begin{array}{r}\text { ND (0.37) } \\
\text { ND (1.2) } \\
\text { ND (1.5) } \\
\text { ND (1.3) } \\
\text { ND (1.4) } \\
\text { ND (0.48) } \\
\text { ND (0.38) } \\
\text { ND (1.1) } \\
\text { ND (0.29) } \\
\text { ND (0.67) } \\
\text { ND (2.6) } \\
\text { ND (2.5) } \\
\text { ND (0.26) } \\
0.646 \\
\text { ND (0.22) } \\
\text { ND (0.71) } \\
\text { ND (0.89) } \\
0.522\end{array}$ & $J$ & $\begin{array}{r}\mathrm{ND}(0.37) \\
\mathrm{ND}(1.3) \\
\mathrm{ND}(1.6) \\
\mathrm{ND}(1.3) \\
\mathrm{ND}(1.6) \\
\mathrm{ND}(0.42) \\
\mathrm{ND}(0.40) \\
\mathrm{ND}(1.2) \\
0.562 \\
\mathrm{ND}(0.71) \\
\mathrm{ND}(2.7) \\
\mathrm{ND}(2.6) \\
\mathrm{ND}(0.27) \\
1.18 \\
\mathrm{ND}(0.23) \\
\mathrm{ND}(0.75) \\
\mathrm{ND}(0.98) \\
9.87\end{array}$ & $B J$ \\
\hline
\end{tabular}

Stream: APF Outlet Collection Method: Multimetals Train Sample Type: Mercury Impingers

\begin{tabular}{|c|c|c|c|c|c|c|c|c|}
\hline Analyte & $\begin{array}{l}\text { Analytical } \\
\text { Technique }\end{array}$ & Units & Run 1 & Com I & Run 2 & Com 2 & $\operatorname{Run} 3$ & Com 3 \\
\hline$\sqrt{\text { Mercury }}$ & $\overline{C V A A}$ & ug/Nm3 & 4.76 & & 2.88 & & 4.87 & \\
\hline
\end{tabular}

Stream: APF Outle Collection Method:Multimetals Trai Sample Type: Nitric Acid Impingers + TL

\begin{tabular}{|c|c|c|c|c|c|c|c|c|}
\hline Analyte & $\begin{array}{l}\text { Analytical } \\
\text { Technique }\end{array}$ & Units & Run 1 & Com I & Run 2 & $\overline{\operatorname{Com} 2}$ & Run 3 & $\operatorname{Com} 3$ \\
\hline Mercury & CVAA & $\mathrm{ug} / \mathrm{Nm} 3$ & 9.30 & & 13.1 & & 9.44 & \\
\hline $\begin{array}{l}\text { Aluminum } \\
\text { Barium }\end{array}$ & $\begin{array}{l}\text { ICAP } \\
\text { ICAP }\end{array}$ & $\begin{array}{l}\mathrm{ug} / \mathrm{Nm} 3 \\
\mathrm{ug} / \mathrm{Nm} 3\end{array}$ & $\begin{array}{r}53.2 \\
0.543\end{array}$ & $\begin{array}{l}B C \\
B C\end{array}$ & $\begin{array}{r}55.0 \\
0.740\end{array}$ & $\begin{array}{l}\mathrm{BC} \\
\mathrm{BC}\end{array}$ & $\begin{array}{r}58.9 \\
0.788\end{array}$ & $\begin{array}{l}B C \\
B C\end{array}$ \\
\hline
\end{tabular}




\section{Analytical Data Used In Calculations}

Stream: APF Outlet Collection Method: Multimetals Train Sample Type: Nitric Acid Impingers + TLR

\begin{tabular}{|c|c|c|c|c|c|c|c|c|}
\hline Analyte & $\begin{array}{l}\text { Analytical } \\
\text { Technique }\end{array}$ & Units & Run 1 & Com 1 & Run 2 & $\operatorname{Com} 2$ & Run 3 & Com 3 \\
\hline $\begin{array}{l}\text { Boron } \\
\text { Calcium } \\
\text { Iron } \\
\text { Magnesium } \\
\text { Phosphorus } \\
\text { Potassium } \\
\text { Silver } \\
\text { Sodium } \\
\text { Titanium }\end{array}$ & $\begin{array}{l}\text { ICAP } \\
\text { ICAP } \\
\text { ICAP } \\
\text { ICAP } \\
\text { ICAP } \\
\text { ICAP } \\
\text { ICAP } \\
\text { ICAP } \\
\text { ICAP }\end{array}$ & $\begin{array}{l}\mathrm{ug} / \mathrm{Nm} 3 \\
\mathrm{ug} / \mathrm{Nm} 3 \\
\mathrm{ug} / \mathrm{Nm} 3 \\
\mathrm{ug} / \mathrm{Nm} 3 \\
\mathrm{ug} / \mathrm{Nm} 3 \\
\mathrm{ug} / \mathrm{Nm} 3 \\
\mathrm{ug} / \mathrm{Nm} 3 \\
\mathrm{ug} / \mathrm{Nm} 3 \\
\mathrm{ug} / \mathrm{Nm} 3\end{array}$ & $\begin{array}{r}377 \\
214 \\
58.0 \\
19.7 \\
\text { ND (18) } \\
\text { ND (250) } \\
\text { ND (1.6) } \\
260 \\
1.87\end{array}$ & $\begin{array}{l}\mathrm{BC} \\
\mathrm{BC} \\
\mathrm{BC} \\
\mathrm{C} \\
\mathrm{BC} \\
\mathrm{B} \\
\mathrm{BC}\end{array}$ & $\begin{array}{r}382 \\
280 \\
36.8 \\
23.1 \\
\text { ND(21) } \\
\text { ND (280) } \\
\text { ND (1.8) } \\
363 \\
2.10\end{array}$ & $\begin{array}{l}\mathrm{BC} \\
\mathrm{BC} \\
\mathrm{BC} \\
\mathrm{C} \\
\mathrm{BC} \\
\mathrm{B} \\
\mathrm{BC}\end{array}$ & \begin{tabular}{r|}
321 \\
361 \\
810 \\
25.3 \\
$\mathrm{ND}(17)$ \\
$\mathrm{ND}(230)$ \\
$\mathrm{ND}(1.5)$ \\
413 \\
2.08
\end{tabular} & $\begin{array}{l}B C \\
B C \\
B C \\
C \\
B C \\
B \\
B C\end{array}$ \\
\hline $\begin{array}{l}\text { Antimony } \\
\text { Arsenic } \\
\text { Barium } \\
\text { Beryllium } \\
\text { Cadmium } \\
\text { Chromium } \\
\text { Cobalt } \\
\text { Copper } \\
\text { Lead } \\
\text { Manganese } \\
\text { Molybdenum } \\
\text { Nickel } \\
\text { Selenium } \\
\text { Vanadium }\end{array}$ & $\begin{array}{l}\text { ICPMS } \\
\text { ICPMS } \\
\text { ICPMS } \\
\text { ICPMS } \\
\text { ICPMS } \\
\text { ICPMS } \\
\text { ICPMS } \\
\text { ICPMS } \\
\text { ICPMS } \\
\text { ICPMS } \\
\text { ICPMS } \\
\text { ICPMS } \\
\text { ICPMS } \\
\text { ICPMS }\end{array}$ & $\begin{array}{l}\text { ug/Nm3 } \\
\text { ug/Nm3 } \\
\text { ug/Nm3 } \\
\text { ug/Nm3 } \\
\text { ug/Nm3 } \\
\text { ug/Nm3 } \\
\text { ug/Nm3 } \\
\text { ug/Nm3 } \\
\text { ug/Nm3 } \\
\text { ug/Nm3 } \\
\text { ug/Nm3 } \\
\text { ug/Nm3 } \\
\text { ug } / \mathrm{Nm} 3 \\
\text { ug/Nm3 }\end{array}$ & $\begin{array}{r}0.0223 \\
2.95 \\
\text { ND }(0.0052) \\
\text { ND }(0.0047) \\
\text { ND }(0.0062) \\
3.22 \\
0.0616 \\
0.751 \\
\text { ND }(0.0050) \\
0.565 \\
7.75 \\
54.5 \\
58.5 \\
1.03\end{array}$ & $\begin{array}{l}\mathrm{C} \\
\mathrm{C} \\
\mathrm{C} \\
\mathrm{C} \\
\mathrm{C} \\
\mathrm{C} \\
\mathrm{C} \\
\mathrm{C} \\
\mathrm{C} \\
\mathrm{C} \\
\mathrm{C} \\
\mathrm{C}\end{array}$ & $\begin{array}{r}0.0230 \\
3.89 \\
\text { ND }(0.0059) \\
\text { ND }(0.0054) \\
\text { ND }(0.0071) \\
1.67 \\
0.0204 \\
0.771 \\
\text { ND }(0.0057) \\
0.717 \\
3.36 \\
6.73 \\
46.1 \\
1.01\end{array}$ & $\begin{array}{l}\mathrm{C} \\
\mathrm{C} \\
\mathrm{C} \\
\mathrm{C} \\
\mathrm{C} \\
\mathrm{C} \\
\mathrm{C} \\
\mathrm{C} \\
\mathrm{C} \\
\mathrm{C} \\
\mathrm{C} \\
\mathrm{C} \\
\mathrm{C}\end{array}$ & $\begin{array}{r}0.0331 \\
4.12 \\
\mathrm{ND}(0.0049) \\
\mathrm{ND}(0.0045) \\
\mathrm{ND}(0.0059) \\
147 \\
0.832 \\
0.885 \\
\mathrm{ND}(0.0047) \\
22.0 \\
3.43 \\
89.1 \\
41.2 \\
1.36\end{array}$ & $\begin{array}{l}C \\
C \\
C \\
C \\
C \\
C \\
C \\
C \\
C \\
C \\
C \\
C \\
C\end{array}$ \\
\hline
\end{tabular}

Stream: APF Outlet Collection Method: PCDD/PCDF for Dioxins and Furans (M23) Sample Type: $47 \mathrm{~mm}$ Filter

\begin{tabular}{|c|c|c|c|c|c|c|c|c|}
\hline Analyte & $\begin{array}{l}\text { Analytical } \\
\text { Technique }\end{array}$ & Units & Run 1 & Com 1 & Run 2 & $\overline{\operatorname{Com} 2}$ & Run 3 & $\operatorname{Com} 3$ \\
\hline $\begin{array}{l}1234678-\mathrm{HpCDD} \\
1234678-\mathrm{HpCDF} \\
123478-\mathrm{HxCDD} \\
123478-\mathrm{HxCDF}\end{array}$ & $\begin{array}{l}\text { Meth 23X } \\
\text { Meth 23X } \\
\text { Meth 23X } \\
\text { Meth 23X }\end{array}$ & $\begin{array}{l}\mathrm{ug} / \mathrm{Nm} 3 \\
\mathrm{ug} / \mathrm{Nm} 3 \\
\mathrm{ug} / \mathrm{Nm} 3 \\
\mathrm{ug} / \mathrm{Nm} 3\end{array}$ & $\begin{array}{l}\text { ND }(0.00000049) \\
\text { ND }(0.00000027) \\
\text { ND }(0.00000044) \\
\text { ND }(0.00000027)\end{array}$ & & $\begin{array}{l}\text { ND }(0.00000080) \\
\text { ND }(0.00000043) \\
\text { ND }(0.00000068) \\
N D(0.00000043)\end{array}$ & & $\begin{array}{l}\text { ND (0.0000021) } \\
\text { ND (0.0000011) } \\
\text { ND }(0.0000018) \\
\text { ND }(0.0000011)\end{array}$ & \\
\hline
\end{tabular}


Stream: APF Outlet Collection Method: PCDD/PCDF for Dioxins and Furans (M23) Sample Type: 47 mm Filter

\begin{tabular}{|c|c|c|c|c|c|c|c|c|}
\hline Analyte & $\begin{array}{l}\text { Analytical } \\
\text { Technique }\end{array}$ & Units & Run 1 & Com 1 & $\overline{\text { Run 2 }}$ & $\overline{\text { Com 2 }}$ & Run 3 & Com 3 \\
\hline$\sqrt{1234789-\mathrm{HpCDF}}$ & Meth 23X & $\sqrt{\mathrm{ug} / \mathrm{Nm} 3}$ & ND $(0.00000040)$ & & ND (0.00000068) & & ND (0.0000018) & \\
\hline 123678-HxCDD & Meth 23X & ug/Nm3 & $\mathrm{ND}(0.00000035)$ & & ND $(0.00000055)$ & & $\operatorname{ND}(0.0000016)$ & \\
\hline 123678-HxCDF & Meth 23X & ug/Nm3 & ND $(0.00000022)$ & & ND $(0.00000031)$ & & ND $(0.00000085)$ & \\
\hline 12378-PeCDD & Meth 23X & ug/Nm3 & $\operatorname{ND}(0.00000040)$ & & ND $(0.00000062)$ & & $\mathrm{ND}(0.0000016)$ & \\
\hline 12378-PeCDF & Meth 23X & $\mathrm{ug} / \mathrm{Nm} 3$ & ND $(0.00000022)$ & & $\mathrm{ND}(0.00000037)$ & & $\mathrm{ND}(0.00000092)$ & \\
\hline 123789-HxCDD & Meth 23X & ug/Nm3 & ND $(0.00000040)$ & & ND $(0.00000062)$ & & $\operatorname{ND}(0.0000016)$ & \\
\hline 123789-HxCDF & Meth 23X & ug $/ \mathrm{Nm} 3$ & $\mathrm{ND}(0.00000027)$ & & ND $(0.00000043)$ & & ND $(0.0000011)$ & \\
\hline 234678-HXCDF & Meth 23X & ug/Nm3 & 0.000000350 & $\mathrm{~F}$ & ND $(0.00000037)$ & & ND $(0.00000099)$ & \\
\hline 23478-PeCDF & Meth 23X & ug/Nm3 & $\operatorname{ND}(0.00000022)$ & & $\mathrm{ND}(0.00000031)$ & & ND $(0.00000092)$ & \\
\hline 2378-TCDD & Meth 23X & ug/Nm3 & $\operatorname{ND}(0.00000022)$ & & ND $(0.00000037)$ & & ND $(0.00000092)$ & \\
\hline 2378-TCDF & Meth 23X & ug/Nm3 & ND $(0.00000018)$ & & ND $(0.00000025)$ & & ND $(0.00000078)$ & \\
\hline OCDD & Meth 23X & ug/Nm3 & $\operatorname{ND}(0.00000080)$ & & $\operatorname{ND}(0.0000013)$ & & ND $(0.0000049)$ & \\
\hline OCDF & Meth 23X & ug/Nm3 & ND (0.00000066) & & $\operatorname{ND}(0.0000011)$ & & $\operatorname{ND}(0.0000042)$ & \\
\hline TOTAL HpCDD & Meth 23X & ug/Nm3 & ND $(0.00000049)$ & & ND $(0.00000080)$ & & ND $(0.0000021)$ & \\
\hline TOTAL HpCDF & Meth 23X & ug/Nm3 & ND $(0.00000031)$ & & ND $(0.00000055)$ & & ND $(0.0000013)$ & \\
\hline TOTAL HXCDD & Meth 23X & ug/Nm3 & ND $(0.00000040)$ & & ND $(0.00000062)$ & & ND $(0.0000016)$ & \\
\hline TOTAL HXCDF & Meth 23X & ug $/ \mathrm{Nm} 3$ & 0.000000350 & $F$ & ND $(0.00000037)$ & & ND $(0.00000099)$ & \\
\hline TOTAL PeCDD & Meth 23X & ug/Nm3 & ND $(0.00000040)$ & & ND $(0.00000062)$ & & ND $(0.0000016)$ & \\
\hline TOTAL PeCDI & Meth 23X & $\mathrm{ug} / \mathrm{Nm} 3$ & ND $(0.00000022)$ & & ND $(0.00000037)$ & & ND $(0.00000092)$ & \\
\hline TOTAL TCDD & Meth 23X & ug/Nm3 & ND $(0.00000022)$ & & ND $(0.00000037)$ & & $\operatorname{ND}(0.00000092)$ & \\
\hline TOTAL TCDF & $23 \mathrm{X}$ & ug/Nm3 & ND $(0.00000018)$ & & ND (0.00000025) & & ND $(0.00000078)$ & \\
\hline
\end{tabular}

Stream: APF Outle Collection Method: PCDD/PCDF for Dioxins and Furans (M23 Sample Type: Filtered Solids/Solvent Rinses/XAD Resi

\begin{tabular}{|c|c|c|c|c|c|c|c|c|}
\hline Analyte & $\begin{array}{l}\text { Analytical } \\
\text { Technique }\end{array}$ & Units & Run 1 & Com 1 & Run 2 & Com 2 & Run 3 & Com 3 \\
\hline $\begin{array}{l}1234678-\mathrm{HPCDD} \\
1234678-\mathrm{HpCDF} \\
123478-\mathrm{HxCDD} \\
123478-\mathrm{HxCDF} \\
1234789-\mathrm{HpCDF} \\
123678-\mathrm{HxCDD} \\
123678-\mathrm{HxCDF}\end{array}$ & $\begin{array}{l}\text { Meth 23X } \\
\text { Meth 23X } \\
\text { Meth 23X } \\
\text { Meth 23X } \\
\text { Meth 23X } \\
\text { Meth 23X } \\
\text { Meth 23X }\end{array}$ & $\begin{array}{l}\text { ug/Nm3 } \\
\text { ug/Nm3 } \\
\text { ug/Nm3 } \\
\text { ug/Nm3 } \\
\text { ug/Nm3 } \\
\text { ug/Nm3 } \\
\text { ug/Nm3 }\end{array}$ & $\begin{array}{r}0.00000877 \\
0.0000113 \\
\text { ND }(0.0000071) \\
0.00000907 \\
\text { ND }(0.0000071) \\
\text { ND }(0.0000060) \\
\text { ND }(0.0000030)\end{array}$ & B & $\begin{array}{r}0.0000223 \\
0.0000174 \\
0.00000346 \\
0.0000239 \\
0.00000446 \\
0.00000570 \\
0.00000545\end{array}$ & $\begin{array}{l}B \\
F \\
B \\
F\end{array}$ & $\begin{array}{r}0.0000103 \\
0.0000128 \\
\text { ND }(0.0000056) \\
0.0000145 \\
0.00000523 \\
\text { ND (0.0000045) } \\
0.00000346\end{array}$ & B \\
\hline
\end{tabular}




\section{Analytical Data Used In Calculations}

Stream: APF Outlet Collection Method: PCDD/PCDF for Dioxins and Furans (M23) Sample Type: Filtered Solids/Solvent Rinses/XAD Resin

\begin{tabular}{|c|c|c|c|c|c|c|c|c|}
\hline Analyte & $\begin{array}{l}\text { Analytical } \\
\text { Technique }\end{array}$ & Units & Run 1 & Com 1 & Run 2 & Com 2 & $\overline{\operatorname{Run} 3}$ & Com 3 \\
\hline \begin{tabular}{|l}
$12378-\mathrm{PeCDD}$ \\
$12378-\mathrm{PeCDF}$ \\
$123789-\mathrm{HxCDD}$ \\
$123789-\mathrm{HxCDF}$ \\
$234678-\mathrm{HxCDF}$ \\
23478-PeCDF \\
$2378-\mathrm{TCDD}$ \\
2378-TCDF \\
OCDD \\
OCDF \\
TOTAL HpCDD \\
TOTAL HpCDF \\
TOTAL HXCDD \\
TOTAL HXCDF \\
TOTAL PeCDD \\
TOTAL PeCDF \\
TOTAL TCDD \\
TOTAL TCDF
\end{tabular} & $\begin{array}{l}\text { Meth 23X } \\
\text { Meth 23X } \\
\text { Meth 23X } \\
\text { Meth 23X } \\
\text { Meth 23X } \\
\text { Meth 23X } \\
\text { Meth 23X } \\
\text { Meth 23X } \\
\text { Meth 23X } \\
\text { Meth 23X } \\
\text { Meth 23X } \\
\text { Meth 23X } \\
\text { Meth 23X } \\
\text { Meth 23X } \\
\text { Meth 23X } \\
\text { Meth 23X } \\
\text { Meth 23X } \\
\text { Meth 23X }\end{array}$ & 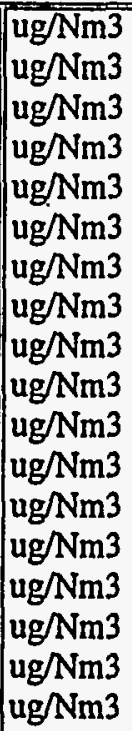 & \begin{tabular}{r|} 
ND (0.0000060) \\
ND (0.0000030) \\
ND (0.0000063) \\
ND (0.0000041) \\
0.00000332 \\
ND (0.0000030) \\
ND (0.0000030) \\
ND (0.0000011) \\
0.0000351 \\
0.0000321 \\
0.00000877 \\
0.0000140 \\
0.00000522 \\
0.00000858 \\
ND (0.0000060) \\
0.00000396 \\
ND $(0.0000030)$ \\
0.00000282
\end{tabular} & $\begin{array}{l}\mathrm{B} \\
\mathrm{F}\end{array}$ & \begin{tabular}{r|}
0.00000292 \\
0.00000684 \\
0.00000567 \\
0.00000253 \\
0.00000599 \\
0.00000499 \\
0.00000121 \\
0.0000120 \\
0.0000446 \\
0.0000661 \\
0.0000223 \\
0.0000243 \\
0.0000458 \\
0.0000512 \\
0.0000412 \\
0.0000529 \\
0.000127 \\
0.0000988
\end{tabular} & $\mid \begin{array}{l}F \\
F \\
B F\end{array}$ & $\begin{array}{r}\text { ND }(0.0000053) \\
\text { ND }(0.0000030) \\
\text { ND }(0.0000053) \\
\text { ND }(0.0000034) \\
0.00000508 \\
\text { ND (0.0000030) } \\
\text { ND (0.0000034) } \\
0.00000450 \\
0.0000345 \\
0.0000423 \\
0.0000103 \\
0.0000199 \\
0.00000520 \\
0.0000178 \\
0.0000104 \\
0.00000719 \\
0.0000136 \\
0.0000122\end{array}$ & BF \\
\hline
\end{tabular}

Stream: APF Outlet Collection Method: VOST Sample Type: Tenax-Tenax + Charcoal A

\begin{tabular}{|c|c|c|c|c|c|c|c|c|}
\hline Analyte & $\begin{array}{l}\text { Analytical } \\
\text { Technique }\end{array}$ & Units & Run 1 & $\longdiv { \operatorname { C o m ~ } 1 }$ & Run 2 & $\overline{\operatorname{Com} 2}$ & Run 3 & $\longdiv { \operatorname { C o m } 3 }$ \\
\hline $\begin{array}{l}\text { 1,1,1-Trichloroethane } \\
\text { 1,1,2,2-Tetrachloroethane } \\
\text { 1,1,2-Trichloroethane } \\
\text { 1,1-Dichloroethane } \\
\text { 1,1-Dichloroethene } \\
\text { 1,2-Dichlorobenzene } \\
\text { 1,2-Dichloroethane } \\
\text { 1,2-Dichloropropane } \\
\text { 1,3-Dichlorobenzene } \\
\text { 1,4-Dichlorobenzene }\end{array}$ & $\begin{array}{l}\text { GCMS } \\
\text { GCMS } \\
\text { GCMS } \\
\text { GCMS } \\
\text { GCMS } \\
\text { GCMS } \\
\text { GCMS } \\
\text { GCMS } \\
\text { GCMS } \\
\text { GCMS }\end{array}$ & $\begin{array}{l}\text { ug/Nm3 } \\
\text { ug/Nm3 } \\
\text { ug/Nm3 } \\
\text { ug/Nm3 } \\
\text { ug/Nm3 } \\
\text { ug/Nm3 } \\
\text { ug/Nm3 } \\
\text { ug/Nm3 } \\
\text { ug/Nm3 } \\
\text { ug/Nm3 }\end{array}$ & $\begin{array}{l}\text { ND (0.47) } \\
\text { ND }(0.47) \\
\text { ND }(0.47) \\
\text { ND }(0.47) \\
\text { ND }(0.47) \\
\text { ND }(0.47) \\
\text { ND }(0.47) \\
\text { ND }(0.47) \\
\text { ND }(0.47) \\
\text { ND }(0.47)\end{array}$ & & $\begin{array}{l}\text { ND (0.47) } \\
\text { ND (0.47) } \\
\text { ND (0.47) } \\
\text { ND (0.47) } \\
\text { ND (0.47) } \\
\text { ND(0.47) } \\
\text { ND (0.47) } \\
\text { ND (0.47) } \\
\text { ND (0.47) } \\
\text { ND }(0.47)\end{array}$ & & $\begin{array}{l}\text { ND (0.55) } \\
\text { ND (0.55) } \\
\text { ND (0.55) } \\
\text { ND (0.55) } \\
\text { ND (0.55) } \\
\text { ND (0.55) } \\
\text { ND (0.55) } \\
\text { ND (0.55) } \\
\text { ND (0.55) } \\
\text { ND (0.55) }\end{array}$ & \\
\hline
\end{tabular}


Stream: APF Outlet Collection Method: VOST Sample Type: Tenax-Tenax + Charcoal A

\begin{tabular}{|c|c|c|c|c|c|c|c|c|}
\hline Analyte & $\begin{array}{l}\text { Analytical } \\
\text { Technique }\end{array}$ & Units & Run 1 & Com 1 & $\overline{\text { Run } 2}$ & Com 2 & $\operatorname{Run} 3$ & $\overline{C o m} 3$ \\
\hline $\begin{array}{l}\text { 2-Butanone } \\
\text { 2-Hexanone } \\
\text { 4-Methyl-2-Pentanone } \\
\text { Acetone } \\
\text { Benzene } \\
\text { Bromodichloromethane } \\
\text { Bromoform } \\
\text { Bromomethane } \\
\text { Carbon Disulfide } \\
\text { Carbon Tetrachloride } \\
\text { Chlorobenzene } \\
\text { Chloroethane } \\
\text { Chloroform } \\
\text { Chloromethane } \\
\text { Dibromochloromethane } \\
\text { Ethyl Benzene } \\
\text { Methylene Chloride } \\
\text { Styrene } \\
\text { Tetrachloroethene } \\
\text { Toluene } \\
\text { Trichloroethene } \\
\text { Trichlorofluoromethane } \\
\text { Vinyl Acetate } \\
\text { Vinyl Chloride } \\
\text { cis-1,3-Dichloropropene } \\
\text { m,p-Xylene } \\
\text { o-Xylene } \\
\text { trans-1,2-Dichloroethene } \\
\text { trans-1,3-Dichloropropene }\end{array}$ & \begin{tabular}{|l} 
GCMS \\
GCMS \\
GCMS \\
GCMS \\
GCMS \\
GCMS \\
GCMS \\
GCMS \\
GCMS \\
GCMS \\
GCMS \\
GCMS \\
GCMS \\
GCMS \\
GCMS \\
GCMS \\
GCMS \\
GCMS \\
GCMS \\
GCMS \\
GCMS \\
GCMS \\
GCMS \\
GCMS \\
GCMS \\
GCMS \\
GCMS \\
GCMS
\end{tabular} & $\begin{array}{l}\text { ug/Nm3 } \\
\text { ug/Nm3 } \\
\text { ug/Nm3 } \\
\text { ug/Nm3 } \\
\text { ug/Nm3 } \\
\text { ug/Nm3 } \\
\text { ug/Nm3 } \\
\text { ug/Nm3 } \\
\text { ug/Nm3 } \\
\text { ug/Nm3 } \\
\text { ug/Nm3 } \\
\text { ug/Nm3 } \\
\text { ug/Nm3 } \\
\text { ug/Nm3 } \\
\text { ug/Nm3 } \\
\text { ug/Nm3 } / N \\
\text { ug/Nm3 } \\
\text { ug/Nm3 } \\
\text { ug/Nm3 } \\
\text { ug/Nm3 } 3 \\
\text { ug/Nm3 } \\
\text { ug/Nm3 } \\
\text { ug/Nm3 } \\
\text { ug/Nm3 } \\
\text { ug/Nm3 } \\
\text { ug/Nm3 } \\
\text { ug/Nm3 } \\
\text { ug/Nm3 } \\
\text { ug/Nm3 }\end{array}$ & $\begin{array}{r}\text { ND (2.3) } \\
\text { ND (2.3) } \\
\text { ND (2.3) } \\
\text { ND (2.3) } \\
10.2 \\
\text { ND (0.47) } \\
\text { ND (0.47) } \\
\text { ND (0.47) } \\
14.9 \\
\text { ND (0.47) } \\
\text { ND (0.47) } \\
\text { ND (0.47) } \\
1.30 \\
9.32 \\
\text { ND (0.47) } \\
\text { ND (0.47) } \\
>1860 \\
\text { ND (0.47) } \\
\text { ND (0.47) } \\
4.66 \\
\text { ND (0.47) } \\
\text { ND (0.47) } \\
\text { ND (2.3) } \\
\text { ND (0.47) } \\
\text { ND (0.47) } \\
\text { ND (0.47) } \\
\text { ND (0.47) } \\
\text { ND (0.47) } \\
\text { ND (0.47) }\end{array}$ & S & $\begin{array}{r}N D(2.3) \\
\text { ND (2.3) } \\
\text { ND (2.3) } \\
\text { ND (2.3) } \\
\text { ND (0.47) } \\
\text { ND (0.47) } \\
\text { ND (0.47) } \\
\text { ND(0.47) } \\
12.6 \\
\text { ND (0.47) } \\
\text { ND (0.47) } \\
\text { ND (0.47) } \\
\text { ND(0.47) } \\
\text { ND (0.47) } \\
\text { ND (0.47) } \\
\text { ND (0.47) } \\
>419 \\
\text { ND (0.47) } \\
\text { ND (0.47) } \\
0.559 \\
\text { ND (0.47) } \\
\text { ND (0.47) } \\
\text { ND (2.3) } \\
\text { ND (0.47) } \\
\text { ND (0.47) } \\
\text { ND (0.47) } \\
\text { ND (0.47) } \\
\text { ND (0.47) } \\
\text { ND (0.47) }\end{array}$ & S & $\begin{array}{r}\mathrm{ND}(2.8) \\
\mathrm{ND}(2.8) \\
\mathrm{ND}(2.8) \\
\mathrm{ND}(2.8) \\
0.938 \\
\mathrm{ND}(0.55) \\
\mathrm{ND}(0.55) \\
\mathrm{ND}(0.55) \\
46.3 \\
\mathrm{ND}(0.55) \\
\mathrm{ND}(0.55) \\
\mathrm{ND}(0.55) \\
\mathrm{ND}(0.55) \\
1.16 \\
\mathrm{ND}(0.55) \\
\mathrm{ND}(0.55) \\
662 \\
\mathrm{ND}(0.55) \\
\mathrm{ND}(0.55) \\
0.993 \\
\mathrm{ND}(0.55) \\
\mathrm{ND}(0.55) \\
\mathrm{ND}(2.8) \\
\mathrm{ND}(0.55) \\
\mathrm{ND}(0.55) \\
\mathrm{ND}(0.55) \\
\mathrm{ND}(0.55) \\
\mathrm{ND}(0.55) \\
\mathrm{ND}(0.55)\end{array}$ & $E$ \\
\hline
\end{tabular}


Analytical Data Used In Calculations

Stream: APF Outlet Collection Method: VOST Sample Type: Tenax-Tenax + Charcoal B

\begin{tabular}{|c|c|c|c|c|c|c|c|c|}
\hline Analyte & $\begin{array}{l}\text { Analytical } \\
\text { Technique } \\
\end{array}$ & $\overline{\overline{\text { Units }}}$ & $\overline{\text { Run } 1}$ & Com 1 & Run 2 & $\widehat{C o m 2}$ & Run 3 & Com 3 \\
\hline $\begin{array}{l}\text { 1,1,1-Trichloroethane } \\
\text { 1,1,2,2-Tetrachloroethane } \\
\text { 1,1,2-Trichloroethane } \\
\text { 1,1-Dichloroethane } \\
\text { 1,1-Dichloroethene } \\
\text { 1,2-Dichlorobenzene } \\
\text { 1,2-Dichloroethane } \\
\text { 1,2-Dichloropropane } \\
\text { 1,3-Dichlorobenzene } \\
\text { 1,4-Dichlorobenzene } \\
\text { 2-Butanone } \\
\text { 2-Hexanone } \\
\text { 4-Methyl-2-Pentanone } \\
\text { Acetone } \\
\text { Benzene } \\
\text { Bromodichloromethane } \\
\text { Bromoform } \\
\text { Bromomethane } \\
\text { Carbon Disulfide } \\
\text { Carbon Tetrachloride } \\
\text { Chlorobenzene } \\
\text { Chloroethane } \\
\text { Chloroform } \\
\text { Chloromethane } \\
\text { Dibromochloromethane } \\
\text { Ethyl Benzene } \\
\text { Methylene Chloride } \\
\text { Styrene } \\
\text { Tetrachloroethene } \\
\text { Toluene } \\
\text { Trichloroethene } \\
\text { Trichlorofluoromethane } \\
\text { Vinyl Acetate }\end{array}$ & \begin{tabular}{|l} 
GCMS \\
GCMS \\
GCMS \\
GCMS \\
GCMS \\
GCMS \\
GCMS \\
GCMS \\
GCMS \\
GCMS \\
GCMS \\
GCMS \\
GCMS \\
GCMS \\
GCMS \\
GCMS \\
GCMS \\
GCMS \\
GCMS \\
GCMS \\
GCMS \\
GCMS \\
GCMS \\
GCMS \\
GCMS \\
GCMS \\
GCMS \\
GCMS \\
GCMS \\
GCMS \\
GCMS \\
GCMS \\
GCMS
\end{tabular} & 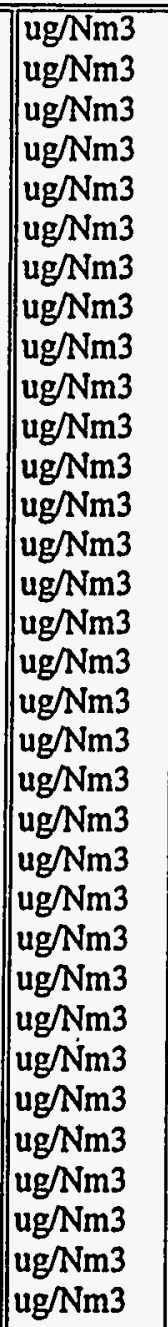 & \begin{tabular}{r|} 
ND (0.34) \\
ND (0.34) \\
ND (0.34) \\
ND (0.34) \\
ND (0.34) \\
ND (0.34) \\
ND (0.34) \\
ND (0.34) \\
ND (0.34) \\
ND (0.34) \\
ND (1.7) \\
ND (1.7) \\
ND (1.7) \\
ND (1.7) \\
5.79 \\
ND (0.34) \\
ND (0.34) \\
ND (0.34) \\
27.9 \\
ND (0.34) \\
ND (0.34) \\
ND (0.34) \\
ND (0.34) \\
0.953 \\
ND (0.34) \\
ND (0.34) \\
$>1230$ \\
ND (0.34) \\
ND (0.34) \\
0.613 \\
ND (0.34) \\
ND (0.34) \\
ND (1.7)
\end{tabular} & 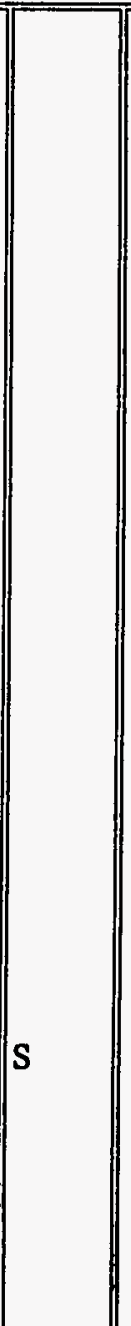 & $\begin{array}{r}\text { ND (0.53) } \\
\text { ND (0.53) } \\
\text { ND (0.53) } \\
\text { ND (0.53) } \\
\text { ND (0.53) } \\
\text { ND (0.53) } \\
\text { ND (0.53) } \\
\text { ND (0.53) } \\
\text { ND (0.53) } \\
\text { ND (0.53) } \\
\text { ND (2.7) } \\
\text { ND (2.7) } \\
\text { ND (2.7) } \\
\text { ND (2.7) } \\
0.850 \\
\text { ND (0.53) } \\
\text { ND (0.53) } \\
\text { ND (0.53) } \\
48.9 \\
\text { ND (0.53) } \\
\text { ND (0.53) } \\
\text { ND (0.53) } \\
\text { ND (0.53) } \\
\text { ND (0.53) } \\
\text { ND (0.53) } \\
\text { ND (0.53) } \\
154 \\
\text { ND (0.53) } \\
\text { ND (0.53) } \\
\text { ND (0.53) } \\
\text { ND (0.53) } \\
\text { ND (0.53) } \\
\text { ND }(2.7)\end{array}$ & $E$ & \begin{tabular}{r|} 
ND (0.49) \\
ND (0.49) \\
ND (0.49) \\
ND (0.49) \\
ND (0.49) \\
ND (0.49) \\
ND (0.49) \\
ND (0.49) \\
ND (0.49) \\
ND (0.49) \\
ND (2.5) \\
ND (2.5) \\
ND (2.5) \\
ND (2.5) \\
0.641 \\
ND (0.49) \\
ND (0.49) \\
4.19 \\
ND (0.49) \\
ND (0.49) \\
ND (0.49) \\
ND (0.49) \\
ND (0.49) \\
3.40 \\
ND (0.49) \\
ND (0.49) \\
ND (0.49) \\
ND (0.49) \\
ND (0.49) \\
ND $(0.49)$ \\
ND (0.49) \\
ND (0.49)
\end{tabular} & \\
\hline
\end{tabular}


Stream: APF Outlet Collection Method: VOST Sample Type: Tenax-Tenax + Charcoal B

\begin{tabular}{|c|c|c|c|c|c|c|c|c|}
\hline Analyte & $\begin{array}{l}\text { Analytical } \\
\text { Technique }\end{array}$ & Units & Run 1 & Com 1 & Run 2 & Com 2 & Run 3 & Com 3 \\
\hline $\begin{array}{l}\text { Vinyl Chloride } \\
\text { cis-1,3-Dichloropropene } \\
\text { m,p-Xylene } \\
\text { o-Xylene } \\
\text { trans-1,2-Dichloroethene } \\
\text { trans-1,3-Dichloropropene }\end{array}$ & $\begin{array}{l}\text { GCMS } \\
\text { GCMS } \\
\text { GCMS } \\
\text { GCMS } \\
\text { GCMS } \\
\text { GCMS }\end{array}$ & $\begin{array}{l}\mathrm{ug} / \mathrm{Nm} 3 \\
\mathrm{ug} / \mathrm{Nm} 3 \\
\mathrm{ug} / \mathrm{Nm} 3 \\
\mathrm{ug} / \mathrm{Nm} 3 \\
\mathrm{ug} / \mathrm{Nm} 3 \\
\mathrm{ug} / \mathrm{Nm} 3\end{array}$ & $\begin{array}{l}\text { ND (0.34) } \\
\text { ND (0.34) } \\
\text { ND (0.34) } \\
\text { ND (0.34) } \\
\text { ND }(0.34) \\
\text { ND }(0.34)\end{array}$ & & $\begin{array}{l}\text { ND (0.53) } \\
\text { ND (0.53) } \\
\text { ND (0.53) } \\
\text { ND (0.53) } \\
\text { ND (0.53) } \\
\text { ND }(0.53)\end{array}$ & & $\begin{array}{l}\text { ND }(0.49) \\
\text { ND }(0.49) \\
\text { ND }(0.49) \\
\text { ND }(0.49) \\
\text { ND }(0.49) \\
N D(0.49)\end{array}$ & \\
\hline
\end{tabular}

Stream: Bed Ash Collection Method: Grab Composite Sample Type: $\mathrm{Ash}+\mathrm{Mg}+\mathrm{Ca}$

\begin{tabular}{|c|c|c|c|c|c|c|c|c|}
\hline Analyte & $\begin{array}{l}\text { Analytical } \\
\text { Technique }\end{array}$ & Units & Run 1 & Com 1 & Run 2 & $\overline{\mathbf{C o m} 2}$ & $\overline{\text { Run } 3}$ & Com 3 \\
\hline Boron & $\overline{I C A P}$ & ug/g & 100 & & $\overline{100}$ & & 89.0 & \\
\hline $\begin{array}{l}\text { Carbon } \\
\text { Sulfur }\end{array}$ & $\begin{array}{l}\text { Ultimate } \\
\text { Ultimate }\end{array}$ & $\begin{array}{l}\% \\
\%\end{array}$ & $\begin{array}{l}\overline{3.44} \\
7.47\end{array}$ & & $\begin{array}{l}3.42 \\
8.06\end{array}$ & & $\begin{array}{l}3.75 \\
7.97\end{array}$ & \\
\hline $\begin{array}{l}\text { Actinium-228@338 } \\
\text { Actinium-228@911 } \\
\text { Actinium-228 @968 } \\
\text { Bismuth-212 @727 } \\
\text { Bismuth-214 @1120.4 } \\
\text { Bismuth-214@1764.7 } \\
\text { Bismuth-214@609.4 } \\
\text { K-40 @1460 } \\
\text { Lead-210 @46 } \\
\text { Lead-212@238 } \\
\text { Lead-214@295.2 } \\
\text { Lead-214@352.0 } \\
\text { Radium-226@186.0 } \\
\text { Thallium-208@583 } \\
\text { Thallium-208 @860 } \\
\text { Thorium-234@63.3 } \\
\text { Thorium-234@92.6 } \\
\text { Uranium-235 @143.8 }\end{array}$ & $\begin{array}{l}\text { gamma } \\
\text { gamma } \\
\text { gamma } \\
\text { gamma } \\
\text { gamma } \\
\text { gamma } \\
\text { gamma } \\
\text { gamma } \\
\text { gamma } \\
\text { gamma } \\
\text { gamma } \\
\text { gamma } \\
\text { gamma } \\
\text { gamma } \\
\text { gamma. } \\
\text { gamma } \\
\text { gamma } \\
\text { gamma }\end{array}$ & $\begin{array}{l}\mathrm{pCi} / \mathrm{g} \\
\mathrm{pCi} / \mathrm{g} \\
\mathrm{pCi} / \mathrm{g} \\
\mathrm{pCi} / \mathrm{g} \\
\mathrm{pCi} / \mathrm{g} \\
\mathrm{pCi} / \mathrm{g} \\
\mathrm{pCi} / \mathrm{g} \\
\mathrm{pCi} / \mathrm{g} \\
\mathrm{pCi} / \mathrm{g} \\
\mathrm{pCi} / \mathrm{g} \\
\mathrm{pCi} / \mathrm{g} \\
\mathrm{pCi} / \mathrm{g} \\
\mathrm{pCi} / \mathrm{g} \\
\mathrm{pCi} / \mathrm{g} \\
\mathrm{pCi} / \mathrm{g} \\
\mathrm{pCi} / \mathrm{g} \\
\mathrm{pCi} / \mathrm{g} \\
\mathrm{pCi} / \mathrm{g}\end{array}$ & $\begin{array}{r}0.240 \\
0.0200 \\
0.0700 \\
0.260 \\
0.370 \\
0.290 \\
0.680 \\
1.00 \\
0.200 \\
0.310 \\
0.470 \\
0.510 \\
0.620 \\
0.0300 \\
\text { ND }(0.28) \\
0.440 \\
0.210 \\
0.0400\end{array}$ & & $\begin{array}{r}0.150 \\
0.0500 \\
0.0700 \\
0.260 \\
0.280 \\
0.450 \\
0.440 \\
0.890 \\
\text { ND }(0.10) \\
0.0800 \\
0.450 \\
0.610 \\
0.900 \\
0.0900 \\
0.0500 \\
1.70 \\
\text { ND }(0.010) \\
0.0600 \\
\end{array}$ & & \begin{tabular}{r|}
0.310 \\
0.100 \\
$\mathrm{ND}(0.010)$ \\
$\mathrm{ND}(0.21)$ \\
0.770 \\
0.520 \\
0.650 \\
1.10 \\
0.580 \\
0.190 \\
0.600 \\
0.640 \\
1.60 \\
0.0600 \\
0.200 \\
0.830 \\
0.190 \\
0.100
\end{tabular} & \\
\hline
\end{tabular}




\section{Analytical Data Used In Calculations}

Stream: Bed Ash Collection Method: Grab Composite Sample Type: $\mathrm{Ash}+\mathrm{Mg}+\mathrm{Ca} \quad \mathrm{FD}$

\begin{tabular}{|c|c|c|c|c|c|c|c|c|}
\hline Analyte & $\begin{array}{l}\text { Analytical } \\
\text { Technique }\end{array}$ & Units & Run 1 & Com 1 & Run 2 & $\overline{\text { Com 2 }}$ & Run 3 & Com 3 \\
\hline Boron & ICAP & ug/g & & & & & 81.5 & \\
\hline \begin{tabular}{|l|} 
Carbon \\
Sulfur
\end{tabular} & $\begin{array}{l}\text { Ultimate } \\
\text { Ultimate }\end{array}$ & $\%$ & & & & & $\begin{array}{l}3.74 \\
7.94\end{array}$ & \\
\hline $\begin{array}{l}\text { Actinium-228 @338 } \\
\text { Actinium-228 @911 } \\
\text { Actinium-228@968 } \\
\text { Bismuth-212 @727 } \\
\text { Bismuth-214 @1120.4 } \\
\text { Bismuth-214 @1764.7 } \\
\text { Bismuth-214 @609.4 } \\
\text { K-40 @1460 } \\
\text { Lead-210 @46 } \\
\text { Lead-212 @238 } \\
\text { Lead-214@295.2 } \\
\text { Lead-214 @352.0 } \\
\text { Radium-226 @186.0 } \\
\text { Thallium-208@583 } \\
\text { Thallium-208 @860: } \\
\text { Thorium-234 @63.3 } \\
\text { Thorium-234 @92.6 } \\
\text { Uranium-235 @143.8 }\end{array}$ & $\begin{array}{l}\text { gamma } \\
\text { gamma } \\
\text { gamma } \\
\text { gamma } \\
\text { gamma } \\
\text { gamma } \\
\text { gamma } \\
\text { gamma } \\
\text { gamma } \\
\text { gamma } \\
\text { gamma } \\
\text { gamma } \\
\text { gamma } \\
\text { gamma } \\
\text { gamma } \\
\text { gamma } \\
\text { gamma } \\
\text { gamma }\end{array}$ & $\begin{array}{l}\mathrm{pCi} / \mathrm{g} \\
\mathrm{pCi} / \mathrm{g} \\
\mathrm{pCi} / \mathrm{g} \\
\mathrm{pCi} / \mathrm{g} \\
\mathrm{pCi} / \mathrm{g} \\
\mathrm{pCi} / \mathrm{g} \\
\mathrm{pCi} / \mathrm{g} \\
\mathrm{pCi} / \mathrm{g} \\
\mathrm{pCi} / \mathrm{g} \\
\mathrm{pCi} / \mathrm{g} \\
\mathrm{pCi} / \mathrm{g} \\
\mathrm{pCi} / \mathrm{g} \\
\mathrm{pCi} / \mathrm{g} \\
\mathrm{pCi} / \mathrm{g} \\
\mathrm{pCi} / \mathrm{g} \\
\mathrm{pCi} / \mathrm{g} \\
\mathrm{pCi} / \mathrm{g} \\
\mathrm{pCi} / \mathrm{g}\end{array}$ & & & & & \begin{tabular}{|r|}
0.290 \\
0.150 \\
ND $(0.050)$ \\
ND $(0.20)$ \\
0.610 \\
0.550 \\
0.560 \\
0.710 \\
ND $(0.60)$ \\
0.230 \\
0.440 \\
0.520 \\
0.900 \\
0.0400 \\
0.0200 \\
0.410 \\
0.760 \\
0.0600
\end{tabular} & \\
\hline
\end{tabular}

Stream: Bed Ash Collection Method: Grab Composite Sample Type: Bottom Ash

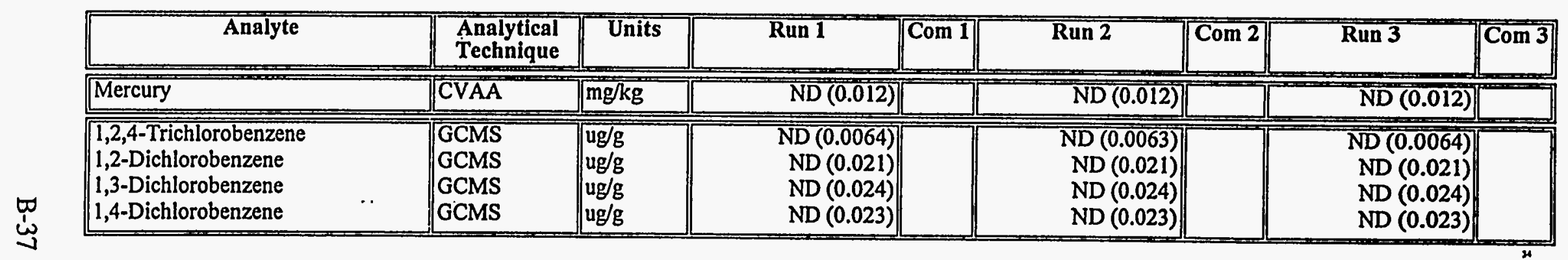




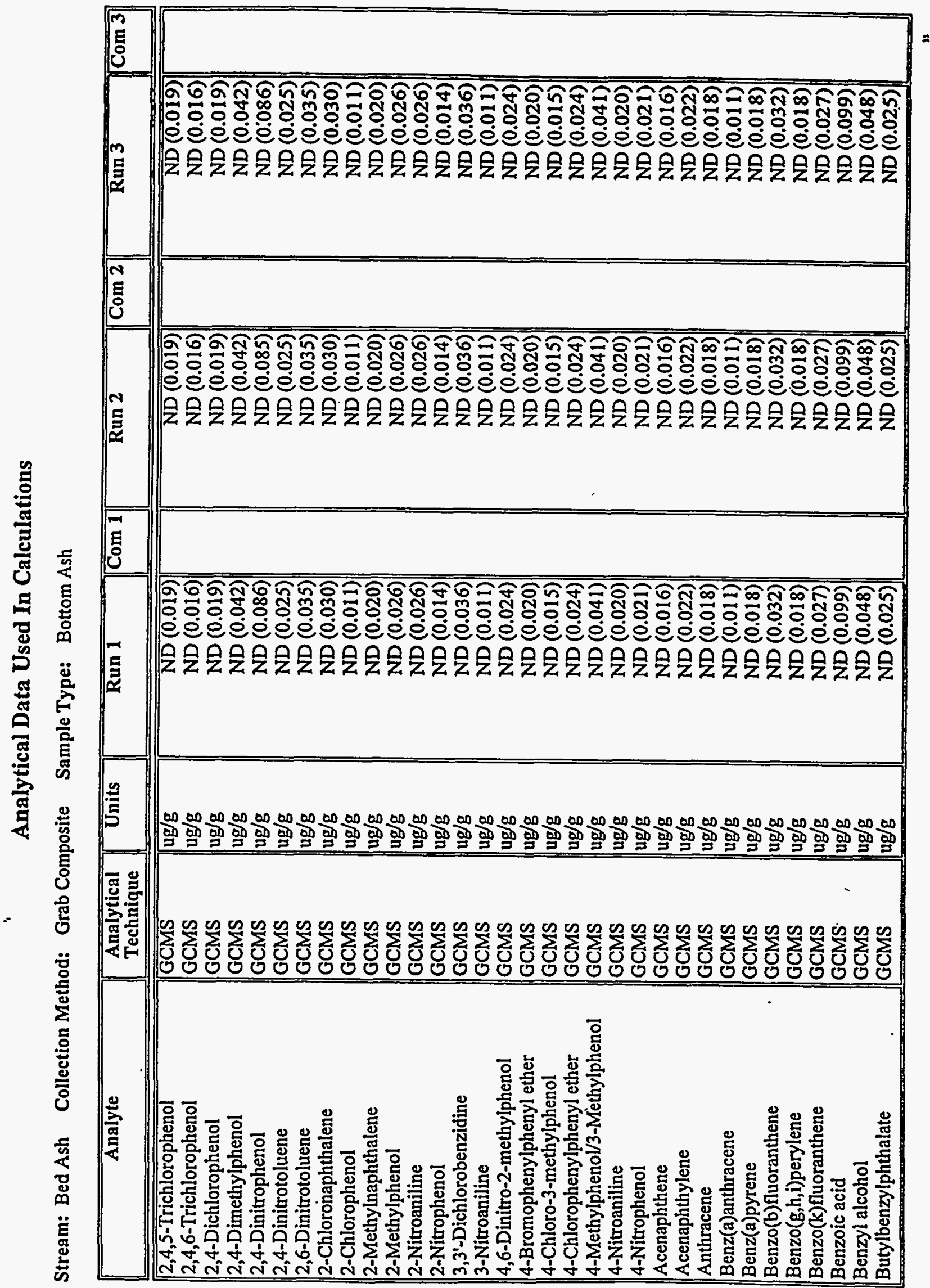




\section{Analytical Data Used In Calculations}

Stream: Bed Ash Collection Method: Grab Composite Sample Type: Bottom Ash

\begin{tabular}{|c|c|c|c|c|c|c|c|c|}
\hline Analyte & $\begin{array}{l}\text { Analytical } \\
\text { Technique }\end{array}$ & Units & Run I & Com 1 & Run 2 & Com 2 & Run 3 & $\operatorname{Com} 3$ \\
\hline $\begin{array}{l}\text { Chrysene } \\
\text { Di-n-butylphthalate } \\
\text { Di-n-octylphthalate } \\
\text { Dibenz(a,h)anthracene } \\
\text { Dibenzofuran } \\
\text { Diethylphthalate } \\
\text { Dimethylphthalate } \\
\text { Diphenylamine/N-NitrosoDPA } \\
\text { Fluoranthene } \\
\text { Fluorene } \\
\text { Hexachlorobenzene } \\
\text { Hexachlorobutadiene } \\
\text { Hexachlorocyclopentadiene } \\
\text { Hexachloroethane } \\
\text { Indeno(1,2,3-cd)pyrene } \\
\text { Isophorone } \\
\text { N-Nitroso-di-n-propylamine } \\
\text { Naphthalene } \\
\text { Nitrobenzene } \\
\text { Pentachlorophenol } \\
\text { Phenanthrene } \\
\text { Phenol } \\
\text { Pyrene } \\
\text { bis(2-Chloroethoxy)methane } \\
\text { bis(2-Chloroethyl)ether } \\
\text { bis(2-Chloroisopropyl)ether } \\
\text { bis(2-Ethylhexyl)phthalate } \\
\text { p-Chloroaniline }\end{array}$ & $\begin{array}{l}\text { GCMS } \\
\text { GCMS } \\
\text { GCMS } \\
\text { GCMS } \\
\text { GCMS } \\
\text { GCMS } \\
\text { GCMS } \\
\text { GCMS } \\
\text { GCMS } \\
\text { GCMS } \\
\text { GCMS } \\
\text { GCMS } \\
\text { GCMS } \\
\text { GCMS } \\
\text { GCMS } \\
\text { GCMS } \\
\text { GCMS } \\
\text { GCMS } \\
\text { GCMS } \\
\text { GCMS } \\
\text { GCMS } \\
\text { GCMS } \\
\text { GCMS } \\
\text { GCMS } \\
\text { GCMS } \\
\text { GCMS } \\
\text { GCMS }\end{array}$ & $\begin{array}{l}\mathrm{ug} / \mathrm{g} \\
\mathrm{ug} / \mathrm{g} \\
\mathrm{ug} / \mathrm{g} \\
\mathrm{ug} / \mathrm{g} \\
\mathrm{ug} / \mathrm{g} \\
\mathrm{ug} / \mathrm{g} \\
\mathrm{ug} / \mathrm{g} \\
\mathrm{ug} / \mathrm{g} \\
\mathrm{ug} / \mathrm{g} \\
\mathrm{ug} / \mathrm{g} \\
\mathrm{ug} / \mathrm{g} \\
\mathrm{ug} / \mathrm{g} \\
\mathrm{ug} / \mathrm{g} \\
\mathrm{ug} / \mathrm{g} \\
\mathrm{ug} / \mathrm{g} \\
\mathrm{ug} / \mathrm{g} \\
\mathrm{ug} / \mathrm{g} \\
\mathrm{ug} / \mathrm{g} \\
\mathrm{ug} / \mathrm{g} \\
\mathrm{ug} / \mathrm{g} \\
\mathrm{ug} / \mathrm{g} \\
\mathrm{ug} / \mathrm{g} \\
\mathrm{ug} / \mathrm{g} \\
\mathrm{ug} / \mathrm{g} \\
\mathrm{ug} / \mathrm{g} \\
\mathrm{ug} / \mathrm{g} \\
\mathrm{ug} / \mathrm{g} \\
\mathrm{ug} / \mathrm{g}\end{array}$ & 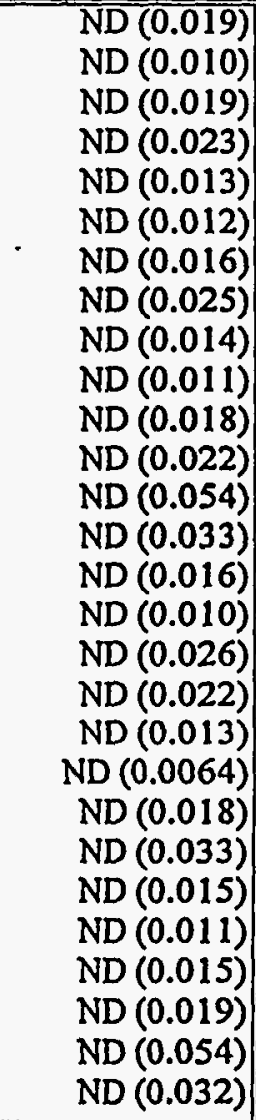 & & 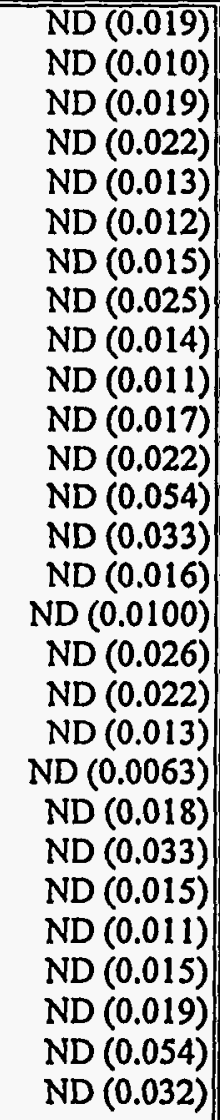 & & $\begin{array}{c}\text { ND (0.019) } \\
\text { ND (0.010) } \\
\text { ND (0.019) } \\
\text { ND (0.023) } \\
\text { ND (0.013) } \\
\text { ND (0.012) } \\
\text { ND (0.016) } \\
\text { ND (0.025) } \\
\text { ND (0.014) } \\
\text { ND (0.011) } \\
\text { ND (0.018) } \\
\text { ND (0.022) } \\
\text { ND (0.054) } \\
\text { ND (0.033) } \\
\text { ND (0.016) } \\
\text { ND (0.010) } \\
\text { ND (0.026) } \\
\text { ND (0.022) } \\
\text { ND (0.013) } \\
\text { ND(0.0064) } \\
\text { ND (0.018) } \\
\text { ND (0.034) } \\
\text { ND (0.015) } \\
\text { ND (0.011) } \\
\text { ND (0.015) } \\
\text { ND (0.019) } \\
\text { ND (0.054) } \\
\text { ND (0.033) }\end{array}$ & \\
\hline $\begin{array}{l}\text { Arsenic } \\
\text { Cadmium } \\
\text { Lead } \\
\text { Selenium }\end{array}$ & $\begin{array}{l}\text { GFAA } \\
\text { GFAA } \\
\text { GFAA }\end{array}$ & $\begin{array}{l}\mathrm{mg} / \mathrm{kg} \\
\mathrm{mg} / \mathrm{kg} \\
\mathrm{mg} / \mathrm{kg} \\
\mathrm{mg} / \mathrm{kg}\end{array}$ & $\begin{array}{r}67.8 \\
\text { ND (1.6) } \\
6.26 \\
5.27\end{array}$ & $\begin{array}{l}\mathrm{B} \\
\mathrm{B}\end{array}$ & $\begin{array}{r}82.6 \\
\mathrm{ND}(0.22) \\
5.06 \\
4.25\end{array}$ & $\begin{array}{l}B \\
B \\
B\end{array}$ & $\begin{array}{r}61.2 \\
\mathrm{ND}(0.23) \\
3.65 \\
4.33\end{array}$ & $\begin{array}{l}B \\
B \\
B\end{array}$ \\
\hline
\end{tabular}


Stream: Bed Ash Collection Method: Grab Composite Sample Type: Bottom Ash

\begin{tabular}{|c|c|c|c|c|c|c|c|c|}
\hline Analyte & $\begin{array}{l}\text { Analytical } \\
\text { Technique }\end{array}$ & Units & Run 1 & Com 1 & Run 2 & Com 2 & Run 3 & $\longdiv { C o m 3 }$ \\
\hline \begin{tabular}{|l} 
Aluminum \\
Antimony \\
Barium \\
Beryllium \\
Calcium \\
Chromium \\
Cobalt \\
Copper \\
Iron \\
Magnesium \\
Manganese \\
Molybdenum \\
Nickel \\
Phosphorus \\
Potassium \\
Silver \\
Sodium \\
Titanium \\
Vanadium
\end{tabular} & $\begin{array}{l}\text { ICAP } \\
\text { ICAP } \\
\text { ICAP } \\
\text { ICAP } \\
\text { ICAP } \\
\text { ICAP } \\
\text { ICAP } \\
\text { ICAP } \\
\text { ICAP } \\
\text { ICAP } \\
\text { ICAP } \\
\text { ICAP } \\
\text { ICAP } \\
\text { ICAP } \\
\text { ICAP } \\
\text { ICAP } \\
\text { ICAP } \\
\text { ICAP } \\
\text { ICAP }\end{array}$ & $\begin{array}{l}\mathrm{mg} / \mathrm{kg} \\
\mathrm{mg} / \mathrm{kg} \\
\mathrm{mg} / \mathrm{kg} \\
\mathrm{mg} / \mathrm{kg} \\
\mathrm{mg} / \mathrm{kg} \\
\mathrm{mg} / \mathrm{kg} \\
\mathrm{mg} / \mathrm{kg} \\
\mathrm{mg} / \mathrm{kg} \\
\mathrm{mg} / \mathrm{kg} \\
\mathrm{mg} / \mathrm{kg} \\
\mathrm{mg} / \mathrm{kg} \\
\mathrm{mg} / \mathrm{kg} \\
\mathrm{mg} / \mathrm{kg} \\
\mathrm{mg} / \mathrm{kg} \\
\mathrm{mg} / \mathrm{kg} \\
\mathrm{mg} / \mathrm{kg} \\
\mathrm{mg} / \mathrm{kg} \\
\mathrm{mg} / \mathrm{kg} \\
\mathrm{mg} / \mathrm{kg}\end{array}$ & $\begin{array}{r}6770 \\
\text { ND (46) } \\
26.1 \\
0.510 \\
160000 \\
19.5 \\
11.1 \\
\text { ND }(3.9) \\
11300 \\
120000 \\
96.3 \\
\text { ND (3.0) } \\
9.30 \\
\text { ND (70) } \\
679 \\
\text { ND (3.5) } \\
210 \\
373 \\
19.0\end{array}$ & \begin{tabular}{|l}
$\mathrm{B}$ \\
$\mathrm{B}$ \\
$\mathrm{B}$ \\
$\mathrm{B}$ \\
$\mathrm{B}$ \\
$\mathrm{B}$ \\
$\mathrm{B}$ \\
$\mathrm{B}$ \\
$\mathrm{B}$ \\
$\mathrm{B}$
\end{tabular} & $\begin{array}{r}12500 \\
\text { ND (54) } \\
45.8 \\
0.877 \\
166000 \\
21.8 \\
15.0 \\
\text { ND (4.6) } \\
21600 \\
133000 \\
119 \\
\text { ND (3.5) } \\
\text { ND (11) } \\
\text { ND (68) } \\
1460 \\
\text { ND (4.1) } \\
198 \\
664 \\
24.3\end{array}$ & $\begin{array}{l}B \\
B \\
B \\
B\end{array}$ & $\begin{array}{r}7690 \\
\mathrm{ND}(50) \\
31.0 \\
0.570 \\
166000 \\
17.1 \\
11.4 \\
\mathrm{ND}(4.3) \\
13000 \\
121000 \\
97.6 \\
\mathrm{ND}(3.3) \\
\mathrm{ND}(9.7) \\
\mathrm{ND}(69) \\
896 \\
\mathrm{ND}(3.8) \\
248 \\
417 \\
16.1\end{array}$ & $\begin{array}{l}\text { B } \\
\text { B } \\
B\end{array}$ \\
\hline $\begin{array}{l}\text { Chloride } \\
\text { Fluoride }\end{array}$ & $\begin{array}{l}\text { SIE } \\
\text { SIE }\end{array}$ & $\begin{array}{l}\mathrm{mg} / \mathrm{kg} \\
\mathrm{mg} / \mathrm{kg}\end{array}$ & \begin{tabular}{|l|}
750 \\
105
\end{tabular} & $B$ & $\begin{array}{r}1050 \\
104\end{array}$ & B & $\begin{array}{l}866 \\
94.5\end{array}$ & B \\
\hline
\end{tabular}

Stream: Bed Ash Collection Method: Grab Composite Sample Type: Bottom Ash FD

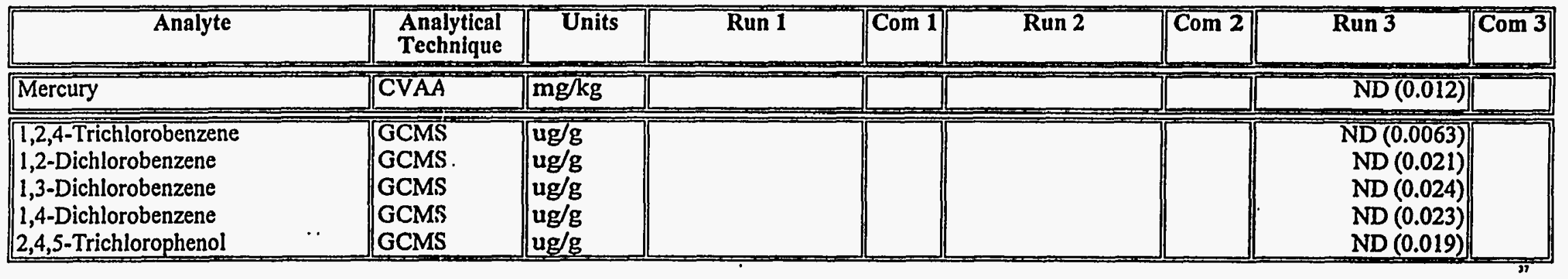


Analytical Data Used In Calculations

Stream: Bed Ash Collection Method: Grab Composite Sample Type: Bottom Ash FD

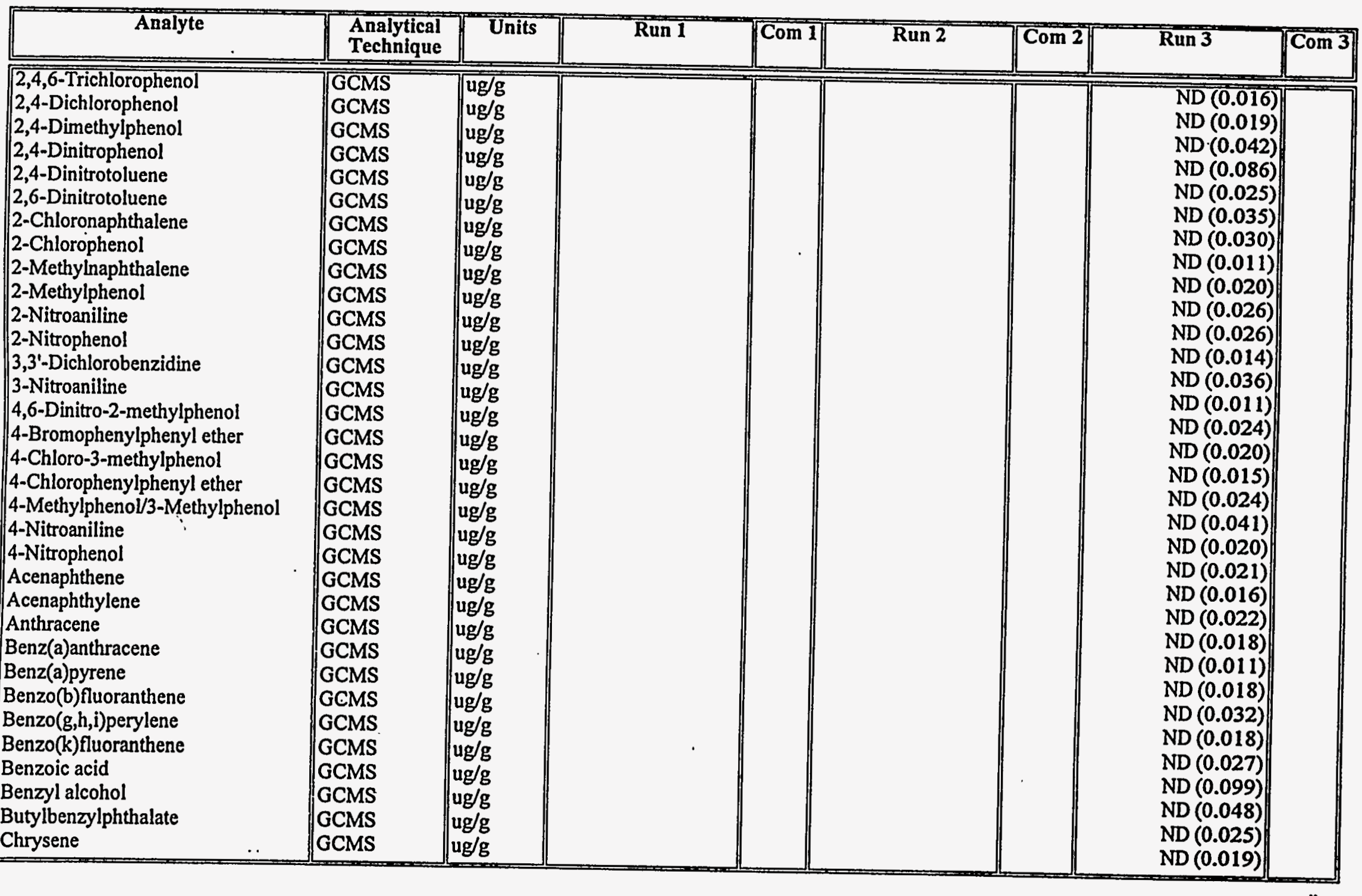


Stream: Bed Ash Collection Method: Grab Composite Sample Type: Bottom Ash FD

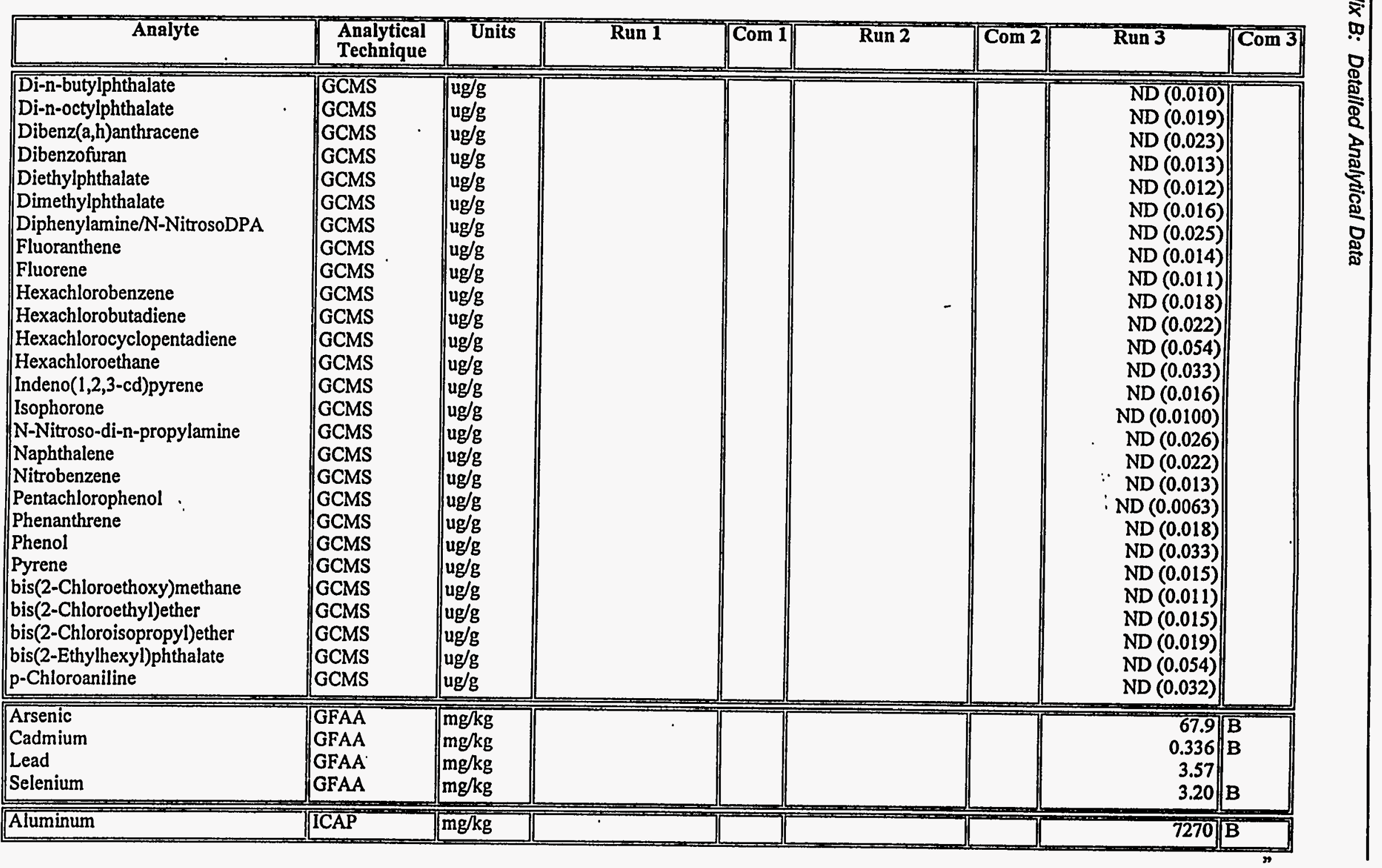


Analytical Data Used In Calculations

Stream: Bed Ash Collection Method: Grab Composite Sample Type: Bottom Ash FD

\begin{tabular}{|c|c|c|c|c|c|c|c|c|}
\hline Analyte & $\begin{array}{l}\text { Analytical } \\
\text { Technique }\end{array}$ & Units & Run 1 & Com 1 & Run 2 & $\overline{\operatorname{Com} 2}$ & Run 3 & Com 3 \\
\hline \begin{tabular}{|l} 
Antimony \\
Barium \\
Beryllium \\
Calcium \\
Chromium \\
Cobalt \\
Copper \\
Iron \\
Magnesium \\
Manganese \\
Molybdenum \\
Nickel \\
Phosphorus \\
Potassium \\
Silver \\
Sodium \\
Titanium \\
Vanadium \\
\end{tabular} & \begin{tabular}{|l} 
ICAP \\
ICAP \\
ICAP \\
ICAP \\
ICAP \\
ICAP \\
ICAP \\
ICAP \\
ICAP \\
ICAP \\
ICAP \\
ICAP \\
ICAP \\
ICAP \\
ICAP \\
ICAP \\
ICAP \\
ICAP
\end{tabular} & $\begin{array}{l}\mathrm{mg} / \mathrm{kg} \\
\mathrm{mg} / \mathrm{kg} \\
\mathrm{mg} / \mathrm{kg} \\
\mathrm{mg} / \mathrm{kg} \\
\mathrm{mg} / \mathrm{kg} \\
\mathrm{mg} / \mathrm{kg} \\
\mathrm{mg} / \mathrm{kg} \\
\mathrm{mg} / \mathrm{kg} \\
\mathrm{mg} / \mathrm{kg} \\
\mathrm{mg} / \mathrm{kg} \\
\mathrm{mg} / \mathrm{kg} \\
\mathrm{mg} / \mathrm{kg} \\
\mathrm{mg} / \mathrm{kg} \\
\mathrm{mg} / \mathrm{kg} \\
\mathrm{mg} / \mathrm{kg} \\
\mathrm{mg} / \mathrm{kg} \\
\mathrm{mg} / \mathrm{kg} \\
\mathrm{mg} / \mathrm{kg}\end{array}$ & & & & & \begin{tabular}{r|}
$\mathrm{ND}(46)$ \\
26.6 \\
0.513 \\
146000 \\
14.6 \\
7.91 \\
$\mathrm{ND}(4.0)$ \\
13200 \\
125000 \\
107 \\
$\mathrm{ND}(3.0)$ \\
$\mathrm{ND}(9.0)$ \\
$\mathrm{ND}(70)$ \\
1100 \\
$\mathrm{ND}(3.5)$ \\
123 \\
409 \\
18.3
\end{tabular} & \begin{tabular}{|l}
$B$ \\
$B$ \\
$B$ \\
$B$ \\
$B$ \\
$B$ \\
$B$ \\
$B$ \\
$B$ \\
$B$
\end{tabular} \\
\hline $\begin{array}{l}\text { Chloride } \\
\text { Fluoride }\end{array}$ & $\begin{array}{l}\text { SIE } \\
\text { SIE }\end{array}$ & $\begin{array}{l}\mathrm{mg} / \mathrm{kg} \\
\mathrm{mg} / \mathrm{kg}\end{array}$ & & & & & $\begin{array}{l}930 \\
146\end{array}$ & B \\
\hline
\end{tabular}

Stream: Coal Paste Collection Method: Grab Composite Sample Type: Filtered Solids 
Stream: Coal Past Collection Method: Grab Composit Sample Type: Filtered Solid

\begin{tabular}{|c|c|c|c|c|c|c|c|c|}
\hline Analyte & $\begin{array}{l}\text { Analytical } \\
\text { Technique }\end{array}$ & Units & Run 1 & Com 1 & Run 2 & Com 2 & Run 3 & Com 3 \\
\hline $\begin{array}{l}\text { Barium } \\
\text { Beryllium } \\
\text { Boron } \\
\text { Calcium } \\
\text { Chromium } \\
\text { Copper } \\
\text { Magnesium } \\
\text { Phosphorus } \\
\text { Titanium } \\
\end{array}$ & $\begin{array}{l}\text { ICAP } \\
\text { ICAP } \\
\text { ICAP } \\
\text { ICAP } \\
\text { ICAP } \\
\text { ICAP } \\
\text { ICAP } \\
\text { ICAP } \\
\text { ICAP }\end{array}$ & $\begin{array}{l}\mathrm{ug} / \mathrm{g} \\
\mathrm{ug} / \mathrm{g} \\
\mathrm{ug} / \mathrm{g} \\
\mathrm{ug} / \mathrm{g} \\
\mathrm{ug} / \mathrm{g} \\
\mathrm{ug} / \mathrm{g} \\
\mathrm{ug} / \mathrm{g} \\
\mathrm{ug} / \mathrm{g} \\
\mathrm{ug} / \mathrm{g}\end{array}$ & $\begin{array}{r}49.0 \\
1.70 \\
79.0 \\
1100 \\
15.0 \\
6.80 \\
840 \\
90.0 \\
680 \\
\end{array}$ & & $\begin{array}{r}51.0 \\
1.50 \\
83.0 \\
1400 \\
17.0 \\
6.70 \\
820 \\
97.0 \\
680 \\
\end{array}$ & & \begin{tabular}{r|}
61.0 \\
1.55 \\
ND $(3.0)$ \\
1400 \\
17.0 \\
7.40 \\
910 \\
99.5 \\
720 \\
\end{tabular} & \\
\hline $\begin{array}{l}\text { Aluminum } \\
\text { Antimony } \\
\text { Arsenic } \\
\text { Cobalt } \\
\text { Iron } \\
\text { Manganese } \\
\text { Molybdenum } \\
\text { Nickel } \\
\text { Potassium } \\
\text { Silver } \\
\text { Sodium } \\
\text { Vanadium }\end{array}$ & $\begin{array}{l}\text { NAA } \\
\text { NAA } \\
\text { NAA } \\
\text { NAA } \\
\text { NAA } \\
\text { NAA } \\
\text { NAA } \\
\text { NAA } \\
\text { NAA } \\
\text { NAA } \\
\text { NAA } \\
\text { NAA }\end{array}$ & $\begin{array}{l}\mathrm{ug} / \mathrm{g} \\
\mathrm{ug} / \mathrm{g} \\
\mathrm{ug} / \mathrm{g} \\
\mathrm{ug} / \mathrm{g} \\
\mathrm{ug} / \mathrm{g} \\
\mathrm{ug} / \mathrm{g} \\
\mathrm{ug} / \mathrm{g} \\
\mathrm{ug} / \mathrm{g} \\
\mathrm{ug} / \mathrm{g} \\
\mathrm{ug} / \mathrm{g} \\
\mathrm{ug} / \mathrm{g} \\
\mathrm{ug} / \mathrm{g}\end{array}$ & \begin{tabular}{r|}
14800 \\
0.441 \\
37.5 \\
3.69 \\
20200 \\
21.8 \\
1.19 \\
12.3 \\
5040 \\
0.799 \\
310 \\
24.8
\end{tabular} & & \begin{tabular}{r|}
15300 \\
0.469 \\
50.4 \\
3.85 \\
17200 \\
25.9 \\
0.304 \\
8.48 \\
4310 \\
0.437 \\
407 \\
21.2
\end{tabular} & & \begin{tabular}{r|}
16800 \\
0.518 \\
47.6 \\
4.20 \\
23200 \\
28.8 \\
$\mathrm{ND}(0.51)$ \\
17.9 \\
3540 \\
0.644 \\
297 \\
25.8
\end{tabular} & \\
\hline $\begin{array}{l}\text { Fixed Carbon } \\
\text { HHV } \\
\text { Volatile }\end{array}$ & $\begin{array}{l}\text { Proximate } \\
\text { Proximate } \\
\text { Proximate }\end{array}$ & $\begin{array}{l}\% \\
\text { Btu/lb } \\
\%\end{array}$ & \begin{tabular}{r|}
53.0 \\
12900 \\
35.8 \\
\end{tabular} & & \begin{tabular}{r|}
53.2 \\
12700 \\
34.9 \\
\end{tabular} & & $\begin{array}{r}50.8 \\
12600 \\
35.1\end{array}$ & \\
\hline $\begin{array}{l}\text { Ash } \\
\text { Carbon } \\
\text { Hydrogen } \\
\text { Moisture } \\
\text { Nitrogen } \\
\text { Oxygen } \\
\text { Sulfur }\end{array}$ & $\begin{array}{l}\text { Ultimate } \\
\text { Ultimate } \\
\text { Ultimate } \\
\text { Ultimate } \\
\text { Ultimate } \\
\text { Ultimate } \\
\text { Ultimate }\end{array}$ & $\begin{array}{l}\% \\
\% \\
\% \\
\% \\
\% \\
\% \\
\%\end{array}$ & $\begin{array}{l}11.2 \\
72.3 \\
.4 .62 \\
3.20 \\
1.58 \\
7.15 \\
3.11\end{array}$ & & \begin{tabular}{l|}
11.8 \\
71.7 \\
4.55 \\
4.17 \\
1.35 \\
7.21 \\
3.35
\end{tabular} & & $\begin{array}{l}14.1 \\
70.3 \\
4.68 \\
2.80 \\
1.37 \\
5.98 \\
3.62\end{array}$ & \\
\hline
\end{tabular}




\section{Analytical Data Used In Calculations}

Stream: Coal Past Collection Method: Grab Composit Sample Type: Filtered Solid

\begin{tabular}{|c|c|c|c|c|c|c|c|c|}
\hline Analyte & $\begin{array}{l}\text { Analytical } \\
\text { Technique }\end{array}$ & Units & Run 1 & Com 1 & Run 2 & Com 2 & Run 3 & $\overline{C o m} 3$ \\
\hline \begin{tabular}{|l} 
Actinium-228 @338 \\
Actinium-228 @911 \\
Actinium-228 @968 \\
Bismuth-212 @727 \\
Bismuth-214@1120.4 \\
Bismuth-214@1764.7 \\
Bismuth-214@609.4 \\
K-40 @1460 \\
Lead-210 @46 \\
Lead-212@238 \\
Lead-214 @295.2 \\
Lead-214@352.0 \\
Radium-226 @186.0 \\
Thallium-208@583 \\
Thallium-208 @860 \\
Thorium-234 @63.3 \\
Thorium-234 @92.6 \\
Uranium-235 @143.8
\end{tabular} & \begin{tabular}{|l} 
gamma \\
gamma \\
gamma \\
gamma \\
gamma \\
gamma \\
gamma \\
gamma \\
gamma \\
gamma \\
gamma \\
gamma \\
gamma \\
gamma \\
gamma \\
gamma \\
gamma \\
gamma
\end{tabular} & $\begin{array}{l}\mathrm{pCi} / \mathrm{g} \\
\mathrm{pCi} / \mathrm{g} \\
\mathrm{pCi} / \mathrm{g} \\
\mathrm{pCi} / \mathrm{g} \\
\mathrm{pCi} / \mathrm{g} \\
\mathrm{pCi} / \mathrm{g} \\
\mathrm{pCi} / \mathrm{g} \\
\mathrm{pCi} / \mathrm{g} \\
\mathrm{pCi} / \mathrm{g} \\
\mathrm{pCi} / \mathrm{g} \\
\mathrm{pCi} / \mathrm{g} \\
\mathrm{pCi} / \mathrm{g} \\
\mathrm{pCi} / \mathrm{g} \\
\mathrm{pCi} / \mathrm{g} \\
\mathrm{pCi} / \mathrm{g} \\
\mathrm{pCi} / \mathrm{g} \\
\mathrm{pCi} / \mathrm{g} \\
\mathrm{pCi} / \mathrm{g}\end{array}$ & $\begin{array}{r}\text { ND }(0.010) \\
0.145 \\
0.155 \\
0.475 \\
0.0207 \\
0.279 \\
0.217 \\
1.34 \\
0.878 \\
0.0826 \\
0.165 \\
0.341 \\
0.186 \\
0.0413 \\
\text { ND }(0.14) \\
0.0207 \\
\text { ND }(0.10) \\
0.0103 \\
\end{array}$ & & \begin{tabular}{r|}
0.146 \\
0.146 \\
ND $(0.021)$ \\
ND $(0.31)$ \\
0.0939 \\
0.0522 \\
0.271 \\
1.57 \\
0.0939 \\
0.115 \\
0.230 \\
0.323 \\
0.616 \\
0.0522 \\
0.104 \\
ND $(0.10)$ \\
0.219 \\
0.0417
\end{tabular} & & $\begin{array}{r}0.206 \\
0.0720 \\
0.216 \\
0.113 \\
0.391 \\
0.0103 \\
0.278 \\
1.95 \\
0.494 \\
0.298 \\
0.144 \\
0.154 \\
\text { ND }(0.10) \\
0.0412 \\
0.0514 \\
0.607 \\
\text { ND }(0.082) \\
\text { ND }(0.010)\end{array}$ & \\
\hline
\end{tabular}

Stream: Coal Paste $:$ Collection Method: Grab Composite Sample Type: Filtered Solids FD

\begin{tabular}{|c|c|c|c|c|c|c|c|c|}
\hline Analyte & $\begin{array}{l}\text { Analytical } \\
\text { Technique }\end{array}$ & Units & Run 1 & Com 1 & Run 2 & Com 2 & Run 3 & $\longdiv { \operatorname { C o m } 3 }$ \\
\hline Mercury & CVAA & $\mathrm{ug} / \mathrm{g}$ & & & & & 0.270 & \\
\hline Fluorine & D3761 & $\mathrm{ug} / \mathrm{g}$ & & & & & $\overline{120}$ & \\
\hline Chlorine & D4208 & $\mathrm{ug} / \mathrm{g}$ & & & & & 1080 & \\
\hline \begin{tabular}{|l} 
Cadmium \\
Lead
\end{tabular} & $\begin{array}{l}\text { GFAA } \\
\text { GFAA }\end{array}$ & $\begin{array}{l}\mathrm{ug} / \mathrm{g} \\
\mathrm{ug} / \mathrm{g}\end{array}$ & & & & & $\begin{array}{r}0.120 \\
7.00\end{array}$ & \\
\hline \begin{tabular}{|l} 
Barium \\
Beryllium \\
Bornn
\end{tabular} & $\begin{array}{l}\text { ICAP } \\
\text { ICAP } \\
\text { ICAP }\end{array}$ & $\begin{array}{l}\mathrm{ug} / \mathrm{g} \\
\mathrm{ug} / \mathrm{g} \\
\mathrm{ug} / \mathrm{g}\end{array}$ & & & & & $\begin{array}{l}58.0 \\
1.50 \\
800\end{array}$ & \\
\hline
\end{tabular}


Stream: Coal Past Collection Method: Grab Composit Sample Type: Filtered Solid FD

\begin{tabular}{|c|c|c|c|c|c|c|c|}
\hline Analyte & $\begin{array}{l}\text { Analytical } \\
\text { Technique }\end{array}$ & Units & Run 1 & Com 1 $\quad$ Run 2 & Com 2 & Run 3 & Com 3 \\
\hline \begin{tabular}{|l} 
Calcium \\
Chromium \\
Copper \\
Magnesium \\
Phosphorus \\
Titanium \\
\end{tabular} & $\begin{array}{l}\text { ICAP } \\
\text { ICAP } \\
\text { ICAP } \\
\text { ICAP } \\
\text { ICAP } \\
\text { ICAP }\end{array}$ & $\begin{array}{l}u g / g \\
u g / g \\
u g / g \\
u g / g \\
u g / g \\
u g / g\end{array}$ & & & & $\begin{array}{r}1600 \\
16.0 \\
7.30 \\
1000 \\
110 \\
710\end{array}$ & \\
\hline $\begin{array}{l}\text { Aluminum } \\
\text { Antimony } \\
\text { Arsenic } \\
\text { Cobalt } \\
\text { Iron } \\
\text { Manganese } \\
\text { Molybdenum } \\
\text { Nickel } \\
\text { Potassium } \\
\text { Silver } \\
\text { Sodium } \\
\text { Vanadium }\end{array}$ & $\begin{array}{l}\text { NAA } \\
\text { NAA } \\
\text { NAA } \\
\text { NAA } \\
\text { NAA } \\
\text { NAA } \\
\text { NAA } \\
\text { NAA } \\
\text { NAA } \\
\text { NAA } \\
\text { NAA } \\
\text { NAA }\end{array}$ & $\begin{array}{l}\mathrm{ug} / \mathrm{g} \\
\mathrm{ug} / \mathrm{g} \\
\mathrm{ug} / \mathrm{g} \\
\mathrm{ug} / \mathrm{g} \\
\mathrm{ug} / \mathrm{g} \\
\mathrm{ug} / \mathrm{g} \\
\mathrm{ug} / \mathrm{g} \\
\mathrm{ug} / \mathrm{g} \\
\mathrm{ug} / \mathrm{g} \\
\mathrm{ug} / \mathrm{g} \\
\mathrm{ug} / \mathrm{g} \\
\mathrm{ug} / \mathrm{g}\end{array}$ & & & & \begin{tabular}{r|}
16500 \\
0.431 \\
45.3 \\
4.42 \\
23100 \\
33.1 \\
1.47 \\
15.9 \\
1130 \\
0.622 \\
329 \\
25.5
\end{tabular} & \\
\hline $\begin{array}{l}\text { Fixed Carbon } \\
\text { HHV } \\
\text { Volatile }\end{array}$ & $\begin{array}{l}\text { Proximate } \\
\text { Proximate } \\
\text { Proximate }\end{array}$ & $\begin{array}{l}\% \\
\text { Btu/lb } \\
\%\end{array}$ & & & & $\begin{array}{r}51.2 \\
12600 \\
35.5\end{array}$ & \\
\hline $\begin{array}{l}\text { Ash } \\
\text { Carbon } \\
\text { Hydrogen } \\
\text { Moisture } \\
\text { Nitrogen } \\
\text { Oxygen } \\
\text { Sulfur }\end{array}$ & $\begin{array}{l}\text { Ultimate } \\
\text { Ultimate } \\
\text { Ultimate } \\
\text { Ultimate } \\
\text { Ultimate } \\
\text { Ultimate } \\
\text { Ultimate }\end{array}$ & $\begin{array}{l}\% \\
\% \\
\% \\
\% \\
\% \\
\% \\
\%\end{array}$ & & & & $\begin{array}{l}13.3 \\
70.5 \\
4.74 \\
2.91 \\
1.37 \\
6.79 \\
3.34\end{array}$ & \\
\hline $\begin{array}{l}\text { Actinium-228@338 } \\
\text { Actinium-228 @911 } \\
\text { Actinium-228@968 }\end{array}$ & $\begin{array}{l}\text { gamma } \\
\text { gamma } \\
\text { gamma }\end{array}$ & $\begin{array}{l}\mathrm{pCi} / \mathrm{g} \\
\mathrm{pCi} / \mathrm{g} \\
\mathrm{pCi} / \mathrm{g}\end{array}$ & & & & $\begin{array}{l}0.154 \\
0.113 \\
0.227\end{array}$ & \\
\hline
\end{tabular}




\section{Analytical Data Used In Calculations}

Stream: Coal Past Collection Method: Grab Composit Sample Type: Filtered Solid FD

\begin{tabular}{|c|c|c|c|c|c|c|c|c|}
\hline Analyte & $\begin{array}{l}\text { Analytical } \\
\text { Technique }\end{array}$ & Units & Run 1 & Com 1 & Run 2 & Com 2 & Run 3 & Com 3 \\
\hline \begin{tabular}{|l} 
Bismuth-212@727 \\
Bismuth-214 @1120.4 \\
Bismuth-214@1764.7 \\
Bismuth-214 @609.4 \\
K-40 @1460 \\
Lead-210 @46 \\
Lead-212 @238 \\
Lead-214 @295.2 \\
Lead-214@352.0 \\
Radium-226 @186.0 \\
Thallium-208 @583 \\
Thallium-208 @860 \\
Thorium-234@63.3 \\
Thorium-234@92.6 \\
Uranium-235 @143.8 \\
\end{tabular} & \begin{tabular}{|l} 
gamma \\
gamma \\
gamma \\
gamma \\
gamma \\
gamma \\
gamma \\
gamma \\
gamma \\
gamma \\
gamma \\
gamma \\
gamma \\
gamma \\
gamma
\end{tabular} & $\begin{array}{l}\mathrm{pCi} / \mathrm{g} \\
\mathrm{pCi} / \mathrm{g} \\
\mathrm{pCi} / \mathrm{g} \\
\mathrm{pCi} / \mathrm{g} \\
\mathrm{pCi} / \mathrm{g} \\
\mathrm{pCi} / \mathrm{g} \\
\mathrm{pCi} / \mathrm{g} \\
\mathrm{pCi} / \mathrm{g} \\
\mathrm{pCi} / \mathrm{g} \\
\mathrm{pCi} / \mathrm{g} \\
\mathrm{pCi} / \mathrm{g} \\
\mathrm{pCi} / \mathrm{g} \\
\mathrm{pCi} / \mathrm{g} \\
\mathrm{pCi} / \mathrm{g} \\
\mathrm{pCi} / \mathrm{g}\end{array}$ & & & & & \begin{tabular}{r|}
0.330 \\
0.0515 \\
0.247 \\
0.175 \\
2.68 \\
0.257 \\
0.288 \\
0.257 \\
0.206 \\
0.402 \\
0.0515 \\
0.196 \\
$\mathrm{ND}(0.22)$ \\
0.206 \\
0.0206
\end{tabular} & \\
\hline
\end{tabular}

Stream: Cyclone Ash Collection Method: Grab Composite Sample Type: Ash $+\mathrm{Mg}+\mathrm{Ca}$

\begin{tabular}{|c|c|c|c|c|c|c|c|c|}
\hline Analyte & $\begin{array}{l}\text { Analytical } \\
\text { Technique }\end{array}$ & Units & Run 1 & Com 1 & Run 2 & Com 2 & Run 3 & Com 3 \\
\hline Boron & ICAP & $\mathrm{ug} / \mathrm{g}$ & 99.0 & & 120 & & 100 & \\
\hline $\begin{array}{l}\text { Carbon } \\
\text { Sulfur }\end{array}$ & $\begin{array}{l}\text { Ultimate } \\
\text { Ultimate }\end{array}$ & $\%$ & $\begin{array}{l}5.16 \\
3.82\end{array}$ & & $\begin{array}{l}5.47 \\
4.07\end{array}$ & & $\begin{array}{l}5.24 \\
3.86 \\
\end{array}$ & \\
\hline $\begin{array}{l}\text { Actinium-228@338 } \\
\text { Actinium-228 @911 } \\
\text { Actinium-228 @968 } \\
\text { Bismuth-212 @727 } \\
\text { Bismuth-214 @1120.4 } \\
\text { Bismuth-214 @1764.7 } \\
\text { Bismuth-214 @609.4 } \\
\text { K-40 @1460 } \\
\text { Lead-210@46 } \\
\end{array}$ & $\begin{array}{l}\text { gamma } \\
\text { gamma } \\
\text { gamma } \\
\text { gamma } \\
\text { gamma } \\
\text { gamma } \\
\text { gamma } \\
\text { gamma } \\
\text { gamma }\end{array}$ & $\begin{array}{l}\mathrm{pCi} / \mathrm{g} \\
\mathrm{pCi} / \mathrm{g} \\
\mathrm{pCi} / \mathrm{g} \\
\mathrm{pCi} / \mathrm{g} \\
\mathrm{pCi} / \mathrm{g} \\
\mathrm{pCi} / \mathrm{g} \\
\mathrm{pCi} / \mathrm{g} \\
\mathrm{pCi} / \mathrm{g} \\
\mathrm{pCi} / \mathrm{g}\end{array}$ & $\begin{array}{l}0.650 \\
0.550 \\
0.500 \\
1.40 \\
1.20 \\
1.00 \\
1.00 \\
7.30 \\
1.00\end{array}$ & & $\begin{array}{r}0.590 \\
0.520 \\
0.850 \\
0.470 \\
1.00 \\
1.10 \\
1.00 \\
6.70 \\
0.990 \\
\end{array}$ & & $\begin{array}{r}0.800 \\
0.600 \\
0.460 \\
0.250 \\
1.10 \\
0.800 \\
0.960 \\
5.80 \\
2.00 \\
\end{array}$ & \\
\hline
\end{tabular}


Stream: Cyclone As Collection Method:Grab Composit Sample Type: $\mathrm{Ash}+\mathrm{Mg}+\mathrm{C}$

\begin{tabular}{|c|c|c|c|c|c|c|c|c|}
\hline Analyte & $\begin{array}{l}\text { Analytical } \\
\text { Technique }\end{array}$ & Units & $\overline{\operatorname{Run} \mathbf{I}}$ & $\overline{\text { Com } 1}$ & $\overline{\text { Run } 2}$ & $\overline{\text { Com 2 }}$ & Run 3 & Com 3 \\
\hline \begin{tabular}{|l} 
Lead-212 @238 \\
Lead-214 @295.2 \\
Lead-214 @352.0 \\
Radium-226 @186.0 \\
Thallium-208 @583 \\
Thallium-208 @860 \\
Thorium-234 @63.3 \\
Thorium-234 @92.6 \\
Uranium-235 @143.8
\end{tabular} & $\begin{array}{l}\text { gamma } \\
\text { gamma } \\
\text { gamma } \\
\text { gamma } \\
\text { gamma } \\
\text { gamma } \\
\text { gamma } \\
\text { gamma } \\
\text { gamma }\end{array}$ & $\begin{array}{l}\mathrm{pCi} / \mathrm{g} \\
\mathrm{pCi} / \mathrm{g} \\
\mathrm{pCi} / \mathrm{g} \\
\mathrm{pCi} / \mathrm{g} \\
\mathrm{pCi} / \mathrm{g} \\
\mathrm{pCi} / \mathrm{g} \\
\mathrm{pCi} \mathrm{g} \\
\mathrm{pCi} / \mathrm{g} \\
\mathrm{pCi} / \mathrm{g}\end{array}$ & \begin{tabular}{r|}
0.650 \\
1.00 \\
1.20 \\
2.30 \\
0.250 \\
0.380 \\
1.80 \\
0.300 \\
0.140
\end{tabular} & & \begin{tabular}{r|}
0.590 \\
0.990 \\
1.00 \\
2.30 \\
0.200 \\
0.320 \\
0.470 \\
0.950 \\
0.140
\end{tabular} & - & \begin{tabular}{r|}
0.660 \\
1.10 \\
1.10 \\
1.40 \\
0.200 \\
ND $(0.44)$ \\
0.720 \\
0.180 \\
0.0900
\end{tabular} & \\
\hline
\end{tabular}

Strenm: Cyclone Ash Collection Method: Grab Composite Sample Type: $\mathrm{Ash}+\mathrm{Mg}+\mathrm{Ca}$ FD

\begin{tabular}{|c|c|c|c|c|c|c|c|}
\hline Analyte & $\begin{array}{l}\text { Analytical } \\
\text { Technique }\end{array}$ & Units & Run 1 & Com 1 & Com 2 & Run 3 & Com 3 \\
\hline Boron & ICAP & ug/g & & & & 87.5 & \\
\hline $\begin{array}{l}\text { Carbon } \\
\text { Sulfur }\end{array}$ & $\begin{array}{l}\text { Ultimate } \\
\text { Ultimate }\end{array}$ & $\begin{array}{l}\% \\
\%\end{array}$ & & & & $\begin{array}{l}5.30 \\
3.57\end{array}$ & \\
\hline $\begin{array}{l}\text { Actinium-228@338: } \\
\text { Actinium-228@911 } \\
\text { Actinium-228@968 } \\
\text { Bismuth-212@727 } \\
\text { Bismuth-214@1120.4 } \\
\text { Bismuth-214@1764.7 } \\
\text { Bismuth-214@609.4 } \\
\text { K-40@1460 } \\
\text { Lead-210 @46 } \\
\text { Lcad-212 @238 } \\
\text { Lead-214@295.2 } \\
\text { Lead-214@352.0 } \\
\text { Radium-226@186.0 } \\
\text { Thallium-208@583 } \\
\text { Thallium-208@860 }\end{array}$ & $\begin{array}{l}\text { gamma } \\
\text { gamma } \\
\text { gamma } \\
\text { gamma } \\
\text { gamma } \\
\text { gamma } \\
\text { gamma } \\
\text { gamma } \\
\text { gamma } \\
\text { gamma } \\
\text { gamma } \\
\text { gamma } \\
\text { gamma } \\
\text { gamma } \\
\text { gamma }\end{array}$ & $\begin{array}{l}\mathrm{pCi} / \mathrm{g} \\
\mathrm{pCi} / \mathrm{g} \\
\mathrm{pCi} / \mathrm{g} \\
\mathrm{pCi} / \mathrm{g} \\
\mathrm{pCi} / \mathrm{g} \\
\mathrm{pCi} / \mathrm{g} \\
\mathrm{pCi} / \mathrm{g} \\
\mathrm{pCi} / \mathrm{g} \\
\mathrm{pCi} / \mathrm{g} \\
\mathrm{pCi} / \mathrm{g} \\
\mathrm{pCi} / \mathrm{g} \\
\mathrm{pCi} / \mathrm{g} \\
\mathrm{pCi} / \mathrm{g} \\
\mathrm{pCi} / \mathrm{g} \\
\mathrm{pCi} / \mathrm{g}\end{array}$ & & & & $\begin{array}{r}0.610 \\
0.750 \\
0.290 \\
0.520 \\
0.820 \\
0.660 \\
1.10 \\
6.50 \\
0.610 \\
0.730 \\
1.10 \\
1.10 \\
1.70 \\
0.200 \\
0.430\end{array}$ & \\
\hline
\end{tabular}




\section{Analytical Data Used In Calculations}

Stream: Cyclone As Collection Method: Grab Composit Sample Type: Ash $+\mathrm{Mg}+\mathrm{C} \quad$ FD

\begin{tabular}{|c|c|c|c|c|c|c|c|c|}
\hline Analyte & $\begin{array}{l}\text { Analytical } \\
\text { Technique }\end{array}$ & Units & Run 1 & Com 1 & Run 2 & Com 2 & Run 3 & Com 3 \\
\hline $\begin{array}{l}\text { Thorium-234 @63.3 } \\
\text { Thorium-234 @92.6 } \\
\text { Uranium-235 @143.8 }\end{array}$ & $\begin{array}{l}\text { gamma } \\
\text { gamma } \\
\text { gamma }\end{array}$ & $\begin{array}{l}\mathrm{pCi} / \mathrm{g} \\
\mathrm{pCi} / \mathrm{g} \\
\mathrm{pCi} / \mathrm{g}\end{array}$ & & & & & $\begin{array}{r}1.40 \\
0.730 \\
0.100\end{array}$ & \\
\hline
\end{tabular}

Stream: Cyclone Ash Collection Method: Grab Composite Sample Type: Fly Ash

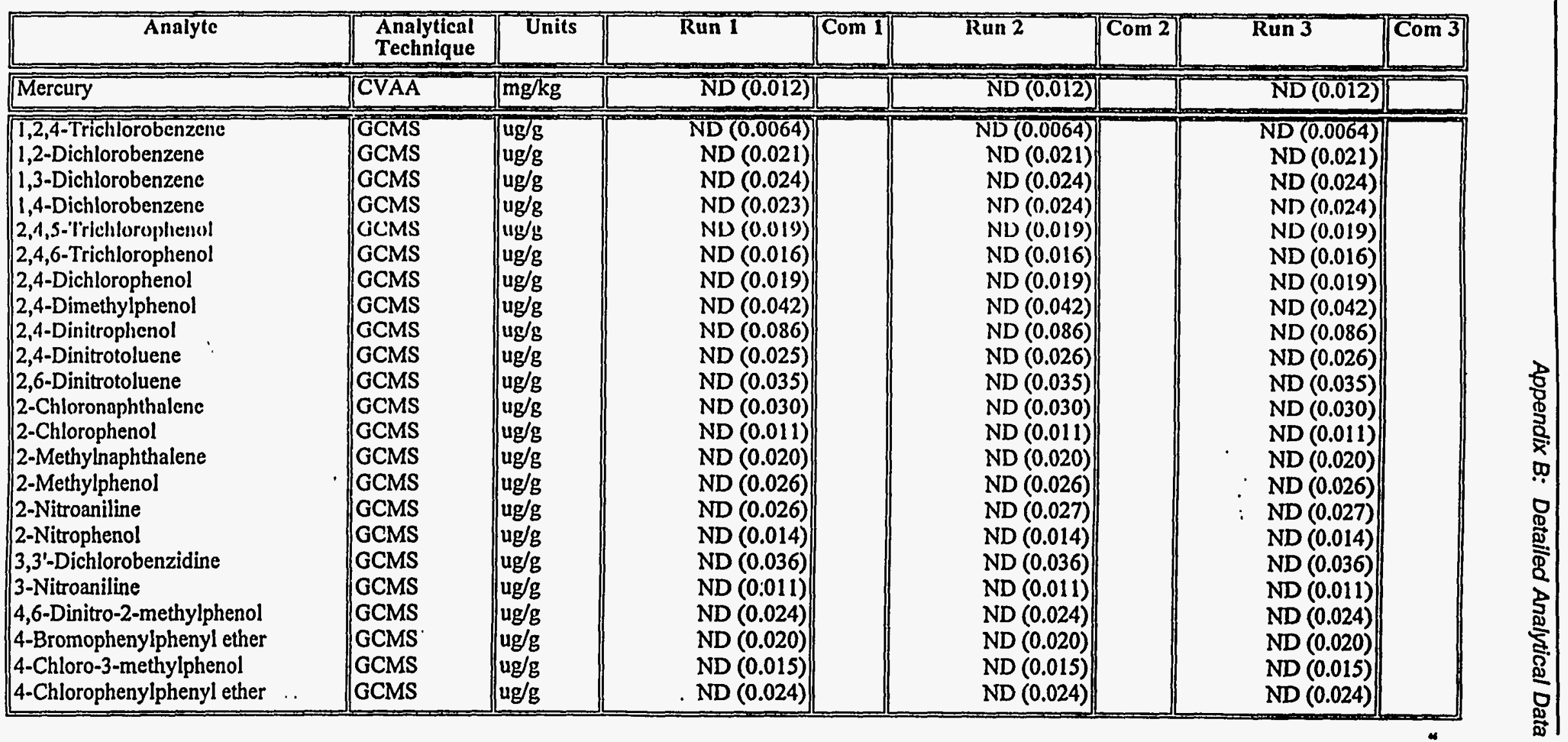


Stream: Cyclone As Collection Method: Grab Composit Sample Type: Fly As

\begin{tabular}{|c|c|c|c|c|c|c|c|c|}
\hline Analyte & $\begin{array}{l}\text { Analytical } \\
\text { Technique }\end{array}$ & Units & Run 1 & Com 1 & Run 2 & Com 2 & Run 3 & Com 3 \\
\hline $\begin{array}{l}\text { 4-Methylphenol/3-Methylphenol } \\
\text { 4-Nitroaniline } \\
\text { 4-Nitrophenol } \\
\text { Acenaphthene } \\
\text { Acenaphthylene } \\
\text { Anthracene } \\
\text { Benz(a)anthracene } \\
\text { Benz(a)pyrene } \\
\text { Benzo(b)fluoranthene } \\
\text { Benzo(g,h,i)perylene } \\
\text { Benzo(k)fluoranthene } \\
\text { Benzoic acid } \\
\text { Benzyl alcohol } \\
\text { Butylbenzylphthalate } \\
\text { Chrysene } \\
\text { Di-n-butylphthalate } \\
\text { Di-n-octylphthalate } \\
\text { Dibenz(a,h)anthracene } \\
\text { Dibenzofuran } \\
\text { Diethylphthalate } \\
\text { Dimethylphthalate } \\
\text { Diphenylamine/N-NitrosoDPA } \\
\text { Fluoranthene } \\
\text { Fluorene } \\
\text { Hexachlorobenzene } \\
\text { Hexachlorobutadiene } \\
\text { Hexachlorocyclopentadiene } \\
\text { Hexachloroethane } \\
\text { Indeno(1,2,3-cd)pyrene } \\
\text { Isophorone } \\
\text { N-Nitroso-di-n-propylamine } \\
\text { Naphthalene } \\
\text { Nitrobenzene }\end{array}$ & $\begin{array}{l}\text { GCMS } \\
\text { GCMS } \\
\text { GCMS } \\
\text { GCMS } \\
\text { GCMS } \\
\text { GCMS } \\
\text { GCMS } \\
\text { GCMS } \\
\text { GCMS } \\
\text { GCMS } \\
\text { GCMS } \\
\text { GCMS } \\
\text { GCMS } \\
\text { GCMS } \\
\text { GCMS } \\
\text { GCMS } \\
\text { GCMS } \\
\text { GCMS } \\
\text { GCMS } \\
\text { GCMS } \\
\text { GCMS } \\
\text { GCMS } \\
\text { GCMS } \\
\text { GCMS } \\
\text { GCMS } \\
\text { GCMS } \\
\text { GCMS } \\
\text { GCMS } \\
\text { GCMS } \\
\text { GCMS } \\
\text { GCMS } \\
\text { GCMS } \\
\text { GCMS }\end{array}$ & $\begin{array}{l}\mathrm{ug} / \mathrm{g} \\
\mathrm{ug} / \mathrm{g} \\
\mathrm{ug} / \mathrm{g} \\
\mathrm{ug} / \mathrm{g} \\
\mathrm{ug} / \mathrm{g} \\
\mathrm{ug} / \mathrm{g} \\
\mathrm{ug} / \mathrm{g} \\
\mathrm{ug} / \mathrm{g} \\
\mathrm{ug} / \mathrm{g} \\
\mathrm{ug} / \mathrm{g} \\
\mathrm{ug} / \mathrm{g} \\
\mathrm{ug} / \mathrm{g} \\
\mathrm{ug} / \mathrm{g} \\
\mathrm{ug} / \mathrm{g} \\
\mathrm{ug} / \mathrm{g} \\
\mathrm{ug} / \mathrm{g} \\
\mathrm{ug} / \mathrm{g} \\
\mathrm{ug} / \mathrm{g} \\
\mathrm{ug} / \mathrm{g} \\
\mathrm{ug} / \mathrm{g} \\
\mathrm{ug} / \mathrm{g} \\
\mathrm{ug} / \mathrm{g} \\
\mathrm{ug} / \mathrm{g} \\
\mathrm{ug} / \mathrm{g} \\
\mathrm{ug} / \mathrm{g} \\
\mathrm{ug} / \mathrm{g} \\
\mathrm{ug} / \mathrm{g} \\
\mathrm{ug} / \mathrm{g} \\
\mathrm{ug} / \mathrm{g} \\
\mathrm{ug} / \mathrm{g} \\
\mathrm{ug} / \mathrm{g} \\
\mathrm{ug} / \mathrm{g} \\
\mathrm{ug} / \mathrm{g}\end{array}$ & $\begin{array}{l}\text { ND (0.041) } \\
\text { ND (0.020) } \\
\text { ND (0.021) } \\
\text { ND (0.016) } \\
\text { ND (0.022) } \\
\text { ND (0.018) } \\
\text { ND (0.011) } \\
\text { ND (0.018) } \\
\text { ND (0.032) } \\
\text { ND (0.018) } \\
\text { ND (0.027) } \\
\text { ND (0.099) } \\
\text { ND (0.048) } \\
\text { ND (0.025) } \\
\text { ND (0.019) } \\
\text { ND (0.010) } \\
\text { ND (0.019) } \\
\text { ND (0.023) } \\
\text { ND (0.013) } \\
\text { ND (0.012) } \\
\text { ND (0.016) } \\
\text { ND (0.025) } \\
\text { ND (0.014) } \\
\text { ND (0.011) } \\
\text { ND (0.018) } \\
\text { ND (0.022) } \\
\text { ND (0.054) } \\
\text { ND (0.033) }(0.016) \\
\text { ND (0.010) } \\
\text { ND (0.026) } \\
\text { ND (0.022) } \\
\text { ND (0.013) }\end{array}$ & & $\begin{array}{l}\text { ND (0.041) } \\
\text { ND (0.020) } \\
\text { ND (0.021) } \\
\text { ND (0.016) } \\
\text { ND (0.022) } \\
\text { ND (0.018) } \\
\text { ND (0.012) } \\
\text { ND (0.018) } \\
\text { ND (0.032) } \\
\text { ND (0.018) } \\
\text { ND (0.027) } \\
\text { ND (0.100) } \\
\text { ND (0.048) } \\
\text { ND (0.025) } \\
\text { ND (0.019) } \\
\text { ND (0.010) } \\
\text { ND (0.019) } \\
\text { ND (0.023) } \\
\text { ND (0.013) } \\
\text { ND (0.012) } \\
\text { ND (0.016) } \\
\text { ND (0.025) } \\
\text { ND (0.014) } \\
\text { ND (0.011) } \\
\text { ND (0.018) } \\
\text { ND (0.022) } \\
\text { ND (0.055) } \\
\text { ND (0.033) } \\
\text { ND (0.016) } \\
\text { ND (0.010) } \\
\text { ND (0.026) } \\
\text { ND (0.022) } \\
\text { ND (0.013) }\end{array}$ & & 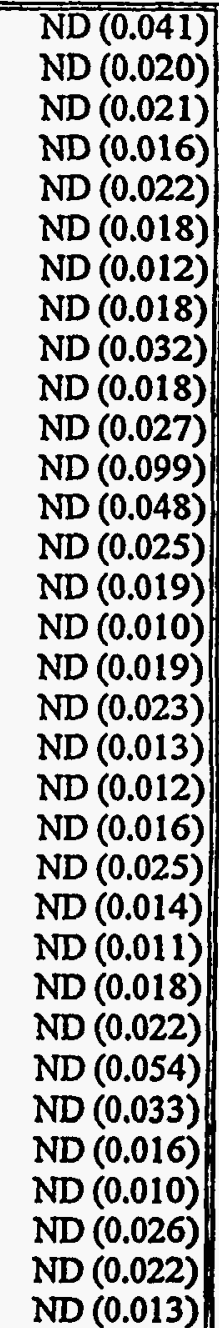 & \\
\hline
\end{tabular}


Analytical Data Used In Calculations

Stream: Cyclone As Collection Method: Grab Composit Sample Type: Fly As

\begin{tabular}{|c|c|c|c|c|c|c|c|c|}
\hline Analyte & $\begin{array}{l}\text { Analytical } \\
\text { Technique }\end{array}$ & Units & Run 1 & Com 1 & Run 2 & Com 2 & Run 3 & $\mathrm{Com} 3$ \\
\hline $\begin{array}{l}\text { Pentachlorophenol } \\
\text { Phenanthrene } \\
\text { Phenol } \\
\text { Pyrene } \\
\text { bis(2-Chloroethoxy)methane } \\
\text { bis(2-Chloroethyl)ether } \\
\text { bis(2-Chloroisopropyl)ether } \\
\text { bis(2-Ethylhexyl)phthalate } \\
\text { p-Chloroaniline }\end{array}$ & $\begin{array}{l}\text { GCMS } \\
\text { GCMS } \\
\text { GCMS } \\
\text { GCMS } \\
\text { GCMS } \\
\text { GCMS } \\
\text { GCMS } \\
\text { GCMS } \\
\text { GCMS }\end{array}$ & $\begin{array}{l}\mathrm{ug} / \mathrm{g} \\
\mathrm{ug} / \mathrm{g} \\
\mathrm{ug} / \mathrm{g} \\
\mathrm{ug} / \mathrm{g} \\
\mathrm{ug} / \mathrm{g} \\
\mathrm{ug} / \mathrm{g} \\
\mathrm{ug} / \mathrm{g} \\
\mathrm{ug} / \mathrm{g} \\
\mathrm{ug} / \mathrm{g}\end{array}$ & $\begin{array}{l}\text { ND }(0.0064) \\
\text { ND }(0.018) \\
\text { ND }(0.034) \\
\text { ND }(0.015) \\
\text { ND }(0.011) \\
\text { ND }(0.015) \\
\text { ND }(0.019) \\
\text { ND }(0.054) \\
\text { ND }(0.033) \\
\end{array}$ & & $\begin{array}{l}\text { ND (0.0064) } \\
\text { ND (0.018) } \\
\text { ND (0.034) } \\
\text { ND (0.015) } \\
\text { ND (0.011) } \\
\text { ND (0.015) } \\
\text { ND (0.019) } \\
\text { ND (0.055) } \\
\text { ND (0.033) }\end{array}$ & & $\begin{array}{l}\text { ND (0.0064) } \\
\text { ND (0.018) } \\
\text { ND (0.034) } \\
\text { ND (0.015) } \\
\text { ND (0.011) } \\
\text { ND (0.015) } \\
\text { ND (0.019) } \\
\text { ND (0.054) } \\
\text { ND (0.033) }\end{array}$ & \\
\hline $\begin{array}{l}\text { Arsenic } \\
\text { Cadmium } \\
\text { Lead } \\
\text { Selenium }\end{array}$ & $\begin{array}{l}\text { GFAA } \\
\text { GFAA } \\
\text { GFAA } \\
\text { GFAA }\end{array}$ & $\begin{array}{l}\mathrm{mg} / \mathrm{kg} \\
\mathrm{mg} / \mathrm{kg} \\
\mathrm{mg} / \mathrm{kg} \\
\mathrm{mg} / \mathrm{kg}\end{array}$ & $\begin{array}{r}87.0 \\
0.284 \\
17.7 \\
1.65\end{array}$ & $\begin{array}{l}\mathrm{B} \\
\mathrm{B}\end{array}$ & \begin{tabular}{r|}
100 \\
0.442 \\
21.3 \\
2.95
\end{tabular} & $\begin{array}{l}\mathrm{B} \\
\mathrm{B}\end{array}$ & $\begin{array}{r}93.1 \\
0.320 \\
16.7 \\
7.46\end{array}$ & $\begin{array}{l}\mathrm{B} \\
\mathrm{B}\end{array}$ \\
\hline $\begin{array}{l}1,2,3,4,6,7,8-\mathrm{HpCDD} \\
1,2,3,4,6,7,8-\mathrm{HpCDF} \\
1,2,3,4,7,8,9-\mathrm{HpCDF} \\
1,2,3,4,7,8-\mathrm{HxCDD} \\
1,2,3,4,7,8-\mathrm{HxCDF} . \\
1,2,3,6,7,8-\mathrm{HxCDD} \\
1,2,3,6,7,8-1 \mathrm{xCDF} \\
1,2,3,7,8,9-1 \cdot 1 \times C D D \\
1,2,3,7,8,9-\mathrm{HxCDF} \\
1,2,3,7,8-\mathrm{PcCDD} \\
1,2,3,7,8-\mathrm{PeCDF} \\
2,3,4,6,7,8-\mathrm{HxCDF} \\
2,3,4,7,8-\mathrm{PeCDF} \\
2,3,7,8-\mathrm{TCDD} \\
2,3,7,8-\mathrm{TCDF} \\
\text { OCDD } \\
\text { OCDF } \\
\text { Total HpCDD } \\
\text { Total HpCDF }\end{array}$ & $\begin{array}{l}\text { HR GCMS } \\
\text { HR GCMS } \\
\text { HR GCMS } \\
\text { HR GCMS } \\
\text { HR GCMS } \\
\text { HR GCMS } \\
\text { IIR GCMS } \\
\text { IIR GCMS } \\
\text { HR GCMS } \\
\text { HR GCMS } \\
\text { HR GCMS } \\
\text { HR GCMS } \\
\text { HR GCMS } \\
\text { HR GCMS } \\
\text { HR GCMS } \\
\text { HR GCMS } \\
\text { HR GCMS } \\
\text { HR GCMS } \\
\text { HR GCMS }\end{array}$ & \begin{tabular}{|l}
$\mathrm{ppt}$ \\
$\mathrm{ppt}$ \\
$\mathrm{ppt}$ \\
$\mathrm{ppt}$ \\
$\mathrm{ppt}$ \\
$\mathrm{ppt}$ \\
$\mathrm{ppt}$ \\
$\mathrm{ppt}$ \\
$\mathrm{ppt}$ \\
$\mathrm{ppt}$ \\
$\mathrm{ppt}$ \\
$\mathrm{ppt}$ \\
$\mathrm{ppt}$ \\
$\mathrm{ppt}$ \\
$\mathrm{ppt}$ \\
$\mathrm{ppt}$ \\
$\mathrm{ppt}$ \\
$\mathrm{ppt}$ \\
$\mathrm{ppt}$
\end{tabular} & $\begin{array}{r}\text { ND (0.90) } \\
\text { ND (0.50) } \\
\text { ND (0.80) } \\
\text { ND (0.80) } \\
\text { ND (0.40) } \\
\text { ND (0.60) } \\
\text { ND (0.30) } \\
\text { ND (0.70) } \\
\text { ND (0.50) } \\
\text { ND (0.70) } \\
\text { ND (0.40) } \\
0.280 \\
\text { ND(0.40) } \\
\text { ND (0.40) } \\
\text { ND (0.30) } \\
\text { ND (1.6) } \\
\text { ND (1.3) } \\
\text { ND (0.90) } \\
\text { ND (0.60) }\end{array}$ & & $\begin{array}{r}\text { ND (0.90) } \\
0.510 \\
\text { ND (0.80) } \\
\text { ND (0.70) } \\
\text { ND (0.40) } \\
\text { ND (0.60) } \\
\text { ND (0.30) } \\
\text { ND (0.60) } \\
\text { ND (0.50) } \\
\text { ND (0.70) } \\
\text { ND (0.40) } \\
\text { ND (0.40) } \\
\text { ND (0.40) } \\
\text { ND (0.30) } \\
\text { ND (0.30) } \\
\text { ND (1.6) } \\
\text { ND (1.4) } \\
\text { ND (0.90) } \\
0.630\end{array}$ & & $\begin{array}{l}\text { ND }(0.80) \\
\text { ND }(0.40) \\
\text { ND }(0.70) \\
\text { ND }(0.70) \\
\text { ND }(0.40) \\
\text { ND (0.60) } \\
\text { ND (0.30) } \\
\text { ND (0.60) } \\
\text { ND (0.40) } \\
\text { ND (0.50) } \\
\text { ND (0.30) } \\
\text { ND (0.40) } \\
\text { ND (0.30) } \\
\text { ND (0.20) } \\
\text { ND (0.20) } \\
\text { ND (1.5) } \\
\text { ND (1.3) } \\
\text { ND (0.80) } \\
\text { ND (0.50) }\end{array}$ & \\
\hline
\end{tabular}


Stream: Cyclone As Collection Method: Grab Composit Sample Type: Fly As

\begin{tabular}{|c|c|c|c|c|c|c|c|c|}
\hline Analyte & $\begin{array}{l}\text { Analytical } \\
\text { Technique }\end{array}$ & Units & Run 1 & $\overline{\mathrm{Com} 1}$ & Run 2 & $\overline{\text { Com 2 }}$ & Run 3 & $\longdiv { \operatorname { C o m } 3 }$ \\
\hline $\begin{array}{l}\text { Total HXCDD } \\
\text { Total HXCDF } \\
\text { Total PeCDD } \\
\text { Total PeCDF } \\
\text { Total TCDD } \\
\text { Total TCDF }\end{array}$ & $\begin{array}{l}\text { HR GCMS } \\
\text { HR GCMS } \\
\text { HR GCMS } \\
\text { HR GCMS } \\
\text { HR GCMS } \\
\text { HR GCMS }\end{array}$ & $\begin{array}{l}\mathrm{ppt} \\
\mathrm{ppt} \\
\mathrm{ppt} \\
\mathrm{ppt} \\
\mathrm{ppt} \\
\mathrm{ppt}\end{array}$ & $\begin{array}{r}\text { ND (0.70) } \\
0.280 \\
\text { ND }(0.70) \\
\text { ND }(0.40) \\
\text { ND }(0.40) \\
\text { ND }(0.30)\end{array}$ & & $\begin{array}{l}\text { ND (0.70) } \\
\text { ND (0.40) } \\
\text { ND }(0.70) \\
\text { ND }(0.40) \\
\text { ND }(0.30) \\
\text { ND }(0.30)\end{array}$ & & $\begin{array}{l}\text { ND }(0.60) \\
\text { ND }(0.40) \\
\text { ND }(0.50) \\
\text { ND }(0.30) \\
\text { ND }(0.20) \\
\text { ND }(0.20)\end{array}$ & \\
\hline \begin{tabular}{|l} 
Aluminum \\
Antimony \\
Barium \\
Beryllium \\
Calcium \\
Chromium \\
Cobalt \\
Copper \\
Iron \\
Magnesium \\
Manganese \\
Molybdenum \\
Nickel \\
Phosphorus \\
Potassium \\
Silver \\
Sodium \\
Titanium \\
Vanadium
\end{tabular} & $\begin{array}{l}\text { ICAP } \\
\text { ICAP } \\
\text { ICAP } \\
\text { ICAP } \\
\text { ICAP } \\
\text { ICAP } \\
\text { ICAP } \\
\text { ICAP } \\
\text { ICAP } \\
\text { ICAP } \\
\text { ICAP } \\
\text { ICAP } \\
\text { ICAP } \\
\text { ICAP } \\
\text { ICAP } \\
\text { ICAP } \\
\text { ICAP } \\
\text { ICAP } \\
\text { ICAP }\end{array}$ & $\begin{array}{l}\mathrm{mg} / \mathrm{kg} \\
\mathrm{mg} / \mathrm{kg} \\
\mathrm{mg} / \mathrm{kg} \\
\mathrm{mg} / \mathrm{kg} \\
\mathrm{mg} / \mathrm{kg} \\
\mathrm{mg} / \mathrm{kg} \\
\mathrm{mg} / \mathrm{kg} \\
\mathrm{mg} / \mathrm{kg} \\
\mathrm{mg} / \mathrm{kg} \\
\mathrm{mg} / \mathrm{kg} \\
\mathrm{mg} / \mathrm{kg} \\
\mathrm{mg} / \mathrm{kg} \\
\mathrm{mg} / \mathrm{kg} \\
\mathrm{mg} / \mathrm{kg} \\
\mathrm{mg} / \mathrm{kg} \\
\mathrm{mg} / \mathrm{kg} \\
\mathrm{mg} / \mathrm{kg} \\
\mathrm{mg} / \mathrm{kg} \\
\mathrm{mg} / \mathrm{kg}\end{array}$ & $\begin{array}{r}32400 \\
\text { ND (43) } \\
142 \\
4.39 \\
127000 \\
44.4 \\
10.8 \\
\text { ND (3.7) } \\
49700 \\
79900 \\
115 \\
\text { ND (2.8) } \\
28.2 \\
\text { ND (67) } \\
6310 \\
\text { ND (3.3) } \\
1040 \\
1740 \\
59.2\end{array}$ & $\mid \begin{array}{l}B \\
B \\
B \\
B \\
B \\
B\end{array}$ & $\begin{array}{r}30600 \\
\text { ND (43) } \\
144 \\
3.61 \\
125000 \\
42.1 \\
12.7 \\
\text { ND }(3.7) \\
51100 \\
79300 \\
110 \\
\text { ND (2.8) } \\
\text { ND (8.4) } \\
\text { ND (70) } \\
5980 \\
\text { ND (3.3) } \\
868 \\
1600 \\
49.8\end{array}$ & $\begin{array}{l}B \\
B \\
B \\
B \\
B \\
B\end{array}$ & $\begin{array}{r}32700 \\
\mathrm{ND}(40) \\
154 \\
3.48 \\
120000 \\
45.6 \\
14.6 \\
\mathrm{ND}(3.4) \\
49800 \\
78700 \\
115 \\
3.18 \\
9.96 \\
\mathrm{ND}(67) \\
6750 \\
\mathrm{ND}(3.0) \\
981 \\
1660 \\
55.4\end{array}$ & $\begin{array}{l}\mathrm{B} \\
\mathrm{B} \\
\mathrm{B}\end{array}$ \\
\hline $\begin{array}{l}\text { Chloride } \\
\text { Fluoride }\end{array}$ & $\begin{array}{l}\text { SIE } \\
\text { SIE }\end{array}$ & $\begin{array}{l}\mathrm{mg} / \mathrm{kg} \\
\mathrm{mg} / \mathrm{kg}\end{array}$ & $\begin{array}{r}313 \\
75.5 \\
\end{array}$ & $B$ & $\begin{array}{l}365 \\
150\end{array}$ & B & $\begin{array}{l}400 \\
104\end{array}$ & B \\
\hline
\end{tabular}




\section{Analytical Data Used In Calculations}

Stream: Cyclone Ash Collection Method: Grab Composite Sample Type: Fly Ash FD

\begin{tabular}{|c|c|c|c|c|c|c|c|}
\hline Analyte & $\begin{array}{l}\text { Analytical } \\
\text { Technique }\end{array}$ & Units & Run 1 & Com 1 & Run 2 & Com 2 & Run 3 \\
\hline Mercury & CVAA & $\mathrm{mg} / \mathrm{kg}$ & & & & & $\mathrm{ND}(0.012)$ \\
\hline $\begin{array}{l}\text { 1,2,4-Trichlorobenzene } \\
\text { 1,2-Dichlorobenzene } \\
\text { 1,3-Dichlorobenzene } \\
\text { 1,4-Dichlorobenzene } \\
\text { 2,4,5-Trichlorophenol } \\
\text { 2,4,6-Trichlorophenol } \\
\text { 2,4-Dichlorophenol } \\
\text { 2,4-Dimethylphenol } \\
\text { 2,4-Dinitrophenol } \\
\text { 2,4-Dinitrotoluene } \\
\text { 2,6-Dinitrotoluene } \\
\text { 2-Chloronaphthalene } \\
\text { 2-Chlorophenol } \\
\text { 2-Methylnaphthalene } \\
\text { 2-Methylphenol } \\
\text { 2-Nitroaniline } \\
\text { 2-Nitrophenol } \\
\text { 3,3'-Dichlorobenzidine } \\
\text { 3-Nitroaniline } \\
\text { 4,6-Dinitro-2-methylphenol } \\
\text { 4-Bromophenylphenyl ether } \\
\text { 1-Chloro-3-mellyylplienol } \\
\text { 4-Chlorophenylphenyl ether } \\
\text { 4-Methylphenol/3-Methylphenol } \\
\text { 4-Nitroaniline } \\
\text { 4-Nitrophenol } \\
\text { Acenaphthene } \\
\text { Acenaphthylene } \\
\text { Anthraccne } \\
\text { Benz(a)anthracene } \\
\text { Benz(a)pyrene } \\
\text { Benzo(b)fluoranthene } \\
\end{array}$ & $\begin{array}{l}\text { GCMS } \\
\text { GCMS } \\
\text { GCMS } \\
\text { GCMS } \\
\text { GCMS } \\
\text { GCMS } \\
\text { GCMS } \\
\text { GCMS } \\
\text { GCMS } \\
\text { GCMS } \\
\text { GCMS } \\
\text { GCMS } \\
\text { GCMS } \\
\text { GCMS } \\
\text { GCMS } \\
\text { GCMS } \\
\text { GCMS } \\
\text { GCMS } \\
\text { GCMS } \\
\text { GCMS } \\
\text { GCMS } \\
\text { GCMS } \\
\text { GCMS } \\
\text { GCMS } \\
\text { GCMS } \\
\text { GCMS } \\
\text { GCMS } \\
\text { GCMS } \\
\text { GCMS } \\
\text { GCMS } \\
\text { GCMS } \\
\text { GCMS } \\
\end{array}$ & $\begin{array}{l}\mathrm{ug} / \mathrm{g} \\
\mathrm{ug} / \mathrm{g} \\
\mathrm{ug} / \mathrm{g} \\
\mathrm{ug} / \mathrm{g} \\
\mathrm{ug} / \mathrm{g} \\
\mathrm{ug} / \mathrm{g} \\
\mathrm{ug} / \mathrm{g} \\
\mathrm{ug} / \mathrm{g} \\
\mathrm{ug} / \mathrm{g} \\
\mathrm{ug} / \mathrm{g} \\
\mathrm{ug} / \mathrm{g} \\
\mathrm{ug} / \mathrm{g} \\
\mathrm{ug} / \mathrm{g} \\
\mathrm{ug} / \mathrm{g} \\
\mathrm{ug} / \mathrm{g} \\
\mathrm{ug} / \mathrm{g} \\
\mathrm{ug} / \mathrm{g} \\
\mathrm{ug} / \mathrm{g} \\
\mathrm{ug} / \mathrm{g} \\
\mathrm{ug} / \mathrm{g} \\
\mathrm{ug} / \mathrm{g} \\
\mathrm{ug} / \mathrm{g} \\
\mathrm{ug} / \mathrm{g} \\
\mathrm{ug} / \mathrm{g} \\
\mathrm{ug} / \mathrm{g} \\
\mathrm{ug} / \mathrm{g} \\
\mathrm{ug} / \mathrm{g} \\
\mathrm{ug} / \mathrm{g} \\
\mathrm{ug} / \mathrm{g} \\
\mathrm{ug} / \mathrm{g} \\
\mathrm{ug} / \mathrm{g} \\
\mathrm{ug} / \mathrm{g}\end{array}$ & & & & & 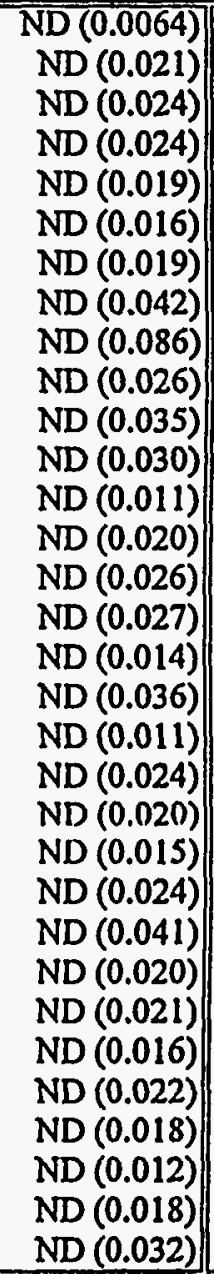 \\
\hline
\end{tabular}




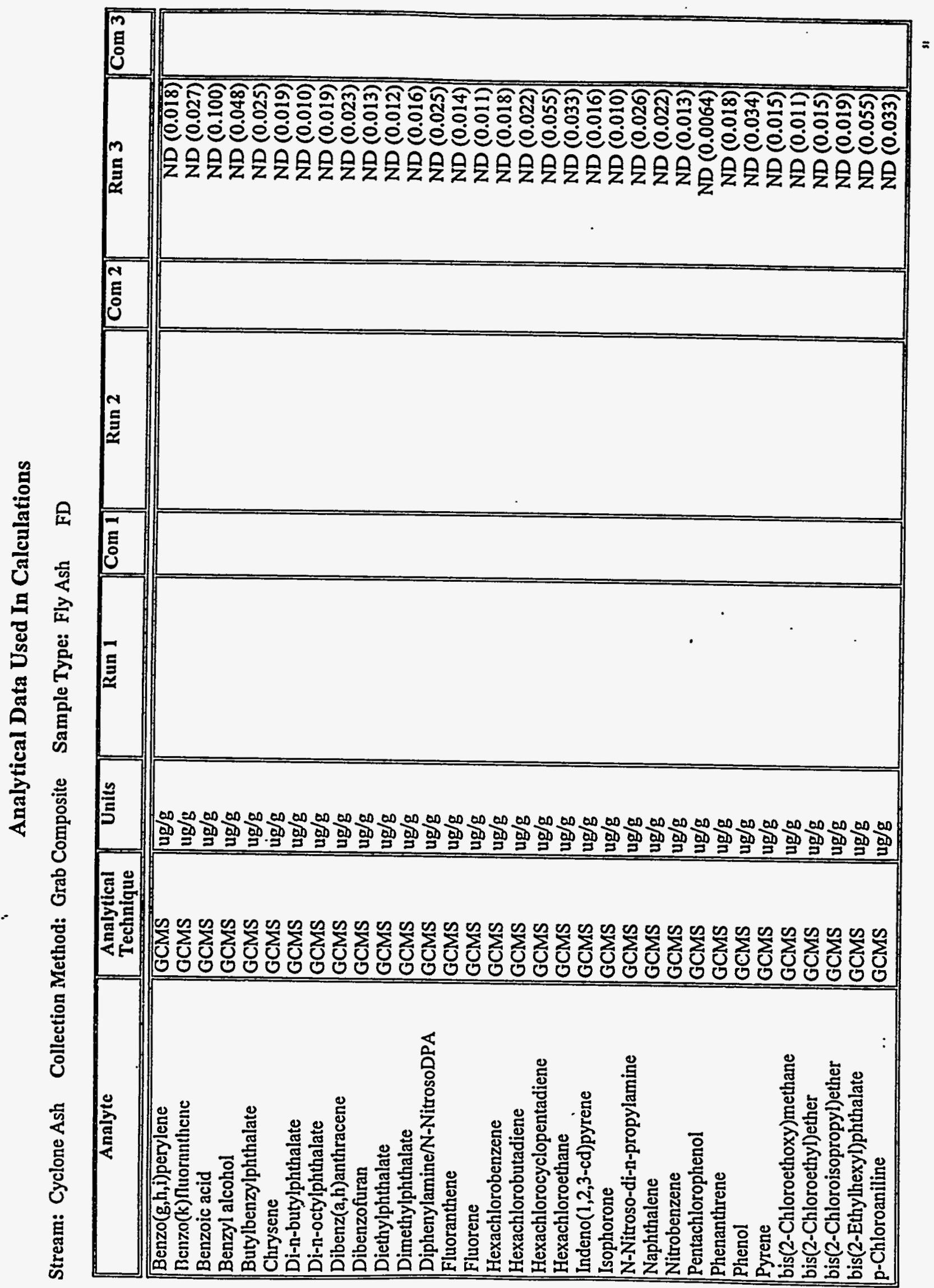


Analytical Data Used In Calculations

Stream: Cyclone Ash Collection Method: Grab Composite Sample Type: Fly Ash FD

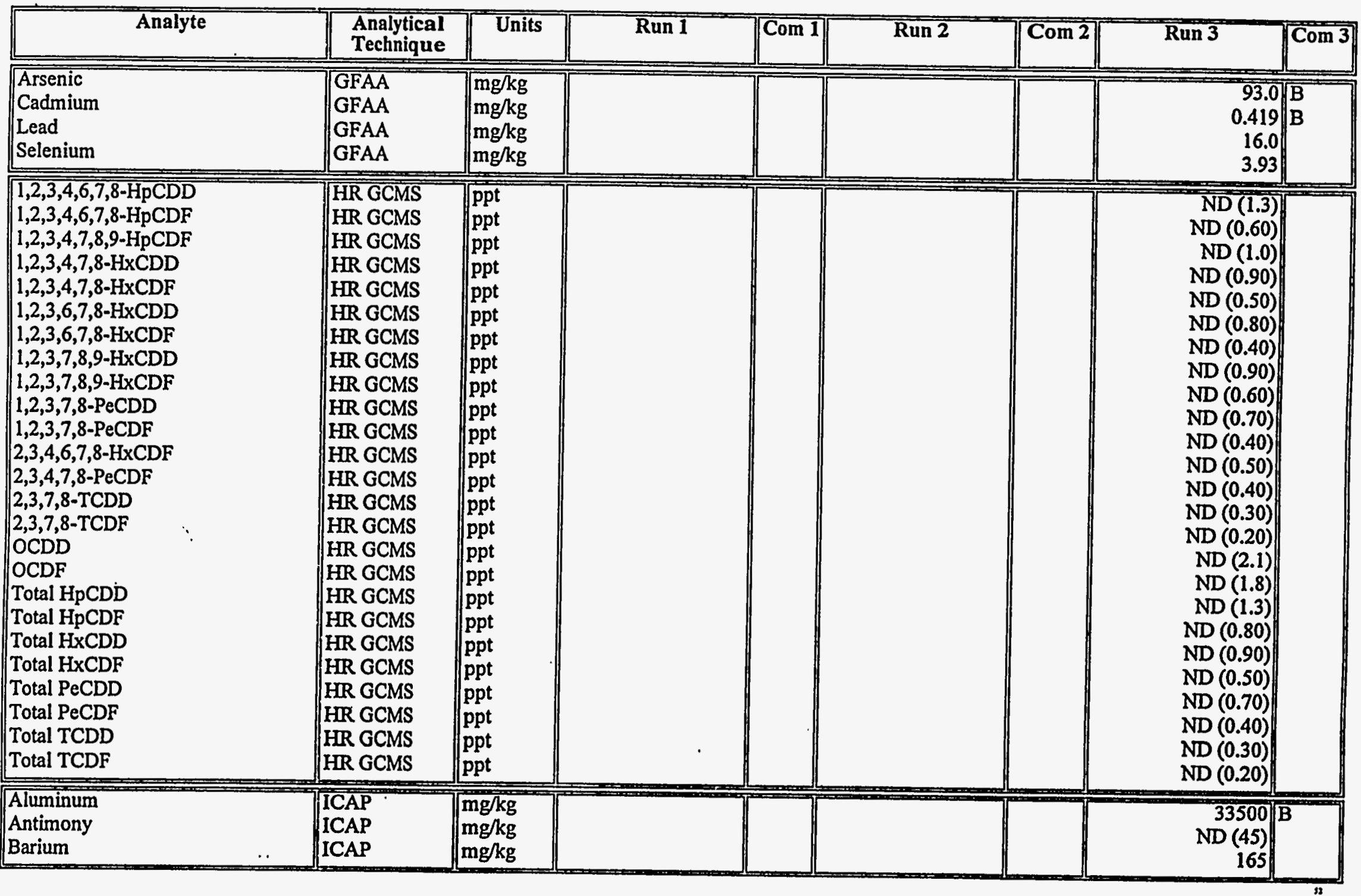


Stream: Cyclone Ash Collection Method: Grab Composite Sample Type: Fly Ash FD

\begin{tabular}{|c|c|c|c|c|c|c|c|c|}
\hline Analyte & $\begin{array}{l}\text { Analytical } \\
\text { Technique }\end{array}$ & Units & Run 1 & Com 1 & Run 2 & $\longdiv { \operatorname { C o m } 2 }$ & Run 3 & Com 3 \\
\hline \begin{tabular}{|l} 
Beryllium \\
Calcium \\
Chromium \\
Cobalt \\
Copper \\
Iron \\
Magnesium \\
Manganese \\
Molybdenum \\
Nickel \\
Phosphorus \\
Potassium \\
Silver \\
Sodium \\
Titanium \\
Vanadium \\
\end{tabular} & \begin{tabular}{|l} 
ICAP \\
ICAP \\
ICAP \\
ICAP \\
ICAP \\
ICAP \\
ICAP \\
ICAP \\
ICAP \\
ICAP \\
ICAP \\
ICAP \\
ICAP \\
ICAP \\
ICAP \\
ICAP
\end{tabular} & $\begin{array}{l}\mathrm{mg} / \mathrm{kg} \\
\mathrm{mg} / \mathrm{kg} \\
\mathrm{mg} / \mathrm{kg} \\
\mathrm{mg} / \mathrm{kg} \\
\mathrm{mg} / \mathrm{kg} \\
\mathrm{mg} / \mathrm{kg} \\
\mathrm{mg} / \mathrm{kg} \\
\mathrm{mg} / \mathrm{kg} \\
\mathrm{mg} / \mathrm{kg} \\
\mathrm{mg} / \mathrm{kg} \\
\mathrm{mg} / \mathrm{kg} \\
\mathrm{mg} / \mathrm{kg} \\
\mathrm{mg} / \mathrm{kg} \\
\mathrm{mg} / \mathrm{kg} \\
\mathrm{mg} / \mathrm{kg} \\
\mathrm{mg} / \mathrm{kg}\end{array}$ & & & & & $\begin{array}{r}3.76 \\
128000 \\
45.9 \\
14.8 \\
\text { ND }(3.9) \\
51100 \\
79400 \\
115 \\
\text { ND (3.0) } \\
26.4 \\
\text { ND (71) } \\
6370 \\
\text { ND (3.4) } \\
1040 \\
1690 \\
55.2\end{array}$ & $\begin{array}{l}\mathrm{B} \\
\mathrm{B} \\
\mathrm{B} \\
\mathrm{B} \\
\mathrm{B} \\
\mathrm{B}\end{array}$ \\
\hline $\begin{array}{l}\text { Chloride } \\
\text { Fluoride }\end{array}$ & $\begin{array}{l}\text { SIE } \\
\text { SIE }\end{array}$ & $\begin{array}{l}\mathrm{mg} / \mathrm{kg} \\
\mathrm{mg} / \mathrm{kg}\end{array}$ & & & & & $\begin{array}{l}382 \\
130\end{array}$ & B \\
\hline
\end{tabular}

Stream: ESP Ash Collection Method: Grab Composite Sample Type: Fly Ash

\begin{tabular}{|c|c|c|c|c|c|c|c|c|}
\hline Analyte & $\begin{array}{l}\text { Analytical } \\
\text { Technique }\end{array}$ & Units & Run 1 & Com 1 & Run 2 & $\overline{C o m} 2$ & Run 3 & Com 3 \\
\hline Mercury & CVAA & $\mathrm{mg} / \mathrm{kg}$ & $\mathrm{ND}(0.012)$ & & $\mathrm{ND}(0.012)$ & & $\mathrm{ND}(0.012)$ & \\
\hline $\begin{array}{l}\text { 1,2,4-Trichlorobenzene } \\
\text { 1,2-Dichlorobenzene } \\
\text { 1,3-Dichlorobenzene } \\
\text { 1,4-Dichlorobenzene } \\
\text { 2,4,5-Trichlorophenol } \\
\text { 2,4,6-Trichlorophenol } \\
\text { 2,4-Dichlorophenol } \\
\text { 2,4-Dimethylphenol }\end{array}$ & $\begin{array}{l}\text { GCMS } \\
\text { GCMS } \\
\text { GCMS } \\
\text { GCMS } \\
\text { GCMS } \\
\text { GCMS } \\
\text { GCMS } \\
\text { GCMS }\end{array}$ & $\begin{array}{l}\mathrm{ug} / \mathrm{g} \\
\mathrm{ug} / \mathrm{g} \\
\mathrm{ug} / \mathrm{g} \\
\mathrm{ug} / \mathrm{g} \\
\mathrm{ug} / \mathrm{g} \\
\mathrm{ug} / \mathrm{g} \\
\mathrm{ug} / \mathrm{g} \\
\mathrm{ug} / \mathrm{g}\end{array}$ & $\begin{array}{l}\mathrm{ND}(0.0064) \\
\mathrm{ND}(0.021) \\
\mathrm{ND}(0.024) \\
\mathrm{ND}(0.024) \\
\mathrm{ND}(0.019) \\
\mathrm{ND}(0.016) \\
\mathrm{ND}(0.019) \\
\mathrm{ND}(0.042)\end{array}$ & & $\begin{array}{r}N D(0.0064) \\
N D(0.021) \\
\text { ND (0.024) } \\
\text { ND (0.024) } \\
\text { ND (0.019) } \\
\text { ND (0.016) } \\
\text { ND (0.019) } \\
\text { ND (0.042) }\end{array}$ & & $\begin{array}{l}\mathrm{ND}(0.0064) \\
\mathrm{ND}(0.021) \\
\mathrm{ND}(0.024) \\
\mathrm{ND}(0.024) \\
\mathrm{ND}(0.019) \\
\mathrm{ND}(0.016) \\
\mathrm{ND}(0.019) \\
\mathrm{ND}(0.042)\end{array}$ & \\
\hline
\end{tabular}




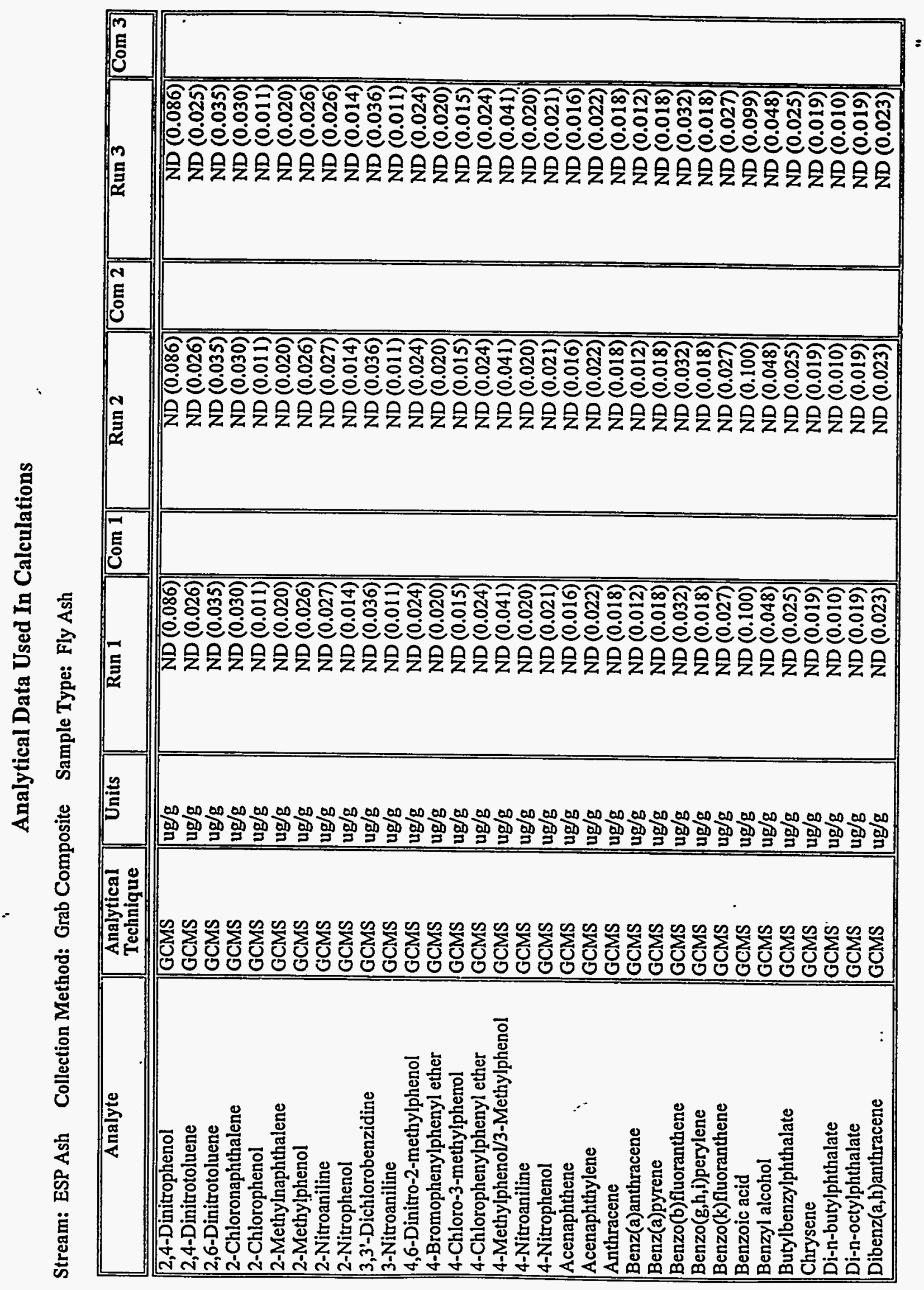


Stream: ESP Ash Collection Method: Grab Composite Sample Type: Fly Ash

\begin{tabular}{|c|c|c|c|c|c|c|c|c|}
\hline Analyte & $\begin{array}{l}\text { Analytical } \\
\text { Technique }\end{array}$ & Units & Run 1 & Com 1 & Run 2 & Com 2 & Run 3 & $\sqrt{\text { Com 3 }}$ \\
\hline 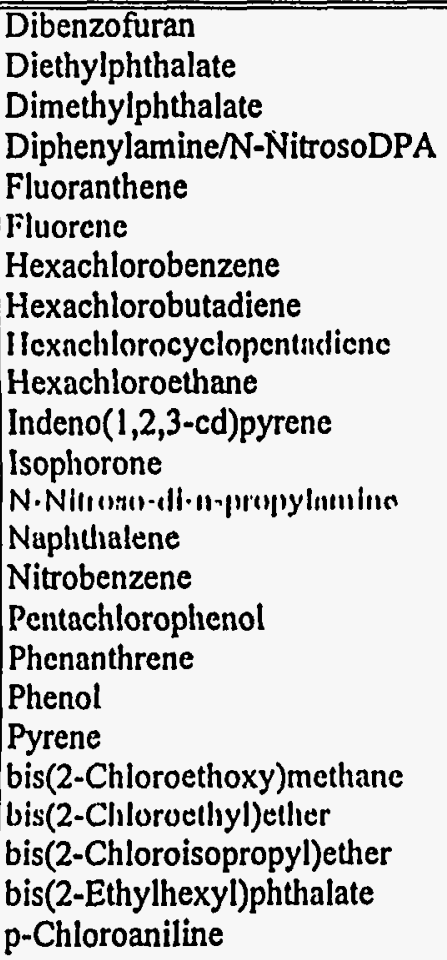 & $\begin{array}{l}\text { GCMS } \\
\text { GCMS } \\
\text { GCMS } \\
\text { GCMS } \\
\text { GCMS } \\
\text { GCMS } \\
\text { GCMS } \\
\text { GCMS } \\
\text { GCMS } \\
\text { GCMS } \\
\text { GCMS } \\
\text { GCMS } \\
\text { GCMS } \\
\text { GCMS } \\
\text { GCMS } \\
\text { GCMS } \\
\text { GCMS } \\
\text { GCMS } \\
\text { GCMS } \\
\text { GCMS } \\
\text { GCMS } \\
\text { GCMS } \\
\text { GCMS } \\
\text { GCMS }\end{array}$ & $\begin{array}{l}\mathrm{ug} / \mathrm{g} \\
\mathrm{ug} / \mathrm{g} \\
\mathrm{ug} / \mathrm{g} \\
\mathrm{ug} / \mathrm{g} \\
\mathrm{ug} / \mathrm{g} \\
\mathrm{ug} / \mathrm{g} \\
\mathrm{ug} / \mathrm{g} \\
\mathrm{ug} / \mathrm{g} \\
\mathrm{ug} / \mathrm{g} \\
\mathrm{ug} / \mathrm{g} \\
\mathrm{ug} / \mathrm{g} \\
\mathrm{ug} / \mathrm{g} \\
\mathrm{ug} / \mathrm{g} \\
\mathrm{ug} / \mathrm{g} \\
\mathrm{ug} / \mathrm{g} \\
\mathrm{ug} / \mathrm{g} \\
\mathrm{ug} / \mathrm{g} \\
\mathrm{ug} / \mathrm{g} \\
\mathrm{ug} / \mathrm{g} \\
\mathrm{ug} / \mathrm{g} \\
\mathrm{ug} / \mathrm{g} \\
\mathrm{ug} / \mathrm{g} \\
\mathrm{ug} / \mathrm{g} \\
\mathrm{ug} / \mathrm{g}\end{array}$ & 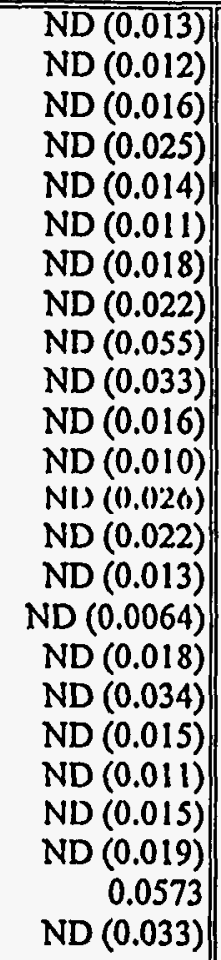 & & $\begin{array}{r}\text { ND (0.013) } \\
\text { ND (0.012) } \\
\text { ND (0.016) } \\
\text { ND (0.025) } \\
\text { ND (0.014) } \\
\text { ND (0.011) } \\
\text { ND (0.018) } \\
\text { ND (0.022) } \\
\text { ND (0.055) } \\
\text { ND (0.033) } \\
\text { ND (0.016) } \\
\text { ND (0.010) } \\
\text { NI) (0.026) } \\
\text { ND (0.022) } \\
\text { ND (0.013) } \\
\text { ND (0.0064) } \\
\text { ND (0.018) } \\
\text { ND (0.034) } \\
\text { ND (0.015) } \\
\text { ND (0.011) } \\
\text { ND (0.015) } \\
\text { ND (0.019) } \\
0.204 \\
\text { ND (0.033) }\end{array}$ & & $\begin{array}{r}\text { ND }(0.013) \\
\text { ND (0.012) } \\
\text { ND (0.016) } \\
\text { ND (0.025) } \\
\text { ND (0.014) } \\
\text { ND (0.011) } \\
\text { ND (0.018) } \\
\text { ND (0.022) } \\
\text { ND (0.054) } \\
\text { ND (0.033) } \\
\text { ND (0.016) } \\
\text { ND (0.010) } \\
\text { NI (0.026) } \\
\text { ND (0.022) } \\
\text { ND (0.013) } \\
\text { ND (0.0064) } \\
\text { ND (0.018) } \\
\text { ND (0.034) } \\
\text { ND (0.015) } \\
\text { ND (0.011) } \\
\text { ND (0.015) } \\
\text { ND (0.019) } \\
\text { ND } 0.753 \\
\text { ND }(0.033)\end{array}$ & \\
\hline $\begin{array}{l}\text { Arsenic } \\
\text { Cadmium } \\
\text { Lead } \\
\text { Selenium }\end{array}$ & $\begin{array}{l}\text { GFAA } \\
\text { GFAA } \\
\text { GFAA } \\
\text { GFAA }\end{array}$ & $\begin{array}{l}\mathrm{mg} / \mathrm{kg} \\
\mathrm{mg} / \mathrm{kg} \\
\mathrm{mg} / \mathrm{kg} \\
\mathrm{mg} / \mathrm{kg}\end{array}$ & \begin{tabular}{r|}
354 \\
1.96 \\
63.7 \\
.5 .38
\end{tabular} & $\begin{array}{l}\mathrm{B} \\
\mathrm{B}\end{array}$ & \begin{tabular}{r|}
403 \\
1.79 \\
85.7 \\
4.41
\end{tabular} & $\begin{array}{l}\mathrm{B} \\
\mathrm{B}\end{array}$ & \begin{tabular}{r|}
388 \\
1.96 \\
102 \\
4.92
\end{tabular} & $\begin{array}{l}\bar{B} \\
B\end{array}$ \\
\hline $\begin{array}{l}1,2,3,4,6,7,8-\mathrm{HpCDD} \\
1,2,3,4,6,7,8-\mathrm{HpCDF} \\
1,2,3,4,7,8,9-\mathrm{HpCDF} \\
1,2,3,4,7,8-\mathrm{HxCDD}\end{array}$ & $\begin{array}{l}\text { HR GCMS } \\
\text { HR GCMS } \\
\text { HR GCMS } \\
\text { HR GCMS }\end{array}$ & $\begin{array}{l}\text { ppt } \\
\text { ppt } \\
\text { ppt } \\
\text { ppt }\end{array}$ & $\begin{array}{l}\text { ND }(0.50) \\
\text { ND }(0.90) \\
\text { ND }(0.80)\end{array}$ & & $\begin{array}{l}1.00 \\
\mathrm{ND}(1.1) \\
\mathrm{ND}(1.8) \\
\mathrm{ND}(1.5)\end{array}$ & & $\begin{array}{l}1.80 \\
\text { ND }(0.50) \\
\text { ND }(0.80) \\
N D(0.70)\end{array}$ & \\
\hline
\end{tabular}




\section{Analytical Data Used In Calculations}

Stream: ESP Ash Collection Method: Grab Composite Sample Type: Fly Ash

\begin{tabular}{|c|c|c|c|c|c|c|c|c|}
\hline Analyte & $\begin{array}{l}\text { Analytical } \\
\text { Technique }\end{array}$ & Units & Run 1 & Com 1 & Run 2 & Com 2 & Run 3 & Com 3 \\
\hline \begin{tabular}{|l}
$1,2,3,4,7,8-\mathrm{HxCDF}$ \\
$1,2,3,6,7,8-\mathrm{HxCDD}$ \\
$1,2,3,6,7,8-\mathrm{HxCDF}$ \\
$1,2,3,7,8,9-\mathrm{HxCDD}$ \\
$1,2,3,7,8,9-\mathrm{HxCDF}$ \\
$1,2,3,7,8-\mathrm{PeCDD}$ \\
$1,2,3,7,8-\mathrm{PeCDF}$ \\
$2,3,4,6,7,8-\mathrm{HxCDF}$ \\
$2,3,4,7,8-\mathrm{PeCDF}$ \\
$2,3,7,8-\mathrm{TCDD}$ \\
$2,3,7,8-\mathrm{TCDF}$ \\
OCDD \\
OCDF \\
Total HpCDD \\
Total HpCDF \\
Total HxCDD \\
Total HxCDF \\
Total PeCDD \\
Total PeCDF \\
Total TCDD \\
Total TCDF
\end{tabular} & \begin{tabular}{|l} 
HR GCMS \\
HR GCMS \\
HR GCMS \\
HR GCMS \\
HR GCMS \\
HR GCMS \\
HR GCMS \\
HR GCMS \\
HR GCMS \\
HR GCMS \\
HR GCMS \\
HR GCMS \\
HR GCMS \\
HR GCMS \\
HR GCMS \\
HR GCMS \\
HR GCMS \\
HR GCMS \\
HR GCMS \\
HR GCMS
\end{tabular} & \begin{tabular}{|l}
$\mathrm{ppt}$ \\
$\mathrm{ppt}$ \\
$\mathrm{ppt}$ \\
$\mathrm{ppt}$ \\
$\mathrm{ppt}$ \\
$\mathrm{ppt}$ \\
$\mathrm{ppt}$ \\
$\mathrm{ppt}$ \\
$\mathrm{ppt}$ \\
$\mathrm{ppt}$ \\
$\mathrm{ppt}$ \\
$\mathrm{ppt}$ \\
$\mathrm{ppt}$ \\
$\mathrm{ppt}$ \\
$\mathrm{ppt}$ \\
$\mathrm{ppt}$ \\
$\mathrm{ppt}$ \\
$\mathrm{ppt}$ \\
$\mathrm{ppt}$ \\
$\mathrm{ppt}$ \\
$\mathrm{ppt}$
\end{tabular} & $\begin{array}{r}\text { ND (0.50) } \\
\text { ND (0.70) } \\
\text { ND (0.40) } \\
\text { ND (0.70) } \\
\text { ND (0.50) } \\
\text { ND (0.70) } \\
\text { ND (0.30) } \\
\text { ND (0.40) } \\
\text { ND (0.30) } \\
\text { ND (0.30) } \\
\text { ND (0.20) } \\
\text { ND (1.8) } \\
\text { ND (1.5) } \\
2.50 \\
\text { ND (0.70) } \\
5.90 \\
\text { ND (0.40) } \\
4.40 \\
\text { ND (0.30) } \\
2.80 \\
\text { ND }(0.20)\end{array}$ & & $\begin{array}{r}\mathrm{ND}(0.90) \\
\mathrm{ND}(1.3) \\
\mathrm{ND}(0.70) \\
\mathrm{ND}(1.4) \\
\mathrm{ND}(0.90) \\
\mathrm{ND}(1.2) \\
\mathrm{ND}(0.60) \\
\mathrm{ND}(0.80) \\
\mathrm{ND}(0.60) \\
\mathrm{ND}(0.50) \\
\mathrm{ND}(0.40) \\
\mathrm{ND}(3.5) \\
\mathrm{ND}(3.0) \\
2.50 \\
\mathrm{ND}(1.3) \\
5.00 \\
\mathrm{ND}(0.80) \\
5.30 \\
\mathrm{ND}(0.60) \\
3.30 \\
\mathrm{ND}(0.40)\end{array}$ & & \begin{tabular}{r|} 
ND (0.40) \\
0.500 \\
ND (0.30) \\
ND (0.60) \\
ND (0.40) \\
ND (0.60) \\
ND (0.30) \\
ND (0.40) \\
ND (0.30) \\
ND (0.30) \\
0.210 \\
1.60 \\
ND (1.4) \\
1.80 \\
ND (0.60) \\
6.40 \\
ND (0.40) \\
4.20 \\
ND (0.30) \\
3.50 \\
0.210
\end{tabular} & \\
\hline \begin{tabular}{|l} 
Aluminum \\
Antimony \\
Barium \\
Beryllium \\
Boron \\
Calcium \\
Chromium \\
Cobalt \\
Copper \\
Iron \\
Magnesium \\
Manganese
\end{tabular} & $\begin{array}{l}\text { ICAP } \\
\text { ICAP } \\
\text { ICAP } \\
\text { ICAP } \\
\text { ICAP } \\
\text { ICAP } \\
\text { ICAP } \\
\text { ICAP } \\
\text { ICAP } \\
\text { ICAP } \\
\text { ICAP } \\
\text { ICAP }\end{array}$ & $\begin{array}{l}\mathrm{mg} / \mathrm{kg} \\
\mathrm{mg} / \mathrm{kg} \\
\mathrm{mg} / \mathrm{kg} \\
\mathrm{mg} / \mathrm{kg} \\
\mathrm{ug} / \mathrm{g} \\
\mathrm{mg} / \mathrm{kg} \\
\mathrm{mg} / \mathrm{kg} \\
\mathrm{mg} / \mathrm{kg} \\
\mathrm{mg} / \mathrm{kg} \\
\mathrm{mg} / \mathrm{kg} \\
\mathrm{mg} / \mathrm{kg} \\
\mathrm{mg} / \mathrm{kg}\end{array}$ & $\begin{array}{r}62900 \\
\mathrm{ND}(59) \\
231 \\
9.12 \\
97.0 \\
94900 \\
97.5 \\
24.4 \\
8.59 \\
27800 \\
47700 \\
114\end{array}$ & $\mid$\begin{tabular}{|l}
$\mathrm{B}$ \\
$\mathrm{B}$ \\
$\mathrm{B}$ \\
$\mathrm{B}$ \\
$\mathrm{B}$
\end{tabular} & $\begin{array}{r}5700 \\
\text { ND (57) } \\
209 \\
7.36 \\
\\
83100 \\
89.7 \\
20.2 \\
\text { ND (4.8) } \\
26200 \\
43100 \\
107\end{array}$ & $\begin{array}{l}\mathrm{B} \\
\mathrm{B} \\
\mathrm{B} \\
\mathrm{B} \\
\mathrm{B}\end{array}$ & \begin{tabular}{r|}
62600 \\
$\mathrm{ND}(57)$ \\
226 \\
7.62 \\
83.0 \\
91200 \\
94.0 \\
20.3 \\
8.52 \\
28100 \\
46100 \\
113
\end{tabular} & $\begin{array}{l}B \\
B \\
B\end{array}$ \\
\hline
\end{tabular}


Stream: ESP Ash Collection Method: Grab Composite Sample Type: Fly Ash

\begin{tabular}{|c|c|c|c|c|c|c|c|c|}
\hline Analyte & $\begin{array}{l}\text { Analytical } \\
\text { Technique }\end{array}$ & Units & Run 1 & $\overline{\operatorname{Com} 1}$ & Run 2 & $\longdiv { \overline { \operatorname { C o m } 2 } }$ & Run 3 & $\widehat{\operatorname{Com} 3}$ \\
\hline \begin{tabular}{|l} 
Molybdenum \\
Nickel \\
Phosphorus \\
Potassium \\
Silver \\
Sodium \\
Titanium \\
Vanadium \\
\end{tabular} & $\begin{array}{l}\text { ICAP } \\
\text { ICAP } \\
\text { ICAP } \\
\text { ICAP } \\
\text { ICAP } \\
\text { ICAP } \\
\text { ICAP } \\
\text { ICAP }\end{array}$ & $\begin{array}{l}\mathrm{mg} / \mathrm{kg} \\
\mathrm{mg} / \mathrm{kg} \\
\mathrm{mg} / \mathrm{kg} \\
\mathrm{mg} / \mathrm{kg} \\
\mathrm{mg} / \mathrm{kg} \\
\mathrm{mg} / \mathrm{kg} \\
\mathrm{mg} / \mathrm{kg} \\
\mathrm{mg} / \mathrm{kg}\end{array}$ & $\begin{array}{r}\text { ND (3.8) } \\
60.3 \\
\text { ND (70) } \\
15800 \\
\text { ND (4.4) } \\
2600 \\
3920 \\
123 \\
\end{array}$ & $\mid \begin{array}{l}\text { B } \\
\text { B } \\
\text { B }\end{array}$ & $\begin{array}{r}\mathrm{ND}(3.7) \\
32.6 \\
\mathrm{ND}(71) \\
14800 \\
\mathrm{ND}(4.3) \\
2630 \\
3650 \\
111\end{array}$ & B & $\begin{array}{r}\mathrm{ND}(3.8) \\
57.3 \\
\mathrm{ND}(68) \\
15600 \\
\mathrm{ND}(4.3) \\
2560 \\
3700 \\
111\end{array}$ & B \\
\hline $\begin{array}{l}\text { Chloride } \\
\text { Fluoride }\end{array}$ & $\begin{array}{l}\text { SIE } \\
\text { SIE }\end{array}$ & $\begin{array}{l}\mathrm{mg} / \mathrm{kg} \\
\mathrm{mg} / \mathrm{kg}\end{array}$ & $\begin{array}{r}\mathrm{ND}(78) \\
143\end{array}$ & $B$ & $\begin{array}{r}\mathrm{ND}(78) \\
109\end{array}$ & $\mid B$ & $\begin{array}{r}\mathrm{ND}(78) \\
69.5\end{array}$ & $\| B$ \\
\hline $\begin{array}{l}\text { Carbon } \\
\text { Sulfur }\end{array}$ & $\begin{array}{l}\text { Ultimate } \\
\text { Ultimate }\end{array}$ & $\%$ & $\begin{array}{r}0.335 \\
13.6\end{array}$ & & & & $\begin{array}{r}0.340 \\
13.9\end{array}$ & \\
\hline $\begin{array}{l}\text { Actinium-228 @338 } \\
\text { Actinium-228 @911 } \\
\text { Actinium-228 @968 } \\
\text { Bismuth-212 @727 } \\
\text { Bismuth-214 @1120.4 } \\
\text { Bismuth-214 @1764.7 } \\
\text { Bismuth-214 @609.4 } \\
\text { K-40 @1460 } \\
\text { Lead-210 @46 } \\
\text { Lead-212 @238 } \\
\text { Lead-214 @295.2 } \\
\text { Lead-214 @352.0 } \\
\text { Radium-226 @186.0 } \\
\text { Thallium-208 @583 } \\
\text { Thallium-208 @860 } \\
\text { Thorium-234 @63.3 } \\
\text { Thorium-234 @92.6 } \\
\text { Uranium-235 @143.8 }\end{array}$ & $\begin{array}{l}\text { gamma } \\
\text { gamma } \\
\text { gamma } \\
\text { gamma } \\
\text { gamma } \\
\text { gamma } \\
\text { gamma } \\
\text { gamma } \\
\text { gamma } \\
\text { gamma } \\
\text { gamma } \\
\text { gamma } \\
\text { gamma } \\
\text { gamma } \\
\text { gamma } \\
\text { gamma } \\
\text { gamma } \\
\text { gamma }\end{array}$ & $\begin{array}{l}\mathrm{pCi} g \\
\mathrm{pCi} / \mathrm{g} \\
\mathrm{pCi} / \mathrm{g} \\
\mathrm{pCi} / \mathrm{g} \\
\mathrm{pCi} / \mathrm{g} \\
\mathrm{pCi} / \mathrm{g} \\
\mathrm{pCi} / \mathrm{g} \\
\mathrm{pCi} / \mathrm{g} \\
\mathrm{pCi} / \mathrm{g} \\
\mathrm{pCi} / \mathrm{g} \\
\mathrm{pCi} / \mathrm{g} \\
\mathrm{pCi} / \mathrm{g} \\
\mathrm{pCi} / \mathrm{g} \\
\mathrm{pCi} / \mathrm{g} \\
\mathrm{pCi} / \mathrm{g} \\
\mathrm{pCi} / \mathrm{g} \\
\mathrm{pCi} / \mathrm{g} \\
\mathrm{pCi} / \mathrm{g}\end{array}$ & $\begin{array}{r}1.20 \\
1.10 \\
1.10 \\
1.50 \\
1.70 \\
1.60 \\
1.90 \\
11.0 \\
6.40 \\
1.00 \\
1.90 \\
2.00 \\
3.10 \\
0.360 \\
0.280 \\
2.20 \\
0.550 \\
0.190\end{array}$ & & $\begin{array}{r}1.10 \\
0.890 \\
1.30 \\
1.40 \\
1.60 \\
1.70 \\
1.80 \\
11.0 \\
0.690 \\
0.970 \\
1.80 \\
1.80 \\
2.50 \\
0.310 \\
0.220 \\
0.860 \\
1.10 \\
0.150\end{array}$ & & $\begin{array}{r}1.20 \\
0.970 \\
0.850 \\
0.940 \\
2.00 \\
1.60 \\
1.70 \\
10.0 \\
7.30 \\
0.940 \\
1.60 \\
1.80 \\
2.20 \\
0.420 \\
0.330 \\
1.60 \\
0.440 \\
0.140\end{array}$ & \\
\hline
\end{tabular}




\section{Analytical Data Used In Calculations}

Stream: ESP Ash Collection Method: Grab Composite Sample Type: Fly Ash -FD

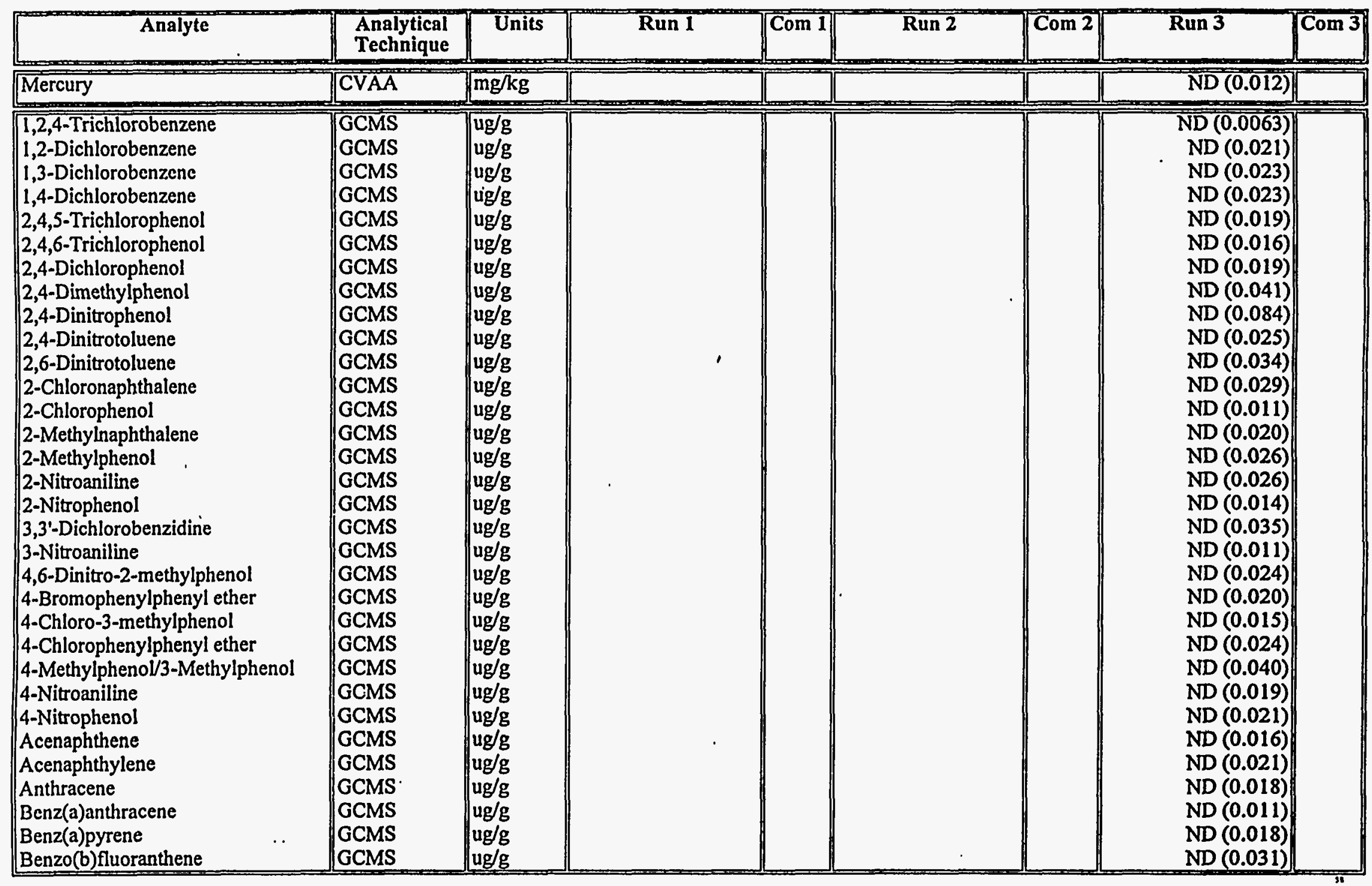


Stream: ESP Ash Collection Method: Grab Composite Sample Type: Fly Ash FD

\begin{tabular}{|c|c|c|c|c|c|c|c|c|}
\hline Analyte & $\begin{array}{l}\text { Analytical } \\
\text { Technique }\end{array}$ & Units & Run 1 & Com 1 & Run 2 & Com 2 & Run 3 & Com 3 \\
\hline \begin{tabular}{|l} 
Benzo(g,h,i)perylene \\
Benzo(k)fluoranthene \\
Benzoic acid \\
Benzyl alcohol \\
Butylbenzylphthalate \\
Chrysene \\
Di-n-butylphthalate \\
Di-n-octylphthalate \\
Dibenz(a,h)anthracene \\
Dibenzofuran \\
Diethylphthalate \\
Dimethylphthalate \\
Diphenylamine/N-NitrosoDPA \\
Fluoranthene \\
Fluorene \\
Hexachlorobenzene \\
Hexachlorobutadiene \\
Hexachlorocyclopentadiene \\
Hexachloroethane \\
Indeno(1,2,3-cd)pyrene \\
Isophorone \\
N-Nitroso-di-n-propylamine \\
Naphthalene \\
Nitrobenzene \\
Pentachlorophenol \\
Phenanthrene \\
Phenol \\
Pyrene \\
bis(2-Chloroethoxy)methane \\
bis(2-Chloroethyl)ether \\
bis(2-Chloroisopropyl)ether \\
bis(2-Ethylhexyl)phthalate \\
p-Chloroaniline
\end{tabular} & \begin{tabular}{|l} 
GCMS \\
GCMS \\
GCMS \\
GCMS \\
GCMS \\
GCMS \\
GCMS \\
GCMS \\
GCMS \\
GCMS \\
GCMS \\
GCMS \\
GCMS \\
GCMS \\
GCMS \\
GCMS \\
GCMS \\
GCMS \\
GCMS \\
GCMS \\
GCMS \\
GCMS \\
GCMS \\
GCMS \\
GCMS \\
GCMS \\
GCMS \\
GCMS \\
GCMS \\
GCMS \\
GCMS \\
GCMS \\
GCMS
\end{tabular} & $\begin{array}{l}\mathrm{ug} / \mathrm{g} \\
\mathrm{ug} / \mathrm{g} \\
\mathrm{ug} / \mathrm{g} \\
\mathrm{ug} / \mathrm{g} \\
\mathrm{ug} / \mathrm{g} \\
\mathrm{ug} / \mathrm{g} \\
\mathrm{ug} / \mathrm{g} \\
\mathrm{ug} / \mathrm{g} \\
\mathrm{ug} / \mathrm{g} \\
\mathrm{ug} / \mathrm{g} \\
\mathrm{ug} / \mathrm{g} \\
\mathrm{ug} / \mathrm{g} \\
\mathrm{ug} / \mathrm{g} \\
\mathrm{ug} / \mathrm{g} \\
\mathrm{ug} / \mathrm{g} \\
\mathrm{ug} / \mathrm{g} \\
\mathrm{ug} / \mathrm{g} \\
\mathrm{ug} / \mathrm{g} \\
\mathrm{ug} / \mathrm{g} \\
\mathrm{ug} / \mathrm{g} \\
\mathrm{ug} / \mathrm{g} \\
\mathrm{ug} / \mathrm{g} \\
\mathrm{ug} / \mathrm{g} \\
\mathrm{ug} / \mathrm{g} \\
\mathrm{ug} / \mathrm{g} \\
\mathrm{ug} / \mathrm{g} \\
\mathrm{ug} / \mathrm{g} \\
\mathrm{ug} / \mathrm{g} \\
\mathrm{ug} / \mathrm{g} \\
\mathrm{ug} / \mathrm{g} \\
\mathrm{ug} / \mathrm{g} \\
\mathrm{ug} / \mathrm{g} \\
\mathrm{ug} / \mathrm{g}\end{array}$ & & & & & \begin{tabular}{r|} 
ND $(0.018)$ \\
ND (0.027) \\
ND (0.097) \\
ND (0.047) \\
ND (0.025) \\
ND (0.019) \\
ND (0.010) \\
ND (0.019) \\
ND (0.022) \\
ND (0.013) \\
ND (0.012) \\
ND (0.015) \\
ND (0.025) \\
ND (0.014) \\
ND (0.011) \\
ND (0.017) \\
ND (0.021) \\
ND (0.053) \\
ND (0.033) \\
ND (0.016) \\
ND (0.0098) \\
ND (0.026) \\
ND (0.022) \\
ND (0.013) \\
ND (0.0063) \\
ND (0.018) \\
ND (0.033) \\
ND (0.015) \\
ND (0.011) \\
ND (0.015) \\
ND (0.019) \\
0.632 \\
ND (0.032)
\end{tabular} & \\
\hline
\end{tabular}




\section{Analytical Data Used In Calculations}

Stream: ESP Ash Collection Method: Grab Composite Sample Type: Fly Ash FD

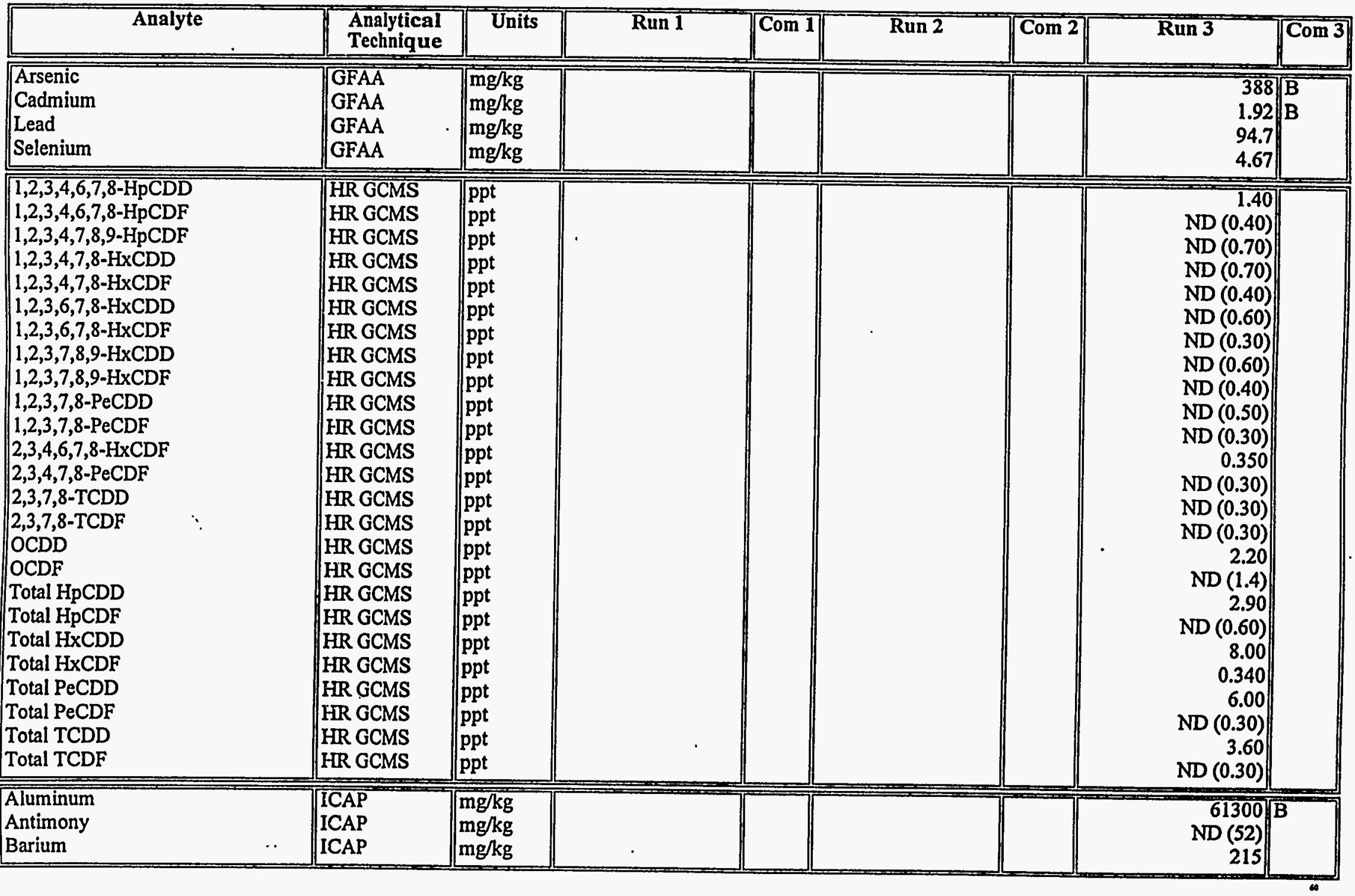




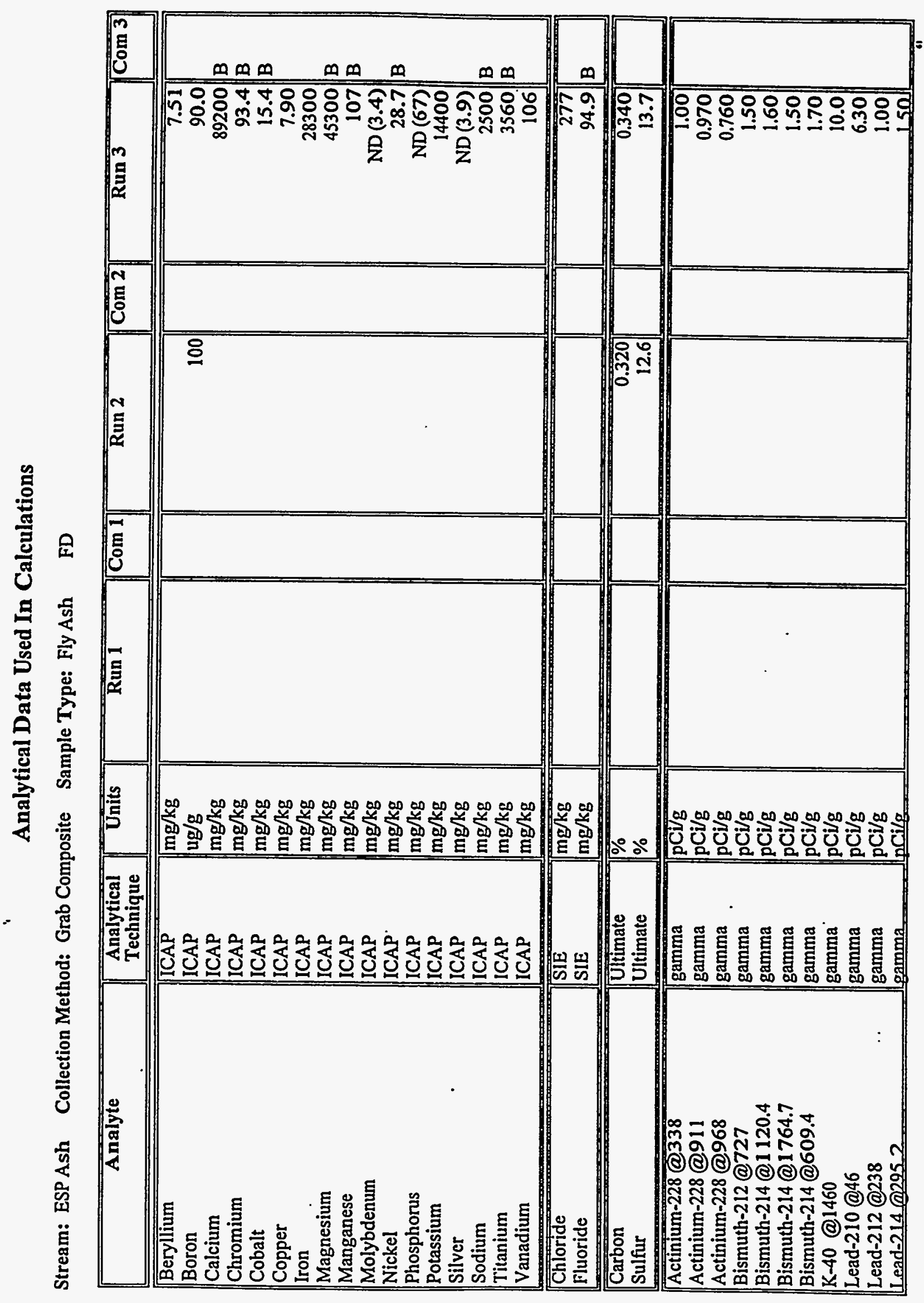




\section{Analytical Data Used In Calculations}

Stream: ESP Ash Collection Method: Grab Composite Sample Type: Fly Ash FD

\begin{tabular}{|c|c|c|c|c|c|c|c|c|}
\hline Analyte & $\begin{array}{l}\text { Analytical } \\
\text { Technique }\end{array}$ & Units & Run 1 & Com 1 & Run 2 & Com 2 & Run 3 & $\operatorname{Com} 3$ \\
\hline $\begin{array}{l}\text { Lead-214@352.0 } \\
\text { Radium-226@186.0 } \\
\text { Thallium-208@583 } \\
\text { Thallium-208 @860 } \\
\text { Thorium-234 @63.3 } \\
\text { Thorium-234 @92.6 } \\
\text { Uranium-235 @143.8 }\end{array}$ & $\begin{array}{l}\text { gamma } \\
\text { gamma } \\
\text { gamma } \\
\text { gamma } \\
\text { gamma } \\
\text { gamma } \\
\text { gamma }\end{array}$ & $\begin{array}{l}\mathrm{pCi} / g \\
\mathrm{pCi} / g \\
\mathrm{pCi} / g \\
\mathrm{pCi} / g \\
\mathrm{pCi} / \mathrm{g} \\
\mathrm{pCi} / \mathrm{g} \\
\mathrm{pCi} / \mathrm{g}\end{array}$ & & & & & \begin{tabular}{r|}
1.80 \\
2.40 \\
0.330 \\
0.380 \\
1.20 \\
1.30 \\
0.150
\end{tabular} & \\
\hline
\end{tabular}

Stream: ESP Inle Collection Method: Ammonia/Cyanide Sample Type: Ammonia Impinger

\begin{tabular}{|l|c|c|c|c|c|c|c|}
\hline Analyte & $\begin{array}{l}\text { Analytical } \\
\text { Technique }\end{array}$ & Units & Run 1 & Com 1 & Run 2 & Com 2 & Run 3 \\
\hline Ammonia - Distiled & Cistil & ug/Nm3 & & Com 3 \\
\hline
\end{tabular}

Stream: ESP Inle Collection Method:Ammonia/Cyanide Sample Type: Impingers

\begin{tabular}{|l|l|l|l|l|l|l|l|}
\hline & $\begin{array}{l}\text { Analytical } \\
\text { Technique }\end{array}$ & Units & Run 1 & Com 1 & Run 2 & Com 2 & Run 3 \\
\hline Cyanide & Com 3 & \\
\hline
\end{tabular}

Stream: ESP Inlet Collection Method: Anions Train Sample Type: Impingers + TLR

\begin{tabular}{|c|c|c|c|c|c|c|c|c|}
\hline Analyte & $\begin{array}{l}\text { Analytical } \\
\text { Technique }\end{array}$ & Units & Run 1 & Com 1 & Run 2 & $\longdiv { \operatorname { C o m } 2 }$ & Run 3 & $\longdiv { \operatorname { C o m } 3 }$ \\
\hline $\begin{array}{l}\text { Chloride } \\
\text { Sulfate }\end{array}$ & IC & $\begin{array}{l}\mathrm{ug} / \mathrm{Nm} 3 \\
\mathrm{ug} / \mathrm{Nm} 3\end{array}$ & $\begin{array}{r}68300 \\
795000 \\
\end{array}$ & & $\begin{array}{r}67300 \\
756000\end{array}$ & & $\begin{array}{r}73600 \\
784000\end{array}$ & \\
\hline Fluoride & SIE & $\mathrm{ug} / \mathrm{Nm} 3$ & .7000 & B & 6340 & & 6360 & B \\
\hline
\end{tabular}


Stream: ESP Inlet Collection Method: Anions/Ammonia/Cyanide/Aldehydes Sample Type: M5 Filter + Solids

\begin{tabular}{|c|c|c|c|c|c|c|c|c|}
\hline Analyte & $\begin{array}{l}\text { Analytical } \\
\text { Technique }\end{array}$ & Units & Run 1 & Com 1 & Run 2 & Com 2 & Run 3 & Com 3 \\
\hline $\begin{array}{l}\text { Chloride } \\
\text { Chloride } \\
\text { Sulfate } \\
\text { Sulfate } \\
\end{array}$ & 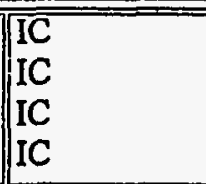 & $\begin{array}{l}\mathrm{ug} / \mathrm{Nm} 3 \\
\mathrm{ug} / \mathrm{g} \\
\mathrm{ug} / \mathrm{Nm} 3 \\
\mathrm{ug} / \mathrm{g}\end{array}$ & $\begin{array}{r}1560 \\
852 \\
9440000 \\
5160000\end{array}$ & & $\begin{array}{r}1790 \\
1020 \\
9150000 \\
5210000\end{array}$ & & $\begin{array}{r}861 \\
481 \\
9260000 \\
5180000\end{array}$ & \\
\hline $\begin{array}{l}\text { Fluoride } \\
\text { Fluoride }\end{array}$ & $\begin{array}{l}\text { SIE } \\
\text { SIE }\end{array}$ & $\begin{array}{l}\mathrm{ug} / \mathrm{Nm} 3 \\
\mathrm{ug} / \mathrm{g}\end{array}$ & $\begin{array}{l}4100 \\
2240\end{array}$ & C & $\begin{array}{l}3170 \\
1800\end{array}$ & $\begin{array}{l}\text { C } \\
C\end{array}$ & $\begin{array}{l}2330 \\
1300\end{array}$ & C \\
\hline
\end{tabular}

Stream: ESP Inlet Collection Method: M0011a Sample Type: Impingers + $\mathrm{MeCl} 2$

\begin{tabular}{|c|c|c|c|c|c|c|c|c|}
\hline Analyte & $\begin{array}{l}\text { Analytical } \\
\text { Technique }\end{array}$ & Units & Run 1 & Com 1 & Run 2 & Com 2 & Run 3 & Com 3 \\
\hline Formaldehyde & HPLC & ug/Nm3 & $\overline{8.74}$ & & 4.48 & & 3.03 & \\
\hline
\end{tabular}

Stream: ESP Inlet Collection Method: MM5 Sample Type: MeCl2 PNR/MM5 Filter

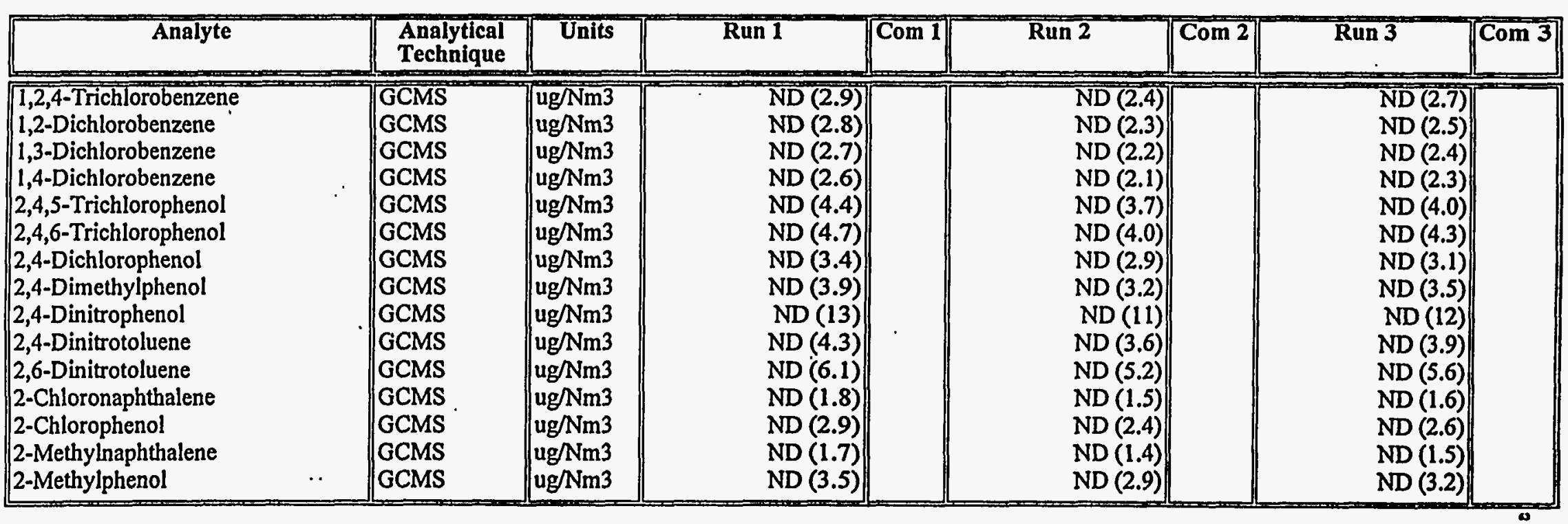


Analytical Data Used In Calculations

Stream: ESP Inlet Collection Method: MM5 Sample Type: MeCl2 PNR/MM5 Filter

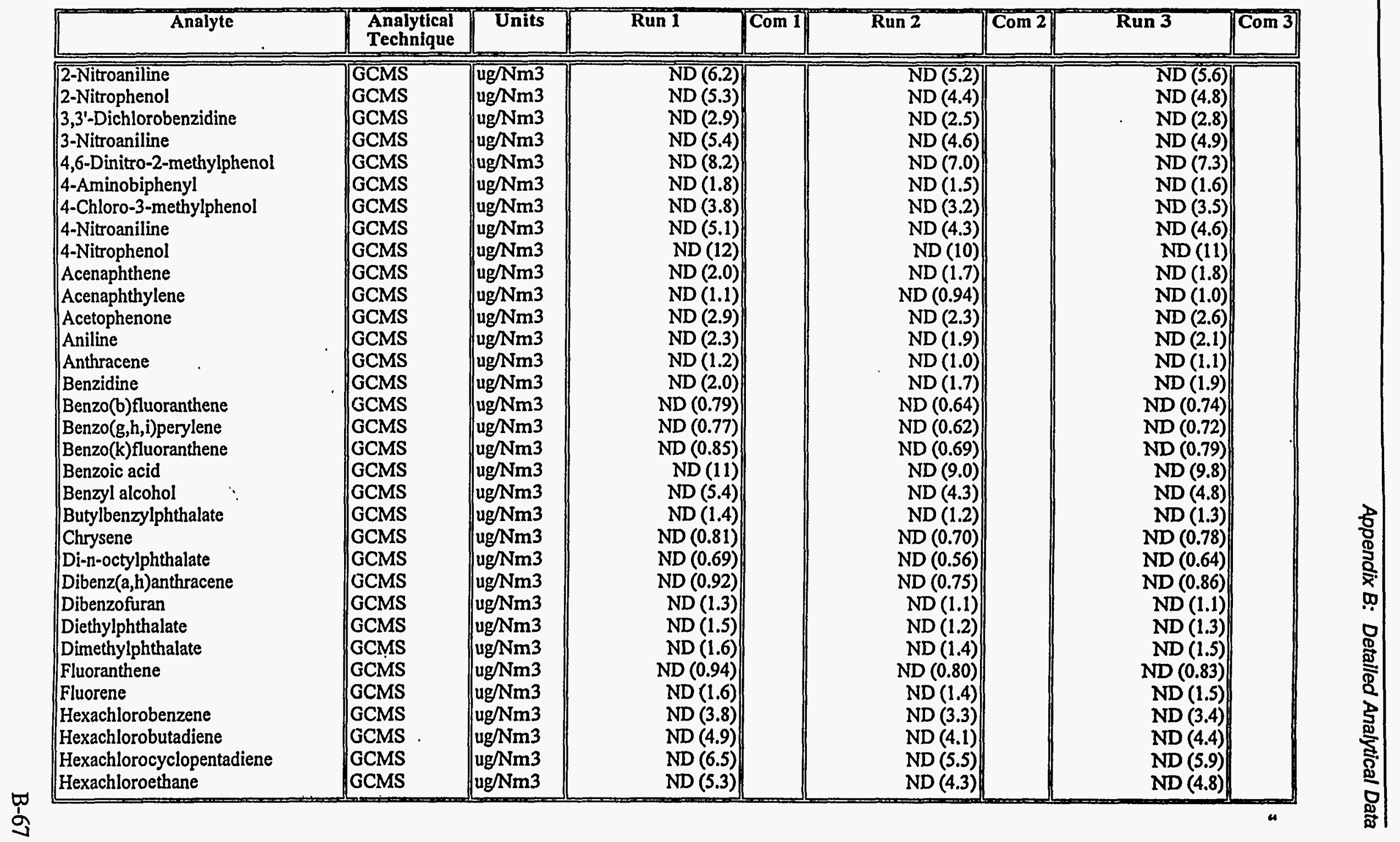


Stream: ESP Inlet Collection Method: MM5 Sample Type: MeCl2 PNR/MM5 Filter

\begin{tabular}{|c|c|c|c|c|c|c|c|c|}
\hline Analyte & $\begin{array}{l}\text { Analytical } \\
\text { Technique }\end{array}$ & Units & Run 1 & Com 1 & Run 2 & Com 2 & Run 3 & Com 3 \\
\hline $\begin{array}{l}\text { Indeno(1,2,3-cd)pyrene } \\
\text { Isophorone } \\
\text { N-Nitroso-di-n-propylamine } \\
\text { Naphthalene } \\
\text { Nitrobenzene } \\
\text { Pentachloronitrobenzene } \\
\text { Pentachlorophenol } \\
\text { Phenanthrene } \\
\text { Phenol } \\
\text { Pyrene } \\
\text { bis(2-Chloroethoxy)methane } \\
\text { bis(2-Chloroethyl)ether } \\
\text { bis(2-Ethylhexyl)phthalate }\end{array}$ & $\begin{array}{l}\text { GCMS } \\
\text { GCMS } \\
\text { GCMS } \\
\text { GCMS } \\
\text { GCMS } \\
\text { GCMS } \\
\text { GCMS } \\
\text { GCMS } \\
\text { GCMS } \\
\text { GCMS } \\
\text { GCMS } \\
\text { GCMS } \\
\text { GCMS }\end{array}$ & $\begin{array}{l}\text { ug/Nm3 } \\
\mathrm{ug} / \mathrm{Nm} 3 \\
\mathrm{ug} / \mathrm{Nm} 3 \\
\mathrm{ug} / \mathrm{Nm} 3 \\
\mathrm{ug} / \mathrm{Nm} 3 \\
\mathrm{ug} / \mathrm{Nm} 3 \\
\mathrm{ug} / \mathrm{Nm} 3 \\
\mathrm{ug} / \mathrm{Nm} 3 \\
\mathrm{ug} / \mathrm{Nm} 3 \\
\mathrm{ug} / \mathrm{Nm} 3 \\
\mathrm{ug} / \mathrm{Nm} 3 \\
\mathrm{ug} / \mathrm{Nm} 3 \\
\mathrm{ug} / \mathrm{Nm} 3\end{array}$ & $\begin{array}{r}\mathrm{ND}(0.69) \\
\mathrm{ND}(1.7) \\
\mathrm{ND}(5.3) \\
5.34 \\
\mathrm{ND}(3.0) \\
\mathrm{ND}(17) \\
\mathrm{ND}(8.7) \\
\mathrm{ND}(1.2) \\
\mathrm{ND}(2.4) \\
\mathrm{ND}(0.69) \\
\mathrm{ND}(2.6) \\
\mathrm{ND}(3.2) \\
8.54\end{array}$ & B & $\begin{array}{r}\mathrm{ND}(0.56) \\
\mathrm{ND}(1.5) \\
\mathrm{ND}(4.3) \\
\mathrm{ND}(0.92) \\
\mathrm{ND}(2.5) \\
\mathrm{ND}(15) \\
\mathrm{ND}(7.4) \\
\mathrm{ND}(1.0) \\
\mathrm{ND}(2.0) \\
\mathrm{ND}(0.60) \\
\mathrm{ND}(2.2) \\
\mathrm{ND}(2.6) \\
4.68\end{array}$ & |BJ & $\begin{array}{r}\mathrm{ND}(0.64) \\
\mathrm{ND}(1.6) \\
\mathrm{ND}(4.8) \\
\mathrm{ND}(1.0) \\
\mathrm{ND}(2.7) \\
\mathrm{ND}(15) \\
\mathrm{ND}(7.7) \\
\mathrm{ND}(1.0) \\
\mathrm{ND}(2.2) \\
\mathrm{ND}(0.67) \\
\mathrm{ND}(2.4) \\
\mathrm{ND}(2.8) \\
5.46\end{array}$ & BJ \\
\hline
\end{tabular}

Stream: ESP Inlet Collection Method: MM5 Sample Type: MeCl2 PNR/MM5 Filter 1:2 dil

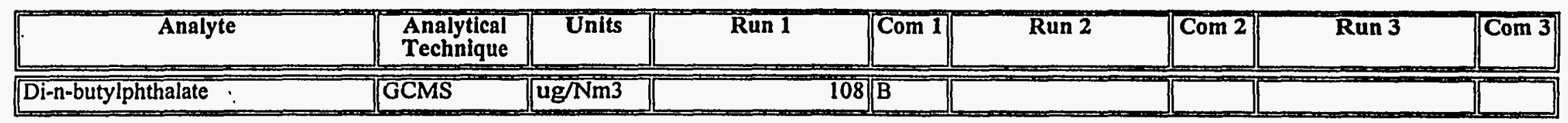

Stream: ESP Inlet Collection Method: MM5 Sample Type: $\mathrm{XAD}$ Resin/Impingers $+\mathrm{MeCl} 2$

\begin{tabular}{|c|c|c|c|c|c|c|c|c|}
\hline Analyte & $\begin{array}{l}\text { Analytical } \\
\text { Technique }\end{array}$ & Units & Run 1 & Com I & Run 2 & Com 2 & Run 3 & Com 3 \\
\hline $\begin{array}{l}\text { 1,2,4-Trichlorobenzenc } \\
\text { 1,2-Dichlorobenzene } \\
\text { 1,3-Dichlorobenzene } \\
\text { 1,4-Dichlorobenzene } \\
\text { 2,4,5-Trichlorophenol } \\
\text { 2,4,6-Trichlorophenol } \\
\text { 2,4-Dichlorophenol } \\
\text { 2,4-Dimethylphenol } \\
\text { 2,4-Dinitrophenol } \\
\end{array}$ & $\begin{array}{l}\text { GCMS } \\
\text { GCMS } \\
\text { GCMS } \\
\text { GCMS } \\
\text { GCMS } \\
\text { GCMS } \\
\text { GCMS } \\
\text { GCMS } \\
\text { GCMS }\end{array}$ & $\begin{array}{l}u g / N m 3 \\
u g / N m 3 \\
u g / N m 3 \\
u g / N m 3 \\
u g / N m 3 \\
u g / N m 3 \\
u g / N m 3 \\
u g / N m 3 \\
u g / N m 3\end{array}$ & $\begin{array}{r}\text { ND (0.90) } \\
\text { ND (0.78) } \\
\text { ND (0.73) } \\
\text { ND (0.72) } \\
N D(1.1) \\
N D(1.2) \\
N D(0.49) \\
N D(0.83) \\
N D(2.7) \\
\end{array}$ & & $\begin{array}{r}\mathrm{ND}(0.98) \\
\text { ND }(0.86) \\
\mathrm{ND}(0.81) \\
\mathrm{ND}(0.79) \\
\mathrm{ND}(1.1) \\
\mathrm{ND}(1.2) \\
\mathrm{ND}(0.53) \\
\mathrm{ND}(0.90) \\
\mathrm{ND}(2.8) \\
\end{array}$ & & $\begin{array}{r}\mathrm{ND}(1.0) \\
\mathrm{ND}(0.91) \\
\mathrm{ND}(0.85) \\
\mathrm{ND}(0.83) \\
\mathrm{ND}(1.3) \\
\mathrm{ND}(1.4) \\
\mathrm{ND}(0.56) \\
\mathrm{ND}(0.95) \\
\mathrm{ND}(3.2)\end{array}$ & \\
\hline
\end{tabular}


Analytical Data Used In Calculations

Stream: ESP Inlet Collection Method: MM5 Sample Type: XAD Resin/Impingers + MeCl2

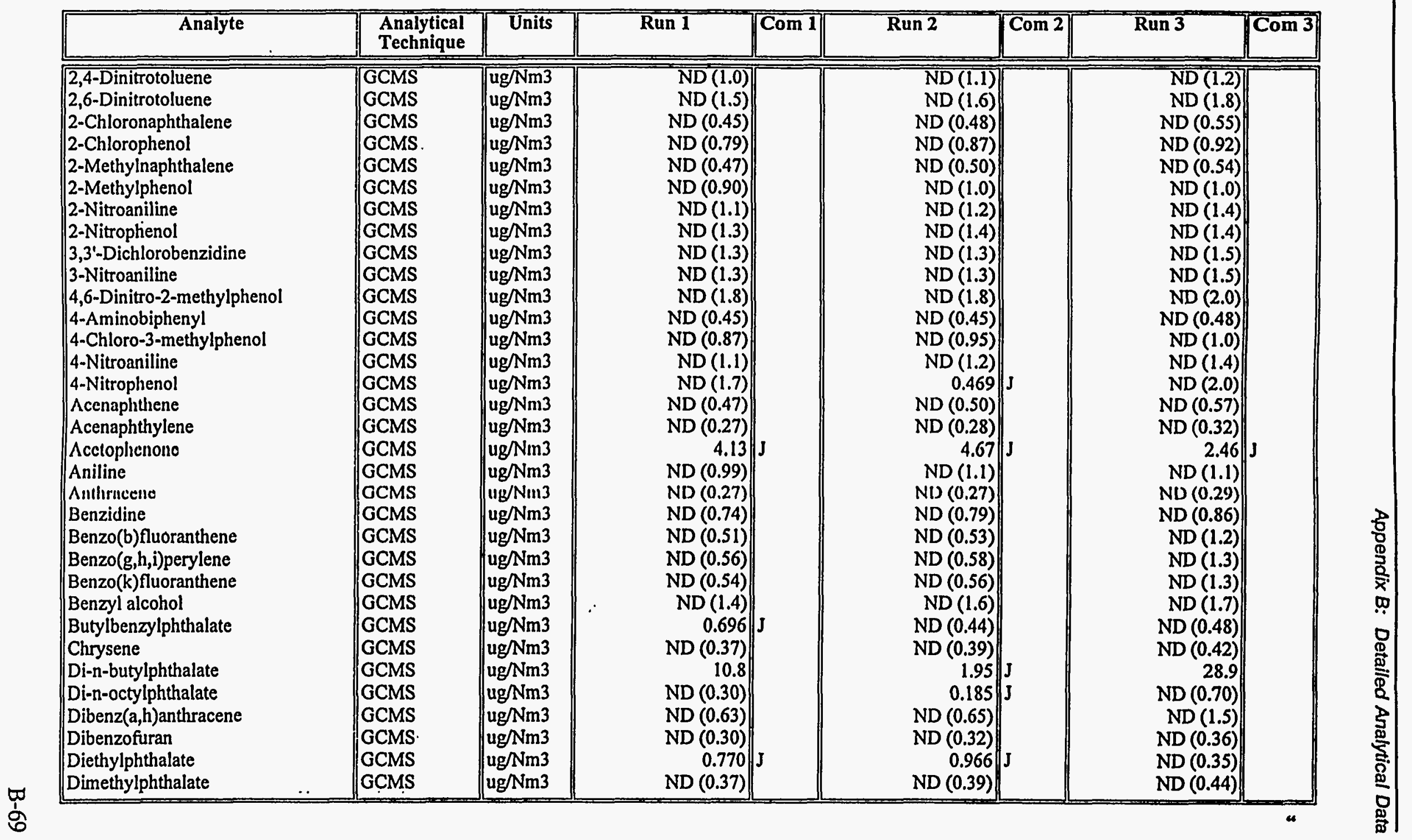


Stream: ESP Inlet Collection Method: MM5 Sample Type: XAD Resin/Impingers + MeCl2

\begin{tabular}{|c|c|c|c|c|c|c|c|c|}
\hline Analyte & $\begin{array}{l}\text { Analytical } \\
\text { Technique }\end{array}$ & Units & Run 1 & Com 1 & Run 2 & Com 2 & Run 3 & $\longdiv { \operatorname { C o m } 3 }$ \\
\hline \begin{tabular}{||l} 
Fluoranthene \\
Fluorene \\
Hexachlorobenzene \\
Hexachlorobutadiene \\
Hexachlorocyclopentadiene \\
Hexachloroethane \\
Indeno(1,2,3-cd)pyrene \\
Isophorone \\
N-Nitroso-di-n-propylamine \\
Naphthalene \\
Nitrobenzene \\
Pentachloronitrobenzene \\
Pentachlorophenol \\
Phenanthrene \\
Phenol \\
Pyrenc \\
bis(2-Chloroethoxy)methane \\
bis(2-Chloroethyl)ether
\end{tabular} & $\begin{array}{l}\text { GCMS } \\
\text { GCMS } \\
\text { GCMS } \\
\text { GCMS } \\
\text { GCMS } \\
\text { GCMS } \\
\text { GCMS } \\
\text { GCMS } \\
\text { GCMS } \\
\text { GCMS } \\
\text { GCMS } \\
\text { GCMS } \\
\text { GCMS } \\
\text { GCMS } \\
\text { GCMS } \\
\text { GCMS } \\
\text { GCMS } \\
\text { GCMS } \\
\end{array}$ & $\begin{array}{l}\text { ug/Nm3 } \\
\text { ug/Nm3 } \\
\text { ug/Nm3 } \\
\text { ug/Nm3 } \\
\text { ug } / \mathrm{Nm} 3 \\
\text { ug } / \mathrm{Nm} 3 \\
\text { ug/Nm3 } \\
\text { ug/Nm3 } \\
\text { ug/Nm3 } / \mathrm{Nm} \\
\text { ug/Nm3 } \\
\mathrm{ug} / \mathrm{Nm} 3 \\
\mathrm{ug} / \mathrm{Nm} 3 \\
\mathrm{ug} / \mathrm{Nm} 3 \\
\mathrm{ug} / \mathrm{Nm} 3 \\
\mathrm{ug} / \mathrm{Nm} 3 \\
\mathrm{ug} / \mathrm{Nm} 3 \\
\mathrm{ug} / \mathrm{Nm} 3 \\
\mathrm{ug} / \mathrm{Nm} 3\end{array}$ & \begin{tabular}{r|}
$\mathrm{ND}(0.26)$ \\
$\mathrm{ND}(0.37)$ \\
33.8 \\
$\mathrm{ND}(1.5)$ \\
$\mathrm{ND}(1.3)$ \\
$\mathrm{ND}(1.5)$ \\
$\mathrm{ND}(0.49)$ \\
$\mathrm{ND}(0.39)$ \\
$\mathrm{ND}(1.1)$ \\
0.668 \\
$\mathrm{ND}(0.68)$ \\
$\mathrm{ND}(2.7)$ \\
$\mathrm{ND}(2.7)$ \\
$\mathrm{ND}(0.27)$ \\
2.80 \\
$\mathrm{ND}(0.23)$ \\
$\mathrm{ND}(0.72)$ \\
$\mathrm{ND}(0.92)$ \\
\end{tabular} & BJ & $\begin{array}{r}\mathrm{ND}(0.26) \\
\mathrm{ND}(0.39) \\
\mathrm{ND}(1.3) \\
\mathrm{ND}(1.6) \\
\mathrm{ND}(1.4) \\
\mathrm{ND}(1.7) \\
\mathrm{ND}(0.50) \\
6.82 \\
\mathrm{ND}(1.3) \\
0.729 \\
\mathrm{ND}(0.73) \\
\mathrm{ND}(2.7) \\
\mathrm{ND}(2.7) \\
\mathrm{ND}(0.27) \\
3.00 \\
\mathrm{ND}(0.24) \\
\mathrm{ND}(0.78) \\
\mathrm{ND}(1.0)\end{array}$ & BJ & $\begin{array}{r}\mathrm{ND}(0.28) \\
\mathrm{ND}(0.44) \\
\mathrm{ND}(1.4) \\
\mathrm{ND}(1.7) \\
\mathrm{ND}(1.6) \\
\mathrm{ND}(1.7) \\
\mathrm{ND}(1.1) \\
11.2 \\
\mathrm{ND}(1.3) \\
\mathrm{ND}(0.34) \\
\mathrm{ND}(0.78) \\
\mathrm{ND}(2.9) \\
\mathrm{ND}(2.9) \\
\mathrm{ND}(0.29) \\
1.66 \\
\mathrm{ND}(0.26) \\
\mathrm{ND}(0.82) \\
\mathrm{ND}(1.1)\end{array}$ & $\mathbf{J}$ \\
\hline
\end{tabular}

Stresun: ESp Inlet Collection Melhod: MMS Sample Type: XAD Resin/lmpingers + MeCl2 1:10 dil

\begin{tabular}{|c|c|c|c|c|c|c|c|c|}
\hline Analytc & $\begin{array}{l}\text { Analytical } \\
\text { Teclinique }\end{array}$ & Units & Run 1 & Com 1 & Run 2 & Com 2 & Run 3 & $\operatorname{Com} 3$ \\
\hline $\begin{array}{l}\text { Benzoic acid } \\
\text { bis(2-Ethylhexyl)phthalate }\end{array}$ & $\begin{array}{l}\text { GCMS } \\
\text { GCMS }\end{array}$ & $\begin{array}{l}\text { ug/Nm3 } \\
\text { ug/Nm3 }\end{array}$ & $\begin{array}{r}89.3 \\
467\end{array}$ & $\bar{J}$ & & & & \\
\hline
\end{tabular}

Stream: ESP Inlet Collection Method: MM5 Sample Type: XAD Resin/lmpingers + MeCl2 1:2 dil

\begin{tabular}{|l|l|l|l|l|l|l|l|l|}
\hline Analyte & $\begin{array}{l}\text { Analytical } \\
\text { Technique }\end{array}$ & Units & Run 1 & Com 1 & Run 2 & Com 2 & Run 3 & Com 33 \\
\hline Benzoic acid & GCMS & ug/ $/ \mathrm{Nm3}^{2}$ & & \\
\hline
\end{tabular}




\section{Analytical Data Used In Calculations}

Stream: ESP Inlet Collection Method: MM5 Sample Type: XAD Resin/Impingers + MeCl2 1:4 dil

\begin{tabular}{|c|c|c|c|c|c|c|c|c|}
\hline Analyte & $\begin{array}{l}\text { Analytical } \\
\text { Technique }\end{array}$ & Units & Run 1 & Com 1 & Run 2 & Com 2 & Run 3 & Com 3 \\
\hline Benzoic acid & $\overline{\mathrm{GCMS}}$ & $\mathrm{ug} / \mathrm{Nm} 3$ & & & $\overline{216}$ & & & \\
\hline
\end{tabular}

Stream: ESP Inlet Collection Method: Multimetals Train Sample Type: Mercury Impingers

\begin{tabular}{|l|c|c|c|c|c|c|c|c|}
\hline & Analytical \\
\hline Analyte & Units & Run 1 & Com 1 & Run 2 & Com 2 & Run 3 & Com 3 \\
\hline \hline Mercury & CVAA & ug/Nm3 & & 3.40 & & & \\
\hline
\end{tabular}

Stream: ESP Inle Collection Method: Multimetals Trai Sample Type: Nitric Acid Impingers + TL

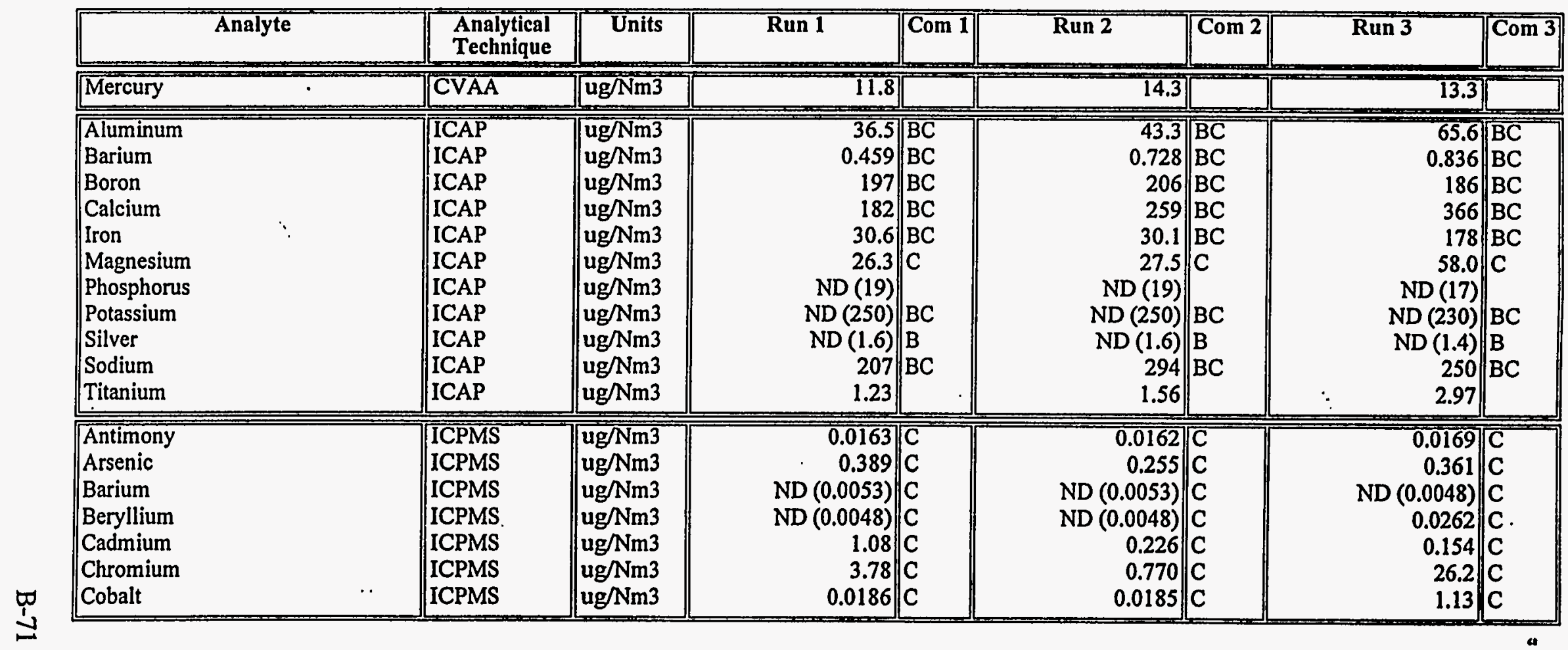


Stream: ESP Inlet Collection Method: Multimetals Train Sample Type: Nitric Acid Impingers + TLR

\begin{tabular}{|c|c|c|c|c|c|c|c|c|}
\hline Analyte & $\begin{array}{l}\text { Analytical } \\
\text { Technique }\end{array}$ & Units & Run 1 & Com 1 & Run 2 & $\longdiv { \mathrm { Com } 2 }$ & Run 3 & $\longdiv { \mathrm { Com } 3 }$ \\
\hline $\begin{array}{l}\text { Copper } \\
\text { Lead } \\
\text { Manganese } \\
\text { Molybdenum } \\
\text { Nickel } \\
\text { Selenium } \\
\text { Vanadium } \\
\end{array}$ & $\begin{array}{l}\text { ICPMS } \\
\text { ICPMS } \\
\text { ICPMS } \\
\text { ICPMS } \\
\text { ICPMS } \\
\text { ICPMS } \\
\text { ICPMS } \\
\end{array}$ & $\begin{array}{l}\mathrm{ug} / \mathrm{Nm}^{3} \\
\mathrm{ug} / \mathrm{Nm} 3 \\
\mathrm{ug} / \mathrm{Nm} 3 \\
\mathrm{ug} / \mathrm{Nm}^{3} 3 \\
\mathrm{ug} / \mathrm{Nm} 3 \\
\mathrm{ug} / \mathrm{Nm} 3 \\
\mathrm{ug} / \mathrm{Nm} 3\end{array}$ & $\begin{array}{r}0.630 \\
\mathrm{ND}(0.0051) \\
1.16 \\
0.143 \\
0.154 \\
20.2 \\
1.46\end{array}$ & $\mid \begin{array}{l}C \\
C \\
C \\
C \\
C\end{array}$ & $\begin{array}{rr}0.232 \\
\mathrm{ND}(0.0050) \\
1.18 \\
\mathrm{ND}(0.0078) \\
0.204 \\
13.9 \\
0.837\end{array}$ & $\begin{array}{l}\bar{C} \\
C \\
C \\
C \\
C\end{array}$ & $\begin{array}{r}2.38 \\
\mathrm{ND}(0.0046) \\
3.32 \\
3.32 \\
29.3 \\
17.5 \\
0.940\end{array}$ & $\begin{array}{l}C \\
C \\
C \\
C \\
C \\
C\end{array}$ \\
\hline
\end{tabular}

Stream: ESP Inlet Collection Method: PCDD/PCDF for Dioxins and Furans (M23) Sample Type: Filtered Solids/Solvent Rinses/XAD Resin

\begin{tabular}{|c|c|c|c|c|c|c|c|c|}
\hline Analyte & $\begin{array}{l}\text { Analytical } \\
\text { Technique }\end{array}$ & Units & Run 1 & Com 1 & $\overline{\text { Run 2 }}$ & Com 2 & Run 3 & Com 3 \\
\hline \begin{tabular}{|l}
$1234678-\mathrm{HpCDD}$ \\
$1234678-\mathrm{HpCDF}$ \\
$123478-\mathrm{HxCDD}$ \\
$123478-\mathrm{HxCDF}$ \\
$1234789-\mathrm{HpCDF}$ \\
$123678-\mathrm{HxCDD}$ \\
$123678-\mathrm{HxCDF}$ \\
$12378-\mathrm{PeCDD}$ \\
$12378-\mathrm{PeCDF}$ \\
$123789-\mathrm{HxCDD}$ \\
$123789-\mathrm{HxCDF}$ \\
$234678-\mathrm{HxCDF}$ \\
$23478-\mathrm{PeCDF}$ \\
$2378-\mathrm{TCDD}$ \\
$2378-\mathrm{TCDF}$ \\
OCDD \\
OCDF \\
TOTAL HpCDD \\
TOTAL HpCDF \\
TOTAL HxCDD \\
TOTAL HxCDF \\
\end{tabular} & $\begin{array}{l}\text { Meth 23X } \\
\text { Meth 23X } \\
\text { Meth 23X } \\
\text { Meth 23X } \\
\text { Meth 23X } \\
\text { Meth 23X } \\
\text { Meth 23X } \\
\text { Meth 23X } \\
\text { Meth 23X } \\
\text { Meth 23X } \\
\text { Meth 23X } \\
\text { Meth 23X } \\
\text { Meth 23X } \\
\text { Meth 23X } \\
\text { Meth 23X } \\
\text { Meth 23X } \\
\text { Meth 23X } \\
\text { Meth 23X } \\
\text { Meth 23X } \\
\text { Meth 23X } \\
\text { Meth 23X }\end{array}$ & 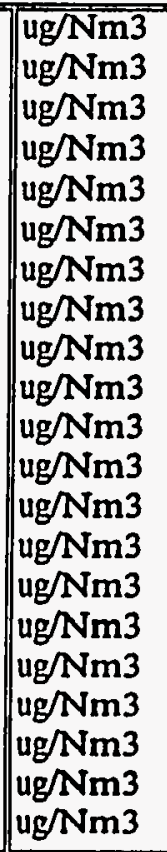 & \begin{tabular}{r|}
0.00000641 \\
0.00000200 \\
ND (0.0000044) \\
0.00000200 \\
ND (0.0000041) \\
ND (0.0000037) \\
ND (0.0000020) \\
ND (0.0000027) \\
ND (0.0000017) \\
ND (0.0000041) \\
ND (0.0000031) \\
0.00000295 \\
ND (0.0000017) \\
ND (0.0000015) \\
ND (0.0000015) \\
0.0000425 \\
0.00000519 \\
0.0000105 \\
0.00000258 \\
0.00000237 \\
0.00000634 \\
\end{tabular} & B & $\begin{array}{r}0.00000638 \\
0.000000490 \\
\text { ND (0.0000041) } \\
0.00000686 \\
\text { ND (0.0000045) } \\
\text { ND (0.0000034) } \\
0.00000220 \\
\text { ND (0.0000026) } \\
0.00000116 \\
\text { ND (0.0000037) } \\
\text { ND (0.000003) } \\
0.00000440 \\
\text { ND (0.0000015) } \\
\text { ND (0.0000017) } \\
\text { ND (0.0000017) } \\
0.0000565 \\
0.00000836 \\
0.00000638 \\
0.00000291 \\
0.00000201 . \\
0.00000720\end{array}$ & \begin{tabular}{|l}
$\mathrm{B}$ \\
$\mathrm{FF}$ \\
$\mathrm{F}$ \\
$\mathrm{BF}$
\end{tabular} & $\begin{array}{r}0.00000345 \\
0.00000179 \\
\text { ND }(0.0000027) \\
0.00000116 \\
\text { ND }(0.0000043) \\
\text { ND }(0.0000020) \\
\text { ND }(0.0000017) \\
\text { ND }(0.0000013) \\
\text { ND }(0.00000099) \\
\text { ND }(0.0000023) \\
\text { ND }(0.0000023) \\
0.00000394 \\
\text { ND }(0.00000099) \\
\text { ND }(0.0000013) \\
0.000000810 \\
0.0000340 \\
\text { ND }(0.0000043) \\
0.00000365 \\
0.00000441 \\
0.00000235 \\
0.00000507\end{array}$ & $\begin{array}{l}\mathrm{BF} \\
\mathrm{F} \\
\mathrm{BF}\end{array}$ \\
\hline
\end{tabular}




\section{Analytical Data Used In Calculations}

Stream: ESP Inlet Collection Method: PCDD/PCDF for Dioxins and Furans (M23) Sample Type: Filtered Solids/Solvent Rinses/XAD Resin

\begin{tabular}{|c|c|c|c|c|c|c|c|c|}
\hline Analyte & $\begin{array}{l}\text { Analytical } \\
\text { Technique }\end{array}$ & $\overline{\text { Units }}$ & Run 1 & Com 1 & Run 2 & Com 2 & Run 3 & $\sqrt{\mathrm{Com} 3}$ \\
\hline $\begin{array}{l}\text { TOTAL PeCDD } \\
\text { TOTAL PeCDF } \\
\text { TOTAL TCDD } \\
\text { TOTAL TCDF }\end{array}$ & $\begin{array}{l}\text { Meth 23X } \\
\text { Meth 23X } \\
\text { Meth 23X } \\
\text { Meth 23X }\end{array}$ & $\begin{array}{l}\mathrm{ug} / \mathrm{Nm} 3 \\
\mathrm{ug} / \mathrm{Nm} 3 \\
\mathrm{ug} / \mathrm{Nm} 3 \\
\mathrm{ug} / \mathrm{Nm} 3\end{array}$ & $\begin{array}{r}0.00000217 \\
0.00000217 \\
0.00000509 \\
\text { ND }(0.0000015)\end{array}$ & $\mathrm{F}$ & $\begin{array}{r}\mathrm{ND}(0.0000026) \\
0.00000537 \\
\mathrm{ND}(0.0000017) \\
\mathrm{ND}(0.0000017)\end{array}$ & & $\begin{array}{r}0.00000199 \\
0.00000103 \\
0.00000159 \\
0.000000810\end{array}$ & F \\
\hline
\end{tabular}

Stream: ESP Inlet Collection Method: VOST Sample Type: Tenax-Tenax + Charcoal A

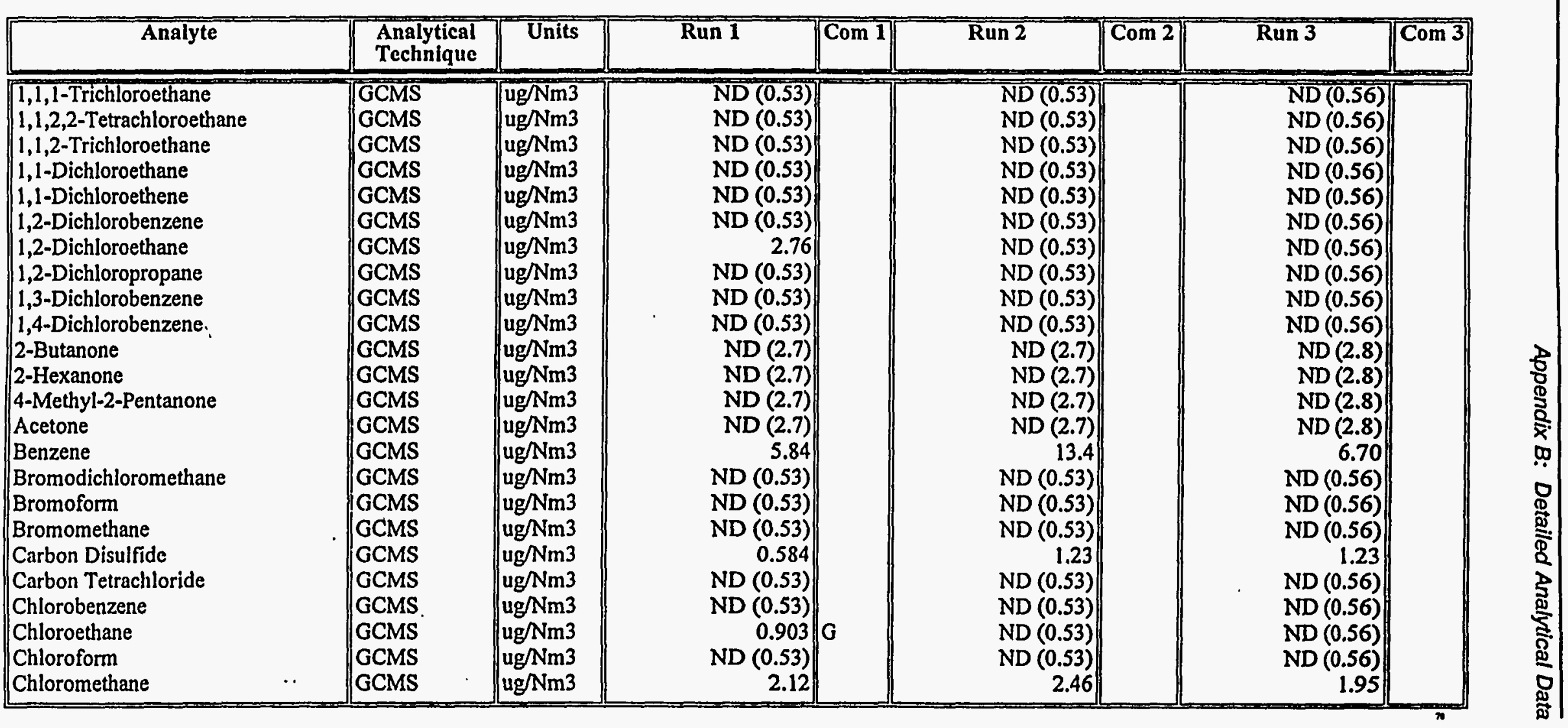


Stream: ESP Inlet Collection Method: VOST Sample Type: Tenax-Tenax + Charcoal A

\begin{tabular}{|c|c|c|c|c|c|c|c|c|}
\hline Analyte & $\begin{array}{l}\text { Analytical } \\
\text { Technique }\end{array}$ & Ünits & Run 1 & $\mathrm{Com} 1$ & Run 2 & Com 2 & Run 3 & Com 3 \\
\hline \begin{tabular}{|l} 
Dibromochloromethane \\
Ethyl Benzene \\
Methylene Chloride \\
Styrene \\
Tetrachloroethene \\
Toluene \\
Trichloroethene \\
Trichlorofluoromethane \\
Vinyl Acetate \\
Vinyl Chloride \\
cis-1,3-Dichloropropene \\
m,p-Xylene \\
o-Xylene \\
trans-1,2-Dichloroethene \\
trans-1,3-Dichloropropene
\end{tabular} & $\begin{array}{l}\text { GCMS } \\
\text { GCMS } \\
\text { GCMS } \\
\text { GCMS } \\
\text { GCMS } \\
\text { GCMS } \\
\text { GCMS } \\
\text { GCMS } \\
\text { GCMS } \\
\text { GCMS } \\
\text { GCMS } \\
\text { GCMS } \\
\text { GCMS } \\
\text { GCMS }\end{array}$ & $\begin{array}{l}\mathrm{ug} / \mathrm{Nm} 3 \\
\mathrm{ug} / \mathrm{Nm} 3 \\
\mathrm{ug} / \mathrm{Nm} 3 \\
\mathrm{ug} / \mathrm{Nm} 3 \\
\mathrm{ug} / \mathrm{Nm} 3 \\
\mathrm{ug} / \mathrm{Nm} 3 \\
\mathrm{ug} / \mathrm{Nm} 3 \\
\mathrm{ug} / \mathrm{Nm} 3 \\
\mathrm{ug} / \mathrm{Nm} 3 \\
\mathrm{ug} / \mathrm{Nm} 3 \\
\mathrm{ug} / \mathrm{Nm} 3 \\
\mathrm{ug} / \mathrm{Nm} 3 \\
\mathrm{ug} / \mathrm{Nm} 3 \\
\mathrm{ug} / \mathrm{Nm} 3 \\
\mathrm{ug} / \mathrm{Nm} 3\end{array}$ & $\begin{array}{r}\text { ND (0.53) } \\
\text { ND (0.53) } \\
0.531 \\
\text { ND (0.53) } \\
\text { ND (0.53) } \\
\text { ND (0.53) } \\
\text { ND (0.53) } \\
\text { ND (0.53) } \\
\text { ND (2.5) } \\
\text { ND (0.53) } \\
\text { ND (0.53) } \\
\text { ND (0.53) } \\
\text { ND (0.53) } \\
\text { ND (0.53) } \\
\text { ND (0.53) }\end{array}$ & & $\begin{array}{r}\text { ND (0.53) } \\
\text { ND (0.53) } \\
2.24 \\
\text { ND (0.53) } \\
\text { ND (0.53) } \\
1.60 \\
\text { ND (0.53) } \\
\text { ND (0.53) } \\
\text { ND (2.7) } \\
\text { ND (0.53) } \\
\text { ND (0.53) } \\
0.748 \\
\text { ND (0.53) } \\
\text { ND (0.53) } \\
\text { ND (0.53) }\end{array}$ & & \begin{tabular}{r|}
$\mathrm{ND}(0.56)$ \\
$\mathrm{ND}(0.56)$ \\
2.57 \\
$\mathrm{ND}(0.56)$ \\
$\mathrm{ND}(0.56)$ \\
1.23 \\
$\mathrm{ND}(0.56)$ \\
$\mathrm{ND}(0.56)$ \\
$\mathrm{ND}(2.8)$ \\
$\mathrm{ND}(0.56)$ \\
$\mathrm{ND}(0.56)$ \\
$\mathrm{ND}(0.56)$ \\
$\mathrm{ND}(0.56)$ \\
$\mathrm{ND}(0.56)$ \\
$\mathrm{ND}(0.56)$
\end{tabular} & \\
\hline
\end{tabular}

Stream: ESP Inlet Collection Method: VOST Sample Type: Tenax-Tenax + Charcoal B

\begin{tabular}{|c|c|c|c|c|c|c|c|c|}
\hline Analyte & $\begin{array}{l}\text { Analytical } \\
\text { Technique }\end{array}$ & Units & Run 1 & $\widehat{C o m ~} 1$ & Run 2 & Com 2 & Run 3 & Com 3 \\
\hline $\begin{array}{l}\text { 1,1,1-Trichloroethane } \\
\text { 1,1,2,2-Tetrachloroethane } \\
\text { 1,1,2-Trichloroethane } \\
\text { 1,1-Dichloroethane } \\
\text { 1,1-Dichloroethene } \\
\text { 1,2-Dichlorobenzene } \\
\text { 1,2-Dichloroethane } \\
\text { 1,2-Dichloropropane } \\
\text { 1,3-Dichlorobenzene } \\
\text { 1,4-Dichlorobenzene } \\
\text { 2-Butanone } \\
\text { 2-Hexanone } \\
\text { 4-Methyl-2-Pentanone }\end{array}$ & $\begin{array}{l}\text { GCMS } \\
\text { GCMS } \\
\text { GCMS } \\
\text { GCMS } \\
\text { GCMS } \\
\text { GCMS } \\
\text { GCMS } \\
\text { GCMS } \\
\text { GCMS } \\
\text { GCMS } \\
\text { GCMS } \\
\text { GCMS } \\
\text { GCMS }\end{array}$ & $\begin{array}{l}\text { ug/Nm3 } \\
\text { ug/Nm3 } \\
\text { ug/Nm3 } \\
\text { ug/Nm3 } \\
\text { ug/Nm3 } \\
\text { ug/Nm3 } \\
\text { ug/Nm3 } \\
\text { ug/Nm3 } \\
\text { ug/Nm3 } \\
\text { ug/Nm3 } \\
\text { ug/Nm3 } \\
\text { ug/Nm3 } \\
\text { ug/Nm3 }\end{array}$ & $\begin{array}{r}\text { ND (1.1) } \\
\text { ND (1.1) } \\
\text { ND (1.1) } \\
\text { ND (1.1) } \\
\text { ND (1.1) } \\
\text { ND (1.1) } \\
1.19 \\
\text { ND (1.1) } \\
\text { ND (1.1) } \\
\text { ND (1.1) } \\
\text { ND (5.4) } \\
\text { ND (5.4) } \\
\text { ND (5.4) }\end{array}$ & & & & $\begin{array}{l}\mathrm{ND}(0.55) \\
\mathrm{ND}(0.55) \\
\mathrm{ND}(0.55) \\
\mathrm{ND}(0.55) \\
\mathrm{ND}(0.55) \\
\mathrm{ND}(0.55) \\
\mathrm{ND}(0.55) \\
\mathrm{ND}(0.55) \\
\mathrm{ND}(0.55) \\
\mathrm{ND}(0.55) \\
\mathrm{ND}(2.8) \\
\mathrm{ND}(2.8) \\
\mathrm{ND}(2.8)\end{array}$ & \\
\hline
\end{tabular}




\section{Analytical Data Used In Calculations}

Stream: ESP Inlet Collection Method: VOST Sample Type: Tenax-Tenax + Charcoal B

\begin{tabular}{|c|c|c|c|c|c|c|c|c|}
\hline Analyte & $\begin{array}{l}\text { Analytical } \\
\text { Technique }\end{array}$ & Units & Run 1 & Com 1 & Run 2 & $\overline{\operatorname{Com} 2}$ & Run 3 & $\overline{C o m} 3$ \\
\hline $\begin{array}{l}\text { Acetone } \\
\text { Benzene } \\
\text { Bromodichloromethane } \\
\text { Bromoform } \\
\text { Bromomethane } \\
\text { Carbon Disulfide } \\
\text { Carbon Tetrachloride } \\
\text { Chlorobenzene } \\
\text { Chloroethane } \\
\text { Chloroform } \\
\text { Chloromethane } \\
\text { Dibromochloromethane } \\
\text { Ethyl Benzene } \\
\text { Mcthylenc Chloride } \\
\text { Styrene } \\
\text { Tetrachloroethene } \\
\text { Toluene } \\
\text { Trichloroethene } \\
\text { Trichlorofluoromethane } \\
\text { Vinyl Acetate } \\
\text { Vinyl Chloride } \\
\text { cis-1,3-Dichloropropene } \\
\text { m,p-Xylene } \\
\text { 0-Xylene } \\
\text { trans-1,2-Dichloroethene } \\
\text { trans-1,3-Dichloropropene }\end{array}$ & $\begin{array}{l}\text { GCMS } \\
\text { GCMS } \\
\text { GCMS } \\
\text { GCMS } \\
\text { GCMS } \\
\text { GCMS } \\
\text { GCMS } \\
\text { GCMS } \\
\text { GCMS } \\
\text { GCMS } \\
\text { GCMS } \\
\text { GCMS } \\
\text { GCMS } \\
\text { GCMS } \\
\text { GCMS } \\
\text { GCMS } \\
\text { GCMS } \\
\text { GCMS } \\
\text { GCMS } \\
\text { GCMS } \\
\text { GCMS } \\
\text { GCMS } \\
\text { GCMS } \\
\text { GCMS } \\
\text { GCMS } \\
\text { GCMS }\end{array}$ & $\begin{array}{l}\mathrm{ug} / \mathrm{Nm} 3 \\
\mathrm{ug} / \mathrm{Nm} 3 \\
\mathrm{ug} / \mathrm{Nm} 3 \\
\mathrm{ug} / \mathrm{Nm} 3 \\
\mathrm{ug} / \mathrm{Nm} 3 \\
\mathrm{ug} / \mathrm{Nm} 3 \\
\mathrm{ug} / \mathrm{Nm} 3 \\
\mathrm{ug} / \mathrm{Nm} 3 \\
\mathrm{ug} / \mathrm{Nm} 3 \\
\mathrm{ug} / \mathrm{Nm} 3 \\
\mathrm{ug} / \mathrm{Nm} 3 \\
\mathrm{ug} / \mathrm{Nm} 3 \\
\mathrm{ug} / \mathrm{Nm} 3 \\
\mathrm{ug} / \mathrm{Nm} 3 \\
\mathrm{ug} / \mathrm{Nm} 3 \\
\mathrm{ug} / \mathrm{Nm} 3 \\
\mathrm{ug} / \mathrm{Nm} 3 \\
\mathrm{ug} / \mathrm{Nm} 3 \\
\mathrm{ug} / \mathrm{Nm} 3 \\
\mathrm{ug} / \mathrm{Nm} 3 \\
\mathrm{ug} / \mathrm{Nm} 3 \\
\mathrm{ug} / \mathrm{Nm} 3 \\
\mathrm{ug} / \mathrm{Nm} 3 \\
\mathrm{ug} / \mathrm{Nm} 3 \\
\mathrm{ug} / \mathrm{Nm} 3 \\
\mathrm{ug} / \mathrm{Nm} 3\end{array}$ & $\begin{array}{r}\text { ND (5.4) } \\
7.12 \\
\text { ND (1.1) } \\
\text { ND (1.1) } \\
\text { ND (1.1) } \\
1.08 \\
\text { ND (1.1) } \\
\text { ND (1.1) } \\
\text { ND (1.1) } \\
\text { ND (1.1) } \\
\text { ND (1.1) } \\
\text { ND (1.1) } \\
\text { ND (1.1) } \\
\text { ND (1.1) } \\
\text { ND (1.1) } \\
\text { ND (1.1) } \\
\text { ND (1.1) } \\
\text { ND (1.1) } \\
\text { ND (1.1) } \\
\text { ND (5.4) } \\
\text { ND (1.1) } \\
\text { ND (1.1) } \\
\text { ND (1.1) } \\
\text { ND (1.1) } \\
\text { ND (1.1) } \\
\text { ND (1.1) }\end{array}$ & & & & $\begin{array}{r}\mathrm{ND}(2.8) \\
6.64 \\
\mathrm{ND}(0.55) \\
\mathrm{ND}(0.55) \\
\mathrm{ND}(0.55) \\
0.719 \\
\mathrm{ND}(0.55) \\
\mathrm{ND}(0.55) \\
\mathrm{ND}(0.55) \\
\mathrm{ND}(0.55) \\
\mathrm{ND}(0.55) \\
\mathrm{ND}(0.55) \\
\mathrm{ND}(0.55) \\
4.43 \\
\mathrm{ND}(0.55) \\
\mathrm{ND}(0.55) \\
0.996 \\
\mathrm{ND}(0.55) \\
\mathrm{ND}(0.55) \\
\mathrm{ND}(2.8) \\
\mathrm{ND}(0.55) \\
\mathrm{ND}(0.55) \\
\mathrm{ND}(0.55) \\
\mathrm{ND}(0.55) \\
\mathrm{ND}(0.55) \\
\mathrm{ND}(0.55)\end{array}$ & \\
\hline
\end{tabular}

Stream: ESP Outlet Collection Method: Ammonia/Cyanide Sample Type: Ammonia Impingers

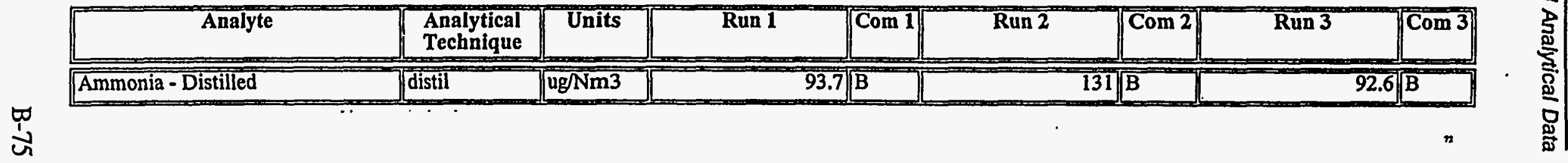


Stream: ESP Outlet Collection Method: Ammonia/Cyanide Sample Type: Impingers

\begin{tabular}{|c|c|c|c|c|c|c|c|c|}
\hline Annlytc & $\begin{array}{l}\text { Annlyllicnl } \\
\text { Technique } \\
\end{array}$ & Units & Run 1 & Com 1 & Run 2 & $\operatorname{Com} 2$ & Run 3 & Com 3 \\
\hline Cyanide & tot $\mathrm{CN}$ & $\mathrm{ug} / \mathrm{Nm} 3$ & 806 & & 374 & & 300 & \\
\hline
\end{tabular}

Stream: ESP Outlet Collection Method: Anions Train Sample Type: Impingers + TLR

\begin{tabular}{|c|c|c|c|c|c|c|c|c|}
\hline Analyte & $\begin{array}{l}\text { Analytical } \\
\text { Technique }\end{array}$ & Units & Run 1 & Com 1 & Run 2 & Com 2 & Run 3 & $\widehat{\operatorname{Com} 3}$ \\
\hline \begin{tabular}{|l} 
Chloride' \\
Sulfate \\
\end{tabular} & $\begin{array}{l}\mathrm{IC} \\
\mathrm{IC} \\
\end{array}$ & $\begin{array}{l}\mathrm{ug} / \mathrm{Nm} 3 \\
\mathrm{ug} / \mathrm{Nm} 3\end{array}$ & $\begin{array}{r}65700 \\
780000 \\
\end{array}$ & & $\begin{array}{r}65600 \\
746000 \\
\end{array}$ & & $\begin{array}{r}69300 \\
135000\end{array}$ & \\
\hline Fluoride & SIE & ug/Nm3 & 5140 & $\overline{\mathbf{B}}$ & 4050 & $\mathrm{~B}$ & 4250 & $\bar{B}$ \\
\hline
\end{tabular}

Stream: ESP Outlet Collection Method: Anions Train Sample Type: Water + Acetone PNR/47 mm Filter + Solids

\begin{tabular}{|c|c|c|c|c|c|c|c|c|}
\hline Analyte & $\begin{array}{l}\text { Analytical } \\
\text { Technique }\end{array}$ & Units & Run 1 & Com 1 & Run 2 & Com 2 & Run 3 & Com 3 \\
\hline $\begin{array}{l}\text { Chloride } \\
\text { Chloride } \\
\text { Sulfate } \\
\text { Sulfate }\end{array}$ & $\begin{array}{l}\mathrm{IC} \\
\mathrm{IC} \\
\mathrm{IC} \\
\mathrm{IC}\end{array}$ & $\begin{array}{l}\mathrm{ug} / \mathrm{Nm} 3 \\
\mathrm{ug} / \mathrm{g} \\
\mathrm{ug} / \mathrm{Nm} 3 \\
\mathrm{ug} / \mathrm{g}\end{array}$ & $\begin{array}{r}1.28 \\
11.3 \\
447 \\
3950\end{array}$ & $\begin{array}{l}C \\
C \\
C \\
C\end{array}$ & $\begin{array}{r}1.20 \\
27.1 \\
4940 \\
112000\end{array}$ & $\begin{array}{l}\mathrm{C} \\
\mathrm{C} \\
\mathrm{C} \\
\mathrm{C}\end{array}$ & \begin{tabular}{r|}
3.80 \\
56.3 \\
198 \\
2940
\end{tabular} & $\begin{array}{l}c \\
C \\
C \\
C\end{array}$ \\
\hline $\begin{array}{l}\text { Fluoride } \\
\text { Fluoride }\end{array}$ & $\begin{array}{l}\text { SIE } \\
\text { SIE }\end{array}$ & $\begin{array}{l}\mathrm{ug} / \mathrm{Nm} 3 \\
\mathrm{ug} / \mathrm{g}\end{array}$ & $\begin{array}{r}\mathrm{ND}(0.12) \\
\mathrm{ND}(1.1)\end{array}$ & C & $\begin{array}{r}\mathrm{ND}(0.13) \\
\mathrm{ND}(2.9)\end{array}$ & $\begin{array}{l}\bar{C} \\
\bar{C}\end{array}$ & $\begin{array}{l}\mathrm{ND}(0.12) \\
\mathrm{ND}(1.8)\end{array}$ & C \\
\hline
\end{tabular}

Stream: ESP Outlet Collection Method: Chromium Test Sample Type: Impingers

\begin{tabular}{|c|c|c|c|c|c|c|c|}
\hline Analyte & $\begin{array}{l}\text { Analytical } \\
\text { Technique }\end{array}$ & Units & Com 1 & $\overline{\text { Run } 2}$ & $\overline{\text { Com 2 }}$ & Run 3 & $\longdiv { \mathrm { Com } 3 }$ \\
\hline Chromium & ICAP & ug/Nm3 & $5.07 \sqrt{\mathrm{B}}$ & ND(1.1) & $\bar{B}$ & & \\
\hline
\end{tabular}




\section{Analytical Data Used In Calculations}

Stream: ESP Outlet Collection Method: Chromium Test Sample Type: Impingers/Nitric Acid Rinses

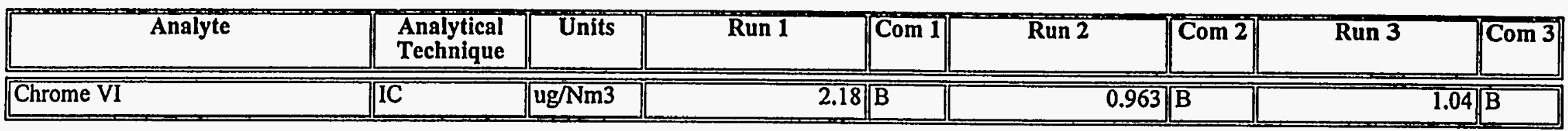

Stream: ESP Outle Collection Method:Chromium Tes Sample Type: Nitric Acid Rinse

\begin{tabular}{|l|c|c|c|c|c|c|c|}
\hline \hline Analyte & $\begin{array}{l}\text { Analytical } \\
\text { Technique }\end{array}$ & Units & Run 1 & Com 1 & Run 2 & Com 2 & Run 3 \\
\hline \hline Chromium & Com 3 \\
\hline
\end{tabular}

Stream: ESP Outlet Collection Method: M001la Sample Type: Impingers $+\mathrm{MeCl} 2$

\begin{tabular}{|c|c|c|c|c|c|c|c|c|}
\hline Analyte & $\begin{array}{l}\text { Analytical } \\
\text { Technique }\end{array}$ & Units & Run 1 & Com 1 & Run 2 & Com 2 & Run 3 & Com 3 \\
\hline Formaldehyde & HPLC & $\mathrm{ug} / \mathrm{Nm} 3$ & 5.14 & & 3.52 & & 3.58 & \\
\hline
\end{tabular}

Stream: ESP Outlet Collection Method: MM5 Sample Type: MeCl2 PNR/MM5 Filter

\begin{tabular}{|c|c|c|c|c|c|c|c|c|}
\hline Analyte & $\begin{array}{l}\text { Analytical } \\
\text { Technique }\end{array}$ & Units & Run 1 & Com 1 & $\overline{\operatorname{Run} 2}$ & Com 2 & Run 3 & Com 3 \\
\hline \begin{tabular}{||l} 
1,2,4-Trichlorobenzene \\
1,2-Dichlorobenzene \\
1,3-Dichlorobenzene \\
1,4-Dichlorobenzene \\
2,4,5-Trichlorophenol \\
2,4,6-Trichlorophenol \\
2,4-Dichlorophenol \\
2,4-Dimethylphenol \\
2,4-Dinitrophenol \\
2,4-Dinitrotoluene \\
2,6-Dinitrotoluene \\
2-Chloronaphthalene \\
2-Chlorophenol \\
2-Methylnaphthalene
\end{tabular} & $\begin{array}{l}\text { GCMS } \\
\text { GCMS } \\
\text { GCMS } \\
\text { GCMS } \\
\text { GCMS } \\
\text { GCMS } \\
\text { GCMS } \\
\text { GCMS } \\
\text { GCMS } \\
\text { GCMS } \\
\text { GCMS } \\
\text { GCMS } \\
\text { GCMS } \\
\text { GCMS }\end{array}$ & $\begin{array}{l}\text { ug/Nm3 } \\
\text { ug/Nm3 } \\
\text { ug/Nm3 } 3 \\
\text { ug/Nm3 } 3 \\
\text { ug/Nm3 } \\
\text { ug/Nm3 } \\
\text { ug/Nm3 } \\
\text { ug/Nm3 } \\
\text { ug/Nm3 } \\
\text { ug/Nm3 } 3 \\
\text { ug/Nm3 } \\
\text { ug/Nm3 } \\
\text { ug/Nm3 } \\
\text { ug/Nm3 }\end{array}$ & \begin{tabular}{c|}
$\mathrm{ND}(1.8)$ \\
$\mathrm{ND}(1.6)$ \\
$\mathrm{ND}(1.5)$ \\
$\mathrm{ND}(1.4)$ \\
$\mathrm{ND}(2.6)$ \\
$\mathrm{ND}(2.8)$ \\
$\mathrm{ND}(2.1)$ \\
$\mathrm{ND}(2.0)$ \\
$\mathrm{ND}(7.5)$ \\
$\mathrm{ND}(2.5)$ \\
$\mathrm{ND}(3.6)$ \\
$\mathrm{ND}(0.99)$ \\
$\mathrm{ND}(1.6)$ \\
$\mathrm{ND}(1.0)$
\end{tabular} & & $\begin{array}{l}\text { ND (1.9) } \\
\text { ND (1.6) } \\
\text { ND (1.5) } \\
\text { ND (1.5) } \\
\text { ND (2.7) } \\
\text { ND (2.8) } \\
\text { ND (2.1) } \\
\text { ND (2.1) } \\
\text { ND (7.6) } \\
\text { ND (2.5) } \\
\text { ND (3.6) } \\
\text { ND (1.0) } \\
\text { ND (1.6) } \\
\text { ND (1.1) }\end{array}$ & & $\begin{array}{l}\mathrm{ND}(2.6) \\
\mathrm{ND}(2.3) \\
\mathrm{ND}(2.2) \\
\mathrm{ND}(2.2) \\
\mathrm{ND}(3.9) \\
\mathrm{ND}(4.1) \\
\mathrm{ND}(3.1) \\
\mathrm{ND}(3.2) \\
\mathrm{ND}(10) \\
\mathrm{ND}(3.7) \\
\mathrm{ND}(5.2) \\
\mathrm{ND}(1.5) \\
\mathrm{ND}(2.4) \\
\mathrm{ND}(1.5)\end{array}$ & \\
\hline
\end{tabular}


Stream: ESP Outlet Collection Method: MM5 Sample Type: MeCl2 PNR/MM5 Filter

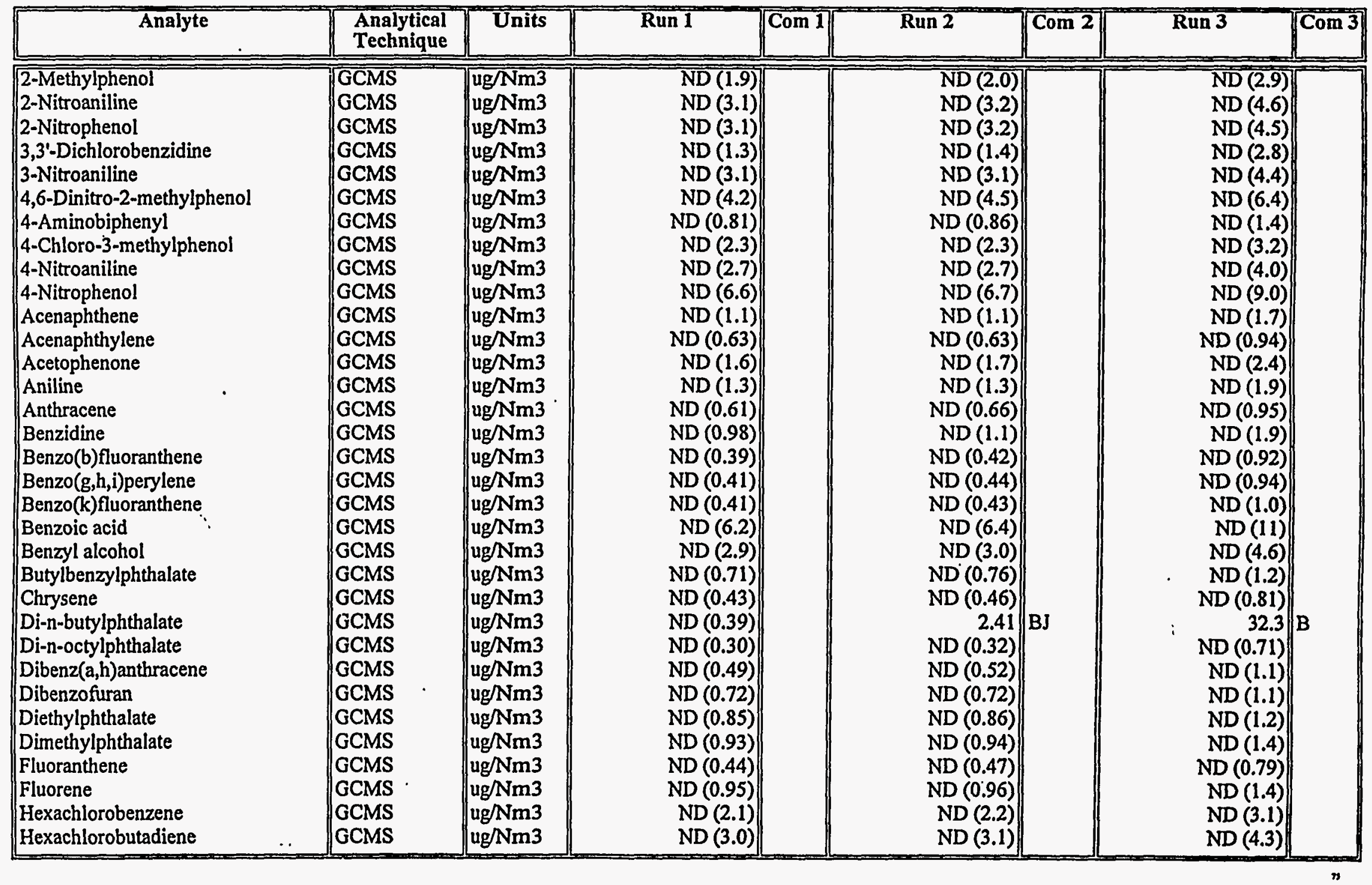




\section{Analytical Data Used In Calculations}

Stream: ESP Outlet Collection Method: MM5 Sample Type: MeCl2 PNR/MM5 Filter

\begin{tabular}{|c|c|c|c|c|c|c|c|c|}
\hline Analyte & $\begin{array}{l}\text { Analytical } \\
\text { Technique }\end{array}$ & Units & Run 1 & $\operatorname{Com} 1$ & Run 2 & Com 2 & Run 3 & Com 3 \\
\hline $\begin{array}{l}\text { Hexachlorocyclopentadiene } \\
\text { Hexachloroethane } \\
\text { Indeno(1,2,3-cd)pyrene } \\
\text { Isophorone } \\
\text { N-Nitroso-di-n-propylamine } \\
\text { Naphthalene } \\
\text { Nitrobenzene } \\
\text { Pentachloronitrobenzene } \\
\text { Pentachlorophenol } \\
\text { Phenanthrene } \\
\text { Phenol } \\
\text { Pyrene } \\
\text { bis(2-Chloroethoxy)methane } \\
\text { bis(2-Chloroethyl)ether } \\
\text { bis(2-Ethylhexyl)phthalate }\end{array}$ & $\begin{array}{l}\text { GCMS } \\
\text { GCMS } \\
\text { GCMS } \\
\text { GCMS } \\
\text { GCMS } \\
\text { GCMS } \\
\text { GCMS } \\
\text { GCMS } \\
\text { GCMS } \\
\text { GCMS } \\
\text { GCMS } \\
\text { GCMS } \\
\text { GCMS } \\
\text { GCMS } \\
\text { GCMS }\end{array}$ & $\begin{array}{l}\text { ug/Nm3 } \\
\text { ug/Nm3 } \\
\text { ug/Nm3 } \\
\text { ug/Nm3 } \\
\text { ug/Nm3 } \\
\text { ug/Nm3 } \\
\text { ug/Nm3 } \\
\text { ug/Nm3 } \\
\text { ug/Nm3 } \\
\text { ug/Nm3 } \\
\text { ug/Nm3 } \\
\text { ug/Nm3 } \\
\text { ug/Nm3 } \\
\text { ug/Nm3 } \\
\text { ug/Nm3 }\end{array}$ & $\begin{array}{r}\text { ND (3.4) } \\
\text { ND (3.1) } \\
\text { ND (0.36) } \\
\text { ND (1.0) } \\
\text { ND (2.8) } \\
\text { ND (0.65) } \\
\text { ND (1.7) } \\
\text { ND (8.1) } \\
\text { ND (5.3) } \\
\text { ND (0.63) } \\
\text { ND (1.3) } \\
\text { ND (0.41) } \\
\text { ND (1.5) } \\
\text { ND (1.8) } \\
1.45\end{array}$ & BJ & $\begin{array}{r}\text { ND (3.4) } \\
\text { ND (3.2) } \\
\text { ND (0.39) } \\
\text { ND (1.0) } \\
\text { ND (2.9) } \\
\text { ND (0.67) } \\
\text { ND (1.8) } \\
\text { ND (8.6) } \\
\text { ND (5.7) } \\
\text { ND (0.67) } \\
\text { ND (1.4) } \\
\text { ND(0.44) } \\
\text { ND (1.6) } \\
\text { ND (1.8) } \\
\text { ND (0.61) }\end{array}$ & & $\begin{array}{r}\mathrm{ND}(6.0) \\
\mathrm{ND}(4.3) \\
\mathrm{ND}(0.84) \\
\mathrm{ND}(1.4) \\
\mathrm{ND}(4.0) \\
\mathrm{ND}(0.94) \\
\mathrm{ND}(2.4) \\
\mathrm{ND}(13) \\
\mathrm{ND}(7.9) \\
\mathrm{ND}(0.96) \\
\mathrm{ND}(2.0) \\
\mathrm{ND}(0.66) \\
\mathrm{ND}(2.2) \\
\mathrm{ND}(2.6) \\
0.638\end{array}$ & \\
\hline
\end{tabular}

Stream: ESP Outlet Collection Method: MMS Sample Type: XAD Resin/Impingers + MeCl2

\begin{tabular}{|c|c|c|c|c|c|c|c|c|}
\hline Analyte & $\begin{array}{l}\text { Analytical } \\
\text { Technique }\end{array}$ & Units & Run 1 & Com 1 & $\overline{\text { Run } 2}$ & Com 2 & Run 3 & Com 3 \\
\hline $\begin{array}{l}\text { 1,2,4-Trichlorobenzene } \\
\text { 1,2-Dichlorobenzene } \\
\text { 1,3-Dichlorobenzene } \\
\text { 1,4-Dichlorobenzene } \\
\text { 2,4,5-Trichlorophenol } \\
\text { 2,4,6-Trichlorophenol } \\
\text { 2,4-Dichlorophenol } \\
\text { 2,4-Dimethylphenol } \\
\text { 2,4-Dinitrophenol } \\
\text { 2,4-Dinitrotoluene } \\
\text { 2,6-Dinitrotoluene } \\
\text { 2-Chloronaphthalene } \\
\text { 2-Chlorophenol }\end{array}$ & $\begin{array}{l}\text { GCMS } \\
\text { GCMS } \\
\text { GCMS } \\
\text { GCMS } \\
\text { GCMS } \\
\text { GCMS } \\
\text { GCMS } \\
\text { GCMS } \\
\text { GCMS } \\
\text { GCMS } \\
\text { GCMS } \\
\text { GCMS } \\
\text { GCMS }\end{array}$ & $\begin{array}{l}\text { ug/Nm3 } \\
\text { ug/Nm3 } \\
\text { ug/Nm3 } \\
\text { ug/Nm3 } \\
\text { ug/Nm3 } \\
\text { ug/Nm3 } \\
\text { ug/Nm3 } \\
\text { ug/Nm3 } \\
\text { ug/Nm3 } \\
\text { ug/Nm3 } \\
\text { ug/Nm3 } \\
\text { ug/Nm3 } \\
\text { ug/Nm3 }\end{array}$ & $\begin{array}{l}\mathrm{ND}(0.89) \\
\text { ND (0.77) } \\
\text { ND (0.72) } \\
\text { ND (0.71) } \\
\text { ND (1.4) } \\
\text { ND (1.6) } \\
\text { ND (0.49) } \\
\text { ND (0.82) } \\
\text { ND (3.6) } \\
\text { ND (1.4) } \\
\text { ND (2.0) } \\
\text { ND (0.60) } \\
\text { ND (0.78) }\end{array}$ & & $\begin{array}{r}\text { ND (0.92) } \\
\text { ND (0.81) } \\
\text { ND (0.76) } \\
\text { ND (0.75) } \\
\text { ND (1.1) } \\
\text { ND (1.2) } \\
\text { ND(0.50) } \\
\text { ND (0.84) } \\
\text { ND(2.7) } \\
\text { ND (1.0) } \\
\text { ND (1.5) } \\
\text { ND (0.46) } \\
\text { ND (0.82) }\end{array}$ & & $\begin{array}{c}\mathrm{ND}(1.1) \\
\mathrm{ND}(0.87) \\
\mathrm{ND}(0.81) \\
\mathrm{ND}(0.80) \\
\mathrm{ND}(5.4) \\
\mathrm{ND}(5.8) \\
\mathrm{ND}(0.61) \\
\mathrm{ND}(1.0) \\
\mathrm{ND}(13) \\
\mathrm{ND}(5.0) \\
\mathrm{ND}(7.3) \\
\mathrm{ND}(2.2) \\
\mathrm{ND}(0.88)\end{array}$ & \\
\hline
\end{tabular}


Stream: ESP Outlet Collection Method: MM5 Sample Type: XAD Resin/Impingers + MeCl2

\begin{tabular}{|c|c|c|c|c|c|c|c|c|}
\hline Analyte & $\begin{array}{l}\text { Analytical } \\
\text { Technique }\end{array}$ & Units & Run 1 & Com I & Run 2 & Com 2 & Run 3 & $\sqrt{\operatorname{Com} 3}$ \\
\hline $\begin{array}{l}\text { 2-Methylnaphthalene } \\
\text { 2-Methylphenol } \\
\text { 2-Nitroaniline } \\
\text { 2-Nitrophenol } \\
\text { 3,3'-Dichlorobenzidine } \\
\text { 3-Nitroaniline } \\
\text { 4,6-Dinitro-2-methylphenol } \\
\text { 4-Aminobiphenyl } \\
\text { 4-Chloro-3-methylphenol } \\
\text { 4-Nitroaniline } \\
\text { 4-Nitrophenol } \\
\text { Acenaphthene } \\
\text { Acenaphthylene } \\
\text { Acetophenone } \\
\text { Aniline } \\
\text { Anthracene } \\
\text { Benzidine } \\
\text { Benzo(b)fluoranthene } \\
\text { Benzo(g,h,i)perylene } \\
\text { Benzo(k)fluoranthene } \\
\text { Benzyl alcohol } \\
\text { Butylbenzylphthalate } \\
\text { Chrysene } \\
\text { Di-n-butylphthalate } \\
\text { Di-n-octylphthalate } \\
\text { Dibenz(a,h)anthracene } \\
\text { Dibenzofuran } \\
\text { Diethylphthalate } \\
\text { Dimethylphthalate } \\
\text { Fluoranthene } \\
\text { Fluorene } \\
\text { Hexachlorobenzene } \\
\text { Hexachlorobutadiene }\end{array}$ & \begin{tabular}{|l} 
GCMS \\
GCMS \\
GCMS \\
GCMS \\
GCMS \\
GCMS \\
GCMS \\
GCMS \\
GCMS \\
GCMS \\
GCMS \\
GCMS \\
GCMS \\
GCMS \\
GCMS \\
GCMS \\
GCMS \\
GCMS \\
GCMS \\
GCMS \\
GCMS \\
GCMS \\
GCMS \\
GCMS \\
GCMS \\
GCMS \\
GCMS \\
GCMS \\
GCMS \\
GCMS \\
GCMS \\
GCMS
\end{tabular} & 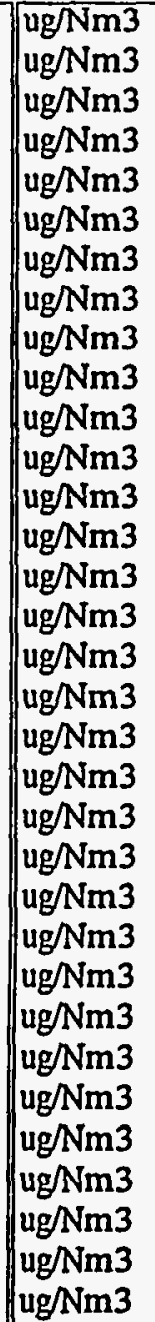 & $\begin{array}{r}\text { ND (0.46) } \\
\text { ND (0.89) } \\
\text { ND (1.5) } \\
\text { ND (1.2) } \\
\text { ND (1.9) } \\
\text { ND (1.7) } \\
\text { ND (1.8) } \\
\text { ND (0.43) } \\
\text { ND (0.86) } \\
\text { ND (1.5) } \\
\text { ND (2.2) } \\
\text { ND (0.63) } \\
\text { ND (0.36) } \\
2.97 \\
\text { ND (0.98) } \\
\text { ND (0.26) } \\
\text { ND (1.1) } \\
\text { ND (6.6) } \\
\text { ND (7.2) } \\
\text { ND (7.0) } \\
\text { ND (1.4) } \\
\text { ND (0.63) } \\
\text { ND (0.56) } \\
19.1 \\
\text { ND (3.9) } \\
\text { ND (8.2) } \\
0.0789 \\
3.26 \\
\text { ND (0.49) } \\
\text { ND (0.25) } \\
\text { ND (0.49) } \\
\text { ND (1.2) } \\
\text { ND (1.5) }\end{array}$ & J & $\begin{array}{r}\text { ND (0.48) } \\
\text { ND (0.94) } \\
\text { ND (1.2) } \\
\text { ND (1.3) } \\
\text { ND (1.3) } \\
\text { ND (1.3) } \\
\text { ND (1.8) } \\
\text { ND (0.44) } \\
\text { ND (0.89) } \\
\text { ND (1.1) } \\
\text { ND (1.7) } \\
\text { ND (0.48) } \\
\text { ND (0.27) } \\
2.71 \\
\text { ND (1.0) } \\
\text { ND (0.26) } \\
\text { ND (0.74) } \\
\text { ND (0.55) } \\
\text { ND (0.60) } \\
\text { ND (0.58) } \\
\text { ND (1.5) } \\
\text { ND (0.42) } \\
\text { ND (0.37) } \\
6.29 \\
\text { ND (0.32) } \\
\text { ND (0.68) } \\
\text { ND (0.30) } \\
\text { ND (0.30) } \\
\text { ND (0.37) }(1.5) \\
\text { ND (0.26) } \\
\text { ND (0.37) }\end{array}$ & $\| \mathrm{J}$ & $\begin{array}{r}\text { ND (0.58) } \\
\text { ND (1.0) } \\
\text { ND (5.6) } \\
\text { ND (1.6) } \\
\text { ND (8.8) } \\
\text { ND (6.2) } \\
\text { ND (4.0) } \\
\text { ND (0.99) } \\
\text { ND (1.1) } \\
\text { ND (5.6) } \\
\text { ND (8.2) } \\
\text { ND (2.3) } \\
\text { ND (1.3) } \\
3.77 \\
\text { ND (1.1) } \\
\text { ND (0.59) } \\
\text { ND (5.2) } \\
\text { ND (0.37) } \\
\text { ND (0.40) } \\
\text { ND (0.39) } \\
\text { ND (1.6) } \\
\text { ND (2.9) } \\
\text { ND (2.6) } \\
13.7 \\
\text { ND (0.22) } \\
\text { ND (0.45) } \\
\text { ND (1.5) } \\
\text { ND (1.4) } \\
\text { ND (1.8) } \\
\text { ND (0.58) (2.8) } \\
\text { ND (1.9) }\end{array}$ & $\mathbf{J}$ \\
\hline
\end{tabular}




\section{Analytical Data Used In Calculations}

Stream: ESP Outlet Collection Method: MM5 Sample Type: XAD Resin/Impingers + MeCl2

\begin{tabular}{|c|c|c|c|c|c|c|c|c|}
\hline Analyte & $\begin{array}{l}\text { Analytical } \\
\text { Technique }\end{array}$ & Units & Run 1 & Com 1] & $\overline{\text { Run 2 }}$ & Com 2 & Run 3 & Com 3 \\
\hline $\begin{array}{l}\text { Hexachlorocyclopentadiene } \\
\text { Hexachloroethane } \\
\text { Indeno(1,2,3-cd)pyrene } \\
\text { Isophorone } \\
\text { N-Nitroso-di-n-propylamine } \\
\text { Naphthalene } \\
\text { Nitrobenzene } \\
\text { Pentachloronitrobenzene } \\
\text { Pentachlorophenol } \\
\text { Phenanthrene } \\
\text { Phenol } \\
\text { Pyrene } \\
\text { bis(2-Chloroethoxy)methane } \\
\text { bis(2-Chloroethyl)ether } \\
\text { bis(2-Ethylliexyl)plthulate }\end{array}$ & $\begin{array}{l}\text { GCMS } \\
\text { GCMS } \\
\text { GCMS } \\
\text { GCMS } \\
\text { GCMS } \\
\text { GCMS } \\
\text { GCMS } \\
\text { GCMS } \\
\text { GCMS } \\
\text { GCMS } \\
\text { GCMS } \\
\text { GCMS } \\
\text { GCMS } \\
\text { GCMS } \\
\text { GCMS }\end{array}$ & $\begin{array}{l}\text { ug/Nm3 } \\
\text { ug/Nm3 } \\
\text { ug/Nm3 } \\
\text { ug/Nm3 } / \mathrm{Nm} \\
\text { ug/Nm3 } \\
\text { ug/Nm3 } \\
\text { ug/Nm3 } \\
\text { ug/Nm3 } \\
\text { ug/Nm3 } / \mathrm{Nm} \\
\text { ug/Nm3 } \\
\text { ug/Nm3 } \\
\text { ug/Nm3 } \\
\text { ug/Nm3 } \\
\text { ug/Nm3 } \\
\text { ug/Nm3 }\end{array}$ & \begin{tabular}{r|}
$\mathrm{ND}(1.7)$ \\
$\mathrm{ND}(1.5)$ \\
$\mathrm{ND}(6.3)$ \\
20.2 \\
$\mathrm{ND}(1.1)$ \\
0.777 \\
$\mathrm{ND}(0.67)$ \\
$\mathrm{ND}(2.6)$ \\
$\mathrm{ND}(2.6)$ \\
$\mathrm{ND}(0.26)$ \\
1.22 \\
$\mathrm{ND}(0.34)$ \\
$\mathrm{ND}(0.71)$ \\
$\mathrm{ND}(0.91)$ \\
22.2
\end{tabular} & BJ & $\begin{array}{r}\mathrm{ND}(1.3) \\
\mathrm{ND}(1.6) \\
\mathrm{ND}(0.52) \\
\mathrm{ND}(0.39) \\
\mathrm{ND}(1.2) \\
0.441 \\
\mathrm{ND}(0.69) \\
\mathrm{ND}(2.6) \\
\mathrm{ND}(2.6) \\
\mathrm{ND}(0.26) \\
1.25 \\
\mathrm{ND}(0.23) \\
\mathrm{ND}(0.73) \\
\mathrm{ND}(0.96) \\
1.63\end{array}$ & BJ & $\begin{array}{r}\mathrm{ND}(6.4) \\
\mathrm{ND}(1.7) \\
\mathrm{ND}(0.35) \\
31.4 \\
\mathrm{ND}(1.3) \\
0.916 \\
\mathrm{ND}(0.84) \\
\mathrm{ND}(5.9) \\
\mathrm{ND}(5.9) \\
\mathrm{ND}(0.60) \\
\mathrm{ND}(0.74) \\
\mathrm{ND}(1.6) \\
\mathrm{ND}(0.89) \\
\mathrm{ND}(1.0) \\
14.2\end{array}$ & BJ \\
\hline
\end{tabular}

Stream: ESP Outlet Collection Method: MMS Sample Type: XAD Resin//mpingers $+\mathrm{MeCl} 2 \quad 1: 2$ dil

\begin{tabular}{|c|c|c|c|c|c|c|c|c|}
\hline Analyte & $\begin{array}{l}\text { Analytical } \\
\text { Technique }\end{array}$ & Units & Run 1 & Com 1 & Run 2 & Com 2 & Run 3 & Com 3 \\
\hline Benzoic acid & GCMS & ug/Nm3 & iII & & 146 & & & \\
\hline
\end{tabular}

Stream: ESP Outlet Collection Method: MM5 Sample Type: XAD Resin/lmpingers $+\mathrm{MeCl} 2$ 1:4 dil

\begin{tabular}{|c|c|c|c|c|c|c|c|c|}
\hline Analyte & $\begin{array}{l}\text { Analytical } \\
\text { Technique }\end{array}$ & Units & Run 1 & Com 1 & Run 2 & Com 2 & $\overline{\operatorname{Run} 3}$ & $\mathrm{Com} 3$ \\
\hline Benzoic acid & GCMS & $\mathrm{ug} / \mathrm{Nm3}$ & & & & & 135 & \\
\hline
\end{tabular}


Stream: ESP Outlet Collection Method: Multimetals Train Sample Type: Acetone PNR/Nitric PNR/M5 Filter + Solids

\begin{tabular}{|c|c|c|c|c|c|c|c|c|}
\hline Analyte & $\begin{array}{l}\text { Analytical } \\
\text { Technique }\end{array}$ & Units & Run 1 & Com 1 & Run 2 & Com 2 & Run 3 & Com 3 \\
\hline $\begin{array}{l}\text { Mercury } \\
\text { Mercury }\end{array}$ & $\begin{array}{l}\text { CVAA } \\
\text { CVAA }\end{array}$ & $\begin{array}{l}\mathrm{ug} / \mathrm{Nm} 3 \\
\mathrm{ug} / \mathrm{g}\end{array}$ & $\begin{array}{r}0.00416 \\
0.0675 \\
\end{array}$ & $\mid \begin{array}{l}\bar{C} \\
C\end{array}$ & $\begin{array}{r}0.00446 \\
0.540 \\
\end{array}$ & C & $\begin{array}{r}\mathrm{ND}(0.0082) \\
\mathrm{ND}(0.15)\end{array}$ & C \\
\hline \begin{tabular}{|l} 
Arsenic \\
Arsenic \\
Cadmium \\
Cadmium \\
Lead \\
Lead \\
Selenium \\
Selenium \\
\end{tabular} & $\begin{array}{l}\text { GFAA } \\
\text { GFAA } \\
\text { GFAA } \\
\text { GFAA } \\
\text { GFAA } \\
\text { GFAA } \\
\text { GFAA } \\
\text { GFAA }\end{array}$ & \begin{tabular}{|l} 
ug/Nm3 3 \\
ug/g \\
ug/Nm3 3 \\
ug/g \\
ug/Nm3 3 \\
ug/g \\
ug/Nm3 3 \\
ug/g
\end{tabular} & $\begin{array}{r}0.776 \\
12.6 \\
0.669 \\
10.9 \\
1.40 \\
22.8 \\
18.6 \\
302 \\
\end{array}$ & $\begin{array}{l}C \\
C \\
C \\
C \\
c \\
C \\
C \\
C\end{array}$ & $\begin{array}{rr}1.05 \\
128 \\
0.274 \\
33.2 \\
\mathrm{ND}(0.027) \\
\mathrm{ND}(3.3) \\
19.2 \\
2330 \\
\end{array}$ & $\begin{array}{l}\mathrm{C} \\
\mathrm{C} \\
\mathrm{C} \\
\mathrm{C} \\
\mathrm{C} \\
\mathrm{C} \\
\mathrm{C} \\
\mathrm{C}\end{array}$ & $\begin{array}{r}0.629 \\
11.6 \\
0.381 \\
6.99 \\
\mathrm{ND}(0.13) \\
\mathrm{ND}(2.4) \\
18.8 \\
344 \\
\end{array}$ & $\begin{array}{l}\bar{C} \\
C \\
C \\
C\end{array}$ \\
\hline \begin{tabular}{|l|} 
Aluminum \\
Aluminum \\
Antimony \\
Antimony \\
Barium \\
Barium \\
Beryllium \\
Beryllium \\
Calcium \\
Calcium \\
Chromium \\
Chromium \\
Cobalt \\
Cobalt \\
Copper \\
Copper \\
Iron \\
Iron \\
Magnesium \\
Magnesium \\
Manganese \\
Manganese \\
\end{tabular} & $\begin{array}{l}\text { ICAP } \\
\text { ICAP } \\
\text { ICAP } \\
\text { ICAP } \\
\text { ICAP } \\
\text { ICAP } \\
\text { ICAP } \\
\text { ICAP } \\
\text { ICAP } \\
\text { ICAP } \\
\text { ICAP } \\
\text { ICAP } \\
\text { ICAP } \\
\text { ICAP } \\
\text { ICAP } \\
\text { ICAP } \\
\text { ICAP } \\
\text { ICAP } \\
\text { ICAP } \\
\text { ICAP } \\
\text { ICAP } \\
\text { ICAP }\end{array}$ & \begin{tabular}{|l}
$\mathrm{ug} / \mathrm{Nm} 3$ \\
$\mathrm{ug} / \mathrm{g}$ \\
$\mathrm{ug} / \mathrm{Nm} 3$ \\
$\mathrm{ug} / \mathrm{g}$ \\
$\mathrm{ug} / \mathrm{Nm} 3$ \\
$\mathrm{ug} / \mathrm{g}$ \\
$\mathrm{ug} / \mathrm{Nm} 3$ \\
$\mathrm{ug} / \mathrm{g}$ \\
$\mathrm{ug} / \mathrm{Nm} 3$ \\
$\mathrm{ug} / \mathrm{g}$ \\
$\mathrm{ug} / \mathrm{Nm} 3$ \\
$\mathrm{ug} / \mathrm{g}$ \\
$\mathrm{ug} / \mathrm{Nm} 3$ \\
$\mathrm{ug} / \mathrm{g}$ \\
$\mathrm{ug} / \mathrm{Nm} 3$ \\
$\mathrm{ug} / \mathrm{g}$ \\
$\mathrm{ug} / \mathrm{Nm} 3$ \\
$\mathrm{ug} / \mathrm{g}$ \\
$\mathrm{ug} / \mathrm{Nm} 3$ \\
$\mathrm{ug} / \mathrm{g}$ \\
$\mathrm{ug} / \mathrm{Nm} 3$ \\
$\mathrm{ug} / \mathrm{g}$
\end{tabular} & $\begin{array}{r}138 \\
2250 \\
\text { ND }(2.0) \\
\text { ND }(33) \\
1.92 \\
31.2 \\
\text { ND }(0.011) \\
\text { ND }(0.18) \\
274 \\
4460 \\
1.70 \\
27.6 \\
\text { ND }(0.19) \\
\text { ND }(3.0) \\
1.64 \\
26.7 \\
221 \\
3590 \\
110 \\
1790 \\
2.37 \\
38.5 \\
\end{array}$ & $\begin{array}{l}\mathrm{C} \\
\mathrm{C} \\
\mathrm{C} \\
\mathrm{C} \\
\mathrm{C} \\
\mathrm{C}\end{array}$ & $\begin{array}{r}55.8 \\
6760 \\
\mathrm{ND}(2.1) \\
\mathrm{ND}(250) \\
0.193 \\
23.4 \\
\mathrm{ND}(0.012) \\
\mathrm{ND}(1.4) \\
227 \\
27500 \\
1.79 \\
217 \\
\mathrm{ND}(0.19) \\
\mathrm{ND}(23) \\
2.29 \\
277 \\
705 \\
85400 \\
93.7 \\
11300 \\
7.44 \\
901 \\
\end{array}$ & $\begin{array}{l}C \\
C \\
C \\
C \\
C \\
C \\
C\end{array}$ & $\begin{array}{r}29.4 \\
539 \\
\mathrm{ND}(2.0) \\
\mathrm{ND}(37) \\
0.110 \\
2.01 \\
\mathrm{ND}(0.011) \\
\mathrm{ND}(0.21) \\
152 \\
2800 \\
0.756 \\
13.9 \\
\mathrm{ND}(0.18) \\
\mathrm{ND}(3.4) \\
0.709 \\
13.0 \\
91.8 \\
1680 \\
61.2 \\
1120 \\
1.02 \\
18.8\end{array}$ & $\begin{array}{l}\mathrm{C} \\
\mathrm{C} \\
\mathrm{C} \\
\mathrm{C} \\
\mathrm{C} \\
\mathrm{C}\end{array}$ \\
\hline
\end{tabular}



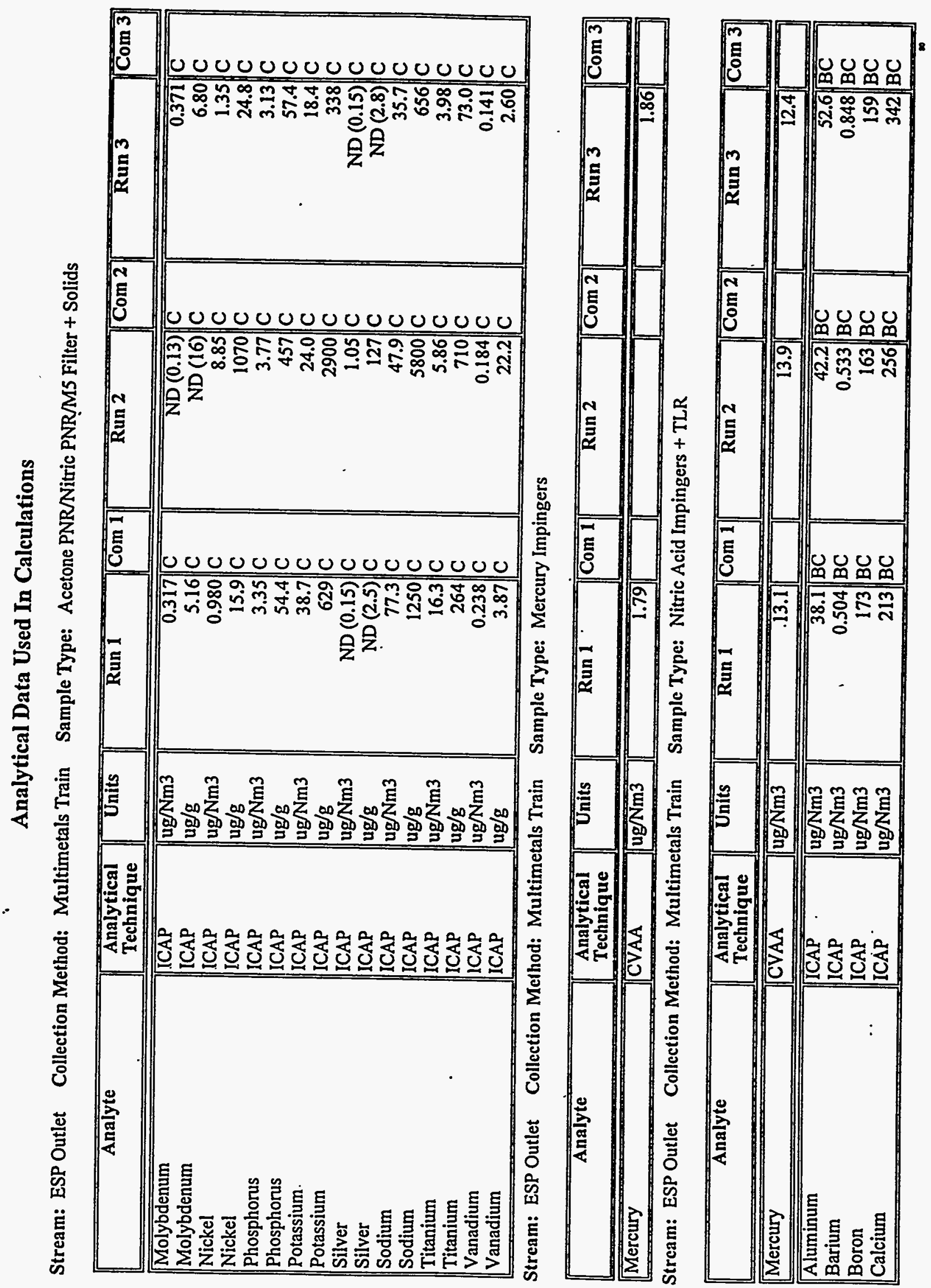
Stream: ESP Outlet Collection Method: Multimetals Train Sample Type: Nitric Acid Impingers + TLR

\begin{tabular}{|c|c|c|c|c|c|c|c|c|}
\hline Analyte & $\begin{array}{l}\text { Analytical } \\
\text { Technique }\end{array}$ & Units & Run 1 & Com 1 & Run 2 & $\overline{\operatorname{Com} 2}$ & Run 3 & $\longdiv { \operatorname { C o m } 3 }$ \\
\hline \begin{tabular}{|l} 
Iron \\
Magnesium \\
Phosphorus \\
Potassium \\
Silver \\
Sodium \\
Titanium \\
\end{tabular} & \begin{tabular}{|l|} 
ICAP \\
ICAP \\
ICAP \\
ICAP \\
ICAP \\
ICAP \\
ICAP \\
\end{tabular} & $\begin{array}{l}\mathrm{ug} / \mathrm{Nm} 3 \\
\mathrm{ug} / \mathrm{Nm} 3 \\
\mathrm{ug} / \mathrm{Nm} 3 \\
\mathrm{ug} / \mathrm{Nm} 3 \\
\mathrm{ug} / \mathrm{Nm} 3 \\
\mathrm{ug} / \mathrm{Nm} 3 \\
\mathrm{ug} / \mathrm{Nm} 3 \\
\end{array}$ & $\begin{array}{r}41.7 \\
24.6 \\
\text { ND (16) } \\
\text { ND (210) } \\
\text { ND (1.3) } \\
287 \\
1.23 \\
\end{array}$ & \begin{tabular}{|l}
$B C$ \\
$B$ \\
$B C$
\end{tabular} & $\begin{array}{r}47.7 \\
15.9 \\
\text { ND (19) } \\
\text { ND (250) } \\
\text { ND (1.6) } \\
308 \\
1.60\end{array}$ & \begin{tabular}{|l}
$\mathrm{BC}$ \\
$\mathrm{C}$ \\
$\mathrm{BC}$ \\
$\mathrm{B}$ \\
$\mathrm{BC}$
\end{tabular} & $\begin{array}{r}61.0 \\
29.9 \\
\text { ND (15) } \\
\mathrm{ND}(210) \\
\mathrm{ND}(1.3) \\
338 \\
1.84\end{array}$ & $\begin{array}{l}\mathrm{BC} \\
\mathrm{C} \\
\mathrm{BC} \\
\mathrm{B} \\
\mathrm{BC}\end{array}$ \\
\hline $\begin{array}{l}\text { Antimony } \\
\text { Arsenic } \\
\text { Barium } \\
\text { Beryllium } \\
\text { Cadmium } \\
\text { Chromium } \\
\text { Cobalt } \\
\text { Copper } \\
\text { Lead } \\
\text { Manganese } \\
\text { Molybdenum } \\
\text { Nickel } \\
\text { Selenium } \\
\text { Vanadium }\end{array}$ & $\begin{array}{l}\text { ICPMS } \\
\text { ICPMS } \\
\text { ICPMS } \\
\text { ICPMS } \\
\text { ICPMS } \\
\text { ICPMS } \\
\text { ICPMS } \\
\text { ICPMS } \\
\text { ICPMS } \\
\text { ICPMS } \\
\text { ICPMS } \\
\text { ICPMS } \\
\text { ICPMS } \\
\text { ICPMS }\end{array}$ & \begin{tabular}{|l}
$\mathrm{ug} / \mathrm{Nm} 3$ \\
$\mathrm{ug} / \mathrm{Nm} 3$ \\
$\mathrm{ug} / \mathrm{Nm} 3$ \\
$\mathrm{ug} / \mathrm{Nm} 3$ \\
$\mathrm{ug} / \mathrm{Nm} 3$ \\
$\mathrm{ug} / \mathrm{Nm} 3$ \\
$\mathrm{ug} / \mathrm{Nm} 3$ \\
$\mathrm{ug} / \mathrm{Nm} 3$ \\
$\mathrm{ug} / \mathrm{Nm} 3$ \\
$\mathrm{ug} / \mathrm{Nm} 3$ \\
$\mathrm{ug} / \mathrm{Nm} 3$ \\
$\mathrm{ug} / \mathrm{Nm} 3$ \\
$\mathrm{ug} / \mathrm{Nm} 3$ \\
$\mathrm{ug} / \mathrm{Nm} 3$
\end{tabular} & $\begin{array}{r}0.0131 \\
0.162 \\
\text { ND }(0.0044) \\
\text { ND }(0.0040) \\
\text { ND }(0.0053) \\
1.35 \\
0.0210 \\
0.456 \\
\text { ND }(0.0042) \\
\text { ND }(0.0059) \\
\text { ND }(0.0065) \\
0.709 \\
13.1 \\
0.671\end{array}$ & $\mid \begin{array}{l}C \\
C \\
C \\
C \\
C \\
C \\
C \\
C \\
C \\
C \\
C \\
C\end{array}$ & $\begin{array}{r}0.0165 \\
0.240 \\
\mathrm{ND}(0.0053) \\
\mathrm{ND}(0.0048) \\
0.551 \\
0.887 \\
0.0477 \\
2.18 \\
0.427 \\
1.03 \\
\mathrm{ND}(0.0078) \\
1.31 \\
18.6 \\
0.849\end{array}$ & 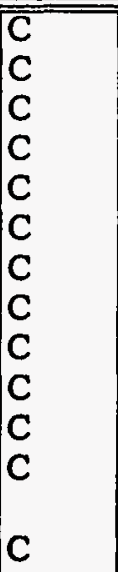 & \begin{tabular}{r|}
0.0233 \\
0.264 \\
$\mathrm{ND}(0.0044)$ \\
0.0485 \\
3.51 \\
4.67 \\
0.0654 \\
4.90 \\
0.527 \\
8.69 \\
0.0711 \\
4.85 \\
29.6 \\
1.03
\end{tabular} & $\begin{array}{l}\mathrm{C} \\
\mathrm{C} \\
\mathrm{C} \\
\mathrm{C} \\
\mathrm{C} \\
\mathrm{C} \\
\mathrm{C} \\
\mathrm{C} \\
\mathrm{C} \\
\mathrm{C} \\
\mathrm{C} \\
\mathrm{C}\end{array}$ \\
\hline
\end{tabular}

Stream: ESP Outlet Collection Method: PCDD/PCDF for Dioxins and Furans (M23) Sample Type: Filtered Solids/Solvent Rinses/XAD Resin

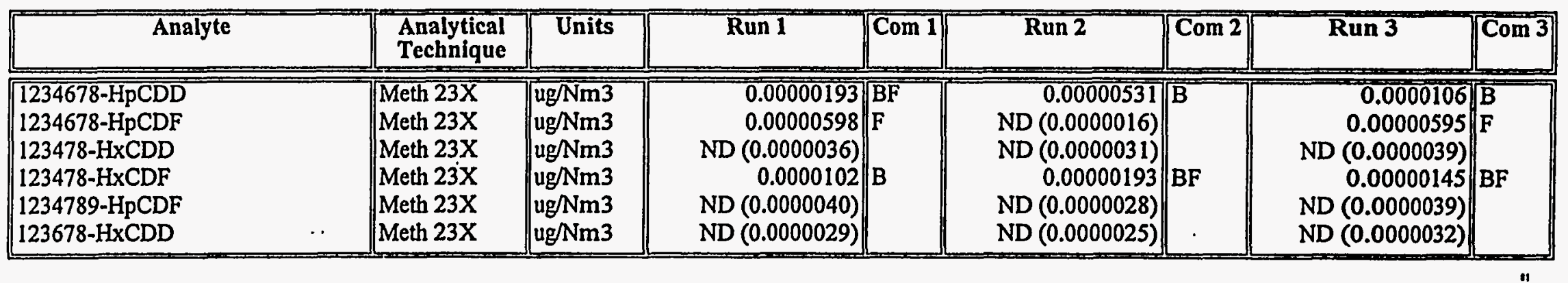


Analytical Data Used In Calculations

Stream: ESP Outlet Collection Method: PCDD/PCDF for Dioxins and Furans (M23) Sample Type: Filtered Solids/Solvent Rinses/XAD Resin

\begin{tabular}{|c|c|c|c|c|c|c|c|c|}
\hline Analyte & $\begin{array}{l}\text { Analytical } \\
\text { Technique }\end{array}$ & Units & Run 1 & Com 1 & Run 2 & Com 2 & Run 3 & $\overline{C o m} 3$ \\
\hline \begin{tabular}{||l}
$123678-\mathrm{HXCDF}$ \\
$12378-\mathrm{PeCDD}$ \\
$12378-\mathrm{PeCDF}$ \\
$123789-\mathrm{HxCDD}$ \\
$123789-\mathrm{HxCDF}$ \\
$234678-\mathrm{HxCDF}$ \\
$23478-\mathrm{PeCDF}$ \\
$2378-\mathrm{TCDD}$ \\
$2378-\mathrm{TCD}$ \\
OCDD \\
OCDF \\
TOTAL HpCDD \\
TOTAL HpCDF \\
TOTAL HXCDD \\
TOTAL HXCDF \\
TOTAL PeCDD \\
TOTAL PeCDF \\
TOTAL TCDD \\
TOTAL TCDF
\end{tabular} & \begin{tabular}{|l} 
Meth 23X \\
Meth 23X \\
Meth 23X \\
Meth 23X \\
Meth 23X \\
Meth 23X \\
Meth 23X \\
Meth 23X \\
Meth 23X \\
Meth 23X \\
Meth 23X \\
Meth 23X \\
Meth 23X \\
Meth 23X \\
Meth 23X \\
Meth 23X \\
Meth 23X \\
Meth 23X \\
Meth 23X
\end{tabular} & $\begin{array}{l}\text { ug/Nm3 } \\
\text { ug/Nm3 } \\
\text { ug/Nm3 } 3 \\
\text { ug/Nm3 } \\
\text { ug/Nm3 } \\
\text { ug/Nm3 } 3 \\
\text { ug/Nm3 } 3 \\
\text { ug/Nm3 } \\
\text { ug/Nm3 } \\
\text { ug/Nm3 } \\
\text { ug/Nm3 } \\
\text { ug/Nm3 } \\
\text { ug/Nm3 } \\
\text { ug/Nm3 } \\
\text { ug/Nm3 } \\
\text { ug/Nm3 } \\
\text { ug/Nm3 } \\
\text { ug/Nm3 } \\
\text { ug/Nm3 }\end{array}$ & $\begin{array}{r}0.00000237 \\
\mathrm{ND}(0.0000018) \\
0.00000204 \\
\mathrm{ND}(0.0000033) \\
\mathrm{ND}(0.0000026) \\
0.00000401 \\
0.00000135 \\
\mathrm{ND}(0.0000015) \\
0.00000248 \\
0.0000278 \\
\mathrm{ND}(0.0000062) \\
0.00000394 \\
0.00000237 \\
\mathrm{ND}(0.0000033) \\
0.0000216 \\
\mathrm{ND}(0.0000018) \\
0.00000667 \\
\mathrm{ND}(0.0000015) \\
0.00000248\end{array}$ & $\mid$\begin{tabular}{|l}
$B$ \\
$F$ \\
$F F$
\end{tabular} & $\begin{array}{r}\text { ND }(0.0000012) \\
\text { ND (0.0000019) } \\
\text { ND (0.0000012) } \\
\text { ND (0.0000028) } \\
\text { ND (0.0000022) } \\
0.00000264 \\
\text { ND (0.0000012) } \\
\text { ND (0.0000012) } \\
\text { ND (0.0000012) } \\
0.0000475 \\
0.00001106 \\
\text { ND (0.0000019) } \\
\text { ND (0.0000028) } \\
0.00000593 \\
0.00000134 \\
\text { ND (0.0000012) } \\
\text { ND (0.0000012) } \\
0.00000106\end{array}$ & $\mid \begin{array}{l}F \\
F\end{array}$ & $\begin{array}{r}\text { ND }(0.0000018) \\
\text { ND (0.0000028) } \\
\text { ND (0.0000018) } \\
\text { ND (0.0000035) } \\
\text { ND (0.0000028) } \\
0.00000389 \\
\text { ND (0.0000018) } \\
\text { ND (0.0000016) } \\
\text { ND (0.0000016) } \\
0.000109 \\
0.0000205 \\
0.0000197 \\
0.00000273 \\
0.00000644 \\
\text { ND (0.0000028) } \\
0.00000319 \\
0.000000800 \\
\text { ND }(0.0000016)\end{array}$ & $\| B$ \\
\hline
\end{tabular}

Stream: ESP Outlet Collection Method: VOST Sample Type: Tenax-Tenax + Charcoal A

\begin{tabular}{|l|l|l|l|l||r|r||}
\hline \multicolumn{1}{|c|}{ Analyte } & $\begin{array}{l}\text { Analytical } \\
\text { Technique }\end{array}$ & Units & Run 1 & Com 1 & Run 2 & Com 2 \\
\hline
\end{tabular}


Stream: ESP Outlet Collection Method: VOST Sample Type: Tenax-Tenax + Charcoal A

\begin{tabular}{|c|c|c|c|c|c|c|c|c|}
\hline Analyte & $\begin{array}{l}\text { Analytical } \\
\text { Technique }\end{array}$ & Units & Run 1 & Com 1 & Run 2 & $\overline{\operatorname{Com} 2}$ & $\operatorname{Run} 3$ & Com 3 \\
\hline $\begin{array}{l}\text { 1,4-Dichlorobenzene } \\
\text { 2-Butanone } \\
\text { 2-Hexanone } \\
\text { 4-Methyl-2-Pentanone } \\
\text { Acetone } \\
\text { Benzene } \\
\text { Bromodichloromethane } \\
\text { Bromoform } \\
\text { Bromomethane } \\
\text { Carbon Disulfide } \\
\text { Carbon Tetrachloride } \\
\text { Chlorobenzene } \\
\text { Chloroethane } \\
\text { Chloroform } \\
\text { Chloromethane } \\
\text { Dibromochloromethane } \\
\text { Ethyl Benzene } \\
\text { Methylene Chloride } \\
\text { Styrene } \\
\text { Tetrachloroethene } \\
\text { Tolucne } \\
\text { Trichloroethene } \\
\text { Trichlorofluoromethane } \\
\text { Vinyl Acetate } \\
\text { Vinyl Chloride } \\
\text { cis-1,3-Dichloropropene } \\
\text { m,p-Xylene } \\
\text { o-Xylene } \\
\text { trans-1,2-Dichloroethene } \\
\text { trans-1,3-Dichloropropene }\end{array}$ & $\begin{array}{l}\text { GCMS } \\
\text { GCMS } \\
\text { GCMS } \\
\text { GCMS } \\
\text { GCMS } \\
\text { GCMS } \\
\text { GCMS } \\
\text { GCMS } \\
\text { GCMS } \\
\text { GCMS } \\
\text { GCMS } \\
\text { GCMS } \\
\text { GCMS } \\
\text { GCMS } \\
\text { GCMS } \\
\text { GCMS } \\
\text { GCMS } \\
\text { GCMS } \\
\text { GCMS } \\
\text { GCMS } \\
\text { GCMS } \\
\text { GCMS } \\
\text { GCMS } \\
\text { GCMS } \\
\text { GCMS } \\
\text { GCMS } \\
\text { GCMS } \\
\text { GCMS } \\
\text { GCMS } \\
\text { GCMS }\end{array}$ & 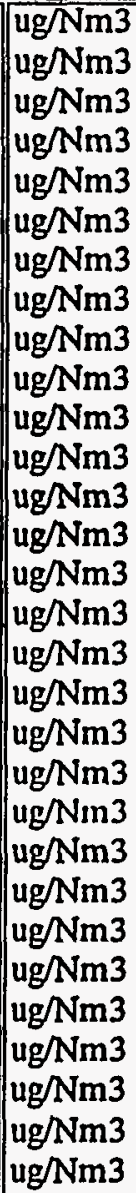 & $\begin{array}{r}\text { ND (0.52) } \\
\text { ND (2.6) } \\
\text { ND (2.6) } \\
\text { ND (2.6) } \\
\text { ND (2.6) } \\
2.63 \\
0.619 \\
\text { ND (0.52) } \\
0.774 \\
1.19 \\
\text { ND (0.52) } \\
\text { ND (0.52) } \\
1.96 \\
\text { ND (0.52) } \\
9.80 \\
\text { ND (0.52) } \\
\text { ND }(0.52) \\
1.24 \\
\text { ND (0.52) } \\
\text { ND (0.52) } \\
1.03 \\
\text { ND (0.52) } \\
\text { ND }(0.52) \\
\text { ND (2.6) } \\
\text { ND (0.52) } \\
\text { ND (0.52) } \\
\text { ND (0.52) } \\
\text { ND (0.52) } \\
\text { ND (0.52) } \\
\text { ND (0.52) }\end{array}$ & $G$ & 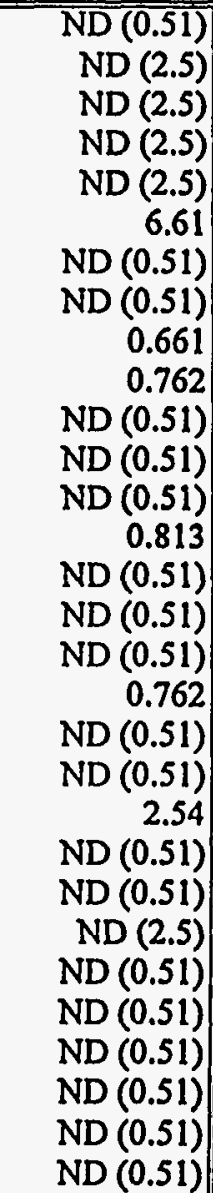 & & $\begin{array}{r}\text { ND }(0.53) \\
N D(2.6) \\
N D(2.6) \\
N D(2.6) \\
N D(2.6) \\
6.84 \\
N D(0.53) \\
N D(0.53) \\
N D(0.53) \\
0.737 \\
N D(0.53) \\
N D(0.53) \\
N D(0.53) \\
N D(0.53) \\
3.68 \\
N D(0.53) \\
N D(0.53) \\
5.79 \\
N D(0.53) \\
N D(0.53) \\
0.894 \\
N D(0.53) \\
N D(0.53) \\
N D(2.6) \\
N D(0.53) \\
N D(0.53) \\
0.631 \\
N D(0.53) \\
N D(0.53) \\
N D(0.53)\end{array}$ & \\
\hline
\end{tabular}


Analytical Data Used In Calculations

Stream: ESP Outlet Collection Method: VOST Sample Type: Tenax-Tenax + Charcoal B

\begin{tabular}{|c|c|c|c|c|c|c|c|c|}
\hline Analyte & $\begin{array}{l}\text { Analytical } \\
\text { Technique }\end{array}$ & Units & Run 1 & $\overline{\text { Com 1 }}$ & $\overline{\text { Run } 2}$ & $\overline{\mathrm{Com} 2}$ & Run 3 & $\sqrt{\operatorname{Com} 3}$ \\
\hline $\begin{array}{l}\text { 1,1,1-Trichloroethane } \\
\text { 1,1,2,2-Tetrachloroethane } \\
\text { 1,1,2-Trichloroethane } \\
\text { 1,1-Dichloroethane } \\
\text { 1,1-Dichloroethene } \\
\text { 1,2-Dichlorobenzene } \\
\text { 1,2-Dichloroethane } \\
\text { 1,2-Dichloropropane } \\
\text { 1,3-Dichlorobenzene } \\
\text { 1,4-Dichlorobenzene } \\
\text { 2-Butanone } \\
\text { 2-Hexanone } \\
\text { 4-Methyl-2-Pentanone } \\
\text { Acetone } \\
\text { Benzene } \\
\text { Bromodichloromethane } \\
\text { Bromoform } \\
\text { Bromomethane } \\
\text { Carbon Disulfide } \\
\text { Carbon Tetrachloride } \\
\text { Chlorobenzene } \\
\text { Chloroethane } \\
\text { Chloroform } \\
\text { Chloromcthane } \\
\text { Dibromochloromethane } \\
\text { Ethyl Benzene } \\
\text { Methylene Chloride } \\
\text { Styrcne } \\
\text { Tetrachloroethene } \\
\text { Toluene } \\
\text { Trichloroethene } \\
\text { Trichlorofluoromethane } \\
\text { Vinyl Acetate }\end{array}$ & \begin{tabular}{|l} 
GCMS \\
GCMS \\
GCMS \\
GCMS \\
GCMS \\
GCMS \\
GCMS \\
GCMS \\
GCMS \\
GCMS \\
GCMS \\
GCMS \\
GCMS \\
GCMS \\
GCMS \\
GCMS \\
GCMS \\
GCMS \\
GCMS \\
GCMS \\
GCMS \\
GCMS \\
GCMS \\
GCMS \\
GCMS \\
GCMS \\
GCMS \\
GCMS \\
GCMS \\
GCMS \\
GCMS \\
GCMS \\
GCMS
\end{tabular} & 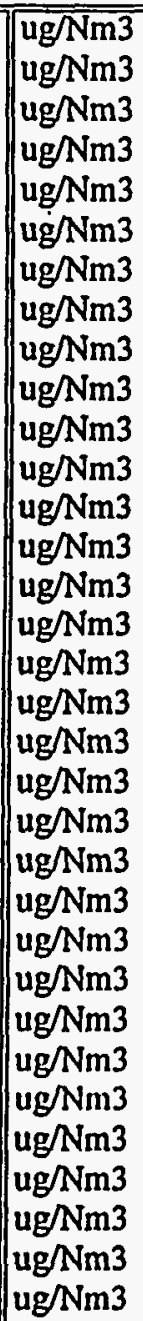 & $\begin{array}{r}0.701 \\
\text { ND }(0.54) \\
\text { ND }(0.54) \\
\text { ND }(0.54) \\
\text { ND }(0.54) \\
\text { ND }(0.54) \\
17.3 \\
\text { ND }(0.54) \\
\text { ND }(0.54) \\
\text { ND }(0.54) \\
\text { ND }(2.7) \\
\text { ND }(2.7) \\
\text { ND }(2.7) \\
\text { ND }(2.7) \\
5.02 \\
0.593 \\
\text { ND }(0.54) \\
0.593 \\
0.863 \\
\text { ND }(0.54) \\
\text { ND }(0.54) \\
\text { ND }(0.54) \\
\text { ND }(0.54) \\
3.56 \\
\text { ND }(0.54) \\
\text { ND }(0.54) \\
2.97 \\
\text { ND (0.54) } \\
\text { ND (0.54) } \\
0.863 \\
\text { ND (0.54) } \\
\text { ND (0.54) } \\
\text { ND (2.7) }\end{array}$ & & 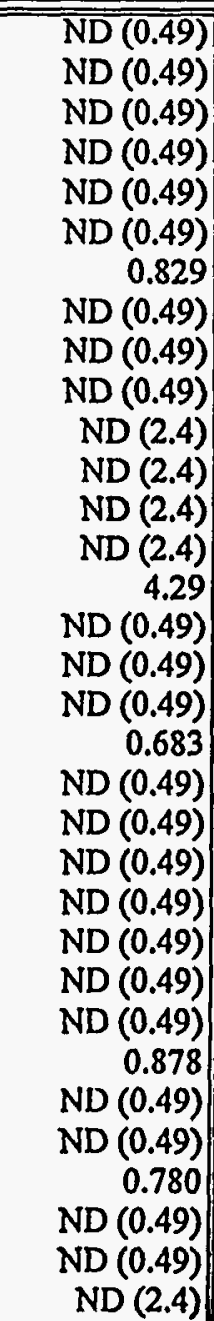 & & & \\
\hline
\end{tabular}


Stream: ESP Outlet Collection Method: vOST Sample Type: Tenax-Tenax + Charcoal B

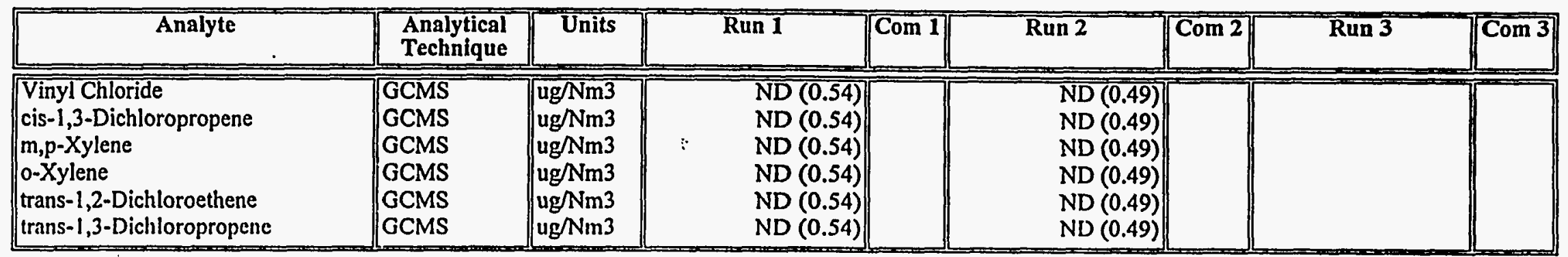

Stream: Service Water Collection Method: Grab Sample Type: Not Specified

\begin{tabular}{|c|c|c|c|c|c|c|c|c|}
\hline Analyte & $\begin{array}{l}\text { Analytical } \\
\text { Technique }\end{array}$ & Units & $\operatorname{Run} 1$ & Com 1 & Run 2 & $\operatorname{Com} 2$ & Run 3 & Com 3 \\
\hline Mercury & $\overline{\text { CVAA }}$ & $\mathrm{mg} / \mathrm{L}$ & ND (0.000033) & & ND (0.000033) & & $\mathrm{ND}(0.000033)$ & \\
\hline $\begin{array}{l}\text { Arsenic } \\
\text { Cadmium } \\
\text { Lead } \\
\text { Selenium }\end{array}$ & $\begin{array}{l}\text { GFAA } \\
\text { GFAA } \\
\text { GFAA } \\
\text { GFAA }\end{array}$ & $\begin{array}{l}\mathrm{mg} / \mathrm{L} \\
\mathrm{mg} / \mathrm{L} \\
\mathrm{mg} / \mathrm{L} \\
\mathrm{mg} / \mathrm{L}\end{array}$ & $\begin{array}{r}\text { ND }(0.00065) \\
\text { ND }(0.00027) \\
0.00626 \\
\text { ND }(0.0018)\end{array}$ & B & $\begin{array}{r}0.00113 \\
\text { ND }(0.00027) \\
0.0124 \\
\text { ND }(0.0018)\end{array}$ & B & $\begin{array}{r}0.00171 \\
\text { ND }(0.00027) \\
0.0125 \\
\text { ND }(0.0018)\end{array}$ & B \\
\hline \begin{tabular}{|l} 
Chloride \\
Sulfate
\end{tabular} & IC & $\begin{array}{l}\mathrm{mg} / \mathrm{L} \\
\mathrm{mg} / \mathrm{L}\end{array}$ & $\begin{array}{l}11.5 \\
59.2\end{array}$ & & $\begin{array}{l}11.6 \\
58.3\end{array}$ & & $\begin{array}{l}12.4 \\
47.1\end{array}$ & \\
\hline $\begin{array}{l}\text { Aluminum } \\
\text { Antimony } \\
\text { Barium } \\
\text { Beryllium } \\
\text { Boron } \\
\text { Calcium } \\
\text { Chromium } \\
\text { Cobalt } \\
\text { Copper } \\
\text { Iron } \\
\text { Magnesium } \\
\text { Manganese } \\
\text { Molybdenum }\end{array}$ & $\begin{array}{l}\text { IICAP } \\
\text { ICAP } \\
\text { ICAP } \\
\text { ICAP } \\
\text { ICAP } \\
\text { ICAP } \\
\text { ICAP } \\
\text { ICAP } \\
\text { ICAP } \\
\text { ICAP } \\
\text { ICAP } \\
\text { ICAP } \\
\text { ICAP }\end{array}$ & $\begin{array}{l}\mathrm{mg} / \mathrm{L} \\
\mathrm{mg} / \mathrm{L} \\
\mathrm{mg} / \mathrm{L} \\
\mathrm{mg} / \mathrm{L} \\
\mathrm{mg} / \mathrm{L} \\
\mathrm{mg} / \mathrm{L} \\
\mathrm{mg} / \mathrm{L} \\
\mathrm{mg} / \mathrm{L} \\
\mathrm{mg} / \mathrm{L} \\
\mathrm{mg} / \mathrm{L} \\
\mathrm{mg} / \mathrm{L} \\
\mathrm{mg} / \mathrm{L} \\
\mathrm{mg} / \mathrm{L}\end{array}$ & $\begin{array}{r}1.25 \\
\mathrm{ND}(0.076) \\
0.0494 \\
0.00156 \\
0.0427 \\
23.9 \\
\mathrm{ND}(0.0052) \\
0.00713 \\
0.0128 \\
3.00 \\
6.27 \\
0.286 \\
\mathrm{ND}(0.0074)\end{array}$ & B & \begin{tabular}{rr|}
2.20 \\
$\mathrm{ND}(0.076)$ \\
0.0691 \\
0.000540 \\
0.0410 \\
25.8 \\
$\mathrm{ND}(0.0052)$ \\
0.00460 \\
0.0173 \\
4.70 \\
6.71 \\
0.438 \\
$\mathrm{ND}(0.0074)$
\end{tabular} & $\begin{array}{l}\mathrm{B} \\
\mathrm{B} \\
\mathrm{B} \\
\mathrm{B} \\
\mathrm{B} \\
\mathrm{B} \\
\mathrm{B} \\
\mathrm{B}\end{array}$ & $\begin{array}{r}1.89 \\
\mathrm{ND}(0.076) \\
0.0659 \\
0.00458 \\
0.0417 \\
21.8 \\
0.00788 \\
\mathrm{ND}(0.0041) \\
0.0212 \\
4.52 \\
5.75 \\
0.432 \\
0.0115\end{array}$ & $\begin{array}{l}B \\
B \\
B \\
B \\
B \\
B \\
B \\
B \\
B\end{array}$ \\
\hline
\end{tabular}




\section{Analytical Data Used In Calculations}

Stream: Service Water Collection Method: Grab Sample Type: Not Specified

\begin{tabular}{|c|c|c|c|c|c|c|c|c|}
\hline Analyte & $\begin{array}{l}\text { Analytical } \\
\text { Technique }\end{array}$ & Units & Run I & Com 1 & Run 2 & Com 2 & Run 3 & Com 3 \\
\hline $\begin{array}{l}\text { Nickel } \\
\text { Phosphorus } \\
\text { Potassium } \\
\text { Silver } \\
\text { Sodium } \\
\text { Titanium } \\
\text { Vanadium. } \\
\end{array}$ & \begin{tabular}{|l} 
ICAP \\
ICAP \\
ICAP \\
ICAP \\
ICAP \\
ICAP \\
ICAP
\end{tabular} & $\begin{array}{l}\mathrm{mg} / \mathrm{L} \\
\mathrm{mg} / \mathrm{L} \\
\mathrm{mg} / \mathrm{L} \\
\mathrm{mg} / \mathrm{L} \\
\mathrm{mg} / \mathrm{L} \\
\mathrm{mg} / \mathrm{L} \\
\mathrm{mg} / \mathrm{L}\end{array}$ & $\begin{array}{r}\mathrm{ND}(0.014) \\
\mathrm{ND}(0.061) \\
1.62 \\
\mathrm{ND}(0.0052) \\
10.4 \\
0.0139 \\
0.00532 \\
\end{array}$ & $\begin{array}{l}\mathrm{B} \\
\mathrm{B} \\
\mathrm{B}\end{array}$ & $\begin{array}{r}\mathrm{ND}(0.014) \\
\mathrm{ND}(0.061) \\
1.76 \\
\mathrm{ND}(0.0052) \\
10.9 \\
0.0229 \\
\mathrm{ND}(0.0045) \\
\end{array}$ & $\begin{array}{l}\mathrm{B} \\
\mathrm{B} \\
\mathrm{B}\end{array}$ & $\begin{array}{r}0.0145 \\
\mathrm{ND}(0.061) \\
1.84 \\
\mathrm{ND}(0.0052) \\
10.1 \\
0.0251 \\
0.00757 \\
\end{array}$ & $\begin{array}{l}\mathrm{B} \\
\mathrm{B} \\
\mathrm{B}\end{array}$ \\
\hline Fluoride & $\overline{\mathrm{SIE}}$ & $\mathrm{mg} / \mathrm{L}$ & 0.114 & $\mathrm{~B}$ & 0.120 & $\bar{B}$ & 0.116 & $\bar{B}$ \\
\hline Total phosphate & tot P & $\mathrm{mg} / \mathrm{L}$ & $\mathrm{ND}(0.020)$ & & ND $(0.020)$ & & 0.0331 & \\
\hline
\end{tabular}

Stream: Service Water Collection Method: Grab Sample Type: Not Specified FD

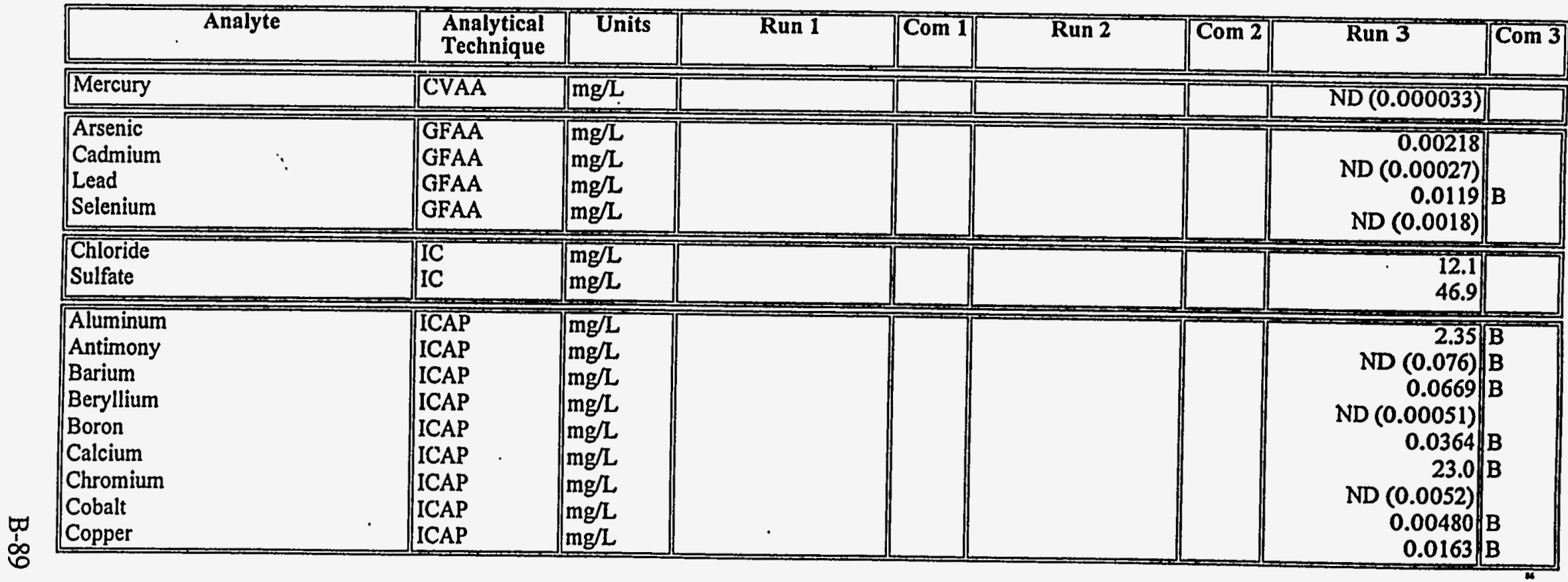




\begin{tabular}{|c|c|c|c|c|c|c|c|c|}
\hline Analyte & $\begin{array}{l}\text { Analytical } \\
\text { Technique }\end{array}$ & Units & $\overline{\text { Run I }}$ & Com 1 & Run 2 & $\longdiv { \text { Com 2 } }$ & $\overline{\text { Run } 3}$ & Com 3 \\
\hline $\begin{array}{l}\text { Iron } \\
\text { Magnesium } \\
\text { Manganese } \\
\text { Molybdenum } \\
\text { Nickel } \\
\text { Phosphorus } \\
\text { Potassium } \\
\text { Silver } \\
\text { Sodium } \\
\text { Titanium } \\
\text { Vanadium } \\
\end{array}$ & $\begin{array}{l}\text { ICAP } \\
\text { ICAP } \\
\text { ICAP } \\
\text { ICAP } \\
\text { ICAP } \\
\text { ICAP } \\
\text { ICAP } \\
\text { ICAP } \\
\text { ICAP } \\
\text { ICAP } \\
\text { ICAP }\end{array}$ & $\begin{array}{l}\mathrm{mg} / \mathrm{L} \\
\mathrm{mg} / \mathrm{L} \\
\mathrm{mg} / \mathrm{L} \\
\mathrm{mg} / \mathrm{L} \\
\mathrm{mg} / \mathrm{L} \\
\mathrm{mg} / \mathrm{L} \\
\mathrm{mg} / \mathrm{L} \\
\mathrm{mg} / \mathrm{L} \\
\mathrm{mg} / \mathrm{L} \\
\mathrm{mg} / \mathrm{L} \\
\mathrm{mg} / \mathrm{L}\end{array}$ & & & & & $\begin{array}{r}5.89 \\
6.02 \\
0.460 \\
\mathrm{ND}(0.0074) \\
0.0160 \\
\mathrm{ND}(0.061) \\
1.87 \\
\mathrm{ND}(0.0052) \\
10.3 \\
0.0281 \\
0.00619\end{array}$ & $\begin{array}{l}B \\
B \\
B\end{array}$ \\
\hline Fluoride & SIE & $\mathrm{mg} / \mathrm{L}$ & & & & & 0.117 & $\overline{\mathrm{B}}$ \\
\hline Total phosphate & $\operatorname{tot} P$ & $\mathrm{mg} / \mathrm{l}$ & & & & & 0.0242 & \\
\hline
\end{tabular}

Stream: Sorbent Collection Method: Grab Composite Sample Type: Dolomite

\begin{tabular}{|c|c|c|c|c|c|c|c|c|}
\hline $\begin{array}{r}\text { Analyte } \\
\text {. }\end{array}$ & $\begin{array}{l}\text { Analytical } \\
\text { Technique }\end{array}$ & Units & Run 1 & Com 1 & Run 2 & Com 2 & Run 3 & $\operatorname{Com} 3$ \\
\hline Mercury & CVAA & $\mathrm{mg} / \mathrm{kg}$ & ND(0.012) & & ND (0.012) & & ND (0.012) & \\
\hline $\begin{array}{l}\text { Arsenic } \\
\text { Cadmium } \\
\text { Lead } \\
\text { Selenium }\end{array}$ & $\begin{array}{l}\text { GFAA } \\
\text { GFAA } \\
\text { GFAA } \\
\text { GFAA }\end{array}$ & $\begin{array}{l}\mathrm{mg} / \mathrm{kg} \\
\mathrm{mg} / \mathrm{kg} \\
\mathrm{mg} / \mathrm{kg} \\
\mathrm{mg} / \mathrm{kg}\end{array}$ & $\begin{array}{r}2.19 \\
0.140 \\
7.30 \\
0.903\end{array}$ & B & $\begin{array}{r}2.12 \\
0.173 \\
6.15 \\
0.475\end{array}$ & $B$ & $\begin{array}{r}1.24 \\
0.0929 \\
7.22 \\
0.982\end{array}$ & B \\
\hline Sulfate & IC & $\mathrm{mg} / \mathrm{kg}$ & 6420 & & 6370 & & 6460 & \\
\hline $\begin{array}{l}\text { Aluminum } \\
\text { Antimony } \\
\text { Barium } \\
\text { Beryllium } \\
\text { Boron } \\
\text { Calcium }\end{array}$ & $\begin{array}{l}\text { ICAP } \\
\text { ICAP } \\
\text { ICAP } \\
\text { ICAP } \\
\text { ICAP } \\
\text { ICAP }\end{array}$ & $\begin{array}{l}\mathrm{mg} / \mathrm{kg} \\
\mathrm{mg} / \mathrm{kg} \\
\mathrm{mg} / \mathrm{kg} \\
\mathrm{mg} / \mathrm{kg} \\
\mathrm{mg} / \mathrm{kg} \\
\mathrm{mg} / \mathrm{kg}\end{array}$ & $\begin{array}{r}659 \\
\text { ND (4.9) } \\
3.45 \\
0.0492 \\
32.9 \\
193000\end{array}$ & $\begin{array}{l}B \\
B \\
B\end{array}$ & $\begin{array}{r}662 \\
\text { ND }(5.5) \\
3.50 \\
\text { ND }(0.031) \\
31.0 \\
192000\end{array}$ & $\begin{array}{l}B \\
B\end{array}$ & $\begin{array}{r}632 \\
\mathrm{ND}(5.5) \\
3.43 \\
\mathrm{ND}(0.031) \\
33.7 \\
193000\end{array}$ & $\begin{array}{l}B \\
B \\
B\end{array}$ \\
\hline
\end{tabular}


Analytical Data Used In Calculations

Stream: Sorbent Collection Method: Grab Composit Sample Type:Dolomite

\begin{tabular}{|c|c|c|c|c|c|c|c|c|}
\hline Analyte & $\begin{array}{l}\text { Analytical } \\
\text { Technique }\end{array}$ & Units & Run 1 & Com 1 & Run 2 & $\overline{\mathrm{Com} 2}$ & Run 3 & Com 3 \\
\hline $\begin{array}{l}\text { Chromium } \\
\text { Cobalt } \\
\text { Copper } \\
\text { Iron } \\
\text { Magnesium } \\
\text { Manganese } \\
\text { Molybdenum } \\
\text { Nickel } \\
\text { Phosphorus } \\
\text { Potassium } \\
\text { Silver } \\
\text { Sodium } \\
\text { Titanium } \\
\text { Vanadium }\end{array}$ & $\begin{array}{l}\text { ICAP } \\
\text { ICAP } \\
\text { ICAP } \\
\text { ICAP } \\
\text { ICAP } \\
\text { ICAP } \\
\text { ICAP } \\
\text { ICAP } \\
\text { ICAP } \\
\text { ICAP } \\
\text { ICAP } \\
\text { ICAP } \\
\text { ICAP } \\
\text { ICAP }\end{array}$ & $\begin{array}{l}\mathrm{mg} / \mathrm{kg} \\
\mathrm{mg} / \mathrm{kg} \\
\mathrm{mg} / \mathrm{kg} \\
\mathrm{mg} / \mathrm{kg} \\
\mathrm{mg} / \mathrm{kg} \\
\mathrm{mg} / \mathrm{kg} \\
\mathrm{mg} / \mathrm{kg} \\
\mathrm{mg} / \mathrm{kg} \\
\mathrm{mg} / \mathrm{kg} \\
\mathrm{mg} / \mathrm{kg} \\
\mathrm{mg} / \mathrm{kg} \\
\mathrm{mg} / \mathrm{kg} \\
\mathrm{mg} / \mathrm{kg} \\
\mathrm{mg} / \mathrm{kg}\end{array}$ & $\begin{array}{r}2.79 \\
0.461 \\
\text { ND (0.42) } \\
2130 \\
106000 \\
72.0 \\
1.42 \\
19.6 \\
\text { ND (6.1) } \\
240 \\
\text { ND (0.37) } \\
194 \\
7.49 \\
4.75\end{array}$ & $\begin{array}{l}B \\
B \\
B \\
B \\
B \\
B \\
B \\
B \\
B\end{array}$ & $\begin{array}{r}2.88 \\
\text { ND }(0.50) \\
\text { ND }(0.47) \\
2430 \\
106000 \\
72.9 \\
1.34 \\
16.8 \\
\text { ND (6.8) } \\
218 \\
\text { ND }(0.41) \\
198 \\
10.9 \\
4.88\end{array}$ & $\begin{array}{l}B \\
B \\
B \\
B \\
B \\
B \\
B \\
B\end{array}$ & $\begin{array}{r}2.86 \\
\text { ND }(0.50) \\
\text { ND }(0.47) \\
2160 \\
106000 \\
71.9 \\
1.62 \\
0.524 \\
\text { ND (6.8) } \\
255 \\
\text { ND (0.41) } \\
202 \\
9.65 \\
5.17\end{array}$ & $\begin{array}{l}\mathrm{B} \\
\mathrm{B} \\
\mathrm{B} \\
\mathrm{B} \\
\mathrm{B}\end{array}$ \\
\hline $\begin{array}{l}\text { Chloride } \\
\text { Fluoride }\end{array}$ & $\begin{array}{l}\text { SIE } \\
\text { SIE }\end{array}$ & $\begin{array}{l}\mathrm{mg} / \mathrm{kg} \\
\mathrm{mg} / \mathrm{kg}\end{array}$ & $\begin{array}{l}369 \\
297\end{array}$ & B & $\begin{array}{l}336 \\
208\end{array}$ & B & $\begin{array}{l}246 \\
136\end{array}$ & $B$ \\
\hline
\end{tabular}

Stream: Sorbent Collection Method: Grab Composite Sample Type: Dolomite FD

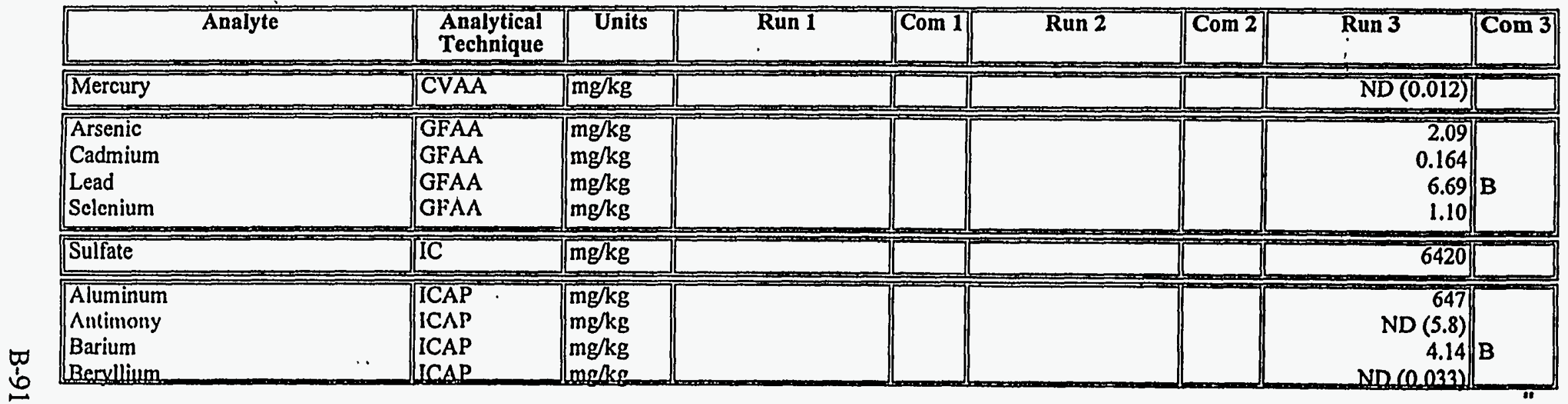


Stream: Sorbent Collection Method: Grab Composit Sample Type: Dolomite FD

\begin{tabular}{|c|c|c|c|c|c|c|c|c|}
\hline Analyte & $\begin{array}{l}\text { Analytical } \\
\text { Technique }\end{array}$ & Units & Run 1 & Com 1 & Run 2 & Com 2 & Run 3 & Com 3 \\
\hline $\begin{array}{l}\text { Boron } \\
\text { Calcium } \\
\text { Chromium } \\
\text { Cobalt } \\
\text { Copper } \\
\text { Iron } \\
\text { Magnesium } \\
\text { Manganese } \\
\text { Molybdenum } \\
\text { Nickel } \\
\text { Phosphorus } \\
\text { Potassium } \\
\text { Silver } \\
\text { Sodium } \\
\text { Titanium } \\
\text { Vanadium }\end{array}$ & \begin{tabular}{|l} 
ICAP \\
ICAP \\
ICAP \\
ICAP \\
ICAP \\
ICAP \\
ICAP \\
ICAP \\
ICAP \\
ICAP \\
ICAP \\
ICAP \\
ICAP \\
ICAP \\
ICAP \\
ICAP
\end{tabular} & $\begin{array}{l}\mathrm{mg} / \mathrm{kg} \\
\mathrm{mg} / \mathrm{kg} \\
\mathrm{mg} / \mathrm{kg} \\
\mathrm{mg} / \mathrm{kg} \\
\mathrm{mg} / \mathrm{kg} \\
\mathrm{mg} / \mathrm{kg} \\
\mathrm{mg} / \mathrm{kg} \\
\mathrm{mg} / \mathrm{kg} \\
\mathrm{mg} / \mathrm{kg} \\
\mathrm{mg} / \mathrm{kg} \\
\mathrm{mg} / \mathrm{kg} \\
\mathrm{mg} / \mathrm{kg} \\
\mathrm{mg} / \mathrm{kg} \\
\mathrm{mg} / \mathrm{kg} \\
\mathrm{mg} / \mathrm{kg} \\
\mathrm{mg} / \mathrm{kg}\end{array}$ & & & & & $\begin{array}{r}33.3 \\
194000 \\
2.84 \\
\text { ND }(0.53) \\
\text { ND }(0.50) \\
2160 \\
107000 \\
72.7 \\
1.54 \\
1.71 \\
\text { ND (7.2) } \\
247 \\
\text { ND (0.44) } \\
200 \\
11.1 \\
5.35\end{array}$ & $\begin{array}{l}\mathrm{B} \\
\mathrm{B} \\
\mathrm{B} \\
\mathrm{B} \\
\mathrm{B} \\
\mathrm{B} \\
\mathrm{B} \\
\mathrm{B} \\
\mathrm{B} \\
\mathrm{B}\end{array}$ \\
\hline $\begin{array}{l}\text { Chloride } \\
\text { Fluoride }\end{array}$ & $\begin{array}{l}\text { SIE } \\
\text { SIE }\end{array}$ & $\begin{array}{l}\mathrm{mg} / \mathrm{kg} \\
\mathrm{mg} / \mathrm{kg}\end{array}$ & & & & & $\begin{array}{l}321 \\
385\end{array}$ & \\
\hline
\end{tabular}




\section{DATA NOT USED IN CALCULATIONS}




\section{Analytical Data Not Used In Calculations}

Stream: APF As Collection Method: Grab Composit Sample Type: Fly As

\begin{tabular}{|c|c|c|c|c|c|c|c|c|}
\hline Analyte & $\begin{array}{l}\text { Analytical } \\
\text { Technique }\end{array}$ & Units & Run 1 & Com 1 & Run 2 & Com 2 & Run 3 & Com 3 \\
\hline $\begin{array}{l}\text { Arsenic } \\
\text { Cadmium } \\
\text { Lead } \\
\text { Selenium }\end{array}$ & $\begin{array}{l}\text { ICAP } \\
\text { ICAP } \\
\text { ICAP } \\
\text { ICAP }\end{array}$ & $\begin{array}{l}\mathrm{mg} / \mathrm{kg} \\
\mathrm{mg} / \mathrm{kg} \\
\mathrm{mg} / \mathrm{kg} \\
\mathrm{mg} / \mathrm{kg}\end{array}$ & $\begin{array}{r}272 \\
\text { ND (2.9) } \\
32.2 \\
\text { ND (45) }\end{array}$ & $B$ & $\begin{array}{r}291 \\
4.41 \\
65.5 \\
\mathrm{ND}(49)\end{array}$ & & $\begin{array}{r}309 \\
\mathrm{ND}(3.2) \\
69.2 \\
\mathrm{ND}(50)\end{array}$ & B \\
\hline
\end{tabular}

Stream: APF Ash Collection Method: Grab Composite Sample Type: Fly Ash FD

\begin{tabular}{|c|c|c|c|c|c|c|c|c|}
\hline Analyte & $\begin{array}{l}\text { Analytical } \\
\text { Technique }\end{array}$ & Units & Run 1 & Com 1 & Run 2 & Com 2 & Run 3 & Com 3 \\
\hline $\begin{array}{l}\text { Arsenic } \\
\text { Cadmium } \\
\text { Lead } \\
\text { Selenium }\end{array}$ & $\begin{array}{l}\text { ICAP } \\
\text { ICAP } \\
\text { ICAP } \\
\text { ICAP }\end{array}$ & $\begin{array}{l}\mathrm{mg} / \mathrm{kg} \\
\mathrm{mg} / \mathrm{kg} \\
\mathrm{mg} / \mathrm{kg} \\
\mathrm{mg} / \mathrm{kg}\end{array}$ & & & & & $\begin{array}{r}307 \\
\mathrm{ND}(2.6) \\
98.4 \\
\mathrm{ND}(41)\end{array}$ & $B$ \\
\hline
\end{tabular}

Stream: APF Inlet Collection Method: M29 Sample Type: Filtered Solids

\begin{tabular}{|c|c|c|c|c|c|c|c|c|}
\hline Analyte & $\begin{array}{l}\text { Analytical } \\
\text { Technique }\end{array}$ & Units & Run I & Com 1 & Run 2 & $\operatorname{Com} 2$ & Run 3 & Com 3 \\
\hline $\begin{array}{l}\text { Arsenic } \\
\text { Cadmium } \\
\text { Lead } \\
\text { Selenium }\end{array}$ & $\begin{array}{l}\text { ICAP } \\
\text { ICAP } \\
\text { ICAP } \\
\text { ICAP }\end{array}$ & $\begin{array}{l}\mathrm{ug} / \mathrm{Nm} 3 \\
\mathrm{ug} / \mathrm{Nm} 3 \\
\mathrm{ug} / \mathrm{Nm}^{3} \\
\mathrm{ug} / \mathrm{Nm} 3\end{array}$ & $\begin{array}{r}959 \\
\text { ND (12) } \\
267 \\
\text { ND (190) }\end{array}$ & $\begin{array}{l}C \\
C \\
C\end{array}$ & $\begin{array}{r}1390 \\
\text { ND (17) } \\
308 \\
N D(270)\end{array}$ & $\begin{array}{l}\mathrm{C} \\
\mathrm{C} \\
\mathrm{C}\end{array}$ & $\begin{array}{r}1310 \\
\text { ND (14) } \\
315 \\
N D(220)\end{array}$ & $\begin{array}{l}C \\
C \\
C\end{array}$ \\
\hline
\end{tabular}

Stream: APF Inlet Collection Method: Multimetals Train Sample Type: Nitric Acid Impingers + TLR

\begin{tabular}{|c|c|c|c|c|c|c|c|c|}
\hline Analyte & $\begin{array}{l}\text { Analytical } \\
\text { Technique }\end{array}$ & $\overline{\text { Units }}$ & Run 1 & $\overline{\text { Com 1 }}$ & Run 2 & Com 2 & Run 3 & $\operatorname{Com} 3$ \\
\hline $\begin{array}{l}\text { Arsenic } \\
\text { Cadmium } \\
\text { Lead } \\
\text { Selenium }\end{array}$ & $\begin{array}{l}\text { GFAA } \\
\text { GFAA } \\
\text { GFAA } \\
\text { GFAA }\end{array}$ & $\begin{array}{l}\text { ug/Nm3 } \\
\text { ug/Nm3 } \\
\text { ug/Nm3 } 3 \\
\text { ug/Nm3 }\end{array}$ & $\begin{array}{r}0.986 \\
0.336 \\
1.50 \\
12.9\end{array}$ & $\begin{array}{l}\mathrm{C} \\
\mathrm{BC} \\
\mathrm{C}\end{array}$ & \begin{tabular}{r|}
9.47 \\
0.191 \\
3.37 \\
20.3
\end{tabular} & $\begin{array}{l}\mathrm{C} \\
\mathrm{BC} \\
\mathrm{C}\end{array}$ & $\begin{array}{r}1.97 \\
0.144 \\
1.26 \\
13.6 \\
\end{array}$ & $\mid \begin{array}{l}\mathrm{C} \\
\mathrm{BC} \\
\mathrm{C}\end{array}$ \\
\hline Antimony & $\mathrm{ICAP}$ & ug $/ \mathrm{Nm} 3$ & ND (21) & $\bar{B}$ & $\mathrm{ND}(23)$ & $\mathrm{B}$ & ND (20) & B \\
\hline
\end{tabular}




\section{Analytical Data Not Used In Calculations}

Stream: APF Inle Collection Method: Multimetals Trai Sample Type: Nitric Acid Impingers + TL

\begin{tabular}{|c|c|c|c|c|c|c|c|c|}
\hline Analyte & $\begin{array}{l}\text { Analytical } \\
\text { Technique }\end{array}$ & Units & $\overline{\overline{R u n} 1}$ & $\sqrt{\text { Com } 1}$ & $\overline{\text { Run } 2}$ & Com 2 & $\operatorname{Run} 3$ & Com 3 \\
\hline $\begin{array}{l}\text { Arsenic } \\
\text { Beryllium } \\
\text { Cadmium } \\
\text { Chromium } \\
\text { Cobalt } \\
\text { Copper } \\
\text { Lead } \\
\text { Manganese } \\
\text { Molybdenum } \\
\text { Nickel } \\
\text { Selenium } \\
\text { Vanadium }\end{array}$ & $\begin{array}{l}\text { ICAP } \\
\text { ICAP } \\
\text { ICAP } \\
\text { ICAP } \\
\text { ICAP } \\
\text { ICAP } \\
\text { ICAP } \\
\text { ICAP } \\
\text { ICAP } \\
\text { ICAP } \\
\text { ICAP } \\
\text { ICAP }\end{array}$ & $\begin{array}{l}\mathrm{ug} / \mathrm{Nm} 3 \\
\mathrm{ug} / \mathrm{Nm} 3 \\
\mathrm{ug} / \mathrm{Nm} 3 \\
\mathrm{ug} / \mathrm{Nm} 3 \\
\mathrm{ug} / \mathrm{Nm} 3 \\
\mathrm{ug} / \mathrm{Nm} 3 \\
\mathrm{ug} / \mathrm{Nm} 3 \\
\mathrm{ug} / \mathrm{Nm} 3 \\
\mathrm{ug} / \mathrm{Nm} 3 \\
\mathrm{ug} / \mathrm{Nm} 3 \\
\mathrm{ug} / \mathrm{Nm} 3 \\
\mathrm{ug} / \mathrm{Nm} 3\end{array}$ & $\begin{array}{r}\mathrm{ND}(13) \\
\mathrm{ND}(0.14) \\
\mathrm{ND}(1.1) \\
39.0 \\
\mathrm{ND}(1.1) \\
166 \\
7.14 \\
33.4 \\
4.97 \\
57.1 \\
\mathrm{ND}(24) \\
\mathrm{ND}(1.2)\end{array}$ & \begin{tabular}{|l} 
\\
$C$ \\
$C$ \\
$B C$ \\
$B C$ \\
$B C$ \\
$B C$ \\
$C$ \\
$C$ \\
$C$
\end{tabular} & $\begin{array}{r}\mathrm{ND}(14) \\
\mathrm{ND}(0.16) \\
\mathrm{ND}(1.2) \\
2.52 \\
\mathrm{ND}(1.3) \\
9.21 \\
8.55 \\
11.3 \\
\mathrm{ND}(2.3) \\
20.8 \\
\mathrm{ND}(27) \\
2.57\end{array}$ & \begin{tabular}{|l}
$\mathrm{C}$ \\
$\mathrm{C}$ \\
$\mathrm{BC}$ \\
$\mathrm{BC}$ \\
$\mathrm{BC}$ \\
$\mathrm{BC}$ \\
$\mathrm{C}$ \\
$\mathrm{C}$ \\
$\mathrm{B}$ \\
$\mathrm{C}$
\end{tabular} & $\begin{array}{r}\mathrm{ND}(13) \\
\mathrm{ND}(0.14) \\
\mathrm{ND}(1.0) \\
13.7 \\
\mathrm{ND}(1.1) \\
52.8 \\
8.46 \\
4.31 \\
\mathrm{ND}(2.0) \\
30.0 \\
\mathrm{ND}(24) \\
\mathrm{ND}(1.2)\end{array}$ & $\begin{array}{l}\mathrm{C} \\
\mathrm{C} \\
\mathrm{BC} \\
\mathrm{BC} \\
\mathrm{BC} \\
\mathrm{BC} \\
\mathrm{C} \\
\mathrm{B} \\
\mathrm{C}\end{array}$ \\
\hline Mercury & ICPMS & ug/Nm3 & 30.9 & $\bar{c}$ & 29.2 & $\sqrt{C}$ & 32.7 & C \\
\hline
\end{tabular}

Stream: APF Outlet Collection Method: M29 Sample Type: $47 \mathrm{~mm}$ Filter + Solids

\begin{tabular}{|c|c|c|c|c|c|c|c|c|}
\hline Analyte & $\begin{array}{l}\text { Analytical } \\
\text { Technique }\end{array}$ & Units & Run 1 & Com 1 & Run 2 & $\overline{C o m ~ 2 ~}$ & $\operatorname{Run} 3$ & $\mathrm{Com} 3$ \\
\hline $\begin{array}{l}\text { Arsenic } \\
\text { Cadmium } \\
\text { Lead } \\
\text { Selenium }\end{array}$ & $\begin{array}{l}\text { ICAP } \\
\text { ICAP } \\
\text { ICAP } \\
\text { ICAP }\end{array}$ & $\begin{array}{l}\text { ug/Nm3 } \\
\text { ug/Nm3 } \\
\text { ug/Nm3 } \\
\text { ug/Nm3 }\end{array}$ & $\begin{array}{r}0.200 \\
\operatorname{ND}(0.021) \\
\operatorname{ND}(0.12) \\
\operatorname{ND}(0.32)\end{array}$ & & $\begin{array}{r}\mathrm{ND}(0.21) \\
\mathrm{ND}(0.023) \\
0.165 \\
\mathrm{ND}(0.36)\end{array}$ & C & $\begin{array}{r}\text { ND (0.16) } \\
\text { ND }(0.017) \\
\text { ND }(0.095) \\
\text { ND }(0.26)\end{array}$ & \\
\hline
\end{tabular}

Stream: APF Outlet Collection Method: MM5 Sample Type: $47 \mathrm{~mm}$ Filter $1: 4$ dil

\begin{tabular}{|c|c|c|c|c|c|c|c|c|}
\hline Analyte & $\begin{array}{l}\text { Analytical } \\
\text { Technique }\end{array}$ & Units & Run 1 & $\overline{C o m ~ 1}$ & $\operatorname{Run} 2$ & Com 2 & $\operatorname{Run} 3$ & Com 3 \\
\hline $\begin{array}{l}\text { 1,2,4-Trichlorobenzene } \\
\text { 1,2-Dichlorobenzene } \\
\text { 1,3-Dichlorobenzene } \\
\text { 1,4-Dichlorobenzene } \\
\text { 2,4,5-Trichlorophenol }\end{array}$ & $\begin{array}{l}\text { GCMS } \\
\text { GCMS } \\
\text { GCMS } \\
\text { GCMS } \\
\text { GCMS }\end{array}$ & $\begin{array}{l}\mathrm{ug} / \mathrm{Nm} 3 \\
\mathrm{ug} / \mathrm{Nm} 3 \\
\mathrm{ug} / \mathrm{Nm} 3 \\
\mathrm{ug} / \mathrm{Nm} 3 \\
\mathrm{ug} / \mathrm{Nm} 3\end{array}$ & & & & & $\begin{array}{c}\mathrm{ND}(1.3) \\
\mathrm{ND}(1.1) \\
\mathrm{ND}(1.0) \\
\mathrm{ND}(0.98) \\
\mathrm{ND}(1.7)\end{array}$ & \\
\hline
\end{tabular}




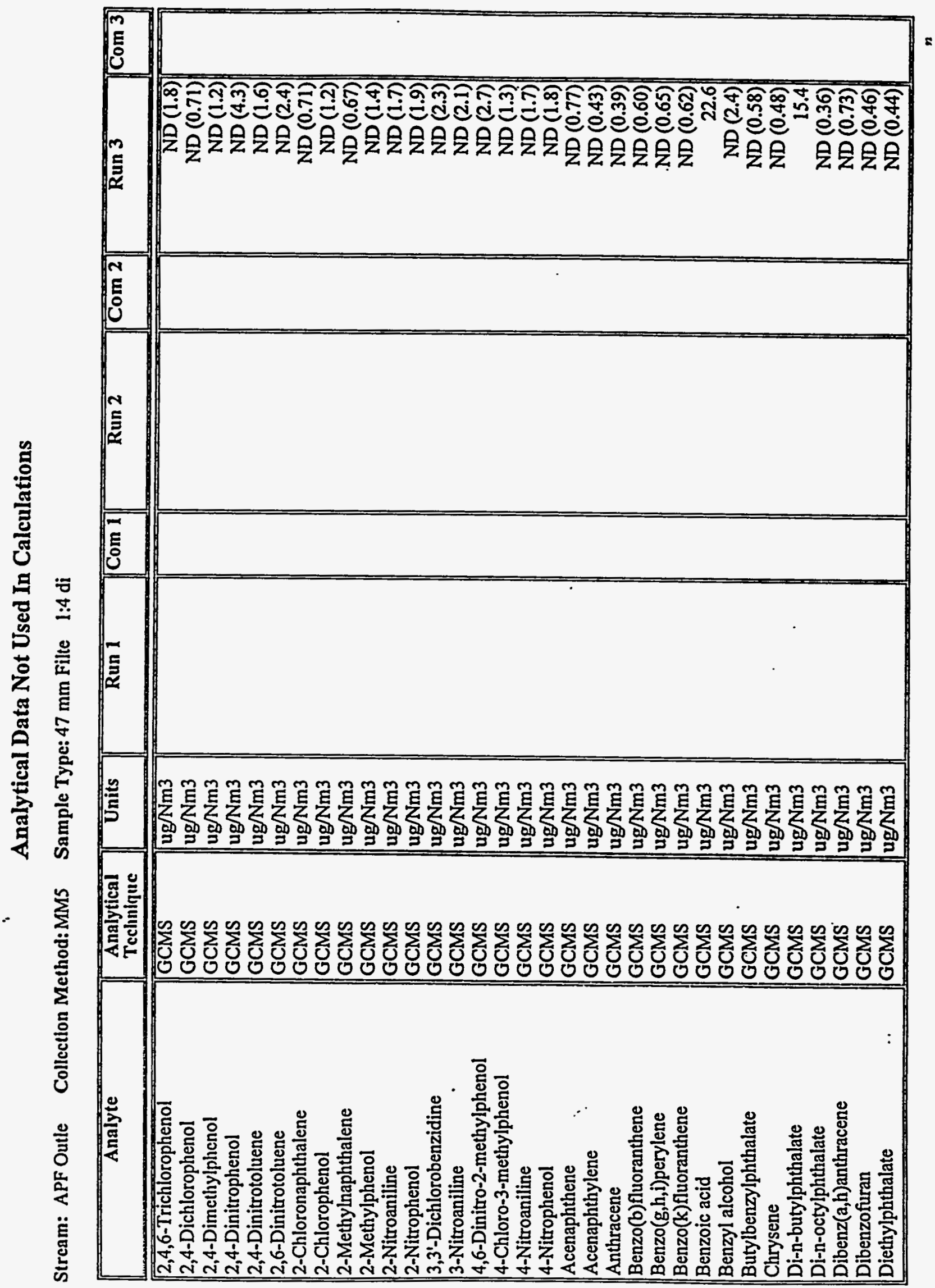


Stream: APF Outle Collection Method: MM5 Sample Type: $47 \mathrm{~mm}$ Filte 1:4 di

\begin{tabular}{|c|c|c|c|c|c|c|c|c|}
\hline Analyte & $\begin{array}{l}\text { Analytical } \\
\text { Technique }\end{array}$ & Units & Run 1 & Com 1 & Run 2 & $\overline{\operatorname{Com} 2}$ & Run 3 & $\mathrm{Com} 3$ \\
\hline $\begin{array}{l}\text { Dimethylphthalate } \\
\text { Fluoranthene } \\
\text { Fluorene } \\
\text { Hexachlorobenzene } \\
\text { Hexachlorobutadiene } \\
\text { Hexachlorocyclopentadiene } \\
\text { Hexachloroethane } \\
\text { Indeno(1,2,3-cd)pyrene } \\
\text { Isophorone } \\
\text { N-Nitroso-di-n-propylamine } \\
\text { Naphthalene } \\
\text { Nitrobenzene } \\
\text { Pentachlorophenol } \\
\text { Phenanthrene } \\
\text { Phenol } \\
\text { Pyrene } \\
\text { bis(2-Chloroethoxy)methane } \\
\text { bis(2-Chloroethyl)ether } \\
\text { bis(2-Ethylhexyl)phthalate }\end{array}$ & $\begin{array}{l}\text { GCMS } \\
\text { GCMS } \\
\text { GCMS } \\
\text { GCMS } \\
\text { GCMS } \\
\text { GCMS } \\
\text { GCMS } \\
\text { GCMS } \\
\text { GCMS } \\
\text { GCMS } \\
\text { GCMS } \\
\text { GCMS } \\
\text { GCMS } \\
\text { GCMS } \\
\text { GCMS } \\
\text { GCMS } \\
\text { GCMS } \\
\text { GCMS } \\
\text { GCMS }\end{array}$ & $\begin{array}{l}\mathrm{ug} / \mathrm{Nm} 3 \\
\mathrm{ug} / \mathrm{Nm} 3 \\
\mathrm{ug} / \mathrm{Nm} 3 \\
\mathrm{ug} / \mathrm{Nm} 3 \\
\mathrm{ug} / \mathrm{Nm} 3 \\
\mathrm{ug} / \mathrm{Nm} 3 \\
\mathrm{ug} / \mathrm{Nm} 3 \\
\mathrm{ug} / \mathrm{Nm} 3 \\
\mathrm{ug} / \mathrm{Nm} 3 \\
\mathrm{ug} / \mathrm{Nm} 3 \\
\mathrm{ug} / \mathrm{Nm} 3 \\
\mathrm{ug} / \mathrm{Nm} 3 \\
\mathrm{ug} / \mathrm{Nm} 3 \\
\mathrm{ug} / \mathrm{Nm} 3 \\
\mathrm{ug} / \mathrm{Nm} 3 \\
\mathrm{ug} / \mathrm{Nm} 3 \\
\mathrm{ug} / \mathrm{Nm} 3 \\
\mathrm{ug} / \mathrm{Nm} 3 \\
\mathrm{ug} / \mathrm{Nm} 3\end{array}$ & & & & & $\begin{array}{r}\text { ND (0.57) } \\
\text { ND (0.34) } \\
\text { ND (0.56) } \\
\text { ND (1.8) } \\
\text { ND (1.8) } \\
\text { ND (1.7) } \\
\text { ND (1.9) } \\
\text { ND (0.55) } \\
\text { ND (0.54) } \\
\text { ND (1.6) } \\
\text { ND (0.44) } \\
\text { ND (0.91) } \\
\text { ND (3.4) } \\
\text { ND(0.39) } \\
\text { ND (1.0) } \\
\text { ND (0.31) } \\
\text { ND(1.1) } \\
\text { ND (1.4) } \\
1.58\end{array}$ & \\
\hline
\end{tabular}

Stream: APF Outlet Collection Method: Multimetals Train Sample Type: Nitric Acid Impingers + TLR

\begin{tabular}{|c|c|c|c|c|c|c|c|c|}
\hline Analyte & $\begin{array}{l}\text { Analytical } \\
\text { Technique }\end{array}$ & Units & Run I & Com 1 & Run 2 & Com 2 & Run 3 & Com 3 \\
\hline $\begin{array}{l}\text { Arsenic } \\
\text { Cadmium } \\
\text { Lead } \\
\text { Selenium }\end{array}$ & $\begin{array}{l}\text { GFAA } \\
\text { GFAA } \\
\text { GFAA } \\
\text { GFAA }\end{array}$ & $\begin{array}{l}\mathrm{ug} / \mathrm{Nm} 3 \\
\mathrm{ug} / \mathrm{Nm} 3 \\
\mathrm{ug} / \mathrm{Nm} 3 \\
\mathrm{ug} / \mathrm{Nm} 3\end{array}$ & $\begin{array}{r}2.82 \\
0.108 \\
\text { ND }(0.62) \\
22.0\end{array}$ & $\begin{array}{l}\mathrm{C} \\
\mathrm{BC} \\
\mathrm{C} \\
\end{array}$ & $\begin{array}{r}3.99 \\
N D(0.066) \\
N D(0.71) \\
53.5\end{array}$ & $\begin{array}{l}\mathrm{C} \\
\mathrm{BC} \\
\mathrm{C}\end{array}$ & $\begin{array}{r}4.89 \\
N D(0.054) \\
0.650 \\
48.1\end{array}$ & $\begin{array}{l}\mathrm{C} \\
\mathrm{BC} \\
\mathrm{C}\end{array}$ \\
\hline $\begin{array}{l}\text { Antimony } \\
\text { Arsenic } \\
\text { Beryllium } \\
\text { Cadmium } \\
\end{array}$ & $\begin{array}{l}\text { ICAP } \\
\text { ICAP } \\
\text { ICAP } \\
\text { ICAP }\end{array}$ & $\begin{array}{l}\mathrm{ug} / \mathrm{Nm} 3 \\
\mathrm{ug} / \mathrm{Nm} 3 \\
\mathrm{ug} / \mathrm{Nm} 3 \\
\mathrm{ug} / \mathrm{Nm} 3\end{array}$ & $\begin{array}{r}\text { ND (23) } \\
\text { ND (14) } \\
\mathrm{ND}(0.15) \\
\mathrm{ND}(1.2) \\
\end{array}$ & C & $\begin{array}{r}\mathrm{ND}(26) \\
\mathrm{ND}(16) \\
\mathrm{ND}(0.18) \\
\mathrm{ND}(1.3)\end{array}$ & C & $\begin{array}{r}\mathrm{ND}(22) \\
\mathrm{ND}(13) \\
\mathrm{ND}(0.15) \\
\mathrm{ND}(1.1)\end{array}$ & C \\
\hline
\end{tabular}




\section{Analytical Data Not Used In Calculations}

Stream: APF Outle Collection Method: Multimetals Trai Sample Type: Nitric Acid Impingers + TL

\begin{tabular}{|c|c|c|c|c|c|c|c|c|}
\hline Analyte & $\begin{array}{l}\text { Analytical } \\
\text { Technique }\end{array}$ & Units & Run I & Com 1 & Run 2 & $\sqrt{\text { Com } 2}$ & Run 3 & Com 3 \\
\hline $\begin{array}{l}\text { Chromium } \\
\text { Cobalt } \\
\text { Copper } \\
\text { Lead } \\
\text { Manganese } \\
\text { Molybdenum } \\
\text { Nickel . } \\
\text { Selenium } \\
\text { Vanadium }\end{array}$ & $\begin{array}{l}\text { ICAP } \\
\text { ICAP } \\
\text { ICAP } \\
\text { ICAP } \\
\text { ICAP } \\
\text { ICAP } \\
\text { ICAP } \\
\text { ICAP } \\
\text { ICAP }\end{array}$ & $\begin{array}{l}\mathrm{ug} / \mathrm{Nm} 3 \\
\mathrm{ug} / \mathrm{Nm} 3 \\
\mathrm{ug} / \mathrm{Nm} 3 \\
\mathrm{ug} / \mathrm{Nm} 3 \\
\mathrm{ug} / \mathrm{Nm} 3 \\
\mathrm{ug} / \mathrm{Nm} 3 \\
\mathrm{ug} / \mathrm{Nm} 3 \\
\mathrm{ug} / \mathrm{Nm} 3 \\
\mathrm{ug} / \mathrm{Nm} 3\end{array}$ & $\begin{array}{r}2.79 \\
\text { ND (1.2) } \\
\text { ND (2.8) } \\
\text { ND (6.5) } \\
1.68 \\
6.10 \\
61.0 \\
61.3 \\
\text { ND (1.4) }\end{array}$ & $\begin{array}{l}\mathrm{C} \\
\mathrm{BC} \\
\mathrm{BC} \\
\mathrm{BC} \\
\mathrm{BC} \\
\mathrm{C} \\
\mathrm{B} \\
\mathrm{C}\end{array}$ & $\begin{array}{r}\mathrm{ND}(1.8) \\
\mathrm{ND}(1.4) \\
\mathrm{ND}(3.2) \\
\mathrm{ND}(7.4) \\
1.95 \\
\mathrm{ND}(2.5) \\
7.97 \\
53.0 \\
\mathrm{ND}(1.6)\end{array}$ & $\begin{array}{l}\mathrm{C} \\
\mathrm{BC} \\
\mathrm{BC} \\
\mathrm{BC} \\
\mathrm{BC} \\
\mathrm{C} \\
\mathrm{B} \\
\mathrm{C}\end{array}$ & $\begin{array}{r}167 \\
\text { ND (1.2) } \\
\text { ND (2.6) } \\
\text { ND (6.1) } \\
-25.6 \\
2.54 \\
99.8 \\
48.6 \\
\text { ND (1.3) }\end{array}$ & $\begin{array}{l}\mathrm{C} \\
\mathrm{BC} \\
\mathrm{BC} \\
\mathrm{BC} \\
\mathrm{BC} \\
\mathrm{C} \\
\mathrm{B} \\
\mathrm{C}\end{array}$ \\
\hline Mercury & ICPMS & $\overline{\mathrm{ug} / \mathrm{Nm} 3}$ & 19.1 & C & 24.4 & C & 18.6 & $\bar{C}$ \\
\hline
\end{tabular}

Stream: Bed Ash Collection Method: Grab Composite Sample Type: Bottom Ash

\begin{tabular}{|c|c|c|c|c|c|c|c|c|}
\hline Analyte & $\begin{array}{l}\text { Analytical } \\
\text { Technique }\end{array}$ & Units & Run 1 & Com 1 & Run 2 & Com 2 & Run 3 & $\operatorname{Com~3}$ \\
\hline $\begin{array}{l}\text { Arsenic } \\
\text { Cadmium } \\
\text { Lead } \\
\text { Selenium }\end{array}$ & $\begin{array}{l}\text { ICAP } \\
\text { ICAP } \\
\text { ICAP } \\
\text { ICAP }\end{array}$ & $\begin{array}{l}\mathrm{mg} / \mathrm{kg} \\
\mathrm{mg} / \mathrm{kg} \\
\mathrm{mg} / \mathrm{kg} \\
\mathrm{mg} / \mathrm{kg}\end{array}$ & $\begin{array}{r}60.8 \\
\text { ND (2.9) } \\
\text { ND (17) } \\
\text { ND (46) }\end{array}$ & $\mathrm{B}$ & $\begin{array}{r}75.9 \\
\text { ND (3.4) } \\
32.1 \\
\text { ND (54) }\end{array}$ & B & $\begin{array}{l}\text { ND (30) } \\
\text { ND (3.2) } \\
\text { ND (18) } \\
\text { ND (50) }\end{array}$ & B \\
\hline
\end{tabular}

Stream: Bed Ash Collection Method: Grab Composite Sample Type: Bottom Ash FD

\begin{tabular}{|c|c|c|c|c|c|c|c|c|}
\hline Analyte & $\begin{array}{l}\text { Analytical } \\
\text { Technique }\end{array}$ & Units & Run 1 & Com 1 & Run 2 & Com 2 & Run 3 & Com 3 \\
\hline \begin{tabular}{|l} 
Arsenic \\
Cadmium \\
Lcad \\
Selenium
\end{tabular} & $\begin{array}{l}\text { ICAP } \\
\text { ICAP } \\
\text { ICAP } \\
\text { ICAP }\end{array}$ & $\begin{array}{l}\mathrm{mg} / \mathrm{kg} \\
\mathrm{mg} / \mathrm{kg} \\
\mathrm{mg} / \mathrm{kg} \\
\mathrm{mg} / \mathrm{kg}\end{array}$ & & & & & $\begin{array}{r}59.6 \\
\text { ND (2.9) } \\
\text { ND (17) } \\
\text { ND (46) }\end{array}$ & $B$ \\
\hline
\end{tabular}


Stream: Coal Past Collection Method: Grab Composit Sample Type: Filtered Solid

\begin{tabular}{|c|c|c|c|c|c|c|c|c|}
\hline Analyte & $\begin{array}{l}\text { Analytical } \\
\text { Technique }\end{array}$ & Units & Run 1 & Com 1 & Run 2 & $\longdiv { \operatorname { C o m } 2 }$ & Run 3 & Com 3 \\
\hline $\begin{array}{l}\text { Arsenic } \\
\text { Selenium }\end{array}$ & $\begin{array}{l}\overline{\text { GFAA }} \\
\text { GFAA }\end{array}$ & $\begin{array}{l}\text { ug/g } \\
\text { ug/g }\end{array}$ & $\begin{array}{r}21.0 \\
N D(0.50)\end{array}$ & & $\begin{array}{r}29.0 \\
0.600\end{array}$ & & $\begin{array}{l}31.0 \\
1.00\end{array}$ & \\
\hline Molybdenum & ICAP & ug/g & $\mathrm{ND}(3.0)$ & & ND (3.0) & & 83.0 & \\
\hline $\begin{array}{l}\text { Barium } \\
\text { Bromine } \\
\text { Cadmium } \\
\text { Calcium } \\
\text { Cerium } \\
\text { Cesium } \\
\text { Chlorine } \\
\text { Chromium } \\
\text { Copper } \\
\text { Europium } \\
\text { Hafnium } \\
\text { Iodine } \\
\text { Lanthanum } \\
\text { Lutetium } \\
\text { Magnesium } \\
\text { Mercury } \\
\text { Neodymium } \\
\text { Rubidium } \\
\text { Samarium } \\
\text { Scandium } \\
\text { Selenium } \\
\text { Strontium } \\
\text { Tantalum } \\
\text { Terbium } \\
\text { Thorium } \\
\text { Tin } \\
\text { Titanium } \\
\text { Tungsten } \\
\text { Uranium }\end{array}$ & $\begin{array}{l}\text { NAA } \\
\text { NAA } \\
\text { NAA } \\
\text { NAA } \\
\text { NAA } \\
\text { NAA } \\
\text { NAA } \\
\text { NAA } \\
\text { NAA } \\
\text { NAA } \\
\text { NAA } \\
\text { NAA } \\
\text { NAA } \\
\text { NAA } \\
\text { NAA } \\
\text { NAA } \\
\text { NAA } \\
\text { NAA } \\
\text { NAA } \\
\text { NAA } \\
\text { NAA } \\
\text { NAA } \\
\text { NAA } \\
\text { NAA } \\
\text { NAA } \\
\text { NAA } \\
\text { NAA } \\
\text { NAA } \\
\text { NAA }\end{array}$ & $\begin{array}{l}\mathrm{ug} / \mathrm{g} \\
\mathrm{ug} / \mathrm{g} \\
\mathrm{ug} / \mathrm{g} \\
\mathrm{ug} / \mathrm{g} \\
\mathrm{ug} / \mathrm{g} \\
\mathrm{ug} / \mathrm{g} \\
\mathrm{ug} / \mathrm{g} \\
\mathrm{ug} / \mathrm{g} \\
\mathrm{ug} / \mathrm{g} \\
\mathrm{ug} / \mathrm{g} \\
\mathrm{ug} / \mathrm{g} \\
\mathrm{ug} / \mathrm{g} \\
\mathrm{ug} / \mathrm{g} \\
\mathrm{ug} / \mathrm{g} \\
\mathrm{ug} / \mathrm{g} \\
\mathrm{ug} / \mathrm{g} \\
\mathrm{ug} / \mathrm{g} \\
\mathrm{ug} / \mathrm{g} \\
\mathrm{ug} / \mathrm{g} \\
\mathrm{ug} / \mathrm{g} \\
\mathrm{ug} / \mathrm{g} \\
\mathrm{ug} / \mathrm{g} \\
\mathrm{ug} / \mathrm{g} \\
\mathrm{ug} / \mathrm{g} \\
\mathrm{ug} / \mathrm{g} \\
\mathrm{ug} / \mathrm{g} \\
\mathrm{ug} / \mathrm{g} \\
\mathrm{ug} / \mathrm{g} \\
\mathrm{ug} / \mathrm{g}\end{array}$ & $\begin{array}{r}88.4 \\
15.5 \\
\text { ND }(2.6) \\
1200 \\
13.9 \\
1.45 \\
848 \\
17.8 \\
14.3 \\
0.289 \\
0.785 \\
1.90 \\
6.65 \\
0.135 \\
627 \\
0.0474 \\
9.34 \\
26.1 \\
1.41 \\
3.21 \\
1.59 \\
18.9 \\
0.236 \\
0.161 \\
2.28 \\
\text { ND }(7.7) \\
809 \\
56.0 \\
0.836\end{array}$ & & $\begin{array}{r}114 \\
16.1 \\
\text { ND }(2.7) \\
1500 \\
14.2 \\
1.57 \\
873 \\
19.7 \\
14.3 \\
0.314 \\
0.804 \\
1.88 \\
8.09 \\
0.137 \\
745 \\
0.110 \\
7.34 \\
19.7 \\
1.46 \\
3.31 \\
1.77 \\
51.6 \\
0.200 \\
0.166 \\
2.35 \\
\text { ND }(7.8) \\
829 \\
65.2 \\
0.719\end{array}$ & & $\begin{array}{r}82.5 \\
15.1 \\
\text { ND }(2.2) \\
1300 \\
15.3 \\
1.57 \\
838 \\
18.2 \\
12.9 \\
0.325 \\
0.913 \\
2.38 \\
7.66 \\
0.168 \\
777 \\
0.0292 \\
6.59 \\
19.0 \\
1.52 \\
3.41 \\
1.91 \\
49.7 \\
0.243 \\
0.174 \\
2.44 \\
\text { ND }(7.7) \\
969 \\
77.6 \\
0.698 \\
\end{array}$ & . \\
\hline
\end{tabular}




\section{Analytical Data Not Used In Calculations}

Stream: Coal Past Collection Method: Grab Composit Sample Type: Filtered Solid

\begin{tabular}{|c|c|c|c|c|c|c|c|c|}
\hline Analyte & $\begin{array}{l}\text { Analytical } \\
\text { Technique }\end{array}$ & Units & Run 1 & Com 1 & Run 2 & Com 2 & Run 3 & Com 3 \\
\hline $\begin{array}{l}\text { Ytterbium } \\
\text { Zinc } \\
\text { Zirconium }\end{array}$ & $\begin{array}{l}\text { NAA } \\
\text { NAA } \\
\text { NAA }\end{array}$ & $\begin{array}{l}\mathrm{ug} / \mathrm{g} \\
\mathrm{ug} / \mathrm{g} \\
\mathrm{ug} / \mathrm{g}\end{array}$ & $\begin{array}{r}0.547 \\
7.72 \\
28.0 \\
\end{array}$ & & $\begin{array}{r}0.460 \\
11.2 \\
20.2\end{array}$ & & $\begin{array}{r}0.420 \\
11.1 \\
36.3\end{array}$ & \\
\hline
\end{tabular}

Stream: Coal Paste Collection Method: Grab Composite Sample Type: Filtered Solids FD

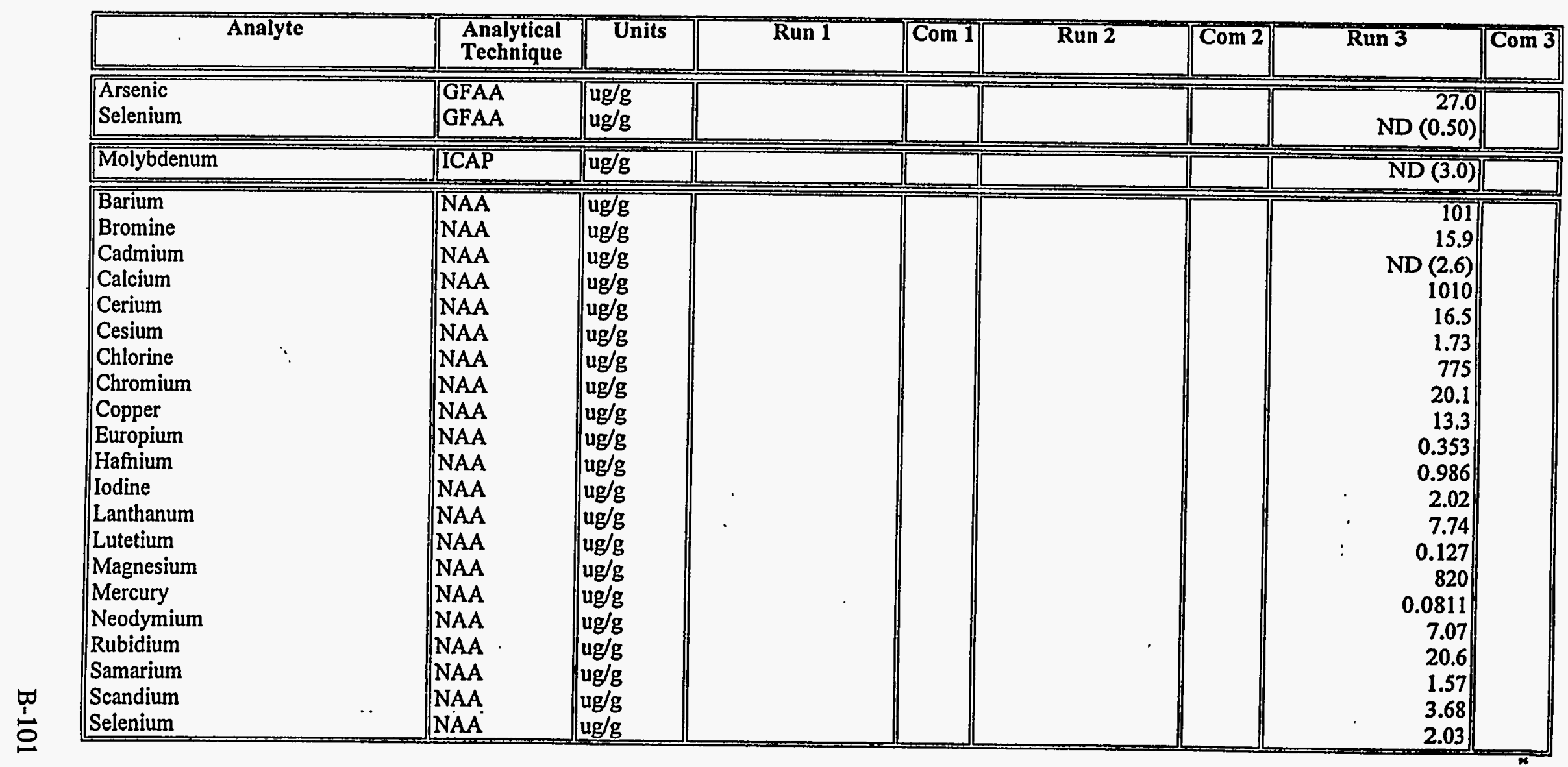


Stream: Coal Past Collection Method: Grab Composit Sample Type: Filtered Solid FD

\begin{tabular}{|c|c|c|c|c|c|c|c|c|}
\hline Analyte & $\begin{array}{l}\text { Analytical } \\
\text { Technique }\end{array}$ & Units & Run 1 & Com 1 & Run 2 & Com 2 & Run 3 & $\operatorname{Com} 3$ \\
\hline \begin{tabular}{|l} 
Strontium \\
Tantalum \\
Terbium \\
Thorium \\
Tin \\
Titanium \\
Tungsten \\
Uranium \\
Ytterbium \\
Zinc \\
Zirconium
\end{tabular} & $\begin{array}{l}\overline{\text { NAA }} \\
\text { NAA } \\
\text { NAA } \\
\text { NAA } \\
\text { NAA } \\
\text { NAA } \\
\text { NAA } \\
\text { NAA } \\
\text { NAA } \\
\text { NAA } \\
\text { NAA }\end{array}$ & $\begin{array}{l}\mathrm{ug} / \mathrm{g} \\
\mathrm{ug} / \mathrm{g} \\
\mathrm{ug} / \mathrm{g} \\
\mathrm{ug} / \mathrm{g} \\
\mathrm{ug} / \mathrm{g} \\
\mathrm{ug} / \mathrm{g} \\
\mathrm{ug} / \mathrm{g} \\
\mathrm{ug} / \mathrm{g} \\
\mathrm{ug} / \mathrm{g} \\
\mathrm{ug} / \mathrm{g} \\
\mathrm{ug} / \mathrm{g}\end{array}$ & & & & & $\begin{array}{r}37.4 \\
2110 \\
0.178 \\
2.52 \\
\mathrm{ND}(7.7) \\
868 \\
60.0 \\
1.01 \\
0.784 \\
25.2 \\
53.8\end{array}$ & \\
\hline
\end{tabular}

Stream: Cyclone Ash Collection Method: Grab Composite Sample Type: Fly Ash

\begin{tabular}{|c|c|c|c|c|c|c|c|c|}
\hline Analyte & $\begin{array}{l}\text { Analytical } \\
\text { Technique }\end{array}$ & Units & Run 1 & Com 1 & Run 2 & Com 2 & Run 3 & Com 3 \\
\hline \begin{tabular}{|l} 
Arsenic \\
Cadmium \\
Lead \\
Selenium
\end{tabular} & $\begin{array}{l}\text { ICAP } \\
\text { ICAP } \\
\text { ICAP } \\
\text { ICAP }\end{array}$ & $\begin{array}{l}\mathrm{mg} / \mathrm{kg} \\
\mathrm{mg} / \mathrm{kg} \\
\mathrm{mg} / \mathrm{kg} \\
\mathrm{mg} / \mathrm{kg}\end{array}$ & $\begin{array}{r}121 \\
\text { ND (2.8) } \\
\text { ND (16) } \\
\text { ND (43) }\end{array}$ & B & $\begin{array}{r}130 \\
\text { ND (2.7) } \\
38.4 \\
\mathrm{ND}(43)\end{array}$ & $B$ & $\begin{array}{r}171 \\
\mathrm{ND}(2.5) \\
41.3 \\
\mathrm{ND}(40)\end{array}$ & B \\
\hline
\end{tabular}

Stream: Cyclone As Collection Method: Grab Composit Sample Type: Fly As FD

\begin{tabular}{|c|c|c|c|c|c|c|c|c|}
\hline Analyte & $\begin{array}{l}\text { Analytical } \\
\text { Technique }\end{array}$ & Units & Run 1 & Com 1 & Run 2 & Com 2 & Run 3 & Com 3 \\
\hline $\begin{array}{l}\text { Arsenic } \\
\text { Cadmium } \\
\text { Lend } \\
\text { SelenlitıI }\end{array}$ & $\begin{array}{l}\text { ICAP } \\
\text { ICAP } \\
\text { ICAP } \\
\text { ICAI }\end{array}$ & $\begin{array}{l}\mathrm{mg} / \mathrm{kg} \\
\mathrm{mg} / \mathrm{kg} \\
\mathrm{mg} / \mathrm{kg} \\
\mathrm{mg} / \mathrm{kg}\end{array}$ & & & & & $\begin{array}{r}129 \\
\text { ND }(2.9) \\
38.7 \\
46.3\end{array}$ & $B$ \\
\hline
\end{tabular}


Analytical Data Not Used In Calculations

Stream: ESP Ash Collection Method: Grab Composite Sample Type: Fly Ash

\begin{tabular}{|c|c|c|c|c|c|c|c|c|}
\hline Analyte & $\begin{array}{l}\text { Analytical } \\
\text { Technique }\end{array}$ & Units & Run 1 & $\sqrt{\mathrm{Com} \mathrm{1}}$ & Run 2 & Com 2 & $\operatorname{Run} 3$ & $\mathrm{Com} 3$ \\
\hline $\begin{array}{l}\text { Arsenic } \\
\text { Cadmium } \\
\text { Lead } \\
\text { Selenium }\end{array}$ & $\begin{array}{l}\text { ICAP } \\
\text { ICAP } \\
\text { ICAP } \\
\text { ICAP }\end{array}$ & $\begin{array}{l}\mathrm{mg} / \mathrm{kg} \\
\mathrm{mg} / \mathrm{kg} \\
\mathrm{mg} / \mathrm{kg} \\
\mathrm{mg} / \mathrm{kg}\end{array}$ & $\begin{array}{r}406 \\
\mathrm{ND}(3.7) \\
80.6 \\
\mathrm{ND}(58)\end{array}$ & B & $\begin{array}{r}350 \\
\mathrm{ND}(3.6) \\
94.2 \\
\mathrm{ND}(56)\end{array}$ & B & $\begin{array}{r}411 \\
\mathrm{ND}(3.6) \\
122 \\
\mathrm{ND}(57)\end{array}$ & B \\
\hline
\end{tabular}

Stream: ESP As Collection Method:Grab Composit Sample Type: Fly As FD

\begin{tabular}{|c|c|c|c|c|c|c|c|}
\hline Analyte & $\begin{array}{l}\text { Analytical } \\
\text { Technique }\end{array}$ & Units & Run 1 & Com 1 $\quad$ Run 2 & Com 2 & Run 3 & Com 3 \\
\hline $\begin{array}{l}\text { Arsenic } \\
\text { Cadmium } \\
\text { Lead } \\
\text { Selenium }\end{array}$ & $\begin{array}{l}\text { ICAP } \\
\text { ICAP } \\
\text { ICAP } \\
\text { ICAP }\end{array}$ & $\begin{array}{l}\mathrm{mg} / \mathrm{kg} \\
\mathrm{mg} / \mathrm{kg} \\
\mathrm{mg} / \mathrm{kg} \\
\mathrm{mg} / \mathrm{kg}\end{array}$ & & & & $\begin{array}{r}350 \\
\text { ND (3.3) } \\
136 \\
\text { ND (52) }\end{array}$ & $B$ \\
\hline
\end{tabular}

Stream: ESP Inlet Collection Method: MM5 Sample Type: MeCl2 PNR/MM5 Filter

\begin{tabular}{|c|c|c|c|c|c|c|c|c|}
\hline Analyte & $\begin{array}{l}\text { Analytical } \\
\text { Technique }\end{array}$ & Units & Run 1 & Com 1 & Run 2 & Com 2 & Run 3 & Com 3 \\
\hline Di-n-butylphthalate & GCMS & ug/Nm3 & & $\overline{\mathrm{BE}}$ & & & & \\
\hline
\end{tabular}

Stream: ESP Inlet Collection Method: MM5 Sample Type: MeCl2 PNR/MM5 Filter 1:2 dil

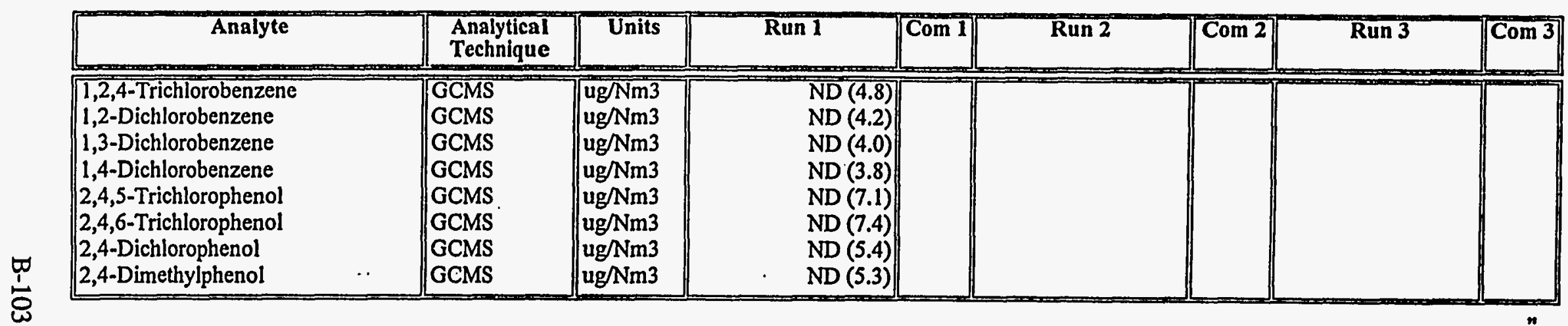


Stream: ESP Inlet Collection Method: MMS Sample Type: MeCl2 PNR/MM5 Filter 1:2 dil

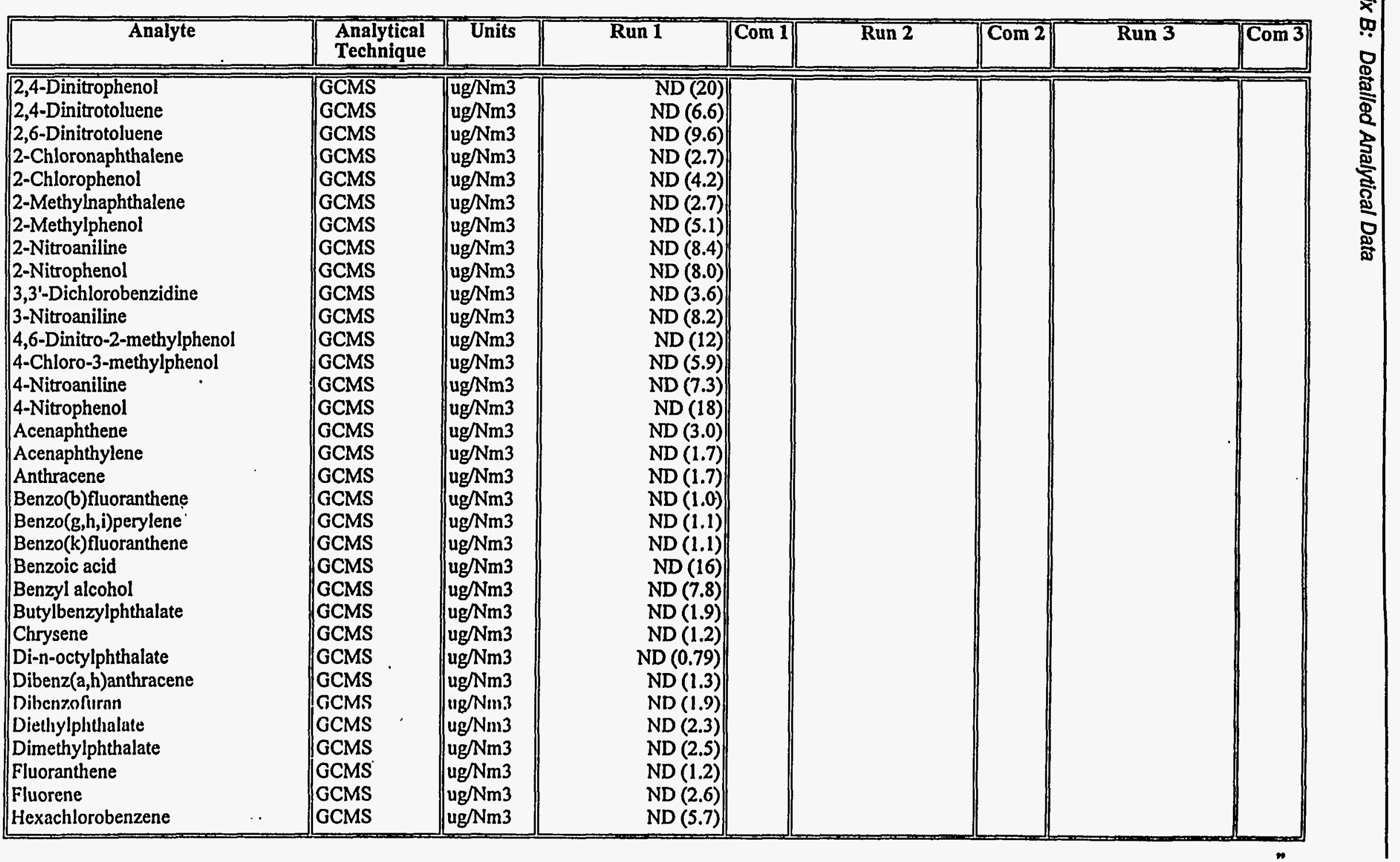




\section{Analytical Data Not Used In Calculations}

Stream: ESP Inlet Collection Method: MM5 Sample Type: MeCl2 PNR/MM5 Filter 1:2 dil

\begin{tabular}{|c|c|c|c|c|c|c|c|c|}
\hline Analyte & $\begin{array}{l}\text { Analytical } \\
\text { Technique }\end{array}$ & Units & Run 1 & Com 1 & Run 2 & Com 2 & Run 3 & Com 3 \\
\hline $\begin{array}{l}\text { Hexachlorobutadiene } \\
\text { Hexachlorocyclopentadiene } \\
\text { Hexachloroethane } \\
\text { Indeno(1,2,3-cd)pyrene } \\
\text { Isophorone } \\
\text { N-Nitroso-di-n-propylamine } \\
\text { Naphthalene } \\
\text { Nitrobenzene } \\
\text { Pentachlorophenol } \\
\text { Phenanthrene } \\
\text { Phenol } \\
\text { Pyrene } \\
\text { bis(2-Chloroethoxy)methane } \\
\text { bis(2-Chloroethyl)ether } \\
\text { bis(2-Ethylhexyl)phthalate }\end{array}$ & $\begin{array}{l}\text { GCMS } \\
\text { GCMS } \\
\text { GCMS } \\
\text { GCMS } \\
\text { GCMS } \\
\text { GCMS } \\
\text { GCMS } \\
\text { GCMS } \\
\text { GCMS } \\
\text { GCMS } \\
\text { GCMS } \\
\text { GCMS } \\
\text { GCMS } \\
\text { GCMS } \\
\text { GCMS }\end{array}$ & $\begin{array}{l}u g / N m 3 \\
u g / N m 3 \\
u g / N m 3 \\
u g / N m 3 \\
u g / N m 3 \\
u g / N m 3 \\
u g / N m 3 \\
u g / N m 3 \\
u g / N m 3 \\
u g / N m 3 \\
u g / N m 3 \\
u g / N m 3 \\
u g / N m 3 \\
u g / N m 3 \\
u g / N m 3\end{array}$ & $\begin{array}{r}\text { ND (7.8) } \\
\text { ND (9.2) } \\
\text { ND (8.2) } \\
\text { ND (0.95) } \\
\text { ND (2.6) } \\
\text { ND (7.4) } \\
4.88 \\
\text { ND (4.5) } \\
\mathrm{ND}(15) \\
\mathrm{ND}(1.7) \\
\mathrm{ND}(3.5) \\
\mathrm{ND}(1.1) \\
\mathrm{ND}(4.0) \\
\mathrm{ND}(4.7) \\
7.28\end{array}$ & BJ & & & $\cdot$ & \\
\hline
\end{tabular}

Stream: ESP Inlet Collection Method: MM5 Sample Type: XAD Resin/Impingers + MeCL2

\begin{tabular}{|c|c|c|c|c|c|c|c|c|}
\hline Analyte & $\begin{array}{l}\text { Analytical } \\
\text { Technique }\end{array}$ & Units & Run 1 & Com 1 & Run 2 & $\overline{\text { Com 2 }}$ & Run 3 & Com 3 \\
\hline $\begin{array}{l}\text { Benzoic acid } \\
\text { bis(2-Ethylhexyl)phthalate }\end{array}$ & $\begin{array}{l}\text { GCMS } \\
\text { GCMS }\end{array}$ & $\begin{array}{l}\mathrm{ug} / \mathrm{Nm} 3 \\
\mathrm{ug} / \mathrm{Nm} 3\end{array}$ & $\begin{array}{l}119 \\
469\end{array}$ & $\begin{array}{l}\mathrm{E} \\
\mathrm{E}\end{array}$ & 228 & $\bar{E}$ & 124 & $\overline{\mathrm{E}}$ \\
\hline
\end{tabular}

Stream: ESP Inle Collection Method:MM5 Sample Type: XAD Resin/Impingers $+\mathrm{MeCl} \quad 1: 10 \mathrm{di}$

\begin{tabular}{|c|c|c|c|c|c|c|}
\hline Analyte & $\begin{array}{l}\text { Analytical } \\
\text { Technique }\end{array}$ & Units & Run I & Com 1 $\quad$ Run 2 & Com 2 Run 3 & $\overline{\operatorname{Com} 3}$ \\
\hline $\begin{array}{l}\text { 1,2,4-Trichlorobenzene } \\
\text { 1,2-Dichlorobenzene } \\
\text { 1,3-Dichlorobenzene } \\
\text { 1,4-Dichlorobenzene } \\
\text { 2,4,5-Trichlorophenol } \\
\text { 2,4,6-Trichlorophenol }\end{array}$ & $\begin{array}{l}\text { GCMS } \\
\text { GCMS } \\
\text { GCMS } \\
\text { GCMS } \\
\text { GCMS } \\
\text { GCMS }\end{array}$ & $\begin{array}{l}\text { ug/Nm3 } \\
\text { ug/Nm3 } 3 \\
\text { ug/Nm3 } 3 \\
\text { ug/Nm3 } \\
\text { ug/Nm3 } \\
\text { ug/Nm3 }\end{array}$ & $\begin{array}{l}\mathrm{ND}(22) \\
\mathrm{ND}(19) \\
\mathrm{ND}(18) \\
\mathrm{ND}(17) \\
\mathrm{ND}(30) \\
\mathrm{ND}(31)\end{array}$ & & & \\
\hline
\end{tabular}


Stream: ESP Inlet Collection Method: MM5 Sample Type: XAD Resin/Impingers $+\mathrm{MeCl} 2 \quad$ 1:10 dil

\begin{tabular}{|c|c|c|c|c|c|c|c|c|}
\hline Analyte & $\begin{array}{l}\text { Analytical } \\
\text { Technique }\end{array}$ & Units & Run 1 & Com 1 & Run 2 & $\longdiv { \operatorname { C o m } 2 }$ & Run 3 & \\
\hline $\begin{array}{l}\text { 2,4-Dichlorophenol } \\
\text { 2,4-Dimethylphenol } \\
\text { 2,4-Dinitrophenol } \\
\text { 2,4-Dinitrotoluene } \\
\text { 2,6-Dinitrotoluene } \\
\text { 2-Chloronaphthalene } \\
\text { 2-Chlorophenol } \\
\text { 2-Methylnaphthalene } \\
\text { 2-Methylphenol } \\
\text { 2-Nitroaniline } \\
\text { 2-Nitrophenol } \\
\text { 3,3'-Dichlorobenzidine } \\
\text { 3-Nitroaniline } \\
\text { 4,6-Dinitro-2-methylphenol } \\
\text { 4-Chloro-3-methylphenol } \\
\text { 4-Nitroaniline } \\
\text { 4-Nitrophenol } \\
\text { Acenaphthene } \\
\text { Acenaphthylene } \\
\text { Anthracene } \\
\text { Benzo(b)fluoranthene } \\
\text { Benzo(g,h,i)perylene } \\
\text { Benzo(k)fluoranthene } \\
\text { Benzyl alcohol } \\
\text { Butylbenzylphthalate } \\
\text { Chrysene } \\
\text { Di-n-butylphthalate } \\
\text { Di-n-octylphthalate } \\
\text { Dibenz(a,h)anthracene } \\
\text { Dibenzofuran } \\
\text { Diethylphthalate } \\
\text { Dimethylphthalate } \\
\text { Fluoranthene } \\
\text { - }\end{array}$ & $\begin{array}{l}\text { GCMS } \\
\text { GCMS } \\
\text { GCMS } \\
\text { GCMS } \\
\text { GCMS } \\
\text { GCMS } \\
\text { GCMS } \\
\text { GCMS } \\
\text { GCMS } \\
\text { GCMS } \\
\text { GCMS } \\
\text { GCMS } \\
\text { GCMS } \\
\text { GCMS } \\
\text { GCMS } \\
\text { GCMS } \\
\text { GCMS } \\
\text { GCMS } \\
\text { GCMS } \\
\text { GCMS } \\
\text { GCMS } \\
\text { GCMS } \\
\text { GCMS } \\
\text { GCMS } \\
\text { GCMS } \\
\text { GCMS } \\
\text { GCMS } \\
\text { GCMS } \\
\text { GCMS } \\
\text { GCMS } \\
\text { GCMS } \\
\text { GCMS } \\
\text { GCMS }\end{array}$ & $\begin{array}{l}\mathrm{ug} / \mathrm{Nm} 3 \\
\mathrm{ug} / \mathrm{Nm} 3 \\
\mathrm{ug} / \mathrm{Nm} 3 \\
\mathrm{ug} / \mathrm{Nm} 3 \\
\mathrm{ug} / \mathrm{Nm} 3 \\
\mathrm{ug} / \mathrm{Nm} 3 \\
\mathrm{ug} / \mathrm{Nm} 3 \\
\mathrm{ug} / \mathrm{Nm} 3 \\
\mathrm{ug} / \mathrm{Nm} 3 \\
\mathrm{ug} / \mathrm{Nm} 3 \\
\mathrm{ug} / \mathrm{Nm} 3 \\
\mathrm{ug} / \mathrm{Nm} 3 \\
\mathrm{ug} / \mathrm{Nm} 3 \\
\mathrm{ug} / \mathrm{Nm} 3 \\
\mathrm{ug} / \mathrm{Nm} 3 \\
\mathrm{ug} / \mathrm{Nm} 3 \\
\mathrm{ug} / \mathrm{Nm} 3 \\
\mathrm{ug} / \mathrm{Nm} 3 \\
\mathrm{ug} / \mathrm{Nm} 3 \\
\mathrm{ug} / \mathrm{Nm} 3 \\
\mathrm{ug} / \mathrm{Nm} 3 \\
\mathrm{ug} / \mathrm{Nm} 3 \\
\mathrm{ug} / \mathrm{Nm} 3 \\
\mathrm{ug} / \mathrm{Nm} 3 \\
\mathrm{ug} / \mathrm{Nm} 3 \\
\mathrm{ug} / \mathrm{Nm} 3 \\
\mathrm{ug} / \mathrm{Nm} 3 \\
\mathrm{ug} / \mathrm{Nm} 3 \\
\mathrm{ug} / \mathrm{Nm} 3 \\
\mathrm{ug} / \mathrm{Nm} 3 \\
\mathrm{ug} / \mathrm{Nm} 3 \\
\mathrm{ug} / \mathrm{Nm} 3 \\
\mathrm{ug} / \mathrm{Nm} 3\end{array}$ & 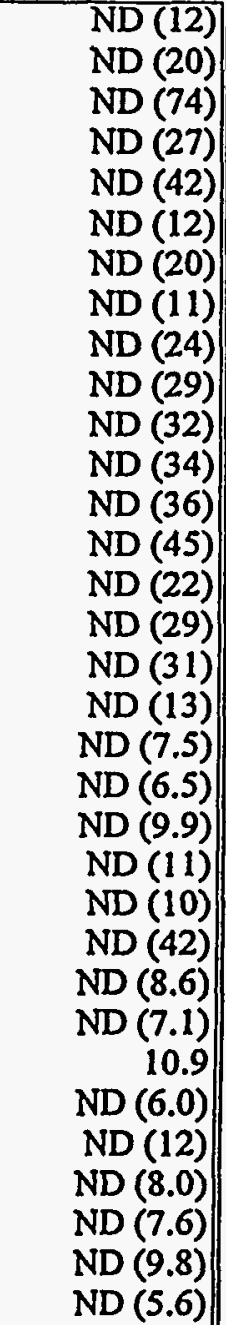 & J & $\cdot$ & & & \\
\hline
\end{tabular}


Analytical Data Not Used In Calculations

Stream: ESP Inlet Collection Method: MM5 Sample Type: XAD Resin//mpingers $+\mathrm{MeCl} 2 \quad$ 1:10 dil

\begin{tabular}{|c|c|c|c|c|c|c|c|c|}
\hline Analyte & $\begin{array}{l}\text { Analytical } \\
\text { Technique }\end{array}$ & Units & Run 1 & Com 1 & Run 2 & Com 2 & Run 3 & $\longdiv { \operatorname { C o m } 3 }$ \\
\hline \begin{tabular}{|l} 
Fluorene \\
Hexachlorobenzene \\
Hexachlorobutadiene \\
Hexachlorocyclopentadiene \\
Hexachloroethane \\
Indeno(1,2,3-cd)pyrene \\
Isophorone \\
N-Nitroso-di-n-propylamine \\
Naphthalene \\
Nitrobenzene \\
Pentachlorophenol \\
Phenanthrene \\
Phenol \\
Pyrene \\
bis(2-Chloroethoxy)methane \\
bis(2-Chloroethyl)ether
\end{tabular} & $\begin{array}{l}\text { GCMS } \\
\text { GCMS } \\
\text { GCMS } \\
\text { GCMS } \\
\text { GCMS } \\
\text { GCMS } \\
\text { GCMS } \\
\text { GCMS } \\
\text { GCMS } \\
\text { GCMS } \\
\text { GCMS } \\
\text { GCMS } \\
\text { GCMS } \\
\text { GCMS } \\
\text { GCMS } \\
\text { GCMS }\end{array}$ & $\begin{array}{l}\mathrm{ug} / \mathrm{Nm} 3 \\
\mathrm{ug} / \mathrm{Nm} 3 \\
\mathrm{ug} / \mathrm{Nm} 3 \\
\mathrm{ug} / \mathrm{Nm} 3 \\
\mathrm{ug} / \mathrm{Nm} 3 \\
\mathrm{ug} / \mathrm{Nm} 3 \\
\mathrm{ug} / \mathrm{Nm} 3 \\
\mathrm{ug} / \mathrm{Nm} 3 \\
\mathrm{ug} / \mathrm{Nm} 3 \\
\mathrm{ug} / \mathrm{Nm} 3 \\
\mathrm{ug} / \mathrm{Nm} 3 \\
\mathrm{ug} / \mathrm{Nm} 3 \\
\mathrm{ug} / \mathrm{Nm} 3 \\
\mathrm{ug} / \mathrm{Nm} 3 \\
\mathrm{ug} / \mathrm{Nm} 3 \\
\mathrm{ug} / \mathrm{Nm} 3\end{array}$ & $\begin{array}{r}\text { ND (9.7) } \\
27.7 \\
\text { ND (31) } \\
\text { ND (30) } \\
\text { ND (34) } \\
\text { ND (9.1) } \\
\text { ND (9.3) } \\
\text { ND (27) } \\
\text { ND (7.5) } \\
\text { ND (16) } \\
\text { ND (57) } \\
\text { ND (6.6) } \\
\text { ND (18) } \\
\text { ND (4.6) } \\
\text { ND (19) } \\
\text { ND (25) }\end{array}$ & $\| \mathrm{J}$ & & & & \\
\hline
\end{tabular}

Stream: ESP Inlet Collection Method: MM5 Sample Type: XAD Resin//mpingers + MeC12 1:2 dil

\begin{tabular}{|c|c|c|c|c|c|c|c|c|}
\hline Analyte & $\begin{array}{l}\text { Analytical } \\
\text { Technique }\end{array}$ & Units & Run 1 & Com 1 & Run 2 & Com 2 & Run 3 & Com 3 \\
\hline $\begin{array}{l}\text { 1,2,4-Trichlorobenzene } \\
\text { 1,2-Dichlorobenzene } \\
\text { 1,3-Dichlorobenzene } \\
\text { 1,4-Dichlorobenzene } \\
\text { 2,4,5-Trichlorophenol } \\
\text { 2,4,6-Trichlorophenol } \\
\text { 2,4-Dichlorophenol } \\
\text { 2,4-Dimethylphenol } \\
\text { 2,4-Dinitrophenol } \\
\text { 2,4-Dinitrotoluene } \\
\text { 2,6-Dinitrotoluene } \\
\text { 2-Chloronaphthalene }\end{array}$ & $\begin{array}{l}\text { GCMS } \\
\text { GCMS } \\
\text { GCMS } \\
\text { GCMS } \\
\text { GCMS } \\
\text { GCMS } \\
\text { GCMS } \\
\text { GCMS } \\
\text { GCMS } \\
\text { GCMS } \\
\text { GCMS } \\
\text { GCMS }\end{array}$ & 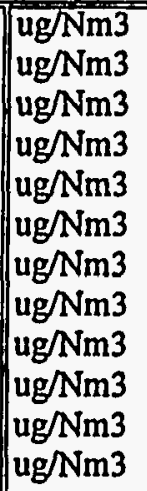 & & & & & $\begin{array}{l}\mathrm{ND}(5.0) \\
\mathrm{ND}(4.3) \\
\mathrm{ND}(4.1) \\
\mathrm{ND}(3.9) \\
\mathrm{ND}(6.3) \\
\mathrm{ND}(6.6) \\
\mathrm{ND}(2.8) \\
\mathrm{ND}(4.6) \\
\mathrm{ND}(16) \\
\mathrm{ND}(5.8) \\
\mathrm{ND}(8.9) \\
\mathrm{ND}(2.6)\end{array}$ & \\
\hline
\end{tabular}




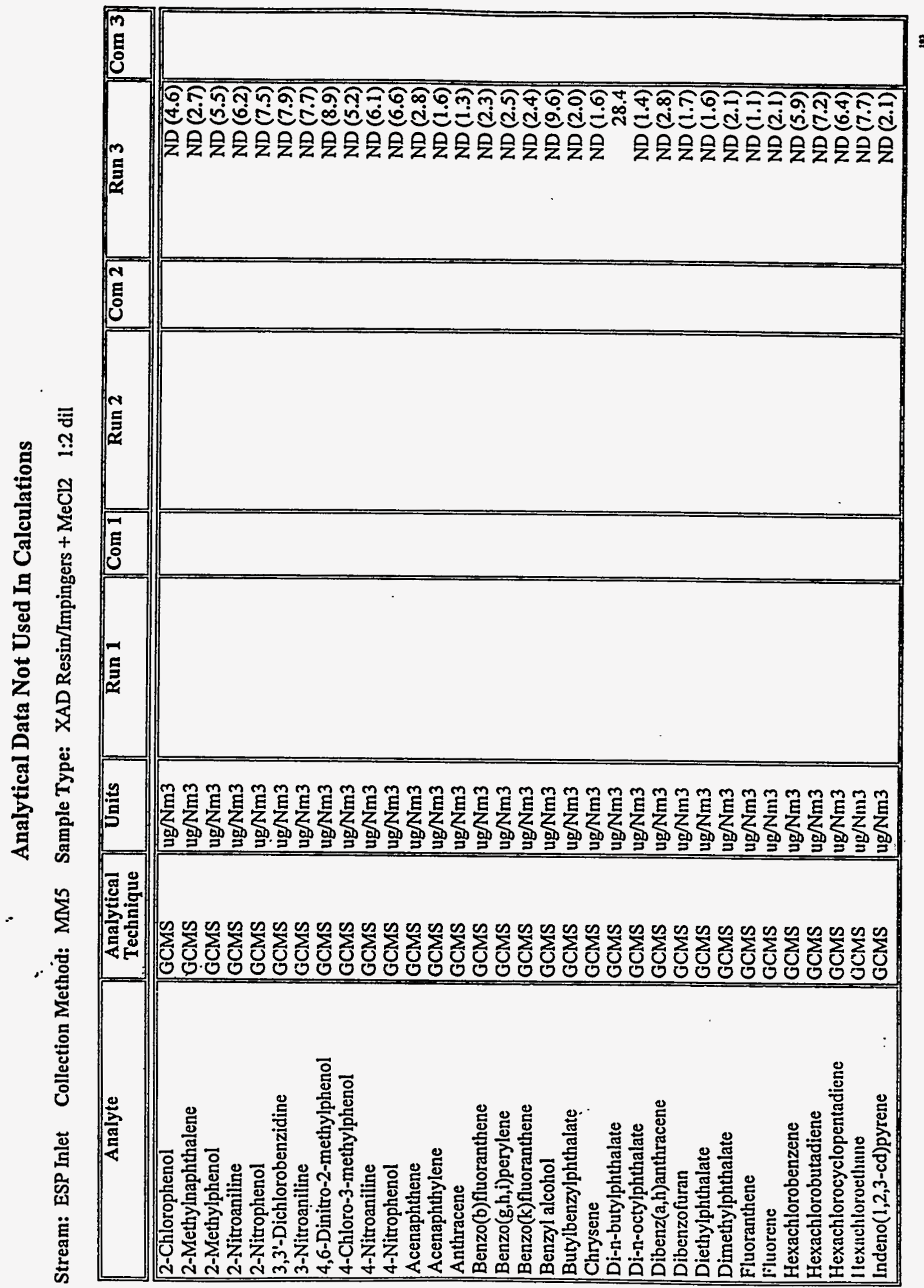




\section{Analytical Data Not Used In Calculations}

Stream: ESP Inlet Collection Method: MM5 Sample Type: XAD Resin/Impingers + MeCl2 1:2 dil

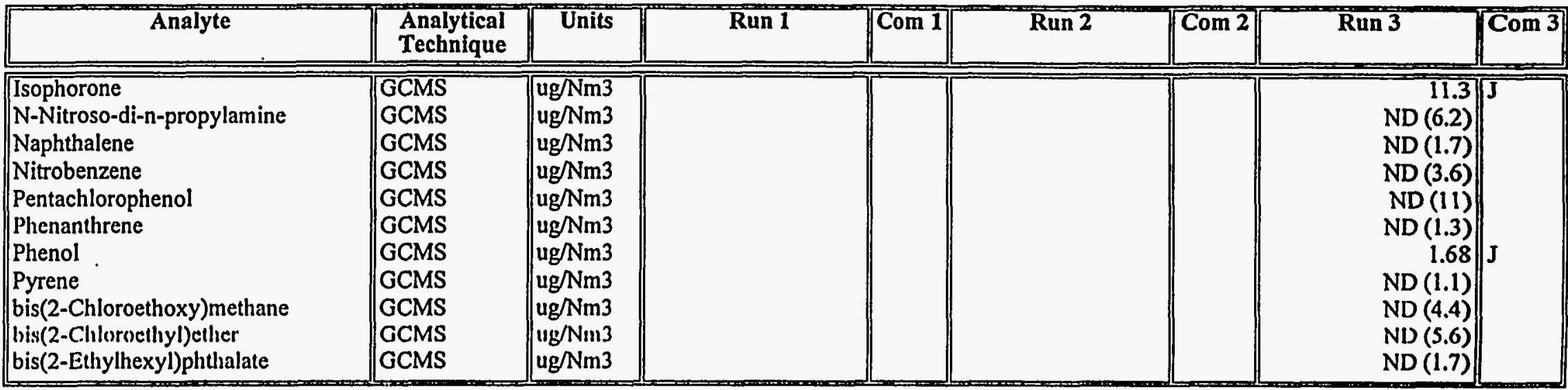

Stream: ESP Inlet Collection Method: MM5 Sample Type: XAD Resin/Impingers + MeCl2 1:4 dil

\begin{tabular}{|c|c|c|c|c|c|c|c|c|}
\hline Analyte & $\begin{array}{l}\text { Analytical } \\
\text { Technique }\end{array}$ & Units & Run 1 & Com 1 & Run 2 & $\operatorname{Com} 2$ & Run 3 & $\operatorname{Com} 3$ \\
\hline \begin{tabular}{|l} 
1,2,4-Trichlorobenzene \\
1,2-Dichlorobenzene \\
1,3-Dichlorobenzene \\
1,4-Dichlorobenzene \\
2,4,5-Trichlorophenol \\
2,4,6-Trichlorophenol \\
2,4-Dichlorophenol \\
2,4-Dimethylphenol \\
2,4-Dinitrophenol \\
2,4-Dinitrotoluene \\
2,6-Dinitrotoluene \\
2-Chloronaphthalene \\
2-Chlorophenol \\
2-Methylnaphthalene \\
2-Methylphenol \\
2-Nitroaniline \\
2-Nitrophenol
\end{tabular} & $\begin{array}{l}\text { GCMS } \\
\text { GCMS } \\
\text { GCMS } \\
\text { GCMS } \\
\text { GCMS } \\
\text { GCMS } \\
\text { GCMS } \\
\text { GCMS } \\
\text { GCMS } \\
\text { GCMS } \\
\text { GCMS } \\
\text { GCMS } \\
\text { GCMS } \\
\text { GCMS } \\
\text { GCMS } \\
\text { GCMS }\end{array}$ & $\begin{array}{l}\mathrm{ug} / \mathrm{Nm} 3 \\
\mathrm{ug} / \mathrm{Nm} 3 \\
\mathrm{ug} / \mathrm{Nm} 3 \\
\mathrm{ug} / \mathrm{Nm} 3 \\
\mathrm{ug} / \mathrm{Nm} 3 \\
\mathrm{ug} / \mathrm{Nm} 3 \\
\mathrm{ug} / \mathrm{Nm} 3 \\
\mathrm{ug} / \mathrm{Nm} 3 \\
\mathrm{ug} / \mathrm{Nm} 3 \\
\mathrm{ug} / \mathrm{Nm} 3 \\
\mathrm{ug} / \mathrm{Nm} 3 \\
\mathrm{ug} / \mathrm{Nm} 3 \\
\mathrm{ug} / \mathrm{Nm} 3 \\
\mathrm{ug} / \mathrm{Nm} 3 \\
\mathrm{ug} / \mathrm{Nm} 3 \\
\mathrm{ug} / \mathrm{Nm} 3 \\
\mathrm{ug} / \mathrm{Nm} 3\end{array}$ & & & $\begin{array}{l}\text { ND (9.7) } \\
\text { ND (8.0) } \\
\text { ND (7.6) } \\
\text { ND (7.2) } \\
\text { ND (13) } \\
\text { ND (14) } \\
\text { ND (5.4) } \\
\text { ND (8.9) } \\
\text { ND (33) } \\
\text { ND (12) } \\
\text { ND (19) } \\
\text { ND (5.4) } \\
\text { ND (8.5) } \\
\text { ND (5.1) } \\
\text { ND (10) } \\
\text { ND (13) } \\
\text { ND (14) }\end{array}$ & & . & \\
\hline
\end{tabular}


Stream: ESP Inlet Collection Method: MM5 Sample Type: XAD Resin/Impingers + MeCl2 1:4 dil

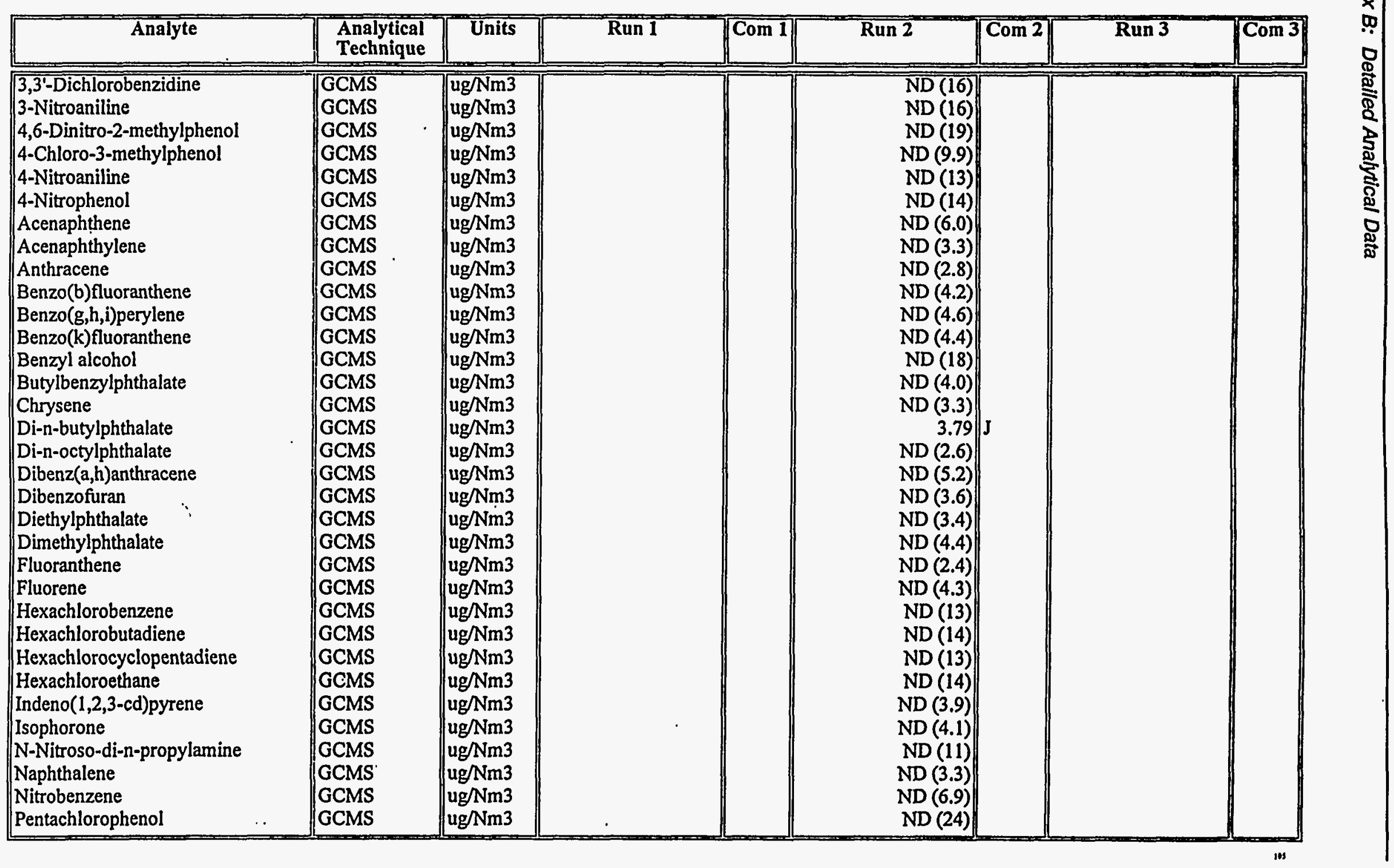




\section{Analytical Data Not Used In Calculations}

Stream: ESP Inlet Collection Method: MM5 Sample Type: XAD Resin/Impingers + MeCL2 1:4 dil

\begin{tabular}{|c|c|c|c|c|c|c|c|c|}
\hline Analyte & $\begin{array}{l}\text { Analytical } \\
\text { Technique }\end{array}$ & Units & Run 1 & $\overline{\text { Com } 1}$ & Run 2 & Com 2 & Run 3 & Com 3 \\
\hline $\begin{array}{l}\text { Phenanthrene } \\
\text { Phenol } \\
\text { Pyrene } \\
\text { bis(2-Chloroethoxy)methane } \\
\text { bis(2-Chloroethyl)ether } \\
\text { bis(2-Ethylhexyl)phthalate }\end{array}$ & $\begin{array}{l}\text { GCMS } \\
\text { GCMS } \\
\text { GCMS } \\
\text { GCMS } \\
\text { GCMS } \\
\text { GCMS }\end{array}$ & $\begin{array}{l}\mathrm{ug} / \mathrm{Nm} 3 \\
\mathrm{ug} / \mathrm{Nm} 3 \\
\mathrm{ug} / \mathrm{Nm} 3 \\
\mathrm{ug} / \mathrm{Nm} 3 \\
\mathrm{ug} / \mathrm{Nm} 3 \\
\mathrm{ug} / \mathrm{Nm} 3\end{array}$ & & & $\begin{array}{r}\mathrm{ND}(2.8) \\
2.84 \\
\mathrm{ND}(2.1) \\
\mathrm{ND}(8.5) \\
\mathrm{ND}(10) \\
11.2\end{array}$ & $J$ & & \\
\hline
\end{tabular}

Stream: ESP Inlet Collection Method: Multimetals Train Sample Type: Nitric Acid Impingers + TLR

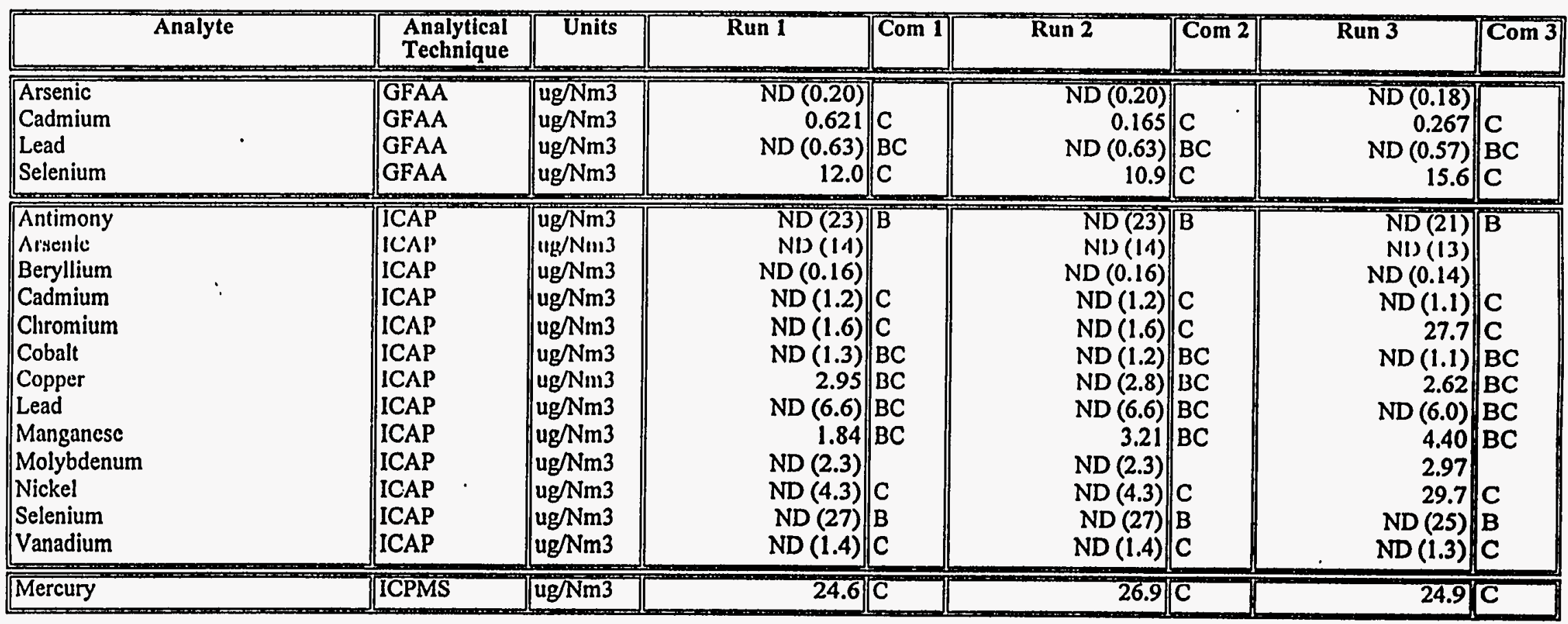


Stream: ESP Outlet Collection Method: MM5 Sample Type: XAD Resin/Impingers + MeCl2

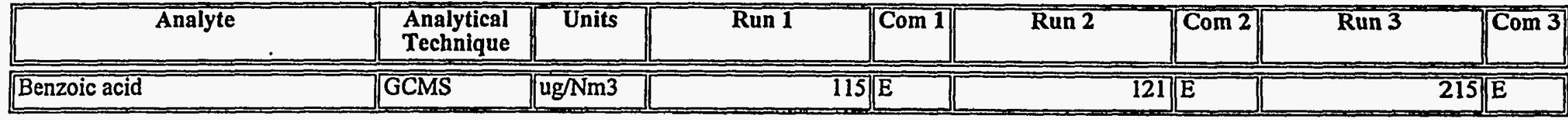

Stream: ESP Outlet Collection Method: MM5 Sample Type: XAD Resin/lmpingers + MeCl2 1:2 dil

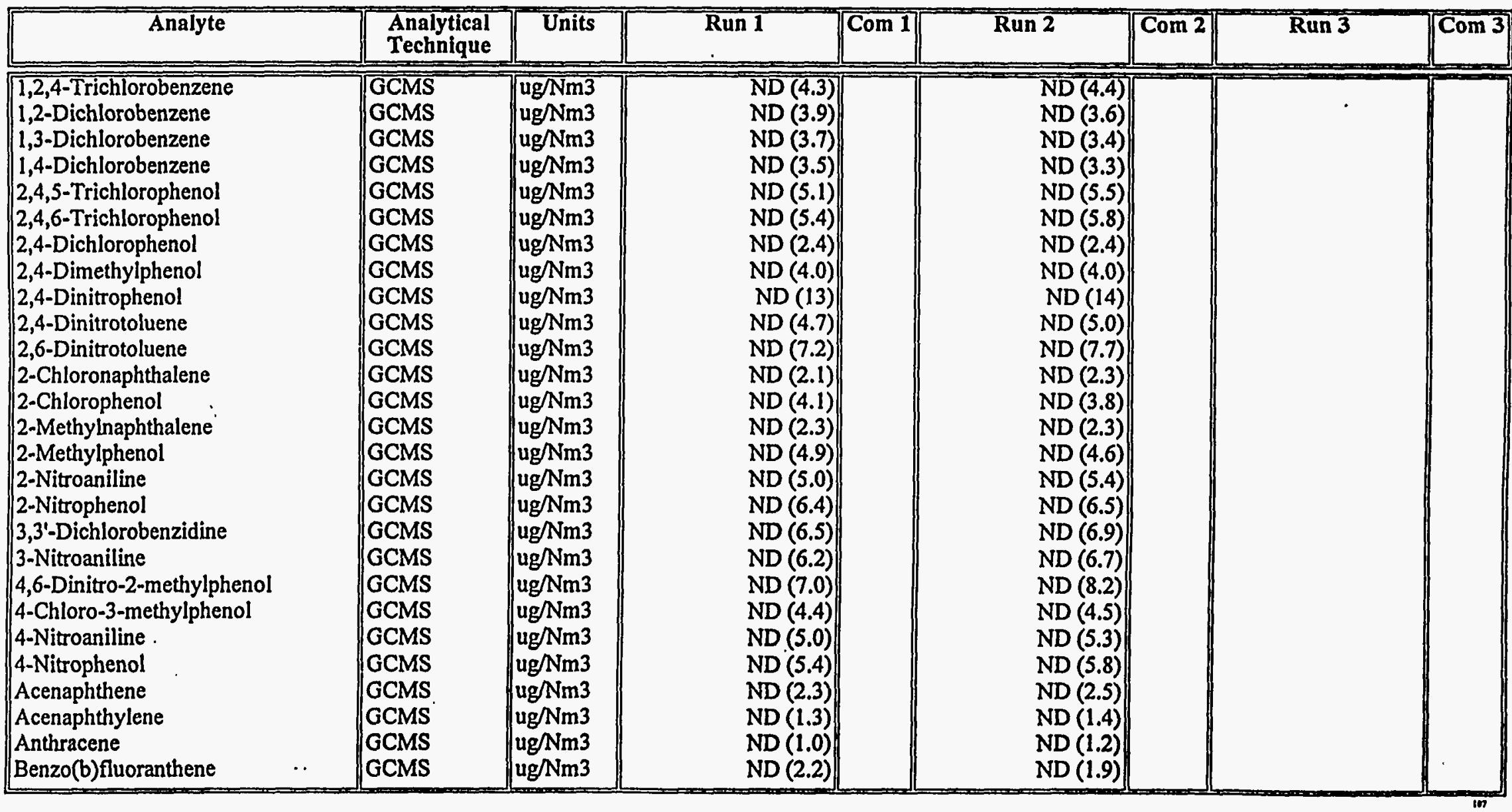


Analytical Data Not Used In Calculations

Stream: ESP Outlet Collection Method: MM5 Sample Type: XAD Resin/Impingers + MeCl2 1:2 dil

\begin{tabular}{|c|c|c|c|c|c|c|c|c|}
\hline Analyte & $\begin{array}{l}\text { Analytical } \\
\text { Technique }\end{array}$ & Units & Run 1 & Com 1 & Run 2 & Com 2 & Run 3 & $\overline{\operatorname{Com} 3}$ \\
\hline $\begin{array}{l}\text { Benzo(g,h,i)perylene } \\
\text { Benzo(k)fluoranthene } \\
\text { Benzyl alcohol } \\
\text { Butylbenzylphthalate } \\
\text { Chrysene } \\
\text { Di-n-butylphthalate } \\
\text { Di-n-octylphthalate } \\
\text { Dibenz(a,h)anthracene } \\
\text { Dibenzofuran } \\
\text { Diethylphthalate } \\
\text { Dimethylphthalate } \\
\text { Fluoranthene } \\
\text { Fluorene } \\
\text { Hexachlorobenzene } \\
\text { Ilexachlorobutadiene } \\
\text { Hexachlorocyclopentadiene } \\
\text { Hexachloroethane } \\
\text { Indeno(1,2,3-cd)pyrene } \\
\text { lsopliofino } \\
\text { N-Nitroso-di-n-propylamine } \\
\text { Naphthalene } \\
\text { Nitrobenzene } \\
\text { Pentachlorophenol } \\
\text { Phenanthrene } \\
\text { Phenol } \\
\text { Pyrene } \\
\text { bis(2-Chloroethoxy)methane } \\
\text { bis(2-Chloroethyl)ether } \\
\text { bis(2-Ethylhexyl)phthalate }\end{array}$ & \begin{tabular}{|l} 
GCMS \\
GCMS \\
GCMS \\
GCMS \\
GCMS \\
GCMS \\
GCMS \\
GCMS \\
GCMS \\
GCMS \\
GCMS \\
GCMS \\
GCMS \\
GCMS \\
GCMS \\
GCMS \\
GCMS \\
GCMS \\
CCMS \\
GCMS \\
GCMS \\
GCMS \\
GCMS \\
GCMS \\
GCMS \\
GCMS \\
GCMS \\
GCMS \\
GCMS
\end{tabular} & 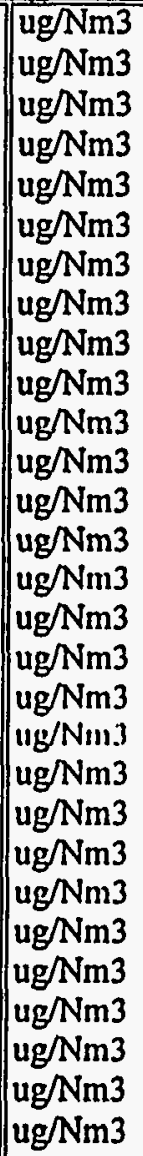 & $\begin{array}{r}\text { ND (2.4) } \\
\text { ND (2.3) } \\
\text { ND (8.7) } \\
\text { ND (1.6) } \\
\text { ND (1.3) } \\
17.6 \\
\text { ND (1.3) } \\
\text { ND (2.7) } \\
\text { ND (1.4) } \\
2.88 \\
\text { ND (1.7) } \\
\text { ND (0.88) } \\
\text { ND (1.7) } \\
\text { ND (4.7) } \\
\text { ND (6.2) } \\
\text { ND (5.2) } \\
\text { ND (6.9) } \\
\text { ND (2.0) } \\
21.7 \\
\text { ND (5.5) } \\
\text { ND (1.5) } \\
\text { ND (3.1) } \\
\text { ND (9.0) } \\
\text { ND (1.0) } \\
1.82 \\
\text { ND (0.87) } \\
\text { ND (3.8) } \\
\text { ND (5.0) } \\
15.4\end{array}$ & $\| \mathrm{J}$ & $\begin{array}{r}\text { ND (2.0) } \\
\text { ND (1.9) } \\
\text { ND (8.1) } \\
\text { ND (1.7) } \\
\text { ND (1.4) } \\
5.86 \\
\text { ND (1.1) } \\
\text { ND (2.3) } \\
\text { ND (1.5) } \\
\text { ND (1.4) } \\
\text { ND (1.8) } \\
\text { ND (1.0) } \\
\text { ND (1.8) } \\
\text { ND (5.4) } \\
\text { ND (6.3) } \\
\text { ND (5.6) } \\
\text { ND (6.4) } \\
\text { ND (1.7) } \\
\text { ND (1.9) } \\
\text { ND (5.2) } \\
\text { ND (1.5) } \\
\text { ND (3.1) } \\
\text { ND (10) } \\
\text { ND (1.2) } \\
1.28 \\
\text { ND (0.92) } \\
\text { ND (3.9) } \\
\text { ND (4.7) } \\
\text { ND (1.5) }\end{array}$ & $J$ & & \\
\hline
\end{tabular}


Stream: ESP Outlet Collection Method: MM5 Sample Type: XAD Resin/Impingers + MeCl2 1:4 dil

\begin{tabular}{|c|c|c|c|c|c|c|c|c|}
\hline Analyte & $\begin{array}{l}\text { Analytical } \\
\text { Technique }\end{array}$ & Units & Run 1 & Com 1 & Run 2 & $\overline{\text { Com 2 }}$ & Run 3 & Com 3 \\
\hline $\begin{array}{l}\text { 1,2,4-Trichlorobenzene } \\
\text { 1,2-Dichlorobenzene } \\
\text { 1,3-Dichlorobenzene } \\
\text { 1,4-Dichlorobenzene } \\
\text { 2,4,5-Trichlorophenol } \\
\text { 2,4,6-Trichlorophenol } \\
\text { 2,4-Dichlorophenol } \\
\text { 2,4-Dimethylphenol } \\
\text { 2,4-Dinitrophenol } \\
\text { 2,4-Dinitrotoluene } \\
\text { 2,6-Dinitrotoluene } \\
\text { 2-Chloronaphthalene } \\
\text { 2-Chlorophenol } \\
\text { 2-Methylnaphthalene } \\
\text { 2-Methylphenol } \\
\text { 2-Nitroaniline } \\
\text { 2-Nitrophenol } \\
\text { 3,3'-Dichlorobenzidine } \\
\text { 3-Nitroaniline } \\
\text { 4,6-Dinitro-2-methylphenol } \\
\text { 4-Chloro-3-methylphenol } \\
\text { 4-Nitroaniline } \\
\text { 4-Nitrophenol } \\
\text { Acenaphthene } \\
\text { Acenaphthylene } \\
\text { Anthracene } \\
\text { Benzo(b)fluoranthene } \\
\text { Benzo(g,h,i)perylene } \\
\text { Benzo(k)fluoranthene } \\
\text { Benzyl alcohol } \\
\text { Butylbenzylphthalate } \\
\text { Chrysene } \\
\text { Di-n-butylphthalate }\end{array}$ & \begin{tabular}{|l} 
GCMS \\
GCMS \\
GCMS \\
GCMS \\
GCMS \\
GCMS \\
GCMS \\
GCMS \\
GCMS \\
GCMS \\
GCMS \\
GCMS \\
GCMS \\
GCMS \\
GCMS \\
GCMS \\
GCMS \\
GCMS \\
GCMS \\
GCMS \\
GCMS \\
GCMS \\
GCMS \\
GCMS \\
GCMS \\
GCMS \\
GCMS \\
GCMS \\
GCMS \\
GCMS \\
GCMS \\
GCMS \\
GCMS
\end{tabular} & $\begin{array}{l}\mathrm{ug} / \mathrm{Nm} 3 \\
\mathrm{ug} / \mathrm{Nm} 3 \\
\mathrm{ug} / \mathrm{Nm} 3 \\
\mathrm{ug} / \mathrm{Nm} 3 \\
\mathrm{ug} / \mathrm{Nm} 3 \\
\mathrm{ug} / \mathrm{Nm} 3 \\
\mathrm{ug} / \mathrm{Nm} 3 \\
\mathrm{ug} / \mathrm{Nm} 3 \\
\mathrm{ug} / \mathrm{Nm} 3 \\
\mathrm{ug} / \mathrm{Nm} 3 \\
\mathrm{ug} / \mathrm{Nm} 3 \\
\mathrm{ug} / \mathrm{Nm} 3 \\
\mathrm{ug} / \mathrm{Nm} 3 \\
\mathrm{ug} / \mathrm{Nm} 3 \\
\mathrm{ug} / \mathrm{Nm} 3 \\
\mathrm{ug} / \mathrm{Nm} 3 \\
\mathrm{ug} / \mathrm{Nm} 3 \\
\mathrm{ug} / \mathrm{Nm} 3 \\
\mathrm{ug} / \mathrm{Nm} 3 \\
\mathrm{ug} / \mathrm{Nm} 3 \\
\mathrm{ug} / \mathrm{Nm} 3 \\
\mathrm{ug} / \mathrm{Nm} 3 \\
\mathrm{ug} / \mathrm{Nm} 3 \\
\mathrm{ug} / \mathrm{Nm} 3 \\
\mathrm{ug} / \mathrm{Nm} 3 \\
\mathrm{ug} / \mathrm{Nm} 3 \\
\mathrm{ug} / \mathrm{Nm} 3 \\
\mathrm{ug} / \mathrm{Nm} 3 \\
\mathrm{ug} / \mathrm{Nm} 3 \\
\mathrm{ug} / \mathrm{Nm} 3 \\
\mathrm{ug} / \mathrm{Nm} 3 \\
\mathrm{ug} / \mathrm{Nm} 3 \\
\mathrm{ug} / \mathrm{Nm} 3\end{array}$ & & & & & $\begin{array}{r}\text { ND (9.5) } \\
\text { ND (8.4) } \\
\text { ND (8.0) } \\
\text { ND (7.6) } \\
\text { ND (12) } \\
\text { ND (13) } \\
\text { ND (5.3) } \\
\text { ND (8.7) } \\
\text { ND (31) } \\
\text { ND (11) } \\
\text { ND (17) } \\
\text { ND (5.1) } \\
\text { ND (9.0) } \\
\text { ND (5.0) } \\
\text { ND (11) } \\
\text { ND (12) } \\
\text { ND (14) } \\
\text { ND (15) } \\
\text { ND (15) } \\
\text { ND (17) } \\
\text { ND (9.8) } \\
\text { ND (12) } \\
\text { ND (13) } \\
\text { ND (5.6) } \\
\text { ND (3.1) } \\
\text { ND (2.5) } \\
\text { ND (10) } \\
\text { ND (11) } \\
\text { ND (10) } \\
\text { ND (19) } \\
\text { ND (3.7) } \\
\text { ND (3.1) }\end{array}$ & \\
\hline
\end{tabular}




\section{Analytical Data Not Used In Calculations}

Stream: ESP Outlet Collection Method: MM5 Sample Type: XAD Resin/Impingers + MeCl2 1:4 dil

\begin{tabular}{|c|c|c|c|c|c|c|c|c|}
\hline Analyte & $\begin{array}{l}\text { Analytical } \\
\text { Technique }\end{array}$ & Units & Run 1 & $\overline{\mathrm{Com} 1}$ & Run 2 & $\longdiv { \operatorname { C o m } 2 }$ & Run 3 & Com 3 \\
\hline $\begin{array}{l}\text { Di-n-octylphthalate } \\
\text { Dibenz(a,h)anthracene } \\
\text { Dibenzofuran } \\
\text { Diethylphthalate } \\
\text { Dimethylphthalate } \\
\text { Fluoranthene } \\
\text { Fluorene } \\
\text { Hexachlorobenzene } \\
\text { Hexachlorobutadiene } \\
\text { Hexachlorocyclopentadiene } \\
\text { Hexachloroethane } \\
\text { Indeno(1,2,3-cd)pyrene } \\
\text { Isophorone } \\
\text { N-Nitroso-di-n-propylamine } \\
\text { Naphthalene } \\
\text { Nitrobenzene } \\
\text { Pentachlorophenol } \\
\text { Phenanthrene } \\
\text { Phenol } \\
\text { Pyrene } \\
\text { bis(2-Chloroethoxy)methane } \\
\text { bis(2-Chloroethyl)ether } \\
\text { bis(2-Ethylhexyl)phthalate }\end{array}$ & $\begin{array}{l}\text { GCMS } \\
\text { GCMS } \\
\text { GCMS } \\
\text { GCMS } \\
\text { GCMS } \\
\text { GCMS } \\
\text { GCMS } \\
\text { GCMS } \\
\text { GCMS } \\
\text { GCMS } \\
\text { GCMS } \\
\text { GCMS } \\
\text { GCMS } \\
\text { GCMS } \\
\text { GCMS } \\
\text { GCMS } \\
\text { GCMS } \\
\text { GCMS } \\
\text { GCMS } \\
\text { GCMS } \\
\text { GCMS } \\
\text { GCMS } \\
\text { GCMS }\end{array}$ & $\begin{array}{l}u g / N m 3 \\
u g / N m 3 \\
u g / N m 3 \\
u g / N m 3 \\
u g / N m 3 \\
u g / N m 3 \\
u g / N m 3 \\
u g / N m 3 \\
u g / N m 3 \\
u g / N m 3 \\
u g / N m 3 \\
u g / N m 3 \\
u g / N m 3 \\
u g / N m 3 \\
u g / N m 3 \\
u g / N m 3 \\
u g / N m 3 \\
u g / N m 3 \\
u g / N m 3 \\
u g / N m 3 \\
u g / N m 3 \\
u g / N m 3 \\
u g / N m 3\end{array}$ & & & ! & & $\begin{array}{r}\mathrm{ND}(6.2) \\
\mathrm{ND}(12) \\
\mathrm{ND}(3.3) \\
\mathrm{ND}(3.2) \\
\mathrm{ND}(4.1) \\
\mathrm{ND}(2.1) \\
\mathrm{ND}(4.1) \\
\mathrm{ND}(11) \\
\mathrm{ND}(14) \\
\mathrm{ND}(13) \\
\mathrm{ND}(15) \\
\mathrm{ND}(9.3) \\
22.0 \\
\mathrm{ND}(12) \\
\mathrm{ND}(3.3) \\
\mathrm{ND}(6.8) \\
\mathrm{ND}(22) \\
\mathrm{ND}(2.5) \\
\mathrm{ND}(8.1) \\
\mathrm{ND}(2.0) \\
\mathrm{ND}(8.3) \\
\mathrm{ND}(11) \\
\mathrm{ND}(3.1)\end{array}$ & $\mathbf{J}$ \\
\hline
\end{tabular}

Stream: ESP Outlet Collection Method: Multimetals Train Sample Type: Acetone PNR/Nitric PNR/M5 Filter + Solids

\begin{tabular}{|l|l|l|l|l||r||r||r||}
\hline & Analyte & Analytical & Units & Run 1 & Com 1 & Run 2 & Com 2 \\
\hline
\end{tabular}


Stream: ESP Outlet Collection Method: Multimetals Train Sample Type: Acetone PNR/Nitric PNR/M5 Filter + Solids

\begin{tabular}{|c|c|c|c|c|c|c|c|c|}
\hline Analyte & $\begin{array}{l}\text { Analytical } \\
\text { Technique }\end{array}$ & Units & Run 1 & $\overline{\operatorname{Com~1~}}$ & Run 2 & $\sqrt{\text { Com 2 }}$ & Run 3 & $\sqrt{\operatorname{Com} 3}$ \\
\hline $\begin{array}{l}\text { Lead } \\
\text { Selenium } \\
\text { Selenium }\end{array}$ & $\begin{array}{l}\text { ICAP } \\
\text { ICAP } \\
\text { ICAP }\end{array}$ & $\begin{array}{l}\mathrm{ug} / \mathrm{g} \\
\mathrm{ug} / \mathrm{Nm} 3 \\
\mathrm{ug} / \mathrm{g}\end{array}$ & $\begin{array}{r}\text { ND (12) } \\
21.7 \\
353\end{array}$ & $\begin{array}{l}\bar{C} \\
C \\
C\end{array}$ & $\begin{array}{r}\mathrm{ND}(90) \\
20.2 \\
2440\end{array}$ & $\begin{array}{l}\mathrm{C} \\
\mathrm{C} \\
\mathrm{C}\end{array}$ & $\begin{array}{r}\text { ND (13) } \\
19.9 \\
365\end{array}$ & \\
\hline
\end{tabular}

Stream: ESP Outle Collection Method: Multimetals Trai Sample Type: Nitric Acid Impingers + TL

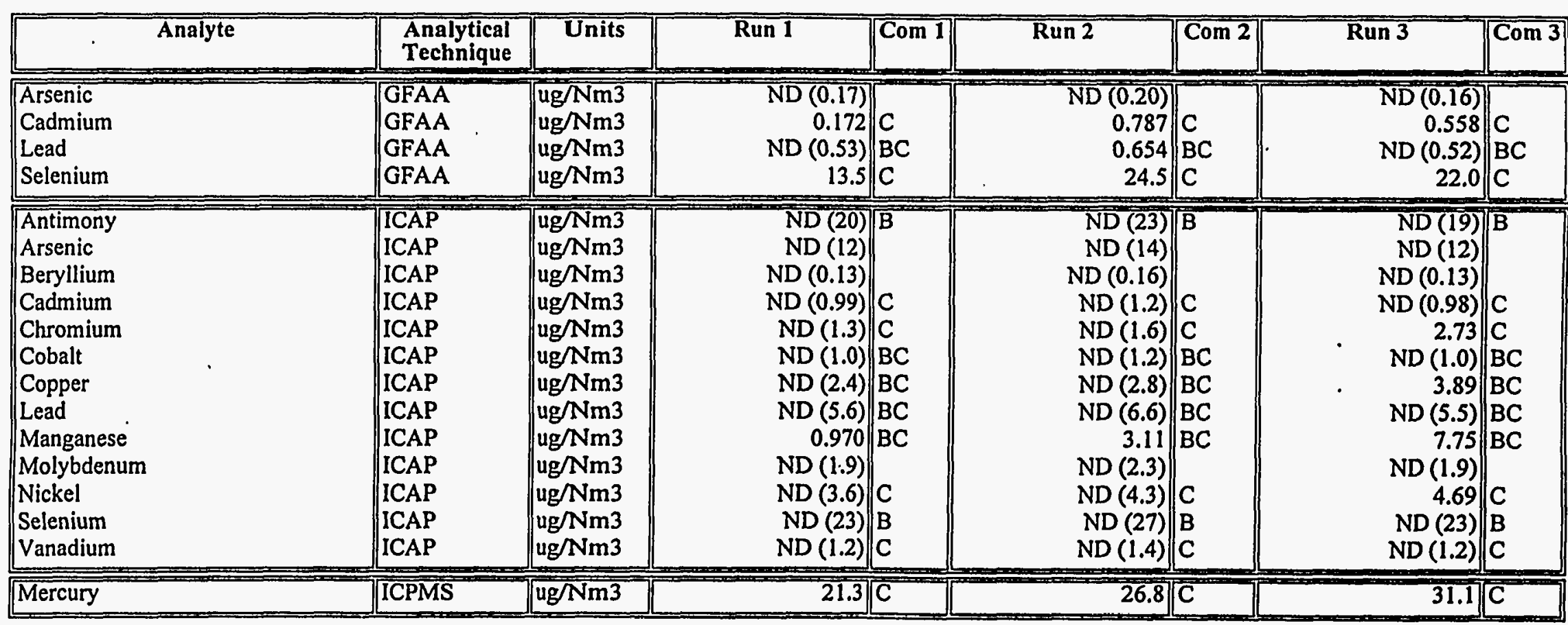




\section{Analytical Data Not Used In Calculations}

Stream: Service Water Collection Method: Grab Sample Type: Not Specified

\begin{tabular}{|c|c|c|c|c|c|c|c|c|}
\hline Analyte & $\begin{array}{l}\text { Analytical } \\
\text { Technique }\end{array}$ & Units & Run 1 & $\sqrt{\operatorname{Com~} 1}$ & Run 2 & Com 2 & Run 3 & $\overline{\operatorname{Com} 3}$ \\
\hline $\begin{array}{l}\text { Arsenic } \\
\text { Cadmium } \\
\text { Lead } \\
\text { Selenium }\end{array}$ & $\begin{array}{l}\text { ICAP } \\
\text { ICAP } \\
\text { ICAP } \\
\text { ICAP }\end{array}$ & $\begin{array}{l}\mathrm{mg} / \mathrm{L} \\
\mathrm{mg} / \mathrm{L} \\
\mathrm{mg} / \mathrm{L} \\
\mathrm{mg} / \mathrm{L}\end{array}$ & $\begin{array}{r}\mathrm{ND}(0.047) \\
0.00482 \\
0.0377 \\
\mathrm{ND}(0.089)\end{array}$ & $\mid \begin{array}{l}B \\
B \\
B\end{array}$ & $\begin{array}{r}N D(0.047) \\
\text { ND }(0.0039) \\
\text { ND }(0.022) \\
\text { ND }(0.089)\end{array}$ & B & $\begin{array}{r}\mathrm{ND}(0.047) \\
0.00500 \\
0.0312 \\
\mathrm{ND}(0.089)\end{array}$ & $\mid \begin{array}{l}B \\
B\end{array}$ \\
\hline
\end{tabular}

Stream: Service Water Collection Method: Grab Sample Type: Not Specified FD

\begin{tabular}{|c|c|c|c|c|c|c|c|c|}
\hline$\overline{\text { Analyte }}$ & $\begin{array}{l}\text { Analytical } \\
\text { Technique }\end{array}$ & Units & Run I & Com I & Run 2 & $\overline{\text { Com } 2}$ & Run 3 & Com 3 \\
\hline $\begin{array}{l}\text { Arsenic } \\
\text { Cadmium } \\
\text { Lead } \\
\text { Selenium }\end{array}$ & $\begin{array}{l}\text { ICAP } \\
\text { ICAP } \\
\text { ICAP } \\
\text { ICAP }\end{array}$ & $\begin{array}{l}\mathrm{mg} / \mathrm{L} \\
\mathrm{mg} / \mathrm{L} \\
\mathrm{mg} / \mathrm{L} \\
\mathrm{mg} / \mathrm{L}\end{array}$ & & & & & $\begin{array}{r}\text { ND (0.047) } \\
0.00446 \\
\text { ND (0.022) } \\
\text { ND (0.089) }\end{array}$ & $\begin{array}{l}B \\
B\end{array}$ \\
\hline
\end{tabular}

Stream: Sorbent Collection Method: Grab Composite Sample Type: Dolomite

\begin{tabular}{|c|c|c|c|c|c|c|c|c|}
\hline Analyte & $\begin{array}{l}\text { Analytical } \\
\text { Technique }\end{array}$ & Units & Run 1 & Com 1 & Run 2 & Com 2 & Run 3 & Com 3 \\
\hline $\begin{array}{l}\text { Arsenic } \\
\text { Cadmium } \\
\text { Lead } \\
\text { Selenium }\end{array}$ & $\begin{array}{l}\text { ICAP } \\
\text { ICAP } \\
\text { ICAP } \\
\text { ICAP }\end{array}$ & $\begin{array}{l}\mathrm{mg} / \mathrm{kg} \\
\mathrm{mg} / \mathrm{kg} \\
\mathrm{mg} / \mathrm{kg} \\
\mathrm{mg} / \mathrm{kg}\end{array}$ & $\begin{array}{r}N D(2.9) \\
0.589 \\
\text { ND (1.8) } \\
\text { ND (4.9) }\end{array}$ & $\begin{array}{l}\overline{\mathrm{B}} \\
\mathrm{B}\end{array}$ & $\begin{array}{r}\mathrm{ND}(3.2) \\
0.552 \\
\mathrm{ND}(11) \\
\mathrm{ND}(5.5)\end{array}$ & B & $\begin{array}{r}\mathrm{ND}(3.2) \\
0.922 \\
\mathrm{ND}(2.0) \\
\mathrm{ND}(5.5)\end{array}$ & B \\
\hline
\end{tabular}

Stream: Sorbent Collection Method: Grab Composite Sample Type: Dolomite FD

\begin{tabular}{|c|c|c|c|c|c|c|c|c|}
\hline Analyte & $\begin{array}{l}\text { Analytical } \\
\text { Technique }\end{array}$ & Units & Run I & Com 1 & $\overline{\operatorname{Run} 2}$ & $\overline{\text { Com } 2}$ & Run 3 & Com 3 \\
\hline $\begin{array}{l}\text { Arsenic } \\
\text { Cadinium } \\
\text { Lead } \\
\text { Selenium }\end{array}$ & $\begin{array}{l}\text { ICAP } \\
\text { ICAP } \\
\text { ICAP } \\
\text { ICAP }\end{array}$ & $\begin{array}{l}\mathrm{mg} / \mathrm{kg} \\
\mathrm{mg} / \mathrm{kg} \\
\mathrm{mg} / \mathrm{kg} \\
\mathrm{mg} / \mathrm{kg}\end{array}$ & & & & & $\begin{array}{r}\mathrm{ND}(3.4) \\
0.763 \\
\mathrm{ND}(2.1) \\
\mathrm{ND}(5.8)\end{array}$ & $\bar{B}$ \\
\hline
\end{tabular}


APPENDIX C: SOURCE SAMPLING DATA SUMMARY AND PSD PLOTS 
Plant Name AEP Tidd Demonstration Plant

Location ESP Inlet

Train Aldehyde

\begin{tabular}{|c|c|c|c|c|}
\hline Run No. & 1 & 2 & 3 & Average \\
\hline Date & $04-12-94$ & $04-13-94$ & 04-14-94 & - \\
\hline Time Start & 1946 & 1500 & 1452 & - \\
\hline Time Finish & 2114 & 1624 & 1620 & - \\
\hline Operator & TJB & TJB & TJB & - \\
\hline Initial Leak Rate & 0.007 & 0.010 & 0.005 & - \\
\hline Final Leak Rate & 0.005 & 0.010 & 0.004 & - \\
\hline Duct Dimensions (ft) & $10 \times 10$ & $10 \times 10$ & $10 \times 10$ & - \\
\hline Pitot Tube Correction Factor (Cp) & 0.84 & 0.84 & 0.84 & 0.84 \\
\hline Dry Gas Meter Calibration (Yd) & 1.009 & 1.009 & 1.009 & 1.009 \\
\hline Nozzle Diameter (inches) & 0.2460 & 0.2850 & 0.2850 & - \\
\hline Barometric Pressure ("Hg) & 29.29 & 29.29 & 29.2 & 29.26 \\
\hline Static Pressure ("H2O). & 2.8 & 2.8 & 2.8 & 2.8 \\
\hline Meter Volume (acf) & 64.002 & 63.769 & 67.129 & 64.967 \\
\hline Average square root of delta $p$ & 0.7740 & 0.6860 & 0.7070 & 0.7223 \\
\hline Average delta H (" $\mathrm{H} 2 \mathrm{O}$ ) & 1.40 & 1.95 & 2.00 & 1.78 \\
\hline Average Stack Temperature (F) & 393 & 392 & 393 & 393 \\
\hline Average DGM Temp (F) & 91.8 & 81.6 & 90.3 & 87.9 \\
\hline Test Duration (minutes) & 89.0 & 84.0 & 88.0 & 87.0 \\
\hline Condensed Water (g) & 140.4 & 151.9 & 121.3 & 137.9 \\
\hline$\% \mathrm{CO} 2$ & 12.0 & 10.0 & 11.0 & 11.0 \\
\hline$\% \mathrm{O} 2$ & 6.0 & 8.0 & 8.0 & 7.3 \\
\hline$\% \mathrm{~N} 2$ & 82.0 & 82.0 & 81.0 & 81.7 \\
\hline Meter Volume (dscf) & 60.705 & 61.704 & 63.740 & 62.050 \\
\hline Flue Gas Moisture (\%) & 9.8 & 10.4 & 8.2 & 9.5 \\
\hline Gas Molecular Weight (Wet) (g/g-mole) & 28.96 & 28.68 & 29.08 & 28.91 \\
\hline Absolute Stack Pressure (" $\mathrm{Hg})$ & 29.50 & 29.50 & 29.41 & 29.47 \\
\hline Absolute Stack Temperature (R) & 853 & 852 & 853 & 853 \\
\hline Average Gas Velocity (f/sec) & 55.54 & 49.43 & 50.71 & 51.90 \\
\hline Avg Flow Rate (acfm) & 333,240 & 296,603 & 304,277 & 311,373 \\
\hline Avg Flow Rate (dscfm) & 183,262 & 162.314 & 169.724 & 171,767 \\
\hline Isokinetic Sampling Rate (\%) & 112.78 & 102.17 & 96.35 & 103.77 \\
\hline
\end{tabular}




\section{Plant Name AEP Tidd Demonstration Plant Location ESP Inlet \\ Train Ammonia/Hydrogen Cyanide}

\begin{tabular}{|c|c|c|c|c|}
\hline Run No. & 1 & 2 & 3 & Average \\
\hline Date & $04-12-94$ & 04-13-94 & 04-14-94 & - \\
\hline Time Start & 1815 & 1317 & 1304 & - \\
\hline Trime Finish & 1921 & 1446 & 1430 & - \\
\hline Operator & TJB & TJB & TJB & - \\
\hline Initial Leak Rate & & 0.010 & 0.007 & - \\
\hline Final Leak Rate & & 0.010 & 0.010 & - \\
\hline Duct Dimensions (ft) & $10 \times 10$ & $10 \times 10$ & $10 \times 10$ & - \\
\hline Pitot Tube Correction Factor (Cp) & 0.84 & 0.84 & 0.84 & 0.84 \\
\hline Dry Gas Meter Calibration (Yd) & 1.009 & 1.009 & 1.009 & 1.009 \\
\hline Nozzle Diameter (inches) & 0.2460 & 0.2850 & 0.2850 & - \\
\hline Barometric Pressure ("Hg) & 29.29 & 29.26 & 29.2 & 29.25 \\
\hline Static Pressure (" $\mathrm{H} 2 \mathrm{O})$ & 2.8 & 2.8 & 3.5 & 3.0 \\
\hline Meter Volume (act) & 42.280 & 66.953 & 65.822 & 58.352 \\
\hline Average square root of delta $p$ & 0.7750 & 0.6860 & 0.7090 & 0.7233 \\
\hline Average delta $\mathrm{H}$ (" $\mathrm{H} 2 \mathrm{O}$ ) & 1.40 & 1.90 & 2.00 & 1.77 \\
\hline Average Stack Temperature (F) & 397 & 391 & 392 & 393 \\
\hline Average DGM Temp (F) & 87.2 & 81.1 & 86.3 & 84.9 \\
\hline Test Duration (minutes) & 66.0 & 89.0 & 86.0 & 80.3 \\
\hline Condensed Water (g) & 115.1 & 149.2 & 170.1 & 144.8 \\
\hline$\% \mathrm{CO} 2$ & 12.0 & 10.0 & 11.0 & 11.0 \\
\hline$\% \mathrm{O} 2$ & 6.0 & 8.0 & 8.0 & 7.3 \\
\hline$\% \mathrm{~N} 2$ & 82.0 & 82.0 & 81.0 & 81.7 \\
\hline Meter Volume (dscf) & 40.439 & 64.770 & 62.957 & 56.055 \\
\hline Flue Gas Moisture (\%) & 11.8 & 9.8 & 11.3 & 11.0 \\
\hline Gas Molecular Weight (Wet) (g/g-mole) & 28.72 & 28.75 & 28.71 & 28.73 \\
\hline Absolute Stack Pressure (" $\mathrm{Hg}$ ) & 29.50 & 29.47 & 29.46 & 29.47 \\
\hline Absolute Stack Temperature (R) & 857 & 851 & 852 & 853 \\
\hline Average Gas Velocity ( $f / s e c)$ & 55.97 & 49.38 & 51.10 & 52.15 \\
\hline Avg Flow Rate (acfm) & 335,827 & 296,260 & 306,599 & 312,895 \\
\hline Avg Flow Rate (dscfm) & 179,784 & 163,187 & 165,843 & 169,605 \\
\hline Isokinetic Sampling Rate (\%) & 103.27 & 100.68 & 99.66 & 101.21 \\
\hline
\end{tabular}


Plant Name AEP Tidd Demonstration Plant Location ESP Inlet

Train Anions

\begin{tabular}{|c|c|c|c|c|}
\hline Run No. & 1 & 2 & 3 & Average \\
\hline Date & $04-12-94$ & $04-13-94$ & $04-14-94$ & - \\
\hline Time Start & 1313 & 1157 & 1126 & - \\
\hline Time Finish & 1500 & $130:$ & 1238 & - \\
\hline Operator & TJB & TJB & TJB & - \\
\hline Initial Leak Rate & 0.005 & 0.007 & 0.010 & - \\
\hline Final Leak Rate & 0.010 & 0.010 & 0.010 & - \\
\hline Duct Dimensions (ft) & $10 \times 10$ & $10 \times 10$ & $10 \times 10$ & - \\
\hline Pitot Tube Correction Factor (Cp) & 0.84 & 0.84 & 0.84 & 0.84 \\
\hline Dry Gas Meter Calibration (Xd) & 1.009 & 1.009 & 1.009 & 1.009 \\
\hline Nozzle Diameter (inches) & 0.2460 & 0.2350 & 0.2850 & - \\
\hline Barometric Pressure ("Hg) & 29.44 & 29.26 & 29.20 & 29.30 \\
\hline Static Pressure ("H2O) & 2.5 & 2.8 & 3.5 & 2.9 \\
\hline Meter Volume (acf) & 66.891 & 51.500 & 55.230 & $57.87 \dot{4}$ \\
\hline Average square root of delta $p$ & 0.7750 & 0.730 & 0.7120 & 0.7367 \\
\hline Average delta $\mathrm{H}$ (" $\mathrm{H} 2 \mathrm{O}$ ) & 1.36 & 2.09 & 2.10 & 1.85 \\
\hline Average Stack Temperature (F) & 386 & 393 & 396 & 392 \\
\hline Average DGM Temp (F) & 81.7 & 83.0 & 74.1 & 79.6 \\
\hline Test Duration (minutes) & 107.0 & 67.0 & 72.0 & 82.0 \\
\hline Condensed Water (g) & 38.8 & 183.2 & 120.6 & 114.2 \\
\hline Filter Weight Gain (g) & 6.9959 & $7.0 \div 68$ & 5.8575 & 6.6501 \\
\hline PNR Weight Gain (g) & 1.0230 & $1 . \div 225$ & 2.6727 & 1.7061 \\
\hline$\% \mathrm{CO} 2$ & 12.0 & .0 .0 & 11.0 & 11.0 \\
\hline$\% \mathrm{O} 2$ & 6.0 & 3.0 & 8.0 & 7.3 \\
\hline$\% \mathrm{~N} 2$ & 82.0 & $\$ 2.0$ & 81.0 & 81.7 \\
\hline Meter Volume ( & 64.951 & 49.572 & 54.046 & 56.223 \\
\hline Particulate Meter Volum & 166.094 & 176.146 & 180.744 & \\
\hline Flue Gas Moisture (\%) & 2.7 & 14.8 & 9.5 & 9.0 \\
\hline Gas Molecular Weight (Wet) (g/g-mole) & 29.83 & 25.15 & 28.93 & 28.97 \\
\hline Absolute Stack Pressure (" Hg) & 29.62 & 25.47 & 29.46 & 29.52 \\
\hline Absolute Stack Temperature (R) & 846 & 853 & 856 & 852 \\
\hline Average Gas Velocity (f/sec) & 54.46 & 5.65 & 51.24 & 52.78 \\
\hline Avg Flow Rate (acfm) & 326,746 & 315.593 & 307.432 & 316,690 \\
\hline Avg Flow Rate (dscfm) & 196,293 & 163.550 & 168,881 & 176,374 \\
\hline Isokinetic Sampling Rate (\%) & 93.71 & 102.09 & 100.35 & 98.72 \\
\hline Particulate Concentration (gr/dsct) & $7.45 \mathrm{E}-01$ & $7.47 E-01$ & $7.28 \mathrm{E}-0 !$ & $7.40 \mathrm{E}-01$ \\
\hline Particulate Concentration (lbs/dscf) & $1.06 \mathrm{E}-04$ & 1.07E-04 & $1.04 \mathrm{E}-04$ & $1.06 \mathrm{E}-04$ \\
\hline Particulate Emission (grams/sec) & 157.97 & $13: 18$ & 132.86 & 141.00 \\
\hline Particulate Emission (lbs/hour) & 1253.79 & 1045.06 & 1054.47 & 1119.11 \\
\hline
\end{tabular}


Plant Name AEP Tidd Demonstration Plant

Location ESP Intet

Train Metals

\begin{tabular}{|c|c|c|c|c|}
\hline Run No. & 1 & 2 & 3 & Average \\
\hline Date & $04-12-94$ & $04-13-94$ & $04-14-94$ & - \\
\hline Time Start & 0903 & 0904 & 0938 & - \\
\hline Time Finish & 1315 & 1333 & 1349 & - \\
\hline Operator & TJB & TJB & TJB & - \\
\hline Initial Leak Rate & 0.010 & 0.002 & 0.010 & - \\
\hline Final Leak Rate & 0.005 & 0.010 & 0.005 & - \\
\hline Duct Dimensions (ft) & $10 \times 10$ & $10 \times 10$ & $10 \times 10$ & - \\
\hline Pitot Tube Correction Factor (Cp) & 0.84 & 0.84 & 0.84 & 0.84 \\
\hline Dry Gas Meter Calibration (Yd) & 1.009 & 1.009 & 1.009 & 1.009 \\
\hline Nozzle Diameter (inches) & 0.2360 & 0.2460 & 0.2500 & - \\
\hline Barometric Pressure ("Hg) & 29.44 & 29.26 & 29.20 & 29.30 \\
\hline Static Pressure ("H2O) & 2.5 & 2.8 & 3.5 & 2.9 \\
\hline Meter Volume (acf) & 101.297 & 104.446 & 100.749 & 102.164 \\
\hline Average square root of delta $p$ & 0.7690 & 0.7590 & 0.6710 & 0.7330 \\
\hline Average delta $\mathrm{H}\left({ }^{\mathrm{N}} \mathrm{H} 2 \mathrm{O}\right)$ & 1.14 & 1.27 & 1.06 & 1.16 \\
\hline Average Stack Temperature (F) & 388 & 388 & 390 & 389 \\
\hline Average DGM Temp (F) & 58.8 & 67.0 & 63.8 & 63.2 \\
\hline Test Duration (minutes) & 175.0 & 175.0 & 175.0 & 175.0 \\
\hline Condensed Water (g) & 247.9 & 238.6 & 223.8 & 236.8 \\
\hline Filter Weight Gain (g) & 2.7063 & 3.1061 & 3.1091 & 2.9738 \\
\hline PNR Weight Gain (g) & 1.2417 & 1.0874 & 0.8819 & 1.0703 \\
\hline$\% \mathrm{CO} 2$ & 12.0 & 10.0 & 11.0 & 11.0 \\
\hline$\% \mathrm{O} 2$ & 6.0 & 8.0 & 8.0 & 7.3 \\
\hline$\% \mathrm{~N} 2$ & 82.0 & 82.0 & 81.0 & 81.7 \\
\hline Meter Volume (dscf) & 102.643 & 103.586 & 100.269 & 102.166 \\
\hline Flue Gas Moisture (\%). & 10.2 & 9.8 & 9.5 & 9.9 \\
\hline Gas Molecular Weight (Wet) (g/g-mole) & 28.92 & 28.75 & 28.93 & 28.87 \\
\hline Absolute Stack Pressure (" Hg) & 29.62 & 29.47 & 29.46 & 29.52 \\
\hline Absolute Stack Temperature (R) & 848 & 848 & 850 & 849 \\
\hline Average Gas Velocity (f/sec) & 54.95 & 54.54 & 48.14 & 52.54 \\
\hline Avg Flow Rate (acfm) & 329.692 & 327,266 & 288,814 & 315,258 \\
\hline Avg Flow Rate (dscfm) & 182,355 & 180,841 & 159,657 & 174,284 \\
\hline Isokinetic Sampling Rate (\%) & 105.90 & 99.19 & 105.30 & 103.46 \\
\hline Particulate Concentration (gr/dscf) & $5.94 \mathrm{E}-01$ & $6.25 E-01$ & $6.14 E-01$ & $6.11 E-01$ \\
\hline Particulate Concentration (Ibs/dscf) & 8.48E-05 & 8.93E-05 & $8.78 E-05$ & 8.73E-05 \\
\hline Particulate Emission (grams/sec) & 116.92 & 122.04 & 105.93 & 114.96 \\
\hline Particulate Emission (lbs/hour) & 927.95 & 968.57 & 840.75 & 912.42 \\
\hline
\end{tabular}




\section{Plant Name AEP Tidd Demonstration Plant Location ESP Inlet \\ Train M23}

\begin{tabular}{|c|c|c|c|c|}
\hline Run No. & 2 & 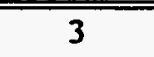 & $\overline{1}$ & Average \\
\hline Date & $04-13-94$ & 04-14-94 & $04-15-94$ & - \\
\hline Time Start & 1835 & 1750 & 0949 & - \\
\hline Time Finish & 2203 & 2235 & 1325 & - \\
\hline Operator & TJB & TJB & TJB & - \\
\hline Initial Leak Rate & 0.005 & 0.010 & 0.010 & - \\
\hline Final Leak Rate & 0.010 & 0.010 & 0.010 & $:$ \\
\hline Duct Dimensions ( $\mathrm{ft}$ ) & $10 \times 10$ & $10 \times 10$ & $10 \times 10$ & - \\
\hline Pitot Tube Correction Factor (Cp) & 0.84 & 0.84 & 0.84 & 0.84 \\
\hline Dry Gas Meter Calibration (Yd) & 1.009 & 1.009 & 1.009 & 1.009 \\
\hline Nozzle Diameter (inches) & 0.2500 & 0.2850 & 0.2770 & \\
\hline Barometric Pressure ("Hg) & 29.26 & 29.2 & 29.26 & 29.24 \\
\hline Static Pressure ("H2O) & 2.8 & 2.8 & 3.1 & 2.9 \\
\hline Meter Volume (act) & 103.858 & 118.665 & 115.014 & 112.512 \\
\hline Average square root of delta $p$ & 0.7050 & 0.6460 & 0.6580 & 0.6697 \\
\hline Average delta $\mathrm{H}\left({ }^{n} \mathrm{H} 2 \mathrm{O}\right)$ & 1.24 & 2.59 & 1.46 & 1.76 \\
\hline Average Stack Temperature (F) & 393 & 392 & 392 & 392 \\
\hline Average DGM Temp (F) & 74.3 & 83.0 & 78.0 & 78.4 \\
\hline Test Duration (minutes) & 175.0 & 175.0 & 175.0 & 175.0 \\
\hline Condensed Water (g) & 221.0 & 289.7 & 248.6 & 253.1 \\
\hline$\% \mathrm{CO} 2$ & 12.0 & 10.0 & 10.0 & 10.7 \\
\hline$\% \mathrm{O} 2$ & 6.0 & 8.0 & 8.0 & 7.3 \\
\hline$\%$ N2 & 82.0 & 82.0 & 82.0 & 82.0 \\
\hline Meter Volume (dscf) & 101.597 & 114.365 & 111.788 & 109.250 \\
\hline Flue Gas Moisture (\%) & 9.3 & 10.7 & 9.5 & 9.8 \\
\hline Gas Molecular Weight (Wet) (g/g-mole) & 29.03 & 28.65 & 28.79 & 28.82 \\
\hline Absolute Stack Pressure (" Hg) & 29.47 & 29.41 & 29.49 & 29.45 \\
\hline Absolute Stack Temperature (R) & 853 & 852 & 852 & 852 \\
\hline Average Gas Velocity ( $f / s e c)$ & 50.55 & 46.65 & 47.34 & 48.18 \\
\hline Avg Flow Rate (acfin) & 303,314 & 279,925 & 284,031 & 289,090 \\
\hline Avg Flow Rate (dscfm) & 167,655 & 152,225 & 156,935 & 158,938 \\
\hline Isokinetic Sampling Rate (\%) & 101.60 & 96.92 & 97.28 & 98.60 \\
\hline
\end{tabular}




\section{Plant Name AEP Tidd Demonstration Plant Location ESP Inlet \\ Train MM5}

\begin{tabular}{|c|c|c|c|c|}
\hline Run No. & 1 & 2 & 3 & Average \\
\hline Date & $04-12-94$ & $04-13-94$ & 04-14-94 & - \\
\hline Time Start & 1850 & 1530 & 1458 & - \\
\hline Time Finish & 2255 & 1917 & 1918 & - \\
\hline Operator & TJB & TJB & TJB & - \\
\hline Initial Leak Rate & 0.010 & 0.010 & 0.010 & - \\
\hline Final Leak Rate & 0.010 & 0.010 & 0.010 & - \\
\hline Duct Dimensions (ft) & $10 \times 10$ & $10 \times 10$ & $10 \times 10$ & - \\
\hline Pitot Tube Correction Factor (Cp) & 0.84 & 0.84 & 0.84 & 0.84 \\
\hline Dry Gas Meter Calibration (Yd) & 1.009 & 1.009 & 1.009 & 1.009 \\
\hline Nozzle Diameter (inches) & 0.2460 & 0.2450 & 0.2770 & - \\
\hline Barometric Pressure ("Hg) & 29.29 & 29.26 & 29.2 & 29.25 \\
\hline Static Pressure ("H2O) & 2.8 & 2.8 & 2.8 & 2.8 \\
\hline Meter Volume (acf) & 110.566 & 96.973 & 114.507 & 107.349 \\
\hline Average square root of delta p & 0.7720 & 0.6880 & 0.6410 & 0.7003 \\
\hline Average delta $\mathrm{H}$ (" $\mathrm{H} 2 \mathrm{O})$ & 1.42 & 1.10 & 1.54 & 1.35 \\
\hline Average Stack Temperature (F) & 389 & 387 & 392 & 389 \\
\hline Average DGM Temp (F) & 76.6 & 67.0 & 82.7 & 75.4 \\
\hline Test Duration (minutes) & 175.0 & 175.0 & 175.0 & 175.0 \\
\hline Condensed Water (g) & 184.3 & 201.0 & 236.7 & 207.3 \\
\hline$\% \mathrm{CO} 2$ & 12.0 & 10.0 & 10.0 & 10.7 \\
\hline$\% \mathrm{O} 2$ & 6.0 & 8.0 & 8.0 & 7.3 \\
\hline$\% \mathrm{~N} 2$ & 82.0 & 82.0 & 82.0 & 82.0 \\
\hline Meter Volume (dscf) & 107.848 & 96.136 & 110.132 & 104.705 \\
\hline Flue Gas Moisture (\%) & 7.5 & 9.0 & 9.2 & 8.6 \\
\hline Gas Molecular Weight (Wet) (g/g-mole) & 29.25 & 28.85 & 28.82 & 28.97 \\
\hline Absolute Stack Pressure (" Hg) & 29.50 & 29.47 & 29.41 & 29.46 \\
\hline Absolute Stack Temperature (R) & 849 & 847 & 852 & 849 \\
\hline Average Gas Velocity (f/sec) & 55.00 & 49.31 & 46.15 & 50.16 \\
\hline Avg Flow Rate (acfm) & 329,995 & 295,885 & 276,920 & 300,933 \\
\hline Avg Flow Rate (dscfm) & 187,097 & 165,286 & 153,061 & 168,481 \\
\hline Isokinetic Sampling Rate (\%) & 99.81 & 101.54 & 98.27 & 99.87 \\
\hline
\end{tabular}




\section{Plant Name AEP Tidd Demonstration Plant \\ Location ESP Inlet \\ Train VOST}

\begin{tabular}{|c|c|c|c|c|c|c|c|}
\hline Run No. $\cdot \cdots$ & $1 \mathrm{AA}$ & IB & $2 \mathrm{~A}$ & $2 \mathrm{~B}$ & $\overline{3 A}$ & $3 \mathrm{~B}$ & Average \\
\hline Date & $04-13-94$ & $04-13-94$ & 04-13-94 & $04-13-94$ & $04-14-94$ & $04-14-94$ & - \\
\hline Time Start & 0032 & 0120 & 2235 & 2320 & 2010 & 2120 & - \\
\hline Time Finish & 0112 & 0140 & 2315 & 0000 & 2050 & 2200 & - \\
\hline Operator & TJB & TJB & TJB & TJB & TJB & TJB & $=$ \\
\hline Initial Leak Rate & $<0.001$ & $<0.001$ & $<0.001$ & $<0.001$ & $<0.001$ & $<0.001$ & - \\
\hline Final Leak Rate & $<0.001$ & $<0.001$ & $<0.001$ & $<0.001$ & $<0.001$ & $<0.001$ & $=$ \\
\hline Tenax Tube ID & $30437 \mathrm{~A}$ & $30441 \mathrm{~A}$ & $30415 \mathrm{~A}$ & $30401 \mathrm{~A}$ & $30411 \mathrm{~A}$ & $30408 A$ & - \\
\hline Tenax/Charcoal Tube ID & 30437B & $30441 B$ & $30415 B$ & $30401 B$ & $30411 B$ & $30408 B$ & - \\
\hline Dry Gas Meter Calibration (Yd) & 1.000 & 1.000 & 1.000 & 1.000 & 1.000 & 1.000 & 1.000 \\
\hline Barometric Pressure (" $\mathrm{Hg}$ ) & 29.29 & 29.29 & 29.26 & 29.26 & 29.2 & 29.2 & 29.25 \\
\hline Meter Volume (liters) & 20.500 & 10.100 & 20.215 & 20.010 & 20.110 & 20.100 & 18.506 \\
\hline Average delta $\mathrm{H}$ (" $\mathrm{H} 2 \mathrm{O}$ ) & 1.13 & 1.25 & 1.00 & 1.50 & 1.20 & 1.20 & 1.21 \\
\hline Average DGM Temp (F) & 66.0 & 66.5 & 61.0 & 65.0 & 80.5 & 75.5 & 69.1 \\
\hline Ist Condenser Temp (F) & 63.5 & 60.5 & 46.5 & 60.0 & 47.0 & 50.5 & 54.7 \\
\hline 2nd Condenser Temp (F) & 63.0 & 61.5 & 59.5 & 47.5 & 47.5 & 52.0 & 55.2 \\
\hline Test Duration (minutes) & 40.0 & 20.0 & 40.0 & 40.0 & 40.0 & 40.0 & 36.7 \\
\hline$\% \mathrm{CO} 2$ & 12.0 & 12.0 & 11.0 & 11.0 & 11.0 & 11.0 & 11.3 \\
\hline$\% \mathrm{O} 2$ & 6.0 & 6.0 & 8.0 & 8.0 & 8.0 & 8.0 & 7.3 \\
\hline$\% \mathrm{~N} 2$ & 82.0 & 82.0 & 81.0 & 81.0 & 81.0 & 81.0 & 81.3 \\
\hline Meter Volumé (dsL) & 20.202 & 9.947 & 20.085 & 19.755 & 19.230 & 19.400 & 18.103 \\
\hline
\end{tabular}


Plant Name AEP Tidd Demonstration Plant

Location ESP Outlet

Train Aldehyde

\begin{tabular}{|c|c|c|c|c|}
\hline Run No. & 1 & 2 & 3 & Average \\
\hline Date & $04-12-94$ & $04-13-93$ & $04-14-94$ & - \\
\hline Time Start & 1950 & 1500 & 1520 & - \\
\hline Time Finish & 2130 & 1640 & 1655 & - \\
\hline Operator & JEH & JEH & JEH & - \\
\hline Initial Leak Rate & 0.005 & $<0.001$ & 0.006 & - \\
\hline Final Leak Rate & 0.009 & 0.007 & & - \\
\hline Stack Diameter (ft) & 10.0 & 10.0 & 10.0 & - \\
\hline Pitot Tube Correction Factor (Cp) & 0.84 & 0.84 & 0.84 & 0.84 \\
\hline Dry Gas Meter Calibration (Yd) & 0.997 & 0.997 & 0.997 & 0.997 \\
\hline Nozzle Diameter (inches) & 0.2500 & 0.2500 & 0.2500 & - \\
\hline Barometric Pressure ("Hg) & 29.41 & 29.14 & 29.35 & 29.3 \\
\hline Static Pressure ("H2O) & 1.6 & 1.5 & 1.6 & 1.566667 \\
\hline Meter Volume (acf) & 64.455 & 69.285 & 66.305 & 66.682 \\
\hline Average square root of delta $p$ & 0.7810 & 0.8370 & 0.8310 & 0.8163 \\
\hline Average delta $\mathrm{H}$ (" $\mathrm{H} 2 \mathrm{O})$ & 1.37 & 1.58 & 1.59 & 1.51 \\
\hline Average Stack Temperature (F) & 389 & 387 & 388 & 388 \\
\hline Average DGM Temp (F) & 87.2 & 83.3 & 99.7 & 90.1 \\
\hline Test Duration (minutes) & 95.0 & 100.0 & 95.0 & 96.7 \\
\hline Condensed Water (g) & 140.5 & 155.2 & 226.6 & 174.1 \\
\hline$\% \mathrm{CO} 2$ & 12.0 & 12.0 & 11.0 & 11.7 \\
\hline$\% \mathrm{O} 2$ & 6.0 & 7.0 & 8.0 & 7.0 \\
\hline$\%$ N2 & 82.0 & 81.0 & 81.0 & 81.3 \\
\hline Meter Volume (dscf) & 61.158 & 65.648 & 61.417 & 62.741 \\
\hline Flue Gas Moisture (\%) & 9.8 & 10.0 & 14.8 & 11.6 \\
\hline Gas Molecular Weight (Wet) (g/g-mole) & 28.97 & 28.98 & 28.29 & 28.74 \\
\hline Absolute Stack Pressure (" Hg) & 29.53 & 29.25 & 29.47 & 29.42 \\
\hline Absolute Stack Temperature (R) & 849 & 847 & 848 & 848 \\
\hline Average Gas Velocity (f/sec) & 55.86 & 60.10 & 60.19 & 58.72 \\
\hline Avg Flow Rate (acfm) & 263,252 & 283,205 & 283,634 & 276,697 \\
\hline Avg Flow Rate (dscfm) & 145,759 & 155,149 & 148,076 & 149,661 \\
\hline Isokinetic Sampling Rate (\%) & 101.78 & 97.51 & 100.61 & 99.97 \\
\hline
\end{tabular}


Plant Name AEP Tidd Demonstration Plant

Location ESP Outlet

Train Ammonia/Hydrogen Cyanide

\begin{tabular}{|c|c|c|c|c|}
\hline Run No. & 1 & 2 & 3 & Average \\
\hline Date & $04-12-94$ & $04-13-94$ & $04-14-94$ & - \\
\hline Time Start & 1803 & 1325 & 1338 & - \\
\hline Time Finish & 1923 & 1436 & 1508 & - \\
\hline Operator & $\mathrm{JEH}$ & JEH & JEH & - \\
\hline Initial Leak Rate & 0.009 & 0.010 & 0.007 & - \\
\hline Final Leak Rate & & 0.007 & 0.014 & - \\
\hline Stack Diameter (ft) & 10.0 & 10.0 & 10.0 & - \\
\hline Pitot Tube Correction Factor (Cp) & 0.84 & 0.84 & 0.84 & 0.84 \\
\hline Dry Gas Meter Calibration (Yd) & 0.997 & 0.997 & 0.997 & 0.997 \\
\hline Nozzle Diameter (inches) & 0.2500 & 0.2500 & 0.2500 & - \\
\hline Barometric Pressure ("Hg) & 29.44 & 29.16 & 29.32 & 29.31 \\
\hline Static Pressure ("H2O) & 1.5 & 1.4 & 2.0 & 1.6 \\
\hline Meter Volume (act) & 56.125 & 50.460 & 60.918 & 55.834 \\
\hline Average square root of delta $p$ & 0.8660 & 0.8440 & 0.8370 & 0.8490 \\
\hline Average delta $\mathrm{H}$ (" $\mathrm{H} 2 \mathrm{O}$ ) & 1.68 & 1.59 & 1.55 & 1.61 \\
\hline Average Stack Temperature (F) & 389 & 389 & 389 & 389 \\
\hline Average DGM Temp (F) & 82.8 & 82.4 & 94.8 & 86.6 \\
\hline Test Duration (minutes) & 80.0 & 76.0 & 90.0 & 82.0 \\
\hline Condensed Water (g) & 145.8 & 117.8 & 133.4 & 132.3 \\
\hline$\% \mathrm{CO} 2$ & 12.0 & 12.0 & 11.0 & 11.7 \\
\hline$\% \mathrm{O} 2$ & 6.0 & 7.0 & 8.0 & 7.0 \\
\hline$\%$ N2 & 82.0 & 81.0 & 81.0 & 81.3 \\
\hline Meter Volume (dscf) & 53.787 & 47.922 & 56.868 & 52.859 \\
\hline Flue Gas Moisture (\%) & 11.3 & 10.4 & 10.0 & 10.6 \\
\hline Gas Molecular Weight (Wet) (g/g-mole) & 28.78 & 28.93 & 28.88 & 28.86 \\
\hline Absolute Stack Pressure (" $\mathrm{Hg}$ ) & 29.55 & 29.26 & 29.47 & 29.43 \\
\hline Absolute Stack Temperature (R) & 849 & 849 & 849 & 849 \\
\hline Average Gas Velocity (f/sec) & 62.13 & 60.69 & 60.03 & 60.95 \\
\hline Avg Flow Rate (acfm) & 292,769 & 286,013 & 282,897 & 287,226 \\
\hline Avg Flow Rate (dscfm) & 159,402 & 155,819 & 155,974 & 157,065 \\
\hline Isokinetic Sampling Rate (\%) & 97.20 & 93.25 & 93.35 & 94.60 \\
\hline
\end{tabular}




\section{Plant Name AEP Tidd Demonstration Plant Location ESP Outlet \\ Train Anions}

\begin{tabular}{|c|c|c|c|c|}
\hline Run No. & 1 & 2 & 3 & Average \\
\hline Date & $04-12-94$ & $04-13-94$ & $04-14-94$ & - \\
\hline Time Start & 1312 & 1148 & 1150 & - \\
\hline Time Finish & 1427 & 1303 & 1313 & - \\
\hline Operator & JEH & JEH & JEH & - \\
\hline Initial Leak Rate & 0.011 & 0.007 & $<0.001$ & - \\
\hline Final Leak Rate & 0.012 & 0.010 & $<0.001$ & - \\
\hline Stack Diameter (ft) & 10.0 & 10.0 & 10.0 & - \\
\hline Pitot Tube Correction Factor (Cp) & 0.84 & 0.84 & 0.84 & 0.84 \\
\hline Dry Gas Meter Calibration (Yd) & 0.997 & 0.997 & 0.997 & 0.997 \\
\hline Nozzle Diameter (inches) & 0.2500 & 0.2500 & 0.2500 & \\
\hline Barometric Pressure ("Hg) & 29.5 & 29.18 & 29.35 & 29.34 \\
\hline Static Pressure ("H2O) & 1.5 & 2.3 & 3.8 & 2.5 \\
\hline Meter Volume (acf) & 53.946 & 50.345 & 56.165 & 53.485 \\
\hline Average square root of delta $p$ & 0.8540 & 0.7940 & 0.8370 & 0.8283 \\
\hline Average delta $\mathrm{H}$ (" $\mathrm{H} 2 \mathrm{O}$ ) & 1.77 & 1.40 & 1.54 & 1.57 \\
\hline Average Stack Temperature (F) & 388 & 390 & 389 & 389 \\
\hline Average DGM Temp (F) & 77.0 & 80.1 & 84.0 & 80.4 \\
\hline Test Dur & .75 .0 & 75.0 & 73.0 & 74.3 \\
\hline Condensed Water (g) & 126.5 & 100.2 & 109.2 & 112.0 \\
\hline Filter Weight Gain (g) & 0.1631 & 0.1426 & 0.1348 & 0.1468 \\
\hline PNR Weight Gain (g) & 0.3358 & 0.0454 & 0.1711 & 0.1841 \\
\hline$\% \mathrm{CO} 2$ & 12.0 & 12.0 & 11.0 & 11.7 \\
\hline$\% 02$ & 6.0 & 7.0 & 8.0 & 7.0 \\
\hline$\% \mathrm{~N} 2$ & 82.0 & 81.0 & 81.0 & 81.3 \\
\hline Meter & 52.370 & 48.022 & 53.520 & 51.304 \\
\hline Partic & 167.315 & 161.593 & 171.804 & \\
\hline Flue Gas Moisture (\%) & 10.2 & 9.0 & 8.8 & 9.3 \\
\hline Gas Molecular Weight (Wet) (g/g-mole) & 28.92 & 29.11 & 29.02 & 29.01 \\
\hline Absolute Stack Pressure (" Hg) & 29.61 & 29.35 & 29.63 & 29.53 \\
\hline Absolute Stack Temperature (R) & 848 & 850 & 849 & 849 \\
\hline Average Gas Velocity (f/sec) & 61.03 & 56.88 & 59.71 & 59.21 \\
\hline Avg Flow Rate (acfm) & 287,610 & 268,025 & 281,375 & 279,004 \\
\hline Avg Flow Rate (dscfm) & 159,023 & $148 ; 613$ & 158,097 & 155,244 \\
\hline Isokinetic Sampling Rate (\%) & 101.19 & 99.29 & 106.86 & 102.45 \\
\hline Particulate Concentration (gr/dscf) & $4.60 \mathrm{E}-02$ & $1.80 E-02$ & $2.75 \mathrm{E}-02$ & $3.05 \mathrm{E}-02$ \\
\hline Particulate Concentration (lbs/dscf) & 6.57E- -06 & 2.57E-06 & $3.93 \mathrm{E}-06$ & $4.36 \mathrm{E}-06$ \\
\hline Particulate Emission (grams/sec) & 7.90 & 2.88 & 4.69 & 5.16 \\
\hline Particulate Emission (lbs/hour) & 62.73 & 22.87 & 37.24 & 40.95 \\
\hline
\end{tabular}




\section{Plant Name AEP Tidd Demonstration Plant Location ESP Outlet Train Chrome IV}

\begin{tabular}{|c|c|c|c|c|}
\hline Run No. & 1 & 2 & 3 & Average \\
\hline Date & $04-12-94$ & $04-13-94$ & $04-14-94$ & - \\
\hline Time Start & 1620 & 0840 & 0820 & - \\
\hline Trime Finish & 1740 & 1010 & 0945 & - \\
\hline Operator & JEH & JEH & JEH & - \\
\hline Initial Leak Rate & 0.011 & $<0.001$ & 0.005 & - \\
\hline Final.Leak Rate & 0.015 & 0.006 & & - \\
\hline Stack Diameter (ft) & 10.0 & 10.0 & 10.0 & - \\
\hline Pitot Tube Correction Factor (Cp) & 0.84 & 0.84 & 0.84 & 0.84 \\
\hline Dry Gas Meter Calibration (Yd) & 0.987 & 0.987 & 0.987 & 0.987 \\
\hline Nozzle Diameter (inches) & 0.2500 & 0.2500 & 0.2500 & - \\
\hline Barometric Pressure ("Hg) & 29.5 & 29.26 & 29.38 & 29.38 \\
\hline Static Pressure ("H2O) & 1.5 & 1.7 & 1.8 & 1.7 \\
\hline Meter Volume (act) & 49.100 & 57.450 & 52.460 & 53.003 \\
\hline Average square root of delta $p$ & 0.6630 & 0.7940 & 0.7680 & 0.7417 \\
\hline Average delta $\mathrm{H}$ (" $\mathrm{H} 2 \mathrm{O}$ ) & 1.00 & 1.44 & 1.28 & 1.24 \\
\hline Average Stack Temperature (F) & 388 & 390 & 389 & 389 \\
\hline Average DGM Temp (F) & 79.3 & 73.4 & 66.2 & 72.9 \\
\hline Test Duration (minutes) & 80.0 & 90.0 & 85.0 & 85.0 \\
\hline$\% \mathrm{CO} 2$ & 12.0 & 12.0 & 11.0 & 11.7 \\
\hline$\% 02$ & 6.0 & 7.0 & 8.0 & 7.0 \\
\hline$\% \mathrm{~N} 2$ & 82.0 & 81.0 & 81.0 & 81.3 \\
\hline Meter Volume (dscf) & 46.901 & 55.090 & 51.184 & 51.058 \\
\hline Flue Gas Moisture (\%) & 10.0 & 10.0 & 10.0 & 10.0 \\
\hline Gas Molecular Weight (Wet) (g/g-mole) & 28.94 & 28.98 & 28.87 & 28.93 \\
\hline Absolute Stack Pressure (" Hg) & 29.61 & 29.39 & 29.51 & 29.50 \\
\hline Absolute Stack Temperature (R) & 848 & 850 & 849 & 849 \\
\hline Average Gas Velocity (f/sec) & 47.36 & 56.95 & 55.05 & 53.12 \\
\hline Avg Flow Rate (acfm) & 223,176 & 268,365 & 259.424 & 250,322 \\
\hline Avg Flow Rate (dscfm) & 123,718 & 147,377 & 143,169 & 138,088 \\
\hline Isokinetic Sampling Rate (\%) & 109.20 & 95.71 & 96.92 & 100.61 \\
\hline
\end{tabular}




\section{Plant Name AEP Tidd Demonstration Plant Location ESP Outlet \\ Train Metals}

\begin{tabular}{|c|c|c|c|c|}
\hline Run No. & 1 & 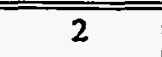 & $\overline{3}$ & Average \\
\hline Date & $04-12-94$ & $04-13-94$ & 04-14-94 & - \\
\hline Time Start & 0915 & 0910 & 0945 & - \\
\hline Time Finish & 1310 & 1300 & 1310 & - \\
\hline Operator & JEH & $\pi M$ & JLM & - \\
\hline Initial Leak Rate & 0.019 & 0.009 & 0.016 & - \\
\hline Final Leak Rate & 0.020 & 0.002 & 0.020 & - \\
\hline Stack Diameter (ft) & 10.0 & 10.0 & 10.0 & - \\
\hline Pitot Tube Correction Factor (Cp) & 0.84 & 0.84 & 0.84 & 0.84 \\
\hline Dry Gas Meter Calibration (Yd) & 0.981 & 0.981 & 0.981 & 0.981 \\
\hline Nozzle Diameter (inches) & 0.2500 & 0.2500 & 0.2500 & - \\
\hline Barometric Pressure ("Hg) & 29.7 & 29.26 & 29.38 & 29.45 \\
\hline Static Pressure ("H2O) & 3.0 & 1.7 & 1.8 & 2.2 \\
\hline Meter Volume (acf) & 113.186 & 115.758 & 119.108 & 116.017 \\
\hline Average square root of delta $p$ & 0.8240 & 0.8090 & 0.8330 & 0.8220 \\
\hline Average delta $\mathrm{H}$ (" $\mathrm{H} 2 \mathrm{O})$ & 1.67 & 1.74 & 1.88 & 1.76 \\
\hline Average Stack Temperature (F) & 388 & 390 & 391 & 390 \\
\hline Average DGM Temp (F) & 70.4 & 83.6 & 89.9 & 81.3 \\
\hline Test Duration (minutes) & 160.0 & 160.0 & 160.0 & 160.0 \\
\hline Condensed Water (g) & 240.6 & 256.5 & 253.2 & 250.1 \\
\hline Filter Weight Gain (g) & 0.0542 & 0.0197 & 0.0070 & 0.0270 \\
\hline PNR Weight Gain (g) & 0.1248 & 0.0039 & 0.1521 & 0.0936 \\
\hline$\% \mathrm{CO} 2$ & 12.0 & 12.0 & 11.0 & 11.7 \\
\hline$\% 02$ & 6.0 & 7.0 & 8.0 & 7.0 \\
\hline$\%$ N2 & 82.0 & 81.0 & 81.0 & 81.3 \\
\hline Meter Volume (dsef) & 110.165 & 108.333 & 110.684 & 109.727 \\
\hline Flue Gas Moisture (\%) & 9.3 & 10.1 & 9.7 & 9.7 \\
\hline Gas Molecular Weight (Wet) (g/g-mole) & 29.02 & 28.97 & 28.90 & 28.97 \\
\hline Absolute Stack Pressure (" Hg) & 29.92 & 29.39 & 29.51 & 29.61 \\
\hline Aosolute Stack Temperature (R) & 848 & 850 & 851 & 850 \\
\hline Average Gas Velocity (f/sec) & 58.49 & 58.03 & 59.74 & 58.75 \\
\hline Avg Flow Rate (acfm) & 275,615 & 273,465 & 281,496 & 276,858 \\
\hline Avg Flow Rate (dscfm) & 155,440 & 150,091 & 155,496 & 153,675 \\
\hline Isokinetic Sampling Rate (\%) & 102.08 & 103.96 & 102.52 & 102.85 \\
\hline Particulate Concentration (gr/dscf) & $2.51 \mathrm{E}-02$ & $3.36 \mathrm{E}-03$ & $2.22 \mathrm{E}-02$ & $1.69 \mathrm{E}-02$ \\
\hline Particulate Concentration (lbs/dscf) & $3.58 \mathrm{E}-06$ & $4.80 \mathrm{E}-07$ & 3.17E-06 & $2.41 E-06$ \\
\hline Particulate Emission (grams/sec) & 4.21 & 0.55 & 3.73 & 2.83 \\
\hline Particulate Emission (lbs/hour) & 33.41 & 4.33 & 29.57 & 22.44 \\
\hline
\end{tabular}


Plant Name AEP Tidd Demonstration Plant Location ESP Outlet

Train M23

\begin{tabular}{|c|c|c|c|c|}
\hline Run No. & 2 & 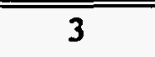 & $\overline{1}$ & Average \\
\hline Date & $04-13-94$ & 04-14-94 & $04-15-94$ & - \\
\hline frime Start & 1840 & 1812 & 0937 & - \\
\hline Time Finish & 2301 & 2106 & 1223 & - \\
\hline Operator & JEH & JEH & $\mathrm{TJC}$ & - \\
\hline Initial Leak Rate & 0.005 & 0.005 & 0.015 & - \\
\hline Final Leak Rate & 0.005 & 0.007 & 0.015 & - \\
\hline Stack Diameter (ft) & 10.0 & 10.0 & 10.0 & - \\
\hline Pitot Tube Correction Factor (Cp) & 0.84 & 0.84 & 0.84 & 0.84 \\
\hline Dry Gas Meter Calibration (Yd) & 0.997 & 0.997 & 0.981 & 0.992 \\
\hline Nozzle Diameter (inches) & 0.2500 & 0.2700 & 0.2700 & - \\
\hline Barometric Pressure ("Hg) & 29.14 & 29.32 & 29.41 & 29.29 \\
\hline Static Pressure ("H2O) & 1.6 & 1.9 & 1.5 & 1.7 \\
\hline Meter Volume (acf) & 126.424 & 113.832 & 111.076 & 117.111 \\
\hline Average square root of delta $p$ & 0.8080 & 0.7980 & 0.7780 & 0.7947 \\
\hline Average delta $\mathrm{H}\left({ }^{\mathrm{H}} \mathrm{H} 2 \mathrm{O}\right)$ & 1.46 & 1.98 & 1.99 & 1.81 \\
\hline Average Stack Temperature (F) & 388 & 389 & 389 & 389 \\
\hline Average DGM Temp (F) & 73.0 & 91.1 & 86.5 & 83.5 \\
\hline Test Duration (minutes) & 187.0 & 146.0 & 144.0 & 159.0 \\
\hline Condensed Water (g) & 252.2 & 242.3 & 230.4 & 241.6 \\
\hline$\% \mathrm{CO} 2$ & 12.0 & 12.0 & 11.0 & 11.7 \\
\hline$\% 02$ & 6.0 & 7.0 & 8.0 & 7.0 \\
\hline$\% \mathrm{~N} 2$ & 82.0 & 81.0 & 81.0 & 81.3 \\
\hline Meter Volume (dscf) & 122.055 & 107.090 & 103.997 & 111.047 \\
\hline Flue Gas Moisture (\%) & 8.9 & 9.6 & 9.5 & 9.3 \\
\hline Gas Molecular Weight (Wet) (g/g-mole) & 29.08 & 29.02 & 28.94 & 29.01 \\
\hline Absolute Stack Pressure (" Hg) & 29.26 & 29.46 & 29.52 & 29.41 \\
\hline Absolute Stack Temperature (R) & 848 & 849 & 849 & 849 \\
\hline Average Gas Velocity (f/sec) & 57.93 & 57.11 & 55.69 & 56.91 \\
\hline Avg Flow Rate (acfm) & 272,997 & 269,144 & 262,443 & 268,195 \\
\hline Avg Flow Rate (dscfm) & 151,368 & 148.794 & 145,766 & 148,642 \\
\hline Isokinetic Sampling Rate (\%) & . $\quad 99.37$ & 97.39 & 97.89 & 98.22 \\
\hline
\end{tabular}




\section{Plant Name AEP Tidd Demonstration Plant Location ESP Outlet Train MM5}

\begin{tabular}{|c|c|c|c|c|}
\hline Run No. & 1 & 2 & 3 & Average \\
\hline Date & $04-12-94$ & $04-13-94$ & 04-14-94 & - \\
\hline Time Start & 1852 & 1523 & 1440 & - \\
\hline Time Finish & 0010 & 1923 & 1900 & - \\
\hline Operator & $\pi M$ & JLM & $\pi M$ & - \\
\hline Initial Leak Raté & 0.020 & 0.020 & 0.010 & - \\
\hline Final Leak Rate & & 0.010 & 0.007 & $=$ \\
\hline Stack Diameter (ft) & 10.0 & 10.0 & 10.0 & - \\
\hline Pitot Tube Correction Factor (Cp) & 0.84 & 0.84 & 0.84 & 0.84 \\
\hline Dry Gas Meter Calibration (Yd) & 0.981 & 0.981 & 0.981 & 0.981 \\
\hline Nozzle Diameter (inches) & 0.2500 & 0.2500 & 0.2500 & - \\
\hline Barometric Pressure ("Hg) & 29.4 & 29.26 & 29.32 & 29.33 \\
\hline Static Pressure ("H2O) & 1.6 & 1.8 & 1.8 & 1.7 \\
\hline Meter Volume (act) & 137.116 & 130.704 & 123.013 & 130.278 \\
\hline Average square root of delta $p$ & 0.8240 & 0.8110 & 0.8190 & 0.8180 \\
\hline Average delta $\mathrm{H}\left({ }^{\mu} \mathrm{H} 2 \mathrm{O}\right)$ & 1.68 & 1.72 & 1.95 & 1.78 \\
\hline Average Stack Temperature (F) & 390 & 388 & 390 & 390 \\
\hline Average DGM Temp (F) & 80.3 & 76.9 & 95.7 & 84.3 \\
\hline Test Duration (minutes) & 200.0 & 184.0 & 162.0 & 182.0 \\
\hline Condensed Water (g) & 389.8 & 252.0 & 220.2 & 287.3 \\
\hline$\% \mathrm{CO} 2$ & 12.0 & 12.0 & 11.0 & 11.7 \\
\hline$\% 02$ & 6.0 & 7.0 & 8.0 & 7.0 \\
\hline$\% \mathrm{~N} 2$ & 82.0 & 81.0 & 81.0 & 81.3 \\
\hline Meter Volume (dscf) & 129.706 & 123.836 & 112.913 & 122.152 \\
\hline Flue Gas Moisture (\%) & 12.4 & 8.8 & 8.4 & 9.9 \\
\hline Gas Molecular Weight (Wet) (g/g-mole) & 28.65 & 29.13 & 29.06 & 28.95 \\
\hline Absolute Stack Pressure (" Hg) & 29.52 & 29.39 & 29.45 & 29.45 \\
\hline Absolute Stack Temperature (R) & 850 & 848 & 850 & 850 \\
\hline Average Gas Velocity ( $f / \sec )$ & 59.33 & 57.97 & 58.61 & 58.64 \\
\hline Avg Flow Rate (acfm) & 279.592 & 273,157 & 276,211 & 276,320 \\
\hline Avg Flow Rate (dscfm) & 149,960 & 152,341 & 154,573 & 152,291 \\
\hline Isokinetic Sampling Rate (\%) & 99.66 & 101.81 & 103.91 & 101.79 \\
\hline
\end{tabular}


Plant Name AEP Tidd Demonstration Plant

Location ESP Outlet

Train VOST

\begin{tabular}{|c|c|c|c|c|c|c|c|}
\hline Run No. & IA & IB & $2 A$ & $2 B$ & $3 \mathrm{~A}$ & $3 B$ & Average \\
\hline Date & $04-12-94$ & $04-13-94$ & $04-13-94$ & $04-13-94$ & $04-14-94$ & $04-14-94$ & - \\
\hline Time Start & 2330 & 0015 & 2105 & 2200 & 2028 & 2115 & - \\
\hline Trime Finish & 0010 & 0055 & 2155 & 2240 & 2108 & 2155 & - \\
\hline Operator & JEH & JEH & JEH & JEH ${ }^{\circ}$ & JEH & JEH & - \\
\hline Initial Leak Rate & $<0.001$ & $<0.001$ & $<0.001$ & $<0.001$ & $<0.001$ & $<0.001$ & - \\
\hline Final Leak Rate & $<0.001$ & $<0.001$ & $<0.001$ & $<0.001$ & $<0.001$ & $<0.001$ & - \\
\hline Tenax Tube ID & 30419A & $30422 A$ & $30417 \mathrm{~A}$ & 30410A & $30432 A$ & 30438A & - \\
\hline Tenax/Charcoal Tube ID & 30419B & 30422B & 30417B & 30410B & 30432B & 30438B & - \\
\hline Dry Gas Meter Calibration (Yd) & 0.992 & 0.992 & 0.992 & 0.992 & 0.992 & 0.992 & 0.992 \\
\hline Barometric Pressure ("Hg) & 29.4 & 29.4 & 29.14 & 29.14 & 29.41 & 29.41 & 29.32 \\
\hline Meter Volume (liters) & 21.180 & 20.400 & 21.500 & 22.430 & 21.200 & 22.300 & 21.502 \\
\hline Average delta $\mathrm{H}\left({ }^{*} \mathrm{H} 2 \mathrm{O}\right)$ & 2.00 & 2.00 & 1.40 & 1.33 & 1.30 & 1.28 & 1.55 \\
\hline Average DGM Temp (F) & 66.8 & 70.3 & 61.3 & 61.8 & 76.8 & 77.0 & 69.0 \\
\hline 1st Condenser Temp (F) & 44.0 & 43.5 & 57.3 & 57.0 & 43.0 & 40.3 & 47.5 \\
\hline 2nd Condenser Temp (F) & 43.3 & 45.3 & 48.8 & 46.8 & 47.0 & 44.5 & 45.9 \\
\hline Test Duration (minutes) & 40.0 & 40.0 & 40.0 & 40.0 & 40.0 & 40.0 & 40.0 \\
\hline$\% \mathrm{CO} 2$ & 12.0 & 12.0 & 12.0 & 12.0 & 11.0 & 11.0 & 11.7 \\
\hline$\% 02$ & 6.0 & 6.0 & 7.0 & 7.0 & 8.0 & 8.0 & 7.0 \\
\hline$\% \mathrm{~N} 2$ & 82.0 & 82.0 & 81.0 & 81.0 & 81.0 & 81.0 & 81.3 \\
\hline Meter Volume (dsL) & 20.798 & 19.900 & 21.115 & 22.003 & 20.399 & 21.448 & 20.944 \\
\hline
\end{tabular}




\section{Plant Name AEP Tidd Demonstration Plant \\ Location APF Inlet \\ Train Aldehyde}

\begin{tabular}{|c|c|c|c|c|}
\hline Run No. & $\overline{I I}$ & 2 & 3 & Average \\
\hline Date & $04-12-94$ & $04-13-94$ & $04-14-94$ & - \\
\hline Time Start & 2025 & 1348 & 1600 & - \\
\hline Time Finish & 0045 & 1538 & 2247 & - \\
\hline Operator & RVW & RVW & RVW & - \\
\hline Initial Leak Rate & 0.005 & 0.012 & 0.008 & - \\
\hline Final Leak Rate & & & 0.006 & - \\
\hline Dry Gas Meter Calibration (Yd) & 0.993 & 0.993 & 0.993 & 0.993 \\
\hline Nozzle Diameter (inches) & 0.2500 & 0.2500 & 0.2500 & - \\
\hline Barometric Pressure ("Hg) & 29.44 & 29.14 & 29.35 & 29.31 \\
\hline Meter Volume (act) & 63.205 & 74.832 & 64.475 & 67.504 \\
\hline Average delta $\mathrm{H}$ (" $\mathrm{H} 2 \mathrm{O}$ ) & 1.50 & 1.50 & 0.93 & 1.31 \\
\hline Average DGM Temp (F) & 100.9 & 97.0 & 91.3 & 96.4 \\
\hline Test Duration (minutes) & 95.0 & 110.0 & 119.0 & 108.0 \\
\hline Condensed Water (g) & 180.4 & 165.2 & 142.5 & 162.7 \\
\hline$\% \mathrm{CO} 2$ & 12.5 & 12.5 & 11.0 & 12.0 \\
\hline$\% 02$ & 5.5 & 5.5 & 8.0 & 6.3 \\
\hline$\% \mathrm{~N} 2$ & 82.0 & 82.0 & 81.0 & 81.7 \\
\hline Meter Volume (dsct) & 58.351 & 68.863 & 60.292 & 62.502 \\
\hline Flue Gas Moisture (\%) & 12.7) & 10.2 & 10.0 & 11.0 \\
\hline Gas Molecular Weight (Wet) (g/g-mole) & 28.66 & 28.98 & 28.87 & 28.84 \\
\hline
\end{tabular}




\section{Plant Name AEP Tidd Demonstration Plant \\ Location APF Inlet \\ Train Ammonia/Hydrogen Cyanide}

\begin{tabular}{|c|c|c|c|c|}
\hline Run No. & 1 & 2 & 3 & Average \\
\hline Date & $04-12-94$ & $04-13-94$ & 04-14-94 & - \\
\hline Time Start & 1810 & 1345 & 1423 & - \\
\hline Time Finish & 1925 & 1455 & 1533 & - \\
\hline Operator & RVW & RVW & - RVW & - \\
\hline Initial Leak Rate & 0.006 & 0.010 & 0.004 & - \\
\hline Final Leak Rate & 0.008 & 0.006 & 0.010 & - \\
\hline Dry Gas Meter Calibration (Yd) & 0.993 & 1.018 & 1.018 & 1.010 \\
\hline Nozzle Diameter (inches) & 0.2500 & 0.2500 & 0.2500 & - \\
\hline Barometric Pressure ("Hg) & 29.44 & 29.14 & 29.35 & 29.31 \\
\hline Meter Volume (acf) & 48.540 & 47.521 & 44.682 & 46.914 \\
\hline Average delta $\mathrm{H}$ (" H2O) & 1.50 & 1.51 & 1.50 & 1.50 \\
\hline Average DGM Temp (F) & 105.3 & 89.5 & 92.9 & 95.9 \\
\hline Test Duration (minutes) & 75.0 & 70.0 & 70.0 & 71.7 \\
\hline Condensed Water (g) & 128.1 & 106.4 & 109.9 & 114.8 \\
\hline$\% \mathrm{CO} 2$ & 12.5 & 12.5 & 11.0 & 12.0 \\
\hline$\% 02$ & 5.5 & 5.5 & 8.0 & 6.3 \\
\hline$\% \mathrm{~N} 2$ & 82.0 & 82.0 & 81.0 & 81.7 \\
\hline Meter Volume (dsct) & 44.464 & 45.444 & 42.772 & 44.227 \\
\hline Flue Gas Moisture (\%) & 12.0 & 10.0 & 10.8 & 10.9 \\
\hline Gas Molecular Weight (Wet) (g/g-mole) & 28.76 & 29.00 & 28.77 & 28.84 \\
\hline
\end{tabular}




\section{Plant Name AEP Tidd Demonstration Plant Location APF Inlet \\ Train Anions}

\begin{tabular}{|c|c|c|c|c|c|}
\hline Run No. & 1 & 2 & 3 & 1 & Average \\
\hline Date & $04-12-94$ & $04-13-94$ & $04-14-94$ & $04-15-94$ & - \\
\hline Time Start & 1315 & 0908 & 1420 & 1627 & - \\
\hline Time Finish & 1415 & 1018 & 1530 & 1735 & - \\
\hline Operator & RVW & RVW & RVW & RVW & - \\
\hline Initial Leak Rate & 0.006 & 0.005 & 0.008 & 0.007 & - \\
\hline Final Leak Rate & & 0.006 & 0.006 & 0.010 & - \\
\hline Dry Gas Meter Calibration (Yd) & 1.018 & 1.018 & 0.993 & 0.993 & 1.006 \\
\hline Nozzle Diameter (inches) & 0.2500 & 0.2500 & 0.2500 & 0.2500 & - \\
\hline Barometric Pressure ("Hg) & 29.44 & 29.14 & 29.35 & 29.41 & 29.34 \\
\hline Meter Volume (acf) & 29.981 & 46.758 & 42.764 & 44.870 & 41.093 \\
\hline Average delta $\mathrm{H}$ (" $\mathrm{H} 2 \mathrm{O}$ ) & 1.00 & 1.50 & 1.50 & 1.50 & 1.38 \\
\hline Average DGM Temp (F) & 95.2 & 73.8 & 87.4 & 87.5 & 86.0 \\
\hline Test Duration (minutes) & 55.0 & 70.0 & 70.0 & 68.0 & 65.8 \\
\hline Condensed Water (g) & & 108.4 & 100.7 & 105.9 & 105.0 \\
\hline$\% \mathrm{CO} 2$ & 12.5 & 12.5 & 11.0 & 11.0 & 11.8 \\
\hline$\% 02$ & 5.5 & 5.5 & 8.0 & 8.0 & 6.8 \\
\hline$\% \mathrm{~N} 2$ & 82.0 & 82.0 & 81.0 & 81.0 & 81.5 \\
\hline Meter Volume (dsci) & 28.630 & 46.029 & 40.330 & 42.395 & 39.346 \\
\hline Flue Gas Moisture (\%) & 0.0 & 10.0 & 10.5 & 10.5 & 7.8 \\
\hline Gas Molecular Weight (Wet) (g/g-mole) & 30.22 & 29.00 & 28.81 & 28.81 & 29.21 \\
\hline
\end{tabular}




\section{Plant Name AEP Tidd Demonstration Plant Location APF Inlet \\ Train Metals}

\begin{tabular}{|c|c|c|c|c|c|}
\hline Run No. & 1 & 2 & 3 & 4 & Average \\
\hline Date & $04-12-94$ & $04-13-94$ & 04-14-94 & $04-15-94$ & - \\
\hline Time Start & 1322 & 0905 & 0955 & 2132 & - \\
\hline Time Finish & 1417 & 1125 & 1215 & 2352 & - \\
\hline Operator & RVW & RVW & RVW & RVW & - \\
\hline Initial Leak Rate & 0.012 & 0.012 & 0.010 & 0.010 & - \\
\hline Final Leak Rate & & 0.014 & & 0.012 & - \\
\hline Dry Gas Meter Calibration (Yd) & 0.993 & 0.993 & 0.993 & 1.018 & 0.999 \\
\hline Nozzle Diameter (inches) & 0.2500 & 0.2500 & 0.2500 & 0.2500 & - \\
\hline Barometric Pressure ("Hg) & 29.44 & 29.14 & 29.35 & 29.41 & 29.335 \\
\hline Meter Volume (acf) & 41.375 & 106.315 & 104.156 & 103.282 & 88.782 \\
\hline Average delta $\mathrm{H}$ (" $\mathrm{H} 2 \mathrm{O})$ & 1.90 & .1 .76 & 1.90 & 1.90 & 1.86 \\
\hline Average DGM Temp (F) & 107.5 & 98.1 & 94.3 & 87.5 & 96.9 \\
\hline Test Duration (minutes) & 55.0 & 140.0 & 140.0 & 140.0 & 118.8 \\
\hline Condensed Water (g) & & 158.3 & 118.5 & 266.1 & 181.0 \\
\hline$\% \mathrm{CO} 2$ & 12.5 & 12.5 & 11.0 & 11.0 & 11.8 \\
\hline$\% \mathrm{O} 2$ & 5.5 & 5.5 & 8.0 & 8.0 & 6.8 \\
\hline$\%$ N2 & 82.0 & 82.0 & 81.0 & 81.0 & 81.5 \\
\hline Meter Volume (dscf) & 37.791 & 97.697 & 97.103 & 100.141 & 83.183 \\
\hline Flue Gas Moisture (\%) & 0.0 & 7.1 & 5.4 & 11.1 & 5.9 \\
\hline Gas Molecular Weight (Wet) (g/g-mole) & 30.22 & 29.35 & 29.42 & 28.73 & 29.43 \\
\hline
\end{tabular}




\section{Plant Name AEP Tidd Demonstration Plant}

Location APF Inlet

Train M23

\begin{tabular}{|c|c|c|c|c|}
\hline Run No. & 2 & 3 & 1 & Average \\
\hline Date & $04-13-94$ & $04-15-94$ & $04-15-94$ & - \\
\hline Time Start & 1803 & 1043 & 2125 & - \\
\hline Time Finish & 2233 & $1550^{\circ}$ & 2350 & - \\
\hline Operator & RVW & RVW & RVW & - \\
\hline Initial Leak Rate & 0.009 & 0.003 & 0.009 & - \\
\hline Final Leak Rate & 0.007 & 0.004 & 0.010 & - \\
\hline Dry Gas Meter Calibration (Yd) & 0.993 & 0.993 & 1.016 & 1.001 \\
\hline Nozzle Diameter (inches) & 0.2500 & 0.2500 & 0.2500 & - \\
\hline Barometric Pressure ("Hg) & 29.14 & 29.41 & 29.41 & 29.32 \\
\hline Meter Volume (act) & 107.555 & 111.103 & 108.501 & 109.053 \\
\hline Average delta $\mathrm{H}\left({ }^{\mathrm{N}} \mathrm{H} 2 \mathrm{O}\right)$ & 0.93 & 1.22 & 1.90 & 1.35 \\
\hline Average DGM Temp (F) & 93.9 & 89.8 & 95.7 & 93.1 \\
\hline Test Duration (minutes) & 200.0 & 200.0 & 165.0 & 188.3 \\
\hline Condensed Water (g) & 327.1 & 267.0 & 7.7 & 200.6 \\
\hline$\% \mathrm{CO} 2$ & 12.5 & 11.0 & 11.0 & 11.5 \\
\hline$\% 02$ & 8.5 & 8.0 & 8.0 & 8.2 \\
\hline$\% \mathrm{~N} 2$ & 79.0 & 81.0 & 81.0 & 80.3 \\
\hline Meter Volume (dscf) & 99.387 & 104.471 & 103.449 & 102.435 \\
\hline Flue Gas Moisture (\%) & 13.4 & 10.8 & 0.4 & 8.2 \\
\hline Gas Molecular Weight (Wet) (g/g-mole) & 28.68 & 28.78 & 30.04 & 29.17 \\
\hline
\end{tabular}


Plant Name AEP Tidd Demonstration Plant

- Location APF Inlet

Train MM5

\begin{tabular}{|c|c|c|c|c|}
\hline Run No. & 1 & 2 & 3 & Average \\
\hline Date & $04-12-94$ & $04-13-94$ & $04-15-94$ & - \\
\hline Time Start & 1928 & 1805 & 1045 & - \\
\hline Time Finish & 0103 & 2230 & 1553 & - \\
\hline Operator & RVW & RVW & RVW & - \\
\hline Initial Leak Rate & 0.002 & 0.008 & 0.006 & - \\
\hline Final Leak Rate & 0.010 & 0.005 & 0.006 & - \\
\hline Dry Gas Meter Calibration (Yd) & 1.018 & 1.018 & 1.018 & 1.018 \\
\hline Nozzle Diameter (inches) & 0.2500 & 0.2500 & 0.2500 & - \\
\hline Barometric Pressure ("Hg) & 29.44 & 29.14 & 29.41 & 29.33 \\
\hline Meter Volume (acf) & 111.710 & 104.953 & 111.810 & 109.491 \\
\hline Average delta $\mathrm{H}$ (" $\mathrm{H} 2 \mathrm{O})$ & 1.50 & 0.93 & 1.19 & 1.21 \\
\hline Average DGM Temp (F) & 94.9 & 84.1 & 88.7 & 89.2 \\
\hline Test Duration (minutes) & 150.0 & 200.0 & 200.0 & 183.3 \\
\hline Condensed Water (g) & 256.6 & 231.0 & 248.5 & 245.4 \\
\hline$\% \mathrm{CO} 2$ & 12.5 & 12.5 & 11.0 & 12.0 \\
\hline$\% 02$ & 5.5 & 5.5 & 8.0 & 6.3 \\
\hline$\%$ N2 & 82.0 & 82.0 & 81.0 & 81.7 \\
\hline Meter Volume (dscf) & 106.875 & 101.215 & 107.986 & 105.358 \\
\hline Flue Gas Moisture (\%) & 10.2 & 9.7 & 9.8 & 9.9 \\
\hline Gas Molecular Weight (Wet) (g/g-mole) & 28.98 & 29.03 & 28.90 & 28.97 \\
\hline
\end{tabular}


Plant Name AEP Tidd Demonstration Plant Location APF Inlet

Train VOST

\begin{tabular}{|c|c|c|c|c|c|c|c|}
\hline Run No. & $\overline{2 \mathrm{~A}}$ & $\overline{2 \mathrm{~B}}$ & $3 \mathrm{~A}$ & $3 \mathrm{~B}$ & IA & IB & Average \\
\hline Date & $04-13-94$ & $04-13-94$ & $04-14-94$ & $04-14-94$ & $04-15-94$ & $04-15-94$ & - \\
\hline Time Start & 2252 & 2340 & 1642 & 2012 & 1624 & 1710 & - \\
\hline Time Finish & 2332 & 0020 & 1722 & 2247 & 1704 & 1750 & - \\
\hline Operator & RVW & RVW & RVW & RVW & RVW & RVW & - \\
\hline Initial Leak Rate & $<0.001$ & $<0.001$ & $<0.001$ & $<0.001$ & $<0.001$ & $<0.001$ & - \\
\hline Final Leak Rate & $<0.001$ & $<0.001$ & $<0.001$ & $<0.001$ & $<0.001$ & $<0.001$ & - \\
\hline Tenax Tube ID & $30442 \mathrm{~A}$ & $30444 A$ & $30428 \mathrm{~A}$ & $30404 \mathrm{~A}$ & $30424 A$ & $30403 a$ & - \\
\hline Tenax/Charcoal Tube ID & 30442B & 30444B & 30428B & $30404 \mathrm{~B}$ & $30424 B$ & $30403 B$ & - \\
\hline Dry Gas Meter Calibration (Yd) & 0.982 & 0.982 & 0.982 & 0.982 & 0.982 & 0.982 & 0.982 \\
\hline Barometric Pressure ("Hg) & 29.14 & 29.14 & 29.41 & 29.41 & 29.41 & 29.41 & 29.32 \\
\hline Meter Volume (liters) & 20.070 & 20.075 & 20.410 & 20.085 & 20.110 & 20.150 & 20.150 \\
\hline Average delta H (" H2O) & 1.20 & 1.20 & 1.40 & 1.20 & 1.20 & 1.20 & 1.23 \\
\hline Average DGM Temp (F) & 82.7 & 86.0 & 98.0 & 100.0 & 97.0 & 47.3 & 85.2 \\
\hline Ist Condenser Temp (F) & 46.7 & 47.3 & 50.7 & 47.7 & 57.7 & 47.3 & 49.6 \\
\hline 2nd Condenser Temp (F) & 50.3 & 48.3 & 57.3 & 55.7 & 60.3 & 51.0 & 53.8 \\
\hline Test Duration (minutes) & 40.0 & 40.0 & 40.0 & 40.0 & 40.0 & 40.0 & 40.0 \\
\hline$\% \mathrm{CO} 2$ & 12.5 & 12.5 & 11.0 & 11.0 & 11.0 & 11.0 & 11.5 \\
\hline$\% 02$ & 5.5 & 5.5 & 8.0 & 8.0 & 8.0 & 8.0 & 7.2 \\
\hline$\% \mathrm{~N} 2$ & 82.0 & 82.0 & 81.0 & 81.0 & 81.0 & 81.0 & 81.3 \\
\hline Meter Volume (dsL) & 18.733 & 18.623 & 18.707 & 18.334 & 18.456 & 20.303 & 18.859 \\
\hline
\end{tabular}




\section{Plant Name AEP Tidd Demonstration Plant Location APF Outlet \\ Train Aldehyde}

\begin{tabular}{|c|c|c|c|c|}
\hline Run No. & 1 & 2 & 3 & Average \\
\hline Date & $04-12-94$ & $04-13-94$ & $04-14-94$ & - \\
\hline Time Start & 1945 & 1345 & 1359 & - \\
\hline Time Finish & 2141 & 1537 & 2041 & - \\
\hline Operator & DJV & DJV & DJV & - \\
\hline Initial Leak Rate & $<0.001$ & $<0.001$ & $<0.001$ & - \\
\hline Final Leak Rate & $<0.001$ & $<0.001$ & $<0.001$ & - \\
\hline Dry Gas Meter Calibration (Yd) & 1.016 & 1.003 & 1.003 & 1.007 \\
\hline Nozzle Diameter (inches) & 0.2500 & 0.2500 & 0.2500 & - \\
\hline Barometric Pressure ("Hg) & 29.44 & 29.14 & 29.35 & 29.31 \\
\hline Meter Volume (act) & 62.303 & .62 .505 & 61.873 & 62.227 \\
\hline Average delta H (" H2O) & 0.93 & 0.93 & 0.93 & 0.93 \\
\hline Average DGM Temp (F) & 106.1 & 101.6 & 108.1 & 105.2 \\
\hline Test Duration (minutes) & 116.0 & 112.0 & 118.0 & 115.3 \\
\hline Condensed Water (g) & 133.4 & 127.5 & 132.7 & 131.2 \\
\hline$\% \mathrm{CO}_{2}$ & 12.0 & 12.0 & 12.0 & 12.0 \\
\hline$\% 02$ & 6.0 & 6.0 & 6.0 & 6.0 \\
\hline$\% \mathrm{N2}$ & 82.0 & 82.0 & 82.0 & 82.0 \\
\hline Meter Volume (dscf) & 58.227 & 57.544 & 56.713 & 57.495 \\
\hline Flue Gas Moisture (\%) & 9.8 & 9.5 & 9.9 & 9.7 \\
\hline Gas Molecular Weight (Wet) (g/g-mole) & 28.97 & 29.01 & 28.95 & 28.98 \\
\hline
\end{tabular}




\section{Plant Name AEP Tidd Demonstration Plant \\ Location APF Outlet \\ Train Ammonia/Hydrogen Cyanide}

\begin{tabular}{|c|c|c|c|c|}
\hline Run No. & 1 & 2 & 3 & Average \\
\hline Date & $04-12-94$ & $04-13-94$ & $04-14-94$ & - \\
\hline Time Start & 1802 & 1346 & 1424 & - \\
\hline Time Finish & 1917 & 1515 & 1542 & - \\
\hline Operator & DJV & DJV & DJV & - \\
\hline Initial Leak Rate & $<0.001$ & 0.005 & $<0.001$ & - \\
\hline Final Leak Rate & $<0.001$ & 0.004 & $<0.001$ & - \\
\hline Dry Gas Meter Calibration (Yd) & 1.003 & 1.016 & 1.003 & 1.007 \\
\hline Nozzle Diameter (inches) & 0.2500 & 0.2500 & 0.2500 & - \\
\hline Barometric Pressure (" $\mathrm{Hg}$ ) & 29.44 & 29.14 & 29.35 & 29.31 \\
\hline Meter Volume (acf) & 40.628 & 42.319 & 42.829 & 41.925 \\
\hline Average delta $\mathrm{H}\left({ }^{n} \mathrm{H} 2 \mathrm{O}\right)$ & 0.95 & 0.93 & 0.93 & 0.94 \\
\hline Average DGM Temp (F) & 101.6 & 90.1 & 101.1 & 97.6 \\
\hline Test Duration (minutes) & 85.0 & 79.0 & 78.0 & 80.7 \\
\hline Condensed Water (g) & 100.1 & 87.4 & 105.1 & 97.5 \\
\hline$\% \mathrm{CO} 2$ & 12.0 & 12.0 & 12.0 & 12.0 \\
\hline$\% \mathrm{O} 2$ & 6.0 & 6.0 & 6.0 & 6.0 \\
\hline$\% \mathrm{~N} 2$ & 82.0 & 82.0 & 82.0 & 82.0 \\
\hline Meter Volume (dscf) & 37.784 & 40.287 & 39.744 & 39.272 \\
\hline Flue Gas Moisture (\%) & 11.1 & 9.3 & 11.1 & 10.5 \\
\hline Gas Molecular Weight (Wet) (g/g-mole) & 28.81 & 29.03 & 28.81 & 28.88 \\
\hline
\end{tabular}




\section{Plant Name AEP Tidd Demonstration Plant Location APF Outlet Train Anions}

\begin{tabular}{|c|c|c|c|c|}
\hline$\longdiv { \text { Run No. } }$ & 1 & $\overline{2}$ & $\overline{3}$ & Average \\
\hline Date & $04-12-94$ & $04-13-94$ & $04-14-94$ & - \\
\hline Time Start & 1315 & 0906 & 0953 & - \\
\hline Time Finish & 1430 & 1025 & 1110 & - \\
\hline Operator & DJV & DJV & DJV & - \\
\hline Initial Leak Rate & $<0.001$ & $<0.001$ & 0.002 & - \\
\hline Final Leak Rate & $<0.001$ & $<0.001$ & 0.002 & - \\
\hline Dry Gas Meter Calibration (Yd) & 1.016 & 1.016 & 1.003 & 1.012 \\
\hline Nozzle Diameter (inches) & 0.2500 & 0.2500 & 0.2500 & \\
\hline Barometric Pressure ("Hg) & 29.44 & 29.14 & 29.35 & 29.31 \\
\hline Meter Volume (acf) & 40.761 & 42.134 & 42.338 & 41.744 \\
\hline Average delta $\mathrm{H}\left({ }^{n} \mathrm{H} 2 \mathrm{O}\right)$ & 0.97 & 0.93 & 0.93 & 0.94 \\
\hline Average DGM Temp (F) & 99.2 & 89.0 & 100.3 & 96.1 \\
\hline Test Duration (minutes) & 85.0 & 79.0 & 77.0 & 80.3 \\
\hline Condensed Water $(\mathrm{g})$ & 97.5 & 93.6 & 91.2 & 94.1 \\
\hline$\% \mathrm{CO} 2$ & 12.0 & 12.0 & 12.0 & 12.0 \\
\hline$\% 02$ & 6.0 & 6.0 & 6.0 & 6.0 \\
\hline$\%$ N2 & 82.0 & 82.0 & 82.0 & 82.0 \\
\hline Meter Volume (dscf) & 38.569 & 40.191 & 39.350 & 39.370 \\
\hline Flue Gas Moisture (\%) & 10.7 & 9.9 & 9.9 & 10.1 \\
\hline Gas Molecular Weight (Wet) (g/g-mole) & 28.86 & 28.96 & 28.96 & 28.93 \\
\hline
\end{tabular}


Plant Name AEP Tidd Demonstration Plant Location APF Outlet

Train Metals

\begin{tabular}{|c|c|c|c|c|}
\hline Run No. & 1 & 2 & 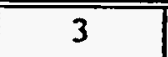 & Average \\
\hline Date & 04-12-94 & $04-13-94$ & 04-14-94 & - \\
\hline Time Start & 0909 & 0904 & 0952 & - \\
\hline Time Finish & 1245 & 1140 & 1229 & - \\
\hline Operator & DJV & DJV & DJV & - \\
\hline Initial Leak Rate & 0.002 & 0.005 & 0.006 & - \\
\hline Final Leak Rate & 0.002 & 0.003 & 0.004 & - \\
\hline Dry Gas Meter Calibration (Yd) & 1.003 & 1.003 & 1.016 & 1.007 \\
\hline Nozzle Diameter (inches) & 0.2500 & 0.2500 & 0.2500 & - \\
\hline Barometric Pressure ("Hg) & 29.44 & 29.14 & 29.35 & 29.31 \\
\hline Meter Volume (acf) & 100.626 & 103.896 & 103.459 & 102.660 \\
\hline Average delta $\mathrm{H}\left({ }^{\prime} \mathrm{H} 2 \mathrm{O}\right)$ & 1.46 & 1.40 & 1.40 & 1.42 \\
\hline Average DGM Temp (F) & 110.4 & 98.1 & 93.8 & 100.8 \\
\hline Test Duration (minutes) & 138.0 & 156.0 & 157.0 & 150.3 \\
\hline Condensed Water (g) & 122.3 & 236.2 & 198.7 & 185.7 \\
\hline$\% \mathrm{CO} 2$ & 12.0 & 12.0 & 12.0 & 12.0 \\
\hline$\% 02$ & 6.0 & 6.0 & 6.0 & 6.0 \\
\hline$\% \mathrm{~N} 2$ & 82.0 & 82.0 & 82.0 & 82.0 \\
\hline Meter Volume (dscf) & 92.265 & 96.351 & 98.657 & 95.758 \\
\hline Flue Gas Moisture (\%) & 5.9 & 10.4 & 8.7 & 8.3 \\
\hline Gas Molecular Weight (Wet) (g/g-mole) & 29.44 & 28.90 & 29.10 & 29.15 \\
\hline
\end{tabular}




\section{Plant Name AEP Tidd Demonstration Plant Location APF Outlet Train M23}

\begin{tabular}{|c|c|c|c|c|}
\hline Run No. & 2 & 3 & 1 & Average \\
\hline Date & $04-13-94$ & $04-15-94$ & $04-15-94$ & - \\
\hline Time Start & 1800 & 1041 & 2058 & - \\
\hline Time Finish & 2129 & 1541 & 2317 & - \\
\hline Operator & DJV & DJV & DJV & $=$ \\
\hline Initial Leak Rate & $<0.001$ & $<0.001$ & $<0.001$ & - \\
\hline Final Leak Rate & $<0.001$ & $<0.001$ & $<0.001$ & - \\
\hline Dry Gas Meter Calibration (Yd) & 1.016 & 1.003 & 1.003 & 1.007 \\
\hline Nozzle Diameter (inches) & 0.2500 & 0.2500 & 0.2500 & - \\
\hline Barometric Pressure ("Hg) & 29.14 & 29.41 & 29.41 & 29.32 \\
\hline Meter Volume (act) & 111.877 & 108.139 & 107.633 & 109.216 \\
\hline Average delta $\mathrm{H}$ (" $\mathrm{H} 2 \mathrm{O})$ & 0.93 & 0.96 & 1.90 & 1.26 \\
\hline Average DGM Temp (F) & 91.0 & 100.6 & 94.3 & 95.3 \\
\hline Test Duration (minutes) & 229.0 & 193.0 & 139.0 & 187.0 \\
\hline Condensed Water (g) & 239.2 & 244.1 & 241.9 & 241.7 \\
\hline$\% \mathrm{CO} 2$ & 12.0 & 12.0 & 12.0 & 12.0 \\
\hline$\% \mathrm{O} 2$ & 6.0 & 6.0 & 6.0 & 6.0 \\
\hline$\%$ N2 & 82.0 & 82.0 & 82.0 & 82.0 \\
\hline Meter Volume (dsct) & 106.339 & 100.658 & 101.556 & 102.851 \\
\hline Flue Gas Moisture (\%) & 9.6 & 10.3 & 10.1 & 10.0 \\
\hline Gas Molecular Weight (Wet) (g/g-mole) & 28.99 & 28.91 & 28.93 & 28.95 \\
\hline
\end{tabular}




\section{Plant Name AEP Tidd Demonstration Plant Location APF Outlet \\ Train MM5}

\begin{tabular}{|c|c|c|c|c|}
\hline Run No. & 1 & 2 & 3 & Average \\
\hline Date & $04-12-94$ & $04-13-94$ & $04-15-94$ & - \\
\hline Time Start & 1850 & 1801 & 1040 & - \\
\hline Time Finish & 2155 & 2121 & 1542 & - \\
\hline Operator & DJV & DJV & DJV & - \\
\hline Initial Leak Rate & 0.005 & $<0.001$ & $<0.001$ & - \\
\hline Final Leak Rate & 0.001 & $<0.001$ & $<0.011$ & - \\
\hline Dry Gas Meter Calibration (Yd) & 1.003 & 1.003 & 1.016 & 1.007 \\
\hline Nozzle Diameter (inches) & 0.2500 & 0.2500 & 0.2500 & - \\
\hline Barometric Pressure ("Hg) & 29.44 & 29.14 & 29.41 & 29.33 \\
\hline Meter Volume (acf) & 107.349 & 110.284 & 106.209 & 107.947 \\
\hline Average delta $\mathrm{H}$ (" $\mathrm{H} 2 \mathrm{O}$ ) & 0.93 & 0.93 & 0.96 & 0.94 \\
\hline Average DGM Temp (F) & 111.8 & 100.1 & 94.5 & 102.1 \\
\hline Test Duration (minutes) & 185.0 & 200.0 & 195.0 & 193.3 \\
\hline Condensed Water (g) & 234.7 & 228.8 & 226.9 & 230.1 \\
\hline$\% \mathrm{CO} 2$ & 12.0 & 12.0 & 12.0 & 12.0 \\
\hline$\% 02$ & 6.0 & 6.0 & 6.0 & 6.0 \\
\hline$\% \mathrm{~N} 2$ & 82.0 & 82.0 & 82.0 & 82.0 \\
\hline Meter Volume (dsce) & 98.052 & 101.797 & 101.249 & 100.366 \\
\hline Flue Gas Moisture (\%) & 10.2 & 9.6 & 9.6 & 9.8 \\
\hline Gas Molecular Weight (Wet) (g/g-mole) & 28.93 & 28.99 & 29.00 & 28.97 \\
\hline
\end{tabular}


Appendix C: Source Sampling Data Summary \& PSD Plots

Plant Name AEP Tidd Demonstration Plant Location APF Outlet

Train vosT

\begin{tabular}{|c|c|c|c|c|c|c|c|}
\hline Run No. & IA & $\overline{\text { IB }}$ & $\overline{2 A}$ & $2 \mathrm{~B}$ & $3 \mathrm{~A}$ & $3 \mathrm{~B}$ & Average \\
\hline Date & $04-12-94$ & 04-13-94 & $04-13-94$ & $04-13-94$ & 04-14-94 & $04-14-94$ & - \\
\hline rime Start & 2325 & 0,013 & 2241 & 2324 & 1645 & 2000 & - \\
\hline rime Finish & 0005 & 0.053 & 2315 & 0000 & 1725 & 2040 & - \\
\hline Operator & DJV & DJV & DJV & DJV & DJV & DJV & - \\
\hline Initial Leak Rate & $<0.001$ & $<0.001$ & $<0.001$ & $<0.001$ & $<0.001$ & $<0.001$ & - \\
\hline Final Leak Rate & $<0.001$ & $<0.001$ & $<0.001$ & $<0.001$ & $<0.001$ & $<0.001$ & - \\
\hline Tenax Tube ID & $30418 \mathrm{~A}$ & $30435 \mathrm{~A}$ & $30414 \mathrm{~A}$ & $30416 \mathrm{~A}$ & $30420 \mathrm{~A}$ & $30430 \mathrm{~A}$ & - \\
\hline Tenax/Charcoal Tube ID & $30418 B$ & $30435 B$ & $30414 B$ & $30416 \mathrm{~B}$ & $30420 B$ & 30430B & - \\
\hline Dry Gas Meter Calibration (Yd) & 1.005 & 1.005 & 1.005 & 1.005 & 1.005 & 1.005 & 1.005 \\
\hline Barometric Pressure ("Hg) & 29.44 & 29.44 & 29.14 & 29.14 & 29.41 & 29.41 & 29.33 \\
\hline Meter Volume (liters) & 24.112 & 32.604 & 23.833 & 20.976 & 20.354 & 22.821 & 24.117 \\
\hline |Average delta H (" H2O) & 1.20 & 1.30 & 1.60 & 1.40 & 1.20 & 1.30 & 1.33 \\
\hline Average DGM Temp (F) & 88.0 & 88.3 & 77.0 & 78.5 & 87.3 & 88.5 & 84.6 \\
\hline |lst Condenser Temp (F) & 44.8 & 45.0 & 50.0 & 50.0 & 46.0 & 44.3 & 46.7 \\
\hline 2nd Condenser Temp (F) & 55.0 & 52.0 & 54.5 & 53.0 & 53.7 & 52.5 & 53.4 \\
\hline Test Duration (minutes) & 40.0 & 40.0 & 34.0 & 36.0 & 40.0 & 40.0 & 38.3 \\
\hline$\% \mathrm{CO} 2$ & 12.0 & 12.0 & 12.0 & 12.0 & 12.0 & 12.0 & 12.0 \\
\hline$\% 02$ & 6.0 & 6.0 & 6.0 & 6.0 & 6.0 & 6.0 & 6.0 \\
\hline$\% \mathrm{N2}$ & 82.0 & 82.0 & 82.0 & 82.0 & 82.0 & 82.0 & 82.0 \\
\hline Meter Volume (dsL) & 23.042 & 31.151 & 23.029 & 20.202 & 19.456 & 21.772 & 23.109 \\
\hline
\end{tabular}


APF Sampling Locations Data Summary

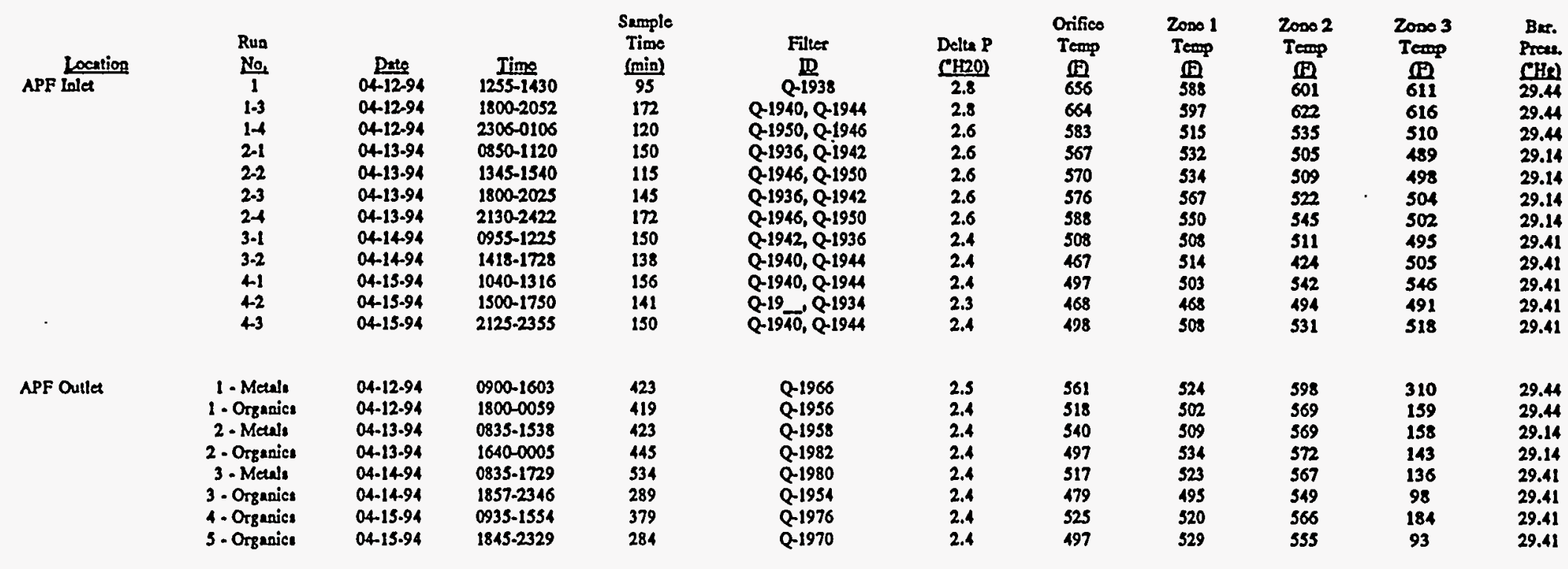

2 Isok Inetic based on process desIgn flow rates and determined to be $3 \mathrm{scfm}$. 


\begin{tabular}{|c|c|c|c|c|c|c|c|c|c|}
\hline APF location & $\begin{array}{l}\text { Run } \\
\text { No. }\end{array}$ & Dele & Time & $\begin{array}{c}\text { Ous Sumplias } \\
\text { Ruts } \\
\text { (ducfor) }\end{array}$ & $\begin{array}{l}\text { Gas Sumple } \\
\text { Volume } \\
\text { dech }\end{array}$ & 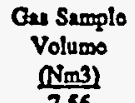 & $\begin{array}{c}\pi \\
\text { Lokinctic }\end{array}$ & $\begin{array}{l}\text { Perticalato } \\
\text { Mest: } \\
\text { (gm) }\end{array}$ & $\begin{array}{l}\text { Particuleto } \\
\text { Loudins } \\
\text { Cer/den }\end{array}$ \\
\hline \multirow{11}{*}{ APF Inlat } & 1 & $04-12-94$ & $1255-1430$ & 3.016 & 286.52 & 7.56 & 101 & N/A & \\
\hline & 1.3 & $04-12-94$ & $\begin{array}{l}1800-2052 \\
2106-0106\end{array}$ & 3.004 & $\begin{array}{l}516.69 \\
360.72\end{array}$ & $\begin{array}{r}13.63 \\
9.52\end{array}$ & 100 & $\begin{array}{l}50.2 \\
33.5\end{array}$ & $\begin{array}{l}1.50 \\
1.43\end{array}$ \\
\hline & 2.1 & $\begin{array}{l}04-12-94 \\
04-13-94\end{array}$ & $\begin{array}{l}2300-0100 \\
0850-1120\end{array}$ & $\begin{array}{l}3.000 \\
3.030\end{array}$ & $\begin{array}{l}300.72 \\
454.13\end{array}$ & $\begin{array}{l}9.32 \\
11.99\end{array}$ & $\begin{array}{l}100 \\
101\end{array}$ & $\begin{array}{l}33.5 \\
37.3\end{array}$ & $\begin{array}{l}1.43 \\
1.94\end{array}$ \\
\hline & $2-2$ & at-13.94 & $1345-1540$ & 3.025 & 347.88 & 9.18 & 101 & 36.8 & 1.63 \\
\hline & $2-3$ & $04-13-94$ & $1800-2025$ & 3.016 & 437.25 & 11.51 & 101 & 34.4 & 1.21 \\
\hline & 24 & $04-13-94$ & $2130-2422$ & 3.021 & 519.61 & 13.71 & 101 & 39.4 & 1.76 \\
\hline & 3.1 & $04-14-94$ & $.0955-1225$ & 3.004 & 450.60 & 11.89 & 100 & 45.5 & 1.56 \\
\hline & $3-2$ & $04-14-94$ & $1418-1728$ & 3.064 & 122.76 & 11.16 & 102 & 38.5 & 1.40 \\
\hline & 41 & $04-15-94$ & $1040-1316$ & 3.009 & 169.33 & 12.38 & 100 & 45.5 & 1.49 \\
\hline & $4-2$ & $04-15.94$ & $1500-1750$ & 3.016 & 425.19 & 11.22 & 101 & 40.9 & 1.48 \\
\hline & $4-3$ & $04-15.94$ & $2125-2355$ & 3.000 & 449.93 & 11.87 & 100 & 33.7 & 1.84 \\
\hline \multirow{8}{*}{ APF Outlet } & 1-Metals & $04-12-94$ & $0900-1603$ & 2.979 & 1259.91 & 33.21 & 99 & 0.00246 & $3.01 \mathrm{E}-05$ \\
\hline & 1. Organist & $04-12-94$ & $1800-0059$ & 2.982 & 1249.25 & 32.96 & 99 & -0.00568 & $-7.00 \mathrm{E}-05$ \\
\hline & 2-Metals & $04-13.94$ & $0835-1538$ & 2.949 & 1247.22 & 32.91 & 98 & 0.01031 & $1.27 \mathrm{E}-04$ \\
\hline & 2-Organics & $04-13.94$ & $1640-0005$ & 3.015 & 1341.68 & 35.10 & 101 & 0.00834 & 9.578-05 \\
\hline & 3-Metala & $04-14-94$ & 0835.1729 & 2.984 & 1593.19 & 12.04 & 99 & 0.00759 & 7.34E-05 \\
\hline & 3-Orgenice & $04-14-94$ & 1857.2346 & 3.043 & 879.43 & 23.20 & 101 & 0.02204 & 3.868-04 \\
\hline & 4. Organica & $04-15.94$ & 0935-1554 & 2.972 & 1126.20 & 29.72 & 99 & 0.01652 & $2.26 \mathrm{E}-04$ \\
\hline & 3. Organics & $04-15-94$ & $1845-2329$ & 3.015 & 856.12 & 22.59 & 100 & 0.01817 & $3.27 \mathrm{E}-04$ \\
\hline
\end{tabular}

₹ Isokinetic based on process design flow rates and determined to be $3 \mathrm{scfm}$. 


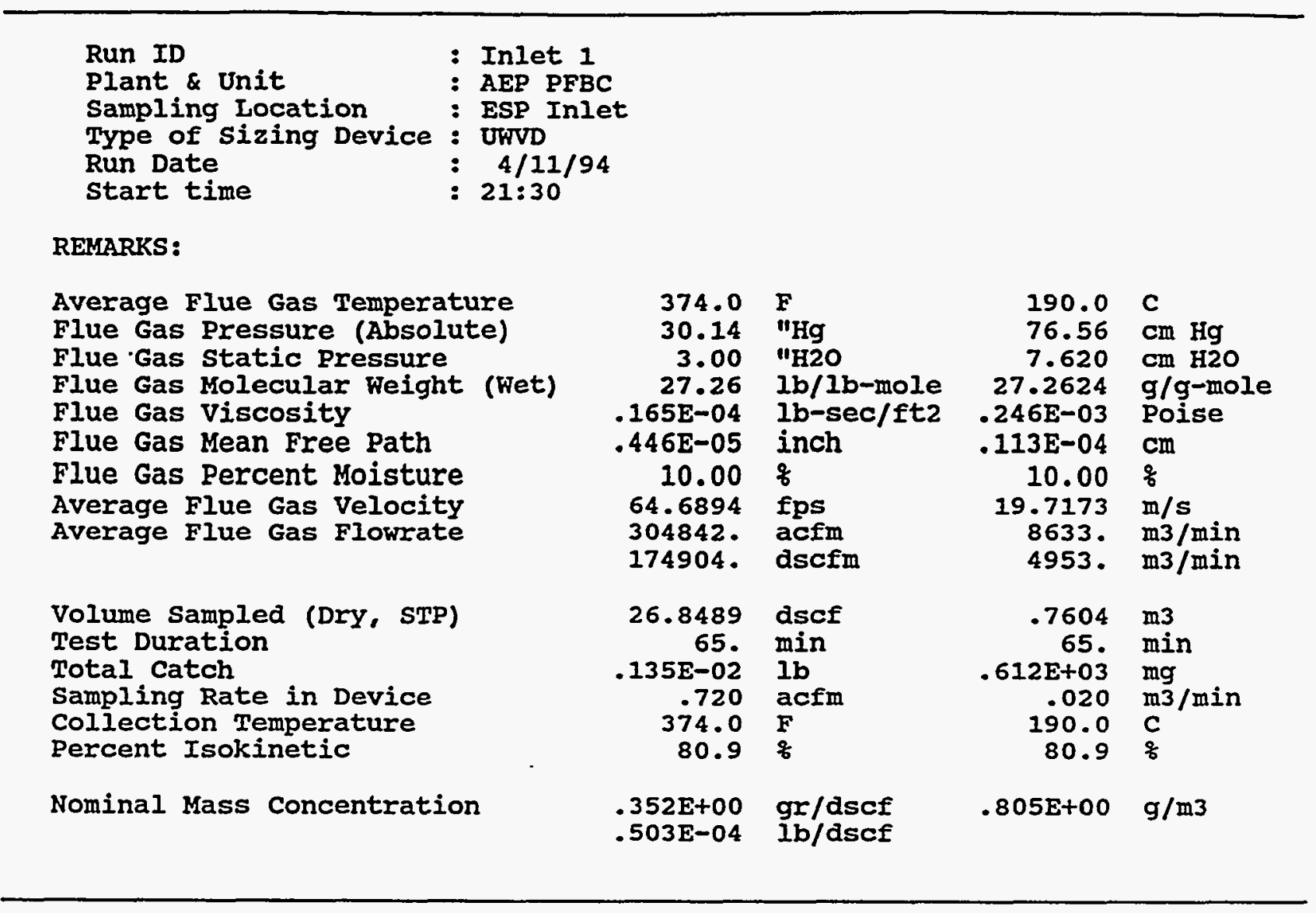




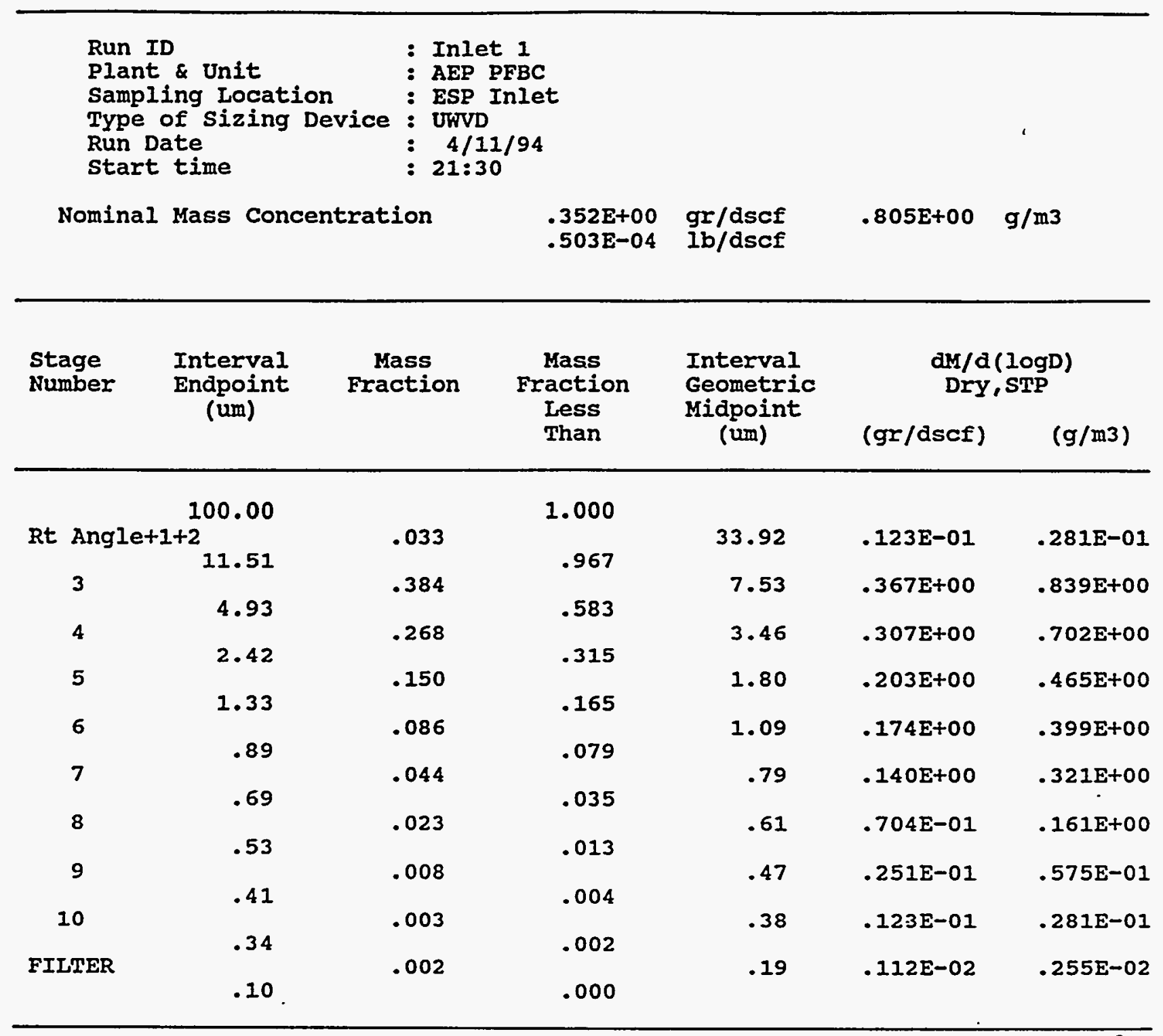




$\begin{array}{ll}\text { Run ID } & \text { : Inlet } 2 \\ \text { Plant \& Unit } & : \text { AEP PFBC } \\ \text { Sampling Location } & : \text { ESP Inlet } \\ \text { Type of Sizing Device } & \text { UWVD } \\ \text { Run Date } & : 4 / 13 / 94 \\ \text { Start time } & : 4: 0\end{array}$

REMARKS :

Average Flue Gas Temperature

Flue Gas Pressure (Absolute)

Flue Gas Static Pressure

Flue Gas Molecular Weight (Wet)

Flue Gas Viscosity

Flue Gas Hean Free Path

Flue Gas Percent Moisture

Average Flue Gas Velocity

Average Flue Gas. Flowrate

Volume Sampled (Dry, STP)

Test Duration

Total Catch

Sampling Rate in Device

Collection Temperature

percent Isokinetic

Nominal Mass Concentration

\begin{tabular}{|c|c|c|c|}
\hline $\begin{array}{r}385.0 \\
30.14 \\
3.00 \\
27.26 \\
.166 \mathrm{E}-04 \\
.453 \mathrm{E}-05 \\
10.00 \\
51.4778 \\
308867 . \\
174905 .\end{array}$ & $\begin{array}{l}\text { F } \\
\text { "Hg } \\
\text { "H2O } \\
\text { lb/1b-mole } \\
\text { lb-sec/ft2 } \\
\text { inch } \\
\text { o } \\
\text { fps } \\
\text { acfm } \\
\text { dscfm }\end{array}$ & $\begin{array}{r}196.1 \\
76.56 \\
7.620 \\
27.2624 \\
.248 \mathrm{E}-03 \\
.115 \mathrm{E}-04 \\
10.00 \\
15.6904 \\
8747 . \\
4953 .\end{array}$ & $\begin{array}{l}\text { C } \\
\mathrm{cm} \mathrm{Hg} \\
\mathrm{cm} \mathrm{H} 2 \mathrm{O} \\
\mathrm{g} / \mathrm{g} \text {-mole } \\
\text { poise } \\
\mathrm{cm} \\
\frac{\mathrm{o}}{\mathrm{m}} \\
\mathrm{m} / \mathrm{s} \\
\mathrm{m} 3 / \mathrm{min} \\
\mathrm{m} 3 / \mathrm{min}\end{array}$ \\
\hline $\begin{array}{r}20.3670 \\
49 . \\
.788 E-03 \\
.734 \\
385.0 \\
103.7\end{array}$ & $\begin{array}{l}\text { dscf } \\
\text { min } \\
\text { Ib } \\
\text { acfm } \\
\text { F } \\
\&\end{array}$ & $\begin{array}{r}.5768 \\
49 . \\
.357 \mathrm{E}+03 \\
.021 \\
196.1 \\
103.7\end{array}$ & $\begin{array}{l}\text { m3 } \\
\text { min } \\
\text { mg } \\
\text { m3/min } \\
\text { C } \\
\frac{9}{6}\end{array}$ \\
\hline $\begin{array}{l}.271 E+00 \\
.387 E-04\end{array}$ & $\begin{array}{l}\text { gr/dscf } \\
\text { Ib/dscf }\end{array}$ & $.619 E+00$ & $g / m 3$ \\
\hline
\end{tabular}


Run ID

Plant \& Unit

Sampling Location

Type of Sizing Device

Run Date

start time
: Inlet 2

: AEP PFBC

: ESP Inlet

: UWVD

: $4 / 13 / 94$

: 4:0

Nominal Mass Concentration

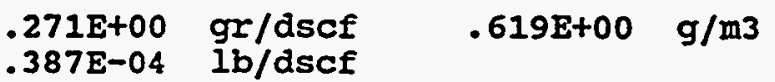

\begin{tabular}{|c|c|c|c|c|c|c|}
\hline \multirow{2}{*}{$\begin{array}{c}\text { Stage } \\
\text { Number }\end{array}$} & \multirow{2}{*}{$\begin{array}{l}\text { Interval } \\
\text { Endpoint } \\
\text { (um) }\end{array}$} & \multirow[t]{2}{*}{$\begin{array}{l}\text { Mass } \\
\text { Fraction }\end{array}$} & \multirow{2}{*}{$\begin{array}{l}\text { Mass } \\
\text { Fraction } \\
\text { Less } \\
\text { Than }\end{array}$} & \multirow{2}{*}{$\begin{array}{l}\text { Interval } \\
\text { Geometric } \\
\text { Midpoint } \\
\text { (um) }\end{array}$} & \multicolumn{2}{|c|}{$\begin{array}{c}\mathrm{dM} / \mathrm{d}(\log \mathrm{D}) \\
\mathrm{DrY}, \mathrm{STP}\end{array}$} \\
\hline & & & & & (gr/dscf) & $(g / m 3)$ \\
\hline \multirow{2}{*}{\multicolumn{7}{|c|}{ Rt Anglet1+2 }} \\
\hline & $1+2$ & .022 & & 33.83 & . $642 \mathrm{E}-02$ & $.147 \mathrm{E}-01$ \\
\hline \multirow{2}{*}{3} & 11.44 & .280 & .978 & 7.49 & $.206 E+00$ & $.470 E+00$ \\
\hline & 4.90 & & .698 & & & \\
\hline \multirow[t]{2}{*}{4} & & .321 & & 3.44 & $.282 E+00$ & $.645 E+00$ \\
\hline & 2.41 & & .377 & & & \\
\hline 5 & 1.32 & .185 & .19 & 1.79 & $.192 E+00$ & $.439 E+00$ \\
\hline \multirow[t]{2}{*}{6} & & .101 & & 1.08 & $.157 E+00$ & $.359 E+00$ \\
\hline & .89 & & .092 & & & \\
\hline 7 & .69 & .053 & & .78 & $.128 E+00$ & $.294 E+00$ \\
\hline \multirow[t]{2}{*}{8} & o & .023 & .039 & .60 & $.550 \mathrm{E}-01$ & $.126 \mathrm{E}+00$ \\
\hline & .53 & & .016 & & & \\
\hline 9 & .41 & .010 & .006 & .47 & $.245 \mathrm{E}-01$ & $.560 E-01$ \\
\hline \multirow[t]{2}{*}{10} & & .006 & & .37 & $.195 \mathrm{E}-01$ & $.445 \mathrm{E}-01$ \\
\hline & .34 & & .000 & & $2285-03$ & $5235-03$ \\
\hline FILTER & .10 & .000 & .000 & $\cdot 18$ & 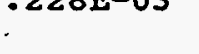 & 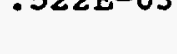 \\
\hline
\end{tabular}




$\begin{array}{ll}\text { Run ID } & \text { : Inlet } 3 \\ \text { Plant \& Unit } & \text { : AEP PFBC } \\ \text { Sampling Location } & : \text { ESP Inlet } \\ \text { Type of sizing Device } & : \text { UWVD } \\ \text { Run Date } & : 4 / 14 / 94 \\ \text { Start time } & : 0: 30\end{array}$

REMARKS:

Average Flue Gas Temperature Flue Gas Pressure (Absolute)

Flue Gas Static Pressure

Flue Gas Molecular Weight (Wet)

Flue Gas Viscosity

Flue Gas Mean Free Path

Flue Gas Percent Moisture

Average Flue Gas Velocity

Average Flue Gas Flowrate

Volume sampled (DrY, STP)

Test Duration

Total Catch

Sampling Rate in Device

collection Temperature

Percent Isokinetic

Nominal Mass Concentration

\begin{tabular}{|c|c|c|c|}
\hline $\begin{array}{r}385.0 \\
30.14 \\
3.00 \\
27.26 \\
.166 \mathrm{E}-04 \\
.453 \mathrm{E}-05 \\
10.00 \\
51.4778 \\
308867 . \\
174905 .\end{array}$ & $\begin{array}{l}\text { F } \\
\text { "Hg } \\
\text { "H2O } \\
\text { lb/lb-mole } \\
\text { lb-sec/ft2 } \\
\text { inch } \\
q \\
\text { fps } \\
\text { acfm } \\
\text { dscfm }\end{array}$ & $\begin{array}{r}196.1 \\
76.56 \\
7.620 \\
27.2624 \\
.248 \mathrm{E}-03 \\
.115 \mathrm{E}-04 \\
10.00 \\
15.6904 \\
8747 . \\
4953 .\end{array}$ & $\begin{array}{l}\text { C } \\
\text { cm Hg } \\
\text { cm H2O } \\
g / g-m o l e \\
\text { Poise } \\
\text { cm } \\
q \\
\mathrm{~m} / \mathrm{s} \\
\mathrm{m} 3 / \mathrm{min} \\
\mathrm{m} 3 / \mathrm{min}\end{array}$ \\
\hline $\begin{array}{r}21.2597 \\
50 \\
.924 E-03 \\
.751 \\
385.0 \\
106.0\end{array}$ & $\begin{array}{l}\text { dscf } \\
\text { min } \\
\text { Ib } \\
\text { acfm } \\
\text { F } \\
q\end{array}$ & $\begin{array}{r}.6021 \\
50 . \\
.419 \mathrm{E}+03 \\
.021 \\
196.1 \\
106.0\end{array}$ & $\begin{array}{l}\mathrm{m} 3 \\
\mathrm{~min} \\
\mathrm{mg} \\
\mathrm{m} 3 / \mathrm{min} \\
\mathrm{C} \\
\frac{\mathrm{o}}{6}\end{array}$ \\
\hline $\begin{array}{l}.304 E+00 \\
.435 E-04\end{array}$ & $\begin{array}{l}\text { gr/dscf } \\
\mathrm{lb} / \mathrm{dscf}\end{array}$ & $.696 \mathrm{E}+00$ & $\mathrm{~g} / \mathrm{m}$ \\
\hline
\end{tabular}




$\begin{array}{ll}\text { Run ID } & \text { : Inlet } 3 \\ \text { Plant \& Unit } & : \text { AEP PFBC } \\ \text { Sampling Iocation } & : \text { ESP Inlet } \\ \text { Type of sizing Device } & : \text { UWVD } \\ \text { Run Date } & : 4 / 14 / 94 \\ \text { Start time } & : 0: 30\end{array}$

Nominal Mass Concentration $\begin{array}{llll}.304 \mathrm{E}+00 & \mathrm{gr} / \mathrm{dscf} & .696 \mathrm{E}+00 & \mathrm{~g} / \mathrm{m} 3\end{array}$

\begin{tabular}{|c|c|c|c|c|c|c|}
\hline \multirow[t]{2}{*}{$\begin{array}{l}\text { Stage } \\
\text { Number }\end{array}$} & \multirow{2}{*}{$\begin{array}{l}\text { Interval } \\
\text { Endpoint } \\
\text { (um) }\end{array}$} & \multirow[t]{2}{*}{$\begin{array}{c}\text { Mass } \\
\text { Fraction }\end{array}$} & \multirow{2}{*}{$\begin{array}{l}\text { Mass } \\
\text { Fraction } \\
\text { Less } \\
\text { Than }\end{array}$} & \multirow{2}{*}{$\begin{array}{l}\text { Interval } \\
\text { Geometric } \\
\text { Midpoint } \\
\text { (um) }\end{array}$} & \multicolumn{2}{|c|}{$\begin{array}{c}\mathrm{dM} / \mathrm{d}(\log \mathrm{D}) \\
\mathrm{DrY}, \mathrm{STP}\end{array}$} \\
\hline & & & & & $(g r / d s c f)$ & $(g / m 3)$ \\
\hline & 100.00 & & 1.000 & & & \\
\hline Rt Ang & & .020 & & 33.63 & $.642 E-02$ & $.147 \mathrm{E}-01$ \\
\hline 3 & 11.31 & 303 & .980 & $7<0$ & $3245+00$ & $7015+00$ \\
\hline 3 & 4.84 & .393 & .587 & 7.40 & $.324 E+00$ & $.741 E+00$ \\
\hline 4 & 2.38 & .287 & .300 & 3.40 & $.284 E+00$ & $.649 \mathrm{E}+00$ \\
\hline 5 & 1.31 & .146 & .154 & 1.76 & $.171 E+00$ & $.391 E+00$ \\
\hline 6 & .88 & .081 & .072 & 1.07 & $.143 E+00$ & $.327 \mathrm{E}+00$ \\
\hline 7 & .68 & .042 & .030 & .77 & $.115 E+00$ & $.263 E+00$ \\
\hline 8 & .52 & .018 & .012 & .60 & $.491 \mathrm{E}-01$ & $.112 \mathrm{E}+00$ \\
\hline 9 & .40 & .007 & .006 & .46 & $.175 \mathrm{E}-01$ & $.401 \mathrm{E}-01$ \\
\hline 10 & .34 & .003 & .002 & .37 & $.124 \mathrm{E}-01$ & $.284 \mathrm{E}-01$ \\
\hline FILTER & .10 & .002 & .000 & .18 & $.135 \mathrm{E}-02$ & $.310 \mathrm{E}-02$ \\
\hline
\end{tabular}




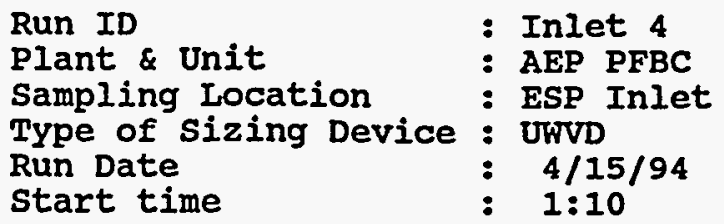

REMARKS:

Average Flue Gas Temperature

Flue Gas Pressure (Absolute)

Flue Gas static Pressure

Flue Gas Molecular Weight (Wet)

Flue Gas Viscosity

Flue Gas Mean Free Path

Flue Gas Percent Moisture

Average Flue Gas Velocity

Average Flue Gas Flowrate

Volume Sampled (DrY, STP)

Test Duration

Total Catch

Sampling Rate in Device

Collection Temperature

Percent Isokinetic

Nominal Mass Concentration

$\begin{array}{rlrl}385.0 & \mathrm{~F} & 196.1 & \mathrm{c} \\ 30.14 & \text { "Hg } & 76.56 & \mathrm{~cm} \mathrm{Hg} \\ 3.00 & \text { "H2O } & 7.620 & \mathrm{~cm} \mathrm{H} 20 \\ 27.26 & \text { lb/lb-mole } & 27.2624 & \mathrm{~g} / \mathrm{g}-\mathrm{mole} \\ .166 \mathrm{E}-04 & \text { lb-sec/ft2 } & .248 \mathrm{E}-03 & \mathrm{Poise} \\ .453 \mathrm{E}-05 & \text { inch } & .115 \mathrm{E}-04 & \mathrm{~cm} \\ 10.00 & \text { q } & 10.00 & \mathrm{q} \\ 52.4972 & \text { fps } & 16.0012 & \mathrm{~m} / \mathrm{s} \\ 314983 . & \text { acfm } & 8920 . & \mathrm{m} 3 / \mathrm{min} \\ 178369 . & \text { dscfm } & 5051 . & \mathrm{m} 3 / \mathrm{min} \\ & & .4378 & \mathrm{~m} 3 \\ 15.4589 & \text { dscf } & 39 . & \mathrm{min} \\ 39 . & \text { min } & .345 \mathrm{E}+03 & \mathrm{mg} \\ .761 \mathrm{E}-03 & \text { 1b } & .020 & \mathrm{~m} 3 / \mathrm{min} \\ .700 & \text { acfm } & 196.1 & \mathrm{c} \\ 385.0 & \mathrm{~F} . & 96.9 & \mathrm{q} \\ 96.9 & \text { \% } & .788 \mathrm{E}+00 & \mathrm{~g} / \mathrm{m} 3 \\ & & & \end{array}$




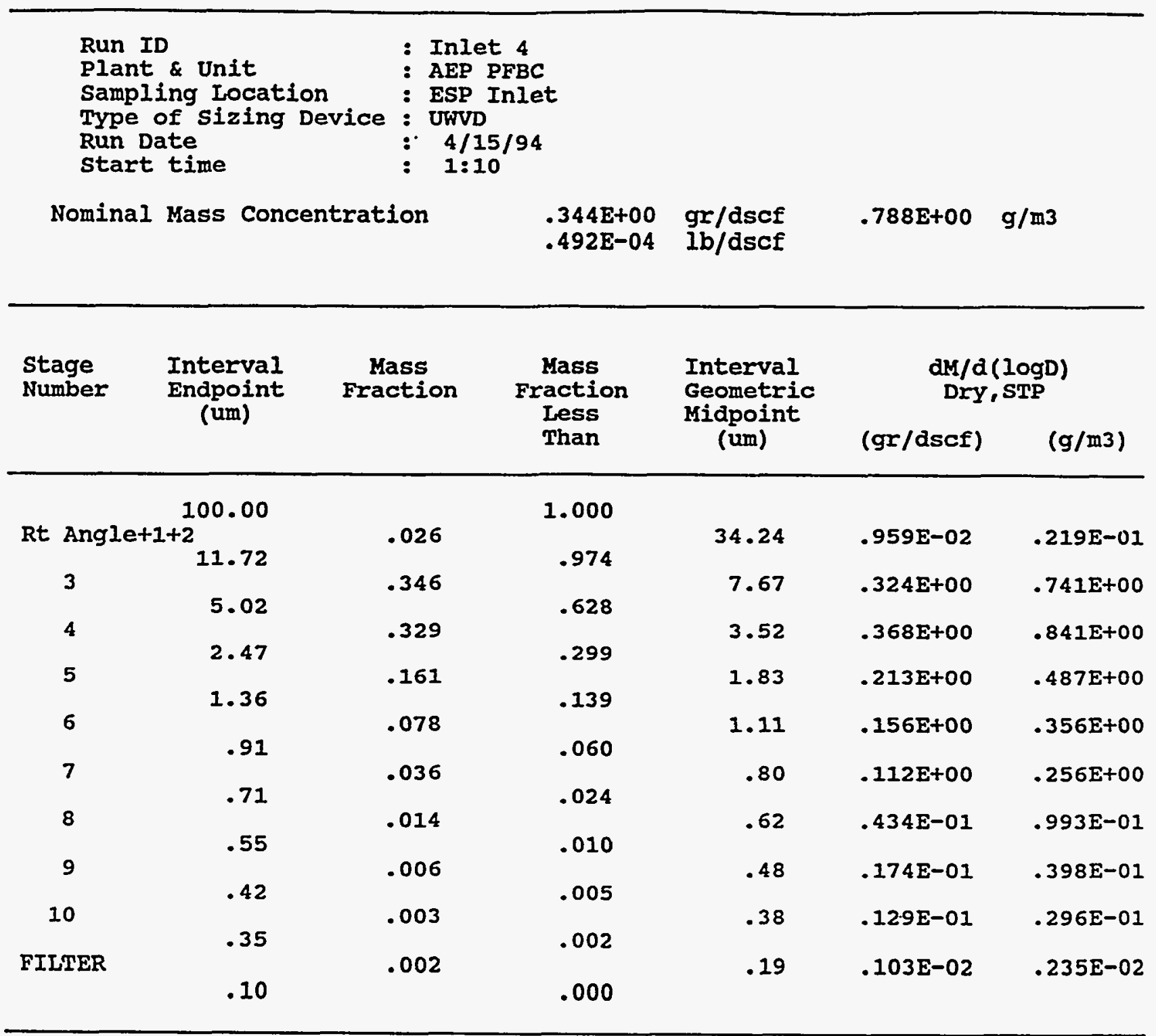




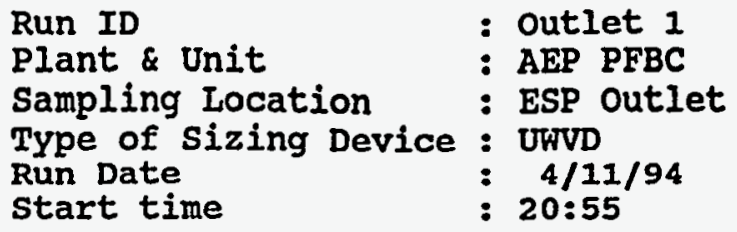

REMARKS:

Average Flue Gas Temperature

Flue Gas Pressure (Absolute)

Flue Gas static Pressure

Flue Gas Molecular Weight (Wet)

Flue Gas Viscosity

Flue Gas Mean Free Path

Flue Gas Percent Moisture

Average Flue Gas Velocity

Average Flue Gas Flowrate

Volume Sampled (DrY, STP)

Test Duration

Total Catch

Sampling Rate in Device

Collection Temperature

Percent Isokinetic

Nominal Mass Concentration

\begin{tabular}{|c|c|c|c|}
\hline $\begin{array}{r}382.0 \\
29.92 \\
3.00 \\
27.26 \\
.166 \mathrm{E}-04 \\
.455 \mathrm{E}-05 \\
10.00 \\
61.0242 \\
287569 . \\
162233 .\end{array}$ & $\begin{array}{l}\text { F } \\
\text { "Hg } \\
\text { "H2O } \\
1 \mathrm{~b} / 1 \mathrm{l}-\text { mole } \\
\text { Ib-sec/ft2 } \\
\text { inch } \\
\text { \% } \\
\text { fps } \\
\text { acfm } \\
\text { dscfm }\end{array}$ & $\begin{array}{r}194.4 \\
76.00 \\
7.620 \\
27.2624 \\
.247 \mathrm{E}-03 \\
115 \mathrm{E}-04 \\
10.00 \\
18.6002 \\
8144 . \\
4594 .\end{array}$ & $\begin{array}{l}\text { C } \\
\text { cm Hg } \\
\text { cm H2O } \\
\text { g/g-mole } \\
\text { Poise } \\
\text { cm } \\
\frac{q}{6} \\
\mathrm{~m} / \mathrm{s} \\
\mathrm{m} 3 / \mathrm{min} \\
\mathrm{m} 3 / \mathrm{min}\end{array}$ \\
\hline $\begin{array}{r}366.9825 \\
1006 \\
.123 \mathrm{E}-03 \\
.647 \\
382.0 \\
94.6\end{array}$ & $\begin{array}{l}\text { dscf } \\
\text { min } \\
\text { Ib } \\
\text { acfm } \\
\text { F } \\
\text { ob }\end{array}$ & $\begin{array}{r}10.3929 \\
1006 \\
.557 \mathrm{E}+02 \\
.018 \\
194.4 \\
94.6\end{array}$ & $\begin{array}{l}\mathrm{m} 3 \\
\mathrm{~min} \\
\mathrm{mg} \\
\mathrm{m} 3 / \mathrm{min} \\
\mathrm{C} \\
\frac{q}{6}\end{array}$ \\
\hline $\begin{array}{l}.234 \mathrm{E}-02 \\
.335 \mathrm{E}-06\end{array}$ & $\begin{array}{l}\text { gr/ascf } \\
\text { lb/ascf }\end{array}$ & $.536 \mathrm{E}-02$ & $\mathrm{~g} / \mathrm{m} 3$ \\
\hline
\end{tabular}

382.0

3.00 "H2O

$5 E-05$

1.0242

287569 .

366.9825

1006 .

23E-03

.647

382.0 $.335 \mathrm{E}-06$

$\mathrm{ib} / \mathrm{dscf}$ 247 E-03

5E-04

8144.

4594 .

.3929

$7 \mathrm{E}+02$

194.4

94.6 $\mathrm{m} 3 / \mathrm{min}$

q

$\mathrm{g} / \mathrm{m} 3$ 
Appendix C: Source Sampling Data Summary \& PSD Plots

Run ID

Plant \& Unit

: outlet 1

Sampling Location

: AEP PFBC

Type of Sizing Device : UWVD

Run Date

start time

: $4 / 11 / 94$

: 20:55

Nominal Mass Concentration

$.234 \mathrm{E}-02$ $.335 \mathrm{E}-06$

gr/dscf

lb/dscf

$.536 \mathrm{E}-02 \mathrm{~g} / \mathrm{m} 3$

Stage

Interval

Endpoint

(um)

$\begin{array}{cc}\text { Mass } & \text { Mass } \\ \text { Fraction } & \text { Fraction } \\ & \text { Less } \\ & \text { Than }\end{array}$

Interval

Geometric

Midpoint

(um)

$d M / d(\log D)$
Dry, STP

uess

$(g r / d s c f) \quad(g / m 3)$

\begin{tabular}{|c|c|c|c|c|c|c|}
\hline \multirow{2}{*}{\multicolumn{2}{|c|}{ Rt Anglet $1+2^{100.00}$}} & \multicolumn{3}{|c|}{1.000} & \multirow{2}{*}{$.929 E-03$} & \multirow{3}{*}{$.213 E-02$} \\
\hline & & .362 & & 34.91 & & \\
\hline 3 & $12 \cdot 19$ & .256 & .638 & 7.98 & $.163 E-02$ & \\
\hline & 5.22 & & .382 & $\ldots \pi$ & 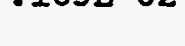 & 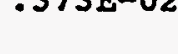 \\
\hline 4 & ? 57 & .157 & 275 & 3.66 & $.120 \mathrm{E}-02$ & $.274 \mathrm{E}-02$ \\
\hline 5 & 2.57 & .058 & $\bullet<<2$ & 1.91 & $.525 E-03$ & $.120 \mathrm{E}-02$ \\
\hline & 1.42 & & .166 & & & \\
\hline 6 & & .052 & & 1.16 & $.707 \mathrm{E}-03$ & $.162 \mathrm{E}-02$ \\
\hline & .95 & & .114 & & & \\
\hline 7 & & .024 & & .84 & $.507 \mathrm{E}-03$ & $.116 \mathrm{E}-02$ \\
\hline 8 & .74 & .018 & .091 & .65 & $.382 \mathrm{E}-03$ & $.875 \mathrm{E}-03$ \\
\hline & .57 & & .072 & & & \\
\hline 9 & & .021 & & .50 & $.443 E-03$ & $.101 \mathrm{E}-02$ \\
\hline 10 & .44 & .024 & .051 & 40 & $715 F-03$ & \\
\hline & .37 & & .027 & .40 & 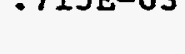 & $-164 \mathrm{E}-02$ \\
\hline FILTER & & .027 & & .19 & $.112 \mathrm{E}-03$ & $.257 \mathrm{E}-03$ \\
\hline & .10 & & .000 & & & \\
\hline
\end{tabular}




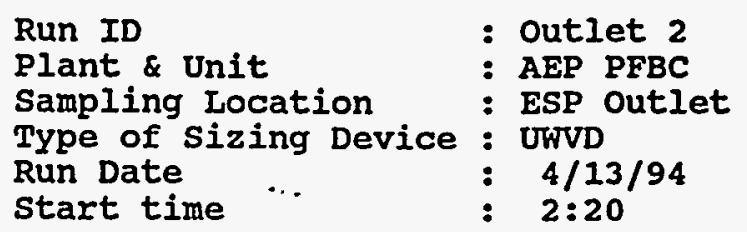

REMARKS :

Average Flue Gas Temperature

Flue Gas Pressure (Absolute)

Flue Gas static Pressure

Flue Gas Molecular Weight (Wet)

Flue Gas Viscosity

Flue Gas Mean Free Path

Flue Gas Percent Moisture

Average Flue Gas Velocity

Average Flue Gas Flowrate

Volume Sampled (Dry, STP)

Test Duration

$374.0 \quad \mathrm{E}$

Percent Isokinetic

Nominal Mass Concentration
30.14 "Hg

3.00 "H2O

27.26

$.165 \mathrm{E}-04$

$.446 \mathrm{E}-05$

10.00

59.6407

281050 .

161253 .

127.3540

347 .

$.422 E-04$

.640

374.0

95.7

lb/lb-mole

dscfm

dsce

min

Ib

acfm

$\mathrm{F}$

of

$.232 \mathrm{E}-02$ gr/dscf $.332 E-06 \mathrm{Ib} / \mathrm{dscf}$
76.56

7.620

27.2624

$.246 \mathrm{E}-03$

$.113 \mathrm{E}-04$

10.00

18.1785

7959 .

4567 .

3.6067

347 .

$.191 \mathrm{E}+02$

.018

190.0

95.7

C

cm $\mathrm{Hg}$

cm $\mathrm{H} 2 \mathrm{O}$

g/g-mole

Poise

cm

\%

$\mathrm{m} / \mathrm{s}$

$\mathrm{m} 3 / \mathrm{min}$

$\mathrm{m} 3 / \mathrm{min}$

m3

$\min$

mg

$\mathrm{m} 3 / \mathrm{min}$

C

$.531 \mathrm{E}-02 \mathrm{~g} / \mathrm{m} 3$ 


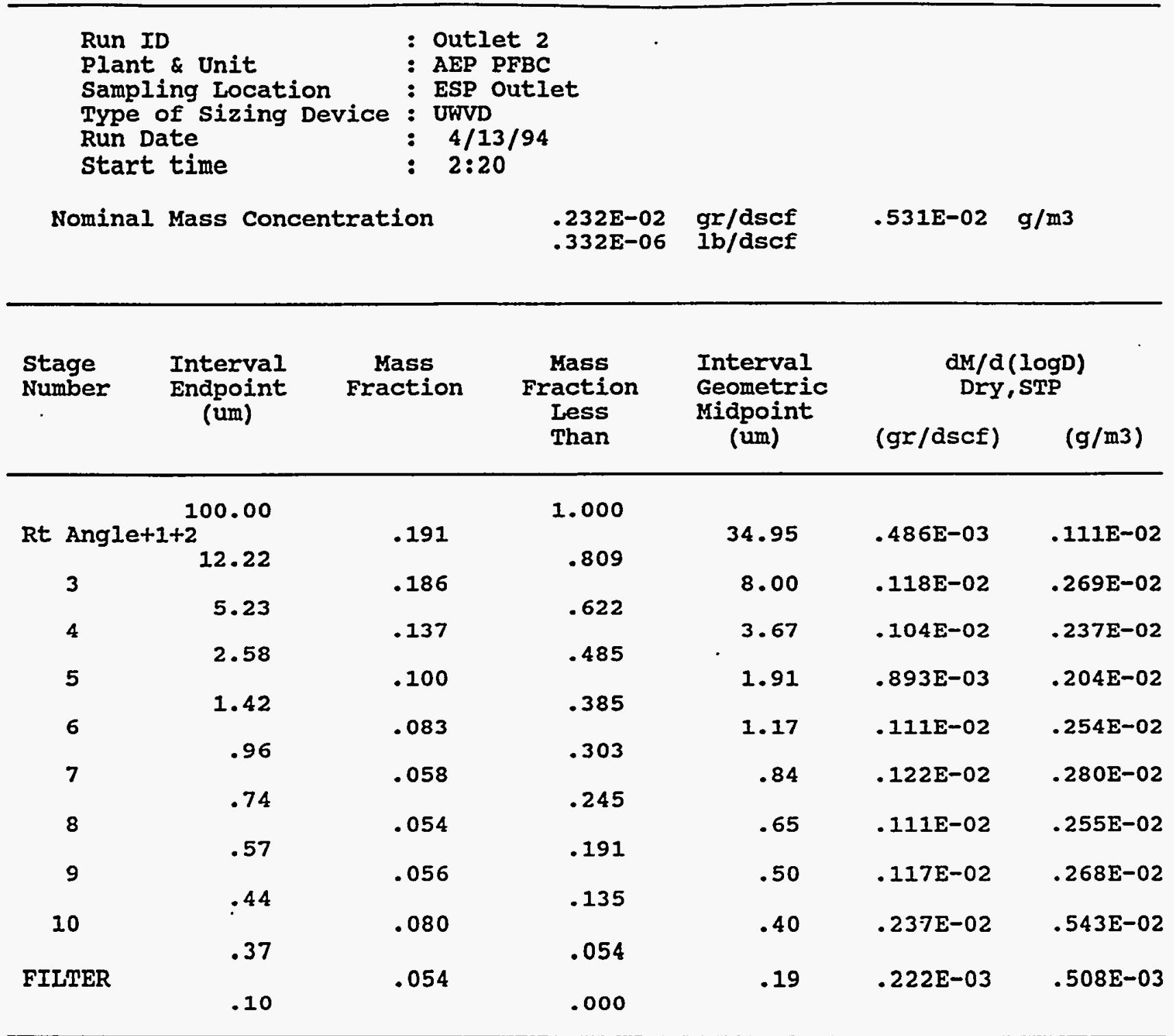




$\begin{array}{ll}\text { Run ID } & \text { : Outlet } 3 \\ \text { Plant \& Unit } & : \text { AEP PFBC } \\ \text { Sampling Location } & : \text { ESP Outlet } \\ \text { Type of Sizing Device } & : \text { UWV } \\ \text { Run Date } & : 4 / 13 / 94 \\ \text { Start time } & : 23: 55\end{array}$

REMARKS:

Average Flue Gás Temperature Flue Gas Pressure (Absolute)

Flue Gas Static Pressure

Flue Gas Molecular Weight (Wet)

Flue Gas Viscosity

Flue Gas Mean Free Path

Flue Gas Percent Moisture

Average Flue Gas Velocity

Average Flue Gas Flowrate

Volume sampled (Dry, STP)

Test Duration

Total Catch

Sampling Rate in Device

Collection Temperature

Percent Isokinetic

Nominal Mass Concentration

$\begin{array}{rlrl}374.0 & \text { F } & 190.0 & \mathrm{C} \\ 30.14 & \text { "Hg } & 76.56 & \mathrm{~cm} \mathrm{Hg} \\ 3.00 & \text { "H2O } & 7.620 & \mathrm{~cm} \mathrm{H2O} \\ 27.26 & \text { Ib/lb-mole } & 27.2624 & \mathrm{~g} / \mathrm{g}-\mathrm{mole} \\ .165 \mathrm{E}-04 & \text { Ib-sec/ft2 } & .246 \mathrm{E}-03 & \mathrm{poise} \\ .446 \mathrm{E}-05 & \text { inch } & .113 \mathrm{E}-04 & \mathrm{~cm} \\ 10.00 & \text { q } & 10.00 & \mathrm{q} \\ 51.1415 & \text { fps } & 15.5879 & \mathrm{~m} / \mathrm{s} \\ 240998 . & \text { acfm } & 6825 . & \mathrm{m} 3 / \mathrm{min} \\ 138273 . & \text { dscfm } & 3916 . & \mathrm{m} 3 / \mathrm{min} \\ & & & \\ 194.4603 & \text { dscf } & 5.5071 & \mathrm{~m} 3 \\ 485 . & \text { min } & 485 . & \mathrm{min} \\ .407 \mathrm{E}-04 & \text { Ib } & .185 \mathrm{E}+02 & \mathrm{mg} \\ .699 & \text { acfm } & .020 & \mathrm{~m} 3 / \mathrm{min} \\ 374.0 & \text { F } & 190.0 & \mathrm{C} \\ 122.0 & \text { \% } & 122.0 & \% \\ .147 \mathrm{E}-02 & \text { gr/dscf } & .335 \mathrm{E}-02 & \mathrm{~g} / \mathrm{m} 3 \\ .209 \mathrm{E}-06 & \text { Ib/dscf } & & \end{array}$


Run ID

Plant \& Unit

Sampling Iocatior

Type of Sizing Device

Run Date

stärt time
: Outlet 3

- AEP PFBC

ESP outlet

UWVD

: 4/13/94

: $23: 55$

Nominal Mass Concentration

$.147 E-02$ gr/dsce $.209 \mathrm{E}-06$ ib/ascf

$.335 \mathrm{E}-02 \mathrm{~g} / \mathrm{m3}$

\begin{tabular}{|c|c|c|c|c|c|c|}
\hline \multirow[t]{2}{*}{$\begin{array}{l}\text { Stage } \\
\text { Number }\end{array}$} & \multirow{2}{*}{$\begin{array}{l}\text { Interval } \\
\text { Endpoint } \\
\text { (um) }\end{array}$} & \multirow[t]{2}{*}{$\begin{array}{c}\text { Mass } \\
\text { Fraction }\end{array}$} & \multirow{2}{*}{$\begin{array}{l}\text { Mass } \\
\text { Fraction } \\
\text { Less } \\
\text { Than }\end{array}$} & \multirow{2}{*}{$\begin{array}{l}\text { Interval } \\
\text { Geometric } \\
\text { Midpoint } \\
\text { (um) }\end{array}$} & \multicolumn{2}{|c|}{$\begin{array}{c}d N / d(\log D) \\
D Y Y, S T P\end{array}$} \\
\hline & & & & & (gr/dscf) & $(g / m 3)$ \\
\hline & 100.00 & & 1.000 & & & \\
\hline \multicolumn{2}{|c|}{ Rt Angle $+1+2$} & .171 & & 34.18 & $.269 E-03$ & $.615 \mathrm{E}-03$ \\
\hline 3 & 11.68 & .086 & .829 & 7.64 & $.340 \mathrm{E}-03$ & $.779 \mathrm{E}-03$ \\
\hline & 5.00 & & .743 & & & \\
\hline 4 & 2.46 & .123 & 620 & 3.51 & $.588 E-03$ & $.135 \mathrm{E}-02$ \\
\hline 5 & & .111 & & 1.83 & $.626 E-03$ & $.143 \mathrm{E}-02$ \\
\hline 6 & 1.35 & & .509 & 111 & & \\
\hline 6 & .91 & .100 & .409 & 1.11 & $.845 E-03$ & $.193 \mathrm{E}-02$ \\
\hline 7 & & .088 & & .80 & $.117 E-02$ & $.268 E-02$ \\
\hline 8 & .71 & .089 & .321 & .62 & $.116 \mathrm{E}-02$ & $.266 E-02$ \\
\hline & .54 & & .232 & & & \\
\hline 9 & & .090 & & .48 & $.117 \mathrm{E}-02$ & $.268 E-02$ \\
\hline & .42 & & .142 & & & \\
\hline 10 & & .083 & & .38 & $.154 \mathrm{E}-02$ & $.352 E-02$ \\
\hline FILTER & .35 & .058 & .058 & .19 & $.158 \mathrm{E}-03$ & $.360 \mathrm{E}-03$ \\
\hline & .10 & & .000 & & & \\
\hline
\end{tabular}




$\begin{array}{ll}\text { Run ID } & \text { : Outlet } 4 \\ \text { Plant \& Unit } & : \text { AEP PFBC } \\ \text { Sampling Location } & : \text { ESP outlet } \\ \text { Type of Sizing Device } & : \text { UWV } \\ \text { Run Date } & : 4 / 14 / 94 \\ \text { Start time } & : 22: 28\end{array}$

REMARKS :

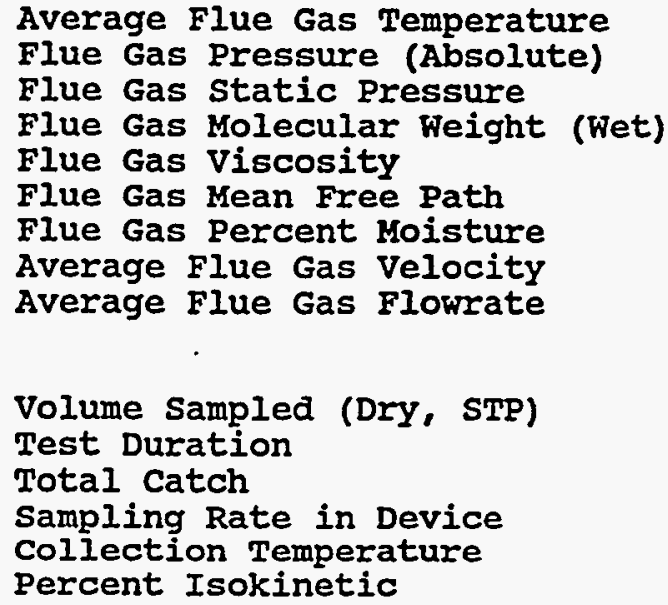

Nominal Mass Concentration

\begin{tabular}{|c|c|c|c|}
\hline $\begin{array}{r}374.0 \\
29.54 \\
1.80 \\
27.26 \\
.165 \mathrm{E}-04 \\
.455 \mathrm{E}-05 \\
10.00 \\
61.1210 \\
288026 . \\
161976 .\end{array}$ & $\begin{array}{l}\text { F } \\
\text { "Hg } \\
\text { "H2O } \\
\text { lb/lb-mole } \\
\text { lb-sec/ft2 } \\
\text { inch } \\
q \\
\text { fps } \\
\text { acfm } \\
\text { dscfm }\end{array}$ & $\begin{array}{r}190.0 \\
75.04 \\
4.572 \\
27.2624 \\
.246 \mathrm{E}-03 \\
.116 \mathrm{E}-04 \\
10.00 \\
18.6297 \\
8157 . \\
4587 .\end{array}$ & $\begin{array}{l}\mathrm{C} \\
\mathrm{cm} \mathrm{Hg} \\
\mathrm{cm} \mathrm{H} 2 \mathrm{O} \\
\mathrm{g} / \mathrm{g}-\mathrm{mole} \\
\text { Poise } \\
\mathrm{cm} \\
\frac{q}{8} \\
\mathrm{~m} / \mathrm{s} \\
\mathrm{m} 3 / \mathrm{min} \\
\mathrm{m} 3 / \mathrm{min}\end{array}$ \\
\hline $\begin{array}{r}297.2570 \\
747 \\
.766 \mathrm{E}-04 \\
.707 \\
374.0 \\
105.6\end{array}$ & $\begin{array}{l}\text { dscf } \\
\text { min } \\
\text { Ib } \\
\text { acfm } \\
\text { F } \\
q\end{array}$ & $\begin{array}{r}8.4183 \\
747 \\
.347 E+02 \\
.020 \\
190.0 \\
105.6\end{array}$ & $\begin{array}{l}\mathrm{m} 3 \\
\mathrm{~min} \\
\mathrm{mg} \\
\mathrm{m} 3 / \mathrm{min} \\
\mathrm{C} \\
\frac{\mathrm{o}}{5}\end{array}$ \\
\hline $\begin{array}{l}.180 \mathrm{E}-02 \\
.258 \mathrm{E}-06\end{array}$ & $\begin{array}{l}\text { gr/dscf } \\
\mathrm{Ib} / \mathrm{dscf}\end{array}$ & $413 \mathrm{E}-02$ & $\mathrm{~g} / \mathrm{m} 3$ \\
\hline
\end{tabular}




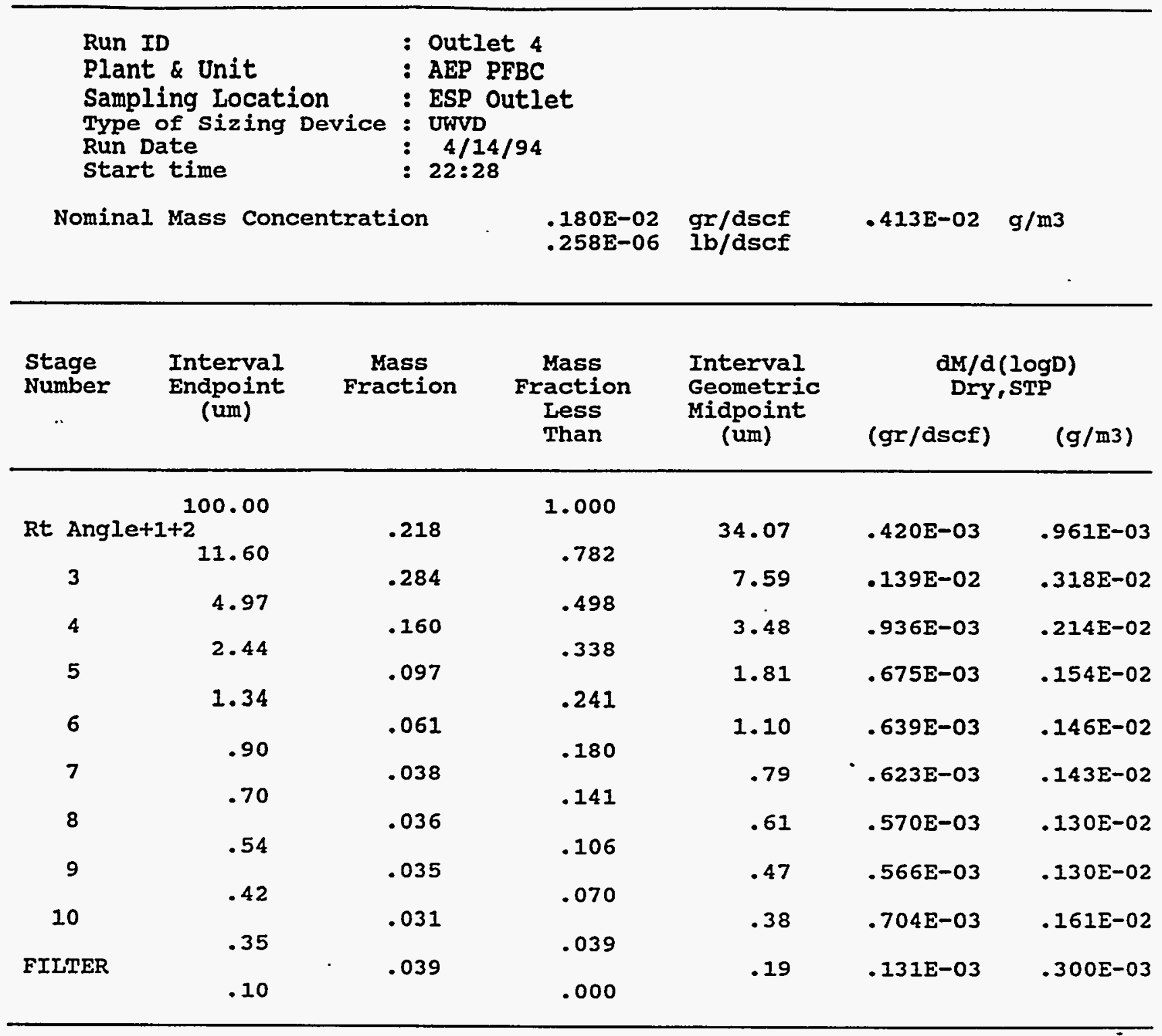


Differential Mass Concentration Plot Inlet 1

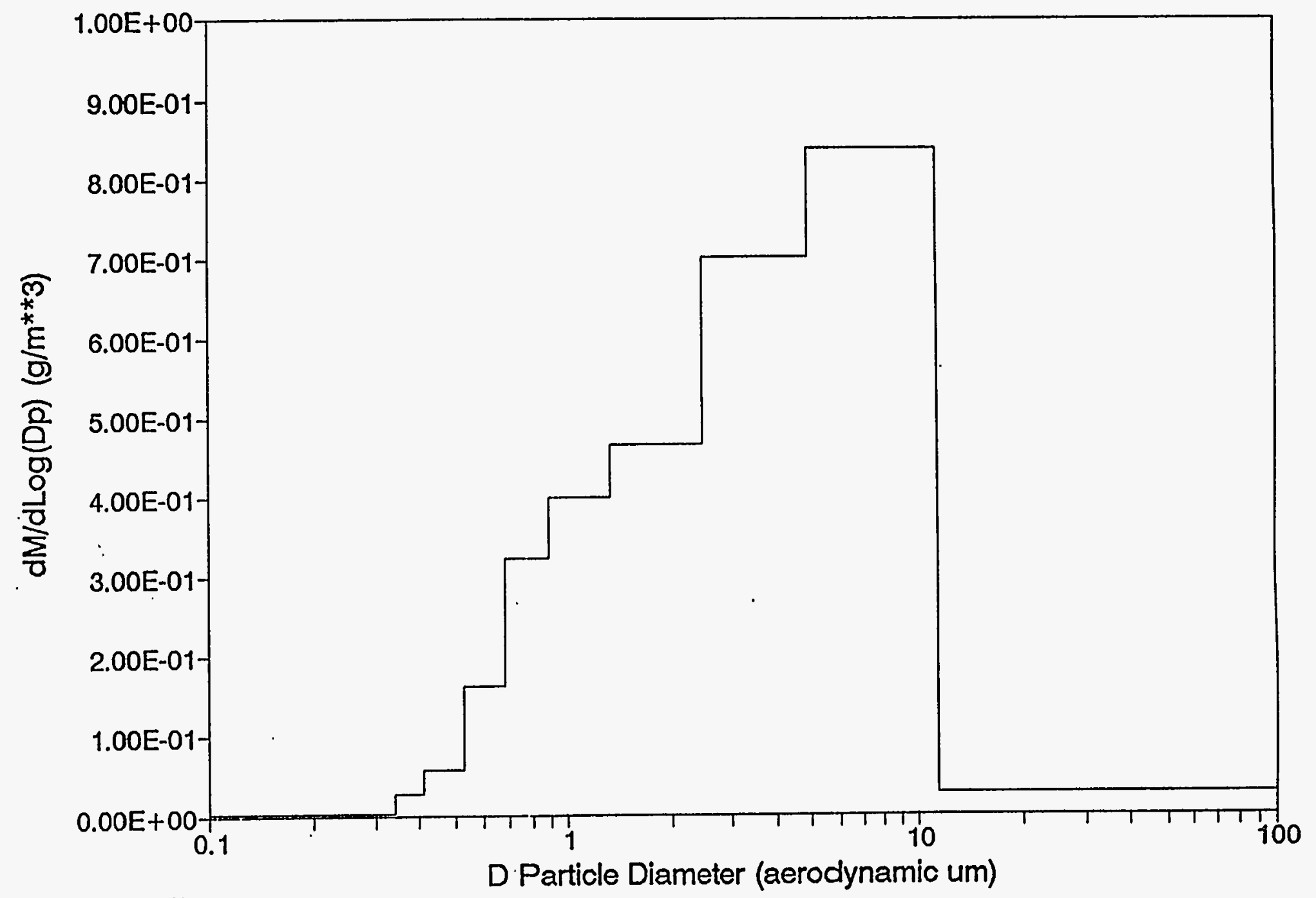




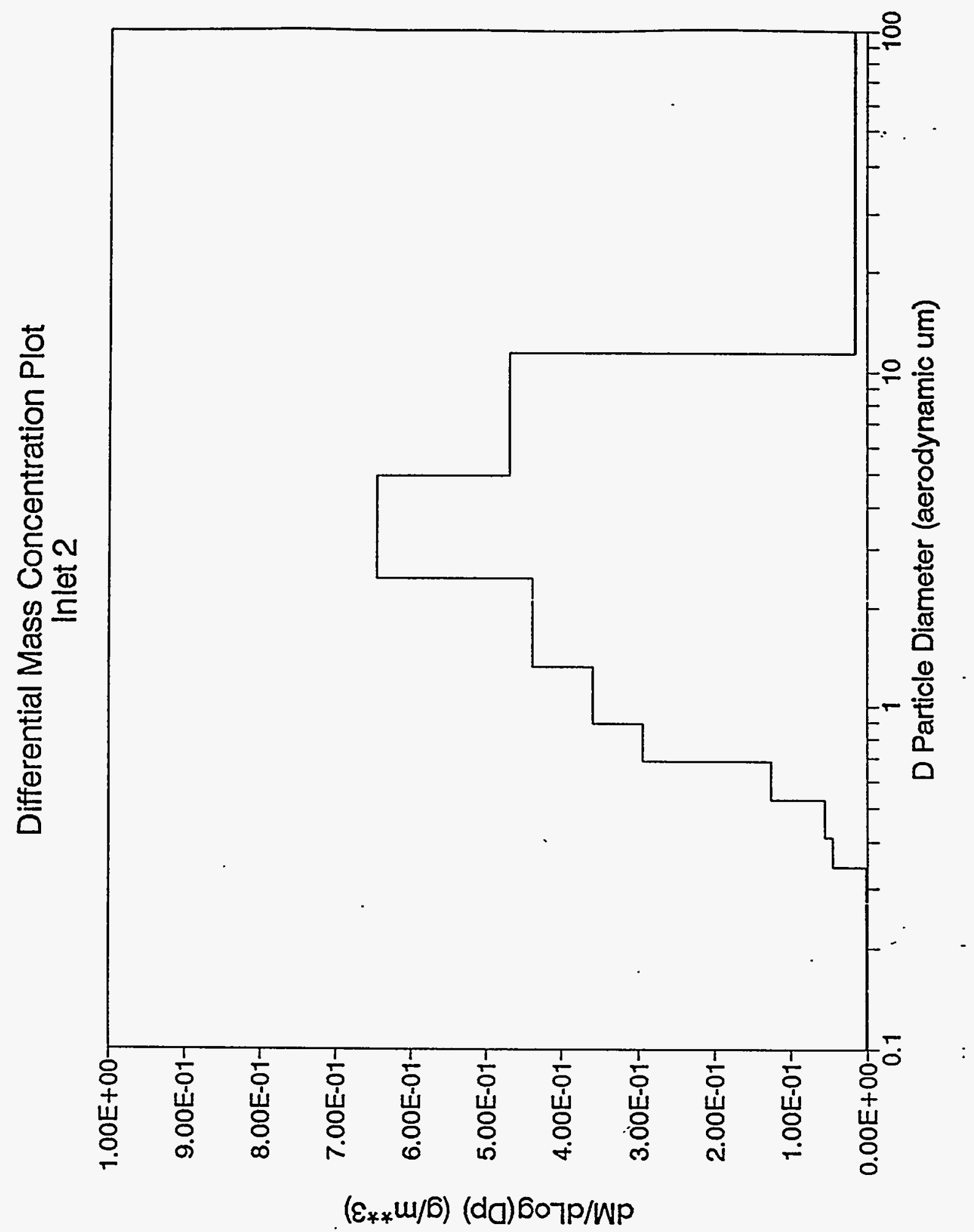




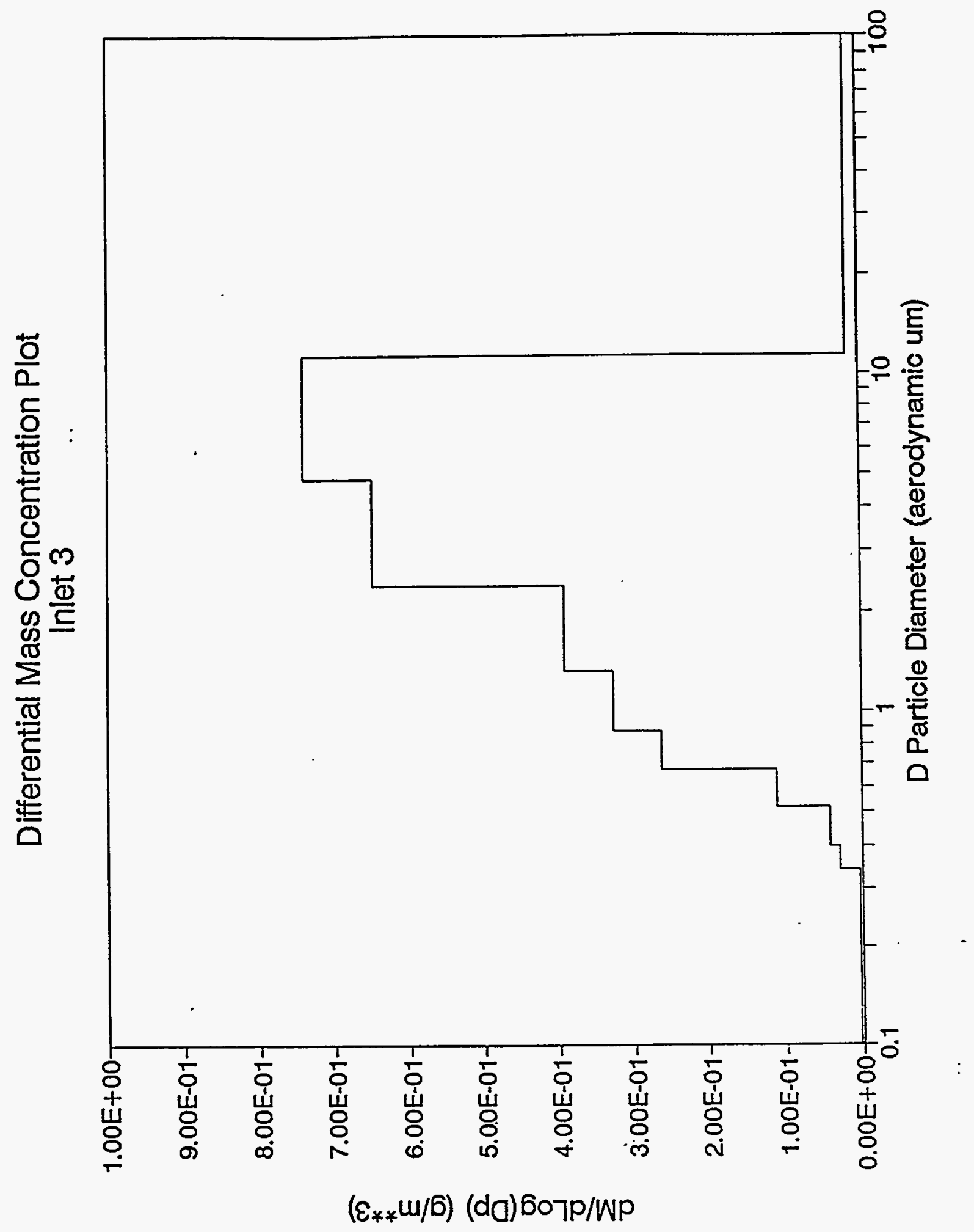


Inlet 4

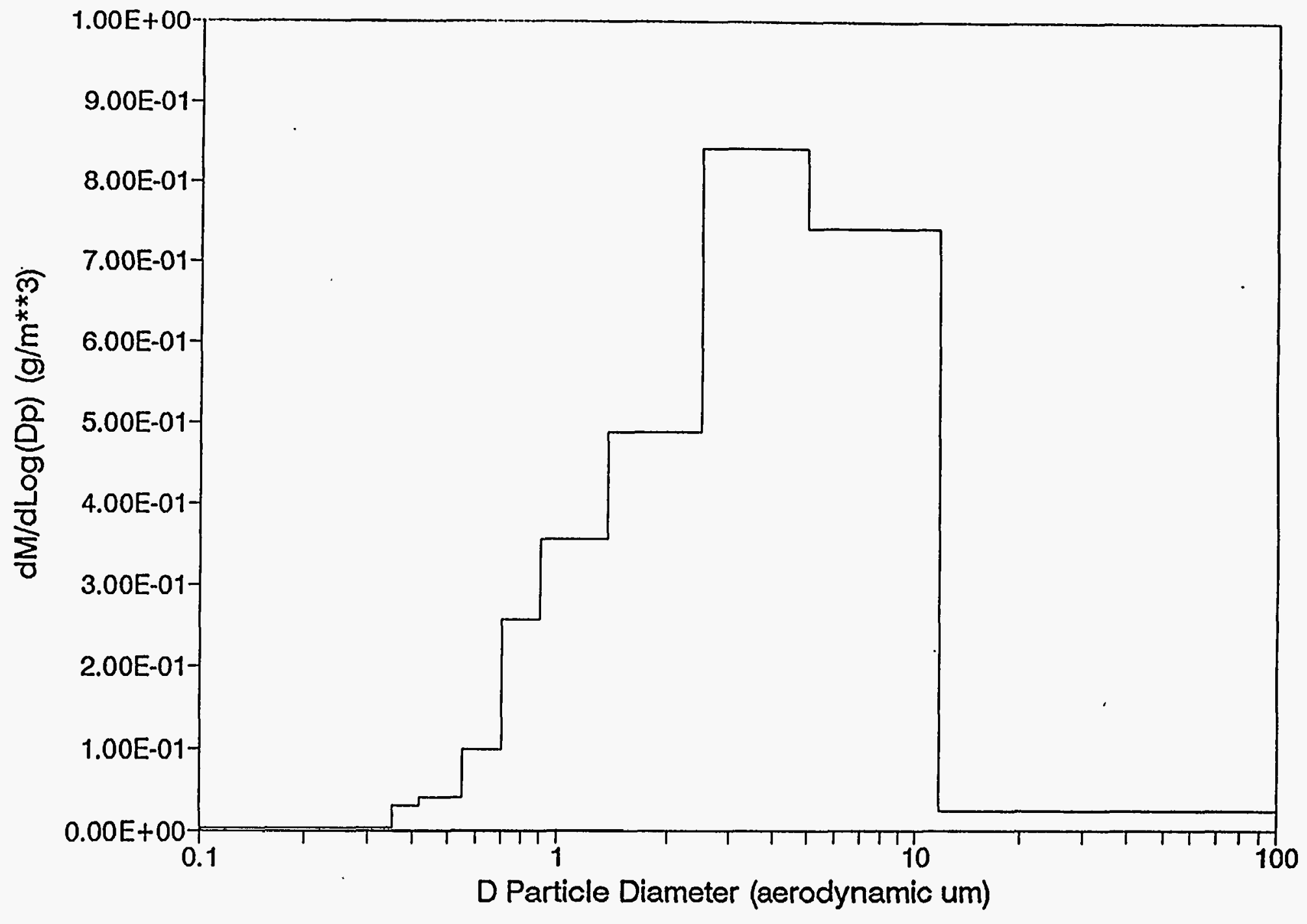


Differential Mass Concentration Plot Outlet 1

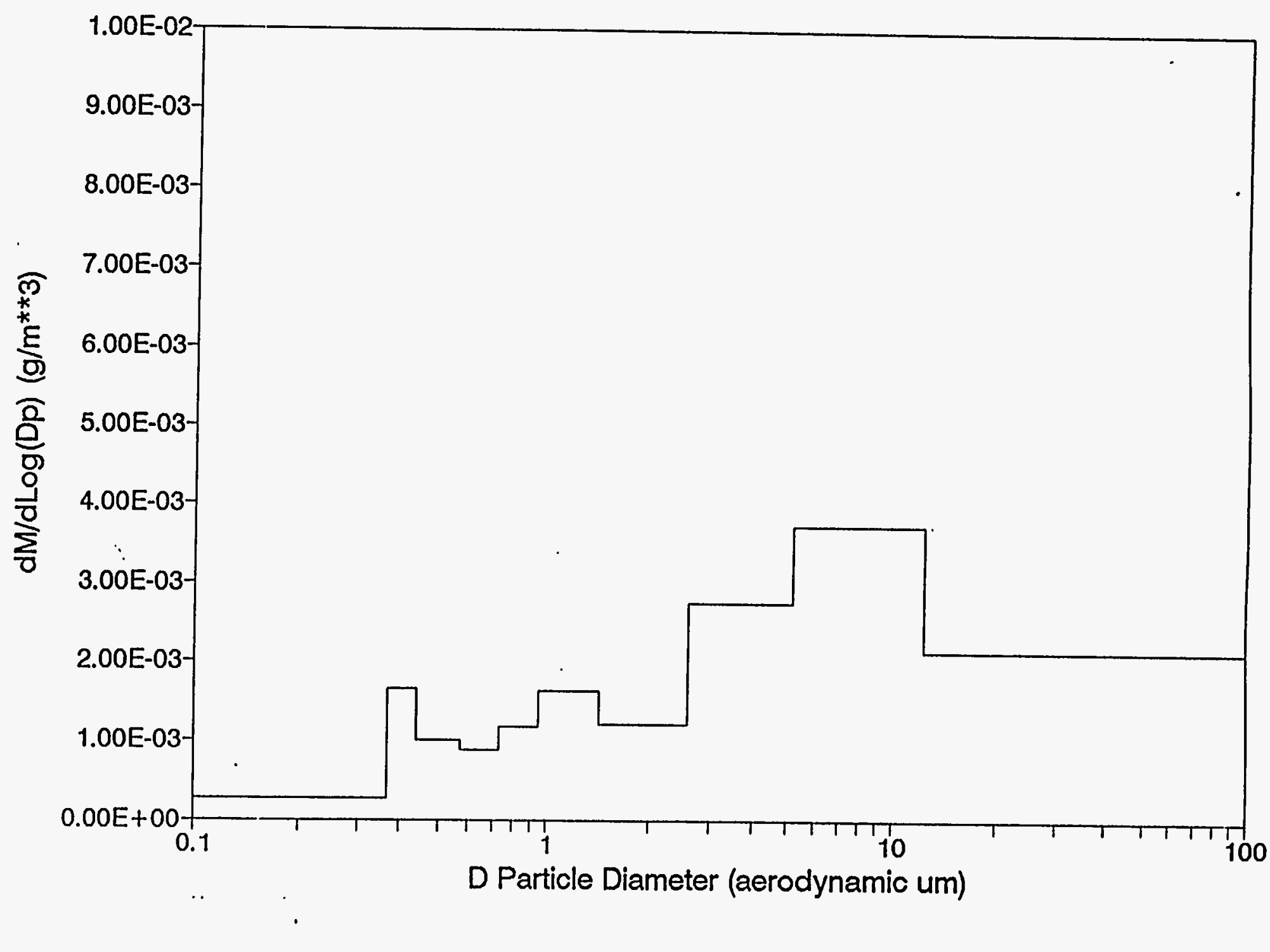


Differential Mass Concentration Plot

Outlet 2

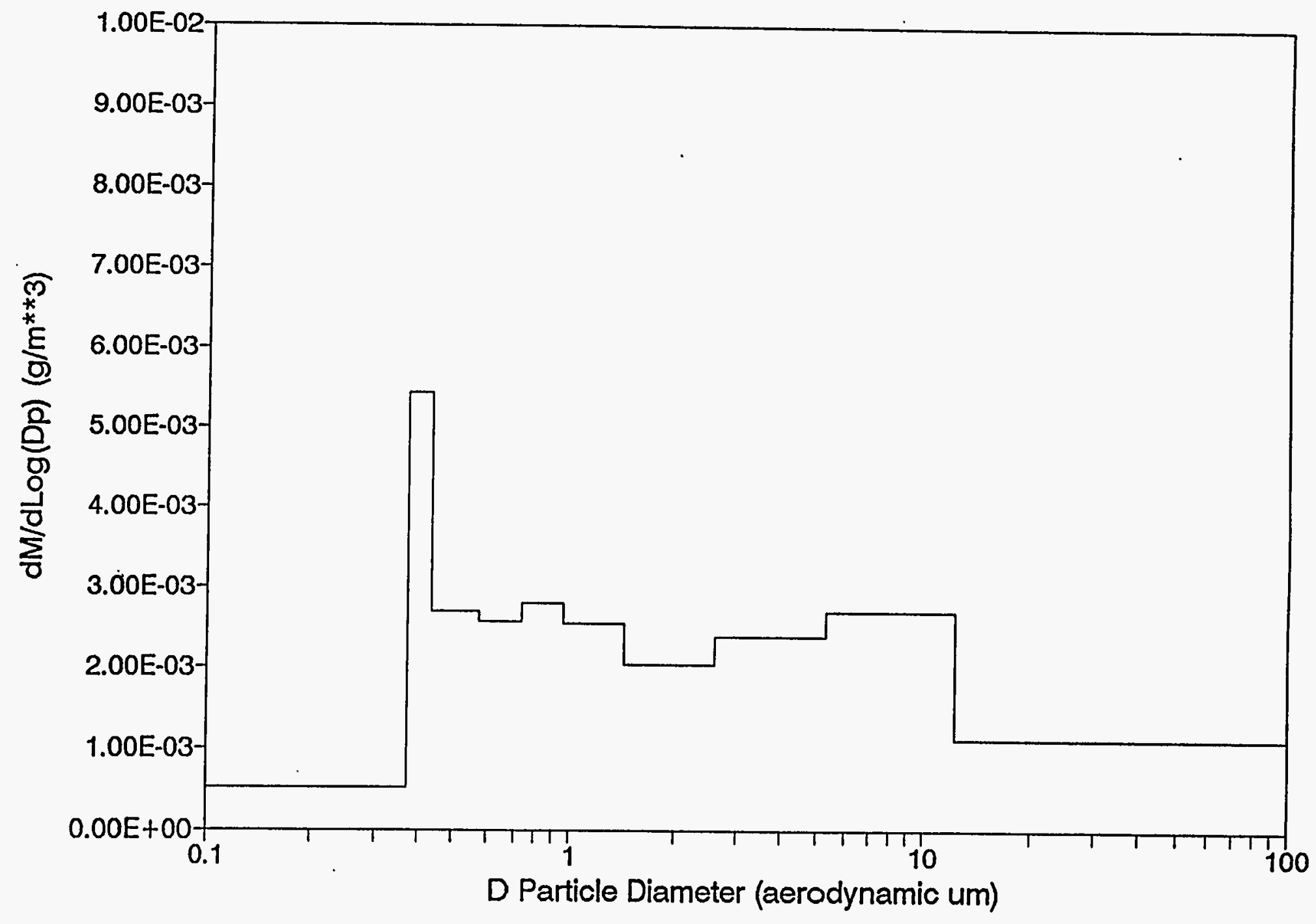




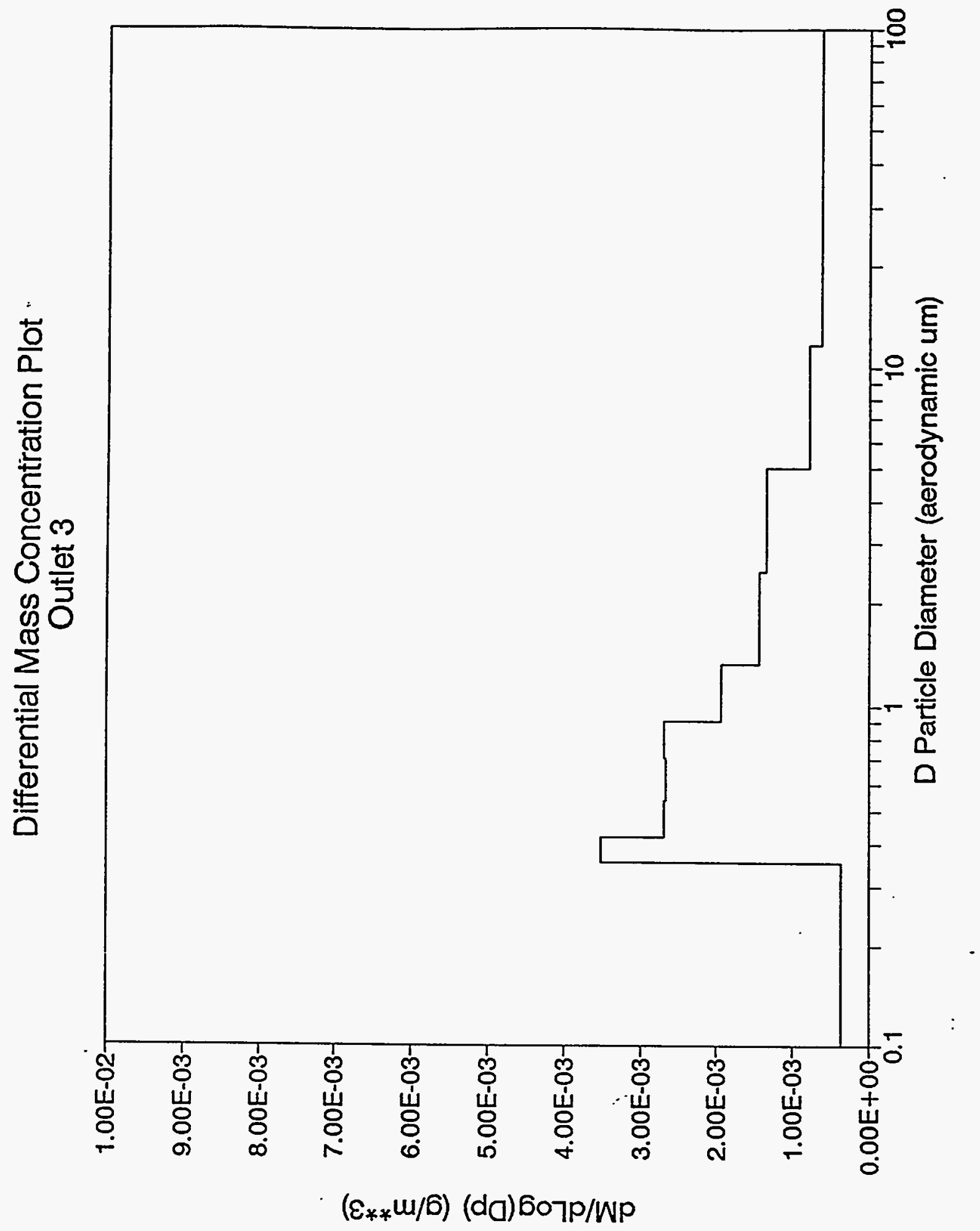


นُ

Differential Mass Concentration Plot

Outlet 4

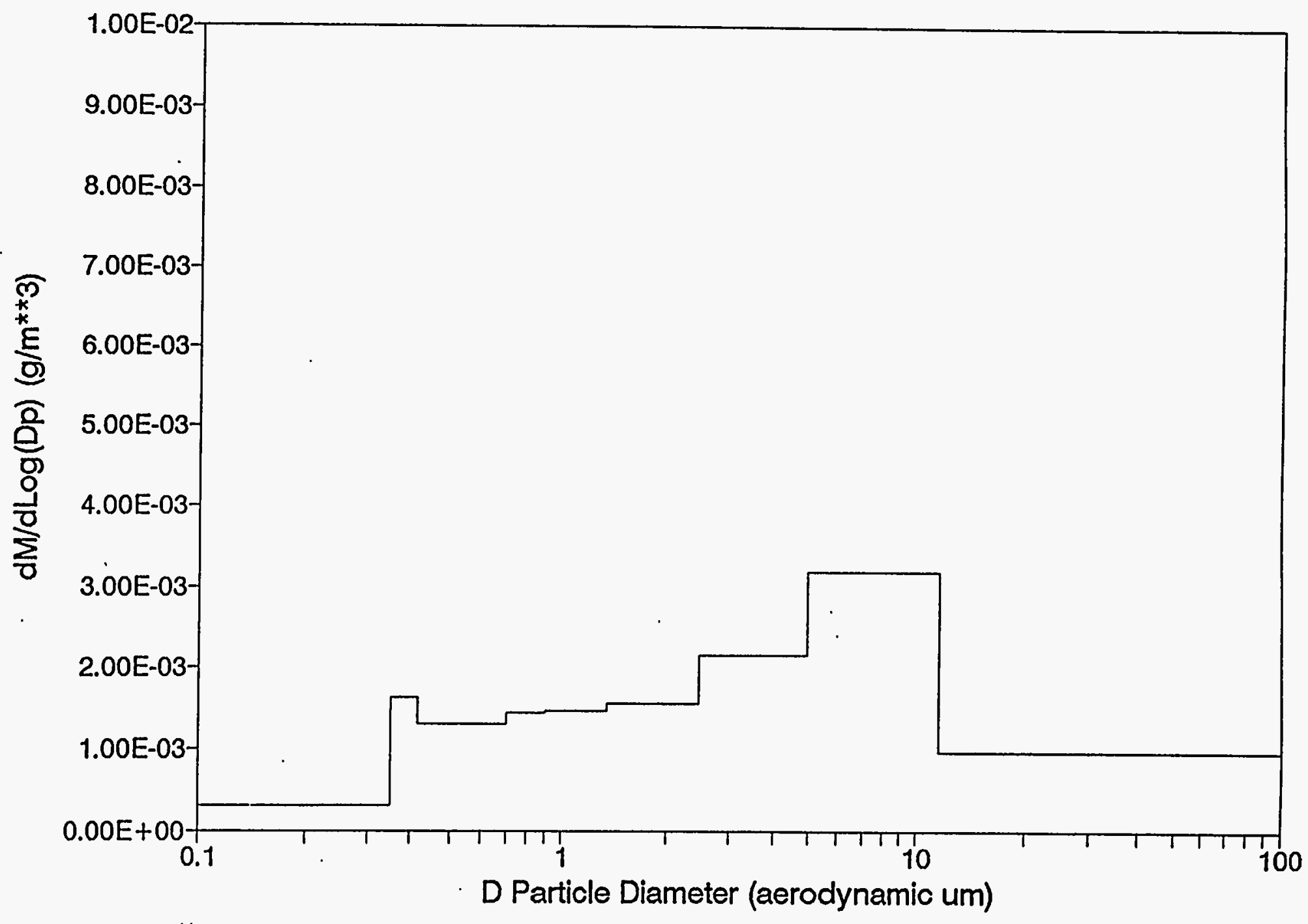




\section{Cumulative Mass Plot}

Inlet 1

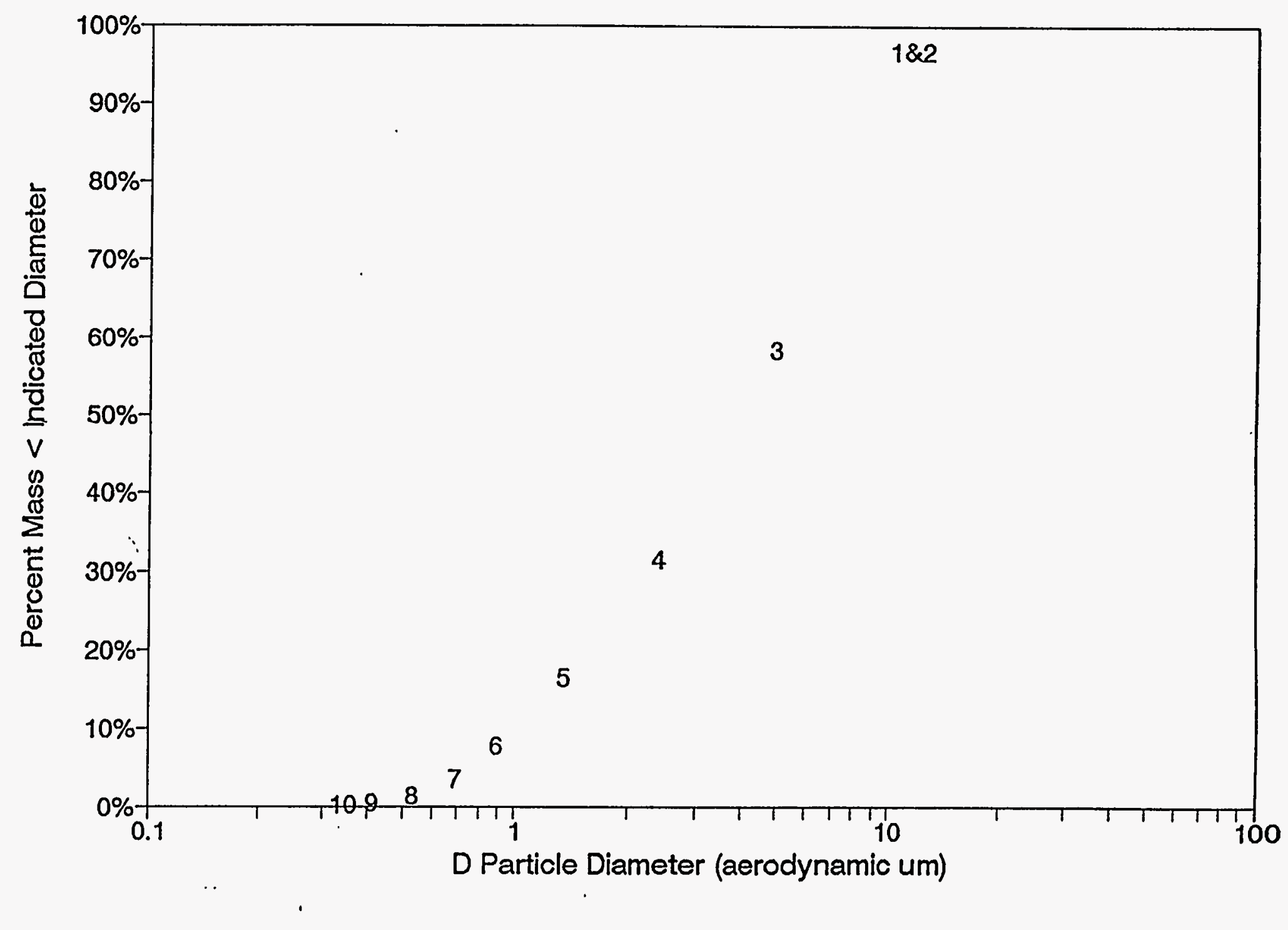




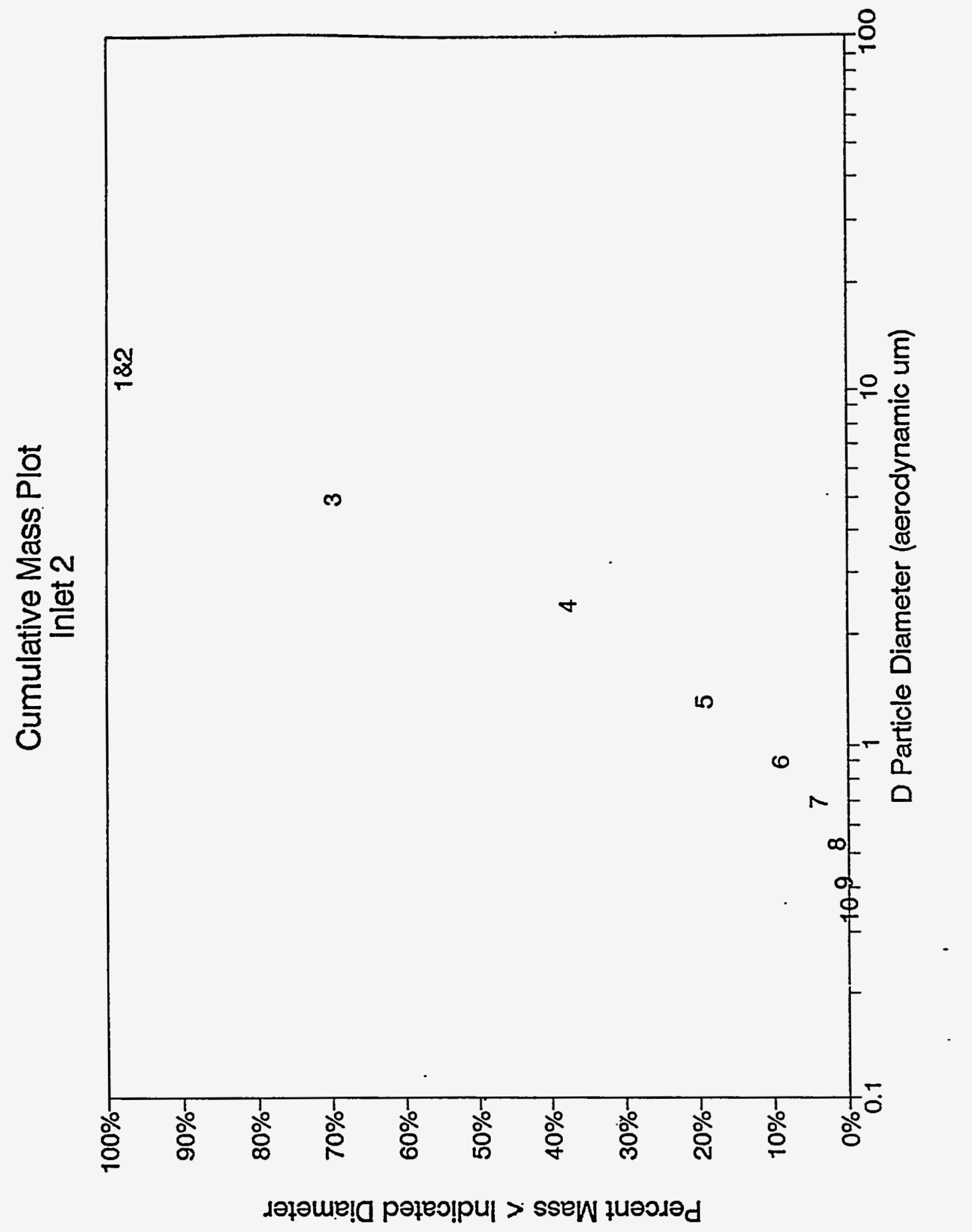


Cumulative Mass Plot Inlet 3

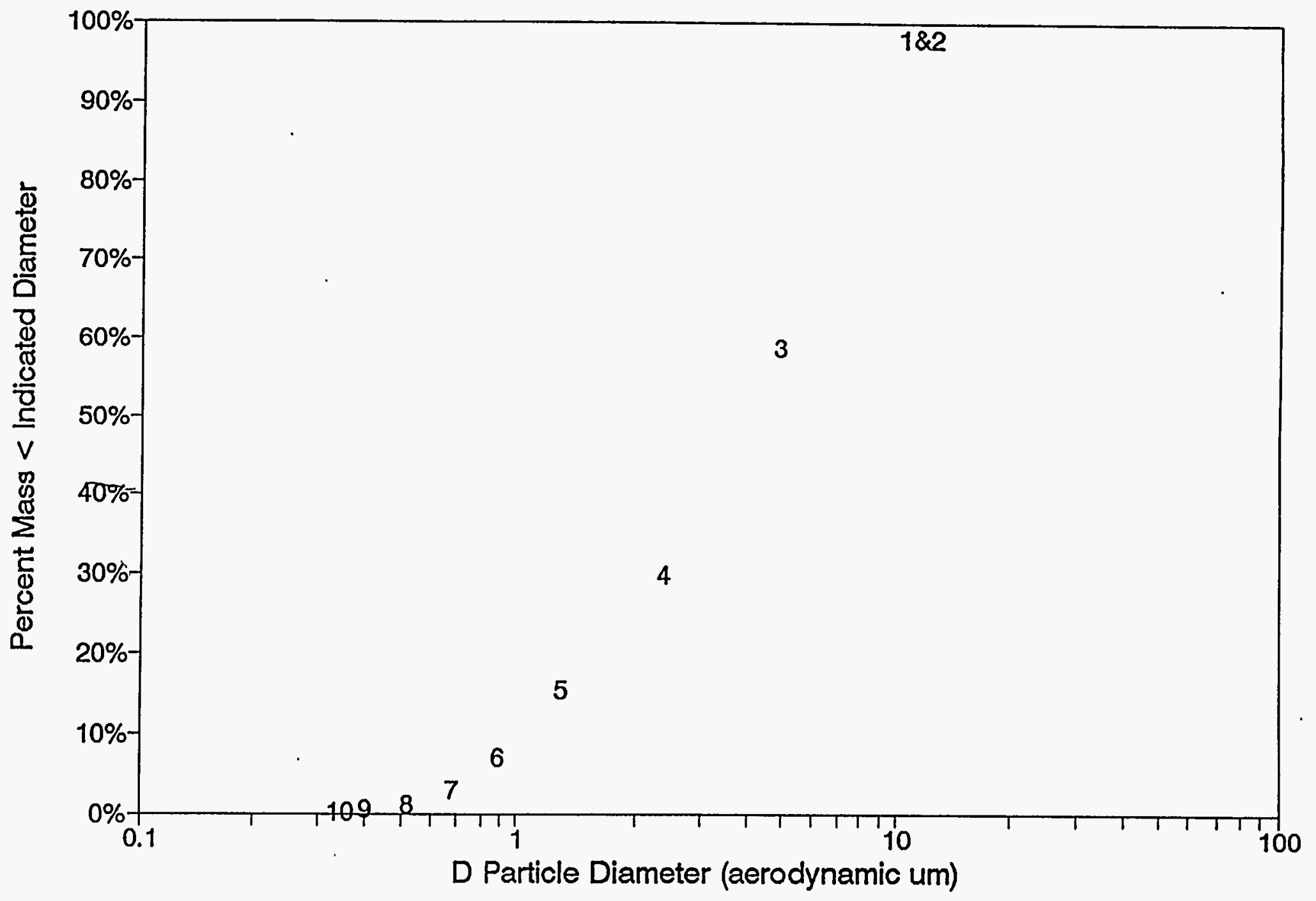




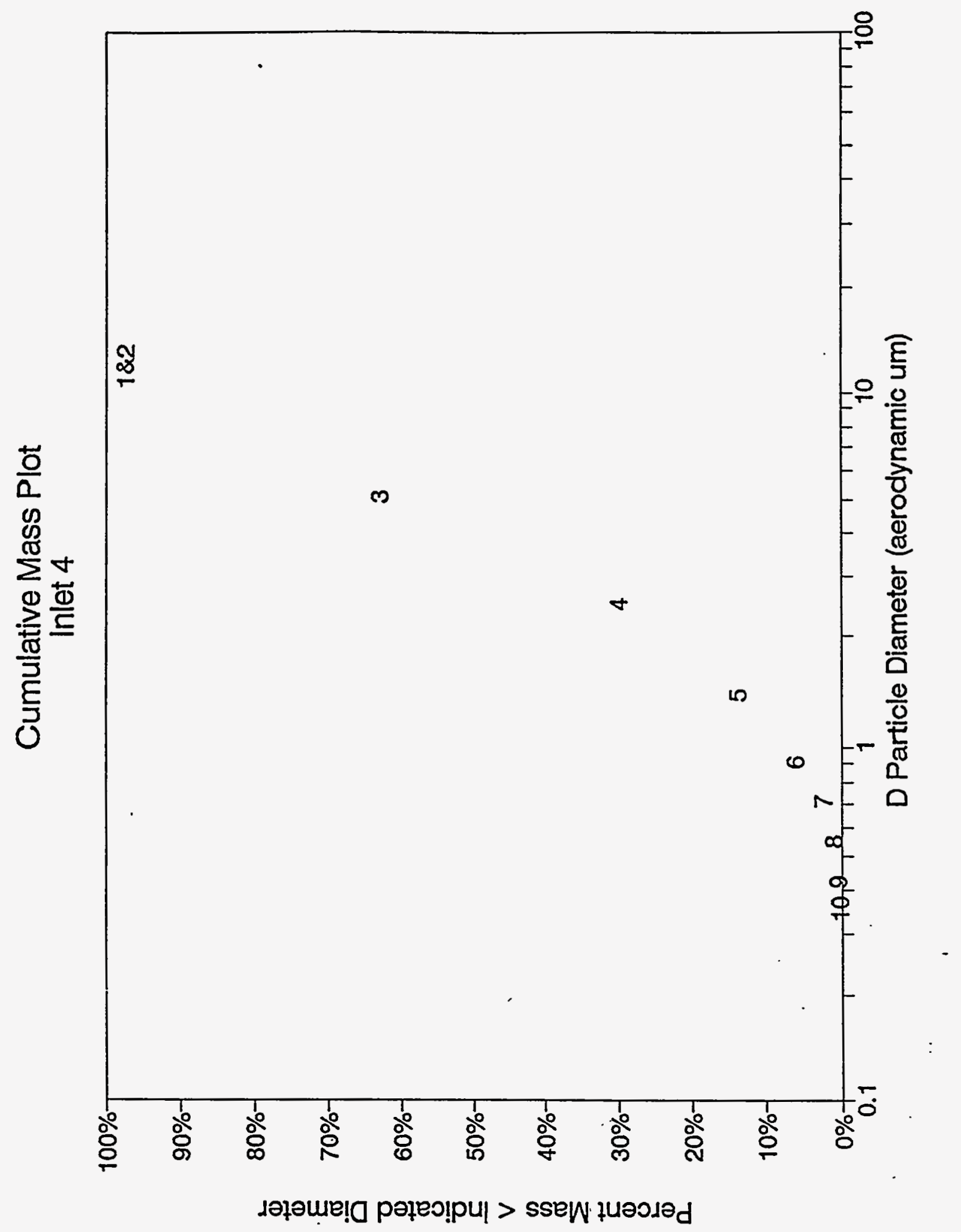


Cumulative Mass Plot Outlet 1

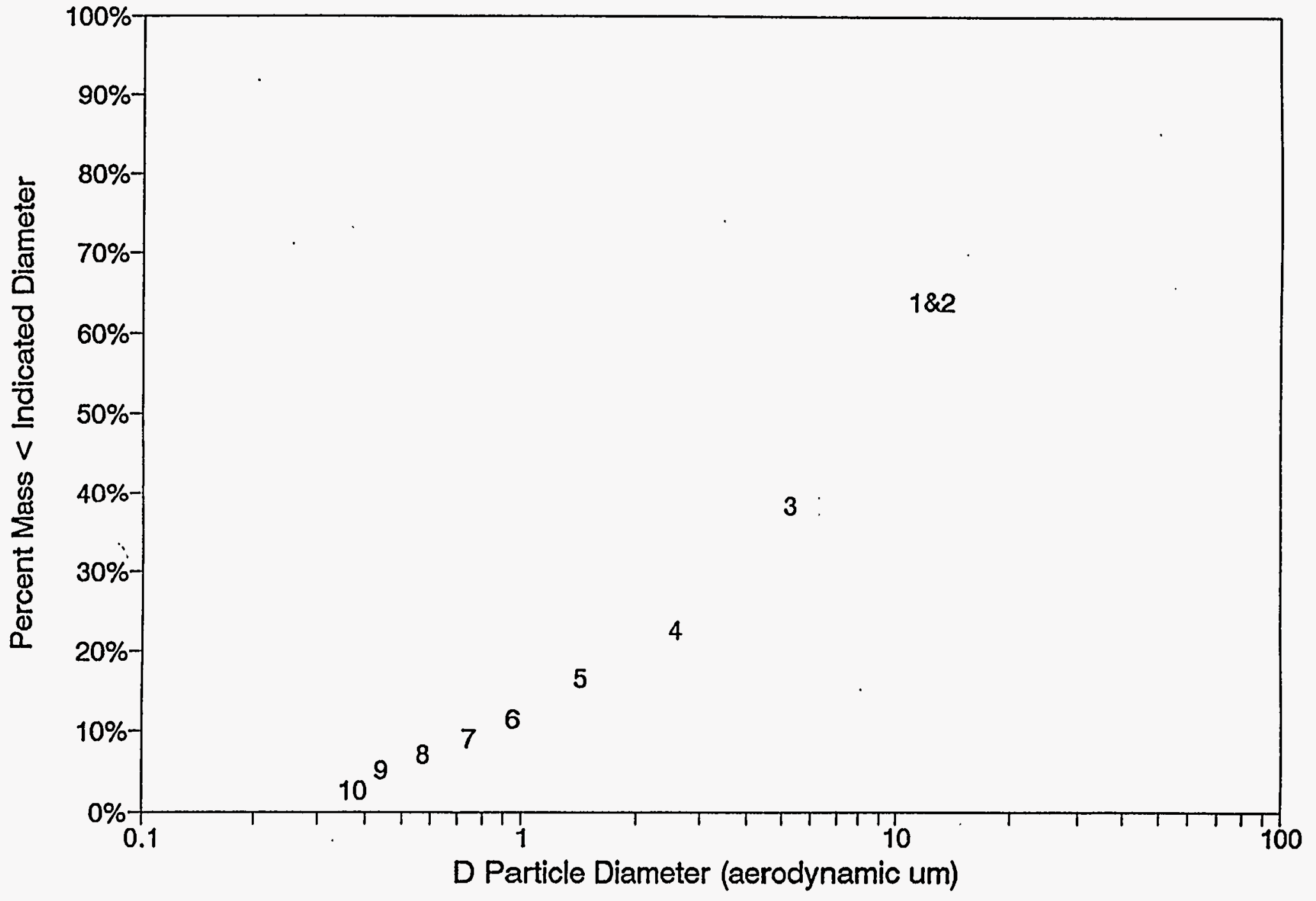

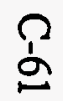


Cumulative Mass Plot

Outlet 2

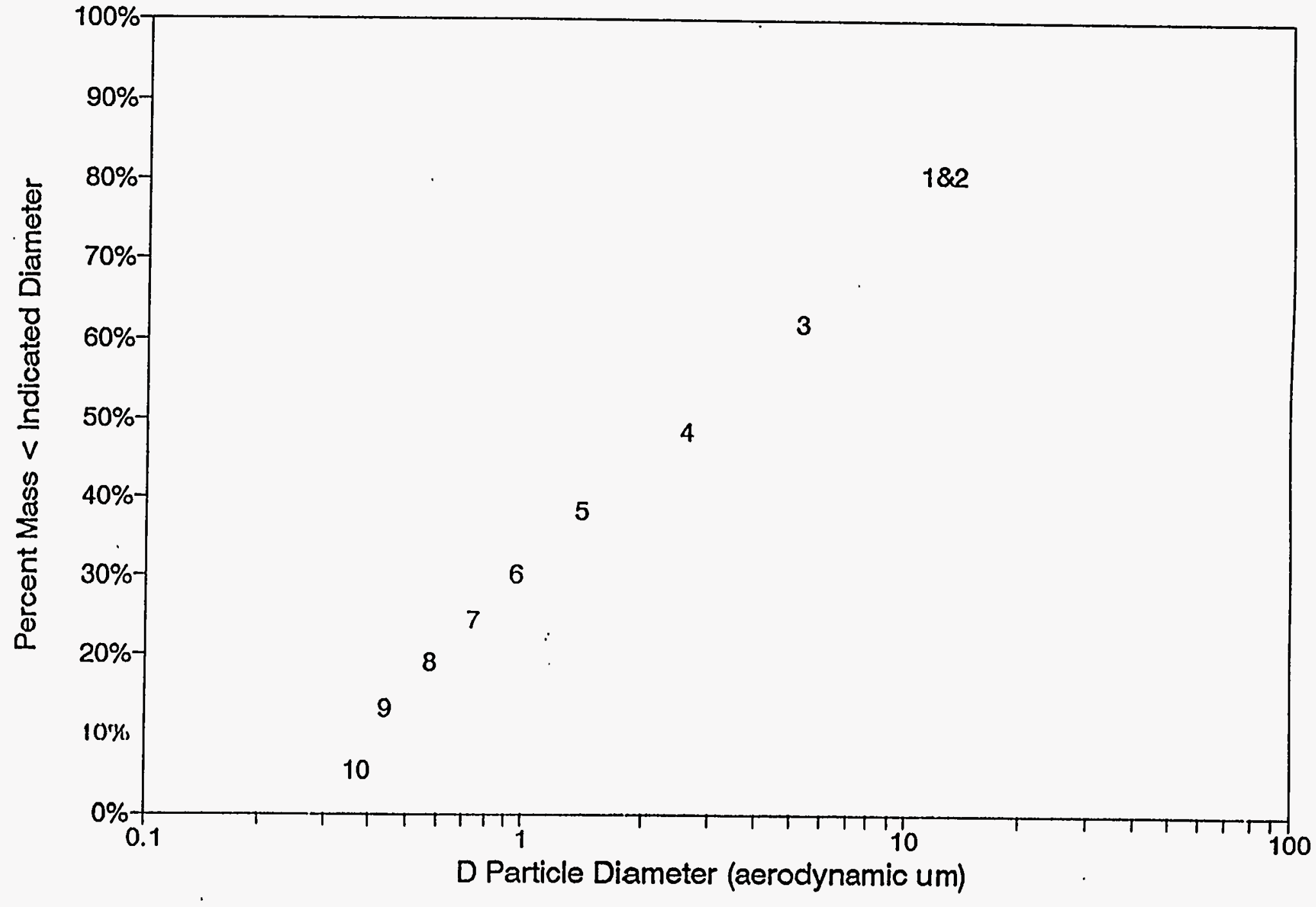


Cumulative Mass Plot

Outlet 3

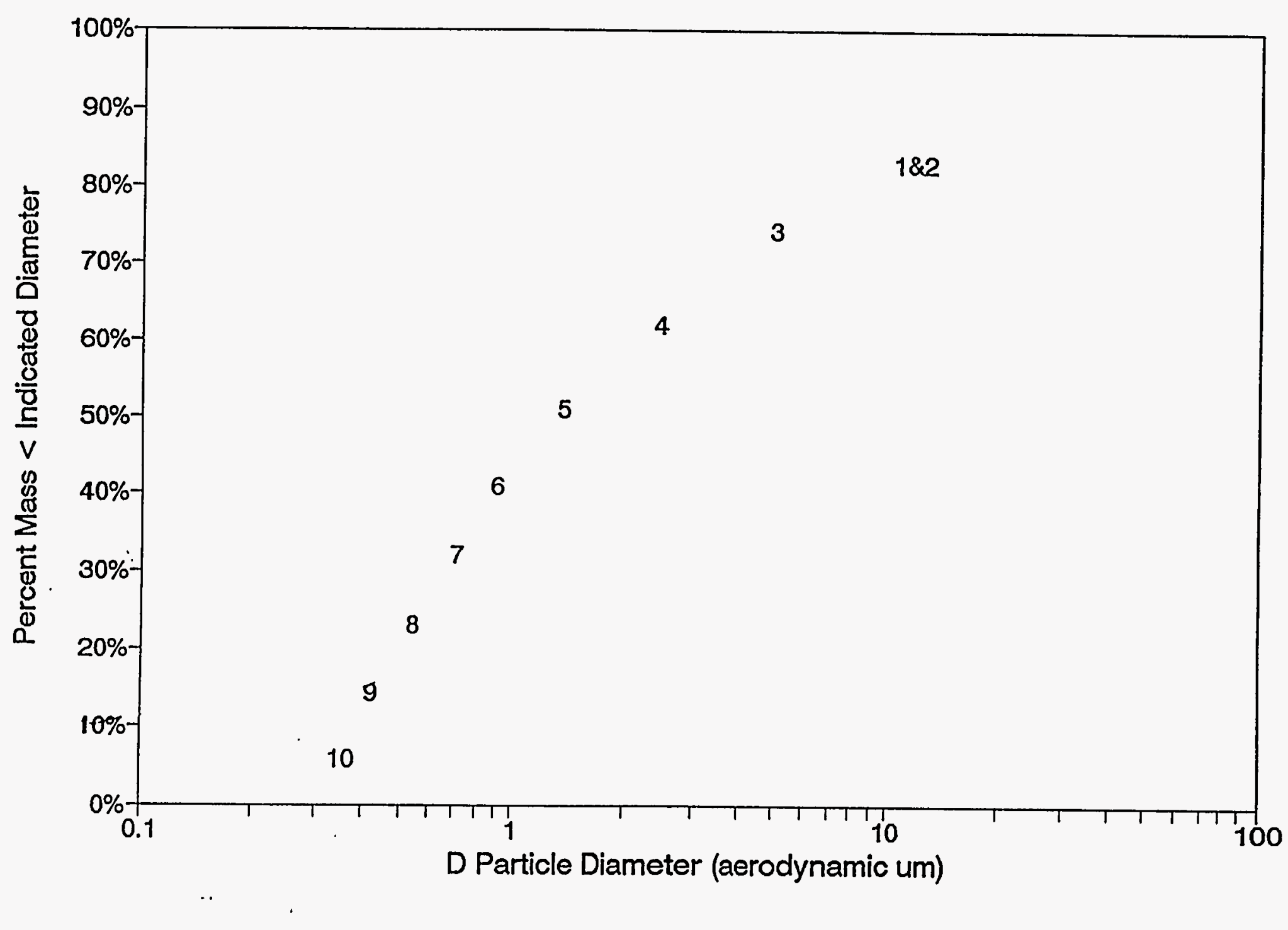


a

Cumulative Mass Plot

Outlet 4

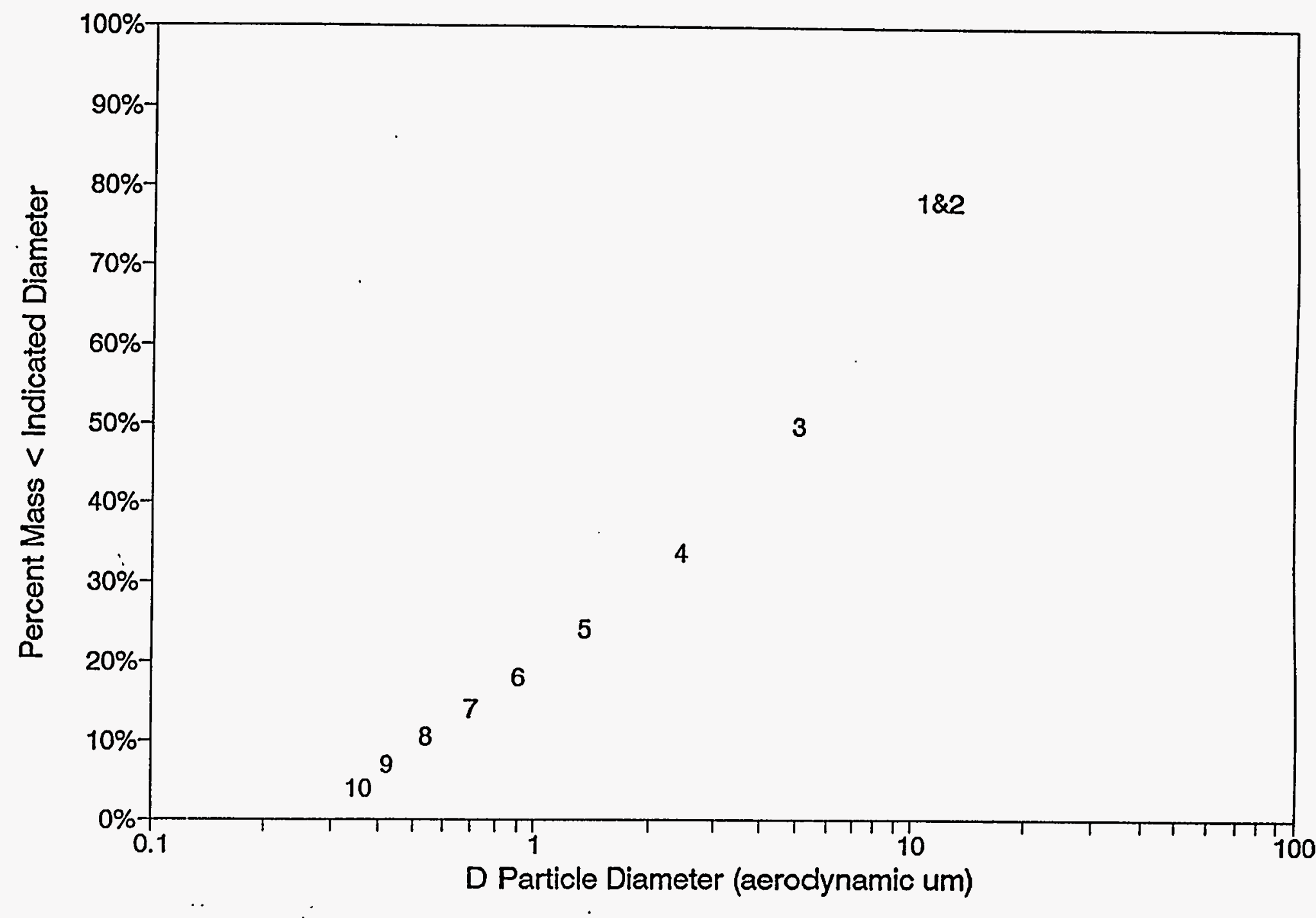


Differential Mass Particle Size Distribution for ESP Hopper 1, Run 1

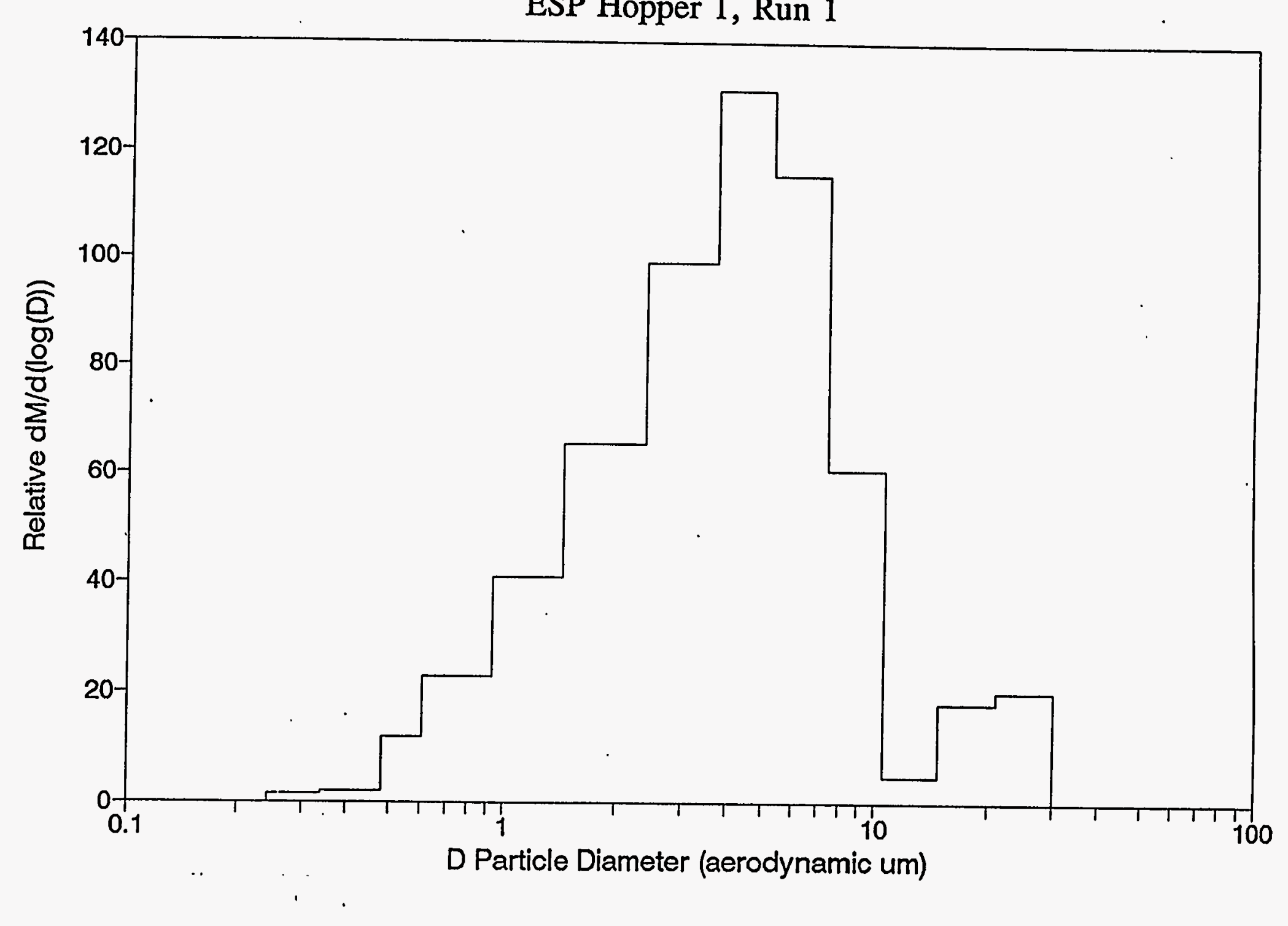


g

Differential Mass Particle Size Distribution for ESP Hopper 1, Run 2

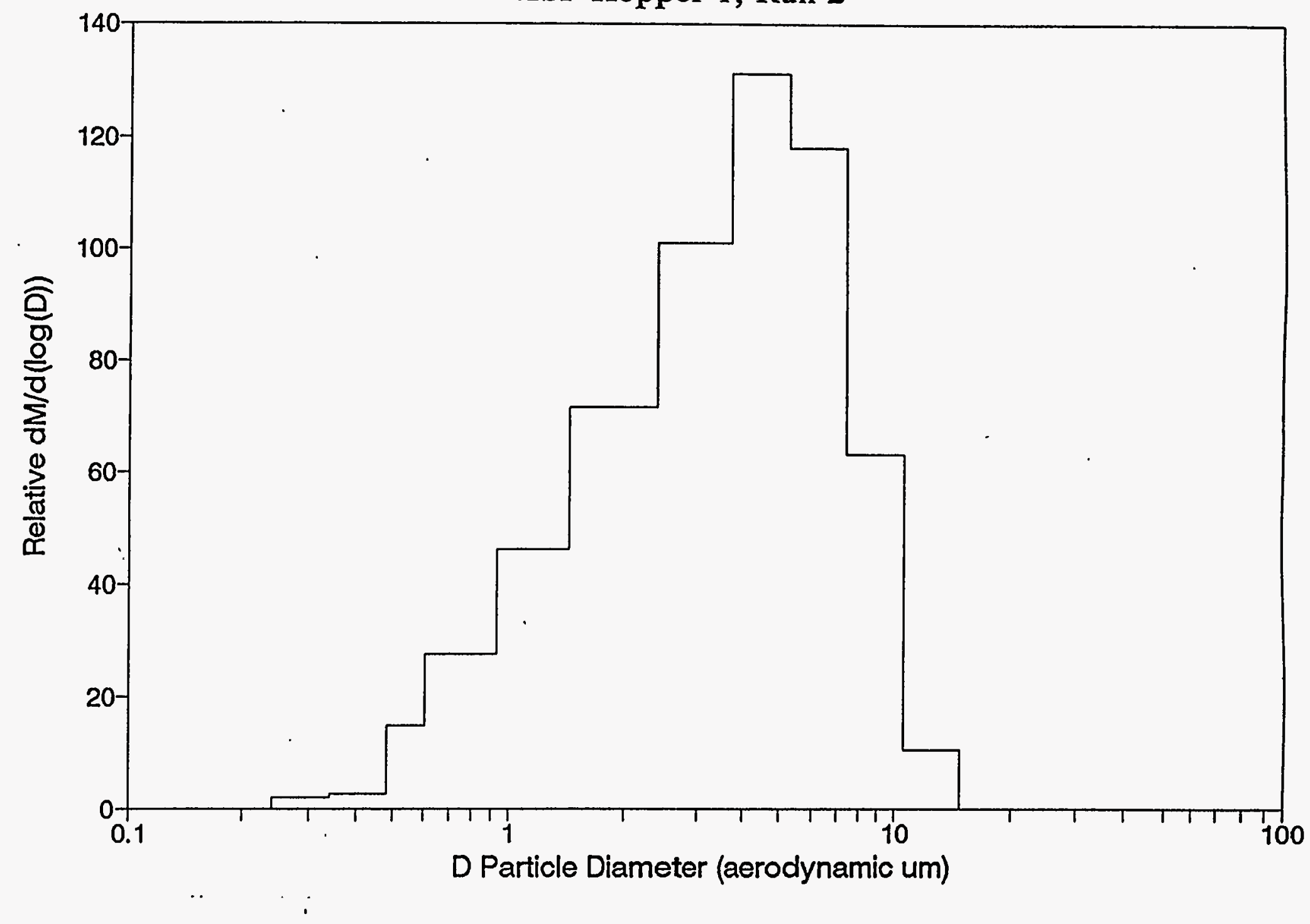


Differential Mass Particle Size Distribution for ESP Hopper 1, Run 3

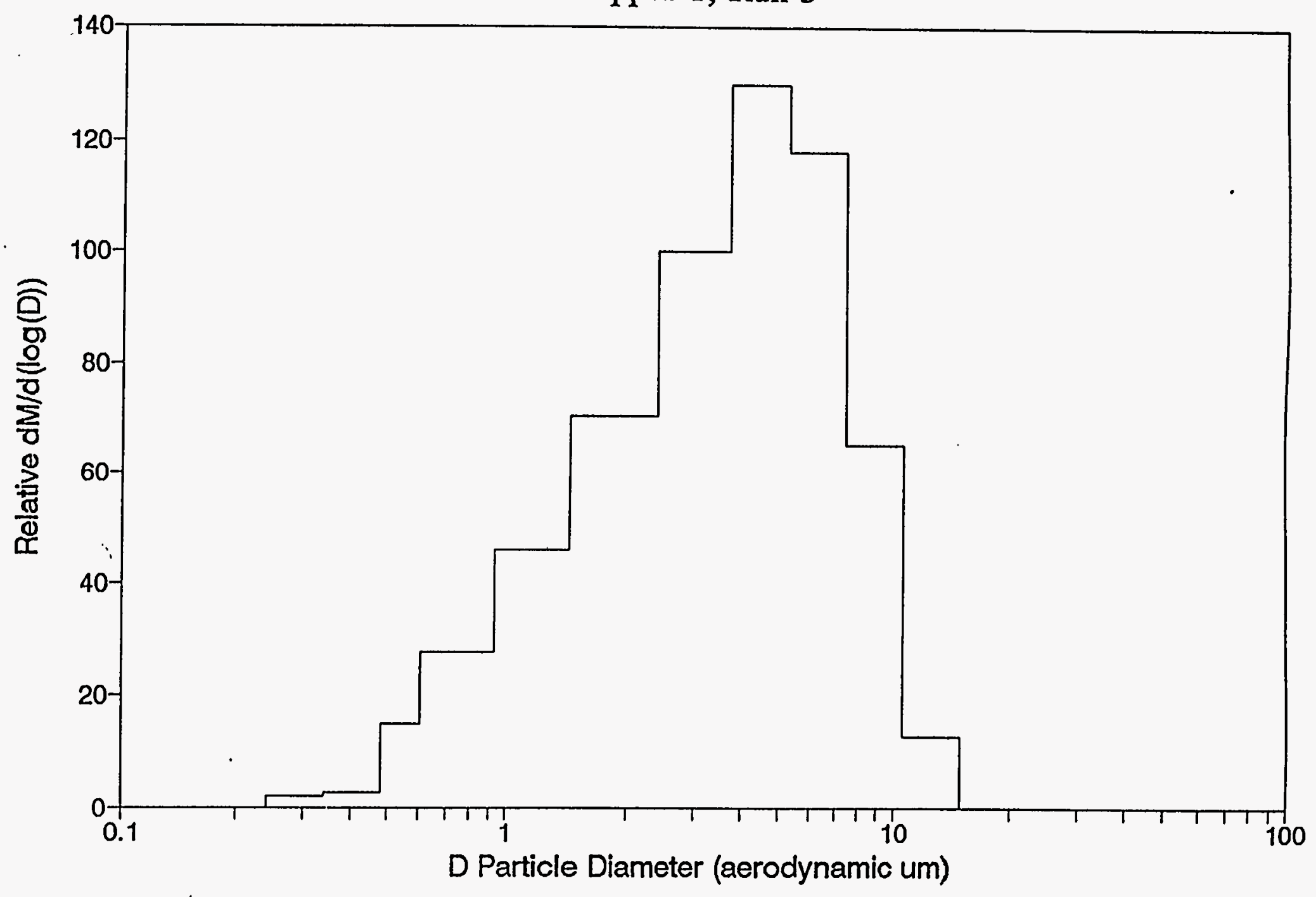


ESP Hopper 1, Run 3 (duplicate)

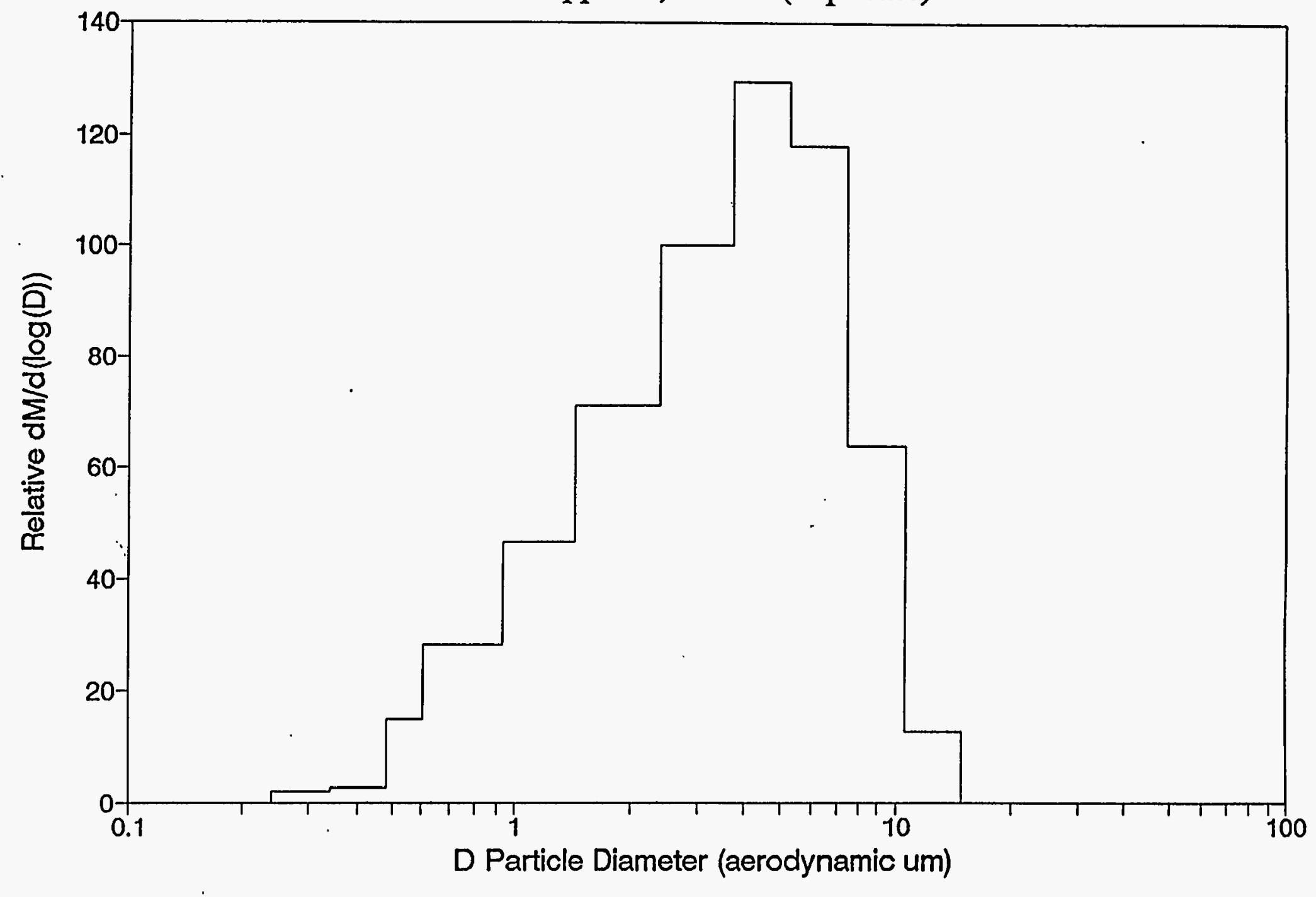




\section{Differential Mass Particle Size Distribution for}

ESP Hopper 2, Run 1

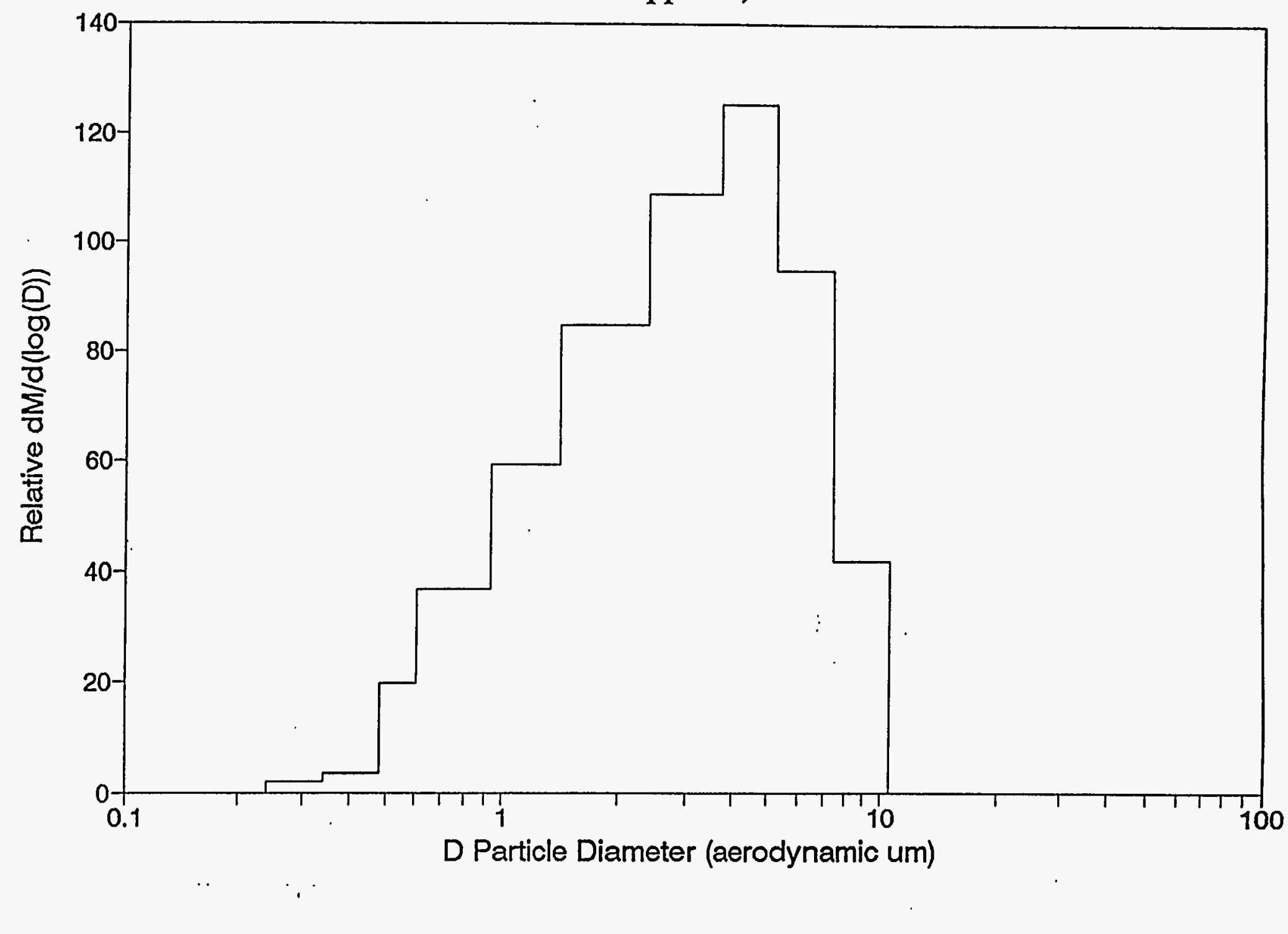


Differential Mass Particle Size Distribution for ESP Hopper 2, Run 2

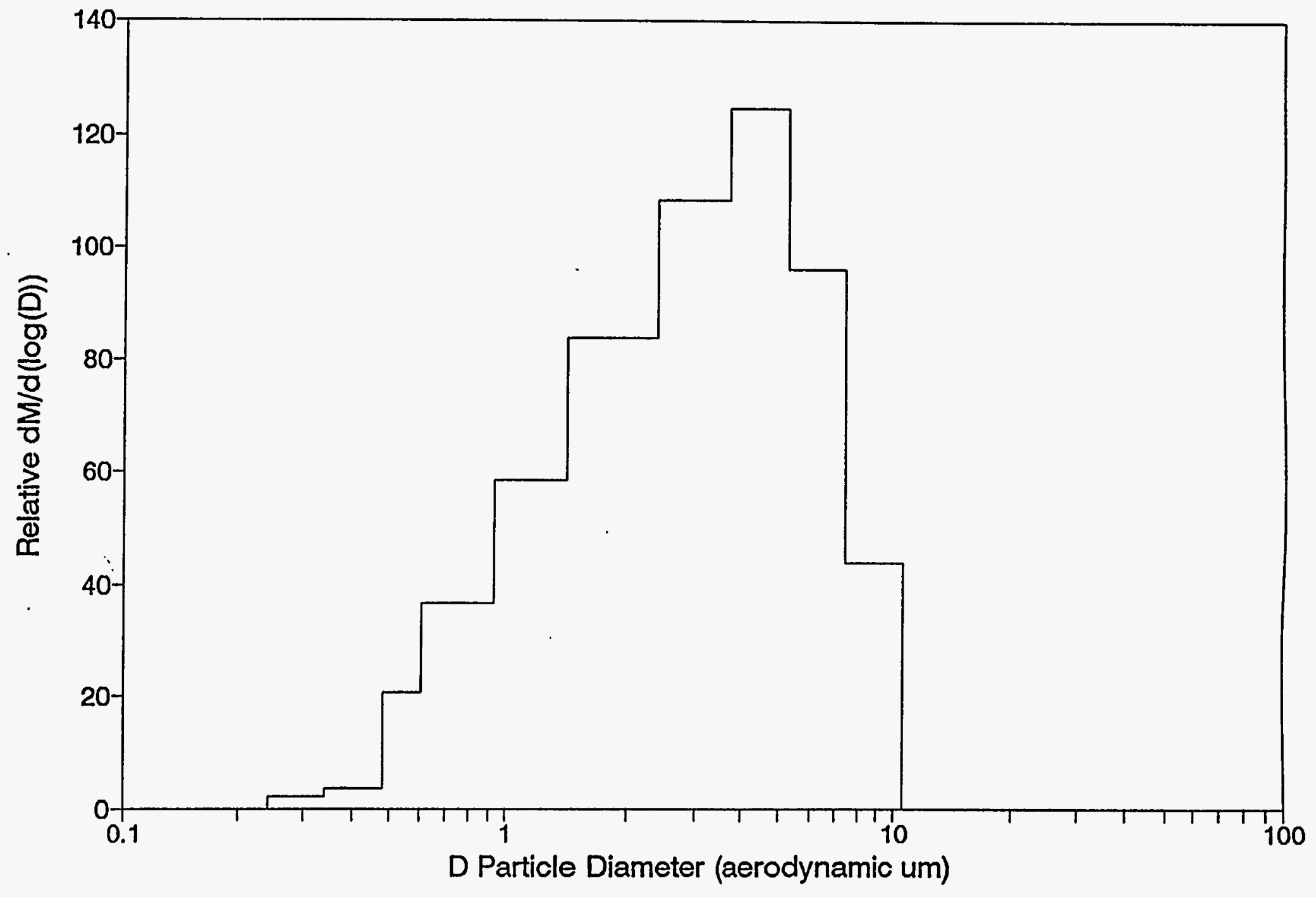


Differential Mass Particle Size Distribution for

ESP Hopper 2, Run 3

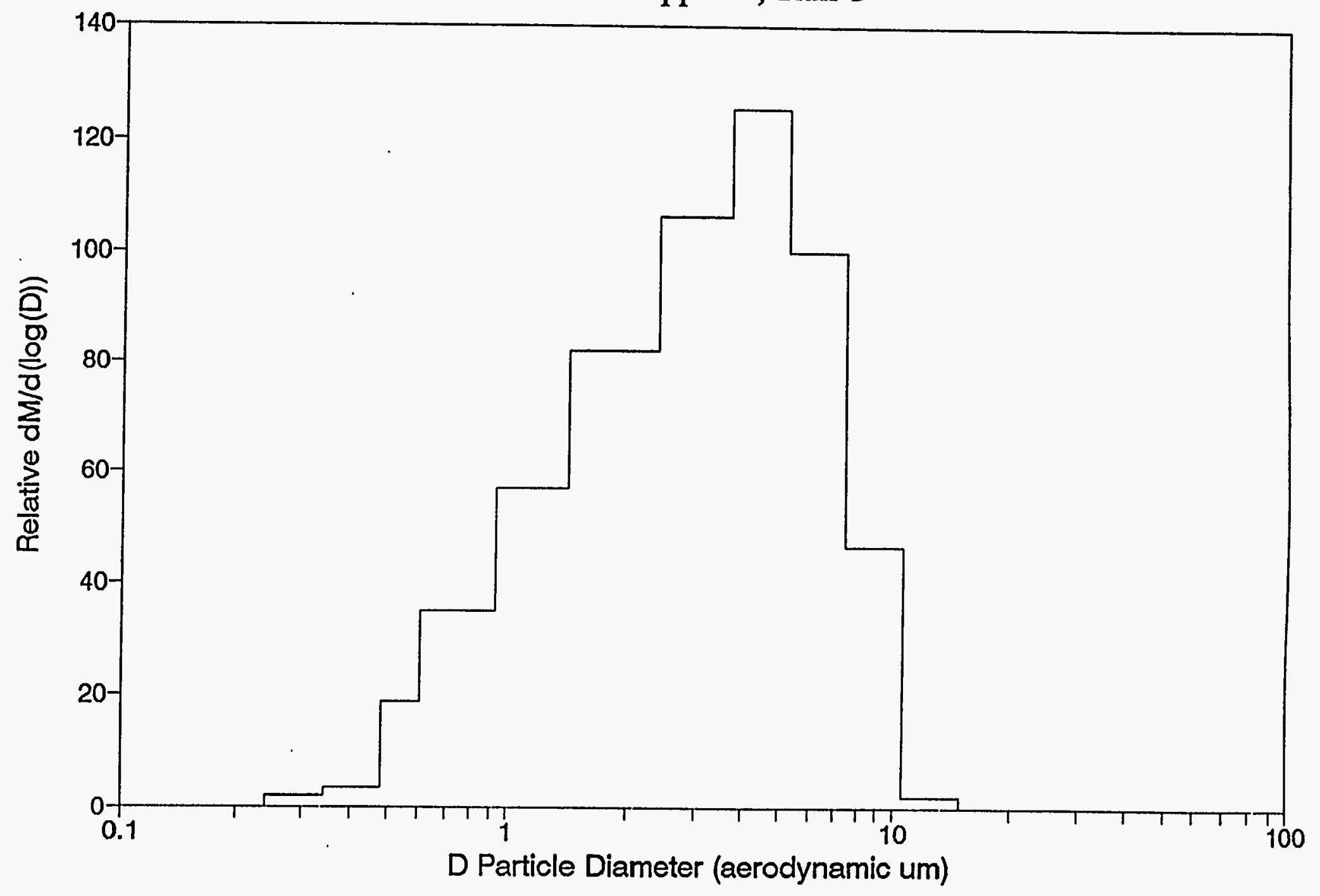


只

Differential Mass Particle Size Distribution for ESP Hopper 2, Run 3 (duplicate)

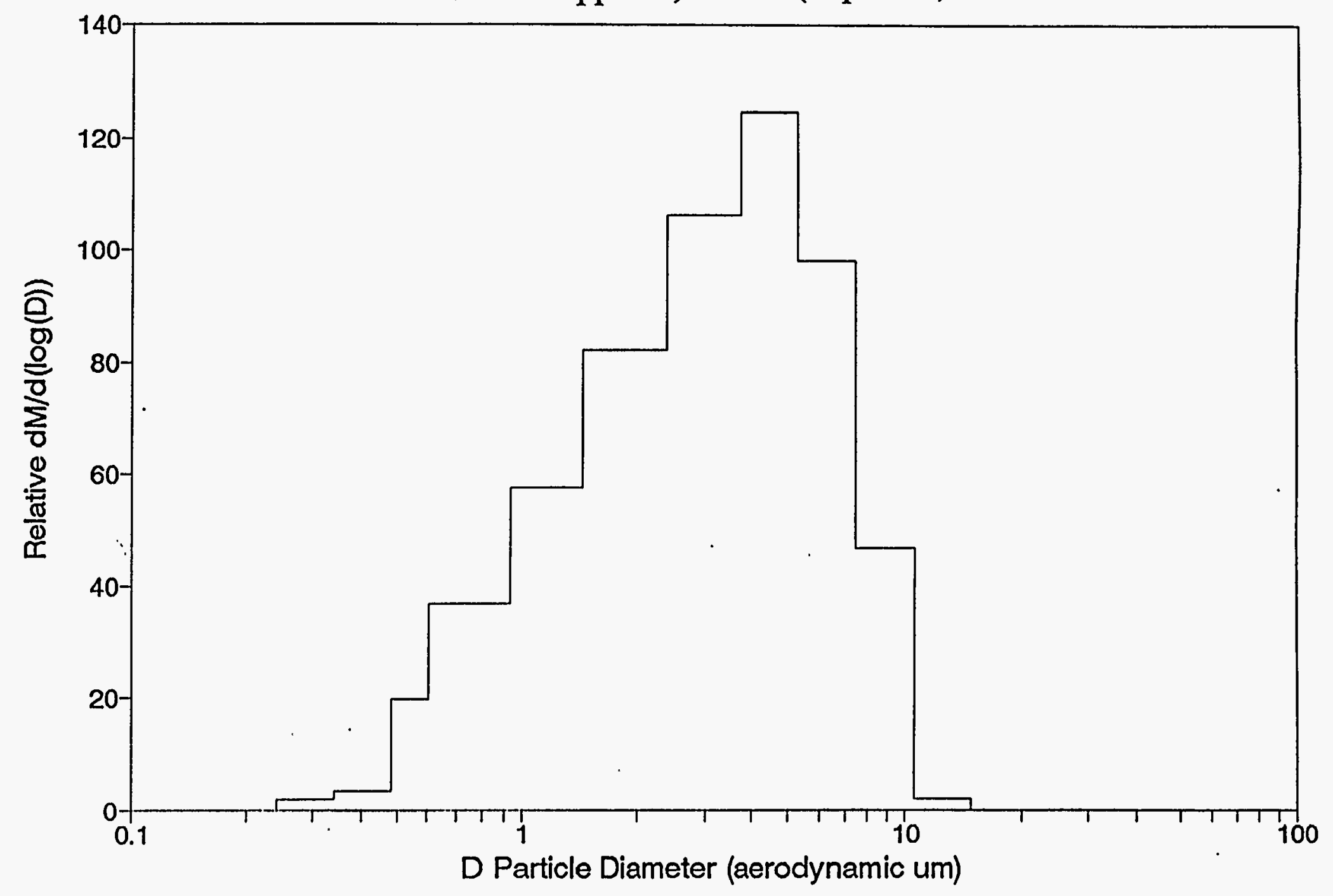




\section{Differential Mass Particle Size Distribution for}

ESP Hopper 3, Run 3

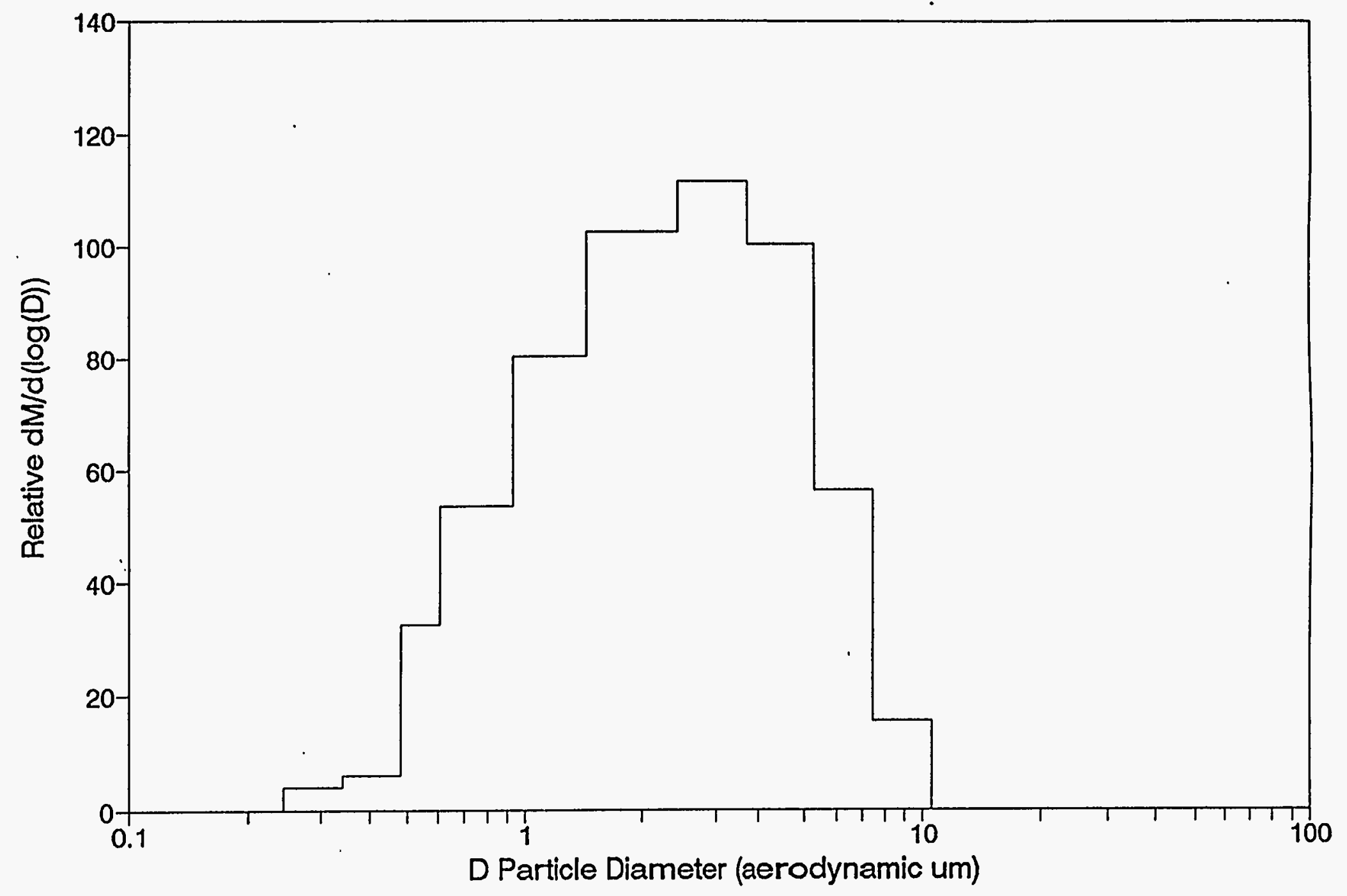


Differential Mass Particle Size Distribution for ESP Hopper 4, Run 3

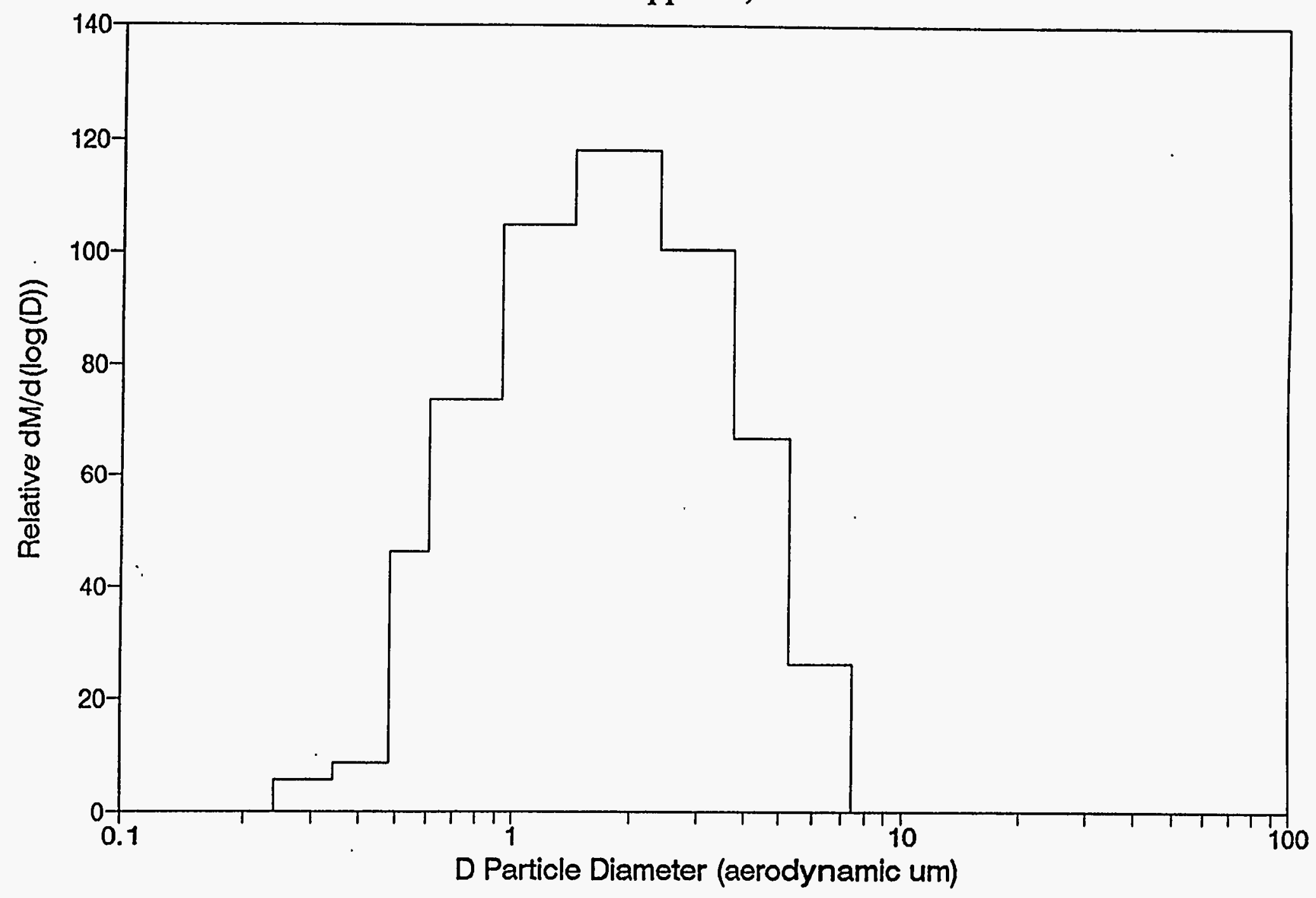

$\frac{R}{4}$ 
$\frac{3}{\text { ลุ }}$

Differential Mass Particle Size Distribution for

ESP Hopper 4, Run 3 (duplicate)

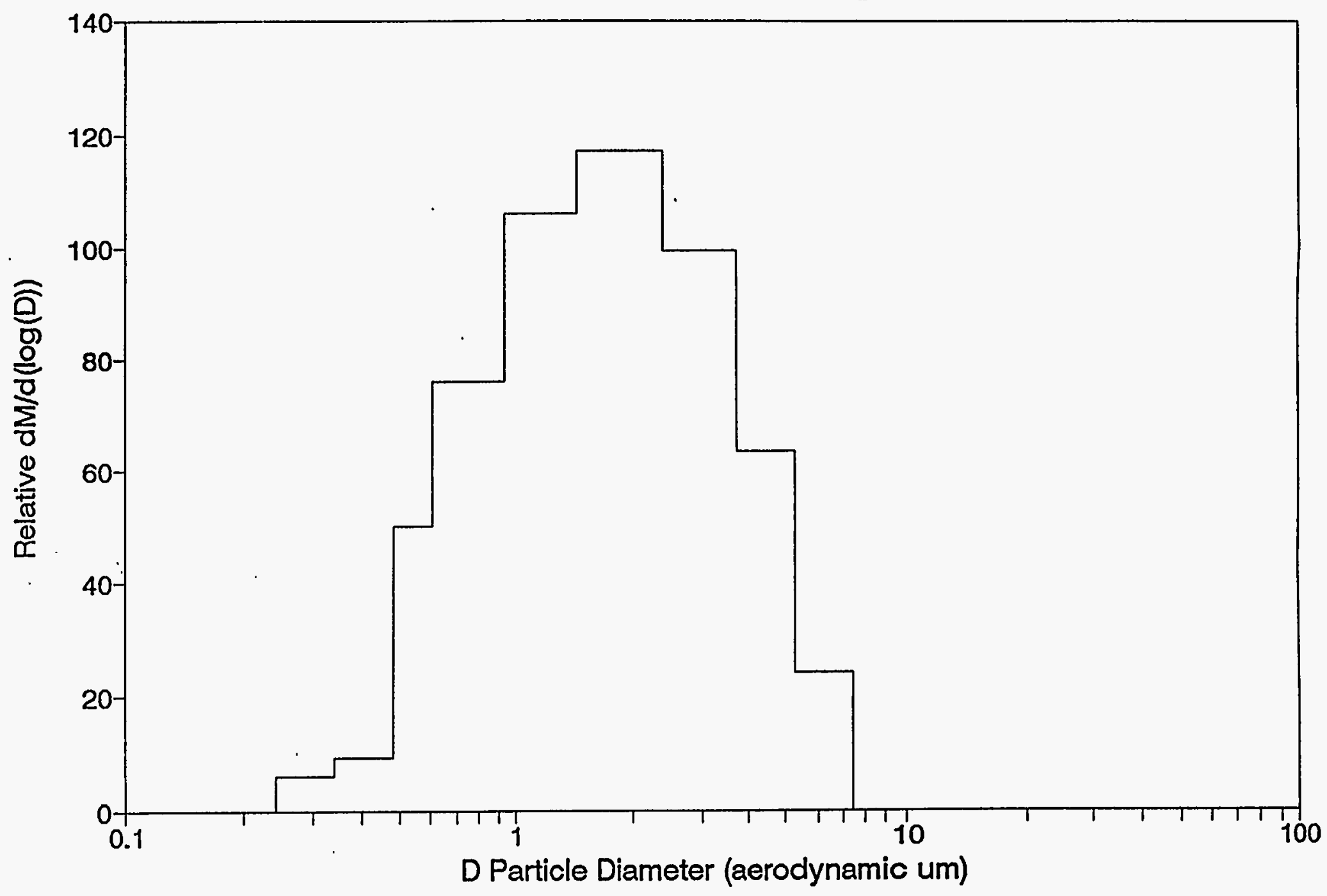




\section{APPENDIX D: QUALITY ASSURANCE/QUALITY CONTROL RESULTS}

Appendix D presents detailed quality control sample results for blank samples (Table D-1), precision and accuracy measurements (Table D-2), and organic surrogate-spiked samples (Table D-3). In each table, the sample type, sample matrix, and sample stream are provided to identify the process samples directly related to the $\mathrm{QC}$ results. The source of the individual sample components listed (e.g., half filter, impinger solution, etc.) for each QC sample are shown in Appendix A, Figures A-2 through A-22. 
Table D-1

Summary of Blank Sample Results

\begin{tabular}{|c|c|c|c|c|}
\hline Analyte & $\begin{array}{c}\text { Number of } \\
\text { Blanks } \\
\text { Analyzed }\end{array}$ & $\begin{array}{c}\text { Number } \\
\text { of } \\
\text { Detects }\end{array}$ & $\begin{array}{c}\text { Range of } \\
\text { Compounds Detected }\end{array}$ & $\begin{array}{l}\text { Detection } \\
\text { Limit }\end{array}$ \\
\hline \multicolumn{5}{|c|}{$\begin{array}{l}\text { Laboratory Method Blanks - } \\
\text { Filtered Solids, Acetone PNR }\end{array}$} \\
\hline \multicolumn{5}{|l|}{ ICP-AES Metals } \\
\hline Aluminum & 2 & 2 & $5.97-7.93 \mu \mathrm{g} / \mathrm{g}$ & $27.6 \mu \mathrm{g} / \mathrm{g}$ \\
\hline Antimony & 2 & 0 & ND & $58.6 \mu \mathrm{g} / \mathrm{g}$ \\
\hline Barium & 2 & 1 & ND-0.460 $\mu \mathrm{g} / \mathrm{g}$ & $0.697 \mu \mathrm{g} / \mathrm{g}$ \\
\hline Beryllium & 2 & 0 & ND & $0.329 \mu \mathrm{g} / \mathrm{g}$ \\
\hline Calcium & 2 & 2 & $18.4-26.6 \mu \mathrm{g} / \mathrm{g}$ & $13.7 \mu \mathrm{g} / \mathrm{g}$ \\
\hline Chromium & 2 & 2 & $7.45-8.15 \mu \mathrm{g} / \mathrm{g}$ & $1.97 \mu \mathrm{g} / \mathrm{g}$ \\
\hline Cobalt & 2 & 2 & $7.68-8.32 \mu \mathrm{g} / \mathrm{g}$ & $5.38 \mu \mathrm{g} / \mathrm{g}$ \\
\hline Copper & 2 & 0 & ND & $5.02 \mu \mathrm{g} / \mathrm{g}$ \\
\hline Iron & 2 & 0 & ND & - \\
\hline Magnesium & 2 & 2 & $29.6-53.0 \mu \mathrm{g} / \mathrm{g}$ & $96.3 \mu \mathrm{g} / \mathrm{g}$ \\
\hline Manganese & 2 & 2 & $0.490-1.99 \mu \mathrm{g} / \mathrm{g}$ & $4.92 \mu \mathrm{g} / \mathrm{g}$ \\
\hline Molybdenum & 2 & 0 & ND & $3.84 \mu \mathrm{g} / \mathrm{g}$ \\
\hline Nickel & 2 & 1 & ND-1.04 $\mu \mathrm{g} / \mathrm{g}$ & $11.4 \mu \mathrm{g} / \mathrm{g}$ \\
\hline Phosphorus & 2 & 2 & $7.67-15.4 \mu \mathrm{g} / \mathrm{g}$ & $7.29 \mu \mathrm{g} / \mathrm{g}$ \\
\hline Potassium & 2 & 1 & ND-122 $\mu \mathrm{g} / \mathrm{g}$ & $441 \mu \mathrm{g} / \mathrm{g}$. \\
\hline Silver & 2 & 1 & ND-1.34 $\mu \mathrm{g} / \mathrm{g}$ & $4.43 \mu \mathrm{g} / \mathrm{g}$ \\
\hline Sodium & 2 & 1 & ND-127 $\mu \mathrm{g} / \mathrm{g}$ & $30.5 \mu \mathrm{g} / \mathrm{g}$ \\
\hline Titanium & 2 & 2 & $0.970-2.43 \mu \mathrm{g} / \mathrm{g}$ & $7.16 \mu \mathrm{g} / \mathrm{g}$ \\
\hline Vanadium & 2 & 1 & ND-3.71 $\mu \mathrm{g} / \mathrm{g}$ & $2.92 \mu \mathrm{g} / \mathrm{g}$ \\
\hline \multicolumn{5}{|c|}{ Laboratory Method Blanks - Nitric PNR } \\
\hline \multicolumn{5}{|l|}{ ICP-AES Metals } \\
\hline Aluminum & 1 & 1 & $0.383 \mathrm{mg} / \mathrm{L}$ & $0.0523 \mathrm{mg} / \mathrm{L}$ \\
\hline Antimony & 1 & 0 & ND & $0.076 \mathrm{mg} / \mathrm{L}$ \\
\hline Barium & 1 & 1 & $0.00023 \mathrm{mg} / \mathrm{L}$ & $0.00086 \mathrm{mg} / \mathrm{L}$ \\
\hline Beryllium & 1 & 0 & $0.0 \mathrm{mg} / \mathrm{L}$ & $0.00051 \mathrm{mg} / \mathrm{L}$ \\
\hline Calcium & 1 & 1 & $0.0306 \mathrm{mg} / \mathrm{L}$ & $0.0175 \mathrm{mg} / \mathrm{L}$ \\
\hline Chromium & 1 & 0 & ND & $0.00524 \mathrm{mg} / \mathrm{L}$ \\
\hline Cobalt & 1 & 0 & ND & $0.00407 \mathrm{mg} / \mathrm{L}$ \\
\hline Copper & 1 & 1 & $0.0100 \mathrm{mg} / \mathrm{L}$ & $0.00916 \mathrm{mg} / \mathrm{L}$ \\
\hline Iron & 1 & 1 & $0.0506 \mathrm{mg} / \mathrm{L}$ & $0.00452 \mathrm{mg} / \mathrm{L}$ \\
\hline Magnesium & 1 & 0 & ND & $0.0479 \mathrm{mg} / \mathrm{L}$ \\
\hline Manganese & 1 & 1 & $0.00308 \mathrm{mg} / \mathrm{L}$ & $0.00155 \mathrm{mg} / \mathrm{L}$ \\
\hline
\end{tabular}


Table D-1 (Continued)

\begin{tabular}{|c|c|c|c|c|}
\hline Analyte & $\begin{array}{c}\text { Number of } \\
\text { Blanks } \\
\text { Analyzed } \\
\end{array}$ & $\begin{array}{c}\text { Number } \\
\text { of } \\
\text { Detects }\end{array}$ & \begin{tabular}{|c|}
$\begin{array}{c}\text { Range of } \\
\text { Compounds Detected }\end{array}$ \\
\end{tabular} & $\begin{array}{c}\text { Detection } \\
\text { Limit }\end{array}$ \\
\hline Molybdenum & 1 & 0 & ND & $0.00739 \mathrm{mg} / \mathrm{L}$ \\
\hline Nickel & 1 & 1 & $0.00052 \mathrm{mg} / \mathrm{L}$ & $0.0141 \mathrm{mg} / \mathrm{L}$ \\
\hline Phosphorus & 1 & 1 & $0.810 \mathrm{mg} / \mathrm{L}$ & $0.061 \mathrm{mg} / \mathrm{L}$ \\
\hline Potassium & 1 & 0 & ND & $0.822 \mathrm{mg} / \mathrm{L}$ \\
\hline Silver & 1 & 1 & $0.00497 \mathrm{mg} / \mathrm{L}$ & $0.00519 \mathrm{mg} / \mathrm{L}$ \\
\hline Sodium & 1 & 1 & $0.00765 \mathrm{mg} / \mathrm{L}$ & $0.0401 \mathrm{mg} / \mathrm{L}$ \\
\hline Titanium & 1 & 1 & $0.00129 \mathrm{mg} / \mathrm{L}$ & $0.00159 \mathrm{mg} / \mathrm{L}$ \\
\hline Vanadium & 1 & 0 & ND & $0.00454 \mathrm{mg} / \mathrm{L}$ \\
\hline \multicolumn{5}{|c|}{$\begin{array}{l}\text { Laboratory Method Blanks - Half } \\
\text { Filter, Filters \& PNRs }\end{array}$} \\
\hline \multicolumn{5}{|c|}{ ICP-AES Metals } \\
\hline Aluminum & 2 & 0 & ND & $2.76 \mu \mathrm{g}$ \\
\hline Antimony & 2 & 0 & ND & $5.86 \mu \mathrm{g}$ \\
\hline Barium & 2 & 0 & ND & $0.0697 \mu \mathrm{g}$ \\
\hline Beryllium & 2 & 0 & ND & $0.0329 \mu \mathrm{g}$ \\
\hline Calcium & 2 & 0 & ND & $1.37 \mu \mathrm{g}$ \\
\hline Chromium & 2 & 2 & $0.360-0.440 \mu \mathrm{g}$ & $0.197 \mu \mathrm{g}$ \\
\hline Cobalt & 2 & 2 & $0.140-0.230 \mu \mathrm{g}$ & $0.538 \mu \mathrm{g}$ \\
\hline Copper & 2 & 0 & ND & $0.502 \mu \mathrm{g}$ \\
\hline Iron & 2 & 1 & ND-0.190 $\mu \mathrm{g}$ & - \\
\hline Magnesium & 2 & 1 & ND-0.090 $\mu \mathrm{g}$ & $9.63 \mu \mathrm{g}$ \\
\hline Manganese & 2 & 0 & ND & $0.492 \mu \mathrm{g}$ \\
\hline Molybdenum & 2 & 0 & ND & $0.384 \mu \mathrm{g}$ \\
\hline Nickel & 2 & 2 & $1.01-1.08 \mu \mathrm{g}$ & $1.14 \mu \mathrm{g}$ \\
\hline Phosphorus & 2 & 2 & $14.7-26.6 \mu \mathrm{g}$ & $7.29 \mu \mathrm{g}$ \\
\hline Potassium & 2 & 0 & ND & $44.1 \mu \mathrm{g}$ \\
\hline Silver & 2 & 0 & ND & $0.443 \mu \mathrm{g}$ \\
\hline Sodium & 2 & 0 & ND & $3.05 \mu g$ \\
\hline Titanium & 2 & 2 & $0.150-0.370 \mu \mathrm{g}$ & $0.716 \mu \mathrm{g}$ \\
\hline Vanadium & 2 & 0 & ND & $0.292 \mu \mathrm{g}$. \\
\hline \multicolumn{5}{|c|}{$\begin{array}{l}\text { Laboratory Method Blanks - } \\
\mathrm{H}_{2} \mathrm{O}_{2} / \mathrm{HNO}_{3} \text { Impingers } \\
\end{array}$} \\
\hline \multicolumn{5}{|l|}{ ICP-AES Metals } \\
\hline Aluminum & 2 & 2 & $0.00304-1.44 \mathrm{mg} / \mathrm{L}$ & $0.0523 \mathrm{mg} / \mathrm{L}$ \\
\hline Antimony & 2 & 1 & $\mathrm{ND}-0.00379 \mathrm{mg} / \mathrm{L}$ & $0.076 \mathrm{mg} / \mathrm{L}$ \\
\hline Barium & 2 & 2 & $0.00014-0.00016 \mathrm{mg} / \mathrm{L}$ & $0.00086 \mathrm{mg} / \mathrm{L}$ \\
\hline
\end{tabular}


Table D-1 (Continued)

\begin{tabular}{|c|c|c|c|c|}
\hline Analyte & $\begin{array}{c}\text { Number of } \\
\text { Blanks } \\
\text { Analyzed }\end{array}$ & $\begin{array}{c}\text { Number } \\
\text { of } \\
\text { Detects }\end{array}$ & $\begin{array}{c}\text { Range of } \\
\text { Compounds Detected }\end{array}$ & $\begin{array}{l}\text { Detection } \\
\text { Limit }\end{array}$ \\
\hline Beryllium & 2 & 0 & ND & $0.000510 \mathrm{mg} / \mathrm{L}$ \\
\hline Calcium & 2 & 2 & $0.0266-0.253 \mathrm{mg} / \mathrm{L}$ & $0.0175 \mathrm{mg} / \mathrm{L}$ \\
\hline Chromium & 2 & 0 & ND & $0.00524 \mathrm{mg} / \mathrm{L}$ \\
\hline Cobalt & 2 & 1 & $0-0.00206 \mathrm{mg} / \mathrm{L}$ & $0.00407 \mathrm{mg} / \mathrm{L}$ \\
\hline Copper & 2 & 2 & $0.00358-0.0102 \mathrm{mg} / \mathrm{L}$ & $0.00916 \mathrm{mg} / \mathrm{L}$ \\
\hline Iron & 2 & 1 & ND-0.00393 mg/L & $0.00452 \mathrm{mg} / \mathrm{L}$ \\
\hline Magnesium & 2 & 1 & ND-0.00205 mg/L & $0.0479 \mathrm{mg} / \mathrm{L}$ \\
\hline Manganese & 2 & 2 & $0.00115-0.0092 \mathrm{mg} / \mathrm{L}$ & $0.00155 \mathrm{mg} / \mathrm{L}$ \\
\hline Molybdenum & 2 & 1 & ND-0.00027 mg/L & $0.00739 \mathrm{mg} / \mathrm{L}$ \\
\hline Nickel & 2 & 1 & ND-0.00161 mg/L & $0.0141 \mathrm{mg} / \mathrm{L}$ \\
\hline Phosphorus & 1 & 0 & ND & $0.0610 \mathrm{mg} / \mathrm{L}$ \\
\hline Potassium & 2 & 2 & $0.022-0.0523 \mathrm{mg} / \mathrm{L}$ & $0.822 \mathrm{mg} / \mathrm{L}$ \\
\hline Silver & 2 & 1 & $0-0.00057 \mathrm{mg} / \mathrm{L}$ & $0.00519 \mathrm{mg} / \mathrm{L}$ \\
\hline Sodium & 2 & 2 & $0.00424-0.0654 \mathrm{mg} / \mathrm{L}$ & $0.0401 \mathrm{mg} / \mathrm{L}$ \\
\hline Titanium & 2 & 1 & ND-0.00033 mg/L & $0.00159 \mathrm{mg} / \mathrm{L}$ \\
\hline Vanadium & 2 & 0 & ND & $0.00454 \mathrm{mg} / \mathrm{L}$ \\
\hline \multicolumn{5}{|c|}{ Field Blank - Half Filter - APF } \\
\hline \multicolumn{5}{|l|}{ ICP-AES Metals } \\
\hline Aluminum & 1 & 1 & $90.8 \mu \mathrm{g}$ & $2.76 \mu \mathrm{g}$ \\
\hline Antimony & 1 & $\mathbf{0}$ & ND & $5.86 \mu \mathrm{g}$ \\
\hline Barium & 1 & 1 & $2.35 \mu \mathrm{g}$ & $0.0697 \mu \mathrm{g}$ \\
\hline Beryllium & $\overline{1}$ & 0 & ND & $0.0329 \mu \mathrm{g}$ \\
\hline Calcium & 1 & 1 & $172 \mu g$ & $1.37 \mu \mathrm{g}$ \\
\hline Chromium & 1 & 1 & $1.89 \mu \mathrm{g}$ & $0.197 \mu \mathrm{g}$ \\
\hline Cobalt & 1 & 0 & ND & $0.538 \mu \mathrm{g}$ \\
\hline Copper & 1 & 0 & ND & $0.502 \mu \mathrm{g}$ \\
\hline Iron & 1 & 1 & $12.7 \mu \mathrm{g}$ & - \\
\hline Magnesium & 1 & 1 & $63.0 \mu \mathrm{g}$ & $9.63 \mu \mathrm{g}$ \\
\hline Manganese & 1 & 0 & ND & $0.492 \mu \mathrm{g}$ \\
\hline Molybdenum & 1 & 1 & $2.22 \mu \mathrm{g}$ & $0.384 \mu \mathrm{g}:$ \\
\hline Nickel & 1 & 1 & 2.06 & $1.14 \mu \mathrm{g}$ \\
\hline Phosphorus & 1 & 1 & $33.3 \mu \mathrm{g}$ & $7.29 \mu \mathrm{g}$ \\
\hline Potassium & 1 & 1 & 25.4 & $44.1 \mu \mathrm{g}$ \\
\hline Silver & 1 & 1 & $0.003 \mu \mathrm{g}$ & $0.443 \mu \mathrm{g}$ \\
\hline Sodium & 1 & 1 & $459 \mu \mathrm{g}$ & $3.05 \mu \mathrm{g}$ \\
\hline Titanium & 1 & 1 & $0.847 \mu \mathrm{g}$ & $0.716 \mu \mathrm{g}$ \\
\hline Vanadium & 1 & 1 & $0.191 \mu \mathrm{g}$ & $0.292 \mu \mathrm{g}$ \\
\hline
\end{tabular}


Table D-1 (Continued)

\begin{tabular}{|c|c|c|c|c|}
\hline Analyte & $\begin{array}{c}\text { Number of } \\
\text { Blanks } \\
\text { Analyzed } \\
\end{array}$ & $\begin{array}{c}\text { Number } \\
\text { of } \\
\text { Detects }\end{array}$ & $\begin{array}{c}\text { Range of } \\
\text { Compounds Detected }\end{array}$ & $\begin{array}{l}\text { Detection } \\
\text { Limit }\end{array}$ \\
\hline \multicolumn{5}{|l|}{$\begin{array}{l}\text { Field Blank - Filter \& } \\
\text { PNR - ESP }\end{array}$} \\
\hline \multicolumn{5}{|l|}{ ICP-AES Metals } \\
\hline Aluminum & 1 & 1 & $437 \mu \mathrm{g}$ & $2.76 \mu \mathrm{g}$ \\
\hline Antimony & 1 & 0 & ND & $5.86 \mu \mathrm{g}$ \\
\hline Barium & 1 & 1 & $7.53 \mu \mathrm{g}$ & $0.0697 \mu \mathrm{g}$ \\
\hline Beryllium & 1 & 1 & $0.016 \mu \mathrm{g}$ & $0.0329 \mu \mathrm{g}$ \\
\hline Calcium & 1 & 1 & $661 \mu \mathrm{g}$ & $1.37 \mu \mathrm{g}$ \\
\hline Chromium & 1 & 1 & $5.66 \mu \mathrm{g}$ & $0.197 \mu \mathrm{g}$ \\
\hline Cobalt & 1 & 1 & $0.613 \mu \mathrm{g}$ & $0.538 \mu \mathrm{g}$ \\
\hline Copper. & 1 & 1 & $1.65 \mu \mathrm{g}$ & $0.502 \mu \mathrm{g}$ \\
\hline Iron & 1 & 1 & $242 \mu \mathrm{g}$ & - \\
\hline Magnesium & 1 & 1 & $181 \mu \mathrm{g}$ & $9.63 \mu \mathrm{g}$ \\
\hline Manganese & 1 & 1 & $1.96 \mu \mathrm{g}$ & $0.492 \mu \mathrm{g}$ \\
\hline Molybdenum & 1 & 1 & $17.6 \mu \mathrm{g}$ & $0.384 \mu \mathrm{g}$ \\
\hline Nickel & 1 & 1 & $2.98 \mu \mathrm{g}$ & $1.14 \mu \mathrm{g}$ \\
\hline Phosphorus & 1 & 1 & $22.4 \mu \mathrm{g}$ & $7.29 \mu \mathrm{g}$ \\
\hline Potassium & 1 & 1 & $86.4 \mu \mathrm{g}$ & $44.1 \mu \mathrm{g}$ \\
\hline Silver & 1 & 1 & $0.174 \mu \mathrm{g}$ & $0.443 \mu \mathrm{g}$ \\
\hline Sodium & 1 & 1 & $320 \mu \mathrm{g}$ & $3.05 \mu \mathrm{g}$ \\
\hline Titanium & 1 & 1 & $26.5 \mu \mathrm{g}$ & $0.716 \mu \mathrm{g}$ \\
\hline Vanadium & 1 & 1 & $1.15 \mu \mathrm{g}$ & $0.292 \mu \mathrm{g}$ \\
\hline \multicolumn{5}{|c|}{$\begin{array}{l}\text { Field Blank - } \mathrm{H}_{2} \mathrm{O}_{2} / \mathrm{HNO}_{3} \text { Impingers - } \\
\text { APF }\end{array}$} \\
\hline \multicolumn{5}{|l|}{ ICP-AES Metals } \\
\hline Aluminum & 1 & 1 & $0.0136 \mathrm{mg} / \mathrm{L}$ & $0.0523 \mathrm{mg} / \mathrm{L}$ \\
\hline Antimony & 1 & 0 & ND & $0.076 \mathrm{mg} / \mathrm{L}$ \\
\hline Barium & 1 & 1 & $0.0004 \mathrm{mg} / \mathrm{L}$ & $0.00086 \mathrm{mg} / \mathrm{L}$ \\
\hline Beryllium & 1 & 0 & ND & $0.00051 \mathrm{mg} / \mathrm{L}$ \\
\hline Calcium & 1 & 1 & $0.328 \mathrm{mg} / \mathrm{L}$ & $0.0175 \mathrm{mg} / \mathrm{L}$ \\
\hline Chromium & 1 & 0 & ND & $0.00524 \mathrm{mg} / \mathrm{L}$ \\
\hline Cobalt & 1 & 0 & ND & $0.00407 \mathrm{mg} / \mathrm{L}$ \\
\hline Copper & 1 & 1 & $0.00183 \mathrm{mg} / \mathrm{L}$ & $0.00916 \mathrm{mg} / \mathrm{L}$ \\
\hline Iron & 1 & 1 & $0.0212 \mathrm{mg} / \mathrm{L}$ & $0.00452 \mathrm{mg} / \mathrm{L}$ \\
\hline Magnesium & 1 & 1 & $0.142 \mathrm{mg} / \mathrm{L}$ & $0.0479 \mathrm{mg} / \mathrm{L}$ \\
\hline Manganese & 1 & 1 & $0.00281 \mathrm{mg} / \mathrm{L}$ & $0.00155 \mathrm{mg} / \mathrm{L}$ \\
\hline
\end{tabular}


Table D-1 (Continued)

\begin{tabular}{|c|c|c|c|c|}
\hline Analyte & $\begin{array}{c}\text { Number of } \\
\text { Blanks } \\
\text { Analyzed } \\
\end{array}$ & $\begin{array}{c}\text { Number } \\
\text { of } \\
\text { Detects }\end{array}$ & $\begin{array}{c}\text { Range of } \\
\text { Compounds Detected } \\
\end{array}$ & $\begin{array}{l}\text { Detection } \\
\text { Limit }\end{array}$ \\
\hline Molybdenum & 1 & 0 & ND & $0.00739 \mathrm{mg} / \mathrm{L}$ \\
\hline Nickel & 1 & 1 & $0.00229 \mathrm{mg} / \mathrm{L}$ & $0.0141 \mathrm{mg} / \mathrm{L}$ \\
\hline Phosphorus & 1 & 0 & ND & $0.061 \mathrm{mg} / \mathrm{L}$ \\
\hline Potassium & 1 & 0 & ND & $0.822 \mathrm{mg} / \mathrm{L}$ \\
\hline Silver & 1 & 0 & ND & $0.00519 \mathrm{mg} / \mathrm{L}$ \\
\hline Sodium & 1 & 1 & $0.672 \mathrm{mg} / \mathrm{L}$ & $0.0401 \mathrm{mg} / \mathrm{L}$ \\
\hline Titanium & 1 & 1 & $0.00068 \mathrm{mg} / \mathrm{L}$ & $0.00159 \mathrm{mg} / \mathrm{L}$ \\
\hline Vanadium & 1 & 0 & ND & $0.00454 \mathrm{mg} / \mathrm{L}$ \\
\hline \multicolumn{5}{|l|}{$\begin{array}{l}\text { Field Blank - } \mathrm{H}_{2} \mathrm{O}_{2} / \mathrm{HNO}_{3} \\
\text { Impingers - ESP }\end{array}$} \\
\hline \multicolumn{5}{|l|}{ ICP-AES Metals } \\
\hline Aluminum & 1 & 1 & $0.0228 \mathrm{mg} / \mathrm{L}$ & $0.0523 \mathrm{mg} / \mathrm{L}$ \\
\hline Antimony & 1 & 0 & ND & $0.076 \mathrm{mg} / \mathrm{L}$ \\
\hline Barium & 1 & 1 & $0.00048 \mathrm{mg} / \mathrm{L}$ & $0.00086 \mathrm{mg} / \mathrm{L}$ \\
\hline Beryllium & 1 & 0 & ND & $0.00051 \mathrm{mg} / \mathrm{L}$ \\
\hline Calcium & 1 & 1 & $0.248 \mathrm{mg} / \mathrm{L}$ & $0.0175 \mathrm{mg} / \mathrm{L}$ \\
\hline Chromium & 1 & 1 & $0.00065 \mathrm{mg} / \mathrm{L}$ & $0.00524 \mathrm{mg} / \mathrm{L}$ \\
\hline Cobalt & 1 & 1 & $0.00078 \mathrm{mg} / \mathrm{L}$ & $0.00407 \mathrm{mg} / \mathrm{L}$ \\
\hline Copper & 1 & 1 & $0.00344 \mathrm{mg} / \mathrm{L}$ & $0.00916 \mathrm{mg} / \mathrm{L}$ \\
\hline Iron & 1 & 1 & $0.0413 \mathrm{mg} / \mathrm{L}$ & $0.00452 \mathrm{mg} / \mathrm{L}$ \\
\hline Magnesium & 1 & 1 & $0.127 \mathrm{mg} / \mathrm{L}$ & $0.0479 \mathrm{mg} / \mathrm{L}$ \\
\hline Manganese & 1 & 1 & $0.00704 \mathrm{mg} / \mathrm{L}$ & $0.00155 \mathrm{mg} / \mathrm{L}$ \\
\hline Molybdenum & 1 & 1 & $0.00048 \mathrm{mg} / \mathrm{L}$ & $0.00739 \mathrm{mg} / \mathrm{L}$ \\
\hline Nickel & 1 & 1 & $0.00246 \mathrm{mg} / \mathrm{L}$ & $0.0141 \mathrm{mg} / \mathrm{L}$ \\
\hline Phosphorus & 1 & 0 & ND & $0.061 \mathrm{mg} / \mathrm{L}$ \\
\hline Potassium & 1 & 1 & $0.484 \mathrm{mg} / \mathrm{L}$ & $0.822 \mathrm{mg} / \mathrm{L}$ \\
\hline Silver & 1 & 0 & ND & $0.00519 \mathrm{mg} / \mathrm{L}$ \\
\hline Sodium & 1 & 1 & $0.629 \mathrm{mg} / \mathrm{L}$ & $0.0401 \mathrm{mg} / \mathrm{L}$ \\
\hline Titanium & 1 & 1 & $0.00046 \mathrm{mg} / \mathrm{L}$ & $0.00159 \mathrm{mg} / \mathrm{L}$ \\
\hline Vanadium & 1 & 1 & $0.00083 \mathrm{mg} / \mathrm{L}$ & $0.00454 \mathrm{mg} / \mathrm{L}$ \\
\hline \multicolumn{5}{|c|}{ Reagent Blank - Filter \& PNR } \\
\hline \multicolumn{5}{|l|}{ ICP-AES Metals } \\
\hline Aluminum & 1 & 1 & $192 \mu \mathrm{g}$ & $2.76 \mu \mathrm{g}$ \\
\hline Antimony & 1 & 0 & ND & $5.86 \mu \mathrm{g}$ \\
\hline Barium & 1 & 1 & $6.21 \mu \mathrm{g}$ & $0.0697 \mu \mathrm{g}$ \\
\hline Beryllium & 1 & $\mathbf{0}$ & $\mathrm{ND}$ & $0.0329 \mu \mathrm{g}$ \\
\hline
\end{tabular}


Table D-1 (Continued)

\begin{tabular}{|c|c|c|c|c|}
\hline Analyte & $\begin{array}{l}\text { Number of } \\
\text { Blanks } \\
\text { Analyzed }\end{array}$ & $\begin{array}{c}\text { Number } \\
\text { of } \\
\text { Detects }\end{array}$ & $\begin{array}{c}\text { Range of } \\
\text { Compounds Detected }\end{array}$ & $\begin{array}{c}\text { Detection } \\
\text { Limit }\end{array}$ \\
\hline Calcium & 1 & 1 & $133 \mu \mathrm{g}$ & $1.37 \mu \mathrm{g}$ \\
\hline Chromium & 1 & 1 & $3.43 \mu \mathrm{g}$ & $0.197 \mu g$ \\
\hline Cobalt & 1 & 1 & $0.658 \mu \mathrm{g}$ & $0.538 \mu \mathrm{g}$ \\
\hline Copper & 1 & 0 & ND & $0.502 \mu \mathrm{g}$ \\
\hline Iron & 1 & 1 & $77.5 \mu \mathrm{g}$ & - \\
\hline Magnesium & 1 & 1 & $23.1 \mu \mathrm{g}$ & $9.63 \mu \mathrm{g}$ \\
\hline Manganese & 1 & 1 & $0.657 \mu \mathrm{g}$ & $0.492 \mu \mathrm{g}$ \\
\hline Molybdenum & 1 & 1 & $18.2 \mu \mathrm{g}$ & $0.384 \mu \mathrm{g}$ \\
\hline Nickel & 1 & 1 & $1.57 \mu \mathrm{g}$ & $1.14 \mu \mathrm{g}$ \\
\hline Phosphorus & 1 & 1 & $25.8 \mu \mathrm{g}$ & $7.29 \mu \mathrm{g}$ \\
\hline Potassium & 1 & 1 & $34.7 \mu \mathrm{g}$ & $44.1 \mu \mathrm{g}$ \\
\hline Silver & 1 & 1 & $0.134 \mu \mathrm{g}$ & $0.443 \mu \mathrm{g}$ \\
\hline Sodium & 1 & 1 & $260 \mu \mathrm{g}$ & $3.05 \mu \mathrm{g}$ \\
\hline Titanium & 1 & 1 & $8.13 \mu \mathrm{g}$ & $0.716 \mu \mathrm{g}$ \\
\hline Vanadium & 1 & 1 & $0.782 \mu \mathrm{g}$ & $0.292 \mu \mathrm{g}$ \\
\hline \multicolumn{5}{|l|}{ Reagent Blank - Half Filter } \\
\hline \multicolumn{5}{|l|}{ ICP-AES Metals } \\
\hline Aluminum & 1 & 1 & $90.6 \mu \mathrm{g}$ & $2.76 \mu \mathrm{g}$ \\
\hline Antimony & 1 & 0 & ND & $5.86 \mu \mathrm{g}$ \\
\hline Barium & 1 & 1 & $0.615 \mu \mathrm{g}$ & $0.0697 \mu \mathrm{g}$ \\
\hline Beryllium & 1 & 0 & ND & $0.0329 \mu \mathrm{g}$ \\
\hline Calcium & 1 & 1 & $173 \mu \mathrm{g}$ & $1.37 \mu \mathrm{g}$ \\
\hline Chromium & 1 & 1 & $1.38 \mu \mathrm{g}$ & $0.197 \mu \mathrm{g}$ \\
\hline Cobalt & 1 & 1 & $0.366 \mu \mathrm{g}$ & $0.538 \mu \mathrm{g}$ \\
\hline Copper & 1 & 0 & ND & $0.502 \mu \mathrm{g}$ \\
\hline Iron & 1 & 1 & $6.10 \mu \mathrm{g}$ & - \\
\hline Magnesium & 1 & 1 & $62.2 \mu \mathrm{g}$ & $9.63 \mu \mathrm{g}$ \\
\hline Manganese & 1 & 0 & ND & $0.492 \mu \mathrm{g}$ \\
\hline Molybdenum & 1 & 1 & $1.97 \mu \mathrm{g}$ & $0.384 \mu \mathrm{g}$ \\
\hline Nickel & 1 & 1 & $1.21 \mu \mathrm{g}$ & $1.14 \mu \mathrm{g}$ \\
\hline Phosphorus & 1 & 1 & $36.7 \mu \mathrm{g}$ & $7.29 \mu \mathrm{g}$ \\
\hline Potassium & 1 & 1 & $29.3 \mu \mathrm{g}$ & $44.1 \mu \mathrm{g}$ \\
\hline Silver & 1 & 0 & ND & $0.443 \mu \mathrm{g}$ \\
\hline Sodium & $\overline{1}$ & 1 & $460 \mu \mathrm{g}$ & $3.05 \mu \mathrm{g}$ \\
\hline Titanium & 1 & 1 & $0.909 \mu \mathrm{g}$ & $0.716 \mu \mathrm{g}$ \\
\hline Vanadium & 1 & 1 & $0.161 \mu \mathrm{g}$ & $0.292 \mu \mathrm{g}$ \\
\hline
\end{tabular}


Table D-1 (Continued)

\begin{tabular}{|c|c|c|c|c|}
\hline Analyte & $\begin{array}{c}\text { Number of } \\
\text { Blanks } \\
\text { Analyzed }\end{array}$ & $\begin{array}{c}\text { Number } \\
\text { of } \\
\text { Detects }\end{array}$ & $\begin{array}{c}\text { Range of } \\
\text { Compounds Detected }\end{array}$ & $\begin{array}{l}\text { Detection } \\
\text { Limit }\end{array}$ \\
\hline \multicolumn{5}{|c|}{ Reagent Blank - $\mathrm{HNO}_{3} / \mathrm{H}_{2} \mathrm{O}_{2}$ Impingers } \\
\hline \multicolumn{5}{|l|}{ ICP-AES Metals } \\
\hline Aluminum & 1 & 1 & $0.00891 \mathrm{mg} / \mathrm{L}$ & $0.0523 \mathrm{mg} / \mathrm{L}$ \\
\hline Antimony & 1 & 0 & ND & $0.076 \mathrm{mg} / \mathrm{L}$ \\
\hline Barium & 1 & 1 & $0.00024 \mathrm{mg} / \mathrm{L}$ & $0.00086 \mathrm{mg} / \mathrm{L}$ \\
\hline Beryllium & 1 & 0 & $0 \mathrm{mg} / \mathrm{L}$ & $0.00051 \mathrm{mg} / \mathrm{L}$ \\
\hline Calcium & 1 & 1 & $0.299 \mathrm{mg} / \mathrm{L}$ & $0.0175 \mathrm{mg} / \mathrm{L}$ \\
\hline Chromium & 1 & 1 & $0.00399 \mathrm{mg} / \mathrm{L}$ & $0.00524 \mathrm{mg} / \mathrm{L}$ \\
\hline Cobalt & 1 & 1 & $0.00348 \mathrm{mg} / \mathrm{L}$ & $0.00407 \mathrm{mg} / \mathrm{L}$ \\
\hline Copper & 1 & 1 & $0.00127 \mathrm{mg} / \mathrm{L}$ & $0.00916 \mathrm{mg} / \mathrm{L}$ \\
\hline Iron & 1 & 1 & $0.0179 \mathrm{mg} / \mathrm{L}$ & $0.00452 \mathrm{mg} / \mathrm{L}$ \\
\hline Magnesium & $\overline{1}$ & 1 & $0.0133 \mathrm{mg} / \mathrm{L}$ & $0.0479 \mathrm{mg} / \mathrm{L}$ \\
\hline Manganese & 1 & 1 & $0.00141 \mathrm{mg} / \mathrm{L}$ & $0.00155 \mathrm{mg} / \mathrm{L}$ \\
\hline Molybdenum & 1 & 0 & $\mathrm{ND}$ & $0.00739 \mathrm{mg} / \mathrm{L}$ \\
\hline Nickel & 1 & 1 & $0.00008 \mathrm{mg} / \mathrm{L}$ & $0.0141 \mathrm{mg} / \mathrm{L}$ \\
\hline Phosphorus & $\overline{1}$ & 0 & ND & $0.061 \mathrm{mg} / \mathrm{L}$ \\
\hline Potassium & 1 & 1 & $0.264 \mathrm{mg} / \mathrm{L}$ & $0.822 \mathrm{mg} / \mathrm{L}$ \\
\hline Silver & 1 & 0 & $\mathrm{ND}$ & $0.00519 \mathrm{mg} / \mathrm{L}$ \\
\hline Sodium & 1 & 1 & $0.513 \mathrm{mg} / \mathrm{L}$ & $0.0401 \mathrm{mg} / \mathrm{L}$ \\
\hline Titanium & 1 & 0 & ND & $0.00159 \mathrm{mg} / \mathrm{L}$ \\
\hline Vanadium & 1 & 1 & $0.0002 \mathrm{mg} / \mathrm{L}$ & $0.00454 \mathrm{mg} / \mathrm{L}$ \\
\hline \multicolumn{5}{|c|}{ Laboratory Method Blank - Ash } \\
\hline \multicolumn{5}{|l|}{ ICP-AES Metals } \\
\hline Aluminum & 2 & 2 & $5.97-7.93 \mu \mathrm{g} / \mathrm{g}$ & $27.6 \mu \mathrm{g} / \mathrm{g}$ \\
\hline Antimony & 2 & 0 & ND & $58.6 \mu \mathrm{g} / \mathrm{g}$ \\
\hline Barium & 2 & 1 & $\mathrm{ND}-0.460 \mu \mathrm{g} / \mathrm{g}$ & $0.697 \mu \mathrm{g} / \mathrm{g}$ \\
\hline Beryllium & 2 & 0 & ND & $0.329 \mu \mathrm{g} / \mathrm{g}$ \\
\hline Calcium & 2 & 2 & $18.4-26.6 \mu \mathrm{g} / \mathrm{g}$ & $13.7 \mu \mathrm{g} / \mathrm{g}$ \\
\hline Chromium & 2 & 2 & $7.45-8.15 \mu \mathrm{g} / \mathrm{g}$ & $1.97 \mu \mathrm{g} / \mathrm{g}$ \\
\hline Cobalt & 2 & 2 & $7.68-8.32 \mu \mathrm{g} / \mathrm{g}$ & $5.38 \mu \mathrm{g} / \mathrm{g}:$ \\
\hline Copper & 2 & 0 & ND & $5.02 \mu \mathrm{g} / \mathrm{g}$ \\
\hline Iron & 2 & 0 & ND & - \\
\hline Magnesium & 2 & 2 & $29.6-53.0 \mu \mathrm{g} / \mathrm{g}$ & $96.3 \mu \mathrm{g} / \mathrm{g}$ \\
\hline Manganese & 2 & 2 & $0.490-1.99 \mu \mathrm{g} / \mathrm{g}$ & $4.92 \mu \mathrm{g} / \mathrm{g}$ \\
\hline Molybdenum & 2 & 0 & ND & $3.84 \mu \mathrm{g} / \mathrm{g}$ \\
\hline Nickel & 2 & 1 & ND-1.04 $\mu \mathrm{g} / \mathrm{g}$ & $11.4 \mu \mathrm{g} / \mathrm{g}$ \\
\hline
\end{tabular}


Table D-1 (Continued)

\begin{tabular}{|c|c|c|c|c|}
\hline Analyte & $\begin{array}{l}\text { Number of } \\
\text { Blanks } \\
\text { Analyzed } \\
\end{array}$ & $\begin{array}{c}\text { Number } \\
\text { of } \\
\text { Detects }\end{array}$ & $\begin{array}{c}\text { Range of } \\
\text { Compounds Detected }\end{array}$ & $\begin{array}{c}\text { Detection } \\
\text { Limit }\end{array}$ \\
\hline Phosphorus & 1 & 0 & ND & $7.29 \mu \mathrm{g} / \mathrm{g}$ \\
\hline Potassium & 2 & 1 & $\mathrm{ND}-122 \mu \mathrm{g} / \mathrm{g}$ & $441 \mu \mathrm{g} / \mathrm{g}$ \\
\hline Silver & 2 & 1 & $\mathrm{ND}-1.34 \mu \mathrm{g} / \mathrm{g}$ & $4.43 \mu \mathrm{g} / \mathrm{g}$ \\
\hline Sodium & 2 & 1 & $\mathrm{ND}-127 \mu \mathrm{g} / \mathrm{g}$ & $30.5 \mu \mathrm{g} / \mathrm{g}$ \\
\hline Titanium & 2 & 2 & $0.970-2.43 \mu \mathrm{g} / \mathrm{g}$ & $7.16 \mu \mathrm{g} / \mathrm{g}$ \\
\hline Vanadium & 2 & 1 & ND-3.71 $\mu \mathrm{g} / \mathrm{g}$ & $2.92 \mu \mathrm{g} / \mathrm{g}$ \\
\hline \multicolumn{5}{|c|}{ Laboratory Method Blank - Sorbent } \\
\hline \multicolumn{5}{|l|}{ ICP-AES Metals } \\
\hline Aluminum & 1 & 0 & ND & - \\
\hline Antimony & 1 & 0 & ND & $5.86 \mu \mathrm{g} / \mathrm{g}$ \\
\hline Barium & 1 & 1 & $0.014 \mu \mathrm{g} / \mathrm{g}$ & $0.0697 \mu \mathrm{g} / \mathrm{g}$ \\
\hline Beryllium & 1 & 0 & ND. & $0.0329 \mu \mathrm{g} / \mathrm{g}$ \\
\hline Calcium & 1 & 1 & $2.29 \mu \mathrm{g} / \mathrm{g}$ & $39.8 \mu \mathrm{g} / \mathrm{g}$ \\
\hline Chromium & 1 & 1 & $0.341 \mu \mathrm{g} / \mathrm{g}$ & $0.197 \mu \mathrm{g} / \mathrm{g}$ \\
\hline Cobalt & 1 & 1 & $0.069 \mu \mathrm{g} / \mathrm{g}$ & $0.538 \mu \mathrm{g} / \mathrm{g}$ \\
\hline Copper & 1 & 0 & ND & $0.502 \mu \mathrm{g} / \mathrm{g}$ \\
\hline Iron & 1 & 1 & $0.165 \mu \mathrm{g} / \mathrm{g}$ & - \\
\hline Magnesium & 1 & 0 & ND & $9.63 \mu \mathrm{g} / \mathrm{g}$ \\
\hline Manganese & 1 & 0 & ND & $0.492 \mu \mathrm{g} / \mathrm{g}$ \\
\hline Molybdenum & 1 & 1 & $0.099 \mu \mathrm{g} / \mathrm{g}$ & $0.384 \mu \mathrm{g} / \mathrm{g}$ \\
\hline Nickel & 1 & 1 & $0.75 \mu \mathrm{g} / \mathrm{g}$ & - \\
\hline \begin{tabular}{|l} 
Phosphorus \\
\end{tabular} & 1 & 0 & ND & $7.29 \mu \mathrm{g} / \mathrm{g}$ \\
\hline Potassium & 1 & 1 & $6.51 \mu \mathrm{g} / \mathrm{g}$ & $44.1 \mu \mathrm{g} / \mathrm{g}$ \\
\hline Silver & 1 & 0 & ND & $0.443 \mu \mathrm{g} / \mathrm{g}$ \\
\hline Sodium & 1 & 1 & $0.076 \mu \mathrm{g} / \mathrm{g}$ & $3.05 \mu \mathrm{g} / \mathrm{g}$ \\
\hline \begin{tabular}{|l|} 
Titanium \\
\end{tabular} & 1 & 1 & $0.09 \mu \mathrm{g} / \mathrm{g}$ & $0.716 \mu \mathrm{g} / \mathrm{g}$ \\
\hline Vanadium & 1 & 0 & $0 \mu \mathrm{g} / \mathrm{g}$ & $0.292 \mu \mathrm{g} / \mathrm{g}$ \\
\hline \multicolumn{5}{|c|}{$\begin{array}{l}\text { Laboratory Method Blank - Service } \\
\text { Water }\end{array}$} \\
\hline \multicolumn{5}{|l|}{ ICP-AES Metals } \\
\hline Aluminum & 1 & 1 & $0.148 \mathrm{mg} / \mathrm{L}$ & $0.0523 \mathrm{mg} / \mathrm{L}$ \\
\hline Antimony & 1 & 1 & $0.0566 \mathrm{mg} / \mathrm{L}$ & $0.076 \mathrm{mg} / \mathrm{L}$ \\
\hline Barium & 1 & 1 & $0.00151 \mathrm{mg} / \mathrm{L}$ & $0.00086 \mathrm{mg} / \mathrm{L}$ \\
\hline Beryllium & 1 & 0 & ND & $0.00051 \mathrm{mg} / \mathrm{L}$ \\
\hline Calcium & 1 & 1 & $0.238 \mathrm{mg} / \mathrm{L}$ & $0.0175 \mathrm{mg} / \mathrm{L}$ \\
\hline Chromium & 1 & 0 & ND & $0.00524 \mathrm{mg} / \mathrm{L}$ \\
\hline Cobalt & 1 & 1 & $0.00177 \mathrm{mg} / \mathrm{L}$ & $0.00407 \mathrm{mg} / \mathrm{L}$ \\
\hline
\end{tabular}


Table D-1 (Continued)

\begin{tabular}{|c|c|c|c|c|}
\hline Analyte & $\begin{array}{c}\text { Number of } \\
\text { Blanks } \\
\text { Analyzed }\end{array}$ & $\begin{array}{c}\text { Number } \\
\text { of } \\
\text { Detects }\end{array}$ & $\begin{array}{c}\text { Range of } \\
\text { Compounds Detected }\end{array}$ & $\begin{array}{l}\text { Detection } \\
\text { Limit }\end{array}$ \\
\hline Copper & 1 & 1 & $0.00324 \mathrm{mg} / \mathrm{L}$ & $0.00916 \mathrm{mg} / \mathrm{L}$ \\
\hline Iron & 1 & 0 & ND & $0.00452 \mathrm{mg} / \mathrm{L}$ \\
\hline Magnesium & 1 & 1 & $0.019 \mathrm{mg} / \mathrm{L}$ & $0.0479 \mathrm{mg} / \mathrm{L}$ \\
\hline Manganese & 1 & 0 & ND & $0.00155 \mathrm{mg} / \mathrm{L}$ \\
\hline Molybdenum & 1 & 1 & $0.00853 \mathrm{mg} / \mathrm{L}$ & $0.00739 \mathrm{mg} / \mathrm{L}$ \\
\hline Nickel & 1 & 0 & ND & $0.0141 \mathrm{mg} / \mathrm{L}$ \\
\hline Phosphorus & 1 & 0 & ND & $0.061 \mathrm{mg} / \mathrm{L}$ \\
\hline Potassium & 1 & 0 & ND & $0.822 \mathrm{mg} / \mathrm{L}$ \\
\hline Silver & 1 & 0 & $0 \mathrm{mg} / \mathrm{L}$ & $0.00519 \mathrm{mg} / \mathrm{L}$ \\
\hline Sodium & 1 & 1 & $0.0198 \mathrm{mg} / \mathrm{L}$ & $0.0401 \mathrm{mg} / \mathrm{L}$ \\
\hline Titanium & 1 & 1 & $0.00082 \mathrm{mg} / \mathrm{L}$ & $0.00159 \mathrm{mg} / \mathrm{L}$ \\
\hline \begin{tabular}{|l} 
Vanadium \\
\end{tabular} & 1 & 1 & $0.00187 \mathrm{mg} / \mathrm{L}$ & $0.00454 \mathrm{mg} / \mathrm{L}$ \\
\hline \multicolumn{5}{|c|}{$\begin{array}{l}\text { Field Blank - } \mathrm{HNO}_{3} / \mathrm{H}_{2} \mathrm{O}_{2} \text { Impingers - } \\
\text { APF }\end{array}$} \\
\hline \multicolumn{5}{|l|}{ ICP-MS Metals } \\
\hline Antimony & 1 & 1 & $0.13 \mu \mathrm{g} / \mathrm{L}$ & $0.003 \mu \mathrm{g} / \mathrm{L}$ \\
\hline Arsenic & 1 & 1 & $0.09 \mu \mathrm{g} / \mathrm{L}$ & $0.008 \mu \mathrm{g} / \mathrm{L}$ \\
\hline Barium & 1 & 1 & $3.57 \mu \mathrm{g} / \mathrm{L}$ & $0.017 \mu \mathrm{g} / \mathrm{L}$ \\
\hline Beryllium & 1 & 1 & $0.01 \mu \mathrm{g} / \mathrm{L}$ & $0.015 \mu \mathrm{g} / \mathrm{L}$ \\
\hline Cadmium & 1 & 1 & $0.49 \mu \mathrm{g} / \mathrm{L}$ & $0.020 \mu \mathrm{g} / \mathrm{L}$ \\
\hline Chromium & 1 & 1 & $3.7 \mu \mathrm{g} / \mathrm{L}$ & $0.020 \mu \mathrm{g} / \mathrm{L}$ \\
\hline Cobalt & 1 & 1 & $0.10 \mu \mathrm{g} / \mathrm{L}$ & $0.003 \mu \mathrm{g} / \mathrm{L}$ \\
\hline Copper & 1 & 1 & $1.70 \mu \mathrm{g} / \mathrm{L}$ & $0.106 \mu \mathrm{g} / \mathrm{L}$ \\
\hline Lead & 1 & 1 & $2.27 \mu \mathrm{g} / \mathrm{L}$ & $0.016 \mu \mathrm{g} / \mathrm{L}$ \\
\hline Manganese & 1 & 1 & $2.02 \mu \mathrm{g} / \mathrm{L}$ & $0.022 \mu \mathrm{g} / \mathrm{L}$ \\
\hline Mercury & 1 & 1 & $0.01 \mu \mathrm{g} / \mathrm{L}$ & $0.021 \mu \mathrm{g} / \mathrm{L}$ \\
\hline Molybdenum & 1 & 1 & $0.46 \mu \mathrm{g} / \mathrm{L}$ & $0.024 \mu \mathrm{g} / \mathrm{L}$ \\
\hline Nickel & 1 & 1 & $5.39 \mu \mathrm{g} / \mathrm{L}$ & $0.024 \mu \mathrm{g} / \mathrm{L}$ \\
\hline Selenium & $\overline{1}$ & 0 & $<0.134 \mu \mathrm{g} / \mathrm{L}$ & $0.134 \mu \mathrm{g} / \mathrm{L}$ \\
\hline Vanadium & $\overline{1}$ & 1 & $0.09 \mu \mathrm{g} / \mathrm{L}$ & $0.006 \mu \mathrm{g} / \mathrm{L}$ \\
\hline \multicolumn{5}{|l|}{$\begin{array}{l}\begin{array}{l}\text { Field Blank - } \mathrm{HNO}_{3} / \mathrm{H}_{2} \mathrm{O}_{2} \\
\text { Impingers - ESP }\end{array} \\
\end{array}$} \\
\hline \multicolumn{5}{|l|}{ ICP-MS Metals } \\
\hline Antimony & 1 & 1 & $0.04 \mu \mathrm{g} / \mathrm{L}$ & $0.003 \mu \mathrm{g} / \mathrm{L}$ \\
\hline Arsenic & 1 & 1 & $0.10 \mu \mathrm{g} / \mathrm{L}$ & $0.008 \mu \mathrm{g} / \mathrm{L}$ \\
\hline Barium & 1 & 1 & $3.87 \mu \mathrm{g} / \mathrm{L}$ & $0.017 \mu \mathrm{g} / \mathrm{L}$ \\
\hline Beryllium & $\frac{1}{1}$ & $\frac{1}{1}$ & $0.02 \mu \mathrm{g} / \mathrm{L}$ & $0.015 \mu \mathrm{g} / \mathrm{L}$ \\
\hline Cadmium & 1 & 1 & $0.46 \mu \mathrm{g} / \mathrm{L}$ & $0.020 \mu \mathrm{g} / \mathrm{L}$ \\
\hline
\end{tabular}


Table D-1 (Continued)

\begin{tabular}{|c|c|c|c|c|}
\hline Analyte & $\begin{array}{c}\text { Number of } \\
\text { Blanks } \\
\text { Analyzed } \\
\end{array}$ & $\begin{array}{c}\text { Number } \\
\text { of } \\
\text { Detects }\end{array}$ & $\begin{array}{c}\text { Range of } \\
\text { Compounds Detected }{ }^{\mathrm{a}}\end{array}$ & $\begin{array}{l}\text { Detection } \\
\text { Limit }\end{array}$ \\
\hline Chromium & 1 & 1 & $2.9 \mu \mathrm{g} / \mathrm{L}$ & $0.020 \mu \mathrm{g} / \mathrm{L}$ \\
\hline Cobalt & 1 & 1 & $0.09 \mu \mathrm{g} / \mathrm{L}$ & $0.003 \mu \mathrm{g} / \mathrm{L}$ \\
\hline Copper & 1 & 1 & $2.04 \mu \mathrm{g} / \mathrm{L}$ & $0.106 \mu \mathrm{g} / \mathrm{L}$ \\
\hline Lead & 1 & 1 & $1.28 \mu \mathrm{g} / \mathrm{L}$ & $0.016 \mu \mathrm{g} / \mathrm{L}$ \\
\hline Manganese & 1 & 1 & $5.63 \mu \mathrm{g} / \mathrm{L}$ & $0.022 \mu \mathrm{g} / \mathrm{L}$ \\
\hline Mercury & 1 & 1 & $0.05 \mu \mathrm{g} / \mathrm{L}$ & $0.021 \mu \mathrm{g} / \mathrm{L}$ \\
\hline Molybdenum & 1 & 1 & $0.68 \mu \mathrm{g} / \mathrm{L}$ & $0.024 \mu \mathrm{g} / \mathrm{L}$ \\
\hline Nickel & 1 & 1 & $1.38 \mu \mathrm{g} / \mathrm{L}$ & $0.024 \mu \mathrm{g} / \mathrm{L}$ \\
\hline Selenium & 1 & 0 & $<0.134 \mu \mathrm{g} / \mathrm{L}$ & $0.134 \mu \mathrm{g} / \mathrm{L}$ \\
\hline Vanadium & 1 & 1 & $0.10 \mu \mathrm{g} / \mathrm{L}$ & $0.006 \mu \mathrm{g} / \mathrm{L}$ \\
\hline \multicolumn{5}{|c|}{ Reagent Blank - $\mathrm{HNO}_{3} / \mathrm{H}_{2} \mathrm{O}_{2}$ Impingers } \\
\hline \multicolumn{5}{|l|}{ ICP-MS Metals } \\
\hline Antimony & 1 & 1 & $0.04 \mu \mathrm{g} / \mathrm{L}$ & $0.003 \mu \mathrm{g} / \mathrm{L}$ \\
\hline Arsenic & 1 & 1 & $0.22 \mu \mathrm{g} / \mathrm{L}$ & $0.008 \mu \mathrm{g} / \mathrm{L}$ \\
\hline Barium & 1 & 1 & $7.58 \mu \mathrm{g} / \mathrm{L}$ & $0.017 \mu \mathrm{g} / \mathrm{L}$ \\
\hline Beryllium & 1 & 1 & $0.09 \mu \mathrm{g} / \mathrm{L}$ & $0.015 \mu \mathrm{g} / \mathrm{L}$ \\
\hline Cadmium & 1 & 1 & $0.95 \mu \mathrm{g} / \mathrm{L}$ & $0.020 \mu \mathrm{g} / \mathrm{L}$ \\
\hline Chromium & 1 & 1 & $3.79 \mu \mathrm{g} / \mathrm{L}$ & $0.020 \mu \mathrm{g} / \mathrm{L}$ \\
\hline Cobalt & 1 & 1 & $0.05 \mu \mathrm{g} / \mathrm{L}$ & $0.003 \mu \mathrm{g} / \mathrm{L}$ \\
\hline Copper & 1 & 1 & $1.56 \mu \mathrm{g} / \mathrm{L}$ & $0.106 \mu \mathrm{g} / \mathrm{L}$ \\
\hline Lead & 1 & 1 & $2.11 \mu \mathrm{g} / \mathrm{L}$ & $0.016 \mu \mathrm{g} / \mathrm{L}$ \\
\hline Manganese & 1 & 1 & $1.80 \mu \mathrm{g} / \mathrm{L}$ & $0.022 \mu \mathrm{g} / \mathrm{L}$ \\
\hline Mercury & 1 & 1 & $2.13 \mu \mathrm{g} / \mathrm{L}$ & $0.021 \mu \mathrm{g} / \mathrm{L}$ \\
\hline Molybdenum & 1 & 1 & $0.47 \mu \mathrm{g} / \mathrm{L}$ & $0.024 \mu \mathrm{g} / \mathrm{I}$ \\
\hline Nickel & 1 & 1 & $0.57 \mu \mathrm{g} / \mathrm{L}$ & $0.024 \mu \mathrm{g} / \mathrm{L}$ \\
\hline Selenium & 1 & 0 & $<0.134 \mu \mathrm{g} / \mathrm{L}$ & $0.134 \mu \mathrm{g} / \mathrm{L}$ \\
\hline Vanadium & 1 & 1 & $0.30 \mu \mathrm{g} / \mathrm{L}$ & $0.006 \mu \mathrm{g} / \mathrm{L}$ \\
\hline \multicolumn{5}{|c|}{$\begin{array}{l}\text { Laboratory Method Blank - Filtered } \\
\text { Solids }\end{array}$} \\
\hline \multicolumn{5}{|l|}{ GFAAS and CVAAS Metals } \\
\hline Arsenic & 2 & 2 & $0.89-2.7 \mu \mathrm{g} / \mathrm{g}$ & $1.82 \mu \mathrm{g} / \mathrm{g}$ \\
\hline Cadmium & 1 & 0 & ND & $0.238 \mu \mathrm{g} / \mathrm{g}$ \\
\hline Lead & 1 & 0 & ND & $0.0776 \mu \mathrm{g} / \mathrm{g}$ \\
\hline Mercury & 1 & 0 & ND & $0.012 \mu \mathrm{g} / \mathrm{g}$ \\
\hline Selenium & 1 & 1 & $0.121 \mu \mathrm{g} / \mathrm{g}$ & $0.101 \mu \mathrm{g} / \mathrm{g}$ \\
\hline
\end{tabular}


Table D-1 (Continued)

\begin{tabular}{|c|c|c|c|c|}
\hline Analyte & $\begin{array}{c}\text { Number of } \\
\text { Blanks } \\
\text { Analyzed }\end{array}$ & $\begin{array}{c}\text { Number } \\
\text { of } \\
\text { Detects }\end{array}$ & $\begin{array}{c}\text { Range of } \\
\text { Compounds Detected }{ }^{2}\end{array}$ & $\begin{array}{l}\text { Detection } \\
\text { Limit }\end{array}$ \\
\hline \multicolumn{5}{|c|}{$\begin{array}{l}\text { Laboratory Method Blank - Acetone } \\
\text { PNR }\end{array}$} \\
\hline \multicolumn{5}{|l|}{ GFAAS and CVAAS Metals } \\
\hline Arsenic & 1 & 1 & $0.296 \mu \mathrm{g} / \mathrm{g}$ & $0.182 \mu \mathrm{g} / \mathrm{g}$ \\
\hline Cadmium & 1 & 0 & ND & $0.783 \mu \mathrm{g} / \mathrm{g}$ \\
\hline Lead & 1 & 0 & ND & $0.776 \mu \mathrm{g} / \mathrm{g}$ \\
\hline Mercury & 1 & 1 & $0.015 \mu \mathrm{g} / \mathrm{g}$ & $0.024 \mu \mathrm{g} / \mathrm{g}$ \\
\hline Selenium & 1 & 0 & ND & $0.0802 \mu \mathrm{g} / \mathrm{g}$ \\
\hline \multicolumn{5}{|c|}{ Laboratory Method Blank - Nitric PNR } \\
\hline \multicolumn{5}{|l|}{ GFAAS and CVAAS Metals } \\
\hline Arsenic & 1 & 0 & ND & $0.00214 \mathrm{mg} / \mathrm{L}$ \\
\hline Cadmium & 1 & 0 & ND & $0.00027 \mathrm{mg} / \mathrm{L}$ \\
\hline Lead & 1 & 0 & ND & $0.000996 \mathrm{mg} / \mathrm{L}$ \\
\hline Mercury & 1 & 0 & ND & $0.000033 \mathrm{mg} / \mathrm{L}$ \\
\hline Selenium & 1 & 0 & ND & $0.000592 \mathrm{mg} / \mathrm{L}$ \\
\hline \multicolumn{5}{|c|}{ Laboratory Method Blank - Half Filter } \\
\hline \multicolumn{5}{|l|}{ GFAAS and CVAAS Metals } \\
\hline Arsenic & 1 & 1 & $0.144 \mu \mathrm{g}$ & $0.182 \mu \mathrm{g}$ \\
\hline Cadmium & 1 & 0 & ND & $0.0783 \mu \mathrm{g}$ \\
\hline Lead & 1 & 0 & ND & $0.0776 \mu \mathrm{g}$ \\
\hline Mercury & 1 & 1 & $0.002 \mu \mathrm{g}$ & $0.0048 \mu \mathrm{g}$ \\
\hline Selenium & 1 & 1 & $0.066 \mu \mathrm{g}$ & $0.0802 \mu \mathrm{g}$ \\
\hline \multicolumn{5}{|c|}{$\begin{array}{l}\text { Laboratory Method Blank - Filter \& } \\
\text { PNRs }\end{array}$} \\
\hline \multicolumn{5}{|c|}{ GFAAS and CVAAS Metals } \\
\hline Arsenic & 1 & 1 & $0.376 \mu \mathrm{g}$ & $0.182 \mu \mathrm{g}$ \\
\hline Cadmium & 2 & 0 & ND & $0.0783 \mu \mathrm{g}$ \\
\hline Lead & 1 & 0 & ND & $0.0776 \mu \mathrm{g}$ \\
\hline Mercury & 1 & 1 & $0.008 \mu \mathrm{g}$ & $0.0048 \mu \mathrm{g}$ \\
\hline Selenium & 1 & 0 & ND & $0.0802 \mu \mathrm{g}$ \\
\hline \multicolumn{5}{|l|}{\begin{tabular}{|l|}
$\begin{array}{l}\text { Laboratory Method Blank - } \\
\mathrm{HNO}_{3} / \mathrm{H}_{2} \mathrm{O}_{2} \text { Impingers }\end{array}$ \\
\end{tabular}} \\
\hline \multicolumn{5}{|l|}{ GFAAS and CVAAS Metals } \\
\hline Arsenic & 1 & 0 & ND & $0.000647 \mathrm{mg} / \mathrm{L}$ \\
\hline Cadmium & 1 & 0 & ND & $0.000191 \mathrm{mg} / \mathrm{L}$ \\
\hline Lead & 1 & 1 & $0.00047 \mathrm{mg} / \mathrm{L}$ & $0.00205 \mathrm{mg} / \mathrm{L}$ \\
\hline Mercury & 1 & 0 & ND & $0.000048 \mathrm{mg} / \mathrm{L}$ \\
\hline Selenium & 2 & 0 & ND & $0.00177 \mathrm{mg} / \mathrm{L}$ \\
\hline
\end{tabular}


Table D-1 (Continued)

\begin{tabular}{|c|c|c|c|c|}
\hline Analyte & $\begin{array}{c}\text { Number of } \\
\text { Blanks } \\
\text { Analyzed }\end{array}$ & $\begin{array}{c}\text { Number } \\
\text { of } \\
\text { Detects }\end{array}$ & $\begin{array}{c}\text { Range of } \\
\text { Compounds Detected }\end{array}$ & $\begin{array}{l}\text { Detection } \\
\text { Limit }\end{array}$ \\
\hline \multicolumn{5}{|c|}{ Field Blank - Half Filter - APF } \\
\hline \multicolumn{5}{|l|}{ GFAAS and CVAAS Metals } \\
\hline Arsenic & 1 & 1 & $0.110 \mu \mathrm{g}$ & $0.182 \mu \mathrm{g}$ \\
\hline Cadmium & 1 & 0 & ND & $0.0783 \mu \mathrm{g}$ \\
\hline Lead & 1 & 0 & ND & $0.0776 \mu \mathrm{g}$ \\
\hline Mercury & 1 & 1 & $0.016 \mu \mathrm{g}$ & $0.0048 \mu \mathrm{g}$ \\
\hline Selenium & 1 & 1 & $0.113 \mu \mathrm{g}$ & $0.0802 \mu \mathrm{g}$ \\
\hline \multicolumn{5}{|c|}{ Field Blank - Filter \& PNR - ESP } \\
\hline \multicolumn{5}{|l|}{ GFAAS and CVAAS Metals } \\
\hline Arsenic & 1 & 1 & $2.36 \mu \mathrm{g}$ & $0.182 \mu \mathrm{g}$ \\
\hline Cadmium & 1 & 1 & $2.02 \mu \mathrm{g}$ & $0.157 \mu \mathrm{g}$ \\
\hline Lead & 1 & 1 & $0.884 \mu \mathrm{g}$ & $0.0776 \mu \mathrm{g}$ \\
\hline Mercury & 1 & 1 & $0.033 \mu \mathrm{g}$ & $0.0048 \mu \mathrm{g}$ \\
\hline Selenium & 1 & 1 & $0.373 \mu \mathrm{g}$ & $0.0802 \mu \mathrm{g}$ \\
\hline \multicolumn{5}{|c|}{$\begin{array}{l}\text { Field Blank - } \mathrm{H}_{2} \mathrm{O}_{2} / \mathrm{HNO}_{3} \text { Impingers - } \\
\text { APF }\end{array}$} \\
\hline \multicolumn{5}{|l|}{ GFAAS and CVAAS Metals } \\
\hline Arsenic & 1 & 0 & ND & $0.000647 \mathrm{mg} / \mathrm{L}$ \\
\hline Cadmium & 1 & 1 & $0.00054 \mathrm{mg} / \mathrm{L}$ & $0.000191 \mathrm{mg} / \mathrm{L}$ \\
\hline Lead & 1 & 1 & $0.00168 \mathrm{~m} / \mathrm{L}$ & $0.00205 \mathrm{mg} / \mathrm{L}$ \\
\hline Mercury & 1 & 0 & ND & $0.00024 \mathrm{mg} / \mathrm{L}$ \\
\hline Selenium & 1 & 1 & $0.00183 \mathrm{mg} / \mathrm{L}$ & $0.00177 \mathrm{mg} / \mathrm{L}$ \\
\hline \multicolumn{5}{|c|}{$\begin{array}{l}\text { Field Blank - } \mathrm{H}_{2} \mathrm{O}_{2} / \mathrm{HNO}_{3} \text { Impingers - } \\
\text { ESP }\end{array}$} \\
\hline \multicolumn{5}{|l|}{ GFAAS and CVAAS Metals } \\
\hline Arsenic & 1 & 0 & ND & $0.000647 \mathrm{mg} / \mathrm{L}$ \\
\hline Cadmium & 1 & $\overline{1}$ & $0.00047 \mathrm{mg} / \mathrm{L}$ & $0.000191 \mathrm{mg} / \mathrm{L}$ \\
\hline Lead & 1 & 1 & $0.00058 \mathrm{mg} / \mathrm{L}$ & $0.00205 \mathrm{mg} / \mathrm{L}$ \\
\hline Mercury & 1 & 0 & ND & $0.00024 \mathrm{mg} / \mathrm{L}$ \\
\hline Selenium & 1 & 1 & $0.0019 \mathrm{mg} / \mathrm{L}$ & $0.00177 \mathrm{mg} / \mathrm{L}$ \\
\hline \multicolumn{5}{|l|}{ Reagent Blank - Half Filter } \\
\hline \multicolumn{5}{|l|}{ GFAAS and CVAAS Metals } \\
\hline Arsenic & 1 & 1 & $0.453 \mu \mathrm{g}$ & $0.182 \mu \mathrm{g}$ \\
\hline Cadmium & 1 & 0 & ND & $0.0783 \mu \mathrm{g}$ \\
\hline Lead & 1 & 0 & ND & $0.0776 \mu \mathrm{g}$ \\
\hline Mercury & 1 & 1 & $0.019 \mu \mathrm{g}$ & $0.0048 \mu \mathrm{g}$ \\
\hline Selenium & 1 & 1 & $0.132 \mu \mathrm{g}$ & $0.0802 \mu \mathrm{g}$ \\
\hline Mercury & & & & \\
\hline
\end{tabular}


Table D-1 (Continued)

\begin{tabular}{|c|c|c|c|c|}
\hline Analyte & $\begin{array}{l}\text { Number of } \\
\text { Blanks } \\
\text { Analyzed }\end{array}$ & $\begin{array}{c}\text { Number } \\
\text { of } \\
\text { Detects }\end{array}$ & $\begin{array}{c}\text { Range of } \\
\text { Compounds Detected }{ }^{2}\end{array}$ & $\begin{array}{l}\text { Detection } \\
\text { Limit }\end{array}$ \\
\hline \multicolumn{5}{|c|}{ Reagent Blank - Filter \& PNR } \\
\hline \multicolumn{5}{|l|}{ GFAAS and CVAAS Metals } \\
\hline Arsenic & 1 & 1 & $0.270 \mu \mathrm{g}$ & $0.182 \mu \mathrm{g}$ \\
\hline Cadmium & 1 & 1 & $0.018 \mu \mathrm{g}$ & $0.0783 \mu \mathrm{g}$ \\
\hline Lead & 1 & 1 & $1.17 \mu \mathrm{g}$ & $0.0776 \mu \mathrm{g}$ \\
\hline Mercury & 1 & 1 & $0.022 \mu \mathrm{g}$ & $0.0048 \mu \mathrm{g}$ \\
\hline Selenium & 1 & 1 & $0.127 \mu \mathrm{g}$ & $0.0802 \mu \mathrm{g}$ \\
\hline \multicolumn{5}{|c|}{ Reagent Blank - $\mathrm{H}_{2} \mathrm{O}_{2} / \mathrm{HNO}_{3}$ Impingers } \\
\hline \multicolumn{5}{|c|}{ GFAAS and CVAAS Metals } \\
\hline Arsenic & 1 & 0 & ND & $0.000647 \mathrm{mg} / \mathrm{L}$ \\
\hline Cadmium & 1 & 1 & $0.00002 \mathrm{mg} / \mathrm{L}$ & $0.000191 \mathrm{mg} / \mathrm{L}$ \\
\hline Lead & 1 & 1 & $0.00069 \mathrm{mg} / \mathrm{L}$ & $0.00205 \mathrm{mg} / \mathrm{L}$ \\
\hline Mercury & 1 & 0 & ND & $0.00024 \mathrm{mg} / \mathrm{L}$ \\
\hline Selenium & 1 & 1 & $0.0014 \mathrm{mg} / \mathrm{L}$ & $0.00177 \mathrm{mg} / \mathrm{L}$ \\
\hline \multicolumn{5}{|c|}{$\begin{array}{l}\text { Laboratory Method Blank - } \mathrm{KMNO}_{4} \\
\text { Impingers }\end{array}$} \\
\hline \multicolumn{5}{|l|}{ CVAAS Metals } \\
\hline Mercury & 1 & $\mathbf{0}$ & ND & $0.000033 \mathrm{mg} / \mathrm{L}$ \\
\hline \multicolumn{5}{|c|}{ Field Blank - $\mathrm{KMNO}_{4}$ Impingers - APF } \\
\hline \multicolumn{5}{|l|}{ CVAAS Metals } \\
\hline Mercury & 1 & 1 & $0.00018 \mathrm{mg} / \mathrm{L}$ & $0.000033 \mathrm{mg} / \mathrm{L}$ \\
\hline \multicolumn{5}{|c|}{ Field Blank - $\mathrm{KMNO}_{4}$ Impingers - ESP } \\
\hline \multicolumn{5}{|l|}{ CVAAS Metals } \\
\hline Mercury & 1 & 1 & $0.00001 \mathrm{mg} / \mathrm{L}$ & $0.000033 \mathrm{mg} / \mathrm{L}$ \\
\hline \multicolumn{5}{|c|}{ Reagent Blank - $\mathrm{KMNO}_{4}$ Impingers } \\
\hline \multicolumn{5}{|l|}{ CVAAS Metals } \\
\hline Mercury & 1 & 0 & ND & $0.000033 \mathrm{mg} / \mathrm{L}$ \\
\hline \multicolumn{5}{|c|}{ Laboratory Method Blank - Ash } \\
\hline \multicolumn{5}{|l|}{ GFAAS and CVAAS Metals } \\
\hline Arsenic & 1 & 1 & $0.082 \mu \mathrm{g} / \mathrm{g}$ & $0.118 \mu \mathrm{g} / \mathrm{g}$ \\
\hline Cadmium & 1 & 1 & $0.060 \mu \mathrm{g} / \mathrm{g}$ & $0.238 \mu \mathrm{g} / \mathrm{g}$ \\
\hline Lead & 3 & 0 & ND & $0.999 \mu \mathrm{g} / \mathrm{g}$ \\
\hline Mercury & 1 & 0 & ND & $0.012 \mu \mathrm{g} / \mathrm{g}$ \\
\hline Selenium & 2 & 1 & $\mathrm{ND}-0.31 \mu \mathrm{g} / \mathrm{g}$ & $1.01 \mu \mathrm{g} / \mathrm{g}$ \\
\hline
\end{tabular}


Table D-1 (Continued)

\begin{tabular}{|c|c|c|c|c|}
\hline Analyte & $\begin{array}{c}\text { Number of } \\
\text { Blanks } \\
\text { Analyzed } \\
\end{array}$ & $\begin{array}{c}\text { Number } \\
\text { of } \\
\text { Detects }\end{array}$ & $\begin{array}{c}\text { Range of } \\
\text { Compounds Detected }\end{array}$ & $\begin{array}{l}\text { Detection } \\
\text { Limit }\end{array}$ \\
\hline \multicolumn{5}{|c|}{ Laboratory Method Blank - Sorbent } \\
\hline \multicolumn{5}{|l|}{ GFAAS and CVAAS Metals } \\
\hline Arsenic & 1 & 0 & ND & $0.118 \mu \mathrm{g} / \mathrm{g}$ \\
\hline Cadmium & 1 & 0 & ND & $0.0238 \mu \mathrm{g} / \mathrm{g}$ \\
\hline Lead & 1 & 1 & $0.016 \mu \mathrm{g} / \mathrm{g}$ & $0.0999 \mu \mathrm{g} / \mathrm{g}$ \\
\hline Mercury & 1 & 0 & ND & $0.012 \mu \mathrm{g} / \mathrm{g}$ \\
\hline Selenium & 1 & 0 & ND & $0.101 \mu \mathrm{g} / \mathrm{g}$ \\
\hline \multicolumn{5}{|c|}{$\begin{array}{l}\text { Laboratory Method Blank - Service } \\
\text { Wàter }\end{array}$} \\
\hline \multicolumn{5}{|l|}{ GFAAS and CVAAS Metals } \\
\hline Arsenic & 1 & 0 & ND & $0.000647 \mathrm{mg} / \mathrm{L}$ \\
\hline Cadmium & 1 & 0 & ND & $0.00027 \mathrm{mg} / \mathrm{L}$ \\
\hline Lead & 1 & 1 & $0.00065 \mathrm{mg} / \mathrm{L}$ & $0.0022 \mathrm{mg} / \mathrm{L}$ \\
\hline Mercury & 1 & 0 & ND & $0.000033 \mathrm{mg} / \mathrm{L}$ \\
\hline Selenium & 1 & 0 & ND & $0.00177 \mathrm{mg} / \mathrm{L}$ \\
\hline \multicolumn{5}{|c|}{$\begin{array}{l}\text { Laboratory Method Blank - Ash and } \\
\text { Sorbent }\end{array}$} \\
\hline \multicolumn{5}{|l|}{ Anions } \\
\hline Chloride (Potentiometric) & 2 & 0 & $0 \mu \mathrm{g} / \mathrm{g}$ & $78.1 \mu \mathrm{g} / \mathrm{g}$ \\
\hline Fluoride (EPA 340.2) & 3 & 3 & $8.40-9.21 \mu \mathrm{g} / \mathrm{g}$ & $11.8 \mu \mathrm{g} / \mathrm{g}$ \\
\hline Sulfur (EPA 300) & 2 & 1 & $0-4.03 \mathrm{mg} / \mathrm{L}$ & $0.0471 \mathrm{mg} / \mathrm{L}$ \\
\hline \multicolumn{5}{|c|}{$\begin{array}{l}\text { Laboratory Method Blank - Service } \\
\text { Water }\end{array}$} \\
\hline \multicolumn{5}{|l|}{ Anions } \\
\hline Chloride (EPA 300) & 1 & 0 & $0 \mathrm{mg} / \mathrm{L}$ & $0.0281 \mathrm{mg} / \mathrm{L}$ \\
\hline Fluoride (EPA 340.2) & 1 & 1 & $0.0126 \mathrm{mg} / \mathrm{L}$ & $0.00551 \mathrm{mg} / \mathrm{L}$ \\
\hline Sulfate (EPA 300) & 1 & 0 & $0 \mathrm{mg} / \mathrm{L}$ & $0.0471 \mathrm{mg} / \mathrm{L}$ \\
\hline Phosphate (EPA 365.2) & 1 & 0 & ND & $0.0200 \mathrm{mg} / \mathrm{L}$ \\
\hline \multicolumn{5}{|c|}{$\begin{array}{l}\text { Laboratory Method Blank - Half Filter, } \\
\text { Filtered Solids, Filter \& PNRs } \\
\end{array}$} \\
\hline Anions & & & & : \\
\hline Chloride (BIF) & 2 & 0 & $0 \mathrm{mg} / \mathrm{L}$ & $0.0225 \mathrm{mg} / \mathrm{L}$ \\
\hline Fluoride (EPA 340.2) & 1 & 1 & $0.0144 \mathrm{mg} / \mathrm{L}$ & $0.00551 \mathrm{mg} / \mathrm{L}$ \\
\hline Sulfate (EPA 300) & 2 & 0 & $0 \mathrm{mg} / \mathrm{L}$ & $0.0471 \mathrm{mg} / \mathrm{L}$ \\
\hline
\end{tabular}


Table D-1 (Continued)

\begin{tabular}{|c|c|c|c|c|}
\hline Analyte & $\begin{array}{c}\text { Number of } \\
\text { Blanks } \\
\text { Analyzed }\end{array}$ & $\begin{array}{c}\text { Number } \\
\text { of } \\
\text { Detects }\end{array}$ & $\begin{array}{c}\text { Range of } \\
\text { Compounds Detected }\end{array}$ & $\begin{array}{l}\text { Detection } \\
\text { Limit }\end{array}$ \\
\hline \multicolumn{5}{|c|}{$\begin{array}{l}\text { Laboratory Method Blank - } \mathrm{CO}_{3} / \mathrm{H}_{2} \mathrm{O}_{2} \\
\text { Impingèrs }\end{array}$} \\
\hline \multicolumn{5}{|l|}{ Anions } \\
\hline Chloride (EPA 300) & 1 & 0 & $0 \mathrm{mg} / \mathrm{L}$ & $0.0281 \mathrm{mg} / \mathrm{L}$ \\
\hline Fluoride (EPA 340.2) & 2 & 2 & $0.0126-0.0143 \mathrm{mg} / \mathrm{L}$ & $0.00551 \mathrm{mg} / \mathrm{L}$ \\
\hline Sulfate (EPA 300) & 2 & 0 & $0 \mathrm{mg} / \mathrm{L}$ & $0.0471 \mathrm{mg} / \mathrm{L}$ \\
\hline \multicolumn{5}{|c|}{ Field Blanks - Half Filter, Filter \& PNR } \\
\hline \multicolumn{5}{|l|}{ Anions } \\
\hline Chloride (BIF) & 2 & 2 & $0.062-0.401 \mathrm{mg} / \mathrm{L}$ & $0.0225 \mathrm{mg} / \mathrm{L}$ \\
\hline Fluoride (EPA 340.2) & 2 & 2 & $0.0291-0.38 \mathrm{mg} / \mathrm{L}$ & $0.00551 \mathrm{mg} / \mathrm{L}$ \\
\hline Sulfate (EPA 300) & 2 & 1 & $0-4.08 \mathrm{mg} / \mathrm{L}$ & $0.0471 \mathrm{mg} / \mathrm{L}$ \\
\hline \multicolumn{5}{|c|}{ Field Blanks - $\mathrm{CO}_{3} / \mathrm{H}_{2} \mathrm{O}_{2}$ Impingers } \\
\hline \multicolumn{5}{|c|}{ Anions } \\
\hline Chloride (EPA 300) & 2 & 2 & $0.389-0.443 \mathrm{mg} / \mathrm{L}$ & $0.0281 \mathrm{mg} / \mathrm{L}$ \\
\hline Fluoride (EPA 340.2) & 2 & 2 & $0.237-0.254 \mathrm{mg} / \mathrm{L}$ & $0.00551 \mathrm{mg} / \mathrm{L}$ \\
\hline Sulfate (EPA 300) & 2 & 0 & $0 \mathrm{mg} / \mathrm{L}$ & $0.0471 \mathrm{mg} / \mathrm{L}$ \\
\hline \multicolumn{5}{|c|}{ Reagent Blank - Filter \& PNR } \\
\hline \multicolumn{5}{|l|}{ Anions } \\
\hline Chloride (BIF) & 1 & 1 & $0.278 \mathrm{mg} / \mathrm{L}$ & $0.0225 \mathrm{mg} / \mathrm{L}$ \\
\hline Fluoride (EPA 340.2) & 1 & 1 & $0.647 \mathrm{mg} / \mathrm{L}$ & $0.00551 \mathrm{mg} / \mathrm{L}$ \\
\hline Sulfate (EPA 300) & 1 & 1 & $1.38 \mathrm{mg} / \mathrm{L}$ & $0.0471 \mathrm{mg} / \mathrm{L}$ \\
\hline \multicolumn{5}{|c|}{ Reagent Blank - $\mathrm{CO}_{3} / \mathrm{H}_{2} \mathrm{O}_{2}$ Impingers } \\
\hline \multicolumn{5}{|l|}{ Anions } \\
\hline Chloride (EPA 300) & 1 & 1 & $0.637 \mathrm{mg} / \mathrm{L}$ & $0.0281 \mathrm{mg} / \mathrm{L}$ \\
\hline Fluoride (EPA 340.2) & 1 & 1 & $0.184 \mathrm{mg} / \mathrm{L}$ & $0.00551 \mathrm{mg} / \mathrm{L}$ \\
\hline Sulfate (EPA 300) & 1 & 1 & $2.25 \mathrm{mg} / \mathrm{L}$ & $0.0471 \mathrm{mg} / \mathrm{L}$ \\
\hline \multicolumn{5}{|c|}{$\begin{array}{l}\text { Laboratory Method Blank - Ammonia in } \\
\text { Stack Gas (EPA 350.2) }\end{array}$} \\
\hline Ammonia & 1 & 1 & $0.0686 \mathrm{mg} / \mathrm{L}$ & $0.0156 \mathrm{mg} / \mathrm{l}$ \\
\hline \multicolumn{5}{|c|}{$\begin{array}{l}\text { Field Blanks - Ammonia in Stack Gas } \\
\text { (EPA 350.2) }\end{array}$} \\
\hline Ammonia & 2 & 2 & $0.167-0.169 \mathrm{mg} / \mathrm{L}$ & $0.0468 \mathrm{mg} / \mathrm{L}$ \\
\hline \multicolumn{5}{|c|}{$\begin{array}{l}\text { Reagent Blank - Ammonia in Stack Gas } \\
\text { (EPA 350.2) }\end{array}$} \\
\hline Ammonia & 1 & 1 & $0.167 \mathrm{mg} / \mathrm{L}$ & $0.0468 \mathrm{mg} / \mathrm{L}$ \\
\hline
\end{tabular}


Table D-1 (Continued)

\begin{tabular}{|c|c|c|c|c|}
\hline Analyte & $\begin{array}{l}\text { Number of } \\
\text { Blanks } \\
\text { Analyzed }\end{array}$ & $\begin{array}{c}\text { Number } \\
\text { of } \\
\text { Detects }\end{array}$ & $\begin{array}{c}\text { Range of } \\
\text { Compounds Detected }\end{array}$ & $\begin{array}{l}\text { Detection } \\
\text { Limit }\end{array}$ \\
\hline \multicolumn{5}{|c|}{$\begin{array}{l}\text { Laboratory Method Blank - Cyanide in } \\
\text { Stack Gas (SW 9012) }\end{array}$} \\
\hline Cyanide & 1 & 0 & ND & $0.00942 \mathrm{mg} / \mathrm{L}$ \\
\hline \multicolumn{5}{|c|}{$\begin{array}{l}\text { Field Blanks - Cyanide in Stack Gas } \\
\text { (SW 9012) }\end{array}$} \\
\hline Cyanide & 2 & 2 & $0.0014-0.0021 \mathrm{mg} / \mathrm{L}$ & $0.00942 \mathrm{mg} / \mathrm{L}$ \\
\hline \multicolumn{5}{|c|}{$\begin{array}{l}\text { Reagent Blank - Cyanide in Stack Gas } \\
\text { (SW 9012) }\end{array}$} \\
\hline Cyanide & 1 & 1 & $0.0020 \mathrm{mg} / \mathrm{L}$ & $0.00942 \mathrm{mg} / \mathrm{L}$ \\
\hline \multicolumn{5}{|c|}{$\begin{array}{l}\text { Field Blanks - Chromium VI in Stack } \\
\text { Gas (Ion Chromatography }\end{array}$} \\
\hline Chromium VI (KOH Impingers) & 1 & 1 & $0.00757 \mathrm{mg} / \mathrm{L}$ & $0.0001 \mathrm{mg} / \mathrm{L}$ \\
\hline \multicolumn{5}{|c|}{$\begin{array}{l}\text { Reagent Blanks - Chromium VI in Stack } \\
\text { Gas (Ion Chromatography) }\end{array}$} \\
\hline Chromium VI (KOH Impingers) & 4 & 4 & $0.00743-0.00955 \mathrm{mg} / \mathrm{L}$ & $0.0001 \mathrm{mg} / \mathrm{L}$ \\
\hline \multicolumn{5}{|c|}{$\begin{array}{l}\text { Laboratory Method Blank - Total } \\
\text { Chromium in Stack Gas (SW 6010) }\end{array}$} \\
\hline Chromium (SW 6010) & 1 & 1 & $0.00233 \mu \mathrm{g} / \mathrm{g}$ & $0.00273 \mu \mathrm{g} / \mathrm{g}$ \\
\hline \multicolumn{5}{|c|}{$\begin{array}{l}\text { Field Blanks - Total Chromium in Stack } \\
\text { Gas (SW 6010) }\end{array}$} \\
\hline Chromium (Nitric Rinse) & 1 & 1 & $0.00618 \mathrm{mg} / \mathrm{L}$ & $0.00524 \mathrm{mg} / \mathrm{L}$ \\
\hline Chromium (KOH Impinger) & 1 & 1 & $0.0221 \mathrm{mg} / \mathrm{L}$ & $0.00524 \mathrm{mg} / \mathrm{L}$ \\
\hline \multicolumn{5}{|c|}{$\begin{array}{l}\text { Reagent Blank - Total Chromium in } \\
\text { Stack Gas (SW 6010) }\end{array}$} \\
\hline Chromium (KOH Impinger) & 1 & 1 & $0.00684 \mathrm{mg} / \mathrm{L}$ & $0.00524 \mathrm{mg} / \mathrm{L}$ \\
\hline \multicolumn{5}{|c|}{\begin{tabular}{|l|} 
Laboratory Method Blank - \\
Formaldehyde in Stack Gas (BIF 0011)
\end{tabular}} \\
\hline Formaldehyde & 2 & 0 & ND & $0.50 \mu \mathrm{g}$ \\
\hline \multicolumn{5}{|c|}{$\begin{array}{l}\text { Field Blanks - Formaldehyde in Stack } \\
\text { Gas (BIF 0011) }\end{array}$} \\
\hline Formaldehyde & 2 & 2 & $5.7-6.0 \mu \mathrm{g}$ & $0.50 \mu \mathrm{g}$ \\
\hline \multicolumn{5}{|c|}{$\begin{array}{l}\text { Reagent Blanks - Formaldehyde in Stack } \\
\text { Gas (BIF 0011) }\end{array}$} \\
\hline Formaldehyde & 4 & 0 & ND & $0.50 \mu \mathrm{g}$ \\
\hline \multicolumn{5}{|c|}{$\begin{array}{l}\text { Laboratory Method Blank - Volatile } \\
\text { Organic Compounds in Stack Gas }\end{array}$} \\
\hline Chloromethane & 6 & 0 & ND & $10 \mathrm{ng}$ \\
\hline Vinyl Chloride & 6 & 0 & ND & $10 \mathrm{ng}$ \\
\hline Bromomethane & 6 & 0 & ND & $10 \mathrm{ng}$ \\
\hline Chloroethane & 6 & 0 & ND & $10 \mathrm{ng}$ \\
\hline
\end{tabular}


Table D-1 (Continued)

\begin{tabular}{|c|c|c|c|c|c|}
\hline Analyte & & $\begin{array}{c}\text { Number of } \\
\text { Blanks } \\
\text { Analyzed } \\
\end{array}$ & $\begin{array}{c}\text { Number } \\
\text { of } \\
\text { Detects }\end{array}$ & $\begin{array}{c}\text { Range of } \\
\text { Compounds Detected }^{2}\end{array}$ & $\begin{array}{c}\text { Detection } \\
\text { Limit }\end{array}$ \\
\hline Trichlorofluoromethane &.. & 6 & 0 & ND & $10 \mathrm{ng}$ \\
\hline 1,1-Dichloroethene & & 6 & 0 & ND & $10 \mathrm{ng}$ \\
\hline Carbon Disulfide & & 6 & 0 & ND & $10 \mathrm{ng}$ \\
\hline Acetone & & 6 & 0 & ND & $50 \mathrm{ng}$ \\
\hline Methylene Chloride & & 6 & 0 & ND & $10 \mathrm{ng}$ \\
\hline trans-1,2-Dichloroethene & & 6 & 0 & ND & $10 \mathrm{ng}$ \\
\hline 1,1-Dichloroethane & & 6 & 0 & ND & $10 \mathrm{ng}$ \\
\hline Vinyl Acetate & & 6 & 0 & ND & $50 \mathrm{ng}$ \\
\hline 2-Butanone & & 6 & 0 & ND & $50 \mathrm{ng}$ \\
\hline Chloroform & & 6 & 0 & ND & $10 \mathrm{ng}$ \\
\hline 1,1,1-Trichloroethane & & 6 & 0 & ND & $10 \mathrm{ng}$ \\
\hline Carbon Tetrachloride & & 6 & 0 & ND & $10 \mathrm{ng}$ \\
\hline Benzene & & 6 & 0 & ND & $10 \mathrm{ng}$ \\
\hline 1,2-Dichloroethane & & 6 & 0 & ND & $10 \mathrm{ng}$ \\
\hline Trichloroethene & & 6 & $\mathbf{0}$ & ND & $10 \mathrm{ng}$ \\
\hline 1,2-Dichloropropane & & 6 & 0 & ND & $10 \mathrm{ng}$ \\
\hline Bromodichloromethane & & 6 & 0 & ND & $10 \mathrm{ng}$ \\
\hline trans-1,3-Dichloropropene & & 6 & 0 & ND & $10 \mathrm{ng}$ \\
\hline 4-methyl-2-Pentanone & & 6 & 0 & ND & $50 \mathrm{ng}$ \\
\hline Toluene & & 6 & 0 & ND & $10 \mathrm{ng}$ \\
\hline cis-1,3-Dichloropropene & & 6 & 0 & ND & $10 \mathrm{ng}$ \\
\hline 1,1,2-Trichloroethane & & 6 & 0 & ND & $10 \mathrm{ng}$ \\
\hline Tetrachloroethene & & 6 & 0 & ND & $10 \mathrm{ng}$ \\
\hline 2-Hexanone & & 6 & 0 & ND & $50 \mathrm{ng}$ \\
\hline Dibromochloromethane & & 6 & 0 & ND & $10 \mathrm{ng}$ \\
\hline Chlorobenzene & & 6 & 0 & ND & $10 \mathrm{ng}$ \\
\hline Ethyl Benzene & & 6 & 0 & ND & $10 \mathrm{ng}$ \\
\hline m,p-Xylene & & 6 & 0 & ND & $10 \mathrm{ng}$ \\
\hline o-Xylene & & 6 & 0 & ND & $10 \mathrm{ng}$ \\
\hline Styrene & & 6 & 0 & ND & $10 \mathrm{ng}$ \\
\hline Bromoform & & 6 & 0 & ND & $10 \mathrm{ng}$ \\
\hline 1,1,2,2-Tetrachloroethane & & 6 & 0 & ND & $10 \mathrm{ng}$ \\
\hline 1,3-Dichlorobenzene & & 6 & 0 & ND & $10 \mathrm{ng}$ \\
\hline 1,4-Dichlorobenzene & & 6 & 0 & ND & $10 \mathrm{ng}$ \\
\hline 1,2-Dichlorobenzene & & 6 & 0 & ND & $10 \mathrm{ng}$ \\
\hline
\end{tabular}


Table D-1 (Continued)

\begin{tabular}{|c|c|c|c|c|}
\hline Analyte & $\begin{array}{c}\text { Number of } \\
\text { Blanks } \\
\text { Analyzed }\end{array}$ & $\begin{array}{c}\text { Number } \\
\text { of } \\
\text { Detects }\end{array}$ & $\begin{array}{c}\text { Range of } \\
\text { Compounds Detected }\end{array}$ & $\begin{array}{c}\text { Detection } \\
\text { Limit }\end{array}$ \\
\hline \multicolumn{5}{|c|}{$\begin{array}{l}\text { Field Blanks - Volatile Organic } \\
\text { Compounds in Stack Gas }\end{array}$} \\
\hline Chloromethane & 12 & 3 & $10-14 \mathrm{ng}$ & $10 \mathrm{ng}$ \\
\hline Vinyl Chloride & 12 & 0 & ND & $10 \mathrm{ng}$ \\
\hline Bromomethane & 12 & 0 & ND & $10 \mathrm{ng}$ \\
\hline Chloroethane & 12 & 0 & ND & $10 \mathrm{ng}$ \\
\hline Trichlorofluoromethane & 12 & 0 & ND & $10 \mathrm{ng}$ \\
\hline 1,1-Dichloroethene & 12 & 0 & ND & $10 \mathrm{ng}$ \\
\hline Carbon Disulfide & 12 & 0 & ND & $10 \mathrm{ng}$ \\
\hline Acetone & 12 & 0 & ND & $50 \mathrm{ng}$ \\
\hline Methylene Chloride & 12 & 3 & $48-230 \mathrm{ng}$ & $10 \mathrm{ng}$ \\
\hline trans-1,2-Dichloroethene & 12 & 0 & ND & $10 \mathrm{ng}$ \\
\hline 1,1-Dichloroethane & 12 & 0 & ND & $10 \mathrm{ng}$ \\
\hline Vinyl Acetate & 12 & 0 & ND & $50 \mathrm{ng}$ \\
\hline 2-Butanone & 12 & 0 & ND & $50 \mathrm{ng}$ \\
\hline Chloroform & 12 & 0 & ND & $10 \mathrm{ng}$ \\
\hline 1,1,1-Trichloroethane & 12 & 0 & ND & $10 \mathrm{ng}$ \\
\hline Carbon Tetrachloride & 12 & 0 & ND & $10 \mathrm{ng}$ \\
\hline Benzene & 12 & 0 & ND & $10 \mathrm{ng}$ \\
\hline 1,2-Dichloroethane & 12 & 0 & ND & $10 \mathrm{ng}$ \\
\hline Trichloroethene & 12 & 0 & ND & $10 \mathrm{ng}$ \\
\hline 1,2-Dichloropropane & 12 & 0 & ND & $10 \mathrm{ng}$ \\
\hline Bromodichloromethane & 12 & 0 & ND & $10 \mathrm{ng}$ \\
\hline trans-1,3-Dichloropropene & 12 & 0 & ND & $10 \mathrm{ng}$ \\
\hline 4-methyl-2-Pentanone & 12 & 0 & $\mathrm{ND}$ & $50 \mathrm{ng}$ \\
\hline Toluene & 12 & 1 & $37 \mathrm{ng}$ & $10 \mathrm{ng}$ \\
\hline cis-1,3-Dichloropropene & 12 & 0 & ND & $10 \mathrm{ng}$ \\
\hline 1,1,2-Trichloroethane & 12 & 0 & $\mathrm{ND}$ & $10 \mathrm{ng}$ \\
\hline Tetrachloroethene & 12 & 0 & ND & $10 \mathrm{ng}$ \\
\hline 2-Hexanone & 12 & 0 & ND & $50 \mathrm{ng}$ \\
\hline Dibromochloromethane & 12 & 0 & ND & $10 \mathrm{ng}$ \\
\hline Chlorobenzene & 12 & 0 & ND & $10 \mathrm{ng}$ \\
\hline Ethyl Benzene & 12 & 0 & ND & $10 \mathrm{ng}$ \\
\hline $\mathrm{m}, \mathrm{p}$-Xylene & 12 & 0 & ND & $10 \mathrm{ng}$ \\
\hline o-Xylene & 12 & 0 & ND & $10 \mathrm{ng}$ \\
\hline Styrene & 12 & 0 & ND & $10 \mathrm{ng}$ \\
\hline Bromoform & 12 & 0 & ND & $10 \mathrm{ng}$ \\
\hline 1,1,2,2-Tetrachloroethane & 12 & 0 & ND & $10 \mathrm{ng}$ \\
\hline
\end{tabular}


Table D-1 (Continued)

\begin{tabular}{|c|c|c|c|c|}
\hline Analyte & $\begin{array}{c}\text { Number of } \\
\text { Blanks } \\
\text { Analyzed }\end{array}$ & $\begin{array}{c}\text { Number } \\
\text { of } \\
\text { Detects }\end{array}$ & $\begin{array}{c}\text { Range of } \\
\text { Compounds Detected }\end{array}$ & $\begin{array}{l}\text { Detection } \\
\text { Limit }\end{array}$ \\
\hline 1,3-Dichlorobenzene & 12 & 0 & ND & $10 \mathrm{ng}$ \\
\hline 1,4-Dichlorobenzene & 12 & 0 & ND & $10 \mathrm{ng}$ \\
\hline 1,2-Dichlorobenzene & 12 & 0 & ND & $10 \mathrm{ng}$ \\
\hline \multicolumn{5}{|c|}{$\begin{array}{l}\text { Trip Blank - Volatile Organic } \\
\text { Compounds in Stack Gas }\end{array}$} \\
\hline Chloromethane & 1 & 0 & ND & $10 \mathrm{ng}$ \\
\hline Vinyl Chloride & 1 & 0 & ND & $10 \mathrm{ng}$ \\
\hline Bromomethane & 1 & 0 & $\mathrm{ND}$ & $10 \mathrm{ng}$ \\
\hline Chloroethane & 1 & 0 & ND & $10 \mathrm{ng}$ \\
\hline Trichlorofluoromethane & 1 & 0 & ND & $10 \mathrm{ng}$ \\
\hline 1,1-Dichloroethene & 1 & 0 & ND & $10 \mathrm{ng}$ \\
\hline Carbon Disulfide & 1 & 0 & ND & $10 \mathrm{ng}$ \\
\hline Acetone & 1 & 0 & ND & $50 \mathrm{ng}$ \\
\hline Methylene Chloride & 1 & 0 & ND & $10 \mathrm{ng}$ \\
\hline trans-1,2-Dichloroethene & 1 & 0 & ND & $10 \mathrm{ng}$ \\
\hline 1,1-Dichloroethane & 1 & $\overline{0}$ & ND & $10 \mathrm{ng}$ \\
\hline Vinyl Acetate & 1 & 0 & ND & $50 \mathrm{ng}$ \\
\hline 2-Butanone & 1 & 0 & ND & $50 \mathrm{ng}$ \\
\hline Chloroform & 1 & 0 & ND & $10 \mathrm{ng}$ \\
\hline 1,1,1-Trichloroethane & 1 & 0 & ND & $10 \mathrm{ng}$ \\
\hline Carbon Tetrachloride & 1 & 0 & ND & $10 \mathrm{ng}$ \\
\hline Benzene & 1 & 0 & ND & $10 \mathrm{ng}$ \\
\hline 1,2-Dichloroethane & 1 & 0 & ND & $10 \mathrm{ng}$ \\
\hline Trichloroethene & 1 & 0 & ND & $10 \mathrm{ng}$ \\
\hline 1,2-Dichloropropane & 1 & 0 & ND & $10 \mathrm{ng}$ \\
\hline Bromodichloromethane & 1 & 0 & ND & $10 \mathrm{ng}$ \\
\hline trans-1,3-Dichloropropene & 1 & 0 & ND & $10 \mathrm{ng}$ \\
\hline 4-methyl-2-Pentanone & 1 & 0 & ND & $50 \mathrm{ng}$ \\
\hline Toluene & 1 & 0 & ND & $10 \mathrm{ng}$ \\
\hline cis-1,3-Dichloropropene & 1 & 0 & ND & $10 \mathrm{ng}$ \\
\hline 1,1,2-Trichloroethane & 1 & 0 & ND & $10 \mathrm{ng}$ \\
\hline Tetrachloroethene & 1 & 0 & ND & $10 \mathrm{ng}$ \\
\hline 2-Hexanone & 1 & 0 & ND & $50 \mathrm{ng}$ \\
\hline Dibromochloromethane & 1 & 0 & ND & $10 \mathrm{ng}$ \\
\hline Chlorobenzene & 1 & 0 & ND & $10 \mathrm{ng}$ \\
\hline Ethyl Benzene & 1 & 0 & ND & $10 \mathrm{ng}$ \\
\hline m,p-Xylene & 1 & 0 & ND & $10 \mathrm{ng}$ \\
\hline o-Xylene & 1 & 0 & ND & $10 \mathrm{ng}$ \\
\hline
\end{tabular}


Table D-1 (Continued)

\begin{tabular}{|c|c|c|c|c|}
\hline Analyte & $\begin{array}{c}\text { Number of } \\
\text { Blanks } \\
\text { Analyzed }\end{array}$ & $\begin{array}{c}\text { Number } \\
\text { of } \\
\text { Detects }\end{array}$ & $\begin{array}{c}\text { Range of } \\
\text { Compounds Detected } \\
\end{array}$ & $\begin{array}{c}\text { Detection } \\
\text { Limit }\end{array}$ \\
\hline Styrene & 1 & 0 & ND & $10 \mathrm{ng}$ \\
\hline Bromoform & 1 & 0 & ND & $10 \mathrm{ng}$ \\
\hline 1,1,2,2-Tetrachloroethane & 1 & 0 & ND & $10 \mathrm{ng}$ \\
\hline 1,3-Dichlorobenzene & 1 & 0 & $\mathrm{ND}$ & $10 \mathrm{ng}$ \\
\hline 1,4-Dichlorobenzene & 1 & 0 & ND & $10 \mathrm{ng}$ \\
\hline 1,2-Dichlorobenzene & 1 & 0 & ND & $10 \mathrm{ng}$ \\
\hline \multicolumn{5}{|c|}{$\begin{array}{l}\text { Laboratory Method Blank - Semivolatile } \\
\text { Compounds in Stack Gas }\end{array}$} \\
\hline Acenaphthene & 2 & 0 & ND & $1.49-6.07 \mu \mathrm{g}$ \\
\hline Acenaphthylene & 2 & 0 & ND & $0.86-3.44 \mu \mathrm{g}$ \\
\hline Anthracene & 2 & 0 & $\mathrm{ND}$ & $0.96-3.54 \mu \mathrm{g}$ \\
\hline Benz(a)anthracene & 2 & 0 & ND & $1.16-3.12 \mu \mathrm{g}$ \\
\hline Benzo(b)fluoranthene & 2 & 0 & ND & $1.29-2.99 \mu \mathrm{g}$ \\
\hline Benzo(e)pyrene & 2 & 0 & ND & $1.38-3.33 \mu \mathrm{g}$ \\
\hline Benzo $(g, h, i)$ perylene & 2 & 0 & ND & $1.19-3.13 \mu \mathrm{g}$ \\
\hline Benzo(k)fluoranthene & 2 & 0 & ND & $1.40-3.19 \mu \mathrm{g}$ \\
\hline Benzoic Acid & 2 & 0 & ND & $5.18-43.22 \mu \mathrm{g}$ \\
\hline Benzyl alcohol & 2 & 0 & ND & $3.52-16.84 \mu \mathrm{g}$ \\
\hline 4-Bromophenylphenylether & 2 & 0 & ND & $5.06-19.08 \mu \mathrm{g}$ \\
\hline Butylbenzylphthalate & 2 & 0 & ND & $1.87-4.65 \mu \mathrm{g}$ \\
\hline 4-Chloro-3-methylphenol & 2 & 0 & ND & $2.76-11.21 \mu \mathrm{g}$ \\
\hline p-Chloroaniline & 2 & 0 & ND & $2.17-8.42 \mu \mathrm{g}$ \\
\hline bis(2-Chloroethoxy)methane & 2 & 0 & ND & $1.79-6.86 \mu \mathrm{g}$ \\
\hline bis(2-Chloroethyl)ether & 2 & 0 & ND & $2.18-8.62 \mu \mathrm{g}$ \\
\hline bis(2-Chloroisopropyl)ether & 2 & 0 & ND & $1.55-5.62 \mu \mathrm{g}$ \\
\hline 2-Chloronaphthalene & 2 & 0 & ND & $1.38-5.43 \mu \mathrm{g}$ \\
\hline 2-Chlorophenol & 2 & 0 & ND & $2.17-9.70 \mu \mathrm{g}$ \\
\hline 4-Chlorophenylphenylether & 2 & 0 & ND & $2.64-11.00 \mu \mathrm{g}$ \\
\hline Chrysene & 2 & 0 & ND & $1.23-3.36 \mu \mathrm{g}$ \\
\hline Di-n-butylphthalate & 2 & 1 & $1.47 \mu \mathrm{g}$ & $2.14 \mu \mathrm{g}$. \\
\hline Di-n-octylphthalate & 2 & 0 & ND & $1.07-2.02 \mu \mathrm{g}$ \\
\hline Dibenz(a,h)anthracene & 2 & 0 & ND & $1.34-3.73 \mu \mathrm{g}$ \\
\hline Dibenzofuran & 2 & 0 & ND & $1.00-3.94 \mu \mathrm{g}$ \\
\hline 1,2-Dichlorobenzene & 2 & 0 & ND & $2.18-9.25 \mu \mathrm{g}$ \\
\hline 1,3-Dichlorobenzene & 2 & 0 & ND & $2.08-8.85 \mu \mathrm{g}$ \\
\hline 1,4-Dichlorobenzene & 2 & 0 & ND & $2.03-8.61 \mu \mathrm{g}$ \\
\hline 3,3-Dichlorobenzidine & 2 & 0 & ND & $3.79-10.54 \mu \mathrm{g}$ \\
\hline 2,4-Dichlorophenol & 2 & 0 & ND & $2.75-11.73 \mu \mathrm{g}$ \\
\hline
\end{tabular}


Table D-1 (Continued)

\begin{tabular}{|c|c|c|c|c|}
\hline Analyte & $\begin{array}{c}\text { Number of } \\
\text { Blanks } \\
\text { Analyzed } \\
\end{array}$ & $\begin{array}{c}\text { Number } \\
\text { of } \\
\text { Detects }\end{array}$ & $\begin{array}{c}\text { Range of } \\
\text { Compounds Detected }^{\mathrm{a}}\end{array}$ & $\begin{array}{l}\text { Detection } \\
\text { Limit }\end{array}$ \\
\hline Diethylphthalate & 2 & 0 & ND & $1.15-4.65 \mu \mathrm{g}$ \\
\hline 2,4-Dimethylphenol & 2 & 0 & ND & $2.51-10.77 \mu \mathrm{g}$ \\
\hline Dimethylphthalate & 2 & 0 & ND & $1.26-5.01 \mu \mathrm{g}$ \\
\hline 4,6-Dinitro-2-methylphenol & 2 & 0 & ND & $7.84-29.52 \mu \mathrm{g}$ \\
\hline 2,4-Dinitrophenol & 2 & 0 & ND & $11.06-50.58 \mu \mathrm{g}$ \\
\hline 2,4-Dinitrotoluene & 2 & 0 & ND & $3.59-14.20 \mu \mathrm{g}$ \\
\hline 2,6-Dinitrotoluene & 2 & 0 & ND & $4.96-19.61 \mu \mathrm{g}$ \\
\hline Diphenylamine/N-Nitroso DPA & 2 & 0 & ND & $2.18-8.13 \mu \mathrm{g}$ \\
\hline bis(2-Ethylhexyl)phthalate & 2 & 1 & $0.90 \mu \mathrm{g}$ & $3.43 \mu \mathrm{g}$ \\
\hline Fluoranthene & 2 & 0 & ND & $0.76-2.72 \mu \mathrm{g}$ \\
\hline Fluorene & 2 & 0 & ND & $1.29-5.11 \mu \mathrm{g}$ \\
\hline Hexachlorobenzene & 2 & 0 & ND & $3.58-13.40 \mu \mathrm{g}$ \\
\hline Hexachlorobutadiene & 2 & 0 & ND & $4.45-18.56 \mu \mathrm{g}$ \\
\hline Hexachlorocyclopentadiene & 2 & 0 & ND & $6.52-23.24 \mu \mathrm{g}$ \\
\hline Hexachloroethane & 2 & 0 & ND & $4.21-16.31 \mu \mathrm{g}$ \\
\hline Indeno(1,2,3)pyrene & 2 & 0 & ND & $1.02-2.80 \mu \mathrm{g}$ \\
\hline Isophorone & 2 & 0 & ND & $1.12-4.32 \mu \mathrm{g}$ \\
\hline 2-Methylnaphthalene & 2 & 0 & ND & $1.39-5.63 \mu \mathrm{g}$ \\
\hline 4-Methylphenol/3-Methylphenol & 2 & 0 & ND & $2.29-10.07 \mu \mathrm{g}$ \\
\hline 2-Methylphenol & 2 & 0 & ND & $2.39-10.44 \mu \mathrm{g}$ \\
\hline N-Nitrosodipropylamine & 2 & 0 & ND & $3.14-12.39 \mu \mathrm{g}$ \\
\hline Naphthalene & 2 & 1 & $4.77 \mu \mathrm{g}$ & $0.87 \mu g$ \\
\hline 2-Nitroaniline & 2 & 0 & ND & $3.61-13.26 \mu g$ \\
\hline 3-Nitroaniline & 2 & 0 & ND & $4.45-17.05 \mu \mathrm{g}$ \\
\hline 4-Nitroaniline & 2 & 0 & ND & $3.81-14.86 \mu \mathrm{g}$ \\
\hline Nitrobenzene & 2 & 0 & ND & $1.98-7.27 \mu \mathrm{g}$ \\
\hline 2-Nitrophenol & 2 & 0 & ND & $4.17-16.67 \mu \mathrm{g}$ \\
\hline 4-Nitrophenol & 2 & 0 & ND & $7.74-31.19 \mu \mathrm{g}$ \\
\hline Pentachlorophenol & 2 & 0 & ND & $7.40-47.23 \mu \mathrm{g}$ \\
\hline Phenanthrene & 2 & 0 & $\mathrm{ND}$ & $0.97-3.52 \mu \mathrm{g}$ \\
\hline Phenol & 2 & 0 & ND & $1.62-6.97 \mu \mathrm{g}$ \\
\hline Pyrene. & 2 & 0 & ND & $1.08-2.90 \mu \mathrm{g}$ \\
\hline 1,2,4-Trichlorobenzene & 2 & 0 & ND & $2.50-10.01 \mu \mathrm{g}$ \\
\hline 2,4,5-Trichlorophenol & 2 & 0 & ND & $3.56-14.79 \mu \mathrm{g}$ \\
\hline 2,4,6-Trichlorophenol & 2 & 0 & ND & $3.79-16.54 \mu \mathrm{g}$ \\
\hline
\end{tabular}


Table D-1 (Continued)

\begin{tabular}{|c|c|c|c|c|}
\hline Analyte & $\begin{array}{l}\text { Number of } \\
\text { Blanks } \\
\text { Analyzed }\end{array}$ & $\begin{array}{c}\text { Number } \\
\text { of } \\
\text { Detects }\end{array}$ & $\begin{array}{c}\text { Range of } \\
\text { Compounds Detected }\end{array}$ & $\begin{array}{c}\text { Detection } \\
\text { Limit }\end{array}$ \\
\hline \multicolumn{5}{|c|}{$\begin{array}{l}\text { Field Blanks - Semivolatile Compounds } \\
\text { in Stack Gas }\end{array}$} \\
\hline Acenaphthene & 4 & 0 & ND & $6.20-7.31 \mu \mathrm{g}$ \\
\hline Acenaphthylene & 4 & 0 & ND & $3.51-4.14 \mu \mathrm{g}$ \\
\hline Anthracene & 4 & 0 & ND & $3.71-4.34 \mu \mathrm{g}$ \\
\hline Benz(a)anthracene & 4 & 0 & ND & $2.91-3.36 \mu \mathrm{g}$ \\
\hline Benzo(b)fluoranthene & 4 & 0 & ND & $2.75-3.12 \mu \mathrm{g}$ \\
\hline Benzo(e)pyrene & 4 & 0 & ND & $3.06-3.47 \mu g$ \\
\hline Benzo $(\mathrm{g}, \mathrm{h}, \mathrm{i})$ perylene & 4 & 0 & ND & $2.87-3.26 \mu \mathrm{g}$ \\
\hline Benzo(k)fluoranthene & 4 & 0 & $\mathrm{ND}$ & $2.93-3.32 \mu \mathrm{g}$ \\
\hline Benzoic Acid & 4 & 0 & ND & $43.48-50.08 \mu \mathrm{g}$ \\
\hline Benzyl alcohol & 4 & 0 & ND & $17.21-19.54 \mu \mathrm{g}$ \\
\hline 4-Bromophenylphenylether & 4 & 0 & ND & $20.00-23.42 \mu \mathrm{g}$ \\
\hline Butylbenzylphthalate & 4 & 0 & $\mathrm{ND}$ & $4.34-5.00 \mu \mathrm{g}$ \\
\hline 4-Chloro-3-methylphenol & 4 & 0 & $\overline{N D}$ & $11.28-12.99 \mu \mathrm{g}$ \\
\hline p-Chloroaniline & 4 & 0 & ND & $8.47-9.76 \mu \mathrm{g}$ \\
\hline bis(2-Chloroethoxy)methane & 4 & 0 & ND & $6.90-7.95 \mu \mathrm{g}$ \\
\hline bis(2-Chloroethyl)ether & 4 & 0 & ND & $8.80-10.0 \mu \mathrm{g}$ \\
\hline bis(2-Chloroisopropyl)ether & 4 & 0 & ND & $5.74-6.52 \mu \mathrm{g}$ \\
\hline 2-Chloronaphthalene & 4 & 0 & $\mathrm{ND}$ & $5.54-6.53 \mu \mathrm{g}$ \\
\hline 2-Chlorophenol & 4 & 0 & $\mathrm{ND}$ & $9.91-11.26 \mu \mathrm{g}$ \\
\hline 4-Chlorophenylphenylether & 4 & 0 & ND & $11.23-13.24 \mu \mathrm{g}$ \\
\hline Chrysene & 4 & 0 & ND & $3.13-3.62 \mu \mathrm{g}$ \\
\hline Di-n-butylphthalate & 4 & 4 & $5.08-10.97 \mu \mathrm{g}$ & - \\
\hline Di-n-octylphthalate & 4 & 0 & $\mathrm{ND}$ & $1.85-2.10 \mu \mathrm{g}$ \\
\hline Dibenz $(a, h)$ anthracene & 4 & 0 & ND & $3.42-3.88 \mu \mathrm{g}$ \\
\hline Dibenzofuran & 4 & 0 & ND & $4.02-4.74 \mu \mathrm{g}$ \\
\hline 1,2-Dichlorobenzene & 4 & 0 & ND & $9.45-10.74 \mu \mathrm{g}$ \\
\hline 1,3-Dichlorobenzene & 4 & 0 & ND & $9.04-10.27 \mu \mathrm{g}$ \\
\hline 1,4-Dichlorobenzene & 4 & 0 & ND & $8.79-9.99 \mu \mathrm{g}$ \\
\hline 3,3-Dichlorobenzidine & 4 & 0 & ND & $9.84-11.35 \mu \mathrm{g}$ \\
\hline 2,4-Dichlorophenol & 4 & 0 & ND & $11.80-13.59 \mu \mathrm{g}$ \\
\hline Diethylphthalate & 4 & 0 & ND & $4.75-5.60 \mu \mathrm{g}$ \\
\hline 2,4-Dimethylphenol & 4 & 0 & ND & $10.84-12.48 \mu \mathrm{g}$ \\
\hline Dimethylphthalate & 4 & 0 & ND & $5.11-6.02 \mu \mathrm{g}$ \\
\hline 4,6-Dinitro-2-methylphenol & 4 & 0 & ND & $30.94-36.22$ \\
\hline 2,4-Dinitrophenol & 4 & 0 & ND & $51.62-60.84 \mu \mathrm{g}$ \\
\hline 2,4-Dinitrotoluene & 4 & 0 & ND & $14.49-17.08 \mu \mathrm{g}$ \\
\hline
\end{tabular}


Table D-1 (Continued)

\begin{tabular}{|c|c|c|c|c|}
\hline Analyte & \begin{tabular}{|c|} 
Number of \\
Blanks \\
Analyzed \\
\end{tabular} & $\begin{array}{c}\text { Number } \\
\text { of } \\
\text { Detects }\end{array}$ & $\begin{array}{c}\text { Range of } \\
\text { Compounds Detected }\end{array}$ & $\begin{array}{l}\text { Detection } \\
\text { Limit } \\
\end{array}$ \\
\hline 2,6-Dinitrotoluene & 4 & 0 & ND & $20.01-23.58 \mu \mathrm{g}$ \\
\hline Diphenylamine/N-Nitroso DPA & 4 & 0 & ND & $8.52-9.97 \mu \mathrm{g}$ \\
\hline bis(2-Ethylhexyl)phthalate & 4 & 2 & $2.54-3.51$ & $3.40-3.69 \mu \mathrm{g}$ \\
\hline Fluoranthene & 4 & 0 & ND & $2.85-3.34 \mu \mathrm{g}$ \\
\hline Fluorene & 4 & 0 & ND & $5.22-6.15 \mu \mathrm{g}$ \\
\hline Hexachlorobenzene & 4 & 0 & ND & $14.04-16.44 \mu \mathrm{g}$ \\
\hline Hexachlorobutadiene & 4 & 0 & ND & $18.67-21.50 \mu \mathrm{g}$ \\
\hline Hexachlorocyclopentadiene & 4 & 0 & ND & $23.72-27.96 \mu \mathrm{g}$ \\
\hline Hexachloroethane & 4 & 0 & ND & $16.66-18.92 \mu \mathrm{g}$ \\
\hline Indeno $(1,2,3)$ pyrene & 4 & 0 & ND & $2.57-2.91 \mu \mathrm{g}$ \\
\hline Isophorone & 4 & 0 & ND & $4.34-5.00 \mu \mathrm{g}$ \\
\hline 2-Methylnaphthalene & 4 & 0 & ND & $5.67-6.53 \mu \mathrm{g}$ \\
\hline 4-Methylphenol/3-Methylphenol & 4 & 0 & ND & $10.29-11.69 \mu \mathrm{g}$ \\
\hline 2-Methylphenol & 4 & 0 & ND & $10.66-12.11 \mu \mathrm{g}$ \\
\hline N-Nitrosodipropylamine & 4 & 0 & ND & $12.66-14.38 \mu \mathrm{g}$ \\
\hline Naphtbalene & 4 & 1 & $31.39 \mu \mathrm{g}$ & $3.52-4.05 \mu \mathrm{g}$ \\
\hline 2-Nitroaniline & 4 & 0 & ND & $13.53-15.95 \mu \mathrm{g}$ \\
\hline 3-Nitroaniline & 4 & 0 & ND & $17.40-20.51 \mu \mathrm{g}$ \\
\hline 4-Nitroaniline & 4 & 0 & ND & $15.17-17.88 \mu \mathrm{g}$ \\
\hline Nitrobenzene & 4 & 0 & ND & $7.31-8.42 \mu \mathrm{g}$ \\
\hline 2-Nitrophenol & 4 & 0 & ND & $16.78-19.32 \mu \mathrm{g}$ \\
\hline 4-Nitrophenol & 4 & 0 & ND & $31.83-37.52 \mu \mathrm{g}$ \\
\hline Pentachlorophenol & 4 & 0 & ND & $49.50-57.96 \mu \mathrm{g}$ \\
\hline Phenanthrene & 4 & 0 & ND & $3.69-4.33 \mu \mathrm{g}$ \\
\hline Phenol & 4 & 0 & ND & $7.12-8.09 \mu \mathrm{g}$ \\
\hline Pyrene & 4 & 0 & ND & $2.71-3.12 \mu \mathrm{g}$ \\
\hline 1,2,4-Trichlorobenzene & 4 & 0 & ND & $10.08-11.60 \mu \mathrm{g}$ \\
\hline 2,4,5-Trichlorophenol & 4 & 0 & ND & $15.09-17.79 \mu \mathrm{g}$ \\
\hline 2,4,6-Trichlorophenol & 4 & 0 & ND & $16.87-19.89 \mu \mathrm{g}$ \\
\hline \multicolumn{5}{|c|}{$\begin{array}{l}\text { Trip Blank - Semirolatile Compounds in } \\
\text { Stack Gas }\end{array}$} \\
\hline Acenaphthene & 1. & 0 & ND & $3.96 \mu \mathrm{g}$ \\
\hline Acenaphthylene & 1 & 0 & ND & $2.25 \mu \mathrm{g}$ \\
\hline Anthracene & 1 & 0 & ND & $2.18 \mu \mathrm{g}$ \\
\hline Benz(a)anthracene & 1 & 0 & ND & $1.53 \mu \mathrm{g}$ \\
\hline Benzo(b)fluoranthene & 1 & 0 & ND & $1.52 \mu \mathrm{g}$ \\
\hline Benzo(e)pyrene & 1 & 0 & ND & $1.66 \mu \mathrm{g}$ \\
\hline Benzo(g,h,i)perylene & 1 & 0 & ND & $1.59 \mu \mathrm{g}$ \\
\hline
\end{tabular}


Table D-1 (Continued)

\begin{tabular}{|c|c|c|c|c|}
\hline Analyte & $\begin{array}{l}\text { Number of } \\
\text { Blanks } \\
\text { Analyzed }\end{array}$ & $\begin{array}{c}\text { Number } \\
\text { of } \\
\text { Detects }\end{array}$ & $\begin{array}{c}\text { Range of } \\
\text { Compounds Detected }\end{array}$ & $\begin{array}{l}\text { Detection } \\
\text { Limit }\end{array}$ \\
\hline Benzo(k)fluoranthene & 1 & 0 & ND & $1.56 \mu \mathrm{g}$ \\
\hline Benzoic Acid & 1 & 0 & ND & $21.82 \mu \mathrm{g}$ \\
\hline Benzyl alcohol & 1 & 0 & ND & $10.57 \mu \mathrm{g}$ \\
\hline 4-Bromophenylphenylether & 1 & 0 & ND & $10.36 \mu \mathrm{g}$ \\
\hline Butylbenzylphthalate & 1 & 0 & ND & $2.73 \mu \mathrm{g}$ \\
\hline 4-Chloro-3-methylphenol & 1 & 0 & $\mathrm{ND}$ & $7.99 \mu \mathrm{g}$ \\
\hline p-Chloroaniline & 1 & 0 & ND & $5.48 \mu \mathrm{g}$ \\
\hline bis(2-Chloroethoxy)methane & 1 & $\mathbf{0}$ & ND & $5.40 \mu \mathrm{g}$ \\
\hline bis(2-Chloroethyl)ether & 1 & 0 & ND & $6.32 \mu \mathrm{g}$ \\
\hline bis(2-Chloroisopropyl)ether & 1 & $\mathbf{0}$ & ND & $4.82 \mu \mathrm{g}$ \\
\hline 2-Chloronaphthalene & 1 & $\mathbf{0}$ & ND & $3.54 \mu \mathrm{g}$ \\
\hline 2-Chlorophenol & 1 & 0 & ND & $5.70 \mu \mathrm{g}$ \\
\hline 4-Chlorophenylphenylether & 1 & 0 & ND & $6.62 \mu \mathrm{g}$ \\
\hline Chrysene & 1 & 0 & ND & $1.64 \mu \mathrm{g}$ \\
\hline Di-n-butylphthalate & 1 & 1 & $7.32 \mu \mathrm{g}$ & - \\
\hline Di-n-octylphthalate & 1 & $\mathbf{0}$ & ND & $1.17 \mu \mathrm{g}$ \\
\hline Dibenz(a,h)anthracene & 1 & $\mathbf{0}$ & ND & $1.88 \mu \mathrm{g}$ \\
\hline Dibenzofuran & 1 & 0 & $\mathrm{ND}$ & $2.56 \mu \mathrm{g}$ \\
\hline 1,2-Dichlorobenzene & 1 & 0 & ND & $5.65 \mu \mathrm{g}$ \\
\hline 1,3-Dichlorobenzene & 1 & 0 & ND & $5.35 \mu \mathrm{g}$ \\
\hline 1,4-Dichlorobenzene & 1 & 0 & ND & $5.20 \mu \mathrm{g}$ \\
\hline 3,3-Dichlorobenzidine & 1 & 0 & ND & $5.10 \mu \mathrm{g}$ \\
\hline 2,4-Dichlorophenol & 1 & 0 & ND & $7.25 \mu \mathrm{g}$ \\
\hline Diethylphthalate & 1 & 0 & ND & $3.05 \mu \mathrm{g}$ \\
\hline 2,4-Dimethylphenol & 1 & 0 & ND & $7.07 \mu \mathrm{g}$ \\
\hline Dimethylphthalate & 1 & $\mathbf{0}$ & ND & $3.32 \mu \mathrm{g}$ \\
\hline 4,6-Dinitro-2-methylphenol & 1 & 0 & ND & $14.95 \mu \mathrm{g}$ \\
\hline 2,4-Dinitrophenol & 1 & 0 & ND & $26.89 \mu \mathrm{g}$ \\
\hline 2,4-Dinitrotoluene & 1 & 0 & $\overline{\mathrm{ND}}$ & $8.79 \mu \mathrm{g}$ \\
\hline 2,6-Dinitrotoluene & 1 & 0 & ND & $12.73 \mu \mathrm{g}$ \\
\hline Diphenylamine/N-Nitroso DPA & 1 & 0 & ND & $5.33 \mu \mathrm{g}$ \\
\hline bis(2-Ethylhexyl)phthalate & 1 & 0 & $11.13 \mu \mathrm{g}$ & - \\
\hline Fluoranthene & 1 & 0 & ND & $1.54 \mu \mathrm{g}$ \\
\hline Fluorene & 1 & $\overline{0}$ & ND & $3.40 \mu \mathrm{g}$ \\
\hline Hexachlorobenzene & 1 & 0 & $\overline{N D}$ & $7.42 \mu \mathrm{g}$ \\
\hline Hexachlorobutadiene & 1 & 0 & ND & $10.46 \mu \mathrm{g}$ \\
\hline Hexachlorocyclopentadiene & $\overline{1}$ & 0 & ND & $12.17 \mu \mathrm{g}$ \\
\hline Hexachloroethane & 1 & 0 & ND & $11.17 \mu \mathrm{g}$ \\
\hline
\end{tabular}


Table D-1 (Continued)

\begin{tabular}{|c|c|c|c|c|}
\hline Analyte & $\begin{array}{c}\text { Number of } \\
\text { Blanks } \\
\text { Analyzed }\end{array}$ & $\begin{array}{c}\text { Number } \\
\text { of } \\
\text { Detects }\end{array}$ & $\begin{array}{c}\text { Range of } \\
\text { Compounds Detected }\end{array}$ & $\begin{array}{l}\text { Detection } \\
\text { Limit }\end{array}$ \\
\hline Indeno $(1,2,3)$ pyrene & 1 & $\mathbf{0}$ & ND & $1.39 \mu \mathrm{g}$ \\
\hline Isophorone & 1 & $\mathbf{0}$ & ND & $3.54 \mu \mathrm{g}$ \\
\hline 2-Methylnaphthalene & 1 & 0 & $\mathrm{ND}$ & $3.62 \mu \mathrm{g}$ \\
\hline 4-Methylphenol/3-Methylphenol & 1 & $\mathbf{0}$ & ND & $6.41 \mu \mathrm{g}$ \\
\hline 2-Methylphenol & 1 & $\mathbf{0}$ & ND & $6.89 \mu \mathrm{g}$ \\
\hline N-Nitrosodipropylamine & 1 & 0 & ND & $9.96 \mu \mathrm{g}$ \\
\hline Naphthalene & 1 & 0 & ND & $2.28 \mu \mathrm{g}$ \\
\hline 2-Nitroaniline & 1 & 0 & ND & $11.19 \mu \mathrm{g}$ \\
\hline 3-Nitroaniline & 1 & 0 & ND & $10.92 \mu \mathrm{g}$ \\
\hline 4-Nitroaniline & 1 & 0 & ND & $9.64 \mu \mathrm{g}$ \\
\hline Nitrobenzene & 1 & 0 & ND & $6.07 \mu \mathrm{g}$ \\
\hline 2-Nitrophenol & 1 & $\mathbf{0}$ & $\mathrm{ND}$ & $10.79 \mu \mathrm{g}$ \\
\hline 4-Nitrophenol & 1 & 0 & $\mathrm{ND}$ & $23.71 \mu \mathrm{g}$ \\
\hline Pentachlorophenol & 1 & 0 & $\mathrm{ND}$ & $18.79 \mu \mathrm{g}$ \\
\hline Phenanthrene & 1 & 0 & ND & $2.23 \mu \mathrm{g}$ \\
\hline Phenol & 1 & $\mathbf{0}$ & $\mathrm{ND}$ & $4.73 \mu \mathrm{g}$ \\
\hline Pyrene & 1 & 0 & ND & $1.57 \mu \mathrm{g}$ \\
\hline 1,2,4-Trichlorobenzene & 1 & 0 & ND & $6.46 \mu \mathrm{g}$ \\
\hline 2,4,5-Trichlorophenol & 1 & 0 & ND & $9.43 \mu \mathrm{g}$ \\
\hline 2,4,6-Trichlorophenol & 1 & 0 & ND & $9.82 \mu \mathrm{g}$ \\
\hline \multicolumn{5}{|c|}{$\begin{array}{l}\text { Laboratory Method Blank - Semivolatile } \\
\text { Compounds in Ash }\end{array}$} \\
\hline Acenaphthene & 1 & 0 & ND & $0.0161 \mu \mathrm{g} / \mathrm{g}$ \\
\hline Acenaphthylene & 1 & 0 & ND & $0.0219 \mu \mathrm{g} / \mathrm{g}$ \\
\hline Anthracene & 1 & 0 & ND & $0.0180 \mu \mathrm{g} / \mathrm{g}$ \\
\hline Benz(a)anthracene & 1 & 0 & ND & $0.0116 \mu \mathrm{g} / \mathrm{g}$ \\
\hline Benz(a)pyrene & 1 & 0 & ND & $0.0180 \mu \mathrm{g} / \mathrm{g}$ \\
\hline Benzo(b)fluoranthene & 1 & 0 & ND & $0.0320 \mu \mathrm{g} / \mathrm{g}$ \\
\hline Benzo(g,h,i)perylene & 1 & 0 & $\mathrm{ND}$ & $0.0185 \mu \mathrm{g} / \mathrm{g}$ \\
\hline Benzo(k)fluoranthene & 1 & $\mathbf{0}$ & $\mathrm{ND}$ & $0.0273 \mu \mathrm{g} / \mathrm{g}$ \\
\hline Benzoic Acid & 1 & 0 & $\mathrm{ND}$ & $0.0997 \mu \mathrm{g} / \mathrm{g}$ \\
\hline Benzyl alcohol & 1 & 0 & ND & $0.0480 \mu \mathrm{g} / \mathrm{g}$ \\
\hline 4-Bromophenylphenylether & 1 & 0 & $\widehat{N D}$ & $0.0203 \mu \mathrm{g} / \mathrm{g}$ \\
\hline Butylbenzylphthalate & 1 & 0 & ND & $0.0250 \mu \mathrm{g} / \mathrm{g}$ \\
\hline 4-Chloro-3-methylphenol & 1 & 0 & ND & $0.0153 \mu \mathrm{g} / \mathrm{g}$ \\
\hline p-Chloroaniline & 1 & 0 & ND & $0.0327 \mu \mathrm{g} / \mathrm{g}$ \\
\hline bis(2-Chloroethoxy)methane & 1 & 0 & ND & $0.0111 \mu \mathrm{g} / \mathrm{g}$ \\
\hline bis(2-Chloroethyl)ether & 1 & 0 & ND & $0.0155 \mu \mathrm{g} / \mathrm{g}$ \\
\hline
\end{tabular}


Table D-1 (Continued)

\begin{tabular}{|c|c|c|c|c|}
\hline Analyte & $\begin{array}{c}\text { Number of } \\
\text { Blanks } \\
\text { Analyzed }\end{array}$ & $\begin{array}{c}\text { Number } \\
\text { of } \\
\text { Detects }\end{array}$ & $\begin{array}{c}\text { Range of } \\
\text { Compounds Detected }\end{array}$ & $\begin{array}{l}\text { Detection } \\
\text { Limit }\end{array}$ \\
\hline bis(2-Chloroisopropyl)ether & 1 & 0 & ND & $0.0190 \mu \mathrm{g} / \mathrm{g}$ \\
\hline 2-Chloronaphthalene & 1 & 0 & ND & $0.0300 \mu \mathrm{g} / \mathrm{g}$ \\
\hline 2-Chlorophenol & 1 & 0 & ND & $0.0109 \mu \mathrm{g} / \mathrm{g}$ \\
\hline 4-Chlorophenylphenylether & 1 & 0 & ND & $0.0244 \mu \mathrm{g} / \mathrm{g}$ \\
\hline Chrysene & 1 & 0 & $\mathrm{ND}$ & $0.0195 \mu \mathrm{g} / \mathrm{g}$ \\
\hline Di-n-butylphthalate & 1 & 0 & ND & $0.0103 \mu \mathrm{g} / \mathrm{g}$ \\
\hline Di-n-octylphthalate & 1 & 0 & ND & $0.0194 \mu \mathrm{g} / \mathrm{g}$ \\
\hline Dibenz(a,h)anthracene & 1 & 0 & ND & $0.0228 \mu \mathrm{g} / \mathrm{g}$ \\
\hline Dibenzofuran & 1 & 0 & ND & $0.0130 \mu \mathrm{g} / \mathrm{g}$ \\
\hline 1,2-Dichlorobenzene & 1 & 0 & ND & $0.0214 \mu \mathrm{g} / \mathrm{g}$ \\
\hline 1,3-Dichlorobenzene & 1 & 0 & ND & $0.0237 \mu \mathrm{g} / \mathrm{g}$ \\
\hline 1,4-Dichlorobenzene & 1 & 0 & ND & $0.0236 \mu \mathrm{g} / \mathrm{g}$ \\
\hline 3,3-Dichlorobenzidine & 1 & 0 & ND & $0.0363 \mu \mathrm{g} / \mathrm{g}$ \\
\hline 2,4-Dichlorophenol & 1 & 0 & ND & $0.0194 \mu \mathrm{g} / \mathrm{g}$ \\
\hline Diethylphthalate & 1 & 0 & ND & $0.0123 \mu \mathrm{g} / \mathrm{g}$ \\
\hline 2,4-Dimethylphenol & 1 & 0 & ND & $0.0423 \mu \mathrm{g} / \mathrm{g}$ \\
\hline Dimethylphthalate & 1 & 0 & ND & $0.0157 \mu \mathrm{g} / \mathrm{g}$ \\
\hline 4,6-Dinitro-2-methylphenol & 1 & 0 & ND & $0.0244 \mu \mathrm{g} / \mathrm{g}$ \\
\hline 2,4-Dinitrophenol & 1 & 0 & ND & $0.0863 \mu \mathrm{g} / \mathrm{g}$ \\
\hline 2,4-Dinitrotoluene & 1 & 0 & ND & $0.0256 \mu \mathrm{g} / \mathrm{g}$ \\
\hline 2,6-Dinitrotoluene & 1 & 0 & ND & $0.0350 \mu \mathrm{g} / \mathrm{g}$ \\
\hline Diphenylamine/N-Nitroso DPA & 1 & 0 & ND & $0.0255 \mu \mathrm{g} / \mathrm{g}$ \\
\hline bis(2-Ethylhexyl)phthalate & 1 & 0 & ND & $0.0547 \mu \mathrm{g} / \mathrm{g}$ \\
\hline Fluoranthene & 1 & 0 & ND & $0.0142 \mu \mathrm{g} / \mathrm{g}$ \\
\hline Fluorene & 1 & 0 & ND & $0.0115 \mu \mathrm{g} / \mathrm{g}$ \\
\hline Hexachlorobenzene & 1 & 0 & ND & $0.0176 \mu \mathrm{g} / \mathrm{g}$ \\
\hline Hexachlorobutadiene & 1 & 0 & ND & $0.0219 \mu \mathrm{g} / \mathrm{g}$ \\
\hline Hexachlorocyclopentadiene & 1 & 0 & ND & $0.0547 \mu \mathrm{g} / \mathrm{g}$ \\
\hline Hexachloroethane & $i$ & 0 & ND & $0.0333 \mu \mathrm{g} / \mathrm{g}$ \\
\hline Indeno $(1,2,3)$ pyrene & 1 & 0 & $\mathrm{ND}$ & $0.0160 \mu \mathrm{g} / \mathrm{g}$ \\
\hline Isophorone & 1 & 0 & ND & $0.0101 \mu \mathrm{g} / \mathrm{g}$ \\
\hline 2-methylnaphthalene & 1 & 0 & ND & $0.0202 \mu \mathrm{g} / \mathrm{g}$ \\
\hline 4-Methylphenol/3-Methylphenol & 1 & $\overline{0}$ & $\mathrm{ND}$ & $0.0413 \mu \mathrm{g} / \mathrm{g}$ \\
\hline 2-Methylphenol & 1 & 0 & ND & $0.0263 \mu \mathrm{g} / \mathrm{g}$ \\
\hline N-Nitrosodipropylamine & 1 & 0 & ND & $0.0262 \mu \mathrm{g} / \mathrm{g}$ \\
\hline Naphthalene & 1 & 0 & $\mathrm{ND}$ & $0.0223 \mu \mathrm{g} / \mathrm{g}$ \\
\hline 2-Nitroaniline & 1 & 0 & ND & $0.0266 \mu \mathrm{g} / \mathrm{g}$ \\
\hline 3-Nitroaniline & 1 & 0 & ND & $0.0107 \mu \mathrm{g} / \mathrm{g}$ \\
\hline
\end{tabular}


Table D-1 (Continued)

\begin{tabular}{|c|c|c|c|c|}
\hline Analyte & $\begin{array}{l}\text { Number of } \\
\text { Blanks } \\
\text { Analyzed }\end{array}$ & $\begin{array}{c}\text { Number } \\
\text { of } \\
\text { Detects }\end{array}$ & $\begin{array}{c}\text { Range of } \\
\text { Compounds Detected }\end{array}$ & $\begin{array}{l}\text { Detection } \\
\text { Limit }\end{array}$ \\
\hline 4-Nitroaniline & 1 & 0 & ND & $0.0200 \mu \mathrm{g} / \mathrm{g}$ \\
\hline Nitrobenzene & 1 & 0 & ND & $0.0130 \mu \mathrm{g} / \mathrm{g}$ \\
\hline 2-Nitrophenol & 1 & 0 & ND & $0.0142 \mu \mathrm{g} / \mathrm{g}$ \\
\hline 4-Nitrophenol & 1 & 0 & ND & $0.0210 \mu \mathrm{g} / \mathrm{g}$ \\
\hline Pentachlorophenol & 1 & 0 & ND & $0.00640 \mu \mathrm{g} / \mathrm{g}$ \\
\hline Phenanthrene & 1 & 0 & ND & $0.0185 \mu \mathrm{g} / \mathrm{g}$ \\
\hline Phenol & 1 & 0 & ND & $0.0337 \mu \mathrm{g} / \mathrm{g}$ \\
\hline Pyrene & 1 & 0 & ND & $0.0154 \mu \mathrm{g} / \mathrm{g}$ \\
\hline 1,2,4-Trichlorobenzene & 1 & 0 & ND & $0.00640 \mu \mathrm{g} / \mathrm{g}$ \\
\hline 2,4,5-Trichlorophenol & 1 & 0 & ND & $0.0195 \mu \mathrm{g} / \mathrm{g}$ \\
\hline 2,4,6-Trichlorophenol & 1 & 0 & ND & $0.0162 \mu \mathrm{g} / \mathrm{g}$ \\
\hline \multicolumn{5}{|c|}{$\begin{array}{l}\text { Laboratory Method Blank - PAHs in } \\
\text { Stack Gas }\end{array}$} \\
\hline Naphthalene & 2 & 2 & $43.1-115 \mathrm{ng}$ & - \\
\hline 2-Methylnaphthalene & 2 & 2 & $12.6-210 \mathrm{ng}$ & - \\
\hline Acenaphthene & 2 & 2 & $2.1-309 \mathrm{ng}$ & - \\
\hline 2-Chloronaphthalene & 2 & 0 & ND & $0.07-0.09 \mathrm{ng}$ \\
\hline Acenaphthylene & 2 & 2 & $0.69-2.6 \mathrm{ng}$ & - \\
\hline Fluorene & 2 & 2 & $8.3-86.8 \mathrm{ng}$ & - \\
\hline Phenanthrene & 2 & 2 & $33.4-59.6 \mathrm{ng}$ & - \\
\hline Anthracene & 2 & 2 & $1.5-1.6 \mathrm{ng}$ & - \\
\hline Fluoranthene & 2 & 2 & $5.5-11.4 \mathrm{ng}$ & - \\
\hline Pyrene & 2 & 2 & 4.7-13.3 ng & - \\
\hline Benzo(a)anthracene & 2 & 2 & $0.56-0.67 \mathrm{ng}$ & - \\
\hline Chrysene & 2 & 2 & $1.1-1.4 \mathrm{ng}$ & - \\
\hline Perylene & 2 & 2 & $0.13-0.40 \mathrm{ng}$ & - \\
\hline Benzo(b)fluoranthene & 2 & 2 & $1.4-1.8 \mathrm{ng}$ & - \\
\hline Benzo(k)fluoranthene & 2 & 2 & $0.41-0.83 \mathrm{ng}$ & - \\
\hline Benzo(a)pyrene & 2 & 2 & $0.56-0.77 \mathrm{ng}$ & - \\
\hline Benzo(e)pyrene & 2 & 2 & $1.3-2.6 \mathrm{ng}$ & - \\
\hline Benzo(g,h,i)perylene & 2 & 2 & $2.7-3.2 \mathrm{ng}$ & - \\
\hline Indeno $(1,2,3-c d)$ pyrene & 2 & 2 & $1.0-1.4 \mathrm{ng}$ & - \\
\hline Dibenz(a,h)anthracene & 2 & 2 & $0.34-0.94 \mathrm{ng}$ & - \\
\hline \multicolumn{5}{|c|}{ Field Blanks - PAHs in Stack Gas } \\
\hline Naphthalene & 4 & 4 & $33.0-1050 \mathrm{ng}$ & - \\
\hline 2-Methylnaphthalene & 4 & 4 & $11.4-110 \mathrm{ng}$ & - \\
\hline Acenaphthene & 4 & 4 & $2.1-29.5 \mathrm{ng}$ & - \\
\hline 2-Chloronaphthalene & 4 & 3 & $0.06-0.38 \mathrm{ng}$ & $0.08 \mathrm{ng}$ \\
\hline
\end{tabular}


Table D-1 (Continued)

\begin{tabular}{|c|c|c|c|c|}
\hline Analyte & $\begin{array}{c}\text { Number of } \\
\text { Blanks } \\
\text { Analyzed }\end{array}$ & $\begin{array}{c}\text { Number } \\
\text { of } \\
\text { Detects }\end{array}$ & $\begin{array}{c}\text { Range of } \\
\text { Compounds Detected }\end{array}$ & $\begin{array}{l}\text { Detection } \\
\text { Limit }\end{array}$ \\
\hline Acenaphthalene & 4 & 4 & $0.60-4.4 \mathrm{ng}$ & - \\
\hline Fluorene & 4 & 4 & $7.9-17.9 \mathrm{ng}$ & - \\
\hline Phenanthrene & 4 & 4 & $35.8-54.9 \mathrm{ng}$ & - \\
\hline Anthracene & 4 & 4 & $1.2-2.6 \mathrm{ng}$ & - \\
\hline Fluoranthene & 4 & 4 & $5.5-20.0 \mathrm{ng}$ & - \\
\hline Pyrene & 4 & 4 & $4.1-13.7 \mathrm{ng}$ & - \\
\hline Benzo(a)anthracene & 4 & 4 & $0.47-3.7 \mathrm{ng}$ & - \\
\hline Chrysene & 4 & 4 & $0.75-10.0 \mathrm{ng}$ & - \\
\hline Perylene & 4 & 3 & $0.16-1.5$ & $0.5 \mathrm{ng}$ \\
\hline Benzo(b)fluoranthene & 4 & 4 & $1.2-12.3 \mathrm{ng}$ & - \\
\hline Benzo(k)fluoranthene & 4 & 4 & $0.24-3.6 \mathrm{ng}$ & - \\
\hline Benzo(a)pyrene & 4 & 4 & $0.47-4.7 \mathrm{ng}$ & - \\
\hline Benzo(e)pyrene & 4 & 4 & $1.8-9.3 \mathrm{ng}$ & - \\
\hline $\operatorname{Benzo}(g, h, i)$ perylene & 4 & 4 & $2.0-11.4 \mathrm{ng}$ & - \\
\hline Indeno(1,2,3-cd)pyrene & 4 & 4 & $0.77-6.2 \mathrm{ng}$ & - \\
\hline Dibenz(a,h)anthracene & 4 & 1 & 1.5 & $0.09-0.9 \mathrm{ng}$ \\
\hline \multicolumn{5}{|c|}{ Trip Blank - PAHs in Stack Gas } \\
\hline Naphthalene & 2 & 2 & $29.1-49.6 \mathrm{ng}$ & - \\
\hline 2-Methylnaphthalene & 2 & 2 & $8.9-34.0 \mathrm{ng}$ & - \\
\hline Acenaphthene & 2 & 2 & $1.7-8.9 \mathrm{ng}$ & - \\
\hline 2-Chloronaphthalene & 2 & 0 & ND & $0.3-0.9 \mathrm{ng}$ \\
\hline Acenaphthalene & 2 & 1 & $2.2 \mathrm{ng}$ & $0.8 \mathrm{ng}$ \\
\hline Fluorene & 2 & 2 & $0.66-23.5 \mathrm{ng}$ & - \\
\hline Phenanthrene & 2 & 2 & $2.8-129 \mathrm{ng}$ & - \\
\hline Anthracene & 2 & 1 & $4.3 \mathrm{ng}$ & $0.8 \mathrm{ng}$ \\
\hline Fluoranthene & 2 & 2 & $1.3-15.3 \mathrm{ng}$ & - \\
\hline Pyrene & 2 & 2 & $2.6-7.6 \mathrm{ng}$ & - \\
\hline Benzo(a)anthracene & 2 & 2 & $0.25-0.64 \mathrm{ng}$ & - \\
\hline Chrysene & 2 & 2 & $0.34-1.5 \mathrm{ng}$ & - \\
\hline Perylene & 2 & 1 & $0.21 \mathrm{ng}$ & $1.3 \mathrm{ng}$ \\
\hline Benzo(b)fluoranthene & 2 & 2 & $0.53-2.0 \mathrm{ng}$ & - \\
\hline Benzo(k)fluoranthene & 2 & 2 & $0.19-0.59 \mathrm{ng}$ & - \\
\hline Benzo(a)pyrene & 2 & 1 & $0.77 \mathrm{ng}$ & $1.1 \mathrm{ng}$ \\
\hline Benzo(e)pyrene & 2 & 2 & $0.81-3.3 \mathrm{ng}$ & - \\
\hline Benzo(g,h,i)perylene & 2 & 2 & $2.9 \mathrm{ng}$ & - \\
\hline Indeno(1,2,3-cd)pyrene & 2 & 2 & $0.85-1.5 \mathrm{ng}$ & - \\
\hline
\end{tabular}


Table D-1 (Continued)

\begin{tabular}{|c|c|c|c|c|}
\hline Analyte & $\begin{array}{c}\text { Number of } \\
\text { Blanks } \\
\text { Analyzed }\end{array}$ & $\begin{array}{c}\text { Number } \\
\text { of } \\
\text { Detects }\end{array}$ & $\begin{array}{c}\text { Range of } \\
\text { Compounds Detected } \\
\end{array}$ & $\begin{array}{c}\text { Detection } \\
\text { Limit }\end{array}$ \\
\hline Dibenz(a,h)anthracene & 2 & 1 & $0.28 \mathrm{ng}$ & $2.1 \mathrm{ng}$ \\
\hline \multicolumn{5}{|c|}{$\begin{array}{l}\text { Laboratory Method Blank - } \\
\text { Dioxins/Furans in Stack Gas }\end{array}$} \\
\hline $2,3,7,8-\mathrm{TCDF}$ & 2 & 0 & ND & $0.005-0.006 \mathrm{ng}$ \\
\hline $2,3,7,8-\mathrm{TCDD}$ & 2 & 1 & $0.009 \mathrm{ng}$ & $0.006 \mathrm{ng}$ \\
\hline 1,2,3,7,8-PeCDF & 2 & 0 & ND & 0.006 \\
\hline $2,3,4,7,8-\mathrm{PeCDF}$ & 2 & $\mathbf{0}$ & ND & 0.006 \\
\hline 1,2,3,7,8-PeCDD & 2 & 0 & ND & $0.01 \mathrm{ng}$ \\
\hline $1,2,3,4,7,8-\mathrm{HxCDF}$ & 2 & 2 & $0.007-0.01 \mathrm{ng}$ & - \\
\hline $1,2,3,6,7,8-\mathrm{HxCDF}$ & 2 & 0 & ND & $0.006-0.008 \mathrm{ng}$ \\
\hline $2,3,4,6,7,8-\mathrm{H} H \mathrm{CDF}$ & 2 & 1 & $0.01 \mathrm{ng}$ & $0.008 \mathrm{ng}$ \\
\hline $1,2,3,7,8,9-\mathrm{HxCDF}$ & 2 & 0 & ND & $0.008-0.01 \mathrm{ng}$ \\
\hline $1,2,3,4,7,8-\mathrm{HxCDD}$ & 2 & 0 & ND & $0.01-0.02 \mathrm{ng}$ \\
\hline $1,2,3,6,7,8-\mathrm{H} \times \mathrm{CDD}$ & 2 & 0 & ND & $0.01-0.02 \mathrm{ng}$ \\
\hline $1,2,3,7,8,9-\mathrm{H} \times \mathrm{CDD}$ & 2 & 0 & ND & $0.01-0.02 \mathrm{ng}$ \\
\hline $1,2,3,4,6,7,8-\mathrm{HpCDF}$ & 2 & 1 & $0.008 \mathrm{ng}$ & $0.009 \mathrm{ng}$ \\
\hline $1,2,3,4,7,8,9-\mathrm{HpCDF}$ & 2 & 0 & ND & $0.01-0.02 \mathrm{ng}$ \\
\hline $1,2,3,4,6,7,8-\mathrm{HpCDD}$ & 2 & 1 & $0.008 \mathrm{ng}$ & $0.02 \mathrm{ng}$ \\
\hline OCDF & 2 & 0 & ND & $0.02 \mathrm{ng}$ \\
\hline OCDD & 2 & 2 & $0.03-0.04 \mathrm{ng}$ & - \\
\hline \multicolumn{5}{|c|}{$\begin{array}{l}\text { Field Blanks - Dioxins/Furans in Stack } \\
\text { Gas }\end{array}$} \\
\hline $2,3,7,8-\mathrm{TCDF}$ & 3 & 1 & $0.004 \mathrm{ng}$ & $0.002-0.006 \mathrm{ng}$ \\
\hline 2,3,7,8-TCDD & 3 & 0 & ND & $0.002-0.007 \mathrm{ng}$ \\
\hline $1,2,3,7,8-\mathrm{PeCDF}$ & 3 & 1 & $0.01 \mathrm{ng}$ & $0.002-0.005 \mathrm{ng}$ \\
\hline $2,3,4,7,8-\mathrm{PeCDF}$ & 3 & 0 & ND & $0.002-0.006 \mathrm{ng}$ \\
\hline $1,2,3,7,8-\mathrm{PeCDD}$ & 3 & 0 & ND & $0.004-0.01 \mathrm{ng}$ \\
\hline $1,2,3,4,7,8-\mathrm{H} \times \mathrm{CDF}$ & 3 & 1 & $0.03 \mathrm{ng}$ & $0.002-0.009 \mathrm{ng}$ \\
\hline $1,2,3,6,7,8-\mathrm{H} \mathrm{HxCDF}$ & 3 & 1 & $0.008 \mathrm{ng}$ & $0.002-0.007 \mathrm{ng}$ \\
\hline $2,3,4,6,7,8-\mathrm{HxCDF}$ & 3 & 3 & $0.006-0.01 \mathrm{ng}$ & - \\
\hline $1,2,3,7,8,9-\mathrm{H} \times \mathrm{CDF}$ & 3 & 0 & ND & $0.002-0.01 \mathrm{ing}$ \\
\hline $1,2,3,4,7,8-\mathrm{H} \times \mathrm{CDD}$ & 3 & 0 & ND & $0.004-0.02 \mathrm{ng}$ \\
\hline $1,2,3,6,7,8-\mathrm{HxCDD}$ & 3 & 1 & $0.01 \mathrm{ng}$ & $0.003-0.01 \mathrm{ng}$ \\
\hline 1,2,3,7,8,9-HxCDD & 3 & 1 & $0.007 \mathrm{ng}$ & $0.003-0.02 \mathrm{ng}$ \\
\hline $1,2,3,4,6,7,8-\mathrm{HpCDF}$ & 3 & 3 & $0.005-0.03 \mathrm{ng}$ & - \\
\hline
\end{tabular}


Table D-1 (Continued)

\begin{tabular}{|c|c|c|c|c|}
\hline Analyte & $\begin{array}{c}\text { Number of } \\
\text { Blanks } \\
\text { Analyzed }\end{array}$ & $\begin{array}{c}\text { Number } \\
\text { of } \\
\text { Detects }\end{array}$ & $\begin{array}{c}\text { Range of } \\
\text { Compounds Detected }\end{array}$ & $\begin{array}{l}\text { Detection } \\
\text { Limit }\end{array}$ \\
\hline $1,2,3,4,7,8,9-\mathrm{HpCDF}$ & 3 & 0 & ND & $0.004-0.02 \mathrm{ng}$ \\
\hline $1,2,3,4,6,7,8-\mathrm{HpCDD}$ & 3 & 2 & $0.01-0.04 \mathrm{ng}$ & $0.004 \mathrm{ng}$ \\
\hline OCDF & 3 & 1 & $0.09 \mathrm{ng}$ & $0.005-0.04 \mathrm{ng}$ \\
\hline OCDD & 3 & 3 & $0.01-0.17 \mathrm{ng}$ & - \\
\hline \multicolumn{5}{|c|}{$\begin{array}{l}\text { Trip Blank - Dioxins/Furans in Stack } \\
\text { Gas }\end{array}$} \\
\hline $2,3,7,8-\mathrm{TCDF}$ & 1 & 0 & ND & $0.003 \mathrm{ng}$ \\
\hline 2,3,7,8-TCDD & 1 & 0 & ND & $0.004 \mathrm{ng}$ \\
\hline $1,2,3,7,8-\mathrm{PeCDF}$ & 1 & 0 & ND & $0.003 \mathrm{ng}$ \\
\hline $2,3,4,7,8-\mathrm{PeCDF}$ & 1 & 0 & ND & $0.003 \mathrm{ng}$ \\
\hline $1,2,3,7,8-\mathrm{PeCDD}$ & 1 & 0 & ND & $0.004 \mathrm{ng}$ \\
\hline $1,2,3,4,7,8-\mathrm{HxCDF}$ & 1 & 1 & $0.004 \mathrm{ng}$ & - \\
\hline $1,2,3,6,7,8-\mathrm{HxCDF}$ & 1 & 0 & ND & $0.003 \mathrm{ng}$ \\
\hline $2,3,4,6,7,8-\mathrm{HxCDF}$ & 1 & 1 & $0.006 \mathrm{ng}$ & - \\
\hline $1,2,3,7,8,9-\mathrm{HxCDF}$ & 1 & 0 & ND & $0.005 \mathrm{ng}$ \\
\hline $1,2,3,4,7,8-\mathrm{HxCDD}$ & 1 & 0 & ND & $0.007 \mathrm{ng}$ \\
\hline $1,2,3,6,7,8-\mathrm{H} x \mathrm{CDD}$ & 1 & 0 & ND & $0.006 \mathrm{ng}$ \\
\hline $1,2,3,7,8,9-\mathrm{HxCDD}$ & 1 & 0 & ND & $0.006 \mathrm{ng}$ \\
\hline $1,2,3,4,6,7,8-\mathrm{HpCDF}$ & 1 & 0 & $\overline{N D}$ & $0.004 \mathrm{ng}$ \\
\hline $1,2,3,4,7,8,9-\mathrm{HpCDF}$ & 1 & 0 & ND & $0.007 \mathrm{ng}$ \\
\hline $1,2,3,4,6,7,8-\mathrm{HpCDD}$ & 1 & 0 & $\mathrm{ND}$ & $0.008 \mathrm{ng}$ \\
\hline OCDF & 1 & 0 & ND & $0.01 \mathrm{ng}$ \\
\hline OCDD & 1 & 1 & $0.01 \mathrm{ng}$ & - \\
\hline \multicolumn{5}{|l|}{$\begin{array}{l}\text { Laboratory Method Blank - } \\
\text { Dioxins/Furans in Ash }\end{array}$} \\
\hline $2,3,7,8-\mathrm{TCDF}$ & 1 & 1 & $0.09 \mathrm{pg} / \mathrm{g}$ & - \\
\hline $2,3,7,8-\mathrm{TCDD}$ & 1 & 0 & ND & $0.1 \mathrm{pg} / \mathrm{g}$ \\
\hline $1,2,3,7,8-\mathrm{PeCDF}$ & 1 & 0 & $\mathrm{ND}$ & $0.1 \mathrm{pg} / \mathrm{g}$ \\
\hline $2,3,4,7,8-\mathrm{PeCDF}$ & 1 & 0 & $\mathrm{ND}$ & $0.1 \mathrm{pg} / \mathrm{g}$ \\
\hline 1,2,3,7,8-PeCDD & 1 & 0 & ND & $0.2 \mathrm{pg} / \mathrm{g}$ \\
\hline $1,2,3,4,7,8-\mathrm{H} \times \mathrm{CDF}$ & 1 & 0 & $\overline{N D}$ & $0.1 \mathrm{pg} / \mathrm{g}$ \\
\hline $1,2,3,6,7,8-\mathrm{HxCDF}$ & 1 & 0 & ND & $0.09 \mathrm{pg} / \mathrm{g}$ \\
\hline $2,3,4,6,7,8-\mathrm{HxCDF}$ & 1 & 1 & $0.29 \mathrm{pg} / \mathrm{g}$ & - \\
\hline $1,2,3,7,8,9-\mathrm{HxCDF}$ & 1 & 0 & ND & $0.1 \mathrm{pg} / \mathrm{g}$ \\
\hline $1,2,3,4,7,8-\mathrm{HxCDD}$ & 1 & 0 & ND & $0.2 \mathrm{pg} / \mathrm{g}$ \\
\hline $1,2,3,6,7,8-\mathrm{H} \times \mathrm{CDD}$ & 1 & 0 & ND & $0.2 \mathrm{pg} / \mathrm{g}$ \\
\hline
\end{tabular}


Appendix D: Quality Assurance/Quality Control Results

Table D-1 (Continued)

\begin{tabular}{||l|c|c|c|c||}
\hline \multicolumn{1}{|c|}{ Analyte } & $\begin{array}{c}\text { Number of } \\
\text { Blanks } \\
\text { Analyzed }\end{array}$ & $\begin{array}{c}\text { Number } \\
\text { of } \\
\text { Detects }\end{array}$ & $\begin{array}{c}\text { Range of } \\
\text { Compounds Detected }\end{array}$ & $\begin{array}{c}\text { Detection } \\
\text { Limit }\end{array}$ \\
\hline $1,2,3,7,8,9-\mathrm{HxCDD}$ & 1 & 0 & $\mathrm{ND}$ & $0.2 \mathrm{pg} / \mathrm{g}$ \\
\hline $1,2,3,4,6,7,8-\mathrm{HpCDF}$ & 1 & 1 & $0.16 \mathrm{pg} / \mathrm{g}$ & - \\
\hline $1,2,3,4,7,8,9-\mathrm{HpCDF}$ & 1 & 0 & $\mathrm{ND}$ & $0.2 \mathrm{pg} / \mathrm{g}$ \\
\hline $1,2,3,4,6,7,8-\mathrm{HpCDD}$ & 1 & 0 & $\mathrm{ND}$ & $0.2 \mathrm{pg} / \mathrm{g}$ \\
\hline OCDF & 1 & 1 & $0.41 \mathrm{pg} / \mathrm{g}$ & - \\
\hline OCDD & 1 & 1 & $0.40 \mathrm{pg} / \mathrm{g}$ & - \\
\hline
\end{tabular}

- All analytes reporting a detectable analytical signal have been reported. Analytes detected at levels below the stated detection limit are presented for information only and are not considered valid for the assessment of blank or background contamination.

$\mathrm{ND}=$ Not detected 
Table D-2

Precision and Accuracy Estimates

\begin{tabular}{|c|c|c|c|c|c|c|c|c|c|c|}
\hline \multirow[b]{2}{*}{ Measurement Parameter } & \multirow{2}{*}{ How Measured } & \multicolumn{2}{|c|}{ Objectives } & \multicolumn{2}{|c|}{$\begin{array}{c}\text { Measured } \\
\text { Accuracy } \\
\text { (\% Recovery) }\end{array}$} & \multirow{2}{*}{\begin{tabular}{|c|}
$\begin{array}{c}\text { Measured } \\
\text { Precision }\end{array}$ \\
(\% RPD)
\end{tabular}} & \multirow{2}{*}{$\begin{array}{c}\begin{array}{c}\text { Andit Sample } \\
\text { Accuracy }\end{array} \\
\text { (\% Recorery) }\end{array}$} & \multicolumn{2}{|c|}{$\begin{array}{c}\text { Measured } \\
\text { Accuracy } \\
\text { (\% Recorery) }\end{array}$} & \multirow{2}{*}{$\begin{array}{l}\text { Measured } \\
\text { Precision } \\
\text { (\% RPD) }\end{array}$} \\
\hline & & $\begin{array}{l}\text { Precision } \\
\text { (\% RPD) }\end{array}$ & $\begin{array}{c}\text { Accuracy } \\
\text { (\% Recorery) }\end{array}$ & MS-1 & MSD-1 & & & MS-2 & MSD-2 & \\
\hline \multicolumn{11}{|l|}{ Metals in Gas Solid Phase - ICP-AES } \\
\hline Filtered Solids: APF, ESP Inlets & $\begin{array}{l}\text { Precision - Matrix-spiked Duplicalc } \\
\text { Accuracy - Matrix-spiked Sample } \\
\end{array}$ & & & & & & & & & \\
\hline Aluminum & & 20 & $75-125$ & $58 \mathrm{Q}$ & $63 Q$ & 8.3 & & $58 Q$ & $63 Q$ & 8.3 \\
\hline Antimony & & 20 & $75-125$ & 95 & 90 & 5.4 & & 95 & 91 & 4.3 \\
\hline Barium & & 20 & $75-125$ & 91 & 91 & 0 & & 91 & 91 & $\mathbf{0}$ \\
\hline Beryllium & & 20 & $75-125$ & 82 & 83 & 1.2 & & 83 & 83 & 0 \\
\hline Calcium & & 20 & $75-125$ & $66 \mathrm{Q}$ & $69 \mathrm{Q}$ & 4.4 & & $66 \mathrm{Q}$ & $69 Q$ & 4.4 \\
\hline Chromium & & 20 & $75-125$ & 82 & 84 & 2.4 & & 83 & 84 & 1.2 \\
\hline Cobalt & & 20 & $75-125$ & 85 & 85 & 0 & & 85 & 85 & 0 \\
\hline Copper & & 20 & $75-125$ & 93 & 95 & 2.1 & & 93 & 95 & 2.1 \\
\hline $180 n$ & & 20 & $75-125$ & 83 & 84 & 1.2 & & 83 & 84 & 1.2 \\
\hline Magnesium & & 20 & $75-125$ & $58 Q$ & $60 Q$ & 3.4 & & $58 Q$ & $60 Q$ & 3.4 \\
\hline Manganese & & 20 & $75-125$ & 84 & 84 & 0 & & 84 & 84 & 0 \\
\hline Molybdenum & & 20 & $75-125$ & 87 & 87 & 0 & & 87 & 86 & 1.2 \\
\hline Nickel & & 20 & $75-125$ & 87 & 86 & 1.2 & & 85 & 86 & 1.2 \\
\hline Phosphorus & & 20 & $75-125$ & 88 & 88 & 0 & & & & \\
\hline Potassium & & 20 & $75-125$ & 91 & 91 & 0 & & 91 & 91 & 0 \\
\hline Silver & & 20 & $75-125$ & $15 Q$ & $18 Q$ & 18 & & $15 Q$ & $18 Q$ & 18 \\
\hline Sodium & & 20 & $75-125$ & 86 & 85 & 1.2 & & 86 & 85 & 1.2 \\
\hline Titanium & & 20 & $75-125$ & 93 & 89 & 4.4 & & 93 & 88 & 5.5 \\
\hline Vanadium & & 20 & $75-125$ & 91 & 91 & 0 & & 92 & 91 & 1.1 \\
\hline
\end{tabular}




\begin{tabular}{|c|c|c|c|c|c|c|c|c|c|c|}
\hline$\tau \tau$ & 16 & 68 & & $\boldsymbol{I}$ & 16 & 06 & SZI-SL & $0 z$ & & un!pptr \\
\hline$\varepsilon^{\prime} l$ & 86 & $6 L$ & & 8 & $\partial z L$ & $8 L$ & SZI-SL & $0 \tau$ & & 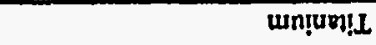 \\
\hline 1.9 & $6 L$ & $\$ 8$ & & 58 & $6 L$ & 98 & SZI-SL & $0 z$ & & unipos \\
\hline 96 & 099 & OEq & & $s t$ & $\partial 89$ & $\partial s 9$ & SZI-SL & $0 z$ & & JoAl!S \\
\hline 0 & 88 & 88 & & 0 & 88 & 88 & $S Z I-S L$ & $0 \tau$ & & unțssmod \\
\hline & & & & $\varepsilon z$ & 68 & $\angle 8$ & SZI-SL & $0 z$ & & snuoydsoud \\
\hline$\tau \cdot I$ & $\angle 8$ & 98 & & 0 & 68 & $\$ 8$ & SZI-SL & $0 z$ & & DXX!N \\
\hline$s^{\prime} \varepsilon$ & $\angle 8$ & $\$ 8$ & & $\tau \cdot 1$ & 98 & 58 & SZT-SL & $0 \tau$ & & wnuopq $\mathcal{K}_{j}$ ow \\
\hline$\theta 2$ & $\$ 8$ & 28 & & 21 & $\varepsilon 8$ & 28 & SZI-SL & 02 & & osour8uny \\
\hline 209 & $\partial s \varepsilon$ & $\partial s 9$ & & $\partial \varepsilon g$ & $\partial s \varepsilon$ & $\partial \angle 9$ & $S Z I-S L$ & $0 \tau$ & & un!ıssu8gw \\
\hline $8^{\circ} \varepsilon$ & $8 L$ & 18 & & 2.9 & $8 L$ & $\varepsilon 8$ & SZI-SL & or & & voll \\
\hline$\tau \cdot z$ & 66 & 26 & & 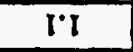 & $\varepsilon 6$ & 26 & $S \Sigma I-\varsigma L$ & $0 \tau$ & & soddos \\
\hline \pm 2 & $\$ 8$ & 28 & & $\tau \cdot 1$ & $\varepsilon 8$ & 28 & SZI-SL & $0 z$ & & 3090J \\
\hline $9^{\prime} \varepsilon$ & 68 & 18 & & $\tau \cdot I$ & $\varepsilon 8$ & 28 & SZI-SL & $0 \tau$ & & 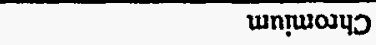 \\
\hline$\partial \tau \varepsilon$ & $\partial r s$ & $\partial z L$ & & $\partial+\varepsilon$ & $\partial \varepsilon s$ & $S L$ & $s Z I-S L$ & $0 \tau$ & & un!?อle \\
\hline 0 & 18 & 18 & & $\tau \cdot 1$ & 08 & 18 & SZI-SL & $0 z$ & & un!!IKSPg \\
\hline 0 & 88 & 88 & & $\varepsilon \tau$ & $\angle 8$ & 68 & $S Z I-S L$ & $0 z$ & & umnurg \\
\hline 9.5 & $\angle 8$ & 26 & & $\tau \cdot \varepsilon$ & 56 & 26 & $S Z I-S L$ & $0 \tau$ & & Kuoungury \\
\hline$\partial \angle 9$ & $\partial \tau \varepsilon$ & $0+9$ & & $\partial k$ & $\partial \tau \varepsilon$ & $\partial \angle 9$ & $S C I-S L$ & 02 & & unnụunny \\
\hline & & & & & & & & & 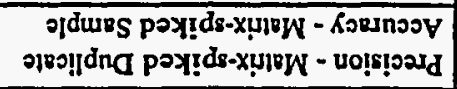 & भIDI dSG :XNd כ00भวगV \\
\hline (बd\& \%) & z-aSW & $\tau-S W$ & 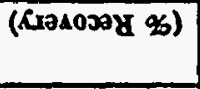 & (वd8 \%) & I-aSW & I-SW & 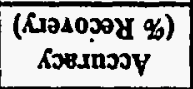 & $\begin{array}{l}\text { (ady q) } \\
\text { notspoard }\end{array}$ & \multirow{2}{*}{ paunsеәЖ моН } & \multirow{2}{*}{ 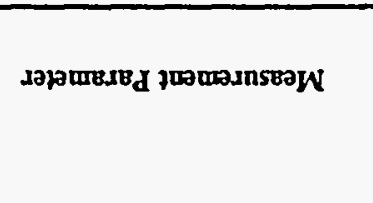 } \\
\hline 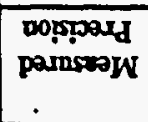 & \multicolumn{2}{|c|}{ 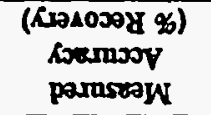 } & 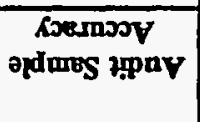 & 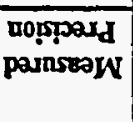 & \multicolumn{2}{|c|}{ 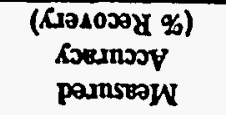 } & \multicolumn{2}{|c|}{ 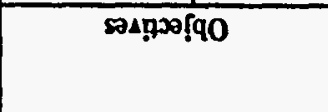 } & & \\
\hline
\end{tabular}

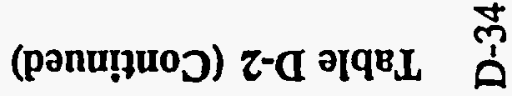




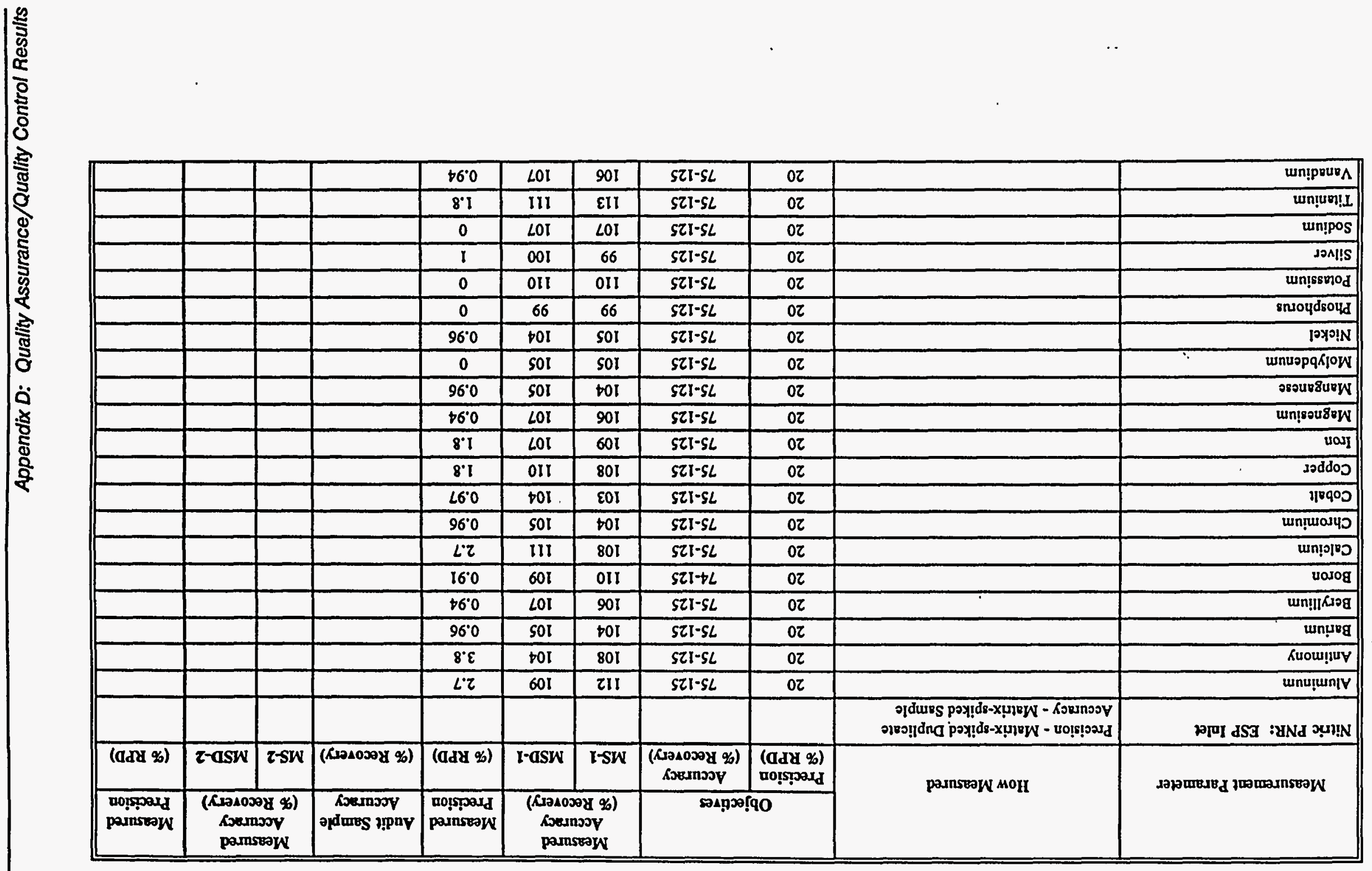




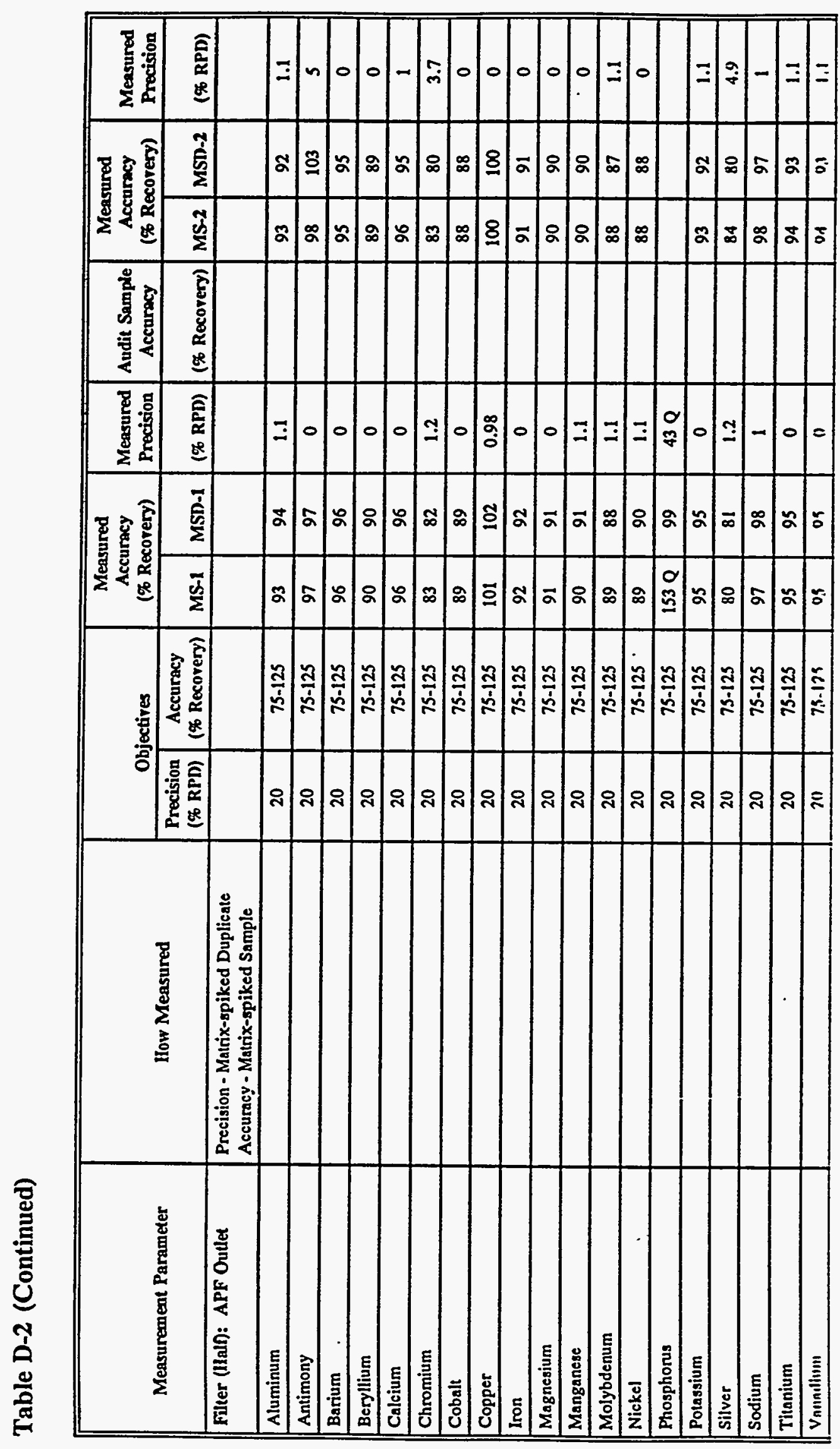


Table D-2 (Continued)

\begin{tabular}{|c|c|c|c|c|c|c|c|c|c|c|}
\hline \multirow{2}{*}{ Measurement Parameter } & \multirow{2}{*}{ How Measured } & \multicolumn{2}{|c|}{ Objectives } & \multicolumn{2}{|c|}{$\begin{array}{c}\text { Measured } \\
\text { Accuracy } \\
\text { (\% Recovery) }\end{array}$} & \multirow{2}{*}{\begin{tabular}{|c|}
$\begin{array}{c}\text { Measured } \\
\text { Precision }\end{array}$ \\
(\% RPD) \\
\end{tabular}} & \multirow{2}{*}{\begin{tabular}{|c}
$\begin{array}{c}\text { Audit Sample } \\
\text { Accuracy }\end{array}$ \\
(\% Recovery)
\end{tabular}} & \multicolumn{2}{|c|}{$\begin{array}{c}\text { Measured } \\
\text { Aceuracy } \\
\text { (\% Recovery) }\end{array}$} & \multirow{2}{*}{$\begin{array}{c}\text { Measured } \\
\text { Precision } \\
\text { (\% RPD) }\end{array}$} \\
\hline & & $\begin{array}{l}\text { Precision } \\
\text { (\% RPD) }\end{array}$ & $\begin{array}{c}\text { Accuracy } \\
\text { (\% Recovery) }\end{array}$ & MS-1 & MSD-1 & & & MS-2 & MSD-2 & \\
\hline Fitter \& PNRs: ESP Outlet & $\begin{array}{l}\text { Precision - Matrix-spiked Duplicate } \\
\text { Accuracy - Matrix-spiked Sample }\end{array}$ & & & & & & & & & \\
\hline Aluminum & & 20 & $75-125$ & 90 & 87 & 3.4 & & 88 & 89 & 1.1 \\
\hline Antimony & & 20 & $75-125$ & 78 & 88 & 12 & & 82 & 91 & 10 \\
\hline Barium & & 20 & $75-125$ & 93 & 91 & 2.2 & & 93 & 94 & 1.1 \\
\hline Horylliwn & & 20 & $75-125$ & 88 & 86 & 2.1 & & 87 & 89 & 2.3 \\
\hline Calcium & & 20 & $75-125$ & 94 & 91 & 3.2 & & 91 & 93 & 2.2 \\
\hline Chromium & & 20 & $75-125$ & 89 & 86 & 3.4 & & 86 & 89 & 3.4 \\
\hline Cohnlt & & 20 & $75-125$ & 85 & 83 & 2.4 & & 84 & 85 & 1.2 \\
\hline Copper & & 20 & $75-125$ & 103 & 99 & 4 & & 101 & 103 & 2 \\
\hline Iron & & 20 & $75-125$ & 89 & 87 & 2.3 & & 87 & 88 & 1.1 \\
\hline Magnesium & & 20 & $75-125$ & 83 & 80 & 3.7 & & 80 & 82 & 2.5 \\
\hline Manganese & & 20 & $75-125$ & 89 & 86 & 3.4 & & 87 & 89 & 2.3 \\
\hline Molybdenum & & 20 & $75-125$ & 89 & 87 & 2.3 & & 86 & 89 & 3.4 \\
\hline Nickel & & 20 & $75-125$ & 85 & 84 & 1.2 & & 82 & 87 & 5.9 \\
\hline Phosphorus & & 20 & $75-125$ & 92 & 92 & 0 & & & & \\
\hline Potassium & & 20 & $75-125$ & 89 & 86 & 3.4 & & 87 & 88 & 1.1 \\
\hline Silver & & 20 & $75-125$ & 80 & 78 & 2.5 & & 78 & 80 & 2.5 \\
\hline Sodium & & 20 & $75-125$ & 93 & 92 & 1.1 & & 91 & 92 & 1.1 \\
\hline Titanium & & 20 & $75-125$ & 93 & 91 & 2.2 & & 91 & 93 & 2.2 \\
\hline Vanadium & & 20 & $75-125$ & 94 & 91 & 3.2 & & 92 & 94 & 2.2 \\
\hline
\end{tabular}


$\underset{山}{\forall}$ Table D-2 (Continued)

$\infty$

\begin{tabular}{|c|c|c|c|c|c|c|c|c|c|c|}
\hline \multirow{2}{*}{ Measurement Parameter } & \multirow{2}{*}{ How Measured } & \multicolumn{2}{|c|}{ Objectires } & \multicolumn{2}{|c|}{$\begin{array}{c}\text { Measured } \\
\text { Accuracy } \\
\text { (\$ Recovery) }\end{array}$} & \multirow{2}{*}{$\begin{array}{c}\begin{array}{c}\text { Measured } \\
\text { Precision }\end{array} \\
(\% \text { RPD })\end{array}$} & \multirow{2}{*}{\begin{tabular}{|c|}
$\begin{array}{c}\text { Audit Sample } \\
\text { Aceuracy }\end{array}$ \\
(\% Recovery)
\end{tabular}} & \multicolumn{2}{|c|}{$\begin{array}{c}\text { Measured } \\
\text { Accuracy } \\
\text { (\% Recorery) }\end{array}$} & \multirow{2}{*}{$\begin{array}{c}\begin{array}{c}\text { Messured } \\
\text { Precision }\end{array} \\
\text { (\% RPD) }\end{array}$} \\
\hline & & $\begin{array}{l}\text { Precision } \\
\text { (\% RPD) }\end{array}$ & $\begin{array}{c}\text { Accuracy } \\
\text { (\% Recovery) }\end{array}$ & MS-1 & MSD-1 & & & MS-2 & MSD-2 & \\
\hline \multicolumn{11}{|c|}{ Metals in Gas Vapor Phase - ICP-AES } \\
\hline $\mathrm{HNO}_{3} / \mathrm{H}_{2} \mathrm{O}_{2}$ Impingers & $\begin{array}{l}\text { Precision - Matrix-spiked Duplicate } \\
\text { Accuracy - Matrix-spiked Sample }\end{array}$ & & & & & & & & • & \\
\hline Aluminum & & 20 & $75-125$ & 89 & 90 & 1.1 & & 89 & 89 & $\mathbf{0}$ \\
\hline Antimony & & 20 & $75-125$ & 91 & 81 & 12 & & 94 & 79 & 17 \\
\hline Barium & & 20 & $75-125$ & 94 & 94 & 0 & & 94 & 94 & $\mathbf{0}$ \\
\hline Beryllium & & 20 & $75-125$ & 91 & 91 & 0 & & 91 & 91 & 0 \\
\hline Boron & & 20 & $75-125$ & 91 & 93 & 2.2 & & 92 & 93 & 1.1 \\
\hline Calcium & & 20 & $75-125$ & 90 & 93 & 3.3 & & 91 & 93 & 2.2 \\
\hline Chromium & & 20 & $75-125$ & 88 & 89 & 1.1 & & 89 & 89 & 0 \\
\hline Cobalt & & 20 & $75-125$ & 88 & 89 & 1.1 & & 89 & 89 & 0 \\
\hline Copper & & 20 & $75-125$ & 92 & 92 & 0 & & 93 & 91 & 2.2 \\
\hline Iron & & 20 & $75-125$ & 89 & 91 & 2.2 & & 90 & 90 & 0 \\
\hline Magnesium & & 20 & $75-125$ & 86 & 87 & 1.2 & & 87 & 87 & 0 \\
\hline Manganese & & 20 & $75-125$ & 88 & 89 & 1.1 & & 89 & 89 & 0 \\
\hline Molybdenum & & 20 & $75-125$ & 90 & 90 & 0 & & 91 & 90 & 1.1 \\
\hline Nickel & & 20 & $75-125$ & 90 & 89 & 1.1 & & 91 & 89 & 2.2 \\
\hline Phosphorus & & 20 & $75-125$ & 101 & 99 & 2 & & & & \\
\hline Potassium & & 20 & $75-125$ & 90 & 92 & 2.2 & & 90 & 90 & 0 \\
\hline Silver & & 20 & $75-125$ & 85 & 85 & 0 & & 86 & 85 & 1.2 \\
\hline Sodium & & 20 & $75-125$ & 92 & 93 & 1.1 & & 92 & 92 & 0 \\
\hline Titanium & . & 20 & $75-125$ & 91 & 92 & 1.1 & & 92 & 91 & 1.1 \\
\hline Vanadium & & 20 & $75-125$ & 95 & 95 & 0 & & 95 & 95 & 0 \\
\hline
\end{tabular}


Table D-2 (Continued)

\begin{tabular}{|c|c|c|c|c|c|c|c|c|c|c|}
\hline \multirow[b]{2}{*}{ Measurement Parameter } & \multirow[b]{2}{*}{ How Measured } & \multicolumn{2}{|c|}{ Objectives } & \multicolumn{2}{|c|}{$\begin{array}{c}\text { Measured } \\
\text { Accuracy } \\
\text { (\% Recovery) }\end{array}$} & \multirow{2}{*}{$\begin{array}{c}\begin{array}{c}\text { Measured } \\
\text { Precision }\end{array} \\
\text { (\% RPD) } \\
\end{array}$} & \multirow{2}{*}{$\begin{array}{c}\begin{array}{c}\text { Audit Sample } \\
\text { Accuracy }\end{array} \\
\text { (\% Recorery) }\end{array}$} & \multicolumn{2}{|c|}{$\begin{array}{c}\text { Measured } \\
\text { Accuracy } \\
\text { (\% Recovery) }\end{array}$} & \multirow{2}{*}{$\begin{array}{c}\text { Messured } \\
\text { Precision } \\
\text { (\% RPD) }\end{array}$} \\
\hline & & $\begin{array}{l}\text { Precision } \\
\text { (\% RPD) }\end{array}$ & $\begin{array}{c}\text { Accuracy } \\
\text { (\% Recorery) }\end{array}$ & MS-1 & MSD-1 & & & MS-2 & MSD-2 & \\
\hline Metals in Coal - ICP-AES & $\begin{array}{l}\text { Precision - Analytical Duplicate } \\
\text { Accuracy - NA }\end{array}$ & & & & & & & . & & \\
\hline Barium & & 20 & $75-125$ & NA & NA & NA & & & & \\
\hline Beryllium & & 20 & $75-125$ & 1.5 & 1.6 & 6.5 & & & & \\
\hline Boron & & 20 & $75-125$ & NA & NA & NA & & & & \\
\hline Calcium & & 20 & $75-125$ & NA & NA & NA & & & & \\
\hline Chromium & & 20 & $75-125$ & 17 & 17 & 0 & & & & \\
\hline Copper & & 20 & $75-125$ & NA & NA & NA & & & & \\
\hline Magnesium & & 20 & $75-125$ & NA & NA & NA & & & & \\
\hline Molybdenum & & 20 & $75-125$ & NA & NA & NA & & & & \\
\hline Phosphorus & & 20 & $75-125$ & 100 & 99 & 1 & & & & \\
\hline Titanium & & 20 & $75-125$ & NA & NA & NA & & & & \\
\hline Metals in Coal - ICP-AES & $\begin{array}{l}\text { Precision - NA } \\
\text { Accuracy - Standard Reference Material }\end{array}$ & & & & & & & & & \\
\hline Beryllium (1633-c) & & 20 & $75-125$ & & & & 101 & & & \\
\hline Chromium (1932-a) & & 20 & $75-125$ & & & & 95 & & & \\
\hline Metals in Ash - ICP-AES & $\begin{array}{l}\text { Precision - Matrix-spiked Duplicate } \\
\text { Accuracy - Matrix-spiked Sample }\end{array}$ & & & & & & & & & \\
\hline Aluminum & & 20 & $75-125$ & $71 Q$ & $70 \mathrm{Q}$ & 1.4 & & 71 & $69 \mathrm{Q}$ & 2.9 \\
\hline Antimony & & 20 & $75-125$ & 86 & 85 & 1.2 & & 91 & 93 & 2.2 \\
\hline Barium & & 20 & $75-125$ & 90 & 91 & 1.1 & & 90 & 90 & 0 \\
\hline Beryllium & . & 20 & $75-125$ & 81 & 81 & 0 & & 81 & 81 & 0 \\
\hline Calcium & & 20 & $75-125$ & $73 Q$ & $74 Q$ & 1.4 & & $73 Q$ & $74 Q$ & 1.4 \\
\hline
\end{tabular}


$\forall$ Table D-2 (Continued)

\begin{tabular}{|c|c|c|c|c|c|c|c|c|c|c|}
\hline \multirow{2}{*}{ Measurement Parameter } & \multirow{2}{*}{ How Measured } & \multicolumn{2}{|c|}{ Objectires } & \multicolumn{2}{|c|}{$\begin{array}{c}\text { Measured } \\
\text { Accuracy } \\
\text { (\% Racovery) }\end{array}$} & \multirow{2}{*}{$\begin{array}{c}\text { Measured } \\
\text { Procision }\end{array}$} & \multirow{2}{*}{$\begin{array}{c}\begin{array}{c}\text { Audit Sample } \\
\text { Accuracy }\end{array} \\
\text { (\% Recovery) }\end{array}$} & \multicolumn{2}{|c|}{$\begin{array}{c}\text { Measured } \\
\text { Accuracy } \\
\text { (\% Recovery) }\end{array}$} & \multirow{2}{*}{$\begin{array}{l}\begin{array}{c}\text { Measured } \\
\text { Precision }\end{array} \\
\text { (\% RPD) }\end{array}$} \\
\hline & & $\begin{array}{l}\text { Precision } \\
\text { (\% RPD) }\end{array}$ & $\begin{array}{c}\text { Accuracy } \\
\text { (\% Recovery) }\end{array}$ & MS-1 & MSD-1 & & & MS-2 & MSD-2 & \\
\hline Chromium & & 20 & $75-125$ & 83 & 84 & 1.2 & & 83 & 84 & 1.2 \\
\hline Cobalt & & 20 & $75-125$ & 84 & 84 & 0 & & 82 & 83 & 1.2 \\
\hline Copper & & 20 & $75-125$ & 93 & 92 & 1.1 & & 93 & 92 & 1.1 \\
\hline Iron & & 20 & $75-125$ & 84 & 85 & 1.2 & & 83 & 84 & 1.2 \\
\hline Magnesium & & 20 & $75-125$ & $65 \mathrm{Q}$ & $64 Q$ & 1.6 & & $65 Q$ & $63 \mathrm{Q}$ & 3.1 \\
\hline Manganese & & 20 & $75-125$ & 83 & 84 & 1.2 & & 83 & 84 & 1.2 \\
\hline Molybdenum & & 20 & $75-125$ & 85 & 86 & 1.2 & & 84 & 87 & 3.5 \\
\hline Nickel & & 20 & $75-125$ & 86 & 85 & 1.2 & & 82 & 82 & 0 \\
\hline Phosphorus & & 20 & $75-125$ & 83 & 90 & 8.1 & & & & \\
\hline Polassium & & 20 & $75-125$ & 89 & 90 & 1.1 & & 89 & 89 & 0 \\
\hline Silver & & 20 & $75-125$ & $27 Q$ & $13 Q$ & $70 Q$ & & $27 Q$ & $13 Q$ & $70 \mathrm{Q}$ \\
\hline Sodium & & 20 & $75-125$ & 82 & 82 & 0 & & 83 & 83 & 0 \\
\hline Titanium & & 20 & $75-125$ & 85 & 83 & 2.4 & & 82 & 82 & 0 \\
\hline Vanadium & . & 20 & $75-125$ & 91 & 91 & 0 & & 90 & 91 & 1.1 \\
\hline Metals in Sorbent - ICP-AES & $\begin{array}{l}\text { Precision - Matrix-spiked Duplicate } \\
\text { Accuracy - Matrix-spiked Sample }\end{array}$ & & & & & & & & & \\
\hline Aluminum & & 20 & $75-125$ & 87 & 84 & 3.5 & & & & \\
\hline Antimony & & 20 & $75-125$ & 81 & 89 & 9.4 & & & & \\
\hline Barium & & 20 & $75-125$ & 86 & 85 & 1.2 & & & & \\
\hline Beryllium & & 20 & $75-125$ & 78 & 78 & 0 & & & & \\
\hline Boron & & 20 & $75-125$ & 85 & 84 & 1.2 & & & & \\
\hline Calcium & & 20 & $75-125$ & $286 Q$ & $286 Q$ & 0 & & $174 Q$ & $274 Q$ & $45 Q$ \\
\hline Chromium & & 20 & $75-125$ & 77 & 77 & 0 & & & & \\
\hline Cobalt & & 20 & $75-125$ & $74 Q$ & $74 \mathrm{Q}$ & 0 & & & & \\
\hline
\end{tabular}


Table D-2 (Continued)

\begin{tabular}{|c|c|c|c|c|c|c|c|c|c|c|}
\hline \multirow{2}{*}{ Measurement Parameter } & \multirow{2}{*}{ How Measured } & \multicolumn{2}{|c|}{ Objectives } & \multicolumn{2}{|c|}{$\begin{array}{c}\text { Measured } \\
\text { Accuracy } \\
\text { (\% Recovery) }\end{array}$} & \multirow{2}{*}{\begin{tabular}{|c|}
$\begin{array}{c}\text { Measured } \\
\text { Precision }\end{array}$ \\
(\% RPD)
\end{tabular}} & \multirow{2}{*}{$\begin{array}{c}\begin{array}{c}\text { Audit Sample } \\
\text { Accuracy }\end{array} \\
\text { (\% Recorery) }\end{array}$} & \multicolumn{2}{|c|}{$\begin{array}{c}\text { Measured } \\
\text { Accuracy } \\
\text { (\% Recovery) }\end{array}$} & \multirow{2}{*}{$\begin{array}{c}\begin{array}{c}\text { Measured } \\
\text { Precision }\end{array} \\
\text { (\% RPD) }\end{array}$} \\
\hline & & $\begin{array}{l}\text { Precision } \\
\text { (\% RPD) }\end{array}$ & $\begin{array}{c}\text { Accuracy } \\
\text { (\% Recovery) }\end{array}$ & MS-1 & MSD-1 & & & MS-2 & MSD-2 & \\
\hline Copper & & 20 & $75-125$ & 87 & 86 & 1.2 & & & & \\
\hline Iron & & 20 & $75-125$ & 75 & $74 Q$ & 1.3 & & & & \\
\hline Magnesium & & 20 & $75-125$ & 113 & 97 & 15 & & & & \\
\hline Manganese & & 20 & $75-125$ & 80 & 79 & 1.3 & & & & \\
\hline Molybdenum & & 20 & $75-125$ & 81 & 80 & 1.2 & & & & \\
\hline Nickel & & 20 & $75-125$ & 76 & 76 & 0 & & & & \\
\hline Phosphorus & & 20 & $75-125$ & 89 & 90 & 1.1 & & & & \\
\hline Potassium & & 20 & $75-125$ & 87 & 86 & 1.2 & & & & \\
\hline Silver & & 20 & $75-125$ & 85 & 83 & 2.4 & & & & \\
\hline Sodium & & 20 & $75-125$ & 89 & 88 & 1.1 & & & & \\
\hline Titanium & & 20 & $75-125$ & 85 & 84 & 1.2 & & & & \\
\hline Vanadium & & 20 & $75-125$ & 85 & 84 & 1.2 & & & & \\
\hline $\begin{array}{l}\text { Metuls in Service Waler - } \\
\text { ICP-AES }\end{array}$ & $\begin{array}{l}\text { Precision - Matrix-spiked Duplicnte } \\
\text { Accuracy - Matrix-spiked Sample }\end{array}$ & & & & & & & & & \\
\hline Aluminum & & 20 & $75-125$ & 102 & 103 & 0.98 & & & & \\
\hline Antimony & & 20 & $75-125$ & 108 & 98 & 9.7 & & & & \\
\hline Barium & & 20 & $75-125$ & 103 & 104 & 0.97 & & & & \\
\hline Beryllium & & 20 & $75-125$ & 99 & 101 & 2 & & & & \\
\hline Boron & & 20 & $75-125$ & 98 & 99 & 1 & & & & \\
\hline Calcium & & 20 & $75-125$ & 94 & 95 & 1.1 & & & & \\
\hline Chromium & & 20 & $75-125$ & 98 & 100 & 2 & & & & \\
\hline Cobalt & & 20 & $75-125$ & 94 & 96 & 2.1 & & & & \\
\hline Copper & & 20 & $75-125$ & 102 & 102 & 0 & & & & \\
\hline Iron & & 20 & $75-125$ & 98 & 99 & 1 & & & & \\
\hline Magnesium & & 20 & $75-125$ & 93 & 93 & 0 & & & & \\
\hline
\end{tabular}


$\forall \quad$ Table D-2 (Continued)

\begin{tabular}{|c|c|c|c|c|c|c|c|c|c|c|}
\hline \multirow[b]{2}{*}{ Measurement Parameter } & \multirow[b]{2}{*}{ How Measured } & \multicolumn{2}{|c|}{ Objectives } & \multicolumn{2}{|c|}{$\begin{array}{c}\text { Measured } \\
\text { Accuracy } \\
\text { (\% Recovery) }\end{array}$} & \multirow{2}{*}{\begin{tabular}{|c|}
$\begin{array}{c}\text { Measured } \\
\text { Precision }\end{array}$ \\
(\% RPD)
\end{tabular}} & \multirow{2}{*}{$\begin{array}{c}\begin{array}{c}\text { Audit Sample } \\
\text { Accuracy }\end{array} \\
\text { (\% Recorery) }\end{array}$} & \multicolumn{2}{|c|}{$\begin{array}{l}\text { Measured } \\
\text { Accuracy } \\
\text { (x Recorery) }\end{array}$} & \multirow{2}{*}{$\begin{array}{c}\begin{array}{c}\text { Measured } \\
\text { Precision }\end{array} \\
\text { (\% RPD) }\end{array}$} \\
\hline & & $\begin{array}{l}\text { Precision } \\
\text { (\% RPD) }\end{array}$ & $\begin{array}{c}\text { Accuracy } \\
\text { (\% Recovery) }\end{array}$ & MS-1 & MSD-1 & & & MS-2 & MSD-2 & \\
\hline \begin{tabular}{|c|} 
Mnnganeac \\
\end{tabular} & & 20 & $75-125$ & 97 & 99 & 2 & & & & \\
\hline Molybdenum & & 20 & $75-125$ & 93 & 93 & 0 & & & & \\
\hline Nickel & & 20 & $75-125$ & 95 & 97 & 2.1 & & & & \\
\hline Phosphorus & & 20 & $75-125$ & 98 & 98 & $\overline{0}$ & & & & \\
\hline Potassium & & 20 & $75-125$ & 101 & 101 & 0 & & & & \\
\hline Silver & & 20 & $75-125$ & 101 & 102 & 0.98 & & & & \\
\hline Sodium & & 20 & $75-125$ & 106 & 104 & 1.9 & & & & \\
\hline Titanium & & 20 & $75-125$ & 94 & 95 & 1.1 & & & & \\
\hline Vanadium & & 20 & $75-125$ & 97 & 98 & 1 & & & & \\
\hline $\begin{array}{l}\text { Metals in Gas Vapor Phase - } \\
\text { ICP/MS }\end{array}$ & $\begin{array}{l}\text { Precision - NA } \\
\text { Accuracy - Matrix-spiked Sample }\end{array}$ & & & & & & & & & \\
\hline \multicolumn{11}{|l|}{$\mathrm{HNO}_{3} / \mathrm{H}_{2} \mathrm{O}_{2}$ Impingers } \\
\hline Antimony & & 20 & $75-125$ & 84 & & & & & & \\
\hline Arsenic & & 20 & $75-125$ & 78 & & & & & & \\
\hline Barium & & 20 & $75-125$ & 80 & & & & & & \\
\hline Beryllium & & 20 & $75-125$ & 95 & & & & & & \\
\hline Cadmium & & 20 & $75-125$ & 95 & & & & & & \\
\hline Chromium & & 20 & $75-125$ & 83 & & & & & & \\
\hline Cobalt & & 20 & $75-125$ & 76 & & & & & & \\
\hline Copper & & 20 & $75-125$ & 77 & & & & & & \\
\hline Lead & & 20 & $75-125$ & 121 & & & & & & \\
\hline Manganese & & 20 & $75-125$ & 82 & & & & & & \\
\hline Mercury & & 20 & $75-125$ & 116 & & & & & & \\
\hline Molybdenum & & 20 & $75-125$ & 105 & & & & & & \\
\hline Nickel & & 20 & $75-125$ & 84 & & & & & & \\
\hline Selenium & & 20 & $75-125$ & $71 Q$ & & & & & & \\
\hline Vanadium & & 20 & $75-125$ & 79 & & & & & & \\
\hline
\end{tabular}


Table D-2 (Continued)

\begin{tabular}{|c|c|c|c|c|c|c|c|c|c|c|}
\hline \multirow[b]{2}{*}{ Measurement Parameter } & \multirow[b]{2}{*}{ How Measured } & \multicolumn{2}{|c|}{ Objectires } & \multicolumn{2}{|c|}{$\begin{array}{c}\text { Measured } \\
\text { Accuracy } \\
\text { (\% Recovery) }\end{array}$} & \multirow{2}{*}{\begin{tabular}{|c|}
$\begin{array}{c}\text { Measured } \\
\text { Precision }\end{array}$ \\
(\% RPD) \\
\end{tabular}} & \multirow{2}{*}{$\begin{array}{c}\begin{array}{c}\text { Audit Sample } \\
\text { Accuracy }\end{array} \\
\text { (\% Recovery) }\end{array}$} & \multicolumn{2}{|c|}{$\begin{array}{c}\text { Measured } \\
\text { Accuracy } \\
\text { (\% Recotery) }\end{array}$} & \multirow{2}{*}{$\begin{array}{c}\text { Measured } \\
\text { Precision }\end{array}$} \\
\hline & & $\begin{array}{l}\text { Precision } \\
\text { (\% RPD) }\end{array}$ & $\begin{array}{c}\text { Accuracy } \\
\text { (\% Recovery) }\end{array}$ & MS-1 & MSD-1 & & & MS-2 & MSD-2 & \\
\hline Metals in Coal - INAA & $\begin{array}{l}\text { Precision - NA } \\
\text { Accuracy - Standard Reference Material } \\
\text { (NIST 1632-A) }\end{array}$ & & & & & & & & & \\
\hline Aluminum & & 20 & $75-125$ & & & & 101 & & & \\
\hline Antimony & & 20 & $75-125$ & & & & 99 & & & \\
\hline Arsenic & & 20 & $75-125$ & & & & 99 & & & \\
\hline Barium & & 20 & $75-125$ & & & & 101 & & & \\
\hline Calcium & & 20 & $75-125$ & & & & 103 & & & \\
\hline Cadmium & & 20 & $75-125$ & & & & NC & & & \\
\hline Chromium & & 20 & $75-125$ & & & & 99 & & & \\
\hline Cobalt & & 20 & $75-125$ & & & & 98 & & & \\
\hline Copper & & 20 & $75-125$ & & & & 100 & & & \\
\hline Iron & & 20 & $75-125$ & & & & 100 & & & $\cdot$ \\
\hline Magnesium & & 20 & $75-125$ & & & & 101 & & & \\
\hline Manganese & & 20 & $75-125$. & & & & 97 & & & \\
\hline Mercury & & 20 & $75-125$ & & & & NC & & & \\
\hline Molybdenum & & 20 & $75-125$ & & & & 103 & & & \\
\hline Nickel & & 20 & $75-125$ & & & & 90 & & & \\
\hline Potassium & & 20 & $75-125$ & & & & 101 & & & \\
\hline Selenium & & 20 & $75-125$ & & & & 104 & & & \\
\hline Silver & $\cdot$ & 20 & $75-125$ & & & & 111 & & & \\
\hline Sodium & & 20 & $75-125$ & & & & 101 & & & \\
\hline Titanium & & 20 & $75-125$ & & & & 101 & & & \\
\hline Vanadium & & 20 & $75-125$ & & & & 111 & & & \\
\hline
\end{tabular}


$\underset{\perp}{\forall} \quad$ Table D-2 (Continued)

\begin{tabular}{|c|c|c|c|c|c|c|c|c|c|c|}
\hline \multirow{2}{*}{ Measurement Parameter } & \multirow{2}{*}{ How Measured } & \multicolumn{2}{|c|}{ Objectives } & \multicolumn{2}{|c|}{$\begin{array}{c}\text { Measured } \\
\text { Accuracy } \\
\text { (\% Recotery) }\end{array}$} & \multirow{2}{*}{$\begin{array}{c}\begin{array}{c}\text { Measured } \\
\text { Precision }\end{array} \\
\text { (\% RPD) }\end{array}$} & \multirow{2}{*}{$\begin{array}{c}\text { Audit Sample } \\
\text { Accuracy }\end{array}$} & \multicolumn{2}{|c|}{$\begin{array}{c}\text { Measured } \\
\text { Accuracy } \\
\text { (\% Recovery) }\end{array}$} & \multirow{2}{*}{$\begin{array}{c}\begin{array}{c}\text { Measured } \\
\text { Precision }\end{array} \\
\text { (\% RPD) }\end{array}$} \\
\hline & & $\begin{array}{l}\text { Precision } \\
(\% \text { RPD) } \\
\end{array}$ & $\begin{array}{c}\text { Accuracy } \\
\text { (\% Recovery) } \\
\end{array}$ & MS-1 & MSD-1 & & & MS-2 & MSD-2 & \\
\hline \multicolumn{11}{|c|}{ Metals in Gas Solid Phase - GFAAS \& CVAAS } \\
\hline $\begin{array}{l}\text { Filtered Solids: APF \& ESP } \\
\text { Inlet }\end{array}$ & $\begin{array}{l}\text { Precision - Matrix-spiked Duplicate } \\
\text { Accuracy - Matrix-spiked Sample }\end{array}$ & & & & & & & & & \\
\hline Arsenic & & 20 & $75-125$ & 93 & 102 & 9.2 & & & & \\
\hline Cadmium & & 20 & $75-125$ & 105 & 102 & 2.9 & & & & \\
\hline Lead & & 20 & $75-125$ & $72 Q$ & 76 & 5.4 & & $71 \mathrm{Q}$ & 76 & 6.8 \\
\hline Mercury & & 20 & $75-125$ & 104 & 105 & 0.96 & & & & \\
\hline Selenium & & 20 & $75-125$ & 81 & 80 & 1.2 & & & & \\
\hline Acetone PNR: ESP Inlet & $\begin{array}{l}\text { Precision - Matrix-spiked Duplicate } \\
\text { Accuracy - Matrix-spiked Sample }\end{array}$ & & & & & & & & & \\
\hline Arsenic & & 20 & $75-125$ & 116 & 114 & 1.7 & & & & \\
\hline Lead & & 20 & $75-125$ & 82 & 79 & 3.7 & & & & \\
\hline Mercury & & 20 & $75-125$ & 106 & 106 & 0 & & & & \\
\hline Selenium & & 20 & $75-125$ & $69 \mathrm{Q}$ & $67 Q$ & 2.9 & & $73 Q$ & $67 Q$ & 8.6 \\
\hline $\begin{array}{r}\text { Nitric PNR: ESP Inlet } \\
\ddots \\
\end{array}$ & $\begin{array}{l}\text { Precision - Matrix-spiked Duplicate } \\
\text { Accuracy - Matrix-spiked Sample }\end{array}$ & & & & & & & & & \\
\hline Mercury & & 20 & $75-125$ & 100 & 98 & 2 & & & & \\
\hline Filter (Half): APF Outlet & $\begin{array}{l}\text { Precision - Matrix-spiked Duplicate } \\
\text { Accuracy - Matrix-spiked Sample }\end{array}$ & & & & & & & & & \\
\hline Arsenic & & 20 & $75-125$ & 104 & 104 & 0 & & & & \\
\hline Cadmium & & 20 & $75-125$ & 93 & 94 & 1.1 & & & & \\
\hline Lead & & 20 & $75-125$ & 105 & 108 & 2.8 & & & & \\
\hline Mercury & & 20 & $75-125$ & 101 & 102 & 0.98 & & & & \\
\hline Selenium & & 20 & $75-125$ & 101 & 101 & 0 & & & & \\
\hline
\end{tabular}




\section{Table D-2 (Continued)}

\begin{tabular}{|c|c|c|c|c|c|c|c|c|c|c|}
\hline \multirow{2}{*}{ Measurement Parameter } & \multirow{2}{*}{ How Measured } & \multicolumn{2}{|c|}{ Objectives } & \multicolumn{2}{|c|}{$\begin{array}{c}\text { Measured } \\
\text { Accuracy } \\
\text { (\% Recorery) }\end{array}$} & \multirow{2}{*}{\begin{tabular}{|c|}
$\begin{array}{c}\text { Measured } \\
\text { Precision }\end{array}$ \\
(\% RPD)
\end{tabular}} & \multirow{2}{*}{$\begin{array}{c}\begin{array}{c}\text { Andit Sample } \\
\text { Accuracy }\end{array} \\
\text { (\% Recorery) }\end{array}$} & \multicolumn{2}{|c|}{$\begin{array}{c}\text { Measured } \\
\text { Accuracy } \\
\text { (\% Recovery) }\end{array}$} & \multirow{2}{*}{$\begin{array}{l}\text { Mensured } \\
\text { Precision } \\
\text { (\% RPD) }\end{array}$} \\
\hline & & $\begin{array}{l}\text { Precision } \\
\text { (\% RPD) }\end{array}$ & $\begin{array}{c}\text { Accuracy } \\
\text { (\% Recovery) }\end{array}$ & MS-1 & MSD-1 & & & MS-2 & MSD-2 & \\
\hline Filter \& PNRs: ESP Outlet & $\begin{array}{l}\text { Precision - Matrix-spiked Duplicate } \\
\text { Accuracy - Matrix-spiked Sample }\end{array}$ & & & & & & & & & \\
\hline Arsenic & & 20 & $75-125$ & 105 & 111 & 5.6 & & & - & \\
\hline Cadmium & & 20 & $75-125$ & 104 & 92 & 12 & & & & \\
\hline Lead & & 20 & $75-125$ & 110 & 100 & 9.5 & & & & \\
\hline Mercury & & 20 & $75-125$ & 111 & 111 & 0 & . & & & \\
\hline Selenium & & 20 & $75-125$ & 82 & 89 & 8.2 & & & & \\
\hline Cadmium (different Batch) & & 20 & $75-125$ & 86 & 82 & 4.8 & & 84 & 86 & 2.4 \\
\hline Mercury (different Batch) & & 20 & $75-125$ & 112 & 113 & 0.89 & & & & \\
\hline \multicolumn{11}{|c|}{ Metals in Gas Vapor Phase - GFAAS \& CVAAS } \\
\hline $\mathrm{INO}_{3} / \mathrm{H}_{2} \mathrm{O}_{2}$ Impingers & $\begin{array}{l}\text { Precision - Matrix-spiked Duplicate } \\
\text { Accuracy - Matrix-spiked Sample }\end{array}$ & & & & & & & & & \\
\hline Arsenic & & 20 & $75-125$ & 103 & 102 & 0.98 & & & & \\
\hline Cadmium & & 20 & $75-125$ & 108 & 110 & 1.8 & & & & \\
\hline Lead & & 20 & $75-125$ & 99 & 100 & 1 & & & & \\
\hline Mercury & & 20 & $75-125$ & 96 & 96 & 0 & & & & \\
\hline Selenium & & 20 & $75-125$ & $38 \mathrm{Q}$ & $41 Q$ & 7.6 & & $56 \mathrm{Q}$ & $61 Q$ & 8.6 \\
\hline Selenium (Different Batch) & & 20 & $75-125$ & $4.6 \mathrm{Q}$ & $14 Q$ & $101 Q$ & & & & \\
\hline $\mathrm{KMnO}_{4}$ Impingers & $\begin{array}{l}\text { Precision - Matrix-spiked Duplicalc } \\
\text { Accuracy - Matrix-spiked Sample }\end{array}$ & & & & & & & & & \\
\hline Mercury & & 20 & $75-125$ & 76 & $72 Q$ & 5.4 & & 76 & & \\
\hline
\end{tabular}




\begin{tabular}{|c|c|c|c|c|c|c|c|c|c|c|}
\hline & & & & 0 & $\varepsilon 6$ & $\varepsilon 6$ & SZI-SL & $0 z$ & & 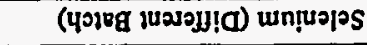 \\
\hline & & & & $\tau^{\prime} \tau$ & 06 & 26 & SZI-SL & $0 z$ & & 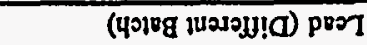 \\
\hline & & & & $\boldsymbol{s}^{\prime} \varepsilon$ & $\angle 8$ & 68 & SZI-SL & $0 z$ & . & un!̣गIOS \\
\hline & & & & 6.5 & 56 & 06 & SZI-SL & $0 z$ & & Sunasow \\
\hline & & & & $\tau$ & 66 & $\angle 6$ & $S Z I-S L$ & $0 z$ & & port \\
\hline & & & & 8.6 & LOI & 201 & SZI-SL & $0 z$ & & unกuppo \\
\hline & & & & 7.6 & 16 & 001 & $S Z I-S L$ & $0 z$ & & 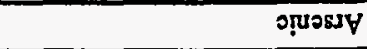 \\
\hline & & & & & & & & & 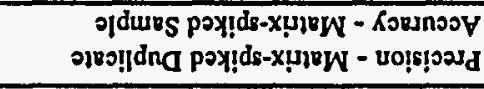 & 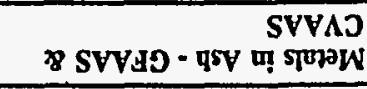 \\
\hline & & & 801 & & & & $S Z I-S L$ & $0 z$ & & 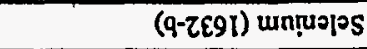 \\
\hline & & & 501 & & & & $S Z I-S L$ & $0 z$ & & (0z Wrys) Sinasow \\
\hline & & & LOI & & & & SZI-SL & $0 z$ & & $(\mathbb{p}-\varepsilon \varepsilon q I)$ p prI \\
\hline & & & $0 \angle \angle 8$ & & & & $S Z I-S L$ & 02 & & 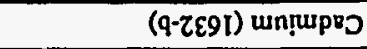 \\
\hline & & & $\partial g L$ & & & & $S Z I-S L$ & $0 z$ & & $(q-Z \varepsilon 91)$ ग!นจะ \\
\hline & & & & & & & & & 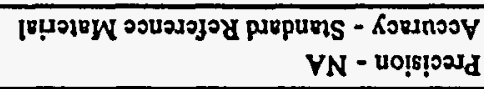 & 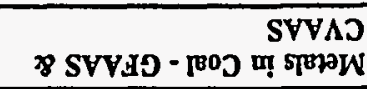 \\
\hline & & & & 0 & $9 \cdot 0$ & $9 \cdot 0$ & SZI-SL & $0 z$ & & unņuशpos \\
\hline & & & & 0 & $8^{\circ} 0$ & $8^{\prime} 0$ & SZI-SL & $0 z$ & & 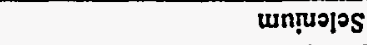 \\
\hline & & & & 5.9 & $9 r^{\circ} 0$ & sto & $S Z I-S L$ & $0 z$ & & SinasoW \\
\hline & & & & 0 & $L$ & $L$ & $S Z I-S L$ & $0 z$ & & peI \\
\hline & & & & 22 & $80^{\circ} 0$ & I'0 & SZI-SL & $0 z$ & & unntupes \\
\hline & & & & +1 & IE & $L \tau$ & $S Z I-S L$ & 02 & & ग़ुuss? \\
\hline & & & & & & & & & 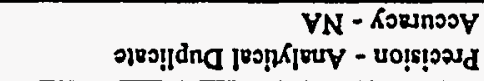 & 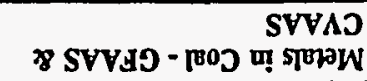 \\
\hline (बdd क) & z-aSW & $2 \cdot 5 W$ & 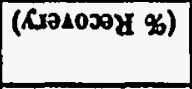 & $(ब d d \%)$ & $\mathfrak{I}-\mathbf{a S W}$ & I-SW & 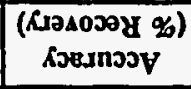 & $\begin{array}{l}\text { (ad8 \%) } \\
\text { no!ş̦add }\end{array}$ & \multirow{2}{*}{ 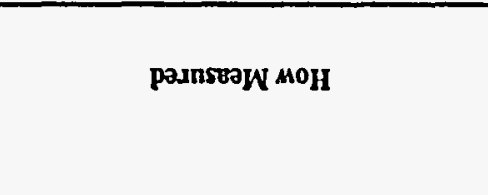 } & \multirow{2}{*}{ 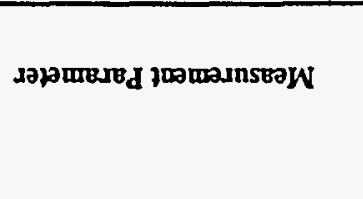 } \\
\hline $\begin{array}{l}\text { ooppoud } \\
\text { panseras }\end{array}$ & \multicolumn{2}{|c|}{ 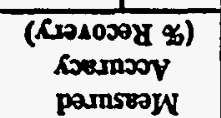 } & 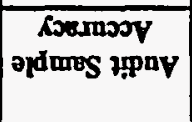 & $\begin{array}{l}\text { copspoud } \\
\text { paunserw }\end{array}$ & \multicolumn{2}{|c|}{ 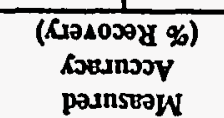 } & \multicolumn{2}{|c|}{$\frac{1}{9 \Delta ! 90 ! q 0}$} & & \\
\hline
\end{tabular}

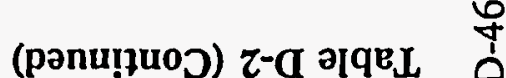


Table D-2 (Continued)

\begin{tabular}{|c|c|c|c|c|c|c|c|c|c|c|}
\hline \multirow{2}{*}{ Measurement Parameter } & \multirow{2}{*}{ How Measured } & \multicolumn{2}{|c|}{ Objectires } & \multicolumn{2}{|c|}{$\begin{array}{c}\text { Measured } \\
\text { Accuracy } \\
\text { (\% Recorery) }\end{array}$} & \multirow{2}{*}{\begin{tabular}{|c|}
$\begin{array}{c}\text { Measured } \\
\text { Precision }\end{array}$ \\
(\% RPD) \\
\end{tabular}} & \multirow{2}{*}{$\begin{array}{c}\begin{array}{c}\text { Audit Sample } \\
\text { Accuracy }\end{array} \\
\text { (\% Recorery) }\end{array}$} & \multicolumn{2}{|c|}{$\begin{array}{c}\text { Measured } \\
\text { Accuracy } \\
\text { (\% Recovery) } \\
\end{array}$} & \multirow{2}{*}{$\begin{array}{l}\begin{array}{c}\text { Measured } \\
\text { Precision }\end{array} \\
\text { (\% RPD) }\end{array}$} \\
\hline & & $\begin{array}{l}\text { Precision } \\
(\% \text { RPD) } \\
\end{array}$ & $\begin{array}{c}\text { Accuracy } \\
\text { (\% Recovery) }\end{array}$ & MS-1 & MSD-1 & & & MS-2 & MSD-2 & \\
\hline $\begin{array}{l}\text { Metals in Sorbent - GFAAS \& } \\
\text { CVAAS }\end{array}$ & $\begin{array}{l}\text { Precision - Matrix-spiked Duplicate } \\
\text { Accuracy - Matrix-spiked Sample }\end{array}$ & & & & & & & & & \\
\hline Arsenic & & 20 & $75-125$ & 111 & 111 & 0 & & & & \\
\hline Cadmium & & 20 & $75-125$ & 113 & 114 & 0.88 & & & & \\
\hline Lead & & 20 & $75-125$ & 108 & 108 & 0 & & & & \\
\hline Mercury & & 20 & $75-125$ & 104 & 108 & 3.8 & & & & \\
\hline Selenium & & 20 & $75-125$ & 97 & 104 & 7 & & & & \\
\hline $\begin{array}{l}\text { Metals in Service Water - } \\
\text { GFAAS \& CVAAS }\end{array}$ & $\begin{array}{l}\text { Precision - Matrix-spiked Duplicate } \\
\text { Accuracy - Matrix-spiked Sample } \\
\end{array}$ & & & & & & & & & \\
\hline Arsenic & & 20 & $75-125$ & 108 & 111 & 2.7 & & & & \\
\hline Cadmium & & 20 & $75-125$ & 105 & 103 & 1.9 & & & & \\
\hline Lead & & 20 & $75-125$ & 92 & 92 & 0 & & & & \\
\hline Mercury & & 20 & $75-125$ & 114 & 98 & 15 & & & & \\
\hline Selenium & & 20 & $75-125$ & 89 & 89 & o & & & & \\
\hline \multicolumn{11}{|l|}{ Anions in Gas Particulate Phase } \\
\hline Filter (IIal): APF Outlet & $\begin{array}{l}\text { Precision - Matrix-spiked Duplicate } \\
\text { Accurncy - Matrix-npiked Snmplo } \\
\end{array}$ & & & & & & & & & \\
\hline Chloride & & 20 & $80-120$ & 101 & 105 & 3.9 & & & & \\
\hline Sulfale & & 20 & $80-120$ & 82 & 80 & 2.5 & & & & \\
\hline Chloride (Different Batch) & & 20 & $80-120$ & 85 & 82 & 3.6 & & & & \\
\hline 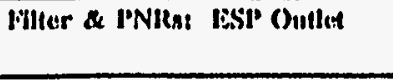 & $\begin{array}{l}\text { Procialuon - Mntrix-uplkod Duyplicnlo } \\
\text { Accuracy - Matrix-spiked Sample }\end{array}$ & & & & & & & & & \\
\hline Fluoride & & 20 & $80-120$ & 100 & 102 & 2 & & & & \\
\hline Anions in Gas Vapor Phase & & & & & & & & & & \\
\hline
\end{tabular}




\begin{tabular}{|c|c|c|c|c|c|c|c|c|c|c|}
\hline & & & 201 & & & & $0 Z 1-08$ & $0 \tau$ & & t\&XXo sosn - snjןns \\
\hline & & & E0I & & & & $0 Z 1-08$ & 02 & . & O-dXS \&VIWWOd - sny|nS \\
\hline & & & & & & & & & 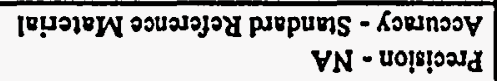 & पSV वा suog̣v \\
\hline & & & & $89^{\circ} 0$ & $8^{\prime} t I$ & $L^{\circ} \bullet \mathrm{I}$ & 0 0乙I-08 & $0 z$ & & Inyjns \\
\hline & & & & & & & & & 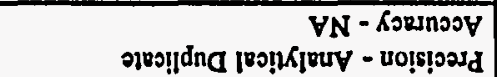 & 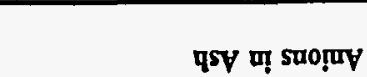 \\
\hline & & & & $\overline{\partial \varepsilon \varepsilon}$ & $\overline{\partial \varepsilon z}$ & $\partial 0 \varepsilon$ & $021-08$ & $0 z$ & & 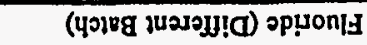 \\
\hline & & & & $\partial s z$ & $\partial s \tau$ & $\partial \tau \varepsilon$ & $0 z I-08$ & $0 z$ & & opỵonis \\
\hline & & & & 0 & 66 & 56 & $021-08$ & $\overline{o z}$ & & गpप̣olu0 \\
\hline & & & & & & & & & 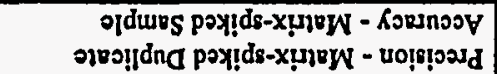 & 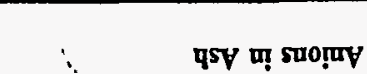 \\
\hline & & & OII & & & & $021-08$ & $0 \tau$ & & 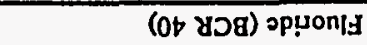 \\
\hline & & & $\angle 8$ & & & & $0 Z 1-08$ & $0 z$ & & (\$86 dd) эpน4이4ว \\
\hline & & & 101 & & & & $0 Z 1-08$ & 02 & & (q-ZE9I SgN) эрчฺ이 \\
\hline & & & & & & & & & 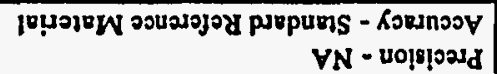 & proj m sü sụny \\
\hline & & & & 0 & 0zा & 021 & $021-08$ & $0 z$ & & optonity \\
\hline & & & & 0 & 066 & 066 & 0 0乙I-08 & $0 \tau$ & & орप̣о니 \\
\hline & & & & & & & & & 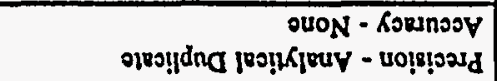 & 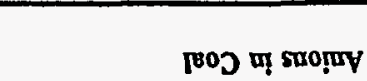 \\
\hline & & & & $I \cdot z$ & 96 & 86 & 0ZI-08 & $0 z$ & & ग80j|ns \\
\hline & & & & $I \cdot I$ & 56 & 76 & $0 Z 1-08$ & $0 z$ & & 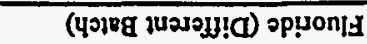 \\
\hline & & & & $L \cdot \varepsilon$ & OII & 901 & $0 Z I-08$ & 02 & & opponifH \\
\hline & & & & $I^{2} t$ & 56 & 66 & $021-08$ & $0 \tau$ & & कpपyol40 \\
\hline & & & & & & & & & 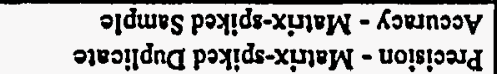 & ssa8mudm \\
\hline$\left(\operatorname{ddd} \sigma_{\sigma}\right)$ & z-OSW & $2-5 w$ & 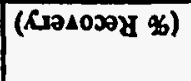 & (बd\& \%) & I-बSW & I-SW & 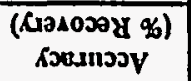 & 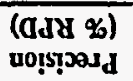 & \multirow{2}{*}{ pansreכW MOHI } & \multirow{2}{*}{ 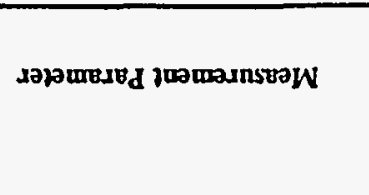 } \\
\hline 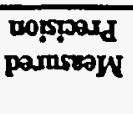 & \multicolumn{2}{|c|}{ 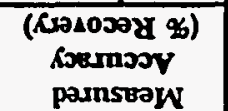 } & 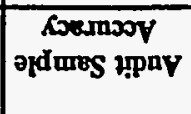 & $\begin{array}{l}\text { mostrpard } \\
\text { painseaw }\end{array}$ & \multicolumn{2}{|c|}{ 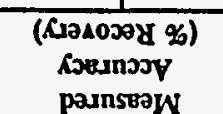 } & \multicolumn{2}{|c|}{$504900 ! 90$} & & \\
\hline
\end{tabular}




\section{Table D-2 (Continued)}

\begin{tabular}{|c|c|c|c|c|c|c|c|c|c|c|}
\hline \multirow{2}{*}{ Measurement Parameter } & \multirow[b]{2}{*}{ How Measured } & \multicolumn{2}{|c|}{ Objectires } & \multicolumn{2}{|c|}{$\begin{array}{c}\text { Measured } \\
\text { Accuracy } \\
\text { (\% Recotery) }\end{array}$} & \multirow{2}{*}{\begin{tabular}{|c|}
$\begin{array}{c}\text { Measured } \\
\text { Precision }\end{array}$ \\
(\% RPD)
\end{tabular}} & \multirow{2}{*}{\begin{tabular}{|c|}
$\begin{array}{c}\text { Audit Sample } \\
\text { Accuracy }\end{array}$ \\
(\% Recorery)
\end{tabular}} & \multicolumn{2}{|c|}{$\begin{array}{c}\text { Measured } \\
\text { Accuracy } \\
\text { (\% Recovery) }\end{array}$} & \multirow{2}{*}{\begin{tabular}{|c}
$\begin{array}{c}\text { Measured } \\
\text { Precision }\end{array}$ \\
(\% RPD)
\end{tabular}} \\
\hline & & $\begin{array}{l}\text { Precision } \\
\text { (\% RPD) }\end{array}$ & $\begin{array}{c}\text { Accuracy } \\
\text { (\% Recovery) }\end{array}$ & MS-1 & MSD-1 & & & MS-2 & MSD-2 & \\
\hline Anions in Sorbent & $\begin{array}{l}\text { Precision - Matrix-spiked Duplicate } \\
\text { Accuracy - Matrix-spiked Sample }\end{array}$ & & & & & & & & & \\
\hline Chloride & & 20 & $80-120$ & 99 & 99 & 0 & & & & \\
\hline Fluoride & & 20 & $80-120$ & $62 Q$ & 80 & $25 Q$ & & & & \\
\hline Sulfate & & 20 & $80-120$ & 83 & 82 & 1.2 & & & & \\
\hline Anions in Service Water & $\begin{array}{l}\text { Precision - Matrix-spiked Duplicate } \\
\text { Accuracy - Matrix-spiked Sample }\end{array}$ & & & & & & & & & \\
\hline Chloride & & 20 & $80-120$ & 108 & 105 & 2.8 & & & & \\
\hline Fluoride & & 20 & $80-120$ & 106 & 107 & 0.94 & & & & \\
\hline Sulfate & & 20 & $80-120$ & 91 & 91 & 0 & & & & \\
\hline Phosphate & & 20 & $75-125$ & 102 & 105 & 2.9 & & & & \\
\hline Carbon \& Boron in Ash & $\begin{array}{l}\text { Precision - NA } \\
\text { Accuracy - Standard Reference Material }\end{array}$ & & & & & & & & & \\
\hline Carbon (DOMTAR CYP-C) & & 20 & $75-125$ & & & & 101 & & & \\
\hline Carbon (MRG-1) & & 20 & $75-125$ & & & & 77 & & & \\
\hline IBUWU" (SAIRM 20) & & 20 & $75-125$ & & & & 101 & & & \\
\hline Carbon \& Boron in Ash & $\begin{array}{l}\text { Precision - Analytical Duplicate } \\
\text { Accuracy - NA }\end{array}$ & & & & & & & & & \\
\hline Cnetion & & 20 & 75.12 .5 & 0.06 & 0.06 & 0 & & & & \\
\hline Carbon & & 20 & $75-125$ & 5.18 & 5.14 & 0.78 & & & & \\
\hline Carbon & & 20 & $75-125$ & 0.35 & 0.32 & 9 & & & & \\
\hline Boron & & 20 & $75-125$ & 110 & 100 & 9.5 & & & & \\
\hline Boron & & 20 & $75-125$ & 81 & 94 & 14.9 & & & & \\
\hline Boron & & 20 & $75-125$ & 81 & 82 & 1.2 & & & & \\
\hline $\begin{array}{l}\text { Ammonia in Gas Vapor Phase } \\
\text { by } 350.2\end{array}$ & $\begin{array}{l}\text { Precision - Matrix-spiked Duplicate } \\
\text { Accuracy - Matrix-spiked Sample }\end{array}$ & & & & & & & & & \\
\hline Ammonia & & 20 & $80-120$ & 97 & 108 & 11 & & & & \\
\hline
\end{tabular}




\begin{tabular}{|c|c|c|c|c|c|c|c|c|c|c|}
\hline \multirow[b]{2}{*}{ Measurement Parameter } & \multirow[b]{2}{*}{ How Measured } & \multicolumn{2}{|c|}{ Objectives } & \multicolumn{2}{|c|}{$\begin{array}{c}\text { Mearured } \\
\text { Accuracy } \\
\text { (\% Recovery) }\end{array}$} & \multirow{2}{*}{$\begin{array}{c}\text { Mensured } \\
\text { Precision } \\
\text { (\% RPD) }\end{array}$} & \multirow{2}{*}{$\begin{array}{c}\text { Audit Sumplo } \\
\text { Accuracy }\end{array}$} & \multicolumn{2}{|c|}{$\begin{array}{c}\text { Measured } \\
\text { Accuracy } \\
\text { (\% Recovery) }\end{array}$} & \multirow{2}{*}{$\begin{array}{c}\begin{array}{c}\text { Measured } \\
\text { Precision }\end{array} \\
\text { ( } \% \text { RPD) }\end{array}$} \\
\hline & & $\begin{array}{l}\text { Precision } \\
\text { (\% RPD) } \\
\end{array}$ & $\begin{array}{c}\text { Accuracy } \\
(\% \text { Recovery) }\end{array}$ & MS-1 & MSD-1 & & & MS-2 & MSD-2 & \\
\hline $\begin{array}{l}\text { Cyanide in Gas Vapor Phase by } \\
335.2\end{array}$ & $\begin{array}{l}\text { Precision - Matrix-spiked Duplicate } \\
\text { Accuracy - Matrix-spiked Sample }\end{array}$ & & & & & & & & & \\
\hline Cyanide & & 20 & $75-125$ & 100 & 98 & 2 & & & & \\
\hline Chromium in Gas Vapor Phase & $\begin{array}{l}\text { Precision - Matrix-apiked Duplicate } \\
\text { Accuracy - Matrix-spiked Sample }\end{array}$ & & & & & & & & & \\
\hline Chromium (Nitric Rinse) & & 20 & $75-125$ & 95 & 98 & 3.1 & & & & \\
\hline Chromium (KOH Impinger) & & 20 & $75-125$ & 92 & 101 & 9.3 & & & & \\
\hline $\begin{array}{l}\text { Formaldehyde in Gas Vapor } \\
\text { Phase }\end{array}$ & $\begin{array}{l}\text { Precision - Analytical Duplicate } \\
\text { Accuracy - NA }\end{array}$ & & & & & & & & & \\
\hline Formaldehyde & & 10 & $70-130$ & 260 & 270 & 3.8 & & & & \\
\hline Formaldehyde & & 10 & $70-130$ & 63 & 60 & 4.9 & & & & \\
\hline $\begin{array}{l}\text { Formaldehyde in Gas Vapor } \\
\text { Phase }\end{array}$ & $\begin{array}{l}\text { Precision - NA } \\
\text { Accuracy - Trip Spike }\end{array}$ & & & & & & & & & \\
\hline Formaldehyde & & 10 & $70-130$ & 94 & & & & . & & \\
\hline Formaldehyde & & 10 & $70-130$ & 74 & & & & & & \\
\hline $\begin{array}{l}\text { Formaldehyde in Gas Vapor } \\
\text { Phase }\end{array}$ & $\begin{array}{l}\text { Precision - NA } \\
\text { Accuracy - Lab Spike }\end{array}$ & & & & & & & & & \\
\hline Formaldehyde & & 10 & $70-130$ & 92 & & & & & & \\
\hline Formaldehyde & & 10 & $70-130$ & 91 & & & & & & \\
\hline Semivolatile Compounds in Ash & $\begin{array}{l}\text { Precision - Matrix-spiked Duplicate } \\
\text { Aecuracy - Matrix-spiked Sample }\end{array}$ & & & & & & & & & \\
\hline Acenaphthene & - & 50 & $47-145$ & 82 & 90 & 9.3 & & & & \\
\hline 4-Chloro-3-methylphenol & & 70 & $22-147$ & 68 & 86 & 23 & & & & \\
\hline 2-Chlorophenol & & 60 & $23-134$ & 75 & 89 & 17 & & & & \\
\hline 1,4-Dichlorobenzene & & 50 & $20-124$ & 83 & 91 & 9.2 & & & & \\
\hline
\end{tabular}




\section{Table D-2 (Continued)}

\begin{tabular}{|c|c|c|c|c|c|c|c|c|c|c|}
\hline \multirow[b]{2}{*}{ Measurement Parameter } & \multirow[b]{2}{*}{ How Measured } & \multicolumn{2}{|c|}{ Objectires } & \multicolumn{2}{|c|}{$\begin{array}{c}\text { Measured } \\
\text { Accuracy } \\
\text { (\% Recovery) }\end{array}$} & \multirow{2}{*}{\begin{tabular}{|c|}
$\begin{array}{c}\text { Measured } \\
\text { Precision }\end{array}$ \\
(\% RPD $)$
\end{tabular}} & \multirow{2}{*}{$\begin{array}{c}\begin{array}{c}\text { Audit Sample } \\
\text { Accuracy }\end{array} \\
\text { (\% Recovery) }\end{array}$} & \multicolumn{2}{|c|}{$\begin{array}{c}\text { Measured } \\
\text { Accuracy } \\
\text { (\% Recovery) }\end{array}$} & \multirow{2}{*}{$\begin{array}{r}\begin{array}{r}\text { Measured } \\
\text { Precision }\end{array} \\
\text { (\% RPD) }\end{array}$} \\
\hline & & $\begin{array}{l}\text { Precision } \\
\text { (\% RPD) }\end{array}$ & $\begin{array}{c}\text { Accuracy } \\
\text { (\% Recorery) }\end{array}$ & MS-1 & MSD-1 & & & MS-2 & MSD-2 & \\
\hline 2,4-Dinitrotoluene & & 50 & $39-139$ & 77 & 86 & 11 & & & & \\
\hline N-nitrosodipropylamine & & 130 & D-230 & 102 & 108 & 5.7 & & & & \\
\hline 4-Nitrophenol & & 80 & D-132 & 3.1 & 1.8 & 53 & & & & \\
\hline Pentachlorophenol & & 90 & $14-176$ & ND & $1.1 \mathrm{Q}$ & NC & & & & \\
\hline Phenol & & 50 & $5-112$ & 76 & 89 & 16 & & & & \\
\hline Pyrene & & 50 & $52-115$ & $49 Q$ & 59 & 18 & & & & \\
\hline 1,2,4-Trichlorobenzene & & 50 & $44-142$ & 90 & 98 & 8.5 & & & & \\
\hline
\end{tabular}

$\mathrm{NA}=$ Not applicable.

$\mathrm{NC}=$ Not calculable.

$\mathrm{ND}=$ Not detected.

$Q=$ Data flag indicating accuracy and precision results that do not meet the stated objectives. 


\section{Table D-3}

\section{Surrogate Spike Data}

\begin{tabular}{|c|c|c|c|c|c|}
\hline Measurement Parameter & How Measured & $\begin{array}{c}\text { Objective } \\
\text { (\% Rec) }\end{array}$ & $\begin{array}{l}\text { Range of } \\
\text { Recovery } \\
(\% \text { Rec) }\end{array}$ & $\begin{array}{l}\text { Number } \\
\text { Analyzed }\end{array}$ & $\begin{array}{l}\text { Number } \\
\text { Outside } \\
\text { Objective }\end{array}$ \\
\hline $\begin{array}{l}\text { Volatile Organics in Vapor } \\
\text { Phase - APF Inlet }\end{array}$ & \begin{tabular}{|l} 
Precision - NA \\
Accuracy - Surrogate Spike Recovery
\end{tabular} & & & & \\
\hline 1,2-Dichloroethane-d4 & & $51-145$ & $92-104$ & 6 & 0 \\
\hline Toluene d-8 & & $77-122$ & $90-99$ & 6 & 0 \\
\hline 4-Bromofluorobenzene & & $60-128$ & $87-96$ & 6 & 0 \\
\hline $\begin{array}{l}\text { Volatile Organics in Vapor } \\
\text { Phase - APF Outlet }\end{array}$ & \begin{tabular}{|l} 
Precision - NA \\
Accuracy - Surrogate Spike Recovery \\
\end{tabular} & & & & \\
\hline 1,2-Dichloroethane-d4 & & $51-145$ & $73-104$ & 6 & 0 \\
\hline Toluene d-8 & & $77-122$ & $87-98$ & 6 & 0 \\
\hline 4-Bromofluorobenzene & & $60-128$ & $82-94$ & 6 & 0 \\
\hline $\begin{array}{l}\text { Volatile Organics in Vapor } \\
\text { Phase - APF Field Blanks }\end{array}$ & $\begin{array}{l}\text { Precision - NA } \\
\text { Accuracy - Surrogate Spike Recovery }\end{array}$ & & & & \\
\hline 1,2-Dichloroethane-d4 & & $51-145$ & $92-105$ & 6 & 0 \\
\hline Toluene d-8 & & $77-122$ & $87-96$ & 6 & 0 \\
\hline 4-Bromofluorobenzene & & $60-128$ & $84-95$ & 6 & 0 \\
\hline $\begin{array}{l}\text { Volatile Organics in Vapor } \\
\text { Phase - ESP Inlet }\end{array}$ & $\begin{array}{l}\text { Precision - NA } \\
\text { Accuracy - Surrogate Spike Recovery }\end{array}$ & & & & \\
\hline 1,2-Dichloroethane-d4 & & $51-145$ & $90-107$ & 6 & 0 \\
\hline Toluene d-8 & & $77-122$ & 91-97 & 6 & 0 \\
\hline 4-Bromofluorobenzene & & $60-128$ & $86-93$ & 6 & 0 \\
\hline $\begin{array}{l}\text { Volatile Organics in Vapor } \\
\text { Phase - ESP Outlet }\end{array}$ & $\begin{array}{l}\text { Precision - NA } \\
\text { Accuracy - Surrogate Spike Recovery }\end{array}$ & & & & \\
\hline 1,2-Dichloroethane-d4 & & $51-145$ & $95-107$ & 6 & 0 \\
\hline Toluene d-8 & & $77-122$ & $83-100$ & 6 & 0 \\
\hline 4-Bromofluorobenzene & & $60-128$ & $74-94$ & 6 & 0 \\
\hline $\begin{array}{l}\text { Volatile Organics in Vapor } \\
\text { Phase - ESP Field Blanks }\end{array}$ & $\begin{array}{l}\text { Precision - NA } \\
\text { Accuracy - Surrogate Spike Recovery }\end{array}$ & & & & \\
\hline 1,2-Dichloroethane-d4 & & $51-145$ & $93-105^{\circ}$ & 6 & 0 \\
\hline Toluene d-8 & & $77-122$ & $91-98$ & 6 & 0 \\
\hline 4-Bromofluorobenzene & & $60-128$ & $91-98$ & 6 & 0 \\
\hline $\begin{array}{l}\text { Volatile Organics in Vapor } \\
\text { Phase - Trip Blank }\end{array}$ & $\begin{array}{l}\text { Precision - NA } \\
\text { Accuracy - Surrogate Spike Recovery }\end{array}$ & & & & \\
\hline 1,2-Dichloroethane-d4 & & $51-145$ & 105 & 1 & 0 \\
\hline Toluene d-8 & & $77-122$ & 97 & 1 & 0 \\
\hline 4-Bromofluorobenzene & & $60-128$ & 94 & 1 & $\mathbf{0}$ \\
\hline
\end{tabular}




\section{Table D-3 (Continued)}

\begin{tabular}{|c|c|c|c|c|c|}
\hline Measurement Parameter & How Measured & $\begin{array}{c}\text { Objective } \\
\text { (\% Rec) }\end{array}$ & $\begin{array}{c}\text { Range of } \\
\text { Recovery } \\
\text { (\% Rec) }\end{array}$ & $\begin{array}{c}\text { Number } \\
\text { Analyzed }\end{array}$ & $\begin{array}{c}\text { Number } \\
\text { Outside } \\
\text { Objective }\end{array}$ \\
\hline $\begin{array}{l}\text { Semivolatile Organics in APF } \\
\text { Ass }\end{array}$ & \begin{tabular}{|l|} 
Precision - NA \\
Accuracy - Surrogate Spike Recovery \\
\end{tabular} & & & & \\
\hline 2-Fluorobiphenyl & & $30-115$ & $92-99$ & 4 & $\mathbf{0}$ \\
\hline 2-Fluorophenol & & $25-121$ & $92-95$ & 4 & 0 \\
\hline Nitrobenzene-d5 & & $23-120$ & $99-103$ & 4 & 0 \\
\hline Phenol-d5 & & 24-113 & $94-99$ & 4 & $\mathbf{0}$ \\
\hline Terphenyl-d14 & & $18-137$ & $98-109$ & 4 & 0 \\
\hline 2,4,6-Tribromophenol & & $19-122$ & $76-88$ & 4 & 0 \\
\hline $\begin{array}{l}\text { Semivolatile Organics in ESP } \\
\text { Ash }\end{array}$ & $\begin{array}{l}\text { Precision - NA } \\
\text { Accuracy - Surrogate Spike Recovery }\end{array}$ & & & & \\
\hline 2-Fluorobiphenyl & & $30-115$ & $90-103$ & 4 & 0 \\
\hline 2-Fluorophenol & & $25-121$ & $84-96$ & 4 & 0 \\
\hline Nitrobenzene-d5 & & 23-120 & $92-104$ & 4 & 0 \\
\hline Phenol-d5 & & $24-113$ & $86-100$ & 4 & 0 \\
\hline Terphenyl-d14 & & $18-137$ & $92-105$ & 4 & 0 \\
\hline 2,4,6-Tribromophenol & & $19-122$ & $77-99$ & 4 & 0 \\
\hline $\begin{array}{l}\text { Semivolatile Organics in Bed } \\
\text { Ash }\end{array}$ & $\begin{array}{l}\text { Precision - NA } \\
\text { Accuracy - Surrogate Spike Recovery }\end{array}$ & & & & \\
\hline 2-Fluorobiphenyl & & $30-115$ & $94-100$ & 4 & 0 \\
\hline 2-Fluorophenol & & $25-121$ & $68-76$ & 4 & 0 \\
\hline Nitrobenzene-d5 & & $23-120$ & $94-98$ & 4 & 0 \\
\hline Phenol-d5 & & $24-113$ & $86-93$ & 4 & 0 \\
\hline Terphenyl-d14 & & $18-137$ & $102-106$ & 4 & 0 \\
\hline 2,4,6-Tribromophenol & & $19-122$ & $26-43$ & 4 & 0 \\
\hline $\begin{array}{l}\text { Semivolatile Organics in } \\
\text { Cyclone Ash }\end{array}$ & $\begin{array}{l}\text { Precision - NA } \\
\text { Accuracy - Surrogate Spike Recovery }\end{array}$ & & & & \\
\hline 2-Fluorobiphenyl & & $30-115$ & $100-104$ & 4 & 0 \\
\hline 2-Fluorophenol & & $25-121$ & $77-93$ & 4 & 0 \\
\hline Nitrobenzene-d5 & & $23-120$ & $100-103$ & 4 & 0 \\
\hline Phenol-d5 & & 24-113 & $96-100$ & 4 & 0 \\
\hline Terphenyl-d14 & & $18-137$ & $72-85$ & 4 & 0: \\
\hline 2,4,6-Tribromophenol & & $19-122$ & $10-36$ & 4 & 2 \\
\hline $\begin{array}{l}\text { Semivolatile Organics in Gas } \\
\text { Solid Phase - APF Inlet }\end{array}$ & $\begin{array}{l}\text { Precision - NA } \\
\text { Accuracy - Surrogate Spike Recovery }\end{array}$ & & & & \\
\hline Phenol-d5 & & $50-150$ & $17-84$ & 6 & 3 \\
\hline Nitrobenzene-d5 & & $50-150$ & $30-80$ & 6 & 3 \\
\hline 1,3,5-Trichlorobenzene-d3 & & $50-150$ & $23-84$ & 6 & 3 \\
\hline 1,4-Dibromobenzene-d4 & & $50-150$ & $44-90$ & 6 & 1 \\
\hline
\end{tabular}


Table D-3 (Continued)

\begin{tabular}{|c|c|c|c|c|c|}
\hline Measurement Parameter & How Measured & $\begin{array}{c}\text { Objective } \\
\text { (\% Rec) }\end{array}$ & $\begin{array}{l}\text { Range of } \\
\text { Recovery } \\
(\% \text { Rec) }\end{array}$ & $\begin{array}{l}\text { Number } \\
\text { Analyzed }\end{array}$ & $\begin{array}{c}\text { Number } \\
\text { Outside } \\
\text { Objective }\end{array}$ \\
\hline $\begin{array}{l}\text { Semivolatile Organics in Gas } \\
\text { Solid Phase - APF Outlet }\end{array}$ & $\begin{array}{l}\text { Precision - NA } \\
\text { Accuracy - Surrogate Spike Recovery }\end{array}$ & & & & \\
\hline Phenol-d5 & & $50-150$ & $31-78$ & 7 & 2 \\
\hline Nitrobenzene-d5 & & $50-150$ & $35-77$ & 7 & 2 \\
\hline 1,3,5-Trichlorobenzene-d3 & & $50-150$ & $33-78$ & 7 & 2 \\
\hline 1,4-Dibromobenzene-d4 & & $50-150$ & $52-96$ & 7 & 0 \\
\hline $\begin{array}{l}\text { Semivolatile Organics in Gas } \\
\text { Solid Phase - ESP Inlet }\end{array}$ & $\begin{array}{l}\text { Precision - NA } \\
\text { Accuracy - Surrogate Spike Recovery }\end{array}$ & & & & \\
\hline Phenol-d5 & & $50-150$ & $46-88$ & 10 & 2 \\
\hline Nitrobenzene-d5 & & $50-150$ & $34-83$ & 10 & 4 \\
\hline 1,3,5-Trichlorobenzene-d3 & & $50-150$ & $29-82$ & 9 & 3 \\
\hline 1,4-Dibromobenzene-d4 & & $50-150$ & $70-115$ & 10 & 0 \\
\hline $\begin{array}{l}\text { Semivolatile Organics in Gas } \\
\text { Solid Phase - ESP Outlet }\end{array}$ & $\begin{array}{l}\text { Precision - NA . } \\
\text { Accuracy - Surrogate Spike Recovery }\end{array}$ & & & & \\
\hline Phenol-d5 & . & $50-150$ & $2-99$ & 8 & 4 \\
\hline Nitrobenzene-d5 & & $50-150$ & $44-80$ & 9 & 2 \\
\hline 1,3,5-Trichlorobenzene-d3 & & $50-150$ & $41-76$ & 9 & 2 \\
\hline 1,4-Dibromobenzene-d4 & & $50-150$ & $66-105$ & 9 & 0 \\
\hline $\begin{array}{l}\text { Semivolatile Organics in Gas } \\
\text { Vapor Phase - APF Field } \\
\text { Blanks }\end{array}$ & $\begin{array}{l}\text { Precision - NA } \\
\text { Accuracy - Surrogate Spike Recovery }\end{array}$ & & & & \\
\hline Phenol-d5 & & $50-150$ & $71-102$ & 2 & 0 \\
\hline Nitrobenzene-d5 & & $50-150$ & $52-96$ & 2 & 0 \\
\hline 1,3,5-Trichlorobenzene-d3 & & $50-150$ & $50-97$ & 2 & 0 \\
\hline 1,4-Dibromobenzene-d4 & & $50-150$ & $75-109$ & 2 & 0 \\
\hline $\begin{array}{l}\text { Semivolatile Organics in Gas } \\
\text { Solid Phase - ESP Field Blanks }\end{array}$ & \begin{tabular}{|l} 
Precision - NA \\
Accuracy - Surrogate Spike Recovery
\end{tabular} & & & & \\
\hline Phenol-d5 & & $50-150$ & $53-70$ & 2 & 0 . \\
\hline Nitrobenzene-d5 & & $50-150$ & $43-72$ & 2 & 1 \\
\hline 1,3,5-Trichlorobenzene-d3 & & $50-150$ & 43-74 & 2 & 1 \\
\hline 1,4-Dibromobenzene-d4 & & $50-150$ & $56-88$ & 2 & $\mathbf{0}$ \\
\hline $\begin{array}{l}\text { Semivolatile Organics in Gas } \\
\text { Vapor Phase - Trip Blank }\end{array}$ & $\begin{array}{l}\text { Precision - NA } \\
\text { Accuracy - Surrogate Spike Recovery }\end{array}$ & & & & \\
\hline Phenol-d5 & & $50-150$ & 60 & 1 & 0 \\
\hline Nitrobenzene-d5 & & $50-150$ & 60 & 1 & 0 \\
\hline 1,3,5-Trichlorobenzene-d3 & & $50-150$ & 65 & 1 & 0 \\
\hline 1,4-Dibromobenzene-d4 & & $50-150$ & 72 & 1 & 0 \\
\hline
\end{tabular}


Table D-3 (Continued)

\begin{tabular}{|c|c|c|c|c|c|}
\hline Measurement Parameter & How Measured & $\begin{array}{l}\text { Objective } \\
\text { (\% Rec) }\end{array}$ & $\begin{array}{l}\text { Range of } \\
\text { Recovery } \\
\text { (\% Rec) }\end{array}$ & $\begin{array}{l}\text { Number } \\
\text { Analyzed }\end{array}$ & $\begin{array}{c}\text { Number } \\
\text { Outside } \\
\text { Objective }\end{array}$ \\
\hline $\begin{array}{l}\text { PAH Organics in Gas Vapor } \\
\text { Phase - APF Inlet }\end{array}$ & $\begin{array}{l}\text { Precision - NA } \\
\text { Accuracy - Surrogate Spike Recovery }\end{array}$ & & & & \\
\hline d10-Fluorene & & $50-150$ & $94-96$ & 3 & $\overline{0}$ \\
\hline d14-Terphenyl & & $50-150$ & 103-121 & 3 & $\mathbf{0}$ \\
\hline $\begin{array}{l}\text { PAH Organics in Gas Solid } \\
\text { Phase - APF Outlet }\end{array}$ & \begin{tabular}{|l} 
Precision - NA \\
Accuracy - Surrogate Spike Recovery
\end{tabular} & & & & \\
\hline d10-Fluorene & & $50-150$ & $93-99$ & 3 & $\mathbf{0}$ \\
\hline d14-Terphenyl & & $50-150$ & $108-115$ & 3 & 0 \\
\hline $\begin{array}{l}\text { PAF Organics in Gas Solid } \\
\text { Phase - ESP Inlet }\end{array}$ & \begin{tabular}{|l} 
Precision - NA \\
Accuracy - Surrogate Spike Recovery
\end{tabular} & & & & \\
\hline d10-Fluorene & & $50-150$ & $75-92$ & 3 & 0 \\
\hline d14-Terphenyl & & $50-150$ & $113-118$ & 3 & 0 \\
\hline $\begin{array}{l}\text { PAH Organics in Gas Solid } \\
\text { Phase - ESP Outlet }\end{array}$ & $\begin{array}{l}\text { Precision - NA } \\
\text { Accuracy - Surrogate Spike Recovery }\end{array}$ & & & & \\
\hline d10-Fluorene & & $50-150$ & $76-97$ & 3 & 0 \\
\hline d14-Terphenyl & & $50-150$ & $95-122$ & 3 & 0 \\
\hline $\begin{array}{l}\text { PAH Organics in Gas Solid } \\
\text { Phase - APF Field Blank }\end{array}$ & $\begin{array}{l}\text { Precision - NA } \\
\text { Accuracy - Surrogate Spike Recovery }\end{array}$ & & & & \\
\hline d10-Fluorene & & $50-150$ & 96 & 1 & 0 \\
\hline d14-Terphenyl & & $50-150$ & 115 & 1 & 0 \\
\hline $\begin{array}{l}\text { PAH Organics in Gas Vapor } \\
\text { Phase - ESP Field Blank }\end{array}$ & $\begin{array}{l}\text { Precision - NA } \\
\text { Accuracy - Surrogate Spike Recovery }\end{array}$ & & & & \\
\hline d10-Fluorene & & $50-150$ & 77 & 1 & 0 \\
\hline d14-Terphenyl & & $50-150$ & 100 & 1 & 0 \\
\hline Dioxins/Furans in APF Ash & $\begin{array}{l}\text { Precision - NA } \\
\text { Accuracy - Surrogate Spike Recovery }\end{array}$ & & & & \\
\hline 37C14-2,3,7,8-TCDD & & $40-130$ & $34-49$ & 4 & 2 \\
\hline $13 \mathrm{C} 12-2,3,4,7,8-\mathrm{PeCDF}$ & & $40-130$ & $49-55$ & 4 & $\mathbf{0}$ \\
\hline $13 \mathrm{C} 12-1,2,3,4,7,8-\mathrm{HxCDF}$ & & $40-130$ & $70-98$ & 4 & 0 \\
\hline $13 \mathrm{C} 12-1,2,3,4,7,8-\mathrm{HxCDD}$ & & $40-130$ & $67-81$ & 4 & 0 \\
\hline $13 \mathrm{C} 12-1,2,3,4,7,8,9-\mathrm{HpCDF}$ & & $25-130$ & $73-82$ & 4 & $\mathbf{0}$ \\
\hline Dioxins/Furans in ESP Ash & $\begin{array}{l}\text { Precision - NA } \\
\text { Accuracy - Surrogate Spike Recovery }\end{array}$ & & & & \\
\hline $37 \mathrm{C} 14-2,3,7,8-\mathrm{TCDD}$ & & $40-130$ & $46-60$ & 4 & 0 \\
\hline $13 \mathrm{Cl} 2-2,3,4,7,8-\mathrm{PeCDF}$ & & $40-130$ & $47-59$ & 4 & $\overline{0}$ \\
\hline $13 \mathrm{C} 12-1,2,3,4,7,8-\mathrm{HxCDF}$ & & $40-130$ & $82-98$ & 4 & 0 \\
\hline $13 \mathrm{C} 12-1,2,3,4,7,8-\mathrm{HxCDD}$ & & $40-130$ & $79-93$ & 4 & 0 \\
\hline $13 \mathrm{Cl} 2-1,2,3,4,7,8,9-\mathrm{HpCDF}$ & & $25-130$ & $71-83$ & 4 & $\mathbf{0}$ \\
\hline
\end{tabular}


Table D-3 (Continued)

\begin{tabular}{|c|c|c|c|c|c|}
\hline Measurement Parameter & How Measured & $\begin{array}{c}\text { Objective } \\
\text { (\% Rec) }\end{array}$ & $\begin{array}{c}\text { Range of } \\
\text { Recovery } \\
(\% \text { Rec) }\end{array}$ & $\begin{array}{l}\text { Number } \\
\text { Analyzed }\end{array}$ & $\begin{array}{c}\text { Number } \\
\text { Outside } \\
\text { Objective }\end{array}$ \\
\hline Dioxins/Furans in Cyclone Ash & $\begin{array}{l}\text { Precision - NA } \\
\text { Accuracy - Surrogate Spike Recovery }\end{array}$ & & & & \\
\hline 37C14-2,3,7,8-TCDD & & $40-130$ & $35-53$ & 4 & 1 \\
\hline $13 \mathrm{C} 12-2,3,4,7,8-\mathrm{PeCDF}$ & & $40-130$ & $44-53$ & 4 & $\mathbf{0}$ \\
\hline 13C12-1,2,3,4,7,8-HxCDF & & $40-130$ & $83-95$ & 4 & 0 \\
\hline $13 \mathrm{C} 12-1,2,3,4,7,8-\mathrm{HxCDD}$ & & $40-130$ & $77-86$ & 4 & $\mathbf{0}$ \\
\hline |13C12-1,2,3,4,7,8,9-HpCDF & & $25-130$ & $78-84$ & 4 & $\mathbf{0}$ \\
\hline $\begin{array}{l}\text { Dioxins/Furans in Gas: APF } \\
\text { Inlet }\end{array}$ & $\begin{array}{l}\text { Precision - NA } \\
\text { Accuracy - Surrogate Spike Recovery }\end{array}$ & & & & \\
\hline 37C14-2,3,7,8-TCDD & & $70-130$ & $88-110$ & 3 & 0 \\
\hline $13 \mathrm{C} 12-2,3,4,7,8-\mathrm{PeCDF}$ & & $70-130$ & $78-108$ & 3 & 0 \\
\hline $13 \mathrm{C} 12-1,2,3,4,7,8-\mathrm{HxCDF}$ & & $70-130$ & $91-127$ & 3 & 0 \\
\hline $13 \mathrm{C} 12-1,2,3,4,7,8-\mathrm{HxCDD}$ & & $70-130$ & $89-118$ & 3 & 0 \\
\hline $13 \mathrm{Cl} 12-1,2,3,4,7,8,9-\mathrm{HpCDF}$ & & $70-130$ & $60-122$ & 3 & 1 \\
\hline $\begin{array}{l}\text { Dioxins/Furans in Gas: APF } \\
\text { Outlet - PNR/XAD Only } \\
\end{array}$ & $\begin{array}{l}\text { Precision - NA } \\
\text { Accuracy - Surrogate Spike Recovery }\end{array}$ & & & & \\
\hline 37C14-2,3,7,8-TCDD & & $70-130$ & $74-79$ & 3 & 0 \\
\hline $13 \mathrm{C} 12-2,3,4,7,8-\mathrm{PeCDF}$ & & $70-130$ & $80-95$ & 3 & 0 \\
\hline $13 \mathrm{C} 12-1,2,3,4,7,8-\mathrm{HxCDF}$ & & $70-130$ & $80-96$ & 3 & 0 \\
\hline $13 \mathrm{C} 12-1,2,3,4,7,8-\mathrm{HxCDD}$ & & $70-130$ & $101-105$ & 3 & $\mathbf{0}$ \\
\hline $13 \mathrm{C} 12-1,2,3,4,7,8,9-\mathrm{HpCDF}$ & & $70-130$ & $68-110$ & 3 & 1 \\
\hline $\begin{array}{l}\text { Dioxins/Furans in Gas: ESP } \\
\text { Inlet }\end{array}$ & \begin{tabular}{|l|} 
Precision - NA \\
Accuracy - Surrogate Spike Recovery
\end{tabular} & & & & \\
\hline 37C14-2,3,7,8-TCDD & & $70-130$ & $85-88$ & 3 & 0 \\
\hline $13 \mathrm{C} 12-2,3,4,7,8-\mathrm{PeCDF}$ & & $70-130$ & $89-96$ & 3 & 0 \\
\hline $13 \mathrm{C} 12-1,2,3,4,7,8-\mathrm{HxCDF}$ & & $70-130$ & $82-108$ & 3 & 0 \\
\hline $13 \mathrm{C} 12-1,2,3,4,7,8-\mathrm{HxCDD}$ & & $70-130$ & $97-106$ & 3 & 0 \\
\hline $13 \mathrm{C} 12-1,2,3,4,7,8,9-\mathrm{HpCDF}$ & & $70-130$ & $99-110$ & 3 & 0 \\
\hline $\begin{array}{l}\text { Dioxins/Furans in Gas: ESP } \\
\text { Outlet }\end{array}$ & \begin{tabular}{|l|} 
Precision - NA \\
Accuracy - Surrogate Spike Recovery
\end{tabular} & & & & \\
\hline 37C14-2,3,7,8-TCDD & & $70-130$ & $85-89$ & 3 & 0 \\
\hline $13 \mathrm{C} 12-2,3,4,7,8-\mathrm{PeCDF}$ & & $70-130$ & $90-94$ & 3 & 0 \\
\hline $13 \mathrm{C} 12-1,2,3,4,7,8-\mathrm{HxCDF}$ & & $70-130$ & $94-112$ & 3 & 0 \\
\hline $13 \mathrm{C} 12-1,2,3,4,7,8-\mathrm{HxCDD}$ & & $70-130$ & $99-105$ & 3 & 0 \\
\hline $13 \mathrm{Cl} 12-1,2,3,4,7,8,9-\mathrm{HpCDF}$ & & $70-130$ & $83-112$ & 3 & 0 \\
\hline
\end{tabular}


Table D-3 (Continued)

\begin{tabular}{|c|c|c|c|c|c|}
\hline Measurement Parameter & How Measured & $\begin{array}{l}\text { Objective } \\
\text { (\% Rec) }\end{array}$ & $\begin{array}{l}\text { Range of } \\
\text { Recovery } \\
\text { (\% Rec) }\end{array}$ & $\begin{array}{l}\text { Number } \\
\text { Analyzed }\end{array}$ & $\begin{array}{c}\text { Number } \\
\text { Outside } \\
\text { Objective }\end{array}$ \\
\hline $\begin{array}{l}\text { Dioxins/Furans in Gas: APF } \\
\text { Field Blank }\end{array}$ & $\begin{array}{l}\text { Precision - NA } \\
\text { Accuracy - Surrogate Spike Recovery }\end{array}$ & & & & \\
\hline 37C14-2,3,7,8-TCDD & & $70-130$ & 84 & 1 & 0 \\
\hline $13 \mathrm{Cl} 2-2,3,4,7,8-\mathrm{PeCDF}$ & & $70-130$ & 89 & 1 & 0 \\
\hline 13C12-1,2,3,4,7,8-HxCDF & & $70-130$ & 92 & 1 & 0 \\
\hline $13 \mathrm{Cl} 2-1,2,3,4,7,8-\mathrm{HxCDD}$ & & $70-130$ & 105 & 1 & 0 \\
\hline $13 \mathrm{Cl} 2-1,2,3,4,7,8,9-\mathrm{HpCDF}$ & & $70-130$ & 96 & 1 & 0 \\
\hline $\begin{array}{l}\text { Dioxins/Furans in Gas: ESP } \\
\text { Field Blank }\end{array}$ & $\begin{array}{l}\text { Precision - NA } \\
\text { Accuracy - Surrogate Spike Recovery }\end{array}$ & & & & \\
\hline 37C14-2,3,7,8-TCDD & & $70-130$ & 85 & 1 & 0 \\
\hline $13 \mathrm{Cl} 2-2,3,4,7,8-\mathrm{PeCDF}$ & & $70-130$ & 90 & 1 & 0 \\
\hline $13 \mathrm{C} 12-1,2,3,4,7,8-\mathrm{HxCDF}$ & & $70-130$ & 109 & 1 & 0 \\
\hline $13 \mathrm{C} 12-1,2,3,4,7,8-\mathrm{HxCDD}$ & & $70-130$ & 99 & 1 & 0 \\
\hline $13 \mathrm{C} 12-1,2,3,4,7,8,9-\mathrm{Hp} \mathrm{CDF}$ & & $70-130$ & 93 & 1 & 0 \\
\hline
\end{tabular}

NA $=$ Not applicable. 
APPENDIX E: PROCESS DATA TREND PLOTS

E-1 
4/12/94

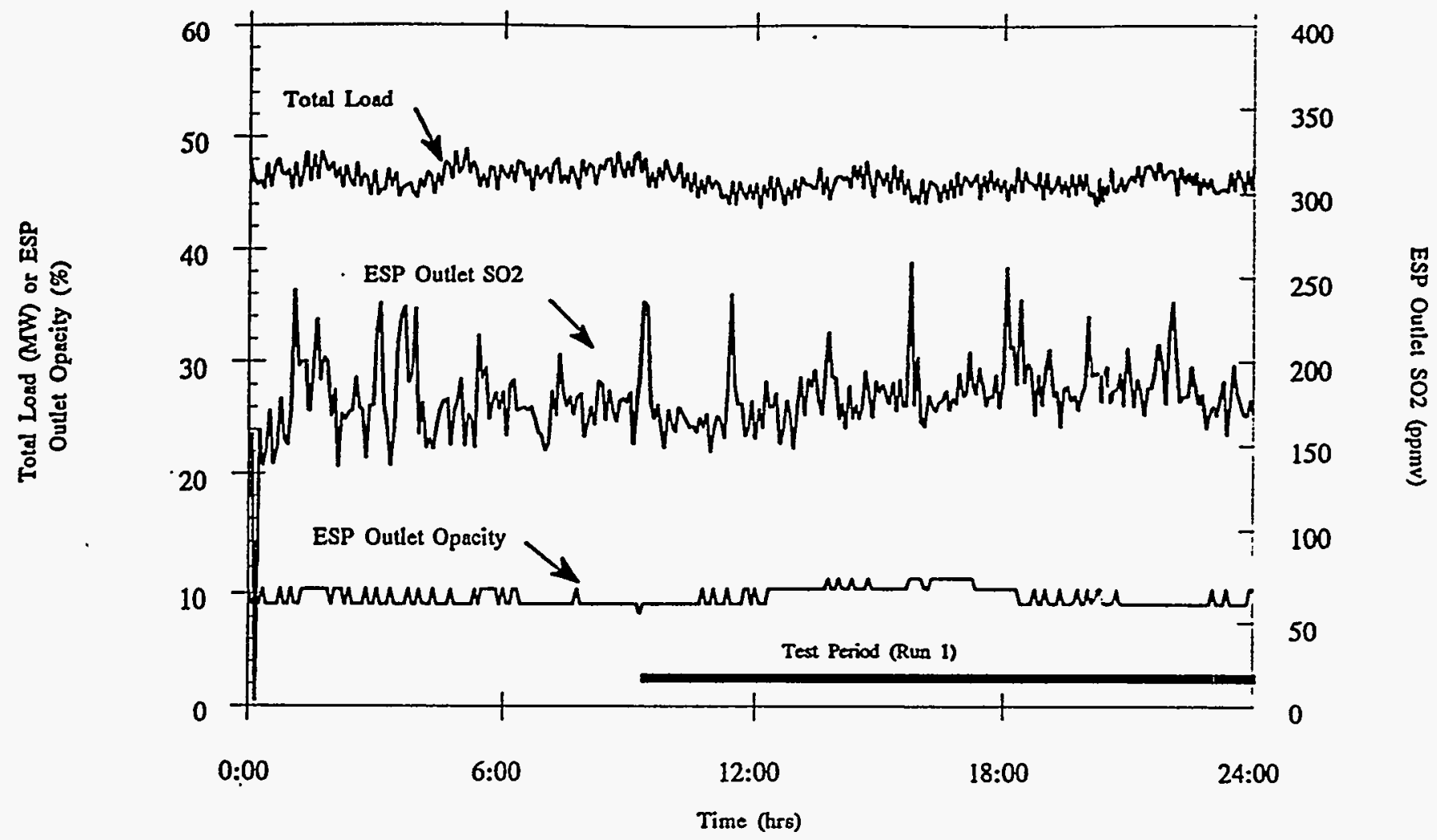

$4 / 13 / 94$

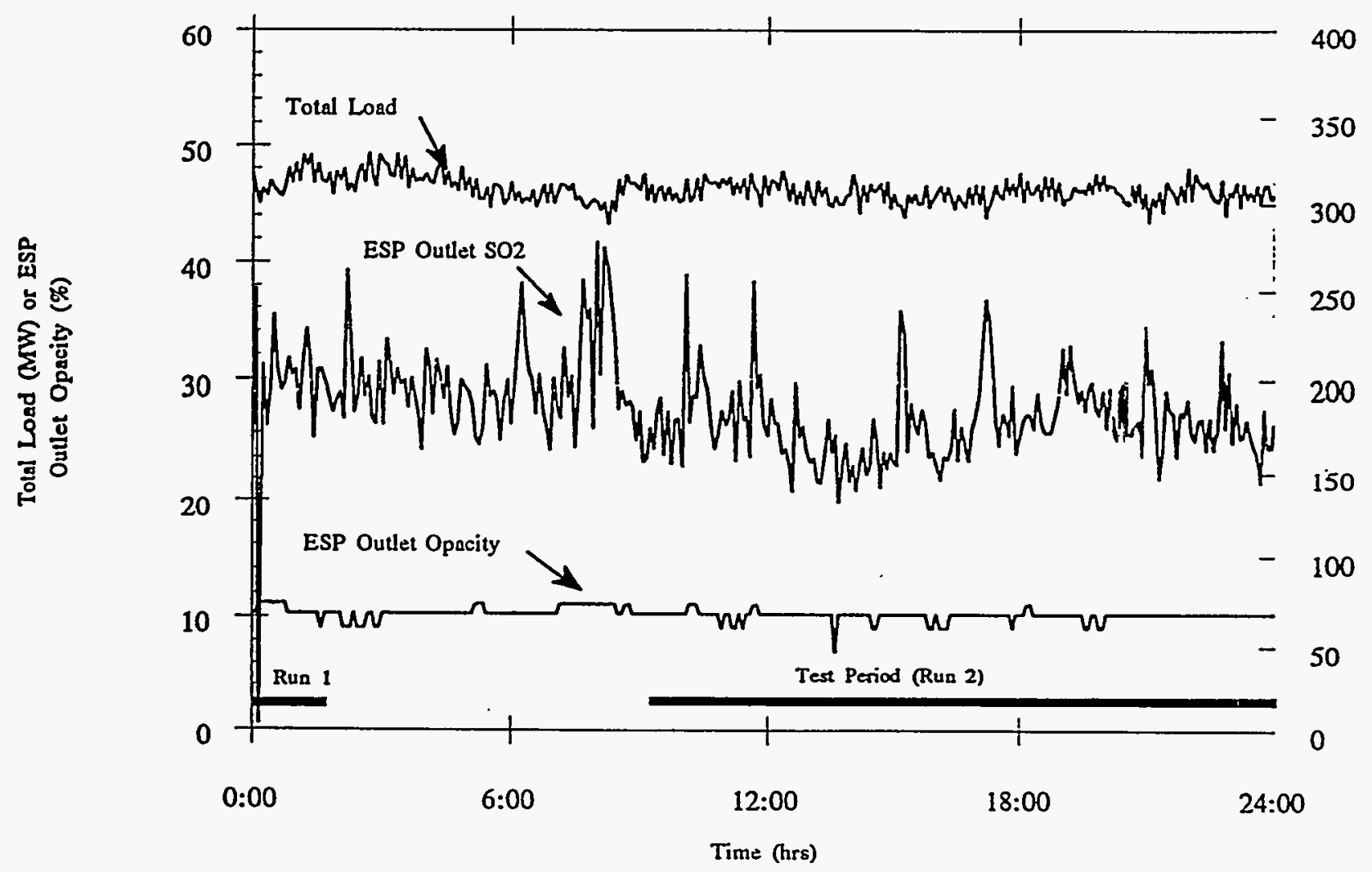

E-2 

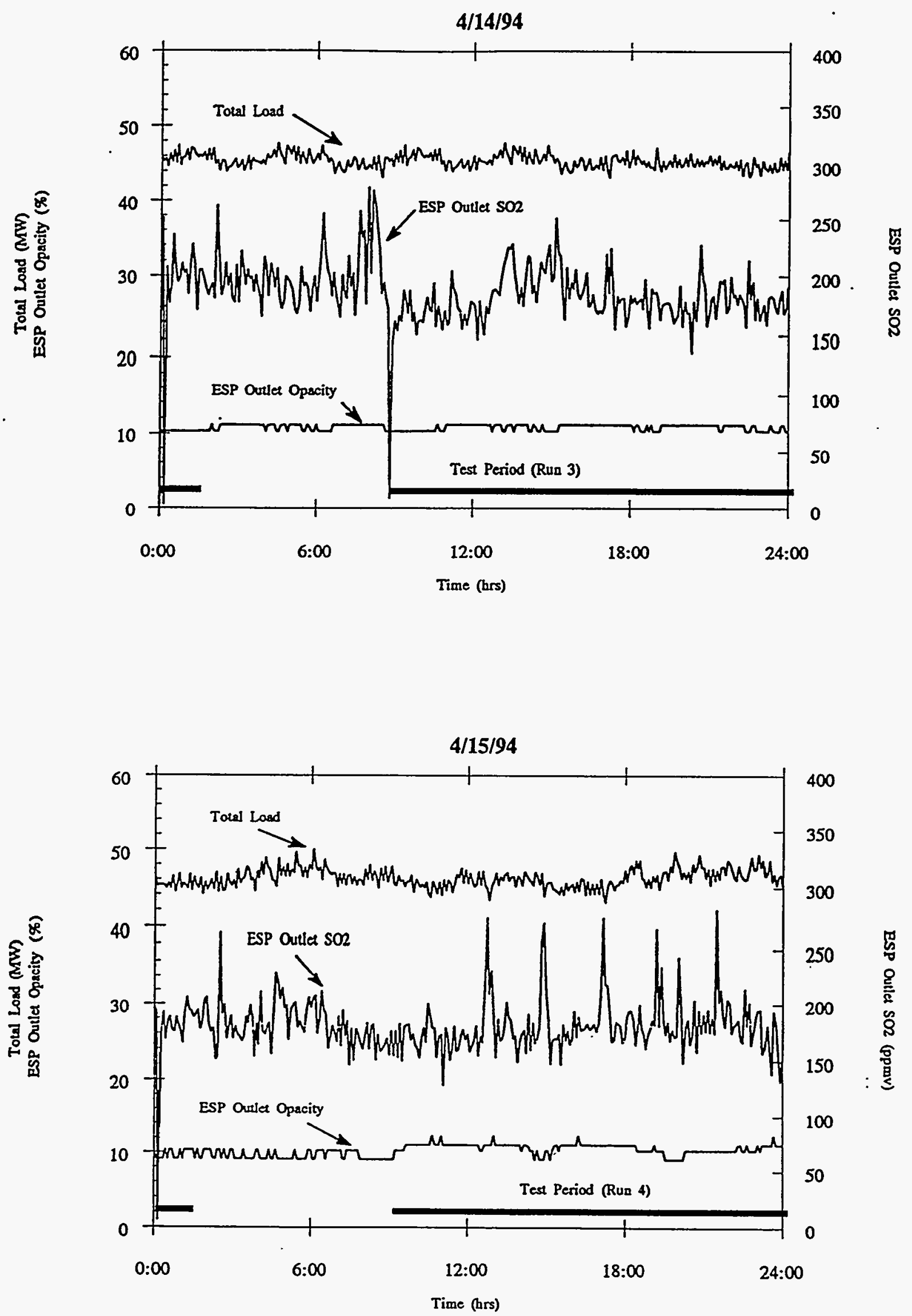

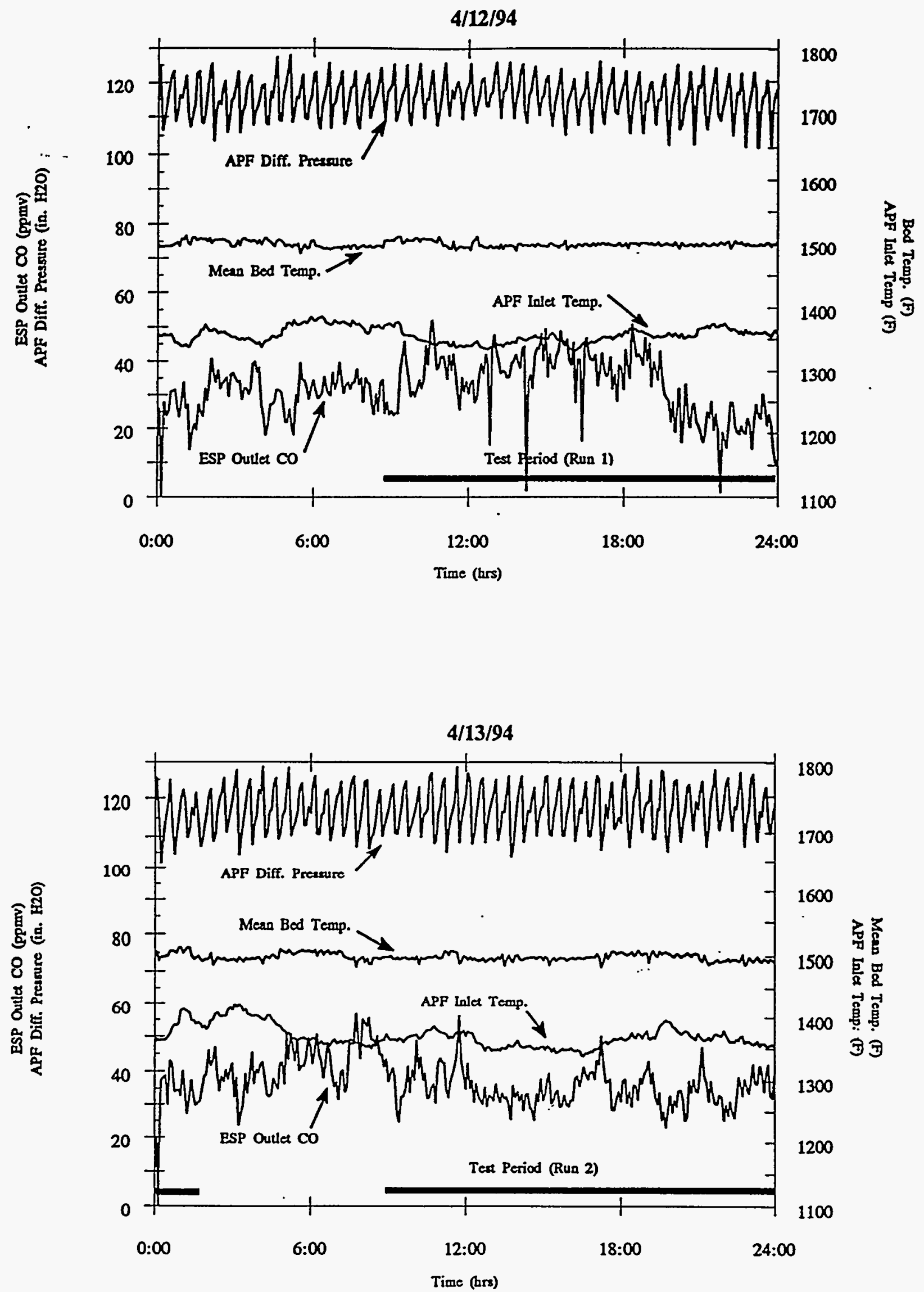

E-4 

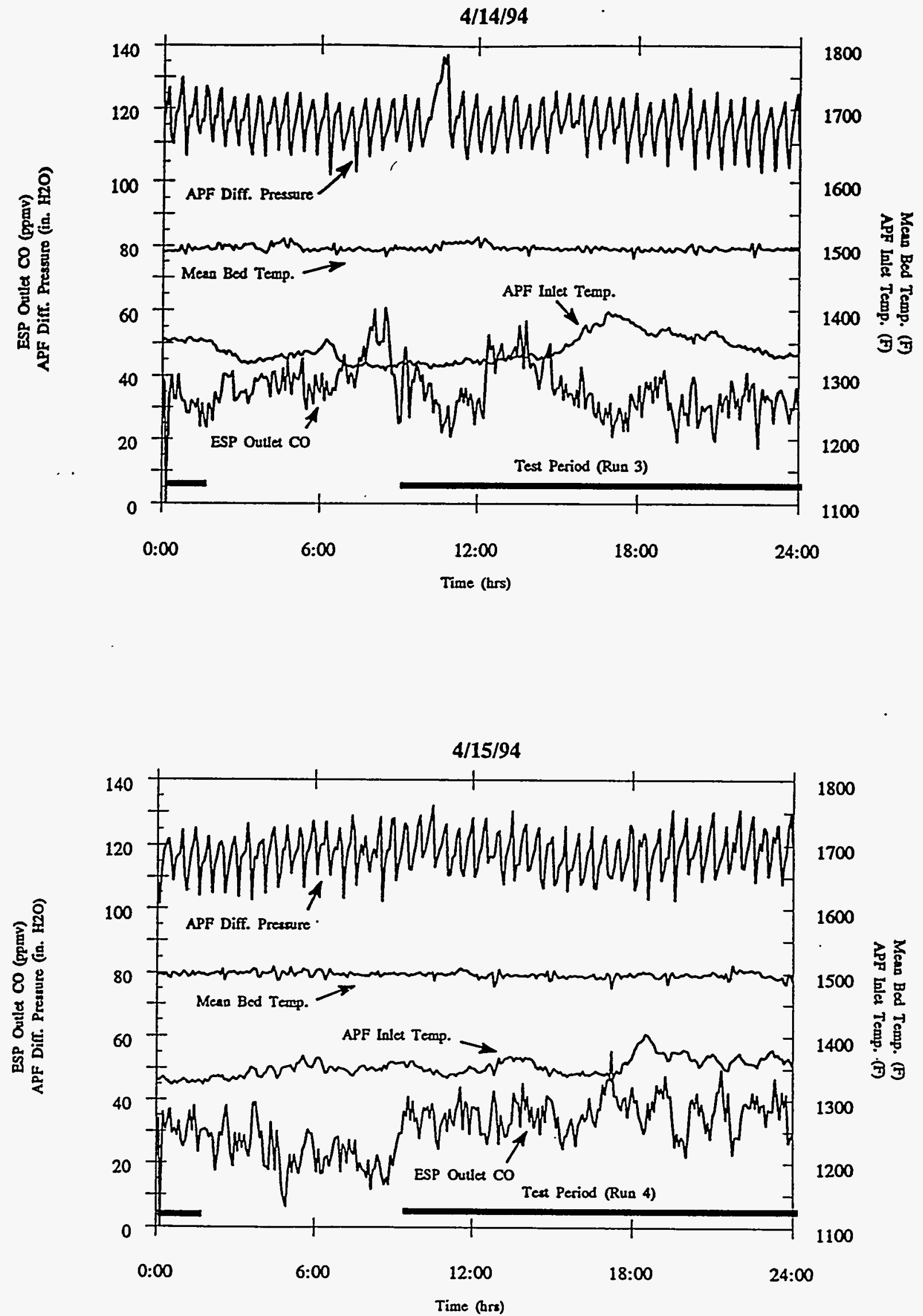


\section{APPENDIX F: FIELD SAMPLING EQUIPMENT CALIBRATION RECORDS AND FIELD DATA SHEETS}

On file at Radian Corporation. 


\section{APPENDIX G: UNCERTAINTY FORMULAS}

An error propagation analysis was performed on calculated results to determine the contribution of process, sampling, and analytical variability, and measurement bias, to the overall uncertainty in the result. This uncertainty was determined by propagating the bias and precision error of individual parameters through the calculation of the results. This uncertainty does not represent the total uncertainty in the result since many important bias errors are unknown and have been assigned a value of zero for this analysis. Also, this uncertainty is only for the period of time that the measurements were taken.

This method is based on ANSI/ASME PTC 19.1-1985, "Measurement Uncertainty."

\section{Nomenclature}

$$
\begin{aligned}
\mathrm{r} & =\text { Calculated result; } \\
\mathrm{S}_{\mathrm{pi}} & =\text { Sample standard deviation of parameter } \mathrm{i} ; \\
\theta_{\mathrm{i}} & =\text { Sensitivity of the result to parameter } \mathrm{i} ; \\
\beta_{\mathrm{pi}} & =\text { Bias error estimate for parameter } \mathrm{i} ; \\
\mathrm{v}_{\mathrm{i}} & =\text { Degrees of freedom in parameter } \mathrm{i} ; \\
\mathrm{v}_{\mathrm{r}} & =\text { Degrees of freedom in result; } \\
\mathrm{S}_{\mathrm{r}} & =\text { Precision component of result uncertainty; } \\
6_{\mathrm{r}} & =\text { Bias component of result uncertainty; }
\end{aligned}
$$


Appendix G: Uncertainty Formulas

$$
\begin{aligned}
t & =\text { Student " } t " \text { factor (two-tailed distribution at } 95 \% \text { confidence); } \\
U_{\mathbf{r}} & =\text { Uncertainty in } r ; \text { and } \\
N_{i} & =\text { Number of measurements of parameter } i .
\end{aligned}
$$

For a result, $r$, the uncertainty in $r$ is calculated as:

$$
\mathrm{U}_{\mathrm{r}}=\sqrt{\beta_{\mathrm{r}}^{2}+\left(\mathrm{S}_{\mathrm{r}} * \mathrm{t}\right)^{2}}
$$

The components are calculated by combining the errors in the parameters used in the result calculation.

$$
\begin{aligned}
& \beta_{x}=\sqrt{\sum_{i=1}^{j}\left(\theta_{i} * \beta_{\overline{p i}}\right)^{2}} \\
& S_{r}=\sqrt{\sum_{i=1}^{j}\left(\theta_{i} * S_{\overline{p i}}\right)^{2}}
\end{aligned}
$$

The sensitivity of the result to each parameter is found from a Taylor series estimation method:

$$
\theta_{i}=\frac{\partial r}{\partial p i}
$$

Or using a perturbation method (useful in computer applications):

$$
\theta_{i}=\frac{r\left(P_{i}+\Delta P_{i}\right)-r\left(P_{i}\right)}{\Delta P_{i}}
$$


Equation 5 was applied to the calculations in this report. The perturbation selected for each parameter was the larger of the normalized standard deviation, $\mathrm{S}_{\overline{\mathrm{p}}}$, or the bias, $\beta_{\mathrm{p}}$.

The standard deviation of the average for each parameter is calculated as:

$$
\mathrm{S}_{\overline{\mathrm{pi}}}=\frac{\mathrm{S}_{\mathrm{pi}}}{\sqrt{\mathrm{N}}}
$$

The degrees of freedom for each parameter is found from

$$
v_{i}=N_{i}-1
$$

and the degrees of freedom for the result is found by weighing the sensitivity and precision error in each parameter.

$$
v_{\mathrm{r}}=\frac{s_{\mathrm{r}}^{4}}{\sum_{\mathrm{i}=1}^{j}\left[\frac{\left(S_{\overline{\mathrm{pi}}} \times \theta_{\mathrm{i}}\right)^{4}}{v_{\mathrm{i}}}\right]}
$$

The student " $t$ " in Equation 1 is associated with the degrees of freedom in the result.

The precision error terms are easily generated from the collected data. The bias error terms are more difficult to quantify. The following conventions were used for this report:

- $5 \%$ bias on coal and ash flow rates.

- No bias in gas flow rates.

- No bias in analytical results if the result is greater than the detection limit. One-half of the detection limit is used for both the parameter value and its bias in calculations if the result is below the detection limit. 
Assignment of the flow rate bias values is based on engineering judgment. No bias is assigned to the analytical results (above the detection limit) or gas flow rate since a good estimate for magnitude of these terms is unknown. These bias terms may be very large (relative to the mean values of the parameters) and may represent a large amount of unaccounted uncertainty in each result. Analytical bias near the instrument detection limit may be especially large. The uncertainty values calculated for this report are, therefore, subject to these limitations.

The calculations assume that the population distribution of each measurement is normal and that the samples collected reflect the true population. Also, the uncertainty calculated is only for the average value over the sampling period. The uncertainty does not represent longterm process variations. In other words, the calculated uncertainty does not include a term to reflect the fact that the sampled system may not have been operating (and emitting). at conditions equivalent to the average conditions for that system over a longer period. Accounting for long-term system variability will require repeated sampling trips to the same location. 